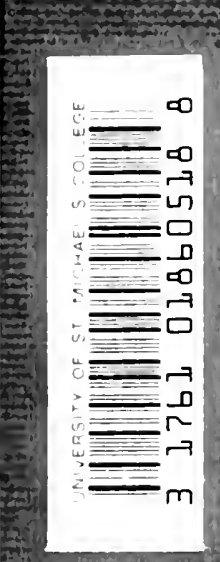



Digitized by the Internet Archive in 2009 with funding from Ontario Council of University Libraries 



\title{
DIE KULTUR DER GEGENWART
}

IHRE ENTWICKLUNG UND IHRE ZIELE

\author{
HERAUSGEGEBEN VON
}

PAUL HINNEBERG

⿷ 
DIE KULTUR DER GEGENWART

TEIL I ABTEILUNG V 


\title{
ALLGEMEINE GESCHICHTE DER PHILOSOPHIE
}

voN

WILHELM WUNDT · HERMANN OLDENBERG · WILHELM GRUBE · TETSUJIRO INOUYE · HANS VON ARNIM · CLEMENS BAEUMKER - IGNAZ GOLDZIHER - WILHELM WINDELBAND

\author{
ZWEITE, VERMEHRTE UND \\ VERBESSERTE AUFLAGE \\ ZWEITER ABDRUCK
}

\section{宅}

VERLAG VON B. G. TEUBNER IN LEIPZIG UND BERLIN I 923 


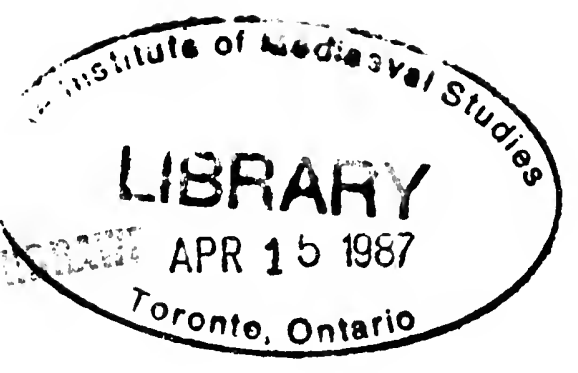

SCHITLFORMLL, FUK DIE VEREINIGTEN STAATEN VON AMERIKA:

COPYRIGHT 1923 RY R. G. TEUENER IN LEIPTIC; 


\section{VORWORT ZUR ZWEITEN AUFLAGE}

Die neue Ausgabe des vorliegenden Bandes gibt zwei von den acht Einzeldarstellungen der ersten Auflage im wesentlichen unverändert wieder: die Chinesische Philosophie des verstorbenen Berliner Sinologen W. Grube, die nach dem Urteil seines Nachfolgers J. J. M. de Groot einer Überarbeitung nicht bedurfte, und die Japanische Philosophie Prof. Ynouyes in Tokyo, deren Text gleichfalls zu Änderungen keinen Anlaß bot. Doch hat $\mathrm{H}$. Haas, der Verfasser der Geschichte des Japanischen Buddhismus in unserem Werk, die Redaktion beider Artikel mit überwacht und die Literaturverzeichnisse am Schlủß teils neu zusammengestellt, teils mit Nachträgen versehen - eine Freundlichkeit, für die ihm an dieser Stelle noch einmal gedankt sei.

Im Gegensatz zu den genannten beiden Darstellungen weist besonders starke Inhaltserweiterungen der Abriß der Indischen Philosophic auf, den $\mathrm{H}$. Oldenberg in wesentlichen Stücken völlig neu gearbeitet hat. Nicht weniger als ihm ist die zweite Auflage Clemens Baeumker zu Danke verplichtet. Neben seinem früheren, die europäischen Denker des Mittelalters behandelnden Beitrag bietet er diesmal noch eine Darstellung der patristischen Philosophie, die den Leser tiefer, als das in der vorhergehenden Auflage geschah, mit der Spekulation der Kirchenväter, besonders Augustins, vertraut macht. Aber auch an die übrigen Artikel des Bandes haben ihre Verfasser sämtlich die bessernde Hand gelegt, so daß die neue Ausgabe mit Zuversicht hoffen darf, zum mindesten dasselbe Maß von Anerkennung bei der Kritik zu finden, das seiner Zeit der ersten Auflage zuteilgeworden ist.

Paui. Hinneberg.

\section{VORIVORT みUM ZWEITEN ABDRUCK}

Dem drohenden Versçwinden verschiedener Bände der „Kultur der Gegenwart" vom Büchermarkt schien es notwendig, trotz der Ungunst der Zeiten soweit irgend möglich wenigstens durch Veranstaltung eines unveränderten Nachdruckes zu begegnen, wenn auch eine eigentliche Neuauflage augenblicklich ausgeschlossen war. Die Herren Mitarbeiter haben sich trotz mancher nicht unbegründeter Bedenken damit einverstanden erklärt und in der Mehrzahl Ergänzungen der Literaturübersichten, zum Teil zu Überblicken über die Fortschritte der liorschung seit Erscheinen des Bancles ausgestaltet, zur Verfügung gestellt.

So wird der Nachdruck auch dieses Bandes vorgelegt in der Hoffnung, daß, wenn er einmal erschöpft ist, dann unter günstigeren Verhältnissen eine eigentliche Neuauflage erscheinen kann.

Herausgeber und Veriag. 


\title{
INHALTSVERZEICHNIS.
}

\author{
EINLEITUNG
}

IJIE ANFÄNGE DER PHILOSOPHIE UNI) DIE PHILOSOPHIE DER PRIMITIVEN VÖLKER

$1-29$

VoN WILHELM WUNDT

Einleitung .

Seite

I. Primitive Logik ...... . . . . . . . . . . . . . . . 6-9

II. Primitive Psychologic. . . . . . . . . . . . . . . . . . . . 10-15

11I. Primitive Naturphilosophie . . . . . . . . . . . . . . 15-22

IV. Primitive Ethik . . . . . . . . . . . . . . . . . . . 22-24

V. Rïckblick und Ausblick in die kommende Philosophie . . . . . . . . 24-26

Literatur. . . . . . . . . . . . . . . . . . . . . . . . . 27-29

\section{A. DIE ORIENTALISCHE (OSTASIATISCHE)}

PHILOSOPHIE

$30-93$

I. DJE INDISCHE PHILOSOPHIE

Einleitung

VON HERMANN OLDENBERG.

I. Die Brahma-Spekulation

11. Überblick über die älteren Systeme der Philosophie. Die philosophischen Texte

$30-58$

III. Die Sānkhya-Philosophie

IV. Die Philosophie des Vedānta. Sankara

V. Anhängsel an Sānkhya und Vedānta

VI. Vaiśeshika und Nyāya

VII. Die Cārvākalehre.

Schlußbetrachtung .

Literatur.

30

$3 \mathrm{t}-32$

$32-36$

$36-40$

$40-46$

$46-48$

$48-51$

$51-52$

$52-56$

$57-58$

II. DIE CHINESISCHE PHILOSOPHIE

Einleitung

VON WILHELM GRUBE $\%$.

$59-79$

$59-62$

$62-64$

$64--71$

11. Konfuzius und seine Schule. . . . . . . . . . . . . . . . .

III. Lao-tszě und der Taoismus (6.-2. Jahrhundert v. Chr.) . . . . . . . $71-76$

IV. Der Neukonfuzianismus und die Erstarrung des geistigen Lebens (vom II. Jahrhundert bis zur Gegenwart) 
III. DIE JAPANISCHE PHILOSOPHIE.

$80-93$

VON TETSUJIRO INOUYE.

Einleitung

$80-8 \mathrm{r}$

I. Die Chu Hi-Schule (vom r 4. Jalırhundert an) . . . . . . . . . $8_{1}-8_{3}$

II. Die Wang Yang-ming-Schule (vom 16. Jahrhundert an). . . . . 83-86

III. Der Urkonfuzianismus in Japan (vom 17. Jahrhundert an). . . . . 86-91

IV. Neue Blüte der Wang Yang-ming-Schule im 19. Jahrhundert . . . . 91-92

V. Die national-philosophische Schule und die moderne Philosophie in Literatur Japan

\section{B. DIE EUROPÄISCHE PHILOSOPHIE \\ UND DIE ISLAMISCHE UND JÜDISCHE PHILOSOPHIE DES MITTELALTERS. \\ I. DIE EUROPÄISCHE PHILOSOPHIE DES ALTERTUMS VON HANS VON ARNIM. \\ Einleitung \\ $94-263$ \\ $94-96$}

A. Die Philosophie Ioniens und Westgriechenlands

$$
\text { (6.-5. Jahrhundert v. Chr.) }
$$

$96-120$

I. Die Begründer der drei Hauptrichtungen (6. Jahrhundert v. Chr.) . .
II. Parmenides und Herakleitos (um 500 v. Chr.) . . . . . . . . . . . $105-109$

III. Fortsetzung der drei Hauptrichtungen (5. Jahrhundert v. Chr.). . . . I09-120

B. Die attische Philosophie (5.-4. Jahrhundert v. Chr.) . . . . 120-181

I. Sophistik und Sokratik (5.-4. Jahrhundert v. Chr.) . . . . . . . I20-I27

II. Platon $(427-347)$. . . . . . . . . . . . . . . $127-148$

III. A ristoteles $(384-322)$. . . . . . . . . . . . . . . . . 148-175

IV. Die peripatetische und altakademische Schule (4.-3. Jahrhundert v. Chr.) $175-$ I 81

C. Die hellenistische Philosophie (4.-2. Jahrhundert v. Chr.). . . I $8 \mathrm{I}-230$

I. Die pyrrhonische Skepsis (4.-3. Jahrhundert v. Chr.). . . . . . . 181-183

II. Der Epikureismus (3. Jahrhundert v. Chr.) . . . . . . . . . . . . . 183-199

III. Der Stoizismus . . . . . . . . . . . . . . . . . . . . . . $193-228$

IV. Die mittlere Akademie . . . . . . . . . . . . . . . . 228-230

D. Die Philosophie der römischen Epoche... . . . 230-260

I. Karneades . . . . . . . . . . . . . . . . . . . . . 230-233

II. Philo von Larisa und Antiochos von Askalon . . . . . . . . . . . 233-236

III. Aenesidem . . . . . . . . . . . . . . . . . . . . . 236-237

IV. Neupythagoreismus und pythagoreisierender Platonismus . . . . . 237-242

V. Philon von Alexandreia . . . . . . . . . . . . . . . . 242-248

VI. Der Neuplatonismus des Plotinus. . . . . . . . . . . . . . . . 248-260

Literatur . . . . . . . . . . . . . . . . . . 26I-263

II. DIE PATRISTISCHE PHILOSOPHIE . . . . . . . . . . . . 264-300

VON CLEMENS BAEUMKER.

Einleitung

$264-265$

I. Stellung der patristischen Zeit zur Philosophie. . . . . . . . . . 265-273

II. Quellen der patristischen Philosophie. Stellung zu den einzelnen Philosophenschulen 
III. Hauptvertreter der philosophischen Spekulation innerhalb der Patristik 282-298 Literatur . . . . . . . . . . . . . . . . . . . 299-300

III. DIE ISI.AMISCHE UND DIE JÜDISCHE PHILOSOPHIE DES MITTELALTERS ....... 301-337 VON IGNAZ GOLDZIHER.

Einleitung

A. Die islamische Philosophie

I. Kalâm und Philosophic

$302-307$

II. Neuplatonische Bearbeitung der Philosophie des Aristoteles. . . . . 307-309

III. Neuplatonische Philosophie. . . . . . . . . . . . . . 309-313

IV. Die Aristoteliker im Islam. . . . . . . . . . . . . . . . . 313-327

V. Die späteren Schicksale der Philosophie im Islam . . . . . . . 327-329

B. Die jüdische Philosophie. . . . . . 330-335

1. Kalâm in der jüdischen Philosophie. . . . . . . . . . . . 330-331

1I. Neuplatonische Einflüsse. . . . . . . . . . . . . . 331-332

III. Aristotelische Philosophic . . . . . . . . . . . . . . . 332-335

l.iteratur. . . . . . . . . . . . . . . . . . . 336-337

\section{IIE CHRISTLICHE PHILOSOPHIE DES MITTELALTERS 338-43I VON CLEMENS BAEUMKER.}

Einleitung . . . . . . . . . . . . . . . . . . 338-339

1. Charakteristik der mittelalterlichen Philosophie. . . . . . . . . 339-362

II. Die Quelien der mittelalterlichen Jhilosophie . . . . . . . . . . . 362-369

A. Die Zeit der werdenden Scholastik . . . . . 369-377

I. Beginn der mittelalterlichen l'hilosophie. . . . . . . . . . . 369-370

II. Von Eriugena bis Alanus . . . . . . . . . . . . . . . . . 370-377

13. J)ie Zeit der entwickelten Scholastik . . . . . 377-427

I. Jie neue Bewegung: erste Versuche . . . . . . . . . . . . . 377-38 I

II. Augustinische Theologie und aristotelische Philosophie . . . . . 38I-386

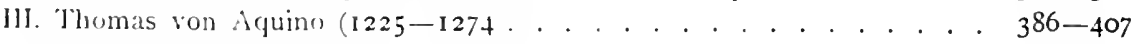

IV. Die naturwissenschaftliche Richtung. . . . . . . . . . . . . 407-410

V. I)uns Scotus . . . . . . . . . . . . . . . . . 410-416

VI. Andere Richtungen . . . . . . . . . . . . . 4 416-418

V'll. I)er Nominalismus des späteren Mittelalters . . . . . . . . . . 418-423

VIII. J) Mystik des späteren Mittelalters . . . . . . . . . . . . . . 423-427

IX. Übergang zur neueren Zeit: Nikolats ron Kues . . . . . . . . . . 427

fiteritur . . . . . . . . . . . . . . . . 428-431

V. DIE NEUERE PHII.OSOPHIE. . . . . . . . . . 432-58I

VON WHLHELM WINIEI,BANH.

Einlestung

A. Die Jhilosophie der Renaissance . . . . . 432-448

1. Der Streit der Tradıtionen. . . . . . . . . . . . . . 433-438

11. Die Antinge der Niturforschung . . . . . . . . . . . . . . 438-443

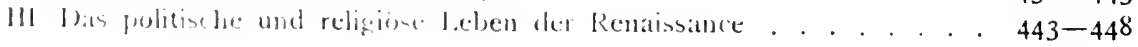


B. Die naturwissenschaftlich-metaphysischen Systeme . . . $\begin{gathered}\text { Seite } \\ 449-496\end{gathered}$

I. Nicolaus Cusanus . . . . . . . . . . . . . . . . . . . 449-452

H. Bruno und Campanella . . . . . . . . . . . . . . . 4 452-458

III. Jakob Böhme . . . . . . . . . . . . . . . . . . . . . . . . . 458-461

IV. Francis Bacon . . . . . . . . . . . . . . . . 46 46 -467

V. Descartes . . . . . . . . . . . . . . . . . . . 4 467-474

VI. Descartes' Zeitgenossen und Schüler . . . . . . . . . . . . . 474-483

VII. Baruch Spinoza . . . . . . . . . . . . . . . . . . . . . . 483-490

VIII. Leibniz . . . . . . . . . . . . . . . . . . . 490-496

C. Die Philosophie der Aufklärung . . . . . 496-520

I. Die psychologische Methode . . . . . . . . . . . . . . 497-500

II. Die Erkenntnistheorie . . . . . . . . . . . . . . . . 500-505

III. Die Moralphilosophie . . . . . . . . . . . . . . . . 505-511

IV. Der Deismus . . . . . . . . . . . . . . . . . . 511-515

V. Der Abschluß der Aufklärung . . . . . . . . . . . . 515-520

D. Kant und der deutsche Idealismus . . . . . . 520-555

I. Kant. . . . . . . . . . . . . . . . . . . . 521-533

II. Fichte . . . . . . . . . . . . . . . . . 533-536

III. Die Romantiker. . . . . . . . . . . . . . . . . . . . . . . 536-538

IV. Schelling . . . . . . . . . . . . . . . . . . . . . . 538-54I

V. Hegel . . . . . . . . . . . . . . . . . $541-548$

VI. Herbart. . . . . . . . . . . . . . . . . . . . . . . . 548-551

VII. Schopenhauer. . . . . . . . . . . . . . . . . 551-555

E. Die Philosophie des 19. Jahrhunderts ..... . 555-585

I. Französische Philosophie. . . . . . . . . . . . . . . . 556-567

II. Englische Philosophie . . . . . . . . . . . . . . . . . . . . 567-573

III. Deutsche Philosophie . . . . . . . . . . . . . . . . . 573-585

Literatur . . . . . . . . . . . . . . . . . . 5 586-587

Register . . . . . . . . . . . . . . . . . 588-620 



\title{
DIE ANFÄNGE DER PHILOSOPHIE UND DIE PHILOSOPHIE DER PRIMITIVEN VÖLKER.
}

\author{
VoN \\ Wilhelm Wundt.
}

Einleitung. Unter „Anfängen der Philosophie“ pflegt man die ersten uns überlieferten Versuche zu verstehen, welche darauf-ausgehen, der bis dahin herrschenden mythologischen Weltanschauung eine auf feste Begriffe gegründete Welterklärung gegenüberzustellen. Während die Mythologie Gemeingut eines Volkes ist, beginnt die Philosophie in diesem wissenschaftlichen Sinne überall als das Werk einzelner Persönlichkeiten, deren Namen uns in vielen Fällen noch überliefert sind. So werden insgemein die Weisen von Milet, ein Thales, Anaximander, Anaximenes, die ältesten unter den griechischen Philosophen genannt. Dagegen spricht man den primitiven Völkern den Besitz einer Philosophie überhaupt ab. Sie sind - so ist die Meinung - völlig in der Mythologie befangen geblieben, und es scheint daher unzulässig, die wirklichen Anfänge der Philosophie mit einer solchen fragwürdigen Philosophie der primitiven Völker zusammenzustellen. So gewiß das nun berechtigt ist, wenn man den ersten dieser Begriffe in dem in der Geschichte der Philosophie üblichen Sinne nimmt, so wenig kann doch bezweifelt werden, daß jenen frühesten Versuchen einer wissenschaftlichen Philosophie, mit denen unsere historischen Darstellungen diese beginnen lassen, mannigfache Vorstellungen vorausgegangen sind, die im Grunde Antworten auf die gleichen Fragen enthaltèn, welche sich später auch die Philosophie stellt, und daß sich selbst bei den primitivsten Völkern ähnliche Vorstellungen finden, so roh und unausgebildet diese auch sein mögen. Wenn so jene vorwissenschaftlichen Anfänge der philosophischen Entwickelung in wesentlichen Zügen mit den Anschauungen primitiver Völker übereinstimmen, so sind wir wohl berechtigt, beide in dem gleichen Sinne eine beginnende Philosophie zu nennen. Nur besteht freilich der Unterschied, da $\beta$ bei den Naturvölkern jene Stufe, von der aus die Kulturvölker zur Wissenschaft vorgedrungen sind, nie überschritten wurde. In der Tat bestätigt sich dies trotz mannigfacher Unterschiede, die natürlich schon im primitiven Denken nicht fehlen, bei jedem Schritt, den die ethnologische und die historische Untersuchung jede auf ihrem Gebiet vorwärts tun. Schienen die Begriffe „Anfänge 
der Philosophie“ und „Philosophie der primitiven Völker“, wenn man Philosophie im üblichen Sinne versteht, zunächst unvereinbar zu sein, so zeigt es sich jetzt, daß sie in dieser erweiterten Bedeutung zusammenfallen.

Hiergegen läßt sich allerdings der Einwand erheben, dabei handle es sich überhaupt nicht um Philosophie, sondern um Mythologie; diese müsse aber schon deshalb von jener geschieden werden, weil sie nicht zum geringsten Teil zugleich Religion sei, also nicht in dem Trieb nach Erkenntnis, sondern in Gemütsbedürfnissen ihren Ursprung habe. Obgleich dies vollkommen zutreffend ist, so liegt jedoch hierin nicht der geringste Grund gegen den oben aufgestellten Begriff einer primitiven Philosophie. Die Mythologie eines primitiven Volkes enthält eben alles das noch zu einem Ganzen vereinigt, was sich später in Religion, Philosophie und in eine Reihe einzelner Wissenschaften scheidet; ja selbst die Dichtung,, die ursprünglich nur die allgemeinen mythologischen Motive weiterführt, sowie die Musik, die mimischen und die bildenden Künste, die sich eng teils mit dem religiösen Kultus teils mit der Poesie verbinden, greifen hier ein. Gerade aus dieser innigen Verbindung verschiedener Elemente im ursprünglichen Mythus entspringt nun aber auch die Aufgabe, zu scheiden, was jedem dieser Gebiete eigen ist, also festzustellen, was davon zur Religion gehört und was nicht, was allgemeine mythische Volksanschauung ist, und was der von einzelnen herrührenden dichterischen Weiterbildung der gemeinsamen Mythenstoffe zufällt, endlich was in diesem ganzen Komplex von Überzeugungen, Meinungen und Maximen primitiver Menschen in das Gebiet der künftigen Philosophie hinüberreiclit. Stellen wir die Frage so, dann kann namentlich der letzte Teil derselben, der uns hier allein angeht, wenigstens im Prinzip unschwer beantwortet werden. Zur primitiven Philosophie gehören unzweifelhaft alle die Probleme, die noch Probleme der späteren, wissenschaftlichen Philosophie sind, nı̈gen auch die lösungen hier und dort ganz verschiedene sein, und mag gleich ein besonders charakteristischer Unterschied der ursprünglichen von der späteren l'hilosophie gerade darin bestehen, daß jene iiberhaupt keine Probleme sieht, wo dieser alles von ihnen erfüllt scheint. Doch je weniger sie sich ihrer bewußt wird, um so freigebiger ist die primitive Philosophie mit deren Lüsungen. Sie selbst stellt keine Fragen. Aber auf jede Frage, die ein späteres wißbegicriges Zeitalter stellen kann, hat sie eine Antwort bereit. Danit ist auch schon gesagt, was in wesentlichen der Inhalt dieser ursprünglichen Plrilosophie sei. Er ist in allem dem enthalten, was in den primitiven Anschauungen den Hauptproblemen der späteren Philosophie und den Versuchen ihrer Lösung entspricht.

In diesen Bemerliungen ist bereits angedeutet, daß wir uns bei der Beurteilung dieser Anfänge der Philosophie überall, im ganzen aber um so mehr, auf einer je früleren Stufe des Denkens wir ihrer habhaft zu werden suchen, vor einem Irrtum hüten müssen, der un immer und immer wieder zu begegnen droht, und von dem selbst die vorzüglichsten Darstellungen der Mythologie nicht frei geblicben sind. Wir sind gewohnt, überall, wo wir in den An- 
schauungen eines Volkes oder eines einzelnen Menschen von unserem eigenen Standpunkte aus die Lösung eines Problems erblicken, zugleich die Stellung dieses Problems zu vermuten. Drch für den Naturmenschen und darum im allgemeinen wohl auch für der Kulturmenschen in der Zeit, wo er seine Mythologie schuf, ist nichts falscher als dieses. Er löst alle Aufgaben spielend mit seiner allezeit geschäftigen Phantasie. Doch er stellt sich keine Aufgaben im Sinne der späteren Wissenschaft. Was bei ihm deren Lösung zu sein scheint, das gilt ihm in Wirklichkeit für eine unmittelbar gegebene Tatsache oder für eine selbstverständliche Verbindung von Tatsachen. So kommen denn gewisse Grundfragen der heutigen Philosophie auch schon in der primitiven Philosophie vor. Aber weil sie in ihr nicht als Fragen, sondern als unmittelbare, aus der Anschauung und aus den von ihr erweckten Assoziationen entstandene Antworten vorkommen, so ist cleren überzeugende Kraft um so größer. Beginnt für den Kulturmenschen alle Philosophie mit dem Zweifel, das heißt mit der Frage, so hört sie für den Naturmenschen mit dieser auf. Er fragt nicht, weil ihn ebenjene .ïberzeugende Kraft seiner Anschauungen jeden Zweifels enthebt. Darum mag die Geringschätzung, mit der der zivilisierte Europäer auf den Aberglauben des Wilden herabsieht, gelegentlich wohl noch durch die Verachtung überboten werden, die diesem die Unwissenheit des ersteren über alle die Dinge einflößt, die er selbst für unzweifelhaft hält.

Nun ist freilich das, was wir nach diesen allgemeinen Merkmalen ,primitive Philosophie" nennen, durchaus kein einheitlicher Begriff, sondern sie ist, so gut wie die spätere Wissenschaft, in die sie übergeht, abhängig von der erreichten Stufe der gesamten Kultur, zu der sie gehört. Gewiß würde es eine lohnende Aufgabe sein, diese vor dem Anfang einer selbständigen Geschichte der Philosophie liegende Urgeschichte derselben aus der Gesamtheit der Kulte, der Mythen und Dichtungen, in die sie unauflöslich verwebt ist, auszusondern und in ihrer Entwickelung bis zu dem Zeitpunkte zu verfolgen, wo sie sich, zunächst noch unsicher tastend und teilweise selbst noch halb Mythus halb Dichtung, zur Wissenschaft entwickelt hat. Doch diese Aufgabe würde mit unsern heutigen Hilfsmitteln vielleicht überhaupt unlösbar, und sie würde jedenfalls so umfassend sein, daß sie die Grenzen, die sich diese Darstellung setzen muß, weit überschreiten würde. Besonders kommt dabei als ein erschwerender Umstand in Betracht, daß, je weiter jene mythologische Entwickelung fortschreitet, zu der diese Urgeschichte gehört, und je näher sie also an die Grenze der Wissenschaft heranrückt, um so mehr zugleich in ihr selbst Motive wirksam werden, die bereits dem eigènsten Bereich philosophischen Nachdenkens angehören. So stellt man gewiß mit Recht die Theogonien der Griechen ihrem wesentlichen Charakter nach zum Naturmythus. Aber sie sind doch so sehr von grübelnder Reflexion durchsetzt, daß sie durchaus nicht mehr jener naiven Philosophie angehören, die dem primitiven Zustande eigen ist. Je mehr eine solche Reflexion herrschend wird, um so mehr verraten aber auch die einzelnen theogonischen 
Dichtungen die Spuren individueller Umgestaltungen der überlieferten Mythen, und um so weiter entfernen sich daher die einzelnen Mythenbildungen voneinander. Die so bereits innerhalb der Mythengeschichte eines einzelnen Volkes hervortretende Vielgestaltigkeit wächst natürlich fast ins Unabsehbare, wenn man die Mythologien der verschiedenen Kulturvölker auf die in ihnen verborgenen philosophischen Gedanken zu prüfen unternimmt. Dann bilden äußere Naturbedingungen, abweichende gesellschaftliche Zustände und geschichtliche Erlebnisse, endlich nicht zum wenigsten auch verschiedene Geistesanlagen so gewichtige Momente, daß gegenüber dieser wachsenden Differenzierung der mythischen Weltanschauungen die Übereinstimmungen und vollends die etwa der Menschheit gemeinsamen Vorstellungen entweder völlig verschwinden oder nur noch in zweifelhaften Spuren nachweisbar sind. Ganz anders, wenn wir bis zu der Stufe primitiven Denkens zurückgehen, die ihrerseits selbst schon an Anfang der Mythologie liegt. Dann zeigt es sich klar, daß jene großen Unterschiede, die uns in der späteren Entwickelung begegnen, in der Tat zum größten Teil Folgen einer fortschreitenden Differenzierung sind, der ein in überraschender Gleichförmigkeit überall wiederkehrender Urzustand menschlicher Lebens- und Weltanschauung vorauszugehen scheint. Wohl fehlt es auch hier nicht an mannigfachen Nuancen des Ausdrucks. Bald scheinen diese, bald jene Motive stärker betont zu sein. Aber die grundlegenden Vorstellungen entfernen sich wenig voneinander, oder, wo dies der Fall ist, da erweisen sich solche Unterschiede immer wieder als die Wirkungen einer verschiedenen Entwickelungsstufe, wie ja überhaupt das, was wir den Naturzustand des Menschen nennen, kein einheitlicher Begriff ist, sondern bereits mannigfache Abstufungen umfassen kann. Trotz allem dem bleibt die Übereinstimmung groß genug, daß der Begriff einer primitiven Kultur und der einer primitiven Philosophie im oben definierten Sinne nahezu sich decken, und daß, wie die primitive Kultur durchweg übereinstimmende Züge aufweist, so auch die primitive Philosophie in der allgemeinen Richtung des Denkens und in den Grundmotiven der Weltanschauung, trotz der Verschiedenheit der Zeiten und Völker, im wesentlichen dieselbe bleibt.

Diese Aufgabe ist allerdings keine ganz leichte; sie ist es nicht einmal in dem beschränkten Sinne, in dem hier versucht werden soll, absehend von allen den Zwischenstufen, die von den allerersten Anfängen des menschlichen Denkens bis zur Schwelle der Wissenschaft führen, ein Bild der primitiven Philosophie zu entwerfen. Die Begriffe dieser Philosophie sind ja nicht, wie etwa die Werke der primitiven Kunst, unmittelbar unserer Unitersuchung zugänglich, sondern sie müssen erst aus ihren Verbindungen mit sonstigen mythischen Bestandteilen, mit Religion und Dichtung losgelöst werden, und diese Verbindungen selbst, aus denen wir sie isolieren sollen, sind lange Zeit einer unsicheren mündlichen Tradition und der Einwirkung auf Lebensgewohnheiten und Sitten überlassen gewesen, ehe an ihre Aufzeichnung und Sichtung gedacht wurde. So ist es denn ein meist unter ganz anderen Gesichtspunkten und zu abweichenden Zwecken gesammeltes ethnologisches und 
historisches Material, aus dem eine solche Betrachtung zu schöpfen hat. Dazu kommt, nicht als die geringste Schwierigkeit, daß uns jener primitive Mensch, dessen Denken wir uns hier vergegenwärtigen sollen, eigentlich nirgends mehr zugänglich ist, weder unter den heute existierenden Völkern noch vollends unter denen, die uns die geschichtliche Überlieferung kennen lehrt. Vielmehr trägt das Bild dieses Menschen fast überall die Spuren irgendwelcher Kultureinflüsse, die entweder in früherer Zeit eingewirkt haben oder noch fortdauernd einwirken. Denn wo ist heute noch ein Volk zu finden, das von dem Einfluß des allgemeinen Verkehrs, der Kolonisation, der Missionare und der Forschungsreisenden unberührt geblieben wäre? Ja man kann wohl sagen, daß, was wir die „Volksseele" nennen, einigermaßen jenen mikroskopischen Objekten ähnlich ist, deren Erforschung dadurch besonders erschwert wird, daß alle Hilfsmittel, die wir zu diesem $Z_{w e c k}$ anwenden, immer auch den Erfolg haben, das Objekt selbst zu verändern. Dennoch besitzen die Bestandteile ursprünglicher Welt- und Lebensanschauungen eine Eigenschaft, die diese Schwierigkeiten bis zu einem gewissen Grade wieder ausgleicht: das ist ihre große Beharrlichkeit, die sie sichtlich nicht zum wenigsten dem Umstande verdanken, daß trot $z$ der wechselnden äußeren $\mathrm{Be}-$ dingungen die psychologischen Motive ihrer ursprünglichen Entstehung lange noch nachwirken, ja $\mathrm{da} \beta$ manche dieser Motive vielleicht nie ganz verschwinden. So kommt es, daß nicht bloß bei den sogenannten Naturvölkern, sondern noch weit in die Schichten der Halbkultur hinein überall, wo es gelingt, zu dem Kern der Lebensanschauungen, wie er besonders in Kultus und Brauch sich erhalten hat, vorzudringen, Erscheinungen uns entgegentreten, die durchaus den Charakter eines primitiven Denkens an sich tragen, und daß schließlich heute noch der Aberglaube der Kulturvölker neben wenigen Rudimenten späterer Mythenbildung der Hauptsache nach aus Überlebnissen gerade jener ursprünglichsten Anschauungen oder manchmal woh1 auch aus Neubildungen besteht, die ihnen gleichen. Doch, wie dem auch sei, aus allem dem erhellt, daß der Inhalt der primitiven Philosophie kein irgendwo vorzufindendes oder aus gewissen Überlieferungen unmittelbar zu konstruierendes System ist, wie etwa die Philosophie der ionischen Physiker oder der Eleaten, sondern daß er aus einem Gemisch sehr verschiedenartiger und vielfach noch durch spätere Einflüsse getrübter Bestandteile durch eine vorsichtig geübte kritische Abstraktion gewonnen werden muß. Um bei diesem Bemühen nicht von vornherein auf Abwege zu geraten, um also insbesondere sogleich alles auszuscheiden, was nicht der primitiven Philosophie selbst, sondern teils der Religion teils einer mehr oder minder willkürlichen Dichtung, insbesondere der gerade von primitiven Völkern mit Vorliebe gepflegten Märchendichtung angehört, werden wir am besten tun, von jenen Fragen auszugehen, die heute noch die Philosophie stellt und zu beantworten sucht, und die, wie oben bemerkt, im allgemeinen auch die primitive Philosophie zwar nicht stellt, aber beantwortet. Die erste dieser Fragen lautet: welchen Normen folgt das menschliche Denken, und worin besteht das Wesen 
Wilhelm WundT: Die Anfänge der Philosophie und aie Philosophie der primitiven Völker.

der Erkenntnis? Die zweite, wie entsteht das geistige Leben, und worin besteht das Wesen der Seele? Die dritte: welche Gesetze beherrschen die Natur? Endlich die vierte: welchen allgemeinen Regeln soll das menschliche Handeln folgen? Die in dem Denken des Naturmenschen uns entgegentretenden Antworten auf diese Fragen dürfen wir demnach wohl als den Inhalt einer primitiven Logik, Psychologie, Naturphilosophie und Ethik bezeichnen.

Die Sprache und die Logik.

I. Primitive Logik. Die Normen der Logik sind zu jeder Zeit abstrahiert worden aus den Formen des wirklichen Denkens, die ihren Ausdruck finden in den Formen der Sprache. Auch die klassische, die Aristotelische Logik ist auf diesem Weg entstanden. Die bewundernswerte Abstraktionskraft des großen Philosophen hat sich nur darin bewährt, daß er alle für den logischen Gedankenzusammenhang unwesentlichen Bestandteile der Sprache zu eliminieren wußte. Eine Feststellung der Gesetze der primitiven Logik wird darum im wesentlichen nicht anders verfahren können. Wenn wir nun diesen einzig möglichen Weg einschlagen, was ergibt sich dann als der allgemeine Charakter jener Logik, in der die Sprachen primitiver Völker, trotz der gewaltigen Unterschiede ihrer sonstigen grammatischen Struktur, im großen und ganzen übereinstimmen? Wir können diese Eigenschaften in ihrem Unterschiede von den uns geläufigen Denkgesetzen im wesentlichen auf drei Merkmale zurückführen:

Konkreter und individueller

Charakter der primitiven Begriffe.
1. Die primitive Logik kennt keine abstrakten und nur in höchst beschränktem Umfang allgemeine Begriffe. Vielmehr ist sie durchweg konkret und individuell. Sie besitzt Begriffe für einzelne Arten der Tätigkeit, wie für das Gehen, Stehen, Schlagen, Stoßen, aber nicht für das Tun überhaupt; sie besitzt solche für einzelne Baumsorten, aber nicht für den Allgemeinbegriff Baum usw. Für die Zahlen kennt sie, soweit sie überhaupt zu Zahlbegriffen fortgeschritten ist, nur anschauliche Objekte, die sie dann auf andere Objekte mit gleichen Zahleigenschaften überträgt, wie „Zehen des Straußes“ für vier, „Hand" für fünf, ein „ganzer Mensch" für zwanzig u, dgl. Ebenso fehlen ihr alle abstrakten Beziehungsbegriffe, und es fehlt ihr völlig die abstrakte Kopula „sein", die bekanntlich in unserer Logik eine so große und wegen der Neigung, der die Logiker folgen, sie auch da ergänzend hinzuzufügen, wo sie tatsächlich nicht vorhanden ist, manchmal wohl überflüssige Rolle spielt. Auf der andern Seite macht diese Logik Unterscheidungen, die unserem sich mit Vorliebe in allgemeinen Begriffen bewegenden Denken völlig ferne liegen. Sie kennt z. B. in einzelnen ihrer Gestaltungen nicht den allgemeinen Begriff „„chießen“, aber sie besitzt für das Schießen auf lebende Wesen und für das auf leblose (Objekte besondere Begriffe. Oder sie unterscheidet ein Hier und ein Dort je nach der verschiedenen Größe der Entfernungen in mehrere Raumbegriffe. Trotz dieser durch und durch konkreten Natur des primitiven Denkens fehlt es aber diesem keineswegs an einer gewissen Ordnung der Begriffe, die offenbar auf die Tendenz zu einer Verallgemeinerung derselben hinweist. Wahrscheinlich fehlen solche Kategorien, wie wir nach der von 
Aristoteles eing eführten Bezeichnung diese Klassen nennen können, in keiner der Spielarten primitiver Logik, die wir aus den Sprachen der Naturvölker kennen. Aber sie lassen sich mit einiger Sicherheit nur da nachweisen, wo sie einen bestimmten Ausdruck gefunden haben. Tatsächlich ist das im allgemeinen auch bei den Aristotelischen Kategorien der Fall, wo z. B. die Substanz dem Substantivum, die Qualität dem Adjektivum entspricht usw. Da nun den primitivsten Sprachen Unterscheidungsmerkmale solcher Wortklassen durchgängig fehlen, so bleiben meist auch die Begriffskategorien unausgesprochen. Doch wo dies je einmal zutrifft, wie bei den freilich schon nicht mehr der niedersten Stufe der Entwickelung angehörenden Bantusprachen, die gegenwärtig unserm deutschen Interesse durch unsere südafrikanischen Kolonien näher gerückt sind, da sind die logischen Gesichtspunkte, unter denen solche Begriffsklassen stehen, wiederum von den unsern völlig abweichende, und sie entsprechen durchaus der in der primitiven Logik herrschenden konkreten Form des Denkens. Die in den Bantusprachen durch übereinstimmende Präfixe gekennzeichneten Wortklassen unterscheiden Begriffe wie Menschen, Tiere, Pflanzen, Flüssigkeiten, Werkzeuge, daneben in buntem Gemenge Ortsbestimmungen, Kollektiv- und Mehrheitsbegriffe und ähnliche. Diese Kategorien beruhen lediglich auf Unterschieden der sinnlichen Wahrnehmung, die zwar einerseits ein Streben nach logischer Ordnung verraten, andererseits aber auch zeigen, wie sehr dieses Streben noch in den konkreten Eigenschaften der Objekte befangen geblieben ist.

2. Hierdurch bildet diese erste zugleich den Übergang zu einer zweiten charakteristischen Eigenschaft: die primitive Logik ist durchaus objektiv. Die objektiven Verhältnisse der Anschauung sind in ihr so klar ausgeprägt, $\mathrm{daß}$ es kaum irgendwelche in der äußeren Wahrnehmung gegebene Erscheinungen gibt, die sie nicht im Denken zu verknüpfen vermöchte. Doch fehlt in ihr ganz die subjektive Beziehung des Denkenden zu den Objekten. $\mathrm{Daß}$ etwas in der Vergangenheit, Gegenwart oder Zukunft geschieht, das bleibt meist ganz außer Betracht oder wird in nachträglichen und schwerfälligen Ergänzungen, die selbst eigentlich wieder eine objektive Bedeutung besitzen, beigefügt. Ebenso verhält es sich mit den Ausdrucksmitteln des Wunsches, der Möglichkeit, der Notwendigkeit usw. Hier überall handelt es sich aber, wie man leicht erkennt, um subjektive Denkbestimmungen, die den objektiven Inhalt der Vorstellungen gar nicht berühren. So ist es z. B. ein objektiver Inhalt der Anschauung, daß ein Stein zur Erde fällt. Ob jedoch dieses Ereignis im gegenwärtigen Augenblick geschieht, oder ob es früher geschehen ist oder in Zukunft erwartet wird, das sind Momente, die, während sie das objektive Bild vollkommen unberührt lassen, jeweils eine subjektive zeitliche Beziehung zum Urteilenden ausdrücken. Dem entspricht es nun auch ganz, daß die primitive Logik Begriffe für subjektive Wahrnehmungen, für rein psychische Zustände und Erlebnisse überhaupt nicht besitzt, eine Eigenschaft, die übrigens selbst in ein fortgeschritteneres Denken noch lange hinüberreicht, da alle unsere psychologischen Begriffe, wie wir 
S Whlelu IVunut: Die Anfänge der Philosophie und die Philosophie der primitiven Völker.

an ihren frühesten Anwendungen meist noch deutlich nachweisen können, dereinst körperliche Eigenschaften oder Vorgänge bedeutet haben. So ist die „Vorstellung“ ursprünglich das, was wir vor uns hinstellen, das „Gefühl“ das Betasten eines Gegenstandes, die Farben- und Geschmacksempfindungen sind durchgängig nach farbigen und schmeckenden Objekten genannt worden usw. Was wir in unsern heutigen Sprachen nur an verhältnismäßig neuen Begriffen mit Sicherheit nachweisen können, das zeigt uns nun das primitive Denken noch in vollkommen unveränderter Form. Begriffe subjektiver Zustände gibt es hier überhaupt nicht. Das verleiht der Gedankenäußerung des primitiven Menschen zum nicht geringsten Teil ihren eigenartigen, zu der des Kulturmenschen stark kontrastierenden Charakter. Er kann die erschütterndsten Ereignisse erzählen, ohne der Gemütsbewegungen der beteiligten Personen anders zu gedenken, als indem er die Schilderung der Handlungen mit dem mimischen Ausdrucke der Affekte begleitet.

Gegenständ liche Natur des primitiven Denkens.

3. Diese Objektivität des primitiven Denkens führt uns endlich noch zu einer dritten Eigenschaft, die im ganzen wohl früher verschwindet als die beiden vorigen, die uns jedoch auf den ersten Stufen geistiger Entwickelung. vielleicht als die markanteste entgegentritt: wir können sie kurz die gegenständliche Natur des Denkens nennen. Sie ist in der Objektivität des letzteren noch nicht eingeschlossen, aber sie ist sozusagen eine Steigerung derselben. Das objektive Denken an sich unterscheidet nicht bloß Gegenstände und deren Eigenschaften, sondern auch Veränderungen und Handlungen, und es schafft besondere Wortkategorien zu deren Ausdruck. Das einseitig aủsgeprägte gegenständliche Denken kennt dagegen eigentlich nur die Kategorien der Gegenstände und ihrer Eigenschaften, und auch diese fließen meist im Ausdruck ineinander, da in der Sprache bald die Eigenschaften nach den Gegenständen, denen sie zukommen, bald die Gegenstände nach den Eigenschaften, die an ihnen bemerkt werden, benannt sind, und unterscheidende Merkmale, wie sie unsere Sprachen in der Regel für Substantiv und Adjektiv besitzen, im allgemeinen nicht existieren. Wo unsere Logik ron einem Gegenstand irgend etwas aussagt, indem sie ihm als dem Subjekt entweder unmittelbar ein verbales Prädikat beifügt oder aber einen andern nominalen Begriff mittels der Kopula, des sogenannten Verbum substantivum „sein“, mit ihm verbindet, da legt die primitive Logik lediglich dem Subjekt ein Attribut bei. Das spricht sich grammatisch darin aus, daß die Sprachen, innerhalb deren diese Logik herrscht, ein eigentliches Verbum überhaupt nicht besitzen. Nur nachträglich werden auch hier gelegentlich Hilfsbegriffe, die aber selbst wiederum von gegenständlicher Natur sind, oder manchmal auch bestimmte Partikeln, die eine sinnmodifizierende Bedeutung angenommen haben, den Hauptbegriffen des Satzes zugefügt. Häufig aber verzichtet das primitive Denken auf alle solche nähere Bestimmungen. Es gewinnt dadurch der Gedankenausdruck und, wie wir wohl schließen dürfen, bis zu einem gewissen Grade auch das Denken selbst einen fragmentarischen Charakter. Die Vorstellungen werden assoziativ aneinander 
gereiht, nicht logisch gegliedert. Ein Beispiel solch primitiver Logik, das manchmal in frappanter Weise an den Gedankenausdruck des Naturmenschen erinnert, besitzen auch wir in der Sprache des Kindes während der Zeit der frühesten Sprachübung, falls man diese möglichst wenig beeinflußt von äußeren Einivirkungen und von dem automatischen Nachsprechen des Vorgesagten beobachtet. Auch das Kind redet unter solchen Umständen hauptsächlich in Substantiven. Gelegentlich werden wohl die Eigenschaften dieser benannt; Verba aber kommen selten und auch wenn sie erscheinen zunächst vorzugsweise in infinitiver Form vor, so daß sie gerade der Elemente entkleidet sind, die ihre logische Bedeutung ausmachen. Schließlich ist es nicht minder das Fragmentarische des Ausdrucks, das, abgesehen von den nie ganz $z u$ vermeidenden Einflüssen der erwachsenen Umgebung und von den völlig abweichenden Gedankeninhalten, in denen sich das Kind gegenüber dem Naturmenschen bewegt, beide Erscheinungen einander nahe bringt.

Mit den erörterten drei Fundamentaleigenschaften der primitiven Logik steht nun schließlich auch das Erkenntnisprinzip, dem dieses ursprüng-primitivenLogik liche Denken folgt, im engsten Zusammenhang. Wir können es kurz in dem Satze formulieren: Alles was in der objektiven Wahrnehmung gegeben ist, das ist unmittelbar so, wie es gegeben ist, gewiß. Die Beziehung dieses Satzes zur konkreten Form des Denkens liegt auf der Hand: in der Wahrnehmung sind unmittelbar nur konkrete Erscheinungen gegeben. Ebenso spiegelt sich in ihm ohne weiteres die Objektivität des primitiven Denkens; denn die Überzeugung von der unmittelbaren Realität der Erscheinungen bezieht sich vor allem auf den Inhalt der objektiven Wahrnehmung. Mit diesem verbindet sich freilich auch noch alles, was die Phantasie des Naturmenschen aus mannigfachen früheren Erlebnissen den von außen erweckten Empfindungen beifügt, so daß daraus ein Ganzes entsteht, dem in allen seinen Teilen für ihn die gleiche objektive Wirklichkeit zukommt. Nicht das Objekt, wie es einer besonnenen Prüfung nach Ausscheidung solcher.Zugaben bleibt, sondern das je nach den obwaltenden Motiven mehr oder weniger phantastisch umgewandelte Objekt ist so der erste Inhalt der unmittelbaren Wirklichkeit. Endlich prägt sich aber auch die dritte Eigenschaft, der gegenständliche Charakter des Denkens, in jenem Erkenntnisprinzip aus: was die objektive Wahrnehmung zunächst festhält, sind Gegenștände mit bestimmten Eigenschaften. Bewegungen und Veränderungen dieser Gegenstände stehen erst in zweiter Linie: sie sind etwas, das sich an den Gegenständen ereignet, also von diesen abhängt. Bei diesem Punkte beginnt nun freilich auch schon im primitiven Denken jenes Erkenntnisprinzip seine unbeschränkte Geltung zu verlieren. Vor andern Eindrücken drängt sich das Unerwartete, das Überraschende in den Vordergrund, und es nimmt besonders dann das Interesse gefangen, wenn das Wohl und Wehe des Menschen selbst davon berührt wird. Hier regt sich daher auch von frühe an, im Gegensatz zu der Selbstverständlichkeit, nit der alles übrige hingenommen wird, die Frage nach dem Warum. 
Seeleavorstellungen des Naturmenschen. Tod und Traum.

II. Primitive Psychologie. Das seelische Leben ist nach der Anschauung des Naturmenschen nichts von dem körperlichen Leben Geschiedenes, sondern beide gehören zusammen; und vermöge des Prinzips der unmittelbaren Wirklichkeit der sinnlichen Wahrnehmung würden die Lebenserscheinungen selbst den Gedanken einer solchen Scheidung schwerlich jemals entstehen lassen, wenn diese nicht durch zwei Tatsachen veranlaßt würde, die schon der frühesten Beobachtung die Trennung des Lebens von seinem körperlichen Substrat fortwährend vor Augen führen. Die erste dieser Tatsachen ist der Tod, die zweite der Traum. In Tod und Traum ist aber die Lösung des Lebens vom Körper jedesmal wieder von anderen Erscheinungen begleitet. Im Moment des Todes sind Aufhören der Atmung und Aufhebung aller andern Lebenserscheinungen aneinander gebunden. Im Traum verkehrt der Schlafende mit Abwesenden, vor allem auch mit jüngst Verstorbenen: entweder erscheinen ihm ihre schattenhaften Bilder, oder er selbst findet sich, während sein Körper unbeweglich bis zum Erwachen liegt, in ferne Umgebungen versetzt. Mit dem ersten dieser Eindrücke verbindet sich die Vorstellung, daß das Leben, das den Körper verläßt, in den Hauch des letzten Atemzuges übergeht, mit dem zweiten die andere, daß ein Schattenbild des Körpers existiert, das sich von ihm trennen kann, sei es im Schlaf, sei es auch im Tode, um entweder zeitweilig oder dauernd ein selbständiges Leben zu führen. Diese beiden Dinge, den Hauch des Aterns und das Schattenbild des Traumes, nennt daher die primitive Psychologie die "Seele“. Schon die Benennungen der Sprache bezeugen diesen doppelten Ursprung: Psyche, anima, spiritus, auch das deutsche Geist weisen auf den Hauch des Atems, Eidolon, Umbra und ähnliche ebenso auf das Schattenbild des Traumes hin. Der Begriff der Seele ist also nicht, wie man zuweilen wohl anniınmt, aus dem Bedürfnis entstanden, die seelischen Vorgänge, Empfindungen, Gefühle, Vorstellungen usw., auf eine Substanz zurückzuführen, als deren Tätigkeiten sie gedeutet werden; sondern dieser Begriff nimmt vielmehr gerade aus solchen Erscheinungen seinen Ursprung, bei deren Eintritt die seelischen Vorgänge ganz oder mindestens, wie im Schlaf, zeitweise unterbrochen werden. Er ist, könnte man sagen, nicht an das seelische Leben selbst, sondern an das Aufhören des Lebens gebunden. Wären nicht der Tod und der Traum, so würde gar nicht abzusehen sein, wie der primitive Mensch jemals zum Begriff einer von dem Körper verschiedenen und von ihm trennbaren Seele kommen sollte. Da es nicht im entferntesten ein Bedürfnis nach irgendeiner Interpretation der seelischen Vorgänge ist, was die primitive Psychologie zu diesem Begriff der Seele führt, so läßt sich jene nun aber auch nicht im geringsten durch die Doppelheit ihres Seelenbegriffs stören, die aus den zwei gänzlich verschiedenen Entstehungsweisen desselben hervorgeht, sondern die Seele hat für sie bald die eine bald die andere Form, je nachdem die unmittelbare Wahrnehmung es fordert. Sowenig jedoch die beiden Seelen, die wir nach diesem ihrem Ursprung als die "Hauchseele“ und die "Schattenseele“ bezeichnคn können 
das seelische Leben selbst erklären sollen, ebensowenig sind sie dazu da, etwa als Hilfsbegriffe zu dienen, um den Tod und den Traum zu erklären. Die primitive Psychologie erklärt nicht, sondern sie konstatiert Tatsachen. Sie sucht nicht durch irgendwelche Hypothesen und Theorien Erscheinungen und ihren Zusammenhang zu deuten, sondern sie gibt lediglich den unmittelbaren Wahrnehmungen und ihren Verbindungen einen nicht mißzuverstehenden Ausdruck. Darum stehen ihr aber auch ihre Begriffe über jedem Zweifel, und einen Widerspruch zwischen ihnen kann es für sie nicht geben. Daß das Leben mit dem letzten Hauch des Atems aufhört, ist eine unmittelbare Tatsache der Beobachtung. Ebenso, daß im Traum Schattenbilder Verstorbener oder Lebender erscheinen. Die Seele in beiderlei Gestalt ist also nicht Hypothese, sondern Wirklichkeit, geradeso gut Wirklichkeit wie der Körper, aus dem jene im Schlaf oder beim Tode entweicht. Dasselbe gilt dann aber von den Modifikationen und Metamorphosen, die diese beiden Seelen erfahren, und bei denen sie teils miteinander teils mit der ursprünglichen Vorstellung der Gebundenheit des seelischen Lebens an den Körper und seine Organe in Beziehungen treten können. Infolge dieser wechselnden Verhältnisse ist die primitive Psychologie naturgemäß kein einheitliches und völlig gleichförmiges System, sondern sie zerfällt in eine Anzahl von Systemen, in denen sich jedesmal die sonstige IVeltanschauung der Völker spiegelt. Immerhin bleiben die letzten Voraussetzungen gemeinsame und in diesem Sinne also allgemeingültige. Auch können die einzelnen Systeme bei aller Mannigfaltigkeit, die sie darbieten, je nach der Vorherrschaft des einen oder andern der grundlegenden Seelenbegriffe in eine gewisse Entwickelungsreihe geordnet werden. Innerhalb dieser lassen sich dann wesentlich drei Stufen unterscheiden, die freilich in den meisten der unserer Beobachtung zugänglichen Systemen bereits vereinigt sind, so daß sie im allgemeinen nur durch das quantitative Übergewicht in der Richtung der einen oder andern Grundanschauung voneinander abweichen.

I. Ausgangspunkt aller primitiven Psychologie ist der Begriff der Einheit des seelischen und körperlichen Lebens. Wo dieser Begriff noch stark genug ist, um durch die an Tod und Traum gebundenen Erscheinungen nicht allzusehr beeinträchtigt zu werden, da bildet sich die Vorstellung aus, daß die Seele nach dem Tode kürzere oder längere Zeit noch im Körper verweile, oder daß sie auch, wenn sie ihn in einer der oben erwähnten Seelenformen verlassen hat, zeitweise wieder in ihn zurückkehre. Wir können diesen Begriff als den der Körperseele bezeichnen. Er hat zu zwei sekundären Begriffen geführt, die übrigens sehr verschiedenen Stufen der Entwickelung der primitiven Psychologie angehören. Der ursprünglichere ist offenbar ron jenem natürlichen Gefühl getragen, clas rornehmlich kurz nach dem Tode ron dem Anbiick der Jeiche die Erinnerung an den Lebenden nicht zu tremmen vermag, und das noch auf einer viel höheren Stufe der Kultur in mannigfachen Leichenbrïuchen und Totenkulten nachwirkt. Besonders gehört die Sitte der Konservierung der Leichen hierher, wie sie 
uns in spärlichen Anfängen bei manchen Naturvölkern und zu einem System ausgebildet, bereits mit wissenschaftlichen Hilfsmitteln ausgerüstet bei den Ägyptern entgegentritt. In primitiven Verhältnissen hat sich jedoch unter dem Einfluß der Aufbewahrung des noch beseelt gedachten Körpers eine Vorstellung ausgebildet, welche die Entfernung der Seele aus dem Leibe an eine bestimmte die Verwesung begleitende Erscheinung knüpft: der erste Wurm, der aus dem verwesenden Leichnam hervorkriecht, trägt die Seele hinweg, die nun möglicherweise weitere Metamorphosen erfahren kann. Der so entstandene Begriff des Seelenwurms ist bei zahlreichen Naturvölkern Ozeaniens, Afrikas und Nordwestamerikas verbreitet oder verbreitet gewesen, und möglicherweise ist der bis noch in die Psychologie der Kulturvölker reichende Glaube an die Verkörperung der Seele in einer Schlange ein spätes Überlebnis der gleichen Anschauung.

Der zweite Seelenbegriff, der an die ursprüngliche Einheit von Körper und Seele anknüpft, gehört, namentlich in seinen ausgebildeteren Formen, einer späteren Stufe an. Es ist der Begriff der Organseelen, des Sitzes einer Seele in mehreren Körperorganen, mit dem sich dann meist zugleich die Vorstellung von einer verschiedenen Leistung dieser Organseelen, also der erste Anfang einer Unterscheidung der später sogenannten „Seelenvermögen" verbindet. In dem Hervortreten dieser Begriffe von Organseelen bemerkt man nun wieder insofern bestimmte Unterschiede, als gewisse Organe früher, andere später als Träger der Seele auftreten, wobei die späteren die früheren allmählich zu verdrängen pflegen. Die ältesten Sitze der Seele scheinen die Nieren und das Blut zu sein. Jene begegnen uns teils allein teils zusammen mit benachbarten Eingeweiden noch heute in dieser Rolle bei zahlreichen Naturvölkern, ebenso an vielen Stellen des Alten Testaments als ein Bestandteil altsemitischen Volksglaubens, und vereinzelt, aber doch deutlich erkennbar in der älteren Überlieferung auch der indogermanischen Völker. Noch verbreiteter und bis in eine jüngere Zeit herabreichend ist clas Blut Träger der Seele. Zu ihm gesellen sich in vielen Fällen gewisse Sekrete des Körpers: so namentlich der Speichel, der wahrscheinlich zugleich in nahe Beziehung zu der im Atem entweichenden Hauchseele gebracht wird. So begreiflich hier die Wertschätzung des Blutes ist, so befremdend erscheint auf den ersten Blick die zentrale Stellung der Nieren in der ältesten Psychologie. Aber wenn man bedenkt, daß die Nieren, wie die Bedeutungsgeschichte der sie bezeichnenden Wörter lehrt, ursprünglich eng mit den Geschlechtsorganen verbunden werden, und dazu erwägt, welch ungeheure Rolle in einer primitiven Kultur überall das Geschlechtsleben spielt, so wird die Stellung, die die Nieren hier als die Träger seelischer Kraft überhaupt einnehmen, wohl verständlich. Erst auf einer etwas späteren Stufe treten dann dazu das $\mathrm{Z}$ werchfell, das $\mathrm{Her} z$, und gleichzeitig beginnt eine gewisse Sonderung der Seelenkräfte, die in diesen verschiedenen Organen ihren Sitz haben sollen. Dabei ist es sichtlich die mehr und mehr sich aufdrängende Beziehung der Affekte zu Atmung und Herzschlag, die einer 
solchen Lokalisation, wie sie uns z. B. in der Homerischen Psychologie begegnet, zugrunde liegt. Loch je mehr in dieser Weise die einzelnen Organe nur für spezielle seelische Funktionen in Anspruch genommen werden, um so leichter kann sich nun auch mit diesen letzten Gestaltungen des Begriffes der Körperseele der andere der selbständigen, im Hauch des Atems ausströmenden oder als Schattenbild wandernden Seele verbinden. So ist es diese Differenzierung der Organseeien, die das ihrige dazu beiträgt, jene Seelenbegriffe andern Ursprungs zu fördern, indem Gebundenheit und Selbständigkeit auf verschiedene Seelenbegriffe verteilt werden. Die Organseelen sterben beim Tode des Leibes, während die Psyche ihn verläßt, um in neuen Formen weiterzuleben.

2. Die nächste Form dieses Übergangs ist der in die Hauchseele. Die Haurhseele Doch der Hauch des Atems, so unmittelbar er sich auch als das Substrat und ibr Überder entweichenden Seele darstellt, ist zu flüchtig, er hält der Wahrnehmung zu wenig stand, als daß diese dauernd an ihn gebunden werden könnte. Da bietet sich denn als eine leichtverständliche, in vielen Systemen primitiver Psychologie dominierende Vorstellung die der Verkörperung der Seele in Tieren, teils in kriechenden, an oder unter der Erde lebenden, wie der Schlange, dem Wurm, teils in leichtbeweglichen, fliegenden: in Vögeln, Schmetterlingen. Entweder geht die Seele als Hauch unmittelbar in das Tier über, ähnlich wie sich auch bei manchen Völkern, nach altgeheiligter Sitte sogar noch bei den Römern, ein naher Angehöriger des Sterbenden über diesen beugte, um seine Seele aufzunehmen. Oder - und das ist wohl der häufigere Fall - der Übergang wird als eine echte Metamorphose gedacht: die als Hauch ausströmende Seele verdichtet sich nachträglich zu einem hinwegflatternden Vogel oder zu einem andern rasch beweglichen Tier. Eine solche Vorstellung ist dann freilich nicht mehr Produkt unmittelbarer Wahrnehmung. Aber sie ist doch auch keineswegs eine freie willkürliche Erfindung, sondern der Geist des Naturmenschen folgt dabei immer und überall zwei sich ihm aufdrängenden Assoziationen. Die eine, die allgemeinere, besteht in der engen Verbindung, in die für ihn das Tun und Treiben der Tiere mit dem des Menschen tritt. Die Tiere sind Wesen, die $i h m$ gleichen. Sie sind nicht bloß, wie eine schon weit gereiftere Stufe es bildlich ausdrückt, seine „jüngeren Brüder“, sondern sie sind seine Ahnen. So ähnlich das Tier dem Menschen ist, so verschieden und so überlegen erscheint es in der instinktiven Sicherheit seines Handelns. Erblickt der Wilde in dem Stammesgenossen sozusagen sein selbstrerständliches Ebenbild, so erregt die Tierwelt in ihrer bunten Mannigfaltigkeit immer von neuem sein Staunen oder auch seine Furcht. So hat sich denn auf einer frühen Stufe, aus der in mancherlei Opferriten und Kultusvorschriften da und dort noch dunkle Erinnerungen in die Anfänge der Kulturvölker herüberreichen, die Vorstellung gebildet, die Tiere oder mindestens gewisse unter ihnen seien dem Menschen geistig überlegen, woran sich dann die Zurückführung des einzelnen Stammes auf einen tierischen Stammvater anlehnt, auf ein „Totem- 
14 Wilhelm WUnd: Die Anfänge der Philosophie und die Philosophie der primitiven Völker.

tier“, dessen Bild als Wahrzeichen und zugleich als Schutzzauber gegen Gefahr der einzelne an seinem Leibe trägt. Zu diesen allgemeinen Bedingungen treten nun die besonderen, die den Tod eines Menschen begleiten. Noch der heutige Volksaberglaube sieht gelegentlich in einem Vogel, einer Maus oder einem andern rasch beweglichen Tier die Seele eines Verstorbenen entweichen. Die gespannte Ėrwartung, die dem. ausströmenden letzten Atemzug folgt, kettet von selbst an die nächste beste Wahrnehmung das weitere Schicksal der Seele, und wenn vollends diese Wal rnehmung ein Tier ist, das sich gleich dem Atem, nur sichtbarer durch die Luft bewegt, so bildet sich eine identifizierende Assoziation, die der Auffassung der entweichenden Seele als Hauch an Sicherheit nicht nachsteht. Auch hier sind es also nicht Hypothesen und Theorien, die sich der primitive Psychologe macht, sondern er konstatiert Tatsachen und Verbindungen von Tatsachen. In der Art, wie er das tut, ist er freilich in den Vorstellungskreis gebannt, der ihm durch Tradition und eigene Erlebnisse geboten wird. An den Übergang in fliegende Wesen knüpft sich daher leicht auch der weitere in andere Tiere. Dabei gewinnen dann die oben berührten, zum Teil schon über dies Gebiet hinausführenden Erscheinungen des „Totemismus" ihren Einfluß. Auch ist unschwer zu sehen, daß hier die Quelle ist, aus der die Idee der Seelenwanderung entspringt. Doch gehört diese Idee selbst einer religionsphilosophischen Spekulation an, die, wie so manche andere Erzeugnisse der späteren religiösen und philosophischen Seelenvorstellungen, zwar in ihrem Keim in die primitive Psychologie zurückreicht, selbst aber dieser noch ferne liegt. Denn die Idee der Seelenwanderung ist innig verwachsen mit Vergeltungsvorstellungen, die hier noch völlig mangeln. Um so wichtiger ist eine andere, von der Verkörperung in Tieren weit abliegende Metamorphose: die der Hauch- in die Schattenseele. Sie durchkreuzt schon auf einer sehr frühen Stufe jene andern Umwandlungen, um sich dann mehr und mehr zur herrschenden zu erheben.

Die Schatten- 3. Diese zweite wichtige Form des Begriffs der selbständigen „Psyche“, seele.

die Schattenscele, zeichnet sich trotz ihrer Flüchtigkeit von Anfang an durch zwei Eigenschaften aus, die ihr eine gewisse Stabilität sichern, und die sie schließlich in dem Widerstreit der verschiedenen Seelenbegriffe im ganzen den Sieg gewinnen lassen. Sie besitzt erstens in den Erscheinungen des Traumes eine unaufhörliche Quelle ihrer Erneuerung, die sich in dem Maße in ihrem Übergewicht geltend macht, als Schlaf und Traum ungleich häufigere Erscheinungen sind als der Tod. Zweitens aber bietet sie zugleich weit vielseitigere Beziehungen zu den mannigfaltigsten sonstigen Erscheinungen des menschlichen Lebens als irgendeine der anderen Seelenformen. So bietet vor allem die $\mathrm{Krankheit}$ in doppelter Beziehung Anknüpfungen an die Schattenseele. In seinen Fieberphantasien sieht der Kranke bald seine Seele wunderbare Wanderungen und Wandlungen erleiden, bald fühit er sich oder sehen ihn andere von einer fremden Seele in Besit\% genommen. Alpträume und Tierverwandlungen im Traum, Vision 
und Ekstase, sie bilden hier die Ausgangspunkte mannigfacher Vorstellungen, die ebenso die Auffassung der Seele selbst wie die der Außenwelt beeinflussen. Alle diese Vorstellungen verbinden sich zunächst in ziemlich wechselnder und irregulärer Weise mit den andern Seelenbegriffen. Doch indem allmählich die Reduktion der allgemeinen Körperseele auf die Organseelen mit ihren spezifischen Lebenskräften die Befreiung der Psyche vollendet, fügt es sich von selbst, daß auch die beiden Hauptgestaltungen der letzteren eine regelmäßige Verbindung eingehen. Beim Tode entweicht - so fixieren sich nun die Vorstellungen - die Psyche als Hauch, dann aber wandelt sie sich in den Schatten, das blasse, für das Auge sichtbare, vor der tastenden Hand in Luft zergehende Ebenbild des Menschen um, das je nach der besonderen Richtung der Vorstellungen bald um das Grab des Toten schwebt, bald an einsamen Stätten haust, bald in einen besonderen Versammlungsort der Verstorbenen eingeht. Das ist die Stufe, die wir beispielsweise auch in der Homerischen Psychologie erreicht sehen: die Seele des Erschlagenen entweicht mit schwirrendem Geräusch zum Hades, wo sie mit den Schatten der vordem Verstorbenen ihr trauriges Dasein führt. Einem Rest der Vorstellung von der im Körper verbleibenden Seele begegnen wir allerdings auch hier noch. Die Leiche muß verbrannt oder begraben werden, damit die Seele zur Ruhe komme und nicht mehr die Unbill empfinde, die dem Körper, solange er unbestattet liegt, widerfahren kann.

Indem die Schattenseele bei diesen Metamorphosen der Psyche zum herrschenden Begriff geworden ist, vollzieht sich nun aber noch ein weiterer wichtiger Wandel, der die primitive Psychologie über ihr eigenes Gebiet hinausführt. Der Schatten, der in ein selbständiges Wesen übergegangen ist, braucht nicht mehr auf die Seele eines bestimmten Menschen, ja er braucht schließlich überhaupt nicht mehr auf ein vorangegangenes seelisches Dasein bezogen $z u$ werden. Er wird zum Gespenst, das den Lebenden schreckt, oder zum Dämon, der ihn unheilbringend oder als Schutzgeist umschwebt; und ähnliche Wandlungen können nun auch die in Tieren wohnenden Seelen erfahren. Auf diese Weise ist mit diesem Übergang zum Dämon die Seele zugleich zu einer Naturmacht geworden. So berührt sich hier unmittelbar die primitive Psychologie mit der primitiven Naturphilosophie.

III. Primitive Naturphilosophie. Nach einer allgemeinen, auch unter Ursprung des Mythologen und Philosophen verbreiteten Meinung soll der Mensch von Anfang an einem ihm innewohnenden Kausalbedürfnis gefolgt sein, sobald er sich Vorstellungen über die Bedeutung und über den Zusammenhang der Naturerscheinungen zu bilden begann. Vollends seitdem die Philosophen in der Kausalität eine a priori in uns liegende Kategorie sahen, von der, wie Schopenhauer meinte, schon das Kind Gebrauch mache, wenn es bei seinen ersten Sinneswahrnehmungen die äußeren Objekte als die Ursachen seiner Empfindungen deute, ist die Überzeugung, daß alle Naturmythologie und demzufolge auch die in dieser enthaltene primitive Naturphilosophie eine 
16 Wilhelm Wundt: Die An fänge der Philosophie und die Philosophie der primitiven Völker.

kausale Interpretation der Natur sei, so fest gewurzelt, daß man fast fürchten muß, paradox $z u$ erscheinen, wenn man es wagt, ihr zu widersprechen. Nun gedenke ich selbstverständlich nicht, hier in eine Diskussion über die Frage einzutreten, wie es sich mit dem philosophischen Wesen der Kausalität überhaupt verhalte. Für uns handelt es sich nur darum, rein tatsächlich zu untersuchen, wie die Naturanschauung des primitiven Menschen wirklich beschaffen ist, und wo in ihr dasjenige Moment einzusetzen beginnt, das wir mit einigem Recht eine kausale Betrachtung nennen dürfen. Denn daran wird hierbei allerdings von vornherein festzuhalten sein, daß es sich um eine Kausalbetrachtung im Sinne einer wenn auch noch so primitiven Naturphilosophie nur da handeln kann, wo nicht wir den Kausalbegriff erst nachträglich in das Denken des Naturmenschen hineintragen, sondern wo der Mensch selbst die Erscheinungen in das Verhältnis von Ursache und Wirkung bringt. In diesem Sinne hält er aber z. B. irgendeinen Gegenstand, den er sieht, nicht für die Ursache seiner Empfindungen - im Grunde tut das erst der Physiolog oder Psycholog, der über diese Dinge reflektiert —, sondern das Objekt ist ihm ein unmittelbar gegebener Gegenstand, und daran, daß es erst eine Wirkung auf seine Sinne ausüben muß, um wahrgenommen zu werden, denkt er überhaupt nicht. Schreibt dagegen der Wilde eine Krankheit, die ihn befallen hat, einem ihm feindseligen Zauberer $z u$, so ist das eine wirkliche und echte Kausalerklärung: Ursache und Wirkung stehen sich hier im Geiste des Wilden ebenso klar geschieden gegenüber, wie in dem unsern die anziehende Kraft der Erde und der Fall des Steins, den wir als die Wirkung dieser Kraft bezeichnen.

Gehen wir nun mit diesem Kriterium ausgerüstet an die Betrachtung des Inhalts der primitiven Naturphilosophie, so kann es keinem Zweifel unterliegen, daß in dieser die Kausalität weder das Ganze der Natur umfaßt noch überhaupt die gleiche Stellung einnimmt, welche ihr die Wissenschaft einräumt, die in Wahrheit eben erst diese Stellung für sie erobert hat. Man macht also bei jener Insinuation eines allgemeinen Kausalbedürfnisses den so oft begangenen Fehler, daß man, statt sich selbst in den Geist des Naturmenschen zu versetzen, vielmehr diesen in den eigenen Geist überträgt, und ihn nach denselben Motiven denken und handeln läßt, aus denen heraus man selbst zu ähnlichen Gedanken und Handlungen gelangen würde - falls das überhaupt möglich wäre, was natürlich in den meisten Fällen nicht zutrifft. Hat man aber einmal diesen falschen Standpunkt gewählt, so ist es nun ganz konsequent, daß man auch die primitive Naturphilosophie nur für eine unvollkommenere Entwickelungsstufe unserer eigenen Naturphilosophie ansieht. Das Unzutreffende dieser Voraussetzung erhellt jedoch schon aus dem oben (S. 9) formulierten allgemeinen Erkenntnisprinzip der primitiven Philosophie, das, weil es sich auf die Kriterien der objektiven Wirklichkeit bezieht, doch vor allen Dingen in der Naturphilosophie gelten muß. Wenn nach diesem Prinzip dem Inhalt der Wahrnehmung als solchem unmittelbare Wirklichkeit zukommt, so kann der primitive Mensch unmöglich allen Erscheinungen mit 
der Frage entgegentreten, woher sie kommen, und wie sie zusammenhängen. Zunächst fragt er ja überhaupt nicht, und er tut das um so weniger, je alltäglicher, je regelmäßiger die Erscheinungen sind. Es ist wahr, man findet schon in der sogenannten Mythologie mancher primitiver Völker allerlei Züge, die man, wenn sie als die Grundbestandteile ihrer Weltanschauung anzusehen wären, allenfalls als eine Art von erklärendem Naturmythus deuten könnte: so etwa die Vorstellung, daß die Sonne ein strahlender Held sei, der am Tage seine Bahn am Himmel zurücklege, um am Abend von einem finstern Ungeheuer verschlungen zu werden; oder die andere, daß die Sonnenstrahlen Seile seien, auf denen die Seelen der verstorbenen Menschen zum Himmel emporkriechen, und ähnliche mehr. Zunächst aber darf wohl bezweifelt werden, ob solche Erzählungen der eigentlichen Mythologie angehören und demzufolge mit der in dieser Mythologie eingeschlossenen Naturphilosophie irgend etwas zu tun haben. Denn meist tragen sie, soweit sie bei primitiven Völkern vorkommen, alle Merkmale der Märchen- und Fabeldichtung an sich. Als solche können sie natürlich, gleich unsern Märchen und Fabeln, an die manche von ihnen sogar auffallend anklingen, auf einen mythischen Kern zurückgehen. Ob jedoch dieser selbst den Orten angehört, an denen man diese Märchen vorfindet, oder ob er von außen zugewandert ist, bleibt angesichts der ungeheuren Verbreitungsfähigkeit, die bekanntlich solchen Märchen- und Fabelmotiven zukommt, in hohem Grad zweifelhaft. Auch wird dieser Zweifel nicht gemindert, wenn man beobachtet, daß diese ganze Märchenmythologie in dem, was der eigentliche und alleinige Prüfstein der wirklich lebendig.gebliebenen Glaubensvorstellungen eines Volkes ist, in dem Kultus, eine außerordentlich geringe Rolle spielt. Doch lassen wir diese hier nicht zu entscheidende Frage beiseite. Nehmen wir an, dieses ganze Gemenge von Märchen, Fabeln, zugetragenen und selbsterfundenen, samt dem spärlichen Kern eines ursprünglichen Mythus, der dahinter verborgen sein mag, sei wirkliche und echt€ Mythologie, so hieße es immer noch die Dinge in eine falsche Beleuchtung rücken, wenn man solche Naturmythen wie die oben angedeuteten als eine Art kausaler Interpretation der Naturerscheinungen betrachten wollte. Der Naturmensch, der in der Sonne einen strahlenden Helden sieht, will dadurch nicht im mindesten den Aufund Niedergang der Sonne erklären. Dieses Phänomen ist ihm eine unmittelbar gegebene Wirklichkeit, die als solche einer Zurückführung auf irgendwelche Ursachen um so weniger bedarf, als es sich alltäglich wiederholt. Auch daß die Sonne ein menschenähnliches Wesen ist, soll keine Erklärung des Phänomens sein. Denn daß ein beweglicher Körper belebt ist, das ist für den Naturmenschen ebenso selbstverstä́ndlich wie die Existenz dieses Körpers. Wiederum handelt es sich hier nur um die Konstatierung von Tatsachen. Wenn aber noch irgend etwas zu den Tatsachen selbst hinzukommt, so sind dies nicht interpretatorische Hilfshypothesen, sondern Phantasiegebilde, die sich so fest mit dem Eindruck verbinden, daß sie den Charakter der gleichen unmittelbaren Wirklichkeit annehmen wie dieser. 
18 Wilhelm Wundt: Die Anfänge der Philosophie und die Philosophie der primitiven Völker.

Die Zauber. vorstellungen.

Doch wenden wir jenes oben angedeutete Kriterium an, daß nicht die Märchendichtung eines Volkes, sondern der Kultus und neben ihm etwa noch der als ein Überlebnis früherer Kultformen zurückgebliebene Brauch über die in ihm wirklich lebende Weltanschauung Aufschluß gibt, so tritt allem Anscheine nach der auf die großen und regelmäßigen Himmelserscheinungen gehende Naturmythus zunächst weit zurück hinter den Motiven, die aus der unmittelbaren Umgebung und den an sie gebundenen praktischen Interessen hervorgehen. Auch hier gilt eben der Satz: je regelmäßiger die Erlebnisse sind, um so selbstverständlicher erscheinen sie zugleich. Wenn wir daher in den Aufzeichnungen über die Naturanschauung primitiver Stämme solchen Äußerungen begegnen wie der, die Sonne sei cin Stück Speck, oder die Sterne seien von andern Menschen gemacht, so liegt darin aller Wahrscheinlichkeit nach mehr von der wirklichen Herzensmeinung des Naturmenschen als in der manchmal üppig aufschießenden Märchendichtung, die man bei den gleichen afrikanischen und ozeanischen Völkern verarbeitet findet. Bedarf aber das Alltägliche und Regelmäßige für den Naturmenschen gar keiner Erklärung, so daß es auch nicht Gegenstand einer primitiven Naturphilosophie sein kann, so verhält es sich genau entgegengesetzt mit dem Ungewohnten, vor allem wenn dies Furcht und Schrecken erregend in sein eigenes Leben eintritt. Hier sind es vor allem zwei Erscheinungen, denen diese Eigenschaft im höchsten Maße zukommt: die Krankheit und der Tod, denen in etwas weiterer Distanz die meteorologischen Erscheinungen, das Gewitter, der bei ausdörrender Hitze mit Sehnsucht erwartete, für das Gedeihen der Nährpflanzen unerläßliche Regen sich anschließen. Die Krankheit, die plötzlich und unerwartet überfällt, und der Tod, besonders wenn er infolge einer Krankheit erfolgt, sie gehören nicht zu den regelmäßigen Ereignissen, die als solche selbstverständlich erscheinen. Je überraschender sie eintreten, um so mehr fordern sie die Frage nach ihrem Ursprung heraus. Diesen Ursprung aber, wie könnte ihn der Naturmensch anders denken als in der Form seines eigenen Wollens und Handelns? Wenn er selbst so manchmal dem ihn bedrängenden Feind Tod und Verderben wünscht, warum sollte er einen solchen Wunsch nicht auch bei diesem voraussetzen, und daneben wohl die Macht, diesen Wunsch zu verwirklichen? Das um so mehr, als hier von selbst Assoziationen mit den Vorstellungen der primitiven Psychologie, die uns oben begegnet sind, zu Hilfe kommen. Der Dämon, der im Traum oder in der Fieberphantasie erscheint, ist zugleich der Bringer von Krankheit und Tod. Aber auch wo er nicht erscheint, da zeigt das Kommen und Schwinden dieser Schattenbilder deutlich genug, daß es für sie kaum eine Schranke von Raum und Zeit gibt. So bildet sich die Vorstellung, daß der Wilie auch da wirken könne, wo der Wollende selbst nicht ist, und daß er durch magische Mittel, die in letzter Instanz immer auf eine Wirkung von Seele auf Seele zurückgehen, solche Fernewirkung vollbringe. Der böse Blick, symbolische Zauberhandlungen und Zaubersprüche sind die verbreitetsten dieser Mittel. Die natürliche Assoziation der Gefühle und Vorstellungen 
bringt es aber mit sich, daß sie geheimnisvoll, unverständlich sein müssen, um zauberkräftig zu sein.

Obwohl nun alle diese Eigenschaften dem, was wir heute zu einer kausalen Interpretation der Erscheinungen fordern, diametral gegenüberstehen, so sind doch gerade sie es, die zum erstenmal den Gedanken der Kausalität in dem naiven Bewußtsein des Naturmenschen aufsteigen lassen. Nicht das Gewohnte und Regelmäßige, sondern das Ungewohnte und Unerwartete regt ihn an. Und dieser Entstehungsweise entspricht die Form dieser Kausalität. Sie verknüpft nicht nach irgendeinem bestimmten Gesetz die Erscheinungen, sondern sie kann jede beliebige Ursache mit jeder beliebigen Wirkung verbinden. In allem dem ist der Zauber der volle Gegensatz zum Kausalbegriff der späteren Wissenschaft, der vielmehr von dem Irregulären, Inkommensurabeln tunlichst abstrahiert, um in der Konstanz der Verknüpfungen das Kriterium seiner Anwendung zu finden. Gleichwohl bezeichnet die Zaubervorstellung das erste Auftauchen des Kausalbegriffs in der primitiven Naturphilosophie. Denn hier zum erstenmal treten im Geiste des Naturmenschen selbst Ursache und Wirkung klar geschieden einander gegenüber. Hier zum erstenmal wird die Frage nach dem Warum gewisser Erscheinungen gestellt und beantwortet.

Wollte man die allmähliche Umwandlung dieser Zaubertheorie zur wissenschaftlichen Naturerklärung näher verfolgen, so würde das eine Entwickelungsgeschichte des Kausalbegriffs selbst sein. Für den gegenwärtigen Zweck muß es genügen, auf die zwei Hauptstadien hinzuweisen, die diese Entwickelung nach den in den mythologischen Anschauungen enthaltenen Zeugnissen durchläuft.

1. Die ersten Anfänge solcher Vorstellungen, die wir, weil sie mit Zauberwirkende jenem ursprünglichen Kausalbegriff operieren, eine primitive NaturphiloDämonen als sophie nennen können, sind allem Anscheine nach gleichzeitig mit dem Beginn der primitiven Psychologie. Daraus erklären sich genugsam die engen Beziehungen, in die beide Gebiete von frühe an miteinander treten. Diese Beziehungen finden darin ihren Ausdruck, daß als die ursächlichen Prinzipien bei der Kausalität der Zauberwirkungen se elenartige We sen angenommen werden. Unter den Bezeichnungen, die zu verschiedenen Zeiten für diese Wesen gebraucht worden sind, hat die der Dämonen unter dem Einfluß der späteren griechischen Philosophie die weiteste Verbreitung gewonnen, und sie ist darum für uns die verständlichste. „Dämonen" sind allgemein glück- und unglückbringende seelenartige Wesen. Sie können in manchen Fällen aus vormaligen Seelen entstehen: die Seelen Verstorbener können zu Dämonen werden, oder die Seelen Lebender, der Zauberer, können dämonische Kräfte ausüben. Aber nichts spricht dafür, daß alle Dämonen aus Seelen entstanden seien. Vielmehr ist es im höchsten Grade wahrscheinlich, daß, nachdem erst der Begriff der "Psyche“, der selbständigen Seele, gebildet war, nun eine Existenz solcher Dämonen vielfach auch da vorausgesetzt wurde, wo der Gedanke an ihre Entstehung aus individuellen Seelen 
20 Wilhelm Wundt: Die Anfänge der Philosophie und die Philosophie der primitiven Völker.

durchaus ferne lag. Sowenig daher diese Vorstellung ohne den eigentlichen Seelenbegriff möglich ist, so wenig läßt sich doch nachweisen, daß in dem Augenblick, wo die Vorstellung der Psyche existierte, nicht auch alsbald die des Dämons als eines der Psyche ähnlich gedachten Naturprinzips hervortrat.

Immerhin läßt sich innerhalb dieses ersten Stadiums der primitiven Naturphilosophie ein Übergewicht solcher dämonischer Zauberwirkungen, die von wirklichen Seelen ausgehen, nicht verkennen. Als Urheber jener Haupterlebnisse, auf die sich ursprünglich die Theorie der Zauberwirkungen gründet, gilt bald die feindlich gesinnte Seele eines Lebenden, der durch den bösen Blick oder durch andere in die Ferne wirkende magische Mittel den Zauber verübt, oder die Seele eines Verstorbenen, die aus irgendwelchen Gründen mißgünstig gesinnt ist. Doch mögen jene Erscheinungen anfänglich noch so sehr in den Vorstellungen des Naturmenschen vorherrschen, sie sind nicht die einzigen, die ihn bewegen. Glück in Jagd und Krieg und in sonstigen Unternehmungen, das Wachstum der Feldfrucht, das Gedeihen der Haustiere, das sind Interessen, auf die sich nicht minder die einmal rege gewordene Kausalität der Zauberwirkungen bezieht, und die mit zunehmender Kultur immer mehr in den Vordergrund treten. Nun füllen sich Feld und Wald, Flüsse und Täler, Schluchten und Berge mit Dämonen von mancherlei Art. Viele begleiten den Menschen als persönliche Schutz- oder Rachegeister, andere sind an den furchterregenden Eindruck einsamer Stätten gebunden. Die meisten aber beeinflussen mit ihren Zauberwirkungen die in das Leben des Menschen eingreifenden Naturerscheinungen, Regen und Sonnenschein, Saat und Ernte, oder sie stehen ihm bei in Kunst und Handwerk oder in dem, was sonst das Leben bringt, und wobei er sich Erfolg wünscht oder Unheil fürchtet. So sind es vornehmlich zwei Merkmale, die dieses erste Stadium der primitiven Naturphilosophie kennzeichnen. Das eine besteht darin, daß die äußeren Naturwirkungen mit dem menschlichen Leben selbst noch überall zusammenfließen. Regenzauber und Krankheitszauber, Vegetationsdämonen und Kobolde oder Hexen, die Vieh und Handwerksgeräte verzaubern, alles das bildet ein buntes Gemenge von Vorstellungen, das durch den ein en Gedanken der Zauberkausalität zu einem Ganzen verbunden wird. Das zweite Merkmal liegt darin, daß sich diese Interpretation der Natur denn hier läßt sich ja wirklich zum erstenmal im eigentlichen Sinne von einer solchen reden - nur auf die nächste Umgebung des Menschen und auf das, was in ihr sein Interesse beschäftigt, bezieht. Es soll damit nicht gesagt sein, daß nicht sporadisch auch hier schon Vorstellungen sich einstellen, die in weitere Ferne reichen. Doch im ganzen gelten auf dieser Stufe die großen Naturerscheinungen, Auf- und Untergang der Sonne, der Wechsel der Jahreszeiten, die Existenz der Menschen, Tiere und Pflanzen, noch als etwas Selbstverständliches, das, weil es immer so gewesen ist, keiner Erklärng bedarf. Beweger der Naturerscheinungen.

2. Hier setzt nun aber das zweite Stadium dieser Entwickelung ein. Indas Wunder. dem sich der Gesichtskreis des Menschen und seines Interesses erweitert, 
treten mehr und mehr den Gegenständen und Erlebnissen der nächsten Umgebung die ferneren Objekte zur Seite. Die natürliche Brücke bilden hierbei jene Erscheinungen, die der Nähe und Ferne zugleich angehören, wie der Regen, der mit der Vegetation in engster Beziehung steht, während er doch'durch seine Herkunft aus der regnenden Wolke und durch seinen Zusammenhang mit dem Gewitter in die Himmelserscheinungen hinüberreicht. Eine nicht minder wirksame Ursache dieser Erweiterung des Gesichtskreises bilden die aus der primitiven Psychologie unter dem Einflusse religiöser Motive hervorgehenden Vorstellungen über die Aufenthaltsorte der Seelen nach dem Tode, die in fortschreitendem Maße, je mehr sich der Glaube an ein Jenseits befestigt, in weitere Fernen verlegt werden. Anfangs in einsamen Schluchten oder auf hohen Bergen gedacht, rücken sie ferner und ferner, nach seligen Inseln, nach dem Himmel und den Gestirnen oder in die Tiefe der Erde. Das sind religiöse Vorstellungen, die an sich nicht dem Gebiet der Naturphilosophie angehören, die aber mächtig auf sie einwirken, indem sie die Grenzen, in denen sich diese Spekulationen bewegen, weiter und weiter ziehen, bis sie schließlich über die sichtbare Welt hinausreichen. Nun rücken daher vor allem auch die Himmelserscheinungen in die Sphäre jener Interessen, die in den eigenen Lebensschicksalen des Menschen ihren Mittelpunkt haben. Wie dies im einzelnen geschieht, ob der Mond oder die Sonne oder der Himmel, oder ob endlich Blitz und Donner und Wolken auf dem so sich eröffnenden gröweren Schauplatz der Naturmächte die Hauptrolle spielen, das ist eine für die spezifische Gestaltung der mythologischen und zum Teil auch der religiösen Vorstellungen sehr wichtige Frage, der Grundgedanke der primitiven Naturphilosophie wird aber davon kaum berührt. Denn dieser bleibt bei allen diesen Gestaltungen des Naturmythus schließlich der nämliche, der er auf der vorigen Stufe gewesen war. Von der Idee des Zaubers ist auch hier die Betrachtung der Erscheinungen beherrscht. Hiermit hängt zugleich die dem Mythus eigne Personifikation der Naturerscheinungen zusammen. Denn jede Zauberwirkung weist auf einen zauberischen Willen zurück, der als solcher an ein beseeltes Wesen, sei dies nun ein Dämon oder ein Gott, gebunden ist. Auch die Götter, die zunächst in den Naturerscheinungen verkörpert, dann als in der Regel unsichtbare Mächte hinter ihnen verborgen gedacht werden, bewahren aber in der Art ihres Wirkens durchaus den Charakter der Dämonen, wie denn diese letzteren zumeist als niedriger stehende Zauberwesen neben den Göttern fortdauern. Was beide, Dämon und Gott, scheidet, ist die größere Macht und der weitere Wirkungskreis sowie der persönliche Charakter der Götter, woran sich zugleich ein verwickelteres System von Regeln anschließt, die diese Zauberkräfte trotz ihrer unberechenbaren Willkür in den Dienst des Menschen zu bringen suchen. Dieses besonders im Opferkultus ausgebildete System bleibt gleichwohl im Prinzip nur eine Wechselwirkung von Zauber und Gegenzauber, wie sie schon in dem ursprünglichsten Dämonenglauben als eine natürliche Reaktion gegen die dem Menschen drohenden 
22 Wilhelm Wundt: Die Anfänge der Philosophie und die Philosophie der primitiven Völker.

dämonischen Mächte zu finden ist. Dennoch vollzieht sich unvermeidlich mit der Zunahme des Machtbereichs der Götter auch ein Wandel, zwar nicht in dem Wesen, aber in der Wertqualität dieser primitiven Kausalvorstellungen. Der ursprüngliche Zauber hat seine Heimat ausschließlich in den nächsten individuellen Lebensinteressen; seine Mittel sind niedrig, ebenso wie seine Macht beschränkt ist. Jene höhere Form des göttlichen Zaubers erstreckt sich dagegen über Stämme und Völker, und, wie sie in gewaltigen Naturerscheinungen zutage treten kann, so verschmäht sie auch mehr und mehr niedrige Hilfsmittel. Indem der Gott schließlich unmittelbar, nur durch seinen Willen, die Dinge fügt, verwandelt sich so der Zauber in das Wunder. Auch das Wunder bleibt seinem Wesen nach Zauber. Nur die unmittelbare Betätigung der zauberhaften Nacht und zumeist die Erhabenheit der Wirkung oder wenigstens des Zwecks zeichnen es zunächst aus. Erst indem es unter dem Einfluß religiöser Motive noch in eine Zeit hinüberreicht, wo die Zauberkausalität der primitiven Naturphilosophie abgelöst worden ist von dem Kausalbegriff der Wissenschaft, nimmt es nun auch noch die weitere Bedeutung einer Ausnahme von der Gesetzmäßigkeit dieser Kausalität an. So ergibt sich denn als das merkwürdige Endresultat dieser Entwickelung, daß alles das, was ursprünglich allein den Inhalt des Kausalbegriffs gebildet hatte, schließlich zum Gegensatz dieses Begriffs geworden ist.

Theogonische und kosmogonische Mythen Vorstufen philusophischer Kosmologie.
Das sittliche Loben und die. Maximen der Sittlichkeit. Früheste Spruchweisheit.

Dieser Wandel der Dinge wird nun noch von einer andern Seite her vorbereitet, bei welcher in dem Naturnythus bereits nahe Beziehungen zur künftigen Naturphilosophie hervortreten. In der mythischen Ausgestaltung der Naturerscheinungen beginnt nämlich der Zusammenhang dieser untereinander, zunächst noch eng assoziiert mit dem Wohl und Wehe des Menschen, dann allmählich selbständig dem letzteren gegenübertretend die Aufmerksamkeit auf sich zu lenken. So erwächst mitten heraus aus dem ursprünglich allein herrschenden praktischen Interesse an den Erscheinungen das the oretische, das sich Rechenschaft zu geben sucht über das Wie und Warum der Dinge. Es entstehen die theogonischen und kosmogonischen Mythen. Auch sie bewegen sich noch ganz im Gedankenkreis der Zauberkausalität. Die Naturgötter werden in ihnen durchaus als dämonisch wirkende beseelte Wesen gedacht. Aber das menschliche Schicksal ist bloß äußerlich mit diesem Wirken verflochten. Je mehr Theogonie und Kosmogonie zusammenfließen, um so mehr werden daher die Dichtungen dieser Art, bei denen nun auch die poetische Gestaltungskraft einzelner Denker einen starken Einfluß ausübt, zu Welterklärungen in mythischer Form. So bereitet sich hier die philosophische Kosmologie vor, die freilich erst in dem Augenblick in die Erscheinung tritt, wo die alte Form der Kausalität abgestreift wird und die neue einer regelmäßigen Ordnung der Erscheinungen ihre Stelle einnimmt.

IV. Primitive Ethik. Die sittlichen Anschauungen der Naturvölker beurteilt man in der Regel ausschließlich nach ihren Sitten und Handlungen, nach den äußeren Wirkungen also, die jene Anschauungen auf ihr Leben aus- 
üben. So berechtigt das nun im allgemeinen sein mag, so würde man doch offenbar mit einem verschiedenen Maße messen, wenn man diese Zustände ihrer Sitte mit den ethischen Systemen vergleichen wollte, die bei den Kulturvölkern durch die gemeinsame Arbeit von Religion und Philosophie entstanden sind. Diese Systeme suchen meist ein Ideal des sittlichen Lebens zu entwerfen, mit dem dieses Leben selbst bekanntlich keineswegs gleichen Schritt hält. Dazu kommt, daß man die Sitten und Handlungen des Naturmenschen nicht selten auch insofern an einem falschen Maße mißt, als man sich hier wiederum nicht in die Motive hineindenkt, von denen sie selbst bestimmt werden, sondern die Motive unseres eigenen Handelns ihnen unterschiebt. Was kann es z. B. unter diesem Gesichtspunkt betrachtet Scheußlicheres geben, als vom Blut des erschlagenen Feindes zu trinken oder von seinem Herzen zu essen? was Empörenderes, als das Fleisch der Angehörigen des eigenen Stamms zu verzehren? Dennoch rücken selbst diese, immerhin seltenen kannibalischen Sitten in eine mildere Beleuchtung, wenn man bedenkt, dab Tier und Mensch im allgemeinen in den Augen des Primitiven einander gleichstehen, und daß man mit dem Blut und Fleisch eines andern dessen seelische Eigenschaften, seinen Mut und seine Stärke sich anzueignen glaubt. Dazu kommt, daß neben den vielen Schattenseiten im Charakter des Naturmenschen auch einige Lichtseiten nicht fehlen, so falsch immerhin jenes Bild eines idealen Naturzustandes ist, das dereinst Rousseau, nicht ohne den Einfluß enthusiastischer Forschungsreisender des I 8. Jahrhunderts, entworfen hat. Das Wort, mit dem, wie erzählt wird, ein Indianer seinem fallenden Genossen in das Kampfgewühl folgte: „Wo der Skalp meines Freundes ist, da soll auch der meine sein!" - dieses Wort bezeichnet treffend die Treue gegen den Nächsten und das mutige Einsetzen der eigenen Person für die Stammesgemeinschaft, die den Naturmenschen nicht selten da auszeichnen, wo er nicht unter der Ungunst der Lebensbedingungen verkümmert ist. Dafür spricht überdies das treue Festhalten an der ererbten Sitte und die feste Geschlossenheit der Geschlechts- und Stammesverbände, der man in der Regel begegnet, falls nicht wiederum ungünstige Verhältnisse zerstörend eingewirkt haben.

Immerhin, wenn wir von einer ,primitiven Ethik" reden, so sollten wir auch hier, nach Analogie mit den andern Teilen der primitiven Philosophie, darunter nur das verstehen, was als der Niederschlag sittlicher Überzeugungen in anerkannten Maximen und in Aussprüchen über das, was lobens- und was tadelnswert sei, bei den Naturvölkern vorzufinden ist. Aus solchen einzelnen Maximen besteht ja auch die Ethik der Kulturvölker in ihren Anfängen, ehe die spätere Philosophie die in ihnen niedergelegten Gedanken zu Systemen zusammenfaßte. Bei den Australiern endet die Männerweihe der Jünglinge die wichtigste unter den Kultzeremonien dieser primitiven Stämme, mit der Einprägung der fünf allgemeinen Lebensregeln: den alten Männern zu gehorchen, den Freunden beizustehen, sein Eigentum mit den Freunden zu teilen, nicht mit Mädchen oder verheirateten Frauen zu verkehren, endlich 
die gemeinsamen Speisegebote zu befolgen. Das sind Normen einer sozialen Ethik neben Kultvorschriften, wie sie uns kaum anders auch in den frühesten Sittengesetzen der Kulturvölker begegnen. Auf der etwas vorgerückteren Stufe der afrikanischen Negerstämme und der nordamerikanischen Indianer findet sich vollends in Reden und Sprichwörtern manches, was sich wohl solchen Aussprüchen, wie sie in Griechenland den „sieben Weisen“ in den Mund gelegt wurden, an die Seite stellen läßt. Insbesondere die Negervölker sind reich an derartigen in Sprichwörtern enthaltenen Maximen praktischer Lebensweisheit; und mögen auch manche unter diesen vielleicht nicht ganz ohne den Einfluß der christlichen Missionare entstanden sein, die sie gesammelt haben, so trägt doch vieles ein hinreichend originelles Gepräge, um es als Ertrag der eigenen ethischen Reflexion dieser Menschen ansehen zu dürfen. Ich beschränke mich auf die folgenden Beispiele, die den allgemeinen, auch in der Einkleidung eigenartigen Charakter der Spruchweisheit der Neger kennzeichnen: „Ein langer Pfeil verbirgt sich nicht im Köcher." (Über das Durchschnittsmaß hinausgehen hat seine Nachteile.) „Schaftreiber laß den Zorn." (Zorn ist schädlich bei einem Geschäft, das Besonnenheit fordert.) „Die Stadt der Streitsüchtigen wird verbrannt.“ (Parteien gefährden ein Gemeinwesen.) „Verächter des Deinigen, du wirst stehlen.“ (Wer eigenes Gut nicht achtet, achtet auch fremdes nicht.) „Wenn du zwei Eisenstangen ins Feuer tust, verbrennt die eine.“ (Ne quid nimis.) „Ein Boot wird an beiden seiten gerudert.“ (Tue nichts halb.) Den Einfluß christlicher Ideen verraten die beiden folgenden, übrigens im Ausdruck unnachahmlichen Sprüche: „Wenn du Gott etwas zu sagen begehrst, so sag es dem Winde." (Gott umgibt dich übera11.) „Wenn die Henne Wasser trinkt, so zeigt sie es Gott.“ (Für alles, was du genießest, danke Gott, - spielt auf die Stellung der Henne beim Trinken an.)

Das sind Maximen, die sich immerhin mit manchem, was uns von den Aussprüchen griechischer oder indischer Philosophen überliefert ist, messen können. Doch, wenn wir von den sichtlich von außen zugeführten, nicht sowohl ethischen als religiösen Gedanken absehen, so bleibt nicht zu verkennen, claß diese ganze Spruchweisheit auf das Gebiet är jerer lebensklugheit beschränkt bleibt. Nach einem Satze, wie er uns von Heraklit überliefert ist: ,Bestünde das Glück in körperlicher Lust, so müßte man die Ochsen glücklich preisen, wenn sie Erbsen fressen", oder wie er schon dem Demokrit zugeschrieben wird: "Wer unrecht tut, ist unglücklicher als wer unrecht leidet“, nach solchen Sätzen wird man sich vergeblich umsehen. Nicht als ob es ganz an der immerhin selbst zu jenen Klugheitsregeln unerläßlichen sittlichen Gesinnung mangelte. Aber noch verbirgt sich diese hinter der Hülle des äußeren Tuns. Noch fehlt es ganz an der sittlichen Selbstbesinnung, die uns aus den Aussprüchen der griechischen Philosophen entgegenleuchtet, und mit der erst eine wirkliche Ethik in das Licht der Geschichte tritt.

V. Rückblick und Ausblick in die kommende Philosophie. Für den Naturmenschen gibt es keine rein theoretischen Probleme, keine Fragen 
an die Natur, die bloß um der Erkenntnis selbst willen von ihm gestellt werden. Ihn beherrscht nur ein praktisches Interesse: sein eigenes Wohl und Wehe, und sein Wehe mehr als sein Wohl. So ist ihm alles, was er wahrnimmt und zugleich phantastisch ergänzt und verknüpft, unmittelbare Wirklichkeit. Dieser naive Glaube beherrscht seine Psychologie und Naturphilosophie, und er reflektiert sich schließlich auch in seinen überall an der Außenseite des Tuns haftenden ethischen Maximen. Wo wird nun zuerst jener große Schritt getan, der von der naiven Überzeugung zum Zweifel, von dem eng begrenzten praktischen Interesse am eigenen Leben zum rein intellektuellen Problem, zu dem ersten noch tastenden Streben nach einem Wissen um des Wissens selbst willen führt? Die Antwort auf diese Frage kann nicht zweifelhaft sein. In der Geschichte der kommenden Philosophie wird sie unzweideutig gegeben. Diese Philosophie, die von dem Zweifel, von der Frage ausgeht, hat als Naturphilosophie begonnen. Der große Umschwung, durch den sich die mythische in die philosophische Kosmologie umwandelt, besteht aber zunächst nicht sowohl darin, daß an die Stelle sinnlicher Bilder allgemeine Begriffe treten - von diesen ist bei den ältesten Philosophen noch wenig zu spüren -, sonder n darin, daß Zauber und Wunder aus der Welt verschwinden, weil nicht das Irreguläre und Unerwartete, sondern das Regelmäßige, das Beharrende und das Gesetz im Wandel der Erscheinungen zur großen Frage der Philosophie wird. Die Erhabenheit der Naturanschauung, die sich damit eröffnet, vertieft zugleich die aus der praktischen Lebenserfahrung geschöpfte Klugheitsre gel zur sittlichen Selbstbesinnung. Diese führt zur Ethik und in weiterer Folg e zu einer dem Zusammenhang der seelischen Vorgänge nachgehenden Psychologie.

Doch mitten hinein in diese Entwickelung der kommenden Philosophie reichen mannigfache Reste und Überlebnisse jener primitiven, die heute noch das Denken der Naturvölker beherrscht, und die dereinst das Denken aller Kulturvölker beherrscht hat. Es ist wohl der Müh e wert, sich nach diesen Resten umzusehen und den Bedingungen nachzuspüren, die ihre Erhaltung begünstigt oder, wo sie abgestorben sind, ihr Verschwinden bewirkt haben. Zweifellos am vollständigsten ist der Sieg des Neuen über das Alte und Primitive in der Naturphilosophie. Die Kausalität des Zaubers ist hier frühe schon völlig verschwunden. Auch das religiöse Bedürfnis, das diesem Gebiet lange noch eine Ausnahmestellung gewährte, hat mehr und mehr auf sie verzichten gelernt. So ist dieser Sieg gleichzeitig ein Ergebnis der philosophischen und der religiösen Entwickelung. War es der religiöse Trieb, der, nach den Wohnstätten der Götter und der Seligen suchend, das Seinige zur Erweiterung der Naturanschauung beitrug, so endete dieses Streben schließlich, eben weil es über jede erreichte Grenze immer wieder hinausführte, notwendig mit dem Verzicht, das Gesuchte überhaupt in der sinnlichen W'elt zu finden. So erhob die Religion ihre Objekte ins Unendliche, Unsichtbare, während die sichtbare Welt der Naturphilosophie und den von ihr aufgestellten natürlichen Prinzipien der Dinge überlassen blieb. Auch die Ethik 
hat sich mit dem Übergang der primitiven in die definitive Philosophie aus der Verbindung, in welcher der Mythus Religion und Philosophie umspannte, nur allmählich gelöst. Aber diese Lösung ist, ebenso wie die Wechselwirkung, die ihr vorausging, in diesem Fall eine völlig andere gewesen. Nicht in der Trennung, sondern in der innigen Durchdringung der Gebiete, in der Rückwirkung eines von der ursprünglichen Zauberwelt dämonischer Mächte befreiten und zum Unendlichen erhobenen religiösen Gefühls hat die sittliche Selbstbesinnung jene Vertiefung erfahren, die ihr schlieblich auch der Religion gegenüber ihreSelbständigkeit sicherte. Der Hauptzeuge dieserWechselbeziehung ist der größte Religionsphilosoph der Griechen, der zugleich trotz Sokrates ihr größter Ethiker ist: Plato. Sind hier die Nachwirkungen der primitiven Philosophie überall vorübergegangen oder im Schwinden begriffen, so reichen sie aber in einem Gebiet noch weit in die Zukunft: in der Psychologi e. Derselbe Plato, der den Homer aus dem Jugendunterricht verbannen wollte, weil er falsche Naturanschauungen und unwürdige sittliche Ideen von den Göttern verbreite, er folgt in seinem Begriff der Psyche und in der Stellung, die er ihr zu den Organseelen anweist, in allem Wesentlichen noch Homerischen Vorstellungen. Was er hinzufügt, das gehört nicht der Psychologie, sondern der Religion an, wie denn auch das ideale Bild, das er von der Psyche und ihrer Zukunft entwirft, aller Wahrscheinlichkeit nach in den Mysterienkulten seine Wurzeln hat, in denen selbst wieder ein uralter Seelenkult fortlebte. Aristoteles aber gibt nur eine sorgfältigere Systematisierung der gleichen Seelenbegriffe, und als endlich im Eingang der neueren Philosophie Descartes auch in der Psychologie das aristotelisch-scholastische Lehrgebäude beseitigt, da reduziert sich seine Reform der Grundbegriffe im allgemeinen darauf, daß er die Organseelen mit Hilfe der mittlerweile zur Herrschaft gelangten mechanischen Naturphilosophie entbehrlich zu machen sucht, um den Begriff der selbständigen Psyche nun um so reiner zurückzubehalten. So ist auch diese letzte Entwickelung noch in direckter Deszendenz aus jener Hauch- und Schattenseele hervorgegangen, in denen der primitive Mensch aller Zeiten und Zonen das Rätsel des Lebens gelöst sieht. Unzweifelhaft ist es wiederum der religiöse Trieb, der hier entscheidend auf die Entwickelung der Vorstellungen gewirkt hat. Doch während er in der Naturphilosophie im Laufe der Zeit mehr und mehr einer völligen Sonderung der Gebiete vorarbeitete, und in der Ethik zuerst eine fördernde Wechselwirkung ausübte, um dann gleichfalls die Selbständigkeit der ethischen Betrachtung sicherzustellen, hat er in der Psychologie bis zum heutigen Tage eine konservative $\mathrm{Kraft}$ bewährt, zu der uns parallele Erscheinungen fast nur noch in der Erhaltung mancher Bräuche begegnen, in denen Gedanken und Handlungen der Urzeit in veränderter oder abgeblaßter Bedeutung unter uns fortwirken. 


\section{Literatur.}

Zu S. 6 ff. Die für die Logik des primitiven Denkens bezeichnenden Eigenschaften der Sprachen der Naturvölker finden sich eingehend erörtert in Bd. 2 meiner Völkerpsychologies, S. $436 \mathrm{ff}$.

Zu S. 6f. Über Zahlwörter in primitiven Sprachen vgl. PoTt, Die quinare und vigesimale Zählmethode (1847); K. voN DEN STEINEN, Unter den Naturvölkern Zentralbrasilieus (1897), S. 84f.; Leo Frobenius, Die Mathematik der Ozeanier, Probleme der Kultur (Igor): P. W. Schmid, Mitteil. der Wiener anthrop. Ges., Bd. 33 (1893).

Zu S. 7. Über die Klassenpräfixe der Bantusprachen vgl. C. Meinhof, Grundriß der Lautlehre der Bantusprachen (1899), S. 12, 200 f.; Grundzüge einer vergl. Grammatik der Bantusprachen (1906), S. I ff. Über ähnliche Erscheinungen in andern afrikanischen Sprachen Christaller, Zeitschr. für afrikan, und ozeanische Sprachen I (I895), S. 23 ff.

Zu S. Io. Für das Gebiet der primitiven Psychologie hat vor allem das Werk von E. B. Tylor, Die Anfänge der Kultur, deutsch von Spengel und Poske, 2 Bde. (1873), als eine erste umfassende Sammlung der Erscheinungen des Seelenglaubens bei verschiedenen Völkern epochemachend gewirkt. Ebenso haben A. BASTIAN in seinen verschiedenen Werken, besonders in seinen Beiträgen zur vergleichenden Psychologie (1868) und WaITz.GERLAND in der Anthropologie der Naturvölker, 6 Bde. (1859-72) mannigfaches Naterial beigebracht, das freilich im allgemeinen nicht zureichend nach psychologischen Gesichtspunkten geordnet ist. Auch bedarf selbst das Tatsächliche in diesem Gebiet der Ergänzung durch mancherlei in neuerer Zeit veröffentlichte Beobachtungen, die in der reichen ethnologischen Literatur über Mythologie, Sitten und Kultus der Naturvölker zerstreut sind. Vieles hat, freilich durchaus unter den Gesichtspunkten seines philosophischen Systems, HERBERT SPENCER in seiner Soziologie, bes. Bd. I und 4, zusammengestellt. (Deutsche Ausgabe von B. VETTER IIKTOR CARUS [1877-97].) Auch hier entspricht aber das Tatsächliche nicht mehr überall unseren heutigen Kenntnissen. Eine gute Errgänzung bildet das umfassende Werk von J. G. FRAzER, The golden Bough, 3. Edit. 4 vol. (1912). Viele hierher gehörige Erscheinungen erörtern ferner $\mathrm{K}$. Тн. PREUSS in seinen Aufsätzen über den Ursprung der Reli. gion und Kunst, Globus, Bd. 26 u. 27 (1904), ferner SPENCER and Gillen in ihren beiden Werken: The native Tribes (1 899) und The northern Tribes of Central Australia (1906) sowie meine Völkerpsychologie IV, 2. Für die Frühzeit der Kulturvölker sind besonders zu nennen: ERwin Rohde, Psyche, Seelenkult und Unsterblichkeitsglaube der Griechen, 2 Bde. (i. Auf. I 893, 3. Aufl. 1903); Oldenberg, Religion des Veda (1894), S. 524 ff.; W. Robertson Smith, Die Religion der Semiten, deutsch von E. STÜbe (1899), bes. S. 162 ff. Eine Entwickelungs geschichte der primitiven Psychologie und ihrer nächsten Weiterbildungen in Kultus und Mythus habe ich in Bd. 2, Teil II meiner Völkerpsychologie zu geben versucht.

Zu S. I2. Über den Seelenwurm und die mit ihm zusammenhängenden Bräuche so wie über deren Verbreitung in Ozeanien, Australien, Nordwestamerika und den westlichen Teilen Afrikas vgl. L. FrobenıUS, Die Weltanschauung der Naturvölker (1898), S. 51 ff:

Zu S. 12. Erscheinungen, die bei den Australiern auf die Nieren als Sitz der Seelen hinweisen, vgl. bei Lumholtz, Unter Menschenfressern (1892), S. 317; A. W. HowrT, The native Tribes of South-East Australia (1904), p. 367 . Unter den alttestamentlichen Stellen 
seien aus vielen anderen nur erwähnt 2. Moses 29, 13; 3. Moses 3, I0; Psalm 7, 10; Hiob 16, 13. Vgl. dazu R. Smith, a. a. O., S. 293 ff. Einerseits gelten bei den Semiten die Nieren als Sitz der Seele, andererseits als ein besonders wertvolles Opfer, eine Doppelheit des Begriffs, die auch schon in den verschiedenen Verwendungen, die sie bei den Wilden Australiens finden, angedeutet ist. Bei den Indogermanen treten diese Vorstellungen in der historisch erreichbaren Zeit zurück. Daß bei der Leichenverbrennung der Inder nach altem Ritus die Nieren des Opfertiers in die beiden Hände der Leiche gelegt wurden, ist aber möglicherweise hierher zu beziehen. (OLDENBERG, a. a. O., S. 577; HARDY, Die vedisch-brahmanische Periode des alten Indiens [1893], S. 187.) Vielleicht noch entscheidender sind die Hinweise der Wortbedeutungen: vєфpoi bedeutet sowohl Nieren wie Hoden wie Gedanken (Suidas s. v.). Über die Rolle des Geschlechtslebens in der älteren Mythologie vgl. K. Th. Preuss, Phallische Fruchtbarkeitsdämonen als Träger des altmexikanischen Dramas, Archiv für Anthropologie, N. F., Bd. 1, S. I $29 \mathrm{ff}$. Durch diese Beziehungen fällt wohl auch ein gewisses Licht auf den zunächst seltsam erscheinenden Brauch des Phallus als Gegenzauber, besonders gegen den bösen Blick, wie er im griechischen und römischen Altertum verbreitet war und noch heute nicht ganz erloschen ist. Gegen die feindliche Seele, die im Blick nach außen wirkt, reagiert die eigene seelische Kraft, die in den Nieren und den von ihnen abhängig gedachten Organen ihren Sitz hat. Wenn der Australier, wie LuMHOLTz berichtet, ein Stück Niere in einem Körbchen um den Hals trägt, um sich gegen den bösen Blick zu schützen, und wenn noch heute in Europa die als Andeutung des Phallus gebrauchte geballte Faust mit eingeschlagenem Daumen zum selben Zweck vorkommt, so scheinen dies also nur Modifikationen einer und derselben ursprünglichen Anschauung zu sein.

Zu S. I3ff. Über den Hauch als Seele bei Indern und Griechen vgl. E. Windisch, Ber. der sächs. Ges. der Wiss. Phil.-hist- Kl. (1891), S. I55If. Wie hier, so spielt auch bei den Naturvölkern im allgemeinen der Körperteil, den wir heute gewohnt sind als den Sitz der Seele zu betrachten, der Kopf, mit verschwindenden Ausnahmen kaum eine Rolle. Auch wenn Plato im Timäus die denkende Seele in den Kopf verlegt (Timäus 69 Cff.), so sind hier ganz andere spekulative Gründe offenbar maßgebend, als wie sie sonst für die Bestimmung des Seelensitzes gelten: das Haupt als der edelste Körperteil ist für den Philosophen der allein würdige, um die unsterbliche Psyche zu tragen. In der Wissenschaft hat sich erst seit dem 16. und 17. Jahrhundert, in der Philosophie vor allem unter dem Einfluß Descartes' die neue Ansicht durchgesetzt. Noch Thomas Hobbes hält mit Aristoteles und der Scholastik das Herz für den Hauptsitz der Seele. Mit dem letzteren wird dann in der Regel zugleich die uralte, an sich ganz selbständig entstandene und allverbreitete Ansicht vom Blut als Sitz der Secle in Verbindung gebracht.

\%u S. 14. Über den Seelenvogel bei Naturvölkern vgl. Frobenius, Weltanschauungen der Naturvölker, S. 3 ff. (Ozeanien, Australien, Nordwestamerika und Afrika); bei Kulturvölkern G. WEICKER, Der Seelenvogel in der alten Literatur und Kunst (1902).

Zu S. 15. Über den Übergang der Hauch-in die Schattenseele bei Homer vgl. bes. 11. 16, $851 \mathrm{ff}$., Od. 11, $69 \mathrm{ff}$. Auch das Blut als seelische Kraft spielt in diese Vorstellungen hinein: durch den Genuß des Blutes der Opfertiere erwachen die Seelen zu einem vorübergehenden Bewußtsein. Doch ist diese Bewußtlosigkeit der Schatten eine Vorstellung, die der Homerischen Psychologie spezifisch eigen zu sein scheint.

Zu S. 17. Die Verbreitung der Sonnenmythen in Ozeanien, Nordwestamerika und Afrika ist eingehend geschildert von Frobenius, a. a. O., S. 94 ff. Der märchenhafte Charakter, den diese Mythen zumeist an sich tragen, dürfte wohl, neben der geringen Bedeutung, die sie in Kultus der meisten dieser Völker besitzen, nicht bloß für eine Rückbildung, wie sie der Verf. annimmt, sondern in vielen dieser Gebiete für eine von Anfang an geschehene Ausbildung in der Märchenform sprechen. Von Fritz Schultze (Psychologie der Naturvölker [1900], S. $316 \mathrm{ff}$.) ist betont worden, in dem Naturmythus habe der Mond ursprünglich gegenüber der Sonne die vorwiegende Bedeutung, worauf dann nach dieser die Sterne und zuletzt der Himmel als solcher auftreten. Der gleichen Anschauung huldigen viele der neueren Naturmythologen, wie SIECKE (Liebesgeschichte des Himmels 1892, Mytho- 
logische Briefe 1901, Drachenkämpfe 1907), EHREnREICH (Allg. Iy thologie auf ethnolog. Grundlage 1910). Die gleichen Anschauungen vertreten im allgemeinen die Arbeiten der seit 1907 erscheinenden ,Mythologischen Bibliothek“, der auch die zitierte Schrift Ehren. REICHS angehört. Eine verwandte Ricitung verfolgt endlich ED. STACKEN in seinem über ein weites Gebiet von Märchen, Legenden und Sagen sich erstreckenden Werk über „Astral. mythen" (1907). Doch sollen nach ihm hauptsächlich" die Sternbilder des Orion und der Plejaden die Substrate der Himmelsmythologie und damit, infolge des vorherrschenden Ein Alusses der Himmelserscheinungen, der Mythologie überhaupt bilden.

Zu S. 19. Über Vegetationsdämonen und mancherlei Bräuche, dic mit ihnen zusammenhängen, vgl. Mannhardt, Wald. und Feldkulte, bes. Bd. 2 (1877); J. G. Fr.zzer, The golden Bough ${ }^{3}$. Über den Übergang der Dämonen in Götter und die Beziehungen beider in den Vegetations- und andern Kulten meine Völkerpsychologie, Bd. 5, S. $419 \mathrm{ff}$. $462 \mathrm{ff}$. sowic Elemente der Völkerpsychologie, 1912, S. $348 \mathrm{ff}$.

Zu S. 22. Rücksichtlich der Vorstellungen über das Seelenland bei Naturvölkern rgl. die Zusammenstellungen von E. B. TyLor, Anfänge der Kultur, Bd. z, S. $73 \mathrm{ff}$; Fr. Schultze, Psychologie der Naturvölker, S. $285 \mathrm{ff}$. Über die Vorstellungen bei den Griechen: DiETERICH, Nekyia (I 893); Radermacher, Das Jenseits im Mythus der Hellenen (1903). Für die Erweiterung der Naturanschauung unter dem Einflusse der Jenseitigkeitsvorstellungen spricht wohl auch die geringe Entwickelung des Naturmythus und einer primitiven Naturphilosophie bei den Israeliten, bei denen jene Vorstellungen durch den Jahvekultus in den Hintergrund gedrängt wurden. (BERTHOLET, Die israelitischen Vorstellungen vom Leben nach dem Tode [1899:; Dafür hat sich bei ihnen in den Totenbräuchen die Erinnerung an den Ur. sprung der Leichenbestatiung aus dem Wunsch, den Seelen der Verstorbenen die Wiederkunft als Dämonen unmöglich zu machen, zum Teil noch deutlich erhalten. Wenn bei den Indogermanen dieser Ursprung linter der Auffassung der Erde als Mutter und der Be ziehung zu den chthonischen Göttern zurückgetreten ist (DIETERICH, Archiv für Religions. wissenschaft, Bd. 8, S. 1 ff.), so hat man auch wohl hierin einen unter dem Einflusse des Naturmythus entstandenen Bedeutungswandel zu sehen, welcher die dereinst wahrscheinlich überall der Bestattung zugrundeliegenden Vorstellungen verändert hat. In voller Wirksam. keit findet man die Dämonenfurcht als Motiv der Bestattungs- und anderer Totenbräuche noch bei manchen Naturvölkern. Vgl. z. B. den Bericht von O. Schellong über die l'apuas auf Neu-Guinea (Zeitschr. für Ethnologie, Bd. 2 I [1889], S. $23 \mathrm{ff}$.) und von HowitT über dic Australier (The native.Tribes of South-East-Australia, p. $446 \mathrm{ff}$.).

$\mathrm{Zu} \mathrm{S.} \mathrm{23.} \mathrm{Über} \mathrm{die} \mathrm{Männerweihe} \mathrm{der} \mathrm{Jünglinge} \mathrm{bei} \mathrm{den} \mathrm{Australiern} \mathrm{vgl.} \mathrm{Howrr}$ a. a. O., p. $509 \mathrm{ff}$; moralische Regeln: p. 633. Daß sich diese Regeln einer weit ausge. dehnten Anerkennung erfreuen, zeigen übrigens Schilderungen sittlicher Zustände von Naturvölkern, die selbst wieder sehr verschiedenen Kulturstufen angehören. Man vgl. z. B. die Angaben von P. und F. SARAsin über die höchst primitiven Weddas auf Ceylon mit den Mitteilungen LEONH. SCHULTzES über die bereits eine relativ hohe wirtschaftliche Kultur repräsentierenden Hottentotten. (P. und F. SARASIN, Ergebnisse naturwissenschaftlicher Forschungen auf Ceylon, Bd. 3, I893, S. 458 ff. Leonh. Schultze, Das Namaland und Kalahari, 1907, S. 332 ff.) Die mitgeteilten Negersprichwörter sind zum größten Teil entnommeı den Sammlungen von A. SEIDEL bəi den Wa-Bondei in Deutsch.Ostafrika (Zeitschr. fur afri kanische und ozeanische Sprachen, Bd. 5 [1900], S. 76) und bei den Nyassa ebenda 13d. 1 [1895], S. 132), einige auch einer solchen von Christaller aus dem Gebiet der Tshi-Nieger (ebenda Bd. 1, S. 184) sowie einer älteren Zusammenstellung von WiTz von den Odschi und Joruba (Anthropol. der Naturvölker, II, S. 245 f.). Vgl. auch C. Mrinнof, Dic I)ichtumgr der Afrikaner, 19II. 


\title{
DIE INDISCHE PHILOSOPHIE.
}

\author{
VON \\ Hermann Oldenberg.
}

Pbilosophie und Religion.
Einleitung. Die Grenzen, die Philosophie und Religion scheiden, sinc in Indien noch unbestimmter als anderwärts. Hier gehörten die ältesten Philosophen dem Priesterstand an. Ihre Dichtungen wurden unter die Opferhymnen des Rigveda aufgenommen. Dem Allwesen, das bald in den Mittelpunkt des Denkens trat, gab priesterliches Selbstbewußtsein jenen Namen, der von alters her die geheime Kraft und Heiligkeit der Priesterkaste und des Vedaworts benannte: Brahma. Und wenn sich aus der Brahma-Spekulation auch frühzeitig Gedanken entwickelten, die mit dem alten Glauben unvereinbar waren, kleideten sich alsbald ernsteste und mächtigste unter ihnen selbst wieder in religiöses Gewand: so die Lehre der buddhistischen Mönchsgemeinde, in der sich überall Ansätze voraussetzungslosen oder Voraussetzungslosigkeit erstrebenden Denkens mit der Bereitwilligkeit zum gläubigen Hinnehmen von Überkommenem unlösbar vermischen. Mochte dann weiter im Lauf der geschichtlichen Entwickelung die Philosophie neben der Religion immer entschiedener ihr eignes Wesen ausprägen: sie hörte doch, soviel sich erkennen läßt, nie auf, den Kontakt mit der einen oder der anderen religiösen Richtung festzuhalten: wovon bezeichnenderweise, wie wir sehen werden, sogar der extreme Materialismus nicht ausgenommen war. Systeme über Systeme buddhistischer Philosophie entstanden und gingen unter. Andere Systeme - unter ihnen die, welche zugleich als die Besitzer des dauerndsten Einflusses und für uns als die am genauesten erforschten im Vordergrunde stehen - haben sich in freundlicher Nähe zum Brahmanentum gehalten oder es mindestens vermieden, Entfernung von ihm äußerlich allzu scharf hervortreten zu lassen. Besab das brahmanische religiöse Wesen doch zugleich höchste Macht über Denken und Leben des Volks und eine vollendete, durch kein Dogma, keine Hierarchie gebundene Beweglichkeit. So war es fähig, auch auf Gedankenkreise, die ihm im Grunde fern standen, Einfluß zu üben, und wenn die Philosophie, von keinen Anziehungskräften einer stark entwickelten Profanwissenschaft in Beschlag genommen, ihm als schätzbarstem Bundesgenossen entgegenkommen mochte, war es wenig disponiert, solche Freundschaft abzuweisen. 
I. Die Brahma-Spekulation. Der Versuch, den ich an anderer Stelle dieses Werkes machte, die Entwickelung der indischen Religionen zu beschreiben - dort ist auch in Kürze von den geschichtlichen, nationalen Voraussetzungen des indischen Denkens gesprochen worden -, konnte aus diesen Gründen nicht anders, als die Gebiete, die der Religion mit der Philosophie gemeinsam sind, vielfach berühren. So war von jenen mächtigen Gedankengängen der jüngeren Vedazeit die Rede, welche der Philosophie Indiens für alle Zukunft die Richtung gegeben haben. Es geschah hier, was sich dann an so vielen Orten, zu so vielen Zeiten immer wieder erneuert hat. Das Denken erlebte das große Erlebnis der Mystik. In die Tiefe des Ich sich versenkend fand es dort, was ebenso Meister Eckhardt und so mancher Suchende da gefunden hat: die über jede Vielheit erhabene Einheit alles Seins. Die Weise, in der sich dies Erlebnis in den mystischen Traktaten des Veda, den Upanișaden darstellt, versuche ich hier nicht von neuem eingehender zu beschreiben: die Gedanken von Dem,

,der schwer zu schaun ist, im Verborgnen weilend,

der in der Höhle haust, der Gott, der Alte" -

die Gedanken vom Brahma, dem All-Einen. Das Brahma ruht in den Tiefen alles Endlichen. Es ist ,hinweg über Hunger und Durst, über Kummer und Wirrsal, über Alter und Tod". Es ist wesensgleich mit dem Ätman, dem lch, und in ihm findet das Ich, wenn es befreit vom Nichtwissen erkennt Tat tvam asi „Das bist Du“, Lust und Leiden von sich abtuend, der Pein der Seelenwanderung entnommen seine Ruhe. Die Spekulation vom Brahma, die Sinnenwelt als wertlos von sich stoßend, wies auf ein höchstes Ziel alles Daseins hin, zu dem das vollkommene Erkennen den Erkennenden führt. Damit war der Philosophie, die auf solcher Grundlage weiterbaute, von vornherein ein wesentlichster Charakterzug aufgeprägt. Das Erkennen wurde hier nicht um seiner selbst willen, sondern als Spender weltentnehmender, leidenthebender Erlösung erstrebt.

Die Konzeption des Brahma aber, wie sie in den Upanisaden dasteht, war - wie konnte es anders sein? - überall von Unsicherheiten und Widersprüchen durchsetzt. Wie verhält sich das Brahma zur Welt? Wie zum Ich? Das Brahma soll das All-Eine sein: „nicht ist hier Vielheit irgendwie“. Und doch drängt sich beständig die Welt der Vielheit als real der Vorstellung auf. Das Ich soll das Brahma sein: „Das bist Du." Und doch bleibt fortwährend das Bewußtsein der eigenen, individuellen, beschränkten Existenz mit unbezwinglicher Macht lebendig: wo sich dann das Einssein mit dem Brahma nicht als die Wahrheit gegenüber dem Schein, sondern als die $\mathrm{Zu}-$ kunft gegenüber der Gegenwart darstellt: „Zu ihm werde ich, wenn ich von hinnen scheide, eingehen."

So klafften die Widersprüche zwischen Weltwirklichkeit und Idee. Sie trieben das Denken vorwärts. Verschiedene Richtungen konnten eingeschlagen werden. Man konnte der Realität von Welt und individueller Seele recht geben: dann war es natürlich, daß die Idee des Brahma erblaßte, viel- 
leicht hinschwand. Oder den Durst des Denkens nach Einheit alles Seienden zu stillen konnte man der Idee des Brahma recht geben: dann mußte schließlich der Gedanke die Oberhand gewinnen, der sich in den Upanisaden nur halb verhüllt ankündigt: daß Welt, individuelle Seele ein bloßer Schein ist, der die Wahrheit des Ewigen, Einen als bunter Trug umspielt.

Die älteren $S_{y}$. steme der Philosophie.

II. Überblick über die älteren Systeme der Philosophie. Die philosophischen Texte. Die Durcharbeitung dieser Probleme knüpft sich, wenigstens in der älteren Zeit, zum großen Teil vielmehr ăn die Namen von Schulen als von einzelnen Denkern, ähnlich wie wir in der Vedapoesie, im Epos Mahäbhārata Schöpfungen ungenannter oder nur von wertlosesten Überlieferungen genannter Verfasser vor uns haben und erst später die bedeutenden Persönlichkeiten von Poeten wie Aśvaghoṣa oder Kälidāsa erkennbar und benennbar werden.

Buddhistische, auch jainistische Quellen lassen uns - leider sehr flüchtige - Blicke in das Wogen der Meinungen tun, die um die Zeit des entstehenden Buddhismus (ca. 500 vor Chr.). den Schauplatz erfüllten. Da fielen Schlagworte wie "Alles scheint mir wahr" und "Alles scheint mir unwahr". Über Ewigkeit und Vergänglichkeit der Welt, über ihre Endlichkeit und Unendlichkeit wurde gestritten, über Lohn und Strafe der guten und bösen Werke und über die These, daß „Weise und Toren, wenn der Körper sich auflöst, der Zerstörung und dem Nichts anheimfallen; sie sind nicht jenseits des Todes". Eine Fülle der Keime von Gedanken und Weltanschauungen. Von ihrem Sichentfalten hören wir aus dieser alten Zeit nur allzu wenig.

Einen festen Punkt bietet uns dann, etwa zwei Jahrhunderte nach der Zeit des Buddha, ein'eben jetzt bekannt gewordenes wichtiges Zeugnis. Es findet sich in einem Traktat über Staatskunde, der dem Kautilya oder Cānakya zugeschrieben wird, jenem vielgenannten Staatsmann, der nach Alexanders des Großen Tode dem auch der griechischen Überlieferung wohlbekannten Candragupta (Sandrokottos) zur Herrschaft verholfen hat. Rührt jene Schrift in der Tat von Canakya oder, was eher anzunehmen scheint, von Schülern, die an ihn anschließen, her - und ernstliche Gründe zum Zweifeln liegen nicht vor - , so ist damit das Alter des betreffenden Zeugnisses mit einer in der älteren indischen Literaturgeschichte leider seltenen Bestimmtheit in die Zeit nicht lange nach 300 v. Chr. gerückt. Dort nun wird in einer Aufzählung der Wissenschaften neben der Vedawissenschaft, der Wissenschaft

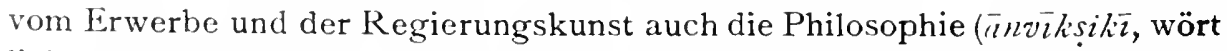
lich „die auf Prüfung beruhende [Wissenschaft]") genannt und von ihr gesagt, daß sie „Recht und Unrecht in der Vedakunde, Gerwinn und Verlust in der Erwerbslehre, gute und schlechte Politik in der Regierungskunst, dazu Kraft und Schwäche aller dieser Wissenschaften mit Gründen prüfend der Menschheit Nutzen bringt, in Mißlingen und Gelingen die rechte Einsicht gibt und Gewandtheit von Denken, Reden und Tun verleiht:

"Als alles Handelns Hilfsmittel, als Leuchte aller Wissenschaft, Als aller Pflichten Grundlage gilt immerdar Philosophie" - 
eine Beschreibung der von der Philosophie gespendeten Güter, der man die Autorschaft des Politikers viel mehr als des Philosophen wohl anmerkt. Solche Philosophien, so belehrt uns nun der Verfasser, gibt es drei: das Sankhya, den Yoga und das Lokāyata.

Sānkhya und Yoga sind eben die Namen, denen zu begegnen man hier in erster Linie erwarten wird. Das Mahābhārata, das große Epos, nennt sie beständig nebeneinander, wenn von den Wegen zur Erfassung des Ewigen - im Sānkhya durch Erkenntnis, im Yoga durch Askese -- die Rede ist.

Anfänge der an den mythischen Namen des Kapila geknüpften Sānkhyalehre reichen, wenn auch nicht bis zu den ältesten, so doch bis zu alten Upanișaden, wahrscheinlich in vorbuddhistische Zeit zurück. Schon der werdende Buddhismus hat wohl, vermutlich durch irgendwelche Mittelglieder hindurch, Einflüsse dieser Richtung erfahren. Die fertige, scharfumrissene Gestalt freilich, in welcher das Sānkhya in seinen klassischen Texten auftritt, scheint mir jünger nicht nur als Buddha, sondern auch als jene Erwähnung des Systems bei Kauṭilya. Man spürt im klassischen Sānkhya die Luft eines späteren Zeitalters, eine ungleich entwickeltere, präzisere, raffiniertere Technik des Denkens, als etwa dem alten Buddhismus eigen war. Das ganze Aussehen dieser Denker ist ein anderes als das des Sakyasohnes oder seiner Rivalen. Ist ein Vergleich mit Gestalten der Griechenwelt gestattet, so möchte man die buddhistischen Philosophen im Mönchsgewande neben jene Angehörigen mystischer, in feierlich bizarren Ordnungen lebender Sekten stellen, wie die Orphiker oder Pythagoreer. Die Lehrer des Sānkhya andererseits würden sich eher der weltlicheren Erscheinung der schulgerechten Dialektiker und Literatoren jüngerer Zeit, wie etwa der Stoiker, vergleichen. Der Typus dieser Denker ist nicht der des geistlichen, bettelnden Asketen, des "Śramaṇa“. Es ist vielmehr der des scharf- und spitzsinnigen Gelehrten, der später auf allen Gebieten der indischen Wissenschaft dominiert - der Typus des „Paṇdit".

Nicht anders als mit dem Alter des Sānkhya steht es mit dem des von Kautilya daneben genannten Systems der Askese, des Yoga. Auch der Yoga ist, wie wir sehen werden, zweifellos älter als der Buddhismus, den er tief beeinflußt hat. Die literarische Formulierung aber, in der er uns vorliegt, muß um eine stattliche Reihe von Jahrhunderten später als die Zeit des Buddha angesetzt werden.

Daß dann bei Kauțilya dem Sānkhya und Yoga an dritter Stelle das Lokāyata angeschlossen wird, steht gleichfalls mit dem, was wir sonst über das Alter dieser Lehre wissen, in gutem Einklang. Minder gut allerdings kann sich ihr Inhalt mit der so sich kundgebenden Anerkennung des Lokāyata seitens des brahmanisch-orthodoxen Staatsmannes zu vertragen scheinen. Das Lokāyata ist nämlich das System des Materialismus, der Leugnung des Jenseits, des Spottes über Vedaglauben und Opfer. Doch in sehr eigenartiger Weise - vollkommen klar zu sehen erlaubt uns hier die dürftige Überlieferung nicht - scheint sich diese Vedaleugnung, anders als etwa der 
Buddhismus, selbst auf den Boden des Veda gestellt zu haben. Gegen die auf dem Veda beruhende Staatsordnung hat sie Angriffe offenbar nicht gerichtet. Und als den Urheber ihrer gottlosen Sätze nennt sie keinen Geringeren als den vedischen Gott Brhaspati in eigener Person: den Lehrer, sozusagen den leitenden Theologen der vedischen Göttergemeinde, der schon in einer Upanișad sein Wissen dazu benutzt, den bösen Geistern die Irrlehre mitzuteilen, die aus Böse Gut und aus Gut Böse macht. Wenn die altbuddhistischen Texte einen in jeglicher Kunde bewanderten Brahmanen beschreiben, rühmen sie ihm - ganz im Einklang mit dem Zeugnis unseres Kauṭilya auch Kenntnis des Lokāyata nach. So muß es wenigstens zeitweise als ein Erfordernis umfassenderer und eleganter Bildung angesehen worden sein, daß man auch mit dieser inıerhalb der Sphäre des Veda den Veda angreifenden Skepsis vertraut war.

Sehr bemerkenswert ist nun aber, was in jener Aufzählung der Systeme nicht erscheint. Ich sehe von heterodoxen Lehren wie dem Buddhismus ab. Gleichviel ob der in jenem Zeitalter schon als auf das Niveau einer Philosophie erhoben erscheiner konnte: in jedem Fall machte seine Stellung unbedingt außerhalb der vedischen Traditionslinie seine Nennung an diesem Orte unmöglich. Weniger klar ist, warum die Lehre, die sich auf das engste an die Upanișadspekulationen über das Brahma anschließt, der Vedānta, nicht erwähnt ist. Wurde der Vedānta weggelassen als der Theologie, nicht der 'nvīksili zugehörig? Oder war er in Kauțilya's Zeit noch nicht zu einem festen System ausgebildet? Hatte er sich - dies wird für nicht unwahrscheinlich zu halten sein - aus dem wohl recht weiten Umfang dessen, was man damals Sānkhya nannte, noch nicht mit hinreichender Bestimmtheit ausgesondert? Eine sichere Entscheidung hierüber scheint einstweilen unerreichbar. Dagegen ist dies kaum zweifelhaft, daß die Nichtnennung der beiden eng untereinander verbundenen Systeme, denen zu begegnen man hier noch erwarten könnte, des Nyāya und Vaiśeșika (s. unten S. 48 f.), in der Tat auf deren damaliger Nichtexistenz beruht. Den Anspruch $\bar{n} n v i k s i^{-} z u$ sein erhob seinerzeit der Nyāya ebenso entschieden wie bcrechtigt. Unverkennbar aber ist, verglichen etwa mit dem Sānkhya, die Entfernung dieser Systeme von den alten Ausgangspunkten der Spekulation eine wesentlich größere, der ganze Charakter ein modernerer geworden. Nicht mehr die Erlösung vom Weltleiden steht im Vordergrund, sondern, wie wir sehen werden, 10gische, erkenntnistheoretische, naturphilosophische Probleme. Die jüngere IIerkunft dieser Systeme, die sich so aus inneren Gründen vermuten läßt, empfängt durch das Zeugnis des Kautilya willkommene Bestätigung.

Was nun die innerhalb der Schulen sozusagen als kanonisch geltenden Haupt- und Crrundtexte aller dieser Systeme anlangt - von ihnen ist uns nur der des Materialismus bis auf Fragmente verloren -, so scheinen diese nach den neuesten Untersuchungen sämtlich aus verhältnismäßig später Zeit zu stammen, vermutlich ungefähr aus dem 3. bis 5 . Jahrhundert n. Chr. Die meisten dieser Texte sind in der Form verfaht, die uns von allen literarischen 
Formen des alten Indien wohl am fremdartigsten anmutet: in der Form des „Sūtra“ („Faden“), der Aneinanderreihung von Maßen kürzester Sätzchen zu knappstem Anhalt für das Gedächtnis des I.ernenden. So hatten vedische Theologen Ritualwissenschaft und Rechtsordnungen abgehandelt; so war mit raffiniertem Scharfsinn, unter Anwendung eines ebenso komplizierten wie sinnreichen Systems von Abkürzungen und Symbolen, das mächtige grammatische System des Pānini auf engstem Raum dargestellt worden. Die Entwickelung philosophischer Gedankengänge in diese Form zu gießen wäre - hätte man es überhaupt im Ernst versucht - selbst der Kunst von Sütraverfassern mißlungen. Es waren eben nur Schlagwörter, die zu geben dieser Stil erlaubte. Von Anfang an muß der Hauptanteil an der Übermittelung der Gedanken selbst, ihres Flusses, ihrer Nuancierungen der Erklärung zugefallen sein, die zu dem im Text Gesagten oder allzuoft Nichtgesagten den Schlüssel gab. Wie wollte man es auch ohne Erklärung verstehen, wenn etwa das Sūtra der Vedāntaschule vom Eingehen des Erlösten in das Brahma und der darauf bezüglichen Schriftlehre in Sätzen wie diesen sprach: „Bei der Erreichung Offenbarwerden wegen des Worts 'eigen'. - Erlöst wegen des Versprechens. - Das Selbst wegen des behandelten Gegenstandes. In Ungeteiltheit wegen der Ersichtlichkeit" usf. Man sieht, wie diese Texte für sich allein betrachtet durchaus farblos und leblos sind, wie sie für unser Verständnis - sofern nicht alte Tradition uns zu Hilfe käme - vielfach hoffnungslos bleiben würden. Die Tradition nun kargt zwar mit ihrer Hilfe nicht; es wäre undankbar das nicht anzuerkennen. Aber bei der Vieldeutigkeit der Texte, die geradezu einen jeden dazu einlud, die eigenen Gedanken in sie hineinzutragen, und bei der Skrupellosigkeit indischer Exegeten sagt man sich leicht, wie oft die Stütze, welche die überlieferte Erklärung uns bietet, nur scheinbar, der Weg, den sie dem Verständnis weist, ein Irrweg sein wird.

An Stelle der Sūtras begegnen hier und da - so in der Darstellung. des Sänkhyasystems - kurzgefaßte Texte in Versen, sogenannte Kārikās. Eine seltsame, echt indische Form poetischer und auch wieder unpoetischer Darstellung. Vielfach sind diese Kārikās kaum anderes als Sūtras in metrischem Gewande und machen so wenig wie diese auch nur den Versuch, den Gedanken selbst und nicht allein eine Erinnerung an ihn zu bieten. Aber dann tritt wiederum auf kürzere, hier und da auch auf längere Strecken eine Form der Darstellung hervor, die nicht Stichworte gibt, sondern entwickelt, begründet, widerlegt, von höchster Gedrängtheit bisweilen freierer Lässigkeit sich nähernd und auch ihre Pforte dem Hereinwehen eines Hauchs der Poesie öffnend. Manch tiefer Gedanke wird da von der Anmut geistreich sinniger Bilder umspielt, oder mystisch helldunkle Andeutungen lassen den Hörer aus dem Reich der Scholastik sich zur Ahnung unausgesprochener, halb ausgesprochener Geheimnisse erheben. Es entbehrte doch nicht der Poesie, wenn in den Sānkhyaschulen über das Spiel der Bindung und Lösung, das die Natur mit sich und mit der Seele spielt, in jenem eintönigen Singsang, wie Inder ihre Verse rezitieren, die Kārikā vorgetragen wurde: 
„Auf sieben Weisen bindet

Natur sich durch sich selbst.

Sie löst sich auf eine Weise,

wirkend im Dienst der Seele" -

oder wenn Vedāntaphilosophen vom Schein der Vielheit, der das eine Allwesen umspielt, das Gleichnis ihrer Kārikā sangen:

„Wie Feuerlinien, Lichtkreise geschwung'ner Funk' erscheinen läBt,

Erzeugt Bewußtseins Umschwingen Erfassens Schein, Erfassers Schein.“

Der volle Zusammenhang der Gedankenreihen freilich, ihr Ineinandergreifen, das lebendige Funktionieren des ganzen Apparats tritt in der Regel doch erst in den an die Sutras oder Kärikās sich anschließenden Kommentaren und systematischen Abhandlungen in die Erscheinung. Da strömt die gedrungene Sprache der wissenschaftlichen Diskussion immer gleich schwerflüssig einher, an Verben arm, reich an überlangen nominalen Zusammensetzungen, komplizierte Begründungen gern in den Ablativ eines einzigen unabsehbaren, ganze Fluten von Vorstellungen in sich aufnehmenden und geschickt disponierenden Kompositums hineinpressend. Einwürfe über Einwürfe werden diskutiert; oft verliert sich die Darlegung perspektivelos in Kleinlichkeiten, in Wortklaubereien. Die Fähigkeit aber, komplizierte Figuren des Gedankens scharf und bestimmt aufzuzeichnen, versagt diesen Kommentatoren nicht leicht. Und daß ihre Sprache den Stolz und die Leidenschaft großer Denkernaturen aus sich herausklingen lassen konnte, hat Śankara bewiesen.

Sannkya. III. Die Sānkhya-Philosophie. Es ist gegenwärtig nicht möglich und wird vielleicht nie möglich werden, die Geschichte der indischen Philosophis als eine Entwickelungslinie darzustellen, welche die durch Ereignisse im Reich des philosophischen Denkens bezeichneten Punkte in einer großen Folge durchläuft. Wir können, für jetzt wenigstens, keinen anderen Weg gehen als die Systeme nacheinander zu überblicken. An ihre Spitze stelle ich das Sānkhya. Auf die schwierigen, bis jetzt meist nur unzureichend aufgehellten Probleme seiner Vorgeschichte einzugehen darf ich hier nicht unternehmen; ich zeichne seine fertige, klassische Gestalt.

Während in den Upanișaden die Gedankenmassen in mächtiger Verwirrung durcheinander wogen, hat sich im Sānkhya das Chaos geklärt. Hier waltet nicht jenes hingenommene Schauen, das jenseits von Welt und Wirklichkeit und zugleich in deren letzten Abgründen die Glorie des AllEinen leuchten sieht und in dessen Lichtglanz alle Gegensätze miteinander verschwimmen läßt, ciamit sie alle die unermeßliche Wesensfülle jenes Einen verherrlichen. Sondern hier herrscht die Stimmung kühler Analyse, die unbedingte Bereitwilligkeit, da, wo es Unvereinbares zu vereinen gäbe, vielmehr auf die Einheit zu verzichten. Man liebt es die Kontraste anzuerkennen, mit ihnen zu arbeiten. Auf der einen Seite das ewig Werdende, auf der anderen das ewig Seiende. Hier das Objekt, dort das Subjekt, schroff einander 
gegenüberstehend, während die Brahmaspekulation dazu neigte, im All-Einen den Gegensatz von Subjekt und Objekt versinken zu lassen. Von selbst fällt dem Objekt die Rolle des Sichwandelns, dem Subjekt die der Wandellosigkeit zu. Was auf der Seite des Werdens steht, wird Natur (Prakṛti, fem.) genannt. Mit ruhigem Vertrauen auf das Zeugnis der Sinne blickt man um sich in die Welt samt aller in ihr herrschenden Bewegung und erkennt ihr ohne Schwanken vollberechtigte Realität zu. Auf die andere Seite, die des Seins, stellt man die Seele, richtiger die unbegrenzte Vielheit der Seelen, auch sie gleich vollberechtigter, aber durchaus andersgearteter Realität teilhaft: von alters her war ja die Überzeugung auf das tiefste eingewurzelt, daß die Seele etwas anderes, Bleibenderes ist als nur eine auftauchende und wieder verschwindende Welle im Meer der Welt und Natur. Man vermeidet für die Seele oft den altgeläufigen Ausdruck Ätman („das Ich“), wohl um nicht die diesem mitanhaftende Vorstellung einer Allseele hervorzurufen; man benennt sie gern als Purușa (mask., Grundbedeutung „Mann“, dann „Geist"). Die Prakṛti ist fruchtbar, handelnd, bewegt; der Purușa ist ruhend und schauend. Die Verbindung beider gleicht der des Blinden und des Lahmen, den jener aus dem Walddickicht trägt. Die blinde Natur arbeitet für die selbst alles Handelns unfähige Seele. Das Endziel ihres Tuns ist die Erlösung. Im Spiel des Naturgeschehens aber auf der einen Seite und auf der anderen im Verhalten der Seelen zu jenem Geschehen ist der Kreis dessen, was die Wirklichkeit erfüllt, was die Philosophie verstehen und zum rechten Ziel lenken will, vollständig geschlossen. Über diesen Kreis hinausgreifend ein Allwesen wie das Brahma anzunehmen und in solcher höchsten Einheit für Welt und Seele, für die Vielheit der nebeneinander stehenden Seelen die gemeinsame Wurzel zu erkennen findet dies Denken keinen Antrieb.

Von Ewigkeit zu Ewigkeit entwickelt die Natur in fester Ordnung immer Die Natur. von neuem die Welt aus sich selbst heraus und läßt sie wieder in sich eingehen. Im Ruhezustand, wenn die Natur ihre Geschöpfe in sich zurückgezogen hat, befinden sich die drei „Guna"“ oder Konstituenten im Gleichgewicht: Sattva, das Leichte, Helle, Frohe - Rajas, das Bewegte, Schmerzliche Tamas, das Starre, Finstere. Das Gleichgewicht wird gestört, und es beginnt der ungeheure Prozeß der Evolution der Prakrti von den feinsten Substanzen bis zum grob materiellen Dasein, auf den dann wiederum in umgekehrter Richtung der Prozeß der Absorption folgt. Die drei Guna tun ihr Werk „sich gegenseitig zu überwältigen, sich aufeinander zu stützen, sich hervorzubringen, sich zu paaren". Auf ihrem mannigfaltigen Spiel beruht die Verschiedenheit aller Dinge. In der Sphäre des der Prakṛti entströmenden, von den Guṇa gestalteten Naturdaseins vollzieht sich auch die Bewegung der scheinbar seelischen Vorgänge wie des Wahrnehmens, Erkennens, Begehrens. Wie man nun einmal alles nach dem einen großen Gegensatz orientierte, war es unvermeidlich, auch dieses Geschehen auf die Seite zu stellen, auf der allein man Geschehen und Werden anzuerkennen bereit war, auf die Seite der Natur; so konnten denn jene Vorgänge allein als in Wahrheit rein natürliche 
Veränderungen aufgefalit werden, die - wir werden sehen, auf Grund welcher Konstruktion - als seelisch nur erscheinen durften. Produkte der Naturprozesse sind die inneren Organe der einzelnen Geschöpfe und ihre den Verkehr mit der Außenwelt vermittelnden Sinne und Kräfte des Handelns: alle diese bilden zusammen mit gewissen feinen Elementen - nicht Luft, sondern Gefühl, nicht Wasser, sondern Geschmack usw. - den „feinen Körper“, das der Natur angehörende Gegenbild der in Wahrheit von der Natur absolut verschiedenen Seele. Der feine Körper ist es, der in der Bewegung der Seelenwanderung von Dasein zu Dasein zieht. Gleich einem Schauspieler, der immer andere Rollen spielt, bekleidet er sich mit wechselnden groben Körpern, wie Verdienst und Schuld seiner Werke ihn durch die Reiche des Sansāra, vom Gott bis zum Grashalm herab, empor- und herniederführt. So ist das alles, was der Seele zu gehören, ihr Dasein auszumachen scheint, in Wahrheit ein Stück Naturlauf.

Secle und Firlösung:

Und die Seele seibst? Sie ist unbewegt „auf dem Gipfel stehend“ Zuschauer aller jener Bewegung. Sie ist wandelloses Licht, reiner Geist. Aber ein Band besteht, das sie mit der Natur verbindet, ein Band, das anfangslos seit Ewigkeit da ist und das doch nicht im Wesen der Seele liegt und darum gelöst werden kann. Das, was dies Band gebunden hat, ist dem ähnlich, was in den Upanișaden als das die Wahrheit des Brahma verhüllende Nichtwissen erschien; hier, wo der Dualismus von Seele und Natur das allbeherrschende Leitmotiv ist, trägt es die Gestalt der "Nichtunterscheidung“ dieser beiden. Die durch die Nichtunterscheidung bewirkte Verbindung zwischen ihnen hat ihre Folgen für den einen wie den anderen Teil. In die Natur fällt das von der Seele ausgehende Licht des Bewußtseins. So wird jene, die ungeistige - oder vielmehr es wird das von ihr, was der Seele besonders nah steht, der „feine Körper" - ,gleichsam geistig“. Der Seele aber ergeht es wie dem farbiosen Kristall, dem man die rote Blüte nahgebracht hat, und rer nun selbst rot scheint. Es ist, wie wenn ein Unschuldiger mit Dieben zusammen ergriffen wird: man hält ihn auch für einen Dieb. So wird durch die Verbindung mit der in Wahrheit allein handelnden Natur oder mit den Guṇa's, ihren Konstituenten, die nichthandelnde Seele "gleichsam handelnd“. Sie scheint in der Natur Treiben verflochten, in jenes Daseinsleid des Alters und Todes, der Wanderung von Existenz zu Existenz, wo auch das spärlich gegönnte Glück, hohl und vergänglich, „für die Unterscheidenden zum Leiden zu rechnen ist": ein Leiden, das doch, als im Reich der unbewußten Natur sich abspielend, im letzten Grunde kein Leiden ist und zum Leiden nur wird oder zu werden scheint, insofern von der Seele her Licht darauf fällt. Die Erretterin vom Leiden aber ist jene Macht, welcher das indische Denken von alters her diese Aufyabe anvertraut hat, die Erkenntnis. Als Frucht der Gedankenarbeit des Philosophen kommt das die Nichtunterscheidung aufhebende Wissen zustande: „Ich bin nicht; nichts ist mein; dies ist nicht ich“: was ein Erklärer deutet: "Ich bin nicht' ... das ist die Leugnung der handelnden Natur des Ich. 'Nichts ist mein' die leugnung jedes Verhältnisses zu 
anderem. 'Dies ist nicht ich' - die Leugnung der Identität (mit der Natur)". Darauf, daß diese Unterscheidung von Seele und Natur im Denkorgan dem feinsten unter den Produkten des Naturprozesses - entstehe, hat das ganze Weltleben hingearbeitet. Nun ist es der Natur gelungen, der Seele den Dienst ohnegleichen zu leisten.
,Wenn der zuschauenden Schar sich die Tänzerin
hat gezeigt, so macht sie dem Tanz ein Ende.
So die Natur, wenn sie der.Seel' ihr Wesen
offenbart hat, tritt sie zurück und verschwindet."

"Nichts Zartfühlenderes gibt es als die Natur, so meine ich, die, wenn sie sieht: 'ich bin durchschaut', sich nicht wieder dem Blick der Seele aussetzt", - man erinnere sich, um den bildlichen Ausdruck zu verstehen, daß Prakrti weiblich ist, Puruṣa „Seele" aber zugleich bedeutet „Mann". So ist denn die Trennung hergestellt; die Seele ist erlöst, wie wenn man von einem brennenden Hause ein anderes abtrennt und es dadurch rettet. Während für die unerlösten Seelen der Naturlauf ins Unbegrenzte weitergeht, tritt die erlöste, wenn der gleichgültige Rest des Erdenlebens abgelaufen ist, in die Vornehmheit reinen Fürsichseins ein als ein Licht, das nichts mehr beleuchtet. Ein jüngerer Dichter sagt:

„Wenn auf des Spiegels Fläche sich kein Berg,
kein Tal, kein Wesen widerspiegelt, so verharrt
die Spiegelkraft allein im eignen Sein.
Dem gleicht, wenn der Erscheinungen Gewirr,
wenn Ich und Du und Welt verschwunden ist,
die Einsamkeit des Sehers, der nichts sieht."

Dies ist die Sānkhya-Philosophie. Sie hat es verschmäht, mit der Vedāntalehre der Seele zuzurufen, daß sie die ganze grenzenlose Fülle des Allwesens in sich trage, und hat sie sich bescheiden gelehrt, eine unter unzähligen zu sein. Sie hat es über sich gewonnen, den Dualismus von Geist und Natur, der ihr unüberbrückbar schien, als Tatsache anzuerkennen, und in echt indischer Weise hat sie ihn zu extremer Schroffheit gesteigert. Dem Schicksal, in ihrem Weltbilde Lücken zu lassen und sich Blößen zu geben, ist sie nicht entgangen. Woher jener anfangslose Irrtum der Nichtunterscheidung, und wie vermag bloßes Irren die Realität des Bandes hervorzubringen, das Seele und Natur aneinander kettet? Was bedeutet in dieser Erlösungslehre das ganze Arbeiten der Natur für die Seele, wenn die Seele es in Wahrheit gar nicht ist, die leidet? Oder was bedeutet das Leiden der Natur, die doch in ihrer Ungeistigkeit nicht fähig ist, Leiden zu empfinden? Über mehr als eine Schwierigkeit muß die Eleganz eines sinnreichen Gleichnisses hinwegtäuschen. Viel Arbeit geschickter Gedankenkunst ist doch in diesem System enthalten, und auch die Kraft poetischen Gestaltens war seinen Schöpfern nicht versagt. Wie zwei Helden eines Dramas stehen sich Madre Natura und die Seele gegenüber. Was sich zwischen ihnen abspielt, hat etwas von der Verwickelung und Lösung eines dramatischen Knotens. Eine Lehre, 
welche die Geister im Sturm hinreißt, ist das Sānkhya nicht gewesen. Aber es kann uns wohl verständlich scheinen, daß es die für dialektische Gewandtheit wie für Poesie so empfängliche Hinduseele auf das ernstlichste beschäftigt hat und durch lange Jahrhunderte in der indischen Wissenschaft eine beherrschende Stellung einnahm, wenn auch freilich in neuerer Zeit, wie sich ein Schriftsteller des I 6. Jahrhunderts ausdrückt, der Mond dieser Lehre von der Sonne der Zeit aufgezehrt worden ist.

Vedānta. Philosophie un Offenbarun:.

Burdanstische Einflüsse.
IV. Die Philosophie des Vedānta. Śankara. - Anders als das Sānkhya, das dem Veda im Grunde fernsteht, beansprucht die VedāntaPhilosophie recht eigentlich die Vertreterin der vedischen Orthodoxie zu sein. An den Veda schließt sie schon ihr Name an, „Vedānta“ d. h. „das Ende des Veda": wohl darauf beruhend, daß die Upanișaden, aus denen heraus sich diese Lehre entwickelt hat, häufig am Ende größerer Vedawerke rituellen Inhalts stehen. Der Vedānta ist allem Anschein nach erheblich später als das rivalisierende System zu systematischer Ausgestaltung gelangt. Unter den Richtungen, die sich in ihm unterscheiden lassen, ist nicht sicher die ursprünglichste, aber ragt durch Großzügigkeit der Denkarbeit weit herror diejenige, deren klassischer Vertreter Śankara ist.

In das Hinstreben der vedāntistischen Gedankengänge auf die liorm, die sie bei Sankara tragen, müssen viele Einflüsse eingegriffen haben, die sich vollständig nie werden entwirren lassen. Es versteht sich von selbst, daß hier das Sānkhya eine bedeutende Rolle gespielt hat. Vielleicht in mancher Hinsicht noch tiefer scheint - für jetzt kann man hier nur vermutungsweise sprechen - ein anderer Faktor gewirkt zu haben, dessen Eingreifen in diesen Zusammenhang eben jetzt den Gegenstand eindringender Untersuchungen bildet: die buddhistische Spekulation. Wohl bekannte sich Sankara, der große Feind des Buddhismus, zu der Überzeugung, daß Buddha durch Aufstellung einander entgegengesetzter Theorien „nur seine ungereinte Schwat zhaftigkeit bekundet hat oder aber seinen Haß gegen die Menschheit, dir: er durch widersprechende Lehren zu verwirren trachtete" - von welchem Lwiespalte der buddhistischen Systeme, wie hier beiläufig bemerkt sei, ein späterer Velantaschriftsteller launig sagte: „War auch der erhabene Buddha der einige Versorger mit Erkenntnis, so griff doch vermöge des verschiedenen lirkennens der von ihm Versorgten eine Vierteilung Platz, wie wenn die Sonne untergegangen ist, die Buhler, Diebe, Vedagelehrten usw. die Zeit zum Stelldichein, zu Raub, zu tugendreicher Aufführung für geeignet erachten". Solche Polemiken und Scherze können nicht ausschließen, daß es unter den in der Tat sich gegenseitig aufhebenden Gedankengängen der budthistischen Schulen auch solche gab, die der Simnesart mancher Denker des Vedinta verwandt waren und diese wohl darin unterstützen mochten, ihre Ideen zu klären und auszusprechen.

Es handelt sich hier besonders um buddhistische Philosopheme, die etwa im z. oder 3. Jahrhundert nach Chr. ihre Gestalt empfangen zu haben scheinen. 
Sie kn̈üpfen sich vor allem an den Namen des großen Lehrers Nāgārjuna. Wie die Chronologie dieser Phasen des Buddhismus, so zeichnen sich uns auch die Gedanken, die er damals hervorgebracht hat, für jetzt nur unbestimmt ab. Allzusehr steht hier die Forschung noch in den Anfängen und wird dadurch erschwert, daß sie über die lückenhafte indische Überlieferung hinauszugreifen genötigt ist zu dem, was Tibet und China uns erhalten haben. Von der schlichten Einfachheit der Gedankenwelt, in der sieben Jahrhunderte früher der Mönch rom Sakyahause und seine Jünger lebten, sind die Spekulationen in der Tat recht weit entfernt, die da im Schoß der Kirche des Mahāyāna („der großen Überfahrt") in Zeiten politischer Wirren und Neubildungen, des Eingreifens von Fremdherrschaft, inmitten eines unendlich erweiterten Gesichtskreises entstanden sind.

Jenseits der weltlich verhüllten Wahrheit, die doch in ihrem Bereich auch Wahrheit ist - so lehrte Nāgārjuna - erhebt sich die absolute Wahrheit. Eine Wahrheit, die selbst keinen positiven Inhalt hat, vielmehr die Aufhebung aller an ihren inneren Widersprüchen zugrunde gehenden niederen Wahrheit ist. „Stellte ich irgendeine Behauptung auf, so wäre ich im Unrecht. Aber ich stelle nicht Behauptungen auf: so bin ich nicht im Unrecht". Keine Lehre vom Sein, keine Lehre vom Nichts. Sein und Nichts wird in gleicher Weise von dieser Dialektik aufgelöst. Das Ziel, bei dem sie anlangt, und ihr beherrschendes Schlagwort ist die Leerheit. Die Leerheit richtig zu durchschauen, dies ist die große Aufgabe, denn falsch verstanden „vernichtet jene den Geringgeistigen, wie eine Schlange, die man fehlerhaft ergriffen hat". Sankara zwar fand diese Doktrin von der Leerheit mit allen Quellen unserer Erkenntnis unverträglich und darum einer eigenen Widerlegung nicht bedürftig. Darum kann doch die von jenem System vorgenommene Unterscheidung einer niederen und höheren Wahrheit sehr wohl dazu beigetragen haben, vedāntistischen Philosophen den Weg zu weisen zur Bemeisterung jener Widersprüche der Upanișaden, die zugleich Widersprüche zwischen Weltwirklichkeit und rücksichtsloser Durchführung der Idee des All-Einen sind. Ließen sich nicht die Ansprüche auf Anerkennung, die das endliche Dasein erhebt, abfinden, indem man sie in ein Reich niederen Wissens verwies? Um so freier konnte dann in der Sphäre höchster Wahrheit, sich erhebend über den Dualismus, wie ihn das Sānkhya lehrte, der nach Einheit alles Seins verlangende Gedanke seinen Flug tun. Da mochte man dann, nicht allzu weit von Nāgārjuna's Idee der Leerheit sich entfernend, die abolute Wesensfülle des Brahma feiern, das eben in seiner Absolutheit in brezug auf jede Begrenzung, jede Bestimmtheit ein Leeres ist. Eine alte, vielleicht die älteste uns erhaltene Darstellung der Vedāntalehre - sie träigt don Namen des Gaudapāda - läßt in Form und Inhalt den Leser beständig die Nähe jener buaddhistischen Philosophie empfinden. Hier wie dort diesclbe Polemik gegen dic realistischen Systeme, auch dieselben auf beiden Soiten gern wiederholten Gleichnisse für die Täuschungen, denen das an der ( )berfläche der Dinge haftende Irren unterliegrt. Nicht ohne Grund wurde den 
Vedāntisten der streng idealistischen Schule von ihren anders gerichteten Rivalen der Vorwurf gemacht, sie seien verkappte Buddhisten. Man zitierte das kräftige Wort eines Purāna, eines der großen religiösen Texte des Hinduismus: dort erklärt Gott Siva selbst, er habe im Kalizeitalter — dem Zeitalter der Sünde und Entartung - in Gestalt eines Brahmanen „die unwahre Lehre von der Māyā verkündet, versteckte Buddhalehre, die den Sinn der Schriftworte entstellt und von der Welt verachtet ist". Mit dem Brahmanen, in dessen Gestalt der Gott so Schlimmes getan hat, ist kein anderer gemeint als jener größte aller Vedāntalehrer, Śankara selbst.

Wir dürfen auf diese merkwürdigen, im Grunde übrigens natürlichen Berührungen zweier in so vieler Hinsicht einander feindlicher Weltanschauungen, des Buddhismus und des Vedānta, hier nur diesen Blick werfen und wenden uns nunmehr dazu, von Śankara und seiner Lehre zu sprechen.

sankara. Der große Bettelmönch, Schriftsteller, geistliche Organisator lebte um $800 \mathrm{n}$. Chr. Unter den indischen Denkern nach Buddha wohl die mächtigste Persönlichkeit. Wir mögen ihn uns vorstellen, die Seele geschwellt vom Triumph des Brahmanentums über den Buddhismus und so viele gegnerische Mächte. Eine im großen Schauen und im Kampf für das souveräne Recht dieses Schauens lebende Natur, feindlich hinwegstoßend, was dessen Majestät und Reinheit in Frage stellen könnte. In seinem wichtigsten Werk, dem Kommentar zu dem von allen Richtungen des Vedānta als grundlegend und maßgebend betrachteten Sutra (s. oben S. 35) des Bādarāyaṇa zeigt er sich - das versteht sich von selbst - keineswegs als guter Kommentator im Sinn eines getreuen Interpreten seines Autors. Mit dem wußte er umzuspringen. Was er gab, war nicht Bādarāyaṇa's System; es war sein System. Immerhin lag für den Vortrag dieses Systems eine starke Erschwerung darin, daß er die Form eines Kommentars zu Bādarāyaṇa's im Grunde von seinen Anschauungen weit genug abliegendem Text gewählt hatte. Und ohnehin war die Kunst klarer und durchsichtiger Darstellung Sankara nicht eigen. Seine Gedankengänge sind nicht frei von Widersprüchen, über die er mit starken Scliviten wegsetzt, von Ungleichmäßigkeiten in bezug auf die Konsequenz, mit der die einzelnen Probleme bis zu Ende verfolgt werden. Überali aber spi icht er die Sprache der in den Tiefen einer starken Seele wurzelnden, vor keinem Extrem zurückscheuenden Überzeugung, voll Härte und Geringschätzung gegen die Andersdenkenden, für große Gedanken das plastische, vollwichtige Wort findend.

Die Philosophie Sankaras bekennt sich zum Verzicht auf den Anspruch, aus eigener Kraft die Wahrheit zu erfassen. Menschliches Nachdenken hat keinen Bestand: „Was die Kenner mühsam erspekuliert haben, wird von anderen, größeren Kennern als bloß scheinbar erkannt, und deren Spekulationen werden wiederum von noch anderen als Schein erwiesen." Fest steht allein der Veda, den das große Wesen in seiner überschwenglichen Allmacht "mühelos spielend" als seinen Aushauch aus sich hervorgebracht und mit seiner Allwissenheit durchtränkt hat. „Nur durch die Offenbarung 
kann man dies übertiefe, höchste Brahma ergründen, nicht durch Nachdenken." Selbstverständlich bedeutet das nun nicht, daß, um die Offenbarung recht aufzunehmen, das Denken überflüssig sei. Nur soll nicht „dürre Reflexion ins Dasein gelangen, sondern allein eine von der Offenbarung gestïtzte Reflexion, als Hilfsmittel für die Auffassung (von deren Inhalt), wird gelten gelassen“. Entspricht Śankara's Verhältnis zum Vedawort in der Tat der damit ausgesprochenen Norm? Man wird das zu verneinen haben; auf solche Unterwerfung unter feststehende Autorität war die Persönlichkeit des Philosophen nicht zugeschnitten. Die alten Denker der Upanișaden, in vielen ihrer Äußerungen ihm durch und durch kongenial, sind ihm willkommene Bundesgenossen; was dem aus den Vorratskammern jener Texte entnommenen Stoff die Form und damit den vollen Sinn gibt, ist schließlich doch das Denken Śankaras.

Es wurde schon berührt, wie in den Upanișaden, denen begreiflicherweise jeder Anflug von System und Kritik fremd ist, sich das Widersprechendste zusammengehäuft findet. Bald verherrlichen sie allein die Glorie des ewigen, einen Brahma; bald lassen sie auch die Welt der Vielheit, des Werdens und Vergehens als vollberechtigtes Objekt des Denkens gelten. Die Philosophie kann diese zweite Seite der Offenbarung nicht beiseite schieben, wie es ihr an sich unmöglich ist, die übermächtig sich aufzwingenden Eindrücke der Weltwirklichkeit - dazu dann jener in Glauben und Phantasie der Inder auf das festeste eingewurzelten Zutaten zum Weltbilde wie der Seelenwanderung und der wirkenden Kraft von Verdienst und Schuld - für nichts zu erachten. Als Ausgleich für das Unausgleichbare bietet sich die Unterscheidung, auf die schon hingewiesen wurde, eines niederen und höheren Wissens, beides in der Offenbarung begründet, beides - der Leser Sankaras kann sich das nicht verbergen - in seiner Darstellung sich nicht selten verwirrend. Hier Akkommodation an die Erfahrung, dort Aufsteigen zu den schroffen Höhen des Gedankens. Hier betrachtet man das Brahma als mit mannigfachen Bestimmungen behaftet, dort als frei von jeder Bestimnung; hier gleichsam das Spiegelbild der Sonne, in unzähligen irdischen Gewässern sich vervielfältigend, dort die Sonne selbst.

Für das niedere Wissen läßt das Brahma, als persönlicher Gott (Iśvara „Herr") auftretend, die Welt aus sich hervorgehen. Was treibt den Allgenugsamen zu solchem Tun? „Wie im täglichen Leben ein König oder ein Minister, der alles hat, was er begehrt, ohne irgendeinen sonstigen Zweck, sich an Stätten der Vergnügung mit Spiel unterhält - oder wie Ausatmen und Einatmen ohne irgendeinen äußeren $Z$ weck sich von selbst vollzieht: so mag auch das Handeln Gottes ohne einen anderen Zweck, allein ron selbst als bloßes Spiel vor sich grehen." Im Alltagsleben freilich werden auch beim Spielen leise Motive, eine gewisse Interessiertheit, wirksam sein. Das trifft auf Gottes Schaffen nicht zu; hat er doch, wie die Schrift sagt, all sein Verlangen erreicht.

Immer von neuem, ohne Anfang, ron Ewigkeit her. schaftt Gott die 
Welt und zieht sie immer wieder in sich zurück. Er ist zugleich die Materie, aus der die Welt geformt ist, und der Former der Materie. Vergleicht man die Welt einem Goldschmuck, ist er Gold und Goldschmied zugleich. In dieser kreatürlichen Welt lebt eine Vielheit von Seelen. In bleibender Verbindung mit einem "feinen Leib" - wir haben hier dieselbe Lehre wie im Sānkhya - wandern die Seelen, geleitet von Verdienst und Schuld ihres Tuns, durch hohe und niedere Daseinsformen und nehmen teil an der ungeheuren Bewegung der Absorptionen und neuen Evolutionen des Kosmos. Hier gilt es durch gute Werke sich den Weg aufwärts bahnen. Doch höher als Werke führt fromme Verehrung und Wissen. Noch handelt es sich nicht um den Besitz der absoluten Erkenntnis, sondern allein um das niedere Wissen vom Brahma; das führt den Wissenden auf dem Götterweg zu jenem empor. Das letzte Ziel kann damit direkt noch nicht erreicht sein. Ausdrücklich betont Sankara, wie unverträglich es mit dem Wesen des höchsten Brahma ist, daß dieses als etwas Fremdes verstanden wird, zu dem ein Hingehen vorgestellt werden kann. Und doch wiederum beruft sich Sankara auf das Wort einer Upanișad von denen, die dorthin gelangt sind: „In jenen Brahmawelten bewohnen sie die höchsten Fernen. Für sie gibt es keine Rückkehr". Einer der Punkte, an denen die Konsequenz ins Wanken zu kommen scheint: Sankara hilft sich mit der Vorstellung, daß denen, die so hoch emporgestiegen sind, in der Brahmawelt die absolute Erkenntnis zuteil werde; so stehen sie am höchsten Ziel.

Mit der Bestimmtheit des orthodoxen Dogmatikers, des sattelfesten Dialektikers zeichnet Sankara dies Bild von Schöpfung, Seele, Seelenwanderung. Und dann - ein seltsames Schauspiel: was noch eben so sicher dazustehen schien, hat sich plötzlich in ein Wogen von Nebeln aufgelöst, zwischen denen sich der Ausblick in unabsehbare, unbewegte Fernen eröffnet. Statt des "niederen Wissens" kommt das ,höhere“ zu Wort.

Nichts ist als das Brahma, nur das Brahma. Es ist Sein, es ist Denken: nicht daß dem Einen damit doppelte Wesenheit zugeschrieben würde. Sondern der gleiche Durst nach Einheit, nur Einheit, der in Griechenland Parmenides das Wort eingab „denn dasselbe ist Denken und Sein“, läßt auch für Sankara im Brahma ,das Sein Denken sein und tas Denken Sein; es gibt keine Sonderung des einen und des anderen". Attribute, die wir dem Gestaltlosen beilegen könnten, „Verbindungen des höchsten Selbst mit räumlichen, z"itlichen oder sonstigen Besonderheiten" sind ausgeschlossen. Sie würden ja in das reine Sein etwas Fremdes hineintragen. So nennt die

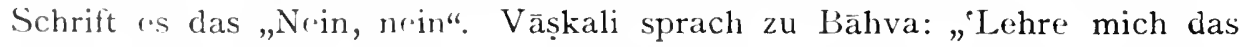
Brahma, Erhabener'. Der aber schwieg still. Da bat ihn jener zum zweiten und zum drittenmal. Da antwortete er: 'Ich lehre es dich ja, du abrr merkst es nicht. Dieser Atman ist stille'.“

Der Atman, den der Weise hier nennt - das Selbst, mein Selbst ist eben das Brahma. „Das Selbst steht nicht vermöge eines Beweises seiner selbst fest... Da das Sc.lbst die Grundlage alles solchen Tuns wie des 
Beweisens ist, steht es vor jenem Tun fest. Eine Widerlegung einer solchen Wesenheit gibt es nicht. Denn widerlegen kann jemand nur, was von außen herankommt, nicht was sein eigenes Wesen ist... Das Feuer kann nicht seine eigene Hitze widerlegen." Dies mein Selbst nun, dies durch sich Gewisse, wäre es nur ein Teil des Brahma? Doch wie sollte das Brahma in Wahrheit teilbar sein? Nein, das ganze ungeteilte Brahma ist in meinem Selbst gegenwärtig. „Das bist Du“, sagt die Schrift.

Und die bunte, bewegte Ausbreitung der Welt? Die Vielheit der wandernden Seelen? Es ist alles Schein, nichts als Schein. Eine Luftspiegelung — „Māyā", ein Zaubertrug: eine Schöpfung, die keine wahre Schöpfung ist. sondern als Gaukelei den Beschauer täuscht. Woher dies Blendwerk? Aus dem Brahma selbst muß es stammen.

\section{„Ein Zauberspiel ist die Natur, der Zaubrer ist der höchste Gott",}

hat schon eine Upanișad gesagt. Wie aber kann das reine Licht des ewig Einen sich $z u$ 'solch buntem Blendwerk trüben? Von diesem letzten Geheimnis den Schleier zu heben hat Sankara nicht versucht, konnte kein Denken versuchen. Doch erinnert er daran, daß ja auch der menschliche Geist unbeschadet seiner Einheit im Schlummer mannigfache Traumgebilde als seine Schöpfung in sich beherbergt — „da sind nicht Wagen noch Gespanne noch Straßen; die Wagen, die Gespanne, die Straßen erschafft er", heißt es in der Schrift.

Und die Seele - die auf der Māyā beruhende scheinbare Vielheit der Seelen - verfällt der Täuschung, ,dem aus Māyā bestehenden großen Tiefschlaf, in dem, der Erkenntnis ihrer wahren Natur entbehrend, die wandernden Lebewesen befangen liegen“. Es ist, „wie wenn der Mond einem kranken Auge vielfach erscheint", ,wie das Licht von Sonne oder Mond durch den Raum dringend irgendwohin trifft und so bei der Berührung mit Substraten wie beispielsweise einem Finger, je nachdem diese etwa gerade oder krumme Form annehmen, die gleiche Form anzunehmen scheint".

Die Erlösung aber von dieser Täuschung des Nichtwissens, wie wird sie erreicht? Gute Werke, fromme Meditation können sie nur vorbereiten. Die wahre Zerstörerin des Nichtwissens ist die Erkenntnis. Aus höchster Höhre muß sie kommen. "Gottes Gnade ist die Ursache der Erkenntnis." Ein Wort, das freilich die Frage herausfordert, wo anders denn Gott der Seele, ein Gebender der Empfangenden, gegenübersteht al.s in der Sphäre des von der Māyā betrogenen Nichtwissens...

Die Seele des Erkenntnisbegnadeten tut - um das Gleichnis eines modernen Inders zu wiederholen - was cler Schwan zu tun weiß. Der trinkt aus dem Gemisch von Wasser und Milch die Milch allein und läßt das Wasser zurück. So läßt die Seele des Weisen die Mãyā dahinten und erfaßt allein das Brahma. Ihr leuchtet in voller Glorie die Intuition der Linheit der Seel. mit dem All-Einen auf. Da ist es denn erreicht, das Ziel der Ziele. ,Dan ist unser Schmuck, daß, wenn wir das Selbst als das Brahma erkannt 
haben, jedes Tunsollen aufhört und Erfüllung aller 'Zwecke eintritt." Der Dichter sagt:

"Wenn die Seele vom Traumblendwerk, dem anfanglosen, ist erwacht, das ungeborne Zweitlose, das schlummerfreie sie erkennt."

Der herabgefallene Strick schien im Dunkeln eine Schlange zu sein: jetzt ist erkannt, daß es nur ein Strick ist, daß es immer nur. ein Strick war. Nicht gelangt der Erkennende jetzt zur Einheit mit Brahma. Vieimehr tritt die Wahrheit hervor: diese Einheit besteht, hat ewig bestanden.

V. Anhängsel an Sānkhya und Vedānta. Der Einfluß des Sānkhya und Vedānta - sei es nun älterer, vorklassischer, sei es der jüngeren Entwicklungsphasen dieser L,ehren — verbreitete sich mächtig über alle Gebiete des indischen Denkens, der Religion, der Poesie.

Wesentlich in den Bahnen des Sänkhya bewegen sich die Doktrinen des Yoga, wörtlich der "Anspannung".

Der Yoga ist das eigentümlichste Zwitterprodukt auf der einen Seite dor Praktiken ron Asketen und Wundermännern, wie sie von ältesten Zeiten her Indien erfüllten und noch erfüllen, auf der anderen Seite der philosophischen Spekulation. Die über die Erde hin verbreiteten Vorstellungen von drn \%auberkräften, die man durch Selbstpeinigung und Herbeiführung von Ekstas erwirbt, waren selbstrerständlich auch in Indien heimisch. Schon in den Hymnen des Rgreda begegnet ihre Spur. In den Umgebungen, in denen Buddha lebte, traten die verschiedensten bald plump grotesken bald verfeinerten und in philosophisches (iewand gekleideten Typen von Asketentum charakteristisch hervor. In Buddhas eigenem Leben haben Bestrebungen dieser Art allem Anschein nach eine erhebliche Rolle gespielt; der Buddhismus und dir ihm ähnlichen Sekten haben ihnen breiten Raum gewährt. Als Alexander den Boden Indiens betrat, sahen die Griechen mit Erstaunen die fremdartigen Gestalten der indischen Asketen, wie sie nackt in den verschirdensten Haltungen dasaßen, lagen, standen, mit bloßen Füßen den Gluten des sonnenerhitzten Erdbodens trotzend. Und so reicht bis zur Gegenwart und wird trotz aller Fortschritte englischer Kultur gewiß durch weite Zukunft reichen das Treiben dieser unübersehbar bunten Massen von Asketen, aus denen in der einen Richtung Männer wie der edle und tiefsinnige Rāmakṛṇa (gestorben 1886) hervorragen, dessen Lebensbeschreibung und greistrolle Aphorismen Max Müller in einer anziehenden Schrıft mitgeteilt hat, in anderer Richtung wiederum I'undertäter wie jener Haridāsa: es steht auf das sicherste fest, daf dessen Begabung und Trainierung ihn befähigte, unter äußerster Herabsetzung seiner Lebenstätigkeit bis zu 40 'Tagen (in Lahore, 1837) im Grabe zuzubringen.

Die mannigfachen Gestalten solches Asketentums fügten sich den verschiedensten Vorstellungskreisen geschmeidig an, und die Erstreber und Besitzer jener geheimnisvollen Kräfte wären keine Inder gewesen, hätten sie es verabsäumt, ihr mehr oder minder heiliges Treiben auch mit einer philo- 
sophischen Theorie auszustaffieren. Als die entscheidenden Schritte dazu geschahen, gehörte die leitende Rolle im Reich der Philosophie dem Sānkhya, und unschwer gab sich das Sānkhyaideal der Sonderung von Seele und Natur dazu her, in jene Bestrebungen hineingedeutet zu werden, die das Denken von aller Berührung mit Äußerlichem losrissen, damit es bewegungslos in der Ruhe seiner eigenen Innenwelt weile. Indem man so, um die Theorie des Yoga zu erbauen, nach den theoretischen Grundlagen des Sănkhya griff, fügte man nur in dessen atheistisches System aus den populären Vorstellungskreisen des alten religiösen Asketentums eine mit jener Philosophie schlecht genug verträgliche Zutat: die Gestalt Gottes des Herrn (İśvara). Man definierte diesen, der Sprache des Sānkhya sich anpassend, als eine „besondere Seele“ (Puruṣa, vgl. S. 37) von eigenartigem höchstem Rang unter den Seelen und empfahl ihm gegenüber fromme Hing ebung als Förderung des Yogastrebens, ohne daß man doch im Rahmen dieses Systems sein Wirken anders als ganz schattenhaft auszumalen imstande war.

„Der Yoga“, heißt es im Eingang des leitenden Textes der Schule, „ist die Unterdrückung der Modifikationen des Denkorgans." Um sich der anzunähern, setzt sich der Yogin in einer der 84 Stellungen nieder, die Gott Śiva aus 8400000 ausgewählt hat - etwa in der Lotusstellung (abgebildet bei R. Schmidt, Fakire und Fakirtum, Fig. 3): überkreuz den rechten Fuß auf den linken Schenkel, den linken Fuß auf den rechten Schenkel legend; hinter dem Rücken kreuzen sich die Arme, und jede Hand ergreift einen großen Zeh, die Augen blicken auf die Nasenspitze. Eine wichtigste Hauptsache für den Erwerb der Herrschaft über das Innenleben ist die Atemregulierung, „deren Funktionen sind Außenrichtung, Innenrichtung, Festhaltung. Nach Ort, Zeit, Zahl wird sie bestimmt, langgedehnt oder zart" usw. Im Verlauf seiner Übungen geht der Yogin durch eine Stufenfolge von Konzentrationen hindurch; vom Welcdasein zieht er sich in sein Inneres, vom Fühlen in Fühllosigkeit zurück; über das Bewußtsein erhebt er sich zur Unbewußtheit. Hypnotische, kataleptische Zustände werden erreicht. Zauberkräfte sollen dem Yogin zuteil werden, wie den eigenen Körper ins Ungeheure zu vergrößern, so daß man mit den Fingern an den Mond reicht, nach Belieben sich an jeden Ort zu versetzen, seinen Körper zu vervielfältigen und ähnliche Fertigkeiten mehr. Das alles aber ist weit davon entfernt, das wahre und letzte Ziel des Strebens zu sein; das Ziel ist allein die Erlösung. Die drei Guṇa (s. oben S. 37), nicht mehr arbeitend für die Seele des Erfolgreichen, ziehen sich zurück; die absolute Isolierung der Seele von der Natur ist erreicht.

Der Abendländer hat es leicht, das Gefühl der eigenen Entferntheit von all diesem Wollen und Vollbringen in spöttischen Ausdruck zu kleiden. Und nicht minder leicht ist es, die unechten, oft skandalösen Beimischungen aufzuweisen, mit denen in alter und neuer Zeit Charlatans mancher Art jene Übungen der Ablösung der Seele von der Welt versetzt haben. Man sollte doch über solchen in gewissem Umfang unzweifelhaft berechtigten 
Betrachtungen auf der anderen Seite die unverdächtigen Zeugnisse ehrlicher Zeugen nicht übersehen, welche jene Versenkungen selbst durchlebt haben, von dem altbuddhistischen Poeten an, der vom Versenkten sagt:

„Kein Glück mag ihm werden, das diesem gleicht",

bis zu Rāmakṛṣna, welcher Versenkung als „den Zustand des Glücks“ beschreibt, „den der Fisch erlebt, den man für eine Zeitlang aus dem Wasser genommen hat und dann wieder hineinsetzt". Wir vergessen die Reserven nicht, die dem Yogawesen gegenüber zu machen uns selbstverständlich ist, wenn wir doch versuchen, nicht verständnislos für die Beseligungen jenes weltentnommenen Schwebens im Leeren und für solche Stimmungen zu bleiben, wie sie aus einer kurzen Parabel des eben genannten Rāmakṛ̣na sprechen: sie möge diese Bemerkungen über den Yoga beschließen.

Einmal lag ein Weiser in tiefer Versenkung zur Seite des Weges. Den sah ein Dieb und dachte bei sich: „Der Mensch, der da liegt, ist gewiß ein Dieb. Er hat nachts einen Einbruch verübt und schläft jetzt seine Müdigkeit aus. Gleich kommt die Polizei und nimmt ihn fest. So will ich rasch verschwinden!" Und er lief von dannen. Bald darauf kam des Weges ein Trunkenbold. Der sagte, als er den Weisen sah: „Halloh! Du bist in den Graben gefallen, weil du einen Schluck zuviel getrunken hast! Ich stehe fester auf meinen Füßen; ich komme nicht zu Fall". Zuletzt kam ein Weiser. Der erkannte, daß der große Weise in Versenkung eingegangen war. Er setzte sich nieder, faßte ihn an und begann sanft seine heiligen Füße zu reiben". -

Vișnuitische und śvaitischo Spekulation.
Die Vermischung von Denk- und Kultformen des populären Hindutums - der Viṣnuverehrung, der Śivaverehrung - mit Ideen des Vedānta, Sānkhya, Yoga hat sich von frühen Zeiten an sehr weit erstreckt. In die höchsten Höhen, zu denen indische Poesie je aufgestiegen ist, reichen manche Stellen des als Episode dem Mahābhārataepos eingefügten wundervollen Gedichts Bhagavadgìtā. Zu den Glanzleistungen indischen Denkens gehört es freilich nicht, wie man hier - vermutlich indem ursprüngliche Verwirrung durch spätere Überarbeitungen noch gesteigert ward - die Verherrlichung ViṣnuKrṣnas und der ihm geweihten mystischen Liebe des Frommen mit einem philosophischen Gewand - richtiger mit Fetzen mehrerer solcher Gewänder - behängt hat. Auf niedrigerem literarischem Niveau stehen sivaitische Spekulationen, wie die anscheinend ziemlich junge Lehre vom pati (Herrn), paśu (Vieh), pāsa (Fessel), d. h. Siva, der Seele, der Natur oder Materie; sie ruht auf der Grundlage des Sānkhya.

Doch wir müssen uns an einer kürzesten Hindeutung auf solche Ausläufer der großen Systeme genügen lassen und uns zwei Doktrinen zuwenden, die sich, im wesentlichen jünger als Sānkhya oder Yoga (vgl. oben S. 34), neben sie gestellt und in der späteren indischen Wissenschaft bedeutenden Einfluß gewonnen haben.

VI. Vaiśeșika und Nyāya. Während die älteren Systeme sich in enger Berührung mit den großen Problemen der Upanișaden halten - Erlösung der Seele aus den Banden der Vergänglichkeit; ihr Hingelangen zum 
Reich des Ewigen - machen sich die Systeme Vaiśeșika und Nyāya in größerer Freiheit von solcher Begrenzung los. In ihnen regt sich das Interesse an anderen, rein theoretischen Fragen, an Logik, an Naturphilosophie. Diese werden in einer Weise untersucht, die verglichen mit der Art von Sānkhya und Vedānta dem, was uns als strenge Wissenschaftlichkeit erscheint, um einen merklichen Schritt näher kommt. Das Ziel des höchsten Heils stellen zwar auch die Textbücher dieser Doktrinen an die Spitze. Aber wenn etwa das Sūtra des Nyāya in seinem ersten Satz die 16 Hauptgegenstände der Erkenntnistheorie und Dialektik aufzählt, um dann zu erklären, daß durch deren Kenntnis jenes Heil erreicht wird, fühlt man doch deutlich, wie hier eben nur eine alte, geläufige Wendung wiederholt, kaum ein wirklich lebendiges Motiv des Denkens ausgedrückt wird.

Das Vaiśeșika wird auf Kaṇāda, der Nyāya - oder die uns vorliegende Gestalt des Nyāya - auf Grautama zurückgeführt. Auf beiden Seiten hat eine kräftige Weiterentwicklung über das ursprüngliche Stadium hinaus stattgefunden. In deren Verlauf haben diese Systeme entsprechend der nah verwandten Stimmung, die in ihnen herrscht, und der Gemeinsamkeit vieler Probleme sich gegenseitig auf das stärkste beeinflußt. Schließlich hat sich geradezu eine Fusion zwischen ihnen vollzogen.

Vaiśeșika und Nyāya halten sich durchaus auf dem Boden des Realismus. In einer offenbar gegen buddhistische Denker (vgl. oben S. 41) gerichteten Auseinandersetzung bestreitet das eine der beiden Textbücher die Leugnung aller Realität. Der richtigen Erkenntnismittel sich bedienend sei man imstande, das Objekt in Wahrheit zu erfassen. Wenn die Gegner Nichtexistenz cler Dinge behaupten, müsse es einen Beweis hierfür entweder geben oder nicht geben. Gibt es ihn, ist die Konsequenz, daß auch jener Beweis nichtexistent ist, sich somit selbst aufhebt. Gibt es ihn nicht, wird die gegnerische Ansicht eben als des Beweises ermangelnd hinfällig. Meint der Gegner, das Vertrauen auf die Erkenntnismittel und auf das durch sie Erkannte stehe auf einer Linie mit dem Glauben an Traum, Zaubertrug, Luftspiegelungen, so wird erwidert, daß es an jeder Begründung dieser Ansicht fehlt; der Glaube an die Traumwelt geht im Erwachen unter, und ebenso findet irriges Meinen sein Ende durch die Erkenntnis der Wahrheit.

In solchem Vertrauen auf die Erkennbarkeit der Dinge unternimmt das Vaiśeșika, dessen Erforschung sich leider noch nicht sehr weit von den Anfängen entfernt hat, eine weit angelegte, analysierende Betrachtung der Weltwirklichkeit unter dem Gesichtspunkt von sechs Kategorien: Substanz, Qualität, Tätigkeit (oder Bewegung), Allgemeinheit, Besonderheit, Inhärenz. Man möchte hier, bei aller Größe des Abstandes, etwas von der Weise wiederfinden, in der Aristoteles sein Weltbild auf breiten Fundamenten aufzubauen wußte. Eingehend wird untersucht, was unter jede dieser Kategorien fällt und in welchen Bezichungen sie zueinander stehen. Substanz ist, "was Tätigkeit und Qualität besitzt und Inhärenzursache ist (Inhärenzursache das, welchem inhärierend das Produkt entsteht, z. B. für das Gewebe die 
Fäden, aus denen es besteht, während die Verbindung der Fäden Nichtinhärenzursache, Webstuhl usw. instrumentale Ursache des Gewebes ist). Die einzelnen Substanzen sind Erde, Wasser, Feuer, Luft, Äther, Zeit, Raum, Seele und innerer Sinn. Es darf in dieser kurzen Skizze nicht versucht werden, das Funktionieren dieses komplizierten, scharfsinnig konstruierten Apparats durch die Einzelheiten - wie z. B. durch die Probleme, die sich um die bedeutsame Kategorie der Inhärenz lagern - zu verfolgen. Nur dies sei hervorgehoben, daß im Laufe der Entwickelung des Vaišșika besonderes Gewicht auf eine im Anfang weniger hervortretende Doktrin fiel, die Lehre von den Atomen. Es gibt kleinste Teile, Atome (paramāṇu) von Erde, Wasser, Feuer, Luft; sie müssen angenommen werden, da sonst ein Regressus in infinitum entstände. Die Atome sind ewig und nicht wahrnehmbar; indem sie sich in bestimmter Weise zu Doppelatomen usf. verbinden, ergeben sie die Welt der wahrnehmbaren Körper. Man möchte meinen, daß sich hier Anfänge von Physik und Chemie hätten entwickeln können. In der Tat läßt sich von solchen doch kaum sprechen. Man erging sich in den freiesten Phantasien beispielsweise über die Bewegungen, in welchen die Atommassen der vier Elemente abwechselnd, mit den Seelen sich verbindend die Welt entstehen machen und sie wiederum, wenn die Seelen von den Leiden der Wanderungen ermüdet sind, in die große Weltennacht zurücksinken lassen: eine Bewegung, in der das Gesetz der Vergeltung, Lohn und Strafe der guten und bösen Werke die treibende Kraft ist. Man sieht, wie das Denken, wo es den Boden der Naturwirklichkeit erreicht $z \mathrm{u}$ haben scheint, doch nicht anders kann als sich alsbald wieder in die Traum- und Zaubersphäre verlieren.

Nyăa. Unter den Leistungen der Nyāyaschule stehen Betrachtungen über die Probleme der Logik und Dialektik im Vordergrund. Erkenntnis entsteht durch Wahrnehmung, Schlußfolgerung, Analogie und glaubwürdige Bezeugung. Die Schlußfolgerung - mit ihr beschäftigte man sich besonders eingehend, während die Lehre vom Urteil nur gestreift, die von der Definition ganz oberflächlich abgetan wurde - beruht auf dem, was die Wahrnehmung geliefert hat. Der Schluß - genauer die Form des Schlusses, in der man einem andern die betreffende Erkenntnis entwickelt - ist fünfgliedrig, nach dem Schulbeispiel:

1. Behauptung: Auf dem Berg ist Feuer.

2. Grund: Denn es raucht dort.

3. Beispiel: Wo Rauch ist, ist Feuer, wie in der Küche.

4. Anwendung: So ist es mit diesem (dem Berg).

5. Schlußfolgerung: Darum ist er ebenso (mit Feuer versehen).

Die Fünfheit der Glieder statt der Dreiheit des aristotelischen Syllogismus erklärt sich daraus, daß es sich um die Belehrung eines anderen handelt. Mit Recht ist bemerkt worden, daß ein latenter Dialog vorliegt: man meint die Zwischenfragen des Mitunterredners, der Schritt für Schritt das Warum oder Wieso wissen will, zwischen den Zeilen zu lesen. Ein- 
gehendste Untersuchung wurde auf den Mittelbegriff (skt. hetu, linga; im obigen Beispiel „Rauch") und auf sein Verhältnis zum Oberbegriff („,Feuer") gerichtet. Die Arbeit von Logikern des Vaiseșika und des Buddhismus griff hier ein und führte vorwärts. Man fragte, welches sachliche Verhältnis zwischen Mittel- und Oberbegriff obwalten muk, damit sich vom ersteren auf den letzteren schließen lasse, und man zählte für dies Verhältnis die Fälle auf von Wirkung und Ursache, von Verbundensein, von Gegensatz, von Inhärenz. Weiterhin schritt man dann von solchen Aufzählungen dazu fort, jenes Verhältnis auf einen einheitlichen Begriff zu bringen: die Konkomitanz (skt. sāhacarya, vj'apti) - die Begleitung nicht im konkret-sachlichen, sondern im logischen Sinne (Feuer im logischen Sinn Begleiter des Rauchs). „Wo Rauch, da ist Feuer; wo kein Feuer, ist auch kein Rauch: wenn jemand, dem dieser Zusammenhang geläufig ist, mit zweifelloser Sicherheit Rauch sieht und sich jener Konkomitanz erinnert, entsteht alsbald in ihm die Gewißheit des Feuers. So bildet stets, was in Raum und Zeit mit etwas anderem untrennbar verbunden ist, ein Merkmal für dies andere". Man sieht, wie in dem oben gegebenen Schlußschema die Worte "wie in der Küche" eine kürzeste Veranschaulichung davon, wie unser Wissen von der Konkomitanz zustandekommt - den Anknüpfungspunkt für eine Lehre von der Induktion hätten abgeben können. Ernstlich verfolgt hat die indische Wissenschaft diesen Weg nicht. Wie hier in der Praxis die Induktion immer unendlich roh gehandhabt worden ist, hat die Theorie tiefere Erkenntnis ihrer Gesetze nicht erstrebt. Statt dessen trat nur allzu stark die Neigung in den Vordergrund, sich in spitzesten Kontroversen, oft mehr um Worte als um Sachen, zu verfangen, scholastische Gebäude - wie etwa die Theorie der Scheingründe - aufzubauen und mit verschnörkelten Zieraten zu schmücken. So erscheint diese Dialektik mehr und mehr nicht als ein scharfes und feines Werkzeug, in die Wirklichkeit einzudringen, sondern als ein Organon für Disputierkünstler, welche die Steine des logischen Brettspiels nach komplizierten Spielregeln gegeneinander schieben, für Philosophen, deren Bild ein Roman des 7. Jahrhunderts zeichnet - wie sie im Walde sitzen, „nachdenkend, gegeneinander angehend, $Z_{\text {weifel }}$ erhebend und auflösend, Etymologien aufstellend, disputierend, studierend, erklärend“.

VII. Die Cārvākalehre (Lokāayata). Schon oben (S. 33f.) wurde er- Materialismus wähnt, daß bereits in der altbuddhistischen Literatur und in Kautilyas der CárvākaÄußerungen über die Philosophie seines Zeitalters (um 300 v. Chr.) die materialistische Weltanschauung als zu einem festen System (Lokāyata) entwickelt erscheint. Für dessen genauere Gestalt sind wir auf Fragmente und einen späteren gegnerischen Bericht angewiesen, der in den Äußerlichkeiten offenbar ein verhältnismäßig junges Entwickelungstadium der Lehre repräsentiert: womit nicht gesagt ist, daß vom wesentlichen Inhalt des vermutlich in älterer und neuerer Zeit ziemlich unveränderten, wohl durch große Einfachheit ausgezeichneten Systems uns viel verloren gegangen sein muß. Die 
Erkenntnistheorie des Materialismus streicht unter den Erkenntnismitteln nicht nur, wie sich von selbst versteht, die Autorität, die Offenbarung, sondern auch die Schlußfolgerung. Zum Wissen von der für diese erforderten Konkomitanz (s. S. 5 I) können wir nicht gelangen. Die äußere Wahrnehmung liefert uns solches Wissen nicht, denn sie betrifft nur das Gegenwärtige, sagt über Vergangenheit und Zukunft nichts aus. Ebensowenig führen alle anderen Wege zum Ziel, auf denen man sich jener Konkomitanz vergewissern und damit eine Schlußfolgerung ermöglichen könnte. So bleibt als einziges Erkenntnismittel die Wahrnehmung übrig. Der Veda, dies Werk von Possenreißern, Betrügern, Kobolden, spricht doch die Wahrheit, wenn er einmal sagt, daß das erkennende Wesen "sich aus diesen Elementen erhebt und mit ihnen untcrgeht; kein Bewußtsein gibt es nach dem Tode". Die einzigen in Wahrheit vorhandenen Wesenheiten sind die vier Elemente. Indem die sich zu einem Leibe gestalten, lassen sie das Geistige entstehen, wie die Mischung gewisser Substanzen berauschende Kraft hervorbringt. Ein Jenseits gibt es nicht. Opfer nützen allein den priesterlichen Schwindlern, die ihren Vorteil dabei zu finden wissen. Ginge das Opfertier zur Himmelswelt, warum schlägt der Opferer nicht lieber seinen Vater tot? Das Ziel des Menschen ist Lust, wie z. B. Frauen zu umarmen. Ist mit der Lust Schmerz verbunden, hört jene darum doch nicht auf, das Ziel zu sein. Man muß es eben verstehen, die Fische zu essen, indem man die Schuppen und Gräten zurückläßt. Wenn das Wild den Saaten schaden kann, wird man es darum doch nicht aufgeben, Reis zu säen. Der Verständige folgt dem Spruch:

„Leb' in Lust, solang du lebest. Borge Geld. Trink Buttertrank.

Ist der Leib gebrannt zu Asche, giebt es keine Wiederkèhr."

Dies die „zum Besten vieler Lebewesen“ verkündete fröhliche Lehre, deren Prophet von den Göttern Bṛhaspati ist, von Menschen dessen Jünger Cārvāka ("der angenehm Redende"), "das Juwel auf dem Haupt der Atheisten“.

Dic indiscbe t'hilosophio und der Westen.
Schlußbetrachtung. Die indische Philosophie und der Westen. Iragt man nach den Einwirkungen der indischen Philosophie auf die westliche Welt, so kann für das Altertum die Antwort, bis jetzt wenigstens, nur unbcstimmt ausfallen. Becinflussung der älteren griechischen Denker durch Indien hat man namentlich für Pythagoras scharfsinnig zu erweisen versucht. Meinerseits müchte ich sie doch kaum für wahrscheinlich halten. Eher glaublịch sind derartige Zusammenhänge für spätere Zeiten, als einem auch wissenschaftliche Gebiete berührenden Verkehr zwischen Indien und dem Westen breite, vicl betretene Bahnen zur Verfügung standen. Hat die Gnosis, hat Plotin sich indische Gedanken angeeignet? Die Bemühungen, die man von indologischer Seite untcrnommen hat, diese an sich gewiß denkbare Annahme konkret zu gestalten und zu erweisen, schließen doch Zweifel nicht aus. Wer mit dem Gedanken an die Schöpfungen Indiens auf die des Westens hinschaut, wird beim Anblick der in die Augen fallenden Ahnlichkeiten oft allzu leicht - je nach seinem wissenschaftlichen Temperament 
und der Orientierung seines Forschens - zur Annahme indischen Einflusses auch da neigen, wo beiderseitige parallele Entwickelung nicht minder glaublich ist. Der Zukunft muß anheimgestellt bleiben, ob die Ungewißheiten, die hier bestehen, überwindbar, die subjektiven Momente ausschaltbar sind.

Wie hat die indische Philosophie auf die moderne Welt gewirkt, seit in den Tagen von William Jones, Colebrooke, Anquetil Duperron der europäischen Wissenschaft die staunenerregende Entdeckung des altindischen Geisteslebens gelungen war? Wenn wir vom Buddhismus als dem religiösen Gebiet angehörig absehen, handelt es sich begreiflicherweise vor allem um die Upanișaden samt dem Vedānta. Die feine Dialektik des Sānkhya oder der jüngeren Systeme mochte Interesse erregen. Nit voller, gewaltiger Wucht konnte doch nur jene andere Lehre, das Triumphlied weltverachtender Denkerkühnheit, die Seelen erfassen.

Die Aufmerksamkeit und eine bei manchen zur Begeisterung sich steigernde Bewunderung für die Philosophie - insonderheit für diese Philosophie - Indiens fand rasch vor allem in Deutschland eine Stätte. Hier hatte Herder das feine Gehör für die Stimmen der Völker erweckt. Hier lebte die Freude der Romantik an den mondbeglänzten Zaubernächten ferner Länder und Vergangenheiten, ihr Streben „das Vergessene und Verkannte ans Licht zu ziehen", wie A. W. Schlegel im Hinblick auf seine Ausgabe der Bhagavadgītā an Goethe schrieb. Das alles traf in Deutschland zusammen mit mächtigen Gärungen des philosophischen Denkens, dem leidenschaftlichen Bedürfnis nach einem zu den letzten Fundamenten hinabdringenden Erkennen. Und unter den Richtungen, die hier die philosophische Bewegung einschlug, gab es eine, die ihre eigene Verwandtschaft mit den Upanișaden, dem Vedānta unmöglich verkennen konnte.

Begreiflich, daß der Erfolg, die indische Philosophie deutschem Denken nah zu bringen, in erster Linie nicht etwa der geistvollen Schrift Friedr. Schlegels „Über die Sprache und Weisheit der Indier" zugefallen ist. Überwiegend mit dem religiösen Wesen Indiens sinnig und phantastisch sich beschäftigend kam Schlegel über die äußersten Vorhallen der indischen Philosophie nicht hinaus, und seine fühlbare Tendenz, auf so weitem Umweg den Parteiinteressen der deutschen Gegenwart zu dienen - Goethe hat darüber bittersten Hohn ergossen - schnitt ihm tiefe, dauernde Wirkung ab. Auch die vornehme Feinsinnigkeit W. v. Humboldts konnte kein allgemeines Gehör finden; dafür sprach sie eine zu leise Sprache. Aus dem widerspruchsvollen Chaos der Bhagavadgitā, über die Humboldt seinen vielbewunderten Aufsatz schrieb, meint man fortwährende Hemmungen in seine Gedankenentwickelung hinüberwirken zu sehen. Die erscheint dort am freiesten und tiefsten, wo sie sich vielmehr nit dem ästhetischen Problem des philosophischen Lehrgedichts als mit der Philosophie jenes Gedichts beschäftigt. Den Punkt, auf den es ankam, in Wahrheit treffen konnte nur ein aus dem Vollen schöpfender l'hilosoph. Und zwar nicht Hegel oder wer Hegel verwandt war. Der großen Anschauung Hegels vom weltumfassenden Prozed der Selbst- 
verwirklichung der Idee mußte das geschichtslose Denken Indiens fremd bleiben, das sich so gern allein an die unbewegten Tiefen des Ewigen heftete und dem Werdenden Sinn und Wert absprach. Da „taumelt das Besondere, ist bestimmt vorüberzugehen", sagte Hegel in seiner Darstellung der indischen Philosophie. „Jenseits steht die intellektuelle Substantialität, diesseits ist es dann trocken und dürftig." Anders wurde ein anderer von der indischen Gedankenarbeit berührt: Schopenhauer.

Man weiß, wie sich an Kants Gegenüberstellung der Erscheinungswelt und des aller Erfahrung unzugänglichen Dinges an sich bei Schopenhauer der Gedanke fügte, daß an einem Punkt der Vorstellende den Zugang zu dem besitzt, was jenseits der Vorstellungswelt liegt. In ihm selbst manifestiert sich unmittelbar, wird von ihm erlebt als das in der Erscheinung objektivierte Ding an sich der Wille; dem vergleichbar, wie sich der indischen Mystik das Brahma, das als allein Seiendes hinter der Scheinwelt der Māyā ruht, in cler Tiefe des eigenen Ich offenbart. Während die Erscheinung des Willens nach Schopenhauers Lehre geformt wird durch das Principium individuationis Raum und Zeit, ist er selbst, gleich dem Brahma der Inder, Einer. So ist, was das Individuum in sich erfaßt, nicht ein Teil von ihm, sondern es ist $\mathrm{Er}$, der Unteilbare, wie es für den Vedānta die Fülle des ganzen Brahma ist, von der das Wort gilt „das bist du“. Als höchstes Ziel aber erscheint dem deutschen Denker die Erlösung vom Elend des Willens, des endlos strebenden, unseligen: wie in Indien von der Zeit der Upanișaden an das letzte Wort der Religionen und Philosophien Erlösung heißt.

$\mathrm{Da} B$ es zwischen jenen alten und diesen modernen Gedankengängen Diskrepanzen gibt, wirl man selbstverständlich nicht übersehen. Die von mystischem Trug erzeugte und durchwogte Scheinwelt des Vedānta stellt sich doch in wesentlich anderem Lichte dar als die Erscheinungswelt, welche Kant in schärfster Prüfung erkenntnistheoretischer Probleme als solche verstehen gelehrt hatte. In anderem Licht auch als Schopenhauers Welt als Vorstellung mit der in ihr herrschenden unverbrüchlichen, von der Naturwissenschaft durchleuchteten Gesetzmäßigkeit. Und vollends jenseits des Vorhangs die erhabene Stille und Lichtnatur des indischen Dinges an sich, des reinen Erkennens, des Brahma, die dem leidenvollen Dunkel von Werden und Vergehen nur das Reich des Scheins überläßt, ist verschieden genug von der blinden, unruhezerwühlten Friedlosigkeit des Schopenhauerschen Dinges an sich, des Willens: hier das Brahma, vom Erkennenden, Erlösten bejaht - dort der Wille, von jenem verneint. Bei alledem fällt doch tiefe Verwandtschaft beicler Weltanschauungen genugsam in die Augen, und was von den indischen Gedankengängen Schopenhauer zugänglich war, reichte vollauf hin - insonderheit für seinen glänzenden Scharfblick -, ihn selbst in den wesentlichsten Beziehungen diesen Gleichklang intensiv empfinden zu lassen. Seine Antipathie gegren das Überspringen der Kluft zwischen der Welt als Vorstellung und ihrem Ansichsein, gegen das Auflösen alles Seins in logische Notwendigkeit, sein $\mathrm{Haß}$ gegen jeglichen Optimismus und sein 
Glaube an die - von anderen indischen Lehren noch schärfer als vom Vedānta betonte - leiderfüllte Vergeblichkeit alles Geschehens und Handelns: für diese suinem Denken und seinem davon unablösbaren Temperament tief eingewurzelten Motive fand er in Indien willkommenen Widerhall. Einsam, zurückgestoßen und zurückstoßend stand er unter seinen Zeitgenossen da; hier mochte dem auch in ihm lebendigen Verlangen nach Anlehnung an Gleichgestimmte seine Befriedigung werden fern von der Atmosphäre deutscher Philosophieprofessoren in der Begegnung mit Gedanken, in denen das Denken eines ganzen Volkes zu gipfeln schien. So strömten denn bei ihm die Betrachtungen, die von Kants Kritik des Erkenntnisvermögens ausgingen, und die Gebilde jenes fremdartig grandiosen Denkens ineinander. Er hatte die Empfindung einer feierlichen Weihe, die sich von dorther über seine Gedankenwelt ergoB. Der Urweisheit des Menschengeschlechts meinte er zu begegnen, unverdrängbar von den Begebenheiten in Galiläa. Neben Kant und Platon erschienen ihm die Veden - er dachte dabei an die Upaniṣaden - als die besten Vorbereiter zur Aufnahme seiner eigenen Lehre, für ihn selbst als der Trost seines Lebens und seines Sterbens. So bürgerte sich denn durch ihn in der Sprache deutscher philosophischer Romantik das "große Wort" der Upanișaden ein, das er so gern wiederholte: Tat tvam asi, „Das bist du“. Die Macht, die statt der Einheit des Dinges an sich dem Beschauer die bunte, Raum und Zeit erfüllende Vielheit erscheinen läßt, nahm den Namen des Schleiers der Mãyā an. Als Muster derer, welche die Verneinung des Willens zum Leben durch Tat und Wandel verwirklicht haben, gelangten die erlösungsdurstigen Asketen Indiens zu hohen Ehren. Mit einem Wort: für Schopenhauer und seine Jünger wurde Indien - in erster Linie das, was die Upanisaden von Indien sehen ließen - zu einem heiligen Lande, in dessen ferner Vergangenheit das Tiefste des eigenen Lebensinhalts vorbildlich verwirklicht war.

Das zeitweise Heranwachsen der Macht Schopenhauers über Denken und Stimmungen vieler ließ auch diese Empfindung, man kann sagen diesen Kultus, in einem Umfang und mit einer Intensität sich ausbreiten, wie das ohne solche Bundesgenossenschaft der indischen Philosophie nie und nimmer zuteil geworden wäre. An die Hinneigung zu Schopenhauer knüpfte sich die Bewunderung für jene im Kreise R. Wagners. Unter dem Zeichen Schopenhauers standen die verdienstlichen Bemühungen, durch die ein überzeugtester Anhänger des Frankfurter Meisters, P. Deussen, unser Wissen von indischer Philosophie gefördert hat - ihm bekannte der freundschaftlich ihm verbundene Nietzsche sich dankbar für das ,große Vergnügen, einmal den klassischen Ausdruck der mir fremdesten Denkweise kennen zu lernen" (I883). Soll in diesem Zusammenhang schließlich auch - last and least - des seltsamen Versuchs gedacht werden, die Lehre des Vedānta als "arische Weltanschauung“ unter das Zeichen der Rassenreinheit zu stellen? Im Verkehr mit so unverfälschtem Indoariertum soll uns - so läßt man uns hoffen - die Selbstbesinnung zuteil werden, den heiligen Kampf um die 
Herrschaft in unserem eignen, durch Fremde schwer bedrohten Hause siegreich zu bestehen. Hätte Śankara diese Waffenbrüderschaft mit den Rasseverwandten im fernen Norden vorausgeahnt, wäre vielleicht über das Gesicht des Südinders, in dessen Adern schwerlich viel weniger dravidisches als arisches Blut floB, ein leises Lächeln geglitten.

Die aber, die der Lehre Schopenhauers fremd gegenüberstehen, werden sie sich die hochgespannten Erwartungen aneignen, die jenen - und damals nicht ihn allein - erfüllten: daß unserem geistigen Leben aus dem Einfluß der Sanskritliteratur und vor allem der Weltbetrachtung der indischen Denker ähnliche Bereicherung und Vertiefung zuteil werden würde, wie einst die Wiederbelebung des griechischen Altertums sie dem I 5. Jahrhundert gebracht hat?

Die Zeiten der ersten Begeisterung über die Entdeckung jener Schöpfungen Indiens liegen wohl weit genug hinter uns, daß wir zu jener Frage heute mit kühlerer Ruhe Stellung nehmen können. Und so dürfen wir uns zu der Meinung bekennen, daß sich die Hoffnungen, die da gehegt wurden, nicht erfüllt haben, nicht erfüllen werden. Sie werden sich nicht erfüllen in bezug auf den Buddhaglauben, auf den eben jetzt eine Augenblicksströmung, wie es scheint, noch mehr als auf die indische Philosophie die Sehnsucht derer hinblicken läßt, die eine geistige Regeneration von Indien her erwarten. Jene Hoffnungen werden sich ebensowenig an der Lehre der Upanișaden und des Vedānta erfüllen. Gewiß wird der Reiz und die Suggestionskraft der Begegnung mit manchem uns nahen Problem in so ferner Welt immer frisch bleiben. Und vor allem wird und soll frisch bleiben unsere Empfindung für die wundervolle Kühnheit und Kraft jener Inder, die die Welt am Maßstab mächtiger jenseitiger Ideale gemessen und das Urteil über sie gesprochen haben - für die ganze Rücksichtslosigkeit ihres Sichlosreißens von dieser Welt, für ihr nicht klagendes Ertragen, sondern beseligtes Ergreifen der Folgen solcher Tat. Aber diese Bewunderung wird uns nicht hinweghelfen über das Gefühl tiefer Fremdheit gegenüber einer Philosophie, die den handelnden Kräften des Menschen, den Mächten der Geschichte, den Bedürfnissen und Werten menschlichen Gemeinschaftslebens so wenig gerecht wird, deren Held der entsagende Mönch oder der Yogin ist. Und wir werden nicht übersehen, wie dieser Philosophie die Wirkung davon aufgeprägt ist, da $\mathrm{B}$ neben ihr - sehr anders als in Griechenland - von positiver Wissenschaft, welche die Wirklichkeit klar, scharf, erfolgreich ergründet, von Naturforschung, von Geschichte nur dürftige Anfänge stehen. Die Erziehung in der strengen Schule solcher Wissenschaft fehlt dem indischen spekulativen Denken. Allzu luftig bleibt so dessen Spicl - Traum, Vision, Ikarusflug. Jene Philosophen sind Brüder der indischen Poeten. Wie die Gestalten der indischen Dichtung, übersponnen von zierlichen Ornamenten, oft im Unendlichen zu verschwimmen scheinen, so umkleiden diese Denker mit dem Rankenwerk einer spitzen Dialektik die düsteren Schöpfungen, man darf sagen die Dichtungen ihrer übergewaltigen Phantasie. Für den westlichen Geist — „welch Schauspiel! aber ach! ein Schauspiel nur!“ 


\section{Literatur.}

Die älteren Phasen der Erforschung der indischen Philosophie dürfen hier übergangen werden. Mit einem Erfolg, der das früher Erreichte in Schatten stellt, haben in neuer Zeit den Vedānta Deussen und Thibau'T behandelt, das Sānkhya Garbe, den Yoga Tuxen, alle drei Systeme, ebenso feinsinnig wie von Illusionen energisch sich freihaltend Oltramare, eine ansehnliche Reihe einzelner Probleme JACOBI. Auf die Verdienste des an erster Stelle genannten Gelehrten um die Erforschung der Upanișaden ist schon in. dem Abschnitt über die indische Religion hingewiesen worden. Hinter unserer Kenntnis von Sānkhya, Vedānta, Yoga ist die der anderen Systeme - namentlich auch der buddhistischen - bis jetzt zurück. geblieben. Sie zu fördern, erscheint als eine Hauptaufgabe der nächsten Zukunft; eine andere möchte ich darin finden, volle Klarheit darüber zu schaffen, was den Materialien einiger Upanișaden, des Manugesetzbuchs und des Mahābhārata für die Aufhellung der Vorgeschichte des Sānkhya abgewonnen werden kann; eine Frage, die trotz der Bemühungen namentlich von Dahlmann, Hopkins, Jacobi, DeUssen noch der sicheren Lösung harrt. Vielleicht werden hier Fortschritte durch Deussens Arbeit „Vier philosophische Texte des Mahābhāratam" (1906) erleichtert werden.

Allgemeines: Max Müller, The six systems of Indian philosophy (1899). R. GARBE, Beiträge zur indischen Kulturgeschichte (1903) S. 37-94 („Die sechs Systeme indischer Philosophie"). - MADHAVA ACHARYA, The Sarva-darśana-samgraha, or Review of the different systems of Hindu philosophy (aus dem I4. Jahrhundert), translated by E. B. Cowell and A. E. Gough (1882). - Oltramare, L'histoire des idées théosophiques dans l'Inde, Bd. I (1906). - P. Deussen, Allgemeine Geschichte der Philosophie, Bd. I, Abt.3 (1908).

Die Systeme in der Zeit des Kauțilya; H. JACOBI, Zur Frühgeschichte der indischen Philosophie (Sitz.-Ber. der K. Pr. Akad. der Wiss. I9 I Nr. 35): überaus fördernde Diskussion der betreffenden Probleme.

Sānkhya und Yoga: R. GARBE, Die Sāmphya.Philosophie (1894). - Derselbe, Sāmpkhya-pravacana-bhāshya, aus dem Sanskrit übersetzt und mit Anmerkungen versehen (1889). - Derselbe, Der Mondschein der Sāṃkhya-Wahrheit, Vācaspatimiśra's Sāṃkhyatattva-kaumudi in deutscher Übersetzung (1891). - Derselbe, Sāṃkhya und Yoga (1896).

- TAKaKuSU, La Sāmnkhya-kārikā étudiée à la lumière de la version chinoise (Bull. de l'École franç. d'Extrême-Orient 1904). - P. Tuxen, Yoga (19II). - J. C. OMAN, The Mystics, Ascetics and Saints of India (1903). - R. Schmin', Fakire und Fakirtum im alten und modernen Indien (1908).

Vedānta: P. Deussen, Das System des Vedānta, 2. Aufl. (1906). - Derselbc, Dic Sütras des Vedānta (1887). - G. ThibaUt, The Vedānta-sūtras, 3 Bde. (I89o. 1896. 1904). - M. Walleser, Der ältere Vedānta, Geschichte, Kritik und Lehre (1910). - V. A. SukHTANKAR, Teachings of Vedānta according to Rāmānuja, Wiener Ztschr. f. d. K. des Morg. XXII (1908).

Vaiseșika und Nyāya; M. Mứller, Beiträge zur Kenntnis der indischen Philosophie (in Ztschr. der D. Morgenl. Gesellschaft VI). - RörR, Die Lehrsprüche der VaiçeshikaPhilosophie (ebd. XXl. XXII). - SUALI, im Giorn. della Soc. As. Italiana (1906-07). W. HANDT, I ic atomistische Grundlage der Vaiśeșikaphilosophie (Igoo). - GaU'Tana, The 
Aphorisms of the Nyáya Philosophy, in Sansk. and English (1850-54; die engl. Übersetzung von Ballantyne). - Hultzsch, Annambhațta's Tarkasamgraha aus dem Sanskr. übersetzt (Abh. der Gött. Ges. der Wiss., phil.hist. Klasse, 1907). - H. JACOBI, Die indische Logik (Nachr. der Gött. Ges. der Wiss., phil.-hist. Klasse, I90I). - W. FREYTAG, Über die Erkenntnistheorie der Inder (Vierteljahrsschrift für wiss. Philosophie, XXIX, 1905).

S. 31. Widersprüche in der Upanișadenlehre über das Verhältnis des Brahma zu Welt und Seele: Deussen, Allg. Gesch. der Philosophie, Bd. 1. Abt. 2, S. 145 ff. 320.

S. 33. Zur Vorgeschichte des Sānkhya: H. JACOBI, Gött. Gel. Anz. 1897 S 265 ff. J. Dahlmann, Die Sāmnkhyaphilosophie als Naturlehre und Erlösungslehre (1902). E. W. Hopkins, The great Epic of Inḍia (1902) S. 85-190. - Verhältnis des Sānkhya zum Buddhismus: H. OldenBerG, Buddha 3. Aufl. (I897), S. 443 ff. und die dort angeführte Literatur. - S. 34. Alter der philosophischen Texte: H. JACOBI, Journal of the Amer. Orient. Soc. XXXI (1910).

S. $36 \mathrm{ff}$. Darstellung der Sānkhyalehre überwiegend nach der Sānkhya-Kārikā. Anführungen: Sānkhya-Kār. 12. 20. 59. 61.64; Gaựapāda zu Kār. 20; Vijñānabhikṣu Sāṃkhyapravacanabhāṣya p. 13. 107; Yogavāsișțha, zitiert ebd. S. 85.

S. 4If. Buddhistische Systeme und Vermutung ihres Einflusses auf den Vedānta: WALleSER, Der ältere Vedânta (s. oben) S. 25 ff., s. auch denselben, Die mittlere Lehre des Nāgārjuna (1911); DE LA VAllÉE POUSSIN, Bouldhisme, opinions sur l'histoire de la dogma. tique (1909), S. I $86 \mathrm{ff}$; derselbe, Vedānta and Buddhism, Journ. of the R. Asiatic Society 1910.

S. $42 \mathrm{ff}$. Die hauptsächlichsten Zitate aus Sankara sind seinem Kommentar zu den Vedāntasūtras I, I, 4; 4, 3; II, I, 6. II. 27. 28. 33; 2, 31. 32; 3, 7. 4I ; 11I, 2, 15. 17. 21 ; IV, 3, 14 entnommen. Upaniṣad über das Nichtzurückkehren aus den Brahmawelten: Bṛhad Aranyaka Up. VI, 2, 15. Vers „Ein Zauberspiel": Śvetāśvatara Upan. 1V, 10. Der Geist im Traum Wagen und Gespanne erschaffend: Bṛhad Äranyaka Up. IV, 3, Io. Vers „Wenn die Seele": Gauḍapāda Mānḍūkyakārikā I, I6.

S. $47 \mathrm{f}$. Stelle über Atemregulierung des Yogin: Yogasūtra 11, 50. Vers "Kein Glück" Theragāthā $518 \mathrm{ff}$. Äußerungen des Rāmakṛ̦na: M. MÜLlLER, Rām., his life and sayings (1898), 140. 122. - S. 48. Dîe Bhagavadgītā: GARBE, Die Bhagavadgītã aus dem Sanskrit übersetzt (1905); Deussen, Vier philosophische Texte (1906) S. 31-107; Oldenberg, Die Literatur des alten Indien S. $172 \mathrm{ff}$.

S. 5of. Th. DE STCherbatskoI, Rapports entre la Théorie Bouddhique de la Con. naissance et l'Enseignement des autres écoles philosophiques de l'Inde (Muséon 1904). Derselbe, Erkenntnisthcorie und Logik nach der Lehre der späteren Buddhisten (russisch. 1903-09). - Nyāyadarśana IV, 2, 29 ff. - Vaiśeșikadarśana I, I, 15; IX, 2, 1. - Tarka. saṃgraha 40. - Praśastapāda Bhāṣya p. 205 (ed. Vizian. Sansk. Series). - Beschreibung der Philosophen in einem Roman: Bāṇas Harșacarita Kap. 8.

S. 5 If. Cārvākalehre: Pizzagalli, Nāstika Cārvāka e Lokāyatika (1907)- - Sarvadarsana-samgraha, erster Abschnitt. Man vergleiche auch die Cārvākaszene im 2. Akt des Dramas Prabodhacandrodaya und Rhys Davids, Sacred Books of the Buddhists II, $166 \mathrm{ff}$.

S. 52. L. v. SCHROEDER, Pythagoras und die Inder (1884); LASSEN, Indische Altertumskunde llI, 379ff. (1 858 ); GARBE, Sāmkhya-Philosophie $85 \mathrm{ff}$.

S. $53 \mathrm{ff}$. W. v. Hummoldt, Über die unter dem Namen Bhagavad-Gita bekannte Episode des Maha-Bharata (1825-26). - M. Hecker, Schopenhauer und die indische Philosophie (1897). - H. ST. Chamberlain, Arische Weltanschauung.

Über die hier angewandte Transkription vergleiche man die Bemerkung zum Abschnitt "Indische Religion" in Teil I, Abteilung 3 dieses Werkes. 


\title{
Nachtrăge zum zweiten Abdruck.
}

\author{
Von \\ MORiz Winternitz.
}

Zur Literatur über die Geschichte der indischen Philosophie im allgemeinen ist jetzt hinzuzufügen: Surendranath Dasgupta, A History of Indian Philosophy, Vol. I, Cambridge 1922. Dieser Band enthält eine Darstellung der Philosophie des Veda (Mantras, Brāhmañas und Upaniṣaden), der buddhistischen Philosophie, der Philosophie der Jainas;, des Sānkhya und Yoga, des Nyāya und Vaiśeșika, der Mīmāṃsā und des Vedānta nach der Schule des Śankara. Über die philosophische Literatur handelt M. Winternitz, Geschichte der indischen Litteratur, Bd. III (1922), S. 417-478.

Von R. GARBE, Die Sāmkhya-Philosophie, ist 1917.eine zweite umgearbeitete Auflage erschienen. Ein kleines, aber nützliches Handbuch ist A. BERRIEDAle KEITH, The SāmphyaSystem (1918). Über Ursprung und Bedeutung der Yogapraxis handelt J. W. HaveR, Die Anfänge der logapraxis (1922). Vgl. auch GARBE in Encyclopaedia of Religion and Ethics, XII, 83I ff.

Über Vaiśeșika und Nyãya s. jetzt die ausführlichen Darstellungen von L. SuALI, Introduzione allo studio della Filosofia Indiana, Pavia 1913; B. FADDEGoN, The VaiçeşikaSystem, Amsterdam 1918 und A. B. KEITH, Indian Logic and Atomism (1921). Über Vaiśeșika s. auch JACOBI, Atomic Theory, in Encyclopaedia of Religion and Ethics II, $199 \mathrm{ff}$. und GARBE ebendas. XII, 568 ff., über Nyāya GARbE ebendas. IX, 422 ff.

Zu S. 32: Daß das dem Kauțilya zugeschriebene Lehrbuch der Staatskunst „,nicht lange nach $300 \mathrm{v}$. Chr." verfaßt ist, muß jetzt ernstlich bezweifelt werden. OLDENBERG selbst drückt sich 1918 (Nachrichten von der Gesellschaft der Wissenschaften zu Göttingen, geschäftliche Mitteilungen S. 97) über die Echtheit des Werkes viel skeptischer aus. Vgl. WinternitZ, Geschichte der indischen Litteratur, III, S. $517 \mathrm{ff}$.

Zu S. 34: Daß sich das die Autorität des Veda leugnende Lokāyata ,selbst auf den Boden des Veda gestellt" haben soll (ähnlich JACOBI, Götting. gel. Anz. 1919, 22 f.), ist höchst unwahrscheinlich.

Zu S. 40 ff.: Über die buddhistische Philosophie s. auch L. DE LA VAllEE POUssin in Encyclopaedia of Religion and Ethics, IX (1917), $846 \mathrm{ff}$.

Zu S. 42: Über Sankara s. auch V. S. GHate in. Encyclopaedia of Religion and Ethics, XI, $185 \mathrm{ff}$. 
7u S. 47: Die Inder betrachten das Jogasystem oft nur als einen Zweig des Sānkhya und nennen es das "theistische Sānkhya" oder das "Sānkhya des Patañjali“.

Zu S. 51: An der Entwicklung der indischen Logik hatten Buddhisten und Jainas hervorragenden Anteil; s. Satis Chandra Vidyabhusana, Mediaeval School of Indian Logic (1909) und C.A.F. Rhys DAvids in Encyclopaedia of Religion and Ethics, VIll, 132 f.; jetzt auch F. I. SchtscherbazkoJ, Erkenntnistheorie und Logik nach der Lehre der späteren Buddhisten, aus dem Russischen übersetzt von O. STRauss. (Zeitschrift für Buddhismus 1922, auch separat.)

Zu S. 52: Die Etymologie von Cārvāka, ,der angenehm Redende", ist zweifelhaft. Die Inder leiten das Wort von der Wurzel carv „,kauen" ab, da die Cãrvākas Leute seien, die nur an das Essen und nicht an die religiösen Pflichten denken; s. DasGupta, a. a. O., p. 79.

Zu S. 52 f.: Über die Beziehungen zwischen indischer und griechischer Philosophie s. auch Winternitz, Geschichte der indischen Litteratur III, $477 \mathrm{f}$. 


\title{
DIE CHINESISCHE PHILOSOPHIE.
}

\author{
VON \\ Wilhelm Grube.
}

Einleitung. Überall und immer, wo sich das Menschendasein zu einem selbständigen Kulturleben erhob, weisen die drei mächtigsten Wesensäußerungen des menschlichen Geistes, Dichtung, Religion und Philosophie, auf den Spieltrieb der Einbildungskraft als ihre gemeinsame Wurzel zurück. Und dieser gemeinsame Ursprung läßt sich in der Regel an einem gewissen Parallelismus oder Kontrast in dem Entwickelungsgange von Religion, Dichtung und Philosophie wahrnehmen, wie es mehr oder weniger bei jedem Kulturvolke zutage tritt: sei es, daß, wie die Geschichte der Israeliten lehrt, die Religion als der herrschende Faktor erscheint, sei es, daß, wie bei den Indern, mystisch-philosophische Spekulation im Vordergrund steht, oder, wie bei den Griechen, alle Triebe zu gleichmäßig harmonischer Entfaltung kommen. In jedem Falle sind wohl Art, Richtung und Intensität der Einbildungskraft ausschlaggebend. Sobald das primitive Staunen zu der ersten Reflexion über die Stellung des Subjektes innerhalb seiner Umgebung erwacht und die Forderung: Jóc $\mu \mathrm{ol} \mathrm{\pi oû} \mathrm{crû} \mathrm{sich} \mathrm{geltend} \mathrm{macht,} \mathrm{scheiden} \mathrm{sich} \mathrm{die} \mathrm{Wege} \mathrm{je}$ nach der Art, wie das naive Bewußtsein zu den Phänomenen der Außen- und Innenwelt Stellung nimmt.

Unter allen Kulturen des Altertums ist die chinesische eine der ältesten und selbständigsten: weniger denn irgendeine andere von außen her beeinflußt, hat sie sich ungestört in ihrer Eigenart entwickeln können und steht als das einzige Denkmal nationaler Gesittung da, das sich aus altersgrauer Vorzeit bis in unsere Tage lebendig erhalten hat. Die chinesische Literatur umspannt einen Zeitraum von vier Jahrtausenden und gewährt, eben weil auch sie bis zum Eindringen buddhistischer Ideen, die sich aber erst in ihrem letzten Entwickelungsstadium deutlicher bemerkbar machen, von fremden Einwirkungen verschont blieb, einen ebenso lehrreichen wie zuverlässigen Einblick in die Psyche dieses für den abendländischen Menschen so schwer verständlichen Volkstums. Fragt man nun aber nach den besonderen Merkmalen, die den spezifischen Charakter jener Literatur bestimmen, so wird wohl in erster Reihe der auffällige Mangel an schöpferischer Einbildungskraft zu nennen sein. Unter allen Gattungen der Pcesie ist die Lyrik 
mit ihren Unterarten der Ode und Elegie, also ein Feld, das der Phantasie einen verhältnismäßig doch nur engbegrenzten Spielraum gewährt, dasjenige Gebiet, das zweieinhalb Jahrtausend lang ausschließlich kultiviert wird. Roman und Drama treten erst im 13. Jahrhundert unserer Zeitrechnung auf, und zudem erscheint der ältere Roman, bezeichnend genug, im Gewande der historischen Erzählung. Das in der Folge so beliebt gewordene Genre des phantastischen Zauberromans und Zauberdramas ist eine ganz moderne Errungenschaft, die überdies auf Schritt und Tritt indisch-buddhistische Einflüsse erkennen läßt. Ein nationales Epos besitzt der Chinese überhaupt nicht.

Und wie der Literatur das Epos so fehlt der Religion die Mythologie. Die Götter der altchinesischen Religion sind blutleere Schemen, persönlich gedachte, aber der Anschauung nicht zugängliche Kräfte, die wohl wirken, aber nicht eigentlich handeln. In der gesamten klassischen Literatur des chinesischen Altertums lassen sich nur zwei Stellen nachweisen, in denen eine anthropomorphe Vorstellung vom höchsten Wesen, dem Schang-ti oder Himmel angedeutet wird. Was sich im Vulgärtaoismus und im modernen Volksglauben an mythologischen Gestalten und Fabeln vorfindet, ist, wo nicht direkt dem Buddhismus entlehnt, so doch auf seine Anregung zurückzuführen. Auch der Glaube an ein Fortleben nach dem Tore, der bereits in den ältesten Zeiten verbreitet war und seinen unmittelbaren Ausdruck in der Ahnenverehrung fand, ließ die Frage nach dem Wo und Wie jenes Fortlebens völlig unerörtert: erst die eschatologischen Lehren des Buddhismus füllten ihn mit einem konkreten Inhalt.

$\mathrm{Daß}$ ein Boden, auf dem Religion und Dichtung nur ungenügende Nahrung fanden, auch dem Gredeihen der Philosophie nicht eben günstig sein konnte, liegt wohl auf der Hand: sind doch, wie für die Religion, so auch für die Philosophie die letzten Fragen die ersten, und die Verschiedenheit beider liegt nur darin, daß, was der naive Glaube als unmittelbaren Besitz sein eigen nennt, das philosophische Denken als einen bewußten Besitz zu erwerben trachtet. Und das A.hnungsvermögen, von dem dieses sich bei seinen ersten Versuchen leiten läßt, ist doch eben im Grunde auch nichcs anderes als ein Ausfluß der Einbildungskraft.

Wenn es wahr ist, daß die Sprache eines Volkes den unmittelbaren Niederschlag und naivsten A usdruck seiner Weltanschauung darstellt, so wird man erwarten dürfen, das Gesagte auch durch die Beschaffenheit der chinesischen Sprache, wenn nicht erklärt, so doch immerhin bestätigt zu finden.

In der Tat springt der abstrakt-begriffliche Charakter des Chinesischen sofort in die Augen, wohingegen das sinnliche Moment konkreter Anschaulichkeit höchst mangelhaft entwickelt ist. Der chinesische Satzbau zeichnet sich durch eine logische Folgerichtigkeit und Präzision aus, die kaum von einer anderen Sprache erreicht, sicherlich aber von keiner überboten wird. Nun sollte man füglich meinen, daß das Chinesische gerade durch seinen logisch-begrifflichen Charakter gewissermaßen zum Werkzeug philosophischen Denkens prädestiniert sein müßte. Nichtssdestoweniger ist dies keines- 
wegs der Fall, denn ein anderes ist der logische Begriff als soḷcher, ein anderes sein sprachlicher Ausdruck. Dazu kommt, daß Umfang und Inhalt eines Begriffes bekanntlich im umgekehrten Verhältnis zueinander stehen. Wenn also z. B. ein Wort wie $t a$, das als solches nur den Begriff der Größe oder des Großseins ausdrückt, seine grammatische Geltung als Redeteil aber erst durch seine Stellung im Satzgefüge erhält, mithin bei unveränderter Lautgestalt Größe, groß, sehr, groß sein und groß machen bedeuten kann, so ergibt sich daraus, da $\$$ hier dem einen logischen Begriff verschiedene grammatische Begriffe gegenüberstehen, deren keinem ein genaues Äquivalent in der lautlichen Form entspricht. Allerdings verleihen die Stellungsgesetze dem chinesischen Satzbau das starre Gefüge und die logische Schärfe einer algebraischen Formel, aber dieser Vorzug ist doch nur ein scheinbarer, denn die Sprache arbeitet nicht wie die Algebra mit unbestimmten, sondern mit bestimmten Größen. Es ist denn auch durchaus nichts Seltenes, daß ein und derselbe chinesische Satz grammat:sch verschiedene Deutungen zuläßt, so daß, wo die grammatische Analyse zu keinem entscheidenden Ergebnis führt, der logische Zusammenhang, und wenn auch dieser nicht ausreicht, der Sprachgebrauch $z u$ Rate gezogen werden muß. Dieser grammatischen Vieldeutigkeit entspricht ferner oft eine fast ebensogroße Unbestimmtheit des Bedeutungswertes, und leider sind es gerade diejenigen Begriffe, deren sich die chinesischen Philosophen mit Vorliebe bedienen, die an diesem Mangel leiden. So hat z. B. sin die Grundbedeutung Herz und wird, genau wie bei uns, im eigentlichen und im übertragenen Sinne gebraucht: dazu kommen aber ferner die Nebenbedeutungen: Geist, Gesinnung, Absicht. ming bedeutet ursprünglich Befeh1, als Verbum befehlen; außerdem, als Befehl des Himmels aufgefaßt, Bestimmung, Fügung, Schicksal, ferner im Sinne des Mandates, mit dem der Himmel den Souverän betzaut, soviel wie Herrschaft und endlich, als die Bestimmung aller Kreatur: Leben. Nicht weniger vieideutig ist der Sinn, den die Chinesen mit dem Worte $l i$ verbinden. Ursprünglich bezeichnete es nur die religiösen Riten, aber schon frühzeitg verband man damit zugleich die Bedeutung der Etikette sowie der konventionellen Umgangsformen, und schließlich wurde es auf die jenen äußeren Formen entsprechende Gesinnung ausgedehnt, so daß $l i$ auch soviel wie Schicklichkeit und Schicklichkeitsgefühl bedeutet. Diese Beispiele, die aufs Geratewohl aus einer Legion ähnlicher Fälle herausgegriffen sind, genügen wohl, um zu zeigen, daß ein Satz, dessen grammatische Analyse zu keinerlei Zweifeln Anlaß geben mag, gleichwohl der logischen Analyse, mithin auch einer exakten und adäquaten Wiedergabe des Gedankens, dessen Ausdruck beabsichtigt war, sehr große, bisweilen kaum überwindliche Schwierigkeiten datbieten kann. - Eine dritte Quelle der Mißverständnisse entspringt endlioh aus der eigentümlichen phonetischen Beschaffenheit der Sprache. Das Chinesische ist nämlich außerordentlich lautarm, besteht zudem ausschließlich aus Einsilblern und besitzt infolgedessen einen großen Reichtum an gleichlautenden Wörtern von verschiedener Bedeutung, ein Übelstand, den nicht 
einmal die chinesische Wortschrift mit ihren Tausenden von Schriftzeichen endgültig $z \mathfrak{u}$ beseitigen vermag. Hiermit steht die besondere Vorliebe des Chinesen für das Wortspiel im engsten Zusammenhange, zugleich aber auch seine bedenkliche Neigung, sich auch dort mit einem Wortspiel zu begnügen, wo eine Begriffsbestimmung geboten war, also etwa einen philosophischen Terminus einfach durch ein gleichlautendes Wort mehr oder weniger ähnlichen Sinnes zu erklären.

Ich glaubte, diese einleitenden Bemerkungen, selbst auf die Gefahr hin, $\mathrm{zu}$ ausführlich zu werden, vorausschicken zu sollen, um dem Leser verständlich zu machen, wie das Chinesische nicht etwa trot $z$, sondern gerade infolge seines abstrakten, begrifflich-logischen Charakters sich als ein für das philosophische Denken im ganzen wenig geeignetes Instrument erweisen mußte.

I. Die ä1teste Zeit (I roo-ca. 500 v. Chr.). Als das älteste Denkmal philosophischer Spekulation in China hat wohl das sogenannte Hung-fan, „die große Regel“, zu gelten, ein kurzer Traktat, der einen Bestandteil des Schu-king bildet. Im Jahre i 22 v. Chr. übergab ihn der Tradition zufolge der Fürst von $\mathrm{Ki}$ dem $\mathrm{Wu}$-wang, dem ersten Könige der neugegründeten Tschou-Dynastie, als ein Dokument, welches der sagenhafte Kaiser Yü (regierte angeblich 2205-2198 v. Chr.) vom Himmel selbst erhalten haben sollte. Eine auch nur annähernde Datierung des Textes ist freilich ausgeschlossen, aber auch abgesehen von der Überlieferung weist schon einmal die Sprache selbst, dann aber vor allem auch die unbeholfene Gliederung des Stoffes und clas lockere Gefüge des Gedankenganges auf ein zweifellos hohes Alter hin. Es ist wohl anzunehmen, daß das Hung-fan ursprünglich als eine Art schematischer Leitfaden für den Träger der obersten Gewalt gedacht war. Wie verschiedenartig die Gegenstände sind, die darin behandelt werden, kann der Leser aus der folgenden Übersicht der neun Abschnitte oder Paragraphen ersehen, in die der Traktat zerfällt:

I. Die fünf Elemente: Wasser, Feuer, Holz, Metall, Erde.

II. Die ehrfurchtsvolle Ausübung der fünf Tätigkeiten: Gebaren, Rede, Gesicht, Gehör, Denken in ihren Beziehungen zum sittlichen Verhalten.

11I. Die gedeihliche Verwaltung der acht Gegenstände der Regierung: Nahrung, Tausch. waren, Opferwesen, Verwa tung der öffentlichen Arbeiten, Verwaltung des Unterrichtswesens, Verwaltung der Rechtspflege, Gastlichkeit, Heerwesen.

IV. Dic entsprechende Benutzung der fünf Zeitregulatoren: Jahr, Monat, Tag, Sterne, und Sternbilder, Zeitrechnung.

V. Die Aufstellung und Ausübung des höchsten Herrscherprinzips: ethische Grundsätze und Verhaltungsmaßregeln für die Ausübung der obersten Gewalt.

VI. Die drei Tugenden: Rechtschaffenheit und Aufrichtigkeit, Herrschaft durch Strenge, Herrschaft durch Milde.

VII. Die cinsichtige Ausübung der Prüfung des Zweifelhaften: durch Zurategehen mit dem eigenen Herzen, mit den Ministern, mit dem gesamten Volk, und durch Befragen des Loses.

VIII. Die überlegte Benutzung der verschiedenen Manifestationen (sc. des Himmels, als Reaktionen des letzteren auf die menschlichen Handlungen): Regen, Sonnenschein, 
Hitze, Kälte, Wind, Jahreszeiten. (Ihr normaler Verlauf ist ein Zeichen guten Regimentes, wohingegen abnorme Naturerscheinungen als Folge schlechten Regimentes gedeutet werden.)

IX. Die ermunternde Ausübung der fünf Segnungen. (Die fünf Arten der Glückselig. keit sind: langes Leben, Reichtum, Ruhe und Frieden, Tugendliebe und ein gutes Lebensende. Ihnen stehen sechs Arten des äußersten Unglücks gegenüber, nämlich: unglücklicher und vorzeitiger Tod, Krankheit, Kummer, Armut, Schlechtigkeit, Schwäche.)

Jeder Paragraph enthält eine Reihe kurzer Betrachtungen über den darin behandelten Gegenstand. So heißt es von den fünf Elementen, daß das Wasser netzt und abwärts fließt, das Feuer flammt und emporsteigt, das Holz krumm oder gerade ist, das Metall nachgibt und sich verändert, die Erde der Saat und Ernte dient. Dann ferner, daß das Netzende und Abwärtsfließende salzig, das Flammende und Emporsteigende bitter, das Krumme und Gerade sauer, das Nachgebende und Sichverändernde ätzend und das Saatempfangende und Erntegebende süß wird. In diesem Parallelismus der Elemente und Geschmacksempfindungen zeigen sich bereits die ersten Anfänge der späteren Naturphilosophie, die den Parallelismus der Phänomene in phantastischer Weise auf eine Reihe anderer Gebiete ausdehnt. So schwer es auch ist, in dem kunterbunten Durcheinander der großen Regel einen leitenden Gedanken zu entdecken, so treten darin doch schon zwei Züge deutlich genug hervor, die für die chinesische Geistesrichtung charakteristisch sind: erstens ein entschiedenes Betonen ethischer Gesichtspunkte, dem gegenüber die metaphysische Speknlation zurücktritt, und zweitens der uralte Glaube an einen inneren Zusammenhang zwischen der natürlichen und der sittlichen Weltordnung.

Gewöhnlich wird das Yih-king, das „kanonische Buch der Wandlungen“, Yih-king. als der älteste Text genannt, den die philosophische Literatur aufzuweisen habe. Dieser Annahme liegt jedoch ein Mißrerständnis zugrunde: man hatte sich allmählich daran gewöhnt, den Grundtext des Yih-king samt den beigefügten, für klassisch geltenden Kommentaren, die jedoch zum Teil einer sehr viel jüngeren Periode angehören, als ein zusammengehöriges Ganzes zu betrachten. Nun besteht aber der ursprüngliche Text des Yih-king lediglich aus 64 Hexagrammen, die aus je sechs teils ganzen, teils gebrochenen Linien zusammengesetzt und mit kurzen Deutungen versehen sind. In dieser seiner ältesten Gestalt war das Yih-king nichts anderes als eine Sammlung von Orakelsprüchen und diente als Handbuch der Wahrsagekunst. Nichtsdestoweniger nimmt es allerdings in der Geschichte der chinesischen Philosophie eine hervorragende Stelle ein, denn gerade durch seine abstruse Unverständlichkeit hat es zu allen Zeiten eine unwiderstehliche Anziehungskraft auf grüblerische Geister ausgeübt und stärker als irgendein anderes Erzeugnis der chinesischen Literatur zu metaphysischer Spekulation angeregt. Unter den klassischen Kommentaren zum Yih-king stellen die sog. „Angehängten Erklärungen“, Hi-tsz ě, den ersten Versuch dar, es philosophisch zu deuten. Aber gerade dieser Krommentar ist relativ jüngeren Ursprungs: 
gegenüber der landläufigen, aber aus inneren Gründen völlig unhaltbaren Tradition, die ihn dem Konfuzius zuschreibt, ist wohl eher mit Legge anzunehmen, daß ihn des Weisen Enkel Tszĕ-szĕ verfaßt habe, mit dessen Tschung-yung es auch mehrfach Berührungspunkte erkennen läßt. Wenn man von einer kabbalistischen Zahlensymbolistik absieht, so ergeben sich daraus etwa folgende Grundgedanken: Den Anfang alles Seins bilden die kosmischen Dualkräfte Yin und Yang. Das Yang ist das lichte, männliche, zeugende Prinzip, dem das Yin als das dunkle, weibliche, empfangende Prinzip gegenübersteht. Das, was am Yin und Yang unergründlich ist (womit wohl ihr Wesensgrund gemeint sein soll), nennt man Geist. Aus dem Wechsel von Yin und Yang entsteht die Norm (tao). Das Yang verkörpert sich im Himmel, das Yin in der Erde. Mit Himmel und Erde ist der Unterschied von hoch und niedrig, vornehm und gering, hart und weich gegeben, Bewegung und Ruhe haben ihre Beständigkeit erlangt, die Tätigkeiten ordnen sich nach Kategorien, die Wesen teilen sich in Klassen, Glück und Unglück nehmen ihren Anfang. Der Himmel bringt die himmlischen Gestirne, die Erde die irdischen Gestalten hervor, und der Umwandlungsprozeß wird offenbar. Er findet seinen Ausdruck in der treibenden Kraft von Donner und Blitz, in der befruchtenden Tätigkeit von Wind und Regen und in dem Kreislauf von Sonne und Mond, der den Wechsel von Wärme und Kälte zur Folge hat. „Der Himmel bringt alles Männliche, die Erde alles Weibliche hervor. Der Himmel waltet über dem Uranfang, die Erde bringt die Wesen zur Vollendung." Der Weise, der die himmlischen und irdischen Phänomene zu ergründen vermag, ist dem Himmel und der Erde ähnlich, sein Wissen umfaßt alle Dinge, daher ist er frei von Irrtum; er freut sich des Himmels und kennt die Bestımmung, daher ist er ohne Sorge; er steht fest in der Menschenliebe, daher ist er der Liebe fähig.

Wie sehr das Studium des Yih-king die Geister zu fesseln vermochte, beweist die bändereiche Literatur, die sich damit befaßt. Den Höhepunkt seiner Blüte erreichte es schließlich in der Naturphilosophie des I1. und I 2. Jahrhunderts.

Konfuzius.

II. Konfuzius und seine Schule. Einen entscheidenden Wendepunkt in der Gesamtkultur Chinas bezeichnet das Jahr 551 v. Chr.: es ist das Geburtsjahr des Konfuzius, der wie kein anderer der Erzieher seines Volkes geworden ist, ja mehr noch: sein „ungekrönter König“, wie ihn eine dankbare Nachwelt preisend genannt hat.

Sein Wirken fällt in eine Zeit beginnenden Niederganges des staatlichen sowohl wie des sittlichen Lebens. Diesem entgegenzuarbeiten erfaßte er als seine Aufgabe. Den Weg sie zu lösen sieht er in der Rückkehr zu den patriarchalischen Daseinsformen des Altertums, und um die Blicke seiner Zeitgenossen eindringlich und nachdrücklich auf dieses Ziel zu lenken, wählt er aus der gesamten poetischen und prosaischen Überlieferung dasjenige aus, was ihm für die sittliche und politische Hebung seines Volkes geeignet er- 
scheint. Aus solchen Erwägungen sind die klassischen Texte entstanden, die in den Augen der Chinesen den wertvollsten Besitz ihrer Literatur ausmachen: sie sind Tendenzliteratur im edelsten Sinne des Wortes.

„Ich bin ein Überlieferer, aber kein Schöpfer, ich glaube ans Altertum und liebe es", - treffender und erschöpfender ließe sich das Wirken und die Persönlichkeit des Weisen nicht charakterisieren, als er es mit diesen Worten selber getan hat. Ein Philosoph im eigentlichen Sinne war Konfuzius nicht, die Gedanken, die er vorträgt, zeichnen sich weder durch kühne Selbständigkeit noch durch überraschende Neuheit aus, und das schlichte Gewand, in die er sie kleidet, entbehrt jeglichen rhetorischen Schmuckes. Die „Unterredungen“, Lun-yü, die einzige authentische Quelle, aus der wir die Kenntnisse seiner Lehren schöpfen, sind zugleich bezeichnend für seine Lehrweise. Es sind keine langatmigen Vorträge und Erörterungen sondern knappe, oft wortkarge Antworten auf Fragen, die seine Jünger an ihn richten, wie der Augenblick oder die Gelegenheit sie eingibt, und gerade dadurch sind sie doppelt wirksam. Worte wie diese: „Tugend bleibt nicht verwaist, sie findet sicher Nachbarn“, oder: „Mache Treue und Aufrichtigkeit zur Hauptsache, befreunde dich nicht mit solchen, die dir nicht gleichwertig sind, hast du gefehlt, so schäme dich nicht, es gut zu machen", oder: „Der Weise hat keinen 'Zweifel, der Menschenliebende keinen Kummer, der Tapfere keine Furcht" u. a. m. haben den Vorzug, praktische Lebensweisheit in einer Form zu bieten, die sich dem Gedächtnis leicht einprägt.

In Mittelpunkt der konfuzianischen Ethik steht das Gebot der Kindespflicht. Auf der einen Seite die absolute väterliche Gewalt, auf der anderen der bedingungslose kindliche Gehorsam: das sind die beiden Grundpfeiler des sittlichen Lebens. Die Kindespflicht in ihrer Zusammenfassung von Gehorsam und Liebe ist die Wurzel, aus der die übrigen Kardinaltugenden, Menschenliebe, Gerechtigkeit und Schicklichkeit, von selbst hervorwachsen. Als Ideal menschlicher Vollkommenheit erscheint bei Konfuzius der Normaltypus des „Edlen“, welcher die sittliche Vollkommenheit mit den Formen weltmännischer Bildung in sich vereinigt. Mit Vorliebe behandelt Konfuzius das Verhältnis von Fürst und Untertanen. Regieren (tscheng) bedeute zum Rechten leiten (tscheng - man achte auf das Wortspiel in dieser Definition), daher habe der Fürst vor allem durch sein Vorbild zu wirken. Aber der strengen Selbstzucht, die von den Regierenden gefordert wird, soll auf seiten der Untertanen nicht sowohl blinder Gehorsam, als vielmehr ehrlicher Freimut entsprechen, denn auf die Frage, wie man dem Fürsten zu dienen habe, erfolgt die Antwort: „Widersprich ihm, aber hintergeh ihn nicht!“ Die Art aber, wie jeder einzelne den Pflichten seiner Stellung genügen solle, ergibt sich aus den lapidaren Worten: „Der Fürst sei Fürst, der Untertan sei Untertan, der Vater sei Vater, der Sohn sei Sohn."

Man sieht, es ist kein Moraltheoretiker, sondern ein Moralprediger, der hier spricht. In der Tat war Konfuzius kein Freund von theoretischen Erörterungen. Das zeigt sich besonders deutlich in seiner völligen Verständnis- 
losigkeit für metaphysische Fragen; und nicht minder charakteristisch ist auch seine Stellung zur Religion. An den religiösen Satzungen und Riten hält er mit peinlicher Gewissenhaftigkeit fest, denn sie gehörten ja zur altgeheiligten Tradition; wer ihm jedoch mit Glaubensfragen kommt, wird mit einem gelassenen non liquet abgespeist. Das ist übrigens weniger ein individueller als ein typisch nationaler Zug, wie denn ja überhaupt das Chinesentum in Konfuzius seine vollendetste und ausgeprägteste Verkörperung gefunden hat. Darin liegt aber auch das Geheimnis der Macht, die er über die Gemüter seiner Zeitgenossen nicht nur, sondern in noch viel höherem Grade der kommenden Geschlechter ausgeübt hat. Will man die chinesische Kultur mit einem kurzen Schlagwort charakterisieren, so wird man sie als konfuzianisch bezeichnen. Nie und nimmer aber ließe sich ein so tiefer und nachhaltiger Einfluß aus den Lehren des Konfuzius allein erklären. Ausschlag= gebend war vielmehr seine Persönlichkeit als Träger und Vorbild dessen, was er lehrte.

Tszę-sžr. Unter Konfuzius' Nachfolgern steht inm sein Enkel Tszĕ-szĕ zeitlich am nächsten. In seiner ,großen Lehre“, Ta-hioh, einer kurzen Abhandlung ethischpolitischen Inhalts, führt er den Gedanken aus, daß die Wohlfahrt eines Staatswesens in der Selbstkultur des einzelnen wurzelt. Das höchste Ziel ist die Offenbarmachung der Tugend, und wer es erreichen will, muß zunächst wissen, wovon er auszugehen habe, dieser Ausgangspunkt aber ist die Einsicht in den ursächlichen Zusammenhang der Dinge. Wer solche Einsicht erlangt hat, wendet sie zunächst auf sich selbst an, indem er "sein Herz rechtschaffen und seine Gedanken wahrhaftig macht". Der geordnete Zustand eines Staatswesens ruht auf der Regelung der Familie und diese auf der Selbstkultur des einzelnen Individuums. „Das gilt für alle, vom Himmelssohn bis zum gemeinen Mann herab, für alle bildet Selbstvervollkommnung die Grundlage." - Folgt Tszě-szĕ hiernach im wesentlichen den Spuren des Meisters, so schlägt er dafür in seinem Traktat „Vom Innehalten der Mitte“, Tschung-yung, seinen eigenen Weg ein. Der Ausdruck „Mitte“, wie er hier gebraucht wird, bezeichnet nicht etwa die goldene Mittelstraße, undèv ărav, sondern das innere Gleichgewicht, als den latenten Zustand der Affekte. „Des Himmels Ordnung (ming, eigentlich „Bestimmung“") heißt Natur, die Gemäßheit der Natur Vernunftnorm (tao); die Pflege der Vernunftnorm heißt Unterweisung. Die Vernunftnorm kann nicht für einen Augenblick verlassen werden; könnte sie das, so wäre sie nicht die Vernunftnorm. Daher ist der Edle behutsam gegenüber lem, was er nicht sieht, und ängstlich gegenüber dem, was. er nicht hört. Nichts ist sichtbarer als das Verborgene und nichts offenbarer als das Geheimnisvolle; daher gibt der Edle acht auf sein Alleinsein. - Den Zustand, da Freude und Zorn, Trauer und Heiterkeit noch nicht hervorgetreten sind, nennt man das innere Gleichgewicht (Mitte); wenn sie, hervorgetreten, das rechte Maß treffen, nennt man das Harmonie. Das innere Gleichgewicht ist das große Fundament der Welt, und die Harmonie ist die die Welt durchdringende Vernunftnorm. Sind inneres Gleichgewicht und 
Harmonie vollkommen, so stehen Himmel und Erde fest, und alle Dinge gedeihen." Diese Ausführungen tragen ein so unverkennbar taoistisches Gepräge, daß sie die Vermutung nahe legen, Tszĕ-szĕ müsse mit der Lehre des Laotszこ vertraut gewesen sein, eine Vermutung, die übrigens an Wahrscheinlichkeit gewinnt, wenn man ihn mit Legge für den Verfasser des Hi-tsz'ě, jenes vorhin erwähnten Kommentares zum Yih-king, hält. Leider ist Tszě-szě nicht über die im obigen Zitat mitgeteilten ersten Anfänge metaphysischer Spekulation hinausgekommen, denn der Rest des Traktates bewegt sich durchweg im seichteren Fahrwasser konfuzianischer Denkweise.

Der begeistertste und einflußreichste Apostel erstand dem Konfuzianis- Mcng.tszz. mus in Meng-tszě (372-289 v. Chr.). Auch bei ihm bilden wie bei Konfuzius ethische und politische Themata das stehende Leitmotiv; durchaus neu und originell ist aber die Art, wie er sie behandelt. Durch Angriffe von gegnerischer Seite, die sich allmählich bemerkbar zu machen begannen, sah er sich nämlich in die Lage versetzt, die Lehren des Meisters nicht nur interpretieren, sondern auch verteidigen $z u$ müssen. $Z u$ diesem $Z$ weck wählte er, im Gegensatz zu den Aphorismen des Lun-yü, die geschlossene Form des zusammenhängenden Dialoges und schuf dadurch das erste Lesebuch, welches diesen Namen verdient und dem kein anderes Erzeugnis der klassischen Literatur an Volkstümlichkeit gleichkommt. Aber nicht nur popularisiert hat er die Lehren des Konfuzius, sondern auch erweitert, entwickelt und philosophisch vertieft. An die Stelle des Moralpredigers tritt jetzt der Moraltheoretiker. Hatte Konfuzius mit Moralbegriffen operiert, die er einfach als gegeben hinnahm, so galt es nunmehr, jene Begriffe selbst erst zu begründen und den Nachweis ihrer Allgemeingültigkeit zu erbringen. Das tut Mengtszĕ, indem er die Lehre aufstellt, daß die vier Kardinaltugenden, Menschlichkeit, Gerechtigkeit, Schicklichkeit und Weisheit, in Gefühlen wurzeln, die dem Menschen angeboren seien: die Menschlichkeit im Gefüh1 des Mitleids und Erbarmens, die Gerechtigkeit inı Gefühl der Scham und des Abscheus, die Schicklichkeit im Gefühl der Achtung und Ehrfurcht und die Weisheit, worunter das sittliche Urteil des Gewissens zu verstehen ist, im Gefühl für Recht und Unrecht. Daher seien die Kardinaltugenden ein fester Besitz des Menschen, aber ein Besitz freilich, der immer erst erworben werden muß, um als solcher empfunden und verwertet werden zu können, woher es denn auch heißt: „Strebe nach ihnen, so erlangst du sie, vernachlässige sie, so verlierst du sie." - Im Gegensatz zu Meng-tszĕ verficht der Philosoph Kao Puh-hai die Ansicht, daß die Menschlichkeit allerdings, ebenso wie der Ernährungs- und Geschlechtstrieb, dem Menschen von Haus aus innewohne, die Gerechtigkeit hingegen etwas von außen her Stammendes sei, denn, sagt er, „wenn einer älter ist und ich ihn als älteren behandle, so geschieht das nicht, weil das Ältersein in mir wäre, und ebenso, wenn etwas weiß ist, so sehe ich es für weiß an, weil sein Weißsein außer mir ist; daher bezcichne ich die Gercchtigkeit als äußerlich." Nun ist es höchst charakteristisch, wie Meng-tszě durch seine Dialektik den Gegner ad absurdum führt. Zwischen 
dem Weißsein eines weißen Pferdes und dem Weißsein eines weißen Menschen sei kein Unterschied zu machen; ob etwa auch nicht $z$ wischen dem Ältersein eines älteren Pferdes und dem Ältersein eines älteren Menschen? Und ferner: ob denn nun die Gerechtigkeit in dem Ältersein liege oder vielmehr in dem Umstande, daß man einen anderen als älteren behandelt? Kao Puh-hai erwidert: „Wenn sich's um meinen jüngeren Bruder handelt: den liebe ich; wenn sich's jedoch um den jüngeren Bruder eines Mannes aus Ts'in handelt: den liebe ich nicht. Mithin bin ich es, der dabei Wohlgefallen empfindet, und daher nenne ich die Menschenliebe innerlich. Hingegen einen älteren Mann unter den Leuten von Tsch $u$ behandle ich als älteren und einen Älteren unter den Meinigen in gleicher Weise. Mithin ist es der Ältere, der dabei Wohlgefallen empfindet, und daher nenne ich die Gerechtigkeit äußerlich." - Die Antwort des Meng-tszě lautet: „Wenn ich mich an dem Braten eines Mannes aus Ts'in labe, so unterscheidet sich das nicht von der Art, wie ich mich an meinem eigenen Braten labe. Da nun solche Dinge auch diese Eigentümlichkeit haben - sollte deshalb etwa der Appetit nach Braten ebenfalls etwas Äußerliches an sich haben?"

Die Lehre von der angeborenen Güte der menschlichen Natur bildet seither die Grundanschauung der chinesischen Ethik. In einer Kinderfibel, die aus dem ersten Jahrhundert v. Chr. stammt und noch gegenwärtig in ganz China dem Elementarunterricht zugrunde gelegt wird, heißt es gleich zu Anfang: „Der Menschen Herz ist von Haus aus gut, ihrer Natur nach sind sie einander nah, erst durch ihre Gewohnheiten entfernen sie sich voneinander." Es darf nicht übersehen werden, daß Meng-tszě in dieser Lehre über Konfuzius hinausgeht, der im Lun-yü nur sagt: "Ihrer Natur nach sind sie einander nah, erst durch ihre Gewohnheiten entfernen sie sich voneinander." Freilich muß dabei betont werden, daß Meng-tszě die angeborene Güte der menschlichen Natur keineswegs im Sinne einer ursprünglichen sittlichen Vollkommenheit auffaßt, die sich hernach, etwa infolge eines Sündenfalles, durch eine Entwickelung in absteigender Linie allmählich verloren hätte, vielmehr erläutert er seine Ansicht dem Kao Puh-hai gegenüber ausdrücklich dahin, daß die angeborenen Triebe des Menschen lediglich die Möglichkeit des

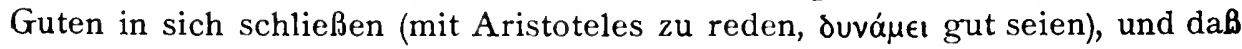
es mithin nicht die Schuld der ursprünglichen Anlage sei, wenn sie sich in entgegengesetzter Richtung äußerten.

Philosophische Nebenströmungen.

Der hier mehrfach genannte Kao Puh-hai, der uns leider nur aus den Dialogen des Meng-tszĕ bekannt ist, läßt bereits einigermaßen erkennen, welcher Art die philosophischen Nebenströmungen waren, die sich allmählich neben und gegenüber dem Konfuzianismus geltend zu machen begannen. Unter ihren sonstigen Vertretern sind besonders zwei zu nennen, die sich durch die Originalität und Selbständigkeit ihrer Gedanken auszeichneten: Yang Tschu und Moh Tih, beide dem Zeitraum zwischen Konfuzius und Mengtszě angehörend.

Yang Tschu. Yang Tschu vertritt einen extremen Egoismus, der, aus pessimistischen 
Grundanschauungen hervorgegangen, in eine zynisch-hedonistische Lebensphilosophie ausläuft. Da der Unterschied zwischen Tugendhaften und Lasterhaften nur im Leben besteht, mit dem Tode aber aufhört, so gilt ihm die Lust als höchster Lebenszweck. Nachruhm ist ein leeres Wort, Befriedigung der Sinne das einzig Reale. „Das, wodurch alle Wesen verschieden sind, ist das Leben; das, worin sie gleich sind, ist der Tod. Im Leben gibt es Weise und Toren, Vornehme und Geringe: darin liegt die Verschiedenheit. Im Tode gibt es moderndes Gebein, Schwund und Vernichtung: darin liegt die Gleichheit. Gleichwohl liegen Weisheit und Torheit, Ansehen und Niedrigkeit in keines Menschen Macht, ebensowenig wie moderndes Gebein, Schwund und Vernichtung. Somit hängen Leben und Tod, Weisheit und Torheit, Ansehen und Niedrigkeit nicht vom Menschen ab, vielmehr leben und sterben alle Wesen in gleicher Weise, wie sie in gleicher Art weise oder töricht, vornehm oder gering sind. Zehnjährige sterben ebensogut wie Hundertjährige, Menschenfreundliche und Weise sterben ebensogut wie Bösewichte und Toren. Die bei Lebzeiten Yao und Schun waren (die das Herrscherideal des Konfuzius verkörperten), sind nach ihrem Tode moderndes Gebein; die bei Lebzeiten Kieh und Tschou waren (zwei berüchtigte Tyrannen des Altertums), sind nach ihrem Tode moderndes Gebein. Als moderndes Gebein sind sie eins; wer vermöchte da ihre Verschiedenheit zu erkennen? So freuen wir uns denn des Lebens, - was kümmert uns, was nach dem Tode kommt!" $\mathrm{DaB}$ in einer solchen Lebensauffassung für Mitleid und Erbarmen kein Platz ist, liegt auf der Hand. Als ein Schüler des Yang Tschu diesen fragt: „Wenn du durch die Entfernung eines Haares der ganzen Mitwelt helfen könntest, würdest du es tun?" gibt er denn auch die ausweichende, aber dennoch hinreichend deutliche Antwort: „Die Welt ist nicht derart, daß ihr durch ein Haar geholfen werden könnte."

Sein schroffer Widerpart ist Moh Tih mit seinem extremen Altruismus "Gibt es ein Wort, wonach man sich sein Leben lang richten kann?" fragt einmal Tszě-kung seinen Meister Konfuzius. „Allenfalls 'Gegenseitigkeit'“, erwidert dieser: „was du nicht willst, daß man dir zufüge, das füg auch keinem andern zu." Und als jemand die Überzeugung ausspricht, daß ein human gesinnter Mann, wenn er sieht, daß einer in einen Brunnen gestürzt ist, sofort nachspringen werde, um ihn zu retten, meint der Weise trocken: „Warum nicht gar! Der Edle wird sich wohl bewegen lassen hinzugehen, aber nicht sich zu ertränken; er mag sich wohl betrügen lassen, aber er läßt sich nie zum Narren halten.“ Die Menschlichkeit, wie er sie verstand, war eben ein mehr oder weniger passives Wohlwollen, das sich zunächst auf die eignen Blutsverwandten bezog. Auch Meng-tszě neigt im wesentlichen dieser Auffassung zu, aber er vertieft immerhin den Begriff der Menschlichkeit, indem er ihn auf das Gefühl des Mitleids und Erbarmens zurückführt. Moh Tih hingegen predigt als erster und einziger das Gebot der ,allumfassenden Liebe“, die sich über alle Mitmenschen ohne Unterschied auszudehnen habe, die sich auch nicht scheue, Leib und Leben zu opfern, falls damit dem allgemeinen

Dib Kultur der Grgenwart. 1. 5. 2. Auf. 
Wohl gedient wird. Alles Übel geht aus dem Mangel an Nächstenliebe hervor und kann daher auch nur durch Liebe beseitigt werclen. Die Liebe braucht nur allgemein zu sein, um allem Elend in der Welt, und damit auch dem Krieg, ein Ende zu machen. Meng-tszĕ mußte, wenn er aus seiner Lehre von der angeborenen Güte der menschlichen Natur die letzten Konsequenzen zog, zu einem ähnlichen Ergebnis kommen, aber es kennzeichnet seine streng konfuzianische Geistesrichtung, daß er in der allumfassenden Liebe die Gefahr einer Lockerung der Familienbande erblickt. So bekämpft er denn auch Moh Tih mit der gleichen Heftigkeit, wie den ganz anders gearteten Yang Tschu als einen gefährlichen Häretiker, dessen verderbliche Lehre mit Stumpf und Stiel auszurotten sei. - Man hat in Moh Tih einen chinesischen Vorläufer des Sozialismus sehen wollen, der er jedoch keineswegs war, denn nicht gegen die soziale Ungleichheit als solche, sondern nur gegen ihre schädlichen Auswüchse wendet sich sein Zorn.

Siün K'oang.

Meng-tszěs ethischer Optimismus fand bald einen heftigen Gegner an Siün K'oang (3. Jahrhundert v. Chr.), der seine Lehre, daß die menschliche Natur von Haus aus böse sei, in origineller Weise dialektisch aus dem nicht wegzuleugnenden Streben nach dem Guten ableitet. Was man bereits besitzt, braucht man nicht erst zu erstreben: der Arme wünscht reich, der Geringe vornehm, der Magere dick zu sein, und ebenso haben die Menschen den Wunsch gut zu sein, offenbar weil sie von Natur böse sind. Naturgemäß sei nur das Streben nach Befriedligung der natürlichen Triebe, naturwidrig hingegen ihre Unterdrückung, wie sie z. B. im Verzicht auf die eigenen Wünsche zugunsten anderer liegen würde. Daher seien sittliche Eigenschaften, wie Schicklichkeit und Gerechtigkeit, anerzogen aber nicht angeboren, genau so wie das Gefäß, zu dem der Töpfer den Ton formt, durch die Kunstfertigkeit des Meisters.entstehe, nicht aber aus der Natur des Tones hervorgehe. - Ihren

Yang Hung. Abschluß findet die Kontroverse, die so lange die Gemüter beschäftigt hatte, mit Yang Hiung ( 53 v. Chr. - I 8 n. Chr.). Nach ihm ist die menschliche Natur ursprünglich ein Gemisch von Gut und Böse; somit nimmt er zwischen dem Optimismus des Meng-tszĕ und dem Pessimismus des Siün K'oang eine vermittelnde Stellung ein. Der natürliche Trieb strebt dem Rosse gleich ohne Unterschied dem fruten wie dem Bösen zu, daher komme es beim sittlichen Handeln einzig auf las Ziel an, das man ins Auge faßt: „Betrachte die Selbstvervollkommnung als Bogen, den entschlossenen Sinn als Pfeil, die Rechtschaffenheit als Ziel; schieße den Pfeil nicht eher ab, als bis du das Ziel ins Auge gefaßt hast, und du wirst es sicher treffen."

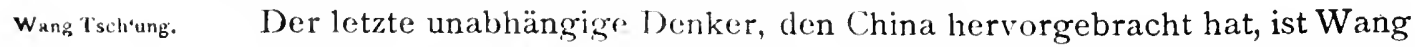
Tsch'ung (27-98). Nâch clem Wenigen, was bisher über seine Lehre bekannt geworden ist, scheint sein Standpunkt der des konsequenten Materialismus gewesen zu sein. Die Seele ist von der Lrbenskraft abhängig, die ihren Sitz im Blute hat. Durch die Zersetzung des Blutes, die mit dem Tode eintritt, wird die Lebenskraft und mit ihr auch die Seele zerstört, so daß von einem Fortleben nach dem Todle keine Rede sein kann. Der Leib verhält sich zur 
Seele wie das Brennmaterial zum Feuer: ist das Feuer erloschen, so kann die Asche nicht wieder zum Brennen gebracht werden. Bemerkenswert ist auch, daß Wang Tsch ${ }^{\circ}$ ung einen fundamentalen Unterschied zwischen Menschenund Tierseele nicht anerkennt.

Wang Tsch'ung ist der letzte unter den chinesischen Denkern, der noch den Mut hat, offen gegen Konfuzius und Meng-tszě zu polemisieren. Mit ihm erlischt die Opposition gegen den Konfuzianismus; auch hat keine der hier flüchtig skizzierten heterodoxen Lehrmeinungen eine dauernde Nachwirkung auszuüben vermocht.

III. Lao-tszĕ und der Taoismus (6.-2. Jahrhundert v. Chr.). In einem vom konfuzianischen toto coelo verschiedenen Gedankenkreise bewegt sich der Taoismus, der im denkbar schroffsten Gegensatz zum Konfuzianismus steht, sowohl durch die weltabgewandte einsiedlerische Tendenz wie auch durch den intuitiv mystischen Charakter seiner Lehre.

Lao-tszĕ (geb. 604 v. Chr.) gilt, und wohl mit Recht, für den Verfasser des Tao-teh-king, des „kanonischen Buches vom Tao und der Tugend“, und als solcher für den Begründer der taoistischen Lehre. Da jedoch seine Persönlichkeit fast völlig im Nebel der Legende verschwindet, so wird von manchen übereifrigen Kritikern unter den europäischen Sinologen nicht nur seine Autorschaft, sondern sogar seine geschichtliche Existenz in Zweifel gezogen. Wie dem auch sei: jenes Buch ist, wie es uns vorliegt, unstreitig als die großartigste und tiefste Schöpfung des chinesischen Geistes zu bezeichnen.

Das vieldeutige Wort Tao, aus dem die Bezeichnung Taoismus gebildet worden ist, umfaßt die Bedeutungswerte: Weg, Norm, Vernunftprinzip sowie auch sprechen, reden; wollte man es übersetzen, so dürfte es mithin vielleicht am besten durch „Logos“ wiederzugeben sein. Als die Substanz und Norm alles Seins ist das Tao gewissermaßen zugleich causa sui und ratio essendi. Selbst unerschaffen, aus dem Nichtsein herrorgegangen, unkorperlich, allgegenwärtig und ewig, bringt es alle Wesen hervor, die nach vollendetem Kreislauf ihrer Entwickelung wieder in den Mutterschoß des Tao zurückkehren. Daß alle Dinge aus ihm hervorgehen, vermögen wir nur durch das Tao selbst zu erkennen: mithin ist es nicht nur Seins-, sondern auch Erkenntnisgrund. Gleichwie die Außendinge ihren Ursprung und ihr Ziel in Tao haben, so auch das denkende Subjekt; daher ist es die höchste Aufgabe des heiligen Menschen, sich ihm zu assimilieren, es in sich zu verkörpern. Hierdurch erscheint es zugleich als die sittliche Norm. „Das Tao ist ewig ohne Tun und doch ohne Nichttun“, d. h. es wirkt ohne zu handeln. Und dasselbe gilt auch für denjenigen, der sich nach ihm richtet: „Der heilige Mensch verweilt in der Tätigkeit des Nichttuns und übt Belehrung aus ohne Worte." Das ist die berühmte Wu-wei-Theorie, die Lehre vom Nichttun, auf der die taoistische Ethik fußt. Der Gegensatz zwischen ihr und der konfuzianischen Ethik tritt am schärfsten in der Tugendlehre zutage.

Alle Erkenntnis beruht auf dem Satze des Widerspruchs: „Erkennen 
alle in der Welt des Schönen Schönsein, dann auch das Häßliche; erkennen vlle des Guten Gutsein, dann auch das Nichtgute; denn
Sein und Nichtsein einander gebären:
Schwer und leicht einander bewähren,
Lang und kurz einander erklären,
Hoch und niedrig einander entkehren."

Genau dasselbe gilt auch von den sittlichen Werten: auch sie werden durch den Gegensatz bestimmt und haben daher nur relative Bedeutung. In diesem Jinne heißt es: „Wenn das Tao in Verfall gerät, dann gibt es Menschlichkeit und Gerechtigkeit; kommt Klugheit und Scharfsinn auf, dann gibt es Heuchelei; sind die sechs Arten von Blutsverwandten uneinig, dann gibt es Kindesliebe und Elternliebe; wenn die Landesherrschaft in Verfall und Zerrüttung gerät, dann gibt es treue Untertanen." Dieses scheinbare Paradoxon ist seither der hauptsächlichste Stein des Anstoßes für den orthodoxen Konfuzianismus geblieben, während es doch, richtig verstanden, nur den logischen Schluß aus den gegebenen Prämissen zieht. Erst im Tao als dem schlechthin Absoluten erfolgt die Aufhebung aller Gegensätze.

Aus der quietistischen Grundstimmung der taoistischen Ethik erklärt sich der mehr oder weniger negative Charakter seiner Tugenden. Die Tugenden, durch die sich der "heilige Mensch" auszeichnet, sind Nachgiebigkeit und Bescheidenheit: „Der heilige Mensch, will er über dem Volke stehen, so muß er mit seiner Rede sich ihm unterordnen; will er dem Volke vorangeken, so muß er mit seiner Person dagegen zurücktreten "; ferner Genügsamkeit und Opferwilligkeit: „Wer sich zu genügen weiß, hat ewig genug“, oder: „Der heilige Mensch sammelt nicht an: je mehr er auf die Menschen verwendet, desto mehr hat er; je mehr er den Menschen gibt, desto reicher ist er"; endlich friedfertige Gesinnung: Der heilige Mensch streitet nicht, „drum vermag keiner in der Welt mit ihm zu streiten". Aus der friedfertigen Gesinnung ergibt sich mit logischer Notwendigkeit die Verurteilung des Krieges. „Wo Heerhaufen lagern, gehn Disteln und Dornen auf. Großer Kriegszüge Folge sind sicherlich Notjahre." Nur im äußersten Notfall greift der Edle zu den Waffen, denn „Waffen sind Unglückswerkzeuge, nicht des Edlen Werkzeuge. Kann er nicht umhin und braucht sie, sind ihm Friede und Ruhe doch das Höchste. Er siegt, aber ungern. Es gern tun ist sich freuen, Menschen zu töten. Wer sich aber freut, Menschen zu töten, kann seine Absicht am Reich nicht erreichen." So werden denn auch Wohlfahrt und Gedeihen des Staates nicht sowohl durch ein vielgeschäftiges Regieren als vielmehr durch das stille Wirken einer vorbildlichen Persönlichkeit erreicht. „Durch Ordnung regiert man den Staat, mit Arglist braucht man Waffen, mit Ungeschäftigkeit gewinnt man das Reich. Woher ich weiß, daß es in der Welt so steht? Daher: Je mehr Verbote und Beschränkungen das Reich hat, desto mehr verarmt das Volk; je mehr scharfe Waffen đas Volk hat, desto mehr werden Staat und Familie beunruhigt; je mehr Gewandtheit und Kunstfertigkeit ein Volk hat, desto wunderlichere Dinge ,kommen auf; je mehr Gesetze und Ver- 
ordnungen kundgemacht werden, desto mehr Diebe und Räuber gibt es. Drum sagt der heilige Mensch: Ich bin ohne Tun, und das Volk bessert sich von selbst; ich liebe die Ruhe, und das Volk wird von selbst redlich; ich bin ohne Geschäftigkeit, und das Volk wird von selbst reich; ich bin ohne Begierden, und das Volk wird von selbst einfach." Superklugheit ist weder für die Regierten noch für die Regierenden von Segen, denn „das Volk ist schwer regieren, wenn es allzu klug ist. Durch Klugheit den Staat regieren ist des Staates Verderben; nicht durch Klugheit den Staat regieren ist des Staates Segen. Wer dies beides weiß, ist auch ein Muster und Vorbild". Was aber not tut, ist Menschenkenntnis und Selbsterkenntnis: „Wer andere kennt, ist klug; wer sich selbst kennt, ist erleuchtet."

Alles in allem genommen, zeigen die Anschauungen des Lao-tszĕ manche unverkennbare Wesensverwandtschaft namentlich mit der buddhistischen, aber auch mit der christlichen Ethik; und es sollte billigerweise nicht vergessen werden, daß Lao-tszĕ es war, der 600 Jahre v. Chr. das erhabene Wort sprach: "Vergilt Feindschaft mit Wohltun!" Der um 50 Jahre jüngere Konfuzius war in diesem Punkte anderer Ansicht, denn auf die Frage, ob man Unrecht mit Güte vergelten solle, erwiderte er: „Womit wolltest du dann Güte vergelten? Mit Gerechtigkeit vergilt Unrecht, Güte mit Güte!"

Der nächstälteste Vertreter der taoistischen Schule ist Lieh-tszĕ, der ver- Lieh-tszø. mutlich der zweiten Hälfte des 5. Jahrhunderts v. Chr. angehört. Obwohl über seine Person und sein Leben keinerlei zuverlässige historische Daten vorliegen, so genügt doch das Buch, das seinen Namen trägt, um ihm einen Ehrenplatz unter den Denkern Chinas zu sichern. Er ist der erste unter ihnen, der den Dualismus von Subjekt und Objekt, von Ding an sich und Erscheinungswelt nicht nur erkennt, sondern auch in eine höhere Einheit aufzulösen versucht. „Das, wodurch die Gestalt Gestalt ist, ist die Wirklichkeit, aber was die Gestalt zur Gestalt macht, hat noch nie vorgelegen. Das, wodurch der Ton Ton ist, ist das Gehör; aber was den Ton zum Tone macht, ist noch nie hervorgetreten. Das, wodurch die Farbe Farbe ist, ist die Sichtbarkeit (oder auch: das Leuchtende); aber was die Farbe zur Farbe macht, ist noch nie offenbar geworden. Das, wodurch der Geschmack Geschmack ist, ist das Geschmacksvermögen; aber was den Geschmack zum Geschmack macht, ist noch nie erschienen." Beruht somit die Wahrnehmung der Außenwelt auf den Sinnen, so liegt ihr eigentliches Wesen, das "Ding an sich", wie wir sagen würden, nach Lieh-tszĕ im „Nichttun“, worunter nach dem Zusammenhange nichts anderes verstanden werden kann als das Tao. Auch darin geht er über Lao-tszě hinaus, daß ihm die kosmologische Antinomie, die sich aus dem Gegensatz des Endlichen und des Unendlichen ergibt, klar zum Bewußtsein kommt: „Wenn es jenseits des Unendlichen noch ein Nichtunendliches und innerhalb des Unbegrenzten noch ein Nichtunbegrenztes gäbe, so würde die Unendlichkeit wiederum nichtunendlich und die Unbegrenztheit wiederum nichtunbegrenzt sein; daher begreife ich wohl die Unendlichkeit und Unbegrenztheit, nicht aber die Endlichkeit und Begrenztheit." Die Formen der 
organischen Welt stehen nach Lieh-tszě in einem genealogischen Zusammenhang untereinander, indem eine aus der anderen hervorgeht. Es scheint ihm dabei (ähnlich wie dem Lao-tszĕ) eine Art Kreislauf der Entwickelung vorgeschwebt zu haben: sobald die Entwickelung der verschiedenen Arten im Menschen ihren Höhepunkt erreicht hat, beginnt der ganze Prozeß aufs neue. So phantastisch nun auch selbstverständlich gerade dieser Teil seiner Lehre ausfällt, so enthält er doch gewissermaßen in nuce bereits den Grundgedanken der modernen Entwickelungslehre. Der Gedanke, daß einerseits das Leben aus dem Tode hervorgehe, anderseits aber dasjenige, was das Leben hervorbringt, kein Ende habe, scheint Lieh-tszě zu der Annahme der Möglichkeit eines persönlichen Fortlebens nach dem Tode geführt zu haben; allerdings beschränkt er sich darauf, diesem Glauben in der Form einer offenen Frage Ausdruck zu geben: „Tod und Leben sind ein Dahinziehen und ein Zurückkommen; sterbe ich also hier, wer weiß, ob ich nicht dort wiedergeboren werde?"

Tschuang-tszč. Neben Lao-tszĕ und Lieh-tszĕ ist Tschuang Tschou oder, wie er gewöhnlich kurzweg genannt wird, Tschuang-tszĕ, d. h. Meister Tschuang (erste Hälfte des 3. Jahrhunderts v. Chr.) der dritte im Bunde. Durchaus unter dem Einfluß seiner beiden Vorgänger stehend, reicht er an eigenem Gedankengehalt zwar kaum an sie heran, überragt sie dafür aber um so bedeutender als Schriftsteller: er war es, der die kostbaren Perlen der Lehre seines Meisters aus der dunklen Tiefe, in der sie verborgen lagen, gleichsam erst ans Tageslicht förderte und zu einem funkelnden Geschmeide vereinigte. Er war der erste und einzige Dichterphilosoph, von dem die Geschichte der chinesischen Literatur zu berichten weiß, wenn auch nicht eben der selbständigste, so doch unbestritten der geistreichste Denker, den China hervorgebracht hat, und als schriftstellerische Individualität von einzigartigem Gepräge. Mit dem ihm eigenen Gemisch von Mystizismus und Skeptizismus, tiefem Ernst und leichtem Humor, nachdenklicher Schwermut und beißender Satire, unerschöpflichem Bilderreichtum und poetischer Anmut weiß er seine Gedanken in immer wechselndem, buntschillerndem Gewande vorzuführen und dem Verständnis näher zu bringen.

Will man das Charakteristische an seiner Lehre mit einem Wort hervorheben, so wird man sie vielleicht am zutreffendsten als Identitätsphilosophie bezeichnen können. Der Gegensatz von Subjekt und Objekt, wie er die ganze sinnlich wahrnehmbare Erscheinungswelt beherrscht, findet seine Versöhnung und Aufhebung im Tao, dessen Erkenntnis daher der Höhepunkt aller Einsicht ist. „Es gibt nichts, was nicht Objekt, nichts, was nicht Subjekt wäre. Wenn man vom Objekt ausgeht, wird es nicht sichtbar, sondern durch die eigene Erkenntnis erkennt man es. Daher heißt es: das Objekt geht aus dem Subjekt hervor, das Subjekt hat das Objekt zur Ursache. Das besagt, daß Subjekt und Objekt auseinander hervorgehen. So ist mit dem Leben der Tod, mit dem Tode das Leben, mit der Unmöglichkeit die Möglichkeit gegeben, und die Bejahung gründet sich auf die Verneinung, wie sich die Verneinung 
auf die Bejahung gründet. Daher befolgt der Heilige nicht diesen Weg, sondern betrachtet es im Lichte des Himmels (d. h. er beruhigt sich nicht bei den Gegensätzen, sondern betrachtet diese sub specie aeternitatis) und gründet sich dabei zugleich auf das Subjekt. Wenn nun das Objekt zugleich Subjekt und das Subjekt zugleich Objekt ist, so schließt jedes von ihnen einen Gegensatz in sich. Bestehen nun also Objekt und Subjekt tatsächlich, oder ist nicht vielmehr keines von beiden vorhanden? - Wenn Objekt und Subjekt ohne Widerpart sind, so nennt man das die Achse des Tao, und wenn diese Achse sich im Mittelpunkt des Ringes befindet, so daß sie dem Unendlichen entspricht, lösen sich Bejahung und Verneinung in eine unendliche Einheit auf. Daher heißt es: Nichts geht über die Einsicht." - Wer aber in dem Tao den ewig-einen Urgrund alles Seins, das allein Wirkliche und Seiende erkannt hat, der betrachtet das Leben als nichtigen Schein, als das bunte Gaukelspiel eines wirren Traumes. Das ist der Gedanke, den Tschuang-tszĕ in dem berühmten „Schmetterlingstraum“ ausführt: „Einst träumte mir, ich, Tschuang Tschou, sei ein Schmetterling, lustig umherflatternd als ein rechter Schmetterling. Ich wußte nicht mehr, daß ich Tschuang Tschou sei. Plötzlich erwacht, war ich wieder der Tschuang Tschou von ehedem. Nun weiß ich nicht, ob Tschuang Tschou im Traume ein Schmetterling oder der Schmetterling im Trạume Tschuang Tschou sei. Und doch besteht zwischen Tschuang Tschou und einem Schmetterling sicherlich ein Unterschied. Das nennt man Umwandlung der Wesen."

Als glänzender Satiriker zeigt sich Tschuang-tszĕ besonders in seiner Polemik gegen Konfuzius. Die unerhört respektwidrige Art, wie er die kleinliche Splitterrichterei und pedantische Wortklauberei des vielgeschäftigen Moralpredigers mit der Lauge seines Hohns überschüttet und dem allgemeinen Gelächter preisgibt, ist eine Erscheinung ohnegleichen in der gesamten chinesischen Literatur. Nichtsdestoweniger ist gerade Tschuang-tszĕ der einzige unter den taoistischen Denkern, der noch heute selbst unter den strengsten Vertretern des Konfuzianismus eifrige Leser und Bewunderer findet, wobei denn wohl freilich die Bewunderung mehr dem sprachgewaltigen Meister des Stiles als dem Philosophen gilt.

Unter den übrigen Vertretern der taoistischen Schule verdient Han Fei- Niederáang tszě (3. Jahrhundert n. Chr.) hervorgehoben zu werden, da er der einzige unter der taoistische ihnen ist, der den Versuch wagt, die Lehre des Lao-tszĕ auf die Praxis des Sichule. staatlichen Lebens anzuwenden, und dadurch gewissermaßen als Vermittler zwischen Taoismus und Konfuzianismus dasteht. Von der Theorie vom Nichttun ausgehend, stellt er eine Art von verantwortungslosem Despotismus als politisches Ideal auf. Sache des Fürsten ist lediglich, die geeigneten ausführenden Organe zu finden, denen er alsdann die verantwortliche Leitung der öffentlichen Angelegenheiten überläßt. Fällt das Resultat günstig aus, so erntet der Fürst den Ruhm, während im entgegengesetzten Fall die Schuld allein die Beamten trifft. Als die wirksamsten Mittel der fürstlichen Gewalt werden die Belohnungen und Strafen genannt. - Von nun an geht es mit 
reißenden Schritten abwärts. Bei Hoai-nan-tszĕ verschwindet die ursprüngliche Lehre des Lao-tszĕ bereits fast gänzlich hinter einem Wust von phantastischen Bildern und mythologischen Allegorien. Seine Bedeutung liegt hauptsächlich darin, daß er der eigentliche Begründer der taoistischen Alchemie ist. Mit ihm erlischt der Taoismus als philosophische Doktrin, um sich von nun an in zwei divergierende Richtungen zu spalten: eine esoterische, die sich allmählich zu einer alchemistischen Geheimlehre entwickelt, und eine exoterische, die, je länger je mehr, den Charakter €ıner religiösen Gemeinschaft annimmt, als welche sie noch heute, stark vom Buddhismus beeinflußt, ein unrühmliches Dasein fristet.

1V. Der Neukonfuzianismus und die Erstarrung des geistigen Lebens (vom 11. Jahrh. bis zur Gegenwart). Der Taoismus bildet die interessanteste Episode in der Geschichte des chinesischen Denkens, aber leider eben nur eine Episode. Die reiche Saat an fruchtbaren Gedanken mußte verkümmern, weil sie auf einen dürren Acker fiel und weder Nahrung noch Pflege fand. Der mystische und weltfremde Zug der taoistischen Spekulation fand kein entgegenkommendes Verständnis, während der Konfuzianismus mit seiner direkt auf das praktische Leben abzielenden Moral, mit seinen auf jeden Einzelfall berechneten Vorschriften und Verboten jedermann verständlich war und in das sichere Fahrwasser einer bequem zu befolgenden ethischen Disziplin hinüberleitete.

Nachdem der Taoismus endgültig erloschen war, gelangte der Konfuzianismus, jeder Konkurrenz ledig, allmählich zur Alleinherrschaft. Wohl kam er zu wiederholten Malen in die Lage, gegen den rasch wachsenden Einfluß des Buddhismus Opposition zu machen, aber diese Opposition richtete sich doch weniger gegen dessen Lehrgehalt als gegen seine Begleiterscheinungen im praktischen Leben, vor allem̌ gegen den Reliquienkult und den damit verbundenen Aberglauben sowie gegen das Überhandnehmen des Klosterwesens. Nicht der Religion als solcher, sondern ihren Institutionen galt der Kampf, in erster Linie der Herrschaft uer toten Hand; der leitende Gesichtspunkt war die Staatsräson, sozialpolitische und volkswirtschaftliche Erwägungen, nicht aber religiöser Fanatismus, der ohnehin bei dem sprichwörtlichen Indifferentismus der Chinesen schwer zu erklären wäre. Und wenn auch der Kampf zuzeiten in blutige Verfolgungen ausartete, so bin ich doch der Ansicht, daß man hier nicht wohl von religiöser Intoleranz reden kann, ohne den Tatsachen Gewalt anzutun.

Tschou-tszě und dio Sing-li. Plilosophie.

Ein volles Jahrtausend hindurch erfreut sich die konfuzianische Schule ihrer Herrschaft, ohne auch nur die leiseste Regung geistigen Lebens zu verraten, bis endlich im 11. Jahrhundert aus dem erneuten Studium des Yih-king ein vorübergehendes Wiederaufleben der philosophischen Spekulation hervorgeht. Tschou Tun-i oder Tschou-tszĕ (1017-1073) ist der Begründer dieser neuen Naturphilosophie, die sich mit dem Namen Sing-li bezeichnet, ein Name, der sich durch "Natur und Vernunft", oder vielleicht dem Sinne besser ent- 
sprechend durch „Vernunftordnung der Natur" wiedergeben läßt. Fußt auch Tschou-tszěs Lehre im wesentlichen auf dem Yih-king und dessen Kommentaren, besonders den „Angehängten Erklärungen“ (s. S. 63), so gebührt ihm immerhin das freilich bescheidene Verdienst, den alten Dualismus der kosmischen Kräfte Yin und Yang in einen Monismus aufgelöst zu haben, indem er die Dualkräfte auf einen gemeinsamen Ursprung zurückführt, den er als das „Urprinzip“, T'ai-kih (eigentlich „das höchste Äußerste“) bezeichnet. Bewegt, erzeugt das Urprinzip die lichte Kraft des Yang, ruhend die dunkle Kraft des Yin. Aus der Verbindung und Wechselwirkung der Dualkräfte entstehen die fünf Elemente, die ihrerseits alle Dinge hervorbringen. Die Ethik des Tschou-tszĕ ist durchaus konfuzianisch und entbehrt jeglicher Originalität. Seine nächsten Schüler, Tsch'eng Hao, Tch'eng I und Tschang Tsai treten, von geringfügigen Abweichungen abgesehen, ganz und gar in seine Fußstapfen. Von größerer Selbständigkeit ist Tschu Hi ( I I 30- I 200), der die Lehre des Meisters weiterentwickelt, indem er die Materie als von Ewigkeit her be- und der Neustehend setzt, aber nicht als Materie schlechthin, sondern als vernunftbegab te Materie. Das Urprinzip ist ihr gegenüber zwar das logisch, aber nicht das zeitlich Frühere.

Aber nicht darin, was Tschu Hi lehrte, liegt seine Bedeutung, sondern in der Tätigkeit, die er als Textkritiker, Exeget und Kommentator entfaltete. Er unterzog die kanonischen und klassischen Bücher einer eingehenden Revision, reinigte sie von nach seiner Ansicht falschen Lesarten und Widersprüchen und versah sie mit einem ausführlichen Kommentar, in dem er eine sozusagen rechtsgültige Norm für die Deutung und Auslegung der konfuzianischen Lehre aufstellt. Und obwohl es ihm in der Folge nicht an Gegnern wie z. B. Wang Yang-ming (1472-1528) gefehlt hat, so ist doch seine Auffassung seither im großen und ganzen die herrschende und allgemeingültige geblieben. Er hat die konfuzianische Lehre zum Dogma erhoben, wodurch sie erst jenen Charakter der Unfehlbarkeit und Intoleranz erhielt, den sie bis dahin nicht oder doch wenigstens lange nicht in solchem Grade besessen hatte. Mit Tschu Hi hat die geistige Entwickelung Chinas vorläufig ihren Abschluß gefunden.

Schlußbetrachtung. Wenn die philosophische Spekulation der Chinesen stets auf halbem Wege stehen blieb und nie zu voller Entfaltung kam, so lag das gewiß zu einem großen Teil an der Isoliertheit ihres geschichtlichen Daseins und ihrer Gesamtkultur, an dem Fehlen geistigen Wettbewerbes mit ebenbürtigen oder überlegenen Rivalen, zum Teil aber doch wohl auch an ihrer ursprünglichen geistigen Organisation. Von alters her leitete sein angeborener Sammeitrieb den Chinesen zur Erwerbung einer Fülle von Einzelkenntnissen, aber sein synthetisches Denken war zu schwach entwickelt, um sie in jenen inneren Zusammenhang zu bringen, der doch erst das Wesen echten Wissens ausmacht. Zudem steht dem Sammeleifer ein gewisser rechtwinkliger Ordnungsfanatismus zur Seite, der nicht eher ruht, als bis der ganze 
Bestand an Einzelkenntnissen fein säuberlich inventarisiert, rubriziert und nach bestimmten ausgeklügelten Kategorien geordnet ist. Das Gesetz der Symmetrie, das die gesamte chinesische Kunst beherrscht, scheint in gewissem Sinne auch das Richtmaß des chinesischen Denkens zu sein. Daraus erklärt sich wohl jener uralte Hang zum Schematismus, der sich bereits im Hung-fan (s. S. 62 f.) erkennen 1äßt und später seinen vollendetsten Ausdruck in einem Schema fand, das in seinen Grundzügen auf Liü Puh-wei (3. Jahrhundert v.Chr.) zurückgeht und noch heute in allgemeiner Geltung steht. Dieses Schema umfaßt eine Anzahl einander koordinierter Kategorien von Phänomenen, wie z. B. die fünf Himmelsgegenden, die vier Jahreszeiten, die fünf Elemente, die fünf Farben, die fünf musikalischen Töne, die fünf Geschmacksarten, die fünf Eingeweide (Milz, Lunge, Herz, Leber, Nieren) usw., und die gegenseitigen Beziehungen dieser Kategorien sind in der Weise gedacht, daß ihre einzelnen Glieder in einem Verhältnis der Abhängigkeit oder Wechselwirkung zueinander stehen. So entspricht z. B. dem Osten unter den Jahreszeiten der Frühling, unter den Elementen das Holz, unter den Farben das Grün, unter den Eingeweiden die Leber usf. Nun braucht man sich nur zu vergegenwärtigen, daß dieses Schema die theoretische Grundlage der chinesischen Heilkunde bildet, um sich einen Begriff der Beschaffenheit dieser „Wissenschaft" zu machen. Nicht minder fußt aber auch die Geheimwissenschaft der Geomantie, die noch heutigen Tages eine unumschränkte Herrschaft über die Gemüter des ganzen Volkes ausübt, auf demselben Schema. Dabei ist überdies die Tatsache wohl zu beachten, daß die Geomantie, das sog. Feng-schui-System, das einzige Beispiel einer bis ins einzelne konsequent durchgeführten Systembildung darstellt, die auf chinesischem Boden entstanden ist: die höchste Ausbildung und zugleich das letzte, aber leider noch sehr lebenskräftige „survival" eines primitiven Schamanismus.

Was China trotz der in ihrer Art bewundernswerten Höhe seiner Kultur bisher gefehlt hat, ist eine Wissenschaft im eigentlichen Sinne des Wortes. Um so erfreulicher ist es daher, daß sich der Wissensdrang gegenwärtig allenthalben im Lande so mächtig regt, daß das Angebot kaum die Nachfrage zu decken vermag. Die chinesische Kultur in ihrer bisherigen abgeschlossenen Eigenart gehört nunmehr unwiederbringlich der Vergangenheit an, aber solange ein Volk noch in die Zukunft zu blicken vermag, darf es auch seiner Zukunft sicher sein. 


\section{Literatur.}

Eine zusammenfassende Darstellung der chinesischen Phlosophie ist bisher nicht geschrieben worden. Indem ich zur allgemeinen Orientierung auf meine Geschichte der chinesischen Literatur (Band VIII der bei C. F. Amelang in Leipzig erscheinenden ,Literaturen des Ostens in Einzeldarstellungen") verweise, beschränke ich mich darauf, im folgenden die für die einzelnen Abschnitte hauptsächlich in Betracht kommenden Hilfsmittel namhaft zu machen.

I. Eine Übersetzung des Hung-fan gibt LEGGE, The Chinese Classics, vol. III, p. $320 \mathrm{ff}$. und Couvreur, Chouking, p. $194 \mathrm{ff}$ - - In betr. des Yih.king s. LEGGE, The Sacred Books of China II (The Sacred Books of the East, ed. by M. MÜLLER, vol. XVI) und CH. DE HARLEZ, Le Yih-king.

II. LEGGE, The Chinese Classics, vol. I-II. -- E. FABER, Eine Staatslehre auf ethischer Grundlage oder Lehrbegriff des chinesischen Philosophen Mencius (Elberfeld, 1877). R. v. PläNCJ'NERS deutsche Übersetzungen des Ta-hioh und Tschung-yung sind völlig unbrauchbar. - R. Dvorák, Confucius und seine Lehre (Münster i. W., I 895). - E. FABFr, Die Grundgedanken des alten chinesischen Sozialismus (Elberfeld, 1877). - FORKE, Wang Ch'ung and Plato on Death and Iminortality, Journ. of the China Branch of the R. As. Soc. XXXI. Die wertvolle Arbeit des letztgenannten: Lun-Hêng, Selected Essays of the Philo. sopher Wang Ch'ung (Mitt. d. Seminars für Orient. Sprachen, Jahrgang IX, S. I8Iff.) konnte leider nicht mehr benutzt werden.

III. Stan. Julien, Lao Tseu Tao Te king, le livre de la voie et de la veriu (Paris, 1848). - Legge, The Sacred Books of the East: the Texts of Tâoism (Sacr. B. of the East, vol. XXXIX-XL). - V. vON STRAUSS, Laò-tsè's Tào-tě-kĩng, aus dem Chinesischer ins Deutsche iibers., eingel. u. kommentiert (Leipzig, 1870). Dieser in ihrer Art genialen Übertragung sind die im Texte angeführten Zitate mit nur geringfügigen. Abweichungen entnommen. Die Übersetzungen des Tao-teh-king von PLÄNCKNER und NOACK sind gänzlich verfehIt. - R. Dvoř́x, Lao-tsï und seine Lehre (Münster, 1903). - E. FABER, Der Naturalismus bei den alten Chinesen... oder die sämtl. Werke des Philos. Licius zum ersten. mal vollst. übers. u. erkl. (Elberfeld, 1877). - H. A. GiLes, Chuang Tszŭ, Mystic, Moralist, and Social Reformer, transl. from the Chinese (London, 1899).

IV. DE HARLEZ, L'école philosophique moderne de la Chine ou Système de la Nature (Sing-li) (Bruxelles, I890). - G. von DER GABELEnTz, Thai-kih-thu des Tschou-tsï, Tafel des Urprinzipes (Dresden, 1876). - LE GALL, Le Philosophe Tschou Hi, sa doctrine, son influence (Chang.hai, 1894).

\section{Nachtrag (von Dr. H. Haas).}

Zu II: R. Wilhelm, Kungfutse Gespräche (Lunyü), aus dem Chines. verdeutscht und erläutert (Jena 1910). - Die Arbeit von FORKE über den Philos. Wang Ch'ung ist mittler. weile vervollständigt in Buchform erschienen (Leipzig, Harrassowitz).

Zu III: L. WiEger, Le Canon Taoiste. Taoïsme, Vol. I.: Bibliographie générale - I. Le Canon (patrologie); II., Les index officiels et privés (Ho Kien fou I9II). - Von den neuesten deutschen Tao-teh-king. Übersetzungen sind zu nennen: J. GRILL, Lao-tszes Buch vom höchsten Wesen und vom höchsten Gut (Tao-tě-king). Aus dem Chines. übers., mit Einleit. versehen und erläutert (Tübingen 1910), sowie R. WilhELM, Laotse, Tao te king. Das Buch des Alten vom Sinn und Leben. Aus dem Chincs, verdeutscht und erläutert (Jena 1911). - Von den letztgenannten Autor sind hier zwei andere Bände seiner bei Eugen Diederichs verlegten Sanmlung „Die Religion und I'hilosophie Chinas" anzuführen: Liä I)si, Das wahre Buch vom qucllenden Urgrund (Tschung hü dschen ging). Die Lehre der I'hilosophen Liä Yü Kou u. Y̌ing I)schu (Jena I9l $\mathfrak{\text { ) }}$, und: Dschuang Dsi, Das wahre Buch vom südlichen Blittenland (Nanhua ds hen ging). A us dem Chines. verdeutscht und erläutert (Jena 1912).

S. ferner: L. Wrecer, Textes philosophiques. Sommaire des notions chinoises, depuis l'origine jusqu'à nos jours, avec textes (Ho Kien fou 1906/08). 


\section{DIE JAPANISCHE PHILOSOPHIE. \\ VON \\ Tetsujiro Inouye.}

Einleitung. Von Philosophie kann man in Japan erst nach der Einführung ausländischer Philosophie und Religion sprechen, und zwar soll die chinesische Philosophie durch den Koreaner Wani (kor. Wang-in) zu Anfang des 5. Jahrhunderts n. Chr. ins Land gebracht worden sein, während die ausländische Religion, der Buddhismus, durch eine koreanische Gesandtschaft im Jahre 552 n. Chr. nach Japan gekommen ist.

Man darf diese Tatsache jedoch nicht so auffassen, als ob es gar kein originelles, einheimisches Ideensubstrat für die japanische Philosophie gegeben habe, und daß diese nichts anderes sei als die eingeführte ausländische Philosophie. Es gab in Japan seit alters her eine eigenartige, für dieses Land charakteristische Geistesströmung, die durch mehr als 2000 Jahre als allgemeine Empfindung des Volkes tätig gewesen ist. Diese Gedankenströmung, die gewöhnlich populär „Yamato-damashii“, deutsch: der japanische Volksgeist, genannt wird, bildet den Stamm, auf welchen die beiden ausländischen Gedankensysteme, welche Japan in früherer Zeit befruchtet haben, die chinesische Philosophie und die indische Religion, aufgepfropft worden sind.

Die Einführung der chinesischen Philosophie in Japan geschah ohne alle Hindernisse, da man sich im Anfang mit der bloßen Erklärung der King, d. h. der heiligen Texte, begnügte. Im Gegensatz zur chinesischen Philosophie hat die Einführung der indischen Religion von Anfang an eine gewaltige geistige Umwälzung hervorgerufen. Das kommt wahrscheinlich daher, daß sie eine neue tiefsinnige Religionslehre zu verbreiten unternahm, die mit der eigenartigen einheimischen Gedankenströmung keine oder sehr geringe Ähnlichkeit hatte. Sie hat sich ungemein schnell der japanischen Kultur zu assimilieren und hier feste Wurzel zu fassen gewußt, und hat bedeutend früher als die chinesische Philosophie einen tiefgehenden Einfluß auf den Geist des japanischen Volkes ausgeübt. Erst in der Kamakura-Zeit, d. h. zu Anfang des 14. Jahrhunderts, gelang es der chinesischen Philosophie, und zwar der der Sung-Dynastie, die gewöhnlich Sōgaku, d. h. „Sung (jap. Aussprache Sō)-Lehre" genannt wird, in Japan festen Fuß zu fassen, und erst 
im Anfang der Tokugawa-Dynastie ( $1603-1867$ ) wurde die chinesische Philosophie das wirklich leitende Prinzip der intellektuellen Welt in Japan.

I. Die Chu Hi-Schule (jap. Shushi-ha, vom 14. Jahrhundert an). Die Philosophie der Sung-Dynastie ist durch den Zusammenstoß des Konfuzianismus mit dem Buddhismus erzeugt und deshalb nicht mehr die einfache Sittenlehre des Urkonfuzianismus, sondern eine verhältnismäßig vertiefte Metaphysik mit mehr oder weniger religiöser Färbung. Unter den Vertretern der Sung-Philosophie ist Chu Hi (jap. Shushi 1 1 30-1 200) ohne Zweifel der größte und einflußreichste. Da er alle Systeme der vorhergehenden Philosophie der Sung-Dynastie in seinem eigenen System zusammenschmolz, so kann man seine Philosophie gewissermaßen als Repräsentantin der SungPhilosophie überhaupt betrachten.

Die Philosophie Chu His ist schon am Anfang des 14. Jahrhunderts in Japan eingeführt worden. Aber gerade von dieser Zeit bis zum Anfang des 17. Jahrhunderts wurde das Land durch unaufhörliche Bürgerkriege beunruhigt. Dieser Zeitraum von über 270 Jahren bildet das dunkle Zeitalter Japans, in welchem nur die Buddha-Priester in den Klöstern bei Kyōto die Sung-Philosophie, besonders die Philosophie Chu His, studierten und unter ihren Schülern verbreiteten. Aber die Buddhapriester zeigten keinen besonderen Eifer, die Philosophie Chu His zu vertreten und fortzubilden, weil diese oft in sehr schroffem Gegensatz zum Buddhismus sich bewegt.

Als das dunkle Zeitalter Japans mit der Begründung der TokugawaDynastie zu Ende gegangen war, fing man zum erstenmal an, die Sung.PhiI. Fujiwara Seigwa. losophie mit wirklichem Eifer zu studieren und zu lehren. Fujiwara Seigwa (1561-1619), in der Hauptstadt Kyōto lebend, war der erste Japaner, dem es gelang, die Philosophie $\mathrm{Chu}$ His weit in der literarischen und wissenschaftlichen Welt zu verbreiten. Ursprünglich Buddhapriester, gab er den Buddhismus auf, weil er die Verzichtleistung auf Familienbande predige und deshalb naturwidrig sei. Obgleich Seigwa ein ausgesprochener Anhänger Chu His ist, beschränkt er sich nicht einseitig und ausschließlich auf dessen Ansichten. Er ist der Meinung, daß sich die verschiedenen philosophischen Anschauungen miteinander in Einklang bringen lassen, und behauptet, daß sie alle schließlich eine und dieselbe Wahrheit darstellen. Auf solche Weise hat er nicht nur die Lehre des Chu $\mathrm{Hi}$ mit der weiter unten dargestellten des Wang Yang-ming, sondern auch den Konfuzianismus mit dem Buddhismus und dem Shintoismus versöhnt. Eine originelle philosophische Ansicht finden wir kaum bei ihm, aber wie gewaltig sein Einfluß war, kann man daraus ersehen, daß er eine Legion von Anhängern sich zu erwerben gewußt hat.

Der bedeutendste seiner Schüler war ohne Zweifel Hayashi Razan (1583-1657), ein Vertrauter des Shoguns Iyeyasu. Die Nachkommen Razans haben drei Jahrhunderte hindurch als eine gelehrte Familie dem TokugawaHause gedient; und da sie so lange einer nach dem anderen die Lehre Chu 
His als Staatsphilosophie hochhielten, so haben sie auf das Erziehungswesen des Landes einen beträchtlichen Einfluß geübt. Das philosophische System Razans ist nicht so originell wie das Seigwas, d. h. dieser letztere ist kein so strenger Anhänger Chu His wie jener. Razan hat gegen den Taoismus und den Buddhismus manche drastische Einwendungen erhoben. Gegen den Buddhismus sagt er folgendes: Die Buddhisten halten die Berge, Flüsse und Erde für etwas Unreales und die menschlichen Verhältnisse für etwas Illusorisches. Daher können sie nicht umhin, die Gerechtigkeit gänzlich zu vernichten. Und daher vergehen sie sich gegen unsere Sittenlehre.

Neben Razan ist Yamazaki Ansai (1618-1682) als der Schöpfer einer besonderen Gedankenrichtung zu betrachten. Als Kind wurde er in einem buddhistischen Kloster zu Kyōto erzogen, war also zeitweilig eine Bonze. Aber schon in seinem Jugendalter wandte er sich aus demselben Grunde wie Fujiwara Seigwa vom Buddhismus gänzlich ab, weil der Buddhismus die menschlichen Familienbeziehungen gar nicht berücksichtige. Bei Tani Jichu, der ebenso wie Fujiwara Seigwa ursprünglich Buddhapriester war und ebenso wie dieser eine berühmte Chu Hi-Schule begründet hatte, die in der Provinz Tosa 1ag, studierte er die Philosophie Chu His und wurde in der Folge ein strenger Anhänger Chu His. Da er ein ungemein rigoroser, unbeugsamer, rechtschaffener Mensch war, so hat er auf seine Schüler einen starken, dauernden Einfluß ausgeübt. Der Zweck seines ganzen Bestrebens war nicht, sich in rein intellektuelle Betrachtungen zu vertiefen, sondern ein moralisch tadelloser Charakter zu werden. Nit anderen Worten: er hat die Vervollkommnung der Persönlichkeit bezweckt. Deshalb war er ein ausgezeichneter Erzieher, abgesehen davon, daß er etwas engherzig, eigensinnig und zu streng war. Obschon er clen Buddhismus aufgab, hat er doch seinen religiösen Eifer bei seinem philosophischen Unterricht beibehalten, indem er anstatt des Buddha Chu Hi andachtsvoll verehrte. Was die Sittenlehre anbetrifft, so hebt er besonders zwei Haupttugenden hervor, Ehrfurcht und Gerechtigkeit. Nach seiner Ansicht soll Ehrfurcht die innere und Gerechtigkeit die äußere Welt beherrschen. Wenn man sich zur inneren Welt mit Ehrfurcht, zur äußeren mit Gerechtigkeit verhält, so kann man moralisch vollkommen werden. Ohne Ehrfurcht ist die Sittlichkeit bloß äußerlich und gar nicht ernsthaft. Ohne Gerechtigkeit gibt es lagegen keine soziale Sittlichkeit. Ähnlich wie Kant die subjektiven Maximen voin objektiven Gesetz, so unterscheidet Ansai die Ehrfurcht von der Gerechtigkeit. Außerlem hat Ansai die japanische Göttersagge vom Standpunkt der Chu Hischen Philosophie zu erklären versucht und einen besonderen. Shintoismus begründet, der unter dem Namen „Suiga-Shintō“ bekannt ist.

Wie bedentend und einflufreich die Schule Ansais war, kann man daraus ersehen, daff er nicht weniger als 6000 sichüler hatte. Nach seinem Tode spaltete sich seine Schule in vier verschiedenc Schulen, an deren Spitze Asami Keisai (1652-1711), Sató Naokata (1650-1719), Myake Shōsai (1662-1741) und Tamaki Isai $\left(?-173^{6}\right)$ standen. Unter diesen vier Schulen hat nur die 
Schule Tamaki Isais den Shintoismus Ansais fortgebildet, während die anderen drei hauptsächlich oder ausschließlich der Philosophie Chu His in deren ursprünglicher Gestalt anhingen. Immerhin sind doch im Laufe der Zeit eine Menge von begeisterten Gelehrten, die entweder dem Shintoismus oder dem Buddhismus anhingen, aus der Schule Ansais hervorgegangen und haben zu den Volksbewegungen am Ende der Tokugawa-Dynastie vielfach beigetragen.

Als Anhänger Chu His war endlich höchst bedeutend und einflußreich 4: Muro Kyuso. Muro Kyusō (1658-1734), welcher größtenteils in Yeddo 1ebte. Er hat sich von Anfang an der Philosophie Chu His angeschlossen und ist während seiner ganzen Lebenszeit durch und durch seiner Ansicht treu geblieben. Unter seinen zahlreichen Schriften ist ein Buch, betitelt "Shuntai-Zatsuwa“, am meisten bemerkenswert. Er hat gegen die Philosophie Wang Yang-mings, Jinsais und anderer manche scharfe Einwendung gemacht und behauptet, daß die Ansicht Chu His gerade die ist, welche Konfuzius und Mencius gemeint haben, und daß sie dieselbe bisher schon festgestellte Auffassung ist, welche, selbst wenn ein neuer Weiser (Seijin) auftritt, bestehen bleiben wird. Was die Sittenlehre anbetrifft, so hielt Muro Kyusō die Herzensreinheit, Aufrichtigkeit und Menschenliebe für das Wichtigste. Ferner sagt er folgendes: „Kein Wesen ist so schnell verständig wie Gott. Es ist für uns nicht möglich, das zu hören, was wir mit den Ohren nicht hören können, und das zu sehen, was wir mit den Augen nicht sehen können. Und, so scharfsinnig wir auch bei unserem Denken sein mögen, es gibt doch eine gewisse Grenze für das Verständnis. Gott braucht keine Ohren, um zu hören, und überhaupt keine Überlegung. Gott empfindet unmittelbar und betätigt sich unmittelbar. Gott ist immer da außerhalb der Zeit und des Raumes und im höchsten Grade scharfsinnig im Hörén und Sehen. Gott geht direkt dahin und kommt direkt hierher. Ja, Gott ist das Wesen aller Dinge und durchdringt den Himmel und die Erde. Ob Gott gleich ganz unsichtbar ist, so empfindet er doch, wenn man aufrichtig ist. Sobald Gott das empfindet, betätigt er sich danach. Wenn man nicht aufrichtig ist, so empfindet Gott nichts. Wenn das Wasser ganz rein und klar ist, so wird der Mond darin herrlich abgespiegelt. So ist auch die menschliche Seele. Wenn sie ganz frei von Begierden ist, so wird Gott da sein, und dadurch Mensch und Gott ganz und gar identisch werden." Kyusō bildet allmählich die orthodoxe Schule der Chu Hi-Philosophie in der ganzen Tokugawa-Dynastie.

II. Die Wang Yang-ming-Schule (jap. O Yōmei-ha, vom 17. Jahrhundert an). Im Verlaufe des 17. Jahrhunderts, während die Chu Hi-Schule noch einen bedeutenden Einfluß ausübte, wurde von Anhängern eines anderen chinesischen Philosophen der Sung-Dynastie, des $\mathrm{W}$ ang Yang-ming (jap. O Yōmei), in einer Gegend Japans, wo man das Aufkommen einer Schule kaum erwartet hätte, die Wang Yang-ming-Schule begründet, deren Lehre im Vergleich mit derjenigen der Chu Hi-Schule viel einfacher, aber weit praktischer und wirksamer ist. Seigwa (s. S. 81) hat zwar die Lehre Wang Yang- 
mings schon gekannt und gegen sie nichts eingewendet. Aber er gehört seiner Überzeugung nach zu völlig zur Schule Chu His.

x. Nakae Tōju. Es war Naka e Tōju (I608-1648) aus der Provinz Ömi, der als wirklich erster Anhänger Wang Yang-mings auftrat. Er war ein so makelloser, tugendhafter Charakter, daß man ihn Ömi-Seijin, den „Weisen aus Ōmi“, genannt hat. Obgleich seine Grundideen natürlich aus der Philosophie Wang Yangmings abgeleitet sind, so ist doch seine Philosophie in manchen Punkten höchst origine11. Tōju stellt wie Chu Hi zwei Grundprinzipien auf, Ri und $\mathrm{Ki}$, aber er hält sie, von einem noch weiter gehenden Standpunkt aus betrachtet, für wesentlich ein und dasselbe Ding. Nach Tōju besteht die Welt aus Ri und $\mathrm{Ki}$; und $\mathrm{Ri}$ ist die Weltseele, während $\mathrm{Ki}$ der Weltstoff ist. Die Weltseele teilt sich, und daraus wird die Natur aller Dinge geschaffen. Auch teilt sich der Weltstoff, woraus die Form aller Dinge gebildet wird. Auf solche Weise scheint er wie Chu Hi eine dualistische Weltanschauung zu vertreten. Aber tatsächlich ist es anders. $\mathrm{Ri}$ und $\mathrm{Ki}$ sind auf eine wunderbare Weise zusammengebunden, und so machen sie ein und dasselbe Ding aus, dessen zwei Seiten zwei verschiedene Benennungen haben. Wenn es ein Ri geben soll, so muß es auch zugleich ein Ki geben. Wenn sie jemals sein sollen, so müssen sie immer zusammen sein. So können sie in der Tat niemals getrennt werden. Ferner hat Töju das Ri und Ki als die zwei Attribute Gottes aufgestellt, eine Ansicht, die uns sofort an Spinoza erinnert. Auch bei Tōju existiert Gott nicht außerhalb von $\mathrm{Ri}$ und $\mathrm{Ki}$, sondern mit und in beiden zusammen. Geteilt sind sie $\mathrm{Ri}$ und $\mathrm{Ki}$, vereinigt sind sie Gott. So kann man die Welt von zweierlei Gesichtspunkten betrachten. A1s Gott ist sie Einheit. Als Ri und $\mathrm{Ki}$ ist sie Vielheit. Also kann man sehen, daß Tōju die Welt als êv kai $\pi \hat{\alpha} v$ aufgefaßt hat. Es ist auch bemerkenswert, daß die Weltauffassung Tōjus entschieden dem Idealismus zuneigt. Er behauptet, da $\beta$ die Seele beide Prinzipien $\mathrm{Ri}$ und $\mathrm{Ki}$ in sich umfaßt, und daß alles nur in der Se le sei, während Chu Hi behauptet, daß die Seele dem $\mathrm{Ki}$, dem Stoff, angehört.

In bezug auf Gott sagt Tōju folgendes: „Gott als das Wesen der Welt umfaßt die Welt, aber befindet sich zugleich ganz in der Nähe von uns, und $z w a r$ in unserem eigenen Leib. Gott ist im ganzen Umlauf der Zeit; daher auch in dem kürzesten Zeitpunkt eines einzigen Hauches. Das Gute und das Böse in einem einzigen Gedanken oder in einer einzigen Angelegenheit werden nie Gott unbekannt bleiben." Ferner hat Tōju die Idee vom allgemeinen und speziellen Ich. Nach ihm ist Gott das allgemeine Ich, während der Himmel in uns das spezielle Ich ist. Der Himmel in uns ist nichts anderes als das Ryōchi, d. h. etwas Übersinnliches in unserer Seele. Da das Wesen der Welt Gott ist, so sind wir in Gott; aber, da das Ryōchi andererseits Gott ist, so ist Gott in uns. Deshalb, wenn wir durch die Selbstbeschauung Gott in unserer See ${ }^{1} e$ entdecken und uns mit ihm vereinigen, so können wir selbst das ganze Universum erfüllen und umfassen.

Nach Toju soll das Ryōchi himmlischen Ursprung haben und deshalb jedem Individuum innewohnen. Was das Ryöchi sei, wird auf folgende Weise 
erörtert: 1. Das Ryōchi ist der Himmel oder Gott in uns. Tōju hält das Ryōchi direkt für Gott, welcher sich in unserer Seele befindet. Deshalb ähnelt das Ryōchi in etwas dem Nyorai, d. h. dem Tathāgata des Buddhismus. Gerade wie Nyorai durch die Vernichtung der Māyā erreicht wird, so wird auch das Ryōchi durch die Beseitigung der Begierden erreicht. 2. Das Ryōchi ist das Ri oder Tenri, d. h. die himmlische Natur. Das Tenri und die menschlichen Begierden sind beide in unserer Seele und einander entgegengesetzt. Wenn das Tenri die Seele beherrscht, so verschwinden die menschlichen Begierden von selbst. Andererseits, wenn die menschlichen Begierden die Seele beherrschen, so verschwindet das Tenri auf der Stelle. 3. Das Ryōchi ist das wahre Ich. Es gibt ein wahres und ein falsches Ich. Die ungereimten Ideen und die verkehrten Meinungen, welche wir uns erworben haben, machen das falsche Ich aus, welches von den meisten für das wahre gehalten wird. Das wahre Ich ist nichts anderes als das Ryōchi. 4. Das Ryōchi wird auch „Alleinsein" genannt, weil es besonders dem Alleinsein eines Individuums spezifisch ist. Das Ryōchi bezieht sich viel mehr auf sich selbst als auf andere. Die Rücksicht auf andere hat kein so großes Gewicht als das sich selbst im Inneren Kennen. Deshalb wird das Ryōchi auch das „Alleinkennen“ genannt. 5. Das Ryōchi ist das höchste Gute oder summum bonum. Wenn man nach dem Ryōchi handelt, so herrscht nur das Gute fortwährend in der menschlichen Seele. 6. Das Ryōchi ist die Wonne, welche unserer Seele von Geburt an eigen ist. Dies erinnert uns an die Taittirîyaka-Upanishad 2,5, wo man den folgenden Satz findet: Von diesem aus Erkenntnis bestehenden verschieden, dessen innerer A tman (Selbst) ist der aus Wonne bestehende (Deussen, Sechzig Upanishads des Veda, S. 231). 7. Das Ryōchi ist das Licht, welches die ganze Welt erleuchtet und alles durchdringt. Das Ryōchi ist in dieser Hinsicht dem Brahman oder Nyorai, besonders Vairochana ähnlich. 8. Das Ryōchi ist die Humanität oder Menschenliebe. Wenn man alle Begierden überwindet, so wird sich die Realität der Seele offenbaren, welche in diesem Falle nichts anderes als die Humanität oder Menschenliebe ist. 9. Das Ryōchi ist allwissend. Keine Geheimnisse der Welt können dem Ryōchi unbekannt bleiben. Das Ryōchi kann man keineswegs betrügen. Io. Das Ryōchi ist allgegenwärtig. 11. Das Ryōchi ist. immerwährend und unvernichtbar. 12. Das Ryōchi ist der Seijin oder der Weise in jedem Herzen. Wenn man das Ryōchi zum höchsten Grade ausbildet, so wird man ein Seijin werden. Tōju hat wahrscheinlich seine Idee aus folgendem Ausdruck Wang Yang-mings entlehnt: „In jedem Herzen wohnt ein Seijin. Nur glaubt man es nicht fest genug, deshalb ist das Ganze eingegraben geblieben." Das Ryōchi ist nach Tōju einerseits bloß empirisch, aber es ist andererseits durchaus transzendental. Empirisch betrachtet ist das Ryōchi natürlich gut, aber transzendental betrachtet, ist es weder gut noch böse. Woher kommt dann das Böse? Nach Tōju kommt das Böse vom Wollen, und das Wollen von den Begierden, welche ihren Ursprung im $\mathrm{Ki}$ haben sollen.

Unter den Schülern Tojus war Kumazawa Banzan (1619-1691) der be-

Kumiana Banzan, Miwa Shissai u. a. 
deutendste. Er war nicht nur ein namhafter Gelehrter, sondern auch ein hervorragender Staatsmann. Etwas später als Banzan ist Miwa Shissai (1669-1744) als ein Verehrer Tōjus aufgetreten und verbreitete die Lehre Wang Yangmings durch verschiedene Schriften, aber besonders durch die Veröffentlichung der japanischen Ausgabe des Buches Denshuroku, „Überlieferte Lehrschriften“, welches als das Hauptwerk Wang Yang-mings betrachtet werden kann. Neben diesen haben sich Nakane Tōri (1694-1765) und mehrere andere der Schule Wang Yang-mings angeschlossen. Außerdem ist zu bemerken, da $B$ am Ende der Tokugawa-Epoche eine Anzahl hervorragender Persönlichkeiten, wie Yokoi Shōnan (1809-1869), Sakuma Shōzan (1811-1864), Saigo Takamori, der berühmte General und Staatsmann (1827-1877), und Yoshida Shōin (1830 bis 1859), mehr oder weniger von den philosophischen Ideen Wang Yangmings beeinflußt waren.

III. Der Urkonfuzianismus in Japan (jap. Kogaku-ha, vom I 7. Jahrhundert an). Neben der Sung-Philosophie ist noch eine andere auf chinesischen Einfluß zurückgehende Philosophenschule auf japanischem Boden zu erwähnen, die der wahren Lehre des Konfuzius die Tore öffnen will.

Ihr Begründer ist Yamaga Soko (1622-1685). Da Sokō bei Razan die Sung-Philosophie studiert hat, so war er ursprünglich ein Anhänger Chu His. Im Alter von 42 Jahren hat er jedoch sein eigenes philosophisches System "Seikyō-Yōroku" veröffentlicht. Dieses Buch hat großes Aufsehen erregt und unerwartet über die Persönlichkeit des Verfassers Unglück gebracht. Da er in diesem Buch manche derbe Einwendungen gegen die Chu Hi-Philosophie, die damalige Staatsphilosophie, machte, so wurde er von Yeddo nach Akō verbannt, wo er zehn Jahre lang verweilen mußte.

Gegen die Scharen von Gelehrten, welche damals entweder der Philosophie Chu His oder Wang Yang-mings sich angeschlossen hatten, hat Sokō allein unverzagt seine kühne selbständige Ansicht geäußert und die Behauptung aufgestellt, daß die Philosophie Chu His nicht der echte Konfuzianismus sei. Wie manche Europäer heutzutage zum Urchristentum, andere zu Kant zurückkehren wollen, so wollte Sokō zum Urkonfuzianismus zurückkehren, welcher, nach seiner Ansicht, seit 2000 Jahren nicht echt erhalten, sondern vielfach verdorben und verfälscht worden ist.

Was die Kosmologie anbetrifft, so hat Sokō folgendes behauptet: Die Welt ist nichts anderes als eine große sichtbare Form der beiden Grundprinzipien Yin, des Negativen, und Yang, des Positiven; sie hat niemals angefangen, durch Schöpfung zu existieren, sondern ist das, was sie ist, auf natürliche Weise, d. h. durch Notwendigkeit geworden. Auch wird sie für immer bestehen, d. h. sie hat weder Anfang noch Ende. Wenn es überhaupt einen Anfang gäbe, so müßte es auch ein Ende geben. Aber wie der Anfang nie bestimmt werden kann, so wird das Ende auch nie erkannt werden. Es gibt in der Welt eine beständlige Erzeugung oder unaufhörliche Entwickelung. Wenn ein Ding sein Ende erreicht, so entsteht zu gleicher Zeit ein anderes 
Ding. Ein wirkliches Ende gibt es also überhaupt nicht, oder genauer gesagt, es gibt nur ein Werden. In bezug auf die Sittenlehre Sokōs muß man bemerken, daß er in manchen Stellen der Nützlichkeitslehre geneigt zu sein scheint, aber doch schließlich von der Lehre des Konfuzius nicht abweichen wollte. Der Unterschied zwischen dem Edlen und dem Unedlen besteht nach seiner Ansicht darin, daß es dem ersteren bloß auf Gerechtigkeit ankommt, während der letztere bloß nach Nützlichkeitsinteressen, nicht aber nach der Gerechtigkeit handelt. Wo immer die Gerechtigkeit besteht, da folgt auch das Interesse notwendig. Das Interesse ist daher als die natürliche Konsequenz der Gerechtigkeit zu betrachten, und in diesem Sinne widerspricht es derselben keineswegs.

Ferner hat Sokō sowohl durch seine Lehre als auch durch seinen persönlichen Charakter zur Ausbildung des Bushidō, auf deutsch: der Volksseele von Japan, vielfach beigetragen. Da er ungemein vielseitige Kenntnisse gehabt hat, so hat er zahlreiche Werke, und zwar 60 verschiedene, welche im ganzen etwa 600 Bände ausmachen, verfaßt. Die meisten von diesen Werken behandeln Gegenstände, die sich, außer der Philosophie, auf den Bushidō beziehen. Sokō sagt: „Das Alter von hundert Jahren kann man vorläufig für das höchste Alter für Menschen halten. Ein großer Mann hält jedoch nur den jeweiligen Tag für die letzte Bestimmung der Tätigkeit. Und wenn viele solche Tage angehäuft werden, so wird daraus ein Monat. Aus vielen solchen Monaten wird ein Jahr. Aus vielen solchen Jahren zehn Jahre, dann hundert Jahre. Ein Tag ist doch schon zu lang. Das, was man berücksichtigen soll, ist eine Stunde. Nein, eine Stunde ist noch zu lang. Es ist eine Minute, ja eine Sekunde, welche man berücksichtigen soll. Daher muß man wissen, daß die Pflicht für tausend und aber tausend Jahre mit einer einzigen Sekunde anfängt und für jeden einzelnen Tag auferlegt ist. Wenn man selbst die Zeitdauer einer einzigen Sekunde vergeudet, so wird man auch einen ganzen Tag und endlich auf gleiche Weise das ganze Leben nutzlos verbringen. Gerade wie die Erzeugungsprozesse der Welt selbst für eine einzige Sekunde nicht aufhören, so soll man nicht einmal eine einzige Sekunde untätig bleiben, sondern beständig danach streben, seine Persönlichkeit zu einem Seijin (d. h. Weisen) zu vervollkommnen." Sokō spricht ferner von der Todespflicht, welche den Geist des Bushidō durchdringt. Da den eigenen Kürper aufzuopfern überhaupt die Pflicht der Untertanen ist, so ist es gerecht, wenn es sich um eine drohende, unvermeidliche Gefahr handelt, den eigenen Körper willig aufzugeben und den Tod völlig zu verachten. Um dem Tocke entschlossen entgegenzusehen, sollte man seine Familienbeziehungen gänzlich vergessen und seine Privatangelegenheiten vollständig unberücksichtigt lassen. Den Tod, welcher für alle Menschen etwas wirklich Ernsthaftes ist, muß man vorher genau erkennen und in würdiger (stoischer) Weise vollzichen. In diesem Sinne hat er, jedesmal wenn er aus seinem Hause trat, seine Fannilienbeziehungen gänzlich abgeschnitten und war jeden Augenblick zum Tod entschlossen. Das ist der Geist des Bushidō. In bezug auf die letzte V'erfügung 
auf dem Sterbebett, welche damals Daimyos oft trafen, sagt er folgendes: „Das, was man heute tut und äußert, das sind eben die Gebote und Vorschriften für die Nachkommen. Daher gibt es nichts Besonders zu sagen und $z u$ verbieten. In der Weise, wie man sich Tag für Tag verhält, in dem, was man täglich tut oder läßt, darin sollen die nachgelassenen Befehle und die nachgelassenen Worte bestehen." Der Einfluß der Lehre Sokōs auf den Bushidō ist so bedeutend gewesen, daß er in Japan als bleibend betrachtet werden kann.

2. Iเ $\overline{\text { Jnsai. }} \quad$ Beinahe gleichzeitig mit Sokō hat Itō Jinsai ( $1627-1705)$ eine ähnliche Lehre aufgestellt und den Urkonfuzianismus zu erneuern versucht. Ob Jinsai von Sokō wirklich angeregt oder beeinflußt wurde, das ist jetzt kaum mehr möglich festzustellen. Es ist eine Tatsache, daß einige Schüler Sokōs aus Akō auch bei Jinsai studiert haben. Daraus kann man einigermaßen vermuten, daß Jinsai von Soko beeinflußt worden ist. Jinsai war eine rornehme Persönlichkeit von ungemein edlem Charakter. Daher hat er als der Hauptführer einer neuen Philosophenschule überaus großen Einfluß geübt. Nach ihm ist die Welt nichts anderes als die eine einzige ursprüngliche Energie (Ichigenki), welche sich in der entzweiten Form der beiden Prinzipien Yin und Yang im Zustande beständigen Flusses befindet. Alles in der Welt ist von der ursprünglichen Energie abgeleitet. Aber die ursprüngliche Energie selbst ist das Grundprinzip, welches von keinem anderen abgeleitet werden kann. Es gibt in der Welt bloß eine fortwährende Erzeugung und keine Vernichtung. Da der Tod eines einzelnen nichts anderes als das Ende des Lebens ist, so kann man nicht sagen, daß der Tod ist, in dem Sinne, wie das Leben ist, welches während einer gewissen Zeitdauer ein positives Dasein hat. Im ganzen als Gattung betrachtet gibt es bloß eine fortwährende Erzeugung. Auch leben die Seelen der Vorfahren, wenn sie durch den Tod dahingerafft werden, in den Nachkommen fort; deren Seelen sollen wiederun in ihren Nachkommen fortleben. Nur in diesem Sinne und in keinem anderen hat er dir. Tatsache der Unsterblichkeit anerkannt.

Man kann wohl bemerken, daß die Weltauffassung Jinsais von der Chu llis swhr verschieden ist. Nach Chu Hi gibt es, wie wir sahen, zwei Grundprinzipien, $\mathrm{Ri}$ und $\mathrm{Ki}$, in der Welt, von denen eines von dem anderen nicht abgeleitet werden kann. Daher ist die Ansicht Chu His ohne Zweifel ein Dualisnus, während die Jinsais ein ausgesprochener Monismus ist. Auch ist die Vorstellung rom $\mathrm{Ri}$ und $\mathrm{Ki}$ bei beiden Philosophen sehr abweichend. Nach Chu IIi ist das Ri das ideelle Prinzip und geht dem Ki, dem materiellen Prinzip, vor. Jinsai leugnet nicht das Vorhandensein des Ri, aber nach ihm ist das $\mathrm{Ri}$ nichts anderes als ein Attribut des $\mathrm{Ki}$. Mit anderen Worten ist das Ri das Hauptprinzip bei Chu Hi, während bei Jinsai das Ki das Hauptprinzip oder vielm(hr das alleinige Grundprinzip ist. Da das Hauptprinzip $\mathrm{Ri}$ ron Chu Hi ganz statisch begriffen ist, so fehlte seiner Weltanschauung das Moment der Bewegung und geht seine Lebensanschauung folgerichtig in eine Art Quietismus übrer. Da das Grundprinzip Ki von Jinsai anderer- 
seits durchaus dynamisch aufgefaßt worden ist, so ist seine Welt- und Lebensanschauung im ganzen durch eine beständige Tätigkeit charakterisiert. Auf solche Weise findet man in manchen Punkten Gegensätze zwischen Jinsai und Chu Hi. Die Denkweise Jinsais hatte zur Folge, daß die damals im Schwung vefindliche Chu Hi-Philosophie von Grund aus umgestürzt wurde.

Ebenso wie Sokō leugnet Jinsai die Schöpfung und behauptet, daß es weder einen Anfang noch ein Ende gebe. Es ist auch bemerkenswert, daß Jinsai nur Bewegung und keine Ruhe in der Welt anerkennt. Ruhe ist nach ihm eine bloße gehinderte Bewegung. Auch erkennt er nur das Gute und kein Böses an. Das Böse ist nach ihm nichts anderes als eine Änderung oder Irrung des Guten. Gutes ist eine Art Leben, während Böses eine Art Tod ist. Gutes und Böses soll daher nicht gleichgestellt werden, da alles im Ganzen fortbesteht oder fortlebt. Was die menschliche Natur anbetrifft, hat Jinsai eine weit gesundere Theorie als Chu Hi vertreten. Da die menschliche Natur nach $\mathrm{Chu} \mathrm{Hi}$ ursprünglich gut war und erst später verdorben wurde, so besteht das sittliche Streben nur darin, die menschlichen Begierden zu unterdrücken und $z u$ der ursprünglichen guten Natur zurückzukehren. Jinsai lehrt nicht, daß man diese Rückkehr zur ursprünglichen Natur erreichen müsse, sondern daß man nur beständig alles Gute in sich entwickeln solle. In dieser Hinsicht sieht man klar, daß die Sittenlehre Jinsais jener modernen ethischen Theorie nahe steht, welche als höchsten Zweck hinstellt, alle Fähigkeiten in uns völlig zur Entwickelung zu bringen. Als sittliches Prinzip hat Jinsai Gerechtigkeit und Menschenliebe betont, gerade wie Schopenhauer, während alle Anhänger Chu His das Ri für das sittliche Prinzip gehalten haben. Bei Jinsai hat die Menschenliebe die größte Bedeutung, denn sie ist der einzige Zweck der Wissenschaften, der einzige Grund der Tugenden und der Inbegriff alles möglichen Guten. Was Jinsai von der Liebe sagt, kann man wohl mit der christlichen Ansicht (1. Korinther I3) vergleichen.

Das philosophische System Jinsais wurde von seinem Sohn Itō Tōgai $(1670-1736)$ fortgebildet und weiter verbreitet. Tōgai ist als Gelehrter viel bedeutender als sein Vater, als Denker aber ist er sein treuer Schüler geblieben.

Unter den Zeitgenossen der Philosophen Sokō und Jinsai nimmt Kai- ${ }_{\text {Ekken. }}^{\text {Kaibara }}$ bara Ekken (1630-1714) einen hervorragenden Platz ein. Er war ein vielseitig gebildeter, aber ungemein bescheidener Gelehrter. Anfänglich hatte er sich der Philosophie Wang Yang-mings angeschlossen, aber später änderte er seine Ansicht völlig und wurde ein Verehrer Chu His. Am Ende hat er dann auch die Philosophie Chu His bezweifelt und ein Buch "Taigiroku“ (Zum großen Zweifel) hinterlassen, das ein eigenes philosophisches System enthält und große Verbreitung gefunden hat. Gerade wie Jinsai hat er gegenüber dem Dualismus Chu His einen ausgesprochenen Monismus vertreten, denn er erkennt bloß das $\mathrm{Ki}$ als einziges Grundprinzip. Das Ri leugnet er nicht ganz. Aber das $\mathrm{Ki}$ ist schließlich nach seiner Ansicht das einzige Grundprinzip, denn das $\mathrm{Ri}$ ist nichts anderes als dessen Attribut. Chu Hi hat einst 
gesagt: das $\mathrm{Ri}$ und das $\mathrm{Ki}$ sind entschieden zwei verschiedene Dinge. Im Gegensatz dazu behauptete aber Ekken: „Das Ri und das Ki sind entschieden ein und dasselbe Ding." Daher stimmt seine Ansicht in dieser Beziehung mit der Wang Yang-mings und Jinsais überein.

Seine Sittenlehre 1eitet Ekken von dem kosmischen Prozesse ab. Da der Himmel und die Erde, kurz die Welt wie der größte Vater und die größte Mutter uns Gnaden und Segen im höchsten Grade schenken, so müssen wir vor allem der Welt gegenüber Dankbarkeit empfinden und diese durch unser Leben bekunden. Um diesen Zweck zu erfüllen, müssen wir den Willen der Welt erkennen und ihn befolgen. Das ist eben die Pietät gegen die Welt. Die Welt erzeugt alles und liebt alles, was sie erzeugt, geradeso wie die Eltern sich zu ihren Kindern verhalten. Die Menschen werden von der Welt am meisten geliebt. Das wissen wir daraus, daß die besten Materialien dem Menschen als Lebensmittel geliefert werden. Deshalb heißt die Mitmenschen lieben den Willen der Welt befolgen. Man muß wissen, daß es in bezug auf die Liebe eine natürliche Ordnung gibt. Unter den Mitmenschen müssen die Eltern zuerst kommen; nächst den Menschen müssen wir die Tiere lieben, dann die Pflanzen usw. Kurz gesagt, die Liebe umfaßt alles in der Welt oder vielmehr durchdringt die ganze Welt, wobei ihre Grade je nach dem Gegenstand verschieden sind.

Es ist auch bemerkenswert, daß Ekken der erste bei uns gewesen ist, der sich recht ernsthaft dem Studium des Erziehungswesens (auch die Frauenerziehung einschließend) gewidmet und in dieser Hinsicht eine neue Epoche heraufbeschworen hat.

Einer von den einflußreichsten Schriftstellern und Denkern in der Tokugawa-Dynastie war Butsu Sorai (1666-1728), welcher in Yeddo lebte. Wahrscheinlich angeregt von Jinsai, hat er auch die Richtung beibehalten, welche darauf zielte, zum Urkonfuzianismus zurückzukehren. Sorai hat jedoch gegen Jinsai manche schroffe Einwendungen gemacht und eine andere literarisch-philosophische Schule gebildet. Jinsai hat die Vervollkommnung der Persönlichkeit bezweckt, während Sorai im Gegenteil die Nützlichkeit zum Grundprinzip machte. Jinsai und Sorai sind beide gegen die SungPhilosophen alrgetreten, und beide wollen zum reinen Urkonfuzianismus zurückkehren. Aber die Erklärungsweise des Urkonfuzianismus ist bei ihnen so verschieden, daß beide in manchen Punkten diametral entgegengesetzt sind. Der Konfuzianismus ist nach der Ansicht Sorais im Grunde Nützlichkeitslehre. Auch behauptet er, daß das Moralprinzip sich nicht in der Natur oder im menschlichen Herzen befindet, sondern erst von den Weisen (Seijin) stamme oder aufgestellt sei. Die menschliche Natur hält er für das, was ursprünglich böse ist. »Homo homini lupus« ist seine Ansicht. Recht und Unrecht sollen nach seiner Ansicht erst nach den Gesetzen entstehen, und die Bestimmungen gut und böse gelten bloß in bezug auf die Nützlichkeit. Also steht Sorai in manchen Punkten dem englischen Philosophen Thomas Hobbes sehr nahe. Auberdem behauptet er gerade wie Schopenhauer, daß der 
menschliche Charakter absolut unveränderlich sei. Obgleich Sorai ein Gegner der Philosophie Jinsais war, hat er doch mit Jinsai einige gemeinsame Punkte. Aber mit den Sung-Philosophen hat er fast keine Berührungspunkte. Die Sung-Philosophie ist die Zusammenschmelzung des Konfuzianismus, des Taoismus und des Buddhismus. Jinsai und Sorai wollen sich von dem Taoismus und Buddhismus befreien und direkt zum reinen Urkonfuzianismus zurückkehren. Aber Jinsai hat den Konfuzianismus idealistisch erklärt, während Sorai denselben utilitaristisch faßt. Sorai scheint manche Ideen von Junshi (chin. Hsün-tzu) entlehnt zu haben, gerade wie Jinsai seine Grundbegriffe von Mencius entnommen hat.

Unter den Schülern Sorais ist hier nur Dazai Shuntai (1680-1 747) 5.Dazai Shuntai. $z u$ berücksichtigen. Man braucht nach seiner Ansicht gar nicht innerlich sittlich zu sein. Wie das innere Herz auch sein möge, wenn man nur äußerlich sittlich ist, so ist man ein Edler.

IV. Neue B1üte der Wang Yang-ming-Schule im 19. Jahrhundert. Am Ende des i8. Jahrhunderts wurden alle anderen Schulen außer der Chu Hi-Schule von der Regierung als Ketzerei unterdrückt. Daher wurde die lebhafte Entwickelung der freisinnigen Denkweise auf einmal verhindert. Die Dazwischenkunft der Regierung ist entschieden schädlich gewesen, denn der philosophische Eifer wurde zeitweise beträchtlich gedämpft. Doch sind trotz dieser Eingriffe in der ersten Hälfte des 19. Jahrhunderts zwei namhafte Vertreter aus der Wang Yang-ming-Schule hervorgegangen.

Der eine ist Satō Issai (1772-1859), welcher in Yeddo lebte. Issai hat x. Satō Istai. als ein sehr gebildeter, vorsichtiger Denker in der letzten Zeit der Tokugawa-Dynastie einen bleibenden Einfluß ausgeübt. Er hat sich öffentlich als Anhänger der Chu Hi-Philosophie erklärt, so daß er mit der Regierung in Eintracht stehen konnte. Aber in der Tat hat er vielmehr die Philosophie Wang Yang-mings vertreten. Unter seinen Schülern sind mehrere, z. B. Yamada Hōkoku (1805-1877), Sakuma Shōzan (181 I-1864) u. a., sehr bedeutende Persönlichkeiten geworden.

Der andere moderne Vertreter der Wang Yang-ming-Schule war Ōshio 2. Öshio Chū «ai. Chusai (1793-1837), in Osaka lebend. Chusai war ein energischer, geistreicher Denker. Wie alle Anhänger Wang Yang-mings hat er das Ryōchi zu seinem Grundprinzip gemacht. Was das Ryōchi sei, das hat er in eigenartiger Weise erklärt. Wenn die Seele ganz frei von Begierden ist, so ist sie frei von der Ichheit und in einem Zustande der bloßen Selbstanschauung. Solch ein von der Ichheit befreiter Zustand der Seele, den er "das Taikyo" nennt, ist natürlich nicht ein bloßes Nichtssein, sondern eine unsterbliche Geistigkeit. Das Taikyo hat ein jeder in seinem Innern, aber jeder ist nicht zugleich in dem Taikyo selbst, denn das Wesen der Welt ist nichts anderes als das Taikyo. Das Taikyo in jedem Individuum und das Taikyo der Welt ist ein und dasselbe, und beide zusammen bilden eine allumfassende Einheit. 
Auf solche Weise hat Chūsai den Makrokosmos und den Mikrokosmos genau entsprechend erklärt. Gott soll nach seiner Ansicht das Ryōchi selbst sein und außer dem Ryōchi soll es keinen Gott geben.

V. Die national-philosophische Schule und die moderne Philosophie in Japan. Beiläufig dürfen wir nicht übersehen, daß vom Anfang der Tokugawa-Dynastie an gegen die aus China überkommene Philosophie und gegen den Buddhismus eine einheimische Gedankenströmung reagiert hat, welche auf das alte Volksempfinden (s. S. 6r) zurückging. Ais die VerYamato- treter dieser den "Yamato-damashii“ offenbarenden Schule sind besonders damashii. Tokugawa Mitsukuni (1628-1700), Kamo Mabuchi (1697-1769), Motoori Norinaga (1730-1801) und Hirata Atsutane (1776-1843) zu erwähnen. Im 19. Jahrhundert ist Japan mit Amerika, England, Rußland, Deutschland und anderen europäischen Staaten mehr und mehr in Berührung gekommen. Diese Berührungen haben den "Yamato-damashii“" zum höchsten Grade erweckt, und, seien es Buddhisten, seien es Konfuzianisten, alle, welche an dem "Yamato-damashii“ teilhaben, haben zusammen schließlich die große Staatsumwälzung hervorgebracht.

Seit der Restauration der Mikado-Herrschaft hat die Philosophie in Japan eine ganz neue Bahn eingeschlagen. Die europäische Philosophie wurde sowohl von den Japanern selbst als auch von den Ausländern eingeführt. Am Anfang hat man besonders Mill, Spencer, Lewes und andere englische Philosophen verehrt. Als man aber die Philosophie mehr als Spezialstudium zu treiben anfing, hat man mehr Kant, Hegel, Schopenhauer, Lotze, Wundt, Paulsen, v. Hartmann und andere deutsche Philosophen $z^{\prime}$. verehren angefangen. Der Materialismus hat wenigstens einen Vertreter gefunden. Auch fehlt es nicht an Denkern, welche den Utilitarismus und sogar den Egoismus vertreten. Nietzsche wurde ebenfalls von einigen jungen Schriftstellern eingeführt, aber er ist nur wie eine flüchtige Mode schnell 'an uns vorbeigegangen. Neuerdings bestreben sich einige, den Sozialismus zu verbreiten, aber er scheint hier keinen großen Erfolg zu haben. Die christlichen Ideen kommen natürlich auch in manche Beziehungen mit der philosophischen Geistestätigkeit. Es ist wohl möglich, daß die Philosophie in Japan durch den Zusammenstoß und die Verschmelzung der morgenländischen Gedanken mit den abendländischen in nicht entfernter Zukunft einen großen Aufschwung nehmen wird. 


\section{Literatur.*)}

Mit vorstehendem Beitrage mag man vergleichen desselben Verfassers dem Internationalen Orientalistenkongre $B$ in Paris 1897 dargebotene Skizze „Sur le développement des idées philosophiques au Japon avant l'introduction de la civilisation européenne". Eine deutsche Übersetzung hievon ist A. GramatzKy, „Kurze Übersicht fiber die Entwicklung der philosophischen Ideen in Japan" (Berlin 1897). Von außerjapanischen Forschern war bis vor wenig Jahren der einzige, der sich eingehender mit dem japanischen Konfuzianismus be. schäftigt hat, G. W. KNox. Siehe seine Veröffentlichungen in Vol. XX der Transactions of the Asiatic Society of Japan (TASJ), sowie die 5. und 6. Vorlesung in seinem Buche „The Development of religion in Japan" (New York and London 1907). Erst die jüngste Zeit hat eine Anzahl weiterer schätzbarer Arbeiten zu Tage gefördert, die wertvollsten unter ihnen veranlaßt durch die großen japanischen Publikationen von Professor Tetsujiro Inouye (Nihon Yōmei-gakuha no tetsugaku, Tokyo 1900; Nihon Kogaku-ha no tetsugaku, I902; Nihon Shushigaku-ha no tetsugaku, 1905): siehe WALTER DENING, „Confucian philosophy in Japan. Reviews of Dr. Inoue Tetsujirō's three volumes on this philosophy" (TASJ. Vol. XXXVI, Part II, p. IOI-152; ARThUR Lloyd „Historical development of the Shushi Philosophy in Japan" (TASJ. Vol. XXXIV, Part IV, p. I -80). Von Aufsätzen, die Leben und Lehre einzelner japanischer Konfuzianer behandeln, verdienen genannt zu werden GALEN M. FISHer, "Nakae Toju; the Sage of Omi" (TASJ. Vol. XXXVI, Part I, p. 25-96); PerEGRINUS, „Notes sur le Confucianisme" (Mélanges Japonais 19c8, p. 375-419); J. B. DUTHU, „Hayashi Razan, un Confucianiste du XVIIe siècle" (ibid. 1909, p. 324-343 und 487-510); J. B. Duthu, „Kumazawa Banzan“ (ibid. 1910, p. I-1 8 und 145-164); J. B. Duthu, „Le Confucianisme Japonais. Notes et essais" (ibid. 1910, p. 45I-480). Verwiesen mag ferner werden auf die die geistigen Strömungen in der Tokugawa-Periode behandelnden Kapitel 27 und 28 in K. Florenz' Geschichte der japanischen Literatur.

Über die japanischen Religionen und die Literatur Japans unterrichten die Monographien in dieser Enzyklopädie: K. Florenz, Shintōismus; H. HaAs, Der Buddhismus: K. Florenz, Die japanische Literatur.

\footnotetext{
*) Zusammengestellt von Dr. Hans Ha.is.
} 


\title{
DIE EUROPÄISCHE PHILOSOPHIE DES ALTERTUMS.
}

\author{
VON \\ Hans von ARnim.
}

Einleitung. Die Geschichte der europäischen Philosophie im Altertum ist die Geschichte der griechischen Philosophie. Denn zu dem philosophischen Gedankenkreis, den die antike Menschheit in den Jahrhunderten des ausgehenden Altertums als Vermächtnis der Vergangenheit besaß und der folgenden Zeit überlieferte, hat außer den Griechen und den ihre Kultur direkt fortsetzenden hellenisierten Völkern kein anderes Volk selbständige Beiträge geliefert. Der Hellenismus der Römer hat sich auf dem Gebiet der Philosophie noch weniger zeugungskräftig erwiesen als auf den übrigen Gebieten idealen Schaffens in Literatur, Wissenschaft und Kunst. Ihre philosophischen Schriftsteller haben sich mit wenigen Ausnahmen begnügt, eine Auswahl aus den Gedanken der griechischen Denker ihrem Publikum nahe zu bringen.

Die Philosophie der Griechen, deren Entwickelung in ihren Hauptzügen auf den folgenden Seiten vorgeführt werden soll, deckt sich nach Begriff und Umfang nicht ganz mit dem, was man in der Neuzeit unter Philosophie versteht. Das Wort Philosophie in dem uns geläufigen Sinne ist der Zeit des Platon und Isokrates noch ganz fremd. Erst bei Aristoteles nähert es sich der modernen Bedeutung. Sachlich aber haben die Männer, die wir zu den griechischen Philosophen rechnen, teils ein engeres, teils ein weiteres Gebiet als die Philosophen späterer Zeiten umspannt: ein engeres zunächst in den Anfangsstadien der Entwickelung, insofern die Teile des philosophischen Gesamtgebietes, einzeln entdeckt und neben- und nacheinander angebaut, erst in den Systemen der Blütezeit vereinigt und als untrennbare Teile eine $r$ Wissenschaft erfaßt wurden; aber auch in der Blütezeit selbst und über sie hinaus, insofern es neben den das Gesamtgebiet umfassenden Systematikern immer noch Philosophen gab, die die philosophische Aufgabe enger begrenzten. Namentlich ist solchen Lehrern, die, von aller Metaphysik, Erkenntnistheorie und Naturlehre absehend, lediglich eine praktische Lebensauffassung begründen und überliefern wollten, nie das Recht bestritten worden, sich Philosophen zu nennen. Daß andererseits vielfach von den grie- 
chischen Philosophen Fragen behandelt wurden, die wir nicht mehr dem Philosophen zuweisen, ist eine Folge der allmählichen Entwickelung der Einzelwissenschaften und ihres Verhältnisses zur Philosophie als der Mutter aller Wissenschaft. Für diese Entwickelung gibt es keine zutreffende allgemeine Formel; sie läßt sich nur für jede Einzeldisziplin besonders charakterisieren. Manche Disziplinen bleiben lange der Philosophie immanent, lösen sich erst spät aus ihrem Zusammenhang; andere treten erst im Laufe der Entwickelung zu ihr in Beziehung.

Streng genommen ist ein historisches Verständnis der philosophischen Systeme nur möglich, wenn zugleich der Besitz an positiven (einzelwissenschaftlichen) Kenntnissen festgestellt werden kann, über den die einzelnen Philosophen verfügen. Zumal die naturphilosophischen Lehren des klassischen Altertums werden erst auf dieser Grundlage verständlich. Andererseits ist wieder die Geschichte der Einzelwissenschaften vielfach durch die der Philosophie bedingt. Diese durchgehende Wechselwirkung zwischen Philosophie und Einzelwissenschaft bei den Griechen zu erkennen, ist uns durch die Dürftigkeit der Überlieferung, namentlich in der älteren Zeit, sehr erschwert und nach dem gegenwärtigen Stand der Forschung unmöglich.

Aber auch die philosophischen Lehren selbst auf Grund der Überlieferung endgültig festzustellen und in der zeitlichen Folge ihres Hervortretens als Momente eines Entwickelungsganges darzustellen, sind wir noch nicht fähig, weil für die grundlegende vorsokratische Periode erst vor kurzem die Sammlung und kritische Bearbeitung der Zeugnisse so weit gefördert worden ist, daß sie der dogmengeschichtlichen Forschung ein sicheres Fundament bietet, und weil für einen Teil der nacharistotelischen Philosophie und für die Philosophie des 4. Jahrhunderts außer Platon und Aristoteles dieses Fundament noch fehlt. Auf Grund solcher Fragmentsammlungen, die das Überlieferungsmaterial vollständig, geordnet und gesichtet vorlegen, wird die dogmengeschichtliche Forschung teils neue Fragen aufwerfen, teils alte von neuem erörtern müssen, ehe wir zu einer endgültigen Feststellung unseres Wissens gelangen.

Die Geschichte der alten Philosophie kann sich sehr verschiedene Ziele stecken und dementsprechend auch verschieden behandelt und dargestellt werden. Anders wird eine Darstellung ausfallen, in der die Philosophie als integrierender Bestandteil der antiken Gesamtkultur hinsichtlich ihrer Wechselwirkung mit anderen Elementen dieser Kultur aufgefaßt wird; anders eine Darstellung, die nur die philosophischen Probleme selbst und die Fortschritte ihrer Behandlung und Lösung verfolgt und diese vom Standpunkte der heutigen Wissenschaft und des Darstellers selbst würdigt; anders drittens eine solche, die sich der gleichen Eingrenzung des Themas bedient, es aber unter dem historischen Gesichtspunkt der immanenten Folgerichtigkeit behandelt. Nach dem ersten Gesichtspunkt sind diejenigen Philosopheme die bedeutendsten, die auf das antike Gesamtleben die größte Wirkung ausgeübt haben; nach dem zweiten die, welche gewisse, heute als Wahrheit geltende Sätze 
entweder schon zureichend begründet oder doch ahnend vorweggenommen haben; nach dem dritten die, welche aus den für den betreffenden Philosophen geschichtlich gegebenen Voraussetzungen folgerichtig entwickelt sind. Für unsere Darstellung ist dieser dritte Gesichtspunkt maßgebend gewesen, da einerseits für die Darlegung des Zusammenhanges zwischen Philosophie und Gesamtkultur der Rahmen zu eng ist, andererseits die Beurteilung der philosophischen Lehren vom Standpunkt der heutigen Wissenschaft das historische Bild trüben würde, das an und für sich einen hohen Wert besitzt.

Die griechische Philosophiegeschichte gliedert sich in dieselben Perioden wie die griechische Literaturgeschichte, insofern wir eine vorattische, eine attische und eine hellenistische Periode unterscheiden können, an die sich das Nachleben der Philosophie in der römischen Epoche anschließt. In der vorattischen Periode, d. i. im 6. und in der ersten Hälfte des 5. Jahrhunderts, sind die Ionier Kleinasiens und die Westgriechen in Sizilien und Unteritalien Träger der philosophischen Bewegung. Es folgt die attische Periode, in der Athen als geistige Kapitale von Griechenland auch in der Philosophie herrscht und in der sokratischen, platonischen und aristotelischen Philosophie der Höhepunkt der Entwickelung erreicht wird. Auch in der hellenistischen Periode bleibt Athen, als Sitz der bedeutendsten Philosophenschulen, die Hauptstätte philosophischer Forschung. Aber die nacharistotelischen Schulen, die in dieser Zeit dem philosophischen Geist das Gepräge geben, entwickeln sich in ausgesprochenem Gegensatz, zur attischen Philosophie und knüpfen wieder an die ionische Philosophie an, die Stoa an Herakleitos, Epikuros an Demokritos.

A. Die Philosophie Ioniens und Westgriechenlands (6.-5. Jahrhundert v. Chr.).

I. Die Begründer der drei Hau ptrichtungen (6. Jahrhundert v. Chr.) In der vorattischen Periode treten drei verschiedene Hauptrichtungen auf, die ungeachtet ihrer mannigfaltigen Wechselwirkung als selbständige Faktoren auf die Folgezeit gewirkt haben: die ionische Naturphilosophie, die eleatische Seinslehre und Begriffsdialektik, die pythagoreische Zahlenlehre und religiöse Mystik. Die ionische Naturphilosophie, begründet durch die drei Milesier Thales, Anaximandros und Anaximenes, fortgesetzt und vertieft durch Herakleitos, gipfelt in dem Dreigestirn Empedokles, Anaxagoras und Leukippos und reicht mit ihren Ausläufern und Fortsetzern bis ins 4. Jahrhundert hinein. Die eleatische Seinslehre zweigt sich durch Xenophanes von der ionischen Naturphilosophie ab, wird von Parmenides systematisch durchgebildet, von Zenon mit eristischer Dialektik verfochten. Der Pythagoreismus, dessen Stifter und ursprünglichste Formen in tiefes Dunkel gehüllt sind, wird durch Philolaos systematisch zu der Form ausgebildet, in der er weiter gewirkt hat. Mit der durch Sokrates, den Begründer der attischen Philosophie, erfundenen ethischen Begriffsforschung hat Platon Elemente aller drei genannten vorattischen Richtungen verbunden. Diese haben die gemeinsame Eigentümlichkeit, daß die Natur den eigentlichen Gegenstand ihrer Forschung bildet, bei 
Pythagoras und Parmenides nicht minder als bei den Ioniern. Der Mensch wird nur im Zusammenhang der Naturbetrachtung gestreift. Eine Wissenschaft von dem Leben und der Aufgabe des Menschen gibt es noch nicht, sie wird erst durch die sophistische Bewegung und ihren bedeutendsten Vertreter Sokrates begründet. Denn die pythagoreische Seelenlehre und Lebensregelung ist religiöse Mystik, nicht Wissenschaft.

Die ionische Naturphilosophie des 6. Jahrhunderts ist ein Erzeugnis der ionischen Aufklärungsbewegung. Früher als die ganze übrige Hellenenwelt hatten die vom Ionertum beherrschten Städte Kleinasiens die aus dem griechischen Mittelalter überkommenen Formen des Adelsstaates und die ständische Gliederung der Gesellschaft abgeworfen. Der Bruch mit dem Überlieferten auf politischem und sozialem Gebiete führte zu dem Streben, auch die ganze Welt- und Lebensanschauung auf neue, rationelle Grundlagen zu stellen; ein Vorgang, der sich ein Jahrhundert später im attischen Kulturkreise wiederholte. So kam es, daß man die aus praktischen Lebensbedürfnissen erwachsene Kenntnis einzelner Naturvorgänge jetzt dazu benutzte, sich von dem ganzen Weltall, seiner Entstehung und Einrichtung ein Bild zu machen. Der Augenblick, wo die Vernunft, nicht mehr zufrieden, den unmittelbaren praktischen Lebensbedürfnissen zu dienen, den rein theoretischen Fragen der

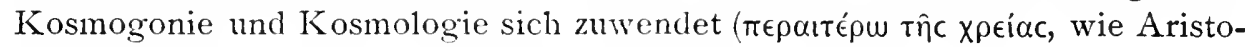
teles von Thales sagt), ist die Geburtsstunde der Philosophie. Von den mystischen Kosmogonien, ihren Vorläuferinnen, unterscheidet sich diese Bestrebung durch ihren rationalistischen Charakter. Das ldeal, das diesen Denkern vorschwebte, kann nur gewesen sein, ihre Konstruktionen des Weltalls aus Tatsachen der Erfahrung mittels einleuchtender Verstandesschlüsse abzuleiten. Es ist daher Aufgabe der geschichtlichen Forschung, die wirklichẹn oder vermeintlichen Erfahrungstatsachen und die bündigen oder nicht bündigen Schlüsse womöglich nachzuweisen, die zu den doxographisch überlieferten Folgerungen geführt haben. Unvollständige, unrichtige oder falsch gedeutete Beobachtungen sind es, aus denen durch kühne Verallgemeinerungen und Analogieschlüsse die kosmologischen Hypothesen entstanden. Immer laufen sie auf eine anschauliche Vorstellung des Weltalls, seines früheren, gegenwärtigen und zukünftigen Zustandes hinaus, die zu rekonstruieren das nicht immer erreichbare Ziel unserer Forschung ist.

Wenn sich die Welt der Anschauung als eine schwer zu ïberblickende Mannigfaltigkeit qualitativ verschiedener Körper und Stoffe darstellt, die sich in mannigfaltiger Weise bewegen und verändern, so ist es das Bestreben der Physiologen, das Weltbild zu vereinfachen und die Mannigfaltigkeit auf möglichst wenige Prinzipien, am liebsten auf ein en Urgrund zurückzuführen. Der Versuch, die Welt als Ganzes aufzufassen und zu erklären, führt sogleich zu dem Stoffprobiem. Wenn die Erfahrung Veränderungen der Körper zeigt, wie den Übergang des kochenden Wassers in Dampf, des schmelzenden Metalls aus dem festen in den flüssigen Aggregatzustand, wem also ein und derselbe Stoff sich in verschiedene Formen verwandeln kann, so wird dadurch der Ge- 
danke nahegelegt, daß überhaupt die ganze empirische Mannigfaltigkeit der Stoffe durch Verwandlung aus einem Urstoffe entstanden sei. Man warf die Frage nach der Beschaffenheit des Urstoffes auf und konnte diesen entweder in einem der empirisch bekannten oder in einem bloß hypothetischen Stoffe finden. Indem man eine Geschichte erzählt, wie aus dem Urstoff die Welt entstand, gibt man nicht nur eine genetische Erklärung des gegenwärtigen Weltzustandes, sondern glaubt auch etwas auszusagen über das wahrhaft Seiende. Wenn aus dem Urstoff alle übrigen stofflichen Dinge entstehen und sich bei ihrer Zerstörung wieder in ihn auflösen, so kommt ihm allein dauernder Bestand gegenüber den wechselnden Produkten des Werdens zu. Die Welt ist nicht nur aus ihm entstanden; er ist auch ihre Substanz, das wahrhaft Seiende, das allen ihren Erscheinungen zugrunde liegt.

Dieser Urstoff muß aber auch die Ursache der Bewegung und Veränderung in sich selbst tragen. Denn es kann neben ihm keine zweite gleich ursprüngliche Wesenheit als Ursache seiner Bewegungen und Veränderungen geben. Eine immaterielle Ursache der Bewegung anzunehmen, konnte diesen auf Anschauung und E.rfahrung fußenden Denkern nicht in den Sinn kommen. Hierzu gesellt sich leicht die Meinung, daß der Urstoff, weil er Lebendiges aus sich hervorbringt, selbst in seinem innersten Wesen lebendig sein müsse, der Hylozoismus. Es empfahl sich daher, einen Urstoff anzunehmen, der, abgesehen von seiner Einfachheit, Beweglichkeit und Veränderlichkeit, auch für das organische und seelische Leben als Erklärungsprinzip brauchbar wäre. Wenn Thales das Wasser, Anaximenes die Luft, Heraklit das Feuer als Urstoff annahm, so waren alle drei von den geschilderten Denkmotiven geleitet.

Die drei Milesier. a) Thales ium $5^{8}$ ).

1. Der älteste der drei Milesier, die als die Begründer der ionischen Naturphilosophie zu bezeichnen sind, ist Thales. Aristoteles, der sowenig wie irgendein anderer antiker Zeuge eine echte Schrift des Thales kannte, vermutet mit Recht, daß Thales das feuchte Element für den Urstoff erklärte, weil im Saft das Leben der Pflanze ist (sie stirbt ja, indem sie verdorrt), im Blut das Leben des Tieres, weil auch der Same der Tiere feucht ist und selbst die Flamme durch Feuchtigkeit genährt wird. Wenn er sich demnach das feuchte Element als Träger des Lebens dachte, so klingt es recht glaublich, daß er die ganze aus ihm entstandene Welt für beseelt (oder „voll von Seelen“) erklärte. Sein anschauliches Weltbild wird nur durch den einen Zug illustriert, daß er sich die Erde als flache Scheibe dachte, die vermöge ihrer Form auf der Oberfläche des Wassers schwimmt, und die Erdbeben aus der Bewegung des Wassers erklärte.

Wir haben uns Thales nicht als Berufsphilosophen zu denken. Seine Lehre vom Urstoff und seine kosmologische Ansicht haben sich ihm als Nebenprodukt empirischer Beschäftigung mit verschiedenen Gebieten der Natur ergeben, und nicht auf ihr beruhte das berechtigte hohe Ansehen, das er bei seinen Zeitgenossen hatte. Dies wird erklärlich durch Leistungen wie die Vorhersagung der Sonnenfinsternis vom 28. Mai 585 , die nicht auf richtiger Einsicht in die Ursachen des Phänomens, sondern auf einer aus der babylo- 
lonischen Wissenschaft entlehnten Periodenrechnung beruhte. Auch in der Geschichte der Mathematik spielt Thales eine Rolle; die Sätze, daß der Durchmesser den Kreis halbiert, daß im gleichschenkligen Dreieck die Basiswinkel gleich sind, daß Scheitelwinkel gleich sind, daß Dreiecke kongruent sind, wenn sie eine Seite und zwei anliegende Winkel gleich haben, werden von unserem zuverlässigsten Berichterstatter Thales zugeschrieben. Die Höhenberechnung der ägyptischen Pyramide aus der Länge ihres Schattens, mittels des am Endpunkt dieses Schattens senkrecht aufgepflanzten Stabes und se ines Schattens, paßt trefflich zu diesen Sätzen. Thales war kein weltfremder Gelehrter, sondern ein Mann des praktischen Lebens, der durch weite Reisen als Kaufmann seine Bildung erweitert hatte und auch politisch eine Rolle spielte. An ihm bewährte sich schon die Wahrheit, daß eine über das praktische Bedürfnis hinausgehende Forschung oft gerade diesem überraschend zu Hilfe kommt.

Schüler des Thales soll sein Mitbürger Anaximandros gewesen sein, b) Anaximandros der im Jahre 547/6 im Alter von 64 Jahren seine auch dem späteren Altertum (um 547). noch bekannte Schrift verfaßte. Als Urstoff setzte er nicht, wie sein Lehrer, einen der durch die Erfahrung gegebenen Elementarstoffe, sondern das Un-

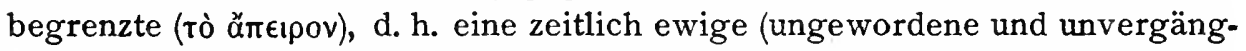
liche), räumlich unendliche Materie. Qualitativ ist diese dadurch charakterisiert, daß die Gegensätze warm und kalt, feucht und trocken sich aus ihr infolge der ewigen Bewegung ausscheiden. Sie enthält also ursprünglich diese gegensätzlichen Qualitäten in ungeschiedener Einheit. Ungeworden und unzerstörbar ist auch der Urstoff des Thales, aber nicht räumlich unendlich. Die Unendlichkeit des Urstoffes glaubte Anaximandros annehmen zu müssen,

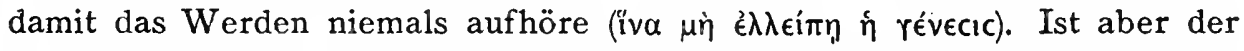
Urstoff unendlich, so kann er keines der empirisch gegebenen Elemente (Feuer, Luft, Wasser, Erde) sein. Denn diese stehen paarweis in qualitativem Gregensatz. Wäre nun eines dieser Elemente unendlich, so müßte es das ihm entgegengesetzte endliche schon längst vernichtet haben. Die ewige Bewegung, deren Art er nicht näher bestimmte, dachte er sich als unabtrennbare Eigenschaft des Stoffes. Aus dem unendlichen Stoffe entstehen neben- und nacheinander unendlich viele Welten, die sich bei ihrem Untergang wieder in den Urstoff zurückbilden. Dieser Wechsel ist an bestimmte Zeiträume gebunden, durch ein Naturgesetz, das Anaximandros einer Schuld durch Buße aufwiegenden Strafgerechtigkeit vergleicht. Hierin so wenig wie in der Bezeichnung der Welten als Götter ist ein Rückfall in theologische Anschauungen zu erblicken. Das Leben des unendlichen All besteht in einem ewigen Kreislauf kosmischen Entstehens und Vergehens. - Die Bewegung, die zur Entstehung unseres Kosmos führt, muß er sich als Kreisen gedacht haben, da er ihn dem Schein folgend kugelförmig denkt. Durch dieses Kreisen scheidet sich aus dem Urstoff zunächst der Stoff aus, der Warmes und Kaltes hervorzu-

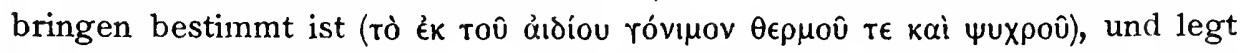
sich als Hohlkugel um den Rest. Durch eine weitere Sonderung scheidet sich in dieser Hohlkugel das Warme vom Kalten: die Feuersphäre umschließt die 
kalte Luftsphäre von außen wie die Rinde den Baum. Ebenso sondert sich in dem Rest das Feuchte vom Trockenen und legt sich als Wassersphäre um die in der Mitte befindliche, nicht kugel-, sondern zylinderförmige Erde, die, weil sie in der Mitte ist, nach keiner Seite fallen kann, sondern frei schwebt, ohne (wie bei Thales) einer tragenden Unterlage zu bedürfen. Bei weiterem Kreisen bersten einzelne Schichten der Feuersphäre und rollen sich zusammen. Indem sich um diese dunkle Luft herumlegt, entstehen Hohlringe aus dunkler Luft, die mit Feuer gefüllt sind und ihre kreisende Bewegung beibehalten. Sie haben Öffnungen, durch die das in ihnen befindliche Feuer sichtbar wird, als Sonne, Mond oder Gestirn; durch deren zeitweilige Verstopfung erklären sich die Finsternisse der Sonne und des Mondes und die Mondphasen. Diese unsichtbaren, die Erde umkreisenden Ringe, welche die Gestirne tragen, sollen die Bewegungen der Gestirne erklären. Wir finden hier die primitivste Form der die Kosmologie des ganzen Altertums beherrschenden Sphärentheorie. Der größte und äußerste Ring ist der, welcher die Sonne trägt; dann folgt der des Mondes; noch näher der Erde befinden sich die Fixsterne und Planeten. Durch die Einwirkung der Sonne wird die Wassersphäre teilweise aufgetrocknet; das Meer bleibt als Überbleibsel zurück. Die bei der Verdunstung entstandenen Dämpfe wirken im Luftraume als Ursachen der Wettererscheinungen weiter. Auf dieser Stufe der Weltentwickelung entstehen auch die Lebewesen aus dem Schlamme. Die Menschen im besonderen sollten zunächst als Fische im feuchten Element gelebt haben und erst nachdem sie entwickelt genug waren, sich selbst ihre Nahrung zu beschaffen, die Schuppenhaut abwerfend ans Land gestiegen sein. - Anaximandros hat zuerst unter den Griechen eine Erdkarte entworfen. Er dachte sich nur die obere Kreisfläche des Erdzylinders (siehe oben) von Menschen bewohnt. Auch die Erfindung der Sonpenuhr und des Gnomon wird ihm vielfach zugeschrieben. Mit Unrecht, denn beide kamen den Griechen aus Babylon zu.

Anaximenes von Milet, der um 546 blühte und zwischen 528 und 525 starb, schlägt in seiner Lehre ganz andere Bahnen ein als sein Vorgänger Anaximandros. Als Urstoff nimmt er die Luft an, die er zwar auch als der Masse und Ausdehnung nach unendlich setzt, wie Anaximandros sein Unbegrenztes, aber nicht Ursprung allein, sondern auch bleibende Substanz der Welt sein läßt. Denn aus der Luft sollen durch Verdünnung und Verdichtung alle in der Welt vorhandenen Stoffe hervorgehen, so daß die Welt fortdauernd in allen ihren Teilen aus Luft besteht und ihrem eigentlichen Wesen nach Luft ist. Hierin liegen die Vorzüge der anaximenischen Verdichtung und Verdünnung vor der anaximandrischen Ausscheidung der Gegensätze: es wird dem philosophischen Postulat der Einheit der Materie genügt und ein wahrhaft Seiendes an den Anfang der Entwickelung gestellt und diese so aufgefaßt, daß sie der Unzerstörbarkeit und (in gewissem Sinne) Unveränderlichkeit des Urstoffes keinen Abbruch tut. Der 1atente Pluralismus in der Urstofflehre Anaximanders wird durch einen strengen Monismus ersetzt. Aus der I-uft wird durch Verdünnung Feuer, durch stufenweise Ver- 
dichtung erst Wind, dann Wolke, Wasser, Erde, Stein; aus diesen einfachen Stoffen (durch Mischung?) alle übrigen. Der Urstoff bildet also weder das obere noch das untere Ende der Stufenleiter. Seine Bestimmung als Luft beruht auf der an volkstümliche Vorstellungen anknüpfenden Meinung des Anaximenes, daß die menschliche Seele aus Luft besteht, also die Luft Lebensprinzip ist, und auf der aus der sinnlichen Anschauung geschöpften Ansicht, daß Luft den ganzen Kosmos umgibt und trägt. Denn Anaximenes folgert aus der Unendlichkeit des Urstoffes nicht mit Anaximandros das Dasein unzähliger Welten; er kennt nur einen Kosmos, den er sich von der unendlichen Luftmasse umgeben und getragen denkt. Die Lehre von der Verdichtung und Verdünnung des Stoffes ist die Vorstufe der atomistischen Physik, zu der eine genauere Untersuchung der Begriffe Verdichtung und Verdünnung führen mußte. Als Grund der Verdichtung und Verdünnung nennt Anaximenes die ewige Bewegung, die er, wie schon Anaximandros seinem Unbegrenzten, der Luft als ursprüngliches Attribut beilegt. Den Gegensatz des Kalten und Warmen leitet er unmittelbar aus der Verdichtung und Verdünnung her; da aus der Luft durch Verdichtung Kaltes, durch Verdünnung Warmes entsteht, muß er die Luft selbst als indifferent hinsichtlich dieses Gegensatzes angesehen haben. Zuerst sollte, bei der Entstehung: des Kosmos, durch Zusammenpressung der Luft die Erde entstanden sein, die er sich als flache Scheibe von der Luft getragen dachte. Aus den bei fortgesetzter Verdünnung feurig gewordenen Ausdünstungen ihrer Gewässer ließ er Sonne, Mond und Sterne entstehen, die er sich ebenfalls als flache, von der Luft getragene Scheiben dachte. Demnach können sich diese nur oberhalb der Erde befinden. Unser Philosoph kennt nämlich in seinem Weltbilde ein Oben und Unten im gewöhnlichen Sinne und will nicht zugeben, daß sich die Sterne, wenn sie untergehen, unterhalb der Erde herumbewegen, sondern wie der Filzhut um unsern Kopf, meint er, drehe sich der Sternenhimmel (ein Kristallgewölbe, an dem die Fixsterne wie Nägel befestigt sind) um unsere Erde. Wir dürfen hierin, nach dem kühnen Anlauf des Anaximandros, einen Rückfall in die Vorstellung des Thales finden. Beide Philosophen haben sich den Kosmos als halbkugelförmig vorgestellt. Die Sonne bewegt sich, wenn sie untergeht, nicht unterhalb der Erdscheibe herum, sondern wird nur durch die am nördlichen Rande der Erde befindlichen Gebirge unsern Blicken entzogen. Um der Luft die Rolle der Allbewegerin zu wahren, hat Anaximenes auch die Bewegung der Himmelskörper und des die Fixsterne tragenden Kristallgewölbes auf Luftströmungen zurückgeführt. Weil er die Luft als Lebensprinzip und Geist auffaßt, hat er sie als Gottheit bezeichnet und, wie es scheint, auch eine Mehrheit luftiger Einzelgötter angenommen. Auch die menschliche Seele besteht aus Luft; sie trägt und regiert den Leib wic die göttliche den Kosmos.

Nachdem wir die erste Hauptrichtung der vorattischen Philosophie in den drei Milesiern auf ihrer ersten Stufe gezeigt haben, können wir sie nicht auf ihre weiteren Stufen begleiten, ohne zuvor die Entstehung der beiden 
anderen Hauptrichtungen, der eleatischen und pythagoreischen Lehre, $z u$ schildern. Xenophanes und Pythagoras stammen beide aus dem ionischen Kulturbereich, jener aus Kolophon, dieser aus Samos. Beide waren mit den Gedanken der Milesier wohlbekannt. Beide sind durch äußere Lebensschicksale in den fernen Westen verschlagen worden. Sie haben die Samenkörner der ionischen Philosophie nach Italien übertragen, wo sie in Elea und Kroton zu neuen Gebilden sich entwickelten.

Xenophanes von Kolophon (geb. um 580 )
2. Xenophanes von Kolophon ist nach glaubwürdiger Überlieferung Schüler des Anaximandros gewesen und wohl nur um wenige Jahre jünger als Anaximenes. Im Alter von 25 Jahren aus seiner Heimat vertrieben, hat er längere Zeit in Zankle und Katana auf Sizilien gelebt und ist um 540 nach dem neugegründeten Elea übergesiedelt. Er hat ein unstetes Wanderleben geführt, indem er seine Dichtungen selbst als Rhapsode in allen Teilen Griechenlands vortrug. Er lebte bis gegen 480 , ein volles Jahrhundert umspannend. Es kann hier nicht die literarische Bedeutung des in mannigfachen Dichtungsformen tätigen Mannes geschildert werden. Wir müssen uns auf seine Philosophie beschränken, die er in dichterischer Form, im Versmaße des Heldenliedes vortrug, nicht wie Anaximandros in schwungvoller oder wie Anaximenes in schlichter ionischer Prosa. Die Wahl der Form ist für seine Richtung bezeichnend. Er ist seinem innersten Wesen nach nicht nüchterner Naturforscher, obgleich ein Teil seiner Lehren sich in den Geleisen der Ionier bewegt; er ist vielmehr ein vom Pathos des Propheten erfüllter spekulativer Theologe. Diese Eigenschaft teilt er mit seinem wenig jüngeren Rivalen Pythagoras, dessen Lehre sich ebendamals in Unteritalien und Sizilien zu verbreiten begann. Beide Männer haben aus der religiösen Bewegung des 6. Jahrhunderts, die auf eine Wiedergeburt der Volksreligion abzielte, entscheidende Antriebe empfangen und sind selbst Führer dieser Bewegung geworden, indem sie die volkstümliche Unterströmung mit der Wissenschaft verquickten. Was uns von kosmologischen und physikalischen Lehren des Xenophanes berichtet wird, zeigt keinen Fortschritt, eher einen Rückschritt gegenüber dem Weltbilde des Anaximandros. Wichtig ist nur seine Lehre von der Einheit und Ewigkeit Gottes. Gott ist für ihn der Inbegriff des wahren Seins. Er ist das All und das Eine. Als Seiendes ist er ewig, d. h. ungeworden und unvergänglich. Denn das Seiende kann weder aus Gleichartigem noch aus Ungleichartigem entstanden sein, weder aus Seiendem noch aus Nichtseiendem. Als Gott ist er einer; denn dem Gottesbegriff, als dem Begriff des mächtigsten Wesens, kann das Merkmal der Pluralität nicht ohne Widerspruch beigelegt werden. Er ist begrenzt und kugclförmig (nach anderer, widersprechender Überlieferung weder begrenzt noch unbegrenzt). Er ist auch unbewegt und unveränderlich (nach anderer Formulierung weder bewegt noch unbewegt). Er ist auch reiner Geist, der mit seinem ganzen Wesen, nicht mit Organen sieht und hört und denkt. Mit dieser Schilderung des göttlichen Wesens trat Xenophanes gleich sehr zu der Volksreligion wie zu der ionischen Physiologie in Gegensatz. An jener be- 
kämpft er den Polytheismus, den Anthropomorphismus, die sittliche Laxheit, von dieser scheidet ihn, daß er das Absolute nicht als Urstoff auffaßt, aus dem durch Veränderungen eine Vielheit von Dingen hervorgeht, sondern als den einen, ewigen, geistigen Gott. Dieser Gott ist zwar das All, aber nicht die Welt, in der wir leben. Denn ihr kommen, nach den eigenen Außerungen des Xenophanes, alle jene Eigenschaften zu, die er der Gottheit abspricht. Sie ist entstanden und vergänglich; in ihr herrscht Bewegung und Veränderung; sie zeigt uns eine Vielheit von Dingen und kann auf zwei gegensätzliche Prinzipien, Erde und Wasser, zurückgeführt werden. Aus dem Urschlamm, in dem Erde und Wasser gemischt sind, bildet sich durch Sonderung dieser Elemente die uns bekannte Welt. In den Urschlamm löst sie sich wieder auf und entsteht von neuem aus ihm, in ewigem Wechsel. Sie ist nicht begrenzt und kugelförmig, sondern ins Unendliche erstrecken sich die Wurzeln der Erde nach unten, unendlich ist auch ihre Oberfläche, auf der wir wohnen. Alles, was wir über uns erblicken, als Wolken, Sonnen, Monde, Sterne, ist aus verdunstetem Wasser entstanden. Wie die Wolken, obwohl geradlinig über unseren Häuptern dahinziehend, einen Halbkreis $z u$ beschreiben scheinen, so ist auch das Kreisen der Gestirne nur scheinbar. Sonne, Mond und Sterne schweben über die Erde geradlinig weiter ins Unendliche. Sie kehren nicht wieder. Der neue Tag bringt eine neue Sonne. -- Wie sich diese Erfahrungswelt zu dem all-einen Seienden verhält, bleibt unklar; nur daß in einem Bruchstück des Lehrgedichtes (fr. 25 Diels) von Gott gesagt wird: „Sonder Mühe schwingt er das All mit des Greistes Gedanken."

3. Auch Pythagoras von Samos, der wahrscheinlich durch die Tyrannis 3. Pythagoras des Polykrates um 532 aus seiner Heimat vertrieben wurde und in Kroton seinen philosophischen Verein begründete, vereinigt wissenschaftliche mit religiösen Bestrebungen; die von ihm ausgehende Verquickung dieser beiden Elemente ist es, die später auf Platon entscheidend eingewirkt hat. Die Bekanntschaft mit der ionischen Physiologic konnte ihm sein Lehrer Pherekydes von Syros vermitteln, der sich in seinem Weltbilde selbst von Anaximandros beeinflußt zeigt. Seine religiösen Impulse schöpft er aus der breiten volkstümlichen Bewegung, die sich in dieser Zeit auf die Wiedergeburt der Religion, die Heiligung des Lebens und die Beteiligung des ganzen Volkes am Kultus richtete, im besonderen aus der in den Mysterienkulten ausgeprägten Form dieser Bewegung, deren bezeichnendes Merkmal ist, daß sie das Los der Seele nach dem Tode von dem Verhalten des Menschen während seines Erdenlebens abhängen läßt und für dieses Verhalten Anweisungen gibt. Diese allen Mysterienkulten gemeinsame Grundtendenz berechtigt uns, sie als einheitliches religionsgeschichtliches Phänomen aufzufassen trotz ihrer in Mythologie, Kult und Lehre mannigfachen Ausgestaltung. Die Scele wird von dieser religiösen Spekulation als ein vom Leibe nach Abkunft und Art verschiedenes Wesen höherer Art aufgefaßt, welches das leibliche Einzelleben überdauernd nach dem Tode von neuem eingekörpert wird. Diese „Seelenwanderung“ kann ewig fortdauern oder mit der endgültigen Rückkehr der 
Seele in ihre himmlische Heimat zum Abschluß gelangen. Mit der letzteren Annahme ist die ewige Fortdauer dieser irdischen Welt und die ewige Neuerzeugung sie bevölkernder Lebewesen unvereinbar, wenn nicht zugleich angenommen wird, daß immer neue Seelen entstehen und ihre Zahl sich im Laufe der Ewigkeit ins Unendliche vermehrt. Gegen diese Vermehrung der Seelen ins Unendliche sträubt sich aber die Phantasie. Wenn ferner ewige Fortdauer der Seelen für die Zukunft angenommen wurde, so lag es auch schon der primitiven Spekulation, aus der dieser religiöse Glaube entstand, nahe, aus der Zukunft auf die Vergangenheit zu schließen und die Seelen als unentstandene, von Ewigkeit her bestehende Wesen zu denken. Wer sich hierfür entschied und eine begrenzte Zahl ewiger Seelenwesen annahm, hatte nur die Wahl zwischen zwei Möglichkeiten: entweder hört der Bestand der irdischen Welt auf, wenn alle Seelen den Kreislauf der Geburten vollendet haben und in ihre himmlische Heinat zurückgekehrt sind, oder die Seelen müssen bis in alle Ewigkeit immer von neuem den Kreislauf der Geburten antreten und in irdische Körper eingehen. Dieser mannigfaltiger Abwandlungen fähige Seelenwanderungsglaube wurde von Pythagoras als Hauptdogma in seine Lehre aufgenommen. Die pythagoreischen Orgien unterscheiden sich dadurch ron den übrigen Mysterienkulten, daß sie diese im niederen Volke sich verbreitende Religion in die höhere Gesellschaftssphäre emporheben und durch Verquickung mit wissenschaftlichen Bestrebungen den Vornehmen und Gebildeten annehmbar machen. Der von Pythagoras in Kroton gestiftete Verein und seine zahlreichen Filialen, die bald in allen unteritalischen Griechenstädten sich bildeten, sollten die neue Religion der Wiedergeburt des Adels und der Erhaltung seiner durch Demokratie und Tyrannis bedrohten Herrschaft dienstbar machen. Sie suchen die Reinigungder Seele, die zu ihrer Seligkeit erforderlich ist, nicht, wie die dionysischen Mysterien, in ekstatischem Taumel und Enthusiasmus, sondern in ihrer Erziehung zu Maß, Ordnung und Harmonie, und wenden dabei als Erziehungsmittel eine Musik an, die das Widerspiel der dionysischen bildet. Die Musik bildet das Bindeglied zwischen den religiös-ethischen und den wissenschaftlichen Bestrebungen des Pythagoras. Denn wie sie praktisch das Mittel ist, die Seele harmonisch zu gestalten, so führt ihre theoretische Betrachtung dazu, die Abhängigkeit der Harmonie ron Zahl und Maß zu erkennen, und weiter in kühner Verallgemeinerung zu dem Gedanken, daß Zahl und Maß die ganze Welt beherrschen, ja ihr Wesen ausmachen und ihren Wert bedingen. Waren die Milesier Naturforscher, so ist Pythagoras der philosophierende Mathematiker; hatten jene einseitig den Stoff, aus dem die Dinge bestehen, als Prinzip verwendet, so macht er mit nicht geringerer Einseitigkeit die Form, die auf Maß und Zahl beruht, zum Wesen der Dinge; und zwar herrschte bei Pythagoras selbst ohne Zweifel die arithmetische Betrachtung vor, und wurden die räumlichen Größen, weil ihre Maßverhältnisse in Zahlen ausdrückbar sind, ohne weiteres als Zahlen angesehen. Als Grundelemente der Zahlen betrachtete Pythagoras das Gerade und Ungerade, wo- 
bei das Gerade mit dem Unbegrenzten, das Ungerade mit dem Begrenzten identifiziert und so, indem das Ungerade als das Bessere galt, dem ontologischen ein axiologischer Gesichtspunkt zugesellt wurde. Ein weiterer axiologischer Gesichtspunkt wurde in die arithmetische Weltbetrachtung durch den musikalischen Begriff der Harmonie eingeführt und durch die Annahme, daß wie in der Musik gewisse Zahlenverhältnisse die Verbindung der hohen und tiefen Töne zum Akkord bedingen, so auch die übrigen Gegensätze in der Welt durch eine auf Zahlenverhältnissen bcruhende Harmonie zur Einheit verbunden werden. Wie Pythagoras aus diesen Prinzipien die Elementarstoffe und die kosmischen Verhältnisse ableitete, und wie er dabei das Weltbild im einzelnen ausmalte, ist uns nicht überliefert, da das Altertum echte Schriften des Pythagoras nicht besaß. Wir kennen das System nur in der Form, wie es von Philolaos in der zweiten Hälfte des 5. Jahrhunderts ausgestaltet worden war und von anderen Pythagoreern, wie Lysis und Archytas, bis ins 4. Jahrhundert hinein vertreten wurde. In dieser Form zeigt es bereits den Einfluß fortgeschrittener astronomischer Kenntnisse und späterer kosmologischer Lehren. Die schwierige Aufgabe, durch dogmengeschichtliche Rückschlüsse weitere Einzelheiten über Pythagoras' eigene Lehre zu ermitteln, liegt außerhalb der Grenzen dieses Abrisses. Doch können die soeben gekennzeichneten Lehren mit Sicherheit dem Schulstifter zugeschrieben werden und rechtfertigen, daß wir ihn als den Begründer einer dritten Hauptrichtung neben die ionische Physiologie und die eleatische All-einslehre stellen.

II. Parmenides und Herakleitos (um 500 v. Chr.). In der nächsten Generation, die schon in das 5. Jahrhundert hinüberreicht, finden wir wieder zwei bedeutende Philosophen, die sich durch die schroffe Gegensätzlichkeit ihres Standpunktes als zusammengehörig erweisen. Der zwischen Xenophanes und den Milesiern hervorgetretene Gegensatz wird von Parmenides und Herakleitos noch schärfer und folgerichtiger durchgebildet, indem Parmenides das Verhältnis zwischen dem einen substantiellen Sein und der Mannigfaltigkeit der Erfahrungswelt auf den Gegensatz der Wahrheit und der bloßen Vorstellung zurückführt, während Herakleitos die Neigung der Urstofflehre, sich zur Substanzlehre zu entwickeln, bekämpft und in die Möglichkeit, alles zu werden, das Wesen des Urstoffes setzt. Sein und Werden fassen beide Forscher als einander absolut ausschließende Gegensätze. Das ist ihr gemeinsam( $r$ Ausgangspunkt. Aber Parmenides verflüchtigt, um dem Seienclen seine Einbeit, Ewigkeit und Unveränderlichkeit zu wahren, die Mannigfaltigkeit und di* Veränderungen in der Erfahrungswelt zu bloßem Schein; Herakleitos dagegen kennt kein dauerbares Sein, das allem Wechsel zugrunde liegt, sondern macht das ewige Werden selbst zum Prinzip. Das Streben, zwischen diesen (xtremen und in ihrer paradoxen Linseitigkeit unbefriedigenden Lehren zu vermitteln, ist den drei Hauptphilosophen der nächsten Generation, Empedoliles, Anaxa- 
goras und Leukippos, gemeinsam und bildet auch einen der Ausgangspunkte der platonischen Metaphysik.

2. Parmenides (nm 500).

Parmenides aus Elea, der seiner Vaterstadt Gesetze gegeben hat, stand um die Wende des 6. und 5. Jahrhunderts in reifem Mannesalter. Die Einkleidung des platonischen Dialogs Parmenides, die ihn mit dem jungen Sokrates in persönliche Berührung bringt, ist ein Anachronismus.' Parmenides hatte außer Xenophanes den Pythagoreer Ameinias zum Lehrer gehabt. Er wird geradezu als Pythagoreer bezeichnet, und der pythagoreische Einfluß ist in seiner Lehre unverkennbar. Doch betrifft dieser Einfluß nur seine Kosmologie, die er als bloße menschliche Vorstellung angesehen wissen wollte, nicht den streng wissenschaftlichen Teil seiner Lehre, in dem er dem Xenophanes folgte. Wie dieser hat er im Versmaß des Epos sein Lehrgedicht verfaßt. Im ersten Teil, der "Wahrheit", weist er nach, daß das „Seiende" notwendig als ungeworden, unvergänglich, unveränderlich, unteilbar, unbeweglich gedacht werden müsse, weil die diesen entgegengesetzten Prädikate alle ein Nichtsein in das Seiende hineintragen und ihm daher nicht ohne logischen Widerspruch beigelegt werden können. Wenn Parmenides gegen die Philosophen polemisiert, welche auch dem Nichtseienden in gewissem Sinne Sein zuschreiben und das Seiende aus Sein und Nichtsein entstehen lassen, so meint er den Pythagoras und seinen Dualismus des Begrenzten und Unbegrenzten. Denn in diesem spielt das Unbegrenzte, durch dessen fortschreitende Begrenzung die Welt entsteht, die Rolle des Nichtseienden. Das "Seiende“ denkt sich Parmenides als ein geistiges Wesen. In ihm fallen Subjekt und Objekt des Denkens zusammen. Denn wenn es nur Subjekt oder nur Objekt des Denkens wäre, würde außer dem Seienden etwas existieren, was dem früher bewiesenen Satze von der Einheit und Unteilbarkeit des Seienden widersprechen würde. Ungeachtet dieser Geistigkeit denkt sich Parmenides das Seiende als räumlich ausgedehnt, voll (also materiell), begrenzt und kugelförmig. Daß ihm das Begrenzte als das Vollkommnere gegenüber dem Unbegrenzten erscheint, ist pythagoreisch. Die Kugelgestalt ist die vollkommenste wegen ihrer in allen Richtungen gleichen Ausdehnung. Indem Parmenides durch Abstraktion von einzelnen Eigenschaften der Körper den Begriff eines höheren geistigen Scins bildete, ist er gewissermaßen auf halbem Wege stehen geblieben, indem er ihm Ausdehnung und Raumerfüllung beließ. - Im zweiten Teil seines Lchrgedichts, der „Vorstellung“, ließ Parmenides auf die Ontologie des ersten Teils eine Kosmogonie und Kosmologie nach Art der ionischen Physiologen folgen. Überzeugt, daßj das vernünftige Denken zur All-einslehre führe und diese allein Wahrheit sei, wollte er doch nicht bestreiten, daß wir, sobald wir nicht von dem Begriff des Seienden ausgehen, notwendig zu einer anderen Weltansicht gelangen, und es erschien ihm der Mühe wert, auch diese mannigfaltige, bewegliche, veränderliche Scheinwelt auf ihre Prinzipien zurückzuführen. Tut man dies, so tritt, da die Welt der „Vorstellung““ von Gegensätzen beherrscht ist, an Stelle des Monisnus notwendig, nach seiner Meinung, eine dualistische Anschauung. Auf diesem Gebiete ist der pythagorcische: Dua- 
lismus berechtigt. An die Stelle der pythayoreischen Zweiheit „Begrenztes und Unbegrenztes" setzt unser Philosoph Feuer und Erde, aus denen er die Gegensätze des Warmen und Kalten, des Lichten und Dunkeln, des Leichten und Schweren, des Männlichen und Weiblichen usw. herleitet. Die ganze rechte Seite in dieser Tafel der Gegensätze sollte das wahrhaft Seiende, die ganze linke Seite das Nichtseiende vorstellen, durch dessen Hinzutreten sich die Welt der "Vorstellung" von der "Wahtheit" unterschiede. Die Einzelausführung dieses Weltbildes können wir hier nicht weiter verfolgen. Es kann einerseits zu Rückschlüssen auf das Weltbild des Pythagoras benutzt werden und zeigt andererseits Abhängigkeit von Anaximanaros. Erwähnt sei nur, daß sich Parmenides die im Mittelpunkt des Kosmos befindliche Erde kugelförmig denkt und kugelförmig auch den Kosmos selbst, der von der Feuersphäre außen wie von einer Mauer umgeben ist. In beidem dürfte ihm Pythagoras vorangegangen sein. Wichtig ist auch, daß bei der Weltbildung ein mythologisches Wesen, eine Göttin, eingeführt wurde, welche die Gegensätze vermittelte, die personifizierte Harmonie der Pythagoreer und die Vorläuferin der empedokleischen Philia.

Herakleitos von Ephesos ist ein genauer Zeitgenosse seines philoso- 2. Herakleitos phischen Antipoden Parmenides: auch er stand um das Jahr 500 im reifen Mannesalter und hat noch die beiden ersten Jahrzehnte des fünften Jahrhunderts erlebt. Bezugnahme des einen auf den anderen läßt sich nicht mit Sicherheit nachweisen. Er war nicht, wie seine milesischen Vorgänger, ein von deutlich umschriebenen Erfahrungstatsachen ausgehender und von ihnen zu einem anschaulichen Gesamtbilde der Welt und ihrer Entstehung fortschreitender Naturforscher, sondern ein spekulativer Philosoph, der seine intuitiv erfaßten Gedanken, unter Verzicht auf nüchternes Schließen und Beweisen, in der Form von Orakelsprüchen vortrug, die wegen ihrer Dunkelheit und schillernden Unbestimmtheit als Offenbarungen tiefster Weisheit gedeutet werden konnten und durch ihre grelle Paradoxie dem einen Leser unter, dem anderen über dem Niveau des gesunden Verstandes sich zu bewegen schienen. In dieser Form hat er nicht nur über Welt und Göttcr, sondern auch über das Menschenleben orakelt, ohne daß wir darin die Anfünge einer Wissenschaft von den menschlichen Dingen erblicken clürften. Die aus seiner Schrift erhaltenen wörtlichen Zitate, bei Diels I 26 meist ganz kurze Sätzchen, erlauben uns nicht, den Gedankengang zu rekonstruieren. Wir müssen uns hier darauf beschränken, diejenigen Gedanken hervorzuheben, die als Fort-

ldung der älteren ocler als Vorstufe der späteren Naturphilosophie Bedeutung haben.

Wenn Herakleitos das Feuer als Urstoff.nennt, wie Anaximenes die Luft, so hat doch diese J.ehre bei ihm einen wesentlich anderen Sinn. Man kann nicht sagen, daß er das Feuer als die Substanz ansieht, die in allem IVechsel erhalten bleibt. Es hat nur insofern einen Vorrang vor den übrigen Stoffen, als es am Anfang und am Ende der Entwickelung steht. Aus clem uranfänglichen Feuerball bildet sich die Welt; in ihn löst sie sich wieder auf; und 
dieser Vorgang wiederholt sich gesetzmäßig, nach einem bestimmten Zeitraum (dem großen Jahr) von Ewigkeit zu Ewigkeit. Aber in den Verwandlungsstufen, die das Feuer bei dem „Weg nach unten“ und dem „Weg nach oben" durchläuft, bleibt von seiner Eigentümlichkeit nichts erhalten als die ewige Lebendigkeit und Veränđerlichkeit, vermöge deren es alle Gegensätze aus sich hervorbringt. Um ihretwillen hat also unser Philosoph das Feuer als Urstoff gewäh1t, sie als das Wesen der Welt und ihres Urgrundes betrachtet. Insofern läuft seine Urstofflehre auf die Leugnung dır Substanz hinaus. Der Urstoff hat keine andere bleibende Bestimmung als das Gesetz (Logos), das sein Werden und seinen Wandel bestimmt. Seine Lebendigkeit ist eine absolute. Er kennt keinen Stillstand und kein Beharren. Sein Schaffen ist Zerstören und sein Zerstören Schaffen. Darum gibt es in der ganzen Welt kein beharrendes Sein, wenn auch unsere Sinne uns eines vortäuschen, sondern nur einen ewigen Strom des Werdens. Den Werdeprozeß denkt sich Herakleitos als ein Umschlagen ins Gegenteil. Jedes Ding, das sich verändert, zeigt entgegengesetzte Eigenschaften aufeinanderfolgend: das Warme wird kalt, das Trockene feucht, das Lebendige tot usw. Aber nicht nur nacheinander, sondern auch miteinander in demselben Augenblick treten an den Dingen entgegengesetzte Eigenschaften hervor. Wenn sich die Dinge unaufhörlich verändern und die Veränderung als ein Umschlagen ins Gegenteil aufgefaßt wird, so folgt, daß jeder momentane Zustand eines Dinges ein Übergangszustand

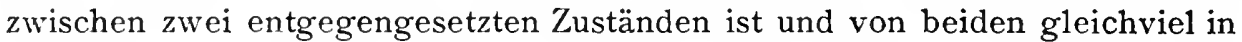
sich trägt. So ist z. B. ein Ding warm und kalt zugleich, warm als Gegensatz eines Kalten, aus dem es geworden, kalt als Gegensatz eines noch Wärmeren, zu dem es wird. So wird als Koëxistenz der Gegensätze aufgefaßt die Relativität der einer graduellen Steigerung fähigen Eigenschaften. Unter demselben Gesichtspunkt hat aber Herakleitos auch die gegensätzlichen Beziehungen eines Dinges zu verschiedenen Dingen außer ihm begriffen. Auch wenn dieselbe Speise dem einen Lebewesen heilsam ist, dem andern verderblich, findet er darin eine Koëxistenz von Gegensätzen. Die Folge und die Koëxistenz der Gegensätze benutzt er gleichermaßen, um zu beweisen, daß es kein beharrendes qualitativ bestimmtes Sein gibt. Alles Werden in der Natur besteht in einem Hervortreten von Gegensätzen aus der unterschiedslosen Einheit und ihrer Wiederauflösung in diese Einheit. Diese Gegensätze bedingen sich gegenseitig. Erst durch Widerstreit wird Harmonie, durch Kampf und Krieg Friede möglich. Der Krieg ist der Vater aller Dinge. Das Menschengeschlecht muß sich, um fortzuleben, in die Gegensätze des Männlichen und Weiblichen spalten, durch deren Vereinigung die Fortpflanzung: erfolgt. In der Musik kann nur durch den Gegensatz der hohen und tiefen Töne eine Harmonie hervorgebracht werden. In den Gegensätzen von Tag und Nacht, von Sommer und Winter bewegt sich der Verlauf der Zeit. So beruht auch das sittliche Leben der Menschen auf dem Gegensatz des Gerechten und Ungerechten, des Guten und Bösen. Vom Standpunkt des Ganzen ist auch das Ungerechte und Böse notwendig, ohne daß es ein Gerechtes und Gutes 
nicht gäbe. Dadurch aber erhält sich das Leben, daß es diese Gegensätze erzeugt, auszugleichen strebt und wieder neu erzeugt. Daß diese Lehre von der Harmonie nicht ohne Einfluß des Pythagoras entstanden ist, liegt auf der Hand. Aber tiefer als der Pythagoreismus begründet Herakleitos die Einheit, zu der im Leben des Kosmos alle Gegensätze zusammenwirken, aus der dem einheitlichen Urgrunde innewohnenden vernünftigen Gesetzmäßigkeit. Alles Geschehen im Kosmos ist nicht allein notwendig, weil es an unabänderliche Gesetze gebunden ist, sondern auch vernünftig und zweckmäßig, wenn es im Zusammenhang des geordneten Ganzen (Kosmos) betrachtet wird. Denn das innere Wesen des Urgrundes, der zugleich Stoff und Bewegungsursache der Welt darstellt, ist vernünftig.

Die Bedeutung der Lehre des Herakleitos liegt in diesen allgemeinen Ideen, nicht in seiner Erklärung der einzelnen Naturvorgänge. Wir brauchen daher nicht bei seiner Kosmogonie zu verweilen, die uns unvollständig bekannt und an fruchtbaren Gedanken arm ist. Nur seiner Auffassung des Menschen und der menschlichen Seele müssen wir kurz gedenken. Der Mensch ist der Mikrokosmos. In ihm sind dieselben Stoffe wie im Kosmos vorhanden und derselbe Stoffwechsel. Als Seele trägt er einen Funken des göttlichen Feuers in sich, einen Absenker gewissermaßen der göttlichen Weltvernunft (des Logos), nicht als Flamme, sondern als trockenes warmes Pneuma, das durch die Ausdünstungen des Blutes genährt und in seiner Tätigkeit durch den (nur im Schlafe unterbrochenen) Zusammenhang mit der umgebenden Luft gefördert wird, d. h. durch Atmung und Sinneswahrnehmung. Daher ist die Seele im wachen Zustande zu vernünftigem Denken fähig, nicht aber im Schlaf. Herakleitos hat Fortdauer der Seele nach dem Tode, aber nicht ewige Fortdauer angenommen, die ja durch die Weltverbrennung, wenigstens im Sinne der individuellen Unsterblichkeit, ausgeschlossen ist. Das Los der Seelen im Jenseits machte er von ihrem Verhalten im Diesseits abhängig. Seine ethische Ansicht ruht auf dem Begriff des Gesetzes. Wie das Weltall von dem göttlichen Gesetze beherrscht wird und die Sonne nicht wagen darf, auch nur einen Schritt von ihrer Bahn abzuweichen, weil sonst die Erinyen, die Gehilfinnen der Dike, sie ereilen würden, wie auch unser Erkennen mit der allgemeinen Vernunft übereinstimmen muß und irrt, sobald es die Pfade subjektiver Willkür betritt, so ist auch für unser Handeln ein auf der allgemeinen Vernunft beruhendes Gesetz maßgebend.

III. Fortsetzung der drei Hauptrichtungen (5. Jahrhundert v. Chr.). In der folgenden Generation, um die Mitte des 5. Jahrhunderts, sehen wir die Philosophie an Verbreitung zunehmen und Athen als Führerin des nationalen Lebens auch in die philosophische Entwickelung eingreifen. Die eleatische Lehre und der Pythagoreismus werden durch namhafte Vertreter fortgeführt, ohne in ihren Grundgedanken modifiziert zu werden: jene durch Zenon und Melissos, diese vor allem duroh Philolaos. Ein ähnliches Verhältnis zur altionischen Physiologie haben Diogenes von Apollonia und Archelaos. Zugleich 
aber wird diese durch Anaxagoras, Empedokles, Leukippos, unter Benutzung der von den Eleaten und Pythagoreern gegebenen Anregungen, auf eine höhere Stufe gehoben in drei neuen Systemen, die ihre geschichtliche Zusammengehörigkeit und ihren Ursprung aus derselben philosophischen Situation auf den ersten Blick verraten. Endlich beginnt in diesem Zeitabschnitt, durch die sogenannte sophistische Bewegung, die Beschäftigung mit den Problemen des Menschenlebens. Durch sie und namentlich durch ihren bedeutendsten Vertreter, Sokrates, wird die Geisteswissenschaft als eine selbständige Disziplin neben die Naturphilosophie gestellt. Beide zu einer Wissenschaft zusammenzufassen haben erst Platon und Aristoteles versucht.

Vie jüngeren Eleaten:

Zenon von El (am 460 ).

Zenon von Elea, der Schüler des Parmenides, der um 460 in reifem ${ }_{2}$ Mannesalter stand, hat den im ersten Teil des parmenideischen Lehrgedichts enthaltenen direkten Beweis für die Einheit und Unbeweglichkeit des Seienden durch indirekte Beweise ergänzt, indem er zu zeigen versuchte, daß sich aus der Annahme, es gebe eine Vielheit von Dingen, und nicht minder aus der Annahme, es gebe eine räumliche Bewegung, absurde Folgerungen ergeben. Er hatte es nur auf eine Verteidigung der parmenideischen All-einslehre abgesehen; mit dem zweiten Teil des parmenideischen Gedichtes und seinem Verhältnis zum ersten scheint er sich nicht beschäftigt zu haben. Von den Beweisen gegen die Vielheit besagt der erste: Wenn die seienden Dinge eine Vielheit sind, so müssen sie unendlich klein und unendlich groß sein. A. Sie müssen unendlich klein sein. Denn jedes der vielen Dinge ist mit sich selbst identisch und eines. Ist es aber eines, so kann es keine Größe haben. Denn eine Größe hat (nach der gegnerischen Voraussetzung) Teile, ist also eine Vielheit. Sind aber die Einheiten, aus denen sich die Vielheit der Dinge aufbaut, ohne Größe, so ist es auch die Vielheit. B. Sie müssen unendlich groß sein. Denn jedes der vielen Dinge muß eine Größe haben. Hätte es nämlich keine Größe, so wäre es überhaupt nicht. Denn ein Ding, das eine vorhandene Größe weder hinzugefügt vermehrt, noch abgezogen vermindert, ist nicht. Wenn also die vielen Dinge sind, so müssen sie eine Größe und Dicke d. h. einen Abstand des einen Endes vom anderen haben. Und von dem Ende gilt wieder dasselbe: es muß eine Größe und Enden haben, und so fort in infinitum. Konklusion: Also, wenn die Dinge eine Vielheit sind, sind sie notwendig unendlich klein und unendlich groß. - Dieser Beweis will also zeigen, daß es unmöglich ist, die räumlichen Größen als Vielheiten, d. h. als Summen von Einheiten aufzufassen, weil Einheiten, die selbst der Größe entbehrten, durch ihre Summierung keine Größe ergäben, und Einheiten, die selbst schon eine Größe hätten, um nichts mehr und in keinem anderen Sinne Einheiten wären als die aus ihnen gebildeten Summen. Zenon will nämlich, mit Parmenides, nur das All als Einheit gelten lassen; die Einheit als Element der sinnlich anschaulichen Vielheit, durch dessen Wiederholung sie entsteht, gilt ihm als ein widerspruchsvoller Begriff. - Wie das erste Argument auf die räumliche Ausdehnung, so bezieht sich das zweite auf die Zahl der vielen Dinge. Es lautet: A. Wenn viele Dinge sind, so müssen es notwendig 
so viele sein, wie es sind, weder mehr noch weniger. Sind es aber so viele, wie es sind, so ist ihre Anzahl begrenzt (ein offenbarer Paralogismus, der sich durch nichts rechtfertigen 1äßt). B. Wenn viele Dinge sind, so sind sie an Zahl unendlich. Denn immer sind andere Dinge zwischen den Dingen und wiederum $z$ wischen jenen andere dazwischen. Also sind sie an Zahl unendlich. Der zweite Teil des Beweises beruht auf der Voraussetzung, daß, wo zwei unterscheidbare Dinge vorhanden sind, etwas zwischen ihnen sein muß, das sie scheidet. - Gegen den Einwand, daß außer dem All-einen zum mindesten noch ein Raum da sein müsse, in dem es sich befinde, scheint sich das Argument Zenons zu richten, daß, wenn alles Seiende im Raume ist und der Raum etwas ist, auch der Raum in einem Raume sein müßte - und so weiter in infinitum. Mit der Widerlegung der Vielheit der Dinge hat dieses Argument direkt nichts zu schaffen, so wenig wie das Gespräch mit Protagoras über das von dem fallenden Scheffel Korn und das von dem einzelnen fallenden Korn hervorgebrachte Geräusch. Wenn Zenon dem Protagoras beweist, daß auch das einzelne fallende Korn ein Geräusch hervorbringt, das zu dem Geräusch des fallenden Scheffels in demselben Verhältnis steht wie die Masse des Korns zu der Masse des Scheffels, so scheint sich dieser Nachweis eines nicht wahrnehmbaren Geräusches gegen den Sensualismus des Protagoras zu richten. Es ist das einzige der überlieferten Argumente, das nicht zu der Verteidigung der parmenideischen Ontologie gehört. Dagegen bilden unzweifelhaft einen Bestandteil dieser Verteidigung die Beweise gegen die Möglichkeit der Bewegung. Im ersten führt Zenon aus, daß die von dem bewegten Körper zu durchlaufende Strecke aufgefaßt werden müsse als eine unendliche Reihe von der Form $\frac{a}{2}+\frac{a}{4}+\frac{a}{8}+\frac{a}{16}$ usw., und daß es unmöglich sei, in begrenzter Zeit unendlich viele Strecken zu durchlaufen. Schon Aristoteles hat gezeigt, daß in diesem Argument quantitative und distributive Unendlichkeit miteinander vermischt werden, und daß die für die Bewegung verfügbare Zeit in demselben (distributiven) Simnc uncndlich ist wie die durchlaufene Strecke. Diesem Einwand scheint das dritte Argument zuvorzukommen, das vom "fliegenden Pfeil" benannt ist. Der Pfeil kann sich in jedem „jetzt" nur an einem Orte befinden. Was sich an einem Orte befindet, ruht. Da nun der Pfeil in allen ,jetzt“, d. h. in allen einzelnen Augenblicken der Flugzeit ruht, so ruht er während der ganzen Flugzeit. Dieser Beweis beruht auf der Auffassung des Raum- und des Zeitkontinuums als Summen diskreter Raum- beziehungsweise Zeitpunkte. - Um dieser und ähnlicher Beweise willen hat Aristoteles den Zenon Erfinder der Dialektik genannt. Sie haben über ihren nächsten Zweck hinaus fördernd gewirkt, indem sie auf Schwierigkeiten in den Begriffen der Einheit und Vielheit, des Raumes, der Zeit, der Bewegung hinwiesen, zu deren Überwindung eine nähere Untersuchung dieser Begriffe crforderlich war; wie auch die in Zenons Fußstapfen tretende eristische Dialektik der Sophisten zur Entstehung einer wissenschaftlichen Logik Veranlassung gegeben hat.

In Melissos von Samos, der als Nauarch im Jahre 44 I einen Seesieg 
über die Athener erfocht, begegnet uns ein Vertreter der eleatischen Lehre in Ionien. Wie Zenon knüpft er nur an die Ontologie des Parmenides an. Auch er ist Begriffsphilosoph, nicht Physiker. An der Einheit, Ewigkeit und Unveränderlichkeit des Seienden hält er fest. Aber während es Parmenides begrenzt und kugelförmig dachte, schreibt er ihm Unendlichkeit zu. Der Beweisgang ist uns im originalen Wortlaut erhalten. Aus der zeitlichen Ewigkeit wird auf die räumliche Unendlichkeit geschlossen, ein Schluß, den schon Aristoteles als untriftig tadelte. Aus der Unendlichkeit und Unbegrenztheit auf die Einheit. Denn wenn es nicht eines wäre, müßte es an ein anderes grenzen. Aus der Einheit auf die Geistigkeit und Unkörperlichkeit. Denn wenn es einen Leib hätte, wäre es nicht mehr eines. Ferner auf seine Gleichartigkeit, Unbewegtheit und Unveränderlichkeit. In der letzteren ist enthalten die Freiheit von Krankheit, Schmerz und Trauer, also die vollkommene Seligkeit des ewigen und unendlichen Geistes. Um die Unbewegtheit zu beweisen, bestreitet Melissos die Existenz des leeren Raumes. „Es gibt kein Leeres; denn das Leere ist ein Nichts; was aber ein Nichts ist, kann unmöglich sein." Daher kann sich das Seiende nicht bewegen. Denn da es kein Leeres gibt, hat es nicht, wohin es ausweichen könnte. Auch durch Verdichtung und Verdünnung des Seienden (nach Anaximenes) kann man die Bewegung nicht erklären. Denn das Dünne ist gegenüber dem Dicken ein weniger Volles; es steht dem Leeren näher. Da nun das Leere ein Nichtseiendes ist, so muß das Seiende absolut voll gedacht werden und kann keinem Bewegten Raum gewähren oder es in sich aufnehmen. In der Annahme, daß Bewegung nur durch den leeren Raum ermöglicht werde, zeigt sich bereits der Einfluß des Jeukippos (siehe unten). „Wenn es viele Dinge gäbe, so müßten sie so beschaffen sein, wie nach meiner Behauptung das Eine beschaffen ist." Nun zeigen aber, wie Melissos in engem Anschluß an Herakleitos ausführt, die vielen Dinge, die wir sin:lich wahrnehmen, alle jene Eigenschaften nicht, die als vernunftnotwendige Prädikate dem wahrhaft Seienden zugeschrieben werden müssen, sondern sind in unaufhörlicher Veränderung begriffen und schlagen in die entgegengesetzte Beschaffenheit um. Hieraus schließt Melissos, daß wir nicht richtig sehen und hören. Die sinnliche Wahrnehmung ist trügerisch. Denn sie zeigt uns kein wahrhaftes, dauerbares Sein. Es ist unverkennbar, daf die zuletzt wiedergegebenen Ausführungen des Melissos schon Platons Synthese des Heraklitismus mit der eleatischen Lehre vorbereiten.

2. Die jüngeren Pythagoreer: L. a. Philolao . um 450 !.

Wir konnten, als von Pythagoras die Rede war, wegen des Mangels einer genauen und zuverlässigen Überlieferung auf ihn nur die allgemeinen Grundgedanken des Pythagoreismus zurückführen; die Frage nach der Beschaffenheit seines Weltbildes mußten wir offen lassen. Im Laufe des 5. Jahrhunderts hat sich das pythagoreische Weltbild lurch die gemeinsame Arbeit vieler Forscher zu jener Form ausgestaltet, an welche Plato in seiner Kosmologie anknüpft und die wir durch aristotelische Zeugnisse als „Lehre der Pythagoreer", davon abgesehen hauptsächlich als Lehre des Philolaos kennen. 
Philolaos, der nach dem Untergang der pythagoreischen Gemeindeorganisation die bis dahin nur mündlich fortgepflanzte Lehre literarisch zu verbreiten begann, ist uns durch authentische Bruchstücke und doxographische Nachrichten am besten bekannt. Wir können hier nur die Grundzüge dieses Weltbildes, nicht die Abweichungen einzelner Pythagoreer berücksichtigen.

Die Zahlenlehre wird von den Pythagoreern auf die verschiedensten Gebiete der Natur und des Menschenlebens angewandt. Sogar sittliche Begriffe, z. B. die „Gerechtigkeit“, die „Freundschaft", sollen ihr Wesen in Zahlverhältnissen haben. Daher gewinnt jede einzelne Zahl vielfache Bedeutung, je nach dem Anwendungsgebiet. Wenn von der Bedeutung und den Kräften einer Zahl gehandelt wird, so wird sie durch alle Gebiete hindurch verfolgt. Auf die rein arithmetische folgt die planimetrische Anwendung, auf diese die stereometrische, auf diese wieder die physikalische. In der Musik, in der Medizin, in der Kosmologie, in der Psychologie bilden Zahlen das eigentliche Erikenntnisobjekt, sei es nun, daß die Dinge selbst Zahlen sind und aus Zahlen wie aus einem Stoffe bestehen, sei es daß sie Ebenbilder von Zahlen vorstellen. Die Zehn als die vollkommene Zahl vereinigt in sich alle Kräfte der Zahlen, und in gewissem Sinne gilt dies auch schon von der Vier (Tetraktys). Die Grundelemente der Zahlen sind Einheit und Vielheit. Dieser Gegensatz soll identisch sein mit dem der Grenze und des Unbegrenzten und in dem Unterschied der geraden und ungeraden Zahlen sich fortsetzen. Auf diesen Gegensatz werden aber auch alle realen Gegensätze in der Natur, wie Ruhe und Bewegung, Licht und Finsternis, Männliches und Weibliches, zurückgeführt. Aus dem Begrenzenden und dem Unbegrenzten lassen die Pythagoreer die Welt entstehen, wie die Physiologen aus stofflichen Prinzipien. Das Begrenzende spielt dabei die Rolle der Bewegungsursache, das Unbegrenzte die des Stoffes; schließlich mündet dieser Dualismus in den ethischen des Vollkommenen und Unvollkommenen, des Guten und Bösen aus. Als Prinzipium der Weltentstehung muß aber die begrenzende Einheit zugleich als ein materieller Körper gedacht werden. Sie wird bei Philolaos und seinen Schülern dem Feuer gleichgesetzt. Die physikalische Deutung des Unbegrenzten schwankt: halb ist es formlose Materie, halb leerer Raum. Vom Mittelpunkt aus nach allen Seiten fortschreitend zieht das schaffende Prinzip immer mehr Unbegrenztes in seine Wirkungssphäre, erhebt es durch Begrenzung zum wahrhaften Sein und schafft so den kugelförmigen Kosmos, den es schließlich auch von außen umgrenzt. Darum ist das Feuer im Kosmos als untere und obere Grenze rein vorhanden, im Mittelpunkt als Zentralfeuer, an der äußeren Oberfläche als umgrenzende Feuersphäre. Zwischen diesen Grenzen drehen sich zehn konzentrische Hohlkugeln; der Fixsternhimmel, die fünf Planetensphären, die Sphären der Sonne, des Mondes, der Erde und der Gegenerde. Letztere wurde nur der heiligen Zehnzahl zuliebe angenommen. Unsere Lirde umkreist das Zentralfeuer im Laufe eines Tages so, daß sie ihm stets dieselbe Seite zuwendet; daher erblicken wir, die wir die andere Seite bewohnen, nicht das Zentralfeuer selbst; sein Licht kommt uns nur durch die 
Sonne zu, die es wie ein Spiegel reflektiert. Die Sphären bringen durch ihre Bewegung Töne hervor, die, weil ihre Abstände vom Zentrum und ihre Geschwindigkeiten nach harmonischen Zahlenverhältnissen abgestuft sind, zu einer Harmonie zusammenklingen. Unsere Ohren freilich können diese Sphärenharmonie nicht vernehmen. Der arithmetisch-musikalische Gesichtspunkt, von dem die Spekulationen der Pythagoreer ausgingen, zeigt sich hier als der beherrschende Gesichtspunkt ihrer Kosmologie, ausgeprägt in einer sinnlich anschaulichen Phantasievorstellung.

3. Anaxagoras, Empedokles, I.cukippos: a) Anaxagoras vou Klazomenä (1.a $500-428)$.

Von den drei Denkern, die um die Mitte des 5. Jahrhunderts das Problem des Seins und Werdens von neuem angriffen, ist der älteste Anaxagoras von Klazomenä, der, um 500 geboren, seit 464 in Athen lebte und lehrte, 434 infolge eines Prozesses Athen verlassen mußte und 428 starb. Er will durch seine Philosophie zeigen, daß die von Herakleitos betonte Veränderlichkeit aller Gegenstände sinnlicher Erfahrung sich mit dem eleatischen Postulat eines unveränderlichen Seins ohne Widerspruch vereinigen läßt. Er gibt den Eleaten $z u$, daß, was ist, ewig und unvergänglich sein muß, nicht aber, daß die Annahme einer Vielheit seiender Dinge zu Widersprüchen führt. Er gibt auch Heraklit die Veränderlichkeit der sinnlichen Welt zu, meint sie aber ohne eigentlichen Qualitätswandel durch räumliche Bewegung erklären zu können. Alles scheinbare Entstehen und Vergehen beruht nur auf der Verbinclung und Trennung unveränderlicher Stoffteile. Das lehrten auch Leukippos und Empedokles. Dem Anaxagoras ist eigentümlich ein unbedingter Glaube an die Zuverlässigkeit der Sinneswahrnehmung, der ihn nötigt, alle irgendwo in der Erfahrung uns begegnenden sinnlichen Qualitäten als Eigenschaften der Substanz selbst aufzufassen. Durch die Trennung und Verbindung der Stoffteile können ihre Qualitäten nicht entstehen oder vergehen, sondern nur für unsere Wahrnehmung zum Vorschein kommen und verschwinden. Es müssen daher alle in der Erfahrung vorkommenden einfachen Stoffe Urstoffe sein. Die Frage, welche Stoffe Anaxagoras als einfache, d. h. gleichteilige ansah, welche als Gemenge, läßt sich mit unserem Material nicht erschöpfend beantworten. Wir sehen nur, daß er im Gegensatz zu cler empedokleischen Elementenlehre, die weiterhin in der antiken Naturwissenschaft herrschend wurde, Luft und Feuer und wohl auch Erde und Wasser als Gemenge ansah. Er war nicht bestrebt, die stoffliche Mannigfaltigkeit aus wenigen Grundformen abzuleiten, sondern setzte die Mannigfaltigkeit der Stoffe als ursprünglich. Aristoteles führt gerade organische Substanzen, wie Fleisch, Knochen, Mark, als Beispiele anaxagoreischer Urstoffe an. Anaxagoras war nämlich von der Beobachtung des Ernährungsprozesses bei Tieren und Pflanzen ausgegangen. Wenn Wasser und Brot dem Menschen genügen, um alle Bestandteile seines Leibes, wie Fleisch, Knochen, Haare, Nägel, Blut, hervorzubringen, so müssen alle diese Dinge schon in Wasser und Brot enthalten sein; bei der Ernährung findet eine Zersetzung und Vereinigung des Gleichartigen statt. Ebenso bei der Ernährung der Pllanzen. Von diesem Gedanken ausgehend, ist Anaxagoras zu der Vorstellung: 
einer ursprünglichen Mischung aller Stoffe vor dem Beginn der Weltbildung gekommen. Dieses Urgemenge sollte aus unendlich vielen und unendlich kleinen Teilen bestehen und so in gewissem Sinne eine einheitliche qualitätslose Materie, ähnlich dem Urstoffe Anaximanders, sein. Durch Ausscheidung aus ihm ließ er dann die Qualitätsgegensätze des Warmen und Kalten, Trockenen und Feuchten, Lichten und Dunkeln usw. entstehen. Die Vielheit der Substanzen, die Anaxagoras an den Anfang alles Werdens stellt, nähert sich somit einer Einheit, die nur potentiell eine Vielheit in sich enthält. Die Entmischung sollte aber keine vollständige und auch nach ihr noch alles in allem enthalten sein. Die in jedem Dinge überwiegenden Bestandteile bieten sich der Wahrnehmung dar und geben dem Dinge seinen Namen. Dieser Annahme glaubte Anaxagoras $z u$ bedürfen, um zu erklären, daß alles aus allem werden kann. Aus dem Feuer scheidet sich Luft aus, aus der Luft Wasser, aus dem Wasser Erde, aus der Erde Stein und aus dem Stein wieder Feuer. Es kann aber alles in allem enthalten sein, weil der Teilung des Stoffes keine Grenzen gesetzt sind und daher das Kleine ebenso wie das Große als eine unendliche Vielheit von Stoffteilen aufgefaßt werden kann. Den Einwand, daß die unendlich kleinen Teile nichts seien, weist er mit der Bemerkung zurück, daß durch Teilung des Seienden nie ein Nichtseiendes entstehen könne. - Von allèn sèinen Vorgängern unterscheidet sich Anaxagoras dadurch, daß er die Bewegung, die zur Weltentstehung führt, nicht als eine dem Stoffe selbst immanente ansieht, sondern als Wirkung einer vom Stoff verschiedenen Bewegungsursache, des Geistes. Der Geist ist das einzige Ding, das sich nicht mit anderen mischt, sondern für sich besteht, das feinste und reinste aller Dinge. Darum hat er über alle Dinge Macht und kann alle Dinge erkennen. Er gibt den Anstoß zu einer Rotation des Stoffes, die von einem Punkt ausgehend sich weiter und weiter fortpflanzt und durch Scheidung der Stoffe zur Weltbildung führt. Nach diesem Anlauf zu teleologischer Naturerklärung kehrte Anaxagoras sogleich zu der mechanischen Betrachtungsweise zurück. Von jenem ersten zweckmäßigen Anstoße abgesehen ließ er alle weiteren Entwickelungen aus natürlichen Ursachen entstehen und nahm nur noch, wo diese versagten, zu dem Geiste seine Zuflucht. Durch die als Folge der Rotation eintretende Scheidung der Stoffe, die zur Vereinigung des Gleichartigen führte, bildeten sich zunächst zwei große Stoffmassen, indem sich alles Dichte, Feuchte, Dunkle, Kalte, Schwere in der Mitte der Welt zusammenfand, alles Dünne, Trockene, Lichte, Warme, Leichte in den oberen, äußeren Regionen. Wir dürfen diese beiden Stoffmassen als ÄtherFeuer und Luft bezeichnen und auf ihre Verwandtschaft mit den Urstoffen der parmenideischen Kosmogonie hinweisen. Weiter bei dem Weltbilde des Anaxagoras und seinen Erklärungen einzelner Naturerscheinungen zu verweilen, müssen wir uns versagen, obgleich diese für die Geschichte der Naturwissenschaft von hohem Interesse sind.

Empedokles von Akragas, der einem der vornehmsten Geschlechter b, Empedokles seiner Heimatstadt entstammte, lebte nicht wie Anaxagoras als weltfremder $\begin{gathered}\text { von Akrakas } \\ \left(+\delta_{t}-t+4\right) \text {. }\end{gathered}$ 
Gelehrter, sondern griff als Staatsmann, Prophet, Wundertäter in das Leben seiner Mitbürger ein. Als Philosoph schafft er ein System, in dem die Einflüsse der drei vorsokratischen Hauptrichtungen, der ionischen Physiologie, der eleatischen Lehre und des Pythagoreismus, zusammenwirken. Durch seine Elementenlehre ist er Fortsetzer der ionischen Urstofflehre; Pythagoreer ist er nicht nur in seinen religiös-eschatologischen Ansichten, sondern auch zum Teil in seinem Weltbilde; aus der eleatischen Lehre hat er, wie vor ihm Anaxagoras, die Folgerung gezogen, daß es Entstehen und Vergehen im eigentlichen Sinne nicht geben kann, sondern nur Trennung und Verbindung unveränderlicher Stoffe. Er nimmt vier Elemente an, Feuer, Luft, Wasser und Erde, die selbst unveränderlich durch ihre in allen denkbaren Kombinationen und Maßverhältnissen erfolgende Mischung die Mannigfaltigkeit der empirischen Stoffe und Dinge hervorbringen. Diese Stoffe benennt er in seinem schwungvoll gtschriebenen Lehrgedicht oft mit Götternamen und redet oft von ihnen, als ob sie lebende Wesen wären; aber sie sollen doch nur Stoffe sein und den Antrieb zur Bewegung von außen empfangen. In der Annahme einer besonderen Bewegungsursache außer dem Stoff folgt Empedokles dem Anaxagoras. Er glaubt aber, da er zwei grundverschiedene Bewegungsarten des Stoffes annimmt, Trennung und Verbindung, auch zweier Ursachen zu bedürfen, die nicht wie der anaxagoreische „Geist" intellektueller Art sind, sondern strebende und begehrende Mächte: die Liebe und der Streit. Liebe nennt er die Tendenz, durch Verbindung verschiedener Elemente nach harmonischen Maßverhältnissen organische Wesen und damit Leben und Geist hervorzubringen; Streit ist die Tendenz, diese Verbindungen aufzulösen und die Elemente zu sondern. Selbstverständlich trennt die Liebe und verbindet der Streit die homogenen elementaren Massen. An dem Weltprozeß sind beide Faktoren in der Weise beteiligt, daß sie um die Herrschaft kämpfen und diese in regelmäßigem Wechsel von Ewigkeit zu Ewigkeit auch erlangen. In der Periode vollkommener Herrschaft der Liebe sind die Elemente so vollkommen durcheinandergemischt, daß nirgends qualitative Gegensätze hervortreten. Sie bilden eine Kugel (Sphairos), in der die Liebe und die vier Elemente sich vollständig durchdringen; nur der Streit befindet sich außerhalb. Diese Kugel können wir mit dem Urgemenge des Anaxagoras hinsichtlich der durch Mischung erzielten Ausgleichung aller Gegensätze, mit dem kugelförmigen Einen des Parmenides hinsichtlich der Form und Vollkommenheit vergleichen. Der göttliche Friede des vollkommensten Zustandes wird durch das Eindringen des Streites gestört, der die Gegensätze des Schweren und Leichten, Kalten und Warmen, Trockenen und Feuchten usw. zugleich mit der Sonderung der Elemente hervortreten läßt. Aus der Mischung scheidet sich zuerst die Luft aus und legt sich als äußerste Sphäre um die übrige Kugel herum. Ihre äußerste Schicht verhärtet sich zu einem festen Kristallgewölbe. Dann bricht auch das Feuer mit explosiver Gewalt aus der zurückgebliebenen Stoffmasse hervor und durchbricht die umgebende Luftschicht. Da aber das Kristallgewölbe seinem Aufwärtsstreber 
eine Grenze setzt, so verdrängt es die Luft aus der ganzen oberen Halbkugel: es entstehen zwei Hemisphären, eine lichte, feurige, der Tag, und eine aus dunkler Luft bestehende, die Nacht, die sich durch den Druck des Feuers um den Kern des Weltalls zu drehen beginnen. So erklärt sich der Wechsel von Tag und Nacht. Weiter scheidet sich dann auch das Wasser aus der Erde aus, so daß nun der Streit seinen Zweck erreicht hat und die elementaren Massen im wesentlichen gesondert sind. Kaum aber ist dieser Zustand erreicht, so setzt auch schon durch das Eingreifen der "Liebe" eine entgegengesetzte Entwickelung ein. Sie ist es, die zunächst im einzelnen, immer voln Streit gehemmt, die Stoffe wieder zu mischen und das vom Streit geschaffene Weltgerüst mit organischen Wesen, mit Pflanzen, Tieren und Menschen zu bevölkern beginnt und so die Erreichung ihres letzten Zieles, die Wiederherstellung des Sphairos, vorbereitet. Die Entstehung der organischen Wesen durch die Tätigkeit der Liebe ist es, in der die empedokleische Naturphilosophie gipfelt. In dem gegenwärtigen Weltzustande denkt er sich zwei Mächte, eine lebenschaffende und eine-lebensfeindliche, um die Herrschaft ringend. Jene ist das gute, göttliche, diese das böse Prinzip. Durch diese Annahme wird in die physikalische Lehre ein religiöses Moment hineingetragen; im übrigen steht die religiöse Doktrin (die Pythagoreische Seelenwanderungslehre) des Empedokles unverbunden neben seiner Physik. Der Welt der organischen Wesen hat Empedokles ein so eingehendes Studium zugewendet, daß man ihn den Begründer der biologischen Forschung bei den Griechen nennen darf. Auch die botanische und zoologische Wissenschaft konnte sich nur aus philosophischen Anfängen heraus entwickeln. Wir können hier nicht bei seinen interessanten botanischen Ansichten verweilen, nur seine Vorstellung von der Entstehung der Tiere und Menschen sei hier kurz berïhrt. Er denkt sich, daß es der schöpferischen Liebe nur allmählich und stufenweise gelingt, lebensfähige und fortpflanzungsfähige Organismen zu schaffen. Anfänglich wachsen nur einzelne Glieder aus dem Erdboden hervor, deren Vereinigung der Liebe nicht glückt. Besser schon gelingt ein zweiter Versuch, es werden mehrere Organe zu einem Leibe zusammengefügt. Aber es kommen seltsame Zwitterbildungen heraus, ähnlich den Fabelgestalt'n der V'olkssage, die sich nicht lebensfähig erweisen. Bei einem aritten Versuch entstehen lebensfähige Tiere und Menschen; aber sie entbehren noch der geschlechtlichen Fortpflanzungsfähigkeit, die erst auf der vierten Stufe erreicht wird. Der Grundgedanke dieser Zoogonie ist, daß die schaffende Naturkraft mur allmählich die ihr widerstrebende $\mathrm{Kraft}$ überwinden und ihre höchsten Gebilde zustande bringen kann. - Von großer Bedeutung für die Naturlehre des Empedokles ist seine Lehre von den Poren und Ausflussen der Dinge: in seiner Erklärung physikalischer sow ohl wie physiologischer Prozesse spielt sie die erste Rolle. Die Poren sind Öffnungen an der Oberfläche der Dinge, die in ihr Inneres hineinführen und, obgleich sic nicht als absolut leere Räume gedacht werden, anderen Stoffen das Eindringen gestatten. Hierdurcli wird die Stoffmischung: der Fundamentairorgang der empedokleischen Physik 
ermöglicht. Dadurch, daß sich von der Oberfläche der Dinge unaufhörlich Stoffteile ablösen und in die Poren anderer Dinge eindringen, erklärt sich jede Fernwirkung, z. B. die Attraktionskraft des Magnetsteins. Dieses Vorganges bedient sich sowohl der Streit, wenn er Gleiches zu Gleichem, wie die Liebe, wenn sie Verschiedenes zueinander bewegt. Aber nur wenn die Größe der heranströmenden Stoffteile zu der Größe der Poren in richtigem Verhältnis steht, kommt eine Wirkung zustande. So erklärt Empedokles nicht nur Ernährung und Wachstum der Organismen, sondern auch die Atmung und Sinneswahrnehmung. Während Parmenides alle Wahrnehmung als ein Leiden durch Berührung mit entgegengesetzten Stoffen auffaßt, lehrt Empedokles Wahrnehmung des Gleichen durch Gleiches. Die Lehre, daß die Sinneswahrnehmung durch Abflüsse (ảnóppolal) der Dinge vermittelt wird, die mit dem Sinnesorgan in direkte Berührung treten, haben die Atomisten und Epikur von Empedokles übernommen.

c) Leukippos (um 450) und Demokrito (geb. ca. 460 ).

Folgerichtiger als Anaxagoras und Empedokles hat Leukippos durch die atomistische Hypothese das Problem des Seins und Werdens gelöst und eine Anschauung begründet, die sich bis auf den heutigen Tag als brauchbare Grundlage der Naturwissenschaft bewährt, obgleich sie von Platon und Aristoteles nicht gebilligt wurde. Leukippos war Schüler des Zenon und Lehrer des Demokritos (geb. ca. 460), der sein System weiter ausbildete. Im folgenden werden die Unterscheidungslehren der beiden nicht berücksichtigt. Demo$\mathrm{kritos}$ hat angeblich über $100 \mathrm{Jahre}$, also noch weit ins 4. Jahrhundert hinein gelebt.

Das atomistische System nimmt wie Anaxagoras und Empedokles an, daß es Entstehen und Vergehen und Qualitätswandel im eigentlichen Sinne nicht gibt, sondern was uns so erscheint, auf Trennung und Verbindung oder auf Änclerungen der Lage und Ordnung an sich ewiger und unveränderlicher Stoffelemente beruht. Aber Leukippos, der Schüler Zenons, nähert seine Vorstellung des Stoffelementes mehr dem eleatischen Seinsbegriff. Es ist nicht nur ewig und unveränderlich, sondern auch eine unteilbare Einheit. Diese unteilbaren Stoffelemente (Atome) sind allerdings in unendlicher Menge vorhanden, und nie können zwei oder mehrere von ihnen zu einem werden, wie im empedokleischen Sphairos und im anaxagoreischen Urgemenge die Urstoffe zur Einheit verschmelzen. Sie bleiben immer eine Vielheit, auch wenn sie Konglomerate bilden. A ber die Vielheit ist nicht eine qualitative, da sich die Atome hinsichtlich der Beschaffenheit des Stoffes nicht voneinander unterscheiden. So wird die Vorstellung von der Substanz einheitlich gestaltet und dem wissenschaftlichen Vereinfachungsbedürfnis genügt. Um die Mannigfaltigkeit der sinnlichen Eigenschaften der Dinge zu erklären, genügt es, Unterschicde der Größe und Gestalt den Atomen zuzuschreiben. Diese sinnlichen Eigenschaften, z. B. rot, grün, süß, bitter, kommen nicht den Dingen selbst zu, sondern sincl subjektive Eindrücke, welche durch die als solche nicht wahrnehmbaren Gestalten und Lagerungsverhältnisse der Atome in unseren Sinnesorganen hervorgerufen werden, ein Schein also, der nach bestimmten 
Gesetzen aus einem Sein entsteht und uns richtig gedeutet dieses Sein enthüllt. Es ist damit der Unterschied primärer und sekundärer Eigenschaften der Körper in die Philosophie eingeführt. Die Atome sind alle so klein, daß sie sich unserer Wahrnehmung entziehen, aber nicht (wie die anaxagoreischen Urstoffe) unendlich klein; sie sind also unteilbar nicht im mathematischen, sondern im physikalischen Sinne. Sie sind unendlich der Zahl nach und haben alle überhaupt denkbaren Gestalten. Sie bewegen sich in einem ebenfalls unendlichen leeren Raume. Den leeren Raum stellen die Atomisten als zweites Urprinzip neben die Materie, als Nichtseiendes neben das Seiende, und verfechten in diesem Sinne den von Parmenides bekämpften Satz, daß auch das Nichtseiende in gewissem Sinne sei. Die Existenz eines leeren Raumes muß angenommen werden, um die Bewegung zu erklären. Denn im Vollen kann sich nichts bewegen. Alle zusammengesetzten Dinge enthalten leeren Raum. Daraus erklärt sich die Möglichkeit der Volumverminderung ohne Verminderung der Masse und der Unterschied des Dichten und Dünnen, von dem das spezifische Gewicht der Körper abhängt. Es gibt Eigenschaften der zusammengesetzten Dinge, die auf der Art ihrer Zusammensetzung beruhen und nicht, wie die Sinnesqualitäten, bloß subjektiv sind. Ein Qualitätswandel ohne Vermehrung oder Verminderung der Masse wird durch veränderte Ordnung oder Lagerung der Atome erklärt. Durch diese physikalischen Fundamentallehren wollte Leukippos die Tatsachen der Erfahrung mit dem Postulat eines substantiellen Seins in Einklang bringen und die hinsichtlich der Begriffe Einheit und Vielheit hervorgetretenen Schwierigkeiten heben.

Da sowohl der leere Raum als die Zahl der Atome unendlich sind, nehmen die Atomisten an, daß es unendlich viele Welten in allen Teilen des Raumes gibt, die entstehen und vergehen und wieder durch neu entstehende abgelöst werden. Die Entstehung eines Kosmos ist nicht às Werk eines Geistes, sondern ewiger Naturgesetze. Einer besonderen Bewegungsursache glaubt Demokritos nicht $z$ u bedürfen. Es genügt die Annahme, daß sich die Atome im leeren Raume von jeher unaufhörlich bewegen, soweit nicht ihre Bewegung durch andere Atome oder Atomkomplexe gehemmt wird. Diese Bewegung hat nichts mit der Schwerkraft zu tun; sie erfolgt auch nicht von oben nach unten, da es im unendlichen Raume kein Oben und Unten gibt, sondern ganz regellos, d. h. in allen Richtungen. Beschränken wir die Betrachtung auf ein einzelnes großes Stück des Raumes, so können wir uns vorstellen, daß in ihm vielfach Atome, die sich in verschiedener Richtung bewegen, zusammenstoßen und je nach ihrer Form entweder voneinander abprallen oder aneinander haften bleiben. Im letzteren Falle bildet sich ein Atomkomplex, der unter günstigen Bedingungen immer mehr anwächst und durch Stöße anderer Atomkomplexe in Rotation versetzt wird. Ist erst ein solcher rotierender kugelförmiger Kern vorhanden, so werden durch ihn immer weitere Atommassen in den Wirbel hineingezogen. Line solche kreisende Stoffmasse bildet schließlich auf ihrer Oberfläche cine Rinde, durch die sie gegen den Weltraum abgegrenzt und gegen weiterc Einwirkungen von außen geschützt wird. Innerhalb 
dieser Kugel werden durch die Wirbelbewegung die Atome gewissermaßen sortiert, so daß sich die ähnlich gearteten zueinander finden; und zwar bildet sich aus den größeren und vermöge ihrer Form schwerer beweglichen Atomen in der Mitte die Erde, aus den leichteren und beweglicheren die Wasser-, Luft- und Feuersphäre. Die letztere besteht aus den feinsten, kugelförmigen Atomen. So gelangt die atomistische Kosmologie von den ihr eigentümlichen Voraussetzungen aus zu dem Punkte, wo sie in die Bahnen der überlieferten Kosmologie einlenken kann, und wir brauchen sie auf diesem Wege nicht weiter zu verfolgen. Nur die Auffassung der menschlichen Seele bei den Atomistikern muß noch berührt werden. Daß sie sie als ein materielles Ding auffassen, ist selbstverständlich und unterscheidet sie nicht von ihren Vorgängern in der Philosophie. Denn der Begriff einer unkörperlichen und unausgedehnten Substanz war damals noch nicht gebildet. Selbst Melissos hat seinen Gott zwar unkörperlich, aber nicht ohne Ausdehnung gedacht. Auck das ist nicht neu, daß dieses stoffliche Seelenwesen von dem ar sich empfindungslosen Leibe unterschieden wird, ebensowenig die Gleichsetzung des Seelenstoffes mit dem Feuer, die sich auch bei Herakleitos findet. Neu ist nur, daß für die Atonistiker auch die Seele aus vielen Atomen besteht und ihre Einheitlichkeit einbüßt. Die Feueratome sind die feinsten, rundesten und glättesten und deshalb beweglichsten A tome. Mit ihren Bewegungen werden die ais Bewegungen aufgefaßten psychischen Vorgänge gleichgesetzt. Um die sinuliche Wahrnehmung zu erklären, nahmen die Atomistiker beim Sehen Ausflüsse der Dinge nach dem Vorgange des Empedokles an, die entweder direkt oder durch das Medium der Luft auf das Auge einwirken, bei den übrigen Sinneswahrnelmungen Eindringen der Atome in die Sinnesorgane.

B. Die attische Philosophie (5-4. Jahrhundert v. Chr.).

I. Sophistik und Sokratik (5.-4. Jahrhundert v. Chr.). Während in dem atomistischen System die ionische „Physiologie“ zu ihrer letzten und in gewissem Sinne abschließenden Form gelangte, erwuchs gleichzeitig im attischen Kulturk reise, aus eigener Wurzel und im Gegensatz zu ihr, eine Wissenschaft von den menschlichen Dingen. Sie wurzelte anfänglich in dem Bildungsund Erzichungsproblem. Im demokratischen Staate sollten nicht Geburt und Besitz, sondern nur Tüchtigkeit und geistige Überlegenheit zu hohen Ansprüchen berechtigen. Daß diese Vorzüge nicht lediglich auf natürlicher Begabung beruhen, sondern oft durch Unterricht in überraschender Weise gefördert werden, lehrte bald die Erfahrung. Daher traten jetzt in den meisten griechischen Städten, besonders aber in Athen, der geistigen Kapitale von Hellas, Lehrer der Weisheit und Tüchtigkeit (Sophisten) auf, die sich anheischig machten, ihre Schüler zugleich reden und denken zu lehren, und großen Zulauf fanden. Sie übten ihre Schüler im Disputieren und in zusammenhängender Recle teils über fingierte Einzelfälle, wie sie vor Gericht und in politischen Ratsversammlungen vorkommen konnten, teils auch über all- 
gemeinere Eragen des privaten und des staatlichen Lebens. Diese an sich dem Erziehungswesen angehörigen Bestrebungen hatten eine Bedeutung für die Philosophie nicht nur in formaler Hinsicht, sofern die Unentbehrlichkeit einer formalen Logik zur Auflösung des täuschenden Scheines ihrer Streitbeweise sich aufdrängen mußte, sondern auch materiell, weil die Probleme des Menschenlebens zum erstenmal einer rationellen, mit Beweisen und Schlüssen operierenden Untersuchung unterzogen wurden. Eine $\mathrm{W}$ issenschaft vom Menschenleben wurde dadurch noch nicht geschaffen, weil es noch an einer wissenschaftlichen Methode gebrach, und weil gerade die philosophisch bedeutendsten Sophisten, Gorgias und Protagoras, dem Skeptizismus huldigten und eine allgemeingültige Erkenntnis wie überhaupt, so auch von den menschlichen Dingen für unmöglich hielten. Gorgias, an die Eristik Zenons des Eleaten anknüpfend, lehrte und bewies, daß ein Seiendes nicht vorhanden, und wenn vorhanden, schlechthin unerkennbar, und wenn erkennbar, so doch jedenfalls unmitteilbar sei. Ob diese Erörterung ernst gemeint war oder nur die Virtuosität des Sophisten im Argumentieren an einer besonders paradoxen Behauptung zur Schau stellen sollte, läßt sich schwer entscheiden.

Protagoras von Abdera war der erste griechische Philosoph, der das erkenntnistheoretische Problem eingehender untersuchte. Er leitete alle Err. Protagoras von Abdera kenntnis aus der Sinneswahrnehmung her. Diese faßte er auf als eine uns zum Bewußtsein kommende Veränderung in dem stofflichen Sinnesorgan, die durch Berührung mit einem stofflichen Ding hervorgerufen wird. Da er nun ferner als durch Herakleitos erwiesen annahm, daß sich alle stofflichen Dinge in einem beständigen Strom der Veränderung befinden, das wahrnehmende Organ nicht minder als der wahrgenommene Gegenstand, so ergab sich für ihn die Folgerung, daß zwar jede Sensation wahr ist, aber nur für das wahrnehmende Subjekt selbst und in dem Moment ihres Zustandekommens. Jede Sensation $\mathrm{mu} ß$ als wahr angenommen werden. Denn da alle auf dieselbe Weise zustande kommen, müßten, wenn eine, alle hinsichtlich ihrer Wahrheit bezweifelt werden, und es würde überhaupt kein Erkennen möglich sein. Aber die Sensation ist von zwei Seiten bedingt, durch den wahrgenommenen Gegenstand und durch das wahrnehmende Subjekt. Daher ist ihre Wahrheit nur eine relative. Sie gilt nur für dieses Subjekt. Wenn ein anderes Subjekt von demselben Gegenstand in demselben Augenblick eine entgegengesetzte Wahrnehmung empfängt, so ist diese ebenfalls wahr, aber auch nur für jenes andere Subjekt. Auch für ein und dasselbe Subjekt ist die Sensation nur wahr im Moment ihres Zustandekommens. Denn schon im nächstfolgenden Moment kann sie durch eingetretene Veränderung des Subjekts oder des Gegenstandes nicht mehr wahr sein. Der Stoff ist alles das, aber auch nur das, was an ihm erscheint und ins Bewußtsein tritt. Die Erscheinung ist das Seiende; was keinem Menschen erscheint, das ist auch nicht. „Der Mensch ist das Maß aller Dinge, des Seienden, daß es ist, und des Nichtseienden, daß es nicht ist.“ In diesem Satze kann, nach dem Zusammenhange der Lehre, unter dem Menschen, dessen Bewußtsein über Sein und Nichtsein maßgebend entscheidet, 
nur der einzelne Mensch verstanden werden. Ferner ist es unmöglich, unter "allen Dingen“ in diesem Satze nur die konkreten Gegenstände der Außenwelt $z u$ verstehen und dadurch die Geltung des Satzes auf Wahrnehmungsurteile einzuschränken. Vielmehr muß der Satz nicht minder auf das begriffliche Denken als auf die sinnliche Wahrnehmung bezogen werden, wenn auch Protagoras in erster Linie an letztere gedacht haben dürfte. Insofern nun diese Lehre für jedes sinnliche Wahrnehmen und denkende Erkennen ein objektives Korrelat in der Natur der Dinge als wirklich existierend annimmt, erscheint sie auf den ersten Blick als das gerade Gegenteil des Skeptizismus: als extremer Objektivismus. Insofern sie aber das Seiende mit dem irgendeinem Menschen Erscheinenden gleichsetzt und zu etwas nur in der Relation zu dem erkennenden Subjekt Gültigen macht, muß man sie als Relativismus und Subjektivismus bezeichnen. Es kann nach dieser Lehre zwar Wertunterschiede $z$ wischen verschiedenen Urteilen geben, insofern eines mehr als das andere das Glück des Urteilenden fördert, nicht aber den Unterschied zwischen allgemeingültiger Wahrheit und subjektivem Irrtum. Mit der Möglichkeit des Irrtums wird auch die Möglichkeit allgemeingültiger Wahrheit und Wissenschaft aufgehoben. Gibt es keinen Irrtum, so gibt es auch nicht widersprechende Urteile über denselben Gegenstand, von denen eines falsch sein muB, wenn das andere wahr ist. Dann aber gibt es auch kein Beweisen und kein Wider-

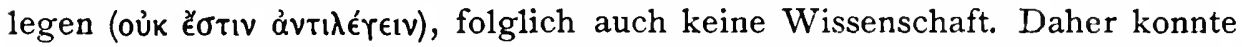
Protagoras ebensowenig wie Gorgias die Wissenschaft von den menschlichen Dingen begründen, welche das Bildungsbedürfnis der attischen Aufklärungsepoche forderte und suchte.

Diese Forderung wurde erst durch Sok rates erfüllt, der wie die übrigen Sophisten von dem Bildungsproblem ausging, aber, indem er es nicht skeptisch, wie Protagoras und Gorgias, im Sinne einer bloß formalen Bildung, sondern positiv-kritisch, im Sinne eines durch methodische Forschung zu gewinnenden Wissens von den Pflichten und Aufgaben des Menschen löste, der Begründer der Geisteswissenschaft bei den Griechen wurde. Die Abwendung von der Naturphilosophie und die Beschränkung auf die Ethik, die im Geiste der Zeit lag, wurde von ihm als Grundsatz aufgestellt und teils mit der Unmöglichkeit des Naturerkennens, die in der mangelnden Übereinstimmung der besten Forscher hervortrete, teils mit dem Hinweis begründet, daß die Erkenntnis, wie wir leben sollen, als die unentbehrlichste vor jeder anderen anzustreben sei. Die dialektische Methode, die Sokrates auf die ethischen Fragen anwendete, unterschied sich von der jungeleatischen und sophistischen Eristik, ihrer Vorläuferin, dadurch, daß sie nicht nur die Widerlegung des Gegners, sondern mit der Zerstörung des Scheinwissens zugleich die Gewinnung echten, allgemeingültigen Wissens bezweckte. Als Ausgangspunkt benutzt Sokrates stets die Meinungen seiner Mitunterredner. Diese prüft er hinsichtlich ihrer logischen Übereinstimmung mit anderen Urteilen, die von ihnen selbst als wahr zugestanden werden, und nötigt sie, die Meinungen als irrtümlich aufzugeben, die mit anderen von ihnen zugestandenen Wahrheiten 
im Widerspruch stehen. Er bedient sich dabei der Induktion (émarwrí), die in die Wissenschaft eingeführt $z u$ haben sein Verdienst ist. Aus vielen zugestandenen Einzelfällen erschließt er den übergeordneten allgemeinen Satz, um aus diesem wieder deduktiv (syllogistisch) den nicht zugestandenen Einzelsatz zu erschließen. Mit dem geschilderten Verfahren steht im engsten Zusammenhang sein Bestreben, das Wesen einer jeden Sache im Begriff zu erfassen und den Begriff in der Definition auszusprechen. Denn nur wenn die Begriffe eindeutig bestimmt sind, können die unter ihnen bestehenden Verhältnisse der logischen Unter- und Überordnung erkannt werden, auf denen Induktion und Deduktion beruhen.

Dieses dialektische Verfahren hat Sokrates benutzt, um ein Wissen von den moralischen Wertbegriffen und damit von den Pflichten und der Aufgabe des Menschen zu gewinnen. Er war nämlich fest überzeugt, daß dieses Wissen genüge, um die Menschen zum richtigen Handeln zu bestimmen. Es erschien ihm selbstverständlich, daß ein Mensch nur aus Unkenntnis des Guten, also unfreiwillig das Schlechte tun könne. Voraussetzung dieser Ansicht ist einerseits die durch die Sprache gegebene Gleichung „gut"=,nützlich“, andererseits eine optimistische Auffassung des menschlichen Wesens, die nur die Vernunft als dessen bezeichnendes Merkmal ansieht (Rationalismus). Genügt das Wissen, um ohne weiteres das richtige Handeln $z u$ erzeugen, so ist die Tugend selbst ein Wissen und lehrbar; und weil (da Wahrheiten einander nicht widersprechen können) alles Wissen eine Einheit bildet, ist auch die Tugend einheitlich. Um dies im einzelnen nachzuweisen, führte Sokrates die volkstümlichen Tugendbegriffe, Einsicht, Besonnenheit, Mäßigkeit, Tapferkeit, Gerechtigkeit, auf ein Wissen zurück. Das notwendigste Stück dieses Wissens ist die Selbsterkenntnis. Ohne sie kann man auch von anderen Dingen keine Einsicht gewinnen. Aus der Selbsterkenntnis ergibt sich die Besonnenheit. Die Mäßigkeit entspringt aus dem Wissen um das Gute. Denn wer dieses hat, wird nicht mehr das Angenehme mit dem Guten verwechseln und dadurch unmäßig werden. Auf die Bedürfnislosigkeit gegenüber den äußeren Dingen legte Sokrates praktisch und theoretisch großes Gewicht. Nichts zu bedürfen, bleibt Gott vorbehalten; so wenig als möglich zu bedürfen, heißt ihm ähnlich werden. Die Gerechtigkeit scheint Sokrates zwar der Gesetzlichkeit gleichgesetzt, letztere aber nicht auf die staatlichen Gesetze eingeschränkt, sondern auf die ungeschriebenen Gesetze, die bei allen Menschen gelten, ausgedehnt $\mathrm{zu}$ haben.

Unter den Schülern des Sokrates hat zunächst nur einer, Platon, die volle Tragweite der von ihm ausgegangenen Erneuerung der Philosophie erkannt und mit seiner Methode arbeitend, an seinen Hauptlehren festhaltend ein die ganze Philosophie umfassendes System zu schaffen versucht. Die übrigen, unter denen Antisthenes, Aristippos und Eukleides die bedeutendsten sind, haben die sokratischen Lehren teils einseitig oder unvollständig aufgefaßt, teils nicht in wahrhaft wissenschaftlichem Geiste fortzuentwickeln verstanden und unterscheiden sich wenig von dem Typus der Sophisten aus 
der älteren Generation. Der Hauptstrom der wissenschaftlichen Entwickelung im 4. Jahrhundert geht daher von Sokrates über Platon zu Aristoteles. Doch hat der von Antisthenes begründete Kynismus gegen Ende des Jahrhunderts seine sophistische Einseitigkeit abgestreift und ein neues großes System, das stoische, aus sich erzeugt. Die von Aristippos begründete kyrenaische Sekte und die megarische des Eukleides, die in ihrer einseitigen Auffassung von der Aufgabe der Philosophie verharrten, haben zwar auch bis ins 3. Jahrhundert hinein fortbestanden, auf die Gesamtentwickelung aber keinen nennenswerten Einfluß ausgeübt.

Aristippos von Kyrene ist nur darin Sokratiker, daß er, der praktischen Philosophie ausschließlich zugewandt und die Naturphilosophie als selbständigen Forschungszweig ablehnend, eine prinzipielle Begründung der Ethik zu geben versucht. Wenn er aber diese Begründung im hedonistischen Sinne gibt, so haben die echten Sokratiker dies mit Recht als einen Abfall von Sokrates beurteilt. Abzuweisen ist die Auffassung, als hätte sich die solsratische Lehre ohne Bruch auch zum Hedonismus weiterbilden lassen. Schon in seiner Erkenntnistheorie folgt Aristippos dem protagoreischen Sensualismus und Subjektivismus, nicht der sokratischen Begriffsdialektik. Wir nehmen nicht die Dinge selbst wahr, sondern nur unsere durch sie hervorgerufenen Affektionen $(\pi \alpha \dot{\theta} \eta)$. Daß ein Gegenstand weiß oder süß ist, können wir nicht behaupten, sondern nur daß wir von ihm die Weißempfindung oder die Süßempfindung empfangen. Diese Empfindungen sind ein Sonderbesitz des einzelnen, nicht ein gemeinsamer Besitz mehrerer Personen, wiewohl alle Menschen ihre Empfindungen mit denselben Worten benennen. Es führt daher von diesen im Subjekt eingeschlossenen Empfindungen kein Weg zu gemeinsamen, für alle Menschen gültigen Begriffen. Die für die praktische Philosophie grundlegenden Empfindungen sind Lust und Schmerz. Wie alle übrigen Lebewesen strebt der Mensch von Natur und vom ersten Atemzuge an nach Lust und sträubt sich gegen den Schmerz. Diese im Innern der Seele, nicht in den Sinnesorganen entstehenden Empfindungen sind es, auf die sich alles zweckmäßige Handeln bezieht. Die Aneignung der Lust ist unser letzter wie unser erster Zweck. Physiologisch ist die Lust eine glatte, der Schmerz eine rauhe Bewegung der Seele. Zwischen beiden in der Mitte liegt ein neutraler Zustand völliger Ruhe, der einem Schlafe vergleichbar und für die Ethik bedeutungslos ist. Ziel des Wollens und Handelns ist die einzelne gegenwärtige Lustbewegung, nicht die Glückseligkeit, die wir uns als einen Inhegriff vieler Lustakte, auch vergangener und zukünftiger, denken. Wir begehren kcineswegs das einzelnc Lusterlebnis um dieser gedachten Glückseligkeit willen, sondern umgekehrt die Glückseligkeit wegen der einzelnen Lust. Denn nicht das Gedlachte, sondern das Empfundene ist das Wirkliche. Aus diesem Kernpunkt der aristippischen Lustlehre crgibt sich die praktische Vorschrift, für den Augenblick zu leben. Über Vergangenes sich zu grämen, ist Torheit. Denn das Vergangene ist nicht. Um Zukünftiges sich zu sorgen hilft nichts. Denn das Zukünftige ist ungewiß. Nur der gegenwärtige Augenblick 
ist unser. Ihn gilt es jedesmal zu ergreifen und sich in seinem Genuß nicht stören zu lassen. Die den jeweiligen Verhältnissen sich anschmiegende Versatilität, die Aristippos selbst in seinem Leben bewährie, war die Anwendung

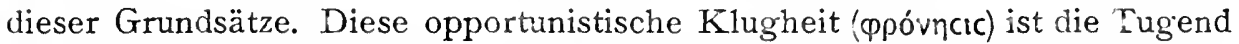
und als Mittel zum Zweck ein Gut. In ihr sind auch die übrigen Einzeltugenden der populären Moral enthalten. Gerecht oder ungerecht, rühmlich oder schimpflich ist keine Handlung an sich und von Natur, sondern nur durch Brauch und Satzung. Doch wird der Weise sich diesen Satzungen fügen, um Strafe und Unehre zu vermeiden. Die Tugend der Mäßigkeit besteht nicht darin, daß man der Lust entsagt, sondern darin, daß man im Genuß sie beherrscht und zum erwünschten Ziele führt. Auch die Stählung des Körpers ist unentbehrlich für den Lebenszweck und gehört zur Tugend.

Antisthenes von Athen war schon, als Schüler des Gorgias, ein namhafter Sophist und Rhetor, bevor er den Einfluß des Sokrates erfuhr. Arm und von geringer Geburt, fühlte er sich besonders durch die Bedürfnislosigkeit und Geringschätzung der äußeren Güter angezogen, die Sokrates empfah1 und in seinem Leben bewährte. Diese Seite des sokratischen Ideals einseitig betonend, schuf er eine praktische Lebensphilosophie, nicht wie andere Sophisten für die Söhne der Reichen, sondern für die Armen und Geringen. Ihnen wollte er zeigen, daß sie ohne das verfeinerte Genußleben und die gelehrte Bildung der höheren Stände besser und zufriedener als die Reichen leben könnten. Während er so in seinem praktischen Ideal an Sokrates anknüpft, gipfelt seine Erkenntnislehre in, einer Bestreitung gerade des Kernpunktes der sokratischen Dialektik. Während Sokrates meint, daß nur im begrifflichen Denken ein Wissen erworben wird, und deshalb auf die Definition der Begriffe dringt, lehrt Antisthenes, daß ein einfaches reales Ding überhaupt nicht definiert, sondern nur benannt werden kann. Darum ist die Betrachtung der Namen das Fundament der Bildung. Die Definition legt, wie jedes andere Urteil, dem Subjekt Prädikate bei. Dadurch kann niemals das Wesen des Subjekts, sondern immer nur seine Beschaffenheit ausgedrückt werden. Die Prädikatsbegriffe drücken nicht, wie die eine Einzelexistenz bezeichnenden Namen, ein Reales (oủcí $\alpha$ ) aus, sondern bloß eine Bescháffenheit, d. h. eine im Gedanken erfaßte Ähnlichkeit eines Realen mit anderen. Daß nämlich diese Beschaffenheiten nicht reale Dinge sind, geht schon daraus hervor, daß wir einem Gegenstand viele Eigenschaften beilegen. Er kann aber unmöglich, sagt Antisthenes mit den Eleaten, eines zugleich und vieles sein. Hieraus folgt, daß nur las einzelne, sinnlich wahrnehmbare Ding real ist, die Begriffe bloße Gedankengebilde. - Diese nominalistische Logik und Ontologie machte es dem Antisthenes unmöglich, in der Weise des Sokrates seine Ethik wissenschaftlich zu begründen. Er leugnete auch ausdrücklich, daß zum Erwerb der Tugend viel Nachdenken und Lernen erforderlich sei. Auf Taten komme es an, nicht auf Worte. Durch Beispiel und Vorbild wollte er seinen Schülern Tugend beibringen. Unter der Tugencl, die er für das einzige wahre Gut und für allein ausreichend zum glückseligen Leben er- 
klärte, verstand er eine durch Übung (ắckncıc) erworbene Tüchtigkeit des Leibes und der Seele, vermöge deren der Mensch seine Bedürfnisse auf ein Minimum reduziert und dadurch die Unabhängigkeit von allem Äußeren, die innere Freiheit und Glückseligkeit erwirbt. Um diese sokratische Stärke zu erwerben, muß man Leib und Seele durch Übung stählen. Nicht nur geistige, sondern auch körperliche Arbeit und Mühe gehören zu einem gesunden Leben. Insofern ist die Mühe ( $\pi$ óvoc) ein Gut, die entnervende Lust ein Übel. Nie darf man die Lust sich zum Ziele setzen. Die im Gefolge der Mühe sich von selbst einstellende Lust ist naturgemäß und unschädlich, desgleichen die aus der Befriedigung wahrer Bedürfnisse fließende. Wie die Lust, so wird auch Reichtum, vornehme Geburt, Ruhm und Ehre von den Kynikern für wertlos erachtet. Unehre und üble Nachrede sind dem Menschen heilsam. Sie härten die Seele ab wie die körperliche Mühe den Leib. Nur der Tugendhafte ist wahrhaft wohlgeboren und wahrhaft reich. - Ganz im Sinne der sophistischen Aufklärung wirtschaftet Antisthenes mit den Begriffen Natur und Satzung. Die der Natur widersprechende Satzung und Konvention ist die Quelle alles Übels. Dieser an sich dehnbare Satz wird von Antisthenes und den Kynikern in radikal kulturfeindlichem Sinne angewendet. Ihre Kritik der bestehenden Staats- und Gesellschaftsordnung schüttet das Kind mit dem Bade aus. Ihr politisches Ideal ist dér Menschheitsstaat: eine Herde, ein Hirte. Das natürliche Recht ist ja überall und für alle Menschen dasselbe. Nur durch mannigfache Abweichungen von ihm entstehen die Unterschiede des positiven Rechts, durch welche jetzt die Menschheit in viele sich bekämpfende Völker und Staaten gespalten ist. In der praktischen Politik schwankten sie zwischen Anarchie und aufgeklärter Monarchie. Auch die monogamische Gesellschaftsordnung und das Familienleben erklärten sie für naturwidrig und wollten sie, hier wie sonst dem Vorbild der Tiere folgend, durch freie Liebe ersetzen. In der Religion hielten sie den Polytheismus der Volksreligion für bióße Konvention und nur den Monotheismus für naturgemäß.

5. Eukleides (gleichzeitig dem vorigen).

Die von Eukleides von Megara begründete Sekte der Megariker vertrat einen durch sokratische Anregungen modifizierten und nach der ethischen Seite hin ergänzten Eleatismus. Wenn Eukleides nicht der Sinneswahrnehmung, sondern allein dem begrifflichen Denken Glauben schenkt, so ist das sokratisch und parmenideisch zugleich. Mit Parmenides nimmt er die Einheit, Unteilbarkeit, Ewigkeit und Unveränderlichkeit des Seienden an. Sokratischer Einfluß hat bewirkt, daß er das Eine Seiende als das Gute bestimmt. Dieses werde mit vielen Namen genannt, bald Gott, bald Vernunft, bald Einsicht, bald mit den Namen anderer Tugenden. Wie nur ein Gutes in der Welt des wahren Seins, so gibt es auch praktisch für den Menschen nur eine Tugend, die mit verschiedenen Namen genannt wird. Mit dieser Lehre, die, dem Eukleides ausdrücklich zugeschrieben wird, ist die Annahme einer Mehrheit von Ideen, die man ihm auf Grund einer mißverstan-

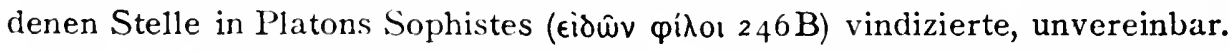
Wenn das Seiende das Gute ist, so muß auch umgekehrt das Gute die Eigen- 
schaften des wahrhaft Seienden im eleatischen Sinne haben. Die Tugend muB ein allem Leiden und aller Veränderung entrückter Zustand der Seele sein. Hierzu stimmt, daß ein jüngerer Megariker, Sti'pon, die Apathie und Autarkie als höchstes Gut aufstellte. Ähnliches wird also auch Eukleides gelehrt haben. Mit den Kynikern teilen die Megariker die Geringschätzung aller äußeren Güter; beide Sekten lehren die Autarkie der Tugend. Aber es begründet einen tiefgehenden Unterschied, daß die sinnlich wahrnehmbaren Dinge für den Kyniker das einzig Reale, für den Megariker nicht seiend sind. Dementsprechend mußte auch die Autarkie von den beiden Sekten ganz verschieden aufgefaßt werden. - Wie schon Zenon der Eleate hatten die Megariker über den positiven Teil ihrer Lehre nicht viel zu sagen. Wie jener, verwendeten sie ihren Scharfsinn hauptsächlich darauf, in der gewöhnlichen Weltauffassung, also in der Annahme einer Vielheit beweglicher und veränderlicher realer Substanzen Widersprüche nachzuweisen, wobei sie sich teils der alten zenonischen, teils neuer, ähnlicher Fangschlüsse bedienten. Deshalb werden sie als die Eristiker und Dialektiker $\kappa \alpha \tau^{\prime}$ ' $\xi \xi o x \eta ́ v$ bezeichnet. Stilpon berührt sich mit Antisthenes (siehe oben S. 125), wenn er die Berechtigung der Prädikation bestreitet. Doch tat er dies zu anderem Zweck und in anderem Zusammenhang. Auf Eubulides, einen erbitterten Feind des Aristoteles, werden verschiedene Trugschlüsse, wie der $\psi \epsilon u \delta o ́ \mu \epsilon v o c$, der cwpítnc u. a., zurückgeführt, auf deren Auflösung später die dogmatischen Logiker viel Tinte verschwendeten. Diodoros Kronos bewies, in Zenons Fußstapfen tretend, die Unmöglichkeit der Bewegung. Sein Beweis, daß nichts möglich sei außer dem, was wahr sei oder sein werde, und seine hiermit zusammenhängende Ansicht, daß alles, was geschieht, mit Notwendigkeit geschehe, lief darauf hinaus, den z. B. für die aristotelische Philosophie so wichtigen Begriff des potentiellen Seins aus der Welt zu schaffen, der, als ein unfaßbares Mittelding zwischen dem Seienden und dem Nichtseienden, das von den Megarikern geleugnete Werden begreiflich machen sollte.

II. P1aton $(427-347)$. Die geschilderten halb-sophistischen und einseitigen Richtungen bilden den Hintergrund, von dem sich die Gestalten des Platon und des Aristoteles, der maßgebenden und geschichtlich wirksamsten Philosophen des 4. Jahrhunderts abheben.

Tiefer als die übrigen Sokratiker hat Platon die sokratische Lehre und Forschungsmethode in ihrer Tragweite und Fruchtbarkeit verstanden und mit Sokrates von der wissenschaftlichen Betrachtung der menschlichen Dinge ausgehend eine nicht auf diese beschränkte, sondern die ganze Wirklichkeit umfassende Philosophie zu begründen versucht. Auch ihm sind, wie seinem Lehrer, die Probleme des Menschenlebens die wichtigsten. Er will das sittliche Bewußtsein des Volkes, das durch die skeptischen und subjektivistischen Theorien der Aufklärung schwankend geworden war, auf neue unerschütterliche Grundlagen stellen, indem er eine wissenschaftliche Ethik und Staatslehre begründet. Dabei glaubte er sich nicht auf Ethik und Politik beschrünken 
zu dürfen. Die Aufgabe des Menschen und des Staates ließ sich wissenschaftlich nur bestimmen, indem die Natur des Menschen und seine Stellung im Universum untersucht wurde. So mußte die Psychologie und die Ontologie in den Kreis der Betrachtung hineingezogen werden. In der Ontologie aber ließen sich keine gesicherten Ergebnisse gewinnen ohne Erkenntnislehre. Indem Platon so das philosophische Forschungsgebiet über die von Sokrates gezogenen Grenzen hinaus erweiterte, ergab es sich von selbst, daß er zu den Lehren der Vorsokratiker über die Welt, den Menschen und die Erkenntnis Stellung nehmen mußte. Was er nach dieser Richtung unternimmt, ist eine großartige Synthese aller bedeutenden Gedanken, die in der bisherigen Philosophie hervorgetreten waren. Er will aus der ganzen Entwickelung das Fazit ziehen und den Wahrheitsgehalt aller älteren Systeme in sein neues System aufnehmen. Die ionische Naturphilosophie in ihrer heraklitischen Form, die Seinslehre der Eleaten, die mathematische Spekulation und die Seelenlehre der Pythagoreer haben ihm wichtige Bausteine geliefert; aber alle diese Gedanken werden dem sokratischen Hauptgedanken der sittlichen Erkenntnis untergeordnet und durch die Strenge der sokratischen Methode auf eine höhere Stufe der Wissenschaftlichkeit gehoben.

Ideal des Wissens: Induktion und Deduktion.

Die dialektische Methode des Sokrates bildete den Ausgangspunkt für Platons erkenntnistheoretische Erwägungen. Aus ihr hatte er sein Ideal des Wissens geschöpft. Dem ganzen Verfahren des Sokrates lag die Überzeugung zugrunde, daß nicht das wahre Urteil als solches ein Wissen ist, sondern nur dasjenige wahre Urteil, das der Urteilende in allgemẹingültiger Weise zu begründen und gegen alle Einwürfe aufrechtzuerhalten vermag. Die ausschlieBlich auf ethische Fragen bezüglichen Untersuchungen des Sokrates pHegten, wie wir sahen, durch Induktion rom Einzelnen zum Allgemeinen aufzusteigen, um aus dem so gewonnenen Prinzip durch Deduktion die Beurteilung cles strittigen Einzelfalles abzuleiten. Die Tugendbegriffe der Gerechtigkeit, Besonnenheit, Tapferkeit und andere Wertbegriffe wurden (so reigte sich hierbei) von allen Mensehen angewendet; doch entstand bei ihrer Anwendung in einzelnen oft Schwanken und Unsicherheit, solange ihr Inhalt nicht durch Definition bestimmt war. Es war aber immer möglich, diese Unsicherheit zu heben, indem man zunächst den Begriff selbst, von seiner anderweitigen Verwendung ausgehend, klärte, um ihn dann wieder auf den zweifelhaften Lall anzuwenden. Bei diesem Verfahren bildete der allgemeine Begriff die (Zuelle des Wissens vom Einzelnen. Keineswegs aber konnten die bei der Aufsuchung des Begriffs verwendeten Einzelanwendungen desselben als seine Quelle angesehen werden. Denn diese setzten alle den Begriff als etwas Gegebenes voraus. Die Induktion diente nur als heuristische Methode, um einen in der Seele vorhandenen, aber nicht geklärten Begriff zu klären, während durch die Deduktion ein neues, absolut sicheres Wissen gewonnen wurde. So bildete sich Platon die Meinung, daß nur durch Deduktion ein Wissen gewonnen werde und die Möglichkeit des Wissens nur so weit wie die Mögliclikeit der Deduktion reiche. Es galt nun den Grund aufzufinden, warum 
nur im begrifflichen Denken ein Wissen gewonnen wird. Jene Wertbegriffe des Wahren, Guten, Schönen stammen nicht aus der Erfahrung, und doch tragen wir sie in uns und können uns an der Hand der Erfahrung ihres Inhalts bewußt werden, und sie bilden die Quelle für alle einzelnen richtigen Werturteile. Aus der Erfahrung können Wertbegriffe, wie die des Guten und Schönen, nicht stammen, weil sich in ihr nichts diesen Begriffer. genau Entsprechendes findet. Was wir in der empirischen Welt gut oder schön nennen, das ist immer am einen Orte gut oder schön, am anderen nicht, in einem Augenblick gut oder schön, im anderen nicht, in einer Beziehung gut oder schön, in anderer nicht usw. Daß wir etwas als relativ gut bezeichnen, ist nur dadurch möglich, daß wir den Begriff eines absolut Guten besitzen, den wir als Maßstab an die Erfahrung anlegen. Ferner, wenn diese Begriffe aus der Erfahrung abgeleitete Gedankengebilde wären, wie könnten sie normative Geltung besitzen, d. h. Forderungen für die Gestaltung der empirischen Wirklichkeit enthalten, deren Gültigkeit von der Frage ihrer tatsächlicher Erfüllung oder Nichterfüllung ganz unabhängig ist. Woher stammen also diese Begriffe, wenn sie weder als Abbilder empirischer Einzeldinge, noch als durch ihre Verarbeitung gewonnene Gedankengebilde aus der Erfahrung stammen? In ihnen offenbart sich uns, indem wir sie an der Hand der Erfahrung klären, eine vor aller sinnlichen Erfahrung vorhandene Erkenntnis, die für ein großes Gebiet des Erfahrbaren die Quelle des Wissens bildet. Diese Erkenntnis muß einen Gegenstand haben, und zwar als von der Sinneswahrnehmung verschiedene und höhere Erkenntnisweise einen von dem Gegenstand der Sinneswahrnehmung verschiedenen und höheren Gegenstand. Dieser Gegenstand ist das Schöne selbst, das Gute selbst usw. als allgemeine Form (€ỉoc). Diese als etwas Nichtreales zu betrachten, geht nach Platons Meinung nicht an, weil sie die Merkmale des wahren Seins (nach eleatischer Doktrin), nämlich Ewigkeit und Unveränderlichkeit, besitzt, was bei den in Raum und Zeit existierenden, sinnlich wahrnehmbaren Gegenständen, die der gewöhnlichen Auffassung als real gelten, nicht der Fall ist. So wahr das Denken, das ja allein ein Wissen ermöglicht, eine höhere Erkenntnisweise ist als die sinnliche Wahrnehmung, so wahr, meint Platon, müssen auch die Gegenstände des Denkens höhere und realere Gegenstände sein als die Gegenstände der sinnlichen Wahrnehmung.

Die ethischen und ästhetischen Wertbegriffe bilden, psychologisch und geschichtlich betrachtet, die erste und hauptsächlichste Wurzel, aus der dem Schüler des Sokrates der Gedanke der Realität und Apriorität der allgemeinen Formen erwuchs, aber nicht die einzige. Durch das Studium pythagoreischer Schriften, zu dem sich später persönlicher Verkehr mit den Pythagoreern gesellte, war Platon auf die Bedeutung der Mathematik für die Naturerkenntnis aufmerksam geworden. Wie auf dem ethischen Gebiet nur durch Anwendung der nichtempirischen Wertbegriffe, so wurde, wie es schien, auf dem Gebiet der Naturerkenntnis nur durch Anwendung der mathematischen Begriffe ein Wissen ermöglicht. Auch diese schienen nicht aus der 
Erfahrung ableitbar. Der mathematische Punkt, die gerade Linie, die Ebene und ähnliche geometrische Grundbegriffe bilden nicht in der sinnlichen Welt vorhandene Gegenstände ab, wohl aber ein Reales im geistigen Sinne; denn es ist ein Wissen von ihnen möglich, das vor aller sinnlichen Erfahrung und unabhängig von ihr gilt und für alles Wissen, das wir von Körpern gewinnen können, die Quelle ist. Hier öffnete sich also der Ausblick in ein zweites Gebiet realer, ewiger und unveränderlicher Formen, das zu dem von ihm geformten Teil der empirischen Welt in analogem Verhältnis stand wie die Wertbegriffe zu der moralischen Welt.

Apriorität der Kategorien.

Ein drittes Gebiet nichtempirischer Begriffe glaubte Platon in den allgemeinsten logischen Begriffen zu entdecken, die allem Denken und Urteilen zugrunde liegen, Begriffen wie die des Seins und Nichtseins, der Gleichheit und Ungleichheit, Selbigkeit und Verschiedenheit, der Größe und Kleinheit, Einheit und Vielheit. Wir haben nirgends bei Platon eine zusammenhängende Betrachtung, in der der nichtempirische Ursprung dieser Begriffe bewiesen wird, aber zahlreiche gelegentliche Bemerkungen zeigen uns, daß er auch diese Begriffe aus analogen Gründen wie die Wertbegriffe und die mathematischen Begriffe für unableitbar aus der sinnlichen Erfahrung gehalten hat. In der letzteren gibt es keine absolute Gleichheit, aus deren Wahrnehmung dieser Begriff stammen könnte. Zwei Dinge der Erfahrungswelt kann man nur mit Einschränkungen und beziehungsweise einander gleich nennen, indem man die bereits vorhandene Idee der absoluten Gleichheit als Maßstab anwendet. Auch Größe im absoluten Sinne kommt keinem Sinnendinge $z u$, sondern $a$ ist mit $b$ verglichen groß, mit $c$ verglichen klein. Ebenso klar schien es, auf Grund der eleatischen Untersuchungen über Einheit und Vielheit, daß kein sinnlich wahrnehmbares Ding weder dem einen noch dem anderen dieser Begriffe entspräche. Denn immer konnte ein und dasselbe Ding in einer Hinsicht als Einheit, in anderer als Vielheit aufgefaßt werden. Das Sein endlich, in der von Heraklit und Parmenides zugrunde gelegten, alles Werden und alle Veränderung ausschließenden Bedeutung, das absolute Sein, mußte ihm ebenfalls als ein nichtempirischer Begriff erscheinen, da die sinnliche Erfahrung kein derartiges Seiendes aufweist.

Ideenlebre. $\quad$ Aus diesen drei Wurzeln erwuchs Platons Ansicht von der Realität der Formen. Doch konnte diese, einmal konzipiert, nicht auf einzelne Begriffsklassen beschränkt werden. Wenn es im Wesen des Begriffs liegt, ein transzendentes Reales erkennend aufzufassen, so müssen für alle klaren Begriffe ohne Ausnahme reale Korrelate angenommen werden. Ist das Denken diejenige Erkenntniskraft, durch welche die Seele ohne störende Einmischung des Leibes mit dem Seienden in unmittelbare Berührung tritt, so gibt es ebensoviel reale Formen (Ideen), wie es klare Begriffe gibt. Es müssen Ideen von allen Dingen angenommen werden, und zwar streng genommen nicht nur von Naturdingen, sondern auch von Artefakten. Alle Art- und Gattungsbegriffe, die viele gleichnamige Einzelgegenstände unter sich befassen, drücken aus, was dieser Gegenstände ewige, unveränderliche Wesenhejt ist. Den 
Einzelgegenständen der sinnlichen Anschauung, die sich, wie Platon mit Herakleitos annimmt, in einem beständigen Fluß der Veränderung befinden, kommt keine wahre Wesenhaftigkeit, kein Sein im eleatischen Sinne zu. Von ihnen ist daher auch kein Wissen möglich. Denn das Wissen als jedem Wandel entzogene, unumstößliche Erkenntnis muß einen unwandelbaren Gegenstand haben. Soll daher überhaupt ein Wissen möglich sein, so muß es einen unwandelbaren Gegenstand geben. Dieser Gegenstand sind nach Platon die Ideen, die in den Art- und Gattungsbegriffen aufgefaßt werden. Jede Idee ist aber nicht nur ewig und unwandelbar, sondern auch einzig in ihrer Art, das Eine im Vielen. Platon will durch seine Ideenlehre auch das von früheren und gleichzeitigen Philosophen erörterte Problem lösen, wie es kommt, daß ein Ding vieles sein kann und viele Dinge ein und dasselbe. Die Tatsache, daß Ein Ding viele Eigenschaften hat, stellte sich für den Griechen aus sprachlichen Gründen in der Form dar, daß ein Ding vieles ist. Dies erschien als ein Widerspruch. Man war noch nicht darauf aufmerksam geworden, daß das Wörtchen „ist“, wo es als Kopula ein Eigenschaftswort mit dem Subjektswort verknüpft, eine andere Bedeutung hat als in den Sätzen, wo es Dasein oder Identität ausdrückt. Als ein analoger Widerspruch erschien es, daß viele Dinge durch gleiche Benennung als wesensgleich bezeichnet werden. Dieses Doppelproblem wird durch die Beschränkung der Realität auf die Formen, deren jede einheitlich und einzig in ihrer Art ist, gelöst. Die zwischen Einheit und Vielheit schwankende, in sich widerspruchsvolle Zwitternatur wird dadurch auf die sinnliche Erfahrungswelt beschränkt, der die volle Realität abgesprochen wird.

Die Gesamtheit der realen Formen erscheint, nach dieser Auffassung, als eine in sich abgeschlossene Welt geistiger Objekte, die neben der sinnlichen Welt besteht und den Inbegriff des wahren Seins ausmacht. Von dem Einen Seienden der eleatisch-megarischen Lehre unterscheidet sich diese intelligible Welt, insofern sie eine Mannigfaltigkeit von Formen enthält. Doch sollte sie sich, ungeachtet dieser Mannigfaltigkeit, zu einer Einheit zusammenschließen. Denn die Ideen stehen untereinander in Gemeinschaft. Jedes Urteil ist ja der Ausdruck einer Beziehung zwischen zwei Ideen. Jede Idee enthält neben dem Sein auch Nichtsein. Denn sie ist von allen übrigen verschieden. Die Verschiedenheit aber ist das Nichtsein des anderen. Durch diese Beimischung des Nichtseins wird das Sein als eine Mannigfaltigkeit von Wesenheiten erst möglich. Ist die Verschiedenheit zwischen zwei Ideen eine absolute, so haben sie keine Gemeinschaft miteinander und können sich nicht $z u$ einem wahren Urteil verbinden. Ist dagegen die Verschiedenheit nur eine relative, so stehen sie in Gemeinschaft, sei es als Art und Gattung (logische Über- und Unterordnung), sei es als Wesens- und Eigenschaftsbegriff. Gewisse allgemeinste Gattungsbegriffe, wie Sein und Nichtsein, Selbigkeit und Verschiedenheit, Einheit und Vielheit, Ruhe und Bewegung, ziehen sich durch alle anderen hindurch und lassen sich mit allen verbinden. Dieses mannigfaltige System in seinem Aufbau und seiner Gliederung darzustellen, ist die Aufgabe der

System der Ideen (Dialektik). 
Sinnliche Welt, ihr V'erhältnis zu den Ideen.

Philosophie. Ihre Methode ist die Dialektik, die durch Begriffsbestimmungen und Einteilungen alle unter den Ideen bestehenden Beziehungen aufsucht. Aus dieser Auffassung des Intelligiblen, insofern sie von der eleatischmegarischen abweicht, ergibt sich als Korrelat eine ebenso stark abweichende der sinnlichen Erfahrungswelt. Für Platon ist diese nicht, wie für die Eleaten, der absolute Gegensatz der intelligiblen undi als solcher etwas Nichtwirkliches, sondern eine Mittelwelt, die zwischen dem Wirklichen und dem Nichtwirklichen, dem Wesenhaften und dem Wesenlosen in der Mitte stehend an beiden Anteil hat, eine Wirklichkeit niederer Ordnung. Genauer das Verhältnis zwischen der sinnlichen und der intelligiblen Welt zu bestimmen, hat Platon nicht vermocht. Er bedient sich für dieses Verhältnis nur bildlicher Ausdrücke. Die Idee wohnt den vielen nach ihr benannten Dingen bei (Parusie), jene nehmen an ihr teil (Methexis). Wie es denkbar sei, daß die in sich ruhende, einheitliche Idee, ohne sich von sich selbst zu entfernen und ohne sich zu zerteilen, vielen Dingen beiwohne, vermag er nicht zu erklären. Wo der Gesichtspunkt des Wertes vorwaltet, und die Ideen nicht nur als das Realere, sondern auch als das Vollkommenere den Dingen der gemeinen Wirklichkeit gegenübergestellt werden, da greift ein anderes Bild Platz, da sind die Ideen Vor- und Musterbilder (Paradigmen), die Sinnendinge unvollkommene Nachahmungen und Abbilder.

Soll die Ideenwelt ein einheitliches System bilden, so daß Sein und Nichtsein, Eines und Vieles sich zu einer mannigfaltig gegliederten Einheit harmonisch zusammenschließen, so muß sie in Einer obersten und allgemeinsten Idee gipfeln. Diese ist nicht die Idee des Seins, denn diese fordert das Nichtsein als ihr Korrelat; auch nicht die der Einheit, denn auch diese bedarf eines Korrelats, der Vielheit. Und noch ein anderer Gegensatz in der Welt des wahren Seins bedarf der Ausgleichung. Das Seiende als Objekt ist die Wahrheit, das Seiende als Subjekt die Erkenntnis. Über diesen muß ein Subjekt-Objekt stehen, das dem Erkannten Wahrleit und dem Erkennenden Wissen verleiht, weil es selbst über diesen Gegensatz erhaben ist. Erkennendes und Erkanntes sind sich korrelat. Wie wäre dies möglich, wenn sie nicht aus einer obersten Quelle flössen? Welche Idee ist es, die alle diese Gegensätze überbrückend die oberste einheitliche Spitze der Ideenpyramide bildet? Rein logiseh könnte als umfangreichster Gattungsbegriff nur der inhaltloseste, das 'Etwas', betrachtet werden. Von der obersten Idee in diesem Sinne spricht Platon nicht. Da aber die Ideen nicht nur Gattungsbegriffe, sondern auch Vorbilder und Ideale sein sollen, die der Werdeprozeß in der sinnlichen Welt zu verwirklichen und nachzubilden strebt, so ergibt sich als 'höchste Jdee' der absolute Zweck, die Idee des Guten. Platons Äußerung, daß die Idee des Guten dem Erkennenden (dem Subjekt der Erkenntnis) Wissen, dem Erkannten (dem Objekt der Erkenntnis) Wahrheit verleihe, und daß überdies auch das Erkannte nur durch die Idee des Guten Dasein und Wesen habe, welche selbst nicht Wesen (Usía) sei, sondern noch jenseits des Wesens liegre, legt die Auffassung nahe, daß sie auch dem logischen Um- 
fange nach als die oberste und umfassendste Idee von Platon angesehen wird. Diese Auffassung ist aber undurchführbar, wenn jeder gleichnamigen Vielheit eine Idee entsprechen soll. Es muß dann auch eine Idee des Schlechten geben, und die Idee des Guten kann nicht alles Seiende umfassen. Diese Lehre paßt also nur zu der Auffassung der Ideen als Musterbilder und Zwecke. Ist wirklich die Idee des Guten die oberste, so ist in der Ideenwelt alles gut. Das wahrhaft Reale fällt mit dem wahrhaft Guten zusammen. Dann aber wird die Ideenwelt ungeeignet, die gemeine Wirklichkeit und das in ihr enthaltene Schlechte zu erklären, wenn nicht ein anderes ihr entgegenwirkendes Prinzip angenommen wird. Verhält sich ferner die Idee des Guten zu dem Gegensatz von Subjèkt und Objekt nicht im negativen, sondern im positiven Sinne neutral, so daß sie nicht keines von beiden, sondern beides ist, und ist sie zugleich die im logischen Sinne oberste und allumfassende Idee, so müßten auch alle Ideen beides sein. Sie würden dadurch zu beseelten, mit Selbstbewußtsein begabten Wesen - eine Folgerung, deren Schwierigkeiten später noch zu erörtern sind. Daß ferner die Idee des Guten als schöpferische Ursache alles Seins beschrieben wird, 1äßt, wenn sie zugleich die allumfassende Idee im logischen Sinne ist, auch alle übrigen Ideen als Ursachen und wirkende Kräfte erscheinen, was sie nach ihrer ursprünglichen Konzeption nicht waren und nicht sein konnten, wenn sie dem Postulat eines unveränderlichen und unbeweglichen Seins entsprechen sollten. Diese Schwierigkeiten ergaben sich, wie weiter unten gezeigt wird, daraus, daß Platon seine ursprünglich als Grundlage der praktischen Philosophie konzipierte Ontologie später auch der Naturerklärung dienstbar zu machen suchte. Um dies darlegen zu können, müssen wir uns zunächst mit Platons Lehre von der Seele beschäftigen. Denn die Seele ist nicht nur für die Ethik, sondern auch für die Naturphilosophie von größter Bedeutung.

In Platons Auffassung der Seele wirken erkenntnistheoretische, psychologische, ethische und naturphilosophische Gesichtspunkte zusammen. Die Erkenntnistheorie bestimmt die Seelenlehre, insofern die Seele das Subjekt des Erkennens ist. Ihr Erkennen ist aber, wie sich aus dem bisher Entwickelten ergibt, von doppelter Art, je nach dem Gegenstand, auf den es sich bezieht. Es ist entweder Wissen, wenn es auf das wahrhaft Seiende (die Ideen), oder Empfindung und Meinung (Doxa), wenn es auf die sinnlichen, immer werdenden, zwischen Sein und Nichtsein schwankenden Dinge sich bezieht. Nichts schien unserem Philosophen gewisser als die gänzliche Verschiedenheit von Meinung und Wissen. Dieses wird durch Belehrung, jenes durch Überredung erzeugt, dieses ist untrüglich, jene kann auch falsch sein, dieses ist sich seiner Gründe bewußt, jene nicht. Die Meinung beruht auf der Empfindung, bei welcher die Seele durch das körperliche Wahrnehmungsorgan mit Körpern in Berührung tritt. Nur im begrifflichen Denken und Wissen tritt sie als Seele rein mit dem Seienden und der Wahrheit in Berührung. Diese erkenntnistheoretische Ansicht führt zu der psychologischen Folgerung, da $B$ die Seele ein Mittelwesen zwischen der sinnlichen und 
der intelligiblen Welt ist, das mit den Wurzeln in die sinnliche Welt eingesenkt nach oben in die intelligible Welt hinübergreift. Will sie zum wahren Wissen gelangen, so muß sie sich von dem Leibe möglichst zu befreien suchen. Dies gelingt ihr durch die dialektische Schulung, die allmählich und stufenweise zur Erkenntnis der Ideen führt. An der gemeinen Wirklichkeit wird sie sich der Ideen bewußt, ohne sie doch aus ihr zu schöpfen, die ja nur mangellafte Abbilder derselben enthält. Sie muß also diese Ideen schon vor aller gemeinen Erfahring geschaut haben. Diese hilft nur dazu, sie an das früher Geschaute zn erinnern, das sie infolge ihrer Verbindung mit dem Leibe vergessen hatte. Das Erkennen ist ein Sicherinnern (Anamnesis), das durch die trüben Abbilder der Sinnenwelt veranlaßt, durch die Dialektik, welche den Zusammenhängen der Ideen nachgeht, weiter gefördert wird. Hier führt die erkenntnistheoretische Anerkennung des Apriori zu weittragenden Folgerungen üher Natur und Schicksale der Seele. Erinnert sich die erkennende Secle nur an früher Geschautes, so hat sie vor ihrem Leben im Leibe für sich existiert. Von hier aus bot sich Platon Gelegenheit, an die in der orphischen und pythagoreischen Mystik ausgebildeten Vorstellungen von den Schicksalen der Seele anzuknüpfen. Daß die Seele infolge früherer Verschuldnng in dcm Leibe wie in einem Gefängnis eingeschlossen ist, daß sie nicht mit dem Leibe, den sie bewohnt, zugrunde geht, sondern in immer andere Leiber wandert und, wenn sie sich in jedem einzelnen Leben in Gott wohlgefälliger Weise verhalten hat, durch eine Stufenfolge von Lebensläufen schließlich zu ihrer himmlischen Heimat zurückkehren kann, das alles waren Vorstellungen, die gut in Platons Gedankenkreis hineinpaßten und sich ihm vor allcm durch ihre ethische Brauchbarkeit, die schon bei ihrer ersten Entstehung mitrewirkt hatte, empfahlen. Denn durch sie wurde der Seele eine über das irdische l,eben hinausreichende, zum höchsten sittlichen Streben anfeuernde Aufgabe geste1lt. So entstand aus gegebenen religiösen Überlieferungen, die durch wissenschaftliche Lirwägungen Bestätigung zu finden schienes, die Lehre von der Unsterblichkeit der Seele. Die aus der Anamnesis gefolgerte Präexistenz der Seele schien zu beweisen, daß die Seele ursprünglich nicht der Welt des Sinnlichen und Vergänglichen, sondern der Welt des Ewigen angehöre und in diese dereinst zurückkehren müsse. Wenn die Seele die Ideen geschaut hat, so muß sie, da Gleiches nur mit Gleichem erkannt wird, zum mindesten eincn Bestandtril enthalten, der den Ideen wesensgyleich, also ewig und unvergänglich ist. Dieser ihr höchster Bestandteil, die Vernunft, das rein (ivistige als Subjekt, macht aber ihr eigentliches Wesen aus. Nur durch ihre Verbindung mit dem Leibe ist sie zeitweise mehrteilig geworden, inclem sich z.u dem Vernünftigen das Vernunftlose, durch den leib Verdunkelte gesellte. Ursprünglich ist sie einfach und besitzt auch hierin, da alles Vergehen nur Auflösung des Zusammengesetzten ist, eine (irwähr ihrer Ewigkeit. Vom naturphilosophischen Standpunkt kann man als wesenbildenıl für die secele die Itlee des Lebens oder der spontanen bewegung ansehen. Sio kann daher, da entgegengesetzte Ideen keine 
Verbindung eingehen, an der Idee des Todes keinen Anteil bekommen. Als Prinzip aller Bewegung wird die Seele nicht von anderem bewegt, sondern bewegt sich selbst. Daher kann ihre Bewegung nie zum Stillstand kommen und ihr Leben nie aufhören. Als Prinzip der Bewegung ist sie ungeworden, also auch unvergänglich. Denn wenn das Prinzip der Bewegung sich zu bewegen aufhörte, so würde alle Bewegung in der Welt aufhören und nie wieder eine Bewegung entstehen können. In diesem Sinne ist die Seele ein für die Naturphilosophie grundlegendes, ein kosmisches Prinzip.

Die wichtigste und bedeutendste Seite von Platons Seelenlehre ist seine Erotik. Erotik. Es ist eine rein empirisch-psychologische Betrachtung, die hier benutzt wird, um das Wesen der Seele und ihre Stellung im Universum darzulegen. Der Liebestrieb, der sich an sinnlicher Schönhieit entzündet und im sinnlichen Zeugungstrieb gipfelt, wird von Platon in die höheren Regionen der Seele hinein verfolgt. Mit der sinnlichen Liebe geht in allen wohlbeschaffenen Seelen eine geistige Liebe Hand in Hand oder entwickelt sich aus ihr. Beim Anblick der sinnlichen Schönheit erwacht in der Seele die Erinnerung an das im Vorleben geschaute Urbild des Schönen und damit an die verlorene Seligkeit der Anschauung des Idealen überhaupt. Aus dieser Erinnerung entspringt die Sehnsucht, sich zu dem.höheren Leben in der Welt des Idealen wieder aufzuschwingen. Der sinnliche Liebestrieb und die Sehnsucht nach dem Schönen und Guten, die sich am reinsten als philosophischer Trieb darstellt, ist ein und derselbe Grundtrieb der menschlichen Seele, dessen Abstufungen durch die größere oder geringere Abhängigkeit der Seele vom Leibe bedingt sind. Darum kann dieser Trieb unser Führer auf dem Wege nach oben sein. Er richtet sich auf den Besitz des Schönen und Guten, und zwar auf den ewigen Besitz dieser höchsten und ewigen Werte. Daher ist in ihm die Forderung eigener ewiger Fortdauer der Seele eingeschlossen. Er ist auch die Sehnsucht nach Unsterblichkeit. Dies zeigt sich in allen seinen Formen. Der sinnliche Zeugungstrieb sucht die dem Individuum versagte ewige Fortdauer wenigstens der Gattung zu sichern. Der Wunsch, sich einen herrlichen Nachruhm zu sichern, der die Menschen zu ihren größten Leistungen anfeuert, ist eine höhere Form desselben Triebes. Es gibt aber auch einen geistigen Zeugungstrieb, der in der Seele des Geliebten und in Gemeinschaft mit ihm geistige Kinder zu zeugen strebt, die das Einzelleben überdauern, Werke nämlich der Kunst, der Wissenschaft, der Gesetzgebung. So läuft auch diese psychologische Betrachtung des Trieblebens der Seele auf dasselbe Ziel hinaus wie die Analyse ihrer Erkenntnistätigkeit, auf den Nachweis der Nittelstellung der Seele zwischen der sinnlichen und der geistigen Welt und auf eine Bestätigung des Unsterblichkeitsglaubens. Was von Natur Gegenstand des Grundtriebes der Seele ist, das muß ihr auch erreichbar sein. Im „, iymposion" wird die individuelle Unsterblichkeit der menschlichen Seele nicht ausdrücklich gelehrt, im „Phaidros“ dagegen benutzt Plạton nicht nur die „Anamnesis“ und den naturphilosophischen Gedankengang, der die Seele als Prinzip der Bewegung faßt (siehe oben), sondern auch die Erotik als Stütze 
des Unsterblichkeitsglaubens. Was Platon im „Symposion“ von dem Eros sagt, daß er weder weise noch unbelehrbar, sondern weisheitliebend, weder Gott noch Sterblicher, sondern ein großer Dämon sei, der zwischen beiden vermittele, das gilt für die Seele selbst, die hier durch ihren Grundtrieb repräsentiert wird. Sie selbst ist ein solches Mittelwesen zwischen der sinnlichen und der intelligiblen Welt. Aus dieser strebt sie zu jener empor.

Dreiteiligkeit der Seele. aus der Analyse ihrer Erkenntnistätigkeit und ihres Trieblebens. Die Annahme aber, daß sie unsterblich sei, ließ sich nach den Grundvoraussetzungen der platonischen Lehre mit dieser Mittelstellung schwer vereinigen. Nur die Ideen sind ewig und unvergänglich. Die Seele aber ist keine Idee, sie hat nur an Ideen Anteil. Es müßte eine Idee der Seele geben, an der die Seelen ebenso teilnähmen wie jedes gleichbenannte Viele an seiner Idee. Ewig kann die Seele nur sein, wenn sie einfach und einheitlich ist. Nun führte aber schon die erkenntnistheoretische Analyse zu der Annahme höherer und niederer Seelenkräfte; und zu demselben Ergebnis gelangte Platon durch die von der Tugendlehre ausgehenden psychologischen Erwägungen. Auf dem Standpunkt des sokratischen Rationalismus konnte es nur eine Tugend, die Einsicht geben, die auf dem seiner Natur nach einheitlichen Wissen beruhte und durch Lernen erworben werden konnte. Dieser Standpunkt erwies sich als undurchführbar. Platon kam zu der Überzeugung, daß nur durch die Annahme eines vernunftlosen Seelenteils neben dem vernünftigen die Schwierigkeiten der Tugendlehre gehoben werden könnten. Innerhalb des vernunftlosen Seelenteils unterscheidet er wieder zwei Bestandteile, den Mut und die Begierde. Die in der "Republik" vorgetragene reife und abschließende Form der platonischen Tugendlehre beruht auf dieser Dreiteiligkeit der Seele und auf der Annahme, daß zum Erwerb der Tugend nicht nur Lernen, sondern auch Übung erforderlich sei. Mit dieser Annahme war die Unsterblichkeit der ganzen Seele nicht vereinbar. Um so unmöglicher wurde diese Annahme, je mehr die Wesensverschiedenheit und Selbständigkeit der einzelnen Teile betont und diese aus Seelenteilen zu Teilseelen wurden. Die Unsterblichkeit konnte nun nur für den höchsten, vernünftigen Seelenteil beansprucht werden. In der Tat unterscheidet die letzte Form der platonischen Seelenlehre (im "Timaeus") den unsterblichen Seelenteil von dem sterblichen. Durch diese Umbildung wurde die Vernunftseele den Ideen angenähert, blieb aber doch immer ein Einzelwesen. Es wirken aber auch andere Gründe mit, die Ideen Seele and Idee. der Secle anzunähern. Ursprünglich als geistige Objekte konzipiert, waren sie als solche unvermögend, den Geist als Subjekt zu erklären. Und doch konnte der Geist, wenn irgendwoher, nur aus der Sphäre des wahren Seins und der wahren Werte abgeleitet werden. Als eine höhere Realität erschienen einerseits die ewigen, unwandelbaren Formen im Gegensatz zu den vergänglichen, wandelbaren Sinnendingen, andererseits die mit Bewußtsein und spontaner Bewegung begabten Wesen im Gegensatz zum Unbelebten. Vom ontologischen Gesichtspunkt erschien das Umwandelbare und folglich auch Un- 
bewegte als das Allerrealste; von dem der kausalen Naturerklärung hingegen mußte dem Prinzip der Bewegung und des Lebens, d. h. der Seele, der Vorrang eingeräumt werden; und vom ethischen Standpunkte aus erschien die Vernunft als ein Höheres gegenüber dem Vernunftlosen, Vernunft aber kann nur in einer Seele wohnen. Daher erklärt sich, daß Plato im „Sophistes“ der Welt des wahrhaft Seienden Bewegung, Leben, Seele und Vernunft beilegt. Er gerät dadurch, wie schon gesagt, mit den Grundvoraussetzungen der Ideenlehre in Widerspruch. Diese Betrachtung lehrt also, daß es Platon nicht gelingen konnte, seine Seelenlehre mit seiner Ontologie in Einklang zu bringen. Wenn auch die Seele den Ideen einige Schritte entgegenkam und umgekehrt die Ideen der Seele, blieb doch immer ein Abgrund zwischen beiden, der sich nicht überbrücken ließ. Wir können daher eine ursprüngliche reine Form der Ideenlehre von ihrer späteren getrübten Form unterscheiden. Die Ethik und Politik Platons beruht überwiegend auf jener, seine Naturerklärung auf dieser. Denn für die Ethik sind nur die Wertbegriffe von grundlegender Bedeutung, die Naturerklärung braucht eine Ursache des Werdens und der Bewegung.

Indem Platon sich auf Naturerklärung und Kosmologie einläßt, kehrt er Kosmologie un zu dem Standpunkt der Vorsokratiker zurück, die, um die Welt zu erklären, die Geschichte ihrer Entstehung erzählten. Er ist sich selbst bewußt gewesen, damit die Bahnen strenger Wissenschaftichkeit im sokratischen Sinne zu verlassen. Darum hat er für die Kosmologie des „Timaeus“ ausdrücklich nur Wahrscheinlichkeit beansprucht. Es galt zu zeigen, daß sich von seinen Voraussetzungen aus ein um nichts weniger wahrscheinliches Bild der Weltentstehung entwerfen lasse, als es den älteren Physikern gelungen war. Am meisten hat er sich bei diesem Versuch an die Pythagoreer angeschlossen. Niemals hatte er, wie die Eleaten, der Erfahrungswelt alle Realität abgesprochen. Nur als eine Wirklichkeit niederer Ordnung hatte er sie aufgefaßt. Darum mußte er sich verpflichtet fühlen, auch sie zu erklären. Ein Wissen freilich von diesem Gegenstand war nach seinen erkenntnistheoretischen Voraussetzungen unmöglich. Sein Erklärungsversuch mußte dualistisch ausfallen, da aus der Ideenwelt allein, dem Inbegriff des Vollkommenen, das Unvollkommene sich nicht erklären ließ, und teleologisch, weil die geistigen Formen nur als Zwecke das Werden verursachen können. Indem die Idee des Guten an die Spitze der Ideenwelt gestellt und mit der höchsten, alles umfassenden Realität gleichgesetzt wurde, war der Zweck und das Seinsollende als Quelle alles Wesenhaften und als oberstes Prinzip der Naturerklärung anerkannt. Ist schon diese Gleichsetzung mit den größten Schwierigkeiten verbunrlen, so fällt es uns noch viel schwerer, die Idee des Guten zugleich als Vernunft und Gottheit zu denken. Die Weltvernunft braucht allerdings nicht notwendig als geistiges Subjekt verstanden zu werden. Die oben berührte Äußerung Platons, daß die Idee des Guten Quelle des Erkennenden sowohl wie des Erkannten, des Wissens wie der Wahrheit ist, kann auch auf ein mystisches Unbewußtes gedeutet werden. Die Bezeichnung des höchsten Wesens als 
Weltursache bringt auch keine Klarheit, obgleich die Stellen, an denen sie erwähnt wird, nicht den Eindruck machen, daß Platon die Ursache nur als

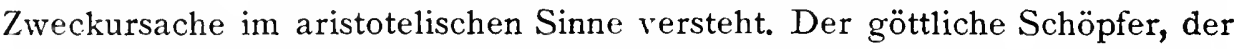
aus der ungeordneten und blindwaltenden Materie durch baumeisterliche Tätigkeit den Kosmos schafft, findet sich nur in der halbmythischen Darstellung des "Timaios", es ist aber schwer, wenn wir dieselbe als mythisch auffassen, den Kern wissenschaftlicher Überzeugung herauszuschälen, den sie in sich birgt. Ich möchte glauben, daß Platon absichtlich diese Fragen nicht mit dogmatischer Bestimm theit beantwortete, weil sie ihm als unerforschliche Geheimnisse galten. Der Schöpfer 'im „Timaios“ schafft nach dem Vorbild der Ideen die sichtbare und berührbare Welt aus der Materie. Diese Materie steht als zweites selbständiges Prinzip dem Schöpfer gegenüber. Sie ist nicht von ihm geschaffen. Denn sie bildet die Schranke seines Schaffens. Sie ist weder wahrnehmbar noch im Begriff faßbar, da sie als solche form- und wesenlos und nur durch die Fähigkeit, alle Formen in sich aufzunehmen, charakterisiert ist. Sie ist das schlechthin Unbestimmte und Unbegrenzte, durch

Materie. dessen Bestimmung und Begrenzung die sichtbare Welt zustande kommt. Diese Materie hat Platon, wie Aristoteles ausdrücklich bezeugt, mit dem Raum identifiziert, der ja auch erst durch Begrenzung vorstellbar wird. Die Räumlichkeit ist ja eines der hauptsächlichsten Unterscheidungsmerkmale der sichtbaren Welt von der intelligiblen, und wenn man von allen Bestimmtheiten der Körperwelt abstrahiert, so bleibt nur eine unbegrenzte Ausdehnung übrig. Ohne Zweifel knüpfte Platon in diesem Punkt an pythagoreische Lehren an. Es ist ein Widerspruch in der Vorstellung dieser Materie, daß sie einerseits ein Nichtseiendes, andererseits die Quelle der Unvollkommenheit in der sichtbaren Welt sein soll. Weil das Gute der höchsten Realität gleichgesetzt war, mußte notwendig das Irreale die Züge des Üblen annehmen. Der beste Schöpfer schafft die Welt nach dem schönsten und besten Vorbilde so vollkommen als möglich, und loch fällt sie unvollkommen aus, weil ihm im Stoffe eine auch seinem Willen unüberwindliche Notwendigkeit entgegentritt. Unklar bleibt auch das Verhältnis des Schöpfers zu der idealen Welt, nach deren Weltschöpfer. Vorbild er die sichtbare Welt erschafft. Nach dem ursprünglichen Sinn der Ideenlehre muß man annehmen, daß jede Idee selbständig für sich besteht, wenn sie auch untereinander und mit der Idee des Guten in Gemeinschaft stehen. Dagegen würde durch die Auffassung der Idee des Guten als Gottheit und zweckmäßig schaffende Intelligenz die Auffassung nahegelegt werden, daß die Idleen ewige Gedanken der göttlichen Vernunft sind. Doch läßt sich diese Auffassung nicht bei Platon selbst nachweisen, sondern erst bei Späteren, die seine Gedanken weiterdachten. Ebensowenig läßt sich aber der persönliche Weltschöpfer, wenn wir ihn als ernst gemeint und nicht bloß mythisch auffassen, auf irgendeine andere Weise mit der platonischen Ideenlehre in einen widerspruchslosen Zusammenhang bringen.

Welt und welt- Die von dem Schöpfer geschaffene Welt mußte, um so schön und vollkommen als möglich $\%$ u sein, selbst ein Lebewesen werden und eine Seele 
bekommen. Sie wurde nach dem Vorbild des höchsten und rollkommensten, intelligiblen Lebewesens geschaffen, welches alle übrigen Lebewesen in sich begreift, und ist selbst ein sichtbarer Gott. Sie ist einzig in ihrer Art, der Inbegriff alles Sichtbaren und Berührbaren, und so in sich abgeschloss' $n$, daß sie von außen her nichts bedarf. Sie hat die rollkommenste Form, dic Kugelgestalt, und wenn sie auch ihrer Natur nach, als etwas Gewordene's, nicht ewig ist, so könnte sie doch, da es außer ihr nichts Sinnfälliges gibt, durch nichts als durch den Willen ihres Schöpfers zerstört werden, der ihr ewigen Fortbestand gewährt. Sie ist aus den vier (empedokleischen) Elementen, den Grundformen der Materie, gebildet und in allen ihren Teilen von einer Seele durchwohnt, von der ihre Bewegung ausgeht. Diese Weltseele ist aus intelligibler und körperlicher Substanz, aus dem Selbigen und den Verschiedenen so nach bestimmten Verhältnissen gemischt und konstruiert, daß sie sowohl das Körperliche der Welt wahrzunehmen als das Intelligible zu denken und dort wie hier Identität und Verschiedenheit zu erkennen vermag. Ihr ist ler höchste, vernünftige Teil der Menschenseele, der im Haupte wohnt, wesensgleich.

Mit der Welt zugleich wurde die Zeit geschaffen als ein Abbild der Ewig- Zeit and Ewigkeit. Die Ewigkeit ruht in sich selbst, während die Zeit in endlosem Kreiskeit. lauf der Tage, Monate und Jahre vorwärtsschreitet. — Zur Vollendung der Welt gehörte auch ihre Bevölkerung mit Lebewesen, deren es vier Klassen Leberesen. gibt, Götter oder Himmelsbewohner, Lufttiere, Wasserticre und Landtiere. Der Schöpfer selbst schuf von diesen nur die Götter und die vernünftigen Menschenseelen, die Schöpfung der übrigen Tiere und des vernunftlosen Teils der Menschenseele überließ er den Untergöttern. Zu den geschaffenen Göttern rechnet Platon vor allem die Himmelskörper und die Erde, die ihm als beseelte Wesen gelten; neben diesen sichtbaren Güttern läßt er aber auch die Götter der Volksreligion bestehen, die nur, wenn es ihnen beliebt, sichtbar werden. Die von den Schöpfer selbst areschaffenen Seelen werden von den duthromulogie. Untergöttern mit einem materiellen J.eibe versehen, dessen Bau in allen Finzelheiten seinem Zweek, die Seele ohne Limbube ihres Wesens in der sinnlichen Welt anzusiedeln, entspricht. Un die Vereinigung der Seele mit dem leeibe zu ermöglichen und sie mit der sinnlichen Welt in Be\%ichung zu bringen, wircl ihr ein sterblicher und vernunftloser leil zugefïgt, der wirder seinerseits in zwei Teile zerfällt, einen edleren, den Mut, der im Her\%en, und einen unetleren, die Begierde, die in der Leher ihren Sit\% hiıt. Durch ihre Einkörperung. gerät die Seele in Gefahr, ihrer höheren IBestimmung untren zu werden. Thre Aufgabe ist, in dem Gesamtwesen, dessen Bestandteil sie jetzt bildet, die Herrschaft zu führen und sich nicht von dem Strome des ewigen Werdens, der durch den Leib und die niederen Seelenteile auf sie einstürmt, fortreiben $\%$ lassen. Diese Aufgabe ist an sich eine erfüllhare, und nicht der Schöpter, sondern lediglich die Seele sellsst ist für ihre Erfüllung verantwortlich. Von ihrer Erfüllung hängt ihr weiteres S'chicksal ab. Hat sie sie erfïllt, so kehrt sie zu dem Stern zuriick, iuf dem sie vor ihrer Einkörperung gewohnt hatte; anderenfalls sinkt sie in ihrem nächsten Leben auf eine tiefere Lebensstufe hinab und 
muß so lange von Leib zu Leib durch die verschiedenen Formen des tierischen Daseins wandern, bis sie durch Erfüllung ihrer jedesmaligen Aufgabe wieder zu ihrem normalen Zustande zurückkehrt. So haben die Vögel, Fische und Vierfüßler im Weltplan keinen anderen Zweck, als die Wanderung der Seelen, ihr Ab- und Aufsteigen zu ermöglichen. Die Schlechtigkeit der Seele, durch die sie auf eine tiefere Daseinsstufe hinabsinkt, ist immer unfreiwillig. Sie tritt unvermeidlich ein, wenn nicht das ganze Lebewesen einschließlich des Leibes so geregelt wird, daß jeder Teil die bei der Erfüllung der Gesamtaufgabe ihm zufallende Einzelfunktion richtig ausübt. Daher ist nicht nur seelische, sondern auch leibliche Erziehung nötig, um die Seele vor Schlechtigkeit $z u$ bewahren. Die musische muß mit der gymnastischen Bildung zusammenwirken, um dem ganzen Lebewesen Gleichmaß und Schönheit zu verleihen. Schlechte Körperbeschaffenheit und Mangel an richtiger Erziehung sind die Hauptursachen seelischer Schlechtigkeit. Die richtige Erziehung aber ist durch die Staatsverfassung und die ihr entsprechende öffentliche Meinung bedingt.

Ethik. Die Anthropologie und Seelenlehre Platons, auf die seine Naturphilosophie hinausläuft, eröffnet uns den Eingang zu seiner Ethik. Aus der Stellung des Menschen und seiner Seele im Weltganzen wird ihre Aufgabe abgeleitet. Da die Seele ein Fremdling in der irdischen Welt ist, so ist ihre Aufgabe eine transzendente. Sie soll sich würdig erweisen, in ihre Heimat zurückzukehren. Insofern aber die Probe dieser Würdigkeit in ihrem Verhalten zu dem vernunftlosen Seelenteil und dem Leibe besteht, ist die Aufgabe eine immanente, auf das irdische Menschenleben bezügliche. Der unsterbliche Seelenteil hat sein früher erworbenes Wissen vom wahrhaft Seienden durch seine Einkörperung zum Teil verloren. Die durch den Eros und die Philosophie vermittelte Wiedergewinnung dieses Wissens geht mit der Vervollkommnung des menschlichen Gesamtwesens Hand in Hand. Denn das echte Wissen hat eine Kraft, die jeder anderen Kraft in uns überlegen ist. Es genügt aber nicht das bloße Wissen. Es müssen auch die niederen Seelenteile dem Wissen entsprechend geregelt und zum Gehorsam gegen die Vernunft und einträchtigen Zusammenwirken mit ihr erzogen werden. So entsteht ein harmonischer Seelenzustand, der durch seine Maßverhältnisse schön und gut ist und seinen Wert in sich selbst trägt. Die von der Vernunft geschauten Wertideen werden in dem menschlichen Gesamtwesen abgebildet. Ist hiermit die sittliche Aufgabe als transzendent zugleich und immanent, als Wissen zugleich und Übung dargelegt, so bleibt noch weiter zu zeigen, inwieweit Platons Ethik individualistisch und sozialistisch ist. Es ist allbekannt, daß Platon die Ethik mit der Staats- und Gesellschaftslehre in den engsten Zusammenhang bringt und sich Verhaltnis der den tugendhaften Menschen nur als Bürger denken kann. Gleichwohl behanEthik zur Politik. delt er die sittliche Aufgabe durchaus als eine Angelegenheit des Individuums und faßt dessen Pflichten als Pflichten gegen das eigene Selbst, nicht gegen die übergeordnete Gemeinschaft auf. Die Aufgabe der Seele, insofern sie transzendent ist, betrifft nur sie selbst als Einzelseele: nur insofern sie imma- 
nent ist, auch den Staat und die Gesellschaft. Hiermit ist die Überordnung der Ethik über die Politik gegeben. Die Gesetze und die Staatsordnung dienen in letzter Linie dem ethischen $Z$ weck, daß möglichst viele Menschen möglichst gut werden. Sie schaffen günstige Bedingungen für das sittliche Streben des einzelnen. Allerdings soll der Mensch das öffentliche und allgemeine Interesse über seinen Privatvorteil stellen, aber nur deswegen, weil dadurch mit dem allgemeinen sein eigenes Heil am besten gefördert wird. Es besteht kein Widerstreit zwischen dem Gemeinnützigen und dem wahren Wohle des einzelnen. Das Wirken im Staat und für den Staat bietet dem einzelnen den Vorteil, ohne von seinem wahren Wohle etwas zu opfern, überdies noch andere $\mathrm{zu}$ retten. Die Notwendigkeit der Staatsordnung und der Gesetze beruht auf der menschlichen Schwäche. Der vollkommen Tugendhafte und Vernünftige würde der Gesetze nicht bedürfen. Denn die Vernunft ist autonom und beugt sich vor keinem anderen Gesetze. Nur weil die Schwäche der meisten Menschen diese Vollkommenheit aus eigener Kraft nicht $z u$ erreichen, ja nicht einmal ihr nahe zu kommen vermag, ist die Staatsordnung notwendig, die Gesetzlichkeit oder heteronome Sittlichkeit neben der autonomen. Es ist aber klar, daß die autonome Sittlichkeit, die auf der Erkenntnis der Ideen beruht, in einem Teile wenigstens des Volkes schon vorhanden sein muß, bevor eine äußere Gesetzesordnung für die Gesamtheit des Volkes stabiliert werden kann. Denn diese ist nur das Abbild jener. Daraus erklärt sich die Rolle, welche den Philosophen als Inhabern der höchsten Staatsgewalt in Platons Idealstaat zufällt. Die gute Staatsverfassung ist Zug um Zug das Ebenbild der Seelenverfassung des Philosophen.

Platons Tugendlehre beruht auf der sokratischen Grundüberzeugung, daß Tugend und Glückseligkeit voneinander untrennbar sind. Der Mensch kann nicht glückselig sein, ohne gut und gerecht zu sein. Aber er kann auch umgekehrt nicht gut und gerecht sein, ohne dafür im Diesseits und im Jenseits den Lohn der Glückseligkeit zu ernten. Die Tugend ist zwar ein Besitz, der von allen äußeren Folgen abgesehen, seinen Wert ganz in sich selbst trägt und um seiner selbst willen erstrebenswert ist. Nichtsdestoweniger ist sie auch um ihrer Folgen willen, als der einzige Weg zur Glückseligkeit, begehrenswert. Eine Hauptaufgabe der Staatslenker im platonischen Idealstaat ist es, diese Überzeugung mit allen verfügbaren Mitteln den Bürgern einzuprägen. Die innere Glückseligkeit der Seele beruht auf ihrer Gesundheit, d. h. auf dem harmonischen Zusammenwirken ihrer Kräfte, deren jede ihre eigentümliche Aufgabe erfüllt. Daß das tugendhafte Leben mehr Lust und Glückseligkeit gewährt als das auf Ehre oder Genuß zielende Leben, wird durch das Zeugnis der Tugendhaften glaubwürdig festgestellt. Denn glaubwürdig ist ihr Zeugnis, weil sie auch die beiden anderen Lebensformen kennen und die Lust, die diese gewähren, mit der des tugendhaften Lebens vergleichen können, während den Vertretern des ehrgeizigen und des genußsüchtigen Lebens die aus Tugend und Philosophie quellende Befriedigung unbekannt bleibt. Der hedonistischen Ethik steht Platon ablehnend gegenüber. Das Gute, auf das 
sich alles Streben richtet, der Lust gleichzusetzen, weist er weit von sich. Es gibt wahre und falsche, gesunde und krankhafte, unschädliche und verderbliche Lustgefühle. Darum kann die Lust nicht als solche das Gute sein. Die sinnliche Lust gehört der Welt des Werdens an, über die sich die Seele zu der des wahrhaften und ewigen Seins erheben soll. Die sinnliche Lust ist vergänglich, ist wesenloser Schein, ist von der Unlust des Bedürfnisses nicht zu trennen. Sie hindert die Seele, ihre wahre Aufgabe zu erfüllen. Die Lust ist also nicht das höchste Gut, auf dessen Aneignung sich der Grundwille der menschlichen Seele richtet und das die königliche Kunst, die ethisch-politische Wissenschaft zu verwirklichen lehrt. Das Gute ist eine selbständige, viel höhere Idee als die Lust, mit der zwar auch die Lust, in viel höherem Grade aber die Ideen der Schönheit, des Maßes und der Wahrheit in Gemeinschaft stehen. Die diesem Ideal entsprechende Gestaltung der menschlichen Seele ist die Tugend im höchsten Sinne; in ihrer Vollendung kann sie nur eine sein, aber sie enthält in sich als Bestandteile alle die einzelnen Vorzüge, die von dem moralischen Bewußtsein des Volkes gefordert und in der Sprache durch verschiedene Benennung unterschieden werden: die Einsicht, die Gerechtigkeit, die Besonnenheit, die Tapferkeit, die Frömmigkeit und viele andere. Faßt man diese einheitliche und höchste Tugend nach Analogie der anderen Künste als die Kunst des glückseligen Lebens auf, so erscheint sie als Mittel zum Zweck; aber sie unterscheidet sich ebendadurch von den anderen Künsten, daß in ihr Mittel und Zweck zusammenfallen. Das Wissen um das Gute ist zugleich die Verwirklichung des Guten in der Seele des Wissenden. Das wahre Wissen, das ja mehr ist als eine bloße richtige Vorstellung, hat solche Kraft, daß sich ihm auch die anderen Teile und Vermögen der Seele außer der wissenden Vernunft willig fügen. Die Definitionen der vier Kardinaltugenden in der Republik, die Platon selbst als nur vorläufig ansieht und später nie wieder verwendet, geben nicht das Wesentliche der platonischen Tugendlehre wieder. Die Vierzahl der Tugenden ist ebensowenig wie die Dreizahl der Seelenkräfte, aus der sie abgeleitet wird, als ein fundamentaler Satz der platonischen Philosophie anzusehen. Wichtiger ist, daß die Einheit, zu der sich diese Einzelvorzüge zusammenschließen, durch die Definitionen ausgedrückt wird. Die Weisheit ist die richtige Beschaffenheit der denkenden Seele. Dem mutartigen Seelenteil fä1lt die Aufgabe zu, mit feurigem Willenseifer an der von der Vernunft gewonnenen Einsicht, was furchtbar ist und was nicht, festzuhalten und sich weder durch Schmerz noch durch Lust davon abbringen zu lassen. Sicine besondere Tugend ist die Tapferkeit. Die Besonnenheit (cwppocúvn) ist niclıt, wie man erwarten sollte, die Sondertugend des begehrenden Seelenteils, sondern eine gemeinsame Tugend der beiden vernunftlosen Teile, vermöge deren sie sich der Vernunft unterordnen und weder mit ihr noch untereinander hadern. Die Gerechtigkeit endlich besteht darin: daß jeder der drei Seelenteile die ihm zufallende Aufgabe erfüllt. Die Einheit der Tugend beruht, wie diese Definitionen zeigen, auf der Herrschaft des vernünftigren Serelentrils; scin Wissen ist die Norm für die anderen Seelen- 
teile. Im Wesen des Wissens liegt die logische Einheitlichkeit und Folgerichtigkeit. Beruht die Tugend auf Wissen, so ist sie ihrer Natur nach lehrbar. Daß sie tatsächlich gelehrt werde, hat zur Voraussetzung, daß I.ehrer vorhanden sind, die das Wissen bereits besitzen. Von der philosophischen, auf Wissen beruhenden Tugend ist die gewöhnliche, nur auf richtiger Meinung und Gewöhnung beruhende zu unterscheiden. Plato weif.j, daß die philosophische Tugend immer nur von einer kleinen Minorität erreicht werden kann. Die ganze Bürgerschaft wenigstens zu der bürgerlichen Tugend auszubilden, ist die Aufgabe der öffentlichen Erziehung, die nur in einem wohlgeordneten Staate möglich ist. Im demokratischen Staate, der auf Grund des individualistischen Freiheitsprinzips jedem einzelnen Bürger freistellt, wie er seine Kinder erziehen will, ist eine gute und wirksame Erziehung unmöglich. Denn die Entwickelung der Zöglinge ist nicht nur durch die erzieherischen Absichten und Maßregeln ihrer Eltern, sondern auch durch die Beschaffenheit des Milieus, in dem sie aufwachsen, bedingt. Nur wenn die Erziehung rom Staate selbst in die Hand genommen und einheitlich geregelt wird, kanii das Milieu von allen schädlichen Einflüssen rein gehalten werden. Dies zu bewirken ist die Hauptabsicht der sozialen und politischen Reformen, die Platon in seinen Büchern rom „Staat" vorschlägt. Auf der bürgerlichen Stufe der Tugend, zu der man durch Tradition und Übung gelangt, treten natürlich die einzelnen Vorzüge mehr in ihrer Besonderheit hervor. Hier kann man durch natürliche Anlage und durch Erziehung die eine Tugend bereits besitzen, während man der anderen noch ermangelt. So sind Naturen ron ruhigem, gleichmäßigem Temperament zur Besonıenheit, feurige, tatkräftige Naturen zur Tapferkeit besser veranlagt. Die Erziehung muß diese Einseitigkeiten auszugleichen suchen. Demselben Zweck kann auch die staatliche Überwachung und Regelung der Ehen dienen, indem sie Personen entgegengesetzten natürlichen Temperaments miteinander vermählt. Auf dieser Stufe also ist die Tugend nicht eine, ist die Tug'nd nicht Wissen. Durch die Unterscheidung zweier Stufen der Tugend lösen sich die Schwierigkeiten und Widersprüche, auf welche ohne diese Unterscheidung die Untersuchung über die Einheitlichkeit der Tugend und i:ar Verhältnis zum Wissen gestoßen war. Außerdem war zur Lösung dieser Schwierigkeiten auch die Überwindung des sokratischen Rationalismus nötig gewesen, der so vorging, als ob der Mensch ein reines Vernunftwesen wäre und durch bloße theoretische Belehrung zum Guten gebracht werden könnte. I'laton legt seiner Auffassung der Tugend die Annahme vernunftloser Seelenkräfte zugrunde, die neben der Vernunft bestehen und zu ihr und untereinander in ein harmonisches Verhältnis gebracht werden müssen. Diese sind theoretischer Belehrung unzugänglich und können nur durch Übung gebändigt werden.

Soll jene Harmonie der seelischen Kräfte, die Platons ethisches Ideal Erziehung. bildet, erreicht werden, so muß die Erzichung, auch wo es sich nur um die bürgerliche Tugend handelt, eine musische zugleich und eine gymnastische sein, nicht nur weil eine gesunde Secle nur in einem gesunden Körper wohnen 
kann, sondern auch um einseitige Entwickelung der Seele selbst zu vermeiden. Gymnastische Ausbildung ohne das Gegengewicht künstlerisch-wissenschaftlicher Erziehung würde die Seele ehrgeizig und mutig, aber auch roh und trotzig machen, musische Erziehung ohne Gymnastik würde die Seele verweichlichen und den Verlust männlicher Wehrhaftigkeit nach sich ziehen. ealstaat. Diese Erziehung läßt aber Platon in seinem Idealstaat nicht der Gesamtheit der Bürger zuteil werden. Von der Erziehung der Gewerbsleute und Ackerbauer, welche die Mehrzahl des Volkes bilden, und von der ihnen angemessenen Stufe der Tugend wird kein Wort gesagt. Die musisch-gymnastische Erziehung genießen nur die Krieger oder Wächter, welche die Aufgabe haben, den Staat gegen äußere und innere Feinde zu schützen. Für diese Aufgabe sollen sie durch ihre Erziehung und Lebensweise geschickt gemacht werden.

Ständische Gliederung. Sie bilden einen bevorrechteten Stand, einen ritterlichen Adel, der wie er ausschließlich dem Staate alle seine Kräfte widmet, so auch ausschließlich politische Rechte genießt. Der aus Bauern und Gewerbetreibenden bestehende Nährstand soll ebenso ausschließlich bloß Nährstand sein und an der Staatsverwaltung keinen Anteil haben. So fordert es nach Platons Meinung das Gesetz der Arbeitsteilung, demzufolge jeder Bürger, damit er seine Arbeit für die Gesamtheit gut verrichte, nur eine Arbeit verrichten und nur eine der Hauptfunktionen des gesellschaftlichen Lebens ausüben darf. Aus der Beobachtung der sozialen Kämpfe in den griechischen Staaten hatte sich Platon die Ansicht gebildet, daß die Erhaltung und Verteidigung des Staates einem Stande anvertraut werden müsse, der nur für diese Aufgabe lebte und außerhalb des wirtschaftlichen Lebens und seiner Kämpfe stünde. Darum zieht er die scharfe Grenzlinie zwischen dem Nährstand und dem Wehrstand und führt für diesen den Kommunismus ein. Während in den Staaten des Kommunismus. wirklichen Lebens politische Macht um wirtschaftlicher Vorteile willen erstrebt und Leistungen für den Staat durch wirtschaftliche Vorteile nach dem Maße ihrer Bedeutung belohnt werden, will Platon die politische Macht und Leistung von dem wirtschaftlichen Vorteil trennen. Darum darf kein Angehöriger des Wächterstandes Privateigentum besitzen. Mit der Aufhebung des Privateigentums muß die der monogamischen Familienordnung Hand in Hand gehen. Der ganze Wächterstand soll eine einzige große Familie bilden. Die Kindererzeugung wird ron dem Staate so geordnet, daß niemand sein Weib und seine Kinder für sich besitzt, sondern auch auf diese der Kommunismus ausgedehnt wird. Der Staat entscheidet nach dem Gesichtspunkte der Rassenverbesserung, mit weichem Weibe jeder Mann Kinder zeugen darf; die Kinder selbst aber werden den Müttern gleich nach ihrer Geburt weggenommen und vom Staate aufgezogen, so daß die liltern ihre eigenen Kinder von den übrigen derselben Altersstufe nicht unterscheiden können und ihre elterliche Liebe allen ohne Unterschied zuwenden müssen. Auf diese Weise hofft Platon die mit der P'rivat- und Familienwirtschaft verbundenen Interessengegensätze Philosophen als aus dem Wächterstande auszuschalten und diesen zu einer Einheit zusammenStatslenker. zuschließen, die dem ganzen Staate Einheit gibt. Aus den Zöglingen der mu- 
sisch-gymnastischen Erziehung werden die intellektuell und ethisch am besten Begabten ausgewählt, um durch einen längeren und mehr in die Tiefe gehenden Bildungsgang zu Philosophen zugleich und Staatslenkern ausgebildet zu werden. Denn nur die Vereinigung wahrer Philosophie und politischer Macht in denselben Personen kann das Heil der Staaten verbürgen. So hebt sich über den Wächterstand, als dritte höchste Stufe der Bürgerschaft, der Stand der Staatslenker empor. Den drei Seelenteilen entspricht im Staat die Dreizahl der Stände. Dem vernünftigen Seelenteil entspricht der durch philosophische Bildung ausgezeichnete Stand der Wächter, dem mutartigen der Kriegerstand, dem begehrenden endlich die große Masse der Gewerbetreibenden und Kaufleute. Jeder dieser Stände hat seine, dem ähnlichen Seelenteil entsprechende Sondertugend, und darin, daß jeder dieser Stände die ihm zufallende Aufgabe im Staate erfüllt, ohne sich in die der anderen Stände einzumischen, besteht die Gerechtigkeit im Staate.

Platon erscheint vom geschichtlichen Standpunkte, den wir allein anerkennen, als der größte Denker, den das griechische Volk und das klassische Altertum überhaupt hervorgebracht hat. Inwiefern ihm sein großer Schüler Aristoteles diesen Ruhm streitig machen kann, wird die weitere Darstellung zu zeigen suchen. Groß erscheint Platon zunächst durch die geschichtliche Nachwirkung seiner Gedanken, die auch in der Gegenwart noch fortdauert. Als der Begründer einer Lebensanschauung, die dem Menschen eine über das irdische Leben hinausreichende Aufgabe stellt, die das Zeitliche vom Standpunkte der Ewigkeit und das Sinnliche vom Standpunkte des Übersinnlichen zu beurteilen uns auffordert, ist er der geistige Ahnherr aller idealistischen Philosophie und Religion. Wie er selbst schon die damaligen Formen der Jenseitsreligion bei seinem Philosophieren mitberücksichtigte, ist er später der weltbeherrschenden Jenseitsreligion ein Haupthelfer bei dem Ausbau ihres dogmatischen Lehrgebäudes geworden. Ohne Platon gäbe es keine spekulative Theologie, aber auch keine idealistische Philosophie. Alle Philosophen, die das Geistige, sei es nun als Objekt oder als Subjekt, für das wahrhaft Reale und zugleich wahrhaft Wertvolle in dieser Welt halten, wandeln in Platons Fußstapfen. Aller Apriorismus in der Erkenntnistheorie, aller Idealismus in der Metaphysik, der subjektive nicht minder als der ihm näherstehende objektive, und alle Transzendenz in der Moral gehen von Platons Lebensarbeit aus und kehren zu ihm zurück.

Aber nicht nur seine tiefe und gewaltige Einwirkung auf die Nachwelt, auch sein Verhältnis zu den Vorgängern ist geeignet, Platons Größe dem geschichtlich Denkenden zu veranschaulichen. Unsere Darstellung hat gezeigt, wie Platon von Heraklit und Anaxagoras, von Parmenides, von den Pytham goreern wichtige Gedanken entlehnt und alle diese Gedanken von dem anthropozentrischen Standpunkt des Sokrates und mit sokratischer Methode zu einem neuen System der Weltanschauung vereinigt, das doch ganz aus einem Gusse ist und in allen Teilen den Stempel seiner Persönlichkeit trägt. Wenn uns die Schriften seiner Vorgänger vollständiger vorlägen, würde uns noch

Verhältnis zu seinen Vor. gängero. 
deutlicher als auf Grund der spärlichen Reste der ungeheure Aufschwung sichtbar werden, den die philosophische Wissenschaft an Strenge der Methode und Vertiefung der Probleme seiner persönlichen Leistung verdankt. Selbst die besten Schriften der Vorsokratiker standen ohne Ausnahme an

Dis Form der platonischen Schriften.
Wissenschaftlichkeit in unserem Sinne hinter den platonischen weit zurück.

Es ist nicht Sache der Philosophiegeschichte, die Größe Platons als Schriftsteller zu würdigen. Aber die Art, wie er philosophische Gegenstände darzustellen pflegt, ist so bedeutungsvoll für die Beurteilung des Philosophen selbst, daß sie auch hier nicht unbeachtet bleiben darf. Als wissenschaftliche Lehrmethode im strengsten Sinne gilt ihm nur das von Sokrates ausschließlich angewendete lehrgespräch, das dialektische Verfahren im ursprünglichen Wortverstand. Dieses nötigt den Lehrer, von jeder einzelnen Behauptung Reclienschaft zu geben, und hindert ihn zu Folgerungen fortzuschreiten, ehe sich der Schüler von der Richtigkeit der Voraussetzungen überzeugt hat. Der zusammenhängende Lehrvortrag kann, nach Platon, woh1 zur Annahme einer Lehrmeinung überreden, nicht aber ein Wissen in dem Schüler erzeugen. Auch das nicht in Worten sich aussprechende Denken ist dialektisch: ein Gespräch der Seele mit sich selbst. Neben dem mündlichen Lehrgespräch hat, nach Platon, die schriftstellerische Darstellung philosophischer Lehren nur eine sekundäre Bedeutung. Sie kann als Hiilfsmittel dienen, um sich die vorausgegangene mündliche Belehrung ins Gedächtnis zu rufen. Die beste philosophische Schriftstellerei ist daher diejenige, welche das mündliche dialektische Verfahren so treu wie möglich abbildet. Aus diesem Grunde hat Platon seinen Schriften die Form von Gesprächen gegeben. Zugleich gab ihm aber diese Form Gelegenheit, seine angeborene dichterische Gestaltungskraft $z u$ betätigen, indem er die Gesprächspersonen durch individuelle Zeichnung belebte und vielfach auch durch Schilderung der das Gespräch veranlassenden und begleitenden Vorgänge greifbare Bilder aus dem Leben der attischen Gesellschaft entwarf. Die Meisterschaft, die er so als Künstler bewährt, wird von den empiristischen und materialistischen Gegnern Platons oft benutzt, um ihn als Philosoplen zu verdächtigen und seine Philosophie als das Erzeugnis eines mehr künstlerischen als wissenschaftlichen Geistes, der der besonnenen Nüchternheit entbehrte, beiseite zu schieben. Demgegenüber kann auf die Tatsache verwiesen werden, daß Platon, wo er eine ernstgemeinte wissenschiaftliche Untersuchung führt, an nüchterner Begriffsstrenge sich mit jedem antiken Philosophen messen kann und hinter den antiken Materialisten in dieser Hinsicht gewiß nicht zurücksteht. Allerdings enthalten seine Schriften neben Das Dichterischa diesen wissenschaftlichen Untersuchungen auch dichterische Bestandteile. Zu
in Platon. genannten Mythen, in denen teils religiöse Überlieferungen zur Ausfüllung der Lücken der wissenschaftlichen Erkenntnis herangezogen, teils selbstgedichtete Erzählungen als Einkleidung philosophischer Lehren benutzt werden. A ber diese Bestandteile heben sich immer deutlich von den wissenschaftlichen Untersuchungen alb und können den Jeser nicht beirren, der die Form der 
platonischen Schriftstellerei richtig auffaßt und weiß, daß die ernstgemeinte Wissenschaft bei Platon nur so weit reicht wie die Anwendung der dialektischen Methode. Die den Kern der platonischen Philosophie bildende Ideenlehre ist nicht aus künstlerischer Intuition hervorgegangen. Sie ist vielmehr der denkbar schärfste Gegensatz künstlerischer Weltbetrachtung, da sie das jeder Anschauung entzogene, nur im begrifflichen Denken erfaßbare Allgemeine für das Realste und Wertvollste erklärt. Das „Urbild des Schönen“ ist nicht ein überirdisch schöner, anschaulicher Gegenstand im überhimmlischen Ort, den die Phantasie des Philosophen in visionärer Entzückung erschaut, sondern eine übersinnliche, rein geistige Form, wie alle übrigen Ideen, die sich z. B. in einer "schönen“ Staatsverfassung viel reiner ausprägt als in einem schönen Menschenantlitz. Der Vorwurf, daß Platon in seiner Metaphysik durch dichterische und künstlerische Neigungen vom Wege der Wissenschaft abgedrängt werde, ist also unberechtigt und scheint auf einem Mißverständnis der Ideenlehre zu beruhen. - Als Dichter erscheint uns Platon auch in seinen erotischen Schilderungen, aber nicht als ein phantastischer, sondern als ein realistischer Dichter, der seine tiefe Kenntnis des menschlichen Seelenlebens in meisterhafter Form zur Darstellung bringt. Daß er diese Seelenkenntnis besaß, war für seine Philosophie, welche die Probleme des Menschenlebens in den Mittelpunkt stellt, kein Hindernis, sondern ein Fördernis. Sein Versuch, auch das Begehren und Wollen des Menschen von den niedrigsten bis zu den höchsten Formen zu verfolgen, es auf eine einheitliche Formel zu bringen und für die Erkenntnis der Weltstellung des Menschen und seiner Aufgabe auszunutzen, enthält einen großen Fortschritt gegenüber dem sokratischen Rationalismus und ist das Tiefste, was das gesamte Altertum auf psychologischem Gebiete geleistet hat.

Es ist also ungerecht, die dichterische und künstlerische Seite in Platons Begabung als einen Mangel seiner wissenschaftlichen Begabung aufzufassen. Vielmehr besteht seine einzigartige Größe in der Vereinigung scheinbar sich ausschließender Fähigkeiten, des zergliedernden, abstrakten Denkens mit künstlerischer Anschauungsfülle und Gestaltungskraft. Derselbe Philosoph, der über mathematischen, und begrifflichen Abstraktionen die anschauliche Wirklichkeit zu vergessen und die Bedeutung der Erfahrung für die Wissenschaft zu unterschätzen scheint, hat andererseits das menschliche Leben, das der Gesellschaft nicht minder als das der Einzelseele, genau gekannt und wenigstens nach dieser Seite einen starken Wirklichkeitssinn bewährt. Die künstlerische Form seiner Schriftstellerei bringt es mit sich, daß in ihr die empirische Seite der Forschung nirgends unmittelbar in die Erscheinung tritt. Doch ist es unverkennbar, daß z. B. die "Gesetze" umfassende Vorstudien über das geltende Recht der einzelnen griechischen Staaten voraussetzen. Auch die Weltschöpfung des „Timaeus“ konnte ohne eingehende empirische Naturstudien (z. B. über Anatomie) nicht geschrieben werden. Diese Seite der wissenschaftlichen Persönlichkeit Platons wird gewöhnlich unterschätzt, weil sie aus seinen Schriften nur mittelbar erschlossen werden kann. Platons prinzipieller 
erkenntnistheoretischer Standpunkt ist hiermit im Einklang. Er fordert geradezu das Ausgehen von der Empirie, da man zur Erkenntnis der Ideen nur von den Gegenständen der sinnlichen Erfahrung aus gelangen kann, die, wenn auch nicht als Quelle, so doch als Erinnerungsbehelf die begriffliche Erkenntnis bedingen. Plato ist nicht reiner Rationalist, sondern sucht durch die Rolle, die er der sinnlichen Erfahrung beim Erkenntnisprozeß zuweist, $z$ wischen Rationalismus und Sensualismus, $z$ wischen Apriorismus und Empirismus zu vermitteln. Die aristotelische Formel, daß die für unsere Erkenntnis früheren Objekte von Natur die späteren sind, entspricht durchaus dem platonischen Standpunkt. Die Vermittelung zwischen Empirismus und Rationalismus erfolgt aber bei Platon im Sinne einer entschiedenen Überordnung dieses über jenen. Dies erschien notwendig, weil die Ideen nicht nur Seinsprinzipien, sondern auch Normen der empirischen Wirklichkeit sein sollten. Als solche mußten sie einen aus dieser nicht völlig ableitbaren Inhalt haben.

III. A ristoteles (384-322). Dèr größte Schüler Platons, Aristoteles, hat sich infolge tiefgehender Meinungsverschiedenheiten von der platonischen Akademie getrennt und eine eigene Schule, die peripatetische, begründet. Trotzdem ist er zeitlebens insofern Platoniker geblieben, als er eine Reihe der wichtigsten Platon eigentümlichen Grundüberzeugungen beibehielt. Es konnte daher in der Folgezeit bald der Gegensatz ihrer Anschauungen in den Schuldebatten hervorgekehrt, bald wieder die platonisch-aristotelische Philosophie als eine Einheit allen übrigen Sekten entgegengestellt werden. Als der bezeichnendste Unterschied der beiden Sysieme erscheint auf den ersten Blick, dạß Aristoteles die von Platon unterschiedenen Stufen der Wirklichkeit, Materie, sinnliche Welt und Ideenwelt, aus ihrer Sonderung zu befreien und in einem einheitlichen Wirklichkeitsbegriff zusammenzufassen sucht. So wird der Charakter der Transzendenz, der der platonischen I.ehre in allen ihren. Teilen anhaftet, von Aristoteles ihr abgestreift und durch den der Immanenz ersetzt. Stoff und Form, Bewegtes und Unbewegtes, Zeit und Ewigkeit, Gott und Welt schließen sich für ihn zu dem Bilde dieser einen erfahrbaren Wirklichkeit zusammen. Dadurch wurde die Sinnenwelt, die bei Platon nur die Vorstufe bildet, über die sich der Geist zu dem höheren Niveau der wahren Erkenntnis und des wahren Seins emporschwingt, selbst in allen ihren Teilen zum würdigen Gegenstande der Wissenschaft. Dies ist der Grund, um deswillen sich die aristotelische Philosophie so viel fruchtbarer für die Einzelwissenschaften erwiesen hat als die platonische. Dennoch bleibt die aristotelische Lehre, wie wir sehen werden, mit Bewußtsein dualistisch und verrät so ihre Entstehung aus der platonischen. Erst das stoische System, indem es in derselben Richtung einige Schritte vorwärts tut, in der sich Aristoteles von Platon entfernt hatte, macht den Versuch, eine streng monistische Weltanschauung durchzuführen.

Logik. Erwägungen über die Methode der wissenschaftlichen Erkenntnis, nament- 
lich über Begriffsbestimmung (Definition) und Einteilung, hatte schon Plato angestellt, aber erst Aristoteles hat den Schritt getan, die wissenschaftliche Methodenlehre als selbständige Disziplin abzusondern und der Behandlung der materiellen Probleme als "Organon" vorauszuschicken. Wegen ihres rein formalen Charakters gilt sie. ihm nicht als ein Teil der Philosophie selbst, sondern als eine Propädeutik $z u$ ihr. Er behandelt in ihr die Lehre vom Urteil, von den Arten des Schließens und vom wissenschaftlichen Beweis. Die erkenntnistheoretisch grundlegenden Fragen nach dem Verhältnis der Wahrnehmung zu ihrem Objekt, der Vorstellung zur Wahrnehmung und des Begriffs zur Vorstellung werden von ihm in diesem Zusammenhange nicht behandelt. Sie sind für ihn psychologische Fragen, die nicht mit den logischen zu einem einheitlichen erkenntnistheoretischen Gedankengang zusammengeschlossen werden. Andererseits steht die Logik bei ihm noch im engsten Zusammenhang mit der Grammatik, insofern er den sprachlichen Aussagesatz von dem Urteil, das seinen Gegenstand bildet, noch nicht scharf genug scheidet, sondern vielfach Unterschiede der sprachlichen Form als logische Unterschiede behandelt.

Der Hauptgegenstand der Logik ist für Aristoteles die Lehre von den Schlüssen (Syllogistik) und vom wissenschaftlichen Beweis (Apodeiktik), von denen er jene in der ersten, diese in der zweiten Analytik behandelt. Die Lehre vom Begriff in logischer Beziehung hat er nirgends im Zusammenhang entwickelt, sondern nur gelegentlich gestreift. Denn die „Kategorien“ betitelte Schrift enthält zwar einzelne für die Logik wichtige Sätze, ist aber in der Hauptsache eine einleitende Betrachtung mehr zur Ontologie als zur Logik. Auch die Lehre vom Urteil, auf die sich die Schrift $\pi \epsilon \rho i ̀ ~ E ́ \rho \eta \eta v i ́ \alpha c$ bezieht, ist nicht vor den Analytiken als Grundlage für die Syllogistik und Apodeiktik, sondern nach ihnen und ohne engere Beziehung zu ihnen von Aristoteles bearbeitet worden.

Im Urteil werden nach Aristoteles zwei Begriffe, ein Subjekts- und ein Prädikatsbegriff, zueinander in Beziehung gesetzt. Diese Beziehung kann eine zwiefache sein, je nachdem das Piädikat dem Subjekt zugesprochen oder abgesprochen wird. Daraus ergeben sich zwei Arten des Urteils, das bejahende und das verneinende. Damit das Urteil wahr sei, muß die Beziehung der Begriffe im Urteil derjenigen der Dinge in der Wirklichkeit entsprechen. Der Trennung der Dinge muß die Trennung der Begriffe, der Verbindung jener die Verbindung dieser entsprechen. Wenn demselben Subjekt dasselbe Prädikat in dem einen von zwei Urteilen zugesprochen, in dem anderen abgesprochen wird, so stehen diese Urteile in kontradiktorischem Gegensatz, und es ist notwendig das eine von ihnen wahr; das andere falsch. Doch stehen die allgemein bejahenden Urteile zu denen, welche dasselbe allgemein verneinen (Alle $A$ sind $B-K$ ein $A$ ist $B$ ) nicht in kontradiktorischem, sondern in konträrem Gegensatz, der eine dritte Möglichkeit (Einige A sind B) offen läßt. Den Satz, daß von zwei kontradiktorisch entgegengesetzten Urteilen notwendig das eine wahr, das andere falsch sein muß, läßt aber Aristoteles 
nicht gelten für Urteile, die sich auf zukünftige Ereignisse beziehen. Von den zwei Urteilen „es wird morgen eine Seeschlacht stattfinden“ und „es wird morgen nicht eine Seeschlacht stattfinden" ist nicht das eine notwendig wahr und das andere notwendig falsch. Es ist in diesem Falle nur das disjunktive Urteil notwendig wahr, daß eine Seeschlacht morgen entweder stattfinden oder nicht stattfinden wird. Diese Einschränkung glaubt Aristoteles machen zu müssen, weil sonst alles Geschehen ein notwendiges Geschehen sein würde und der für seine Philosophie so wichtige Begriff des Möglichen seine Berechtigung verlöre. Bezüglich der Quantität teilt Aristoteles die Urteile in allgemeine, partikuläre und (hinsichtlich der Quantität) unbestimmte ein. Doch sind die letztgenannten für seine Syllogistik ohne Bedeutung. Bezüglich der Modalität kennt Aristoteles Wirklichkeits-, Möglichkeits- und Notwendigkeitsurteile und faßt auch diese Unterschiede als im Objekt des Urteils, nicht in dem subjektiren Gewißheitsgrade des Urteilenden gelegene auf. Da das Mögliche etwas ist, das objektiv sein oder auch nicht sein kann, so steht zu dem Urteil "es ist möglich, daß A sei“ in kontradiktorischem Gegensatz nicht das Urteil „es ist möglich, daß A nicht sei“, sondern das Urteil „es ist nicht möglich, daß A sei“. Desgleichen ist dem Notwendigkeitsurteil „es ist notwendig, daß A sei" nicht das Urteil „es ist notwendig, daß A nicht sei“, sondern das Urteil ,es ist nicht notwendig, daß A sei“ kontradiktorisch entgegengesetzt.

Größere Verdienste als um die Urteilslehre hat sich Aristoteles um die Lehre von den Schlüssen erworben, die von Platon noch vernachlässigt, von ihm zuerst in ihrer für allen Fortschritt und Zusammenhang des menschlichen Denkens grundlegenden Bedeutung erkannt und in relativ abschließender Weise erforscht wurde. Der Syllogismus wird von ihm als ein Gedankengang definiert, in dem aus gegebenen Urteilen ein von ihnen verschiedenes Urteil durch das Gegebensein jener mit Notwendigkeit hervorgeht; und zwar müssen immer zwei Urteile als Prämissen gegeben sein, damit sich der Schlußsatz ergebe. In jeder der beiden Prämissen ist ein Subjektsbegriff und ein Prädikatsbegriff. Sie müssen aber, um einen Schluß zu ermöglichen, einen Begriff, den sogenannten Mittelbegriff, gemeinsam haben, also im ganzen nur drei Begriffe enthalten. Der Mittelbegriff ermöglicht durch sein logisches Verhältnis zu dem Ober- und Unterbegriff (maior und minor) die Verknüpfung. der letzteren zu einem neuen Urteil, dem Schlußsatz. Je nachdem nun der Mittelbegriff in beiden Prämissen Prädikat, in beiden Subjekt oder im Obersatz Subjekt, im Untersatz Prädikat ist, ergeben sich drei Schlußfiguren. In der ersten Schlußfigur ist der Mittelbegriff Subjekt im Obersatz, Prädikat im Untersatz, d. h. er steht an Umfang in der Mitte zwischen den im Schlußsatz verknüpften Begriffen. In der zweiten Schlußfigur ist der Mittelbegriff in beiden Prämissen Prällikat, d. h. er übertrifft beide im Schlußsatz verknüpften Begriffe an Umfang. In der dritten Schlußfigur ist der Mittelbegriff in beiden Prämissen Subjekt, d. h. er ist an Umfang geringer als beide im Schlußsatz verknüpfte Begriffe. Die größte Bedeutung hat nach Aristoteles clie erste Schlulfigur, die allein „vollkommene" Schlüsse liefert, d. h. solche, bei denen 
die Notwendigkeit der Schlußfolgerung aus den Prämissen selbst, ohne Hinzutreten weiterer Sätze erhellt. Die Beweiskraft der zweiten und dritten Schlußfigur glaubt Aristoteles durch Zurückführung auf die erste beweisen. zu müssen. Er untersucht weiter, wie in jeder der Schlußfiguren die Prämissen hinsichtlich ihrer Qualität (bejahend oder verneinend) und ihrer Quantität (allgemein oder partikulär) beschaffen sein müssen, und stellt in der ersten und zweiten Figur je vier, in der dritten sechs verschiedene Modi auf. Ferner verfolgt er den Einfluß der Modalität der Prämissen (ob Wirklichkeits-, Möglichkeits- oder Notwendigkeitsurteile) auf die Modalität des Schlußsatzes.

Im Syllogismus wird das Einzelne aus dem Allgemeinen abgeleitet. Das Verfahren ist ein hinabsteigendes (deduktives). Umgekehrt wird in dem aufsteigenden (induktiven) Beweisverfahren der allgemeine Satz aus den einzelnen Erfahrungstatsachen erschlossen. Was von allen Einzelwesen einer Art gilt, das wird durch dieses Schlußverfahren als Prädikat des Artbegriffes, und was von allen Arten derselben Gattung gilt, als Prädikat des Gattungsbegriffes erschlossen. Als Bedingung der Gültigkeit stellt Aristoteles die Vollständigkeit der Induktion auf. Es ist klar, daß diese Forderung gegenüber der unbegrenzten Menge der Einzelwesen praktisch unerfüllbar ist. Auch wäre ein allgemeiner Satz für den deduktiven Beweis von Einzeltatsachen wertlos, wenn man schon alle unter ihn fallenden Tatsachen kennen müßte, um $z \mathfrak{u}$ ihm $z u$ gelangen.

Auf der Grundlage der Syllogistik baut sich bei Aristoteles die Lehre vom wissenschaftlichen Beweis als der Quelle des wahren Wissens auf. Um einen Syllogismus zum wissenschaftlichen Beweis zu machen, muß zu der formalen Richtigkeit, deren Bedingungen in der ersten Analytik erörtert werden, noch etwas Weiteres hinzukommen. Die Prämissen müssen wahr und notwendig sein, damit auch der Schlußsatz diesen Charakter habe. Denn es liegt in dem Begriff des Wissens, wie Aristoteles mit Plato annimmt, das Gewußte aus seinem zureichenden Grunde als etwas, das nicht anders sein kann, $z u$ erfassen. Das Wissen hat es nicht nur mit dem „Was", sondern immer auch mit dem "Warum" zu tun. Nicht von dem, was einem Dinge nur zufällig. zukommt, ist ein Wissen im strengen Wortverstande möglich, sondern nur von dem, was ihm als solchem, vermöge seiner im Begriff zu erfassenden Wesenheit zukommt. Das wahre Wissen vollendet sich also im Begriff. Als Ideal des Wissens betrachtet Aristoteles ein System von Begriffen, in dem alle einzelnen Begriffsbestimmungen demonstriert werden können. Die Demonstration besteht in der Ableitung des Besonderen aus dem Allgemeinen. Denn jenes hat seinen zureichenden Grund in diesem, nicht umgekehrt. Darum ist die Methode des wissenschaftlichen Beweises syllogistisch und deduktiv.

Das Beweisen besteht in dem Ableiten einer neuen Erkenntnis aus einer Unbrweisbare schon vorher vorhandenen. Diese muß selbst bereits bewiesen sein, um ihre Prinzipien. Gewißheit und Notwendigkeit auf die aus ihr abgeleitete übertragen zu können. Diese Ableitung aus immer höheren und allgemeineren Sätzen kann aber 
nicht ins Unendliche weitergehen, da in diesem Falle überhaupt kein Wissen möglich wäre; sondern wie nach unten hin die Deduktion ihre Grenze findet in den untersten Artbegriffen, unter denen nur noch eine unbegrenzte Vielheit von Einzelwesen begriffen ist, die sich höchstens durch zufällige Eigenschaften unterscheiden und insofern die Wissenschaft nichts angehen, ebenso müssen die Ketten der Deduktion oben Anfänge haben in gewissen obersten und allgemeinsten Grundsätzen und Begriffsbestimmungen, die nicht deduktiv beweisbar sind. Gleichwohl müssen diese Prinzipien als gewiß und notwendig gewußt werden, wenn alles aus ihnen Abgeleitete gewiß und notwendig sein soll. Ja, sie müssen gewisser als alles übrige sein. Es gibt also ein unmitte1bares, seiner Natur nach unbeweisbares Wissen, das alles beweisbare Wissen bedingt. Von dem Einzelnen und sinnlich Wahrnehmbaren sind diese Prinzipien am weitesten entfernt und werden, wenn man von der Wahrnehmung ausgeht, am letzten und am schwersten erkannt, für den Verstand aber sind sie das Erste und am leichtesten Begreifliche.

Diese obersten Prinzipien sind teils Prinzipien der einzelnen Wissenschaften, teils Prinzipien aller Wissenschaft überhaupt. Es gibt nämlich nach Aristoteles eine Mehrheit von Wissenschaften, deren jede ihre besonderen, nicht weiter ableitbaren Prinzipien hat. Er nimmt nicht die Einheit der Wissenschaft in dem Sinne an, als ob die Grundbegriffe und obersten Grundsätze der Einzelwissenschaften aus gemeinsamen Grundbegriffen aller Wissenschaft ableitbar wären. Wiederholt stellt er die methodische Forderung auf, daß in jeder Wissenschaft aus den ihr eigentümlichen Prinzipien bewiesen werde. Außerdem gibt es aber auch Grundbegriffe aller Wissenschaft, die durch alle Einzelwissenschaften hindurchgehen, und ohne welche in keiner von ihnen wissenschaftliche Erkenntnis möglich wäre. Denn es gibt eine Wissenschaft von dem Seienden als solchem, die erste Philosophie oder Ontologie, die von den verschiedenen Arten des Seienden, auf welche sich die verschiedenen Einzelwissenschaften beziehen, absieht. Ihre Prinzipien und Grundbegriffe sind daher von allgemeiner Bedeutung.

Erkenatniswert der Allgemein begriffe.

Fragen wir nun, wie es denn möglich sei, daß diese Prinzipien ohne Beweis den erforderlichen Grad von Gewißheit für uns haben, und wie sie uns überhaupt zum Bewußtsein kommen, so gibt uns Aristoteles statt einer zwei Antworten, die wir nur schwer in Einklang bringen können. Einmal sagt er, die Vernunft (vô̂c), die höchste menschliche Erkenntniskraft, die nicht, wie das mit Schlüssen wirtschaftende Denken, irren, sondern ihren Gegenstand nur entweder haben oder nicht haben kann, erfasse diese Prinzipien. Andererseits läßt er die Prinzipien, wie alle übrigen Allgemeinbegriffe, aus der sinnlichen Anschauung durch einen fortgesetzten Abstraktionsprozeß hervorwachsen und erklärt die Induktion für die zu wissenschaftlicher Nachprüfung dieses ursprünglich unbewußt sich vollziehenden Prozesses geeignete Methode. Diese beiden Auskünfte erscheinen zunächst als widersprechend, für Aristoteles aber sind sie es nicht, da er sie in einer und derselben Gedankenreihe miteinander verbindet (am Schluß der zweiten Analytik). Er schildert hier 
den Abstraktionsprozeß, durch den aus den einzelnen Wahrnehmungen die Allgemeinbegriffe entstehen, unter dem Bilde eines fliehenden Heeres. Wie da erst ein Mann zum Stehen kommt, dann ein anderer, dann noch einer und so fort bis zu den letzten, so kommen in der Flucht der Wahrnehmungen erst die untersten Artbegriffe zum Stillstand, dann die ihnen übergeordneten Gattungsbegriffe, und so fort bis zu den obersten Prinzipien. So entsteht aus dem flüchtigen Heer der Wahrnehmungen das in Reih und Glied aufgestellte Heer der Begriffe. Den Inhalt des Allgemeinbegriffes bildet der identische Teil vieler einander ähnlicher Wahrnehmungsvorstellungen. Die menschliche Seele ist so beschaffen, daß sie das Allgemeine aus dem Einzelnen herauszuschälen vermag, in dem es als seine Form enthalten ist. Dieses Allgemeine ist nicht ein bloß subjektives Erzeugnis des Geistes, sondern etwas Reales, das der Geist berührt und in sich reproduziert. Die Vernunft verhält sich zu den intelligibeln Objekten ganz analog wie die Wahrnehmung zu den wahrnehmbaren. Sie ist der Anlage nach ein Inbegriff aller jener Formen, die von ihr erkannt werden, aber sie würde eine „tabula rasa" bleiben, wenn sie nicht durch die Erfahrung mit ihnen in Berührung käme. Es handelt sich also bei der Erkenntnis der Prinzipien durch die Vernunft weder um ein angeborenes Wissen, noch um ein durch Beweis vermitteltes Wissen, noch um bloß subjektive Begriffe, die durch willkürliche Umgestaltung des von der Wahrnehmung gelieferten Vorstellungsstoffes gebildet werden, sondern um eine geistige Intuition realer Objekte. Weil diese Intuition durch die Vernunft, unser höchstes Erkenntnisvermögen, das nicht irren kann, erfolgt, liefert sie Erkenntnisse, die gewisser sind als alles aus ihnen Abgeleitete. Aristoteles sucht einen Mittelweg zwischen Apriorismus und Empirismus mit Hilfe seiner noch weiter zu erläuternden Unterscheidung von Potentialität und Aktualität. Potentiell sind die Begriffe a priori in der Vernunft enthalten, die auf empirischem Wege in ihr aktualisiert werden. Auch windet er sich zwischen dem reinen Rationalismus und dem reinen Sensualismus hindurch. Dem Sensualismus macht er das Zugeständnis, daß die Entwickelung unserer Erkenntnis mit der sinnlichen Wahrnehmung anhebt, und daß ihre Objekte, die für uns die nächsten und am leichtesten erkennbaren sind, den Erkenntnisgrund für die geistigen Objekte abgeben. Dem Rationalismus nähert er sich andererseits, indem er die von der Vernunft gedachten Formen und Begriffe für die innere Wesenheit und für die Daseinsgründe der sinnlichen Welt erklärt. Sie sind zwar für uns das Fernere und Spätere, an sich aber und von Natur das Frühere.

Aus dieser Anschauung ergibt sich, welche Rolle nach Aristoteles De- Deciuktion und duktion und Induktion in der Forschung zu spielen und wie sie zusammenzuwirken haben, um die Wissenschaft zu erzeugen. Das Ideal des Wissens vollendet sich in der deduktiven Methode, die das Einzelne aus dem Allgemeinen ableitet und aus seinen Gründen als notwendig beweist. Aber die Deduktion kann erst an ihre Arbeit gehen, wenn ihr die Induktion vorgearbeitet hat. $\mathrm{Zu}$ den Prinzipien jeder einzelnen Wissenschaft kann man nur 
auf dem Wege der Induktion gelangen. Hiermit hängt es auch zusammen, daß Aristoteles der „Dialektik“ eine Bedeutung für die Auffindung der Prinzipien zuschreibt. Unter dialektischen Schlüssen versteht er die Prüfungs-

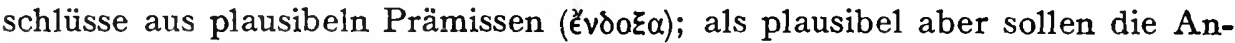
nahmen gelten, die von allen oder von den meisten Menschen oder von den Weisen oder der Mehrzahl der Weisen gehegt werden. Derartige Sätze sind offenbar deswegen geeignet, bei der Aufsuchung der Prinzipien gute Dienste zu leisten, weil sie selbst der Niederschlag einer umfassenden Induktion sind, einer umfassenderen als sie von einem einzelnen Menschen und in einem einzigen Leben angestellt werden kann.

Ontologie. Wenden wir uns nun, nachdem wir die Methodenlehre des Aristoteles kennen gelernt haben, seiner Ontologie oder „ersten Philosophie“ zu. Sie handelt von dem Seienden als solchem und seinen wesentlichen Eigenschaften. Sie hat also ihren besonderen Gegenstand und ist insofern von allen Einzelwissenschaften verschieden, die nur Arten des Seienden erforschen. Das Seiende als solches hat diese Wissenschaft in derselben Weise auf seine Prinzipien und letzten Gründe zurückzuführen, wie es jede Einzelwissenschaft für ihren besonderen Gegenstand tut.

Kategorien. Das Sein ist ein Ausdruck, der in vielfacher Bedeutung gebraucht wird. Das „ist“ als Kopula im Urteil bezeichnet kein selbständiges Sein, sondern die Wahrheit der in dem Urteil enthaltenen Begriffsverknüpfung. Wo aber ein selbständig Seiendes gemeint ist, da ist dies entweder Wesen (Substanz) oder Größe (Quantität) oder Beschaffenheit (Qualität) oder Beziehung (Relation) oder Wo (Ort) oder Wann (Zeitpunkt) oder Lage oder Haben oder Wirken oder Leiden. Bei der Aufstellung dieser zehn Kategorien geht Aristoteles insofern von der Sprache aus, als er sagt, jedes Einzelwort im Satze bedeute eines dieser zehn Dinge. Mit Wortklassen haben aber diese Kategorien ebensowenig zu tun wie mit Satzteilen. Diese Zusammenstellung beruht auf inhaltlichen, nicht auf formal-grammatischen Gesichtspunkten. Die Kategorien'bilden ein Fächerwerk für die Klassifizierung (scheinbar der Worte, in Wahrheit aber) der ihnen entsprechenden Seinsformen. Denn daß jedem Wort und Begriff ein Seiendes entspricht, steht für Aristoteles fest. Bei der Zusammenstellung der Kategorientafel ist der Gesichtspunkt maßgebend gewesen, unter Absehung von jedem bestimmten Seinsinhalt nur die Form des Seins als solchen in Betracht zu ziehen. Doch hat Aristoteles nirgends eine Begründung der getroffenen Auswahl gegeben. Die Aufzählung will vollständig sein. Lage und Haben scheint Aristoteles später absichtlich fortgelassen, d. h. unter andere Kategorien subsumiert zu haben.

Einzelsubstanz,
Art- und Gattungsbegrift, onymie, d. h. keine Namensgleichheit ohne Wesensgemeinschaft, sondern dadurch gerechtfertigt, daß das im eigentlichen Sinn Seiende alle durch die Kategorien bezeichneten Seinsweisen in sich verknüpft. Dieses im eigentlichen Sinn Seiende ist die sinnlich wahrnehmbare Einzelsubstanz, die stets eine Größe und eine Beschaffenheit hat, irgendwo im Raume und irgendwann 
in der Zeit existiert und mit anderen neben ihr existierenden Substanzen in Beziehung steht, auf sie wirkt und durch sie leidet. Die Substanz ist also der einheitliche Träger aller Kategorien, in deren Zusammensein sich ihre Wirklichkeit vollendet und dokumentiert. Darum bilden auch alle den Gegenstand einer und derselben Wissenschaft, die in erster Linie von der Substanz, von ihren Prinzipien, Ursachen und Arten zu handeln hat.

Platon hatte die Objekte der Art- und Gattungsbegriffe für unabhängig von den Sinnendingen existierende Wesenheiten, d. h. für Substanzen erklärt. Die Einzelwesen ließ er nur als unvollkommene, halbwirkliche Abbilder jener gelten. Diese Vorstellung verwirft Aristoteles, weil sie zu der Annahme einer intelligiblen Welt neben und über der sinnlichen führt, deren Verhältnis zu der sinnlichen Welt sich nicht begreiflich machen und aus der sich die tatsächliche Beschaffenheit der sinnlichen Welt nicht erklären läßt. Er stellt daher die umgekehrte Ansicht auf, daß nur das Einzelwesen Substanz im ersten und eigentlichsten Sinne sei, die Art habe weniger und erst in zweiter Linie Anrecht auf diesen Namen, noch weniger die zunächst ihr übergeordnete Gattung, am allerwenigsten die höchsten und allgemeinsten Gattungsbegriffe. Je weiter wir uns, auf der Begriffsleiter aufwärtssteigend, ^von den sinnlichen Einzelsubstanzen entfernen, desto ärmer an Wirklichkeitsgehalt werden bei zunehmendem Umfang die Begriffe. Je größer die Zahl der Subjekte wird, von denen ein Begriff als Prädikat ausgesagt werden kann, desto kleiner wird die Zahl der Prädikate, die ihm selbst beigelegt werden können, und damit sein Wirklichkeitsgehalt. Die Einzelsubstanz erweist sich dadurch als das allem zugrunde Liegende, daß sie von nichts prädiziert werden kann. Den übrigen Kategorien außer der Substanz kommt nur insofern Dasein zu, als sie von der Substanz, sei es als ihr Wesen bildend, sei es als ihr anhaftend, ausgesagt werden können.

Wenn nun Aristoteles gleichwoll mit Platon amnimmt, daß ein Wissen substanz und nur vom Allgemeinen möglich sei und das Wissen nur so weit reichen läßt wie die Deduktion aus Begriffen, so scheint dies mit der eben dargestellten Ansicht in Widerspruch zu stehen. Denn wenn die Einzelsubstanz das Wesenhafteste ist, das Wissen aber auf das Wesen der Dinge geht, so, scheint es, müßten die Einzelsubstanzen das eigentliche Objekt des Wissens bilden. Statt dessen erklärt Aristoteles ausdrücklich, daß das Allgemeine das an sich Frühere und Erkennbarere ist, daß es die Daseinsgründe für das Einzelne und Wahrnehmbare enthält, und daß das Einzelne nur aus dem Allgemeinen und in der Form des Allgemeinen erklärt werden kann. Zur Lösung dieser Schwierigkeit kann uns vielleicht die Tatsache verhelfen, daß Aristoteles den Ausdruck oúcí $\alpha$ in doppeltem Sinne gebraucht, sowohl für die Einzelsubstanz als für das Essentielle einer Sache, ihr im Begriff zu erfassendes Wesen, welches die Definition zum Ausdruck bringt. Die oúci a als substantia hat eine oúcí als esscntia, und aus dieser ist alles ableitbar, was an jener wissenschaftlich erkennbar und erklärbar ist. Die untersten Artbegriffe, die den Einzelwesen am nächsten stehen, drücken die Form aus, die den Einzelwesen Wirk- 
lichkeit gibt. Da die Determination eines Gattungsbegriffes durch das Hinzutreten eines artbildenden Merkmales von Aristoteles als das Formen eines Stoffes aufgefaßt wird, so stellen die komplexesten Begriffe die fertige Form dar, durch die das Wirkliche wirklich ist. Von dieser ihrer essentia unterscheiden sich die substantiae nur durch das Hinzutreten des Stoffes. In dieser Betrachtung liegt die Lösung des Widerspruchs. Durch das stoffliche Substrat haben die Einzelsubstanzen allerdings etwas vor der Art oder Form voraus, die ihr Wesen ausmacht, und haben insofern mehr Anspruch, als Substanzen zu gelten. Aber dieses Substrat fügt ihrer essentia nichts hinzu, daher sind sie kein Objekt der Wissenschaft, die es mit der oủcí als essentia, nicht als substantio zu tun hat.

Stoff und Form. Um dies noch klarer zu machen, müssen wir die aristotelischen Begriffe des Stoffes und der Form und die mit ihnen eng zusammenhängenden der Möglichkeit und der Wirklichkeit untersuchen. Die Form im aristotelischen Sinne ist nicht nur die äußere, körperliche Form, sondern der Inbegriff aller der Merkmale, welche ein Seiendes zu dem machen, was es ist. Jede Form ist aber die Form eines Stoffes. Aristoteles gewinnt die Begriffe der Form und des Stoffes durch eine Analyse des Werdens, welche die von seinen Vorgängern in diesem Begriff und seinem Verhältnis zum Seinsbegriff aufgedeckten Schwierigkeiten heben soll. Die Forderung, mit der empirisch gegebenen Veränderlichkeit aller Sinnendinge das unveränderliche Sein zu vereinigen, welches Objekt eines Wissens sein kann, erfüllt Aristoteles, indem er in jedem Werdeprozeß drei an sich unveränderliche Elemente nachweist. Beim Werden nimmt etwas eine Form an, die es zuvor nicht hatte. Wir müssen dieses Etwas als das beharrende Substrat von dem an ihm sich vollziehenden Vorgang unterscheiden, der zwischen zwei Endpunkten, dem Nichthaben und dem Haben der Form, verläuft. Da der Stoff ohne irgendwelche Form wohl in abstracto gedacht werden, aber nicht in concreto existieren kann, so können wir für das Nichthaben der neuen Form auch das Haben einer anderen Form setzen, und so betrachtet besteht die Veränderung in der Ablösung einer Form des Stoffes durch eine andere. Das Substrat als solches muß als beharrend gedacht werden; aber auch die Formen als solche verändern sich nicht, sie lösen sich nur ab. Die neue Form entsteht nicht, sie wird nur dem Stoffe eingeprägt. Um auf einen Stoff übertragen zu werden, muß sie schon vorher dagewesen sein. Was von dem einzelnen Werdeprozeß gilt, das kann man verallgemeinern: weder der Stoff noch die Formen entstehen oder vergehen. Sie sind die ewigen Prinzipien alles Wirklichen.

Bei jedem in der Erfahrung vorkommenden Werden hat der Stoff schon vor dem Werdeprozeß eine bestimmte Form. Das Metall, aus dem der Künstler eine Bildsäule fertigt, ist im Verhältnis zu der Bildsäule bloßer Stoff, insofern er die Form noch nicht hat, die er bekommen soll. An sich aber ist er bereits geformter Stoff, da er qualitativ bestimmt ist. Das gilt auch von den Grundstoffen, aus denen nach Aristoteles die Welt besteht, den vier empedokleischen Elementen. Wenn man sich nun vorstellt, daß jedes Geformte 
wieder den Stoff für eine Formung bilden kann, so ergibt sich die Unterscheidung der ersten (absoluten oder abstrakten) Materie von den späteren bis zur letzten. Die erste Materie muß absolut eigenschaftslos gedacht werden und ebendarum fähig jede Form anzunnehmen. Bei den späteren ist die Möglichkeit der Formung bereits durch eine bestimmte Beschaffenheit eingeschränkt. Insofern enthält der Stoff in diesem relativen Sinne immer schon die Eignung für die Ausprägung bestimmter Formen und ist der Möglichkeit nach (potentiell) das, was aus ihm werden kann. Jedes Werden ist Potentialität die Verwirklichung einer Möglichkeit. Durch die Formung wird der Stoff das und Aktualität. in Wirklichkeit (aktuell), was er vorher nur potentiell war. Deshalb gilt dem Aristoteles die Materie als das Prinzip der Möglichkeit, die Form als das der Wirklichkeit. Es ist nicht zu verkennen, daß der Begriff der Möglichkeit, auf die erste Materie angewendet, einen wesentlich anderen Sinn bekommt, als er bei der empirischen Materie hat. Bei der letzteren drückt er positiv die Eignung für bestimmte Formen aus und damit ein zur kausalen Erklärung des Werdens brauchbares Moment; dagegen ist die abstrakte Möglichkeit, alle Formen anzunehmen, gleichbedeutend mit dem Mangel jeder positiven Eignung und für kausale Erklärung unbrauchbar. Ebensowenig ist es mit diesem Begriff der Materie vereinbar, daß sie das Zufällige und Unvollkommene in der Natur verursacht. Eine Schwierigkeit liegt auch darin, daß der Materie die Form als Prinzip gegenübergestellt wird. Denn während die Materie ihrem Begriffe nach einheitlich ist, sind die Formen viele und mannigfaltige. Da sie weder Bestandteile eines einheitlichen Wesens'noch von einem einheitlichen Wesen geschaffen sind, so sind sie nicht geeignet, als einheitliches Prinzip der Materie gegenübergestellt zu werden. Da die Formen nicht getrennt von den Einzelsubstanzen, sondern nur in ihnen existieren, so bildet der vielen gleichnamigen Wesen gemeinsame Art- oder Gattungstypus keine reale und substantielle, sondern nur eine logische Einheit. Es kann daher auch das ganze System der Formen nur eine logische, nicht eine reale Einheit bilden. Dennoch nimmt Aristoteles an, daß die Welt durch ihre Form ein einheitliches Ganze bildet. Aus dem Formprinzip als solchem ist dies nicht $z u$ verstehen, sondern nur aus der Beziehung, in welche Aristoteles den Formbegriff zu denen der Bewegungsursache, des Zwecks und des Geistes gesetzt hat.

Aristoteles wendet die Begriffe Stoff und Form, Möglichkeit und Wirk- Lehre von don lichkeit auch da an, wo kein Werden stattfindet, z. B. auf das Verhältnis des Artbegriffs zum Gattungsbegriff, ihre hauptsächlichste Rolle aber spielen sie doch in der Erklärung des Werdens, für.die sie ursprünglich erfunden sind, mag es sich nun um das Werden in der Natur oder um die Kunsttätigkeit des Menschen handeln. Bei jedem solchen Werden sind außer der stofflichen und der formalen noch zwei weitere Ursachen im Spiele, die Bewegungsursache und der Zweck. Bei der Verfertigung einer Statue ist der Künstler die Bewegungsursache. Die Tätigkeit aber, durch die er das Erz formt, erhält ihre Richtung durch den $Z$ weck, den sie zu verwirklichen strebt. Dieser fällt 
mit der Form zusammen, die der Künstler im Geist schauen muß, ehe er sie im Stoffe verwirklicht. Analog stellt sich Aristoteles auch das Schaffen der Natur vor, nur daß hier, bei dem Werden und Wachsen der organischen Wesen, Form und Zweck nicht, wie bei der Statue, von außen in den Stoff hinein, sondern im Stoffe selbst, von innen heraus formend und gestaltend wirken. Die Formen, die wir bisher nur von ihrer logischen und ontologischen Seite her kennen geiernt hatten, gewinnen hier plötzlich ein ganz anderes Ansehen. In der Naturphilosophie spielen sie die Rolle unbewußt zweckmäßig Gattungstypen wirkender Kräfte, von denen jede in einem Teil des Stoffes sich verwirklicht. als zielstrebige In dem Samen ist das Wesen, Tier oder Pflanze, der Anlage nach schon ent-
Krafte. halten, das sich aus ihm entwickelt. Um die Anlage zu verwirklichen, bedarf es äußerer Ursachen, z. B. der Wärme und der Feuchtigkeit. Aber richtunggebend für den Verlauf der Entwickelung ist vielmehr die innere Ursache, die in dĕm Stoff enthaltene Anlage zur Herausbildung einer bestimmten Form. Aus dem Samen entsteht ein Wesen derselben Art, wie jenes bereits vollentwickelte Wesen, das den Samen hervorgebracht und abgesetzt hat. Denn nur ein vollentwickeltes Wesen konnte den Samen hervorbringen, der potentiell das enthält, was das Wesen selbst aktuell ist. Es ist daher das Aktuelle seinem Begriff nach früher als das Potentielle, die Pflanze früher als das Samenkorn und die Henne früher als das Ei. Hieraus ergibt sich die Unvermehrbarkeit der Gattungstypen und der reale, einheitliche Zusammenhang innerhalb der Gattung. Der Gattungstypus überträgt sich von einem Einzelwesen aufs andere und erhält sich durch diese Übertragung. Ihm kommt daher, obgleich er nur in den Einzelwesen sich verwirklicht, ein ewiges und notwendiges Sein $z u$, während jedes Einzelwesen vergänglich ist und sein oder auch nicht sein kann.

Die Einheit der Natur und der höchste $Z$ weck.

Aus dieser Betrachtung erhellt, in welchem Sinne jede einzelne Art und Gattung eine Einheit bildet. Es ist die Einheit des kausalen Zusammenhanges. Wenn Aristoteles einen solchen auch zwischen verschiedenen Arten annähme, im Sinne der modernen Entwickelungslehre, so wäre damit die Möglichkeit gegeben, alle vorhandenen Formen als Glieder eines einheitlichen genetischen Zusammenhanges zu betrachten und so Welt und Natur als eine Einheit aufzufassen. Da aber dieser Gedanke dem Aristoteles noch völlig fern liegt, so muß er sich mit einem Surrogat desselben begnügen. Wir haben die Art- und Gattungstypen als unbewußt zweckmäßig wirkende Kräfte kennen gelernt. Der Zweck, den eine jedle von ihnen verfolgt, fällt aber mit ihrem Wesen zusammen. Ihre Zwecktätigkeit erschöpft sich in ihrer Selbstdarstellung im Stoff. Mit dieser Anschauung, nach der jeder Gattungstypus Selbstzweck ist, hat aber Aristoteles eine andere verbunden, nach der unter den Formen und Zwecken eine Wertabstufung vom Niederen zum Höheren besteht. Hiermit ist zugleich die Vorstellung eines hüchsten und letzten Zweckes gegeben, der durch die Welt als Ganzes verwirklicht werden soll. Für eine auf die Verwirklichung dieses Zweckes hinstrebende Tätigkeit fehlt aber in seinem System das Subjekt. Denn dieses kann weder in der Materie gefunden werden, noch 
in den einzelnen, in ihrer Selbstdarstellung sich erschöpfenden Naturkräften. Auch gibt das Formprinzip als solches keinen Gesichtspunkt her, aus welchem der Vorrang der einen Form vor der anderen hergeleitet werden kann. Aristoteles glaubt zwar die Wertabstufung derFormen aus dem Verhältnis von Form und Stoff in der Weise ableiten zu können, daß er auf den höheren Stufen die Aktualität immer mehr die Potentialität überwiegen läßt, so daß schließlich die reine stofflose Form, die Wirklichkeit ohne alle Möglichkeit die höchste, abschließende Stufe der Entwickelungsreihe bildet. Die Schwierigkeit dieser Annahme liegt darin, daß das Verhältnis der Form zu ihrem Stoffe immer das gleiche und einer graduellen Steigerung nicht fähig ist. Auch liegt es im Wesen des zwischen Form und Stoff bestehenden korrelativen Verhältnisses, daß eine Form ohne allen Stoff ebensowenig denkbar ist wie ein Stoff ohne alle Form. Es wird also hier der Begriff der Form in einem neuen Sinne gebraucht. Die reine Form ist der Geist, und die Wertabstufung der Formen besteht in ihrer allmählichen Annäherung an diese höchste Form als den $Z$ weck aller Zwecke. Insofern nun die Natur in diesem Sinne als ein Stufenreich von Lebensformen sich darstellt, das in einer höchsten Form gipfelt, ist sie ein einheitliches Ganzes.

Die Gleichsetzung der reinen Form mit dem Geist ist bei einem Platoniker leicht begreiflich. Hatte doch schon Platon die Ideen, als die geistigen Objekte, der Seele, als dem geistigen Subjekt, anzunähern versucht. Die Formen werden vom Geiste gedacht. Da nun nach der aristotelischen Erkenntnislehre das erkennende Organ dem erkannten Objekt im Erkenntnisvorgange wesensgleich wird, so muß dasselbe auch von dem Geist im Verhältnis zu dem Begriff gelten. Wenn nun der endliche Geist in diesem vorübergehenden Begriffwerden noch ein potentielles Moment aufweist, so muß man sich den göttlichen Geist als ewige Einheit des Denkens und seines Gegenstandes und damit als reine Aktualität und Form vorstellen.

Also nicht aus dem Formprinzip als solchem, sondern erst aus der Gleich- Absturung des setzung des Formprinzips mit dem geistigen Prinzip wird die aristotelische Formprinzips. Auffassung der Natur als eines einheitlichen Systems vom Niederen zum Höheren abgestufter Lebensformen verständlich. Die unbewußt zweckmäßig wirkenden Kräfte und Formen erscheinen von diesem Gesichtspunkte aus als Vorstufen der mit Bewußtsein wirkenden. Die niedrigste Stufe bildet die unorganische Natur, in der sich nur schwache Andeutungen des Lebens finden. Leben und Seele im eigentlichen Sinne hat erst die Pflanzenwelt. Die Pflanzenseele ist die niedrigste Form der Seele, deren Funktion auf Ernährung und Fortpflanzung beschränkt ist. Die nächsthöhere Form ist die animalische Seele, in der zu den der Pflanzenseele eigenen Kräften die Fähigkeit der Empfindung und der spontanen Ortsveränderung hinzukommt. Beim Menschen endlich tritt zu der vegetativen und der animalischen Seele noch die Denkseele. Jedes höher organisierte Wesen hat auch die seelischen Fähigkeiten der niederen, nur um ein neues Vermögen vermehrt. Die niederen Fähigkeiten bilden eben die Grundlage und Voraussetzung der höheren. So führt also diese ganze Be- 
trachtung dazu, in der kontinuierlichen Stufenfolge der Lebensformen die Einheit der Natur zu finden.

$\mathrm{Zu}$ einer wesentlich anderen Auffassung dieser Einheit scheint dagegen die Lehre von der Bewegung und ihrer Ursache zu führen, die in dem Nachweis eines unbewegten ersten Bewegers gipfelt und, da dieser mit der Gottheit gleichgesetzt wird, den göttlichen Geist von einer neuen Seite zeigt. Der Begriff Bewegung befaßt als Arten unter sich die quantitative Bewegung (Zunahme oder Abnahme bei bleibender Form), die qualitative Bewegung (Veränderung der Beschaffenheit) und die Ortsveränderung. Entstehen und Vergehen im eigentlichen Sinne gibt es nicht. Die örtliche Bewegung liegt den beiden anderen Arten zugrunde. Dieser Satz ist aber bei Aristoteles nicht in demselben Sinne wie bei den Atomisten zu verstehen. Jene führen den Qualitätswechsel auf bloße Ortsveränderung an sich unveränderlicher Atome zurück, d. h. sie leugnen den Qualitätswechsel. Aristoteles dagegen, als Vertreter der dynamischen, nicht mechanischen Naturerklärung, nimmt wirklichen Qualitätswechsel an und meint nur, daß jeder Qualitätswechsel durch eine vorausgehende örtliche Bewegung bedingt sei, insofern sich das die Veränderung bewirkende Ding an das sie erleidende heranbewegen und es berühren muß. Die Bewegung also in diesem jede Art von Veränderung umfassenden Sinne definiert Aristoteles als die Entelechie (Verwirklichung) des Beweglichen, insofern es beweglich ist. Der Gegenstand, der eine Veränderung erleiden soll, muß für diese (z. B. einen Qualitätswechsel) die Anlage haben. Diese kann als Anlage zu dem Vorgang der Veränderung als solchem oder auch als Anlage zu dem fertigen Zustand aufgefaßt werden, in dem die Veränderung ihr Ziel hat und ihren natürlichen Abschluß findet. So ergeben sich zwei Arten der Entelechie. Die Anlage zur Veränderung als solcher verwirklicht sich in der Bewegung, die zu dem fertigen Zustand erst, wenn die Bewegung aufhört. Die Bewegung steht also in der Mitte zwischen dem Potentiellen und dem Aktuellen. Sie bildet den Übergang von dem einen zum anderen.

Jede Bewegung setzt ein Bewegendes als ihre Ursache voraus. Es ist ungenau gesprochen, wenn man sagt: ein Ding bewegt sich selbst. Auch wo dies scheinbar der Fall ist, muß man innerhalb dieses Dinges das Bewegende von dem Bewegten unterscheiden. Denn das Bewegende muß das schon als fertige Wirklichkeit besitzen, zu dem sich das Bewegte erst entwickelt; z. B. $\mathrm{muß}$ wirkliches Feuer schon vorhanden sein, um durch seine Berührung ein Holz in Brand zu stecken. Das Bewegende, das eine Bewegung verursacht, kann selbst entweder bewegt oder unbewegt sein. Ist es bewegt, so rührt seine Bewegung von einem anderen Bewegenden her. Hieraus ergibt sich, daß jede Bewegung sich bis zu einem ersten Bewegenden zurückverfolgen läßt, das selbst unbewegt ist. Denn sonst ergäbe sich ein regressus in infinitum, d. h. es würde überhaupt keine Bewegung zustande kommen. Ewigkeit der Es muß aber ferner die Bewegung im Weltall ewig sein. Denn wenn sie einen
Beweguag.

Anfang hätte, so müßten die beiden Faktoren der Bewegung, der zum Be- 
wegen befähigte (die Form) und der bewegliche (die Materie), vor diesem Anfang als solche schon vorhanden oder noch nicht vorhanden gewesen sein. Waren sie (oder doch einer von beiden) noch nicht vorhanden, so müßten sie vor dem Anfang der Bewegung entstanden sein. Man müßte also eine Bewegung und Veränderung vor dem Anfang der Bewegung annehmen; was absurd ist. Aber auch daß sie vorhanden waren und doch noch keine Bewegung entstand, ist absurd. Denn auch so müßte, um den späteren Anfang der Bewegung zu erklären, eine mit beiden oder doch mit einem von beiden vor diesem Anfang vorgegangene Veränderung angenommen werden, und wir hätten auch so eine Bewegung vor der ersten. Aber auch ein Ende der Bewegung ist undenkbar. Denn was aufhört zu bewegen, hört nicht zugleich auf, die Fähigkeit zum Bewegen zu besitzen, und was aufhört, bewegt zu werden, hört nicht zugleich auf, beweglich zu sein. Es müßte also eine der letzten nachfolgende Bewegung angenommen werden; was ebenfalls absurd ist. Also ist die Bewegung ohne Anfang und ohne Ende. Verbinden wir dieses Ergebnis mit dem früheren, daß sich jede Bewegung bis zu einem unbewegten ersten Beweger zurückverfolgen läßt, so ergibt sich, daß es einen unbewegten ersten Beweger gibt, der selbst ewig ist. Denn einen ewigen Beweger setzt die ewige Bewegung im Weltall voraus. Die sich selbst bewegenden, beseelten Wesen sehen wir entstehen und vergehen und wieder neu entstehen. Daß dem so ist, und zwar mit Notwendigkeit in alle Ewigkeit das muß einen Grund haben. Dieser Grund kann aber nicht in den beseelten Wesen selbst, weder in einzelnen noch in ihrer Gesamtheit gefunden werden. Ihr Entstehen und Vergehen, ihr Anfangen und Aufhören mit der Bewegung sind ja selbst Bewegungen, die einen Beweger voraussetzen, der ebenso ewig und notwendig ist wie sie selbst. Es gibt also einen ewigen unbewegten ersten Beweger, der für alle in der Natur wirkenden Lebenskräfte Ursache der Bewegung ist, wie diese für alles übrige. Dieser ewige Beweger ist reine Form, reine Aktualität, höchster Zweck, absoluter Geist. Als höchster Zweck setzt er alle Kräfte der Welt in Bewegung. Alle Wesen, Pflanzen, Tiere, Menschen, sehnen sich nach diesem höchsten Gut und tun, was sie ihrer Natur gemäß tun, um seinetwillen. So wird durch die Lehre von der Bewegung und ihrem Urheber die Einheit der Welt in einem ganz anderen Sinne erwiesen als durch die Lehre von der Abstufung der Lebensformen. Die Einheit der bewegenden Ursache und der Zweckursache begründet eine reale Einheitlichkeit der Welt. Es ist freilich nicht zu verkennen, daß diese Lehre mit den größten Schwierigkeiten verknüpft ist. Die Sehnsucht aller Wesen nach dem höchsten Zweck mutet uns an wie eine Reminiszenz an den platonischen Eros; den aristotelischen immanenten Naturformen ist solch transzendentes Streben wenig angemessen; sie sind ja ewig und gut und sollten keine über ihre eigene Verwirklichung hinausliegenden Zwecke kennen. Auch die Verbindung, in die Aristoteles seine metaphysisch-theologischen Annahmen mit der Kosmologie und Astronomie gesetzt hat, ist nicht geeignet, diese Schwierigkeiten zu heben. 
Kosmologie: Fixsternhimme

Dem ewigen Beweger muß ein ewig Bewegtes in der Welt entsprechen, dessen Bewegung ununterbrochen, gleichmäßig und allem Wechsel enthoben ist. Diese Eigenschaften kann aber, bei ewiger Dauer, nur die in sich zurückkehrende Kreisbewegung haben. Eine solche nehmen wir an dem Fixsternhimmel wahr. Er bildet die äußerste Sphäre des kugelförmigen Kosmos und durch seine Unveränderlichkeit und die vollkommene Gleichmäfigkeit seiner ewigen Bewegung den vollkommensten 'Teil der Welt. Seine Bewegung wird von der Gottheit selbst bewirkt und verursacht ihrerseits die Bewegung der folgenden Sphären. Die Gottheit wirkt also von der Peripherie her auf die Weltkugel ein, indem sie sie berührt, ohne wieder von ihr berührt zu werden. Berühren muß sie die Welt, weil nach Aristoteles jede Wirkung durch Berührung hervorgebracht wird; berührt werden kann sie nicht, weil die reine Aktualität jedes Erleiden ausschließt. Die äußere Grenze der Fixsternsphäre bildet die Grenze des Raumes. Denn der Raum ist nichts anderes als der Ort eines beweglichen Körpers, die unbewegliche Grenze des Umschließenden gegen das Umschlossene. Was daher nicht umschlossen wird, das ist auch nicht im Raume. Das Dasein des Raumes ist an das der Körperwelt gebunden. Ein unendlicher leerer Raum außerhalb des Kosmos ist daher nicht anzu. nehmen. Gott ist nicht im Raume, obwohl er von der Peripherie her auf die Weltkugel einwirkt. Er ist auch nicht in der Zeit, sondern in der Ewigkeit. Denn die Zeit ist ein Akzidens der Bewegung, ist also nur da, wo es bewegte Körper gibt. Sie ist das Maß (die Zahl) der Bewegung hinsichtlich ihrer sphären. früheren und späteren Momente. Die von Grott ausgehende Bewegung des Fixsternhimmels teilt sich den folgenden Sphären (konzentrischen, aus Äther gebildeten Kugelschalen) mit, welche die Planeten, die Sonne und den Mond tragen. $\mathrm{Da}$ aber die Planeten außer der Bewegung, die sie mit dem Fixsternhimmel teilen, noch eine Eigenbewegung haben, so sieht sich Aristoteles genötigt, für jeden von ihnen mehrere Sphären anzunehmen, die zum.Teil rückläufige Bewegung haben, und aus dem Zusammenwirken ihrer Bewegung die tatsächliche Bewegung der Planeten zu erklären. Jede dieser Sphären denkt sich Aristoteles beseelt. Die Sphärengeister sind selbständige Wesen, die gewissermaßen als Untergötter neben der Gottheit stehen und dem Philosophen eine willkommene Gelegenheit bieten, an den Polytheismus der Volksreligion anzuknüpfen. Es ist klar, daß schon hier die Einheit der Bewegung im Weltall durchbrochen wird. Denn für die rückläufigen Bewegungen sind die Sphärengeister selbst erste Beweger; und obwohl man vielleicht sagen kann, daß sie auch diese Bewegungen um des höchsten Zweckes willen ausführen und insofern von ihm den Antrieb empfangen, so ist es doch mißlich, daß die von Gott als Zweck und die von Gott als Bewegungsursache bedingten Bewegungen in entgegengesetzter Richtung verlaufen und uns an der Einheit des letzten Zwecks mit der ersten Bewegungsursache irre machen.

Sublunarisclie

Die Sphären in ihrer Gesamtheit bilden die obere Welt, die sich von Welt.

der sublunarischen schon durch ihren Stoff unterscheidet. Sie ist aus unvergänglichem Stoff, dem Äther, gebildet, den Aristoteles als quinta essentia 
neben die vier dem Stoffwechsel unterliegenden Elemente stellt, aus denen die sublunarische Welt besteht. Der Minderwertigkeit des Stoffes entspricht in der letzteren die Ungleichmäßigkeit der Bewegungen und das ewig abwechselnde Entstehen und Vergehen aller Einzelwesen. Ein absoluter Gegensatz besteht aber doch nicht zwischen der unteren und der oberen Welt. Insofern schon die Planetenregion unvollkommener als der Fixsternhimmel ist, bildet sie schon eine Übergangsstufe zu der noch unvollkommeneren Welt unter dem Monde und bewirkt sogar den in ihr herrschenden Stoffwechsel. Doch wiederholt sich hier, hinsichtlich der einheitlichen Ableitung der Bewegung, dieselbe Schwierigkeit, die uns in der oberen Welt begegnet ist. Denn die von den Prinzipien der lebendigen und beseelten Wesen ausgehenden Bewegungen können, wenn überhaupt, jedenfalls nicht in derselben Weise wie der Stoffwechsel der Elemente durch die oberste, einheitliche Bewegungsursache bedingt sein.

Was Aristoteles auf Grund seiner allgemeinen naturphilosophischen Anschauungen für die Erklärung der einzelnen Naturvorgänge geleistet hat, Qualitative, dy namisthe, können wir hier nicht verfolgen, weder seine Meteorologie, noch seine Ana- Naturerklärung. tomie und Physiologie der Tiere, die vor allem seinen Ruhm als Naturforscher begründet hat. Die Methode, die er auf dem Gebiet der organischen Natur zur Erklärung der Erscheinungen anwendet, hat ihre bezeichnenden Merkmale in der Überordnung der qualitativen über die quantitative, der dynamischen über die mechanische, der teleologischen über die kausale Betrachtungsweise und bildet in diesen drei Beziehungen den ausgesprochenen Gegensatz zu der von der atomistischen Schule befolgten Methode. Qualitativ ist seine Betrachtungsweise, insofern ihm Qualitäten wie warm und kalt, trocken und feucht, rot und grün, süß und bitter als reale Eigenschaften der Objekte selbst gelten, nicht, wie den Atomisten, als subjektive Erscheinungen, denen in den Objekten selbst nur Unterschiede der Größe, Gestalt und Anordnung der Stoffteile entsprechen. Der Qualitätswechsel ist daher für ihn ein von der Ortsveränderung verschiedener Vorgang, der nicht auf die mechanischen Bewegungsprinzipien, Schwere, Druck und Stoß, zurückgeführt werden kann. Dynamisch also, nicht mechanisch ist seine Betrachtungsweise, insofern er sich veranlaßt sieht, wirkende Kräfte in der Natur anzunehmen, die nicht aus den Stößen und Gegenstößen der kleinsten Stoffteilchen ableitbar sind, sondern die ihnen unterworfene Materie zu mannigfaltigen Wesen ausgestalten. Insofern diese $\mathrm{Kräfte} \mathrm{als} \mathrm{zweckmäßig} \mathrm{wirkend} \mathrm{gedacht} \mathrm{werden,}$ ist die kausale Auffassung der teleologischen untergeordnet. Wenn Aristoteles bei der Erklärung der Phänomene aus Zwecken oft in uns befremdender Weise fehlgreift, so liegt das viel weniger an der Unrichtigkeit seiner methodischen Grundanschauung als an der Unzulänglichkeit seiner Tatsachenkenntnis.

Was die organischen Wesen von den unorganischen unterscheidet, ist Die Seele. nach Aristoteles der Besitz einer Seele. Der organische (mit Organen, d. h. Werkzeugen ausgestattete) Leib ist auf den Besitz einer Seele angelegt, und 
Seele kann nur in einem organischen Leibe sein. Die Organe sind da, um gebraucht zu werden. Sie setzen also eine Seele voraus, die von ihnen Gebrauch macht. Unter Seele verstehen wir das Prinzip des Lebens, Leben aber schreiben wir denjenigen Wesen zu, die sich ernähren und wachsen. Zur Aneignung und Verarbeitung der Nahrung bedarf die Seele körperlicher Organe. Daraus folgt, daß nur in einem organischen Leibe Seele sein kann. Der organische Leib und die Seele verhalten sich also zueinander wie der Stoff zur Form, wie die Potentialität zur Aktualität. Die Seele ist die Entelechie eines organischen, d. h. zum Leben angelegtèn Körpers; und zwar seine erste Entelechie. Man muß nämlich die Fähigkeit zu den Lebensfunktionen von der Funktion selbst unterscheiden. Jene ist das Frühere und dauert fort, auch wenn die Funktion selbst (z. B. im Schlafe) zeitweilig aussetzt. Jene ist also die erste Entelechie. Diese aristotelische Auffassung der Seele sucht einen Mittelweg einzuschlagen $z$ wischen dem platonischen Dualismus, der die Seele als eine mit dem Leibe verbundene zweite Substanz auffaßt, und der materialistischen Auffassung, die das Seelenleben aus den Bewegungen der Atome entstehen läßt. Leib und Seele sind nicht zwei voneinander trennbare Substanzen, sondern bilden als Stoff und Form eine untrennbare Einheit; aber in dieser Wesenseinheit ist die Seele das Frühere und das herrschende Prinzip. Das Ganze ist früher als die Teile, der $\mathrm{Z}$ weck früher als die zu seiner Verwirklichung führende Entwickelung. So ist hier in der a11: gemeinen Auffassung der Seele der Dualismus vermieden, doch wird sich zeigen, daß er in der Auffassung der menschlichen Seele und ihrer Kräfte in ähnlicher Weise wieder zum Durchbruch kommt wie in der Metaphysik und Kosmologie.

Abstufung der seelischen Kräfte.
Wir haben früher gesehen, daß Aristoteles niedere und höhere Formen der Seele kennt, durch die sich die niederen und höheren Gattungen lebender Wesen voneinander unterscheiden. Die Pflanze hat die Fähigkeit, sich $z u$ ernähren, zu wachsen und Frucht zu tragen, aber es fehlt ihr das Wahrnehmungsvermögen. Durch dieses unterscheidet sich die Tierseele von der Pflanzenseele. Die Tierseelen sind wieder untereinander nach der Zahl ihrer Sinnesorgane abgestuft. Manche haben nur die niedrigsten Sinne, Tastsinn und Geschmack, andere auch die höheren, durch die man entfernte Gegenstände wahrnehmen kann. Um aus der Wahrnehmung des Entfernten Nutzen ziehen zu können, haben diese höheren Tiere auch die Fähigkeit, sich selbst von Ort zu Ort zu bewegen. Von der Wahrnehmung ist die Lust- und Unlustempfindung nicht zu trennen; mit dieser verbindet sich der Trieb, die Lust zu suchen und die Unlust zu meiden. Also muß auch das Begehrungsvermögen als Bestandteil der animalischen Seele gelten. Immer finden sich die höheren Kräfte nur, wo auch die niederen vorhanden sind. Letztere bilden den Stoff und die Möglichkeit für die Ausbildung der höheren. Dies gilt auch von der Menschenseele, die außer der vegetabilischen und der animalischen Seele eine Denkseele enthält. Indem der Mensch alle durch die stufenweise Überwindung der Materie entwickelten Formen der Lebenskraft 
bis zum reinen Geiste hinauf in sich trägt, ist er gewissermaßen ein Mikrokosmos.

Von den einzelnen psychischen Vorgängen hat Aristoteles am genauesten die Erkenntnisfunktionen untersucht und ihren von der Sinneswahrnehmung bis zum spekulativen Denken hinaufreichenden inneren Zusammenhang verfolgt. Die Sinneswahrnehmung, die der Mensch mit den Tieren teilt, ist eine durch den Leib vermittelte Veränderung in der Seele, deren Bewegungsursache das wahrgenommene Objekt ist. Das Wahrnehmungsorgan muB mit dem Objekt, sei es unmittelbar, sei es durch ein Medium in Ber̈̈hrung treten, um eine Einwirkung von ihm zu erleiden. Es muß ferner dasjenige potentiell sein, was das Objekt aktuell ist. Hieraus erklärt sich, daß das Auge nur Farben, das Ohr nur Klänge usw. wahrnehmen kann. In dem Wahrnehmungsvorgang geht die Form des Wahrgenommenen ohne den Stoff auf das Organ über, wodurch die potentiell in ihm vorhandene Qualität aktualisiert wird. Die Wahrheit der Sinneswahrnehmung besteht darin, daß der Wahrnehmungsakt ein einheitlicher Vorgang ist. Das Tönen z. B. und das Hören sind zwar ihrem Begriffe nach voneinander verschieden, identisch aber, insofern das Tönen des Objekts und das Hören des Subjekts ein und derselbe reale Vorgang sind, nur von zwei Seiten betrachtet. In der Wahrnehmung wird die objektive Qualität subjektiv. Die fünf Sinnesorgane befördern die empfangenen Eindrücke weiter zu dern im Herzen befindlichen Zentralorgan. Hier ist der Sitz der ,gemeinsamen Wahrnehmung“, die aus den Daten der Einzelsinne das Gesamtbild des Gegenstandes zusammensetzt; von Eigenschaften, die nicht spezifisches Objekt eines Einzelsinnes sind, son-

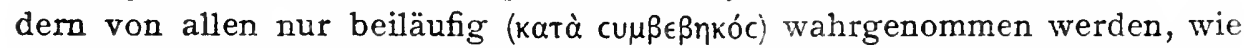
Gestalt, Größe, Zahl, Bewegung oder Ruhe, kommt erst durch sie ein deutliches Bild zustande. Zustände dieses „gemeinsanen“ Wahrnehmungsorgans sind Schlaf und Wachen. Von der Gesamtwahrnehmung bleibt im Zentralorgan ein Abbild dauernd erhalten, das, wenn es ohne die örtlichen und zeitlichen Umstände seiner Entstehung reproduziert wird, anschauliche Vorstellung heißt. Durch mehrfach wiederholte Wahrnehmung desselben Objekts entsteht eine Vertrautheit mit diesem. Die anschauliche Vorstellung betritt zwar schon den Weg der Verallgemeinerung, indem sie gewisse Zufälligkeiten des Wahrnehmungsbildes, wie örtliche und zeitliche Umstände, ausschaltet; aber sie geht immer noch auf das Einzelne und Zufällige, das sein oder auch nicht sein kann. Von der anschaulichen Vorstellung verschieden ist der Begriff. Jene hat auch das Tier, für diesen ist ein anderes seelisches Vermögen erforderlich, die Denkkraft, die den Menschen vom Tier unterscheidet. Diese ist entweder theoretisch oder praktisch. Für die Psychologie der Erkenntnisfunktionen haben wir es zunächst nur mit der theoretischen Vernunft $\mathrm{zu}$ tun. Diese hat die Fähigkeit, im Begriff das allgemeine und notwendige Wesen der Dinge zu erfassen. Sie ist in Ansehung der Begriffe als der intelligibeln Objekte ein analoges Vermögen, wie die sinnliche Wahrnehmung hinsichtlich der sinnlichen Objekte: sie schaut die- 
Schaffende Vernunft. selben. Diese Analogie führt zu der Auffassung, daß die Vernunft potentiell alles das ist, was sie zu denken vermag, sowie jedes Wahrnehmungsorgan potentiell das ist, was es wahrzunehmen vermag. Im Denken wird diese Potenz für den jedesmal gedachten Begriff aktualisiert. Wodurch wird diese Aktualisierung bewirkt? Man könnte meinen: durch die Wahrnehmungsvorstellungen. Denn in ihnen sind ja die allgemeinen Formen enthalten, und wir wissen, daß ohne Wahrnehmung kein begriffliches Denken zustande kommt. Aber dies ist nicht die aristotelische Auffassung. Die Vernunft kann sich zu dem von den niederen Seelenkräften gelieferten Vorstellungsstoff nicht leidend, sondern nur schaffend und verwirklichend verhalten. Nach dem Grundsatz, daß die Ursache einer Aktualisierung das, was sie verwirklichen hilft, selbst schon in voller Wirklichkeit sein muß, nimmt Aristoteles eine schaffende Vernunft in der Menschenseele neben und über der leidenden an, die nicht bald denkt und bald nicht denkt, sondern reine Aktualität und deshalb Denken und Gegenstand des Denkens zugleich ist. Diese ist es, durch die in der leidenden Vernunft die in ihr angelegten Begriffe verwirklicht werden. Thre Einwirkung entspricht aber nicht der Einwirkung des Sichtbaren auf das Auge beim Sehen, sondern der des Lichtes. Wie das Licht, sagt Aristoteles, die potentiell vorhandenen Farben wirklich macht, so auch die schaffende Vernunft die Begriffe. Wenn in diesem Bilde die schaffende Vernunft dem Licht entspricht, die leidende dem Auge, so bleibt für die Wahrnehmungsvorstellung der farbige Gegenstand als Korrelat übrig. Da nun, nach der aristotelischen Theorie des Sehens, das Licht als die Energie des durchsichtigen Mediums die Farbe dem Auge zuführt, so kann man in dem Bilde den Gedanken ausgedrückt finden, daf die in den Wahrnehmungsvorstellungen nur potentiell enthaltenen Begriffe durch die schaffende Vernunft erst wirklich gemacht und dann von der leidenden empfangen werden. Doch ist es unmöglich, dieser schwierigen Lehre in der Nacherzählung mehr Klarheit zu verleihen, als ihr der Philosoph selbst zu geben vermocht hat.

Bei der Entstehung dieser Lehre hat gewiß das Bestreben mitgewirkt, den Menschen auch darin zum Abbild der Welt im kleinen zu machen, daß ihm ein seelisches Vermögen beigelegt würde, welches sich zu seinem übrigen Wesen wie Gott zur Welt verhält. Diese Vernunft ist das Göttliche im Menschen, der allein ewige und unsterbliche Teil seines Wesens. Sie ist stofflose Form, also nicht an ein leibliches Organ gebunden. Darum kann sie das leibliche Leben überdauern. Während alle übrigen Seclenkräfte als Produkte einer stufenweisen Entwickelung der dem Stoffe immanenten Form dargestellt werden, kommt dieser göttliche Funke ron oben her zu dem menschlichen Wesen hinzu. Hier ist der Punkt, wo der metaphysische Dualismus auch in der Psychologie zum Durchbruch kommt. Dem religiösen Bedürfnis kann die Unsterblichkeit dieses jeder Individualität entbehrenden Seelenteiles nicht genügen; und wie es kommt, daß jeder einzelne Mensch ein Stück Gottheit in sich trägt, hat Aristoteles zu erklären nicht einmal versucht. 
Daß unsere Seele die schaffende Vernunft besitzt, erschließen wir nur Die Meinung aus ihren Wirkungen. Die Denktätigkeit, die wir in uns beobachten, gehört (Doxa). ausschließlich der leidenden Vernunft an. Diese kann auch irren, zwar nicht in der Erfassung der obersten, absolut einfachen Begriffe, wohl aber bei ihrer Verknüpfung im Urteil. Die Meinung (ঠóそa) faßt Aristoteles als ein Urteil auf, das sich auf Dinge bezieht, die sein oder auch nicht sein können, also auf das Einzelne und Stoffliche. Danach müßte sie streng genommen zum wahrnehmenden Teil der Seele gehören, in der ja auch die anschauliche Vorstellung zustande kommt. Da sie aber den Tieren ausdrücklich abgesprochen wird, so scheint es doch, als ob sie Aristoteles zur Denkseele rechnete. Jedenfalls ist das begriffliche Denken, das wir als besonderes Seelenvermögen von der Vernunft zu unterscheiden keinen Grund sehen, in seinen Urteilen dem Irrtum unterworfen, und für ein irrtümliches oder der zureichenden Begründung entbehrendes Urteil stehen nur die Ausdrücke Meinung

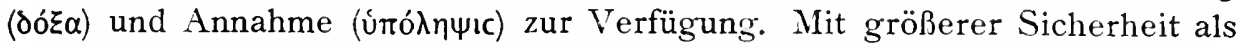
die Meinung können wir das Wissen als eine Leistung der (leidenden) Vernunft in Anspruch nehmen. Wenn Aristoteles gelegentlich die Vernunft, durch welche die unbeweisbaren, obersten Prinzipien gefaßt werden, dem Wissen als eine höhere Erkenntnisart gegenüberstellt, so will er nicht verschiedene Seelenteile oder Vermögen, sondern nur verschiedene Leistungen der Denkseele unterscheiden. So werden wir auch die praktische Vernunft nicht als ein besonderes Vermögen aufzufassen haben, sondern als eine von der theoretischen begrifflich verschiedene Betätigung desselben Seelenteils. Um diese Betätigung zu verstehen, müssen wir noch einmal zu den niederen Seelenteilen zurückkehren.

In dem wahrnehmenden Seelenteil verbinden sich mit den $W^{\top}$ ahrneh- Fühlcn, Begeb mungen die Gefühle der Lust und der Unlust, von denen jene aus der Funktionsförderung, diese aus der Funktionshemmung seelischer oder körperlicher Anlagen entspringt. $\mathrm{Ob}$ auch die reine, dauerhafte Lust, die sich mit der ungehemmten Funktion der Denktätigkeit als des höchsten seelischen Vermögens verbindet, von der animalischen Seele empfunden wird oder von der Denkseele selbst, kann man zweifeln. Die Affekte sind Mischungen aus Lust und Unlust, in denen bald diese, bald jene überwiegt. Aus dem Gefühl entspringt das Begehren, ohne das es kein Handeln gäbe. Aristoteles nimmt nicht mit Platon einen besonderen Seelenteil als Träger des Begehrens an, sondern verlegt dieses in das empfindende und fühlende Zentralorgan. Erstreben und Meiden sind analoge Funktionen auf dem Gebiet des Fühlens wie Bejahen und Verneinen auf dem des Denkens. Die Fähigkeit körperlicher Ortsveränderung, durch die sich jede Handlung verwirklicht, wird vom Begehrungsvermögen aus in Bewegung gesetzt. Nur durch dieses ist die Seele das Bewegungsprinzip des Körpers. Das Begehren seinerseits entsteht nicht ohne die Vorstellung eines begehrenswerten Gegenstandes. Dieser ist stets ein Gut oder wenigstens ein scheinbares Gut, das als erreichbar clurch unsere Tätigkeit vorgestellt wird. Nicht weil wir es begehren, erscheint es uns gut, 
sondern weil es uns gut scheint, begehren wir es. Indem Aristoteles so den Vorgang der Willensbildung in ein Erkennen und ein Begehren zerlegt und jenem die Herrschaft über dieses zuschreibt, führt er die Abstufungen des Wollens auf die Abstufung der Erkenntnisfunktionen zurück. Es kann eine Wahrnehmung sein oder eine anschauliche Vorstellung oder eine Meinung oder ein Vernunftgrundsatz, durch den das Begehrungsvermögen in Bewegung gesetzt und veranlaßt wird, seinerseits den Körper zur Handlung zu bewegen. Ein durch sinnliche Wahrnehmung oder anschauliche Vorstellung veranlaßtes Begehren heißt Begierde. Es richtet sich nur auf das Einzelne und Gegenwärtige. Ist eine generelle Meinung der bestimmende Faktor, so findet eine Subsumption des Einzelfalles unter den allgemeinen Satz, eine Art von Syllogismus statt, dessen Schlußsatz der Entschluß zum Handeln bildet. In diesem

Praktische Vernunft.

Die Ethik: Der höcbste Zweck.
Falle sprechen wir nicht von Begierde, sondern von Willen. Wenn endlich die Vernunft und das beratschlagende Denken eingreifen, so entsteht ein vernünttiger Wille. Die Vernunft, wenn sie sich in dieser Richtung betätigt, heißt praktische Vernunft. Von der theoretischen unterscheidet sie sich nur durch ihren Gegenstand und ihr Ziel. Ihr selbst ist jedes Wollen und Begehren fremd. Ihre Aufgabe ist nur Erkenntnis des praktisch Guten. Als beratschlagendes Denken wägt sie die verschiedenen Handlungsmöglichkeiten gegeneinander $a b$ und entscheidet $z$ wischen ihnen durch Subsumption des Einzelfalles unter einen allgemeinen, praktischen Vernunftgrundsatz. So kommt der seiner Gründe sich bewußte vernünftige Vorsatz zustande, indem sich das Begehrungsvermögen von der Vernunfterkenntnis leiten läßt. Denn dieses ist zwar an und für sich vernunftlos, hat aber im Gegensatz zu der vegetativen Seele die Fähigkeit, zu der Vernunft in Beziehung zu treten.

Diese psychologischen Ansichten bilden die Grundlage für die Ethik des Aristoteles, insofern das psychologisch-genetische Verständnis der beim Handeln mitwirkenden seelischen Faktoren für die richtige Wertbeurteilung der menschlichen Handlungen und des menschlichen Lebens eine unerläßliche Vorbedingung bildet. Den Ausgangspunkt der ethischen Betrachtung bildet für Aristoteles der Zweckbegriff. Jedes Handeln ist durch Zwecke bestimmt. Wir sahen, daß immer nur die Vorstellung eines Gutes, und zwar eines solchen, dessen Verwirklichung durch unser Handeln als möglich vorgestellt wird, den Willen in Bewegung setzt, aus welchem die Handlung entspringt. Durch die richtige Zwecksetzung ist also der Wert des Handelns bedingt. Es muß ein wirkliches, nicht nur ein scheinbares Gut sein, auf das die wertvolle Handlung ausgeht. Erwägt man nun, daß der nächste $Z$ weck oft nur als Mittel zu einem höheren Zwecke erstrebt wird, der selbst wieder ein Mittel zu einem noch höheren Zwecke bildet, so entsteht die Vorstellung einer Stufenleiter der Güter und der Zwecke, die unmöglich ins Unendliche fortgehen kann, sondern in einem letzten $Z$ weck ihren $A b s c h l u ß$ finden muß. Die relativen $Z$ wecke sind eben nur $Z$ wecke durch ihre Beziehung auf den absoluten $Z$ weck. Bei manchen Tätigkeiten ist der $Z$ weck ein von ihnen hervorgebrachtes Werk, wie z. B. beim künstlerischen Schaffen, bei anderen liegt der $Z$ weck 
in der richtigen Art der Betätigung selbst. Der höchste Zweck kann nach Aristoteles nur von der letzteren Art sein. Dies steht in Einklang mit der metaphysischen Lehre, die in der reinen Tätigkeit (Energie) das höchste Reale findet. Von dieser Seite her gewinnt Aristoteles für den volkstümlichen Begriff der Glückseligkeit als des höchsten praktischen Gutes einen bestimmten Inhalt. Die Glückseligkeit besteht in der tugendgemäßen Betätigung der Seele. Die Glückselig Die Seele ist ja das Daseinsprinzip des Menschen. Der Leib ist nur um der keit. Seele willen da. Also muß in einer seelischen Betätigung der Zweck liegen. Unter Tugend versteht Aristoteles die Eignung eines Wesens zu stetiger und vollkommener Ausübung der ihm seiner Anlage und Bestimmung nach zukommenden Tätigkeit. Die tugendgemäße Betätigung ist also diejenige, bei der die spezifische Anlage des betreffenden Wesens voll verwirklicht wird, und zwar auf Grund einer dauernden, diese Betätigung ermöglichenden Seelenbeschaffenheit. Die letztere Bestimmung ist nötig, weil wir uns die Glückseligkeit als höchstes Gut nur in einem ganzen, vollen Menschenleben verwirklicht denken können. Denn eine Schwalbe macht noch keinen Lenz. Da die spezifische Begabung des Menschen in seiner Vernunft besteht, so ist ihre Tüchtigkeit die spezifisch menschliche Tüchtigkeit und ihre der Tüchtigkeit entsprechende vollkommene Betätigung die spezifisch menschliche Glückseligkeit. Die Vernunft betätigt sich aber, wie wir sahen, nicht nur als theoretische, sondern auch als praktische Vernunft. Als solche ist sie auf das $\mathrm{Zu}-$ sammenwirken mit dem Begehrungsvermögen angewiesen und hat in den durch dieses vermittelten Handlungen ihr Ziel. Also gehört zur menschlichen Gesamttugend auch die richtige Beschaffenheit der animalischen Seele. $\mathrm{Zu}$ freiem und ungehemmtem Handeln gehört aber auch ferner eine richtige Körperbeschaffenheit und endlich eine angemessene Ausstattung mit äußeren Gütern. Darum sind auch diese zur vollen Glückseligkeit erforderlich, aber nur als Mittel für die seelische Betätigung. Die Lust ist nicht das höchste Gut, aber sie ist als Nebenprodukt in demselben enthalten. Die höchste Lust verbindet sich mit der Betätigung des reinen Denkens. Darum kann es dem Tugendhaften nie an Lust fehlen. Durch diese Auffassung des höchsten Gutes vermittelt Aristoteles zwischen Platons transzendenter Zielsetzung, die dem Menschen aufgibt, Gott ähnlich zu werden, und der hedonistischen Ethik Demokrits.

Eingehend beschäftigt sich Aristoteles mit der Tugendlehre. Die Gesamttugend besteht aus einer großen Zahl einzelner Vorzüge, die teils das Denkvermögen als solches, teils das Gefühls- und Begehrungsvermögen in seinem Verhältnis zum Denkvermögen betreffen. Jene heißen dianoëtische Tugenden, z. B. Weisheit, Einsicht, Scharfsinn usw., diese ethische, z. B. Freigebigkeit, Besonnenheit. Nur die ethischen haben für die Ethik in unserem Sinne Bedeutung. Sie gehören, wie alle Tugenden, in die Gattung der habituellen Zustände. Wie die Tugend oder Trefflichkeit eines körperlichen Organs, z. B. des Auges, in einer dauernden Beschaffenheit besteht, durch die es seine von Natur ihm zukommende Funktion (das Sehen) gut auszuüben vermag, so be- 
steht auch die seelische Trefflichkeit in einer entsprechenden Beschaffenheit der Seele und im besonderen die ethische Trefflichkeit der Seele in einer dauernden Beschaffenheit des Gefühls- und Begehrungsvermögens, durch die es gut und richtig zu fühlen und zu begehren befähigt wird. Diese treffliche Beschaffenheit ist nicht von Natur als angeborene Eigenschaft in der Seele vorhanden, sondern entsteht durch Übung und Gewohnheit. Da es viele verschiedene Gefühle und Begehrungen gibt, so gibt es auch viele Tugenden. Diese sind voneinander trennbar. Man kann hinsichtlich einiger Arten des Fühlens und Begehrens den richtigen Habitus schon besitzen, hinsichtlich anderer noch nicht. Da aber jeder solche Habitus darauf beruht, daß sich der fühlende Seelenteil gewöhnt hat, gemäß den Forderungen der vernünftigen Einsicht zu funktionieren, diese aber einheitlich ist, so schließen sich doch schließlich bei dem ethisch vollkommenen Menschen alle diese Vorzüge zu einer einheitlichen Gesamttugend zusammen. Wie nun überhaupt bei jeder Tätigkeit die kunstgerechte Ausübung in der Meidung der schädlichen Extreme, des Zuviel und des Zuwenig, besteht, so besteht auch das richtige Richtige Mittc. Fühlen und Begehren in der Einhaltung der richtigen Mitte. Diese Mitte ist aber nicht objektiv als arithmetisches Mittel zu bestimmen, sondern in Beziehung auf das Subjekt. Die richtige Mitte läßt sich nicht für alle Menschen gleichmäßig in allgemeingültiger Weise bestimmen, sondern nur für den einzelnen Menschen nach Maßgabe der besonderen obwaltenden Umstände. Die Rücksicht auf die ungehemmte Gesamtfunktion seines Wesens und die Erfüllung seiner Gesamtaufgabe ist es, die jedem einzelnen Fühlen, Begehren und Wollen seine Grenze zieht. Die vernünftige Einsicht hat die Aufgabe, die richtige Mitte zu bestimmen.

Nach der eigenen Äußerung des Aristoteles kann eine solche Bestimmung der richtigen Mitte nur bei einem teiloaren Kontinuum stattfinden. Sie bezieht sich daher in erster Linie auf die Gefühle und Begelırungen, die bezüglich ihrer Intensität teilbare Kontinua sind. Aristoteles lenkt aber, wenn er von der richtigen Mitte spricht, nicht nur an eine Intensitätsstufe, sondern auch an das richtige Verhältnis der Gefühle zu ihren Gegenständen und Veranlassungen. Wann wir ein Gefühl haben sollen und aus welchen sachlichen Gründen und gegenüber welchen Personen und zu welchem Zweck und wie, bestimmt die Tugend. Es ist klar, daß es sich bei diesen Gesichtspunkten nicht mehr um ein teilbares Kontinuum handelt, also der Gesichtspunkt des juste milieu hier schon gewaltsam gestreckt wird. Es handelt sich ja nicht um die Zahl der Fälle, die als steigerungsfähig anzuerkennen wäre, sondern um die in jedem Einzelfall das Gefühl verursachenden Umstände. Lassen sich auch diese in eine Skala ordnen? Aber auch bei Handlungen soll es eine richtige Mitte zwischen Übermaß und Untermaß geben; eine allgemeine Erläuterung dieses Punkes gibt Aristoteles nicht, sondern überläßt uns, aus seiner Besprechung der einzelnen Tugenden zu entnehmen, wie es gemeint ist. Einige Tugenden bezieht er auf Gefühle, z. B. die Tapferkeit auf Furcht und Zuversicht, die Mäßigkeit (Sophrosyne) auf Lust und Unlust, die Milde 
auf den Zorn, oder auf Begehrungen, z. B. die Hochherzigkeit und die Ehrliebe auf die Ehrbegierde; bei anderen Tugenden, wie der Freigebigkeit und der Gerechtigkeit, sind es die äußeren Handlungen, für die es einc Mittellinie $z u$ finden und einzuhalten gilt. In der Begriffsbestimmung der Tugend hingegen zeigt es sich, daß Aristoteles weder die Gefühle und Begehrungen noch die äußeren Handlungen, sondern die Willensvorsätze als das Gebiet betrachtet, in dessen vernunftgemäßer habitueller Regelung nach dem Prinzip der richtigen Mitte die Tugend und der sittliche Charakter besteht. Auch aus den oben besprochenen psychologischen Ansichten des Aristoteles ergibt sich, daß er nicht das Gebiet der Gefühle und nicht das der äußeren Handlungen, sondern nur das des vernünftigen Wollens als den eigentlichen Gegenstand der ethischen Werturteile betrachten konnte. Denn nur die freiwillige Handlung kann sittlich gut sein. Freiwillig aber ist nur eine Handlung, die ohne äußeren Zwang, mit vollem Bewußtsein der Umstände und der Folgen, auf Grund vorausgegangener Überlegung vollzogen wird. Darin liegt, daß der freie Willensvorsatz der Gegenstand des sittlichen Werturteils ist. Insofern muß die Tugend als ein Habitus hinsichtlich der Willensbildung, als dauernde Willensrichtung aufgefaßt werden. Die Beschaffenheit der Gefühle, die dem Vorsatz vorangehen und ihn begleiten, und der Handlungen, in denen er verwirklicht wird, kommen nur abgeleiteterwo cise als ethischer Gegenstand in Betracht. Aus dieser Betrachtung ergibt sich, daß das Prinzip der richtigen Mitte, das Aristoteles nur auf Gefühle und Handlungen anwendet, nicht als das beherrschende Prinzip seiner Ethik betrachtet werden kann, obgleich es ihm beliebt hat, die Tugendiehre von diesem Gesichtspunkte aus darzustellen. Der oberste Gesichtspunkt ist vielmehr der eudämonistische. Der Einsicht, d. h. der Tugend der praktischen Vernunft, bleibt es überlassen, für jedes einzelne Gebiet des Fühlens, Begehrens und Handelns die richtige Mitte $z$ wischen dem Übermaß und dem Untermaß zu bestimmen. Den Gesichtspunkt dieser Bestimmung kann nur das höchste praktische Gut, die Glückseligkeit, bilden. Die Lehre von der Glückseligkeit, nicht die vom juste mlieu, ist der beherrschende Gesichtspunkt der aristotelischen Ethik.

In sehr gewaltsamer Weise hat Aristoteles in seiner Behandlung der einzelnen Tugenden den Gesichtspunkt des justc miliєu durchgeführt, uncl die Fülle treffender, aus Erfahrung und feinsinniger Beobachtung geschöpfter Bemerkungen, die sich in dieser Partie der nikomachischen Ethik finden, kann nicht darüber hinwegtäuschen, daß der zugrundegelegte Hauptgesichtspunkt in das innere Wesen des Gegenstandes keinen Einblick gewährt. Wenn die Tapferkeit als ein Mittleres zwischen Frechheit und Feigheit aufgefaßt wird, so wird man zunächst meinen, es könne sich bei diesem Mittleren nur um den Intensitätsgrad oder um die Häufigkeit der Gefühle Furcht und Zuversicht handeln, deren Regelung Aufgabe der Tapferkeit ist. Wenn wir aber weiter lesen, tapfer sei, wer dem ehrenvollen Tode gegenüber sich furchtlos verhält, so zeigt sich, daß es nicht auf den Intensitätsgrad oder die Häufigkeit der Furchtgefühle, sondern auf ihr Verhältnis zu den sie verursachenden Gegen- 
ständen ankommt. Wenn der Tapfere um des sittlich Schönen willen selbst dem Tode furchtlos entgegengeht, so kann dieses Verhalten nicht als das Einhalten einer richtigen Mitte bezüglich der Furcht charakterisiert werden. Vielmehr besteht hier das tugendhafte Verhalten nur in dem unbedingten Gehorsam des Gefühls gegenüber der praktischen Vernunft, die zu entscheiden hat, ob irgendein Gegenstand furchtbar oder nicht furchtbar, ein Tod schön oder nicht schön ist. - Die Mäßigkeit soll ein mittleres Verhalten hinsichtlich der Lust, und zwar der niederen sinnlichen Lust sein, dern die schädlichen Extreme der Zuchtlosigkeit und der Unempfindlichkeit zur Seite stehen. Aber Aristoteles erklärt selbst, daß ein Untermaß in dem Empfinden und Begehren der Lust bei normal veranlagten Menschen überhaupt nicht vorkommt. Also versagt auch hier die Theorie des juste milieu. Denn eine Abweichung von der normalen menschlichen Veranlagung, wie es die totale Unempfindlichkeit gegen sinnliche Lust nach Aristoteles ist, fällt außerhalb des Gebietes der Ethik. - Sanftmütig nennt Aristoteles denjenigen, der im Zürnen die richtige Mitte einhält, indem er zur rechten Zeit und aus dem rechten Grunde und den richtigen Personen und so heftig und solange es recht ist, zürnt. Statt zweier schädlicher Extreme ergeben sich mehrere. Denn der Jähzornige, dessen Zorn heftig aber kurz ist, ist verschieden von dem Unversöhnlichen, der länger, als recht ist, zürnt und dessen Zorn erst endet, wenn er sich Genugtuung verschafft hat. Hieraus geht schon hervor, daß das richtige Zürnen nicht ein einheitliches Mittleres zwischen zwei schädlichen Extremen (einem Zuviel und einem Zuwenig) ist, sondern nach einer Mehrheit voneinander unabhängiger Gesichtspunkte beurteilt wird. Das Untermaß des Zornes nennt Aristoteles Aorgesie. Wer über erniedrigende Beleidigungen seiner Person oder seiner Angehörigen nicht zürnt, verfällt nach seiner Ansicht mit Recht der Verachtung der Menschen. Das Bedenkliche liegt hier darin, daß der Ausdruck "Aorgesie" ein zum Zürnen unfähiges Gemüt bezeichnet. Wie soll man aber einen Gemütszustand nennen, der über manche Dinge zu wenig und über andere zu viel zu zürnen geneigt ist? Er entspricht weder dem Übermaß noch dem Untermaß noch der richtigen Mitte. - Die Liberalität (Anständigkeit in Geldangelegenheiten) ist die richtige Mitte zwischen Geiz und Verschwendung. Diese Auffassung kann man gelten lassen, solange man nur das Verhältnis des gesamten Aufwandes zu dem Vermögen in Betracht zieht. Aber die Liberalität als Tugend erschöpft sich nach Aristoteles keineswegs in der Einhaltung dieses Verhältnisses. Es ist vielmehr wesentlich für sie, nicht nur im richtigen Ausmaße; sondern auch am rechten Ort, zur rechten Zeit, in der rechten Weise und zu dem rechten $Z$ wecke zu geben und Aufwand zu machen. Das Einhalten der richtigen Mitte ist also nur einer der Gesichtspunkte, die für den tugendhaften Gebrauch des Geldes maßgebend sind. A ristoteles fordert, daß der Liberale das Sittlich-Schöne höher schätzt als den Geldbesitz und daher um sittlich-schöner Zwecke willen auch zu großem Aufwand bereit ist. Es ergeben sich also hier dieselben Bedenken, die oben gegen die Auffassung der Tapferkeit erhoben wurden. Daß Aristoteles von der Liberalität als eine 
besondere Tugend die „Großartigkeit“ unterscheidet, d. h. die Fähigkeit, von sehr großem Reichtum den richtigen Gebrauch zu machen, ist theoretisch nicht haltbar, so schön und bezeichnend für hellenische Denkweise auch seine Schilderung dieser Tugend ist. Überhaupt liegt der Wert dieser Partien der nikomachischen Ethik viel mehr in der aus feiner Lebensbeobachtung geschöpften Zeichnung typischer Charaktere als in der wissenschaftlichen Begründung einer ethischen Doktrin. - Die „Ehrliebe“ und die „Hochherzigkeit" sind zwei auf das Streben nach Ehre bezügliche Tugenden, die sich ebenso zueinander verhalten wie die Liberalität zu der Großartigkeit in Geldsachen. Die Ehrliebe bezieht sich auf kleine oder mäßige, die Hochherzigkeit auf großartige Verhältnisse. Natürlich besteht die Tugend bezüglich des Strebens nach Ehre darin, daß man weder zu viel noch zu wenig Ehre für sich beansprucht und aus den richtigen Gründen und auf die richtige Weise. Diese Bestimmung scheint für große wie für kleine Verhältnisse auszureichen. Aristoteles behandelt aber an erster Stelle und am ausführlichsten den besonderen Fall, daß ein in jeder Hinsicht vortrefflicher und deswegen der höchsten Ehre würdiger Mensch diese beansprucht. Dieser Fall bietet vom ethischen Standpunkt nichts Besonderes. Denn die Tugend fordert nur, daß die Ehransprüche des Menschen seinen Verdiensten entsprechen. Wie groß diese Verdienste sind, tut nichts zur Sache. Es gilt also auch hier, was gelegentlich der "Großartigkeit in Geldsachen" bemerkt wurde, daß Aristoteles weniger die ethische Theorie fördert, als bestimmte, in der Erfahrung vorkommende Charaktertypen schildert. Für das Humanitätsideal des Aristoteles ist aber die Schilderung des Hochsinnigen besonders bezeichnend. Denn da der Hochsinn den Besitz aller übrigen Vorzüge voraussetzt und nur als abschließender und vollendender Vorzug zu ihnen hinzukommt, so dürfen wir in dem Hochsinnigen den Idealmenschen des Aristoteles erblicken. - Aristoteles behandelt noch die Tugenden des geselligen Verkehrs. Der Liebenswürdige hält die richtige Mitte ein zwischen dem Schmeichler und dem Rücksichtslosen; der gute Gesellschafter die Mitte zwischen dem Possenreißer, der den Spaß über die Grenze des Anstandes und guten Geschmackes hinaustreibt, und dem Sauertöpfischen, der keinen Spaß versteht; der wahrhaft Bescheidene die Mitte zwischen dem Großtuer und dem Kleintuer. Die wahre Bescheidenheit besteht nicht darin, daß man die Vorzüge, die man tatsächlich besitzt, versteckt und ableugnet - das wäre Kleintuerei und nicht löblich sondern darin, dẩ man sich gibt, wie man ist.

Am allerwenigsten will sich die Tugend der Gerechtigkeit der Theorie vom juste milieu fügen. Aristoteles gesteht selbst, die Gerechtigkeit sei ein Mittleres nicht in demselben Sinne wie die übrigen Tugenden. Aber auch die übrigen sind es ja unter sich nicht in dem gleichen Sinne. - Aristoteles unterscheidet von der Gerechtigkeit als Gesetzlichkeit, die er als Funktion aller Tugenden im Verhältnis zu den Mitmenschen auffaßt, die Gerechtigkeit als Einzeltugend. Sie ist die habituelle Willensrichtung auf die Verwirklichung des Rechtes. Das Recht aber als äußere Ordnung läßt sich auf das Prinzip 
der richtigen Mitte zurückführen, insofern es darauf abzielt, jedem Menschen den ihm zukommenden Teil der Lebensgüter zu sichern, ein Mittleres also zwischen dem Zuriel und dem Zuwenig. Die Ausführung dieses Gedankens bei Aristoteles geht eigentlich mehr die Rechtsphilosophie als die Ethik an. Er zeigt nicht, daß ein natürliches Begehren (etwa der Besitz- und Erwerbstrieb) durch die Tugend der Gerechtigkeit auf ihr richtiges Mittelmaß gebracht wird, sondern er begnügt sich, das Mittelmaß als Prinzip der äußeren Rechtsordnung nachzliweisen. Die Gerechtigkeit als Tugend erhält daher nur eine äußerliche und indirekte Beziehung zu .dem Hauptgesichtspunkt der aristotelischen Tugendlehre. Die Gerechtigkeit als Rechtsordnung ist entweder austeilende oder ausgleichende Gerechtigkeit. Jene regelt die Güterverteilung unter die Glieder einer Gemeinschaft (eines Staates) nach dem Prinzip der proportionalen Gleichheit: wie sich die Empfangenden nach ihrer Würdigkeit zueinander verhalten, so auch die Güter und Rechte, die ihnen zugeteilt werden. Diese gleicht die durch Schädigung oder Übervorteilung eines Rechtssubjektes durch ein anderes entstandene Ungleichheit dadurch aus, daß sie dem Schäcliger so viel an Gütern entzieht oder an Übeln zufügt und dem Geschädigten so vie1 an Gütern zufügt oder an Übeln entzieht, daß die Differenz der beiderseitigen Gütersumme (in der die Übel als negative Güter in Rechnung gestellt werden) dieselbe wird wie vor der Schädigung. Hier bezieht sich also das juste milieu nicht einmal mehr auf Handlungen, sondern auf äußere Güter und Übel.

Ettik und Politik. Die Ethik des Aristoteles ist, wie aus der bisherigen Betrachtung hervorgeht, eine individualistische, insofern individuelle Glückseligkeit als höchstes Ziel aller Handlungen des Individuums angesehen wird und auch die Tugenden zunächst nur als habituelle seelische Beschaffenheiten bestimmt werden, die zur Erreichung dieses individuellen Zieles befähigen. Doch wird diese einseitig individlualistische Betrachtungsweise, die Aristoteles in der Ethik anwendet, durch die Beziehung, in die er die Ethik zur Politik setzt, ergänzt und modifiziert. Nur im gesellschaftlichen, und staatlichen Leben kann sich der Mensch seiner Natur gemäls tugendhaft betätigen. Er ist von Natur darauf angelegt, Glied eines Staates zu sein. Denn er besitzt als Einzelner nicht Selbstgenügsamkeit (Autarkie). Auch die Familie und die durch Zusammenschluß mehrerer Hausstände entstehende Dorfgemeinde besitzen diese nicht, sondern erst der Staat. Dieser ist das Ziel, zu dem die natürliche Entwickelung des menschlichen Lebens hinstrebt. Dieser erst ist ein wahrhaftes Ganze. Da nun das Ganze von Natur früher ist als der Teil und das Ziel früher als die $z u$ ihm hinstrebende Entwickelung, so ist auch der Staat von Natur früher als Dorfgemeinde, Familie und Einzelmensch, obgleich er in der zeitlichen Entwickelung zuletzt hervortritt. Der Staat entsteht um des Lebens willen, sein letzter Zweck: aber ist das gute, d.h. glückselige und tugendhafte Leben seiner Bürger. Wenn wir diese das Verhältnis der Politik zur Ethik regelnden Sätze betraclıten, erscheint uns der Standpunkt des Aristoteles nicht mehr als individualistisch; vielmehr erkennen wir auch hier jene verınittelnde Ten- 
denz wieder, die seine ganze Philosophie durchzieht. Wie das ontologische Problem der Realität des Einzelnen und des Allgemeinen, so wird auch die Frage, ob der Lebenszweck im Glück des Einzelnen oder im Glück der Gesamtheit liegt, nicht einseitig entschieden. Die Auffassung des Einzelnen als eines Gliedes der Gesamtheit scheint den Zweck in die Gesamtheit zu verlegen, aber der Zweck des Staates liegt doch nur darin, daß er den einzelnen Bürgern ein tugendhaftes und glückseliges Leben ermöglicht. . Auf die nähere Ausführung der aristotelischen Staatslehre kann hier nicht eingegangen werden.

IV. Die peripatetische und altakademische Schule (4.-3. Jahrhundert v. Chr.). Die Philosophie des Aristoteles ist von seinen unmittelbaren Schülern, unter denen seine Nachfolger Theophrastos, Eudemos von Rhodos, Aristoxenos von Tarent und Dikaiarchos von Messene die bedeutendsten sind, noch mit selbständigem Forschergeiste, der auch vor starken Abweichungen von der Lehre des Meisters nicht zurückscheute, weiter gepflegt worden. Theophrastos $(\dagger 287)$ stellte den zoologischen Arbeiten seines Lehrers, die durch das ganze Altertum und Mittelalter kanonische Geltung behielten, eine ebenso epochemachende Leistung auf dem Felde der Botanik an die Seite. Die philosophiegeschichtlichen Studien seines Lehrers fanden ebenfalls in ihm einen berufenen Fortsetzer: seinem Werk „die Lehren der Physiker" verdanken wir indirekt den größten Teil unserer Kenntnis der Vorsokratiker. Dieselbe Bedeutung hatte ein Werk des Eudemos für die Geschichte der Mathematik und Astronomie. A ristoxenos, der in mancher Hinsicht an die pythagoreische Schule anknüpfte (z. B. die Seele als Harmonie des Leibes auffaßte, zu der die einzelnen psychischen Vorgänge in demselben Verhältnis stehen sollten wie die Töne und Akkorde zur Stimmung der Leier), hat auch die musiktheoretischen Studien der Pythagoreer mit der von seinem Lehrer überkommenen induktiven Methode weitergeführt und auf eine im ganzen Altertum nicht mchr übertroffene Höhe gehoben. Von Dikaiarchos, der sich hauptsächlich mit Geographie, Kulturgeschichte und Politik beschäftigte, hören wir auch, daß er die Substantialität und Unsterblichkeit der Seele bestritt. Die Kraft, die sich in allen Lebensvorgängen und psychischen Tätigkeiten offenbart, lachte er sich von der Materie untrennbar. Von der verschiedenen Formung der an sich einheitlichen und einfachen Materie sollte es abhängen, ob sich diese Kraft nur als vegetative Lebenskraft oder als psychische Tätigkeit äußerte. Diese Ansicht des Dikaiarchos und die des Aristoxenos über die Seele zeigen das gemeinsame Bestreben, in der Überwindung des platonischen Dualismus über Aristoteles hinauszugehen. In derselben Richtung bewegte sich auch die Lehre des Straton von Lampsakos, der als Nachfolger des Theophrastos 287-269 die Schule 1eitete. Straton bearbeitete das Gebiet der Naturphilosoplie, dem er sich hauptsächlich widmete, mit großer Selbständigkeit. Die scharfsinnige Kritik, die er an der Physik des Demokrit sowohl als des Aristoteles übte, rühmt der Historiker Polybios, wenn er auch, als Stoiker, seine positiven Lehren nicht gelten läßt. 
Auch Straton ist Gegner des aristotelischen Dualismus von Gott und Welt, Geist und Natur. Wie er im Weltall nur Natur, aber keinen Gott findet, so bekämpft er auch in der Einzelseele die Sonderstellung der Vernunft. Die Seele ist einheitlich, das Wahrnehmungs- und Gefühlsvermögen von dem Denkvermögen nicht verschieden. Sie hat ihren Sitz im Kopfe, zwischen den Augenbrauen. Die psychischen Vorgänge sind Bewegungen der Seele, und zwar die Wahrnehmungen solche, die durch äußeren Anstoß hervorgerufen werden. Nicht in dem Sinnesorgan, sondern in dem seelischen Zentralorgan kommt Wahrnehmung und Gefühl zustande. Der Schein, als ob sie in dem Sinnesorgan zustande kämen, entsteht dadurch, daß die Seele Wahrnehmung und Gefühl an den Ort zurückverlegt, wo der verursachende Vorgang stattgefunden hat. Der äußere Eindruck wird der Seele durch ein Pneuma übermittelt. Wird diese Vermittelung unterbrochen, z. B. durch Zusammenschnüren des Gliedes, an dessen Ende der verursachende Vorgang stattfindet, so kommt keine Wahrnehmung zustande. Es ist hiernach wahrscheinlich, wenn auch nirgends bezeugt, daß sich Straton auch die Seele selbst als Pneuma dachte. Von den Wahrnehmungen bleibt in der Seele ein dauernder Eindruck zurück. Aus den ohne äußeren Anstoß erfolgenden Bewegungen dieser Eindrücke in der Seele selbst entsteht das Denken. Denn wir können nicht denken, was wir nicht zuvor wahrgenommen haben. Das Bestreben, einen psychischen Monismus durchzuführen, das uns in diesen Lehren deutlich wird, stand ohne Zweifel mit einem monistischen Naturalismus der gesamten Weltanschauung im Zusammenhang. Der Grundbegriff seiner Lehre ist der der Natur, die er sich als eine vom Stoffe nicht trennbare unbewubt wirkende Kraft vorgestellt zu haben scheint. Auf sie muß er irgendwie die Mehrheit von Kräften zurückgeführt haben, durch die der Stoff differenziert und qualifiziert wird, vor allem Wärme, Kälte und Schwere. Seine Bekämpfung der atomistischen Naturlehre bezog sich gewiß nicht nur auf die Annahme unteilbarer Körper und eines unendlichen leeren Raumes, sondern auch auf die mechanische Erklärung der Naturvorgänge. Er selbst hielt an dem dynamischen Naturbegriff seines Lehrers fest, indem er alle Qualitäten und auch Leben und Bewußtsein auf im Stoffe wirkende und von ihm untrennbare Kräfte zurückführte. Die Materie dachte er sich aus Molekeln (nicht unteilbaren Atomen) zusammengesetzt, zwischen denen sich leere $Z$ wischenräume, die kleiner sind als die Molekeln, befinden. Nur durch Anwendung von Gewalt kann z. B. die Luft so zusammengepreßt werden, daß sie zwischen ihren Molekeln keine leeren Zwischenräume mehr enthält. Sobald der Druck aufhört, kehrt sie aus diesem naturwidrigen Zustand von selbst in den naturgemäßen zurück, indem sich die leeren $Z$ wischenräume wiederherstellen. Aber auch ein größeres, in sich zusammenhängendes Vakuum ist naturwidrig und kann nur künstlich hergestellt werden. Ist ein solches entstanden, so strebt die Natur alsbald, es wieder auszufüllen, indem sie den angrenzenden Körper in das Vakuum eindringen läßt. Von der atomistischen Ansicht unterscheidet sich diese Lehre nicht nur durch die Leugnung eines zusammenhängenden leeren Raumes und unteil- 
barer kleinster Stoffteile, sondern auch durch die Annahme wirkender Naturkräfte außer Stoß und Schwere. Denn weder die Elastizität (Eutonie), vermöge deren ein Körper die naturgemäßen Vakua. zwischen seinen Molekeln wiederherstellt, noch den horror vacui, vermöge dessen ein entstandenes größeres Vakuum durch Nachrücken des angrenzenden Körpers ausgefüllt wird, konnte Straton auf Stoß oder Schwere zurückführen. Auch Qualitäten wie Wärme und Kälte sind für Straton besondere, nicht aus Verhältnissen qualitätsloser Atome ableitbare Naturkräfte. Die Schwere faßt er, im Gegensatz zu Aristoteles, als gemeinsame Eigenschaft aller Körper auf. Zwischen den Elementen Erde, Wasser, Luft, Feuer findet eine Abstufung der Schwere statt. - Leider erlaubt uns die spärliche Überlieferung vorläufig nicht, das physikalische System dieses bedeutenden Denkers als Ganzes zu rekonstruieren. Was wir erkennen, zeigt einen Versuch, zwischen Aristoteles und Demokrit zu vermitteln, und in der Methode einen entschiedenen Fortschritt über Aristoteles nach der Seite der empirischen und experimentellen Forschung.

Nach Straton verliert die peripatetische Schule ihre Bedeutung für den Fortschritt der Philosophie. Lykon aus Troas, der nach Stratons Tode 44 Jahre lang (269-225) die Schule leitete, scheint sich mehr der praktischen Pädagogik als der wissenschaftlichen Forschung gewidmet zu haben. Die dialektisch-rhetorischen Übungen, die schon Aristoteles eingeführt und als wertvolles Mittel formaler Geistesbildung gehandhabt hatte, bildeten jetzt das Hauptstück des Unterrichts. Die strengphilosophischen Lehrschriften des Aristoteles wurden so wenig studiert, daß sie fast ganz in Vergessenheit gerieten. Andere Peripatetiker, wie Ariston von Keos, der Nachfolger Lykons, und Hieronymos, beschäftigten sich mit einer auf die weiteren Kreise der Gebildeten berechneten ethischen Schriftstellerei. Auch wurden die literar- und kulturgeschichtlichen Studien von Peripatetikern in Athen und Alexandria fortgesetzt. In der ersten Hälfte des zweiten Jahrhunderts scheint Kritolaos von Phaselis, den wir als Teilnehmer an der berühmten Philosophengesandtschaft ${ }_{5} 6$ v. Chr. in Rom finden, einen Anlauf zu erneuter Bearbeitung der eigentlich philosophischen Probleme gemacht zu haben. Dies war die letzte Regung selbständigen Forschergeistes im Peripatos. Im ersten Jahrhundert v. Chr. tritt die Schule durch Andronikos von Rhodos in ein neues Entwickelungsstadium. Sie verzichtet fortan auf selbständige Arbeit an den Problemen und findet ihre Aufgabe nur noch in der treuen Erhaltung und Erklärung der Lehre ihres Stifters. Die bisher vernachlässigten Lehrschriften des Aristoteles wurden in der sullanischen Zeit von dem Philologen Tyrannion textkritisch gereinigt, von dem Philosophen Andronikos gesichtet, systematisch geordnet und kommentiert. Diese Männer sind es, denen wir die Erhaltung des aristotelischen Schriftenkorpus in der uns vorliegenden Gestalt verdanken. Ihr Verdienst ist es auch, daß das aristotelische System, das in den folgenden Jahrhunderten durch eine lange Reihe von Kommentatoren nach seinem ganzen Inhalt und Zusammenhang wieder und wieder erläutert wurde, den ihm gebührenden Vorrang vor anderen philosophischen Lehr-

Kritolaos

(1. Hälfte des Jahrhunderts v. Chr.). 
systemen wieder eroberte und als Hauptvermächtnis antiker Wissenschaft in die Bildung des Mittelalters überging.

Während Aristoteles, der größte Platoniker, sich von der Akademie absonderte und eine selbständige neue Schule begründete, deren Entwickelung wir bisher verfolgt haben, bestand die Akademie Platons in Athen weiter und durchlief in der Zeit von Platons Tode bis ins erste vorchristliche Jahrhundert mehrere scharf unterschiedene Entwickelungsstadien, die als die alte, die mittlere und die neuere Akademie bezeichnet werden. Die alte Weitere Ent- Akademie, zu der außer Platons nächsten Nachfolgern Speusippos (347-339) wicklung der und Xenokrates (339-314) noch Polemon, Krates und Krantor gerechnet Akademie. werden, vertritt den Plantonismus als dogmatisches System. Speusippos und Xenokrates sind selbständige Denker, die an Platons pythagorisierende Altersphilosophie anknüpfend das ganze Gebiet der Philosophie, nicht ohne tiefgreifende Abweichungen von der Lehre des Meisters, neu bearbeiten. Polemon, Krates und Krantor scheinen, dem allgemeinen Zuge der nacharistotelischen Philosophie folgend, das Hauptgewicht auf die Ethik gelegt zu haben. Die mittlere Akademie von Arkesilaos († 24I) begründet, verlieB die Bahn des Dogmatismus und wendete sich dem Skeptizismus zu. Die neuere Akademie des Karneades ( +129 ), zu der wir auch Philon von Larisa und Antiochos von Askalon, die Lehrer Ciceros, rechnen, verbindet mit der skeptischen Bekämpfung der dogmatischen Systeme als positive Ergänzung eine Wahrscheinlichkeitslehre und mündet allmählich in den Eklektizismus aus.

Speusippos, Platons Schwestersohn und Nachfolger, ist uns so unzureichend bekannt, daß wir kein klares Bild von seiner Lehre gewinnen können. Er unterschied eine Mehrheit intelligibler Wesenheiten als Prinzipien der verschiedenen Seinsgebiete, ein besonderes Prinzip für die Zahlengrößen, ein besonderes für die Raumgrößen, ein besondleres für die Seele, ein besonderes für die sinnlich wahrnehmbaren Dinge. Aus diesen intelligiblen Prinzipien konstruierte er die Erfahrungswelt. Unter diesen Prinzipien sollte eine Abstufung stattfinden vom Einfachen zum Komplexen und das letztere als das Bessere und Vollkommenere gelten. Die Raumgröße ist also besser und vollkommener als die Zahl, weil sie zahlenmäßige Bestimm theit mit der Ausdehnung verbindet, die Seele besser als beide, weil in ihr zu Ausdehnung und Zahl die harmonische Bestimm theit hinzukommt. Dieser Gedankengang führt notwendig zu der dem echten Platonismus zuwiderlaufenden Ansicht, daß die sinnlich wahrnehmbaren Dinge besser und vollkommener sind als die intelligiblen, zumal Speusippos annahm, daß alle Wesen im Kosmos von Seelenkraft durchwohnt seien. Unter diesen mußte er wieder diejenigen für die vollkommensten halten, bei denen zu der allgemeinen Seelenkraft die Vernunft hinzutritt. Diese ganze Konstruktion steht dem Pythagoreismus näher als dem Platonismus. Zu diesen ontologischen Sätzen stimmt vortrefflich, was wir über die Erkenntnıstheorie des Speusippos erfahren. Das Intelligible wird durch den wissenschaftlichen Logos erkannt, das Wahrnehmbare durch die wissenschaftliche Wahrnehmung. Wissenschaftlich heißt diejenige Wahrnehmung 
die an der Wahrheit des begrifflichen Denkens teilnimmt, so wie der Fingersatz des Zitherkünstlers durch Übung erzogen ist, gewissen begrifflich erfaßten Regeln zu folgen. Wenn das Konkrete das Beste und Vollkommenste ist, so muß auch die komplexeste Erkenntnisweise, in der sich das Wahrnehmen mit dem Denken verbindet, die vollkommenste sein. Es ist also klar, daß Speusippos die sinnliche Wahrnehmung höher als sein Lehrer gewertet hat. - Wir sahen, daß Speusippos die allgemeinsten Begriffskategorien, das Eine, das Seiende, das Ausgedehnte, das Leben, die Vernunft, das Gute als intelligible Realitäten behandelte, durch deren Zusammenwirken er die wirkliche Welt entstehen ließ. Es ist ganz löblich und folgerichtig, daß er jede Gleichsetzung inhaltlich verschiedener Begriffselemente verwarf, z. B. des Einen mit dem Seienden, der Vernunft mit dem Guten. Das Eine stand bei ihm. am Anfang, das Gute am Ende der Stufenfolge. Das Gute tritt als krönender Abschluß zu der aus allen Seinselementen entwickelten Wirklichkeit im Einzelnen und im Ganzen hinzu. - Die Glückseligkeit, nach der alle Menschen streben, besteht in einem dauernd und vollkommen naturgemäßen Zustand. Zur Erreichung dieses Zustandes bilden die sittlichen Vorzüge die wichtigsten Mittel. Die Aochlesie (Freiheit von Störungen) ist das Ziel, nach dem die Guten streben. Die Tugend allein vermag den Menschen glückselig zu machen, doch ist sie nicht selbst schon die Glückseligkeit des Menschen und der Inbegriff der für ihn erreichbaren Güter. Wichtig ist, daß wir hier zum erstenmal das Prinzip des naturgemäßen Lebens als Grundlage der Ethik finden, das Zenon später von seinem Lehrer Polemon übernommen und das weiterhin die ganze nacharistotelische Ethik beherrscht hat.

Xenokrates von Chalkedon, der Nachfolger des Speusippos, unterscheidet mit Platon drei Erkenntnisweisen, sinnliche Wahrnehmung, begriffliches Wissen und die zwischen beiden in der Mitte stehende Meinung (Doxa). Begriffliche Erkenntnis und sinnliche Wahrnehmung sind jede für sich genommen wahr, aber nicht auf die gleiche Weise. Die begriffliche Erkenntnis ist fest und unveränderlich wie ihr Gegenstand, die intelligiblen Objekte, die sinnliche Wahrnehmung veränderlich wie die sinnlichen Objekte. Nur auf dem aus beiden gemischten Gebiet der „Meinung“, wo es gilt, Begriffe auf Objekte der Wahrnehmung anzuwenden, ist Irrtum möglich. Die Meinungen sind daher teils wahr, teils falsch. Diesen drei Erkenntnisweisen sollen drei Klassen von Wesenheiten entsprechen, die intelligiblen, die sich außerhalb des Himmelsgebäudes befinden, die sinnlich wahrnehmbaren, welche die sublunare Region des Kosmos erfüllen, und die aus beiden gemischte Wesenheit, welche die obere Region des Kosmos (über dem Monde) bildet. Die letztgenannte ist zugleicl sinnlich wahrnehmbar und infolge ihrer Unveränderlichkeit intelligibel. Daß, wie sich aus dieser Darstellung unseres Berichterstatters Sextus zu ergeben scheint, die superlunaren Himmelskörper und ihre Bewegungen das ausschließliche Objekt der „Meinung“ bilden, also nur hinsichtlich dieser ein Irrtum möglich sei, kann natürlich nicht die Ansicht des Xenokrates gewesen sein. Es muß hier ein Mißrerständnis untergelaufen 
sein, das wir nicht aufzuklären vermögen. - Im übrigen zeigen die Nachrichten über die Kosmologie des Xenokrates sein Anknüpfen an Platons pythagoreische Altersperiode und im besonderen an die Kosmogonie des „Timaeus“. Platons dichterisch-mythologische Darstellung wird zum Dogma ausgeprägt und namentlich die in ihr enthaltenen theologischen Fäden weitergesponnen. Im Gegensatz zu dem Verfahren des Speusippos werden Begriffskategorien verschiedener Seinsgebiete einander gleichgesetzt und dann noch überdies personifiziert und als Götter bezeichnet. Die Einheit ist nicht nur das Ungrade und die Grenze, sondern auch das männliche Prinzip im Weltall und Vernunft und oberste Gottheit. Die unbegrenzte $Z$ weiheit ist das Grade und das Weibliche, die Göttermutter und die Weltseele. Diese Weltseele wird aber auch als der unterste Zeus dem höchsten, der den Fixsternhimmel bewohnt, entgegengesetzt. Außerdem gibt es sowohl über wie unter dem Monde noch eine Menge Götter, über dem Monde die Sternsphärengeister, unter dem Monde die Elementargeister. Auch ist der Raum unter dem Monde von zahlreichen bösen und guten Dämonen erfüllt, die den menschlichen Seelen wesensgleich sind. Xenokrates hat die Seele als eine durch sich selbst bewegte Zahl definiert. Er knüpfte an die Seelenschöpfung im „Timaeus“ an, indem er die Seele aus der Einheit und der Zweiheit (d. h. aus der intelligiblen und der sinnlich wahrnehmbaren Substanz) und, damit sie in sich selbst das Prinzip der Bewegung wie der Ruhe hätte, überdies aus dem Selbigen und dem Verschiedenen zusammengesetzt dachte. So war sie auch bei ihm ein Mittelwesen zwischen der unteren und der oberen Welt. $\mathrm{Da}$ er auch die pythagoreisch-platonische Seelenwanderungslehre annahm, nach der die Menschenseelen in verschiedene Tierleiber fahren, scheint aus der Nachricht hervorzugehen, daß er auch den Tierseelen den Gottesbegriff und die Unsterblichkeit zuschrieb. In einem durch Plutarch erhaltenen Mythos hatte er die Schicksale der Seele nach dem Tode, ihre Rückkehr in die himmlische Heimat in phantasievoller Weise ausgemalt. All dies läßt deutlich erkennen, daß Xenokrates weit mehr als Speusippos der pythagoreischen Mystik zuneigt. Seine Ethik stimmt mit der des Aristoteles und des Speusippos nicht nur in der Lehre vom höchsten Zweck (der Eudämonie), sondern auch in der Güterlehre überein. Zur Glückseligkeit ist für den Menschen außer der spezifisch menschlichen Tüchtigkeit ein gewisses Maß von leiblichen und äußeren Gütern erforderlich, das die ungehemmte Betätigung jener ermöglicht. Gesch affen wird die Glückseligkeit durch die Tugend, mitbe dingt durch die Ausstattung mit leiblichen und äußeren Gütern; die Bestand teile aber, aus denen sie sich zusammensetzt, sind treffliche Handlungen, Stimmungen, Zustände, Bewegungen und Haltungen (cxécєıc) der Seele.

Die Nachfolger des Xenokrates, Polemon, Krates und Krantor haben auf dem ontologischen und erkenntnistheoretischen Gebiet nichts selbständig Polemon geneuert. Wenn Polemon den höchsten Lebenszweck setzt in ein sittlich ${ }^{\left(3^{2} 4^{2}-20\right)}$ gutes Leben verbunden mit dem Genuß der ursprünglichen Naturgüter (honeste wivere fruentem rebus iis, quas primas hominu natura conciliet), so stimmt 
diese Definition zwar hinsichtlich der Grundanschauung ( $\mathrm{daß}$ zu der Eudämonie außer der Tugend leibliche und äußere Güter gehören) mit den Lehren des Aristoteles, Speusippos und Xenokrates überein, doch ist die Abgrenzung des außer der Tugend geforderten Güterbesitzes neu. Sie beruht hier zum erstenmal auf dem Begriff der ursprünglichen Naturgüter, d. h. derjenigen Güter, auf die sich vor aller vernünftigen Erwägung der ursprüngliche Naturtrieb richtet. Dieser Begriff ist nicht nur von der stoischen, sondern auch von der epikureischen Schule aufgenommen worden und steht fortan im Mittelpunkt der Erörterungen über den höchsten Lebenszweck und die Güterlehre. Er ist aufgestellt worden, um der Güterlehre eine empirische Grundlage zu geben. Polemons Schüler Krantor, den Verfasser der berühmten Trost-

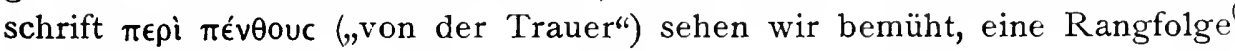
der Lebensgüter aufzustellen. Den ersten Preis gibt er der Tugend, der Gesundheit den zweiten; der Lust räumt er den dritten, dem Reichtum den vierten Platz ein.

\section{Die hellenistische Philosophie (4.--2. Jahrhundert v. Chr.).}

I. Die pyrrhonische Skepsis (4.-3. Jahrhundert v. Chr.). Da die Wendung, welche die Akademie seit Arkesilaos macht, erst durch den Kampf gegen die großen nacharistotelischen Schulen der Stoiker und Epikureer verständlich wird, müssen wir diese zuerst besprechen. Auch die pyrrhonische Skepsis und die jüngere megarische Eristik werden von Arkesilaos vorausgesetzt. Die pyrrhonische Skepsis und die Philosophie Epikurs sind beide Sprößlinge der Schule Demokrits, während die stoische Lehre die von Sokrates begründete, von Platon und Aristoteles gepflegte Gedankeneinrichtung weiter verfolgt und sie durch Zurückgreifen auf den in Herakleitos gipfelnden ionischen Hylozoismus zu verbessern sucht.

Pyrrhon von Elis (ca. 360-270) war ein Schüler des Demokriteers Anaxarchos, den er als Teilnehmer der Expedition Alexanders des Großen nach Indien begleitete. Später lebte er in seiner Vaterstadt Elis. Für den dauernden Fortbestand seiner Schule hat er nicht, wie Platon und Aristoteles, Sorge getragen, sondern nur wenige einzelne Schüler unterrichtet, unter denen Timon von Phlius der bedeutendste war (ca.320-230). Aus den Schriften Timons stammte alles, was man im Altertum von Pyrrhons Lehre wußte. Denn Pyrrhon selbst hatte keine Schriften hinterlassen. Mit Timons Tode wurde die Tradition des Pyrrhonismus unterbrochen und erst in ciceronischer Zeit durch Aenesidemus erneuert, um dann ohne Unterbrechung bis zur Zeit des Sextus Empiricus fortzubestehen, der um 200 n. Chr. seine uns erhaltene Darstellung der skeptischen Lehre verfaßte. Von der mit feinster Dialektik durchgeführten und gegen alle Einwände der Dogmatiker verschanzten Form des Skeptizismus, die uns bei Sextus und anderen jüngeren Skeptikern begegnet, war die Lehre Pyrrhons selbst mit ihrer schlichten Einfachheit noch weit entfernt.

Wir werden annehmen dürfen, daß Pyrrhon durch Demokrits Lehre von 
der Subjektivität der sinnlichen Wahrnehmung, die ihm Anaxarchos vermittelt hatte, zu seinem Agnostizismus getrieben wurde. Wenn Demokritos zwar die Sinnesqualitäten für bloß phänomenal erklärt, für die physikalische Weltansicht aber, nach der das All aus leerem Raum und in ihm sich bewegenden Atomen besteht, volle wissenschaftliche Wahrheit in Anspruch genommen hatte, so lag die Erwägung nahe, daß auch diejenigen Daten, aus denen der Verstand die physikalische Weltansicht aufbaut, aus der sinnlichen Wahrnehmung stammen. Wenn aber der Verstand den Inhalt aller seiner Begriffe aus der sinnlichen Wahrnehmung entlehnt, was gibt ihm dann die Berechtigung, an ihr Kritik zu üben und ihre Daten teils zu verwerfen, teils anzuerkennen? Warum sollen wir der sinnlichen Wahrnehmung, die sich bezüglich der Sinnesqualitäten als unzuverlässig erwiesen hat, hinsichtlich der räumlichen Gestalt, Undurchdringlichkeit, Schwere und Bewegung der Materie Glauben schenken? So konnte Pyrrhon von demokriteischen Voraussetzungen aus zu der Ansicht gelangen, daß die Dinge für uns überhaupt unerkennbar sind. Doch findet sich in der Überlieferung nichts davon, daß Pyrrhon die Abhängigkeit des Denkens von der Wahrnehmung betonte. Es wird ihm nur die Erwägung zugeschrieben, daß weder die Sinneswahrnehmung noch das Denken immer wahre oder falsche Angaben macht. Dies ergibt sich daraus, daß bald die eine Wahrnehmung mit der anderen, bald der eine Gedanke mit dem anderen, bald der Gedanke mit der Wahrnehmung streitet. Denn von zwei kondradiktorisch entgegengesetzten Aussagen muß, wenn die eine wahr ist, die andere falsch sein. Um solchen Streit der Wahrnehmungen und Gedanken schlichten und die Wahrheit ermitteln zu können, müßten wir ein Kriterion besitzen, das selbst über allen Zweifel erhaben wäre. Ein solches Kriterion gibt es aber nicht. Nichts berechtigt uns, eine Wahrnehmung der anderen, einen Gedanken dem anderen ihm widersprechenden vorzuziehen. Jeder Wahrnehmung läßt sich eine widersprechende gegenüberstellen, sei es nun die gleichzeitige einer anderen Person, sei es eine frühere oder spätere derselben Person; ebenso läßt sich jedem Argument ein gleich starkes für die entgegengesetzte Behauptung gegenüberstellen. Diese Dartstellung verrät nirgends demokriteische Voraussetzungen, sondern deckt sich im wesentlichen mit den Ansichten des Protagoras und Aristippos.

Ist also das Gedachte gleichermaßen wie das sinnlich Wahrgenommene ein bloßes Phänomen, so ergibt sich, daß wir zur Erkenntnis der Dinge selbst überhaupt nicht gelangen können. Es ziemt uns also bezüglich aller über das bloß Phänomenale hinaus auf das Wesen der Dinge gehenden Fragen die Urteilsenthaltung (griech. epoché). Jede meiner Äußerungen darf nur als ein Bekenntnis des mir Erscheinenden, nicht als eine Behauptung über das wahrhaft Seiende auftreten. Daß ein Gegenstand mir weiß erscheint, darf ich behaupten, nicht aber daß der Gegenstand an sich weiß oder nicht weiß ist. $D a ß$ ich sehe, daß ich denke, weiß ich; wie mein Sehen und Denken zustande kommt, weiß ich nicht. Werde ich gefragt, ob das Ding selbst so oder so beschaffen ist, so antworte ich: „Es ist um nichts mehr so als so be- 
schaffen" oder "es ist sowohl so als auch nicht so beschaffen" oder "es ist weder so noch auch nicht so beschaffen". Alle diese Sätze sind in dem Sinne $z u$ verstehen, daß durch sie über das Wesen der Dinge selbst überhaupt nichts ausgesagt wird. Wir bekennen nur in diesen Sätzen, daB wir uns für keine der entgegengesetzten Behauptungen entscheiden, sondern die Wage unseres Urteils im Gleichgewicht schwebt. Auch dies ist nur das Bekenntnis eines Phänomens. Für die Bedürfnisse des praktischen Lebens genügt es durchaus, den Phänomenen zu folgen.

Am wichtigsten für das menschliche Leben ist die Urteilsenthaltung bezüglich der Wertbegriffe des Schönen und Häßlichen, des Guten und Ublen, des Gerechten und Ungerechten, die ebenfalls Gegenstand unentscheidbaren Meinungsstreites sind. Dieser Streit macht es uns unmöglich, irgendeine Sache als an sich und von Natur gut oder übel, gerecht oder ungerecht zu erkennen. Wir müssen daher auch auf diesem Gebiete uns des Urteils enthalten und bekennen, daB die betreffende Sache um nichts mehr schön als häBlich, um nichts mehr gut als schlecht, um nichts mehr gerecht als ungerecht ist. Hier zeigt sich der große praktische Vorteil der Urteilsenthaltung. Durch die Werturteile wird unser Suchen und Fliehen, Begehren und Meiden bedingt, welches unseren Seelenfrieden stört. Enthalten wir uns der Werturteile, so wird unser Streben und Meiden und damit die Störung der Seelenruhe auf ein Mindestmab zurückgeführt, auf diejenigen Strebungen nämlich, die auf einer Naturnotwendigkeit, nicht auf Meinungen beruhen. So ist es z. B. naturnotwendig, daß wir Hunger, Durst und Schmerz fliehen, aber unnötig ist es, daß wir die Summe des Begehrens durch unbegründete und voreilige Werturteile steigern. So ergibt sich aus der Urteilsenthaltung und folgt ihr, gleichsam als ihr Schatten, das Maximum des dem Menschen erreichbaren Seelenfriedens, der Ataraxie. In diesen ethischen (eudämonistischen) Folgerungen nähert sich Pyrrhon der epikureischen und stoischen Ethik. Auch seine Lehre verfolgt das praktische Ziel der Unabhängigkeit von allem Äußeren, der inneren Freiheit. Besonders nahe berührt er sich mit Epikur, indem er die auf der „Meinung“ beruhenden Begierden ausrotten möchte und nur die naturnotwendigen gelten läßt.

II. Der Epikureismus (3. Jahrhundert v. Chr.). Epikuros, der Sohn Epikuros des Neokles, eines auf Samos als Kleruch lebenden attischen Bürgers, genoB schon vor seinem achtzehnten Lebensjahre in Teos den Unterricht des Demokriteers Nausiphanes und wurde so mit dem atomistischen Systeme vertraut, das für alle Teile seines Lehrgebäudes die Grundlage bildet. Auch Pyrrhons Lehre lernte er durch Nausiphanes kennen und begeisterte sich für das von ihm aufgestellte Ideal der Ataraxie. Doch suchte er nicht auf dem Wege des Skeptizismus, sondern auf dem des Dogmatismus dieses Ideal zu verwirklichen. Andererseits trennte ihn bald von Nausiphanes und den Demokriteern seine abweichende Auffassung von der Aufgabe der Philosophie. Die Naturforschung war ihm nicht wie jenen Selbstzweck - Wissenschaft 
um der Wissenschaft willen -, sondern nur das unentbehrliche Mittel, um das wahre Ziel aller philosophischen Forschung, die Glückseligkeit des menschlichen Lebens, erreichbar zu machen. So kommt er in der Zielsetzung mit Pyrrhon und den Stoikern überein; der Weg aber, den er einschlägt, um zum Ziele zu gelangen, ist die Physik des Demokritos. Epikur hat, nachdem er fünf Jahre in Mitylene und Lampsakos gelehrt hatte, im Jahre 306 seine Schule nach Athen verlegt und dort bis zu seinem Tode (270) mit seinen Freunden und Jüngern den "Garten" bewohnt, der auch nach seinem Tode der Schule Stätte und Namen lieh.

Kanonik (ErNach Epikur hat die Philosophie zwei Teile: Physik und Ethik. Die Er-

kenntnistheorie und Logik hat er nicht als dritten selbständigen Teil anerkannt, sondern die Erörterung über das Kriterion (d. h. die Norm, durch welche wahre von falschen Behauptungen unterschieden werden können) als einen akzessorischen Bestandteil der Physik angesehen. Von der psychologischen Beschreibung des Erkenntnisprozesses, die natürlich zur Physik gehörte, hat er die erkenntnistheoretischen Folgerungen nicht getrennt. Ich darf meine Darstellung der Lehre Epikurs mit der Lehre vom Kriterion beginnen, da ihre auf dem atomistischen Systeme beruhenden physikalischen Voraussetzungen den Lesern dieses Abrisses schon bekannt sind. Epikurs Behandlung des Erkenntnisproblems geht von derselben Problemstellung aus, die den Pyrrhon zu seinem Agnostizismus geführt hatte. Die Aussagen der sinnlichen Wahrnehmung, so lehrten Pyrrhon und Timon, sind widerspruchsvoll, da von demselben Gegenstand verschiedene Personen oder auch dieselbe Person zu verschiedenen Zeiten und bei verschiedenem Abstande von ihm verschiedene Wahrnehmungseindrücke empfangen. Diese Widersprüche kann nicht die sinnliche Wahrnehmung selbst schlichten, da von mehreren widersprechenden Sinneszeugnissen jedes als solches den gleichen Anspruch auf Glaubwürdigkeit hat. Also ist die sinnliche Wahrnehmung nicht das Kriterion. Ebensowenig kann aber das begriffliche Denken als Kriterion anerkannt werden, da sich jedem Argument für irgendeine Behauptung ein gleich starkes für die kontradiktorisch entgegengesetzte gegenüberstellen läßt. Also gibt es überhaupt kein Kriterion, um wahre von falschen Behauptungen zu unterscheiden. Epikur gibt das Vorkommen von Widersprüchen sowohl auf dem Felde der sinnlichen Wahrnehmung wie auf dem des Denkens zu. Er gibt ferner zu, daß, wenn weder Wahrnehmung noch Denken Kriterion ist, überhaupt kein Kriterion vorhanden und wissenschaftliche Erkenntnis unmöglich ist. Dieser Folgerung möchte er aber um jeden Preis entrinnen, da er nicht wie Pyrrhon das phänomenale Weltbild mit allen seinen Widersprüchen für eine ausreichende Richtschnur der praktischen Lebensführung hält. Da er nun ferner mit größter Entschiedenheit den ganzen Inhalt des Denkens aus der sinnlichen Wahrnehmung ableitet - eine Ansicht, die vielleicht auch Pyrrhon hegte, obgleich die Überlieferung davon nichts meldet -, so mußte er versuchen, Irrtum und Widerspruch auf das Gebiet des Denkens einzuschränken, die Sinnestäuschungen dagegen und die Widersprüche der Wahr- 
nehmung als bloß scheinbar zu erweisen, um die Wahrnehmung, aus der alles Denken abgeleitet ist, als Kriterion zu retten. Dies bewirkt er durch die physikalische Wahrnehmungstheorie des Empedokles und Demokritos, die bekanntlich Ausflüsse der Dinge das Sinnesorgan berühren und die Empfindung in ihm erzeugen läßt und die besonders das Gesicht, die wichtigste Wahrnehmung, auf Bilder der Dinge zurückführt, die sich unaufhörlich von ihrer Oberfläche ablösen und unter Wahrung der ursprünglichen Form und Farbe mit großer Geschwindigkeit durch den Raum bewegen, bis sie auf das Auge treffen. Diese Vorstellung wird von Epikur benutzt, um die Zuverlässigkeit der Sinneswahrnehmung als solche, ungeachtet der bei ihr vorkommenden Widersprüche und Täuschungen, aufrechtzuhalten. Den unmittelbaren Gegenstand der sinnlichen Wahrnehmung bilden nicht die Dinge selbst, sondern ihre zum Sinnesorgan gelangenden Ausflüsse und Abbilder. Bezüglich dieser lügen die Sinne nie. Dafür spricht erstens die Natur des Empfindungsvorganges, der in einem mit Bewußtsein verbundenen Affiziertwerden durch den Gegenstand besteht. Es ist undenkbar, daß den Inhalt des mit dieser Affektion verbundenen Bewußtseins etwas anderes bilden sollte als die Affektion selbst und damit eine Eigenschaft des Gegenstandes. Denn die Wahrnehmung, welche vernunftlos ist, denkt und meint nicht, sondern leidet. Sie tut nichts hinzu, sie 1äßt nichts fort, sie ändert nichts. Es spricht aber auch $z$ weitens für die Untrüglichkeit der Wahrnehmung, daß, wenn eine falsch wäre, wir dasselbe von allen ohne Ausnahme glauben müßten, da sie alle auf die gleiche Weise zustande kommen und sich nur durch ihren Gegenstand unterscheiden. Drittens würde, wenn wir auch nur einer einzigen Wahrnehmung den Glauben versagten (selbst wenn damit nicht auch alle übrigen verworfen würden), die Wahrnehmung nicht mehr als Kriterion und feste Grundlage aller Erkenntnis gelten können, und da es auch kein anderes Kriterion gibt, die Möglichkeit wissenschaftlicher Erkenntnis und der auf ihr beruhenden rationellen Lebenspraxis aufgehoben werden. - Epikur nimmt die Lehre Demokrits von den Sinnesqualitäten insoweit an, als auch er Farbe, Geschmack, Geruch den Atomen abspricht; doch gibt er nicht zu, daß diese Eigenschaften nur in der menschlichen Vorstellung bestehen. Denn er sagt ausdrücklich, daß die Abbilder, die unser Auge treffen, dem Gegenstande nicht nur an Gestalt, sondern auch an Farbe gleich sind. Er sieht also die Farbe als eine Qualität an, die durch bestimmte Verbindung und Lagerung der Atome in den Gegenständen selbst entsteht, und hält auch nach dieser Seite hin die Glaubwürdigkeit des Sinnenzeugnisses aufrecht. Doch unterscheidet sich seine Lehre von der demokriteischen mehr im Ausdruck als in der Sache. Durch die eben geschilderte Theorie glaubt Epikur die Sinneswahrnehmung als untrügliches Kriterion aufrechterhalten und doch die Tatsachen der Sinnestäuschung und der widersprechenden Wahrnehmung erklären zu können. Die Sinneswahrnehmung lügt nie, aber sie bezieht sich unmittelbar nur auf die Abbilder, auf den Gegenstand selbst nur mittelbar. Sache des Urteils, der „Doxa“, ist es, aus dem Abbild auf den Gegenstand 
zu schließen. Hierbei sind Irrtümer nicht ausgeschlossen, da erstens die Abbilder auf ihrem Wege zu dem Sinnesorgan sich bisweilen verändern, $z w$ eitens durch zufälliges Zusammentreffen von Atomen Bilder entstehen und von uns perzipiert werden, die von keinem festen Gegenstande herrühren, drittens - hier wird ein Gedanke des Empedokles verwertet - nur die den Poren des Sinnesorgans symmetrischen Atomgruppen in diese eindringen und eine Wahrnehmung hervorbringen können, so daß, da jeder wahrgenommene Gegenstand aus Atomen der verschiedensten Art zusammengesetzt ist, jeder nur die Arten von Atomen wahrnimmt, die seinem Organ symmetrisch sind. Das dritte Argument soll zeigen, daß selbst gleichzeitige widersprechende Wahrnehmungen verschiedener Subjekte von demselben Gegenstande nichts gegen die Untrüglichkeit der Sinneswahrnehmung in dem von Epikur angenommenen Sinne beweisen. Die auf diese Weise entstandenen Irrtümer können wir korrigieren, indem wir von neuem an das Sinneszeugnis appellieren. Da von den festen Körpern unaufhörlich Bilder sich ablösen, so wird die adäquate Wahrnehmung durch viele nachfolgende desselben Subjekts oder anderer Subjekte bestätigt werden, während bei der inadäquaten die Bestätigung ausbleibt. So werden Irrtümer bezüglich der sinnlich wahrnehmbaren Gegenstände korrigiert; aber auch für Urteile über nichtwahrnehmbare Dinge bildet die sinnliche Wahrnehmung das Kriterion. Der Gesichtspunkt für ihre Prüfung ist, ob sie mit den Aussagen der Wahrnehmung in logischer Übereinstimmung stehen oder nicht. Die Widerlegung solcher Urteile besteht in dem Nachweis, daß Wahrnehmungstatsachen vorhanden sind, mit denen sie in Widerspruch stehen. Ein direkter Beweis ist für sie niemals möglich; Epikur betrachtet sie als ausreichend bewährt, wenn sie nicht durch den Widerspruch mit Wahrnehmungstatsachen widerlegt werden können. Die logische Folgerichtigkeit, die bei dem zuletzt geschilderten Verfahren das entscheidende Moment ist, hat Epikur, wie ihm seine Gegner mit Recht vorwerfen, nicht näher untersucht und ihre Prinzipien nicht zu den Kriterien gerechnet. Auch ist es ein mißlicher Punkt seiner Theorie, daß ein Urteil so immer nur als unwiderlegt, niemals aber als unwiderlegbar dargetan werden kann. - In eine Reihe mit den Affektionen der Sinnesorgane stellt Epikur die Affektionen des inneren Gefühls, Lust und Unlust. Sie sind ebenfalis als Affektionen, zu denen das vernunftlose Gefühl nichts hinzutut und von denen es nichts hinwegnimmt, untrüglich und bilden in entsprechender Weise das Kriterion des Wollens und Handelns, wie die Sinneswahrnehmung das Kriterion des Erkennens. Auch hier ist Irrtum erst in der auf das Gefüh1 sich gründenden Meinung (Doxa) über gut und böse möglich. Wenn nun Epikur neben der sinnlichen Wahrnehmung bisweilen auch die natürliche Idee (Prolepsis) als Kriterion anerkannte, so läßt sich leicht ermitteln, wie dies gemeint war. Da er an dem Grundsatz festhält: „nihil est in intellectu, quod non fuerit in sensu", so kann er weder ursprüngliche, angeborene Ideen angenommen, noch auch Ideen als ein selbständiges Kriterion von gleichem Range der Wahrnehmung koordiniert haben. Er will nur 
sagen, daß Gattungsbegriffe, die den gemeinsamen Typus irgendeiner Gattung anschaulicher Wesenheiten auf Grund zahlreicher vorausgegangener Einzelwahrnehmungen ausprägen, mit Naturnotwendigkeit in uns entstehen, und daß bei ihrer Entstehung kein Irrtum unterläuft. Diese Begriffe müssen immer schon vorausgesetzt werden, wenn ein Urteil, eine Problemstellung; eine Untersuchung, ein Beweis zustande kommen soll. Da es nicht möglich und auch nicht nötig ist, sie immer wieder von neuem aus Einzelwahrnehmungen abzuleiten, insofern ihr Inhalt nicht Gegenstand der Kontroverse werden kann, sind sie in gewissem Sinne selbst Kriterion. Es ist auch nicht nötig, sie zu definieren, da das bloße Aussprechen des Wortes schon gerügt, um jedem Hörer den Begriff mit einer Klarheit zu vergegenwärtigen, die durch umständliche Umschreibungen nach Art der Definitionen nicht gesteigert, sondern nur getrübt wird. Einem solchen Gattungsbegriff entspricht keine außer den Einzelwesen rorhandene selbständige Wesenheit in der Natur der Dinge. Das Reale, auf das sich der Gattungsname bezieht, sind die konkreten Einzelwesen, die zu der Gattung gehören. Das Abstrakte, das die Bedeutung der Worte ausmacht, ist kein Seiendes. Es ist hiernach klar, daß durch die Nennung der „natürlichen Ideen“ als des zweiten Kriterion neben der Sinneswahrnehmung Epikurs Erkenntnislehre nicht aufhört, eine rein sensualistische $z u$ sein. Ihre charakteristische Eigentümlichkeit ist die Ansicht, daß, wenn auch nur eine einzige Wahrnehmung falsch ist, die wissenschaftliche Erkenntnis überhaupt unmöglich ist. Selbst die Halluzinationen eines Geisteskranken und die Traumgesichte eines Schlafenden machen keine Ausnahme. Auch die Träume sind Wahrnehmungen, wie Epikur mit Demokrit annimmt; während des Schlafes dringen Bilder nicht in die Sinnesorgane, sondern durch die Poren des Leibes direkt in das Zentralorgan der Seele, den Sitz der Wahrnehmung, ein. Ob solche Traumgesichte von einem realen körperlichen Wesen herrühren, also wahr sind, oder von zufällig auf andere Weise entstandenen Bildern, kann nur wissenschaftliche Überlegung im einzelnen Falle entscheiden. Epikur hat einerseits den Glauben, daß es Götter in Menschengestalt gibt, für den, wenn er als „natürliche Idee" gelten sollte, eine Wahrnehmungsgrundlage nachgewiesen werden mußte, auf wahre Traumgesichte zurückgeführt, andererseits den Glauben an zukunftkündende, ron den Göttern gesendete Träume als einen die Gemütsruhe bedrohenden Aberglauben aufs schärfste bekämpft.

Dem erkenntnistheoretischen Sensualismus entspricht bei Epikur eine materialistische Ontologie. Nur das Körperliche, die Materie ist etwas Rea- Die Atome und les. Außer ihr gibt es eine „unberührbare Wesenheit", den Raum, von dem nichts weiter $\mathrm{zu}$ sagen ist, als daß er unendlich ist, daß die Körper in ihm als ihrem Orte sind und sich bewegen, und daß er als Leeres zwischen den Stoffteilen vorhanden ist. Er ist vorhanden und doch ein Nichtseiendes. Außer den Körpern und dem Raum gibt es nichts, was für sich als selbständige Wesenheit existiert. Alles übrige, was den Gegenstand einer Vorstellung oder sprachlichen Bezeichnung bilden kann, haftet als Akzidens an diesen beiden 
Wesenheiten, sei es als dauernde (untrennbare) Eigenschaft, sei es als vorübergehender Zustand, sei es als Bewegung und Vorgang. An den Zuständen und Vorgängen haftet wiederum die Zeit als ein Akzidentielles zweiter Ordnung, ein Akzidens des Akzidens. - Die Körper bestehen aus Atomen, d. h. aus Stoffteilen, die physikalisch nicht mehr teilbar sind, weil sie kein Leeres in sich enthalten und deshalb absolut hart und undurchdringlich sind. Der Grund ihrer Unteilbarkeit ist also nicht ihre Kleinheit, obgleich sie zu klein sind, um wahrgenommen zu werden. Die Eigenschaften der Atome außer der Undurchdringlichkeit (Unteilbarkeit, Unzerstörbarkeit, Ewigkeit) sind Größe, Schwere und Gestalt. Der Größe nach unterscheiden sich die Atome innerhalb einer oberen und einer unteren Grenze. Die obere Grenze ist dadurch gegeben, daß alle unter dem Maße des kleinsten Wahrnehmbaren zurückbleiben, die untere dadurch, daß jedes Atom noch mathematisch teilbar ist Das „Kleinste“. und aus einer Anzahl materieller Minima besteht. Im Gegensatz zu der in der Mathematik schon damals herrschenden Annahme der unendlichen Teilbarkeit des Raumkontinuums hat Epikur den Begriff des Minimums aufgestellt als einer endlichen Größe, die auch mathematisch nicht mehr teilbar ist. Dieses kleinste Ausgedehnte bildet die Einheit, durch die alle Raumgrößen gemessen werden. Wir sollen uns dieses „Kleinste“ vorstellen nach Analogie des kleinsten Wahrnehmbaren, d. h. derjenigen Raumgröße, an der die sinnliche Wahrnehmung keine Teile mehr unterscheiden kann. Ganz analog muß es auch auf dem Gebiet der nur im Gedanken erfaßbaren Größen eine letzte Einheit geben. Ganz entsprechend diesen kleinsten Raumgrößen nimmt Epikur kleinste Zeitteile an, aus denen jede Zejtdauer sich zusammensetzt. Er glaubt durch diese Theorie die Schwierigkeiten heben zu können, die Zenon von Elea und die Megariker gegen die Bewegung geltend machten. Die Strecke, die ein körperlich „Kleinstes“ in bestimmter Zeit durchläuft, besteht aus einer begrenzten Zahl kleinster, nicht mehr teilbarer Strecken, wie auch die hierfür gebrauchte Zeit aus einer begrenzten Zahl kleinster, nicht mehr teilbarer Zeitmomente besteht. Von der ganzen Strecke kann man sagen, daß sich der Körper durch sie bewegt, von ihren kleinsten Einheiten, daß in jeder derBewegung der selben der Körper ein bewegter ist. — Doch kehren wir zu den Eigenschaften
Atome. der A tome zurück. Unter Schwere versteht Epikur die Eigenschaft der Atome, sich im leeren Raume, wo sie auf keinen Widerstand stoßen, gradlinig nach unten zu bewegen. Er findet es nämlich zulässig, im unendlichen leeren Raume, obgleich derselbe weder obere noch untere Grenze hat, eine Richtung der Bewegung von oben nach unten anzunehmen. Die Schwere der Atome variiert in demselben Verhältnis wie ihre Größe. Doch begründen diese Unterschiede der Größe keine Unterschiede der Fallgeschwindigkeit im leeren Raume. In ihm bewegen sich größere und kleinere Atome mit der gleichen Geschwindigkeit. Epikur hält dies für eine notwendige Folgerung aus seiner eben geschilderten Auffassung der Bewegung. Denn wenn ein Körper zur Durchmessung eines kleinsten Raumteiles mehr Zeit brauchte als ein anderer, so würde sich ergeben, daß er in der gleichen Zeit nur einen Bruchteil jenes 
kleinsten Raumteiles durchmäße, und wir würden so zu der Annahme der. unendlichen Teilbarkeit begrenzter Raumgrößen genötigt, aus der sich nach Zenon und den Megarikern die Unmöglichkeit der Bewegung ergibt. Man muß daher annehmen, daß es Geschwindigkeitsdifferenzen der kontinuierlichen Bewegung überhaupt nicht gibt. Die Geschwindigkeitsdifferenzen beruhen auf der Diskontinuität der Bewegung, die durch Zusammenstöße mit anderen Atomen unterbrochen wird. - Eine weitere Eigenschaft der Atome, Atomformen. durch die sie sich voneinander unterscheiden, ist ihre Form. Die Zahl der Atomformen ist unbestimmbar groß, aber nicht unendlich. Denn die Zahl der möglichen Formen ergibt sich aus der Zahl der in den einzelnen Atomen enthaltenen kleinsten Stoffteile, die eine begrenzte ist, und aus der Zahl ihrer möglichen Anordnungen, die ebenfalls eine begrenzte ist. Es gibt also nur eine begrenzte Anzahl möglicher Formen. Von jeder einzelnen Form aber müssen unendlich viele Atome angenommen werden. Denn nur so wird die Gesamtzahl aller Atome unendlich groß sein; was notwendig angenommen werden muß, da eine endliche $Z$ ahl von Atomen im unendlichen Raume sich verlieren und keine Welt zustande bringen würde.

Außer den genannten Eigenschaften (Undurchdringlichkeit, Größe, Abweichung von Schwere, Form) glaubt Epikur den A tomen noch eine weitere Eigentümlich- $\stackrel{\text { der vertikalen }}{\text { Fallrichtung. }}$ keit zuschreiben zu dürfen, die Fähigkeit nämlich, bisweilen ohne äußeren Grund, wo oder wann es ihnen beliebt, um eine „kleinste“ Winkelgröße von der graden Fallrichtung abzuweichen. Die Absicht dieser befremdlichen Annahme ist eine doppelte. Erstens würden, wenn sich alle Atome in gleicher Richtung und mit gleicher Geschwindigkeit von oben nach unten bewegten, keine Zusammenstöße, also auch keine Weltbildung erfolgen können. Zweitens würde, wenn nicht schon den Prinzipien alles Existierenden ein gewisses $\mathrm{Ma}$ spontaner Bewegung eigen wäre, überhaupt in der ganzen Welt keine spontane Bewegung zustande kommen. Alles würde mit blinder Notwendigkeit nach dem Verhängnis geschehen, die menschliche Willensfreiheit wäre undenkbar. Die Willensfreiheit aber glaubte Epikur als Grundlage der Ethik, in der seine ganze Philosophie gipfeln sollte, nicht entbehren zu können, und in dem Glauben an ein unentrinnbares Verhängnis erblickte er eine um nichts weniger bedrohliche Gefahr für die menschliche Seelenruhe als in der Götterund Todesfurcht. Es ist bemerkenswert, daß er Empfindung und Bewußtsein den Urprinzipien des Seins nicht schon deswegen zuschreiben zu müssen glaubt, weil sie bei den zusammengesetzten Wesen vorkommen; die spontane Bewegung aber der Lebewesen muß notwendig aus den Prinzipien abgeleitet werden, weil sie unmittelbar in den Mechanismus des Weltgeschehens eingreift. Methodologisch glaubte sich Epikur zu der Annahme berechtigt, weil sie durch kein Sinnenzeugnis widerlegt werden kann. Jene „kleinste“ Winkelgröße, um welche das Atom von der senkrechten Fallrichtung abweicht, bleibt natürlich weit unter der Grenze menschlicher Wahrnehmungsfähigkeit.

Die besprochenen Unterschiede der Atome genügen, nach Epikurs Meinung, um alle in der Erfahrung vorkommenden Qualitäten aus ihnen abzu- 
leiten. Außer der Größe, Form und Bewegung der einzelnen Atome begründen die Unterschiede der Mischung, Lage und Anordnung der Atome in den zusammengesetzten Körpern mannigfaltige Sinneseindrücke. Aber nicht allein der Bestand der Erfahrungswelt, sondern auch ihre Entstehung läßt sich aus der atomistischen Grundhypothese erklären. Durch die Zusammenstöße der Atome, die vermöge ihrer Undurchdringlichkeit voneinander abprallen, entstehen weitere Bewegungen außer den beiden bisher besprochenen Arten, dem Fall und der Ablenkung. Viele A tome bleiben auch, wenn sie zusammenstoßen, vermöge ihrer Form aneinander haften und verflechten und verklammern sich miteinander. Ganz wie Demokrit läßt Epikur aus den Bewegungen und Zusammenstößen der Atome unendlich viele Welten neben- und nacheinander im unendlichen Raume entstehen und wieder vergehen. Wir verweilen nicht mehr bei den Einzelheiten seiner Kosmogonie, die geringes philosophisches Interesse bieten, und ebensowenig bei seinen ätiologischen Nethode der Erklärungen einzelner Naturerscheinungen. Wichtig ist, daß in seiner ErNaturerklärung. klärungsmethode überall der beherrschende Gesichtspunkt seiner Naturphilosophie hervortritt, der Gesichtspunkt der Aufklärung; der Bekämpfung des "religiösen Aberglaubens“. Die Naturwissenschaft erweckt ihm kein selbständiges theoretisches Interesse. Wenn man ohne sie zur Gemütsruhe und zur Glückseligkeit gelangen könnte, würde er sich nicht mit ihr beschäftigen. Wichtig ist ihm vor allem der. Satz, daß die Welt und alles, was in ihr geschieht, nicht von übermächtigen denkenden und wollenden Wesen, den Göttern, sondern von blinder Naturgesetzlichkeit beherrscht wird. Um zu zeigen, daß mit diesem Satze die Erfahrung nirgends in Widerspruch gerät, muß er vor allem diejenigen eindrucksvollen Naturvorgänge auf ihre Ursachen zurückzuführen suchen, bei denen die gewöhnliche Ansicht ein übernatürliches, göttliches Eingreifen vermutet. Es ist aber durch den Zweck diesem Forschungsbemühen eine Grenze gezogen. Wewn sich ein Naturvorgang auf mehrere, der sinnlichen Erfahrung nicht widerstreitende Weisen erklären läßt, so soll man diese als Möglichkeiten nebeneinander gelten lassen und nicht um jeden Preis eine Entscheidung herbeizuführen suchen. Es genügt für den Zweck, wenn wir zeigen, daß sich die betreffenden Vorgänge so oder so jedenfalls ohne Zuhilfenahme übernatürlicher Faktoren erklären lassen.

Götterlebre. So will Epikur durch seine Lehre die abergläubische Götterfurcht ausrotten, die ihm als eine der schlimmsten Gefahren für die menschliche Gemütsruhe gilt. Gleichwohl betritt er nicht, wie man nach seiner ganzen Geistesrichtung erwarten sollte, die Bahn des Atheismus. Daß es Götter gibt, ist ihm eine zweifellose Tatsache. Der Götterglaube ist eine „natürliche Idee“, wie der consensus gentium beweist. Aber die Auffassung der Götter in der Volksreligion widerstreitet dieser "natürlichen Idee“ ebensosehr wie die der philosophischen Theologie der anderen Schulen. Die natürliche Idee der Gottheit schreibt ihr Ewigkeit, Glückseligkeit, Unberührtheit von allem Übel zu. Hiermit ist der volkstümliche Glaube unvereinbar, der den Göttern HaB, Zorn und andere menschliche Leidenschaften andichtet. Sie könnten weder selig noch 
ewig sein, wenn ihre Seelen von Leidenschaften zerrüttet würden. Aber auch die Vorstellung von Gott als dem Schöpfer, Erhalter und Regenten der Welt widerstreitet der natürlichen Gottesidee. Denn sie lädt ihm Sorge, Mühe und Arbeit auf, die seine Seligkeit aufheben würden. $\mathrm{Zu}$ verwerfen ist auch der (stoische)Pantheismus, derGott in und mit derWeltkugel kreisen läßt, wie einen aufs Rad geflochtenen Verbrecher, und ihn alles, was in der Welt geschieht, selbst tun und erleiden läßt. Die natürliche Gottesidee fordert vielmehr, daß wir die Götter frei von aller Sorge und Arbeit und in ungetrübtem Selbstgenuß ihres Daseins nur mit der Erhaltung ihrer eigenen Seligkeit beschäftigt denken. Da nun in den Wirbeln der Atombewegung, in dem Strome des Werdens und Vergehens, der durch alle Welten unablässig strömt, nirgends ein Ort ungestörten Friedens zu finden ist, so muß man annehmen, daß die Götter in den Zwischenräumen, welche die Welten voneinander trennen (den Metakosmien), wohnen, ohne je tätig in das Weltleben einzugreifen. Wir müssen sie in menschlicher Gestalt denken, da nur diese für ein dem menschlichen analoges Seelenleben ein geeignetes Gefäß bildet. Wenn wir so die natürliche Gottesidee von jeder erniedrigenden Beimischung rein halten, sind wir wahrhaft fromm und werden durch den Seelenfrieden, der aus diesem Glauben quillt, für unsere Frömmigkeit belohnt werden. Nicht der frevelt gegen die Götter, der die Götter des Volksglaubens verwirft, sondern der, welcher ihr Bild durch die Erfindungen des Volksglaubens verunstaltet.

Wenn wir nun auch im übrigen die Einzelausführung der epikureischen Die Seele. Physik übergehen dürfen, so müssen wir doch bei der physikalischen Auffassung des Menschen und der menschlichen Seele noch einen Augenblick verweilen, weil sie eine Hauptstütze der ethischen Doktrin bildet. Für jede materialistische Doktrin erheben sich die größten Schwierigkeiten, wenn sie sich anschickt, die psychischen Vorgänge, wie Wahrnehmen, Denken, Fühlen, Wollen, aus ihren Voraussetzungen zu erklären. Da psychische Vorgänge uns nur durch innere, physische nur durch äußere Wahrnehmung gegeben sind, stehen sich diese und jene für alle Ewigkeit als zwei völlig unvergleichbare Klassen von Vorgängen gegenüber. Für den Atomismus entsteht eine weitere Schwierigkeit, weil von der Vielheit diskreter Atome keine gangbare Brücke zu der Einheit des Seelenlebens führt. Diese Schwierigkeiten konnte auch Epikur nicht 1ösen, ja soweit wir urteilen können, hat er sie sich nicht einmal genügend klar gemacht. Den Gegensatz der Lebewesen zu den nicht lebendigen, zu denen er auch die Pflanzen rechnet, führt auch er auf eine substantielle Seele zurück, die den Lebewesen einwohnt und Trägerin und Ursache der Lebensvorgänge ist. Da die Seele wirkt und leidet, so muß sie, nach den Grundvoraussetzungen des Systems, ein körperliches Wesen sein; und da sie mit dem Leibe in Wechselwirkung steht, nicht in durchgängigem Parallelismus des beiderseitigen Erlebens, so muß die Seele ein vom Leibe verschiedenes Wesen sein. Diese Annahme teilt Epikur mit der gesamten antiken Philosophie. Natürlich kann die Seele, weil sie leidet und empfindet, nicht aus einem einzigen Atom bestehen. Denn die einzelnen Atome 
können, weil sie ewig und unveränderlich sind, nicht leiden und nicht empfinden. Vielmehr besteht die Seele aus vielen Atomen, die dem ganzen Leibe beigemischt sind und dennoch unter sich ein Ganzes bilden, das im Herzen sein Zentrum hat. Wir müssen annehmen, daß aus empfindungslosen Bestandteilen durch die Art ihrer Zusammensetzung und Ordnung ein empfindendes Wesen entsteht. Die Empfindung selbst und alle übrigen Lebens- und Bewußtseinsvorgänge müssen als Bewegungen in diesem Atomkomplex aufgefaßt werden. Alle Lebenserscheinungen, nicht nur die Bewußtseinsvorgänge führt Epikur auf die Seele zurück, auch die Lebenswärme, welche die Lebewesen auszeichnet, und die Fähigkeit, den Leib spontan aus der Ruhe in Bewegung und aus der Bewegung in Ruhe zu versetzen. Um sowohl die Mehrheit der Funktionen wie die Einheit des Seelenlebens zu erklären, nimmt er an, daß die Seelensubstanz aus mehreren Stoffen gemischt ist, die aber bei der Mischung ihre Selbständigkeit und eigentümliche Wirkungsweise nicht verlieren. In derselben Weise, wie die ganze Seele dem Leibe beigemischt ist, ohne jedoch dabei den zu selbständiger Betätigung erforderlichen inneren Zusammenhang einzubüßen, sind auch die Bestandteile der Seele so ineinander eingeschachtelt, daß immer der nächst höhere und feinere in dem nächst gröberen, wie die Seele im Leibe enthalten ist. Da ist zunächst ein luftartiger Bestandteil, der als der gröbste (aus den gröbsten Atomen bestehende) und mindest bewegliche das Prinzip der Ruhe in der Seele ist. Da ist ferner eine pneumatische Substanz, ein feineres beweglicheres Gas, das die Ursache der Bewegungen ist. Da ist ferner ein feuriger Wärmestoff, die Ursache der Lebenswärme. Da ist endlich ein vierter, noch viel feinerer Stoff, den man mit keines sonst vorkommenden Stoffes Namen zutreffend benennen kann, der sozusagen den innersten Kern und die Seele der Seele bildet und Träger aller im engeren Sinne psychischen Tätigkeiten, d. h. der Bewußtseinsvorgänge ist. So versucht Epikur die Einheit des Seelenwesens neben der Mehrheit der Seelenfunktionen zu wahren. Aber strenggenommen erstreckt sich Leib und Seele. diese Einheit auf das ganze, aus Seele und Leib zusammengefügte Wesen. Wir haben fünf nach der Feinheit des Stoffes abgestufte Bestandteile des Lebewesens, die durch Mischung zur Einheit verbunden sind. Der Gegensatz von Leib und Seele im Sinne Epikurs ist begrifflich nicht faßbar. Denn was haben die vier Bestandteile der Seele im Gegensatz zum Leibe gemeinsam? Man fühlt die Absicht des Philosophen, den Gegensatz des Physischen und Psychischen durch eine Abstufung zu überbrücken und aus einem absoluten in einen relativen zu verwandein. Aber bei dem Übergang vom dritten zum vierten Seelenbestandteil bricht dieser Gegensatz wieder in seiner ganzen Schärfe hervor. - Seele und Leib sind aufs innigste miteinander verbunden und können nur in dieser engen Verbindung bestehen und, wie es ihrer Natur entspricht, funktionieren. Die Seele, die aus den feinsten und beweglichsten Atomen besteht, kann nur dadurch, daß sie von dem Leibe zusammengefaßt und gedeckt wird, bestehen. Ohne diese feste Hülle würde sie sich bald verflüchtigen und in ihre Atome auflösen. In besonderen sind auch die ihr 
eigentümlichen Bewegungen, auf denen Wahrnehmung und Denken beruht, durch die besondere Art ihrer Einfügung in die leiblichen Organe bedingt. Andererseits ist auch der Fortbestand des Leibes durch die Anwesenheit der Seele bedingt. Die Seele kann sich aus der innigen Verschlingung mit dem Leibe nicht lösen, ohne ihn zu zerstören. Aus diesen physikalischen Ansichten ergibt sich der für Epikurs Lehre grundlegende Satz, daß die Seele wie ein gewordenes, so auch ein vergängliches Wesen ist, und daß mi dem Augenblick des Todes Wahrnehmung und Gefühl aufhören.

Epikur legt deshalb so großes Gewicht auf die Bestreitung des Unsterblich- Leugnung der keitsglaubens, weil dieser den Menschen verhindert, von seinem Erdenleben den richtigen Gebrauch zu machen. Auch sieht er in diesem Glauben die Hauptursache der Todesfurcht, die als die Quelle aller Furcht überhaupt ein Haupthemmnis der Glückseligkeit für die Menschen bildet und sie zu den meisten moralischen Verirrungen verleitet. Wenn unsere Seele nach dem Tode weiterlebte, so würde sich uns eine unabsehbare Perspektive zukünftiger Leiden eröffnen. Immer müßten wir vor den unbekannten Schrecken des Jenseits bangen, zumal wenn sich die Todesfurcht mit der Götterfurcht verbindet und wir als Vergeltung unserer Sünden ewige Höllenstrafen befürchten. Wer den Tod fürchtet, der fürchtet alles, was zur Todesgefahr in näherer oder fernerer Beziehung steht, wie Schmerz, Krankheit, Armut, Verbannung, Schande.

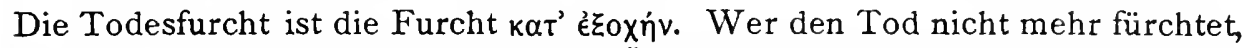
für den verlieren auch alle sonstigen Übel des Menschenlebens ihren schärfsten Stachel. Hat man sich auf Grund der Naturlehre überzeugt, daß mit dem Tode das bewußte Leben aufhört, so hat man auch die Gewißheit, daß er das Ende aller Leiden ist. Der Tod ist kein Übel für uns, er betrifft uns überhaupt nicht. Denn solange wir sind, ist er nicht, und wenn er ist, sind wir nicht. - Epikur bekämpft den Anspruch des Menschen auf ewige Fortdauer seiner Seele als eine unersättliche Begierde, welche die von der Natur jedem Einzelwesen gesetzten Schranken verkennt. Diese Begierde hat ihre Hauptursache darin, daß wir die uns zugemessene Lebenszeit nicht zu Rate halten. Täten wir dies, so würden wir sie ausreichend finden, den ganzen Kreis der dem Menschen erreichbaren Genüsse zu durchmessen, und würden, wenn der Tod kommt, gesättigt von der Tafel des Lebens aufstehen, um anderen Gästen Platz zu machen. Denn der Genußmöglichkeit sind durch unsere Organisation unüberschreitbare Grenzen gezogen. Ein ewiges Leben könnte daher nur eine ewige Wiederholung derselben Genüsse bringen. Wer weise ist, dem genügt das Erdenleben, der Tor würde auch mit einer Ewigkeit nichts anzufangen wissen. In diesen Betrachtungen zeigt sich die hohe Bedeutung der Seelenlehre für die ethische Lebensanschauung Epikurs. Die Theologie, die die Götterfurcht, und die Seelenlehre, die die Todesfurcht bannen soll, sind zwei Hauptsäulen der epikureischen Ataraxie. Was er sonst noch über die Seele lehrt, bezieht sich hauptsächlich auf die Sinneswahrnehmung. Soweit es für die Erkenntnislehre von Bedeutung ist, wurde es oben bereits berücksichtigt. Die vier Teile der Seele werden von Epikur zu einer physikalischen 
Erklärung der Temperamente und Charaktere in ganz ähnlicher Weise verwertet wie die vier humores in der medizinischen Temperamentenlehre.

Ethik:

Die Glückselig keit.

Wir wollen jetzt den ethischen Gesichtspunkt weiter verfolgen, der uns schon in der Bekämpfung der Götter- und Todesfurcht entgegengetreten ist. Die Aufgabe der Philosophie ist, nach Epikur, den Menschen zur Glückseligkeit zu führen. Um ihretwillen tun ja alle Menschen alles, was sie tun; auch sind sie nicht im Zweifel, worin die Glückseligkeit besteht; dennoch verfehlen sie ihr Ziel, wenn sie nicht von der Philosophie gelernt haben, worauf es ankommt. Was die Inhaitsbestimmung des Glückseligkeitsbegriffs angeht, so führt er zunächst auf den Begriff des Gutes. Absolute Glückseligkeit ist ununterbrochener ewiger Besitz aller Güter und ununterbrochene ewige Freiheit von Übeln. Sie ist nur vollkommenen und ewigen Wesen, den Göttern, erreichbar. Die Glückseligkeit des Menschen besteht darin, daß während seines ganzen Lebens die Güter über die Übel das Übergewicht behalten. Suchen wir weiter den Begriff des Guten zu bestimmen, so müssen wir es dem an sich (um seiner selbst willen) Erstrebenswerten gleichsetzen. Nun ist aber die Lust das einzige, was ein Lebewesen um seiner selbst willen erstrebt. Also ist die Lust das einzige, wahre und höchste Gut, und ihr Gegenteil, die Unlust, das einzige, wahre und höchste Übel. Das Endziel aber unseres Strebens ist nicht die einzelne Lust, sondern die Glückseligkeit, d. h. ein Die Lust. lusterfülltes Leben. - $\mathrm{DaB}$ sich auf die Lust der ursprünglichste Naturtrieb aller Wesen richtet, ist eine unleugbare Tatsache, die für die Bestimmung des höchsten Gutes maßgebend ist. In dem ursprünglichen Trieb redet die unverfälschte Natur selbst, die nicht irren kann, wie menschliche Meinungen. Die beiden Grundgefühle, Lust und Unlust, bilden das Kriterion des Strebens und Handelns in ganz entsprechender Weise wie die Sinneswahrnehmung das Kriterion des Erkennens. Auch ihnen kommt Evidenz zu, und wenn wir auch nur bezüglich einer einzigen Lust bezweifelten, daß sie als solche gut und erstrebenswert ist, würden wir die Möglichkeit rationellen Handelns überhaupt aufheben. Da aber unser Ziel nicht die einzelne Lust, sondern ein möglichst lusterfülltes Leben ist, und da verschiedene Lüste sich an Dauer und Intensität voneinander unterscheiden, so wird der Weise nicht jede Lust (obgleich sie als solche ein Gut ist) erstreben und nicht jede Unlust (obgleich sie als solche ein Übel ist) meiden, sondern stets so handeln, daß die bei Einbeziehung aller zuküntigen Folgen seiner Handlung sich ergebende LustUnlust-Bilanz einen möglichst großen Überschuß auf der Lustseite aufweist. Er wird also oft eine kleinere Lust opfern oder eine kleinere Unlust auf sich nehmen, um eine größere Lust zu gewinnen oder eine größere Unlust zu vermeiden; wobei die Abmessung des Größeren und Kleineren sowohl die Dauer als die Intensität der Lust und Unlust zu berücksichtigen hat. Der ursprüngliche Trieb richtet sich auf die Lust schlechthin, auf die rechte Weise aber kann sie sich nur derjenige aneignen, der ihre verschiedenen Arten zu unterscheiden und nach ihrem Werte gegeneinander abzumessen gelernt hat. Die Lust besteht entweder in der Befriedigung eines Bedürfnisses oder in 
einem Zustand des Nichtbedürfens. Jedes unbefriedigte Bedürfnis ist mit Unlust verbunden. Indem der Akt der Bedürfnisbefriedigung vor sich geht, empfinden wir eine Lust, z. B. der Hungrige während des Essens, der Durstige während des Trinkens. Diese Art der Lust muß physikalisch als eine Bewegung bestimmt werden, durch welche die Atome in ihre naturgemäße Lage und Ordnung zurückkehren. Sie ist nicht rein, sondern mit Unlust gemischt und ihrem Wesen nach an die Unlust gebunden. Sie findet ihren natürlichen Abschluß in der Aufhebung des Bedürfnisses und der mit ihm verbundenen Unlust. Der hiermit erreichte Zustand der Freiheit von Unlust ist die reine Lust, die nicht in einer Bewegung, sondern in einer Ruhe besteht. Epikur lehrt also, daß es ein Mittleres zwischen Lust und Unlust, einen rein indifferenten Gefühlszustand nicht gibt. Mit der Aufhebung der Unlust tritt ipso facto die Lust ein und erreicht ihren Höhepunkt mit dem Augenblick, wo der Schmerz des Bedürfens völlig gestillt ist. Dies ist eine wichtige Abweichung Epikurs von der kyrenaischen Lehre, die einen indifferenten Gefühlszustand annimmt und dementsprechend die bewegte Lust höher schätzt und für das höchste Gut erklärt.

Auf seine Auffassung der Lust begründet Epikur seine Zurückführung Die Begierdan. der Begierden auf ihr natürliches $\mathrm{Maß}$, die wir als die dritte Hauptsäule seiner Glückseligkeitslehre bezeichnen dürfen. Wenn die Freiheit von Unlust das höchste erreichbare Maß der Lust ist, das keine Steigerung, sondern höchstens eine unwesentliche Variation zuläßt, so ist jedes über dieses $\mathrm{Maß}$ hinausgehende Begehren ein maßloses, das nicht befriedigt werden kann und nur eine Störung der Gemütsruhe bewirkt. Hat das Begehren die ihm von der Natur gezogene Grenze einmal überschritten, so findet es überhaupt keine Grenze mehr, sondern wird unersättlich. Unersättliche Begierde ist neben Todesfurcht und Götterfurcht die Hauptquelle des menschlichen Elends. Sie jagt vermeintlichen Gütern nach, die nur in der leeren Vorstellung, nicht in der Wirklichkeit bestehen. Daß Epikur zu den beiden Arten von Begierden, deren Unterscheidung durch diesen Gedankengang gefordert wird, den natürlichen und notwendigen (auf zwingendem Naturbedürfnis beruhenden) einerseits und den weder natürlichen noch notwendigen andererseits, noch eine dritte Art hinzufügt, nämlich die natürlichen, aber nicht notwendigen Begehrungen, ist der am meisten bezeichnende Zug seiner Lehre von der Einschränkung der Begierden. Theoretisch ist diese Einteilung anfechtbar. Denn es liegt der Einwand nahe, daß in ihr der hedonistische Gesichtspunkt nicht rein durchgeführt ist. Beruht jede Lust auf der Befriedigung eines natürlichen Bedürfnisses und ist jedes unbefriedigte Bedürfnis mit Unlust verbunden, so ist auch jedes Begehren notwendig, das aus natürlichem Bedürfnis entspringt. Denn es ist eine Notwendigkeit für den Menschen, die Unlust als solche zu meiden. Wenn Epikur unter den natürlichen Begehrungen notwendige und nicht notwendige unterscheidet, so denkt er wohl daran, daß die Nichtbefriedigung mancher Bedürfnisse Gesundheit und Leben bedroht, die anderer nur das Behagen. Er mischt also den Gesichtspunkt der Selbst- 
erhaltung ein, auf dem die stoische Ethik beruht, und führt den hedonistischen Gesichtspunkt nicht rein durch. Vom rein hedonistischen Gesichtspunkt aus konnte immer nur eine Abstufung schwächerer und stärkerer Bedürfnisse, nimmermehr aber ein prinzipieller Gegensatz notwendiger und nicht notwendiger Bedürfnisse folgerichtig konstruiert werden. Es ist aber nicht schwer einzusehen, welche Denkmotive den Philosophen in diese Inkonsequenz verwickelten. Er ist nicht nur Hedonist, sondern auch Optimist. Er will zeigen, $\mathrm{da} B$ der Weise vom Schicksal unabhängig ist und unter allen Umständen ein glückseliges, ja göttergleiches Leben führen kann. Dieser Gesichtspunkt treibt ihn, die wahren Bedürfnisse der Menschen als möglichst gering und leicht erfüllbar darzustellen. Denn wenn der Mensch zu seiner Glückseligkeit nur ganz weniges und nur solche Dinge bedarf, die jederzeit leicht zu beschaffen sind, so ist sein Glück unabhängig vom Schicksal. Mit diesem Optimismus ist aber seine Lustlehre unvereinbar. Wenn es der Schmerz des Bedürfnisses ist, aus dessen Aufhebung die Lust entspringt, so ist der Mensch um so reicher an Lust, je reicher er an Bedürfnissen ist, die befriedigt werden können. Ihre Befriedigung aber hängt nicht von den Menschen selbst, sondern vom Schicksal ab, und jede Lust muß mit einer Unlust erkauft werden. Diese Auffassung birgt in sich den Keim des Pessimismus. Um seinen OptiNegative und mismus zu retten, hat Epikur die negative Lust (=Freiheit von Unlust) für positive Lust. die höchste erklärt. Aber sein Ideal ist keineswegs eine durch kein Bedürfnis unterbrochene Fortdauer derselben. Denn er weiß wohl, daß der Mensch der Abwechselung bedarf. Abwechselung aber kann nur das Bedürfnis bringen. Die Bedürfnislosigkeit selbst ist keiner Abwechselung fähig. Darum ist die positive, bewegte Lust, wenn auch weniger rein, ein unentbehrliches Element des glückseligen Lebens. Die negative Lust der Schmerzlosigkeit ist der Gleichgewichtszustand, zu dem unser Gemüt aus den vom Bedürfnis zur Befriedigung verlaufenden Wellenbewegungen immer wieder zurückkehrt. Sie wird nur dann recht genossen, wenn ein nicht schmerzloser Zustand ihr vorausging. So bilden also auch für Epikur die Bedürfnisse und Begierden Genußmöglichkeiten, und er ist keineswegs gewillt, jedes Begehren, das über die dringendste Leibesnotdurft hinausgeht, zu verwerfen und in die Sphäre der „leeren Meinung“ $z u$ verweisen. Aber er will verhüten, daß die Begehrungen dieser Art die Gemütsruhe stören und den Menschen vom Schicksal abhängig machen. Wir sollen aus dem über die Notdurft Hinausgehenden Genuß schöpfen können, wenn es leicht zu beschaffen ist, und es doch andererseits nicht entSinnlicho und behren, wenn es uns nicht zu Grebote steht. - Die Auffassung Epikurs wird geistige Lust. noch klarer, wenn wir seine Erörterungen über den vergleichsweisen Wert der sinnlichen und der geistigen Lust heranziehen. Sie entspricht vollkommen seiner vergleichsweisen Wertung der sinnlichen Wahrnehmung und der begrifflichen Erkenntnis. Epikur bestreitet, daß es eine selbständige geistige Lust gibt, die nicht mittelbar oder unmittelbar auf eine sinnliche Bezug hätte. Aber er hält die geistige Lust für größer und wertvoller als die sinnliche. Auch hierin weicht er von der kyrenaischen Lehre ab. Der Vorrang der 
geistigen Lust besteht darin, daß sie nicht, wie die sinnliche, auf das Gegenwärtige beschränkt ist, sondern Vergangenes und Zukünftiges mit umfaßt. Alle Lust, die Leib und Seele jemals früher genossen haben, bleibt in der Erinnerung aufbewahrt und kann jederzeit zu einer Quelle neuer Genüsse werden. So hoch schätzt Epikur dieses reproduktive geistige Genießen, daß er ihm die Kraft zutraut, gegenwärtigen körperlichen Schmerz aufzuwiegen und ihm zum Trotz die Seelenruhe zu erhalten. Andererseits ist jeder sinnliche Genuß nur dann ungetrübt, wenn die zuversichtliche Hoffnung auf künftige Lust ihn begleitet. Wenn Furcht unsere Seele erfüllt, ist auch der sinnliche Genuß unmöglich. Der geistige Genuß ist aber nicht nur größer als der sinnliche, sondern dieser ist ohne jenen selbst nicht denkbar. Der sinnliche Genuß vollendet sich erst in dem geistigen Bewußtsein, zu genießen und genossen zu haben. Daß der Leib von Schmerz frei sei und die Seele von Furcht, ist das Ziel unseres Strebens. Es ist hiernach klar, dał die Glückseligkeit, die Epikur seinen Adepten verspricht, in einer dauernden Heiterkeit der Seele besteht, die zwar alle ihre Freuden mittelbar oder unmittelbar aus den Sinneserlebnissen schöpft, selbst aber in dem Auf- und Abwogen jener ihr Gleichgewicht zu erhalten und der Lust Dauer zu verleihen weiß.

Wie der Lust so ist auch dem Schınerz von der Natur eine Grenze gezogen. Wer die Grenze der Lust kennt, bleibt von maßlosen Begierden, wer die des Schmerzes kennt, von Furcht verschont. Die Grenze des Schmerzes besteht darin, daß Dauer und Intensität des Schmerzes in umgekehrtem Verhältnis stehen. Der langdauernde Schmerz ist klein, der heftige von kurzer Dauer. Wir brauchen nicht zu befürchten, daß ein Schmerz sich ins Ungemessene steigern, ein unerträglicher Schmerz uns dauernd quälen wird. Mäßige Schmerzen können wir durch geistige Lust aufwiegen. Die stärksten Schmerzen heben die Besinnung und das Leben auf. Epikur glaubt daher, daß der Weise selbst auf der Folter seine Gemütsruhe bewahren kann.

An die Güterlehre schließt sich die Tugendlehre an, deren oberster Sat $\%$ Tugendlebre. ist, daß man nicht angenehm leben kann, ohne verständig, mäßig, tapfer und gerecht zu leben, und umgekehrt nicht verständig, mäßig, tapfer und gerecht, ohne angenehm zu leben. Der Besitz sämtlicher Tugenden ist von dem angenehmen Leben unabtrennbar. Es ist sinnlos, die Tugend als höchstes Gut aufzustellen oder zu behaupten, daß sie um ihrer selbstwillen erstrebenswert sei. Nur darauf beruht der Wert der Tugend, daß sie ein unentbehrliches Mittel zur Verwirklichung des angenehmen Lebens ist. Die Tugend ist die Lebenskunst und hat wie andere Künste (z. B. die ärztliche Kunst, die Steuermannskunst) ihren Wert nicht in sich selbst, sondern in dem Nutzen, den sie stiftet. Die Weisheit oder Einsicht (Phronēsis) lehrt uns die Natur des Alls und unsere eigene Stellung im Weltall verstehen und zeigt uns das wahre Ziel unseres Strebens und den Weg, es zu erreichen; dadurch befreit sie uns von Götterfurcht und Todesfurcht und maßloßen Begierden und schenkt uns den Seelenfrieden. Es ist klar, daß wir die Weisheit um dieser Folgen, nicht um ihrer selbst willen begehren. - Die Mäßigkeit ist die Tugend, vermöge

\footnotetext{
Die Kultur der Grgenwart. 1. 5. 2. Auf.
} 
deren wir uns solcher Genüsse enthalten, die größere Unlust im Gefolge haben. Das Voraussehen zwar dieser schädlichen Folgen ist Sache der Einsicht. Aber sie allein genügt nicht; es muß die Mäßigkeit hinzukommen, vermöge deren wir trotz der schmeichelnden Lockung der Lust an der Einsicht festhalten und Genüsse meiden, die wir durch Krankheit, Schande, gesetzliche Strafe büßen müßten. Es ist also klar, daß auch die Mäßigkeit nur um ihrer nützlichen Folgen willen ein Gut ist. - Die Tapferkeit ist die Tugend, vermöge deren wir Mühen, Schmerzen und Gefahren standhaft ertragen und selbst den Tod nicht fürchten, wenn sie nicht zu vermeiden sind. Auch diese Tugend hat die Einsicht zur Voraussetzung, die uns lehrt, daß der Tod kein Übel und der Schmerz ein erträgliches Übel ist, und daß wir bisweilen kleinere Mühen und Schmerzen auf uns nehmen müssen, um größere zu vermeiden. Aber die Einsicht genügt nicht, es muß zu ihr die Kraft hinzukommen, wirklich die Furcht $z u$ bannen und den Schmerz zu ertragen und notwendige Mühen auf sich zu nehmen. So liegt denn der Wert der Tapferkeit darin, daß sie die Heiterkeit des Gemütes in Schmerzen und Gefahten aufrechterhält. Die Gerechtig- Auch für die soziale Tugend der Gerechtigkeit gibt Epikur eine egoistische
keit. Begründung. Wir müssen vorausschicken, daß er das Recht selbst als einen Inbegriff konventioneller Satzungen auffaßt, die den Verkehr unter den Gliedern einer politischen Gemeinschaft zum Zwecke ihres gemeinsamen Nutzens regeln. Der natürliche Rechtsbegriff enthält nichts weiter als diese allgemeine Norm. Der positive Inhalt des Rechtes kann, ohne gegen diese natürliche Idee zu verstoßen, in verschiedenen Staaten und auch in demselben Staate zu verschiedenen Zeiten ein verschiedener sein. Denn mit den gesamten Verhältnissen wechselt auch der Nutzen. Ein geltendes Gesetz ist nicht gerecht, wenn es dem durch die natürliche Rechtsidee vorgezeichneten Zweck nicht entspricht, und hört auf gerecht zu sein, wenn es ihm nicht mehr entspricht. Es scheint nun, daß Epikur die Gerechtigkeit als Tugend des einzelnen Menschen auf die geltende Rechtssatzung, nicht auf den natürlichen Rechtsbegriff bezogen hat. Denn als ihren Nutzen gibt er an, daß, wer gegen die Gesetze verstößt, nie vor Verfolgung und Strafe sicher sein kann, auch wenn er seine Übertretung mit der größten Heimlichkeit ausgeführt hat. Hieraus folgt, daß die Gerechtigkeit für die Erhaltung der Gemütsruhe unentbehrlich ist. Auch sucht Epikur zu zeigen, daß die Vorteile und Genüsse, die wir um der Gerechtigkeit willen opfern, stets kleiner sind als die Nachteile, die wir uns durch diese Opfer erspaten. Nicht leicht wird uns das Gesetzesrecht die Befriedigung unserer notwendigen und natürlichen Bedürfnisse verwehren. Wer nach den Vorschriften Epikurs seine Begierden auf das natürliche Maß eingeschränkt hat, der wird nicht leicht mit den Gesetzen in Konflikt kommen, und wem diese Einschränkung der Begierden noch nicht gelungen ist, der wird durch die äußerliche Gesetzlichkeit in seinem moralischen Streben gefördert werden. - Das Merkmal der Tugendlehre Epikurs ist also ein egoistischer Utilismus. Die Gesellschaft bedarf keine altruistische Gesinnung ihrer einzelnen Glieder. Wenn die einzelnen zielbewußte und folgerichtige 
Egoisten sind, wird auch die Gesellschaft wohl bestellt sein. Selbst die Freundschaft, die er zu den höchsten und unentbehrlichsten Lebensgütern rechnet, hat Epikur aus egostischen Motiven abgeleitet. Teilnahme am öffentlichen Leben hat er seinen Anhängern widerraten, das „Glück im Winkel“ gepriesen.

Die Geschichte der epikureischen Schule brauchen wir für unseren $Z$ weck nicht zu berücksichtigen, da sie neue wissenschaftliche Gedanken nicht zutage gefördert hat. Eine Ausnahme bildet nur Zenons des Sidoniers Versuch, die Theorie der Induktions- und Analogieschlüsse zu vervollkommnen, den wir durch Philodems Schrift über diesen Gegenstand kennen lernen. Die Schule hat zu allen Zeiten an der Lehre des Meisters mit strenger Orthodoxie festgehalten und sich nur mit ihrer Erläuterung und Verteidigung: gegen die Angriffe der übrigen Schulen befaßt. Seit dem 1. Jahrhundert v. Chr. begann sie unter den Römern Anhänger zu gewinnen. In der augusteischen Zeit bekennen sich viele der einflußreichsten Dichter und Schriftsteller zum Epikureismus, der durch das Gedicht des Lukretius Verbreitung gefunden hatte und der individualistischen Geistesrichtung der Zeit angemessen war. In den drei ersten Jahrhunderten der christlichen Ära hat die epikureische Lehre allen denen eine Zuflucht geboten, die den immer weiter um sich greifenden Aberglauben und Mystizismus ablehnten. Erst der Sieg des Christentums als Staatsreligion hat den Epikureismus getötet, und als Kaiser Julian den alten Glauben und die alte Wissenschaft zu erneuern versuchte, war er so völlig ausgestorben, daß selbst die Bücher kaum noch aufzutreiben waren.

III. Der Stoizis mus. Ungefähr gleichzeitig mit der epikureischen Schule (das Jahr läßt sich nicht mit Sicherheit bestimmen) ist die stoische Schule ins Leben getreten. Ihr Begründer Zenon aus Kition auf der Insel Kypros Zenon von Kition hatte den Kyniker Krates, den Megariker Stilpon und den Akademiker Pole(t 264). mon zu Lehrern gehabt. Er leitete die Schule, die ursprünglich nach ihm als die der „Zenoneër", später nach dem Unterrichtslokal als die „Stoa“ (=Halle) benannt wurde, bis zu seinem Tode $\left(26_{4} / 3\right.$ v. Chr.). Die stoische Schule gehört mit der epikureischen in demselben Sinne zusammen wie Xenophanes mit Pythagoras, Parmenides mit Herakleitos: weil beide in derselben Zeit entstehen und denselben Stand der philosophischen Forschung voraussetzen, haben sie eine Reihe gemeinsamer Eigentümlichkeiten, z. B. den Materialismus, den Empirismus, die üb.erwiegende Betonung der Ethik; aber sie sind zugleich Antipoden, indem sie an verschiedene Richtungen der älteren Philosophie anknüpfen, Epikur an den Atomismus Demokrits, Zenon an die von Sokrates ausgegangene Gedankenrichtung, der er im Gegensatz zu der platonischaristotelischen Philosophie durch Zurückgreifen auf den Hylozoismus des Herakleitos eine neue Wendung zu geben sucht. Vom ethischen Standpunkt betrachtet erscheint der Stoizismus als ein Versuch, die kynische Ethik unter Beibehaltung ihres strengen Moralismus von ihrer Einseitigkeit und Unwissenschaftlichkeit zu befreien, um sie sowohl praktisch brauchbarer zu machen als auch theoretisch durch einen erkenntnistheoretisch-logischen und natur- 
philosophischen Unterbau zu stützen. Das von Krates Erlernte hat Zenon mit der dialektischen Schulung, die er dem Stilpon verdankte, verteidigt und durch Elemente der Sittenlehre Polemons ergänzt. Vom metaphysischen Standpunkt betrachtet ist der Stoizismus ein Versuch, den Dualismus der platonisch-aristotelischen Philosophie zu überwinden und eine streng monistische Weltansicht zu begründen. Der Monismus der Stoa ist von der einen Seite betrachtet Materialismus, von der anderen Pantheismus. Ihr Materialismus ist nicht der mechanische der Atomisten, sondern der dynamische der Hylozoisten. - Nach dem Tode Zenons schien es zunächst, als ob sein System Kleanthes keinen dauernden Erfolg haben würde; denn nicht Kleanthes, der, streng (264-232). an der Lehre des Meisters festhaltend, von 264-232 die stoische Schule leitete, beherrschte zunächst die öffentliche Meinung, sondern ein anderer, glänzend begabter Schüler Zenons, Ariston von Chios, der zu dem Ausgangspunkte Zenons, dem kynischen Moralismus, zurückkehrend, den erkenntnistheoretischen und metaphysischen Dogmatismus seines Lehrers verwarf. Auch die gleichzeitigen Angriffe des skeptischen Akademikers Arkesilaos schienen die Lebensfähigkeit des stoischen Dogmatismus, namentlich sein erkenntnistheoretisches Fundament in Frage zu stellen. Aber die Situation änderte sich Chrysippos völlig, seit auf Kleanthes als Vorsteher der stoischen Schule Chrysippos von (232-ca. 204). Soloi (in Kiiikien) gefolgt war. Während seines bis gegen das Ende des 3. Jahrhunderts dauernden Scholarchates wurde die stoische Schule die einflußreichste Schule Athens, da in dieser Zeit keine der anderen Schulen über einen bedeutenden und selbständigen Denker verfügte. Ihm gelang es, den Standpunkt des Ariston als unhaltbar zu erweisen und die Einwände der akademischen Skepsis gegen die dogmatische Erkenntnistheorie mit Erfolg $z u$ bekämpfen und überhaupt das stoische System in allen seinen Teilen weniger durch materielle Lehrneuerungen als durch scharfe Begriffsbestimmungen und sonstige dialektische Technik widerstandsfähig zu machen. In der von Chrysippos ihm gegebenen Form hat dann das stoische System im 2. Jahrhundert durch seine Nachfolger Diogenes von Babylon und Antipatros von Tarsos fortbestanden und auch in der römischen Welt Eingang gefunden. Den Römern der republikanischen Zeit hat der Stoizismus mehr als die anderen Schulen zugesagt. Neben ihm spielte die skeptische Akademie hauptsächlich wegen ihrer rhetorischen Brauchbarkeit, als Schule formaler Geistesbildung eine Rolle. Der Epikureismus begann erst in augusteischer Zeit in den leitenden Kreisen $F u ß$ zu fassen. Der Akademiker Antiochus von Askalon, der Lehrer Ciceros, vertrat in der Schule Platons einen stoisch gefärbten Eklektizismus. Vom Geiste des Eklektizismus wurde auch die Stoa selbst bei ihrem Fortleben in der römischen Welt zeitweilig ergriffen. Wie Antiochos von der akademischen Seite, so haben von der stoischen Panaitios, der Freund des jüngeren Scipio Africanus, und Poseidonios, auch ein Lehrer Ciceros, eine Ausgleichung des $z$ wischen der stoischen und platonisch-aristotelischen Philosophie bestehenden Gegensatzes gesucht. Aber dieser Eklektizismus, trotz seines großen zeitweiligen Erfolges, bildet doch nur eine Episode in der 
Geschichte der stoischen Schule. In der römischen Kaiserzeit spaltet sich ihre Entwickelung in eine popularphilosophische Richtung, die sich zum Teil dem Kynismus annähert und im r. Jahrhundert durch Musonius Rufus, Dio von Prusa, Seneka, im 2. Jahrhundert durch Epiktet und Kaiser Marc Aurel vertreten ist, und eine gelehrte Richtung, ganz analog der peripatetischen Schule seit Andronikos, welche zu der altstoischen Lehre, besonders zu Chrysippos zurückkehrt und sich mit der Erläuterung und Fortpfląnzung der alten Schriften und Gedanken befaßt. Zu dieser Richtung gehört z. B. Cornutus, der Lehrer des Satirikers Persius, und in hadrianischer Zeit Hierokles, von dessen Lehrbuch der Ethik kürzlich auf einem ägyptischen Papyrus ein großes Stück gefunden wurde. So kehrt also die Entwickelung schließlich wieder zu der chrysippischen Orthodoxie zurück. Es liegt in der Natur der Sache, $\mathrm{daB}$ auch der vorliegenden Darstellung diese zugrunde gelegt und von den Unterscheidungslehren der einzelnen Stoiker meist abgesehen wird.

Die Stoiker definieren die Weisheit, nach der die Philosophie strebt, als die Wissenschaft von den göttlichen und menschlichen Dingen. Sie zerfällt in drei Hauptteile: Logik, Physik und Ethik. Denn die Logik ist ein den Logik. beiden anderen gleichberechtigter Teil der Philosophie selbst. Sie ist die Lehre von der Sprache, die sowohl von den Zeichen (also von Lauten, Silben, Worten, Sätzen) als von dem Bezeichneten (also von Begriffen, Urteilen, Schlüssen) zu handeln hat. Die Stoiker rechnen also die Grammatik und Sprachphilosophie zur Logik; und in der Tat dürfte ein engerer Zusammenhang $z$ wischen diesen Disziplinen bestehen, als gewöhnlich angenommen wird. Der Gegenstand der stoischen Logik ist der Logos, welcher einer und derselbe bleibt, mag er nun im Innern des Bewußtseins eingeschlossen sein oder als sprachliche Äußerung heraustreten. Wir sehen hier von der Sprachlehre ab und befassen uns nur mit dem zweiten Teil der Logik, der vom Bezeichneten handelt. Das Ziel dieses Teiles ist, Kennzeichen des Wahren und Falschen aufzustellen. Denn wie das Zeichen nur als Symbol des Bezeichneten so interessiert uns das Bezeichnete nur durch seine Beziehung auf etwas Vorhandenes. Je nach der Art dieser Beziehung ist das Bezeichnete wahr oder falsch. Dieser Teil der Logik (die Dialektik) ist also seiner Absicht nach Erkenntnistheorie. Das Zeichen ist ein sprachliches Lautgebilde, das Bezeichnete ist ein Vorstellungsgebilde; dieses wiederum will und soll sich beziehen auf ein Vorhandenes, das auch unabhängig von der Vorstellung in der Natur der Dinge enthalten ist. Das Wesen der Vorstellung und ihre Beziehung auf etwas Vorhandenes ist also der naturgemäße Ausgangspunkt der Logik. Die Stoiker lehren nun, daß nur durch die sinnliche Wahrnehmung etwas Vorhandenes (mag es nun ein Körper sein oder eine Qualität oder eine Bewegung oder eine Relation) Gegenstand unserer Vorstellung werden kann. Der Fundamentalsatz des Sensualismus: nihil est in intellectu, quod non fuerit in sensu steht ihnen ebenso fest wie dem Epikur. Also ist die sinnliche Vorstellung die ursprünglichste und für alle grundlegende Art der Vorstellung. Die Wahrheit aller unserer Vorstellungen ist bedingt durch die Art ihrer 
Ableitung aus den sinnlichen und durch die Beschaffenheit der sinnlichen Vorstellungen selbst. Wie müssen diese beschaffen sein, um eine zuverlässige kiterion. Grundlage zu bilden? - Die sinnliche Vorstellung ist eine Modifikation in der Seele, die, indem sie uns zum Bewußtsein kommt, zugleich das Objekt, durch das sie hervorgerufen wurde, uns zum Bewußtsein bringt. Zenon und Kleanthes hatten von einem Abdruck des Objekts in der Seele gesprochen; Chrysippos ersetzte die sinnliche Ausdrucksweise durch eine abstraktere, indem er von einer Modifikation sprach. Wahr ist die sinnliche Vorstellung, wenn sie das Objekt, so wie es ist, mit allen seinen tatsächlich vorhandenen Eigenschaften abbiidet. Es gibt aber zweifellos auch sinnliche Vorstellungen, die trügerisch sind. Die Stoiker glauben nicht, wie Epikur, daß man alle sinnlichen Vorstellungen ohne Ausnahme (z. B. auch Träume und Halluzinationen) als untrüglich anerkennen muß, damit eine wissenschaftliche Erkenntnis möglich werde. Woran erkennen wir nun, ob eine sinnliche Vorstellung wahr ist? Wenn es kein Kriterion gibt, durch das wir die adäquate sinnliche Vorstellung, die das Objekt abbildet, wie es ist, von der inadäquaten unterscheiden können, dann gibt es überhaupt kein Kriterion der Wahrheit. Die Stoiker glauben, daß es sichere Unterscheidungsmerkmale gibt, durch deren Beachtung der menschliche Geist vermeiden kann, einer inadäquaten sinnlichen Vorstellung zuzustimmen. Er wird sich überzeugen, ob er selbst und das die Wahrnehmung vermittelnde Sinnesorgan sich in normalem Zustand befindet, ob der räumliche Abstand des Objektes und seine Stellung zum Organ geeignet sind; ob der Wahrnehmungsakt lange genug dauert und gründlich genug ist, um alle Eigenschaften des Objektes aufzufassen, ob ein zwischen Objekt und Organ befindliches Medium die Wahrnehmung stört, ob wiederholte eigene oder,fremde Wahrnehmung den ersten Eindruck bestätigt. Wenn eine solche nach allen Seiten hin durchgeführte Prüfung zu dem Ergebnis führt, daß die Vorstellung den Gegenstand abbildet, wie er ist, Kataleptische so heißt die Vorstellung eine katalēptische. Die katale ptische Vorstellung ist das Kriterion der Erkenntnis. Die Prüfung der sich darbietenden Vorstellung ist freilich Sache des Geistes, aber die Gesichtspunkte der Entscheidung entnimmt der Geist aus der Beschaffenheit der Vorstellung selbst. Insofern ist sie das eigentliche Kriterion. Wenn der Geist einer Vorstellung seine Zustimmung (Synkatáthesis) gibt, so entsteht ein Wahrnehmungsurteil. Stimmt er einer wirklich kataleptischen Vorstellung $z u$, so entsteht ein adäquates Wahrnehmungsurteil, eine Katalëpsis. Der Urteilsakt oder die Zustimmung gehört zu den Dingen, die bei uns stehen, d. h. er ist eine Betätigung unserer Willensfreiheit. Die Menschen sind nicht durch äußere Ursachen genötigt zu irren, sie sind für ihre Irrtümer selbst verantwortlich. Was für Vorstellungen sich uns anbieten, hängt nicht von uns ab, wohl aber, wie wir uns zu ihnen verhalten. Die voreilige Zustimmung zu einer ungeprüften Vorstellung ist die Ursache der unsicheren oder irrigen Meinung (Doxa). Einer kataleptischen Vorstellung können wir die Zustimmung nicht versagen; sie ruft selbst die Zustiminung herror. Gerade darin liegt ihr unterscheidendes Moment, daß 
sie allen Zweifeln und Bedenken gegenüber ihre Evidenz behauptet. Die Bedeutung dieser Sätze für die Lehre von der Willensfreiheit wird im Zusammenhang der Ethik zu besprechen sein.

Wenn der Mensch geboren wird, gleicht sein Geist einer unbeschriebenen Der Begriff. Tafel (tabula rasa). Diese wird allmählich von der sinnlichen Wahrnehmung beschrieben. Aus vielen gleichartigen Wahrnehmungen, deren Abbild im Gedächtnis festgehalten wurde, entsteht ein empirischer Begriff, in dem das Gemeinsame jener Wahrnehmungen zusammengefaßt wird. Man muß unterscheiden den natürlichen Begriff (Prolēpsis), der sich bei allen Menschen gleichmäßig und notwendig auf Grund der Erfahrung herausbildet, und den durch absichtliches Nachdenken gebildeten. Die natürlichen Begriffe sind untrüglich; sie werden von Chrysipp bisweilen neben der kataleptischen Vorstellung als Kriterion genannt. Aus der Ansammlung der natürlichen $\mathrm{Be}-$ griffe bildet sich bis zum vollendeten siebenten Jahre der Logos. Die Gattungsbegriffe sind Gebilde unserer Einbildungskraft; das Objekt, das in ihnen gedacht wird, ist ein bloßes Phantasma. Die Röte eines einzelnen wahrnehmbaren Gegenstandes ist etwas Reales, ist in der Natur der Dinge vorhanden; aber dem Begriff der roten Farbe entspricht nichts Wirkliches. Unser Geist hat die Fähigkeit, die von der Wahrnehmung gelieferten auschaulichen Vorstellungen in mannigfaltiger Weise umzubilden: er kann sie vergrößern oder verkleinern, z. B. aus der Vorstellung eines Menschen von natürlicher Größe die eines Riesen oder die eines $Z_{w}$ erges bilden; er kann mehrere aus der Erfahrung stammende Vorstellungen zusammensetzen, z. B. die eines Menschen und eines Pferdes zu dem Phantasiegebilde eines Centauren; er kann von den einzelnen Bestandteilen einer anschaulichen Vorstellung in der Phantasie einige fortlassen oder durch andere ersetzen oder die Anordnung der Bestandteile ändern. Auf dieser Fähigkeit unseres Geistes, die sinnlichen Anschauungen frei zu bearbeiten, beruht nach stoischer Auffassung auch die Bildung der Gattungsbegriffe. Nur sind diese keine willkürlichen Bildungen, wie der Centaur und der Riese, sondern notwendige, durch welche Sprache und Denken erst möglich wird. In jedem Gattungsbegriff werden unendlich viele und darum unübersehbare Einzelfälle, insoweit sie gleichartig sind, zusammengefaßt. Dadurch wird erst Ordnung in unsere Erfahrung gebracht; sie wird übersichtlich und begreiflich. Das Vermögen unseres Geistes, solche logische Vorstellungen aus den auf das Einzelne gehenden Wahrnehmungsvorstellungen $z u$ bilden und vermittels derselben allgemeine Urteile zu fällen, die für ihr Geltungsbereich alle jemals mögliche Erfahrung zusammenfassen und begreiflich machen, heißt Logos. Es ist Denk- und Sprachvermögen zu- Der Looros. gleich. Es ist die Fähigkeit, die uns von den unvernünftigen Tieren unterscheidet und die wir mit Gott teilen. Weil unser Logos der das Weltall durchwaltenden Vernunftkraft, welche den Stoff nach ihren Gedanken modelt, wesensgleich ist, hat er die Fähigkeit, ihre Gedanken in sich zu reproduzieren und sich dadurch die Wirklichkeit denkbar und aussprechbar zu machen. Die Welt geistiger Objekte, jener nicht wirklichen, aber denk- und aussprechbaren 
Dinge, die der Mensch in seinem Denken schafft und setzt, ist nur insoweit wertvoll, als sie mit der in der wirklichen Welt waltenden Vernunft übereinstimmt. Die menschliche Vernunft ist nicht vollkommen wie die göttliche; sie kann auch irren. Es gibt also in der Welt der geistigen Objekte ein Reich des Wahren und ein Reich des Falschen. Dies ist der bezeichnende Zug der stoischen Erkenntnistheorie, daß sie „wahr" und „falsch" nicht als Bestimmungen der psychischen Akte des Vorstellens und Urteilens auffaßt, die materielle Modifikationen in der Seelensubstanz $\sin 1$, sondern als Bestimmungen der den Vorstellungen und Urteilen entsprechenden intelligiblen $\mathrm{Ob}-$ jekte. Wer denkt und sagt, so hatte schon Platon gelehrt, der denkt und sagt „etwas“. Dieses „Etwas“ muß von dem Denken und Sagen, dessen Inhalt es bildet, unterschieden werden. Nur geben die Stoiker Platon nicht $z u$, daß dieses „Etwas" ein Seiendes und Wirkliches ist. Wohl aber ist ein Teil desselben das Wahre.

Dialektik. Aus dem Gesagten ergibt sich, daß die sinnliche Wahrnehmung, obgleich die Quelle aller Erkenntnis, nicht selbst schon Wissenschaft ist. Darin sind die Stoiker ganz mit Aristoteles einverstanden, daß die begriffliche Beweisbarkeit das Kennzeichen der wissenschaftlichen Erkenntnis ist. Die Wissenschaft bildet ein System von wahren Urteilen, die alle unter sich in logischer Übereinstimmung stehen, so daß nach den Gesetzen logischer Folgerichtigkeit eines aus dem anderen demonstriert werden kann. Zur Weisheit gehört daher nicht allein das richtige Verhalten gegenüber den Wahrnehmungsvorstellungen (nur kataleptischen zuzustimmen), sondern auch die Fähigkeit, richtige Schlüsse zu ziehen und die beim Schließen vorhandenen Quellen des Irrtums zu vermeiden. Dies ist das Ziel der stoischen Dialektik. Der Weise muß ein vollkommener Dialektiker sein. Dazu gehört zunächst genaue Bekanntschaft mit den sprachlichen Bezeichnungsmitteln des Gedankens. Man muß vor allem die in ihnen enthaltenen Zweideutigkeiten (Amphibolien) zu erkennen und aufzuklären wissen, da sie sonst eine Quelle von Fehlschlüssen werden. Die Wissenschaft vom Bezeichneten stellt zunächst die Elemente fest und klassifiziert sie, aus denen die Gedanken sich aufbauen, die aber selbst

Das Urteil noch keine vollständigen Gedanken sind. Weiter klassifiziert sie die vollständigen Gedanken und stellt fest, daß nur eine Art derselben, das Urteil, die Eigentümlichkeit hat, wahr oder falsch zu sein, und infolge davon den

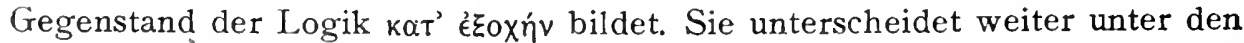
Urteilen einfache und zusammengesetzte; bei den einfachen beachtet sie die von Aristoteles aufgestellten Unterschiede der Qualität, Quantität und Modalität und sucht die aristotelische Theorie durch genauere Definitionen zu vervollkommenen; die zusammengesetzten teilt sie in kopulative, disjunktive, hypothetische und eine ganze Reihe minder wichtiger Formen. Bei allen diesen einfachen und zusammengesetzten Urteilen untersucht sie die formalen BeSyllogistik. dingungen ihrer Wahrheit. Am ausführlichsten behandeln die Stoiker die Lehre vom Schluß; denn in ihr finden sie den Zweck der ganzen Logik. Die übrigen Teile der Logik bilden nur den Unterbau für die Lehre vom wissen- 
schaftlichen Beweis. Bezeichnend für die Syllogistik des Chrysippos ist, daß er diejenigen Schlußformen für die ursprünglichsten und keiner weiteren $\mathrm{Ab}$ leitung bedürftigen hält, in denen der Obersatz durch ein zusammengesetztes Urteil, ein hypothetisches, kopulatives oder disjunktives, gebildet wird. $\mathrm{Hy}-$ pothetisch: I. Wenn A ist, so ist $B$; nun ist aber A; folglich ist $B$. - II. Wenn $A$ ist, so ist $B$; nun ist aber nicht $B$; ; also ist nicht $A$. - Kopulativ: III. Es ist nicht $A$ und $B$; nun ist aber $A$; also ist nicht $B$. - Disjunktiv: IV. Es ist entweder A oder B; nun ist aber A; also ist nicht B. - V. Es ist entweder A oder B; nun ist aber nicht A; also ist B (nicht das eine, also das andere von beiden). - Definitionen und Einteilungen können, um für diese Schlußformen brauchbar gemacht $\mathrm{zu}$ werden, in hypothetische Urteile verwandelt werden, z. B. die Definition: „,der Mensch ist ein logisches, sterbliches Lebewesen" in das hypothetische Urteil: „wenn ein Wesen ein Mensch ist, so ist es ein logisches, sterbliches Lebewesen" und die vollkommene Einteilung: „von den Menschen sind die einen Hellenen, die anderen Barbaren“ in das hypothetische Urteil mit disjunktivem Folgesatz: „wenn gewisse Wesen Menschen sind, so sind sie entweder Hellenen oder Barbaren". - Eingehend hat sich Chrysippos mit den verschiedenen A.rten der Trugschlüsse und der Auflösung des ihnen innewohnenden Scheines von Evidenz beschäftigt. Für die Begründung einer dogmatischen Erkenntnistheorie, welche die uneingeschränkte wissenschaftliche Erkenntnis der Wahrheit als erreichbares Ziel aufstellte, war die Bekämpfung der logischen Skepsis ebenso unentbehrlich wie die der Zweifel an der sinnlichen Erfahrung.

Ein spezielleres Eingehen auf die stoische Logik und Syllogistik, die neben der aristotelischen den Schulbetrieb des späteren Altertums beherrschte, müssen wir uns versagen und wenden uns nun der stoischen Ontologie und Metaphysik zu.

Die stoische Metaphysik läßt sich am besten, wie schon bemerkt, als eine Umbildung der aristotelischen im monistischen Sinne verstehen. Schon bei Aristoteles sind Stoff und Form durch Abstraktion gewonnene Bestandteile jedes Wirklichen und in concreto nicht voneinander trennbar. Für die Materie wird auch dieser Gedanke durchgeführt: eine Materie ohne alle Form hat nie existiert. Nicht so für die Form: der göttliche Geist wird als reine Form ohne Materie, als reine Aktualität ohne Potentialität aufgefaßt. Er ist der unbewegte erste Beweger und zugleich der $Z_{w e c k}$ alles Weltgeschehens. Dies ist der Rest des Dualismus bei Aristoteles. Zenon hat ihn ausgeschaltet, indem er die Korrelativität von Stoff und Form, von Körper und Geist folgerichtig durchführte. An den ionischen Hylozoismus anknüpfend, faßt er die Welt als eine einheitliche stofflich-körperliche Substanz, welche lebendig ist und die Kraft besitzt, sich unbeschadet ihrer Einheitlichkeit zu einem System mannigfaltiger Wesenheiten auszugestalten. Wenn die Stoiker Stoff und Kraft Priozipien des als Prinzipien des Seins aufstellen, so darf man dieses Dogma nicht in duaSeienden. listischem Sinne verstehen. Sie unterscheiden nur begrifflich die zwei Attribute der Einen Substanz, neben der es nichts Wirkliches gibt. Sie war von 
jeher (und wird immer sein) geformte oder vielmehr von innen heraus sich formende Substanz, lebendiger Körper. In den Berichten über diese Lehre und in der Polemik der dualistischen Denker gegen sie wird oft die abstraktbegriffliche Unterscheidung der beiden Prinzipien vermengt mit dem in der stoischen Kosmologie hervortretenden Gegensatz wirkender und leidender körperlicher Substanzen. Die Prinzipien sind intelligibel, der Stoff nicht minder als die Kraft. Die wirkenden und leidenden Substanzen gehören der sinnlich-wahrnehmbaren, d. h. der wirklichen Welt an. Das allbeseelende Pneuma, das die ganze Welt und alle einzelnen Wesen durchwohnt, ist körperlich und muß von dem Kraft- und Formprinzip, welches intelligibel ist, scharf unterschieden werden.

Kategoricn. Es gibt nach stoischer Auffassung nur Eine Art des Seienden, die Körper. Die Kategorien, die sie aufstellen, bedeuten also nicht verschiedene Arten des Seienden, sondern nur verschiedene Betrachtungsweisen der Körper, die in menschlichen Gedanken und menschlicher Rede vorkommen. Stelle ich den Körper zu seinen Eigenschaften in Gegensatz (z. B. das Blatt ist grün), so denke ich ihn als Substanz. Denke ich ihn dagegen durch eine Eigenschaft charakterisiert (z. B. der Weise), so daß ich Ding und Eigenschaft in Eine Vorstellung zusammenfasse, so gehört diese Vorstellung in die Kategorie des Qualifizierten (toóv). Denke ich einen qualifizierten Körper in einem Zustand der Bewegung oder Ruhe begriffen und fasse diesen mit ihm zu Einer Vorstellung zusammen (z. B. der Sterbende, der Schlafende), so ge-

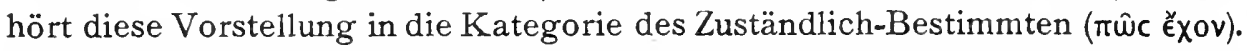
Mit beiden Vorstellungen, sowohl mit der des qualitativ als mit der des zuständlich bestimmten Körpers, kann sich noch überdies die Vorstellung einer Relation verbinden, in der sich dieser Körper vermöge seiner Qualität oder seines Zustandes zu einem anderen Körper befindet. Die Vorstellung eines tödlichen Giftes ist die eines Körpers, der durch eine Qualität charakterisiert ist, deren Wesen in einer Beziehung auf einen anderen Körper besteht. Vorstellungen dagegen wie „mein Onkel“, „mein Nachbar" drücken aus, daß

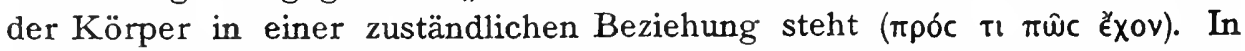
diesem Sinne ist wohl die stoische Kategorienlehre aufzufassen: als eine Einteilung der Körper nach den verschiedenen Vorstellungsformen, in denen sie, mit oder ohne ihre Akzidentien und Relationen, gedacht werden. Zu der Substanz treten immer weitere Bestimmungen hinzu, von denen jede folgende alle früheren voraussetzt. Weil bei allen vier Kategorien der Körper (die Substanz) als Träger hinzugedacht wird, sind sie Gattungen des Seienden.

Die ontologische Auffassung der Stoiker wird durch diese Einteilung nicht enthüllt, sondern durch eine andere. Als oberste Gattung stellen sie nicht das Seiende auf, sondern das „Etwas“. Ein' „Etwas“ kann ein Körperliches oder ein Nichtkörperliches sein. Das Körperliche identifizieren sie mit dem Seienden. Nur dasjenige hat Dasein, was wirken und leiden kann. Wirken und leiden aber kann nur ein Körper. Die Materie ist es, die dem Körper Dasein gibt, als die allgemeine Grundlage alles Daseins überhaupt (Usia). 
Aber sie macht ihn nicht zu einem bestimmten, von anderen unterschiedenen Einzelwesen. Das tut die Kraft. Durch das Zusammenwirken des substantiellen und des essentiellen Prinzips kommt ein bestimmter Körper, ein Wirkliches zustande. Außer der Stofflichkeit und der Fähigkeit zu wirken und zu leiden ist die dreidimensionale Ausdehnung den Körpern eigen. Die andere Art des „Etwas", das Unkörperiiche, hat kein substantielles Dasein, da es an dem substantiellen Prinzip, der Materie, keinen Anteil hat. Vier solche unkörperliche Dinge zählen die Stoiker auf: den Raum, das Leere, die Zeit und die Denkobjekte $(\lambda \in \kappa \tau \alpha \dot{\alpha})$. Der Raum ist ein Etwas, das von Körperlichem (Seien- Kaum und Zrit. dem) ausgefüllt zu werden fähig und auch wirklich ausgefüllt ist; das Leere ein Etwas, das zwar fähig ist, ausgefüllt zu werden, aber nicht ausgefüllt ist. Der Raum ist begrenzt, das Leere unbegrenzt und unendlich. Für das Ganze, das den Weltraum und das außer ihm befindliche Leere umfaßt, den unendlichen Raum in unserem Sinne, hatten die Stoiker keinen Ausdruck. Raum und Leeres sind ein „Etwas", das sich im Anschluß an das Dasein des Körperlichen "miteinstellt". Analog ist die Auffassung der Zeit. Sie wird von den Stoikern bald als der Abstand der Bewegung überhaupt, bald als der Abstand der Weltbewegung definiert. Die erste Definition bezieht sich auf jede beliebige Zeitgröße, die zweite auf die alle begrenzten Zeitgrößen umfassende unbegrenzte Zeitreihe. Die Zeit ist also, wie der Raum, ein Maß, eine Ausdehnung; beide sind etwas durch die Existenz des Körperlichen nebenbei Gegebenes, der Raum durch die stoffliche, die Zeit durch die tätige Seite des Wirklichen. - Zu den unkörperlichen Dingen werden außer Raum und Lektá.

Zeit die Denkobjekte ( $\lambda \in \kappa \tau \alpha ́$ ) gerechnet, deren Begriff uns schon in erkenntnistheoretischem Zusammenhang begegnet ist. Es befremdet vielleicht, daß Raum und Zeit nicht zu den Lekta gerechnet werden, da doch auch sie intelligible Objekte sind. Aber es liegt wohl dieser Trennung ein (wenn auch nicht ganz klares) Bewußtsein zugrunde, daß Raum und Zeit anschauliche Größen sind, nicht wie die Lekta Begriffe. Der unendliche Raum verhält sich $z u$ allen begrenzten Räumen und die unendliche Zeit $z u$ allen begrenzten Zeiträumen wie das Ganze zu seinen Teilen, nicht wie die Gattung zu ihren Arten. Die Lekta hingegen sind Gattungsbegriffe, und zwar von allen Arten des Seienden und von seinen Akzidentien. Unter den Gattungen des Seienden zählen die Stoiker die qualifizierten (mit Qualität begabten) Dinge auf und die -zuständlich bestimmten und die in Relation stehenden, nicht aber die Qualitäten und die Zustände und die Relationen; letztere sind Gattungsbegriffe und bloße Denkobjekte. Die Kreisbewegung eines bestimmten Körpers nimmt als Zustand desselben an seiner Wirklichkeit teil; die Kreisbewegung als allgemeine Form hat keine Wirklichkeit. Dasselbe gilt bezüglich der Qualitäten und der Relationen.

Der Begriff des Substrats (Hypokeimenon) läßt eine mehrfache Anwendung zu. Fasse ich das Substrat als Gegensatz jeder besonderen BestimmtQualität und Zustand. heit, so fällt sein Begriff mit dem der qualitätslosen Materie zusammen. Sie ist das allgemeine Substrat alles Seienden. Ich kann aber auch einen bereits 
qualifizierten Körper als Substrat weiterer Eigenschaften, Zustände und Relationen denken. Als Gegensatz des Substrats in der ersten Bedeutung ist jeder wie immer geartete Unterschied, der an ihm hervortritt, zu denken. Eine begriffliche Scheidung von Qualität und Zuständlichkeit gibt es für diese Betrachtungsweise nicht. Diese ergibt sich erst, wenn ich gewisse Eigenschaften als wesenbildend mit zu dem Substrat rechne und ihnen andere gegenüberstelle, die, ohne das Substrat in seinem Wesen zu verändern, hinzugetan oder hinweggenommen werden können. Hierauf beruht die stoische Unterscheidung der Eigenschaft (Qualität, Hexis) und des Zustandes (Schěsis). Nicht die Dauer oder die Widerstandsfähigkeit ist für sie der maßgebende Gesichtspunkt, sondern die Zugehörigkeit zum Wesen der betreffenden Substanz. Die Hexis betrifft immer das ganze Ding, nicht einen Teil desselben. Sie ist von sich aus, ihrer eigenen Natur nach, dauerbar, kann aber äußeren Einflüssen gegenüber sich mehr oder weniger widerstandsfähig zeigen. Umgekehrt ist die Schesis an sich nicht auf Dauer angelegt, kann aber durch äußere Einflüsse Dauer erlangen.

Körperlichkeit der Qualitäten.

Es ist eine der merkwürdigsten Seiten der stoischen Lehre, daß sie Qualitäten für Körper erklärt. Es kann dies freilich nicht von den vier ursprünglichsten Qualitäten (Wärme, Kälte, Feuchtigkeit, Trockenheit) gelten, durch welche die vier Elemente (Feuer, Luft, Wasser, Erde) charakterisiert sind. Denn die Qualitäten sollen aus einem Pneuma bestehen, das aus Feuer und Luft gemischt ist. Die Elemente samt den sie charakterisierenden Qualitäten werden also für die Entstehung des Pneuma schon vorausgesetzt. Auf diese Grundqualitäten kann also der Satz daß die Qualitäten pneumatische Körper sind, die den qualifizierten Gegenstand in allen seinen Teilen durchdringen, keine Anwendung finden. Wohl aber wird das Pneuma als Träger und Ursache aller der Eigenschaften gedacht, durch die jedes einzelne Ding das ist, was es ist. Der Gegensatz, der abstrakt in der Unterscheidung der beiden Prinzipien, des wirkenden und leidenden, zum Ausdruck kommt, wiederholt sich in concreto in dem Gegensatz, den die Stoiker zwischen den beiden oberen Elementen, Feuer und Luft, und den beiden unteren, Wasser und Erde, statuieren. Jene sind die wirkenden, formgebenden Elemente, aus denen auch Leben und Bewußtsein hervorgeht, diese die stofflichen, leidenden, die von jenen Form und Leben empfangen. Jene haben die Kraft, sich selbst und anderen Einheit und Zusammenhalt zu geben; diese sind dazu unvermögend. Jene sind von Natur leicht und streben nach oben, wo ihr natürlicher Ort ist, diese sind schwer und streben nach unten. Diese scharfe Gegenüberstellung der oberen und der unteren Elemente läßt sich kaum mit der Vorstellung in Einklang bringen, daß die niederen Elemente durch stufenweise Verdichtung aus dem Urfeuer hervorgegangen sind und dabei ihre Kraft verloren haben. Denn hiernach müßte man erwarten, daß auch hinsichtlich der inneren Kraft nur eine Abstufung stattfände, daß also selbst die Erde ihre eigene Kraft hätte. Die Stoiker aber gehen nicht diesen Weg, weil sie das ganze Weltall als ein einheitliches, wie der Mensch aus Leib und Seele zusammengesetztes 
und in allen seinen Teilen von Seele durchdrungenes Lebewesen erweisen wollen. Den Dualismus von Leib und Seele, den sie für den Menschen festhalten zu müssen glaubten, übertragen sie auf den ganzen Kosmos. In den obersten Prinzipien hatten sie den Dualismus glücklich vermieden; hier bricht er wieder durch, indem sie dem materiellen Pneuma alle die Funktionen zuschreiben, die im platonisch-aristotelischen Dualismus dem immateriellen Faktor zugeschrieben werden. Alle Form, alles Essentielle, alle Kraftwirkung in dem Kosmos im ganzen und in allen einzelnen Wesen sollte als Wirkung der Weltseele erscheinen. Aus dieser pantheistischen Gesamttendenz der stoischen Lehre erklärt sich auch jene auffallende Lehre von der Körperlichkeit der Qualitäten. Die pneumatische Hexis, die jeden einzelnen Körper durchdringt, die ihm Einheit gibt und Gestalt, die Träger seiner wesenbildenden Eigenschaften ist - sie ist nichts anderes als eine Seele niederer Ordnung. Sie ist die ins Materialistische übersetzte aristotelische Entelechie. Die Abstufung der Elemente war nicht ausreichend, um nach dem Vorgange des Aristoteles die Natur als ein Stufenreich darzustellen, in dem der Mensch die höchste Stufe nächst der Gottheit einnimmt. Es mußte daher das göttliche Pneuma selbst abgestuft werden. Es durchwohnt die ganze Welt, aber in verschiedener Reinheit und Feinheit. Von der Feinheit der ihr inneres Wesen begründenden Pneumaform hängt die Organisationsstufe jeder einzelnen Klasse von Wesen ab. In der unorganischen Natur ist das Pneuma nur als Hexis vorhanden, in der Pflanzenwelt als Physis (Natur), in der Tierwelt als Seele, in den Menschen und in dem allumfassenden kosmischen Lebewesen als vernünftige Seele. Die Stoiker schließen sich in dieser Lehre eng an Aristoteles an, auch darin, daß jede höhere Pneumastufe nicht ohne die niederen in einem Wesen vorhanden sein kann. Nur machen sie aus den geistigen, unkörperlichen Formen des Aristoteles pneumatische Körper und geben diesen nicht nur einen einheitlichen Ursprung aus dem göttlichen Geiste, sondern auch einen fortdauernden Zusammenhang mit dem Leben des Alls.

Das Pneuma durchdringt die Körper vollständig, nicht indem es sich in Totale Durchleere Zwischenräume zwischen den Molekülen einschiebt, sondern so, daß in den kleinsten Teilen beide Stoffe vorhanden sind. Es geht wirklich Stoff durch Stoff, das Volle durch das Volle hindurch. Diese paradoxe Annahme brauchten die Stoiker notwendig, um die Einheit und Kontinuität des Pneuma zu wahren, und suchten sie durch den Hinweis auf das glühende Eisen, das vom Feuer ganz durchdrungen sei, glaublich zu machen. Bei dieser Durchdringung sollten beide Stoffe in der ihnen eigentümlichen Qualität erhalten bleiben. Die unendliche Teilbarkeit der Körper, welche die Stoa im Gegensatz zu den Atomisten verfocht, schien geeignet, ihre Hypothese glaublicher zu machen. Diese Hypothese bot, abgesehen davon, daß sie die Kontinuität des allgegenwärtigen göttlichen Pneuma erklärte, ein vorzügliches Mittel dar, den psychophysischen Dualismus wieder in die Einheit des Wesens aufzuheben; und da sich ebensowohl wie zwei, diese Möglichkeit einmal zugegeben, beliebig viele Körper totaliter durchdringen können, ließ sich auch das alte Problem von dem 
Einen Ding und seinen vielen Eigenschaften von dieser Seite her lösen. So viele wesenbildende Eigenschaften ein Ding hat, so viele materielle Formen durchdringen es und sich in ihm. Die Gesamtheit dieser ohne Verlust ihrer Sondereigentümlichkeit durch totale Mischung geeinten Pneumata bildet

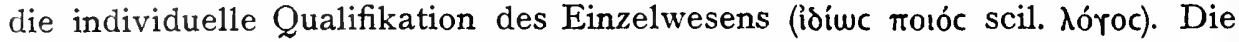
Stoiker nehmen an, daß jedes Einzelwesen durch eine individuelle Bestimmtheit sich von allen übrigen unterscheidet, einen besonderen Gedanken des göttlichen Geistes verwirklicht und insofern ein unentbehrliches Glied in dem kosmischen System bildet.

In diesem Sinne also schreiben die Stoiker nicht nur dem Substrat, sondern Ruhe. auch den Qualitäten substantielle körperliche Realität zu. Die Zustände dagegen und die Relationen sind etwas Unkörperliches; und zwar muß natürlich unterschieden werden der an den einzelnen Dingen vorhandene Zustand, der ein unkörperlicher Bestandteil der Wirklichkeit ist, in demselben Sinne wie Raum und Zeit, und zwar nicht existiert, aber doch in dem Existierenden subsistiert, von dem Zustande als allgemeiner Form, der ein bloßes Denkobjekt ist. Die Zuständlichkeit kann entweder eine Ruhe oder eine Bewegung sein. Beide, auch die Ruhe, sind Kraftwirkungen. Da die göttliche Kraft immer und überall im ganzen Kosmos gegenwärtig ist, so darf kein Ruhezustand im Kosmos aus der Kraftlosigkeit träger Materie hergeleitet werden. Die Ruhe ist aufzufassen als ein Gleichgewicht in entgegengesetzter Richtung wirkender Kräfte. Die Stoiker unterscheiden drei Arten der Bewegung, die Ortsveränderung, die Qualitätsveränderung und die tonische Bewegung. Es liegt aber allen drei Arten die Ortsveränderung zugrunde. Denn die Qualitätsveränderung, durch welche die Elemente aus dem Urstoff hervorgehen und in ihn zurückkehren, beruht auf Verdichtung und Verdünnung. Die tonische Bewegung aber, welche den pneumatischen Körpern eigen ist, besteht in einer inneren Bewegung ihrer Teile, die in doppelter Richtung vom Zentrum nach der Oberfläche und von der Oberfläche zum Zentrum zurück verläuft, abwechselnd hinsichtlich der einzelnen Teile, gleichzeitig in Ansehung des

Tünos. Ganzen. Durch diese Doppelbewegung entsteht eine Spannung (Tŏnos), von der die tonische Bewegung ihren Namen hat. Auf die verschiedenen Grade dieser Spannung führen die Stoiker jene Abstufung der Pneumaformen zurück, aus der sie die Abstufung höherer und niederer Wesen in der Natur erklären. Auf der unorganischen Stufe bewirkt das Pneuma durch die nach innen gehende Bewegung Einheit des Körpers und Zusammenhalt seiner Teile (daher Hexis von échein $=$ halten), durch die nach außen gehende Bewegung Größe und Gestalt; auch die übrigen physikalischen Eigenschaften sind Wirkungen des Pneuma. Die in der vegetabilischen und animalischen Welt hinzutretenden neuen Kräfte erklären sich aus größerer Spannung und Feinheit des Pneuma. So suchen die Stoiker den absoluten und seiner Natur nach unüberbrückbaren Gegensatz von Körper und Geist, von physischen und psyKausalität. chischen Vorgängen durch eine Abstufung zu überbrücken. - Im Anschluß an die Bewegung müssen wir noch von der Kausalität handeln. Das Haupt- 
absehen der Stoiker ist bei der Kausalität darauf gerichtet, auch bezüglich des kausalen Zusammenhanges den WeltprozeB als einheitlich darzustellen. Alles Geschehen in der Welt fließt aus einer und derselben einheitlichen Kraftquelle. In abstracto kann man das verursachende Moment im Urstoff von dem stofflichen, leidenden unterscheiden; in concreto kommt es nirgends ohne stofflichen Träger vor. Ursachen im eigentlichen Sinne sind nur Körper; und zwar sind nur die oberen Elemente, Feuer und Luft, und das aus ihnen gemischte Pneuma fähig, etwas zu verursachen. Andere Körper haben diese Fähigkeit nur vermöge des ihnen innewohnenden Pneuma. Wie der wirkende Faktor so muß auch der die Einwirkung erleidende ein Körper sein. Dasjenige aber, was verursacht wird, ist stets ein Unkörperliches. Die allgemeine Form des Verursachungsvorganges ist: ein Körper wird für einen anderen Ursache eines Unkörperlichen, nämlich einer Zuständlichkeit (Bewegung, Veränderung, Lage). Außer dem wirkenden Faktor und dem leidenden sind freilich bei jedem kausalen Vorgange noch andere Umstände beteiligt, ohne welche die Folge nicht eintreten würde (condicio sine qua non). Aber die Stoiker lehnen ausdrücklich $\mathrm{ab}$, diese Bedingungen Ursachen zu nennen. Noch weniger können Umstände, die den Erfolg nur nicht hindern, als Ursachen gelten. Aus dem Gesagten ergibt sich auch, daß Wechselwirkung nicht $z$ wischen Ursache und Verursachtem, sondern nur in dem Sinne möglich ist, daß der Körper A für den Körper B und gleichzeitig der Körper B für den Körper A Ursache von etwas ist. - Eine ursachlose Bewegung ist etwas Undenkbares; Fatum. und jede Verursachung tritt nach bestimmten Naturgesetzen ein, so daß, wenn ein wirkender Körper von bestimmter Beschaffenheit einen leidenden von bestimmter Beschaffenheit berührt, bei im übrigen gleichen Umständen ein bestimmter Erfolg mit Notwendigkeit eintritt. So entsteht die Vorstellung einer ununterbrochenen Kette ursächlich bedingten, also notwendigen Geschehens, in welcher alle einzelnen Vorgänge des Weltprozesses, selbst die spontanen Handlungen der Lebewesen, inbegriffen sind. Es gibt nur Eine solche Kette, da alle Bewegung und Verursachung von einem einzigen ersten Beweger ausgeht, der aber nicht, wie bei Aristoteles, als selbst unbewegt zu denken ist. Indem aus dem lebendigen göttlichen Urstoff der Kosmos mit Notwendigkeit sich herausbildet, zerteilt sich der ursprünglich einheitliche Strom der verursachenden Kraft in zahllose Flüsse, Bäche und Bächlein, ohne doch dadurch seine Einheitlichkeit zu verlièren; und wenn sich der Kosmos wieder in den Urstoff zurückbildet, vereinigen sich alle diese Bächlein des Geschehens wieder zu dem einen Strome. Diesen einheitlichen und notwendigen ursächlichen Zusammenhang alles Geschehens, dessen Träger das einheitliche Pneuma ist, nennen die Stoiker Heimarménē (= Fatum).

Für die Ethik ist es von grundlegender Bedeutung, daß die Stoiker die menschliche Seele und ihre Handlungen als miteinbegriffen in diesen ursächFatum and Vorsehung. lichen Zusammenhang betrachten und ihr doch in gewissem Sinne die Freiheit der Willensentscheidung wahren zu können glauben. Um dies verständlich zu machen, ist es gut vorauszuschicken, daß sie in der Schilderung des 
ganzen Weltprozesses mit der bisher besprochenen kausalen die teleologische Auffassung verbinden. Das göttliche Urfeuer, aus dem die Welt hervorgeht, ist nicht nur Urstoff (materielle Ursache) und erster Beweger und Gesetz des ursächlichen Geschehens, sondern auch allerkennende Vernunft und zwecksetzende Intelligenz. Neben der unerbittlichen Heimarmene steht die gütig vorsorgende Pronoia (= providentia, Vorsehung). Ja, es ist ein und dasselbe reale, materielle Wesen, das beide Funktionen ausübt, die kausale Bewirkung alles Geschehens und die Hinführung dieses Geschehens zum schönsten, besten und vernünftigsten $Z$ weck. In der göttlichen Substanz, ehe sie sich zur Mannigfaltigkeit eines Kosmos entfaltet, kann der Gegensatz von Heimarmene und Pronoia nicht hervortreten. In ihr ist, wie im Samen der Pflanze, der ganze Kosmos potentiell enthalten. Jedes einzelne Wesen, das hernach bei der Entwickelung hervortritt, ist in ihr bereits als Begriff gedacht, als Zweck in dem System der Zwecke gewollt, als reales Wesen durch eine auf seine Verwirklichung hinstrebende Triebkraft ursächlich bedingt. Die göttliche Substanz enthält die keimhaften Zweckgedanken (spermatikoi lógoi) aller Wesen. In dem Begriff des spermatikós lógos sind alle vier aristotelischen Ursachen, die materielle, die dynamische, die logische und die teleologische, zur Einheit zusammengefaßt. Hier sind also Fatum und Vorsehung eins. Was bei dem menschlichen Wollen und Handeln stattfindet, daß der Wille ein begrifflich Gedachtes zum Zweck erhebt und diesen $Z$ weck durch Verursachung einer Bewegung, die nach rein mechanischen Gesetzen verläuft, in der körperlichen Welt verwirklicht, das wird analogisch auf den gesamten WeltprozeB übertragen und als sein eigentliches inneres Wesen angenommen. Nun besteht aber die Entfaltung der Einen Substanz zu einem Kosmos in einem heraklitischen Weg nach unten; einem teilweisen Hinabsinken der Substanz auf niedere Daseinsstufen, indem aus dem Urfeuer Luft, Wasser, Erde entstehen. Zwar bleibt die Einheit insofern gewahrt, als auch die niederen Elemente von dem göttlichen Pneuma durchdrungen sind. Aber auch dieses Pneuma stuft sich in verschiedenen Graden der Kraft und Reinheit ab. In der unorganischen Natur wirkt es nur noch als blinde Kausalität, in der Pflanzenwelt als blinde, aber doch von innen heraus zweckmäßig wirkende und gestaltende Naturkraft, in der animalischen Welt als begriffsblinde, aber doch zweckmäßig begehrende und von Vorstellungen geleitete Seele; und erst im Menschen wirkt es wieder logisch, als vernünftig erkennende und das Vernünftige wollende Seele. Insofern nun dieses sich so mannigfaltig betätigende göttliche Pneuma doch als ein einheitliches Wesen angefaßt wird, konnte Chrysipp sagen, daß alles, was nach dem Fatum geschieht, auch nach der Vorsehung geschieht. Wenn man dagegen die durchaus verschiedene Wirkungsweise des Pneuma in den verschiedenen Naturbereichen ins Auge faßte, so konnte man mit Kleanthes sagen, daß zwar alles durch Vorsehung Geschehende auch durch das Fatum, nicht aber alles durch das Fatum Geschehende auch durch Vorsehung geschehe. Man mußte dann zwischen Vorsehung und Fatum als vermittelnden Begriff den der Natur einschieben, der mit der Vorsehung das Merkmal des zweck- 
mäBigen Wirkens, mit dem Fatum den Mangel bewußter Vernünftigkeit teilt. So wurde auch dieser absolut scheinende Gegensatz in einen fließenden verwandelt. Die Auffassung des Kleanthes erleichterte die Erklärung der Übel Theodicee. und $\operatorname{der}$ Zweckwidrigkeiten im Weltlauf. Diese konnten dem von der providentiellen Leitung verlassenen, auf eigene Hand weiterwirkenden Fatum in Rechnung gestellt werden. Dagegen betont die Anschauung des Chrysippos energischer die Einheitlichkeit des Kosmos und will nicht anerkennen, daß. irgendein Übel sozusagen gegen den Willen der Vorsehung in die Welt gekommen sei. Doch zeigen seine Äußerungen über diesen Punkt ein gewisses Schwanken. Manchmal nähert er sich dem konsequenten Optimismus, welcher behauptet, daß die unserem beschränkten Standpunkt als Übel erscheinenden Dinge vom Standpunkte des großen Ganzen und der göttlichen Vernunft keine Übel sind. Manchmal betrachtet er sie als sogenannte „notwendige Übe1“, die sich bei der Verwirklichung der Naturzwecke als ungewollte, aber unvermeidliche Nebenerfolge herausstellten. Erleichtert wird ihm die Durchführung des Optimismus durch den anthropozentrischen Standpunkt seiner Teleologie. Ist, wie die stoische Ethik lehrt, das physische Übel unvermögend, dem Menschen seine Glückseligkeit zu rauben, ist es überhaupt kein wahres Übel, so braucht nur noch das moralische Übel mit der Vorsehung in Einklang gebracht zu werden. Da hat es denn Chrysipp leicht zu zeigen, daß ohne das Böse auch das Gute nicht existieren könnte, daß also das Böse einen unentbehrlichen Bestandteil des göttlichen Weltplanes bildet. Das moralisch Gute und Böse wurzeln beide gleichermaßen in der Organisation der mit Vernunft und Willensfreiheit begabten Wesen. Der Zweck der ganzen Schöpfung war, diese Wesen hervorzubringen, die in unzählbaren individuellen Formen das Ebenbild des Schöpfers widerspiegeln. Dies konnten sie aber nur, wenn sie die Freiheit erhielten, der Vernunft gemäß zu leben oder nicht. Ihre Aufgabe ist, als freiwillige und selbständige Mitarbeiter Gottes an der Verwirklichung des Vernünftigen im Kosmos mitzuarbeiten. Wenn sie zum Teil diese Aufgabe nicht erfüllen, so ist das allerdings vom Standpunkt ihrer Aufgabe das Böse, aber kein Übel vom Standpunkt des Ganzen. Sie sinken damit nur auf die nächstniedere, die animalische Wesensstufe hinab; und sowenig es vom Standpunkt des Ganzen ein Übel ist, daß es neben den Menschen auch Tiere und Pflanzen gibt, so wenig ist die Existenz schlechter und unvernünftiger Menschen vom Standpunkt des Ganzen ein Übel. Wer nicht freiwillig an dem Werke Gottes mitarbeitet, der wird wider seinen Willen von der Notwendigkeit vorwärts geschleppt und den göttlichen $Z$ wecken dienstbar gemacht.

Wir können nun zu der oben gestellten Frage zurückkehren, in welchem Sinne die Stoiker das menschliche Wollen und Handeln als frei und doch Faturn und Willensfreibeit. inbegriffen in der Notwendigkeit des Fatums ansehen. Sie gehen bei ihrer Behandlung dieses Problems von den verschiedenen Arten der Bewegung aus, durch welche sich die niederen und die höheren Naturwesen voneinander unterscheiden. Ein unorganischer Körper kann nur von außen d. h. von einem anderen bewegten Körper den Anstoß zur Bewegung empfangen. Die Pflanze 
hat ein Prinzip der Bewegung in sich selbst. Sie bewegt und entfaltet sich von innen heraus und verarbeitet die ihr von außen zukommende Nahrung, wie es ihrer Natur entspricht. Beim Tier ist die innere Bewegungsursache eine psychische. Durch die Vorstellung, daß ein seiner Natur Gemäßes ihm erreichbar ist, wird in dem Tiere eine Triebregung ausgelöst, durch die es jener Vorstellung zustimmt. Aus der Triebregung folgt die auf Aneignung jenes Naturgemäßen gerichtete körperliche Handlung. Insofern das Tier mit innerer Zustimmung und aus eigenem Antrieb handəlt, sagen wir, daB die Handlung eine freiwillige ist, daB sie bei ihm steht. Nichtsdestoweniger tritt die Handlung mit Notwendigkeit ein. Die Vorstellung wird dem Tier von außen, ohne sein Zutun gegeben. Wie es auf diese Vorstellung reagiert, ist durch seine eigene Natur bedingt. Es muß also eine äußere und eine innere Ursache zusammentreffen, damit die Handlung zustandekommt. Aber die äußere wirkt nur als Veranlassung, als condicio, sine qua non; die innere, die in der mit Zustimmung verbundenen Triebregung besteht, ist die eigentlich entscheidende. Denn erst durch sie wird aus der als möglich vorgestellten Handlung eine wirkliche. Die natürliche Organisation des Tieres (mag man diese nun generell oder individuell auffassen) ist die Ursache dafür, daß es auf diese bestimmte Vorstellung mit dieser bestimmten Triebregung antworten muB; und diese Organisation selbst ist als ein Erzeugnis des Weltprozesses kausal bedingt. Die Freiheit des Tieres besteht nicht darin, daß seine Betätigungen aus dem kausalen Zusammenhang des Weltprozesses gelöst sind (dies wäre nur möglich, wenn es nicht ein Teil der Welt, sondern eine Welt für sich wäre), sondern darin, daß es sich als Ich, mit williger $\mathrm{Zu}$ stimmung aus eigenem Antriebe betätigt. Der ganze Unterschied der menschlichen von der tierischen Willensfreiheit besteht nun darin, daß zu der Vorstellung und der Triebregung als drittes verursachendes Moment der Handlung das vernünftige (logische) Denken hinzutritt. Der Mensch, soweit er als Mensch und als vernünftiges Wesen handelt, wird der Vorstellung, daß eine mögliche Handlung ihm zukomme, erst dann zustimmen, wenn er sie geprüft und als kataleptisch erkannt hat. Die in der Erkenntnistheorie nachgewiesene theoretische Freiheit des Menschen, vermöge deren er die Möglichkeit hat, von Irrtum frei zu bleiben, ist die Grundlage seiner praktischen Freiheit. Denn jedem Willensakt liegt ein Urteil über das Erstrebenswerte oder Nichterstrebenswerte zugrunde. Indem sie sich auf ein solches Vernunfturteil gründet, wird die Triebregung zum vernünftigen Willen. Der Mensch hat dann eine höhere Freiheit als das Tier, wenn der innere entscheidende Faktor in seiner Seele, sein Ich, nicht mehr der Naturnotwendigkeit, sondern der Vernunftnotwendigkeit folgt. Geboren wird er als animalisches Wesen, aber mit der potentiellen Anlage, ein Vernunftwesen zu werden. Ganz vollendet sich diese Anlage nur in dem Weisen, der das ganze System der Vernunftwahrheiten umspannt, in dessen Zusammenhang sich jeder einzelne Satz als eine demonstrable, unumstößliche Erkenntnis darstellt. Wer diese Stufe erreicht hat, ist im höchsten Sinne frei, so frei wie die Gottheit selbst. Auf 
dieser Stufe sind Freiheit und Notwendigkeit ein und dasselbe. Es besteht also die Willensfreiheit, die der Mensch erlangen kann, nicht darin, daß sein Wollen und Handeln keine Ursache hat, sondern darin, daß es die Ursachen hat, die seinem Charakter als Vernunftwesen entsprechen: logische Ursachen.

Die Freiheit des Menschen in diesem Sinne ist mit der Annahme wohl Das Lufällige vereinbar, daß alle Geschehnisse, auch die menschlichen Handlungen, von Ewigkeit vorherbestimmt sind. Diese Annahme und der Weissagungsglaube stützen sich gegenseitig. Wenn aber auch alle Dinge mit Notwendigkeit geschehen, so sind wir doch von unserem Standpunkt berechtigt, viele Greschehnisse, deren Ursachen wir nicht durchschauen, zufällig zu nennen. Auch wird durch diese Annahme der Begriff der Möglichkeit nicht aufgehoben. Wir können zukünftige Ereignisse möglich nennen, wenn keines der uns bekannten allgemeingültigen Naturgesetze ihr Eintreten a priori ausschließt. Was durch ein solches Naturgesetz gefordert wird, z. B. daß alle Menschen sterben müssen, ist in einem anderen Sinne notwendig, als in dem wir alles Geschehen überhaupt notwendig nennen. Es läßt sich in der Form eines allgemein und notwendig wahren Urteils aussprechen. Aus diesem zweiten Notwendigkeitsbegriff entspringen die Begriffe des Möglichen und des Unmöglichen. Was in diesem Sinne "notwendig nicht ist“, das ist unmöglich, und was in diesem Sinne „nicht notwendig ist", das ist möglich.

Es gibt nur einen einzigen Kosmos, der begrenzt und kugelförmig, aber Kosmologie. von einem unendlichen leeren Raum umgeben ist. Im Innern des Kosmos ist nirgends leerer Raum vorhanden. Denn dadurch würde seine Einheit, auf welche die Stoiker das Hauptgewicht legen, aufgehoben werden. Er ist geeint durch das Pneuma, das ihn in allen seinen Teilen durchdringt, so wie die Seele den Leib, und alles, was in ihm geschieht, in einem einzigen Bewußtsein umfaßt. Der Kosmos ist ein vernünftiges Lebewesen. Er ist aus dem Urfeuer entstanden und wird sich wieder in dasselbe auflösen und von neuem aus ihm entstehen; und so wechseln von Ewigkeit zu Ewigkeit Perioden der Diakosmesis, in denen die Substanz zu einer Mannigfaltigkeit von Wesen entfaltet ist, mit solchen Perioden, wo alle Unterschiede in der Einheit der göttlichen Substanz aufgehoben sind. Die Ekpyrōsis (Weltverbrennung) und Palingenesie (Wiedergeburt der Welt) haben die Stoiker von Herakleitos übernommen. Der Hauptzweck, um deswillen die göttliche Substanz aus sich heraus und in den Zustand der Diakosmēsis übergeht, ist die Hervorbringung vernünftiger Wesen. Um der Menschen willen ist die Welt geschaffen; oder richtiger um der Menschen und Götter willen. Denn auch die Gottheit selbst differenziert sich in der Diakosmessis zu einer Vielheit göttlicher Einzelpersonen. Die Gesamtheit der vernünftigen Wesen, für die der Kosmos als gemeinsames Wohnhaus errichtet ist, bildet eine Staatsgemeinde, das Vorbild aller irdischen Gemeinden. Jeder Mensch kann Zutritt zu dieser Gemeinde erlangen, aber nur der Weise ist in ihr ein vollberechtigtes Mitglied. Bürger dieses Vernunftreiches zu werden, ist die den Menschen gestellte Aufgabe.

Der Mensch besteht aus Körper und Seele. Auch die Seele ist ein Der Mensch 
Körper, und zwar ein pneumatischer, dem die tonische Bewegung eigen ist. Sie besteht aus acht Teilen, nämlich aus den fünf Sinnesorganen, dem Stimmorgan, dem Zeugungsorgan und dem führenden Seelenteil. (Hēgemonikón), von dem die übrigen Teile als Pneumaströmungen ausgehen. Das Hegemonikón hat seinen Sitz im Herzen und ist der Träger aller rein geistigen Funktionen, also nicht nur des Vorstellens, Urteilens, Schließens, sondern auch des Fühlens und des Wollens. Wie in dem Hegemonikón erst allmählich, durch die von den Sinnesorganen gemachten Wahrnehmungen, der Logos als ein Komplex von Begriffen zustande kommt, haben wir schon gesehen. Die ursprünglich animalische Seele wird durch diese Entwickelung erst zu einer vernünftigen Menschenseele. Ob die Seele nach der Trennung vom Leibe fortbesteht, hängt von dem Grade des Tonos ab, den sie während ihres Lebens im Leibe erlangt hat. Die tugendhaften Seelen sind dauerbarer und leben als Dämonen weiter. Gern knüpfen hier die Stoiker an den volkstümlichen Dämonenglauben an. Ewig aber kann auch die tugendhafte Seele nicht fortleben. Bei der Ekpyrosis kehrt sie in die Einheit der göttlichen Substanz zurück. Tritt dann die Palingenesie ein, so nimmt die Weltentwickelung wieder genau denselben Verlauf wie das vorige Mal. Es treten also auch dieselben Menschenseelen wieder ins Dasein. Da ihre individuelle Existenz unterbrochen war, können sie sich des früheren Lebens nicht erinnern.

Ethik: Das einstimmige und das naturgemäße Leben.

Auf diesen Grundlagen bauen nun die Stoiker ihre praktische Philosophie auf, die wir als den wichtigsten, für ihre Stellungnahme auch zu den theoretischen Problemen ausschlaggebenden Teil ihrer Lehre ansehen dürfen. Auch die Stoiker erkennen, wie die meisten antiken Ethiker, in der Glückseligkeit das höchste Ziel alles menschlichen Strebens. Aber der Glückseligkeitsbegriff ist nur ein allgemeines Schema. Die Art, wie es mit bestimmtem Inhalt ausgefüllt wird, ist das Entscheidende. Zenon, der Begründer der Stoa, hat gelehrt, daß die Glückseligkeit und das Ziel, auf das all unser Wollen und Handeln bezogen werden müsse, in einem einstimmigen Leben bestehe. Er meinte damit die logische Übereinstimmung unserer Gedanken untereinander und die Übereinstimmung unseres Fühlens, Wollens und Handelns mit unseren Gedanken. Kleanthes machte diese Lehre nicht klarer, indem er statt des „einstimmigen Lebens“ das „mit der Natur einstimmige Leben“ für das höchste Gut erklärte. Die Frage, ob die Natur des Menschen oder die Natur des Weltalls gemeint sei, hat Chrysippos dahin entschieden, daß beides verstanden werden müsse. Denn die Natur des Menschen sei dieselbe wie die des Weltalls. Das Wort „Natur" ist hier nicht in dem Sinne zu verstehen, in dem es einen Gegensatz zur Seele und zur Vernunft bildet, sondern in der umfassenden Bedeutuug, die alle diese Pneumaformen in sich begreift. Das unterscheidende Merkmal der menschlichen Natur ist ja gerade der Logos. Daher kann die Übereinsímmung des Lebens eines Menschen mit seiner Naturbeschaffenheit nur in einer Übereinstimmung mit dem Logos bestehen. Der Logos aber ist zugleich das Gesetz, das den ganzen Kosmos regiert und jedem einzelnen Wesen vorschreibt, was es zu tun und zu lassen hat. Die vollkom- 
men ausgebildete menschliche Vernunft ist mit der göttlichen identisch. Also besteht das mit der Natur übereinstimmende Leben für den Menschen darin, daß er gemäß dem göttlichen Weltgesetz lebt. Unter der Natur des Menschen, Die rugend als mit der in Übereinstimmung zu leben seine Glückseligkeit ausmacht, ist das böchstes Gut. höchste $\mathrm{Maß}$ von Vollkommenheit zu verstehen, das er durch Ausbildung seiner natürlichen Anlage erreichen kann. Denn erst im Laufe seiner Entwickelung wird er sich seiner wahren Natur bewußt und wird das in Wirklichkeit, was er bei seiner Geburt nur der Möglichkeit nach war. Das Ideal, auf dessen Erreichung ihn seine Anlagen hinweisen, ist seine wahre Natur. Diese vollkommene Ausbildung ist es, die Tugend genannt wird. Also ist das mit der Natur übereinstimmende Leben mit dem tugendhaften Leben identisch. Das tugendhafte Leben ist das glückselige Leben. Die Tugend sollen wir nicht um irgendwelcher Folgen willen, die sich aus ihrem Besitz ergeben, sondern um ihrer selbst willen zu besitzen streben. Ihr Besitz ist schon allein zur Glückseligkeit ausreichend. Nur das Schöne (d. h. das Löbliche, lat. honestum) ist ein wahrhaft Gutes. Die Tugend ist die Kunst der richtigen Lebensführung. Sie gehört zu der Art von Künsten, bei denen der Zweck nicht in einem Werk, das sie herstellen, oder einem Erfolg, den sie bewirken, sondern in der kunstgerechten Betätigung selbst gelegen ist. Das höchste Ziel des Strebens setzen die Stoiker, wie Aristoteles, in eine Betätigung.

Um die Richtigkeit ihrer Bestimmung des höchsten Lebenszweckes zu Der ursprüngbeweisen, berufen sich auch die Stoiker, wie Epikur, auf den ursprünglichen Naturtrieb. Der letzte $Z$ weck muß mit dem ersten übereinstimmen. Der ursprüngliche Naturtrieb kann nicht irren. Denn in ihm redet die Natur selbst, unbeirrt von schwankenden Meinungen. Epikur hatte behauptet, daß die Lust oder doch die Freiheit von Unlust den Gegenstand des ursprünglichen Naturtriebs bilde und dementsprechend auch den höchsten Lebenszweck bestimmt. Die Stoiker widersprechen dieser Auffassung. Nach ihrer Meinung ist der ursprüngliche Naturtrieb bei allen Lebewesen Selbstliebe und Selbsterhaltungstrieb. Diesen Trieb mußte die Natur ihren Geschöpfen einpllanzen, wenn sie ihre Erhaltung wünschte. Sein Ziel ist die Erhaltung des Wesens im naturgemäßen Zustand. Was diesen Zweck fördert, wird instinktiv von der Geburtsstunde an von jedem Lebewesen gesucht, was ihn gefährdet, gemieden. Die Lust ist nur eine Begleiterscheinung, die sich bei der Förderung und Erhaltung des naturgemäßen Zustandes einstellt. Aus dieser Auffassung des Naturtriebes entspringt der Begriff des „ursprünglich Naturgemäßen“ (prōta katá physin), der die Gesundheit, Kraft und Schönheit des Leibes und die ungehemmte Funktion aller leiblichen und seelischen Kräfte umfaßt. Es ist aber der Natur nicht nur an der Erhaltung des Individuums, sondern auch an der Erhaltung der Gattung gelegen, die auf der geschlechtlichen Fortpflanzung beruht. Darum hat sie den Lebewesen den Trieb zur Erzeugung und Erhaltung von Nachkommen eingepflanzt. In der Liebe zu den Nachkommen äußert sich der Selbsterhaltungstrieb der Gattung. Aber der Mensch bleibt nicht auf dieser Stufe des Trieblebens stehen, die er mit allen animalischen 
Ubbertragung der Selbstliebe anf den Logos.

Wesen teilt. Da er das Vermögen der Begriffsbildung hat, wandelt sich bei ihm das instinktive Suchen und Meiden in ein bewußtes Wollen. Er erkennt generell und begrifflich, daß und warum ihm dieses gemäß und jenes nicht gemäß ist, warum ihm diese Handlungsweise zukommt und jene nicht. Damit hebt die Entwickelung des Logos an, der ursprünglich im Dienste des animalischen Naturtriebes steht, bald aber selbst zum Gegenstand eines sublimierten Selbsterhaltungstriebes wird. Der Mensch fühlt, daß der Logos, der sich in ihm herausbildet, sein eigentliches inneres Wesen ausmacht. So überträgt er denn auf ihn die Selbstliebe und den Selbsterhaltungstrieb. Er sucht die höhere Natur, die er in sich entdeckt hat, zur Vollendung zu bringen. Ihre Vollendung aber besteht in der Ausbildung eines logisch einstimmigen Systems begrifflicher Erkenntnis. Deswegen haben die Stoiker ihren höchsten Lebenszweck als mit der Natur, nicht mit der Vernunft übereinstimmendes Leben formuliert, weil diese Formulierung auf das ganze Leben des Menschen und nicht nur auf den Menschen, sondern auch auf alle übrigen Naturwesen paßt. Für den reifen Menschen aber geht die Übereinstimmung mit der Natur in Übereinstimmung mit der Vernunft, in Weisheit und Tugend über.

$\nabla$ erhältais des Logos zum animalischen Leben.

Guiterlehre: Güter, Übel und Adiaphora.
Erinnern wir uns nun, daß nach der stoischen Erkenntnistheorie die Verstandesbegriffe nicht reale, neben den körperlichen Einzeldingen existierende Wesenheiten auffassen, sondern nur die Gedankenformen, die der Wirklichkeit zugrunde liegen und ihren Sinn und ihr Wesen bilden, so verstehen wir, daß die in der Menschenseele ausgebildete logische Natur sich nicht von der animalischen loslösen und für sich bestehen kann. Wie die theoretische Bedeutung der Begriffe darin liegt, daß sie die Körperwelt begreiflich machen, so liegt auch die praktische Bedeutung des Logos darin, daß er uns als körperlichen Wesen in der körperlichen Welt die richtige Betätigung ermöglicht. Wir hören nicht auf, animalische Wesen zu sein, indem wir Vernunftwesen werden. Die animalischen Triebe bestehen in uns weiter, und es kommt uns $z u$, sie soweit als möglich zu befriedigen. Aber die Seite unseres Wesens, in der diese Triebe walten, erscheint uns nur noch als der Stoff, an dem wir unser eigentliches, geistig vernünftiges Wesen zu betätigen haben. Die Seele ist nicht um des Leibes willen geschaffen und die Vernunft nicht um der Seele willen, sondern umgekehrt: der Leib soll der Seele und die Seele der Vernunft das unentbehrliche leidende Substrat ihrer Betätigung darbieten. Die Betätigung der Vernunft in einer Wirklichkeit ist der höchste Zweck wie im ganzen Kosmos so auch in jedem einzelnen vernünftigen Wesen. Dies ist der Grundgedanke der stoischen Ethik, aus dem sich ihre Güterlehre und ihre Tugendlehre ableiten läßt.

Wahre Güter sind nur diejenigen Dinge, die zu unserem höchsten Ziele etwas beitragen, wahre Übel nur die, welche zu seinem Gegenteil etwas beitragen. Gut sind die Tugenden, die tugendgemäßen Betätigungen, die tugendhaften Menschen, kurz alles, was zur Glückseligkeit sei es als Bestandteil, sei es als bewirkende Ursache in Beziehung steht. Schlecht sind die Laster, die lasterhaften Handlungen, die lasterhaften Menschen und überhaupt alles, was 
dem tugendgemäßen Leben in irgenđeiner Weise schädlich und hinđerlich ist. Gut kann ein Ding nur genannt werden, insofern es für den höchsten Lebenszweck etwas nützt. Alle moralisch indifferenten Dinge, Zustände, Erlebnisse sind auch im Sinne der Güterlehre indifferent, d. h. sie sind weder Güter noch Übel. Sie tragen nichts zur Glückseligkeit oder ihrem Gegenteil bei. Dies gilt im besonderen von allen Dingen, die dem natürlichen Menschen als Güter und Übel erscheinen, weil sie Gegenstände natürlicher Triebregungen, eines Strebens oder Meidens in der untervernünftigen Sphäre unseres Seelenlebens sind. Lust, Gesundheit, Kraft, Reichtum, Ehre sind keine wahren Güter, Schmerz, Krankheit, Armut, Verbannung keine wahren Übel. Von allen diesen Dingen kann man einen guten oder einen schlechten Gebrauch machen und lediglich von unserem Verhalten zu ihnen hängt es $a b$, ob sie zur Glückseligkeit etwas beitragen oder nicht. Es liegt also nicht in ihnen selbst die Fähigkeit zu nützen oder zu schaden. Alle diese Dinge stehen nicht bei uns. Nicht von unserem freien Willen, sondern von dem unabänderlichen Naturlauf hängt es ab, welche von diesen Dingen uns zuteil werden. Dagegen hängt es lediglich von uns ab, wie wir uns $z$ ihnen verhalten, und dadurch allein ist unsere Glückseligkeit bedingt. Als animalische Wesen sind wir von diesen äußeren Dingen abhängig und erleiden durch sie Lust und Schmerz, als vernünftige Wesen sind wir frei von allem $\ddot{A}$ ußeren und finden unser Glück in der vollkommenen Betätigung unseres innersten Wesens, an der uns keine Macht des Himmels und der Erde hindern kann. "Si fractus illabatur orbis, impavidum ferient ruinae."

Aber nichtsdestoweniger bilden diese äußeren Dinge den Stoff, auf den sich unser Handeln als körperliche Wesen bezieht. Wir sind nicht nur zum Erkennen, sondern auch zum Handeln von der Natur bestimmt. Das Handeln ist durch Triebregungen bedingt, die der animalischen Seite unseres Wesens angehören und sich auf die Aneignung des Naturgemäßen und die Meidung des Naturwidrigen beziehen. Die Vernunft hat die Aufgabe, diese Triebregungen einheitlich zu regeln, ein System praktischer Grundsätze aufzustellen, aus dem sich in jedem einzelnen Falle ergibt, ob einem Triebe zuzustimmen ist oder nicht und welchem von zwei einander widersprechenden Trieben der Vorzug gebührt. Dies ist nur möglich, wenn die Vernunft unter den Gegenständen dieser Triebe Wertunterschiede statuiert und unter ihnen diesen Unterschieden entsprechend eine Auswahl zu treffen lehrt. Es zeigt sich also, daß die Dinge, die vom Standpunkt des Glückseligkeitsstrebens für indifferent erklärt werden mußten, vom Standpunkt des naturgemäßen Lebens keineswegs indifferent sind. Sie sind vielmehr teils naturgemäB, teils naturwidrig. Den naturgemäßen Dingen kommt ein positiver Wert zu, insofern sie zum naturgemäßen Leben beitragen, den naturwidrigen ein negativer Wert oder Unwert, insofern sie zur Naturwidrigkeit des Lebens beitragen. Das "naturgemäße Leben", um das es sich hier handelt, ist verschieden von dem „mit der Natur übereinstimmenden Leben“, welches das höchste Ziel bildet. Hier handelt es sich um die niedere, animalische Natur im Menschen, 
um Natur im Gegensatz zum Logos, dort um die ganze Natur des Menschen, in welcher das Animalische nur Stoff, die Vernunft Form und Wesen ist. Der Wert der äußeren Dinge ist nun abgestuft, je nach dem Maße ihrer Beitragsleistung zum naturgemäßen Leben. Daraus entwickelt sich die vergleichende Wertbestimmung und vernünftige Auswahl. Auswählen ist in praktischer Hinsicht die Hauptfunktion der Vernunft. Naturgemäße Dinge von beträchtProēgména. lichem Wert nennen die Stoiker „bevorzugte Dinge“ (Proēgména), nicht Güter; naturwidrige Dinge von beträchtlichem negativen Wert „negativ bevorzugte Dinge" (A poproēgména), nicht Übel. Die positiv bevorzugten Dinge teilen sie, wie der Peripatos die Güter, in seelische, leibliche und äußere. $\mathrm{Zu}$ den seelischen gehören z. B. Talent, gutes Gedächtnis, Schärfe des Denkens, Fortschritte in der Wissenschaft, auch diejenigen gewerblichen und künstlerischen Fertigkeiten, die zum naturgemäßen Leben ein Beträchtliches beitragen; zu den leiblichen Kraft, Schönheit, Gesundheit, Schärfe der Sinnesorgane; zu den äußeren Eltern, Kinder, mäßiger Besitz, Beliebtheit bei den Menschen. Die seelischen Proēgména haben höheren Wert als die leiblichen und die äußeren. Außerdem muß man die um ihrer selbst willen bevorzugten Dinge von denen unterscheiden, die nur als Mittel zur Erlangung jener bevorzugt werden.

Erstrebenswertes und Annehmbares.

Tugendhafte und blos angemessene Hand! ungen.
Als Gegenstände unseres Wollens und Handelns sind die Güter erstrebenswerte, die Übel meidenswerte Dinge; dagegen ist das Naturgemäße (moralisch Indifferente) nur ein mehr oder weniger Annehmbares und das Naturwidrige (moralisch Indifferente) nur ein mehr oder weniger Unannehmbares. Ganz scharf wird durch diese terminologische Untercheidung ausgedrückt, daß wir zur Aneignung der Güter selbst die Initiative ergreifen müssen, während wit bei den indifferenten Dingen nur annehmen, was uns dargeboten wird, und unter den dargebotenen Möglichkeiten den Wert vor dem Unwert und den höheren Wert vor dem niederen bevorzugen.

Die von den Stoikern durchgeführte Unterscheidung der wahren Güter und Übel einerseits und der indifferenten Dinge andererseits ist die Grundlage ihrer Klassifikation der menschlichen Handlungen nach dem moralischen Werte. Wir können bei jeder menschlichen Handlung fragen I. ob sie dem naturgemäßen Leben, 2. ob sie dem einstimmigen, tugendgemäßen Leben angemessen ist. Handlungen, die dem naturgemäßen Leben nicht angemessen sind, können auch dem tugendgemäßen Leben nicht angemessen sein. Handlungen, die dem tugendgemäßen Leben angemessen sind, entsprechen auch dem naturgemäßen Leben. Aber Handlungen, die dem naturgemäßen Leben angemessen sind, genügen deswegen noch nicht den Anforderungen der Tugend. Es ergeben sich also drei Arten von Handlungen. Wie es Güter, Übel und indifferente Dinge gibt, so auch gute, schlechte und indifferente Handiungen. Diese indifferenten Handlungen können absolut indifferent sein, auch vom Standpunkt des naturgemäßen Lebens, oder nur indifferent vom Standpunkt der Glückseligkeit und Tugend. Die letzteren bilden ein mittleres, den Weisen und Toren gemeinsames Gebiet. Tugendhafte Handlungen (kator- 
thōmata) kann nur der Weise ausführen, fehlerhafte Handlungen (hamartēmata) nur der Unweise. Mittlere, angemessene Handlungen (mésa kathékonta) sind den Weisen und den Unweisen gemeinsam. Auch die bloß angemessenen Handlungen haben eine Beziehung zum Logos. Sie können definiert werden als Handlungen, für deren Ausführung sich ein vernünftiger Grund anführen läßt. Auch die tugendhafte Handlung ist eine angemessene, aber sie ist mehr als dies. Sie unterscheidet sich von der bloß angemessenen durch die Einsicht und Absicht des Handelnden. Die Absicht des Handelnden ist bei ihr mit klarem Bewußtsein auf den höchsten Lebenszweck gerichtet; die Einsicht, aus der die tugendhafte Handlung hervorgeht, ist ein wahrhaftes, unerschütterliches Wissen, welches nur im Zusammenhang eines Systems streng beweisbarer Erkenntnisse und als Bestandteil des vollkommen ausgebildeten Logos denkbar ist. Die tugendhafte Handlung ist die zur Vollendung gebrachte, in die Region der reinen Vernunft erhobene "angemessene Handlung". Die bloß angemessenen Handlungen sind Ausflüsse und Bestandteile des natürlichen Lebens und beziehen sich auf die naturgemäßen, aber indifferenten Dinge; die tugendhaften Handlungen sind Ausflüsse und Bestandteile des einstimmigen Vernunftlebens und beziehen sich auf die Aneignung der wahren Güter und auf die Meidung der wahren Übel. Für die bloß angemessene Handlungsweise sind die naturgemäßen Dinge, die sie sich aneignet und unter denen sie eine Auswahl trifft, Selbstzweck; für die tugendhafte Handlungsweise bilden sie nur den Stoff, an dem sich der Handelnde als Vernunftwesen betätigt. Wenn übrigens gelehrt wird, daß diese „mittleren Handlungen“ Weisen und Toren gemeinsam sind, so kann das nur auf die äußere Handlung als solche, abgesehen von der Gesinnung, aus der sie hervorgeht, bezogen werden. Denn da der Weise jede einzelne Tat aus der richtigen Gesinnung heraus tut und in der richtigen Absicht und Einsicht, so ist jede seiner Taten eine tugendhafte Tat, auch wenn die äußere Handlung sich von der bloB angemessenen eines Toren nicht unterscheidet. Ein Unterschied der tugendhaften Handlung von der bloß angemessenen liegt auch darin, daß diese das Lob der Angemessenheit erst erhalten kann, wenn sie zu Ende geführt ist, während bei jener schon der bloße Anlauf, ja die bloße Absicht löblich ist. Die Ausführung der Handlung kann durch Zwischenfälle, die zu verhindern nicht in unserer Macht steht, unterbrochen werden. Dadurch erleidet die Vollkommenheit der tugendhaften Betätigung keinen Abbruch. Erst wenn man die Betätigung eines Menschen längere Zeit beobachtet, wird auch in den äußeren Handlungen selbst der Unterschied des tugendhaften Handelns von dem bloß angemessenen bemerkbar. Denn nun erst zeigt sich die aus der Festigkeit der Grundsätze entspringende Gleichmäßigkeit und Zuverlässigkeit des Handelns.

Die Tugend ist es, deren Besitz oder Nichtbesitz diesen Unterschied der Tugendlebre. Handlungen begründet. Sie ist ein einstimmiger Seelenzustand, die richtige Vernunft in ihrer Vollendung, eine zugleich theoretische und praktische Kunst, welche die ganze Lebensbetätigung des Menschen, d. h. alle seine freiwilligen 
Handlungen regelt. Einmal erworben ist sie unverlierbar, ein character indelebilis. Sie läßt keine Abstufung zu, da sie ein Ideal der Vollkommenheit ist. Man kann sie entweder besitzen oder nicht besitzen. Auch die einzelne tugendhafte Handlung kann nicht mehr oder weniger tugendhaft sein, sowenig ein Urteil mehr oder weniger wahr oder falsch sein kann. Alle Fortschritte, die ein Mensch auf der Bahn zur Tugend macht, sind sittlich indifferent, sind bloße Proēgména. Sie bilden auch nicht ein mittleres Gebiet zwischen Tugend und Schlechtigkeit, zwischen Weisheit und Torheit; sondern der Mensch bleibt schlecht und töricht, bis er den letzten Schritt getan, das Ziel erreicht, seine sittliche Aufgabe erfüllt hat. Die Tugend ist keinem Menschen angeboren, sondern wird auf Grund einer allen angeborenen natürlichen Anlage von dem einzelnen Menschen durch theoretische Belehrung und praktische Übung erworben. In den ersten Lebensjahren ist der Mensch vernunftlos, insofern ihm noch die natürlichen Begriffe fehlen, aus denen sich der Logos aufbaut, aber weder unvernünftig noch vernünftig, weder unsittlich noch sittlich. Erst wenn der Logos in ihm erwachsen ist, tritt die sittliche Verantwortlichkeit an ihn heran, und er ist nun zunächst schlecht. Dann beginnt im günstigen Fall der Fortschritt, der in dem Erwerb der Tugend und Weisheit seinen Abschluß findet. Die Tugend ist lehrbar. Ihre Erlernung ist aber mit großen Schwierigkeiten verbunden, da die Gefühle und Triebe uns irreführen und von dem geraden Wege der Vernunft ablenken (z. B. die Lust, die nicht einmal ein Proẹgménon ist, als das wahre und höchste Gut erscheinen lassen), und da auch unsere Umgebung, Eltern, Lehrer und Erzieher eingeschlossen, das Ihrige tut, unsere Begriffe zu verwirren. Doch darf man den Erwerb der Tugend und Weisheit nicht für unmöglich halten. „Vor die Tugend haben die Götter den Schweiß gesetzt." - Es gibt eine Mehrheit von Tugenden, die aber voneinander untrennbar sind und sich zu einer einheitlichen Gesamttugend zusammenschließen. Da das Wissen als System eine Einheit bildet und da auch ein und dasselbe Seelenvermögen Träger aller Tugenden ist, Ein Seelenvermögen aber nur Eine, ihm eigentümliche Vollkommenheit haben kann, so scheint es, daß es nur Eine Tugend geben kann, die Einsicht, die in ihren Relationen zu verschiedenen Lebensgebieten mit verschiedenen Namen benannt wird. Aber Chrysippos hat diese von Ariston vertretene Ansicht verworfen und qualitative Verschiedenheit der vielen Tugenden angenommen. Wie er sich das Hēgemonikón trotz seiner Einheitlichkeit mit vielen Kräften und Vermögen ausgesiattet denkt, so nimmt er auch keinen Anstand, ihm viele qualitativ verschiedene Tugenden zuzuschreiben. Unter den Tugenden unterscheidet er solche, die Wissenschaften oder Künste sind, von bloßen Fähigkeiten, die sich auf Grund jener durch Übung entwickeln. Die Gesamttugend, die alle diese Vorzüge in sich schließt, ist dieselbe für Männer und Frauen, für Menschen und Götter. Eine höhere Vollkommenheit als die menschliche gibt es im Kosmos nicht. Denn die menschliche Vernunft ist der göttlichen wesensgleich. Wir wollen die stoische Tugendlehre, die von den vier altbekannten Kardinaltugenden ausgehend diesen zahlreiche Spezialtugenden 
unterordnet, nicht weiter ins Einzelne verfolgen, sondern uns nun der stoischen Auffassung und Erklärung des moralisch Schlechten zuwenden.

Natürlich ist die Auffassung des Lasters durch die der Tugend bestimmt. Laster und Ist die Gesamttugend der vollkommen durchgebildete Logos und sind die hauptsächlichsten Einzeltugenden Wissenschaften und Künste, so müssen die Laster in Unwissenheit und Kunstmangel ihr Wesen haben. Das Wollen wird von den Stoikern nicht als Äußerung eines besonderen Seelenvermögens neben der Denkkraft, sondern als eine Seelenregung aufgefaßt, die sich mit gewissen Urteilen unmittelbar verbindet. Was mir als ein Gut erscheint, das muß ich notwendig, wenn es mir dargeboten wird, erstreben, und was mir als ein Ubel erscheint, das muß ich notwendig, wenn es sich mir nähert, meiden. Gebe ich solchen Urteilen über Güter und Übel meine Zustimmung (Synkatathesis), so gehen sie unmittelbar in Willensregungen über. Ebendarum halten es die Stoiker für so wichtig, die verbreiteten unrichtigen Meinungen über Güter und Übel zu berichtigen. Mit dieser rationalistischen Auffassung geht aber die physikalische immer Hand in Hand, so daß die Urteile und Triebregungen zugleich als physikalische Vorgänge, die Wissenschaften und Unwissenheiten als zuständliche Modifikationen in der Seelensubstanz angesehen werden. Dies zeigt sich auch in der Lehre von den Affekten, die den Stoikern als die Hauptquelle der menschlichen Schlechtigkeit und Unglückseligkeit gelten. Der Affekt wird definiert als eine übermäßige Triebregung, die das vom Logos gesetzte Maß überschreitet, die dem Logos ungehorsam ist. Er wird von Chrysipp der Bewegung eines Laufenden verglichen, welcher der Laufende, selbst am Ziel angelangt, nicht sogleich Halt gebieten kann. Wie in diesem Falle die Körperbewegung über das von dem Trieb gesetzte Ziel, so könne auch der Trieb selbst über die vom Logos gesetzte Grenze hinausschießen. An anderen Stellen dagegen vernehmen wir, daß die Affekte falsche Urteile sind. Die Trauer wird physikalisch als ein Zusammensinken, die Lust als ein Aufschwellen der Seele gedeutet. Zugleich aber ist die Trauer der frische Glaube an die Gegenwart eines Übels und die Lust der frische Glaube an die Gegenwart eines Gutes. Ob die Meinung beidemal als Ursache des physikalischen Vorgangs zu gelten hat, oder ob derselbe reale Vorgang sich zweiseitig darstellt, darüber hat innerhalb der Schule selbst nicht Einmütigkeit geherrscht. Diese Unklarheit sitzt sehr tief. Denn auch bei der göttlichen Substanz ist keineswegs klar, ob ihr Denken mit den physikalischen Veränderungen identisch oder nur Ursache dieser Veränderungen ist. Einerseits meinen die Stoiker, daß nur ein Körper wirken und verursachen kann, und lassen daher das körperliche Pneuma als wirkenden Faktor die leidenden Stoffe durchdringen. Daraus würde folgen, daß im Pneuma selbst zwischen Denken und Bewegung kein ursächliches Verhältnis, sondern Identität besteht; und dasselbe müßte natürlich für die göttliche Substanz vor ihrer Entfaltung gelten. Andererseits wird doch wieder das in der göttlichen Substanz als Attribut enthaltene geistige Prinzip als Ursache bezeichnet. Aus dieser metaphysischen Unklarheit entspringen auch die Unklarheiten in der Psychologie 
und Affektenlehre. Klar ist aber, daß nicht jede falsche Meinung ein Affekt ist, sondern nur diejenige, die sich mit einer starken Triebregung verbindet. Es erscheint als ein Widerspruch, daß bald der Affekt als Ursache des Irrtums, bald der Irrtum als Ursache des Affektes gelten soll. Beide Auffassungen lassen sich aus Chrysipp belegen. Alle diese Schwierigkeiten wurzeln in dem psychischen Monismus, den die Stoa dem metaphysischen Monismus zuliebe vertritt. Es ist ihr nämlich nicht gelungen, diesen Monismus durchzuführen. Dem Monismus zuliebe werden Denken und Wollen, Wähnen und wissenschaftliches Erkennen als Betätigungen desselben einheitlichen Seelenvermögens dargestellt. Dadurch wird es unmöglich, sie durch kausale Erklärung auseinander abzuleiten. Wie kommt es, daß das vernünftige Denken auf Schwierigkeiten stößt und vom rechten Wege abirrt? Ist der Affekt die Ursache davon, so kann er nicht selbst ein Vernunftirrtum sein; sondern entweder muß der wollende und strebende Faktor von dem denkenden oder der irrende und wähnende von dem wissenschaftlich erkennenden unterschieden werden.

Vier Grund. affekte.

Krankbeiten, Schwächen, Anfälligkeiten.
Die spezielle Ausführung der Lehre von den Affekten ist ein Gegenstück zur Tugendlehre. Wie vier Kardinaltugenden gibt es auch vier Grundaffekte, Lust und Trauer, die sich auf Gegenwärtiges, Begierde und Furcht, die sich auf Zukünftiges beziehen. Jedem dieser vier Grundaffekte sind zahlreiche Spezialformen untergeordnet. Begierde und Furcht sind ursprünglicher als Lust und Trauer. Haben wir erlangt, was wir begehrten, oder sind entronnen dem, was wir fürchteten, so stellt sich die Lust ein, und desgleichen die Trauer, wenn wir nicht erlangt haben, was wir begehrten, oder dem anheimgefallen sind, was wir fürchteten.

Die Affekte sind einzelne Seelenbewegungen. Aus ihnen entstehen habituelle Seelenzustände, die als Krankheiten, Schwächen, Anfälligkeiten der Seele nach Analogie der pathologischen Körperzustände aufzufașsen sind. Der Unterschied der Krankheit von der Anfälligkeit liegt darin, daß bei der Anfälligkeit nur eine Prädisposition vorhanden ist, durch die wir leicht in gewisse Affekte verfallen, die Krankheit dagegen in einer fest eingewurzelten, habituell gewordenen falschen Meinung und Willensrichtung besteht. Der Jähzorn ist eine Anfä1ligkeit, die uns zu Zornausbrüchen prädisponiert; der Geiz und die Habsucht sind Krankheiten, die in eingewurzelter falscher Wertung des Geldbesitzes beziehungsweise Gelderwerbes ihr Wesen haben. Es gibt zwei Arten von Krankheiten: den einen liegt die Begierde zugrunde und die falsche Wertung eines Dinges als höchst erstrebenswertes Gut, den anderen die Furcht und die falsche Wertung eines Dinges als höchst meidenswertes Übel. Krankheiten der letzteren Art sind z. B. Ungastlichkeit, Weiberhaß, Menschenhaß. Eine besondere Gattung der Krankheiten bilden die Schwächezustände. Von allen bisher genannten pathologischen Seelenzuständen sind die vier Kardinallaster: Unverstand, Zuchtlosigkeit, Ungerechtigkeit, Feigheit zu unterscheiden, die den vier Kardinaltugenden: Einsicht, Mäßigkeit, Gerechtigkeit und Tapferkeit entgegengesetzt sind. Diese sind Unwissen- 
heiten, von denen man nur durch den Erwerb der vollkommenen Weisheit und Tugend befreit werden kann. Man kann von vielen einzelnen Krankheiten, Schwächen und Anfälligkeiten schon geheilt sein, worin der sittliche Fortschritt besteht, und dabei doch immer noch zuchtlos und feige, also schlecht und töricht geblieben sein. Diese den Tugenden entgegengesetzten Laster schwinden erst, wenn durch die Vollendung des Logos die volle Einstimmigkeit des Lebens erreicht ist.

Da der Hauptgrund aller Unglückseligkeit und mangelnden Einstimmigkeit des menschlichen Lebens in den Affekten liegt, so muß ihre völlige Ausrottung (Apathie), nicht bloß ihre Mäßigung (Metriopathie), wie die Peripatetiker lehren, gefordert werden. Dies ist eine notwendige Konsequenz der Auffassung der Affekte als falscher Urteile und übermäßiger, dem Logos ungehorsamer Seelenregungen. Wenn die Stoiker von Affekten (Pathē) reden, so denken sie dabei stets an leidenschaftliche, maßlose Gefühle oder an solche, die auf irrigen Urteilen beruhen. Der Arzt darf nicht aus Mitleid mit dem Kranken eine schmerzhafte Operation unterlassen, die zu seiner Heilung nötig ist, der Richter nicht aus Mitleid dem Schuldigen die verdiente Strafe erlassen. Das Mitleid ist Trauer über fremde Übel; und Trauer findet unter keinen Umständen Eingang in die Seele des Weisen. Wohl aber entsprechen den drei übrigen Affekten „berechtigte Gefühle“, der Begierde der Wunsch, der Furcht die Vorsicht, der Lust die Freude. Die Freude tritt in der Seele des Weisen nicht ab und zu als plötzliche Gefühlsregung auf, sondern begleitet ihn, der ja immer Grund zur Freude hat, durchs ganze Leben.

Die Stoiker stellen das höchste sittliche Ideal abgesondert allen vorausliegenden Momenten der sittlichen Entwickelung gegenüber. Nur die vollWeise und Toren. kommene Weisheit und Tugend und was teil an ihr hat, besitzt einen absoluten Wert. Alles übrige ist, mit dem absoluten Maßstabe gemessen, wertlos. Ihr Ideal verkörpern sie in der Gestalt des Weisen, der glückselig, reich, schön und frei ist; und mit derselben Paradoxie malen sie das Bild des Toren aus, dem alle wahren Vorzüge fehlen.

Nach einer gewissen Seite hin kann das stoische Tugendideal als das der Apathie bezeichnet werden. Aber die Freiheit von Begierde und Furcht, die den Inhalt dieses Ideals ausmacht, führt zunächst nur zu zweien von den vier Kardinaltugenden, zur Mäßigkeit und zur Tapferkeit. Freilich sind diese Tugenden nur möglich durch die Wissenschaft von den Gütern, Übeln und indifferenten Dingen, die sich nach der praktischen Seite als Wissenschaft von dem, was man tun soll und nicht tun soll, als Einsicht (Phrónēsis) dokumentiert. Aber der Gesichtspunkt der Apathie reicht nicht aus, um die vierte Tugend verständlich zu machen, die soziale Tugend der Gerechtigkeit. Pfichten gegen Indem wir diese ins Auge fassen, tritt eine neue Seite der stoischen Ethik die übergeordin unsern Gesichtskreis und alles bisher Besprochene in eine neue Beleuchtung. Die Ableitung der ethischen Pflichten aus dem Selbsterhaltungstrieb und der Selbstliebe erweckt zunächst den Anschein, als ob es sich auch bei den Stoikern um eine egoistische Ethik handelte, als ob sie uns den Vernunft- 
egoismus an die Stelle des Lustegoismus gesetzt hätten. Dies ist aber durchaus nicht der Fall. Die früher geschilderte Entwickelung, durch die sich unser Selbsterhaltungstrieb von unserer animalischen Natur auf unsere geistig-vernünftige Natur überträgt, führt zugleich über den Egoismus hinaus zur altruistischen und sozialen Gesinnung. Der Logos, der sich in der Seele des Individuums aufbaut, ist seinem inneren Wesen nach nichts Individuelles, sondern etwas Allgemeingültiges. Er regiert im ganzen Kosmos als ein Imperativ, der vorschreibt, was geschehen soll, und verbietet, was nicht geschehen soll. Dieselbe imperative Gesetzeskraft bewährt der Logos in jeder Menschenseele, in der er sich verwirklicht. Er ist aber nicht nur ein abstrakter Imperativ, sondern ein lebendigwirkendes Wesen, das seinen Forderungen in der Wirklichkeit Geltung zu schaffen vermag: Dieses Gesetz bezieht sich nicht nur auf den einzelnen Menschen, dem es zum Bewußtsein gekommen ist, sondern auf die ganze Welt. Daher wird der Mensch, in dem dieses Gesetz als lebendige Kraft wirkt, nicht nur in seiner eigenen Person, sondern in dem ganzen Umkreis äußerer Betätigung, der ihm erschlossen ist, das wahrhaft Gute, das Vernünftige, das Gottgewollte zu verwirklichen suchen. Jeder Weise ist ein König und Richter, der in seinem Reich dem Gesetz Geltung verschafft. Dazu befähigt ihn die Tugend der Gerechtigkeit, die eine Wissenschaft und Kunst ist, jedem das seinem Wert Entsprechende zuzuteilen. So wird also durch die Entwickelung zum Logos der egoistische Standpunkt des animalischen Wesens überwunden. Vom Standpunkt der Tugend und Weisheit schwindet der Gegensatz des individuellen und des gemeinnützigen Interesses. Der Weise stellt das Wohl der übergeordneten Gemeinschaft über sein eigenes, ja er opfert ihm im Notfall sein Leben, aber gerade dadurch bleibt er sich und seiner Aufgabe treu und fördert sein wohlverstandenes eigenes Interesse, indem er seine höhere und eigentliche Natur vor Schädigung bewahrt.

Konzentrische l'fichtenkreise.

Schon der ursprüngliche Naturtrieb führt über den Egoismus hinaus. Er treibt uns, Kinder zu erzeugen und für ihre Erhaltung und für ihr Wohl wie für unser eigenes zu sorgen. Weiter erstreckt sich dann die natürliche Liebe und Fürsorge auf Eltern und Geschwister, auf Blutsverwandte und Geschlechtsgenossen. Immer weitere Kreise umfaßt in seiner natürlichen Entwickelung dieses uns eingeborene Gefühl derZusammengehörigkeitmitanderen Menschen. Wir fühlen instinktiv, daß wir zum Gemeinschaftsleben geboren sind und nur in ihm unsere Befriedigung finden können, daß wir nicht nur gegen uns selbst, sondern auch gegen andere Wesen Pflichten haben. Wir finden uns im Mittelpunkt zahlloser konzentrischer Kreise, von denen jeder engere uns auf einen nächstfolgenden weiteren hinweist, auf den sich unser Zugehörigkeitsgefühl und unsere Fürsorge erstrecken sollte. Man kann hier nirgends haltmachen, bis man bei dem weitesten Kreise angelangt ist, der das ganze Menschengeschlecht umspannt. Was uns so durch den dunkeln Naturtrieb und seine Entwickelung nahe gelegt wird, das bestätigt schließlich der Logos und bringt es zu voller wissenschaftlicher Klarheit. Er lehrt 
uns, daß alle Menschen Brüder, alle Kinder desselben himmlischen Vaters sind; er kann dies lehren, weil er selbst das Kennzeichen der Kindschaft ist, das der Vater auf alle seine Kinder vererbt hat. Soweit der Logos reicht, so weit reicht auch die Gemeinschaft, in die wir durch unsere Geburt hineingestellt und in der wir zu wirken berufen sind. Weil auch die Götter zu dieser Gemeinschaft gehören, haben wir Pflichten gegen sie, die Pflichten der Frömmigkeit; die vernunftlosen Tiere hingegen stehen außerhalb der Gemeinschaft des Logos; daher haben wir gegen sie keine Pflichten. Man kann diese den ganzen Kosmos umfassende Gemeinschaft der vernünftigen Wesen als einen Staat auffassen, in dem das natürliche, auf der allgemeingültigen Vernunft beruhende Recht Gesetzeskraft hat. Dieses natürliche Recht ist Vorbild und Quelle für das positive Recht der einzelnen Staaten. Das positive Recht ist nur insoweit Recht, als es mit dem natürlichen Recht übereinstimmt. Die mannigfaltige Verschiedenheit der Rechtssätze über dieselbe Materie bei verschiedenen Völkem und in verschiedenen Staaten beruht auf Abweichungen von dem natürlichen Recht. In dem Menschheitsstaat und nach dem natürlichen Recht gibt es keine Unterschiede der politischen und sozialen Berechtigung mit Ausnahme der moralischen. Die Götter und die Weisen sind in diesem Staate die Adligen und die Vollbürger; die übrigen Menschen nehmen als Minderberechtigte an ihm teil. Doch ist es jedem freigestellt, sich durch eigene Kraft zur höchsten Rechtsstellung emporzuschwingen.

Indem die stoische Philosophie ihre Jünger zu energischer Mitarbeit an Verhältnis des dem staatlichen und gesellschaftlichen Leben auffordert, tritt sie als männEinzelnen zum Staat. lichere Lehre in scharfen Gegensatz zu der Lehre Epikurs, der das „Glück im Winkel" preist. Diese Seite des Stoizismus ist es gewesen, die ihm vor allem in der römischen Welt Eingang verschafft hat. Der stoische Kosmopolitismus, den wir geschildert haben, ist der Arbeit für das eigene Volk und für den eigenen Staat nicht hinderlich. Es wurde stets von der Schule anerkannt, daß die Pflichten gegen das engere Vaterland näherliegende Pflichten sind, wie in jenem Bild von den konzentrischen Kreisen zum Ausdruck kommt. Ein großes Verdienst der Stoa war es, den Menschheitsgedanken in die bis dahin vom nationalen und lokalen Patriotismus zerklüftete antike Welt hineinzutragen. Dem Stifter der Schule hat gewiß bei dieser Lehre das Weltreich Alexanders vorgeschwebt, dessen Gründung er selbst erlebt hat. Aber auch das römische Weltreich fand in diesen weitverbreiteten Ideen eine Stütze, und die christliche Idee des Gottesreiches, einer christlichen Menschheit, kann ihre Abkunft von dem stoischen Kosmopolitismus nicht verleugnen.

Das stoische System ist die letzte große selbständige Systembildung der antiken Philosophie; es kommt an historischer Bedeutung für die antike Kultur der platonischen und aristotelischen Lehre noch gleich und steht den Vorgängern um kein Haar unselbständiger gegenüber als A ristoteles dem Platon. Weiterhin treten dann neue wissenschaftliche Gedanken kaum noch in der antiken Philosophie auf. Die vorhandenen dogmatischen Systeme werden, bekämpft vom Skeptizismus und sich untereinander bekämpfend, von Gene. 
ration zu Generation fortgepflanzt. Neben der gelehrten Schultradition, die namentlich bei der peripatetischen Lehre seit Andronikus und bei der stoischen vorhanden ist, gehen Versuche einher, die Philosophie dem weiten Kreise der Gebildeten und selbst den weitesten Kreisen des niederen Volkes durch Popularisierung zugänglich zu machen. Namentlich tritt dies Bestreben hervor, seit im 2. Jahrhundert v. Chr. die Griechen Lehrmeister der Römer werden. Es galt zunächst, die gebildete römische Welt für die griechische Philosophie zu gewinnen. Das war nur durch Nachlassen der wissenschaftlichen Strenge möglich. Im Zusammenhang mit diesem Streben stehen die wiederholten Versuche, das Wertvolle aus den hauptsächlichsten Systemen $z u$ verbinden und die Schulgegensätze auszugleichen: der Eklektizismus. In anderer Weise äußert sich das Erlahmen des wissenschaftlichen Geistes in dem Aufkommen mystischer Richtungen. Der Pythagoreismus, der im r. Jahrhundert v. Chr. als Neupythagoreismus plötzlich wieder auftaucht, und der Platonismus, der im 3. Jahrhundert n. Chr. in den Neuplatonismus übergeht, zeigten sich besonders aufnahmefähig für mystische Elemente und geneigt, die Grenzen zwischen Philosophie und Religion zu verwischen. Wir können daher diese ganze philosophisch unproduktive, aber von philosophischer Bildung durchtränkte Zeit als die Nachgeschichte der griechischen Philosophie bezeichnen.

IV. Die mittlere Akademie. Den Übergang zur römischen Epoche bildet die mittlere und neuere Akađemie, die unter Arkesilaos (Schulhaupt 270-24r) und Karneades (160-I 29) durch ihre gegen den stoischen und epikureischen Dogmatismus gerichtete Skepsis im höchsten Grade anregend und befruchtend wirkte, schließlich aber in ihren letzten Vertretern, den Lehrern Ciceros, Philo und Antiochos, in den Eklektizismus einlenkte. Arke-

Arkesilaos (270-24Iv.Chr.) silaos, wie Zenon ein Schüler des Polemon, war der erste Scholarch der Akademie, der die an Platons Greisenalter anknüpfende "altakademische" Gedankenrichtung aufgab und durch Zurückgreifen auf Sokrates und auf den jungen Platon der Schule neue Lebenskraft einhauchte und sie zu ungeahnten Erfolgen führte. Die stoische und epikureische Weisheit erschien ihm als eine anspruchsvolle Scheinweisheit, ihre Bekämpfung mit den Waffen der Dialektik als die für den Fortschritt der Wissenschaft dringendste Aufgabe. Auch Sokrates hatte sich ja die Bekämpfung der Sophisten als Hauptaufgabe gestellt und hatte seine Überlegenheit über sie dem Bekenntnis des Nichtwissens verdankt. Auch Platon erschien in seinen meist ohne positives Ergebnis verlaufenden Jugenddialogen als ein Fortsetzer dieser Richtung. So konnte sich Arkesilaos sagen, daß der Verzicht auf die Begründung eines positiven Lehrsystems und die Beschränkung auf die Kritik fremder Lehren mit der Stellung eines akademischen Schulhauptes wohl vereinbar sei. Auch dürfen wir nicht vergessen, daß jener Typus formeller Geistesbildung, der in der Fähigkeit, das Für und Wider jeder Kontroverse zu erörtern, sein Ziel findet, den Griechen seit der Sophistenzeit vertraut war und stets als praktisch wertvoll ge- 
golten hatte. Arkesilaos übte seine Schüler nach Sophistenart in der Kunst, jede These sowohl zu beweisen als zu widerlegen. Auch in der peripatetischen Schule waren ähnliche dialektische Übungen schon von Aristoteles selbst eingeführt worden. Arkesilaos widmete seine ganze Kraft der mündlichen Lehrtätigkeit und hinterließ keine Schriften. Sein Ideal der Weisheit war die Freiheit von Irrtum. Dieses Ideal, meinte er, könne man nur crreichen durch die Zurückhaltung des Urteils (Epochē), durch den Verzicht auf jede bestimmte Behauptung über das wahre Wesen der Dinge. Durch Epikur und Zenon war die Frage nach dem Kriterion der Erkenntnis, wie wir gesehen haben, in den Mittelpunkt der erkenntnistheoretischen Erörterungen g: ilickt worden. Epikur hatte jede Wahrnehmung ohne Ausnahme, Zenon die katan leptische Vorstellung für das untrügliche Kriterion der Wahrheit erkiärt. Arkesilaos bemühte sich, dieses Fundament des Dogmatismus zu erschütern, indem er zeigte, daß diese Kriterien unzureichend seien. Im besonderen wandte er gegen die stoische Erkenntnislehre ein, dab sie mit Unrecht die Katalepsis als ein Mittleres zwischen dem Wissen und der trüglichen Meinung einschiebe, das dem Weisen und Nichtweisen gemeinsam sei. Die Katalepsis, die als Zustimmung zu einer kataleptischen Vorstellung definiert werde, müsse entweder eine fes.e und unumstößliche oder eine schwache und trügerische Zustimmung sein; ein drittes gebe es nicht. Im ersten Falle sei sie Wisser, im zweiten trügliche Meinung. Ferner machte er geltend, daß die Katalepsis als Zustimmung zu einer kataleptischen Vorstellung undenkbar sei, da man nur einem Urteil, nicht einer Vorstellung beistimmen könne. Ein Urteil aber sei bereits ein Logos, d. h. ein mit Begriffen operierender Gedanke. Drittens führte er aus, daß es keine wahre Vorstellung gebe, der sich nicht eine von ihr ununterscheidbare falsche zur Seite stellen ließe. Dieser Einwand richtete sich gegen den Kernpunkt der stoischen Erkenntnislehre, gegen die Annahme, $\mathrm{daB}$ gewisse Wahrnehmungsvorstellungen durch ihre eigene Beschaffenheit kundgeben, daß sie ein Wirkliches, so wie es ist, getreu abbilden. Gibt es aber keine kataleptische Vorstellung, so gibt es auch keine Zustimmung zu ihr, keine Katalepsis, und alle Dinge sind unerkennbar. Den Einwand der Stoiker, daß durch diese Ansicht die Möglichkeit vernünftigen Handelns und der Erreichung der Glückseligkeit aufgehoben werde, die ohne Kriterion unmöglich sei, bekämpfte Arkesilaos von stoischen Voraussetzungen aus. Die Glückseligkeit sei nach stoischer Ansicht eine Folge der Einsicht (Phrónēsis), die Einsicht aber betätige sich in tugendhaften Handlungen; diese seien die vollkommen angemessenen Handlungen; angemessen aber seien die Handlungen, für die sich ein vernünftiger Grund anführen ließe. Es genüge also, den „vernünftigen Grund“(das Eülogon) zur Richtschnur zu nehmen, um tugendhaft $z u$ handeln und dadurch glückselig zu sein. Es ist klar, daß in dieser Beweisführung nicht, wie man fälschlich geglaubt hat, eine ernstgemeinte Theorie des Arkesilaos zu erkennen ist, sondern nur eine Widerlegung des stoischen Einwandes von stoischen Voraussetzungen aus. Das Eulogon in der stoischen Definition der angemessenen Handlung entspricht genau der Kata-

Dib Kultur der Gegrnivart. I. 5. 2. Auf. 
lepsis. Es bezeichnet eine Vorstufe des Wissens, die auch den Unweisen zugänglich ist. Wie wäre es denkbar, daß Arkesilaos, der die Katalepsis verwarf, ihr Gegenstück, das Eulogon, gläubig akzeptiert hätte. - Arkesilaos beschränkte sich nicht darauf, das erkenntnistheoretische Fundament des stoischen Dogmatismus zu erschüttern. Er folgte auch den Stoikern in alle Einzelheiten und wies die ungelösten Schwierigkeiten und Widersprüche in ihrer an Paradoxien reichen Lehre nach. Zenons Nachfolger Kleanthes geriet durch diese Polemik in starke Bedrängnis, und da gleichzeitig auch Ariston von Chios die stoische Orthodoxie bekämpfte, so würde sich diese schwerlich als grundlegender Faktor der antiken Kultur behauptet haben, wenn ihr nicht in Chrysippos ein Vorkämpfer erstanden wäre. Dieser hat sich besonders bemüht, wie den Indifferentismus des Ariston so auch den akademischen Skeptizismus aus dem Felde zu schlagen. Es kam ihm dabei zustatten, daß nach dem Tode des Arkesilaos Philosophen von geringerer geistiger Bedeutung, Lakydes und Euandros, an der Spitze der akademischen Schule standen. Erst als im zweiten Drittel des 2. Jahrhunderts wieder ein bedeutendes Talent, Karneades, der Sohn des Philokōmus, die Akademie leitete, gewann diese wieder Ansehen, und Chrysipps Nachfolger, Diogenes von Babylon und Antipatros von Tarsos, hatten Mühe, sich gegen Karneades zu behaupten. Mit der Darstellung der karneadeischen Lehre gehen wir zu der römischen Epoche über.

\section{Die Philosophie der römischen Epoche.}

I. Karneades. Karneades hat den Chrysippos in derselben Weise, wie Arkesilaos den Zenon, bekämpft. Auch er hinterlieb keine Schriften, sondern beschränkte sich auf mündliche Lehrtätigkeit. Doch haben seine Schüler, vor allem Kleitomachos, seine scharfsinnigen, auch der Form nach glänzenden Vorträge aus Nachschriften publiziert. Karneades erneuerte die schon von Arkesilaos geführte Polemik gegen alle dogmatische Erkenntnistheorie. Auch für ihn war die Frage nach der Existenz eines Kriterion die erkenntnistheoretische Grundfrage. Er bewies zunächst, daß weder Sinneswahrnehmung noch Vorstellung noch begriffliches Denken schlechthin und ohne weiteres als Kriterion angenommen werden können, da keine dieser Erkenntnisfunktionen untrüglich sei. Er verwarf also von vornherein die epikureische Lehre von der Untrüglichkeit der sinnlichen Wahrnehmung. Wenn es überhaupt ein Kriterion gebe, so müsse es mit den Stoikern in einer besonders qualifizierten Wahrnehmungsvorstellung gesucht werden. Das begriffliche Denken (hierin ist er mit seinen Gegnern einverstanden) schöpft seinen Stoff aus der sinnlichen Wahrnehmung. Es kann also nicht selbst Kriterion sein. Was das Lebewesen vom seelenlosen unterscheidet, ist das Wahrnehmungsvermögen, durch das es seiner selbst und äußerer Gegenstände inne wird. Wir würden überhaupt nichts erkennen, wenn wir nicht durch äußere Gegenstände affiziert würden. Affiziert wird zunächst das Sinnesorgan, in dem durch das äußere Objekt eine Veränderung bewirkt wird. Aber zum 
Bewußtsein kommt uns diese Veränderung in Form einer Vorstellung, als Affektion der Seele. Hier ist also, wenn irgendwo, das Kriterion zu suchen. Karneades akzeptiert vollkommen die stoische Auffassung, dab nur die zutreffende Wahrnehmungsvorstellung als eine Veränderung in der Seele, die uns gleichzeitig sich selbst und das sie verursachende Objekt so, wie es ist, zum Bewußtsein bringt, Kriterion sein kann. Nun erhebt sich aber die Frage, ob wir in der Lage sind, zu unterscheiden, ob die Vorstellung von einem wirklichen Objekt herrührt oder nicht, und ob sie es so wiedergibt, wie es wirklich ist, oder nicht. Die Stoiker hatten sich dabei beruhigt, daß sich die kataleptische Vorstellung von der akataleptischen durch einen ihr eigentümlichen Charakter der Evidenz unterscheide und unsere Zustimmung erzwinge. Karneades bestreitet dies, indem er die Behauptung des Arkesilaos wiederholt, daß sich jeder wahr scheinenden Vorstellung eine ihr ununterscheidbar gleiche falsche zur Seite stellen lasse. Es gibt also kein Unterscheidungsmerkmal, an dem wir die kataleptische Vorstellung als solche erkennen können. Die Vorstellung hat eine doppelte Beziehung, eine zu dem vorgestellten Objekt, eine zu dem vorstellenden Subjekt. Auf dem Verhältnis zu dem vorgestellten Objekt beruht die Wahrheit der Vorstellung, wenn sie mit ihm übereinstimmt, oder ihre Falschheit, wenn sie nicht mit ihm übereinstimmt. Diese Beziehung fällt außerhalb unseres Bewußtseins; wir sind uns nur der anderen Beziehung bewußt, der Beziehung der Vorstellung $z u$ uns selbst als dem vorstellenden Subjekt. In dieser Beziehung kann eine Vorstellung sich als überzeugend oder als nicht überzeugend darstellen. Der Fehler der Stoiker besteht nach Karneades darin, daß sie das Wahrnehmen der Vorstellung (ihre Beziehung zum Subjekt) mit ihrem Wahrsein (ihrer Beziehung zum Objekt) verwechseln. Die Vorstellungen sind untereinander abgestuft hinsichtlich der Überzeugungskraft, die sie für uns haben. Aber selbst die mit dem größten Schein der Wahrheit ausgestattete, wie die Stoiker ihre kataleptische Vorstellung schildern, bietet keine absolute Gewähr der Wahrheit. Karneades meint daher, $\mathrm{da} ß$ uns für die Erkenntnis des wirklichen Wesens der Dinge überhaupt kein Kriterion zur Verfügung stehe, doch genüge als Kriterion unseres praktischen Verhaltens die hinlänglich überzeugende Vorstellung. Welches Maß von Überzeugungskraft hinlänglich sei, hänge im einzelnen Falle von der Wichtigkeit der Sache ab. Karneades unterschied drei Stufen der Probabilität: I. die probable Vorstellung, 2. die probable und unwidersprochene, 3. die probable unwidersprochene und allseitig geprüfte. Bei der ersten Stufe, der einfachen Probabilität, denkt Karneades an die der Vorstellung selbst innewohnende Deutlichkeit und Stärke, die durch die Normalität der Sinnesorgane sowie durch die Entfernung und Lage des Objekts bedingt ist. Die Vorstellung wird hier, mag sie auch noch so komplex sein, als Einheit aufgefaßt und zugleich aus der Gruppe der sie begleitenden Vorstellungen herausgehoben und für sich als einzelne Vorstellung betrachtet. Die zweite Stufe der Probabilität, die probable und unwidersprochene Vorstellung, wird nach Karneades durch eine doppelte Prüfung erreicht. Erstens besteht ja die kom- 
plexe Vorstellung aus mehreren Elementen. Wenn keines dieser Elemente, z. B. Farbe, Größe, Gestalt, Bewegung, Lage, bei gesonderter Apperzeption der Überzeugungskraft entbehrt oder der Gesamtvorstellung widerspricht, so ist in diesem analytischen Sinne die Vorstellung unwidersprochen. Es ist aber nicht allein jede Dingvorstellung ein Komplex von Merkmalen, die wie die Glieder einer Kette ineinandergefügt sind, es tritt auch jede Dingvorstellung in der Wahrnehmung als Glied einer Gruppe von Dingvorstellungen auf. Es gehört daher $z$ weitens zu den Erfordernissen der unwidersprochenen Vorstellung, daß auch die übrigen zu der Gruppe gehörigen Dingvorstellungen weder selbst der Deutlichkeit und einfachen Probabilität entbehren, noch auch sonst gegen die Wahrheit der fraglichen Vorstellung Bedenken wecken. Die dritte Stufe der Probabilität wird nach Karneades dadurch erreicht, daß alle Elemente der Vorstellung selbst und der Gruppe data opera auf ihre Probabilität geprüft werden. Für die zweite Stufe genügt es schon, daß keines der Gruppenelemente Bedenken weckte, für die dritte Stufe muß ich mich überzeugt haben, daß kein Element bei der Prüfung übersehen wurde, daß ich die Prüfung wirklich zu Ende geführt habe. Es ist klar, daß diese drei Stufen Zwischenstufen zulassen. Der Kern dieser Lehre ist also nicht die Dreizah1 der Próbabilitätsstufen, sondern der Gedanke, daß die Probabilität einer Ab. stufung fähig ist und selbst die höchste uns erreichbare Probabilitätsstufe die Wahrheit nicht verbürgt. Sie empfiehlt sich nur in Vergleich mit geringeren Graden der Probabilität, ist relativ, nicht absolut glaubwürdig. - Mit der Probabilitätslehre hängt nun eine sehr wichtige Abweichung des Karneades von Arkesilaos zusammen. Arkesilaos hatte jedes Wähnen, d. h. jede Zustimmung zu einer nicht kataleptischen Vorstellung als der Weisheit widersprechend verpönt. Karneades lehrt, daß der Weise der nach Maßgabe des Gegenstandes probabeln Vorstellung zustimmen wird. Er wird sich nur immer bewußt sein, daß er ihr als einer probabeln, nicht als einer wahren und das Wesen des Gegenstandes ergreifenden zustimmt. Die Unterscheidung des Probabeln vom Nichtprobabeln und der verschiedenen Stufen der Probabilität ist ein ausreichendes Fundament für die Beurteilung unseres Strebens und Meidens und unserer Handlungen. Diese Auffassung führt zu einer Philosophie des gesunden Menschenverstandes, die sich den Bedürfnissen des praktischen Lebens anschmiegt und die krassen Paradoxien, zu denen der Dogmatismus neigt, zu vermeiden sucht. Auch in theoretischen Fragen brauchte Karneades nicht bei dem Nachweis ihrer wissenschaftlichen Unentscheidbarkeit stehen zu bleiben; er konnte auch bei ihnen eine mehr oder weniger probable Entscheidung anstreben. Hierdurch wurde ihm eine Kritik der dogmatischen Systeme auch hinsichtlich ihres positiven Lehrgehaltes ermöglicht. Wenn er einen einzelnen stoischen Lehrsatz in der Weise behandelte, daß er für ihn und gegen ihn gleich starke Gründe beibrachte, so wurde durch eine derartige zweiseitige Erörterung nur sein formaler Skeptizismus, die These von der wissenschaftlichen Unerkennbarkeit der Dinge, gestützt. In vielen Fä1len aber begnügte er sich damit nicht, sondern zeigte, daß der stoische 
Lehrsatz gegen die Wahrscheinlichkeit und den gesunden Menschenverstand streite. So konnte er zu materiellen positiven Ergebnissen gelangen, die aber als bloß probabel keine systematische Zusammenfassung ertrugen. Die Vorträge über die Gerechtigkeit, die Karneades im Jahre 156 in Rom hielt, in denen er die Gerechtigkeit am ersten Tage als in der Natur begründet und um ihrer selbst willen erstrebenswert, am zweiten Tage als bloß konventionelle Satzungen zugunsten der Schwachen und für die Starken unverbindlich darstellte, scheinen ohne Ergebnis abgeschlossen zu haben. Denn es ist nicht glaublich, daß Karneades die praktische Forderung der Gerechtigkeit aufheben wollte. Dagegen ist es unverkennbar, daß er die stoischen Lehren vom Gesamtgott und den Einzelgöttern, von Fatum und Vorsehung, von der Mantik und nicht minder die stoische Güterlehre auf das heftigste angriff, d. h. als nicht probabel zu erweisen suchte. Wir können hier natürlich auf diese Polemik nicht eingehen, so reich sie an zutreffenden Einwürfen ist.

II. Philo von Larisa und Antiochos von Askalon. Die unmittelbaren Schüler des Karneades, unter denen sein Nachfolger Kleitomachos der bedeutendste war, blieben dem Standpunkte ihrers Lehrers treu. Dagegen zeigt sich bei dem Nachfolger des Kleitomachos, Philo von Larisa, der im Philo von Larise Jahre 88 durch den mithridatischen Krieg aus Athen vertrieben nach Rom (sullanischeZeit) flüchtete und hier der Lehrer des Cicero wurde, ein merkwürdiges Schwanken. Anf änglich war auch bei ihm keine Lehrabweichung von der Karneadeischen Schule bemerkbar, mit der Zeit aber zeigte sich, daß er mehr als Karneades auf ein positives Lehrsystem, namentlich der Ethik, hinarbeitete. Zwar hielt auch er an den von der Akademie seit Arkesilaos verteidigten Sätzen fest, $\mathrm{daB}$ es keine kataleptische Vorstellung im Sinne der Stoiker gebe, daß sich jeder wahr scheinenden Vorstellung eine ununterscheidbar gleiche falsche zur Seite stellen lasse, und daß das wahre Wesen der Dinge unerkennbar sei. Aber diese Sätze nahmen bei ihm einen ganz anderen Sinn an. Er behauptete nämlich, daß sie die Erkennbarkeit der Dinge nicht überhaupt, sondern nur in dem von den Stoikern angenommenen Sinne ausschlössen. Es sei ein Mißverständnis, sagte er, wenn man die neuakademische Lehre von der altakademischen unterscheide, als ob sie mit ihr unvereinbar wäre. Es gebe nur eine einzige echt akademische Lehre. Arkesilaos und Karneades hätten nur, um den echten Platonismus gegen die Stoa zu verteidigen, die stoische Lehre vom Kriterion widerlegt, nicht um die Erkennbarkeit der Dinge überhaupt zu leugnen. Es ist durch den Widerspruch der Zeitgenossen, namentlich des Antiochos, sicher, daß Philo in diesem Punkte irrte, doch können wir nicht nachweisen, wie er zu seinem Irrtume kam; auch ist nicht klar, welches Kriterion er an die Stelle des stoischen setzte. Er sprach von evidenten Wahrheiten (perspicua), die dem denkenden Geiste eingeprägt seien, ohne doch in der von den Stoikern geschilderten Weise ergriffen zu werden. Man sieht wohl, daß hier auf die natürlichen Begriffe Gewicht gelegt wird, und kann vermuten, daß er diese überhaupt nicht oder doch anders als die Stoiker aus 
Antiochos von Askalon (t 68 v. $\mathrm{Cbr}$.).

der sinnlichen Wahrnehmung entstehen ließ. Wie er sich zu dieser und zu der Probabilitätslehre des Karneades stellte, können wir nicht erraten.

Philos Schüler und Nachfolger, Antiochos von Askalon ( +68$)$, den Cicero im Jahre 70 in Athen hörte, wandte sich mit noch größerer Entschiedenheit als Philo vom Skeptizismus ab. Er bestritt die Ansicht Philos, daß es nur Eine echt-akademische Ansicht gebe. Seit Arkesilaos, meinte er, habe die Akademie den Irrweg des Skeptizismus eingeschlagen und sei dadurch unfähig geworden, die als Grundlage des praktischen Lebens unentbehrlichen Überzeugungen zu begründen. Man müsse daher zu der Lehre der alten Akademie zurückkehren. Außerdem behauptete er, daß zwischen der altakademischen und peripatetischen Lehre kein wesentlicher Unterschied bestehe. Ja selbst die stoische Lehre weiche nur in wenigen Punkten wirklich von der akademisch-peripatetischen ab; im übrigen bestehe mehr eine Wortals eine Meinungsdifferenz. In der Trennung und dem Streit dieser drei aus sokratischer Wurzel entsprossenen Schulen erblickte Antiochos eine unnötige Zersplitterung des wissenschaftlichen Lebens, die er durch Betonung der allen gemeinsamen Überzeugungen zu überwinden hoffte. In der scharfen Unterscheidung der neuakademischen Skepsis von dem altakademischen Dogmatismus hatte Antiochos ohne $Z$ weifel recht gegen Philo. Das Bedürfnis nach einer systematisch durchgebildeten Welt- und Lebensanschauung, das er einer mächtigen Zeitströmung folgend mit Philo teilte, ließ sich wirklich nicht befriedigen, wenn man an der Akatalepsie des Arkesilaos und Karneades festhielt. Dagegen macht die Ansicht, daß die akademische, peripatetische und stoische Lehre in der Hauptsache übereinstimme, dem wissenschaftlichen Sinne des Antiochos wenig Ehre. Sie erklärt sich aus dem Streben, den Gebildeten der griechischen und noch mehr der römischen Gesellschaft, die des endlosen Schulgezänkes müde vor allem die Begründung einer praktischen Lebensanschauung von den Philosophen erwarteten, den Reingewinn der gesamten philosophischen Entwickelung in dogmatischer Form darzubieten. Es ist wohl begreiflich, daß einmal die Frage aufgeworfen wurde, ob denn ein solcher Reingewinn, eine Summe allen großen Schulen gemeinsamer Überzeugungen vorhanden sei. Die Verneinung dieser Frage, welche die Skeptiker aussprachen, war geeignet, in der gebildeten Welt das Ansehen der Philosophie zu untergraben. Antiochos bejahte diese Frage für die drei Schulen, in denen das sokratische Erbe nach seiner Auffassung treu gewahrt wurde, die stoische, die peripatetische und die akademische in ihrer alten unverfälschten Gestalt. Die Spitze seines Unternehmens richtete sich gegen den Skeptizismus und gegen den Epikureismus. So war denn Antiochos bemüht, den gemeinsamen geistigen Besitz der drei genannten Schulen herauszuarbeiten. Wenn irgend möglich suchte er die Unterscheiđungslehren auf bloße Verschiedenheit der Formulierung eines gemeinsamen Gedankenbesitzes zurückzuführen. Wo dies durchaus nicht anging, konnte er die Streitfrage‡ı entweder als unlösbar beiseite schieben oder selbst eine Entscheidung treffen. Ersteres tat er bei Fragen, die ihm für die praktische Lebensanschauung irrelevant schienen. Im 
anderen Falle schloß er sich bald an diese, bald an jene Schule enger an, wodurch sein System den Charakter des Eklektizismus erhielt. Es läßt sich nicht bestreiten, daß schon die Denkweise des Karneades dem Eklektizismus vorgearbeitet hatte. Denn wer ohne einen durchgreifenden systematischen Zusammenhang anzustreben philosophische Einzelfragen nach dem Wahrscheinlichkeitsprinzip behandelt, verfährt auch eklektisch. Der große Unterschied zwischen dem Eklektizismus des Karneades und dem des Antiochos liegt darin, daß jener skeptisch, dieser dogmatisch und systematisch ist. Auch in der stoischen Schule selbst finden wir bei Panaitios und Poseidonios das Bestreben, zwischen der platonisch-aristotelischen und der stoischen Philosophie zu vermitteln. Wir ersehen daraus, wie sehr der Geist der Zeit zum Eklektizismus neigte. Auch die peripatetische Schule blieb von ihm nicht unberührt. In Antiochos erreichte diese Bewegung ihren Höhepunkt. Seinem Einflusse ist es zuzuschreiben, wenn in augusteischer Zeit der Stoiker Arius Didymus und der Akademiker Eudorus eklektisch philosophieren und der Alexandriner Potamon gar ausdrücklich seine Schule als die eklektische bezeichnet und den Eklektizismus zum Prinzip erhebt.

In der Erkenntnistheorie schloß sich Antiochos eng an Chrysippos an. Er lehrte, daß alle Erkenntnis von der sinnlichen Wahmehmung ausgehe, aber erst im begrifflichen Denken sich vollende. Die kataleptische Vorstellung verteidigte er gegen die Angriffe des Arkesilaos und Karneades. $\mathrm{Zu}$ beweisen, daß durch sie wirklich die Gegenstände, wie sie sind, ergriffen werden, und daB sie von der akataleptischen unterscheidbar sei, war sein Hauptbestreben. Was die Verstandesbegriffe angeht, ging er nicht auf die platonische Ideenlehre zurück. Wie für Aristoteles und die Stoiker ist für ihn nur die Einzelexistenz ein Seiendes. Doch gibt er den Stoikern nicht zu, daß nur die Körper etwas Seiendes sind. Es"gibt von Anfang an zwei Naturen, die wirkende und die leidende, Kraft und Stoff, die aber voneinander untrennbar sind. Was aus beiden zusammengesetzt ist, heißt ein Körper. Die wirkende Natur ist in jedem einzelnen Körper als Form, Kraft oder Seele gegenwärtig. Sie gibt dem Körper sein Wesen, seine bestimmte Beschaffenheit. Diese wird im Begriff aufgefaßt. Aber trotz ihrer Verteilung auf viele Einzelwesen bleibt die wirkende Natur ein einheitliches Wesen, das als Gottheit, Vorsehung, Vernunft, Notwendigkeit bezeichnet werden kann. Durch die Anerkennung der Realität und Wirksamkeit eines nichtkörperlichen Faktors wurde die Pneuma. lehre der Stoa mit allen ihren paradoxen Folgesätzen (z. B. der Körperlichkeit der Qualitäten) eliminiert. - Auch in der Ethik schlägt Antiochos einen Mittelweg $z$ wischen der peripatetisch-akademischen und der stoischen Lehre ein. Den höchsten Lebenszweck setzt auch er in das naturgemäße Leben und versteht darunter das der allseitig vollendeten Menschennatur entsprechende Leben. $\mathrm{Zu}$ dieser gehört nicht nur die Vernunft und die Seele, sondern auch der Leib. Daher sind auch die leiblichen Güter ein Bestandteil des höchsten Gutes und um ihrer selbst willen begehrenswert (z. B. Schönheit, Gesundheit, körperliche Kraft). Endlich gibt es auch noch äußere Güter, die zwar nicht, 
wie die seelischen und leiblichen, einen Bestandteil des höchsten Lebens$z$ weckes bilden, aber doch um ihrer selbst willen begehrt werden (z. B. Eltern, Kinder, Freunde, Vaterland). Antiochos hält es für eine eigensinnige Silbenstecherei, daß die Stoiker nur die Tugend und was an ihr. Anteil hat als ein Gut anerkennen, alle übrigen Dinge aber, die für den Menschen von Wert sind, nicht Güter, sondern Proēgména nennen. Allerdings haben ja die seelischen Güter einen viel höheren Wert als die leiblichen und die äußeren; und unter den seelischen sind wieder die auf der Willensfreiheit beruhenden sittlichen Güter von so überragendem Wert, daß man wohl sagen darf, die Tugend genüge allein zu einem glücklichen Leben. Da man aber nicht leugnen kann, daß durch den Hinzutritt der leiblichen und äußeren Güter der Wert eines solchen Lebens noch erhöht wird, kommt erst durch sie das allerglückseligste Leben zustande. Man begreift hiernach, dab Antiochos den paradoxen Satz von der Gleichheit aller Fehltritte verwarf. Denn wer eine Wertabstufung unter den Gütern anerkennt, muß sie auch unter den Übeln anerkennen; und wer sie bei den Gegenständen des Handelns findet, muß sie auch bei den Handlungen selbst finden. Dagegen überrascht es, Antiochos als Vertreter der Apathie zu finden, obgleich dieses Ideal aus der einseitig rationalistischen Auffassung der Menschennatur entspringt, die er so entschieden bekämpft; und noch mehr, ihn die stoischen Paradoxa wiederholen $z u$ hören, daß allein der Weise reich, frei und schön sei, alle Unweisen Sklaven und Verrückte.

Anesidem (ciceroniscbe Zeit).
III. Anesidem. Die durch Philo und Antiochos vollzogene Abwendung der Akademie vom Skeptizismus veranlaßte noch in der Zeit Ciceros eine Erneuerung der pyrrhonischen Skepsis, die seit Timons Tode als philosophische Sekte verschollen war, wenn sie auch unter den empirischen Arzten stets Anhänger zählen mochte. Änesidem von Knossos war es, der die von Pyrrhon begründete Lehre nicht nur wiederaufnahm und verteidigte, sondern auch durch Benutzung des in der neueren Akademie ausgebildeten Beweismaterials bereicherte und durch eigenen Scharfsinn feiner ausbildete. Mit ihm beginnt eine ununterbrochene Tradition des Pyrrhonismus bis zu Sextus Empiricus, der gegen Ende des 2. Jahrhunderts n. Chr. die uns erhaltene vortreffliche Darstellung der neupyrrhonischen Lehre verfaßte. Änesidem hat zum erstenmal die skeptischen Gründe für die wissenschaftliche Unerkennbarkeit der Dinge in zehn sogenannte Tropen zusammengefaßt, die schon dem wenig jüngeren Philo Judaeus bekannt sind. Die Formulierung und Zahl dieser Tropen hat bei den Nachfolgern Änesidems mancherlei Abwandlungen erfahren. Änesidem vertritt die reine und absolute Skepsis, die jede Überzeugung und Behauptung, die über das Konstatieren subjektiver Phänomene hinausgeht, verwerfen zu müssen glaubt. Er verwirft also auch die karneadeische Probabilitätslehre und meint, daß als Grundlage der praktischen Lebensführung die Phänomene als solche genügen. Wie die Neuakademiker begnügt sich Änesidem nicht, die formale Möglichkeit des Wissens zu bestreiten, sondern 
widerlegt auch materiell die einzelnen Lehrsätze der Dogmatiker. Man sieht noch deutlich bei Sextus, daß die pyrrhonische Schule die neuakademische Tradition fortsetzt und aus diesem Grunde die Stoiker mehr als alle anderen Dogmatiker verfolgt. Interessant ist es, daß sich Änesidem für seine Lehre auch auf Herakleitos berief und diese als den Schlüssel zur heraklitischen Philosophie bezeichnete.

IV. Neupythagoreismus und pythagoreisierender Platonismus. Als besondere Arten des Eklektizismus sind auch der Neupythagoreismus und die jüdische Religionsphilosophie des Philon von Alexandreia aufzufassen. Nur erwecken sie größeres historisches Interesse als die übrigen eklektischen Systeme, weil in ihnen zuerst als Mischungsbestandteil ein neues Element, die religiöse Mystik auftritt, welche in der Folge großen Einfluß auf die philosophische Entwickelung gewann und durch ihr Überwuchern den Verfall der griechischen Philosophie beschleunigte.

Der Pythagoreismus war als philosophische Schule schon im 4. Jahrhundert erloschen. Seine lebensfähigsten Elemente hatte Platon, namentlich in seinem höheren Alter, in seine Lehre aufgenommen. Die Lehren, welche ursprünglich aus der pythagoreischen Wissenschaft oder Mystik stammten, also einerseits die Lehre von den Schicksalen der unsterblichen Seele, andererseits die Auffassung der Zahlen und der übrigen mathematischen Größen als wesenhafter Elemente der Wirklichkeit, waren von Platon in einen größeren $\mathrm{Zu}-$ sammenhang hineingestellt worden und in sein System aufgegangen. Schließlich war Platon im "Timaeus" auch in der Kosmologie den Spuren der Pythagoreer gefolgt. Seine Nachfolger, Speusippos und Xenokrates, waren dieser Richtung treu geblieben. Man begreift, daß hierdurch der Pythagoreismus als selbständige Philosophie überflüssig wurde. Als dann dieser pythagoreisch gefärbte Platonismus durch die einschneidende Kritik, die Aristoteles an ihm und dem Pythagoreismus selbst übte, und durch den Erfolg der beiden materialistischen Systeme in Mißkredit kam und die Akademie sich von ihm abwendete, hörte die wissenschaftliche Tradition der pythagoreischen Lehre überhaupt auf, obgleich es ohne $Z$ weifel stets pythagoreische Vereine gab, in denen sich die religiösen Lehren und das pythagoreische Ideal sittlichreiner Lebensführung erhielt. Diese Vereine blühten im Verborgenen, bis in der vom wissenschaftlichen Skeptizismus und Dogmatismus unbefriedigten Menschheit das Bedürfnis nach einem durch Autorität und göttliche Offenbarung gestützten Dogma erwachte. Dieses Autoritätsbedürfnis konnten die Pythagoreer besser als andere Schulen befriedigen, weil ihr Stifter nicht nur viel. älter war als die aller übrigen bestehenden Schulen, sondern auch von alters her als ein Träger der Wissenschaft zugleich und der geheimnisvollen göttlichen Offenbarung erschien. Hierdurch wurden die Pythagoreervereine, wahrscheinlich zuerst in Alexandreia, angeregt, sich wieder mit Philosophie zu befassen. Natürlich knüpften sie nicht an den echten vorsokratischen Pythagoreismus, sondern an die pythagoreische Seite der platonischen und altaka- 
demischen Lehre an. Indem sie die pythagoreischen Elemente des Platonismus als die Hauptsache betonten und auf die Autorität des großen Weisen und Propheten hinwiesen, von dem Platon die Hauptstücke seiner Lehre entlehnt habe, erneuerten sie in Wahrheit mehr den Platonismus als den Pythagoreismus und verliehen ihm durch das zeitgemäße Offenbarungsprinzip neue Kraft und Lebensfähigkeit. Aber die Form, in der sie den Platonismus erneuerten, wich von dem echten nicht nur durch die einseitige Betonung der pythagoreischen Bestandteile, sondern vor allem anch dadurch $a b$, daß sie sich genötigt sahen, gewisse peripatetische und stoische Lehren, die in das wissenschaftliche Gemeinbewußtsein ihrer Zeit übergegangen waren, mit dem Platonismus zu verbinden. Darin zeigt sich unverkennbar, daß es die Zeit des Eklektizismus war, in welcher der Pythagoreismus erneuert wurde. Man glaubte fest, daß Pythagoras als der vollkommene und aus göttlicher Offenbarung schöpfende Weise alle Wahrheitserkenntnis müßte besessen haben. Dieser Glaube, der das Ideal des Wissens nicht wie der gesunde wissenschaftliche Trieb in der Zukunft, sondern mit krankhafter Verirrung im grauen Altertume sucht, ist der Zerstörungskeim, den der Neupythagoreismus in das antike Geistesleben hineinpllanzt. Durch diesen Irrglauben werden die Neupythagoreer verleitet, alles, was sie selbst für wahr halten, auf Pythagoras und seine Jünger zurückzuführen und die Lehren, die sie selbst von Platon, Aristoteles und Zenon entlehnen, für Entlehnungen dieser Männer von Pythagoras auszugeben. Da sich nur wenig altpythagoreische Literatur erhalten hatte, und da wirklich bis auf Philolaos die Lehrüberlieferung hauptsächlich mündlich und esoterisch gewesen war, so konnte es glaublich scheinen, daß die platonisch-aristotelische und die nacharistotelische Philosophie viel mehr, als sich urkundlich nachweisen ließ, aus pythagoreischer Quelle geschöpft hätte. Indem man den Sinn und Zusammenhang der als pythagoreisch überlieferten Sätze rekonstruierend zu ermitteln suchte, geriet man unwillkürlich in die ausgefahrenen Geleise der aristotelischen und stoischen Naturlehre. Dem frommen Glauben folgte der fromme Betrug auf dem Fuße. Neupythagoreische Schriftsteller schickten ihre Erzeugnisse als Schriften alter Pythagoreer unter fingierten oder altüberlieferten Namen in die Welt hinaus. Besonders in der zweiten Hälfte des 1. Jahrhunderts v. Chr. scheint diese apokryphe Schriftstellerei geblüht zu haben, durch welche die Vorstellungen der Späteren von Pythagoras und dem Pythagoreismus durchweg beeinflußt sind. In diesem Sinne ist der Neupythagoreismus eine geschichtliche Einheit: ein eklektisch getrübter pythagoreisierender Platonismus, der sich auf die Prinzipien der Autorität, der Offenbarung, der Überlieferung stützt. Aber er ist kein einheitliches System. In verschiedenem Verhältnis mischen die Vertreter dieser Richtung die Ingredienzien. Meist heben sie mit einer transzendenten, dualistischen Ontologie und metaphysischen Prinzipienlehre an, folgen dann in der Physik und Kosmologie den aristotelischen oder stoischen Geleisen (auch in der Logik, falls sie dieselbe behandeln), kommen in der Anthropologie und Seelenlehre wieder ins platonisch-pythagoreische Fahrwasser und schließen 
mit einer transzendenten asketischen Ethik und der Verherrlichung des „py thagoreischen Lebens" ab. Fast der ganze Platonismus der folgenden Jahrhunderte bis zur Entstehung des eigentlichen Neuplatonismus ist vom Neupythagoreismus beeinflubt, und es macht im Grunde wenig aus, ob sich diese Philosophen nach Platon oder nach Pythagoras benennen, ob sie pythagoreisierende Platoniker oder platonisierende Pythagoreer sind. Alle diese Männer vertreten mit immer steigender Wirkung, im Gegensatz zu den Peripatetikern, Stoikern und Epikureern, eine in der Jenseitsreligion gipfelnde Philosophie. Diese ist das weitaus Wichtigste, was die Nachgeschichte der griechischen Philosophie noch bringt.

Es kann in diesem kurzen $A b r i ß$ nicht versucht werden, die mannigfaltigen Formen, welche die geschilderte Gedankenrichtung bei ihren einzelnen Vertretern annimmt, einzeln vorzuführen. Unter den Römern hatte der Neupythagoreismus in Nigidius Figulus, einem Freunde Ciceros, seinen ersten Vertreter. Auch die Schule des $Q$. Sextius, zu der sich (außer seinem gleichnamigen Sohne) Sotion von Alexandreia und Celsus, der Verfasser der erhaltenen acht Bücher de medicina, bekannten, scheint mit stoischen pythagoreische Lehren verschmolzen zu haben. Im r. Jahrhundert $\mathrm{n}$. Chr. sind die namhaftesten Neupythagoreer Moderatus von Gades und Apollonios v on Ty ana, der in seiner Person und Lebensführung als Prophet und Wundertäter das Pythagorasideal, so wie es damals aufgefaßt wurde, zu verwirklichen suchte. Aus dem 2. Jahrhundert $\mathrm{n}$. Chr. kennen wir am besten Nikomachos von Gérasa und Numenios von Apameia. Als Platoniker der pythagoreisierenden und eklektischen Richtung ist vor allem Plutarch von Chäronea (ca. 48- izo n. Chr.) zu nennen. Aber auch die anderen Platoniker dieser Zeit, wie Gajus, Attikus, Albinus, wenn sie auch zum Teil nach Herstellung des reinen echten Platonismus streben, sind von Eklektizismus nicht frei.

Gemeinsam ist allen diesen Philosophen der Gegensatz gegen den $\mathrm{Ma}$ terialismus. Alle nehmen unkörperliche Wesenheiten (Zahlen oder Ideen) als das wahrhaft Seiende an. Die Materie wird als an sich Nichtseiendes aufgefaßt, das erst durch die zahlenmäßige Bestimmung Form und Wesenhaftigkeit erlangt. Die Zahlen werden als Symbole metaphysischer und physischer Begriffe verwendet. Einheit und unbestimmte $Z$ weiheit sind die obersten Prinzipien. Sie drücken den Gegensatz von Form und Stoff, Geist und Materie, Wirkendem und Leidendem, Vollkommenem und Unvollkommenem aus. Die Einheit wird als das Gute, das Vollkommene, das Absolute geschildert. Die unbestimmte $Z$ weiheit ist die Quelle alles Unvollkommenen, Ungeordneten, Veränderlichen; sie ist das materielle Prinzip. Wir müssen nun unterscheiden $z$ wischen einer Denkweise, die das Eine mit der Gottheit, die Zweiheit mit der Materie geradezu identifiziert, und einer anderen, die in den Zahlen nur die ewigen, unveränderlich en Urbilder erblickt, nach denen Gott als Bewegungsursache und Weltschöpfer (Demiụrg) die außer ihm von Ewigkeit her vorhandene Materie ordnet und zu einer Welt bestimmter Wesen ausbildet. Die erste dieser beiden Auffassungen spaltet sich wieder in eine streng mo-

Apollonius von Tyana Jahrhunder n. $\mathrm{Chr}$.).

Plutarch on Chäronea (ca. 48-I20 n. Chr.). 
nistische, die aus der Einheit als dem Urwesen und allein wahrhaft Seienden die unbestimmte $Z$ weiheit (die Materie) hervorgehen läßt, und eine dualistische, die beide Prinzipien als ursprünglich annimmt. Von dem zweiten Standpunkt aus konnten die Zahlen und Formen entweder als dem göttlichen Geiste innewohnende Gedanken von Gott abhängig gemacht oder als unabhängig neben ihm bestehend gedacht werden. Es konnte ferner an der Materie entweder mehr das rein potentielle Moment betont werden, vermöge dessen sie für die Verwirklichung der göttlichen Gedanken ein brauchbares Substrat und die allgemeine Möglichkeit hergibt, oder das Moment des Widerstrebens gegen die Form; das die Unvollkommenheit der materiellen Gegenstände im Vergleich mit der Reinheit der Formen rechtfertigt. Je strenger der Begriff der Materie als eines absolut eigenschafts- und bestimmungslosen Etwas durchgeführt wurde, desto mehr entstand das Bedürfnis, einen besonderen Grund ihres Widerstrebens, eine besondere Quelle des Bösen, die von ihr selbst verschieden in ihr wohnt, anzunehmen. So entsteht bei manchen Platonikern die Vorstellung einer bösen Weltseele, die ursprünglich in der Materie ihren Sitz hat und dem göttlichen Einfluß entgegenarbeitet. Es ist also klar, daß es sich in diesen Spekulationen immer um vier Dinge handelt, die, wenn ihr Begriff scharf gefaßt wird, nicht einander gleichgesetzt werden können und nicht auseinander ableitbar sind: 1 . das unkörperliche Wesensprinzip (Form, Zahl), 2. das stoffliche Prinzip (Materie), 3. die Ursache der Ordnung (des Guten) in der Welt (der Demiurg), 4. die Ursache des Übels und des Bösen (böse Weltseele). Diese Prinzipien ließen sich auf zwei zurückführen, wenn man einerseits dem göttlichen Geist die Formen als seine Gedanken, andererseits der Materie den Widerstand gegen die Ordnung, die Ursache der Unvollkommenheit ursprünglich innewohnen ließ. Bei diesem Verfahren wurden der reine Formbegriff und der reine Stoff begriff geopfert, der Gegensatz zwischen dem vollkommenen, unkörperlichen, geistigen Agens und dem unvollkommenen, körperlichen hervorgekehrt. Wollte man schließlich auch diesen Dualismus überwinden, um mit der Stoa in der strengen Durchführung des Monismus zu wetteifern, so mußte natürlich der göttliche Geist als das Erste gesetzt, die Materie und die Körperwelt als aus $\mathrm{ihm}$ irgendwie hervorgehend gedacht werden. Hierin aber lag die größte Schwierigkeit. Wie sollte das Vollkommene die Ursache des Unvollkommenen, das Gute selbst die Ursache des Bösen sein können. Denker, für die der ethische Gesichtspunkt der allbeherrschende war, konnten über diese Schwierigkeit nie hinwegkommen; sie mußten beim Dualismus stehen bleiben. Aber als formales Postulat mußten doch auch diese Philosophen die Ableitung alles Bestehenden aus Einem Urprinzip anerkennen. Denn erst wenn diese gelungen war, durften sich die Freunde des Unkörperlichen rühmen, den Materialisten an strenger Geschlossenheit und Einheitlichkeit des Lehrsystems gleichgekommen zu sein. In diesem Sinne bildet das System Plotins den Zielpunkt, auf den die ganze platonisch-pythagoreische Philosophie seit dem I. Jahrhundert v. Chr. hinstrebt. Er erfüllt erst das Postulat, an dessen Erfüllung alle früheren Vertreter der transzendenten Meta- 
physik seit Platon gescheitert waren, die Durchführung eines streng monistischen Spiritualismus.

Aber der Dualismus litt nicht nur an dem formalen Mangel, daß er dem Einheitsbedürfnis des menschlichen Erkenntnistriebes nicht zu genügen vermochte, er geriet auch in große Verlegenheit, wenn er die Einwirkung des Geistes auf die Materie, des Unkörperlichen auf das Körperliche begreiflich zu machen versuchte. Je ausschließender der Gegensatz zwischen den beiden Prinzipien aufgefaßt wurde, desto unbegreiflicher mußte es erscheinen, wie das eine mit dem anderen in Berührung treten und Ursache seiner Wandlungen werden könnte. Zumal von den Denkern, deren innerstes Denkmotiv eine überschwengliche Religiosität war, wurde Gott so rein und so vollkommen und die Materie so unrein und unvollkommen geschildert, daß es unbegreiflich scheinen mußte, wie ein solcher Gott auf eine solche Materie und in einer solchen Materie wirken könnte. Der Versuch, Ein unkörperliches Wesen als Urgrund der Welt zu konstruieren, führte notwendig zu dem Begriff eines über alle Gegensätze erhabenen, daher auch jeder denk- und aussprechbaren Beschaffenheit entbehrenden Etwas. Was hier wieder auftaucht, ist im Grunde nichts anderes als der eleatische Begriff des Einen Seienden, der sich aus lauter negativen Merkmalen zusammensetzt: der Unbegrenztheit, Ewigkeit, Unveränderlichkeit, Unbeweglichkeit, Unteilbarkeit. Als einziges positives Merkmal wurde hinzugefügt: die Kraft und Fähigkeit, eine Welt wie die uns gegebene aus der Materie zu gestalten. Durch diese Eine Bestimmung aber wurden dem Absoluten alle Bestimmungen, die man ihm abgesprochen hatte, potentiell zurückgegeben. Es entstand der in sich widerspruchsvolle Begriff eines absolut einheitlichen Wesens, in dem doch potentiell die ungeheure Vielheit der Einzelwesen enthalten ist, wenn nicht dem Stoffe so doch der. Form nach. Aus diesen Denkschwierigkeiten suchen nun viele Denker dieser Richtung dadurch einen Ausweg, daB sie zwischen das Absolute und die Materie Mittelstufen einschieben, die ihren absoluten Gegensatz stufenweise überbrücken und erklären sollen, wie Gott auf die Materie einwirken und wie der absolut Eine in ihr eine Vielheit von Wesen hervorbringen kann. Verwendete man als vermittelndes Glied die Ideenwelt, so wurden die Ideen einerseits, im Widerspruch mit ihrem eigentlichen Wesen, zu Keimkräften (lógoi spermatikoi), die in der Materie wirkten, andererseits zu göttlichen Gedanken. Es war sehr schwierig das Verhältnis dieses Mittelgliedes nach beiden Seiten klar zu bestimmen. Wern die Ideen Gedanken im göttlichen Geiste oder göttliche Kräfte sind, so gehören sie zu dem göttlichen Wesen und können nicht zwischen diesem und der Materie vermitteln. Auch rauben sie ihm die absolute Einheitlichkeit und Bestimmungslosigkeit. Werden sie andererseits von Gott losgelöst und als selbständige Wesen ihm gegenübergestellt, so können sie weder seine Gedanken noch seine Kräfte sein, sondern werden gewissermaßen Untergötter oder Engel. Dadurch wird aber wieder die einzige positive Leistung des Gottesbegriffs, daß er nämlich die einheitliche Ursache alles Daseins und Geschehens bedeutet, in Frage gestellt. 
Denn hinsichtlich des Kausalverhältnisses zwischen dem höchsten Gott und jenen Untergöttern oder selbständig wirkenden Kräften wiederholen sich dieselben Schwierigkeiten, die, weil sie die Hervorbringung der sinnlichen Einzeldinge durch Gott unglaubhaft machten, zur Einschiebung des Mittelgliedes geführt hatten. Wie kommt das vollkommene und sich selbst genügende AllEine dazu, diese Mehrheit minder vollkommener Wesen hervorzubringen, und wie kann es, nachdem sich diese von ihm losgelöst und selbständig zu wirken begonnen haben, noch immer, wie es sein Begriff verlangt, als die Ursache von allem gelten? Besteht dagegen das Mittelglied zwischen Gott und Welt nicht aus hypostasierten Kräften, sondern aus Ideen im echt-platonischen Sinne, aus Gattungstypen also, die Vorbilder der ihnen gleichnamigen Einzelwesen sind, so kann es allerdings als Begriffssystem den Übergang von der Einheit zur Vielheit bilden, das es ebensosehr Eins wie Vieles ist; es wird aber auch gleichzeitig unbrauchbar für die kausale Erklärung der Natur. Es muß also diese Mittelwelt, wenn sie die Aufgabe im Zusammenhang des Systems erfüllen soll, für die sie ersonnen ist, zugleich abhängig und unabhängig von Gott, zugleich einheitliches und unveränderliches Begriffssystem und Vielheit beweglicher wirkender Kräfte sein. Ähnliche Schwierigkeiten ergeben sich bezüglich des Verhältnisses dieser Mittelwelt zu der Materie. Ist in jedem einzelnen Körper eine $\mathrm{K}$ raft vorhanden, die seiner Materie Gestalt und Wesen gibt, so ist die Welt der Kräfte ebenso geteilt, veränderlich, vergänglich und unvollkommen wie die Körperwelt selbst und nicht geeignet, die Kluft zwischen dieser und der Gottheit zu überbrücken.

Diese Betrachtung zeigt die Schwierigkeiten, auf welche die von dem Gegensatz Gottheit - Materie ausgehende dualistische Metaphysik stoßen mußte, wenn sie den Gegensatz durch Einschiebung eines Mittelgliedes zu überbrücken suchte. Ich habe dabei hauptsächlich das System des jüdischen Religionsphilosophen Philon von Alexandreia im Auge gehabt, das uns von allen dem Neuplatonismus voraufgehenden eklektisch-platonischen Systemen am genauesten bekannt ist und das mit allen eben geschilderten Schwierigkeiten zu kämpfen hat. Sein System und viele ähnliche, die mit denselben Schwierigkeiten kämpften, waren den Gründern des Neuplatonismus, Ammonius Sakkas und Plotinus, bekannt, als sie zur Überwindung dieser Schwierigkeiten ihr eigenes System ersannen.

Philon von Alexandreia (ca. 30 v. Chr. bis ca. 50 n. Chr.).
V. Philon von Alexandreia. Philon von Alexandreia, der um den Beginn der christlichen Ära in jugendlichem Mannesalter stand (denn als er im Jahre $40 \mathrm{n}$. Chr. als Abgesandter der alexandrinischen Judengemeinde zu Kaiser Caligula nach Rom ging, war er ein Greis), stanımte aus jüdischem priesterlichen Geschlechte. Er ist für uns der Repräsentant der bei den alexandrinischen Juden längst angebahnten, durch ihn aber auf den Höhepunkt gebrachten Ausgleichung jüdischer Theologie und griechischer Philosophie. Bezüglich des Pentateuchs am strengsten Inspirationsglauben festhaltend, entwickelt er seine philosophischen Ansichten größtenteils in Form von Kom- 
mentaren zu dieser heiligen Urkunde. Um den Gesetzgeber der Juden als Verkünder der wahren Philosophie und den Pentateuch als die Quelle aller Weisheit der Hellenen zu erweisen, deutet er durch allegorische Auffassung und durch die Annahme eines tieferen, von dem buchstäblichen verschiedenen Schriftsinns alle ihm selbst wahr erscheinenden Lehren der griechischen Zeitphilosophie in die heiligen Texte hinein. Natürlich folgte er dem damals in Flor gekommenen eklektischen pythagoreisierenden Platonismus, der auch Entlehnungen aus der peripatetischen und stoischen Philosophie nicht ausschlieBt. Nur ist bei ihm dieser Eklektizismus durch die Berücksichtigung der jüdischen Religion und ihrer Glaubenslehren gefärbt.

Die Erkenntnis Gottes ist nach Philo das eigentliche Ziel der Philosophie. Diese Erkenntnis ist uns aber nicht völlig erreichbar. Selbst mit unserer höchsten Erkenntniskraft, der Vernunft (dem Nas) können wir nur erkennen, $\mathrm{daB}$ Gott is t, nicht aber tiefer in sein Wesen eindringen. Wirklich erkennbar ist für uns nur Gottes Ebenbild, der Logos, den wir mit dem uns innewohnenden Logos, einer vom Nus verschiedenen Erkenntniskraft, auffassen. Den dritten Gegenstand der Philosophie bildet der Kosmos, das sinnliche Abbild des Logos, das durch unsere dritte Erkenntniskraft, die sinnliche Wahrnehmung; erkannt wird. Die gewöhnliche Bezeichnung Gottes bei Philo ist „das Seiende“, die eleatische Bezeichnung des Absoluten. Das Seiende ist eines und absolut einfach, während jedes abgeleitete Wesen eine Vielheit ist. Es ist unveränderlich und unvergänglich, sich selbst genug, ohne Beziehung auf etwas anderes außer sich, auch nach der Weltschöpfung. Es ist nicht in der Welt, auch nicht im Raume. Denn kein Raum kann das Seiende befassen, das vielmehr alles übrige in sich befaßt. Es ist reine Substanz und als solche qualitätslos. Es ist der oberste Gattungsbegriff. Es gibt keinen Namen, mit dem es treffend benannt werden könnte. Selbst der Name "Gott" bezeichnet nur eine seiner Kräfte. Dasselbe gilt von der Bezeichnung „das Gute“. Das Seiende liegt eben jenseits des Bereiches des Logos. Insofern es die Ursache der Welt ist, wird es Schöpfer und Vater genannt. Es ist das wirkende Prinzip, dem als leidendes eine Materie gegenübersteht. Insofern es immateriell ist, ist es reine Vernunft (Nus) und damit besser als die Tugend, besser als das Wissen, besser als die Idee des Guten und Schönen. Die Materie, die an sich formlos, seelenlos, unbewegt und ungeordnet ist, wurde durch das wirkende Prinzip bewegt, geformt, beseelt und zum Kosmos, dem vollkommensten sinnlichen Gebilde, ausgestaltet. Aber der Schöpfer durfte bei seiner Schöpfungstätigkeit nicht selbst die Materie berühren. Es waren daher außer dem Schöpfer, von dem, und auBer dem Stoffe, aus dem die Welt geschaffen wurde, Werkzeuge nötig, durch die es geschah. Diese Werkzeuge sind die Kräfte Gottes. Seine obersten Kräfte sind die Güte, die in der Schöpfung, und die Macht, die in der Erhaltung und Regierung der Welt sich betätigt. Mit dem obersten unaussprechlichen Seienden zusammen bilden die Güte und die Macht eine Dreieinigkeit. Zwischen der Güte und der Macht aber steht vermittelnd oder auch über ihnen, beide umfassend, der Logos. Dieser göttliche Logos ist der Ver- 
mittler des Schöpfungsaktes. Er steht auf der Grenze zwischen dem Schaffenden und dem Geschaffenen. In diesem Logos ist, wenn Gott zur Schöpfung schreitet, wie in der Seele des Baumeisters, wenn er ein Haus zu bauen beginnt, ein geistiges Urbild des geplanten Baues enthalten, das dann im Stoffe nachgebildet wird. Der göttliche Logos ist der intelligible Ort der intelligiblen Welt. Diese intelligible Welt enthält in sich die Formen (Ideen) aller Wesen, die zu der sinnlichen Welt gehören. Es wird aber von Philo nicht der echt platonische Begriff der Ideen als vorbildlicher Gattungstypen festgehalten, sondern diese Ideen, aus denen die intelligible Welt besteht, werden zugleich als Logoi und Kräfte, ja sogar als Seelen und Engel bezeichnet. Der Logos selbst ist der Erzengel, der erstgeborne Sohn Gottes, der zweite Gott. Auch nach der Schöpfung bleibt er der Mittler zwischen Gott und den Sterblichen. Wie nun durch den Logos und die in ihm enthaltenen Ideen und Kräfte die Materie verwandelt und zum Kosmos ausgestaltet wird, hat Philon nirgends geschildert, so wie auch schon beim Logos und der intelligiblen Welt die Art ihres Hervorgehens aus der Gottheit nicht in klaren Begriffen erläutert, sondern nur in mannigfach wechselnden Bildern der Einbildungskraft vorgemalt wird. Der Logos ist ein Ebenbild oder ein Schatten Gottes oder auch eine Ausstrahlung des göttlichen Urlichtes. In dem letztgenannten Bilde ist wohl der Keim jener in vielen neuplatonischen und gnostischen Systemen herrschenden Vorstellung nicht zu verkennen, die wir als Emanationslehre bezeichnen. Die Wurzel der Ausstrahlungslehre liegt schon hier in dem Streben, die Ursächlichkeit Gottes im Verhältnis zur Welt mit seiner vollkommenen Abgeschlossenheit und Selbstgenugsamkeit zu vereinigen. Wenn Gott bei seinem Wirken Zwecke verfolgte, die außerhalb seines Selbst liegen, so würde er nicht mehr der Nichtsbedürfende sein. Das unerschöpfliche Urlicht, das durch alle Ewigkeit Lichtstrahlen aussendet, ohne dadurch in seinem eigenen Wesen im geringsten verändert zu werden, ist das sinnliche Symbol eines Wesens, das immer wirkt, ohne außer sich liegende $Z$ wecke zu verfolgen, und für dessen eigenes Wesen die von ihm ausgehenden Wirkungen ganz ohne Bedeutung sind. Ferner liegt in dem Bilde vom Licht und seinen Strahlen, daß das Hervorgebrachte dem Hervorbringenden wesensgleich und doch von geringerer Vortrefflichkeit ist. Derselbe Vorgang der Ausstrahlung oder Abschattung wiederholt sich dann im Verhältnis der intelligiblen zur sinnlichen Welt, die also wieder um eine Stufe weniger vortrefflich ist. Aber es ist hier doch nur der Keim der Emanationslehre, nicht diese selbst in ihrer ausgebildeten Form zu erkennen. Philo hat sich nirgends data opera mit diesem Problem beschäftigt und ist nicht zu einer dogmatischen Beantwortung der Frage gelangt. Mannigfaltige Bilder und unter sich widersprechende Vorstellungsweisen gehen bei ihm nebeneinander her, namentlich bezüglich des Verhältnisses der intelligiblen Welt zur sinnlichen. Besteht die intelligible Welt aus vorbildlichen Gattungstypen, dann muB sie ebenso wie der höchste Gott in sich abgeschlossen sein, und auch sie muß wirken, wie das Licht, ohne daß ihre Wirkungen sie selbst in Mitleidenschaft ziehen. Diese Vorstellung 
hat aber Philo, wie schon gesagt, nicht durchgeführt, sondern die Elemente der intelligiblen Welt bald als Ideen, bald als Kräfte, bald gar als persönliche Wesen (Seelen, Engel, Dämonen) aufgefaßt. Ideen können durch ihre logische Über- und Unterordnung ein einheitliches System, einen Logos, bilden; schwer ist es schon, diese Über- und Unterordnung auf Kräfte anzuwenden; ganz unmöglich ist ihre Anwendung auf persönliche Wesen. Eine andere Schwierigkeit liegt darin, daß ja die Kräfte in der sinnlichen Welt, im Raume, in den einzelnen Körpern gegenwärtig gedacht werden müssen und doch andererseits Bestandteile der intelligiblen Welt sein sollen, die getrennt und unabhängig von der sinnlichen besteht. Wenn die Kräfte in die Materie eindringen und sie gestalten, so ist es schwer, an ihrer Unkörperlichkeit festzuhalten. Die Kraft, die ein einzelnes Wesen durchwohnt, erscheint dann verschieden von der ein anderes Wesen derselben Gattung durchwohnenden Kraft und beide verschieden von dem als einheitliche Kraft gedachten Gattungstypus. Diese Erwägung könnte zur Unterscheidung des intelligiblen Logos von den in der Körperwelt wirkenden Logoi und zu der stoischen Auffassung der letzteren als körperlicher Pneumaströmungen führen. In der Tat finden sich bei Philo Ansätze zur Unterscheidung zweier Arten des Logos, die sich zueinander verhalten sollen wie beim Menschen der innere und der ausgesprochene (endiáthetos und prophorikós). Auch eignet sich Philo die stoische Lehre von den aus Luft bestehenden pneumatischen Körpern an, die als Hexis die anorganischen, als Natur die vegetativen, als Seele die animalischen Wesen durchdringen. Aber zu einer klaren Durchführung der durch diese Ansätze nahegelegten Theorie ist er nicht gelangt. Denn an anderer Stelle sagt er wieder, daß der Logos die Welt anzieht wie ein Gewand, wie ein Band sie zusammenhält, als Gesetz sie beherrscht, als Ursache sie durchdringt, ohne an die Unterscheidung eines zweifachen Logos zu erinnern. Er kennt also nicht die Unterscheidung der Weltseele vom Logos, sondern verwendet den Logos selbst sowohl als Urbild und Ursache wie als Seele der Welt.

Die Kosmologie und Naturlehre Philos bietet nichts Selbständiges und Eigentümliches. Sie bewegt sich in einem platonisch-stoischen Eklektizismus und macht auch von der neupythagoreischen Zahlenmystik den weitgehendsten Gebrauch. Da er an dem jüdischen Hauptdogma der göttlichen Weltschöpfung festhalten muß, so verwirft er die aristotelische Auffassung, $\mathrm{daB}$ die Welt ohne Anfang von Ewigkeit her bestand. Die Welt ist geworden, aber durch den Ratschluß ihres Schöpfers unvergänglich. Allerding's soll die Entstehung der Welt nicht zeitlich aufgefaßt werden. Denn die Zeit ist wie der Raum erst mit der Welt zugleich entstanden. Daher sollen auch die Schöpfungstage des mosaischen Schöpfungsberichts nicht wirkliche Zeiträume bedeuten, sondern nur die in dem Schöpfungsakt enthaltenen Momente, wie sie dem Gedanken nach eine Ordnung und Folge haben, auseinanderlegen. Im übrigen interessiert sich unser Philosoph für naturwissenschaftliche Fragen nur insoweit, als sie entweder zu Gott oder zum Menschen Be- 
ziehung haben. Der wichtigste Teil der Schöpfung sind, wie ja auch der mosaische Schöpfungsbericht voraussetzt, die Menschen. Der Mensch ist das vorzüglichste aller Geschöpfe. Er steht an der Grenze der sinnlichen und der übersinnlichen Welt; und zwar ist es seine Seele, die beiden Welten angehört. Nicht nur der Leib, sondern auch der vernunftlose Teil seiner Seele gehört der körperlichen Welt an. Für die pflanzliche und tierische Seele, die zusammen den vernunftlosen Seelenteil ausmachen, akzeptiert Philo den stoischen Materialismus und mit ihm die Abstufung Hexis, Physis, Psyche. Er sieht also diesen Seelenteil als einen luftartigen Körper an, der sich von dem Lebensprinzip der Pflanze und von dem Formprinzip des anorganischen Körpers nur durch höheren Spannungsgrad unterscheidet. Für die tierische Seele akzeptiert er die stoische Achtteiligkeit: sie besteht aus den fünf sinnlichen Wahrnehmungsvermögen, dem Zeugungsvermögen, dem Sprachvermögen und dem führenden Seelenteil (Hēgemonikón). Das Hegemonikón ist mit Vorstellung und Trieb begabt. Beim Menschen ist, im Gegensatz zu den Tieren, das Vorstellungsvermögen und infolgedessen auch das Sprachvermögen ein logisches. Philo wendet neben der stoischen Achtteilung auch die platonische Dreiteilung der Seele an: das Hegemonikón der Menschen besteht aus Begierde, Mut und Logos. Begierde und Mut bedeuten die höheren und niederen Triebe, entsprechen also dem stoischen Begriff des Trieb-

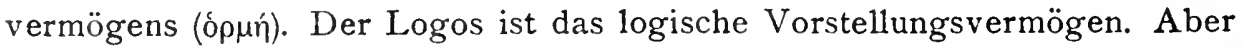
wie im All über dem Logos als ein höheres Wesen der Nūs, der göttliche Geist, steht, so auch in Menschen, der als Mikrokosmos alle im Makrokosmos vorhandenen Wesensstufen in sich trägt. Dieser unkörperliche Geist, der zu seiner Seele von oben her hinzutritt, ist es, der den Menschen zum Ebenbilde Gottes macht. In diesen psychologischen Lehren Philos tritt uns die Vermischung stoischer mit platonischen und peripatetischen Lehren besonders deutlich entgegen. Es konnte unmöglich bei einem solchen Eklektizismus ein widerspruchsfreies Gebilde herauskommen. Wir sehen, daß es dem Philosophen besonders auf den Dualismus des Sinnlichen und des Übersinnlichen ankommt. Der Nūs, hören wir, ist unkörperlich, die übrige Seele körperlich. Dabei bleibt aber die Mittelstellung des Logos zwischen dem Nūs und der sinnlichen Wahrnehmung unverständlich. Nach den Voraussetzungen des Systems muß auch er übersinnlich und unkörperlich sein. Doch wird von Philo die Unkörperlichkeit nur für den Nus in Anspruch genommen und die Stellung des Logos, der als mittleres Erkenntnisvermögen zwischen Nūs und Sinnlichkeit genannt wird, zu dem Gegensatz des Körperlichen und Unkörperlichen bleibt unklar. Der menschliche Nus soll ein Ausfluß oder Absenker des göttlichen sein und mit diesem, da das Göttliche keine Teilung und Trennung, sondern nur Ausdehnung zuläßt, fortwährend verbunden bleiben. Andererseits soll wieder der menschliche Nas die Freiheit haben, sich für oder gegen Gott zu entscheiden. Aus freiem Willen versenkt er sich in die sinnliche Welt, geht die Verbindung mit den niederen Seelenteilen ein und büßt dadurch seine Vollkommenheit ein. Aus freiem Willen 
löst er sich auch wieder aus der Sinnlichkeit und kehrt zu seiner Heimat in Gott zurück. Es ist aber ein offenbarer Widerspruch, für dessen I.ösung Philo nichts getan hat, daß der menschliche Nūs vollkommen zugleich und unvollkommen ist, ewig mit Gott verbunden bleibt und doch oft sich von ihm trennt. - Ihrem Wesen nach ist die menschliche Seele, nach Philo, eine der Kräfte Gottes, die er in die Welt ausstrahlen läßt. Wir haben schon gesehen, daß diese Kräfte auch als Engel, Dämonen, Seelen aufgefaßt werden. Der Luftraum unter dem Monde ist von solchen Seelenwesen erfüllt, die ihre Reinheit und Vollkommenheit bewahren. Nur einige von ihnen sinken abwärts in menschliche Leiber und verstricken sich in die Sinnlichkeit. Für sie ist der Leib ein Grab und ein Gefängnis. Gelingt es ihnen sich von der Sinnlichkeit zu befreien, so kehren sie zu dem früheren körperlosen Dasein zurück. Ist diese Befreiung ihnen noch nicht gelungen, so müssen sie in andere sterbliche Leiber wandern. Bedenkt man, daß die Ausstrahlung der göttlichen Kräfte durch den Logos vermittelt wird, daß sie selbst auch Logoi genannt werden, so ist klar, daß nicht nur der Nūs, sondern auch der Logos des Menschen als beteiligt an dieser Präexistenz und Postexistenz, an dem Sündenfall und an der Rückkehr nach oben gedacht werden muß. Wie aber steht es mit den übrigen Seelenkräften, der Sinneswahrnehmung, den Trieben, dem vegetativen Leben? Auch sie können ihren Ursprung nicht aus der Materie haben, auch sie sind Kräfte göttlichen Ursprungs. Mit welchem Rechte wird also zwischen ihnen und den höheren Seelenkräften eine schroffe Trennung vollzogen? Diese Betrachtung dürfte lehren, daß es Philo auch in seinen psychologischen Lehren nicht gelungen ist, die aristotelisch-stoische Stufenfolge mit dem platonisch-pythagoreischen Dualismus, der einen absoluten, unüberbrückbaren Gegensatz zwischen dem Sinnlichen und dem Übersinnlichen statuiert, in befriedigender Weise auszugleichen.

Auch in der Ethik verfährt Philo eklektisch, indem er die stoische Sittenlehre, deren herbe Strenge ihn anzieht, mit platonischer Transzendenz der Zielsetzung verbindet und ihre pantheistische Religiosität ins Theistische umbildet. In der Güterlehre nimmt er für die Stoa gegen den Peripatos Partei, indem er nur das Sittlichschöne - die Tugend und alles was an ihr Anteil hat - für wahrhaft gut erklärt. Die Anerkennung der körperlichen Vorzüge und äußeren Vorteile als Güter - d. h. die peripatetische Ansicht - erscheint ihm als zu lax, als nicht männlich genug. Auch er will den Weisen von allem Äußeren unabhängig machen und schwärmt für kynische Bedürfnislosigkeit. Er verwirft die peripatetische Metriopathie (Mäßigung der Leidenschaften) und entscheidet sich für die stoische Apathie (völlige Ausrottung der Leidenschaften). Die Paradoxa, in denen die Stoiker ihren Weisen feierten, eignet er sich gerne an. Aber die wörtliche Aneignung so vieler stoischer Einzelsätze darf uns nicht vergessen machen, daß ein fundamentaler Unterschied zwischen seiner und der stoischen Ethik besteht: die stoische Ethik ist eine autonome, die Philos eine heteronome. Die Stoa meint daß der Mensch das Vernunftgesetz in sich selbst trägt und nur trachten 
soll, sein ganzes Wesen und Verhalten mit diesem Gesetz und dadurch mit sich selbst in Einklang zu bringen. Philo dagegen meint, daß der Mensch nicht aus eigener Kraft der Gelüste Ketten zerreißen und zur Tugend gelangen kann; er verweist uns auf den religiösen Weg zur sittlichen Besserung; Gott allein ist es, der die Tugenden in die Seele pflanzen kann; nur durch gläubige Hingebung an ihn können wir zur Weisheit gelangen. Philo bevorzugt das theoretische vor dem praktischen Leben, in noch höherem Grade als Aristoteles. Denn seine niedrige Schätzung der sinnlichen Welt verbietet ihrn, die Betätigung in ihr für die Hauptaufgabe des Menschen zu halten. Auch hierin steht er zu der Stoa in Gegensatz, für die sich jeder Logos auf ein körperlich Reales bezieht und daher auch die Weisheit und Tugend nicht ohne Handeln in der körperlichen Welt gedacht werden kann. Die Theorie aber, die Philo empfiehlt, ist weit entfernt von dem universellen Interesse an allem Wirklichen, das den Aristoteles auszeichnet. Sie beschränkt sich im Grunde auf Gott und das Verhältnis des Menschen zu Gott. Alle Forschungsgegenstände, die nicht zu der religiös-ethischen Aufgabe des Menschen in Beziehung stehen, schiebt Philo beiseite. Auch bezüglich der wissenschaftlichen Erkenutnis wie bezüglich der praktischen Tätigkeit fehlt ihm das Zutrauen zu der menschlichen Kraft. Darum äußert er sich über die Möglichkeit der Erkenntnis oft ganz im Sinne der absoluten Skepsis und hat sich in einer seiner Schriften die damals modernste Form der Skepsis, die Tropen Aenesidems, angeeignet. Daß er trotzdem, wie wir gesehen haben, ein dogmatisches System aufstellt, ist ein Widerspruch, der sich von seinem Standpunkt aus durch den Hinweis auf die Offenbarungsautorität heben läßt. Er glaubt ja fest, daß in den heiligen Urkunden alle die Lehren enthalten sind, die er durch halsbrechende Kunststücke in sie hineinerklärt, und daß ihre Verfasser vom göttlichen Geist inspiriert waren. Eine kataleptische Erkenntnis ist von Gott, dem Hauptgegenstande der Philosophie, allerdings nicht müglich, aber der menschliche Geist, der sich zu seinem Urquell hinwendet, kann durch Gottes Gnade mit Gott in unmittelbare Berührung treten und ihn selbst und die göttlichen Geheimnisse schauen.

VI. Der Neuplatonismus des Plotinus. Die Strömung des philosophischen Denkens, für die wir das philonische System als Beispiel vorgeführt haben, ging während des 1. und 2. Jahrhunderts, durch Pythagoreer und Platoniker vertreten, in mannigfach modifizierten Formen neben den älteren Systemen her, olne einen entscheidenden Erfolg zu erringen. Zum Siege wurde sie erst durch Plotin geführt, teils weil der religiöse Geist immer mehr den wissenschaftlichen in den Hintergrund drängte, teils weil gerade in der Schärfe der dialektischen Begrundung und der wissenschaftlichen Folgerichtigkeit Plotin alle früheren Vertreter dieser Richtung weit hinter sich ließ.

Plotinus war von seinem 28. bis zu seinem 39. Lebensjahre in Alex(20+-270 n.Chr.) andreia Schüler des Ammonius Sakkas gewesen, zu dem er sich ähnlich verhält wie Platon zu Solrates. Er hat sich in seinen Lehrvorträgen nicht 
als Begründer einer neuen Philosophie, sondern als Vertreter und Fortsetzer der Philosophie des Ammonius gegeben. Da aber dieser keine Schriften hinterlassen hatte, können wir nicht feststellen, inwieweit die Gedanken, welche den Neuplatonismus von den älteren Vertretern der platonisch-pythagoreischen Richtung unterscheiden, schon von Ammonius stammen. Erst im letzten Jahrzehnt seines Lebens begann Plotin seine Lehre schrifstellerisch darzustellen, unterstützt von seinem bedeutendsten Schüler Porphyrios (geb. 233, † nach 300 , unter Diokletian), der auch das Werk seines Lehrers in die uns vorliegende Form, sechs Gruppen von je neun inhaltlich zusammengehörigen Abhandlungen (secis Enneaden) gebracht hat. Unter allen im Altertum gemachten Versuchen, die platonischen Gedanken zu Ende zu denken und sie in die Form eines abgeschlossenen dogmatischen Systems zu bringen (was Platon selbst unterlassen hatte), ist der Versuch Plotins weitaus der bedeutendste. Plotin will nicht eine neue eigene Lehre aufstellen, sondern durch Weiterspinnen aller in Platons Schriften angesponnenen Gedanken den wahren Sinn der platonischen Lehre ermitteln und ihr den gebührenden Platz in der Schätzung der philosophisch Gebildeten, der ihr bisher versagt geblieben, endlich nach 500 Jahren erobern. Platon ist für ihn in ähnlichem Sinne bindende Autorität wie der Pentateuch für Philo. Aber auch die polytheistische Volksreligion, die sich damals schon durch das Christentum schwer bedrängt sah, ist für Plotin eine unantastbare Autorität. In seiner weiteren Entwickelung hat der Neuplatonismus die Verteidigung des Heidentums gegen das Christentum immer mehr in den Vordergrund geste11t, als treuer Vorkämpfer einer überwundenen Welt und einer verlorenen Sache. Plotin aber ist nicht nur von Platon, sondern auch von der ganzen nachplatonischen Philosophie, besonders von Aristoteles und den Stoikern beeinflußt. Auch der Eklektizismus, den wir seit dem I. Jahrhundert v. Chr. bemüht sahen, den Reingewinn der philosophischen Entwickelung zusammenzufassen, wird durch Plotin fortgesetzt. Alle Lehren der älteren Philosophen, die sich mit der transzendentalreligiösen Grundrichtung seines Denkens in Einklang bringen ließen, hat Plotin seinem System einverleibt. Er ist dabei viel selbständiger und folgerichtiger verfahren als irgendein früherer Eklektiker. Eine Folge seiner Geistesarbeit ist es, daß von nun an alle übrigen Schulen durch den Platonismus in den Hintergrund gedrängt wurden. Es fehlt Plotin durchaus nicht an begrifflicher Schärfe. An dialektischer Gewandtheit kommt er den großen Philosophen der Blütezeit, einem Aristoteteles und Chrysippos, nahe. Aber da sich seine Spekulation mit Vorliebe in Regionen bewegt, die jenseits aller auf Erfahrung gegründeten Begriffe liegen, so schlägt er oft auf den höchsten Höhen der Abstraktion, wie wir sehen werden, ins Anschauliche und Bildliche um, indem er sinnliche Anschauungen als Symbole undefinierbarer Begriffe verwendet. Als der hervorstechendste Unterschied der Philosophie Plotins von der seiner neupythagoreischen und platonischen Vorläufer erscheint die Überwindung des Dualismus, die bisher keinem Vertreter dieser Richtung gelungen war. 
Das Urwesen.

Plotin nimmt eine einheitliche oberste Ursache alles Daseins und alles Geschehens in der Welt an. Der Gegensatz des Wirkenden und des Leidenden, des Geistes und der Materie, des Stoffes und der Form ist ihm wie alle Gegensätze etwas Abgeleitetes. Das Urwesen muß frei von allen Gegensätzen, muß schlechthin Eines sein. Jede Vielheit ist eine Vielheit von Einheiten, setzt also das Eine schon voraus. Nun ist aber nicht nur jedes sinnlich wahrnehmbare Ding, sondern auch jeder bestimmte Begriff eine Mehrheit. Denn jedes Ding hat mehrere Eigenschaften, jeder Begriff mehrere Merkmale. Darin liegt schon eine zahlenmäßige Bestimmtheit. Die Zahl aber entsteht erst aus der Einheit. Jedes Seiende ist nur seiend dadurch, daß es Eines ist. Denn raubt man ihm die Einheit, so ist es nicht mehr das, als was es bezeichnet wurde. Also ist das Eine früher als das Seiende. Jedes Seiende ist Eines durch Anteinahme an der Einheit; wir aber suchen das Eine, das nicht an sich eine Vielheit und nur durch Anteilnahme am Einen eine Einheit ist, sondern das an sich und wahrhaft Eine. Das Zusammengesetzte bedarf die Einheiten, aus denen es besteht, und ist abhängig von ihnen. Das Erste aber muß bedürfnislos und unabhängig sein. Wenn Plotin dem Ersten Sein und Wesenheit abspricht, so will er es damit natürlich nicht für ein Nichtseiendes erklären. Es ist vor allem Wesen, jenseits alles Wesens, ein Überseiendes. Diese Auffassung Plotins hängt mit seiner Auffassung des Seinsbegriffes zusammen. Das Seiende ist ihm, wie wir sehen werden, das Denkbare, setzt also einen Denkenden und ein Denken voraus und ist daher nicht schlechthin unabhängig. Hieraus folgt auch, daß er das Erste und Eine nicht, wie z. B. Philo, als Geist oder Denken bestimmen kann. Denn Denken und Sein sind Korrelatbegriffe. Von dem Denkenden ist das Denken und das Gedachte verschieden. Keines dieser drei Momente kann ohne die beiden anderen für sich bestehen. Es ist also keines von ihnen das Erste und Absolute. Bei dem sich selbst denkenden Geist muß wenigstens das Denken von dem sich selbst Objekt gewordenen Subjekt des Denkens unterschieden werden. Ebensowenig wie ein Denken kann aber ein Wollen dem Einen zugeschrieben werden, nicht nur weil das Wollen von dem Wollenden verschieden ist, sondern auch weil es sich auf das Gute richtet, wie das Denken auf das Gedachte. Es kann überhaupt nichts von dem Einen prädiziert werden. Wir können nur sagen, was es nicht ist, nicht, was es ist. Es ist jenseits von allem Denkbaren, daher unerkennbar und unbenennbar. Selbst die Namen, die Plotin gewöhnlich zur Bezeichnung des Urwesens gebraucht, das Eine und das Gute, kommen ihm nicht in dem Sinne zu, wie sie sonst gebraucht werden. Die Benennung als das Eine ist auch nur negativ zu verstehen; sie drückt den Mangel jeglicher Vielheit aus. Der Name des Guten aber drückt nur aus, was es für die übrigen Wesen, nicht was es an sich ist. Ein positives Moment aber bleibt doch nach allen Negationen an der Vorstellung des Urwesens haften. Es ist eben das Urwesen, das Erste und als solches die Ursache von allem. Dieses Moment der Ursächlichkeit konnte nicht aufgehoben werden, weil es durch die Fragestellung gegeben war, die zu der 
Bildung des Begriffs führte: „Wie muß die erste Ursache alles Daseins und Geschehens in der Welt gedacht werden?" Auch ist nicht zu verkennen, daß der negative Begriff für das Gefühl des Philosophen in die positive Vorstellung des höchsten Wertes und der höchsten Vollkommenheit umschlägt. Da alles Endliche und Bedingte unserem Philosophen als ein Unvollkommenes gilt und nur Endliches und Bedingtes in Begriffen ausgedrückt werden kann, so ist für ihn gerade die völlige Unbegreiflichkeit des Ersten seine höchste Vollkommenheit.

Gerät aber nicht Plotin mit sich selbst in Widerspruch, wenn er dem Die göttliche absolut Bestimmungslosen nun doch eine Bestimmung beilegt, die Eigenschaft nämlich, diese bestimmte Welt mit ihrem ganz konkreten Inhalt hervorzubringen? Ist ein Hervorbringen nicht Tätigkeit, die dem Einen so gut wie Denken und Wollen abgesprochen werden muß, weil sie seine Abgeschlossenheit aufhebt und ihm eine Beziehung nach außen gibt? Muß das Eine, das eine Vielheit von Dingen hervorbringt, nicht diese Vielheit wenigstens potentiell schon in sich tragen? Diesen naheliegenden Einwänden mußte der Philosoph durch eine besondere Auffassung der göttlichen Kausalität auszuweichen suchen. DaB das Urwesen, um alles hervorzubringen, Aktualität (Energie) haben muß, gibt er zu. Es ist aber diese Energie nicht ein von ihm unterscheidbares $Z$ weites, sondern es ist selbst Energie. Das Urwesen ist vollkommen; weil es vollkommen ist, besitzt es alle Kräfte und Fähigkeiten, also auch die Fähigkeit, ein anderes Wesen hervorzubringen. Die Fähigkeit des Hervorbringens muß dem Urwesen beigelegt werden. Denn ohne sie wäre es nicht das Urwesen. Aber indem wir ihm diese Fähigkeit zuschreiben, sagen wir nicht von ihm etwas aus, sondern nur von der übrigen Welt. Diese Kausalität ist kein korrelatives Verhältnis, bei dem das Wesen der Ursache in der Hervorbringung dieser Wirkung aufgeht und durch sie bestimmt werden kann, sondern die Wirkung ist für das Urwesen als solches ganz außerwesentlich. Die hervorgebrachte Welt hängt von ihrer Ursache ab, blickt und wendet sich zu ihr empor; das Urwesen aber wendet sich nicht zu dem hinab, was unter und nach ihr ist. Es brauchte nicht die Schöpfung eines zweiten Wesens sich vorzunehmen, sondern diese war eine ungesuchte Folge seines Daseins. Es ist eine Eigentümlichkeit aller Wesen auch in der sinnlichen Welt, sagt Plotin, wenn sie zur Vollendung gelangt sind, zu zeugen. Das Tier, die Pflanze, wenn sie zur Reife gelangt sind, erzeugen andere ihresgleichen; sie selbst aber bleiben nach der Erzeugung, was sie vorher gewesen sind. Wie sollte also das allervollkommenste Wesen hierzu unvermögend sein oder mißgünstig seinem Vermögen Einhalt tun. Das Urwesen ist Überfülle; darum floß es gewissermaßen über. Aus seinem Überfluß wurde ein zweites Wesen. Aber das Urwesen verlor dadurch nichts von seiner Fülle. Auch trennte sich der Strom nicht von seiner Quelle, die Pflanze nicht von ihrer Wurzel. Das Abgeleitete bleibt in dem Urwesen, nicht aber das Urwesen in ihm. Es ist nicht ein und dasselbe mit ihm und doch auch nicht von ihm gesondert. Schon Platon hatte die Idee des Guten mit einer Sonne 
Das Geschaffene verglichen. Auch Plotin gebraucht das Verhältnis der Sonne zu ihrem Licht als Ausstrahlung. als Symbol für das Verhältnis des Schöpfers zum Geschaffenen. Die Sonne strahlt das Licht aus und bleibt dabei unverändert dieselbe; sie gibt, ohne daß sich ihre Fülle erschöpfte oder auch nur im geringsten minderte. Neben diesem Bilde, das uns schon bei Philo begegnet ist, bedient sich Plotin auch noch anderer, um das unfaßbare Verhältnis des Geschaffenen zum Schöpfer zu bezeichnen; es soll sich zu ihm verhalten wie sein Schatten oder sein Spiegelbild. In den letztgenannten Bildern tritt eine andere für das System wesentliche Seite hervor, die Unvollkommenheit des Abbildes im Vergleich mit der Vollkommenheit des Urbildes. Platon hatte zwischen den Ideen und den Sinnendingen das Verhältnis von Urbild und Abbild angenommen, zu dem an sich ein direkter kausaler Zusammenhang nicht gehört. Schatten und Spiegelbild enthalten dieses kausale Moment. Plotin, der die Ideenwelt nicht für das Erste hielt, sondern das Gute, das bei Platon nur die höchste Idee gewesen war, über die Ideenwelt hinausheben wollte, als ein vor ihr und über ihr beștehendes selbständiges IVesen, übertrug auf das Verhältnis des Guten zu den Ideen, was Platon vom Verhältnis der Ideen zu den Sinnendingen gelehrt hatte. Nur modifizierte er die platonische Vorstellung der Gesamtabsicht seines Systemes gemäß durch Hinzufügung des kausalen Momentes. Hieraus entstand die für seine ganze Lehre grundlegende, aus dem Kausalitätsbegriff nicht ableitbare Vorstellung, daß die Wirkung unvollkommener ist als die Ursache, und aus dieser Vorstellung die einer stufenweise vom Vollkommenen zu immer unvollkommeneren Wesen fortschreitenden Entwickelung. Doch soll diese Entwickelung, da Zeit und Raum erst auf ihrer letzten Stufe in der sinnlichen Welt auftreten, natürlich weder als ein Vorgang in der Zeit noch als eine Bewegung im Raume aufgefaßt werden. Da die Einheit für Plotin die Vollkommenheit ist, so besteht die Zunahme der Unvollkommenheit in dern immer stärkeren Hervortreten der Vielheit, Teilbarkeit und Veränderlichkeit. Aus dem Ersten geht als zweites Wesen der Geist oder die intelligible Welt hervor, aus diesem als drittes Wesen die Seele, die wieder ihrerseits die Materie schafft. So werden alle Wesensstufen, die Materie nicht ausgeschlossen, in eine einheitliche Kette kausalen Zusammenhanges geordnet und damit wenigstens hinsichtlich des Gesamtaufbaues der Lehre eine Geschlossenheit erreicht, wie sie kein früheres System besaß. Denn das Verhältnis jeder folgenden Seinsstufe zu der ihr vorausgehenden ist, von gewissen Modifikationen abgesehen, immer dasselbe, welches wir in unserer Besprechung der Kausalität des Urwesens geschildert haben. Es ist das Verhältnis der Wirkung zur Ursache, des Akzidentiellen zum Substantiellen, des Abbildes zum Vorbild, der Erscheinung zum Ding an sich. Alle diese verschiedenen Beziehungen sind in dem enthalten, was Plotin "Nachfolgen“ und „Spätersein" nennt; und überdies hat er noch das Verhältnis des Strebens zum Zweck hineingetragen. Die absteigende Entwickelung erfolgt zwecklos, durch bloße Naturnotwendigkeit, die rückläufige aufsteigende ist vom Zweck beherrscht. Jedes Nachfolgende wendet 
sich $z u$ dem Nächsthöheren hin, an dem und in dem es sein Dasein hat, und findet in ihm seinen $Z$ weck.

Wir müssen nun die einzelnen Wesenstufen der Reihe nach betrachten, Der Geist oder und zwar zuerst den Geist oder die intelligible Welt. Das Wesen, das von die intelligible dem Ersten erzeugt wurde, mußte eine Vielheit sein, um verschieden vom Einen und von geringerer Vollkommenheit zu sein; und doch auch wieder eine Einheit, als Ebenbild des Einen. Dieses Wesen ist der Geist (Nüs). Plotin setzt als zweite Seinsstufe an, was auf Grund der durch Aristoteles weitergebildeten platonischen Lehre von den Denkern dieser Richtung sunst als erste und höchste angesetzt wurde, den göttlichen Geist. Darin bestand eben seine Neuerung, daß er das Gute noch über den Geist stellte. Nun lenkt er in die bekannten Wege ein. Seine Auffassung des Geistes ist nicht nur von Plato, sondern auch von Aristoteles und den späteren Platonikern beeinflußt. Das Wesen des Nus besteht in der Einheit von Denken und Sein. Das Seiende ist das Gedachte oder Denkbare. Es kann aber bei dem höchsten Geist, dessen Denken vollkommene Wahrheit ist, das Gedachte nicht als etwas von dem Denkenden Verschiedenes außer ihm bestehen. Denn vollkommene Wahrheit hat nur das Denken, das seinen Gegenstand selbst besitzt. Dies ist unmöglich, wenn das Gedachte außer dem Denkenden besteht. In diesem Falle kann nämlich das Denken nur einen Typus seines Gegenstandes besitzen und nicht vollkommen wahr sein. Daher ist der Geist ein Denken, das sich selbst denkt. So ist er als Denkendes der Geist, als Gedachtes das Seiende. Die Tätigkeit des Geistes ist das Denken. Es ist aber bei dem göttlichen Geist die Tätigkeit vom Wesen, das Denken rom Denkenden nicht verschieden. Er ist selbst reine Tätigkeit (Energie). Daher ist Denkendes, Denken und Gedachtes in ihm ein und dasselbe. Sein Denken ist nicht ein suchendes, durch Schlüsse und Beweise von Urteil zu Urteil fortschreitences Denken, sondern ein ruhendes, anschauendes Denken, das ewig und unveränderlich seinen Gegenstand besitzt. Der Geist ist dem Einen, das ihn erzeugt hat, zugewendet und spiegelt dieses ab. Das Eine ist die Ursache seines Seins und seines Denkens. Von ihm wird der Geist mit Inhalt erfüllt. Aber was in dem Urwesen Einheit ist, stellt sich in ihm als eine Vielheit dar, die ein einheitliches System bildet. Der Allgeist ist alles Seiende. Diese Allheit besteht aber aus vielen einzelnen Momenten, von denen jedes zugleich Geist und Seiendes ist. Alle diese Momente sind im Geiste klar geschieden und doch zur Einheit verbunden. Es gibt für ihn wedcr Vergangenes noch Zukünftiges, sondern sein ganzer Inhalt ist ihm immer gleichzeitig gegenwärtig. Außer dem Denken und Sein, Die Kategoricn. von dem schon die Rede war, ist in ihm Bewegung und Ruhe, Identität und Verschiedenheit. Als dem Denkenden kommt ihm Leben und Bewegung, als dem Seienden Ruhe und Beharren zu. Die Identität beruht darauf, daß es ein und dasselbe Wesen ist, das sich als Denkendes und Seiendes darstellt. Auch haben die vielen Denkobjekte alle unter sich etwas Gemeinsames. Die Verschiedenheit ist dadurch gegeben, daß das Denkende vom Gedachten und daß die Denkobjekte untereinander verschieden sind. Denn jedes Seiende 
kann nur als von anderen verschieden gedacht werden. Aus der Mehrzahl des Seienden entsteht die Kategorie der Zahl und der Quantität, aus der Eigentümlichkeit jedes einzelnen Seienden die der Qualität. Die Vielheit, die der

Ideen und Zahlea. Geist in sich befaßt, besteht in den Begriffen oder Ideen, die Plotin auch mit den Pythagoreern als Zahlen ansieht. Die soeben aufgezählten sind die Grundbegriffe (Kategorien), die sich auf alles Seiende erstrecken. Die übrigen sind aus ihnen abgeleitet; und zwar gibt es ihrer so viele im Nūs wie Einzelwesen in der sinnlichen Welt. Die platonischen Ideen haben also bei Plotin ihren ursprünglichen Charakter als Gattungstypen ganz abgestreift und sind Urbilder der Einzelwesen geworden. Allen Ideen liegt etwas Gemeinsames zugrunde, ein Substrat, in dem die unterschiedlichen Formen ausgeprägt sind: die intelligible Materie. Bezüglich der Ideen gilt auch, was oben über die kausale Grundrichtung von Plotins Denken bemerkt wurde. Da die Ideen nicht nur Urbilder der Einzelwesen, sondern auch Ursachen ihrer Entstehung sein sollen, so werden sie von Plotin als wirkende Kräfte aufgefaßt. Die früher (bei Gelegenheit des philonischen Systems) berührte Schwierigkeit, Denkobjekte mit den Gedanken eines Subjektes und die letzteren mit wirkenden Wesen zu identifizieren, ist von Plotin durch seine Lehre vom Nús geschickt vermieden. Hier ist wirklich der Unterschied von Denkobjekt und Denksubjekt aufgehoben, und ganz folgerichtig wird dann auch jeder Einzelgedanke als ein selbstdenkender Geist aufgefaßt. Ist er aber dies, so kann er auch wirken und verursachen. Der Nūs kann nun, insofern in ihm die sinnliche Welt mit allen in ihr enthaltenen Einzelwesen vorgebildet ist, die intelligible Welt genannt werden. Sie unterscheidet sich von der sinnlichen dadurch, daß sie nicht in Raum und Zeit ist. Die Vielheit ist in ihr zur Einheit verbunden. Sie ist frei von jeder Unvollkommenheit, sie ist ewig und unveränderlich. Es herrscht in ihr Harmonie, Schönheit und Seligkeit.

Wie das Urwesen den Nūs, so bringt der Nūs, mit Naturnotwendigkeit und ohne darauf sein Absehen zu richten, ein drittes Wesen hervor: die Seele. Die Seele ist Wirkung, Erscheinung, Abbild des Nūs. Sie verhält sich zu ihm wie der ausgesprochene Logos zu dem gedachten. Wie jedes Abbild ist sie unvollkommener als das Urbild; die Unvollkommenheit aber besteht in einem stärkeren Hervortreten der Vielheit auf Kosten der Einheit. Sie ist $z$ war an und für sich als intelligibles Wesen unteilbar, aber sie hat die Fähigkeit, sich zu teilen, indem sie in die räumlich-sinnliche Welt, die von ihr geschaffen wird, eingeht und alle ihre Teile und die einzelnen Körper und ihre Teile beseelt. Aber was sich teilt, ist doch nur ihre Wirkung, nicht sie selbst. Da die Körper vermöge ihrer eigenen Teilbarkeit nicht die ganze Wirkung der Seele in sich aufzunehmen vermögen, zeigen sich an ihnen Teilwirkungen. Diese Lehre Plotins ist aus der Stelle im Timäus herausgesponnen, wo Platon die Seele aus der teilbaren und der unteilbaren Substanz mischen läßt. Das Denken ist eine Tätigkeit der Seele, die ihr als dem Abbild des Nus zukommt. Nur ist ihr Denken ein weniger vollkommenes, ein suchendes und fortschreitendes Denken. Auch ist das Denken nicht ihre einzige Tätigkeit. 
Blickt sie auf den, der ihr vorausgeht, den Nūs, so denkt sie; blickt sie auf sich selbst, so sucht sie sich zu erhalten; blickt sie auf das, was nach ihr kommt (die Materie), so sucht sie es zu ordnen und zu gestalten nach den Mustern, die sie im Nūs geschaut hat. Hiermit hängt es zusammen, daß bei ihr zum Denkvermögen das Begehrungsvermögen hinzutritt. Sie hat schon ihrem Wesen nach eine doppelte Beziehung, eine nach oben und eine nach unten, was beim Nūs, obgleich er auch zwischen einem Oberen und einem Unteren in der Mitte steht, nicht der Fall ist.

In der Natur der Seele liegt es, die Materie hervorzubringen. Sie ist das Die Materie. letzte Glied der intelligiblen Welt; was nach ihr kommt, ist das Sinnliche. In der stufenweisen Ableitung aus dem Einen und Guten ist jetzt eine Stufe erreicht, wo die Kraft zur Erzeugung eines weiteren Wesens zwar noch vorhanden ist, dieses Wesen aber (die Materie) den Abschluß des ganzen Erzeugungsvorganges bilden muß, da sie von dem Guten und Einen nichts mehr hat. Die Lichtatmosphäre der intelligiblen Sonne endet hier und geht in Finsternis über. Die Materie ist ohne Einheit, ohne Ordnung, ohne Form und Gestalt. Sie ist ein Nichtseiendes, weil sie von allem Seienden verschieden ist. Sie ist aber nicht das absolute Nichts. Sie ist in einem anderen Sinne als das Seiende. Wir können uns von ihr keine anschauliche Vorstellung bilden, sondern nur aus dem Qualitätswechsel der Körper erschließen, daß den wechselnden Qualitäten ein bleibendes, selbst qualitätsloses Substrat zugrundeliegt. Wir bilden uns diese Vorstellung durch Abstraktion von allen bestimmten Eigenschaften der Körper. Als Widerspiel und völlige Privation des Guten ist diese Materie das Böse. Die Seele konnte das ihr innewohnende Streben nach Betätigung ihrer Kräfte (d. h. der vom Nũs entlehnten Ideen) nicht befriedigen, ohne sich ein solches Substrat zu erzeugen. Natürlich sind diese Erzeugung und Gestaltung der Materie durch die Seele nicht als in der Zeit stattfindende, zeitlich aufeinanderfolgende Vorgänge aufzufassen. Nur zum Zwecke der Verdeutlichung, sagt Plotin, zerlegen wir diesen Vorgang begrifflich in frühere und spätere Momente. Es war nie eine Zeit, wo die Seele aus dem Nūs hervorgegangen war, aber noch keine Körperwelt existierte. Sie könnte gar nicht, sagt er, hervortreten, wenn es keinen Körper gäbe; denn einen anderen Ort gibt es nicht, in dem zu sein ihrem Wesen entspräche. Auch gab es nie eine ungeordnete Materie. Es ist also ein ewiger einheitlicher Vorgang, den wir begrifflich in drei aufeinanderfolgende Momente zerlegen: Hervortreten der Seele aus dem Nūs, Erzeugung der Materie durch die Seele, Ausgestaltung der Materie durch die Seele zu einer Körperwelt. Hierin liegt die Leugnung eines zeitlichen Anfanges der Welt und eines Weltunterganges. Auch die sinnliche Welt ist als Ganzes ewig, wenn auch ihre einzelnen Teile vergänglich sind.

Alles bisher Gesagte gilt zunächst von der allgemeinen Seele oder Welt- Weltseele und seele. Man kann an dieser, vermöge ihrer Doppelstellung, zwei Seiten unterNatur. scheiden. Nach der einen Seite ist sie dem Nũs zugewendet, als ein intellektuelles Wesen, das von ihm die Ideen übernimmt, nach der anderen Seite ist 
sie der Körperwelt zugewendet und gestaltet diese nach dem Muster jener Ideen. Bisweilen scheint Plotin eine höhere und eine niedere Weltseele zu unterscheiden, aber er will dadurch die Einheit der Weltseele nicht aufheben, sondern legt nur die beiden in ihrem Wesen enthaltenen Grundfunktior ən begrifflich auseinander. In ihrer der Körperwelt zugewandten Funktion heißt Einzelseelen. die Weltseele Natur und wirkt ohne Bewußtsein. Alle Einzelseelen sind in der Weltseele enthalten und zu einem einheitlichen System von Seelen verbunden. Diese Einzelseelen sind identisch mit den Ideen, welche die Seele rom Nus übernimmt. Auch die Ideen im Nus werden ja von Plotin, wie wir sahen, als wirkende Kräfte und Geister aufgefaßt. In der Seele, dem Ebenbild des Nus, entsprechen diesen Geistern ebensoviele Keimkräfte (spermatikol lógoi), die in der Materie wirken. Hier kann sich Plotin die stoische Vorstellung von den Keimkräften im wesentlichen aneignen. Die Abstufung der Naturformen bis hinauf zum Menschen beruht nach ihm darauf, daß die Seele der Materie nur so viel von ihrer $\mathrm{Kraft}$ mitteilt, als diese zu fassen vermag. Daher zeigt sich an den Naturwesen bald ein größerer, bald ein geringerer Teil der seelischen Kräfte. Die Seele selbst bleibt dabei ungeteilt. Auch das räumliche Nebeneinanderbestehen der Körper betrifft nur die Materie. Die Seele selbst ist nicht im Raume, also auch nicht räumlich geSympathie und teilt. Die Einheitlichkeit derWeltseele ist für Plotin der Grund ihrer Schönheit Schöaheit des
Kosmos. in dem alles mit allem in sympathetischem Zusammenhange steht. Wie schon für die Stoiker bildet auch für ihn die Lehre von der Sympathie des Kosmos die theoretische Grundlage für die Verteidigung der Magie und der Mantik. Es ist bemerkenswert, daß Plotin trotz seiner Verachtung der Sinnlichkeit den Kosmos in begeisterten Worten als schön, harmonisch, vollkommen preist. Die Schönheit, die dem Kosmos als dem Abbild der intelligiblen Welt zukommt, wird also durch den Umstand nicht aufgehoben, daß er aus der Materie, dem Prinzip des Bösen, gebildet ist. Wenn auch weniger vollkommen als die intelligible Welt, ist diese Welt doch in ihrer Art vollkommen, so vollkommen wie ein materieller Kosmos sein kann. Sie bildet einen notwendigen Bestandteil des Alls. Wenn also der Kosmos als Ganzes durch die Materie nicht verdorben ist, so kann diese offenbar nur wegen der Rolle, die sie im Leben der einzelnen Menschenseele spielt, als das böse Prinzip bezeichnet werden.

Wir kommen nun zu der Lehre Plotins von der Menschenseele, von ihren Munschensecle. Schicksalen und ihrer Aufgabe, der offenbar die ganze Metaphysik, die wir bisher besprochen haben, als Unterbau dienen soll. Es sind die uralten pythagoreischen Vorstellungen von dem Fall der Seele und von ihrer Rückkehr in die himmlische Heimat, die uns hier in einen größeren systematischen Zusammcnhang hineingestellt wieder begegnen. Die einzelne Menschenseele ist, wie wir schon sahen, ein Teil der Weltseele, dem aber die Gabe selbständigen und freien Handeln verliehen ist. Vor ihrer ersten Einkörperung hat die Seele, als Teil der Weltseele, in der intelligiblen Welt gelebt und dort, den höheren Regionen zugewendet, alles Seiende und das überseiende 
Gute geschaut. Ihre Einkörperung beruht auf der allgemeinen Notwendigkeit, vermöge deren die Weltseele nicht umhin kann, das, was nach ihr kommt, mit ihren Kräften, d. h. eben mit den Seelen zu durchdringen und zu gestalten. Zugleich aber ist die Einkörperung eine freiwillige Handlung der einzelnen Seele. Denn die allgemeine Notwendigkeit äußert sich in ihr als ein eigener unwiderstehlicher Drang. Nachdem aber die Einzelseele sich dem Wirken in der sinnlichen Welt zugewendet hatte, vergaß sie ihre Würde und Herkunft, gab sich ganz dem niederen Berufe hin und verlor den innigen Zusammenhang mit den höheren Regionen und mit Gott. Es ist nicht Plotins Meinung, daß die Einzelseele sich je völlig von der Weltseele loslösen und aufhören kann, ein Teil derselben sein. Aber es findet eine Abwendung der Seele von Gott Abwendung der statt, durch die sie ihn und sich selbst nicht mehr kennt und statt dessen Dinge begehrt und hochschätzt, die weit unter ihrer Würde sind. Was sie nun tut, nachdem sie die Abwendung einmal vollzogen hat, ist nicht mehr freiwillig, sondern unfreiwillig. Denn die Freiheit besteht für sie darin, der ihrer eigenen Natur entsprechenden höheren Notwendigkeit zu folgen. Jetzt ist sie unfrei, weil sie einer niederen, aus der Materie stammenden Notwendigkeit folgt. Plotin denkt sich den Abstieg der Seele in die Körperwelt bildlich wie die Ausdehnung einer dehnbaren Substanz, die oben befestigt ist, nach unten. Indem sie sich nach unten ausstreckt, bleibt ihr Haupt in der Höhe. $\mathrm{Da}$ das Himmelsgewölbe als der vollkommenste Teil des Kosmos der intelligiblen Welt am ähnlichsten ist, so wird es zuerst und von den meisten Seelen bevölkert. Dort nehmen sie einen Körper an und steigen mit ihm weiter abwärts. Manche sinken bis in die tiefste Region, bis in die feste, erdartige Substanz hinab, die an wenigsten geeignet ist, an dem Unkörperlichen teilzunehmen. Dies ist wohl nötig für das Ganze, damit alle, auch die niedrigsten Körper, soviel als es ihre Beschaffenheit erlaubt, beseelt und gestaltet werden; aber für sie selbst ist es nicht gut. Wie sollen wir uns nun die Verbindung der Seele mit dem Körper denken? Offenbar muf sie nach der Analogie der Seele und übrigen Zusammenhänge zwischen je zwei aufeinanderfolgenden Seinsstufen Körper. gedacht werden. Unmöglich kann die Seele, die ein intelligibles Wesen ist, in dem Körper wie in einem Gefäß eingeschlossen sein. Immer ist es ja das höhere Wesen, welches das niedere umfaßt, hält und trägt. Das niedere Wesen ist eine Ausstrahlung, eine Erscheinung des Höheren. Dies muß auch von dem Verhältnis des Leibes zu seiner Seele gelten. Man kann in dem Leibe zwei Bestandteile unterscheiden: I. die Materie, die sich die Seele, um ihre Logoi ausprägen zu können, schaffen mußte, wie der Nūs die intelligible Materie als gemeinsames Substrat aller Ideen; 2. die Einstrahlung der Seele in die Materie. Diese ist nur ein Schattenbild, eine Erscheinung der wirklichen Das SchattenSeele. In gewissem Sinne gehört sie mehr zum Körper als zu der Seele, und doch auch wieder zu der Seele selbst. Denn wenn diese sich von dem Körper entfernt, zieht sie auch dies ihr Scheinbild aus ihm heraus. Diese Einstrahlung, dieses Schattenbild benutzt Plotin, um die Gemeinschaft der Seele mit dem materiellen Körper begreiflich zu machen. Auch in der Welt 
gibt es ja eine höhere und eine niedere Weltseele, die sich ebenso zueinander verhalten wie die Einzelseele zu ihrer Ausstrahlung in den Leib. Diese Seelenerscheinung im Körper entspricht den niederen, vernunftlosen Seelenteilen der platonischen Lehre und der vegetabilischen und animalischen Seele bei Aristoteles. Plotin verwendet sie, um von der eigentlichen Seele die Zerteilung fernzuhalten. Der Leib ist in allen seinen Teilen belebt, und zwar in verschiedener Weise. Man darf aber nicht glauben, daß die Seele selbst sich auf die Teile des Leibes verteilt und jeden derselben mit einem ihrer Teile belebt. Sondern sie wirkt auf jeden Teil des Körpers ganz; nur kann je nach der Beschaffenheit der einzelnen Teile immer nur ein Teil ihrer Kräfte an ihm zur Erscheinung kommen. Ferner erklärt Plotin die sinnliche Lust und Unlust, die sinnliche Begierde, die sinnliche Wahrnehmung für Erlebnisse jenes Schattenbildes der Seele, die von der eigentlichen Seele nicht erlitten, sondern nur vorgestellt werden. Unser „Ich“ ist eigentlich der göttliche Teil der Seele, aber durch die Beziehung zum Leibe hat sich diesem ein tierischer unten angehängt, der so zu ihr gehört wie die Wärme zu dem Feuer, von dem sie ausgestrahlt wird. Nur in dem uneigentlichen, erweiterten Sinne des Ichbegriffs sind daher die Gefühle, Begierden und Sinneswahrnehmungen die meinen. Plotin geht noch weiter. Er lehrt, daß auch die Sünden und Schlechtigkeiten und die ethischen Tugenden und die ihnen entsprechenden Handlungen nur Zustände und Handlungen des erweiterten "Ich", nicht der eigentlichen Seele sind. Die letztere ist fehlerfrei, und nicht sie ist es, die im Hades für ihre Sünden gestraft wird und von Körper zu Körper wandern muß. Die Vorstellung, daß alles Leid und Unglück des menschlichen Lebens gar nicht unser eigentliches Selbst betrifft, sondern nur Die Einbildungs-das Tier, das wir mit uns tragen, soll uns über dieses Leid erheben. - Auf der Grenze der niederen und der höheren Seele steht die Einbildungskraft. Sie ist eine Tätigkeit der Seele selbst, an der der Körper nicht beteiligt ist, aber ihren Gegenstand bilden noch die sinnlich wahrnehmbaren Dinge. Die Der Logos. höhere Seele selbst besteht aus dem Logos und dem Nūs, die sich zueinander verhalten wie Stoff und Form. Dèr Logos, die der Seele in Gegensatz zum Nūs eigentümliche Erkenntniskraft, ist der Sitz des suchenden, fortschreitenden Denkens. Der Logos denkt, wenn er sich dem Nūs zuwendet; wendet Rückkehr der er sich von ihm ab, so bleibt er leer. Er empfängt also vom Nus die Begriffe, Seele zu Gott. die in jenem ewig aktuell sind. So kann also die Seele (der Logos) ihre Aufgabe nur erfüllen durch die Abwendung von der Sinnlichkeit und durch die Hinwendung zum Nūs und (durch seine Vermittelung) zu dem übervernünftigen Guten, zu Gott. Solange die Seele mit dem Leibe verbunden ist, kann sie dieses Ziel, die Rückkehr zu Gott und die Verähnlichung mit Gott, nicht oder doch nur selten und für kurze Augenblicke erreichen. Um es aber nach dem Tode erreichen zu können, muß die Seele schon in ihrem irdischen Leben auf ihre Losłösung vom Leibe Bedacht genommen haben. Hat sie sich zu tief in die Sinnlichkeit verstrickt und ihres hohen Ursprunges vergessen, so ist sie auch nach dem Tode unfähig, sich in die übersinnliche 
D. Die Philosophie der rörnischen Epoche. VI. Der Neuplatonismus des Plotinus. 259

Welt aufzuschwingen. Sie muß sich mit einem anderen Leibe verbinden, je nach dem Grade ihrer Verschuldung mit einem menschlichen, tierischen oder pflanzlichen Leibe. Die reineren Seelen werden auf die Gestirne des Himmels versetzt, und nur die allerreinsten dürfen zu Gott zurückkehren.

Auf diesen Voraussetzungen baut sich die Tugendlehre Plotins auf. Er verwirft nicht nur die epikureische Tugendlehre, die die Lust für ein Gut, die Unlust für ein Übel und das Erstreben der Lust und das Meiden der Unlust für Tugend hält, sondern auch die stoische, die zwar anfänglich, indem sie die Tugend für das höchste Gut erklärt, einen höheren Flug zu nehmen scheint, bald aber mit ihrer schönen Tugend sich wieder zu ebener Erde befindet, wenn sie die rechte Auswahl sinnlicher Dinge für Tugend ausgibt. Er selbst folgt Platon, der als die Aufgabe des Menschen bezeichnete: Gott ähnlich zu werden. Die vier Kardinaltugenden aber, deren Begriffe Platon in der "Republik“ entwickelt hatte, sind nach Plotin nicht die Tugenden, durch die wir Gott ähnlich werden. Sie sind bürgerliche Tugenden und beziehen sich auf das handelnde Leben. Dieses aber bewegt sich in der sinnlichen Welt und führt uns nicht dazu, Gott ähnlich zu werden. Die bürgerlichen Tugenden haben ihr Wesen in einer Ordnung und Mäßigung des Trieblebens der niederen Seele. Dies kann nicht genügen, weil die Befleckung durch den Leib an und für sich ein Übel für die Seele ist. Es gilt also, nicht nur die Gefühle und Begierden zu mäßigen, sondern überhaupt die Seele aus der befleckenden Verbindung mit dem Leibe zu lösen. Das Wesen der höheren Tugend ist Reinigung (Katharsis). Aber die Reinigung ist nur der Weg, der zur Reinheit führt. Die karthartische Tugend kann also auch nicht die Tugend sein, die uns Gott ähnlich macht. Wenn alles, was uns von Gott trennte, durch die Reinigung aufgehoben ist, dann muß sich die Seele wieder ihrem Urquell zuwenden. In der Vereinigung mit dem Nūs erwirbt sie die höchsten Tugenden. Aus diesem Gedankengang geht hervor, daß Plotins Ethik der Praxis nur einen untergeordneten Wert beimißt und die höchste Aufgabe des Menschen in die Theorie setzt. Er erklärt auch ausdrücklich, daß alle Praxis um der Theorie willen da sei. Es gibt aber noch ein höheres Ziel als das Leben im Nūs: die Vereinigung mit dem jenseits des Nas liegenden Einen, mit der Gottheit selbst. Zu ihr kann man nicht durch Denken gelangen, da sie jenseits von allem Denkbaren ist, sondern nur durch eine ekstatische Verzückung, in der alle Vielheit der Vorstellung aus unserem Bewußtsein schwindet und die selbst einsgewordene Seele mit cem Einen in unmittelbare Berührung tritt.

In religiöser Beziehung kann man Plotins Lehre als eine ausgleichende Vermittelung zwischen Theismus und Pantheismus, zwischen Monotheismus und Polytheismus bezeichnen. Insofern er den höchsten Gott von der Welt unterscheidet und hoch über sie hinaushebt, ist er Theist; insofern er alle übrigen Wesen nicht nur aus dem Einen hervorgehen, sondern auch als Ausstrahlung desselben in ihm und an ihm bleiben, von ihm getragen und gehalten werden läßt, ist er Pantheist. Für diese Auffassung schwindet auch der Ge- 
Polythessmus. gensatz von Monotheismus und Polytheismus. Plotin findet den Polytheismus mit seinem Kultus des Absoluten vereinbar und wirft sich zu seinem Verteidiger auf. Alle in ihrer Art vollkommenen Offenbarungen des göttlichen Wesens sind Gottheiten, nicht nur der Nūs und die in ihm enthaltenen Einzelgeister, sondern auch die Weltseele und die in ihr enthaltenen Einzelseelen, soweit sie in der höheren Region des Kosmos bleiben und nicht in die sublunare Region hinabsinken. Auf diese Weise gewinnt Plotin die Möglichkeit, die polytheistische Religion seinem System einzuverleiben. Es entsteht die Vorstellung einer an Wert und Würde mannigfach abgestuften Götterwelt. Auch die Gestirne gelten ihm als sichtbare Götter. Die Nachfolger Plotins haben diese theologische Seite seines Systems weiter ausgebildet. Bei Porphyrius und Iamblichus gipfelt der Neuplatonismus in einer philosophischen Dämonenglaube.Apologie des Polytheismus. Die Luftregion unter dem Monde denkt sich Plotin wie andere Philosophen vor ihm mit guten und bösen Dämonen bevölkert. Auch dieser Dämonenglaube artete bei seinen Nachfolgern immer mehr in phantastisch-abergläubische Vorstellungen aus. Durch seinen extremen Spiritualismus hat Plotin ganz das Verständnis verloren für den gesetzlichen Zusammenhang der physikalischen Vorgänge. Alle Wirkungen in der Welt sind geistiger oder seelischer Natur. Die durch Druck und Stoß vermittelten mechanischen Vorgänge sind nur unwesentliche Akzidentien der Seelenwirkung. Da nun alles seelische Leben im Kosmos eine Einheit bildet, so können über die weitesten $Z$ wischenräume hinweg sympathetische Fernwirkungen ausgeübt werden. Diese Seite von Plotins Lehre war es vor allem, die bei seinen NachMagre und folgern zu dem ausschweifendsten Aberglauben führte. Magie und Theurgie Theurgie. wird in der Schule des Iamblichus zu einem ständigen Zubehör der Philosophie. Vor allem handelte es sich um die Frage, ob die Seele bei ihrer Flucht aus der Sinnlichkeit und ihrer Rückkehr zu Gott sich der Hilfe der Dämonen und Engel zu bedienen habe, und ob es möglich sei, sich diese Hilfe durch Beschwörungen, Weihen und andere magische Handlungen zu sichern. Diese ganze Entwickelung soll hier nicht weiter verfolgt werden, da sie für die Geschichte der Philosophie ohne Bedeutung ist.

Spätere In philosophischer Beziehung hat die das 4. Jahrhundert beherrschende Nouplatoaiker. Schule des Iamblichus hauptsächlich das von Plotin entworfene Bild der intelligiblen Welt durch Einschiebung weiterer Zwischenwesen ausgebaut. Auch diese Entwickelung gedenken wir nicht zu verfolgen. Im 5. Jahrhundert hatte der Neuplatonismus noch einmal in Proklos (410-485), dem Haupt der platonischen Schule in Athen, einen achtbaren Vertreter. Ihm folgten Marinus, Isidorus und Damascius. Im Jahre 529 wurde durch ein Edikt. des Kaisers Justinian die platonische Schule zu Athen aufgehoben. Ihre letzten Vertreter, unter denen sich außer Damascius und Priscianus auch Simplicius, der treffliche Kommentator aristotelischer Schriften, befand, wanderten zum König Chosroës nach Persien aus. Aus ihrer Heimat vertrieben, mußte die griechische Philosophie bei den Barbaren eine Zufluchtsstätte suchen. So endete ruhmlos eine mehr als tausendjährige Entwickelung. 


\section{Literatur.}

\section{Quellen.}

Bezüglich der antiken Quellen ist zu bemerken, daß uns von den Schriften der Philosophen vor Platon nur Bruchstücke erhalten sind, die durch dogmengeschichtliche (doxographische) Überlieferungen ergänzt werden. Dasselbe gilt von den Zeitgenossen des Platon und Aristoteles. Dagegen ist Platons ganzer literarischer Nachlaß unverkürzt erhalten und von ARISTOTELES die Mehrzahl der strengwissenschaftlichen Lehrschriften, während seine für ein größeres Publikum bestimmten Schriften und die ganze Masse der einzelwissenschaftlichen Stoffsammlungen wieder nur durch Bruchstücke vertreten sind. Von THEOPHRAST haben wir mehrere vollständige Schriften und anderweitige Reste. Von EPIKUR sind drei Lehrbriefe und eine Art von philosophischem Katechismus bei Diogenes Laërtius erhalten; von dem physikalischen Hauptwerk haben sich nur dürftige Papyrusfetzen in.Herculanum gefunden, ein Ausfall, für den das Lehrgedicht des Lucretius de rerum natura, weil es die epikureische Physik für Anfänger darstellt, keinen genügenden Ersatz zu bieten vermag. Von den Häuptern der älteren und mittleren Sto a haben wir, abgesehen von dem Zeushymnus des KLeAnTHES, wieder keine vollständige Schrift. Doch lernen wir von der mittleren Stoa manches (z. B. Panaetius' Buch über die Pflichten) durch Ciceros lateinische Bearbeitungen kennen. Ohne Cicero würden wir auch von der mittleren und neueren Akademie sehr wenig wissen. Seine Schriften sind unsere reichste Quelle für die hellenistische Philosophie des 3. bis I. Jahrhunderts v. Chr. Doch ist bei ihrer Benutzung Vorsicht und Kritik geboten, da Cicero nur in der neuakademischen Lehre volle Sachkunde besitzt. Aus der römischen Kaiserzeit haben wir sehr zahlreiche philosophische Schriften in griechischer wie in lateinischer Sprache. Auch ein erheblicher Teil der christlichen $\mathrm{Li}^{-}$ teratur muß zu diesen hinzugerechnet werden. Sie beleuchten zum Teil, soweit sie neue Gedanken enthaiten, die philosophische Entwickelung ihrer Entstehungszeit, ganz überwiegend aber wirtschaften sie mit dem aus der attischen und hellenistischen Periode überkommenen Gedankenschatze und müssen uns zur Rekonstruktion der verlorenen älteren Werke die Bausteine liefern. Für den Platonismus erhalten wir umfangreiche Schriftenmassen von Plutarch von Chaeronea, der aber auch für alle übrigen Schulen, namentlich die hellenistischen, reichen Stoff liefert, von Plotin, PORPhyrios, Iamblichos, Proklos und anderen Neuplatonikern. Auch die umfangreiche Schriftstellerei des PHILON von Alexandreia gehört hierher. Für die aristotelische Philoșophie fließt eine reiche Quelle in der langen Reihe von Aristoteleskommentaren (Commentaria in Aristotelem graeca edita consilio et auctoritate Academiae Regiae Borussicae), unter denen die 'des AlEXANDER voN APHRODISIAS und des Simplicius die wichtigsten sind. Die des letztgenannten, namentlich der von H. Diels herausgegebene Kommentar zur Physik, bilden eine unserer Hauptquellen für die Vorsokratiker. Die Schriften des Arztes Galenus enthalten eine zwischen der aristotelischen und stoischen Lehre vermittelnde Naturphilosophie. Der Stoizismus ist durch Schrift. steller wie Seneca, Musonius, Epiktet, Hierokles, Marc Aurel reichlich vertreten; die pyrrhonische Skepsis durch die trefflichen Werke des SExtus EmpIRICUS, die auch für Aenesidem und die neuere Akademie und nicht minder für die von den Skeptikern be. kämpften Dogmatiker, namentlich die Stoiker sich ausgiebig erweisen. Für alle Schulen liefert uns Materialien das Werk des Diogenes LaERTius, „Lebensbeschreibungen der Philo- 
sophen", das auch doxographische Abrisse der einzelnen Systeme enthält, sowie die eigentlichen Doxographen (Arius Didymus, Aëtius), die von H. Diels in seinen Doxographi Graeci (Berlin, Reimer, 1879) musterhaft herausgegeben wurden.

\section{Fragmentsammlungen.}

Aus dieser Literatur der Kaiserzeit, von der wir einige Hauptwerke genannt haben, schöpfen hauptsächlich unsere „Fragmentsammlungen“, in denen der Versuch gemacht wird, das zur Kenntnis der verlorenen philosophischen Werke vorhandene Material übersichtlich und kritisch gesichtet und bearbeitet zusammenzustellen. Doch sind schon die Werke des Aristoteles, der seinen eigenen Erörterungen meist eine kritische Geschichte des behandelten Problems vorauszuschicken pflegte, eine Fundgrube höchst wertvoller Nachrichten über die älteren Denker. Die wichtigsten dieser Fragmentsammlungen sind: Die Frag. mente der Vorsokratiker, griechisch nnd deutsch von Hermann Diels, 2. Aufl, Berlin, Weidmann 1906-1910. - Poëtarum philosophorum fragmenta ed. H. Diels (Poë. tarum graecorum fragmenta auctore U. de Wilamowitz collecta III I) (Weidmann, I9or). (Für die alte Akadenie haben wir nur einzelne Vorarbeiten, wie Heraclidis Pontici fragmenta von OTTO Voss Rost. Doktordissertation, Xenokrates, Darstellung der Lehre und Sammlung der Fragmente von RICHARD HEINzE.) - Aristotelis qui ferebantur librorum fragmenta collegit VAL. ROSE (Teubner, 1886). - (Von den meisten älteren Peripatetikern haben wir noch keine geniggenden Fragmentsammlungen.) - Die Fragmente Timons von Phlius, des literarischen Hauptvertreters der pyrrhonischen Skepsis, sind gesammelt in C. WACHSMUTH, Sillographorum graecorum reliquiae (Leipzig, 1885). - Epicurea ed. Herm. Usener (Teubner, 1887) (enthält die erhaltenen Schriften Epikurs und die Frag.

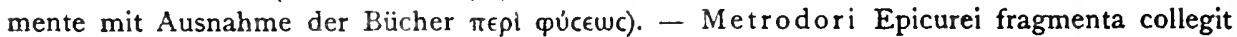
ALFRED KOERTE (Bonner Doktordissertation), - Stoicorum veterum fragmenta collegit J. AB ARnim, Vol. I-III (Teubner, 1903-5). - PEARSON, the fragments of Zeno and Cleanthes (Cambridge, I891).

\section{Literatur.}

Eine sorgfältige Zusammenstellung der Literatur über die Geschichte der griechischen Philosophie enthält FrIEDR. ÜBERwegS Grundriß der Geschichte der Philosophie. Erster Teil: Das Altertum, bearb. und herausgeg. von M. HeINZE (Berlin, 1886). Reich an Literaturangaben ist auch A. BONHÖFFERS treffliche Neubearbeitung von WINDELBANDS Gesch. d. antiken Philosophie in J. Müllers Handbuch d. klass. Altertumswissenschaft V 1. 3. Aufl. 1912. Es kommen in Betracht: 1. Gesamtwerke über die Geschichte der Philosophie, wie Dietr. Tiedemann, Geist der spekulativen Philosophie (Marburg, 1791-97); Wilk. Gotrl. Tennemann, Geschichte der Philosophie (Leipzig, 1798-1819) (vom kantianischen Standpunkt); HEINR. RrTTER, Geschichte der Philosophie (Hamburg, r 829 ff.) (vom Schleiermacherschen Standpunkt). Heute wird zu diesen Werken nur noch der gelehrte Forscher greifen, der die geschichtliche Entwickelung, sei es der Gesamtauffassung der griechischen Philosophie, sei es der Auffassung eines einzelnen Problems verfolgen will. - 2. Spezial. darstellungen der griechischen Philosophie: CHrist. AUg. Brandis, Handbuch der Geschichte der griechisch-römischen Philosophie (Berlin, 1835ff.); Ed. ZELler, Die Philosophie der Griechen in ihrer geschichtlichen Entwicklung, 5 Bde. 4. Aufl. (1876 ff.; Bd. I u. 2 in 5. Aufl. 1892 f.). Dieses großartige Werk war sowohl bezüglich der Sammlung und kritischen Sichtung des Sîfies als bezüglich der geschichtlichen und philosophischen Verarbeitung desseiben in so hohem Grade epochemachend, dab dadurch alle älteren Darstellungen in Schatten gestellt und verdrängt wurden, und dieses Buch allein für eine gelehrte Vertiefung in die Geschichte der griechischen Philosophie ausreicht, da überall die der Darstellung zugrunde liegenden Quellenstellen in den Anmerkungen im originalen Wortlaut mitgeteilt werden. Das ZELLERsche Weak ist aber, trotz seiner unvergleichlichen Vorzüge, selbstverständlich nicht als eine endgültig abschließende Darstellung aufzufassen. Vielmehr ist gerade infolge seines Erscheinens eine erhöhte Regsamkeit der Forschung auf dem 
Gebiet der griechischen Philosophie entstanden, die in vielen Punkten sowohl bezüglich der Kritik der Überlieferung und Ermittelung der dogmengeschichtlichen Tatsachen als bezüglich der historischen Zusammenhänge und der Denkmotive, aus denen die Lehren der einzelnen Denker entsprangen, wertvolle neue Ergebnisse gezeitigt hat. Doch wird ZELLERS Werk noch für lange Zeit als das unerreichte Meisterwerk historisch-kritischer Behandlung der alten Philosophie in Geltung bleiben. - Einen ganz anderen Charakter trägt das Werk von THEODOR GOMPERz, Griechische Denker. Eine Geschichte der antiken Philosophie. I. Bd. 2. Auf. (1903) (von den Anfängen bis zur Sophistik); 2. Bd. 2. Aufl. (1903) (Sokrates, die Sokratiker und Platon); 3. Bd. (1906f.) (Aristoteles). Auf die Mitteilung des Quellenmate. rials verzichtend, gibt GOMPERZ ein auf selbständiger Durcharbeitung der Quellen beruhendes, aber in seiner klaren und geschmackvollen Form für die weiteren Kreise der Gebildeten berechnetes Gesamtgemälde der antiken Philosophie. Während Zellers Standpunkt ein modifizierter Hegelianismus ist, der aber die Auffassuug des Tatsächlichen niemals trübt, schreibt GOMPERZ seine Geschichte der antiken Philosophie vom Standpunkt der modernen, aller Metaphysik abgeneigten Aufklärung und eines überwiegend naturwissenschaftlichen Empirismus. Hiermit hängt es zusammen, daß in seiner Darstellung die ionischen Naturphilosophen und andere Vertreter der "Aufklärung" in das hellste Licht gerückt werden, während die platonische und aristotelische Metaphysik als Abirrung von der richtigen Entwickelungslinie erscheint. - 3. Spezialwerke über die Entwickelung einzelner philosophischer Disziplinen und Probleme, die ihren Gegenstand teils nur durch die antike, teils durch die ganze Philosophiegeschichte verfolgen. Wir greifen hier nur einige Hauptwerke heraus: HeRm. SiEBECK, Geschichte der Psychologie (Gotha, 1880. 84); THEOB. Ziegler, Geschichte der Ethik. I. Abt. Die Ethik der Griechen und Römer (Bonn, 1881); KARL Prantl, Geschichte der Logik im Abendlande, Bd. I. Die Entwicklung der Logik im Altertum (Leipzig 1855); A. B. KRISCHE, Die theologischen Lehren der griechischen Denker (Göttingen, 1840); M. HEINZE, Die Lehre vom Logos in der griechischen Philosophie (Oldenburg, 1872); P. NATORP, Forschungen zur Geschichte des Erkenntnisproblems im Altertum (Berlin, 1884). - 4. Eine überaus umfangreiche Literatur über einzelne Philosophen oder Philosophenschulen sowie über einzelne Werke oder Lehren derselben, für die wir auf die Literaturverzeichnisse bei ÜBERWEG-HEINZE und bei den einzelnen Abschnitten von ZELLERS Phil. d. Gr. verweisen.

Wer auf bequeme Weise, aus einem einzelnen Buche die Hauptlehren der griechischen Philosophen kennen lernen möchte, wie sie sich in ihrer eigenen Sprache nach dem Wortlaute der antiken Quellen ausnehmen, der greife zu dem trefflichen Werke: Historia philosophiae graecae; testimonia auctorum collegerunt notisque instruxerunt H. RITTER et L. Preller. Editio septima q. cur. Fr. Schultess et Ed. WellahanN (Gotha, 1888; die erste Auflage war 1838 erschienen).

\section{Einzelne Schriften,}

von denen außer den obengenannten die vorstehende Darsteilung an den zitierten Stellen beeinfluBt wurde:

S. 97 ff. Vorsokratiker: TANNERY, Pour l'histoire de la science hellène.

S. 121. Protagoras: H. GOMPERZ, Sophistik und Rhetorik, Teubner 1912.

S. $127 \mathrm{ff}$. Plato von W. WINDElband (in Frommanns Klassikern der Philosophie), P. Shorey, The unity of Plato's thought (Chicago 1903).

S. $148 \mathrm{ff}$. Aristoteles von H. SIEBECK (in Frommanns Klassikern der Philosophie).

S. 199 ff. Stoische Philosophie: L. STEIN, Die Psychologie der Stoa (Berlin, Calvary. I886). - AD. BONHÖFFER, Epictet und die Stoa. Untersuchungen zur stoischen Philosophic (Stuttgart, 1890). 


\section{Nachträge zum zweiten Abdruck.}

Die Fragmente der Vorsokratiker von H. Diels (Berlin, Weidmannsche Buchhandlung) erschienen 1915 in 3. Auflage, die viele Zusätze und Verbesserungen enthält, eine 4. Auflage wird demnächst erscheinen.

F. ÜBerweG'S Grundriß der Geschichte der Philosophie, erster Teil (Berlin, E. S. Mittler \& Sohn), ist nunmehr in der von K. PRÄCHTER herausgegebẹnen II. Auflage zu benutzen.

Von einer neuen Gesamtdarstellung, K. JOEL's Geschichte der antiken Philosophie (Tübingen, J. C. B. Mohr) erschien 192 I der I. Band, der die Vorsokratiker, die Sophistik und Sokratik mit Ausnahme Platons enthält. Der Verfasser will die philologisch-historische Quellen. forschung mit der problemgeschichtlichen Behandlungsweise verbinden und den Bedürfnissen des weiteren Kreises der Gebildeten und des engeren der Gelehrten gleichzeitig genügen.

Für die vorsokratische Philosophie brachte viele wertvolle neue Einsichten JoHN BURNET'S Werk Early Greek Philosophy, das in deutscher Übersetzung von ELSE ScheNkL unter dem Titel: Die Anfänge der griechischen Philosophie (Leipzig, B. G. Teubner) I913 erschien. Über desselben Verfassers Greek Phılosophy l Thales to Plato London 1914 siehe unten bei Sokrates und Platon.

Viele die Vorsokratiker, namentlich die Eleaten und Herakleitos betreffende Fragen wurden in K. Reinhardis Parmenides und die Geschichte der griechischen Philosophie geistvoll und tiefgründig, aber nicht immer überzeugend behandelt.

Durch ein in den Oxyrynchos Papyri Vol. XI verötfentlichtes umfängliches Bruchstück des Sophisten Antiphon wurde unsere Kenntnis der Sophistik, im besonderen der Rechtsund Gesellschaftsphilosophie der älteren Sophisten, bereichert.

Die Untersuchungen über den historischen Sokrates wurden eifrig, aber ohne Eınigung der maßgebendsten Forscher weitergeführt. H. MAIER in seınem bedeutenden Buch: Sokrates, sein Werk und seine geschichtliche Stellung (Tübingen, J. C. B. Mohr!, 1913 spricht den aristotelischen Zeugnissen über die Lehre und geschichtliche Stellung des Sokrates selbständigen Quellenwert ab. Von Xenophons Memorabilien hält er nur B. I I u. 2, von Plato nur wenige frühe Dialoge für eine brauchbare Grundlage unserer Kenntnis des historischen Sokrates. Die platonische Apologie hält er für eine nur mit einzelnen Reminiszenzen aus der wirklich von Sokrates gehaltenen Rede ausgestattete freie Schöpfung Platos; die xenophontische für echt, aber geschichtlich wertlos. Hauptstützen seines Sokratesbildes sind Rück. schlüsse aus den Lehren der Sokratiker, namentlich des Anthisthenes und Aristippos. Die Philosophie des Sokrates war nicht Wissenschaft, sondern nur ein „Suchen nach persönlichsittlichem Leben"; seine Lehrtätigkeit war die eines Weckers und Mahners zum Streben nach dem sittlichen Ideal, das sich formal als das der Autonomie und Autarkie der sittlichen P'ersönlichkeit darstellt und mit der Glückseligkeit zusammenfällt, inhaltlich aber von Sokrates als ein der besondern Anlage und Lebensstellung des einzelnen angemessenes und auf sachkundigem Wissen beruhendes Wirken im geordneten Zusammenhang der Gesellschaft und des Kulturganzen gedacht wircl. Es wird also in dem sokratischen Vollkommenheitsideal 
die Erlösung von aller Heteronomie und die innere Freiheit verbunden mit der lebendigen Beziehung zum Kulturganzen, die der Tugend ein reiches Betätigungsfeld eröffnet. Die Religion spielt in dem sittlichen Glauben des Sokrates, ohne die Autonomie der Persönlichkeit durch theonome Bindungen zu beschränken, doch insofern eine Rolle, als Sokrates glaubt, daß die göttliche Vorschung dafür gesorgt hat, daß das tugendgemäße Leben seinen Lohn in sich selbst trägt und mit der Glückseligkeit zusammenfällt. An diesem sokratischen Vollkommenheitsideal mißt H. Maier in dem letzten Teil seines Buches alle griechischen Ethiker. Plato hat, indem cr die Wissenschaft zum Inhalt des Tugendwissens machte, diese aber einer Minorität, den Regenten, in seinem Idealstaat vorbehielt (der auf die Verwirklichung dieses Ideals bei einer Minorität angelegt ist), der Mehrheit der Menschen das formale Vollkommenheitsziel, die Autonomie, Autarkie und Erlösung durch innere Freiheit genommen. Er ist am weitesten von der echten Sokratik abgeirrt. Die kynische, megarische, kyrenaische Schule haben sich, indem sie durch skeptische Erkenntuistheorie und Eristik den Aufbau der Wissenschaft zu hintertreiben suchten, von diesem Fehler Platos freigehalten. Aber ihnen fehlt dafür der den sokratischen Individualismus ergänzende Hinweis auf die Gesellschaft und den Staat als das natürliche Betätigungsfeld der Tugend. Auch die Stoa, die Erbin des Kynismus, hat dessen anarchisch-kosmopolitische Einseitigkeit, obwohl sie den Menschen auf das Wirken im Dienste der ihm übergeordneten Gemeinschaften hinwies, nicht recht zu uberwinden vermocht. Immerhin stehen Antisthenes und die Stoa dem echten sokratischen Geiste noch am nächsten. Bei dem Schulmeister Aristoteles, der sich als der wabre Fortsetzer der Sokratik fühlt, ist von dem echten sokratischen Vollkommenheitsideal nichts mehr übrig. geblieben. - $\mathrm{Ob}$ die von $\mathrm{H}$. Maier vertretene Auffassung der Geschichte der griechischen Ethik einen Fortschritt bedeutet, hängt hauptsächlich von der Entscheidung zweier Fragen ab: 1. (die Tatsachen der Entwicklung betreffend) Hat Sokrates die Tugenden in ganz anderm oder in demselben Sinne wie die irgendein einzelnes Gebiet der Natur oder des Lebens beherrschenden Wissenschaften $\boldsymbol{\varepsilon} \boldsymbol{\pi} \boldsymbol{\sigma} \boldsymbol{\tau} \boldsymbol{\tau} \dot{\eta} \boldsymbol{\mu} \alpha \boldsymbol{i}$ genannt? 2. (die Wertung der einzelnen Ethiker betreffend) Kann der einzelne Mensch in einem nicht wohlgeordneten Staate zu derselben Höhe sittlicher Betätigung gelangen, wie in einem wohlgeordneten?

Die Auffassung des Sokrates in Wilamowitz' Platobuch gründet sich auf die gleiche Wertung der Quellen wie die H. Maiers und steht ihr überhaupt sehr nahe. Wilamowitz betont sogar noch mehr als H. Maier das voluntaristische Moment in Sokrates' sittlichem Glauben und in seiner Erziehungstätigkeit auf Kosten des Rationalen (der Begriffsdialektik).

Den schärfsten Gegensatz zu diesen bildet die von zwei englischen Forschern A. E. TAYLOR, Varia Socratica (St. Andrews University Publications Vol. IX.); Plato's Biography of Socrates Proceedings of the British Academy) und JOHN BURNET, Greek Philosophy I London 1914: The Socratic doctrine of the soul (Proceed. of the Brit. Acad.) vertretene Ansicht, daß das Bild des echten Sokrates, für dessen Herstellung auch nach ihnen Xenophon und Aristoteles nichts oder fast nichts Brauchbares beisteuern, aus der Gesamtheit der platonischen Schriften, in denen Sokrates Gesprächsleiter ist, aufgebaut werden müsse. Bis gegen sein 60 tes Jahr hat Plato in seinen Dialogen nur die Philosophie des Sokrates dargestellt; auch die Ideenlehre und die Seelen. und Unsterblichkeitslehre in "Phaidon" und „Republik" gehören dem Sokrates; nur aus den Alterswerken Platons, in denen Sokrates nicht mehr Gesprächsleiter ist, haben wir die eigene Lehre Platons, soweit sie von der des Sokrates verschieden ist, zu entnehmen. Die Ideenlehre hat Sokrates schon als ganz junger Mann erfunden; denn als solcher vertritt er sie im "Parmenides". Das pythagoreische Element ist nicht erst von Platon, sondern schon von Sokrates, der selbst Vorstand eines Pythagoreerbuncles in Athen war, in seine Lehre aufgenommen worden. Im Anschluß an die älteren Pythagoreer (denn die jüngeren setzten Seele $=$ Harmonie) hat Sokrates die bis dahin den Griechen unbekannte Ansicht, daß die Seele Trägerin des ganzen Bewußtseinslebens und der sittlichen Eigenschaften des Menschen, also sein Ich sei, zum Gemeingut gemacht und auch ihre Unsterblichkeit gelehrt. Platons eigene Leistung besteht in einer Umbildung der pythagoreischen Metaphysik des Sokrates, durch welche die Idealzahlen und ihre Grundbe- 
standteile, Einheit und unbestimmte Zweiheit (= Grenze und Unbegrenztes) an die Stelle der Ideen gesetzt, aus der Begrenzung des Raumes durch die aus den Zahlen abgeleiteten geometrischen Formen die sinnlich wahrnehmbare Welt erklärt und so der der älteren Form der Ideenlehre (in "Phaidon" und "Republik") anhaftende Dualismus überwunden wurde. Ich kann mich von der Richtigkeit der Burnetschen Abgrenzung der platonischen von der sokratischen Philosophie ebensowenig überzeugen wie von der Richtigkeit der H. Maierschen Abgrenzung, sondern glaube, daß die ältere "herkömmliche" Ansicht die Grenze richtiger in der Mitte zwischen diesen beiden gezogen hat. Doch wird durch die Ablehnung dieser Abgrenzung der Wert von Burnet's Erläuterung des Sinnes und Zusammenhanges der plato. nischen Altersphilosophie nicht beeinträchtigt. Sie ist auch für die späteren Platoniker und Pythagoreer von Bedeutung.

ERnst Horneffer Platon I. Bd. Die Apologie des Sokrates und Platon 1921 sieht in der platonischen "Apologie" die einzige absolut zuverlässige Urkunde über den historischen Sokrates und bekämpft mit sehr beachtenswerten Gründen die Ansicht, die in ihr eine freie Dichtung Platos sieht und die Unmöglichkeit, daß der historische Sokrates sich so vor Gericht verteidigt habe, erweisen will. Von der "Apologie" ausgehend gelangt er zu der Auffassung, die tiefste Quelle alles Forschens und Lehrens des Sokrates sei religiöser Glaube an seine ihm offenbarte göttliche Sendung gewesen, die ihm gebot, seine und seiner Mitbürger Seelen durch Ausbildung der Vernunft zu vervollkommnen.

In der Platoforschung ist das neueste Ereignis von Bedeutung U. v. WiLAMowrtz Platon 2 Bde. (Berlin, Weidmannsche Buchhandlung) 1919.

Der Verfasser will nicht ein Stück Philosophiegeschichte geben, sondern vom Stand punkt der klassischen Altertumswissenschaft, unter deren deutschen Vertretern er eine führende Stellung einnimmt, Platon den Menschen und seine Werke den Lesern nảhebringen. Lis will als Plilologe und Interpret zur Biographie Platons vordringen und zeigen, wie dieser Mensch geworden ist, was er gewollt, gedacht, gewirkt hat. Das Buch ist für den weiteren Kreis der Gebildeten geschrieben und verwendet griechische Zitate nur in den Beilagen des zweiten Bandes. Die Aufgabe, an Platons Gedanken Kritik zu üben und sie in die Entwicklung der menschlichen Erkenntnis einzuordnen, überläßt Wilamowitz den Philosophen. Es ist klar, da@ sie diese Aufgabe erst lösen können, wenn sie die in der Biographie enthaltene Belehrung über die geschichliche Stellung und die Entstehungsbedingungen der platonischen Philosophie in sich aufgenommen haben.

Zu A ristoteles sei auch hier auf W. W. JAEGER's Studien zur Entstehungsgeschichte der aristotelischen Metaphysik (Berlin, Weidmannsche Buchhandlung) 1912 hingewiesen, die sich keineswegs auf die Metaphysik beschränken, sondern die Frage nach dem Verhältnis der aristotelischen Pragmatien zu der mündlichen Lehrtätigkeit des Philosophen und der Entstehung ihres uns vorliegenden Textzustandes auch allgemein behandeln. Doch ist dieses Werk nur für Leser bestimmt, die in Aristoteles durch das Studium seiner Schriften tiefer eindringen wollen.

Für das Studium des Epikureismus kann der des Italienischen kundige Leser aus keinem andern einzelnen Buche so viele und gründliche Belehrung schöpfen, wie aus Giussani's großer kommentierter Ausgabe des Lucretius, deren erster Band ausführliche Prolegomena uber Epikur's Leben und Lehre und eine Reihe von Exkursen über die schwerverständlichen oder umstrittenen Punkte der letzteren enthält.

Von den Stoikern ist neuerdings besonders Poseidonios Gegenstand wetteifernder Forschung vieler Gelehrter gewesen. Es seien hier außer W. W. Jaegers Nemesios von Emesa Berlin 1914 nur die beiden 1921 erschienenen Bücher von J. HEINEMANN und K. REINHARdT (München, G. H. Beck) erwähnt. Vgl. Überweg.Prächter Grundriß 1. Teil 177". Auch von W. CAPELle steht eine Gesamtdarstellung des Poseidonios zu erwarten. K. Reinhardt sieht in Poseidonios, dem Hauptrertreter der "mittleren Stoa", dem Lehrer Cicero's, nicht wie die herkömmliche Auffassung einen Eklektiker, der die Schroffheiten und Einseitigkeiten der stoischen Orthodoxie durch Entlehnungen aus Aristoteles und Platon zu mildern und zu 
ergänzen suchte, sondern einen originalen Denker, den einzigen großen Philosophen zwischen Aristoteles und Plotin. Er will beweisen, daß sich Poseidonios durch ein neues Forschungs. prinzip und durch neue, folgerichtig durchgeführte Grundbegriffe von der stoischen Orthodoxie unterscheide; deren Intellektualismus habe er durch psychophysischen Parallelismus und Vitalismus ersetzt, die uriāchliche Erklärung der Welt aus Kräften, die in den Elementen und ihren mannigfach kombinierten und abgestuften Mischungen verkörpert sind, als Hauptaufgabe der Philosophie betrachtet und zu diesem Zwecke Astronomie, Meteorologie, Geographie, Ethnographie mit der Kosmologie und Physik in systematischen Zusammenhang gebracht. Sehr verdienstlich ist es, daB REINHARDr, von dem Streben geleitet, die geschlossene Einheitlichkeit des poseidonischen Systems nachzuweisen, der allzugroßen Freigebigkeit entgegentritt, mit der die neueren Quellenuntersuchungen ein Sammeisurium unvereinbarer Gedanken ihm zum Geschenk gemacht hatten. 


\title{
DIE PATRISTISCHE PHILOSOPHIE.
}

\author{
VON \\ Clemens Baeumker.
}

Gegenüber der überwältigenden Fülle fruchtbarster Arbeit, welche der Lehre, Disziplin und Verfassung der alten Kirche, den offiziellen und privaten Dokumenten ihres Glaubens und ihrer religiös-dogmatischen Entwickelung von Theologen, Historikern und Philologen gewidmet wurde, ist der Anteil, den die Philosophiegeschichte an jener Zeit zu nehmen pllegt, die man nach ihrer literarischen Betätigung als die „patristische“, die Zeit der Kirchenväter, bezeichnet, meist nur ein geringer. In der patristischen Literatur findet der Philosophiehistoriker keine originalen, allseitig durchgeführten Systeme, wie im Ausgang der Antike der Neuplatonismus Plotins noch einmal ein solches schuf. Auch zeigt das philosophische Denken in derselben keinen in sich beschlossenen Entwickelungsgang; vielmehr ist es von dem Gange.abhängig, den die außer ihr stehende Philosophie der alten Philosophenschulen nimmt. Zudem bilden diese philosophischen Anschauungen nicht ein Ganzes für sich, sondern sind in den Zusammenhang eizer in ihren tiefsten Grundlagen aus ganz anderer Quelle entsprungenen Weltanschauung eingesprengt. Und doch ist es von Interesse, die mannigfachen Gestaltungen zu verfolgen, in denen die nimmer ruhenden philosophischen Fragen in der Welt des christlichen Altertums auftreten. Bleibt doch das Bild der Antike unvollständig, wenn es nicht auch die Formen verzeichnet, welche gemeinsame literarische und ideelle Strömungen auf dem Boden der mehr und mehr erstarkenden und zuletzt zum Siege gelangenden christlichen Gesellschaft annehmen. Und wenn auch nicht neue Systeme, so entstehen hier doch mancherlei neue Modifikationen, teils durch die Verbindung mit dem objektiv gegebenen theologischen Gedankenmaterial, teils deshalb, weil verbreitete Gedanken von Männern aufgenommen werden, die, wie Augustin, aus der Tiefe ihrer religiös gestimmten genialen Persönlichkeit heraus auch Übernommenes in einem eigenartigen, selbständig erfaßten Weltbilde neu zu gestalten wissen. Vor allem aber ist $z u$ beachten, daß die philosophische Gedankenbildung der patristischen Zeit nicht nur eine Parallelströmung oder gar nur eine schwächliche Nebenerscheinung der Antike darstellt, sondern daß sie zugleich ein Neues anfängt. Sie legt den Grund für die tausendjährige Gedankenent- 
wickelung des Mittelalters. Ohne einen Augustin ist die Scholastik, ohne einen Dionysius den Pseudo-Areopagiten die Mystik des Mittelalters nicht verständlich. Ja bis tief in die Neuzeit geht der Einfluß jener Periode. Man denke etwa an die Vorbilder, die Augustin zu des Cartesius „Cogito, ergo sum" bietet, oder an die unmittelbaren Beziehungen, die Malebranche nicht nur mit Descartes, sondern auch mit Augustin verknüpfen.

I. Stellung der patristischen Zeit zur Philosophie. - Nicht aus dem Christentum nach seiner ursprünglichen Eigenart heraus ist das Bedürfnis nach philosophischem Forschen hervorgegangen. Das neue Leben, das es in die Welt bringt, vollzieht sich im Glauben an die Fülle der göttlichen Offenbarung in Christus, in der inneren Umwandlung aus dem Zustande der Schuld und in der Erhebung zu einem neuen gesteigerten Dasein durch Gottes gnadenreiche Erbarmung. Zur Philosophie dagegen steht es zunächst so wenig in einem Verhältnis, wie zur weltlichen Bildung überhaupt und zum Staat. Beides schließt sich weder ein noch aus; es gehört verschiedenen Welten an. Verschieden ist das Lebensprinzip, aus dem der Glaube hervorgeht, und das des rein vernünftigen Forschens; nur in dem objektiven Inhalt einzelner Sätze findet wohl eine Berührung statt. Macht der letztere Umstand es erklärlich, daß schon Paulus bald vor der Verführung durch die Philosophie und durch trügerische Menschensatzung warnt, bald von dem Gesetze spricht, das auch den Heiden in das Herz gegraben sei, ja gelegentlich vor den Heiden die Worte griechischer Denker heranzieht, so kennt doch die Urkirche bis weit in das zweite Jahrhundert hinein keinen Versuch, ihre Glaubensüberzeugung durch philosophische Vernunftgründe zu stützen. Den Sonderbestrebungen, insbesondere den Gnostikern, setzt sie zunächst ihre Glaubensüberlieferungen und ihre Symbole entgegen. Nicht der Spekulation, sondern der religiös-ethischen Lebensgestaltung ist das innerkirchliche Leben zugewandt; hierauf bezieht sich die Tätigkeit und die Lehre der Vorsteher und Lehrer der Gemeinden. So tragen denn auch die ältesten literarischen Erzeugnisse der alten Kirche, die Zwölf-Apostellehre und die Schriften der „apostolischen-Väter" - der Barnabasbrief, der Korintherbrief des römischen Bischofs Clemens, die sieben Briefe des Ignatius von Antiochien, die Briefe Polykarps von Smyrna - einen durchaus pastoralen Charakter, und noch der in apokalyptischen Bildern sich bewegende, in vielem so rätselhafte "Hirt" des Hermas, der schon den Gnostizismus zurückweist, bleibt auf diesem praktischen Felde.

Eine Wendung wird zuerst durch die „A pologeten" herbeigeführt. Es gehören dahin, wenn wir von dem „Kerygma Petr1" und den apologetischen Apologeten. Partien in den pseudo-klementinischen Homilien absehen wollen, unter den Griechen Quadratus, Aristides von Athen, Justin der Märtyrer, Tatian der Assyrer, der Kleinasiate Miltiades, Apollinaris von Hierapolis, der unbekannte Verfasser der pseudojustinischen „Mahnrede an die Griechen“, A thenagoras von Athen, Theophilus von Antiochien, Melito von Sardes, der vermutlich ziemlich 
späte Hermias, unter den Lateinern Minucius Felix und Tertullian, aus späterer Zeit Arnobius und in gewisser Weise auch Lactantius. Als nämlich mit der zunehmenden Ausbreitung des Christentums auch philosophisch Gebildete in größerer Zahl ihm beitraten, da kam zu jenen, von den Vorstehern der Gemeinden ausgehenden, innerkirchlichen literarischen Dokumenten der Urkirche eine ganz neue Gattung von Schriften hinzu. Nicht mehr um Ermahnungen an die Gemeinde und pastorale Fragen handelte es sich, sondern den Außenstehenden, der Gesamtheit der Gebildeten und dem Oberhaupte des Reiches selbst, sollte der Nachweis geliefert werden, daß die Verwerfung der Volks- und der Staatsreligion durch die Christen und das Leben, das sie führten, weder unvernünftig noch unsittlich sei. Nicht Aufseher — „Bischöfe“ - der Kirche sind es, denen jene Apologien zunächst verdankt wurden, sondern einfache Mitglieder, Laien. Denn daß der älteste jener Apologeten, Quadratus, nicht mit dem Bischof Quadratus von Athen identisch war, wie Hieronymus meinte, steht fest. Aristides, dessen Apologie in der griechischen Urform uns annähernd durch die Legende von Barlaam und Joasaph erhalten ist, wird von Eusebius als athenischer Philosoph bezeichnet. Justin zog nach seinem Übertritt zum Christentum gleich den Kynikern der Kaiserzeit im Philosophenmantel umher. Minucius Felix war Sachwalter. Dementsprechend ist das, was diese Apologeten erstreben, nicht eine spekulative Durchbildung des Dogmas - mochte eine solche im Zusammenhange mit dem hellenischen Geiste auch immerhin schon auf dem Wege sein -, sondern eine Auseinandersetzung mit den Christengegnern. Nicht eine nähere Entwickelung der christlichen Lehre für Christen bieten sie. Wer, entgegen ihrer offenbaren Absicht, solches bei ihnen erwartet, muß ihr Christentum sehr dürftig finden; bei einigen, wie Aristides und Minucius Felix, würde es von dem platonischstoischen Monotheismus der Zeitphilosophie nur in sehr wenigem sich abheben. Vielmehr besteht ihre Verteidigung vor allem im Angriff. Hierin aber war ihnen die antike Philosophie vorangegangen; denn seit Xenophanes und Heraklit stand diese im Gegensatz zur Volks- und Staatsreligion, seit Anaxagoras und Sokrates waren die Philosophen der Gottlosigkeit angeklagt. Damals war es vor allem die populär gehaltene stoische und kynische Diatribe, die den Widersinn des Volksglaubens und seines Kults in oft drastischer Weise dartat und die zugleich eine reine Moral in volkstümlicher Weise predigte. Hier konnten die Apologeten anknüpfen und haben es, wie die vielfachen, durch diese ganze Literatur hindurchgehenden Gemeinplätze zeigen, auch in reichem Maße getan.

Diese Polemik, in der man mit der Philosophie zusammensteht, ist indes nur die negative Seite. Im christlichen Glauben und der christlichen Lebensgestaltung haben die Apologeten einen Besitz, der nicht nur Vorrecht einzelner, sondern allen gemein ist, nicht Theorie bleibt, sondern das Leben erfüllt, nicht mehr dem $Z$ weifel untersteht, sondern als beseligende Gewißheit empfunden wird. Dieses das ganze Sein umwandelnde Erlebnis hat ihnen die Philosophie noch nicht geboten. Wie ein Suchen ohne Finden erscheint sie 
ihnen darum, zumal der oft betonte Widerspruch der Systeme untereinander zum Skeptizismus in der Philosophie hindrängt. So ist ihnen das Christentum, was die Philosophie sein will. Das Christentum ist ihnen ,unsere Philosophie:" eine Ausdrucksweise, die Justin, Miltiades, Tatian, auch der Bischof Melito, unbedenklich gebrauchen, mögen andere, wie Athenagoras und Theophilus, auch den Namen vermeiden.

Aus diesen - schon bei Paulus wirksamen - widerstreitenden Motiven ergibt sich bei den Apologeten eine schwankende Stellungnahme zur Philosophie. Mit der Anerkennung ihres Wahrheitsgehaltes streitet ihre Verwerfung als ausreichender Lebensgrundlage. So läßt wie ein Stoiker Justin das ganze Menschengeschlecht am Logos teilhaben. Auch unter den Heiden will er alle, die mit dem Logos lebten, wie Sokrates und Heraklit, für Christen erklären. Aber schon in der Apologie schwächt er diesen Gedanken dahin $a b$, daß er, hellenistisch-jüdischem Vorgange folgend, das Wahre bei den alten Philosophen auf eine Bekanntschaft mit den Mosaischen Schriften zurückführt, und noch schärfer betont er das Unzureichende der Philosophie, die keine Gewißheit gebe, im Dialog mit dem Juden Trypho. Athenagoras findet bei den Philosophen ein Wehen des göttlichen Geistes. Insbesondere die Einheit Gottes haben sie geahnt - stammt doch des Athenagoras vie1 gerühmter dialektischer Beweis gegen die Möglichkeit einer Vielheit von Göttern wahrscheinlich aus einer skeptischen Quelle-. Aber dann weist er hin auf die Widersprüche, in die die Philosophen verfielen, weil sie nicht von Gott, sondern nur von sich lernen wollten. $\mathrm{Zw}$ :schen der Lehre des Christentums und der der Philosophen von der Einheit Gottes findet der an Cicero und Seneca gebildete Minucius Felix eine solche Übereinstimmung, daß er glauben möchte, entweder die Christen seien Philosophen, oder die Philosophen seien schon damals Christen gewesen. Zum Schluß aber wendet er sich ab von den Philosophen, auch von dem "attischen Possenreißer" Sokrates - man wird an Nietzsches Schmähwort von dem "Hanswurst" Sokrates erinnert -, und jubelt hell auf im Bewußtsein, einer Gemeinschaft anzugehören, die nicht Großes rede, sondern Großes lebe, die nicht suche, sondern das besitze, was jene suchten und nicht fanden: Sätze, die in ähnlicher Weise auch bei dem doch von griechischer Denkweise und griechischer Formschönheit erfüllten Laktanz, dem "christlichen Cicero", wiederkehren. Alles $\mathrm{Maß}$ aber überschreiten Männer, wie Tatian und der zuletzt zu den montanistischen Separatzirkeln übergetretene Tertullian. „Was haben“, fragt dieser, "Athen und Jerusalem, was die Akademie und die Kirche, was die Häretiker und die Christen miteinander gemein?" Nichts wissen will er von einem stoischen oder platonischen oder dialektiscnen Christentum; Plato ist ihm der Patriarch der Häretiker, die "Gewürzkiste“, aus der alle Irlehrer geschöpft haben. Wenn er glaubt, so verlangt er nichts weiter als zu glauben. Ist Tertullian doch der Mann, der in seiner (übrigens schon aus der montanistischen Periode stammenden) Schrift: „De carne Christi“ die scharf antithetisch zugespitzten Worte gebraucht: „Gekreuzigt ist Gottes Sohn: wir schämen uns des 
nicht, weil es schmählich ist; gestorben ist Gottes Sohn: es ist vö1lig glaubhaft, weil es töricht ist (prorsus credibile est, quia ineptum 'est); und begraben, ist er auferstanden: es ist gewiß, weil es unmöglich ist" - Worte, aus denen man das in dieser Form nirgendwo in der kirchlichen Literatur sich findende Schlagwort: „Credo, quia absurdum est" geformt hat.

c) BeiGnostikern Indes, Tertullian ist nicht nur Verteidiger des Christentums gegen die und Heiden, so wenig wie Justin und Tatian, Melito und Miltiades, und nicht in seinem „A pologeticum" finden sich jene harten Worte, sondern in Schriften, die gegen die Häretiker, insbesondere gegen den Gnostizismus, gerichtet sind. Damit kommen wir zu einem zweiten Moment, das innerhalb der christlichen Welt zu einer Auseinandersetzung mit der antiken Philosophie hinführte: die sich entwickelnde religiöse Spekulation. Auch hier verbinden sich Ablehnung und assimilierende Herübernahme.

Der Anfang zu dieser Spekulation wird - wenigstens in größerem Umfange - nicht im kirchlichen Christentum gemacht. Er geht vom Gnostizìsmus aus, jener Richtung, die ihren Namen davon trägt, daß sie mit dem einfachen Glauben des Anhängers der altorientalischen, griechischen, jüdischen, christlichen Kulte sich nicht begnügt, sondern darüber hinaus die Gnosis, das spekulative Wissen, zu besitzen und durch dieses Wissen ihren Anhängern die Erlösung und den Aufstieg zum Lichtreich zu sichern sich rühmt. Es ist ein mannigfach schillernder Kreis von Gemeinschaften: Ophiten, Naassener, Kainiten, Sethianer, Archontiker, und von hervorragenden Einzelpersonen, anfangend von Cerinth und Satornil im ersten Jahrhundert zu Basilides, Karpokrates, Valentinus, Marcion im zweiten bis zu dem Syrer Bardesanes um die Wende des zweiten und dritten Jahrhunderts, vor allem blühend im zweiten Jahrhundert, und damals durch sein Entgegenkommen gegen den halb hellenistischen, halb orientalischen Geist der Zeit, durch die Energie seiner Propaganda und seine schriftstellerische Fruchtbarkeit ein ebenso gefährlicher Gegner der.Großkirche, wie deren heidnische Bekämpfung. Eine nähere Charakteristik und Würdigung der so interessanten und historisch bedeutsamen Bewegung zu geben, ist nicht dieses Ortes und muß der Religionsgeschichte überlassen bleiben. Wirkliche Philosophie ist so gut wie keine bei ihr zu finden, wenn man auch ihren extremen Spiritualismus mit dem Platonismus der Zeit in Zusammenhang bringen und auf diese oder jene Parallele zum Stoizismus und zu dem erst später entstandenen Neuplatonismus hinzuweisen vermag. Auch spezifisch christlich ist der Gnostizismus nicht. Gab es doch auch eine heidnische Gnosis, und wo sich Christliches bei ihm findet, da ist es synkretistisch eingefügt, wie die Bestandteile anderer Religionen und Philosopheme. Es handelt sich beim Gnostizismus um eine allgemeine religionsgeschichtliche Erscheinung, die durch den religiösen Synkretismus und Symbolismus der Zeit bedingt ist unclorientalische Religionen und griechische Denkweise, Spekulation und mystische Kulte, Theismus und Polytheismus, Dualismus und monistische Anschauungen, phantastische Metaphysik und astronomische Phantasien, abstrakte Theorie und handgreifliches Zauber- und 
Beschwörungswesen, erlösungssehnsüchtige Askese und - wenigstens bei einzelnen Gruppen - antinomistische Hinwegsetzung über das Sittengesetz in mannigfach wechselnden Kombinationen verbindet.

Dem Gnostizismus, der zeitweilig den Bestand der Kirche zu erschüttern drohte, traten schon mehrere unter den Apologeten, wie Justin, Miltiades, Theophilus, in uns nicht mehr erhaltenen Schriften entgegen. Ihnen schließen die großen „Antignostiker" des zweiten und dritten Jahrhunderts sich an: der aus dem griechischen Kleinasien stammende Bischof von Lyon, Irenäus, der gleichfalls griechisch schreibende römische Bischof Hippolyt, ferner Tertullian von Karthago, denen noch im vierten Jahrhundert Epiphanius mit einer Schrift gegen ältere und jüngere Häretiker und im fünften der mehr unmittelbar gegen die Philosophen sich richtende Apologet Theodoret als späte Nachzügler folgten. Betont Irenäus trotz gelegentlicher Polemik gegen Plato vor allem gegenüber der gnostischen Spekulation das Positive, die in der Kirche zu findende apostolische Glaubenstradition, ohne über die Philosophie als solche ein Urteil abzugeben, so sehen Tertullian und Hippolytus, auch hier, wie auf dem Gebiete der kirchlichen Disziplin, schroffe Rigoristen, in der Weisheit der Hellenen die Quelle aller Irrtümer und aller Häresien. In ihre Fußtapfen treten Epiphanius, der die griechischen Philosophenschulen selber unter den „Häresien“ aufführt, und Theodoret, dem die Philosophie eine „hellenische Krankheit“ ist.

Aber ein solcher extremer Standpunkt ließ sich auch innerhalb der christlichen Kreise nicht durchführen, zumal nicht innerhalb der Welt des griechischen Geistes, dem die Gabe des Systematisierens und Deduzierens, des begrifflichen Unterscheidens und begrifflichen Aufbauens im höchsten Maße beschieden war. Hat doch selbst der an griechischem Geiste genährte Römer Tertullian trotz seines ganz anders gearteten Naturells der Einwirkung der Philosophie und der hellenischen Wissenschaft sich nicht entziehen können. Nicht Plato, wohl aber die Stoa wird sein Lehrmeister. So widerstreitet selbst bei diesem schroffen Philosophengegner die Praxis dem theoretischen Prinzip.

Die enge Verbindung zwischen griechischer Philosophie und christlicher d) Bei spekula. Überlieferung, aus der mit den Mitteln einer bei ihrer Aneignung zugleich tiven Theologen. modifizierten griechischen Philosophie die spekulative Dogmenentwickelung und die systematische Dogmatik erwächst, vollzieht sich vor allem in der alexandrinischen Schule des Pantänus, Clemens, Origenes. In Alexandrien hatte schon der Jude Philo platonische Transzendenzlehre und platonischen Spiritualismus zusammen mit der stoischen Logoslehre und derstoischen Naturphilosophie, auch mit manchen Elementen stoischer Ethik, mit der alttestamentlichen Religionslehre verbunden. Dabei hatte ihm die ja auch durch die Stoa an der alten Religion und den alten Dichtern geübte allegorische Erklärung eingern benutztes Hilfsmittel geboten. Clemens von Al exandrien ist der Wortführer der philosophiefreundlichen christlichen Schule in der geistigen Hauptstadt der hellenistischen Welt. Selbst von griechischen Plato- 
nikern, von Philo und insbesondere auch von der Stoa mannigfach angeregt - die Zeichnung des wahren Gnostikers bei Clemens z. B. entspricht in wesentlichen Stücken dem von ihm hochgeschätzten Bilde des stoischen Weisen -, sieht er in der Philosophie, die mit Unrecht von manch€n wie ein Schreckgespenst gescheut werde, ein Geschenk der göttlichen Vorsehung. Sie ist ihm die besondere Gabe der Hellenen, diesen als Vorbereitung auf Christus verliehen, wie den Juden das Gesetz. Freilich sei auch unter die Philosophie Unkraut gesät, wie die hedonistische Lehre Epikurs. Aber die Philosophie ist Clemens auch nicht identisch mit der Lehre dieses oder jenes Einzelphilosophen; vielmehr sucht er sie als philosophia perennis im Leibnizischen Sinne nach ethisch-religiösem Gesichtspunkte aus den platonischen, aristotelischen und stoischen Lehren auszulesen. Und wenn auch die einzelnen Philosophen gegen die Stimme des Evangeliums taub gewesen seien und sie als barbarisch gering geschätzt hätten, so bleibe doch die griechische Philosophie selbst der Schemel für die von Christus verkündete „Philosophie“; denn den Glauben will auch Clemens zur Gnosis, zur spekulativen Durchdringung, führen. Aber nur Vorstufe ist für Clemens die Philosophie der Griechen, die er zudem, wie Justin, nach hellenistisch-jüdischem Vorgang mit der alttestamentlichen Offenbarung in einen genetischen Zusammenhang bringen will. Hier prägt er in der christlichen Welt zuerst die nach ihm von den Theologen oft wiederholte Formel aus, die der Sache nach schón von Philo gegeben war, ja in ihrem ersten Teile auf den Stoiker.Posidonius zurückgeht: Wie die übrigen Wissenschaften (die enzyklopädische Bildung) eine Propädeutik für die Philosophie ausmachen, so bereitet die Philosophie auf die wahre Weisheit, die spekulative Durchdringung der Glaubenssätze, Origenes. vor. - Des Clemens großer Schüler Origenes, der Begründer der systematischen Religionsphilosophie und systematischen spekulativen Dogmatik, denkt im ganzen ähnlich wie sein Lehrer; doch betont er schärfer den Gegensatz gegen die reine Philosophie und ihre Vorherrschaft. Nur Mittel, nicht Zweck, ist ihm die profane Wissenschaft. Aber auch er erkennt den Wahrheitsgehalt in der hellenischen Philosophie an, welche die Einheit Gottes und die Unsterblichkeit der Seele lehre. - Wohl bei Origenes zuerst findet sich derVergleich der weltlichen Wissenschaft mit den silbernen und goldenen Geräten der Ägypter, die von den Kindern Israels bei ihrem Auszug aus Ägypten mitgerührt wurden. Gregor von Nyssa, Augustinus und zahlreiche andere nach ihnen haben dieses Bild wiederholt, das auch im Mittelalter zur Charakteristik des Verhältnisses von profaner und theologischer Wissenschaft von Theologen gern gebraucht wurde.

An nicht wenigen Sätzen, zu denen Origenes durch die spekulative Verwendung der Philosophie auf theologischem Gebiete geführt wurde, besonders in seinem systematischen Werke „Über die Prinzipien", hat das kirchliche Bewußtsein starken Anstoß genommen. Namentlich im Zusammenhang mit den die ganze Kirche erschütiernden arianischen Glaubensstreitigkeiten verfiel nicht weniges, was er gelehrt, der kirchlichen Verurteilung, 
und manches andere wurde stillschweigend in der weiteren Entwickelung verlassen. Aber das von ihm vertretene Prinzip, die Verbindung der antiken Philosophie mit der theologischen Spekulation, ist von da bei den führenden Geistern der patristischen Periode das herrschende geblieben und - besonders durch die Vermittelung Augustins - von ihr auf die mittelalterliche Scholastik übergegangen. Origenes steht in der Patristik ähnlich da, wie Abälard in der Scholastik. Trotz alles Kampfes gegen viele Gedanken der beiden haben die Späteren ihre Denkmethode doch sich zu eigen gemacht.

So haben denn auch vereinzelte Widersprüche von seiten der ganz dem Positiven zugewandten Theologen, insbesondere der Polemiker, wie Epiphanius und Theodoret, die freundliche Stellungnahme zur Philosophie als einer den Materialismus des Lebens überwindenden Vorbereitung zum Glauben und eines Denkmittels für die Spekulation nicht zurückdrängen könner. Denn auch in der Zeit, wo die Erhebung des Christentums zur Staatsreligion die Christen anspornen mußte, auf allen Gebieten sich die Schätze antiker Geistesbildung zu eigen zu machen, fehlte es nicht an Gegnern dieser Bildung. Solchen Angriffen gegenüber schrieb Basilius seinen Essai: „An die Jünglinge, wie sie aus heidnischen Schriften Nutzen ziehen sollen", ein christliches Gegenstück zu Plutarchs Schrift: „Wie soll der Jüngling die Dichter lesen?" Und Gregor von Nazianz hält solchen Fanatikern vor, daß sie nur deshalb der Verbreitung der profanen Bildung sich widersetzten, damit ihre eigene Dummheit nicht allzusehr absteche. Typisch auch für die Folgezeit war der Kampf, den der inmitten einer stark einseitig asketisch gerichteten Umgebung von Einsiedlern und Mönchen lebende Hieronymus bestehen mußte. In Worten, die unverständigen Eiferern gegenüber seitdem unzählige Male wiederholt sind, verteidigt er sich dagegen, indem er sich auf das Beispiel der „besten Schriftsteller", Quadratus, Aristides, Justinus, Pantänus, Clemens, Origenes, ja selbst des Apostels Paulus beruft. Vor allem aber war es Augustin, der in seiner für die kirchliche Wissenschaft der Folgezeit maßgebenden Schrift De doctrina christiana die Auffassung von der Bedeutung der Philosophie auch für den Theologen begründete. „Wenn die Philosophen“, sagt er dort, „etwas Wahres und dem Glauben Gemäßes gesagt haben, so ist das nicht nur nicht zu fürchten, sondern wir sollen es von ihnen als wie von unberechtigten Besitzern zu unserm eigenen Gebrauch in Anspruch nehmen". So ist Augustins prinzipielle Stellung dieselbe wie die des Origenes. Die hellenische Philosophie ehrt und schätzt er, wie er sie denn auch selbst in reichem Maße sich zu eigen macht und in seiner Spekulation verwendet; aber auch ihm ist sie nicht Selbstzweck, sondern Mittel. Sie dient ihm, dem der Glaube die Grundlage seiner Welt- und Lebensanschauung ist, einmal dazu, den Geist überhaupt zu bilden; dann aber, eine spekulative Ausbildung der Glaubensbegriffe und Glaubenssätze durchzuführen; denn wie Clemens und Origenes will auch er im Prinzip vom bloßen Glauben zum "Wissen", d. h. zur spekulativen Durchdringung voranschreiten. In diesem Sinne beruft er sich auf ein Wort Jesajas: „Wenn ihr nicht glaubt, so werdet 
ihr nicht einsehen." Es ist das Programm, dem Anselm von Canterbury später den schlagwortartigen Ausdruck gab: Credo ut intelligam.

e) Charakteristik der patristischen Philosophic. Aufgabe einer Darstellung derselben.

So kennt die Patristik eine selbständige Philosophie als für sich bestehende Wissenschaft - von einzelnen kleinen Monographien, insbesondere des jungen Augustin, und von Erscheinungen, bei denen das christliche Bekenntnis keine Rolle spielt, wie Nemesius und Synesius, abgesehen - nur in der Antike. In der patristischen Denkart selbst ist die Philosophie nur ein in den theologischen Zusammenhang eingefügtes Element. Und zwar hat dieses Element in den Glaubensüberzeugungen und Glaubensinteressen seinen Maßstab. Von hier aus bestimmt es sich, welchen Zweigen der Philosophie man seine Aufmerksamkeit zuwendet - den Lehren von Gott, von der Seele und den ethischen Untersuchungen -; hieher entnimmt man zugleich die letzten Gesichtspunkte für die Beurteilung der sachlichen Richtigkeit der philosophischen Lehren. Von einer „Philosophie“ der Kirchenväter kann also nicht im Sinne in sich abgeschlossener selbständiger philosophischer Systeme die Rede sein. Nur aus dem größeren, und zwar theologischen Zusammenhange heraus kann losgeschält werden, wie sie sich zu den Systemen der antiken Philosophie stellen und wie sie - wenigstens einzelne von ihnen - hier philosophisch weiterdenken und selbständige philosophische Gesichtspunkte entwickeln. Freilich könnte man darüber hinaus dem Philosophiehistoriker weitere Aufgaben stellen. Man könnte von ihm erwarten, daß er zeige, wie die Aufnahme der hellenischen Philosophie in der patristischen Zeit die Dogmenentwickelung beeinflußt und für die Gestaltung der theologischen und kirchlichen Lehre Bedeutung gewinnt. Man könnte auch, ausgehend von dem Gedanken, daß Philosophie Weltanschauung sei, zu bestimmen suchen, wie bei den verschiedenen Vertretern der Patristik auf dem Boden des Christentums eine abgeschlossene Welt- und Lebensanschauung sich ausbildet, in der Natur und Übernatur in gegenseitiger Durchdringung sich zu einem Ganzen vereinen. Indes ist für beides eine Geschichte der Philosophie wohl kaum der rechte Ort. Den Einfluß des Hellenismus, seiner Philosophie, seiner Mysterien, seiner Amtseinrichtungen auf die Denkweise und die Einrichtungen innerhalb der sich konsolidierenden Kirche zu entwickeln, ist vielmehr Aufgabe der Religionsgeschichte. Hier, und in der allgemeinen Welt- und Kulturgeschichte, wird auch der Platz für eine Betrachtung der religiös bestimmten gesamten Lebensauffassung jener Periode sein. Die folgende Darstellung beschränkt sich daher darauf, in kurzer Skizze zu schildern, wie einige der bedeutendsten Geister des patristischen Kreises sich zu den besonderen Aufgaben der griechischen Philosophie stellten, rezeptiv und in manchem auch durch selbständige Auffassungen die überlieferten Gedanken bereichernd. Als Parallelbewegung zu der heidnischantiken philosophischen Entwicklung soll hier die patristische Philosophie behandelt werden, indem alles übrige der theologischen Dogmen- und Literaturgeschichte überlassen bleibt.

Demgemäß tritt die Geschichte der patristischen Philosophie gegenüber 
der antiken zwar einigermaßen in den Hintergrund. Denn das, was die Geistesgeschichte im höchsten Sinne, als eigentliche Geschichte, ausmacht, ist die Entwickelung neuer Aufgabe11. Solche neue Aufgaben von höchster Bedeutung hatte die patristische Zeit auf dem Gebiete des Glaubens und der Theologie. Hier sind Dogmengeschichte und Geschichte der altchristlichen Literatur Wissenschaften von durchaus eigenartiger und grundlegender Bedeutung. Wo es sich dagegen, wie bei der Anteilnahme der patristischen Zeit an der Philosophie, mehr um die Rezeption von Gedanken und die dadurch geschaffenen Zustände handelt, da haben wir es mit einem Ausschnitt aus der uneigentlichen Geschichte, der Kulturgeschichte, zu tun. Hier fällt daher der Nachdruck mehr auf das Zuständliche und allgemein Verbreitete als auf die einzelnen Individuen. Nur wo diese, wie ein Tertullian, ein Origenes, ein Gregor von Nyssa, ein Dionysius Pseudo- Areopagita und besonders der durch die kraftvolle Ursprünglichkeit seiner tiefgründigen Persönlichkeit so einzigartige Augustin, der Lehrer vieler kommenden Jahrhunderte, auch durch besondere Eigenart der Synthese und durch schöpferische Neugedanken sich abheben, wird für die hier zu gebende Skizze ein längeres Verweilen bei dem Einzelnen gerechtfertigt sein. Das Gemeinsame wird breiter darzulegen sein; für das Einzelne können wir uns auf ausgewählte Bilder beschränken.

II. Quellen der patristischen Philosophie. Stellung zu den einzelnen Philosophenschulen. - Aus diesem Charakter der patristischen Philosophie ergibt es sich, daß für die Analyse ihrer gemeinschaftlichen Grundzüge eine eingehendere Betrachtung der Stellung nötig ist, welche sie zu den einzelnen Philosophenschulen einnimmt. Denn selbst diejenigen unter den Denkern der patristischen Zeit, welche auch auf philosophischem Gebiete eine größere Selbständigkeit aufweisen, stehen natïrlicherweise doch in ihrer Zeit und folgen dem Gange der philosophischen Bewegung ihrer Zeit. Wo sie - zustimmend oder abweisend - mit der antiken Philosophie zusammentreffen, da beruht deshalb diese Berührung nicht auf einer entsprechend der eigenen Denkweise frei getroffenen rein literarischen Auswahl, sondern sie folgt dem Gange, den die antike Philosophie selbst in ihrer zeitgenössischen Entwickelung nimmt.

In einem freilich blieb man sich von Anfang an gleich: in der Zurück- a) Abweisung weisung des Epikureismus. Seine antireligiöse Grundstimmung und seine $\begin{gathered}\text { des } \\ \text { Epikureismus. }\end{gathered}$ hedonistische Lebensansicht standen zur transzendenten Lebensauffassung des Christentums und seiner das Opfer fordernden Ethik im schroffsten Gegensatz. So ist zwischen Christentum und Epikureismus ein unversöhnlicher Streit, der auch literarisch vielfach zutage tritt. Hat doch Origenes in der Empfindung dieses Gegensatzes den eklektischen Platoniker Celsus, den Verfasser einer Kampfschrift gegen das Christentum, für einen Epikureer gehalten. Dionysius von Alexandrien $(† 265)$ schrieb ein ganzes Buch gegen die Physik Epikurs, auf Grund derer dieser die Abhängigkeit der Welt von Gott bestritt, und auch sonst sind in der älteren Patristik die Äußerungen, 
welche gegen Epikur sich richten, zahlreich, besonders scharf z. B. bei Laktanz. Wenn vom dritten Jahrhundert an der Epikureismus mehr und mehr verschwindet, so liegt die Ursache dafür nicht nur in der allgemeinen Umstimmung der Kulturseele gegenüber dem eigentlichen Hellenismus, die philosophisch in der Entstehung des metaphysisch und religiös gerichteten Neuplatonismus sich offenbart, sondern vor allem auch in der zunehmenden Verbreitung des Christentums. Beider Geschicke stehen nach Useners treffender Bemerkung in Wechselwirkung; mit dem Siege des Christentums verödet Epikurs Schule. Für Augustin gehört sie nur noch der Vergangenheit an.

b) Gerrensatz zur Skepsis.

c) Aristoteles ohne größere Bedeutung für die Yatristik.

So wenig wie der Epikureismus, hat die Skepsis in ihren verschiedenen Formen positiv für die Patristik zu bedeuten. Ursprünglich der Skepsis angehörige Argumente gegen die Götterlehre finden sich zwar gelegentlich, wie z. B. bei Athenagoras, wenn er die Annahme einer Vielheit von Göttern dialektisch zerpflückt; aber sonst ist die Stellung zur Skepsis nur eine negative. $\mathrm{Zu}$ dem skeptischen Zweifël bildet die christliche Glaubens- und Heilsgewißheit den größten Gegensatz. Gerade durch die Loslösung von der akademischen Skepsis, durch die er verzweifelnd hindurchgegangen, gewinnt Augustin die innere Freiheit und Sicherheit. Insbesondere auch die akademischeBestreitung einer allgemeingiltigen Sittenregel und die relativistische Auflösung der Ethik, die in den beiden Reden des Karneades zu Rom für und wider die Gerechtigkeit typischen Ausdruck fand, findet schon in der altchristlichen Zeit Widerspruch. Schon die pseudoklementinischen Homilien wiederholen die aus der Verschiedenheit der Völkersitten entnommenen Einwendungen, um sie dann durch den Mund des Petrus in stoischer Weise widerlegen zu lassen. Vor allem ist Augustin, der, müde des manichäischen Wahnes, selbst der akademischen Skepsis zeitweilig sich ergeben hatte, der Überwinder des Skeptizismus. Theoretisch setzt er ihm eine stoisch-platonische Erkenntnistheorie entgegen, sowie die ihm eigene Berufung auf die unmittelbare Gewißheit des Selbstbewußtseins; auf der: praktischen Gebiete überwindet erden ethischen Relativismus durch die Ausbildung desGedankens der lex aeterna, die aller Sittlichkeit Grund und Richtschnur ist.

Noch eine dritte Schule scheidet, entsprechend der Zeitentwickelung, tis Quelle für die patristische Philosophie aus: die des A ristoteles. Während der Werdezeit der patristischen Philosophie geht die peripatetische Schule f st ganz in gelehrter literarischer Tätigkeit auf, insbesondere in gelehrter Exegese des Aristoteles. Den lebendigen Strom des geistigen Lebens der Zeit beherrscht diese Gelehrtenarbeit nicht mehr. So kommt sie für die mitten im Leben stehenden älteren Vertreter der Patristik kaum in Betracht. Nicht viel anders wird das Verhältnis, als die neuplatonische Schule das Erbe, wie der Akademie, so auch des Peripatos antritt. Auch hier ist das, was übernommen wird, vor allem die gelehrte Exegese. Wo Begriffe und Sätze der aristotelischen Philosophie selbst in das neuplatonische System eingeher da sind sie entweder von formaler Art, wie die aristotelische Logik und Kategorionlehre, oder sie betreffen nur untergeordnete Fragen, wie die 
Gliederung der Sinnesvermögen oder die Arten der natürlichen Veränderungen. So haben denn auch die dem Platonismus nahestehenden christlichen Denker zwar wohl einige Kleinigkeiten von Aristoteles und den Peripatetikern übernommen, Augustin z. B. die Einteilung der äußeren und inneren Sinnesvermögen, auch die Kategorienlehre, die längst in den allgemeinen Besitz übergegangen war, der gelehrte Bischof von Cäsarea, Eusebius, Argumente der Peripatetiker Diogenian und Alexander von Aphrodisias gegen den stoischen Fatalismus; aber die entscheidenden Grundlagen sind nicht aristotelisch. Selbstverständlich ist die deistische Fassung des Verhältnisses der Gottheit zur Welt, welche die Gottheit der Welt durchaus äußerlich verbleiben läßt, ohne Wissen von ihr und ohne eine auf sie gerichtete Tätigkeit, für die Patristik unannehmbar; aber auch die aristotelische Bestimmung der Gottheit durch den Begriff des reinen Aktes, welche für die theistische Metaphysik der Scholastik eine Hauptstütze bildet, ist der patristischen Spekulation in dieser Form fremd. Und wenn auch Begriffe, wie Wesenheit, Substanz, Natur, sachlich und terminologisch schon der aristotelischen Philosophie angehören, so waren diese Begriffe, deren Durchbildung im theologischen Zusammenhang eine Hauptarbeit in den trinitarischen und christologischen Streitigkeiten bildete, schon längst Gemeingut geworden. Von einer unmittelbaren Entlehnung derselben aus der peripatetischen Philosophie kann um so weniger die Rede sein, als die dazugehörigen Begriffe der Hypostase und der Person bei Aristoteles überhaupt noch nicht entwickelt sind. Ebensowenig hat sich die Patristik die in der entwickelten Scholastik herrschende aristotelische Fassung der Seele als der Wesensform des Körpers und die daraus sich ergebende Auffassung der Sinneswahrnehmung als eines nicht bloß psychischen sondern psycho-physischen Prozesses zu eigen gemacht. Überall zeigt sich, daß aristotelische Anschauungen nur insoweit für die Patristik Unterlage sind, als sie in den allgemeinen Besitz der Zeit übergegangen waren. Eine eigentliche Quelle ist, wie gegenüber immer wiederkehrenden Versuchen, welche die Auffassungen der Hochscholastik insgesamt in die patristische Periode zurückprojizieren möchten, betont werden muß, Aristoteles für die Patristik nicht. Erst ganz zum Schluß der patristischen Periode wird die gelehrte Aristoteleserklärung der Neuplatoniker auch für die christliche Welt von Bedeutung. Der christliche Neuplatoniker Philoponus (um 600) ist selbst Aristoteleserklärer, und bei den Theologen Leontius von Byzanz (6. Jahrh.) und Johannes Damascenus (um 700) bereitet sich durch steigende Mitbenutzung der aristotelischen Philosophie ebenso in der griechischen Welt der Ubergang in das Mittelalter vor, wie bei dem lateinischen Neuplatoniker Boethius (der an Marius Victorinus in gewisser Weise einen Vorläufer hatte) im Abendlande.

Die wirklichen antiken Quellen für die Patristik - von gelegentlichen Einzelheiten und von mehr historisch gehaltenen Erörterungen, wie in der Schrift des einer späten Periode angehörigen Nemesius „über die Natur des Menschen" abgesehen - sind die Stoa, der - Platonisches, Stoisches und 
Neupythagoreisches in wechselnden Mischungsverhältnissen verbindende eklektische Platonismus, die selbst von beidem beeinflußte jüdisch-alexandrinische Religionsphilosophie Philos und zuletzt, aber nicht an letzter Stelle, der Neuplatonismus.

d) EinfluB der stoisch-platonischen Popular philosophie und der stoischen Natur. philosophie.

Den Anfang macht im zweiten Jahrhundert jene aus der Durchdringung von Stoizismus und einem ziemlich vagen Platonismus entstandene Popularphilosophie, die auch von den kynischen Wanderpredigern vertreten wurde und durch eine reiche Literatur, insbesondere die sogenannten „Diatriben“, in Scherz und Ernst, in Prosa und in eingestreuten Versen eine intensive Wirksamkeit entfaltete. Dem stoischen Pantheismus hatte sie, wie man auch aus Seneca und Epiktet ersieht, eine theistische Wendung gegeben. Mit mancherlei Argumenten, darunter auch solchen aus skeptischem Zusammenhange, bekämpft sie den polytheistischen Götterdienst. Dem Philosophen als Seelenarzt stellt sie die Aufgabe der sittlichen Reinigung und Läuterung, die zum Ideale des Weisen führt. Bei den griechischen und lateinischen Apologeten, doch auch noch bei Clemens von Alexandrien, begegnet uns ein starker Einfluß dieser Literatur. - In der Form aber, die Cicero der stoischen Ethik des Panätius gegeben hatte, wirkt sie nicht nur bei Lactantius stark nach, sondern noch Ambrosius in seiner Ciceros Werk De officiis nachgebildeten Schrift über die Pflichten der Kleriker hat sie fast ganz aufgenommen und ins Christliche und Geistliche gewandt. Und auch der Einfluß von Senecas Ethik ist neben dem Ciceros bei Minucius Felix und Laktanz mannigfach zu verspüren.

In jener Popularphilosophie spielt die Physik der Stoa kaum eine Rolle. Die stoische Logoslehre freilich ist weitverbreitet und zu einem allgemeinen Bestandstück des philosophischen Denkens der Zeit geworden. Sie wird uns noch beschäftigen. Aber der in der stoischen Pneumalehre liegende von Heraklit stammende Materialismus und Evolutionismus sowie die sensualistische Erkenntnislehre der Stoa treten in der altchristlichen Literatur nur in Spuren auf; der Materialismus natürlich, wie übrigens auch bei der Stoa selbst, nur in der den Dualismus einschließenden Form, die auch das Geistige, um seine wirkungskräftige Realität vor Verflüchtigung in das bloß Gedachte zu wahren, noch als ein Körperliches, aber als ein Körperhaftes von feinster und sublimster Art, vorstellt, im Gegensatz zu den grob materiellen Dingen. Der eigentliche Materialismus, der das Bewußtsein den sonstigen Leibesfunktionen im Prinzipe gleichstellt, bleibt selbstverständlich ausgeschlossen. So ist heraklitisierend und stoisch gefärbt die Lehre der pseudoklementinischen Homilien vom Hervorgang der Welt aus dem alles durchdringenden göttlichen Urlicht und von der Rückwandlung und Rückkehr von allem in seinen Ursprung, gleich wie bei den Winterdünsten, die von der Sonne aufgesogen werden. Vor allem aber hat Tertullian die stoische Physik, Psychologie und Erkenntnislehre sich zu eigen gemacht. Gegenüber der alles Positive verflüchtigenden extrem spiritualistischen Anschauungsweise der Gnostiker, für die das Körperliche ein Nichtseinsollendes, ein Böses 
ist, lehnt sich sein auf das Faßbare und Positive gerichteter Geist an die Stoa an und faßt, um die Substantialität Gottes und die Wirkungsfähigkeit der Seele zu retten, im Sinne der stoischen Pneumalehre Gott und Seele als Körper ihrer Art, feiner als die materielle Körperwelt, auf. Wenn die Platoniker die Sinneserkenntnis zu einer bloßen Gelegenheitsursache für die in sich selbständige Vernunfterkenntnis herabdrücken wollen und damit das Konkrete, Historische zu zeitlosen Abstraktionen verflüchtigen, so nimmt er den Kampf auf, den schon Antisthenes gegen die platonische Ideenlehre führte. Nicht Plato und Philo, wohl aber die Schule Zenos und philosophierende Naturforscher, wie der stoisch gerichtete Mediziner Soranus, sind seine Lehrer. - In den Kreis der Stoa werden wir auch durch den lateinischen Apologeten Arnobius geführt, der gleichfalls die reine Geistigkeit der Seele bekämpft und der platonischen Lehre von der Wiedererinnerung die Auffassung gegenüberstellt, daß die Seele von sich aus völlig leer sei und nur aus der Wahrnehmung die Erkenntnis erhalte. Was dem zu widersprechen scheine, sei durch die soziale Einwirkung auf den heranwachsenden Menschen zu erklären: eine Theorie, die Arnobius durch die seitdem öfter wiederholte Fiktion eines in völliger Einsamkeit aufwachsenden Menschen zu erläutern sucht. Auch bei Laktantius, der vor seinem Übertritt zum Christentum als Lehrer der lateinischen Beredsamkeit zu Nikomedien der stoischen Schule wenigstens nahe stand, fehlen die stoischen Einflüsse nicht. Namentlich in seiner Schrift De mundi opificio, die auf den Wegen der stoischen Naturteleologie den göttlichen Schöpfer erweisen will, tritt die Abhängigkeit von der lateinischen stoischen Literatur, von Varro, Cicero, Seneca, aufdas deutlichste hervor. Später verschwindet der unmittelbare Einfluß der Stoa. Ihre Lehre wirkt nur noch nach, insoweit sie in die Zeitphilosophie als bleibender Bestandteil eingegangen ist. Wie den Epikureismus, bezeichnet Augustin auch den Stoizismus als zu seiner Zeit erloschen.

In einem freilich tritt die altchristliche Zeit der stoischen Lehre durchweg entgegen, in ihrem die Willensfreiheit ausschließenden fatalistischen und psychologischen Determinismus. Hier steht man auf Seite der Platoniker. Eusebius, Diodor von Tarsus, Lactantius bekämpften den stoischen Fatalismus. Verfaßte doch auch ein Gnostiker, der Syrer Bardesanes (Bar Daisan), oder einer seiner Schüler, eine eigene Schrift, das Buch der Gesetze der Iänder, in dem die astrologische Form des Determinismus bekämpft wird, welche den Willen zwing enden siderischen und klimatischen Einflüssen unterstellen will. Vor allem wendet sich in historisch einflußreicher Weise Augustin gegen das „Fatum“. Aber freilich, daß die göttliche Providenz voraussehend alles im Weltlauf vorher geordnet habe, das hält auch sein Glauben fest. Wer nur den Zufall herrschen lasse, den will er noch schärfer bekämpfen, als die Stoiker es taten. Und wenn einer mit dem Worte „Fatum“ nicht das blinde Schicksal meine, sondern dies Walten der Vorsehung, so möge er die Sache behalten und nur das Wort verbessern. - Boethius in seinem „Philosophischen Trostbüchlcin" hat später diese Fassung des ,Fatums" 
näher entwickelt. So ist der umgebildete stoische Begriff auch auf das Mittelalter, z. B. auf Thomas von Aquino, übergegangen.

e) Einfub Plato und des Platonismus.

Ganz entsprechend dem allgemeinen Gange der zeitgenössischen Philosophie ist der unmittelbare Einfluß P1atos in der patristischen Periode, namentlich in ihrem Beginn, nicht übermäßig groß. Hohe Verehrung freilich wird seinem erhabenen Geiste wohl von allen gezollt, die überhaupt der Philosophie freundlich gesinnt sind. Der Grieche Eusebius, der Plato „mehr denn andere Griechen als Freund erachtet", und Augustin, für den „das Antlitz Platos im reinsten und hellsten Lichte erstrahlt", sprechen in gleich rühmender Weise von ihm. Auch manche unmittelbare Beziehungen auf Plato finden sich in der Patristik, angefangen von Justin, der in der $X$-förmigen Ausdehnung der Weltseele im Platonischen Timäus ein Vorbild des am Kreuz ausgespannten Logos erblicken will, und von Athenagoras, der sich gegen die Verehrung materieller Götterbilder auf Platos Satz von der steten Veränderung und Hinfälligkeit alles Körperlichen beruft, bis auf Gregor von Nyssa, der seinen Dialog über Seele und Auferstehung dem Platonischen Phädon nachbildet, wie schon vorher Methodius von Olympus sein „Gastmahl der zehn Jungfrauen" dem Platonischen Symposion, sowie bis auf Gregor von Nazianz und Augustin, die aus Platons Politeia den schönen Vergleich der Idee des Guten und ihrer Stellung im Reiche des Intelligibeln mit der Sonne, die in der sichtbaren Welt allem Sichtbarkeit und Gedeihen verleiht, in christlicher Umbildung wiederholen. Auch getadelt hat man Plato, insbesondere wegen seiner Lehre von der Präexistenz der Seelen, die nur von wenigen geteilt wird, bei denen die Abhängigkeit vom Platonismus oder Neuplatonismus besonders stark ist, wie von Origenes im dritten, von Nemesius im vierten und dem christlichen Neuplatoniker Synesius im fünften Jahrhundert. Auch die Unsterblichkeitsbeweise Platons fand man nicht ausreichend, weshalb z.B. Justin die Unsterblichkeit als göttliches Gnadengeschenk betrachten will, während Augustin, der hier überhaupt nicht direkt an Plato anknüpft, sie umbildet. Indes, trotz mancherlei unmittelbarer Rücksichtnahme auf Plato ist das, was in der Patristik eigentlich wirksam ist, doch nicht Plato selbst, nicht die Platonischen Schriften, sondern der zeitgenössische Platonismus in seiner wechselnden Entwickelung: in der älteren Zeit die eklektischen Platoniker und Philo, in der späteren dieser und der Neuplatonismus.

Dieser lebendige Platonismus hat von Justin bis zu Augustin den philosophischen Denkern im Christentum den Blick für das Reich des Geistes und des Intelligibeln eröffnet. Der philosophische Transzendenzgedanke entstammt auch in der patristischen Philosophie dem Platonismus. Von den Platonikern rühmt Augustin, daß sie „Gott suchend, alle Körper übersteigen“ (transcendunt), weshalb sie ,nicht mit Unrecht an Ruhm und Ehre allen übrigen vorangehen". Erst der Platonismus gab dem in manichäische Sinnesphantastik Verstrickten die Kraft, ein rein geistiges Sein zu denken. Andererseits führte der im Platonismus liegende extreme Spiritualismus, für den die Materie das Prinzip des Bösen bildet, nicht nur gegenüber dem Gnostizismus, sondern 
auch innerhalb der Kirche zu polemischen Auseinandersetzungen. Die Origenistischen Streitigkeiten drehen sich zu einem guten Teile um diesen Punkt. Von größter Bedeutung ferner auch für das philosophische Denken der Patristik ist der aus der heraklitisch-stoischen Lehre in den späteren Platonismus übergegangene Logosbegriff, namentlich in der Form, die er bei Philo erhalten hat. In den trinitarischen Glaubensstreitigkeiten vollzieht sich innerhalb der Kirche die Auseinandersetzung des kirchlichen Bewußtseins mit dem philosophischen Begriff. Für Origenes ist der Logos im Sinne der Platoniker die Idee der Ideen und das notwendige Übergangs. und Bindeglied $z$ wischen der Einheit des Vaters und der Vielheit der geschaffenen Dinge. Im Arianismus, dieser, die ganze Kirche erschütternden, im Konzil von Nicäa ausgestoßenen Bewegung, werden die Gedanken, die bei Origenes in gelehrtem Zusammenhange sich finden, in gesteigerter und vergröberter Form Schlagworte einer großen Partei. Athanasius als Führer der Orthodoxen gibt dem philosophischen Logosbegriff die von seinem platonischen Ursprunge.weitabliegende Form, in welcher er nicht der Vermittlung zwischen dem Einen und Vielen, zwischen der absolut jenseitigen Gottheit und der dieser unwürdigen niederen Materie dienen, sondern gegenüber derjenigen Form des Monotheismus, die das göttliche Sein als ein starr in sich beruhendes denkt, ein innergöttliches unendliches Leben begründen soll. Mit dem Logosbegriff gewinnt endlich auch die Ideenlehre hohe Bedeutung für die Patristik. Wieder kommt hier nicht ihre originale Platonische Form in Betracht, sondern die Umbildung, die sie bei den Platonikern seit der Zeit des Attikus und Philo erfahren hat. Die im Logos beschlossenen Ideen sind vorbildliche Gedanken der Gottheit, in denen die Nachahmbarkeit des göttlichen Wesens nach außen hin sich ausdrückt. Augustin ist es, der nach langen Vorbereitungen der Ideenlehre innerhalb der Patristik die abschließende Gestaltung gegeben hat, in der sie dann in der Metaphysik des Mittelalters heimisch wurde. Daß auch, abgesehen von der stoischen Gruppe Tertullian, Arnobius und Laktanz, hinsichtlich der psychischen Funktionen, insbesondere des Erkenntnisprozesses, die Patristik platonisch denkt und Aristotelisches nur insoweit berücksichtigt, als es in den Platonismus übernommen war, ist schon bemerkt worden.

Welche einzelnen Vertreter des Platonismus auf die christlichen Denker einwirkten, läßt sich nicht immer mit Sicherheit sagen; nur Gruppen lassen sich, entsprechend der zeitlichen Entwicklung, angeben. Den Anfang macht natürlich der stark stoisch gefärbte eklektische Platonismus, in den auch mancherlei Neupythagoreisches eingegangen ist. Das Letztere tritt stark bei Origenes hervor, der des platonisierenden Neupythagoreers Numenius rühmend gedenkt. Von durchschlagender Bedeutung aber ist der jüdische Religionsphilosoph Philo von Alexandrien, sowohl durch seine, Platonismus und stoische Naturphilosophie, insbesondere die stoische Logoslehre, mit dem mosaischen Gottes- und Schöpfungsbegriff verbindende religionsphilosophische Synthese, wie auch als Vorgänger in allegorischer Schrifterklärung und in

Eklektischer Platonismas.

Numenius.

Pbilo. 
der Apologetik gegenüber dem Heidentum. „Sein Andenken,“ sagt mit Recht sein neuester Herausgeber Leopold Cohn, "von den Juden nicht weniger wie von den Heiden insgemein vernachlässigt, hängt ganz ab von der christlichen Kirche". Hat ihn doch Hieronymus, freilich mit besonderer Begründung, unter die scriptores ecclesiastici eingereiht. Nicht nur die Griechen, von der pseudojustinischen Mahnrede an die Hellenen und von Clemens von Alexandrien an zu Origenes und Eusebius von Cäsarea und weiter zu Gregor von Nyssa, haben ihn als Philosophen und philosophischen Exegeten gekannt und benutzt, sondern auch Lateiner, wie außer Hieronymus insbesondere der Bischof von Mailand Ambrosius, der in Briefen und Abhandlungen lange Stellen aus Philo in lateinischer Ubersetzung fast wörtlich ausschreibt. Besonders Origenes ist von Philo stark abhängig. Die mit Athanasius anhebende, in den Glaubenssymbolen von Nicäa und Konstantinopel ihren kirchlich dogmatischen Ausdruck findende Auseinandersetzung mit dem origenistischen und arianischen Logosbegriff - die wir als rein theologisch von unserer Darstellung ausschließen - kann auch eine Auseinandersetzung mit Philo genannt werden. Und um noch eine andere Einzelheit herauszuheben: auch des Origenes platonisierende Vorstellung von dem vorzeitlichen und vorempirischen rein geistigen Menschen, der erst durch den Sündenfall in den materiellen Körper eingeschlossen sein soll, geht zunächst auf Philos platonisierende Bibelexegese zurück.

Der in mannigfachen Variationen kaleidoskopisch schillernde eklektische Platonismus, der während der älteren Periode der Patristik herrscht, weist Neuplatonismus. keine systematische Geschlossenheit auf. Philo aber ist eine literarische Einzelerscheinung, von der mancherlei Ausstrahlungen ausgehen, die aber nicht schulebildend wirkt. So läßt die ältere patristische Periode $z$ war mancherlei Einwirkungen des Platonismus erkennen, aber eigentliche Platoniker, die man einfach einer der antiken platonischen Schulen einreihen könnte, weist sie nicht auf. Das wird anders, seitdem im Neuplatonismus durch Plotin ein in seinen wesentlichen Bestandteilen geschlossenes System mit fester Schultradition und schulmäßiger Gliederung geschaffen war. Jetzt gibt es auch unter den Christen Platoniker, die zwar diesem oder jenem einzelnen Punkte und ganz besonders der neuplatonischen Neubelebung der alten Götterlehre durch Umdeutung derselben in eine metaphysische Begriffswelt ablehnend gegenüberstehen, die aber, vom Neuplatonismus herkommend, das eigentlich Philosophische des Neuplatonismus auch als Christen in seiner systematischen Geschlossenheit festhalten. So der philosophierende Rhetor Marius Viktorinus im 4. Jahrhundert, der als Greis zum Christentum übertrat und dessen im Geiste Plotins und Jamblichs gehaltenen Abhandlungen ebenso wie die lateinischen Übersetzungen, die er von neuplatonischen Schriften veranstaltete, noch seiner heidnischen Zeit angehören; so der nachmalige Bischof von Kyrene, Synesius ( $f$ um 413), der Schüler der alexandrinischen Philosophin Hypatia, wenigstens soweit die für ihn charakteristischen Schriften seiner ersten Periode in Betracht kommen; so der christliche Erklärer (und Über- 
setzer) des Platonischen Timäus, Chalcidius (dessen philosophische Quellen übrigens noch vorplotinisch sind), und Boethius, der in seinem philosophischen Trostbüchlein stoische Lebensanschauung mit neuplatonischer Metaphysik verbindet (von seinen theologischen Schriften sehen wir hier ab). Näher auf diese Neuplatoniker christlichen Bekenntnisses im Zusammenhange der patristischen Philosophie einzugehen, haben wir ebensowenig Veranlassung, wie man etwa Spinoza der jüdischen Religionsphilosophie einreihen wird. Aber auch auf Denker von spezifisch christlichem Gepräge hat der Neuplatonismus starke Einwirkungen ausgeübt. Um nur einige der bedeutendsten zu nennen: Gregor von Nyssa weist in den ihm eigentümlichen Lehren auf das deutlichste seine Spuren auf, und auch das Platonische bei Augustin ist wohl zumeist neuplatonisch vermittelt, insbesondere durch den von Augustin fleißig gelesenen Marius Viktorinus. Auch die Mystik der späteren patristischen Zeit ist in ihren intellektualistischen Elementen vielfach vom Neuplatonismus inspiriert. Schon bei Gregor von Nyssa finden sich Spuren dieser Mystik. Ganz und gar aber sind die für eine ganze Richtung der mittelalterlichen Mystik grundlegenden Schriften des Dionysius Pseudo-Areopagita vom Geiste des Plotin und des Proklus erfüllt. Neuplatonisch sind dort alle die Formeln von der überseienden und nur negativ zu erkennenden Gottheit, von der Ausbreitung der göttlichen Güte, von der negativen Natur des Bösen, von der Stufenordnung der Wesen, bei der das obere Glied in Einheit umfaßt, was die unteren in Vielheit sich trennen und scheiden lassen, und das mittlere die Eigenschaften der oberen und unteren Stufe verknüpft; neuplatonisch wenngleich durchaus nicht $b 10 B$ neuplatonisch - auch die Art, wie die ekstatische Vereinigung mit der Gottheit, die im Dunkel mystischer Schauung sich vollzieht, von Dionysius geschildert wird.

Diesen mancherle: Übereinstimmungen gegenüber dürfen aber die durchgreifenden Verschiedenheiten nicht übersehen werden, welche die platonische Denkweise innerhalb der Patristik von dem antiken Neuplatonismus trennen. Plotins „Erstes," das er auch als das Eine und das Gute bezeichnet, ist unpersönlich. Erst in seinen Emanationen, dem Nus und der Seele, kommt die als Schranke gedachte Persönlichkeit zur Entfaltung. Dem christlichen Evangelium ist Gott der Vater. Hierauf beruhen der Halt und die Hoffnung, die es dem Leben gibt. Sein Gottesbegriff ist der des persönlichen, seines Wesens bewußten und allerkennenden Gottes. Darum ist in der spekulativen Entfaltung des christlichen Dogmas und der christlichen Theologie auch das trinitarische persönliche Leben ein solches, das nicht erst im WeltprozeB sich vollendet, sondern transzendent und innergöttlich verbleibt. Der WeltprozeB selbst aber erscheint demgemäB nicht als eine notwendige Entwickelung der göttlichen Natur, sondern als eine freie Tat der göttlichen Güte, als freie Schöpfung. Dieser Gegensatz der inneren Notwendigkeit und der freien Tatsächlichkeit führt hinsichtlich der Auffassung des in die Zeit gestellten Geschichtlichen zu einem weiteren charakteristischen Gegensatz zum Neuplatonismus. Während bei diesem der WeltprozeB geschichtslos ist und alle 
Entwickelung zuletzt als logische Ordnung eines ewigen metaphysischen Seins erscheint, ist der Patristik die Menschengeschichte die um Christus als Mittelpunkt sich bewegende historische Wirklichkeit, die nicht in eine Begriffsordnung aufgelöst werden darf: ein Unterschied, den vor allem Augustin mit prinzipieller Klarheit hervorhebt. Darum ist auch die Erlösung nicht, wie bei Indern, Gnostikern und Neuplatonikern, eine in der bloßen Erkenntnis sich vollziehende Aneignung ewiger Wahrheiten. Wie in dem historischen Jesus Christus, dem Stifter und zugleich dem wesentlichen Inhalt des Christentums, sich Göttliches und Menschliches auf das innigste durchdringen, so soll auch die Erlösung des einzelnen nicht durch abstrakte Erkenntnis, sondern durch die gnadenvolle Herablassung Gottes und seine das ganze individuelle Eigenleben umgestaltende und erhebende Hilfe erfolgen. Von diesen Paulinischen Grundgedanken läßt die Patristik nicht, trotz einiges Schwankens hinsichtlich dieses oder jenes Einzelpunktes in der ersten Zeit, insbesondere bei Origenes. Sie bezeichnen eine unübersteigbare Schranke gegenüber der Welt- und Lebensauffassung des genuinen antiken Neuplatonismus.

III. Hauptvertreter der philosophischen Spekulationinnerhalb der Patristik. - Eine geschichtliche Übersicht der patristischen Philosophie kann nicht den Gruppierungen und Zusammenhängen folgen, welche durch die the ologische Entwickelung gegeben werden. Da aber auf dem rein philosophischen Gebiete in der Patristik eine selbständige Schulentwickelung und geschlossene Schulenfolge überhaupt nicht vorliegt, so wird die philosophiegeschichtliche Darstellung, wenn sie auf ihrem eigenen Felde verbleiben will, die patristische Philosophie in ihrer Parallelbewegung zur antiken Philosophie verfolgen und von dem Verhältnis zu dieser die leitenden Gesichtspunkte der Einteilung hernehmen. Im vorigen Abschnith, der das Verhältnis der Patristik zu den sich teils ablösenden, teils nebene:nander verlaufenden antiken Schulen besprach, haben wir die Grundlagen einer solchen Gruppierung gegeben und dort, sowie bei Besprechung des Verhältnisses der Patristik zur Philosophie überhaupt, zugleich die Grundzüge des Gemeinsamen und Zuständlichen jener Periode des christlichen philosophischen Denkens und seiner Grundrichtungen skizziert. So erübrigt noch, daß wir, um innerhalb des gegebenen Rahmens das Besondere zu erläutern, die Charakteristik einiger bedeutender Vertreter der patristischen Philosophie in Einzelbildern vorführen, wobei natürlich nur die selbständigeren Geister, die neue Aufgaben zu stellen verstanden, Berückşichtigung finden können. Und auch bei ihnen wird es bei der Fülle des Stoffes nur möglich sein, einzelne besonders charakteristische Züge herauszugreifen.

I. Justin und die griechischen Apologeten.

Einen typischen Vertreter der griechischen Apologeten - ihre Namen wurden bereits früher aufgezählt - haben wir in Justin, dem „Philosophen und Märtyrer", wie schon Tertullian ihn nennt, dem Verfasser des Dialogs mit dem Juden Trypho, der einzigen erhaltenen antijüdischen Apologie, einer größeren antiheidnischen Apologie an den Kaiser Antoninus Pius, seine 
Adoptivsöhne Mark Aurel und Lucius Verus, den Senat und das ganze römische Volk, um 150 verfaßt, einer gewissermaßen einen Nachtrag bildenden kleineren Apologie und verlorener antignostischer Schriften. Dank der freilich schriftstellerisch aufgemachten, aber in der Hauptsache doch wohl autobiographischen Angaben im Dialog mit Trypho tritt der zu Flavia Neapolis in Samaria als griechischer Kolonistensohn geborene, um $165 \mathrm{zu}$ Rom als Märtyrer verstorbene liebenswürdige und feingebildete Mann als lebendige Persönlichkeit vor uns, deren Lebensentwickelung den Gang veranschaulichen mag, den mancher von der antiken Bildung unbefriedigte religiös gesinnte Geist genommen haben wird. Vom Wahrheitsdurst beseelt, geht Justin zuerst bei einem Stoiker in die Lehre; aber da er bei diesem nichts von Gott hört, so wendet er sich von ihm ab und geht zu einem Peripatetiker. Allein dessen alsbaldiges Drängen auf das Honorar scheint ihm eines Philosophen unwürdig, weshalb er sich zu einem Pythagoreer begibt. Doch da dieser nur auf dem langen Wege über Musik, Astronomie und Geometrie ihn zur Philosophie führen.zu können erklärt, so ergreift er mit Freuden die Unterweisung eines jüngst angekommenen Platonikers, der ihm das Auge für die Welt des rein geistigen Seins öffnet und ihn zur Anschauung Gottes zu bringen verspricht. A.ber diese letzte Beruhigung des sehnenden Herzensverlangens findet er nicht. Im Gespräch mit einem ehrwürdigen Greise muß er sich überzeugen, daß Gewißheit über das nie zu Sehende nicht vom eigenen Suchen, sondern nur von der Mitteilung von seiten dessen, der es geschaut hat, zu erwarten ist. Von den Philosophen wendet er sich zu den Propheten, zur Verkündigung des Evangeliums. Hier erlebt er, nicht zum mindesten auch angesichts der Glaubenszuversicht der Märtyrer, die für ihren Glauben in den Tod gehen, die das ganze Leben durchdringende, tröstende Gewißheit, die ihm die Philosophie nicht gegeben hatte. Aber eine Vorhalle bleibt ihm die Philosophie zum Christentum, in welch letzterem der Logos, der bei den Philosophen erst sich ankündigt, sich voll offenbart hat.

In dieser Stellungnahme Justins zur Philosophie liegt für den Philosophiehistoriker seine Bedeutung, weniger in seinen einzelnen philosophischen Anschauungen, von denen nur weniges hervorgehoben sei. Stoisch-platonische Erkenntnislehre ebenso wie Paulinische Lehre ist es, wenn Justin den Begriff Gottes und sein Gesetz dem Menschen von Natur eingepflanzt sein läßt. Aber Gottes Wesen mit dem Geistesauge zu schauen, geht über die Kräfte der Natur. Justin polemisiert gegen die Platonische Lehre von einer Schau des reinen Seins, das die Ursache von allem sei, wobei freilich weder die Darstellung der Platonischen Lehre von einer gewissen Einseitigkeit, noch die Polemik von Trivialität ganz freigesprochen werden kann. Nur aus seinen Werken erkennen wir Gott; von dorther sind daher auch seine Namen hergenommen. Die Logoslehre hat Justin weitergeführt. Dèr Logos ist das Schöpferwort und der Offenbarer Gottes an den menschlichen Geist, samenhaft in allen Menschen sprechend, voll hervorgetreten in Christus. Die Form, in der Justin die Logoslehre spekulativ verwendet, steht der Philonischen vielfach nahe 
und führt zu einer subordinatistischen Auffassung. Aber diese christologische Frage, sowie Justins Lehre vom göttlichen Geist, sind vorwiegend theologischer Natur und müssen daher hier ausscheiden. Gegen den aus der Idee des Lebens geschöpften Unsterblichkeitsbeweis des Platonischen Phädon polemisiert Justin. Die Seele ist nicht Leben, sondern hat nur Teil am Leben solange es Gott gefällt. Die Unsterblichkeit ist darum ein göttliches Gnadengeschenk, wie ethische Erwägungen nahelegen, aber erst die Offenbarung gewiß macht.

2. Tertullian und die lateinischen Apologeten.

Gewissermaßen die Antithese zu Justin als Persönlichkeit und in seinem spekulativen Denken bildet Tertullian, wohl die geschlossenste und gewaltigste Natur unter den Lateinern bis auf den größeren, weil weiterblickenden und harmonischeren Augustin. Geboren um $160 \mathrm{zu}$ Karthago als Sohn eines römischen Centurio - den "schwarzen Knecht Gottes" konnte nur groteske historische Unwissenheit ihn nennen -, nach stürmischen Jugendjahren Sachwalter, dann, tieferschüttert durch die sichere Glaubenszuversicht der Märtyrer, zum feurigen Kämpfer für das Christentum umgewandelt, Presbyter der Kirche, allmählich aber durch seinen eifervollen Rigorismus, dem die Wiederaufnahme sittlich oder im Glauben Gefallener eine Befleckung der Reinheit und Heiligkeit der Kirche erschien, der allgemeinen Kirche entfremdet und der visionär-schwärmerischen Gemeinde der Montanisten zugewandt, zuletzt innerhalb dieser abermals mit einem Häuflein exaltierter Schwärmer zu einem Sepàratkonventikel sich absondernd, hat Tertullian seit seinem Bekenntnis zum Christentum in allen Perioden seiner religiösen Entwicklung als rede- und federgewandter Sachwalter in zahlreichen Schriften für seine neue Sache gefochten. Diese Schriften - nicht in glatter und gewählter rein literarischer Sprache abgefaßt, wie der „Octavius" des Minucius Felix oder die apologetischen Werke des zwar gleichfalls Afrika entstammenden, jedoch im griechischen Osten mit feinerem Gefühl erfüllten eleganten Laktanz, sondern, wenn auch nicht ohne rhetorischen Schmuck, in der anschaulichen, an Wortnuancen reichen Sprache des Lebens geschrieben - sind darum so anziehend, weil sie fast nie eine unpersönliche rein sachliche Erörterung bieten, sondern weil stets der ganze Mensch dahinter steht. Und dieser Mensch ist trotz aller seiner Fehler einer, der etwas ist und etwas zu sagen hat. Nach den Büchern „des Meisters" verlangte täglich der ruhig sichere Bischof von Karthago, Tertullians Schüler Cyprian, der in seinen eigenen Schriften mit sicherem Takte abstreifte, was bei Tertullian der kirchlichen Gedankenentwicklung nicht entsprach, der aber doch von seiner Verehrung für den glaubensund sitteneifrigen Lehrer nicht abließ. Vermittlung kennt Tertullian nicht. Er ist eine sich überhastende, stürmische Willensnatur, ein Mann des Streites, der stets ganz sich einsetzt, mag es nun dem Kampfe gegen die eigene Sinnlichkeit, dem Kampfe gegen die das Christentum fälschende Gnosis und deren angebliche Quelle, die griechische Weltweisheit, oder dem Kampfe gegen die bei der Kirche ihm als sträfliche Laßheit erscheinende Milde in der Disziplin und gegen ihre Schonung den reuig Zurückkehrenden gegenüber gel- 
ten, ein Mann, dem Haß und Zorn - die er deshalb auch Gott im eigentlichen Sinne beilegen will - allezeit näher liegen als Liebe.

So sind Tertullians Schriften - dem Theologen wichtig wegen dessen, was sie zur Geschichte der Dogmenentwicklung, der Häresien, der kirchlichen Disziplin und Verfassung bringen - zugleich ein wertvolles "menschliches Dokument". Für die eigentliche Philosophiegeschichte bieten sie weniger, weil philosophisch der Philosophenhasser Tertullian doch weniger selbständiger Denker, als Schüler der Stoa ist, deren naturphilosophische und logische Lehren ja auch die römische Rechtstheorie, Tertullians ursprüngliches Fachstudium, beherrschten, und weil er zu einer eigentlichen Systematisierung nicht gekommen ist. Die übernommene, das sinnlich Anschauliche wahrende realistische Anschauungsart der Stoa soll ihm Mittel bieten, der auf den Platonismus zurückgeführten extrem spiritualistischen gnostischen Denkart zu steuern; sie selbständig zu entwickeln, fehlt ihm der philosophische Trieb. Doch kommt er aus dem christlichen Gedanken heraus immerhin zu einigen Modifikationen des Stoizismus. Den in der stoischen Lehre vom Urpneuma liegenden evolutionistischen Pantheismus teilt er nicht, ja er legt in unhistorischer Weise schon dem Stifter der Stoa, Zeno, eine dualistische Auffassung bei. Wenn er ferner die aus der stoischen Pneumalehre folgende Auffassung der Seele als eines, von den groben $\mathrm{Körperstoffen} \mathrm{freilich} \mathrm{verschiedenen,} \mathrm{feinen} \mathrm{hauch-}$ artigen Körpers auch teilt, ja für sie in angeblichen Visionen einer montanistischen Schwester, welcher im Entzückungszustande - in „Trance, “ würden wir sagen - die Seele als strahlende Materie in den Umrißformen des Körpers geoffenbart wurde, neue Stützen sucht, und annimmt, daß die durch den „Hauch“ Gottes dem Menschen zuerst eingeblasene Seele sich den Schößlingen eines Baumes gleich (tradux, daher "Traducianismus") von den E1tern auf die Kinder fortpflanze, so betont er andererseits in mehr platonischer Weise die Einheit der Seele, aus der ihre Unsterblichkeit folge. Und auch wo er stoisch denkt, weiß er dem Gedanken doch manchmal eine eigenartige Wendung zu geben. So sieht er (übrigens nach dem Vorgang von Minucius Felix) im Apologeticum und in einer eigenen kleinen Schrift „Über das Zeugnis der Seele" in der instinktiven Sprachform der natürlichen Äußerungen der Seele, die in höchster Not und bei starker Erregung nicht von vielen Göttern, sondern von dem einen Gotte rede, einen Hinweis auf den Monotheismus des Christentums als eine in der Natur der ,anima naturaliter christiana“ selbst gelegene innere, von der Gewohnheit nur überdeckte Überzeugung.

In dem Versuche einer religionsphilosophischen Systematik war, wie 3. Die alexandrischon bemerkt, der ursprünglich ganz anderen Tendenzen entsprungene Gno- ${ }_{\text {philosophie. }}$ stizismus vorangegangen. Während die Antignostiker diesen negativ bekämpften, bildet das positive Gegenstück die systematische theologische Spekulation der alexandrinischen Schule. Ihre äußere Organisation findet diese in der um I70 entstandenen „Katechetenschule“ zu Alexandrien, der nach des Origenes Übersiedlung nach Palästina die Schule von Cäsarea folgte. Wenn wir die Einrichtungen der letzteren als schon für die von Alexandrien 
geltend annehmen dürfen, so bildete diese ein Seitenstück zu den heidnischen Philosophenschulen, doch mit theologischem Überbau und mit theologischer Grundrichtung. Entsprechend den schon von Philo aufgestellten drei Stufen: der enzyklopädischen Bildung als Propädeutik, der Philosophie und der göttlichen Weisheit, führte die Schule durch Mathematik und Astronomie zur Logik, Physik und Metaphysik und von da zu der mit einem umfassenden Bibelstudium verbundenen Religionsphilosophie und christlichen Ethik. Die biblischen Studien zu würdigen, die einen Hauptruhmestitel der Schule ausmachen, ist nicht dieses Ortes, nur die religionsphilosophische und ethische Spekulation kann hier in das Auge gefaßt werden. Durch Aufnahme der Philosophie nämlich, insbesondere der platonisch-philonischen Metaphysik und der stoischen Ethik, suchte man eine spekulative Verarbeitung der religiösen Lehren zu geben, durch welche die in den Glaubensquellen gegebenen Sätze, das $D a \beta$, zur inneren Durchdringung, zur Erkenntnis des Wie und Weshalb, gebracht und der bloße Glaube, die Pistis, zum Wissen, zur wahren Gnosis, oder, wie Origenes lieber mit Philo sagt, zur „Weisheit" entwickelt werden solle. Gewiß wurde dadurch der schlichte Ton der Evangelien und der pastoralen altchristlichen Dokumente verlassen, aber zugleich etwas geschaffen, das nicht mehr bloß dem einfachen Sinne schlichter Geister eine Welt neuer Lebensinhalte erschloß, sondern zugleich auch kulturell der heidnischen Bildung ebenbürtig zur Seite treten konnte.

a) Pantänus. Als Begründer der alexandrinischen Schule wird Pantänus, wohl aus Sizilien gebürtig, genannt. Wenn er "Stoiker" heißt, so ist dabei wohl in erster Linie an die auch von seinem Schüler Clemens rezipierte stoische Ethik zu denken oder auch an jenen platonisch modifizierten Stoizismus der Kaiserzeit, der unter der herrschenden eklektischen Stimmung dem theistischen Standpunkt sich fast ununterscheidbar genähert hatte. Von Pantänus waren keine Schriften vorhanden. Um so reicher ist der schriftstellerische Nachlaß seines Schülers Clemens von Alexandrien und gar - trotz gewaltigster Verluste - der des Origenes, den man „Adamantios“ (den Mann von Stahl) nannte, wie der Grammatiker Didymos wegen seines unermüdlichen Fleißes im Schreiben der "Mann mit den ehernen Eingeweiden“ (Chalkenteros) hieß.

b) Clomens von Alexandrien.
Des Pantänus Schüler ist Clemens von Alexandrien (um 200), dessen Stellung zur Philosophie überhaupt, wie zu den Platonikern, insbesondere Philo, und zu den Stoikern - namentlich kommt Musonius in Betracht -, bereits dargelegt wurde. In drei an Gelehrsamkeit reichen (wenn sie auch oft erst aus zweiter oder dritter Hand geschöpft ist), sich aneinander anschließenden Schriften, dem Protreptikos, dem Pädagogen und den wegen der Buntheit ihres Inhalts so genannten Stromateis (d. h. Teppiche), gibt er zwar noch nicht, wie sein Schüler Origenes, ein sachlich geordnetes System der christlichen Spekulation, wohl aber einen vom Heidentum zur christlichen Gnosis aufsteigenden psychologischen Entwickelungsgang. Die echt stoische Vorstellung vom Philosophen als Seelenarzt wandelt er ins Christliche um. Der Logos mahnt den noch im Heidentum befindlichen Kranken zur Losreißung 
von der Leidenschaft (Protreptikos), führt ihn dann als Erzieher durch den Glauben zur Tugend (Paidagogos) und erfüllt ihn endlich als belehrender Logos mit der Fülle der Weisheit, so daß er als christlicher Gnostiker das Idealbild des stoischen Weisen vollendet (Stromateis; trotz neueren Einspruchs doch wohl das an dritter Stelle beabsichtigte Werk). Von philosophischen Einzelgedanken möge die für die platonisierende Richtung der-Folgezeit grundlegende Art erwähnt werden, in der der Gedanke der göttlichen Transzendenz durchgeführt wird. Gott ist der im Verborgenen Wohnende (auch biblisch!), Unerfaßbare, der über alle Kategorien erhaben ist. Die Platonische Lehre von der Präexistenz der Seele und von ihrem Herabsinken aus dem ursprünglichen Geistzustande in das Gefängnis des Körpers wird dagegen bekämpft.

Der Vollender der alexandrinischen Religionsphilosophie ist Origenes c) Origenes. (185-254), wohl der größte Gelehrte der patristischen Zeit, jedenfalls der größte Gelehrte unter den christlichen Schriftstellern der ersten drei Jahrhunderte. Seine Schrift gegen den ersten literarischen Widersacher des Christentums, Celsus, imponierte auch des Celsus Nachfolger, dem Neuplatoniker Porphyrius. Anerkennend sagt dieser von Origenes: „Plato war sein immerwährender Gesellschafter, und die Schriften des Numenius und Kronius, des Apollophanes, Longinus und Moderatus, des Nikomachus und der berühmten Männer der pythagoreischen Schule hatte er fort und fort in den Händen. Auch gebrauchte er die Bücher des Stoikers Chäremon und des Kornutus". Dabei gibt diese Aufzählung nur einen verschwindenden Bruchteil der Autoren, die er benutzte, und zwar zumeist aus erster Hand. Plato, Philo, die Stoa und der Neupythagoreismus haben ihn vor allem philosophisch beeinflußt. Seine Schülerschaft bei dem Begründer des Neuplatonismus, Ammonius Sakkas, bleibt dagegen zweifelhaft. Jedenfalls steht Origenes zum entwickelten Neuplatonismus in keinerlei Schülerverhältnis, sondern bildet $z u$ diesem eine Parallelerscheinung. Mancher spätere neuplatonische Gedanke ist bei ihm sogar vorweggenommen. So ist es eine Antizipation der späteren Lehre des Proklus, nach dem in der Stufenreihe der Ursachen der Einfluß einer Ursache um so tiefer reicht, je höher sie selbst steht, wenn Origenes den Einfluß des Vaters sich auf alles Seiende erstrecken läßt, den des Logos nur auf die vernünftige Welt und den des göttlichen Geistes nur bis auf die Seelen der Gerechten.

Die besondere Bedeutung des Origenes auf dem dogmatisch-spekulativen Gebiete bestand darin, daß er zuerst ein allseitig ausgebautes religionsphilosophisches System durchführte. Dasselbe war enthalten in seiner Schrift „Über die Grundlehren“ ( $\pi \in \rho i \alpha \alpha \rho x \omega v)$ ), von deren Originalform uns nur Fragmente enthalten sind, während das Ganze in einer das Heterodoxe mildernden lateinischen Übersetzung des Rufin von Aquileja vorliegt. Mit Clemens bezeichnet Origenes Gott als den Unaussprechlichen, Unerkennbaren, über alle Kategorien Erhabenen, in keinen Begriff zu Fassenden. Er ist Einheit, Monade, erkennt sich selbst und ist darum Persönlichkeit. Die unendliche 
ewige Macht des ersten Prinzips verlangt ein ewiges Wirken. So geht aus dem Vater von Ewigkeit als Sohn der Logos hervor und durch diesen der göttliche Geist. Das Verhältnis innerhalb dieser göttlichen Dreiheit ist das der Unterordnung. Durch den Logos ist die Welt geschaffen. Indem nun hier mit Aristoteles und den Platonikern daran festgehalten wird, daß eine ewige Ursache auch eine ewige Wirkung haben müsse, andererseits aber mit Plato die Welt als das stets Werdende betrachtet wird, entsteht eine Antinomie, die Origenes dadurch zu lösen sucht, daß er eine unendliche Zahl aufeinanderfolgender Welten annimmt. Freilich sollen diese nicht, wie bei den Stoikern, in unendlicher Wiederkehr des Gleichen wie ein stets sich neu aufziehender Uhrlauf aufeinanderfolgen. Wieder im Sinne Platos ist es, wenn das, was Origenes zuerst vom Logos hervorgebracht sein läßt, ein intelligibles Geisterreich ist. Diesen Geistern kommt freie Willensentscheidung zu, wie denn Origenes auch sonst die Verteidigung der ethischen Willensfreiheit sich zur besondern Aufgabe macht. Nur ein Teil der Geister bleibt dem Guten getreu. Diejenigen, welche für das Böse sich entschieden, sanken hinab. So entstand die grob materielle Welt. Ein Teil der gefallenen Geister wurde als Seelen zur Strafe in menschliche Leiber gefesselt, während die noch tiefer gefallenen zu Dämonen wurden. Durch den fleischgewordenen Logos ist die Erlösung gebracht. Durch den Logos werden am Ende dieser Weltzeit alle, auch die Dämonen, wiederhergestellt werden (Apokatastasis).

Es ist ersichtlich, daß diese Form der Religionsphilosophie mit den positiven Überlieferungen der Kirche und - namentlich hinsichtlich der Trinitätslehre - mit der Richtung sich nicht vereinen ließ, in der die kirchliche Lehrentwicklung vorging. So entstanden die durch Jahrhunderte sich hinziehenden origenistischen Streitigkeiten, in deren Gesichtskreis auch der Kampf zwischen Arius und A thanasius und dessen weitere Fortsetzungen gehören. Besonders Methodius von Olympus, selbst stark vom Platonischen Geiste berührt, ist ein scharfer Gegner des Origenes. Aber wieder müssen diese Dinge einer anderen Stelle überlassen bleiben. - Wurde so auch der Inhalt des origenistischen Systems in vielem verlassen, weil sein Versuch einer Systematisierung vom kirchlichen Standpunkte aus verfrüht war, so fand, wie schon oben bemerkt, sein Prinzip, die dogmatische Spekulation aus platonisierenden philosophischen Anschauungen heraus, doch Fortsetzung.

Dio Kappadozier.

Gregor von Nyssa.

Innerhalb der griechischen Kirche geschieht dieses am glänzendsten durch die drei großen Kappadozier Basilius, Gregor von Nazianz, den Freund, und Gregor von Nyssa, den jüngeren Bruder des Basilius. Während die beiden ersteren vor allem als Redner und gewaltige Kirchenmänner hervorragen - doch sei auf des Basilius Homilien zum Sechstagewerk, in denen ein frischer Sinn für die Schönheit der Natur zutage tritt, als auch philosophiegeschichtlich beachtenswert hingewiesen - , ist Gregor von Nyssa mehr eine stille Gelehrtennatur. Philosophiegeschichtlich ist $z u$ beachten, daß neben den älteren Formen des Platonismus jetzt, wie schon bemerkt, auch ein starker direkter Einfluß des Neuplatonismus sich geltend macht, der inzwischen 
durch Plotin seine Ausgestaltung und Systematisierung erfahren hatte. Namentlich bei Gregor von Nyssa zeigt sich dies, auf den als auf den philosophisch bedeutendsten unsere Darstellung sich beschränken möge.

Gregor von Nyssa (ca. 335-394) ist der Geisteserbe des Origenes, aber auch von dessen Gegner Methodius von Olympus. Philosophische Spekulation und die Glaubensüberlieferung der Väter sucht er im Einklang zu halten, das Heterodoxe bei Origenes möglichst auszuscheiden, wenn auch einzelnes bei ihm verbleibt, das außerhalb der kirchlichen Lehrentwickelung sich bewegt. So hat er hinsichtlich der Trinitätslehre und der Christologie die origenistischen Auffassungen ganz verlassen und schreitet hier innerhalb der durch Athanasius und das Nicänum gegebenen Richtlinien vor; aber anderseits teilt er die Annahme einer allgemeinen Apokatastasis mit Origenes, und die philonisch-origenistische Auffassung von den Seelen als in materielle Leiber gebannten gefallenen Geistern, die er in ihrer ursprünglichen Form als lächerlich zurückweist, formt er in seltsamem Kompromiß dahin um, daß er den Menschen als solchen der göttlichen Idee nach geistig und geschlechtslos denkt, den individuellen Menschen aber von Gott in Voraussicht des Sünden. falls sofort in seinem empirischen Zustande geschaffen sein läßt.

Doch das sind rein theologische Fragen, deren Würdigung der Dogmengeschichte überlassen bleiben muß. Philosophiegeschichtlich von Bedeutung ist es, wie innerhalb dieser theologischen Spekulationen eine entschieden platonische Erkenntnistheorie hervortritt. Im Gegensatz zum Nominalismus entwickelt Gregor einen extremen Realismus, wie er später im Mittelalter z. B. bei Eriugena wieder hervortritt. Insbesondere die theologische Lehre von der Einheit des göttlichen Wesens bei der Dreiheit der göttlichen Personen will er dadurch philosophisch nahebringen, daß er allgemein die Gattung ihrem Wesen nach als eine nicht nur logische, sondern auch reale Einheit faßt. Die einzelnen Menschen z. B. sind wohl in ihren individuellen Eigentümlichkeiten, aber nicht hinsichtlich ihres Wesens untereinander verschieden. Natürlich ist die so entstehende Einheit in Wahrheit nur die des abstrakten Begriffs; aber bei Gregor wird sie unter dem Einfluß der neuplatonischen Denkart sofort zur realen Einheit einer allgemeinen Natur des Menschen, die allen Individuen gemeinschaftlich ist und an der die Individuen, wie bei Plato an der transzendenten Idee, nur teilhaben.

Mancherlei verschiedene Elemente verbinden sich in Gregors Psychologie der Gotteserkenntnis. Ein Ahnen der Gottheit liegt schon von Natur in der menschlichen Vernunft. Aber ethische und intellektuelle Anlagen verkrüppeln leicht die seelische Anlage. Nur der Glaube gewährleistet ein sicheres Aufsteigen. Eine natürliche Verstandeserkenntnis des göttlichen Wesens, wie Eunomius sie behauptete, gibt es nicht. Durchschaut die Seele doch nicht einmal sich selbst; um so weniger die Gottheit, für die es kein anderes Maß gibt als die Unendlichkeit. Mit dieser Polemik gegen den Rationalismus des Eunomius nun verbindet der Nyssener andererseits eine Mystik, die der neuplatonischen parallel geht und auf Dionysius den Pseudoareopagiten 
hinweist. Im Zustande mystischer Erhebung, durch welche die Seele wie in einer nüchternen Trunkenheit aus sich heraustritt, vereinigt sie sich geheimnisvoll mit der Gottheit. - Neuplatonisch ist auch die stark an Plotin erinnernde, von Gregor nur versuchsweise aufgestellte, von Eriugena dagegen zu einer Grundlage seines Systems gemachte spiritualistische Theorie der Materie. Um zu erklären, wie von dem rein geistigen Gott eine körperliche Schöpfung ausgehen könne, sucht er zu zeigen, daß diese Körper sich bei der begrifflichen Analyse in ein Netzwerk von Qualitäten auflösen, deren jede den Inhalt eines Begriffs ausmache und daher geistiger Natur sei. Es ist wie eine Antizipation des Machschen Standpunktes, nur daß an Stelle der Knotenpunkte sich verflechtender Empfindungen die Kreuzungen sich verflechtender Begriffe gesetzt sind. Hinter dem phänomenalen Sensualismus steht bei dem Platoniker Gregor ein transzendentaler Intellektualismus.

5. Augustin und seine Zeitgenossen.

Der mehrden praktischen Aufgaben der Kirchenorganisation, des Kirchenregiments und der Disziplin zugewandte und hier Großes leistende lateinische Okzident brachte in dieser Zeit auf dem Gebiete der Spekulation und der Gelehrsamkeit keine völlig selbständigen Leistungen hervor, die denen der Griechen ebenbürtig wären. Wo uns hier Hervorragendes begegnet, wie bei dem Athanasianer Hilarius von Poitiers ( $t 366)$, bei dem gelehrten Hilarius, Rufinus, Übersetzer Rufinus von Aquileja ( $f 410)$, bei Hieronymus $(\dagger 420)$, dem Hieronymus. sprachen- und literatur-, bibel- und geschichtskundigen Urheber der verbreiteten lateinischen Bibelübertragung (Vulgata) und vieler exegetischer Schriften, dem fleißigen Übersetzer und scharfen Polemiker, insbesondere gegen Origenes, da haben die Betreffenden durch langen Aufenthalt im Orient die Spekulationsweise oder, wie der der Spekulation abholde Hieronymus, die Gelehrsamkeit der griechischen kirchlichen Welt sich zu eigen gemacht. Ambrosius. Auch A mbrosius († 397), der gewaltige Prediger und Verwalter des Bischofsamts, als Mensch und als Mann der Kirche eine Persönlichkeit von hoher Geistesgröße und mannhafter Selbständigkeit, entbehrt nach der spekulativen Seite hin doch der Ursprünglichkeit. Bis in den Ausdruck hinein schlieBt er sich nicht selten den Griechen an, insbesondere Philo, Origenes, Basilius u. a., wobei er, wie Gregor von Nyssa, das Heterodoxe bei Origenes geschickt vermeidet; und wenn er daneben auch den Römer Cicero stark benutzt, so ist eben auch dieser in dem Inhalt seiner philosophischen Gedanken durchaus von den Griechen abhängig.

Augustin. Einen Mann aber weist das lateinische Abendland auf, der durch die Tiefe und Weite seiner Spekulation, durch die Verbindung von genialer Eigenart des Denkens und Fühlens und von fleißigster Aneignung der Leistungen anderer, durch die glückliche Mischung von Verstandesklarheit und mystischer Wärme, durch das Zusammengehen einer hohen analytischen Schärfe des Geistes, die sowohl eine sachliche Frage in ihre Elemente logisch zu zerlegen, wie die kompliziertesten Regungen der Seele psychologisch zu zergliedern versteht, mit einer ebenso großen Kraft des intuitiven $\mathrm{Zu}$ sammenschauens, die das einzelne sofort in seinen großen Zusammenhang 
stellt, endlich durch die suggestive Kraft des Wortes und der Rede, aus der stets die ganze gewaltige und ursprüngliche Persönlichkeit spricht, kurz einen Mann, der durch dieses alles für sich allein eine ganze Schar von Talenten aufwiegt. Es ist Augustin, der große theologische Lehrer des lateinischen Abendlandes.

Wie bei Plato und Leibniz ist bei Augustin das Werden die Erklärung des Seins. So sehr seine Weltanschauung die Allgemeingiltigkeit der Wahrheit als einer unabhängig von jeder subjektiven Auffassung bestehenden Macht, ihre aller Subjektivität entnommene, einen jeden bindende objektive Geltung betont, so ist doch das, was die Richtung seiner Spekulation, die Wertabstufung für die Auswahl der zu behandelnden Fragen und die Besonderheit der Problemstellung bestimmt, mit einem Worte: was die charakteristische Nuance seiner Denkweise ausmacht, nur aus seiner Lebensentwickelung zu erklären. In seinen „Bekenntnissen“, dem persönlichsten Buch des Altertums, hat Augustin über diese Entwickelung einen Bericht erstattet, der nur gelegentlich aus den schriftstellerischen Produkten der betreffenden Perioden als objektiven Zeugnissen eine leichte Retusche erfährt.

Geboren 354 zu Thagaste in Numidien als Sohn eines noch heidnischen Vaters und einer heißgeliebten christlichen Mutter, Monika, kommt Augustin nach einer in Thagaste und Madaura verbrachten Schulzeit nach Karthago, wo er als Zögling der Hochschule dem Studium der Rhetorik obliegt, aber auch sich in alle Strudel eines ungeregelten Lebens stürzt. Doch mitten im Sinnesgenuß wird ihm Ciceros „Hortensius“ ein Mahnruf, der die ihn quälenden Fragen nach der Wahrheit und nach dem Ursprung des Bösen, das er anfängt als eine drückende Last zu empfinden, in ihm erweckt. Das Trostbuch seiner Mutter, das lateinische Neue Testament, dessen ungelenke Sprache so gar nicht den Anforderungen der rhetorischen Kunstprosa entsprach, weist er von sich und wendet sich der einflußreichen manichäischen Gemeinde $z u$, die durch ihre kosmologischen Spekulationen ihm über alle Dinge des Jenseits und des Diesseits Aufklärung zu geben versprach und deren Dualismus des guten und des bösen Urprinzips ihm den sittlichen Zwiespalt im eigenen Herzen am besten zu erklären, den sittlichen Fall als etwas Naturgemäßes zu entschuldigen schien. Damals tritt er auch selbst als Lehrer der Rhetorik in Thagaste und Karthago auf. Doch genügt seinem auf das Sachliche gerichteten Sinn diese mehr formale Tätigkeit nicht. Die auf der Mathematik sich aufbauenden Disziplinen bildeten den Gegenstand eifrigen Studiums, insbesondere auch die Physik des Himmels, die Astronomie, durch die er von der Phantastik der manichäischen Kosmologie überzeugt wird. Aber unfähig, in den Fragen der Weltanschauung zu einer sichern positiven Antwort zu gelangen, ergibt er sich der akademischen Skepsis, bei der ja auch Cicero sich beruhigt hatte. In solcher Geistesverfassung zieht er 383 nach Rom, wo er als Lehrer der Rhetorik eine Anstellung findet. Bald darauf finden wir ihn in gleicher Stellung in Mailand, wo die Predigten des Ambrosius durch ihre rhetorische Gewalt ihn fesseln. Dem Christentum selbst 
steht er noch fern. Erst der Weg über den Platonismus führt ihn, wie so viele, an die Pforte dazu. Er liest Schriften und Übersetzungen seines Landsmannes Marius Viktorinus, des gefeierten Lehrers der Beredsamkeit in Rom, der noch im Alter dem Christentum beigetreten war, und wird mit Plato und Plotin bekannt. Jetzt erschließt sich seinem Auge der Blick auf die intelligibele geistige Welt, deren Realität ihm so lange undenkbar geblieben war, als er mit den Manichäern nur das sinnlich Wahrnehmbare für wirklich hielt und die Metaphysik eines geistigen göttlichen Lichtes nur in der vergröberten anschaulichen Form eines in der Gestirnwelt sich verbreitenden physisch-materiellen Lichtes erfaßte. Nunmehr ist für die religiöse Krisis die Vorbedingung geschaffen. Beim Lesen der Bibel erfährt Augustin plötzlich die trostvolle Gewißheit des neuen religiösen Lebens. Der Wandel vollzieht sich, indem zu dem metaphysischen Idealismus der historische Glaube an den menschgewordenen Gottessohn hinzutritt. Augustin hat später in den „Bekenntnissen“ den Satz vom fleischgewordenen Logos im Prolog des Johannesevangeliums als denjenigen bezeichnet, bei dem der Neuplatoniker nicht mehr mitgehe, bei dem Neuplatoniker und Christ sich scheiden. So verbinden sich philosophische und religiöse Wandlung. In ländlicher Zurückgezogenheit gestaltet er in Gesprächen mit einem Freundeskreise, denen eine Reihe von Schriften den Ursprung verdankt, seine platonisierende Metaphysik und Erkenntnistheorie aus und erfährt zugleich in heißem Ringen das Heranreifen seiner religiösen Umwandlung. Im Frühjahr 387 empfängt er von Ambrosius die Taufe. Nach Afrika zurückgekehrt (388), setzt er die schriftstellerische Tätigkeit eifrig fort, ältere Pläne vollendend und neue ausführend, zugleich auch mit dem Manichäismus sich auseinandersetzend, wie u. a. in der Schrift für die Willensfreiheit. Inzwischen (391) zum Priester geweiht, wird er 395 zum Bischof von Hippo Regius erwählt. Als solcher wird er in vollem Maße von den neuen Aufgaben der kirchlichen Verwaltung, sowie von den Kämpfen mit den sich als Gemeinde der Heiligen fühlenden Donatisten und von denen mit den Pelagianern über die Gnade in Anspruch genommen. So wird auch seine literarische Tätigkeit mehr und mehr eine theologische. Exegetische Schriften in großer Zahl, wie die zwei Werke über die Genesis, dogmatische, wie besonders die für lange Zeit maßgebende erste systematische Zusammenfassung der kirchlichen Lehraufgaben in lateinischer Sprache, die Schrift De doctrina christiana, 15 Bücher über die Trinität, das gewaltige apologetische und geschichts-philosophische Werk „über den Gottesstaat", Streitschriften gegen Donatisten und Pelagianer, Predigten, asketische Werke und Briefe in großer Zahl sind zwar vorwiegend theologischen Inhalts, schließen aber vielfach philosophische Erörterungen ein, die gegenüber den Jugendschriften nicht selten einen Fortschritt zum mehr persönlich Eigenartigen, einen entwickelteren Standpunkt zeigen. Im Jahre 430 beschloB Augustin sein arbeitsreiches Leben, durch das der abendländischen kirchAugustins Philo- lichen Wissenschaft auf Jahrhunderte der Weg gegeben war.
sophie.

lur Charakter. Die Philosophie Augustins ist objektiver Idealismus, natürlich nicht im 
hegelschen, sondern im platonischen Sinne. Die Wirklichkeit im höchsten Sinne ist beschlossen in einem System objektiver, über aller individuellen subjektiven Erfassung stehender ewiger Wahrheiten (veritates oder rationes aeternae), die das eigentliche Sein und die Gesetzmäßigkeit der Dinge, sowie die objektiv giltigen Werte und Normen des Handelns (die lex aeterna) ausmachen, und die in Gott, der Urwirklichkeit, Urwahrheit und dem absoluten Urwerte, ihren letzten Grund haben. So ist Augustins Erkenntnislehre zugleich Metaphysik und Ethik; und all das ist ihm im letzten Grunde Gotteslehre. Die alte platonisch-stoische Einteilung der Philosophie in Logik, Physik und Ethik deutet er theozentrisch dahin, daß sie Grott als Grund des Erkennens, als Ursache des Seins und als Norm des Lebens auffasse.

Aber zu dieser himmel- und erdumfassenden Schau führt der steile Berg-Erkenntnislebr pfad kritisch methodischer Prüfung. Der Skeptizismus muß negativ und positiv überwunden werden. Die negative Überwindung war längst von den Stoikern gegeben: der Skeptizismus als Theorie hebt sich selbst auf - wer alles Wissen leugnet, muß doch wissen, was Wissen ist - und ist praktisch unmöglich. Aber es gilt auch positiv aufzubauen. Bloßes Suchen ohne Finden läßt unselig, hatte schon Laktanz gesagt.

Der augustinische Weg hat zwei Stufen. Zuerst ist es nötig, einen positiven Ausgangspunkt zu gewinnen. Nicht in der äußeren Wahrnehmung wie die Stoiker in der allseitig geprüften (kataleptischen) Vorstellung - findet ihn Augustin. Sein nach innen gewandter psychologisch geschulter Blick bestimmt auch für die Erkenntnistheorie die Richtung nach innen. In der Selbstgewißheit des eigenen Bewußtseinserlebnisses sieht Augustin - lange vor Descartes - die erste unbezweifelbare Gewißheitsetappe im methodischen Fortgang der Erkenntnis. „Ob die Kraft des Lebens, des Behaltens, Verstehens, Wollens, Denkens, Wissens, Urteilens der Luft zukomme oder dem Feuer oder dem Gehirn oder dem Blut oder den Atomen oder einem fünften Stoff neben den Elementen, oder ob die Zusammensetzung und das Mischungsverhältnis unsers Körpers jene Funktionen bedinge, darüber zweifeln die Menschen, und der eine hat dieses, der andere hat jenes darzutun versucht. Aber da $\beta$ er lebt, behält, versteht, will, denkt, weiß und urteilt, daran zweifelt niemand. Natürlich: eben wenn er zweifelt, dann lebt er; wenn er zweifelt, hält er im Bewußtsein, weshalb er zweifelt; wenn er zweifelt, weiß er, daß er noch nichts Sicheres weiß; wenn er zweifelt, urteilt er, daß er nicht grundlos seine Zustimmung geben darf. Mag einer also auch sonst zweifeln über was er will: über all dieses kann er nicht zweifeln; denn wenn dieses nicht wäre, so könnte er überhaupt nicht über irgend etwas zweifeln". - Was aber die äußere Erfahrung anlangt, so gibt Augustin zu, daß uns etwas anders erscheinen könne, als es ist; wenn aber überhaupt außer uns nichts wäre, so könne uns auch nichts erscheinen. An Kant und an den Satz, der eine Grundlage von Herbarts Metaphysik bildet: „So vie1 Schein, so viel Hinweisung auf ein Sein", werden wir hier erinnert. 
Aber wie soll dieses über das enge Gebiet des eigenen Selbstbewubtseins hinausreichende Sein bestimmt werden, wenn die Sinneserfahrung als solche kein ausreichendes Kriterium dafür abgibt? Bei dieser zweiten Stufe seines erkenntnistheoretischen Aufbaus geht Augustin andere Bahnen als Kant und Herbart und bleibt den Wegen Platos und der Neuplatoniker getreu. Die richtunggebenden Maßstäbe für die Bestimmung des Seins der Wissenschaft erblickt auch er in ursprünglichen Vernunftprinzipien, die nicht aus der sinnlichen Erfahrung abstrahiert, sondern in dem erkennenden Geiste selbst gegeben sind. Aber diese Prinzipien sind nicht bloß formaler, sondern auch inhaltlicher Natur. Sie sind auch nicht Formen eines „Bewußtseins überhaupt", eines „hyperindividuellen Bewußtseins", sondern sie sind Abspiegelungen ewiger Wahrheiten des absoluten göttlichen Denkens im Spiegel des individuellen geschöpflichen Bewußtseins. Daß erst durch solche ursprüngliche Maßstäbe ein konkretes theoretisches, ästhetisches und ethisches Urteilen möglich sei, wird Augustin zu wiederholen nicht müde. Unabhängig von aller Erfahrung stehen die logischen Gesetze des Widerspruchs und des ausgeschlossenen Dritten sowie der Abfolge von Grund und Folge fest. Die mathematischen Idealgebilde sind der apriorische Maßstab für die Beurteilung der sinnlich wahrnehmbaren Formen. Auf ästhetischem Gebiete bestimmt nicht erst das tatsächliche Gefallen, was schön ist, sondern weil etwas unserer Idee des Schönen entspricht, so gefällt es. Nicht anders auf ethischem Gebiete, wo gewisse Normen, wie die Forderungen gerecht zu leben und jedem das Seine zu geben, von dem tatsächlichen Verhalten der Menschen unabhängig sind. Und auch subjektiv geht der allgemeine Zug nach Wahrheit und Glückseligkeit den tatsächlich gewonnenen Einzelerkenntnissen und den erlebten besonderen Zuständen des Glücksgefühls vorauf, nimmer rastend oder schweigend, auch wo der Wahrheitstrieb in die Irre geht und das Glück auf falschen Wegen gesucht wird.

Dieser in nichts Endlichem befriedigte subjektive Wahrheits- und Glückseligkeitstrieb aber weist ebenso über die Bewußtseinsimmanenz hinaus, wie dies die Eigenschaften der Wahrheit tun, die vom Geiste als objektiver Inhalt erfaßt wird. Denn die Wahrheit, die in den wissenschaftlichen Disziplinen dem Geiste gegenübersteht, ist ewig und unveränderlich; der Geist aber ist wandelbar. Jene Wahrheit ist ein und dieselbe für alle, die erkennenden Subjekte aber sind verschieden geartet. Darum kann die Wahrheit nicht Erzeugnis des Geistes sein; sie muß über ihm stehen. Der Geist bringt sie nicht hervor, sondern berührt sie nur. Sie ist das höhere Licht, das im Geiste nur widerscheint. Für Augustin aber ist eine solche Wahrheit als bloßes abstraktes Gelten von vornherein undenkbar, eine bewußtseinsimmanente Transzendenz von vornherein ein Widerspruch; das Gelten kann nur in einem Sein wurzeln. So müssen alle objektiven Wahrheiten in der Wahrheit begründet sein, die zugleich das absolute Sein und die absolute Güte ist: in Gott. Sein transzendentes Innewohnen im Menschengeist ist es zugleich, was in Verstand und Willen jenes Rühren hervorruft, das als unauslöschlicher Zug nach der Wahr- 
heit und Glückseligkeit subjektiv sich äußert. Damit mündet Augustins Erkenntnislehre in die Metaphysik.

Zwei Fragen sind es, in denen sich bei Augustin schon in seinen ersten Gotteslehre. Schriften der Inhalt seines Forschens konzentriert: Gott und die Seele. Die Natur interessiert seinen theologisch orientierten Geist nur insoweit, als sie Gottes Werk und darum auch ein vorbereitender Weg zu seiner Erkenntnis ist, nicht sein Bild, wohl aber die Spur, die zu ihm hinführt. Durch die Einkehr in sich dagegen wendet die Seele sich ab von allem, was sie ablenken könnte. Indem der Geist das Bild Gottes in der Seele und die von ihm ausstrahlende unveränderliche Wahrheit erfaßt, steigt er zu Gott selbst auf, der für Augustin den Mittelpunkt alles seines Denkens bildet.

Gottes Dasein erschlieBt Augustin in platonischem Geiste vor allem aus der Forderung einer subsistierenden höchsten Wahrheit, die der Grund aller Wahrheit ist, einer unveränderlichen metaphysischen Urgüte, die allem Veränderlichen den Grad seiner Güte erteilt, eines unveränderlichen, ewigen Seins, an dem - ohne substantielle Vermischung - alles veränderliche Seiende teilhat. Das Wesen Gottes dagegen ist in menschlichen Begriffen nicht zu erfassen; „durch Nichtwissen wird er gewußt“. Er ist über alle Kategorien des Denkens erhaben. Erst indem wir diese wieder zerbrechen, ahnen wir den, der ohne Raum überall ganz, ohne Zeit ewig ist, der, ohne sich selbst zu verändern, alles Veränderliche hervorbringt. Auch die endliche Kategorie der Substanz im Gegensatz zum Accidens findet auf Gott keine eigentliche Anwendung; er hat keine Eigenschaften, wie Güte und Größe, sondern ist alles in höchster Einheit. Ein Bild des ewigen innergöttlichen trinitarischen Lebens aber erfaßt die Seele, wenn sie ihre dreifache Grundbetätigung und die Immanenz ihres Wesens in dieser betrachtet. Im Gedächtnis als Macht des Behaltens hat sie sich und all ihren Besitz, mit der Vernunft erfaßt sie denkend sich und all ihren Besitz, im Willen liebt sie sich, wie sie sich be. sitzt und erkennt, und ist doch in allen drei Betätigungen (memoria, intellectus dilectio) ein und dieselbe wesentliche Natur. Mittelalterliche Scholastik und Mystik haben hier angeknüpft.

Die Welt als werdende und veränderliche hat kein wahres Sein im Sinne Die Welt. des platonischen Seinsbegriffs, der Sein und Werden exklusiv gegenüberstellt. Sie ist nur durch die Teilnahme am wahren Sein. Darauf stützt Augustin seinen spekulativen Schöpfungsbegriff, der von dem neuplatonischen sich dadurch unterscheidet, daß er den Hervorgang der Welt nicht als naturhafte Notwendigkeit einer Emanation des Vielen aus dem Einen, sondern als freie Schöpfertat des persönlichen Gottes faßt. Von Gott geschaffen, muß die Welt von ihm auch fortwährend im Sein erhalten werden, um nicht in das Nichts zu versinken. Die Erhaltung der Welt ist eine fortgesetzte Schöpfung.

Weil veränderlich, ist die geschöpfliche Welt nicht reine Form. Indem Augustin den Begriff der Veränderlichkeit zu einer realen Potenz hypostasiert, gelangt er mit Plotin zu dem Begriffe einer Materie, die in allem Geteilten und sich Verändernden die Vielheit und Veränderlichkeit herbeiführt. 
Auch in der Geisteswelt, in der Seele, gibt es eine solche. Denn wenn es dort auch keinen Wandel der Substanz gibt, so doch einen solchen der Tätigkeit. Selbstverständlich soll diese geistige Materie nichts Körperliches an sich haben. Geht doch der Gegensatz Augustins gegen den Materialismus so weit, daß er selbst in der Körperwelt ein aktives Tun nur so weit gelten läßt, als geistige Kräfte in sie hineinragen. - Bewegt sich Augustin hier ganz auf neuplatonischen Pfaden, so ist das gleiche hinsichtlich des letzten Substrates der Körperwelt, der körperlichen Materie, der Fall. Sie ist ihm die unterste Wirklichkeit, an der Grenze des Nichts, ein „prope nihil“, wie ähnlich schon Chalcidius und andere Platoniker sich ausgedrückt hatten. Nur die emanatistische Ableitung der Materie macht sich Augustin nicht zu eigen; wie schon die pseudojustinische Mahnrede an die Griechen, fügt er sie dem biblischen Schöpfungsbericht ein.

Bei der spekulativen Durchführung des Schöpfungsberichts verbindet Augustin das Johannesevangelium mit dem Platonischen Timäus. Die griechischen kirchlichen Lehrer waren ihm darin vorangegangen. Gott hat alles nach dem Muster seiner vorbildlichen Gedanken, der idealen Urgründe, geschaffen, die im göttlichen Worte, dem Logos, vereint sind. Dort hat alles, was an Vollkommenheit in der Welt sich findet, sein urbildliches Leben. Das Üble und Böse aber ist nicht ein wirklich Seiendes; es ist ein Abfall, eine Negation, und bedarf deshalb keiner positiven Ursache, sondern nur der Schwäche, die mit dem Endlichen verbunden ist. Die biblischen Schöpfungstage deutet Augustin auf logische Momente; die. Schöpfung ist eine einmalige, simultane Setzung. Bei dieser ist die Entwickelung der Natur potentiell angelegt. Der auch vom Neuplatonismus übernommene stoische Begriff der Keimkräfte bildet für Augustin das Mittel zur Erklärung einer solchen Entwicklung.

Auch Augustins Psychologie ist trotz einzelncr aristotelischer Einschläge in allem Wesentlichen platonisch und neuplatonisch. Die Seele ist ihm der wahre Mensch. Sie ist eine rein geistige Substanz, in sich unräumlich und darum nach der plotinischen Formel ganz in jedem Teile des Leibes. Ihre Präexistenz zwar stellt er in Abrede. Dafür verlegt er die Schau der Idee, für welche Plato die rein geistige Präexistenz verlangte, in abgeschwächter Form in das Diesseits. Von der göttlichen Urwahrheit und den ewigen Erkenntnisgründen kommt dem Geiste das Licht, wie dem Auge von der Sonne. Das „Wie“ dieses Schauens freilich erklärt Augustin nicht; Scholastik und Mystik des Mittelalters, Malebranche, Freunde und Gegner des Giobertischen "Ontologismus" haben dazu die verschiedensten Deutungsversuche gegeben. Auch die sinnliche Wahrnehmung ist nicht, wie bei Aristoteles, ein passiver Vorgang des aus Leib und Seele geeinten Ganzen, sondern das Wesentliche bei ihı ist eine durch die physischen Affektionen veranlaßte aktive Hinwendung; ein aktives Aufmerken der Seele allein. Dem Willen, der mit dem „Gedächtnis", d. h. dem Sich-bei-sich-haben der Seele, und mit dem Intellekt dic Trias der oberen Seelenkräfte ausmacht, wird eine gewisse Vorzugsstellung eingeräumt, da er alle anderen Seelenkräfte bewegt. 
Auch darin zeigt sich dieser „Primat des Willens“ bei Augustin, daß seine Ethik nicht, wie die des Neuplatonismus, intellektualistisch orientiert, sondern eine Willensethik ist. „Der Wille ist es, durch den wir sowohl sündigen als recht leben," sagt er. Nicht im Erfolge liegt die Sittlichkeit, sondern in der Gesinnung; "Gott schaut nicht auf die Macht, sondern auf den Willen“. Das schlechthin Gute ist der sittliche Wille. Der sittliche Wille aber hat sein $\mathrm{MaB}$ in der ewigen Ordnung, die in Gott als dem Urguten ihren Grund hat. Durch die Einfügung in diese Ordnung in Gottes- und Nächstenliebe erfüllt sich das Sehnen des Menschenherzens, das „unruhig ist, bis es ruht in Gott." Nicht irgendwelche Seligkeit im Sinne des epikureischen Eudämonismus, für den der Inhalt des Glücksgefühls gleichgiltig ist, sondern allein diese wahre Freude, die durch ihren höchsten Inhalt selbst bedingt ist, kann nach Augustin das letzte Ziel des sittlichen Glückseligkeitsstrebens bilden.

Wie dies Gottesreich durch die Not der Zeit hindurch sich vollende, das zu entwickeln ist die positive Aufgabe von Augustins Schrift vom Gottesstaate. Eine nähere Entwicklung der darin enthaltenen gesellschaftlichen und geschichtsphilosophischen Theorien in ihrer Größe und in ihrer historisch verständlichen schroffen Einseitigkeit würde hier zu weit führen. Bei der Besprechung ihres Einflusses auf das Mittelalter wird sich Gelegenheit bieten, darauf zurückzukommen.

Nach dem glänzenden Abschluß Augustin weist die abendländische Patristik keinen Denker von selbständiger Eigenart mehr auf, nur noch Geister $z$ weiten oder dritten Ranges, wie Claudianus Mamertus. Denn Boethius, mögen auch einige theologische Schriften von ihm verfaßt sein, gehört durch seine selbständigen Schriften und seine Aristoteles-Erklärungen, durch die er neben Augustin der Hauptlehrer des früheren Mittelalters wurde, der rein philosophischen Entwicklungsreihe an.

Anders im Orient. Zwar bei dem eklektischen Platoniker Nemesius und dem Neuplatoniker Synesius brauchen wir nicht länger zu verweilen, da sie im Verhältnis zur antiken Denkweise nichts Eigenartiges bieten. Aber der unbekannte Verfasser einer zusammengehörigen Gruppe von Schriften über die göttlichen Namen, über die mystische Theologie, über die himmlische und die kirchliche Hierarchie und von Briefen, die unter dem Namen Dionysius gehen, führt' uns in eine ganz eigenartige Gedankenwelt, die für die weitere Entwickelung der Mystik im Morgen- und Abendlande, bei Griechen und Syrern, Romanen und Germanen von maßgebendem Einfluß wurde. Ins Christliche gewandter Neuplatonismus und christianisierte Mysterienvorstellungen, in einer feierlich und schwer einherschreitenden unanschaulichbilderreichen Sprache vorgetragen, gehen mit spezifisch christlich theologischen und kultischen Elementen eine charakteristische Mischung ein. Der Verfasser gibt sich - bewußt oder unbewußt - den Anschein, der Areopagite Dionysius zu sein, der nach der Apostelgeschichte von Paulus für das Christentum gewonnen wurde; aber alles weist darauf hin, daß die Schriften kaum vor dem J. 500 entstanden sind. Finden sich doch deutliche

6. Die spätgriechische Mystik und Scholastik.

\section{a) Dionysius- Pseudo-} Areopagita. 
Spuren einer Abhängigkeit von dem Neuplatoniker Proklus darin. Wir sprechen darum von Dionysius dem Pseudo-Areopagiten.

Zwei Wege der Gottesbetrachtung unterscheidet er, den positiven, der von den göttlichen Wirkungen in der Schöpfung ausgeht und darum Gott als den Vielnamigen nach allen Vollkommenheiten benennt, und den negativen, der ihn als den über alle Bestimmungen Erhabenen, Überseienden und Überwesentlichen betrachtet. Ihre Güte läßt die Gottheit sich mitteilen; durch das Überfließen ihrer Überfülle entstehen die Stufen der Wesen, in denen die Krafteinheit immer geringer, der Abfall zur Vielheit immer größer wird; denn alles ist um so einfacher, je näher es dem Zentrum bleibt. In diesem Zentrum, in Gott, fallen alle Gegensätze zusammen (coincidentia oppositorum). Er ist das einfache Sein; durch ihn hat alles sein Sein, ja das Sein des Ersten Seins ist das Sein der Kreaturen, wie später nach dem Areopagiten auch Meister Eckhart und Nikolas von Kues lehren. Darum sehnt sich alles nach Gott und sucht zu ihm aufzusteigen. Dem geschaffenen Geiste wird diese beseligende Einigung zuteil, wenn er durch die Stufen der Reinigung, Erleuchtung und Vollendung hindurch sich von allem Äußeren zurückzieht, vom Logos mit göttlicher Kraft erfüllt wird und nun in lautloser, bildloser Stille, von den Strahlen des unnahbaren Lichtes getroffen, in ekstatischer Liebe zur Gottförmigkeit gelangt. - Maximus der Bekenner (580-662) hat diesen mystischen Überschwang im orthodoxen Sinne zu erklären versucht.

Den Abschluß der patristischen Periode bildet für die griechische Welt

Johannes von Damaskus ( $f$ um 750 ), der bereits der Zeit der sarazenischen Herrschaft angehört. Seine "Quelle der Erkenntnis" ist eine systematische Zusammenarbeitung der voraufgehenden Väterspekulation, zu der aber jetzt neben dem platonischen Einschlag auch die längst von den Syrern gepflegte aristotelische Philosophie ein wesentliches Hilfsmittel abgibt. So ist im Damaszener bereits der Geist der Scholastik rege. Ja auch für die la teinische Scholastik wird er eine nicht unwichtige Quelle, seitdem Burgundio von Pisa im 12. Jahrhundert sein Werk ins Lateinische übertrug. 


\section{Literatur.}

In der vorstehenden Skizze ist der Versuch gemacht, aus der Geschichte der patri. stischen Philosophie prinzipiell all das auszuscheiden, was nicht Philosophie an sich ist, sondern Verwendung der philosophischen Begriffe zum spekulativen Ausbau der Glaubensdogmen. Indem die nähere Darstellung dieser Einwirkung der Philosophie auf die theologische Spekulation den theologischen Disziplinen, insbesondere der Dogmengeschichte, überlassen bleibt, wird hier die patristische Philosophie insofern ins Auge gefaßt, als sie sich als eine Seitenbewegung zur außerchristlichen griechisch-römischen Philosophie darstellt; weshalb auch manche große Theologen hier ganz übergangen werden. Für die Literatur kommen dagegen, und zwar zum Teil an erster Stelle, auch die aus dem dogmengeschichtlichen, oder dem allgemein literargeschichtlichen Gesichtspunkte geschriebenen Werke in Betracht.

Von philosophiegeschichtlichen Werken seien genannt: RITTER, Geschichte der Philosophie, Bd. V-VI (184I). Fr. Ueberwegs Grundriß der Geschichte der Philosophie, 9. Aufl., hrs. v. M. Heinze, II (1905). O. Willmann, Geschichte des Idealismus, II ( ${ }^{2} 1907$ ). J. Huber, Die Philosophie der Kirchenväter (1859). A. STÖCKL, Geschichte der christlichen Philosophie zur Zeit der Kirchenväter (1891). W. MöLLER, Geschichte der Kosmolugie in der griechischen Kirche bis auf Origenes (1860). - Ferner die betreffenden Partien bei W. WindELBAND, Geschichte der antiken Philosophie, 3. A. bearb. von A. BonHÖFFER (1912), S. 311-323 (nur bis Origenes einschl.) und J. PICAVET, Esquisse d'une histoire générale et comparée des Philosophies médiévales ('1907).

Von dogmengeschichtlichen, literargeschichtlichen und allgemeingeschichtlichen Werken: AD. HARNACK, Lehrbuch der Dogmengeschichte I-III ('1909-10); Geschichte der altchristlichen Literatur bis Eusebius I (1893, mit E. PREUSCHEN), II I-2 (1897-1904). J. A. SchwaNe, Dogmengeschichte I-IV (1862-90; I-II, 2. A., I892-95). F. LoOFs, Leitfaden zum Studium der Dogmengeschichte ('1906); Grundriß der Dogmengeschichte (1907). R. SEEBERG, Lehrbuch der Dogmengeschichte, I-II (1895-98, I '1907). O. BARDENHEwER, Patrologie ('1910); Geschichte der altkirchlichen Literatur, I-III (1902-I1). G. KRÜGER, Geschichte der altchristlichen Literatur in den drei ersten Jahrhunderten (1895). A. EHRHARD, Die altchristliche Literatur und ihre Erforschung von 1880-84 (1894); von 1884-1900, I (1900). A. EBERT, Allgemeine Geschichte der Literatur des Mittelalters im Abendlande, I. Gesch. der christlich-lateinischen Literatur von ihren Anfängen bis zum Zeitalter Karls d. Gr. $\left({ }^{2} 1889\right)$. E. NORDEN, Die antike Kunstprosa ('igog). P. WENDLAND, Die griechisch-christliche und die römisch-christliche Literatur, in: Einleitung in die Altertumswissenschaft, hrsg. von A. GERCKE und E. NORDEN, I ('1912), S. $246 \mathrm{ff}$., $398 \mathrm{ff}$, P. BATTIFOL, Anciennes littératures chrétiennes, I. La littérature grecque $\left({ }^{2} \mathrm{I} 898\right)$. P. MONCEAUX, Histoire littéraire de l'Afrique chrétienne, depuis les origines jusqu'à l'invasion arabe (1901 ff.). G. ATZBERGER, Geschichte d. christl. Eschatologie innerhalb der vornizänischen Zeit (1896). C. VAN ENDERT, Der Gottesbeweis in der patristischen Zeit (1869). - P. WENDLAND, Die hellenisch-römische Kultur in ihren Beziehungen zu Judentum und Christentum ( $\left.{ }^{2} 1912\right)$. H. KELlNER, Hellenismus und Christentum (1866). E. Hatch, Griechentum und Christentum, deutsch von E. PreuscheN (1892). K. J. Neumann, Der römische Staat und die allgemeine Kirche bis auf Diokletian, I (1890). R. REITZENSTEIN, Die hellenistischen Mysterienreligionen, ihre Grundgedanken und Wirkungen (1910).

Einzelnes: A pologeten: J. GefrKen, Zwei griechische Apologeten (1907). J. M. PFäTTrSCH, Der Einfluß Platos auf die Theologie Justins des Märtyrers (1910). A. HauCK, Tertullians Leben und Schriften (1877). G. ESSER, Die Seelenlehre Tertullians (1893). Ch. GUIGNE. BERT, Tertullien (I9OI).

Clemens von Alexandrien: E. DE FAYE, Clément d'Alexandrie. 1898. P. WENDLAND, Quaestiones Musonianae. I886.

Origenes: REDEPENNIG, Origenes. I841-46. J. DENIS, De la philosophie d'Origène (1884). 
Gregor von Nyssa: F. Diekamp, Die Gotteslehre des hl. Gregor von Nyssa (1896). A. REICHE, Die künstlerischen Elemente in der Welt- und Lebensanschauung des Gregor von Nyssa (1897). F. HILt, Des h. Gregor von Nyssa Lehre vom Menschen. 1890.

Augustin: A. DORNER, Augustin, sein theologisches System u. seine religionsphilosophische Anschauung (1873). J. STORz, Die Philosophie des h. Augustin (1882). G. von HertLING, Augustin (1901). W. ThImme, Augustins geistige Entwickelung in den ersten Jahren nach seiner „Bekehrung“, 386-392 (1908). H. BECKER, Augustin. Studien zu seiner geistigen Entwickelung (1908). J. MaUSBaCH, Die Ethik des hl. Augustinus I-II (1909). R: SEIDEL, Die Lehre vom Staat beim h. Augustinus (1909). O. Schilling, Die Staats- u. Soziallehre des hl. Augustinus (1910). Übersicht von M. Baumgartner in v. Aster, Große Denker II, und in dem Artikel von PortaliE in Vacant-Mangenot, Dict. de théol. cath. I 2268-247 I. - Die S. 293 zitierte Stelle: De trin. X, ro; die Stellen S. 297: Retract. I 9, 4. Enarr. in ps. 83, 3. Conf. I, 1 .

Dionysius Pseudo-Areopagita. Mißglückte teilweise Rechtfertigungsversuche von F. HipleR (1861) und J. DRÄSEKE (1889. 1897). Den überzeugenden Nachweis für das 5. Jahrhundert lieferten besonders STIGLMaYR (1895) und H. KOCH (1900).

Johannes von Damaskus und die byzantinische Theologie überhaupt: A. EHRHARD in K. KRUMBACHER, Geschichte der byzantinischen Litteratur ( $\left.{ }^{2} 1897\right), 37-218$.

Zu S. 267 (Sokrates bei Minucius Felix): A. HARNACK, Sokrates und die alte Kirche (Reden und Aufsätze I, 27-48); zu S. 273 (eigentliche und uneigentliche Geschichte): K. VOSSLER, Kulturgeschichte und Geschichte, in: Logos III (1912) S. 192-205; zu S. 274: H. USENER, Epicurea (1887) S. LXXVI; zu S. 280: L. COHN in; PHILonis Alexandrini opera quae supersunt ed L. CoHN et P. WendLAND, Vol. I (1896) S. I.

\section{Nachtrăge zum zweiten Abdruck.}

$\mathrm{Zu}$ den S. 299 genannten allgemeineren Werken sei noch hinzugefügt: G. RAUSCHEN, Grundriß der Patrologie ( $\left.{ }^{3} 1910\right)$. H. JORDAN, Geschichte der aitchristlichen Literatur (191 I). J. 'Tixeront, Dogmengeschichte; ins Deutsche übertragen von K. Ziesché I. (1913). Gust. KRÜGER, Die christliche Literatur von Augustinus bis Gregor d. Gr. (M. SCHANZ, Gesch. d. röm. Lit. IV, 2, von M. Schanz, C. Hosius, G. KRÜGer 1921). Von Bardenhewer, Gesch. d. altkirchl. Lit., erschienen Bd. I u. II in 2. Auf. (1913. 1914). - Spezielles: O. Schllling, Naturrecht und Staat nach der Lehre der alten Kirche (1914). Eine insbesondere von L. Brentano, Die wirtschaftlichen Lehren des christlichen Altertums (1902), angeschnittene Frage behandelt O. Schilling, Reichtum und Eigentum in der altkirchl. Literatur (1908). Vgl. auch E. TroeltsCh, Die Soziallehren der christlichen Kirchen (1908. 1909. Gesammelte Schriften I, 1912).

Zu S. 265 (Stellung der patristischen Zeit zur Philosophie): J. StIGlMayr, Kirchenväter und Klassizismus (1913).

Zu S. 275 (Leontius von Byzanz): F. LOOFS, L. v. B u. d. gleichnamigen Schriftsteller d. griechischen Kirche (1887), und J. P. JUnGLAS, L. v. B. (1908), der zeigt, daß Leontius im Sachlichen (nicht formal Logischen) keineswegs Aristoteliker ist.

Zu S. 285 (alexandrinische Schule): W. BousSET, Jüdisch.christlicher Schulbetrieb in Alexandrien und Rom (1915).

Zu S. 290 ff. (Augustin): E. Troeltsch, Augustin, die christliche Antike u. d. Mittelalter. Im Anschluß an die Schrift "De Civitate Dei" (1915). M. Grabmann, Die Grundgedanken des hl. Augustinus über Seele und Gott (1916). Monographien über Augustins Erkenntnislehre in ihrem Verhältnis zum Platonismus und "Ontologismus" und seinen Gottesbeweis von J. Hessen, (1916 - Beitr. G. Ph. M.-A.-s. XIX, 2 - . 1920. 1922) und B. KäliN (1920).

Zu S. 297 (Dionysius): H.F.MUller, Dionysios, Proklos, Plotinos (1918.13eitr.XX, 3-4). 


\title{
DIE ISLAMISCHE UND DIE JÜDISCHE PHILOSOPHIE DES MITTELALTERS
}

\author{
VoN \\ IGNAZ Goldziher.
}

Einleitung. Die islamische und die von dieser beeinflußte jüdische Philosophie können wegen der Wirkung, die sie auf die abendländische Scholastik geübt haben, eine beachtenswerte Stelle in der Philosophiegeschichte des Mittelalters beanspruchen. Man hat früher die im Islam entfaltete Philosophie vorzugsweise die arabische genannt, und auch heute wird sie noch häufig mit diesem geläufigen Namen bezeichnet, weil ihre großen Vertreter, ob Araber, Perser oder Türken, ihre Werke zumeist in der klassischen Sprache der islamischen Religion, der arabischen, geschrieben haben. Da aber auch die diesem Kulturgebiet angehörigen jüdischen Denker für die Darstellung ihrer philosophischen Ideen sich derselben Sprache bedienten, ist es richtiger, die beiden in den folgenden Blättern behandelten Gedankenbildungen als die islamische und die jüdisch-mittelalterliche Philosophie zu unterscheiden.

Die Anfänge dieser Bewegung wurzeln in dem Umschwunge, den um die Mitte des 8. Jahrhunderts das politische und geistige Leben im Kalifat erfuhr. Im Dienste der 'abbasidischen Kalifen haben sprachkundige syrische Gelehrte des 8.-10. Jahrhunderts arabische Übertragungen und Paraphrasen griechischer Werke veranstaltet, durch welche die arabische Sprache zum erstenmal Organ wissenschaftlicher Gedanken wurde. Der mit der Ausgestaltung ihrer religiösen Institution beschäftigten gelehrten Welt des arabischen Islams wurde dadurch das Gebiet der Philosophie und der Naturwissenschaften zugänglich, deren Tradition im Osten bisher nur Gelehrte syrischer Zunge gepflegt hatten. In der Anpassung an die neuen Gedankenkreise, in dem Erweis des Vermögens, mit ihren Formenmitteln und ihrem Sprachschatz der fremden Bildung Genüge zu leisten, hat die arabische Sprache eine ebenso glänzende Probe ihrer Aneignungsfähigkeit geliefert wie in der Schöpfung einer feinen sprachwissenschaftlichen Terminologie.

Es dauerte einige Zeit, bis die neue Gedankenwelt auf das große geistige Leben des Islams ihre Wirkung ausübte. $\mathrm{Zu}$ einem lebendigen Element des Geisteslebens wurden die philosophischen Bestrebungen im Orient erst mit 
dem Zeitpunkt, als sie in enge Beziehung zu den religiösen Gedanken des Islams traten, als sich sowohl dem Kreise der Philosophierenden als auch dem der Theologen das Bedürfnis aufdrängte, Stellung zueinander zu nehmen.

Wir dürfen nicht voraussetzen, daß die aus der griechischen Literatur in die arabische übernommenen Schriften die ganze Peripherie umschreiben, in der die Wechselbeziehung zwischen den philosophischen und den religiösen Gedanken sich kundgab. Mehr als die Literatur hat auch hier der lebendige Verkehr gewirkt. Als z. B. im 7. Jahrhundert die Streitfrage über die Willensfreiheit des Menschen aus den Kreisen des orientalischen Christentums in die der mohammedanischen Theologen drang und dort zu heftigen Disputationen Anlaß gab, aus denen der traditionelle fatalistische Glaube mit arger Beschädigung hervorging, da war von der theologischen Literatur der morgenländischen Christen noch nichts ins Arabische übersetzt, woraus die Gottesgelehrten des Islams sich über den Stand der Fragen in der christlichen Literatur hätten unterrichten können; ihre Kenntnis des Problems war nur durch persönlichen Verkehr vermittelt. Ebenso wird auch von den Ideen der älteren griechischen Denker, wie des Aristoteles und der Neuplatoniker, in die islamischen Kreise durch mündliche Übertragung mehr eingedrungen sein, als die Übersetzungsliteratur allein vermuten läßt.

\section{A. Die islamische Philosophie.}

Kalâm und Mutakallimûn.
I. Kalâm und Philosophie. Die Leute, die sich, unter Einwirkung des in die gebildeten Schichten eindringenden philosophischen Geistes, nicht nur mit den streng genommen in das Gebiet der Religion gehörigen Fragen, sondern, im Zusammenhang mit diesen, auch mit den metaphysischen Problemen beschäftigten, führen in der Geschichte der islamischen Philosophie den Namen Mutakallimûn wörtlich: Sprecher. Dieser Name will besagen, daß Lehrsätze, die vom religiösen Glauben als der Diskussion nicht unterworfene Wahrheiten gedankenlos hingenommen wurden, im Kreise jener Leute Gegenstände der Erörterung waren, daß sie darüber rodeten und verhandelten, sie in Formen faßten, die sie denkenden Köpfen annehmbar machen, sie mit spekulativen Beweisen stärkten, die sie gegen den Widerspruch konservativer und radikaler Gegner schützen sollten. Ihre Tätigkeit nennt man Kalàm (das Reden, die mündliche Verhandlung); dementsprechend ist es auch die dialektische Methode, in der sie sich bewegen.

Die ältesten Mutakallimûn traten den orthodoxen Lehrern mit ihren Zweifeln und Einwürfen entgegen und erklärten vom Standpunkt des Glaubens an die göttliche Gerechtigkeit aus nicht alles in Ordnung, was und wie es diese zu bekennen auftrugen. Die ersten Keime ihrer den Anschauungen der breiten Orthodoxie zuwiderlaufenden Gesinnung wurzeln noch nicht in philosophischen Erwägungen. Vielmehr sind es zunächst religiöse Motive, die ihren Widerspruch gegen die hergebrachten Lehren hervorriefen. Thre ältesten Vertreter waren frommgesinnte Leute, Asketen, mu'tazila d.h. sich (vom Irdischen) Zurückziehende. Ihr religiöser Sinn sträubte sich gegen die 
groben Vorstellungen der traditionellen Orthodoxie. Daher der Name Mu'taziliten für die aus diesen Keimen sich entwickelnde dialektische Schule. Denn als im spätern Verlauf ihr ablehnendes Verhalten gegenüber den traditionellen Anschauungen die radikalen Elemente der Rationalisten in ihre Reihen führte, erweitert sich ihr Gegensatz zur Orthodoxie immer mehr, und der Name mu'tazila gibt zu der Fabel Veranlassung, sie seien vom Anfang an wegen ihrer "Absonderung“ von der unzweideutigen Rechtgläubigkeit mit demselben belegt worden. Jedenfalls geben sie, durch die von ihnen ausgehende Erschütterung des traditionellen Lehrbegriffes, dem religiösen Rationalismus im Islam eine mächtige, dauernde Anregung. Ihr Verdienst ist es, neben der sinnlichen Erfahrung und dem traditionellen Wissen ein drittes Kriterium der Erkenntnis aufgestellt zu haben: den 'akl, die Vernunfterkenntnis.

Der Dissens der Muetaziliten von der herrschenden religiösen Anschau- Ihr monotheistiung bekundete sich zu allererst in Fragen, die mit dem Gottes- und Offenbarungsbegriff zusammenhängen. Die Opposition gegen die herrschendeLehre von der Unfreiheit des Willens hatten sie aus einer älteren Generation (Kadariten) ererbt. Es kam ihnen, vom religiösen Gesichtspunkt aus, hauptsächlich darauf an, den Gottesbegriff vor jeder Trübung des geistigen Monotheismus zu bewahren (sie bekämpfen die Annahme von akzessorischen Attributen im göttlichen Wesen), die Konkurrenz des göttlichen Gesetzes mit dem göttlichen Wesen abzulehnen - wozu die traditionelle Annahme führen mußte, daß das Gottesbuch, der Koran, ewig sei, wie Gott selbst - und den Glauben an die Gerechtigkeit des ewigen Wesens nicht durch den Schein fatalistischer Willkür und Grausamkeit verdunkeln zu lassen. Sie lieben es demnach, sich vorzugsweise als "Leute der Gotteseinheit und -gerechtigkeit (ashâb al-'adl wal-tauhîd)" zu bezeichnen.

Man würde die Mu'taziliten aber falsch beurteilen, wenn man sie, wie Unduldsamkeit. dies ja in der Regel auch heute noch geschieht, die Freisinnigen des Islams nennen wollte. Auch ihr Kreis ist der Tummelplatz dogmatischer Engherzigkeit, formalistischer Beschränkung gewesen. Nur ihre Formel sei wahr; wer ihr widerspricht, sei als Ketzer zu betrachten, und gegen ihn sei das einem solchen gegenüber gebührliche Verfahren zu beobachten. Ihr Rationalismus vereinigt sich überdies ganz gut mit der Zulassung persönlicher Autorität; manche ihrer hervorragenden Lehrer reden dem ImâmGlauben der Schi'iten (s. Teil I, Abt. III, I, S. I 2 I dieses Werkes) das Wort, wie sich denn auch die Entwicklung der Mu'taziliten vielfach in der Nähe des Schi'itentums bewegt. Ihre theologische Haltung kann uns in diesem Zusammenhang nicht tiefer interessieren. Unter den öden Formeln ihrer Religionsphilosophie tritt als leuchtender Punkt hervor ihre Tendenz, die das schrankenlose Walten ausschließende Allgüte und Gerechtigkeit Gottes gegenüber der in der Orthodoxie vorherrschenden Auffassung von seiner Willkür in den Vordergrund zu stellen. Nach einigen mu'tazilitischen Lehrern wird selbst das unschuldig leidende Tier für die ihm hienieden gewordene

Güte und Gerechtigkeit Gottes. 
Unbill im Jenseits schadlos gehalten. Gott wäre ungerecht, wenn er dies nicht notwendig gewährte. Ferner legen sie Gewicht auf das Vorwiegen der Vernunftmäßigkeit in der Bewertung der Gesetzlichkeit. Gegenüber der altorthodoxen Auffassung, daß Gottes Gesetzgebung völlig souverän und vom Gesichtspunkt der Vernunftmäßigkeit völlig unabhängig sei, betonen die Mu'taziliten die letztere als oberstes Motiv der göttlichen Gesetze und als Maßstab aller ethischen Beurteilung. Nicht darum sei eine Handlung gut oder schlecht, weil sie Gott befohlen oder verboten hat (dies ist die orthodoxe Formel): sondern Gott habe sie angeordnet oder verboten, weil sie gut oder schlecht ist. Das Kriterium für diese Bewertung biete die Vernunft. Sie sei das Prius, womit die Weisheit und Gerechtigkeit Gottes notwendig im Einklang ist.

Es ist leicht begreiflich, daß das fortschreitende Eindringen positiven griechischen Denkstoffes sowie die Mitarbeit philosophisch gerichteter Denker das Spekulationsgebiet der Mútaziliten, den Kalâm, entsprechend erweiterte, daß sie mit der Zeit Punkte gewahrten, an denen sich ihre theologischen Fragen mit den Problemen der Philosophie berührten. Aus theologischen Thesen und Voraussetzungen hat sich mit der Zeit ihre lebendige Teilnahme an erkenntnistheoretischen und metaphysischen Fragen herausgebildet. Wir müssen deshalb dem Maimûnî recht geben, wenn er in seiner Kritik der Kalâm-Methode die Meinung ausspricht, daß ihre Stellungnahme in metaphysischen Fragen, wenn sie auch einem späteren Geschlecht als unabhängig und voraussetzungslos erschien, historisch betrachtet, sich als bedingt erweist von theologischen Voraussetzungen, zu deren Stützung zu dienen sie in ihrem Ursprung berechnet war.

Eine feste philosophische Stellung nehmen die Mutakallimûn der alten Schule noch nicht ein. Es ist eher der Eindruck ruhelosen Hin- und Hertastens als der einer abgeklärten philosophischen Ansicht, die wir von ihren ältesten Autoritäten empfangen. Bei allen Differenzen ihrer Lehrrichtung können wir aber dem arabischen Historiker zustimmen, der ihre Denkweise einheitlich dahin kennzeichnet, daß sie sich nicht an die griechischen "Gottes-

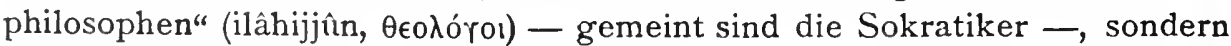
an deren historische Vorgänger anlehnen, an die "Naturphilosophen“ (tabîiijjûn, quбเкoî). Im Grunde jedoch ist ihr Charakter eklektisch, was auch durch die peripatetischen Elemente erwiesen wird, die bei einem und dem anderen der Mu'taziliten Raum finden. Einige werden geradezu beschuldigt, unter der Flagge des Kalâm ,:philosophische" Lehrmeinungen eingeschmuggelt zu haben. Doch ist dies nur ein Ausdruck für den Mangel der Einheitlichkeit, in dem der mannigfach sich verästelnde, in ihren einzelnen Vertretern zuweilen einander schroff widersprechende Lehrinhalt der Mu'taziliten zur Darstellung kommt. Zahlreich ist in den dritthalb Jahrhunderten ihrer Entwicklung (9.-11. Jahrhundert) die Reihe der einander widersprechenden Schulmeinungen, die ihre Lehrer, ob nun aus eigner Spekulation oder in Anlehnung an griechische Denker, hervorbrachten. In neuester Zeit ist S. Ho- 
rovitz den hellenischen Anknüpfungspunkten ihrer Theorien im einzelnen nachgegangen und hat namentlich den entscheidenden Einfluß der Philosophie der Stoa auf die Gedankengänge einiger der hervorragendsten Mu'taziliten, besonders des Nazzâm († 845), sowie den der platonischen Philosophie auf die Systeme anderer Vertreter der Schule, zumeist auf das des Mu'ammar ( +850$)$ aufgezeigt. Max Horten hat sogar auf Berührungspunkte mit Problemen der indischen Philosophie hingewiesen.

Am allerweitesten sind sie wohl auf der ganzen Linie ihrer philoso- besonders zur phierenden Versuche von Aristoteles entfernt. Dessen Lehre von der Ewigkeit der Welt, sein Bekenntnis zu der Unverbrüchlichkeit der Naturgesetze ist eine Scheidewand, die diese philosophierenden Islamtheologen bei aller Freiheit der spekulativen Tätigkeit von der Philosophenschule des Stagiriten trennt.

Dann ist bei ihrer Beurteilung in Betracht zu ziehen, daß sich in ihren Schulen nicht nur ein Nebeneinander der verschiedenen Ansichten kundgibt, sondern auch eine historische Entwickelung der Gesichtspunkte. Halbiert wird ihre Geschichte durch das Auftreten des früheren Mutazilitenjüngers Abu-1-Hasan al-Asch'arî aus Basra (873-935), dessen Lehrbegriff eine Reaktion nach der Richtung des Traditionalismus bedeutet, um zuletzt völlig in das Fahrwasser der Orthodoxie einzulenken. Die rückläufige Tendenz, der auch der überhandnehmende finstere Zug der Politik im Kalifenreiche günstig war, hat starke Wirkung auf die Entwicklung des Kalâm in Form und Inhalt geübt. Spätere Darstellungen unterscheiden deshalb bald zwischen Mu'taziliten und Mutakallimûn und geben diese letztere Benennung vorzugsweise den Asch'ariten, die nur noch von den intransigenten Verächtern aller Vernünftigkeit befeindet, im Grunde aber vom Gesamtgefühl der islamischen Welt als Inbegriff der dogmatischen Orthodoxie anerkannt werden (vgl. Teil I, Abt. III, I, S. I 6 dieses Werkes).

Auf dieser Stufe tritt nun die scharfe, schon in den früheren Momenten vorherrschende Opposition des Kalâm gegen die Lehren der Philosophen in voller Schärfe hervor. Weder die aristotelische noch die neuplatonische Lösung des Weltproblems konnte Befriedigung gewähren, eine Formel bieten, bei der sich die Denkgläubigen zu beruhigen vermochten. Sie konnten den Gott des Islams, den persönlichen Schöpfer der Welt, und sein allmächtiges Walten in der Natur und im sittlichen Leben des Menschen nicht als das in ewiger Ruhe befindliche metaphysische Urprinzip der Bewegung fassen, als das sich selbst denkende Wesen, dessen Wirkungen sich nur in der ewigen Unabänderlichkeit der Naturgesetze kundgeben, das aber den einzelnen Ereignissen der Welt fernsteht, zu ihnen weder mit seinem Allwissen noch mit seinem bestimmenden Willen in Beziehung stehen und nicht auf sie einwirken kann, weil ein Wissen von den Einzeldingen und ein auf sie gerichteter Wille seinen eigenen Begriff als den des unveränderlichen Wesens aufhöbe. Die bei den Peripatetikern heimischen Definitionen Gottes mochten sie nicht als Ausgangspunkte nehmen bei der Gestaltung ihrer Vorstellung 
vom höchsten Wesen, das ihnen Gegenstand nicht nur metaphysischer Vertiefung, sondern auch ethischer Anschauung war. Ebensowenig aber konnten sie für ihre Gottesvorstellung einen beruhigenden Standpunkt gewinnen in der an der Spitze der Emanationenwelt der Neuplatoniker stehenden absoluten Einheit, aus deren unbegrenzter Fülle durch Vermittelung der aus ihr stufenweise ausstrahlenden geistigen Wesenheiten, ohne unmittelbare Willenswirkung auf diese, sich schließlich die Vielheit der Erscheinungswelt gestaltet.

Treffend faßt ein Philosoph des i 2. Jahrhunderts den Unterschied, der Philosophen und Mutakallimûn voneinander trennt, in der Betrachtung zusammen: „Die Philosophen nennen Gott die erste Ursache, aber jene, die man unter dem Namen Mutakallimûn kennt, gehen dieser Benennung mit großer Sorgfalt aus dem Weg und nennen Gott den Hervorbringer; denn - sagen sie - würden sie ihn die erste Ursache nennen, so wäre damit die Mitexistenz der Wirkung gesetzt, und dies führte zur Annahme der Ewigkeit der Welt." Den Schöpfungsgedanken, das Bekenntnis zur zeitlichen Entstehung des Universums hat der Kalâm auf allen Stufen seiner Entwickelung unverbrüchlich festgehalten.

Große Vorliebe hatten die Mutakallimûn für die A to mistik. Durch sie konnten sie am natürlichsten der Annahme der Grenzenlosigkeit der Zeit entgehen. Gott erschaffe in jedem Zeitatom von neuem die Substanzatome und erschaffe an diesen die Akzidense, die je ein Zeitatom dauern und durch fortwährende Neuschöpfung ihr Dasein fristen. Dies hört infolge des Ausbleibens ihrer Neuschöpfung auf. Das Substanzatom büßt seine Existenz ein, wenn ihm Gott statt eines positiven Qualitätsakzidens das Akzidens der Privation, der Nichtexistenz anerschafft. An Stelle der aristotelischen revecis und $\varphi \theta 0 \rho a ́$ tritt die Vereinigung und Trennung. Im leeren Raum (Tò kєvóv) bewegen sich die Atome zueinander hin; aus ihrer Aneinanderreihung entstehen die wechselnden Formen der Dinge. Dies alles sind Gedanken, die Leugnung der sich an griechische Atomistik anlehnen. Ganz treulos verlassen aber, zumal Kausalität.

die Asch'ariten, den alten griechischen Meister mit einer anderen Richtung ihrer Thesen. Sie stemmen sich gegen die Zulassung irgendeiner Kausalität, sie lehnen die konstanten Naturgesetze, die Anerkennung unveränderlicher Naturformen des Seins ab. Nur so gewinnen sie Raum für die Erklärung der Wunder. Das Naturleben wirke nicht nach festen Gesetzen. Wenn die Erfahrung dieselben Wirkungen derselben Ursachen aufweist, so sei es eitel Schein, darin die Betätigung der Kausalität, der gesetzmäßigen Wiederkehr zu finden. Durch Gottes Willen geschehe alles nach einer gewissen Gewohnheit, die aber Gottes Wille beständig durchbrechen — sie sagen „zerreißen" - kann. Und in jedem Augenblick erneuert Gott die Naturfunktionen, die der Philosoph auf gesetzmäßige Notwendigkeit zurückführt. Welche Lücke klafft zwischen dieser Weltanschauung und dem Worte des Demokrit, daß alles „aus einem Grunde und durch Notwendigkeit geschieht"! Mit der Ablehnung aller Kausalität sind die Mutakallimûn vielmehr Schüler des Carneades und des Sextus Empirikus. Ihre philosophischen Gegner erheben 
auch - etwas generalisierend - fortwährend den Vorwurf gegen sie, daß sie sich zur Anschauung von der logischen Gleichwertigkeit und Beweisbarkeit des Für und Wider jeder These bekennen, takâfu' al-adilla, was sich

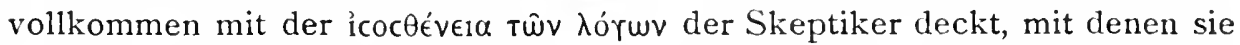
zudem in der Prämisse übereinstimmen, dạß auch die sinnliche Erfahrung

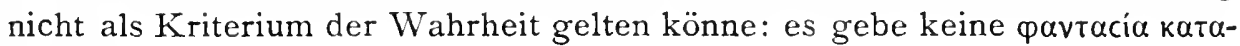
$\lambda \eta \pi \tau$ เкń.

Wie nun der Kalâm kein geschlossenes philosophisches System darstellt, Gegensatz der so ist er von allem Beginne an, auch in seiner mu'tazilischen Ausbildung, den Angriffen der Philosophen, der Platoniker ebenso wie der Aristoteliker, ausPhilosophie gegen den Kàlâm. gesetzt gewesen. Sie machen seinen Vertretern den Vorwurf, daß sie unter den Formen des Denkens schwankende Phantasiegebilde einschmuggeln, die Erscheinungen der Natur nicht in ihrer Wirklichkeit und nach ihren wahren Gründen erfassen, sondern ihre Erklärung nach falschen Voraussetzungen modeln, in ihren Beweisführungen eine Unkenntnis der Gesetze der Logik an den Tag legen, durch täuschende Dialektik den Schein der Folgerichtigkeit hervorrufen wollen usw. Sie verschmähen es - so äußert sich namentlich der christlich-arabische Aristoteliker Jahjâ b. 'A dî († 974) -, sich mit den Mutakallimûn in die meritorische Bekämpfung ihrer Lehrsätze einzulassen, weil sie keinen wissenschaftlichen Berührungspunkt mit diesen finden, sie nicht als Philosophen gelten lassen, ein Name, den sie sich übrigens, wegen der besonderen Einschränkung desselben auf die Aristoteliker, auch selbst nicht beilegen.

II. Neuplatonische Bearbeitung der Philosophie des Aristo- Anfange des teles. Der Aristotelismus hält seinen Einzug in die islamische Gedanken- Aristotelisinus. welt durch die Pforten der aristotelischen Logik und Naturwissenschaft in der Gestalt, in der die bezüglichen Schriften durch die Übersetzer überliefert waren, also in der Form, die ihnen ihre Erklärer aus der späteren peripatetischen und der neuplatonischen Schule gegeben hatten. Es waren zumeist muslimische Ärzte, die sich für die griechische Wissenschaft interessierten, und daraus erklärt sich die vorwiegende Aufmerksamkeit für Schriften, die der Vertiefung ihrer Berufskenntnisse förderlich sein konnten.

Man hat früher die führende Rolfe der aristotelischen Werke in den Anfängen der Philosophie bei den Arabern überschätzt. Es ist das Verdienst des holländischen Gelehrten T. J. de Boer, scharf betont zu haben, in welch großem Maße neben solchen aristotelischen Anfängen der überragende Einfluß platonischer, stoischer u. a. Quellen zur Geltung kommt. Besonders tritt eine entscheidende Wirkung des Plato auf die erste Periode der arabischen Philosophie in den Vordergrund. Man kann als möglichen Grund für diese dem Plato bezeigten Sympathien mit gutem Recht an das günstige Verhältnis denken, in welchem der platonische Idealismus zu den Erwartungen des religiösen Sinnes im Islam steht. Für psychologische, ethische und zum Teil auch politische Lehren hai man sich mit Vorliebe zu ihm gewandt. Auch 
Einflüsse des Neuplatonismus.

der Einfluß vorplatonischer Ideenkreise, namentlich solcher, die mit der Philosophie des Pythagoras zusammenhängen, macht sich in der älteren Periode der arabischen Philosophie geltend. Für die Fortdauer solcher Einflüsse waren dann auch in den Entwickelungsperioden, in welchen die arabischen Denker glaubten auf aristotelischem Boden zu stehen, literarhistorische Tatsachen maßgebend, die dem platonischen Zuge der arabischen Philosophie einen dauernden Charakter gaben.

Die dem Arabertum aus dem Heilenismus zufließende geistige Bereicherung sprudelte aus recht trüben Quellen. Es ist bereits angedeutet worden, daß das ihnen als aristotelische Philosophie Zugehende nicht das ungefälschte Gedankensystem des Stagiriten war. Seine späteren, besonders die neuplatonischen Erklärer hatten es in eine ihm ursprünglich fremde Richtung gelenkt, es durch die Mittel der Umschreibung und Erklärung zum Inbegriff einer Weltanschauung umgestempelt, die Aristoteles selbst weit von sich gewiesen hätte. Die in arabischer Sprache gepflegte philosophische Literatur arbeitete nun mit dem Aristoteles des Alexander von Aphrodisias und vornehmlich mit dem der Neuplatoniker Themistius und Porphyrius.

Pseudo-aristoteische Schriften in arabischer Sprache.
Auf letzterem Wege wurde der Friede zwischen zwei Systemen angebahnt, deren Grurddideen sich in gegensätzlichen Richtungen entfaltet hatten. Den Erfolg dieses Fusionswerks hat auch der Umstand begünstigt, daß es Werken von unleugbar neuplatonischer Tendenz gelungen war, in die arabische Literatur unter dem Namen des Aristoteles eingeführt zu werden. Das hervorragendste und weitaus wirkungsreichste unter diesen ist die als "Theologie des Aristoteles" bekannte Schrift, die unter solchem Autornamen im ersten Viertel des 9. Jahrhunderts in die arabische Literatur aufgenommen wurde. Auf Grund der Übersetzungen wurde sie bereits von S. Munk (1859), nach Herausgabe des Originals durch Fr. Dieterici noch spezieller von Valentin Rose als Bearbeitung eines Auszuges aus Plotin erwiesen. Die ältesten Vertreter der peripatetischen Philosophie unter den Arabern hatten sie aber als echtes aristotelisches Werk anerkannt. Dieselbe Anerkennung als genuines aristotelisches Produkt wurde u. a. auch dem durch die Ausgabe Bardenhewers (1882) zugänglichen arabischen Auszug aus

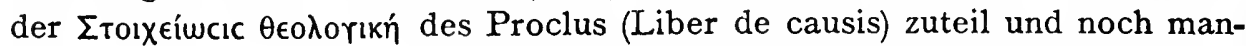
chen anderen minder bedeutenden neuplatonischen Schriften, die, wie-das „Apfe1buch", den Aristoteles aus Platons Gedankenwelt fließende Lehren aussprechen ließen.

Zur Festigung der neuplatonischen Weltanschauung trugen auch noch pseudepigraphische Produkte anderer Art bei. Dem Orientalen mußte es bei seiner hohen Schätzung alles Vorzeitlichen nicht wenig imponieren, die Hauptbestandteile der neuplatonischen Emanations- und Seelenlehre, oder mindestens mit ihnen verwandte, auf sie hinführende Gedanken von vorplatonischen Denkern ausgesprochen zu finden, die seine primitive Philosophiegeschichte zum Unterschied von den Lehrern der nachplatonischenZeit deshalb mit dem Namen „Säulen der Weisheit" bezeichnet. Unter diesen eignete 
sich besonders Empedokles als Träger von Ideen, die in dem neuplatonischen Lehrgebäude zu einem geschlossenen System verdichtet wurden. So hat sich denn auch Pseudoempedokles, ebenso wie Pseudoaristoteles als wirksamer Faktor bewährt in der Ausgestaltung einer Philosophie, die, so sehr sie sich auch mit Stolz und Selbstbewußtsein zu dem „ersten Lehrer" - so nannte man Aristoteles - bekennt, die grundlegenden Gedanken seiner Weltlehre unbewußt mit fremdartigen Vorstellungen durchsetzte.

Es ist ein naheliegender Parallelismus, den uns diese Tatsache der Philosophiegeschichte des Orients aufdrängt. Sowie das Christentum in vielen Teilen des Morgenlandes - freilich nicht eben in jenen, in denen sich die Entwickelung der Philosophie bewegt - seine Wirkung durch den Einfluß der um den Bibelkanon sich schlingenden apokryphen Literatur betätigt hat, so wird auch der Einzug der griechischen Philosophie im mohammedanischen Orient durch Pseudepigraphen gefördert.

III. Neuplatonische Philosophie. Der völlige Mangel kritischer Fähigkeit drückte von allem Anfang der arabischen Philosophie den Stempel des Eklektizismus auf, der sich in jeder der Richtungen, in denen sie sich entfaltet hat, in unverkennbarer Weise bekundet.

Neben der neuplatonisch gewendeten aristotelischen Philosophie entwickelt sich auch ein in den äußeren Formen der peripatetischen Philosophie erscheinender Neuplatonismus, der durch seine Wirkungen auf die weiten Kreise der islamischen Welt ein wichtiges Moment ihrer Philosophie bildet.

Nach geringeren Anfängen, deren literarische Denkmäler wohl vorausgesetzt, aber nicht nachgewiesen werden können, verdichtet sich diese philosophische Richtung im 1o. Jahrhundert in dem Schriftenzyklus eines religiösphilosophischen Bundes, dessen arabischen Namen (ichwân al-șafâ) man früher als „die lauteren Brüder" erklärț hat, den man aber, aus sprachlichen Gründen, angemessener als die „Lauteren" oder die „A ufrichtigen“ übersetzt.

Es ist dies der Name eines von Basra ausgehenden, aber auf eine Ver- "Die Lauteren“" breitung über die ganze islamische Welt angelegten Vereins islamischer ihre Enxy Idealisten, die ohne äußere Ablehnung des Islams die höchste Vervollkommnung des Geistes, die Erfassung der letzten Wahrheiten und ihre Verkörperung in der Gesellschaft durch philosophische Vertiefung anstrebten. Durch die wahre Erkenntnis der Erscheinungswelt und der sich in ihr offenbarenden Harmonie und Symbolik strebten sie in stufenweisem Fortschritt die Entschleierung der Geheimnisse der Natur und der Seelenwelt an. Die Läuterung der durch ihre zeitweilige Beherbergung in der Welt der Dimensionen getrübten und mit den Schlacken der Materie behafteten Seele durch die Erlangung „wahrer Erkenntnisse und frommer Handlungen" ist der Zweck des Daseins; sein Ziel ist die Befreiung der Seele aus diesem Erdenkerker, die Rückkehr der gereinigten Individualseele in ihre himmlische Heimat, in das Reich der intelligiblen Welt, ihr Eingehen in die. Weltseele, von der sie losgelöst war. 
Ihr vorzüglichstes Dogma ist die in diesem Sinne verstandene Rückkehr der Seele (ma âd, das Wort findet man in einem Titel des lateinischen Avicenna wieder: Mahad), gegen deren Leugner sie sich in den härtesten Ausdrücken aussprechen. Das Zentrum ihres Denkens ist die Seelenlehre, die sich bei ihnen in einer Doktrin von der Entwickelung der Seele aus den niedrigen Formen zur individuellen Menschenseele und ihrer Wiedererhebung zur Vollkommenheit ihres Urquells ausprägt. Die Weltanschauung, deren Kern diese Spekulation bildet, ist die Emanationslehre der Plotinisten mit ihrem Universalintellekt und ihrer alles durchdringenden Universalseele, deren gestaltende Tätigkeit sich in der Natur und in der Schöpfung des Menschen kundgibt, wozu noch pythagoreische Zahlensymbolik hinzutritt, um das Emanationssystem durch Zahlenverhältnisse zu veranschaulichen. Auch sonstige Symbolik, wie die der Buchstaben, Tonharmonie u. a. m., tritt für die Darlegung der Tatsache hinzu, daß alles in der materiellen und geistigen Welt ein Abbild ist der stufenweisen Ausströmung aus der Welt der reinen Geistigkeit, aus der Sphäre des allgemeinen, selbst aus der absoluten göttlichen Einheit ausstrahlenden Weltintellektes, zu dem zurückzukehren das höchste Ziel des letzten Schöpfungsdings, des Menschen, ist, der mit den Faktoren seiner körperlichen und geistigen Existenz ein Abbild des Universums darstellt, einen Mikrokosmos. Die Gattungen der Geschöpfe unserer Welt seien nur schattenhafte Abbilder der Gattungen der Sphärenwelt, in der ihre ewigen Urbilder in Wirklichkeit leben. Diese Weltanschauung ist identisch mit ihrer Religion, einer absoluten Religion, deren Zweck die Reinigung der Seele und das Ähnlichwerden mit Gott durch die Philosophie ist. Neben den wahren Erkenntnissen legt sie großes Gewicht auf die frommen Handlungen. Askese ist ein mächtiges Mittel der Abstreifung des materiellen Schleiers, der die Seele verdeckt und ihr wahres Wesen, die Erkenntnis ihrer Bestimmung vor ihr verbirgt. Aber die Lauteren reden dabei fortwährend auch von dem großen Wert der positiven Religionen, zumal des Islams, von dem hohen Rang der Propheten, Religionsstifter und Gottesmänner. Diese sind jedoch nur Durchgangsphasen, pädagogische Mittelgrade für die absolute Religion, Gleichnisse und Symbole der ewigen Wahrheit. Daher die Tendenz der Lauteren, alles Positive sinnbildlich zu gestalten, ein Erbteil des Philo, unbewußt eines ihrer geistigen Ahnen. Ihr System haben sie in einer aus vier Hauptteilen und 51 Abhandlungen bestehenden Enzyklopädie der Wissenschaften dargestellt, deren äußere Anlage durch die Einteilung des Zyklus der aristotelischen Schriften bestimmt ist, mit deren formellen Elementen die Lauteren gerne prunken, und deren Material sie sich in ganz äußerlicher Weise aneignen. Dies enzyklopädische System läuft jedoch in seinem vierten Teile auf eine für seine Ziele im höchsten Grade charakteristische Darstellung des Okkultismus der Lauteren aus, wohl Pforte und Übergang zu einer für ihre, zur Stufe der Pneumatiker herangereiften Mitbrüder bestimmten esoterischen Lehre. Eingehend und ernst behandeln sie hier die Modalitäten der Fortdauer der Seele, die Hierarchie der Geister- 
welt, die Art und Weise der Wirkung der die Planeten bewohnenden Geisterwesen, Astrologie, Alchimie, Zauberei, die Macht des Menschen, der sich den Fesseln der Materie entwunden und auf dem Wege zur Erhebung die höchsten Seelenstufen erreicht hat.

Die Ausbildung der neuplatonischen Philosophie in arabischer Sprache, thre Wirkungen deren Höhepunkt die Enzyklopädie der Lauteren darstellt, war von großen im Ostea und Folgen begleitet in der philosophischen Literatur und im öffentlichen Leben sowohl in seinen religiösen als auch in seinen politischen Beziehungen. Bereits vor dem Hervortreten der Enzyklopädie waren die neuplatonischen Gedanken sowohl in die religiöse Gesellschaft als auch in die philosophische Literatur des westlichen Islams eingedrungen. Unter diesem Einfluß ist die im 9. Jahrhundert in Spanien auftretende, von den Arabern auf die Wirkung pseudoempedokleischer Schriften zurückgeführte Bewegung des aus dem Osten heimkehrenden Cordovaners Muhammed ibn 'Abdallah Ibn Masarra (883-931) zu begreifen, deren genaue Erforschung eine der nächsten Einzelaufgaben dieses Teilgebietes der orientalischen Wissenschaft sein sollte. Den raschen Einzug des Neuplatonismus in die weitesten Gebiete der philosophischen Literatur bezeugt am besten die Tatsache, daB bereits am Anfang des ı. Jahrhunderts, in Kairawân (Nordafrika), der jüdische Philosoph und Arzt, Isak b. Salomon Isrâêli, dessen Werke in die abendländische Literatur durch die lateinische Übersetzung des Constantinus Africanus verpflanzt wurden, obgleich nicht Neuplatoniker, sowohl in seinem "Buch der Elemente“ als auch in seinem „Buch der Definitionen“ den neuplatonischen Einflüssen einen breiten Raum gewährt. Die Schriften der Lauteren selbst sind bald nach ihrem Erscheinen, bereits am Anfang des Ir. Jahrhunderts, nach Spanien eingedrungen. Hier wird die große Wirkung der neuplatonischen Philosophie besonders durch den lange Zeit rätselhaften Namen des Avencebron vergegenwärtigt, dessen Identität mit dem jüdischen Denker und Dichter Salomon ibn Gebîrol Salomon Munk in einer für die Geschichte der mittelalterlichen Philosophie bahnbrechenden scharfsinnigen Untersuchung (1 846) entdeckt hat. Die „Fons Vitae“ dieses Neuplatonikers, in welcher die Darstellung der zugrunde liegenden neuplatonischen Philosophie und Weltanschauung mit Elementen der aristotelischen Prinzipienlehre verwebt ist, ist zwar ebenso wie die obengenannten Schriften des Isak Isrâêli in keiner Weise mit der Lehre eines speziellen Bekenntnisses verknüpft. Aber wenn auch nicht durch bestimmte konfessionelle Dogmen bedingt, betätigt Avencebron, gleich seinen muslimischen Vorgängern, die Modifizierung der hellenischen Gedanken im Sinne allgemeiner religiöser Voraussetzungen. Die in diesem berühmten Werke entwickelte Theorie hat die europäische Scholastik des Mittelalters in hervorragender Weise beeinflußt.

Es sind dies bedeutende Zeichen des raschen Eindringens der im Osten gepflegten Philosophie nach den westlichen Ländern des Islams. Wie im Osten, so bildet auch im Westen die auf den Islam angewandte neuplatonische Philosophie den Kristallisationspunkt, um welchen sich die religiösen Ge- 
danken der durch die Forderungen der islamischen Dogmatik und die Außerlichkeiten des Ritualismus nicht befriedigten tieferen Geister sammeln.

Neuplatonische Ethik. Einflu 8 auf staatliche Theorien.
Unter den philosophischen Disziplinen ist es besonders die Ethik, die auch in ihrer von aristotelischen Gesichtspunkten bestimmten Gestaltung tiefe Spuren der neuplatonischen Ánschauungen an sich trägt. Die „vier platonischen Tugenden" beherrschen die Darstellungen des ethischen Systems, und die aristotelische Mecótnc, als Prinzip des sittlichen Lebens, muß mit jenen in mehr oder minder organische Verbindung treten. Neben fortwährenden Zitaten aus der nikomachischen Ethik strömt die „Verfeinerung der Sitten" des Abû "Alî ibn Miskaweihî († 1030) über von neuplatonischen Exkursen über die Verdüsterung der in den Menschen eingepflanzten "göttlichen Substanz" durch ihre Einwickelung in die Hülle der Naturexistenz, über den sehnsüchtigen Aufblick der Seele nach dem „reinen Guten“, das seinen Glanz auf sie strahlen läßt, und über die endliche Reinigung der Seele durch ihr Emporstreben zur Urquelle und ihre Vereinigung mit dieser durch das Abstreifen des derben Gewandes der irdischen Leiblichkeit. Die Lehre von der Liebe und ihren verschiedenen Arten und Graden, die ihre höchste Vollkommenheit in der ,göttlichen Liebe“ erringen, erhält hier einen hervorragenden Raum in der Ethik, wie sie bei den Lauteren ihre Stelle in der Lehre von der Weltseele (36. Abhandlung) erhalten hatte. Und um den platonischen Einfluß über jeden Zweifel zu erheben, überrascht uns dieser ethische Schriftsteller mit einer Darlegung des schädlichen Einflusses der altarabischen Ritterpoesie auf die Erziehung der Kinder, der sein System der Sittenlehre große Berücksichtigung widmet. Derselben Anregung folgend hat übrigens auch Averroës die Poesie der Araber als sittlich gefahrbringend proskribiert.

Und auch im mohammedanischen Staatsleben war es dem Neuplatonismus beschieden, einen geradezu grundstürzenden Einfluß zu betätigen. Die Bewegungen der Karmathen und Ismailliten, die ihre feste staatliche Gestaltung durch das Emporkommen der Herrschaft der Fatimiden gewannen, fanden in den neuplatonischen Theorien ihre philosophische Stütze. Hier bildet sich der künstliche Parallelismus der in den Emanationen sich bekundenden kosmischen Ordnung mit der Einwickelung der in periodischer Wiederkehr sich offenbarenden theokratischen Reihenfolge von großen und kleinen Propheten und Sprechern, die alle nach Gottes vorherbestimmtem Weltplane auf die Manifestation des Weltintellekts in dem in Erscheinung tretenden Mahdî hinauslaufen. Hier erlangt dann in praktischer Anwendung die Theorie von dem allegorischen Sinn des mohammedanischen Gesetzes und der heiligen Erzählungen ihren Höhepunkt. Darum nennt man die Gemeinde, die diese politisch-religiöse Revolutionsbewegung schuf: Bâtinijja, d. h. die der inneren Bedeutung nachhängen. Was sie darstellt, ist nicht mehr Islam $z u$ nennen; es ist die Zersetzung des Islams (vgl. Teil I, Abt. III, S. I 25).

Die dauerndste Wirkung aber, die der Neuplatonismus innerhalb des Islams hervorbrachte, ist die theosophische Richtung des über den ganzen 
Islam verbreiteten Suffismus. Während er nach außen in dem widerlichen Derwischwesen und in der Gemeinschaf: müßiger Klosterbrüder sich kundgibt, liegen an seinem Grunde die tiefen Theorien der Neuplatoniker von der Wesenlosigkeit der Erscheinungswelt, die bloß eine Spiegelung der einzig wirklichen allumfassenden göttlichen Realität sei, von der vom göttlichen Urquell weit entfernten Materie und der durch Askese und Ekstasis $z u$ erreichenden Vereinigung der Seele mit Gott. Schon der erste wissenschaftliche Darsteller des Suffismus Friedrich August Tholuck (1821) hat die neuplatonischen Wurzeln des Sufiwesens erkannt; Adalbert Merx hat sie näher bestimmt (1 893), und in jüngster Zeit haben die Engländer E.H.Whinfield und Reynold A. Nicholson in ihren Bearbeitungen der mystischen Gedichte des größten Sufidichters Dschelâl al-dîn Rûmî († I 270 ) treffende Parallelen zu den hier herrschenden Begriffen aus den Enneaden des Plotin beigebracht. Dabei ist aber nicht übersehen worden, daß dem Sûfismus in seinen zentralasiatischen Berührungen mit dem Buddhismus auch aus dessen Gedankenkreis Ideen und Ziele sich angegliedert haben, zu deren Erklärung die neuplatonischen Anfänge des Sûfismus nicht ausreichen. Die Auslöschung der Individualität (mahw), ihr Aufgehen in das Nichtsein (fanâ, istihlâk) leiten zur Idee des Nirvana zurück. Und dies ist wohl das wichtigste, aber nicht das einzige buddhistische Element, das der Suffismus sich einverleibt und in sich verarbeitet hat.

Der Suffismus, der auf die Vertiefung der islamischen Gedanken einen mächtigen Einfluß übte, stellt in den verschiedenen Richtungen (tarîka, Weg), in denen er zur Ausprägung gelangte, trotz der Gemeinsamkeit der Grundlehren, kein einheitlich geschlossenes System dar. Unter seinen zahlreichen Verzweigungen darf aus dem Gesichtspunkt der in demselben wirkenden Einflüsse und wegen seiner größeren Entfernung von der Heerstraße des allgemeinen Sûfismus, das System des Schihâb al-dîn a1-Suhrawerdî besondere Hervorhebung beanspruchen. Mit Vorherrschaft der platonischen Ideenlehre stellt es eine Mengung von altiranischen Gedanken, Gnostizismus und Emanationstheorien dar. Die Geisterwelt sei eine aus dem „Licht der Lichter" (der Gottheit) ausstrahlende Lichtwelt, in der die Vielheit der Intelligenzen webt; sie bilde den Gegensatz zu der der Finsternis angehörenden Körperwelt. Aus diesem Ausgangspunkt konstruierte Suhrawerdî eine Weltanschauung, die er selbst, ,Philosophie derErleuchtung“( (hikmat al-ischrâk) "Philosophie der benannte. Wegen seiner der Orthodoxie anstößigen Lehre, von der es z. B. keine Brücke zur islamischen Kosmologie gibt, wurde er I Igi in Aleppo hingerichtet.

IV. Die Aristoteliker im Islam. Indem wir von der neuplatonischen Schule zur aristotelischen übergehen, treten wir in keine wesentlich neue Sphäre philosophischer Bestrebung ein. Die peripatetische Philosophie der Mohammedaner ist von der neuplatonischen nicht so sehr dem Wesen als dem Verhältnis nach verschieden, in dem sie die neuplatonischen Grundlehren 
Dreistufensystem der wis senschaftlichen Erkenntnis.

Al - Kindî (t ca. 870 )

auf sich wirken läßt. Ihre Vertreter haben - wie bereits eingangs hervorgehoben wurde - die aristotelische Philosophie im Sinne ihrer neuplatonischen Erklärer übernommen und neuplatonische Schriften als Denkmäler der aristotelischen Philosophie verarbeitet. Von der im vorhergehenden Abschnitte behandelten neuplatonischen Richtung unterscheidet sie sich hauptsächlich durch die größere Bedeutung, die sie in ihrem System dem aristotelischen Aufzug neben dem neuplatonischen Einschlag zuerkennt. In formeller Beziehung wird sie besonders gekennzeichnet durch die grundlegende Wich. tigkeit, die sie dem Dreistufensystem zueignet, das sie von der fortschreitenden wissenschaftlichen Erkenntnis fordert: erst die propädeuțischen (Logik, Mathematik), dann die naturwissenschaftlichen Kenntnisse, drittens auf diesen aufgebaut das metaphysische Studium. Diese hodegetische Forderung stellt sie vorzugsweise im Unterschied von den Mutakallimún auf, die, ohne „die Natur der existierenden Dinge“ zu kennen, den Problemen der Metaphysik an den Leib rücken.

Auch die Lauteren hatten formell das aristotelische Schema hochgehalten, aber in seiner Anwendung ihre phantastischen Träumereien betätigt und in allen Stufen ihres aufwärts steigenden Lehrganges ihre Seelenlehre antizipiert. Mit bewußtem Ernst bauen die arabischen Peripatetiker ihr System auf jene methodische Forderung. Al-Kindî ( $†$ ca. 870) wird als der arabische Philosoph genannt, der in diesem Kreise die ersten Schritte auf dem Wege des Aristotelismus unternahm. Man kann ihn wohl noch nicht als entschiedenen Vertreter dieser Richtung kennzeichnen. Mit seinen Anfängen wurzelt er in einer von ihm niemals aufgegebenen, mit Elementen neuplatonischer und pythagoraischer Weltanschauung durchsetzten Naturphilosophie. Dabei sind ihm auch die im Kalâm verhandelten religionsphilosophischen Probleme, ohne Zweifel im Sinne ihrer mu'tazilitischen Lösungen, nicht fremd. Sein Interesse an aristotelischer Philosophie betätigt er durch seine Teilnahme an der Erklärung logischer und physischer Schriften des Aristoteles und sein Bekenntnis zu den in den letzteren dargelegten kosmischen Lehren. Er vergegenwärtigt mit dieser Vermengung einander zuwiderlaufender Weltbetrachtungen die eklektischen Anfänge aller arabischen Philosophie, in der er jedoch zuallererst für Aristoteles einen breiten Raum beansprucht. $\mathrm{DaB}$ er für das Studium der Philosophie den für die arabische Peripatetik charakteristischen Dreistufengang fordert, bekundet er in Schriften, deren Titel „Daß die Philosophie nur durch die propädeutische Wissenschaft erreicht werden kann" und „Der Nutzen der Propädeutik“ von prinzipieller Bedeutung für seine Auffassung von dem Wege des philosophischen Studiums sind.

Dem entspricht auch der Eifer, mit dem er logische, arithmetische, geometrische und astronomische (einschließlich astrologische) Gegenstände bearbeitet. Diese Auffassung vom Studium der Philosophie zieht sich durch die ganzen vier Jahrhunderte philosophischer Produktivität der arabisch schreibenden Denker und konnte sich am besten an einer in immer umfassen- 
derem Maße hervortretenden Bearbeitung der aristotelischen Werke auf Grund ihrer zu den Arabern gelangten Überlieferung kundgeben.

Nach Al-Kindî sind es im besonderen drei Namen, mit denen vom 10.-I 2. Jahrhundert die Höhepunkte der aristotelischen Philosophie im Islam bezeichnet werden: Alfârâbî, Avicenna und Averroës.

Während A I fâ râbî († 950), als erster wirklicher Aristoteliker „der zweite Lehrer" genannt, durch die Bearbeitung der logischen Schriften hervorragt, Alfârâbî und das Material der Logik, namentlich den syllogistischen Teil derselben, weiter entwickelt, ringt sich, gegenüber der um sich greifenden Verfälschung der philosophischen Gesichtspunkte, in Averroës, wie wir im folgenden noch sehen werden, das ehrliche Streben empor, den Gedanken des Aristoteles möglichst ungetrübt zu verdolmetschen, ihn von den durch die Vorgänger unablässig fortgesetzten Versuchen zu erlösen, die Gegensätze zu den Forderungen des religiösen Glaubens abzuschwächen, oder mindestens die Schärfe des Widerspruches durch Umbiegung des wahren Sinnes zu mildern. Da war eben die gefährlichste Klippe, an der die den Frieden mit der Religion suchenden Philosophen niemals unversehrt vorübersteuern konnten: die aristotelische Lehre von der Anfangslosigkeit der Welt. Alfârâbî hat diesen Stein des Anstoßes im Zusammenhang mit seinem platonisch-aristotelischen Synkretismus hinweggeräumt. Nach dem Muster des Ammonius Sakkas hat auch er, der die Theologie des Aristoteles, an deren arabischer Redaktion sein Vorgänger Al-Kindî mitgearbeit hatte, als authentisches Werk anerkennt, eine Harmonistik der platonischen und aristotelischen Philosophie versucht. Er stellt dabei entschieden in Abrede, daß Aristoteles die Ewigkeit der Welt gelehrt habe. Man konnte also Aristoteliker sein, ohne den Glauben an eine Weltschöpfung aufzugeben. Und auch innerhalb der streng philosophischen Terminologie ist ein Ausweg gefunden worden. Nicht erst Avicenna, wie man vielerseits annimmt, sondern bereits Alfârâbî hat gegen die Verlegenheit, welche die Annahme der Notwendigkeit des Universums als Wirkung der ersten bewegenden Ursache bereitet, Hilfe gesucht in der spitzfindigen Aufstellung einer Kategorie des relativ Notwendigen, das an sich in die Kategorie der Möglichkeit gehört. Die Sphären, an denen man potentielles und tatsächliches Sein, Materie und Form unterscheiden kann, erhalten ihre Qualität der notwendigen Existenz erst durch ihr Kausalitätsverhältnis zur ersten Ursache; sie sind demnach nicht in absolutem, sondern in relativem Sinne notwendig; an sich gehört ihr Sein in die Kategorie des Möglichen oder nur des bedingt Notwendigen. Dies half aber wenig, denn trotzdem sind nach Avicenna Ursache und Wirkung gleichzeitig und unzertrennlich. Der Forderung der Ewigkeit von Zeit und Bewegung konnte man auf diesem Wege nicht entgehen.

$\mathrm{Zu}$ den meist charakteristischen Theorien der arabischen Peripatetiker gehören ihre Erkenntnistheorie und ihre kosmologische Konstruktion. Nach Anleitung des Alexander Aphrodisias und des Themistius haben sie die einErkentrinis theorit der arabichen Peripatetiker. fache Unterscheidung des Aristoteles zwischen materiellen und tätigem In- 
tellekt zu einem komplizierten System des intellektuellen Entwickelungsprozesses vom potentiellen zum angeeigneten Intellekt umgestaltet, dessen Grundzüge schon von Al-Kindî an allen gemeinsam sind, in dessen Einzelheiten sie aber manche Varianten aufweisen. Die Aneignung des Erkennens des Wesens der Dinge werde durch einen außerhalb des Menschen befindlichen kosmischen Faktor bewirkt, der die Quelle des Erkennens sei, ebenso wie die Sonne, die Quelle des Lichtes, unserer Sehkraft erst die Möglichkeit ihrer Betätigung verleiht. Diese außerhalb des Menschen befindliche Quelle aller Erkenntnis sei die tätige Vernunft; in diesem Zusammenhange in ganz anderer Bedeutung, als sie Aristoteles seinem voûc moıntıkóc zueignete.

Die tätige Vernunft der arabischen Aristoteliker ist das Glied einer Emanationsreihe, als welche sie die supralunarische Welt konstruieren. Von dem einzigen, ewigen, unveränderlichen, sich selbst denkenden Wesen ausgehend, das die Ursache der Bewegung der obersten, umfassenden Sphäre ist, werden in absteigender Linie unkörperliche geistige Substanzen (separate Intellekte) hervorgerufen, die je durch das Erkennen ihrer selbst und ihrer Ursache wieder zur Quelle werden einesteils anderer durch sie hervorgerufener geistiger Substanzen, anderenteils von Sphären, die unter dem Einfluß der ihnen entsprechenden Sphärengeister stehen. Die Himmelskörper seien denkende, mit hoher, die des Menschen weit überragender Intelligenz begabte Wesen, die aus Sehnsucht nach ihrer Ursache, der sie ähnlich zu werden streben, die vollkommenste aller Bewegungsarten, die sphärische, vollziehen. Der erste B ew eg er werde als solcher in dem Sinne genannt, daB die Sehnsucht nach ihm die Zielursache der Kreisbewegung der Sphären ist. Sie seien unvergänglich und bestehen aus einem ätherischen Stoff, der als fünfter von den vier körperlichen Elementen verschieden ist. Mit der Mondsphäre ende die Reihe der emanierten Himmelskörper. Diese kosmologische Theorie wird nicht von allen Philosophen in gleicher Weise konstruiert; die Zahl und das Tätigkeitsgebiet der Sphären wird verschieden angegeben. Bereits Alfârâbî hat in den „Ansichten der Leute des Musterstaates" ein verwickeltes System der Emanation der Sphären und der separaten Intellekte aufgestellt, das aber durch das in der Metaphysik des Avicenna entworfene Bild verdrängt worden ist. Aus dem höchsten Intellekt, Gott, gehen stufenweise zehn Sphärengeister hervor; der Intellekt der Sphäre des täglichen Umkreises, der das ganze Universum umschließt, strahlt unmittelbar aus Gott aus; der letzte, aus dem Intellekt der Mondsphäre ausstrahlende Sphärengeist ist der tätige Intellekt. In ihm sind die Formen der elementaren Welt beschlossen; jede Form, die in der Welt entsteht, ist nur durch sein Hineinströmen bewirkt; er teilt jedem Empfangenden die Formen zu, für die es vorbereitet ist; durch sein Einstrahlen auf die potentielle Vernunft des Menschen wird auch das Erkennen bewirkt. Die geistige Vollkommenheit des Menschen ist bedingt von dem Grade und der Dauer seiner Empfänglichkeit für diese Einwirkung. Die Erkenntnistätigkeit hat zum Ziele, daß die tätige Vernunft

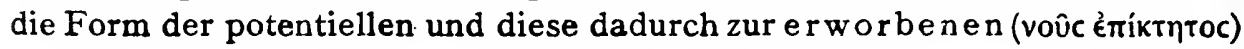


Vernunft werde; darin besteht die Vollkommenheit der dem Menschen physisch anerschaffenen (hylischen) potentiellen Vernunftgabe.

Die Philosophen, die als Vorbereiturig für die metaphysischen Einsichten eine reale naturwissenschaftliche Schulung stürmisch fordern und den philosophischen Schiffbruch ihrer Kalâmgegner dem Umstande zuschreiben, daß sie ohne Naturerkenntnis ins Blaue hinein philosophieren, geben da eine Kosmologie und Psychologie, die hart an die Grenze des Mythologischen streifen, wenn sie diese nicht bereits überschritten haben. Und der mythische Harmonisierung Charakter ihrer Konstruktion wird noch erhöht, wenn sie, um mit den traditionellen Religionsvorstellungen Frieden zu halten, ihre separaten Sphärenmit den Religions. vorstellungen. intellekte mit den biblischen und koranischen Engeln identifizieren. Sie bewegen sich dabei vollends in neuplatonischem Fahrwasser; und es war für Denker, die für solche Gebilde empfänglich waren, ein leichtes, zu diesen in die aristotelische Philosophie eingeschmuggelten und in ihren Kreisen als aristotelisch umgehenden Theorien noch etliches hinzuzutun, wobei die starken neuplatonischen Einflüsse sich zuweilen in ganz greller Weise kundgeben. Sie stellen abergläubische Vorstellungen in den Dienst ihrer philosophischen Theorien. Ihre logische Strenge und die Forderung peinlich wissenschaftlichen, apodiktischen Beweisverfahrens hindert sie nicht, okkul- sche Theorien. tistischen Anschauungen zu huldigen, sogar Afterwissenschaften eine Berechtigung neben ihrer aristotelischen Disziplin zuzuerkennen. Die Mutakallimûn sind in diesen Dingen nüchterner; sie sind z. B. erklärte Gegner der Astrologie. Mit den Aristotelikern hat diese sich ganz gut vertragen. Al-Kindî schreibt über esoterische Philosophie, worunter man eben mit Recht die mystischen Dinge verstehen wird, die er neben der gemeinen Philosophie betrieb. Steht er auch im Kampfe gegen den berühmten Arzt A bû Bekr-al Râzî̀ (Rhazes † 923), dem gegenüber er der Alchimie allen Wert und alle Berechtigung aberkennt, so schreibt er doch andererseits über Omina und Auguria; er ist Astrolog und sein von Otto Loth (1874) herausgegebenes astrologisches Werk über die Schicksale des islamischen Reiches einer der wenigen literarischen Reste, die von ihm erhalten sind. Die Theorie von der hohen Vernünftigkeit der himmlischen Körper konnte ja recht leicht auch zur Vorstellung ihres bewußten Einflusses auf die irdischen Ereignisse hinüberleiten. Als Mediziner hat er neben der hippokratischen Wissenschaft auch die „spirituelle Medizin“ gepflegt.

Wenn auch von Alfârâbî nicht gesagt werden kann, daß er in den dunklen Regionen der esoterischen Erkenntnisse schwärmt, so hat dennoch auch er zuweilen unbewußt die Grenzen der philosophischen Überlieferung überschritten und gern ein Wort gesprochen, das ihn als Schüler des Plotin, durch Vermittelung der Theologie des Aristoteles, erkennen läßt. Er ist ja Sufi. „Du hast" - so sagt er - „außer den Kleidern, die deinen Körper verhüllen, auch in dir etwas, was dein Wesen verdeckt. Strebe danach, daß der Schleier gehoben werde und du dein wahres Wesen enthüllest, dann kannst du zum Ziel gelangen. Frage dann nicht danach, was du erfährst. Empfindest 
du Schmerz - wehe dir; bleibst du unversehrt - heil dir! Du bist dann in deinem Körper, als ob du nicht in ihm wärest, als ob du dich vielmehr im Gebiet des Himmelreiches befïndest. Du erfährst, was noch kein Auge erschaut, kein Ohr gehört hat und in kein menschliches Herz gedrungen ist. Dort ergreife die Wahrheit als Bündnis für eine Zeit, da sie dir völlig angehören wird." Außer den in der Philosophie unterschiedenen Intellektstadien nimmt er - nicht erst Avicenna - noch einen mystischen "heiligen Geist" an (die abendländischen Scholastiker übersetzen: intellectus sanctus) und erklärt die Gabe der Prophetie mit Hilfe dieser Annahme. Wie die Mystiker operiert er mit den an koranische Ausdrücke anknüpfenden Begriffen „Welt der Kreatur (chalk)“, „Welt des Logos (amr)“. „Der menschliche Geist ist aus der Substanz der Welt des a m r; er nimmt keine Form an, hat keine Bewegung. Er kann das noch nicht und das nicht mehr Bestehende erfassen; er schwebt in der Welt des Himmelreiches, von dort erhält er seine Eindrücke, die sich vom Siegel der Allmacht in ihn einprägen." Mit solchen geheimnisvollen Sprüchen ergänzt auch der strenge Logiker seinen trockenen Schematismus.

Avicenna Viel mehr aber als Alfârâbî hat der im Grunde gesinnungslose, zu sinn(t ro37). lichen wie geistigen Ausschreitungen geneigte A vicenna (Ibn Sînâ, † 1037) neben dem großen Strom seiner philosophischen Summa-Werke (besonders „die Heilung" - al-Schifâ — und dessen Auszug „die Rettung“ — al-Nadschât -), die den Charakter der arabischen Peripatetik ausgeformt haben, kleinere Bächlein von Gelegenheitsschriften fließen lassen, in denen er zeigt, wie neben dem philosophischen System, zu dem er sich bekannte, und das er sich bemühte, mit den Grundlehren der Religion in Einklang zu setzen, eine dessen Gedanken zuwiderlaufende Mystik Platz greifen konnte; wie der Naturkundige, dessen auf die griechische Medizin gegründeter „Kanon“ durch Jahrhunderte als gesetzgebende Autorität der Heilkunde galt, neben seiner exakten Methode auch noch für die Anerkennung superstitiöser Vorstellungen und Bräuche Raum übrig hatte. In einer Einteilung der Wissenschaften ordnet er im Rahmen des Schemas des Aristoteles Disziplinen ein, die nur aus positiv theologischen Gesichtspunkten Bedeutung haben, ja zuweilen geradezu in das Gebiet des Aberglaubens gehören. In die Physik läßt er die Physiognomik, Traumdeutung, Theurgie, Alchimie, natürliche Magik, Talismankunde hinein; in die Metaphysik die Lehre von der höheren und niederen Engelwelt, von Wunder, Offenbarung u. a. Eingang finden. Nur die Mathematik und Logik bleiben unbeschädigt. Die Astrologie, der er wohl als einer konjekturalen Kenntnis formell eine Stelle im Katalog der Wissenschaften einräumt, lehnt er wieder in einer besonderen Schrift ab. Er spricht ferner mit theoretischem Ernst von den physischen Einwirkungen der Seele auf die Objekte der Außenwelt wie z. B. von den Wirkungen des bösen Auges u. a. m. Er verweist auf den Rapport zwischen dem Seelenleben und den Naturkräften, auf die „Geheimnisse der Natur“, durch deren Kenntnis das Verstïndnis für alle diese geheimnisvollen Erscheinungen erschlossen wird. Außer der von 
den Peripatetikern seiner Zeit allgemein anerkannten Sphärenlehre hat er auch das neuplatonische Emanationssystem dargestellt und, den Lauteren ähnlich, in den Buchstaben des Alphabets, ihrer Reihenfolge und ihrem Zahlenwert Symbole der sukzessiven Ausstrahlung der geistigen Substanzen gefunden. Eine Reihe seiner kleineren Schriften hat das kontemplative Leben zum Gegenstand; in denselben huldigt er völlig dem sûfischen Neuplatonismus. In der Erkenntnis der Wahrheiten sei eine höhere Stufe anzustreben, als die durch spekulative Tätigkeit und durch subtile Vernunftabstraktionen erreicht werden kann: die beschauliche Konzentration der Seele auf die Gottesidee. Er stand mit dem hervorragendsten zeitgenössischen Vertreter dieser Weltanschauung (Abu Sa îd Abu-1-Cheir) in fruchtbarem Ideenaustausch und wechselte mit ihm Briefe über die Bedeutung des Gräberkultus. Die Wirkungen der religiösen Ekstase auf Erscheinungen der physischen Welt stellt er unter den Gesichtspunkt seiner mystischen Theorien. Die Aneignung der kontemplativen Erkenntnis hat er auch in einigen Allegorien dargestellt, unter denen der Typus des Hajj ibn Jakzân in literarhistorischer Beziehung der bemerkenswerteste ist, weil er ein Jahrhundert später den Philosophus autodidactus angeregt hat. Auch die allegorische Interpretation von spezifisch islamischen Religionsvorstellungen $(z$. B. der Himmelfahrt Mohammeds) weiß er für seine theosophischen $Z$ wecke $z u$ verwenden und unterscheidet sich darin gar nicht von den echten Neuplatonikern und Sufis, die sich übrigens zuweilen auf ihn als Gesinnungsgenossen berufen. Dabei liebt er es, in seinen Lesern die Ahnung unaussprechbarer esoterischer Geheimnisse hervorzurufen, von Lehren ,die nur angedeutet und nur in verhüllter Weise gelehrt werden dürfen, da ihre Veröffentlichung die Verderbnis der Welt verursachen könnte" - wie er sich z. B. in seiner Abhandlung über das ,.Mysterium der Prädestination" ausdrückt. Man hat so mit vollem Recht von einem philosophischen Doppelspiel des Avicenna gesprochen. Ganz unvermittelt steht seine aristotelische Enzyklopädie neben seinen mystischen Schriften, die wohl, der morgenländischen Weisheit"(al-hikma al-maschrikijja) angehören, auf die er selbst als Ergänzung seiner Philosophie hinweist.

Auf den religiösen Glauben der Massen übte die Philosophie nicht viel Gleichgültigkeit Wirkung. Ihre Vertreter selbst hatten es vom Anfang an nicht darauf ab- der Massen gesehen, die rohen religiösen Begriffe des Volkes zu modifizieren. Auch sopbie. die Formeln, die sie für die Ermöglichung des Aristotelismus neben den Grundlehren des Islams aufstellten, waren ja nicht auf allg emeine Wirkung berechnet, sondern sollten nur zu theoretischer Beruhigung dienen. Während die Mutakallimûn die große Menge in den Kreis ihres räsonnierenden Glaubens einbeziehen, ihr ihre Formeln und Beweisführungen verpflichtend aufdrängen, nehmen die Philosophen dem Volk gegenüber ein€ aristokratische Haltung ein. Mit Vorliebe zitieren und variieren sie einen Satz des Galen, der ,nicht zu allen Leuten reden will, sondern zu einzelnen Auserwählten, deren jeder einzelne Tausende und Zehntausende Leute aus der Menge aufwiegt". „Die Wahrheit" - so schließt er — „hat nicht den Beruf von vielen 
ergriffen, vielmehr nur den, von den Vernünftigen und Hervorragenden verstanden zu werden." Sie sind frei von der aufdringlichen Propaganda der Mutakallimûn, an denen sie nicht nur die Mängel ihrer Denkmethode tadeln, sondern denen sie auch die schädliche Bemühung vorwerfen, mit ihrem Rationalismus die Köpfe unreifer Leute zu verdrehen.

Die Philosophic von Ghazâli

bekämpft.

Die Philosophen waren einsame Leute, die fern vom Getriebe des Marktes den Ideen der Auserwählten der Vergangenheit lebten und sie weiterdachten. Sie hatten weder die Absicht noch den Erfolg, in das dogmatische Wesen des Islams einzugreifen. Nichtsdestoweniger werden sie von Ghazâlî ( der in früheren Zeiten selbst ihre Schulung erfahren, als Feinde der Religion auf die Anklagebank geführt. Ghazâlî läßt diesem Angriff eine objektive Darstellung der peripatetischen Philosophie („Absichten der Philosophen“) vorangehen, um auf diese Grundlage sein kämpfendes Werk aufzubauen, das zusammen mit den Widerlegungen des größten Aristotelikers des Islams, Averroës, der philosophischen Weltliteratur angehört. In seinem „Die Widersprüche der Philosophen "(Tahâfut al-falâsifa) oder wie die Schrift nach dem Titel der hebräischen und lateinischen Übersetzung gewöhnlich genannt wird "Destructio philosophorum", unternimmt er es zunächst, die Mängel der Beweisführung der Aristoteliker für ihre Thesen über Fragen der Metaphysik, Naturlehre und Psychologie dialektisch nachzuweisen. Dabei ist sein $Z$ weck nicht, der abgelehnten Weltanschauung in allen Fällen eine andere, seine eigene, gegenüberzustellen. Seine Absicht ist die bloß negative, die Unzulänglichkeit der gegnerischen Argumente nachzuweisen; das Positive ist ihm hier Nebensache, wenn er sich auch dieser Aufgabe nicht vollends entschlägt. Selbst auf die Unterstützung verzichtet er, die der Religion aus den Gedanken der Philosophen zukommen könnte - Avicenna hatte ja solche Hilfeleistung öfters versucht. "Die Religion" - so sagt er wörtlich - „erfahre größeren Schaden durch jemand, der sie auf fremdem Wege unterstützt, als durch jemand, der sie auf ihrem eigenen Wege angreift.“ Daneben zielt er vielmehr darauf ab, die Schädlichkeit der philosophischen Lehren für den religiösen Glauben zu betonen. Er legt den Finger ganz besonders auf drei dem System der Philosophen notwendig innewohnende Lehrsätze: die Welt sei ewig, nicht in der Zeit erschaffen; Gottes Wissen (und demnach auch seine Vorsehung) erstrecke sich nicht auf die besonderen Momente des Weltgeschehens; die Fortdauer nach dem Tode sei in geistigem Sinne zu verstehen: es gäbe nach ihrer Lehre - und dieser Angriff gegen die Philosophen ist am leichtesten ins Volk gedrungen keine individuelle Unsterblichkeit, nicht leibliche Freuden des Paradieses und nicht materielle Pein der Hölle, nicht körperliche Auferstehung und Weltgericht. Aber damit war ihr Sündenregister bei weitem noch nicht erschöpft. Auf ihr Verhalten gegenüber den „Wundern“ sowie ihre Theorie vom Prophetismus, wonach dieser das Resultat eines bloß psychischen Vorganges sei, bei dem eine unmittelbare Einwirkung Gottes gar nicht in Betracht kommt, wird in diesem Katalog von ketzerischen Lehren nicht be- 
sonderes Gewicht gelegt. Freilich hatte Ibn Sîna für diese Fragen, in seiner Weise, Kompromisse mit den religiösen Anschauungen angebahnt.

Es ist nicht bekannt, daß aus den Reihen der Anhänger der Philosophie im Osten sich eine Stimme zur Abwehr dieses, wahrscheinlich um das Jahr 1095 erfolgten harten Angriffes gegen die Arbeit der Aristoteliker erhoben hätte. Als ob die philosophische Produktivität im Osten vollends erschlafft, und als ob es bloß ein Gnadenstoß gewesen wäre, was ihr der streitbare Verfall der Philosophio im stlicben Islam und Verfolgung der philosophi. Ghazâlî versetzte. Wir begegnen fortan den philosophischen Werken zuweilen auf den Scheiterhaufen, die fromme Kalifen in Bagdad für sie errichten ließen. Aus dem Jahre I 60 erfahren wir, daß die Bibliothek eines in Ungnade gefallenen Kâdî auf Befehl des Kalifen konfisziert wurde und die darin befindliche philosophische Enzyklopädie des Avicenna und die Abhandlungen der Lauteren öffentlich dem Feuer überliefert wurden. Kurz nachher wurde dem Kalifen die philosophische Bibliothek eines Sohnes des berühmten Mystikers 'Abdalkâdir al-Dschîlânî denunziert, und sie wurde auf Grund dieser Anklage ausgeforscht und auf den Scheiterhaufen geworfen. Der fromme Vollstrecker dieses Urteils leitete das auf dem Platze Rahbijja in Bagdad vollzogene Autodafé mit einer Schmährede gegen die Philosophen und ihre Werke ein und gab jedem einzelnen Buche, ehe er es den Flammen übergab, eine lästernde Charakteristik mit auf den Weg. Wir besitzen den Bericht eines Augenzeugen (des Josef b. 'Aknîn, Schülers des Maimûnî) über diesen fanatischen Glaubensakt, der nicht nur philosophische, sondern auch allgemein wissenschaftliche Werke betraf. Das astronomische Werk des Ibn Haitham vorzeigend und auf eine Tabellenfigur deutend sagte der Vollstrecker: „Und dies ist die schändlichste Versuchung, ein stummes Unglück und blindes Verhängnis." Damit warf er das gelehrte Werk ins Feuer. Das war nicht die Atmosphäre, in der es die Jünger der Wissenschaft zur Philosophie hätte hinziehen können. Wir hören nur noch von Widerlegungen der Philosophie und Angriffen gegen sie; wenig hören wir von selbständigen Systematikern; höchstens vertreten noch scholastische Kommentatoren die Fortpflanzung der philosophischen Methode.

Dafür erblüht die Philosophie für kurze Zeit im westlichen Islam, wo Aufschwung der ihr auch fast ein Jahrhundert nach den Angriffen des Ghazâlî ein Rächer Philosopbie im ersteht in Averroës aus Cordova (Ibn Roschd, † 1 198), dem größten arabischen Peripatetiker. In seiner unter dem Namen Destructio destructionis berühmten Apologie der Philosophie weist er den Dilettantismus der Gegner in ihre Schranken zurück. Mit den logischen Defekten der Kalâmmethode könne kein Schritt auf dem Gebiete metaphysischer Fragen unternommen werden. Mit überlegenem Sarkasmus zeiht er Ghazâlî der Oberflächlichkeit und Sophisterei und geizt nicht mit Berveisen dafür, daß „dieser Mann“ für aristotelisch und philosophisch ausgibt, was der vermittelnde Avicenna in die Philosophie eingeführt hatte, und was nicht schlechthin als philosophische Lehre gelten könne.

Die Aufgabe, die sich Averroës in seiner ein ausgedehntes Gebiet der Die Kultur der Gegenwart. I. 5. 2. Aul. 
A ristotelesliteratur umfassenden reichen Tätigkeit als Kommentator gesetzt, bestand eben in dem Zurückgehen darauf, was er für die echte aristutelische Lehre hielt. Er wollte sie von den Trübungen reinigen, die sie ir. der bisherigen Überlieferung der islamischen Peripatetik erlitten hatte. Er verschont dabei die Logik des Alfàrâbî ebensowenig wie die Physik und MetaZurückweisung physik des Avicenna. „Der größte Teil der philosophischen Enzyklopädie früherer
Vermittlungen. Behauptungen zusammengewebt, daß Leute, die in diese Kenntnisse eingeführt werden wollen, am besten tun, jene Bücher zu fliehen; denn sie können den Menschen eher irreführen und der Wahrheit entziehen, als ihn leiten und clem Richtigen zuführen." Vor der Strenge seiner philosophischen Kritik kommt Avicenna kaum besser davon als vor den religiösen Nörgeleien des Ghazâlî. Freilich ist auch er, nicht weniger als seine Vorgänger, in der Aristotelesüberlieferung des Alexander und des Themistius, namentlich des letzteren, befangen. Die beiden Auswüchse des neuplatonischen Aristotelismus, die Sphärenemanation und die Intellekttheorie hat auch er aus seinem System nicht ausgeschaltet; beiden hat er sogar eine feinere Ausbildung verliehen. Die Formulierung der Lehre von den sphärischen Bewegungen und der Zahl der Beweger, die ja bei seinem Aristoteles selbst als nicht unumstößlich hingestellt war, hat er den seitherigen Fortschritten der Astronomie (durch Ptolemäus) angepaßt, einer Wissenschaft, in der er ja selbst kein Laie war; er brachte es bis zur Zahl von 45 Bewegern (separaten Intellekten). Hingegen wendet sich sein Purismus in anderen Fragen gegen die Umdeutungen aristotelischer Lehren in der arabischen Schule. Er verwirft den Versuch, durch die Aufstellung der Kategorie des Relativ-Möglichen die Lehre von der Anfangslosigkeit der Welt abzuschwächen. Alles Entstehen ist Veränderung. Jede Veränderung geschieht an einem Subjekt. Das Subjekt ist die ewige Materie. Und auch eine andere Vermittelungsformel des Avicenna lehnt er entschieden ab. Die Schöpfung sei - wie er dies dem Galen nachspricht - die Verleihung der Formen an die Materie; darin bestehe der Schöpfungsakt. Dies kann Averroës nicht annehmen. Die Form ist kein Neues, was die Materie von außen her erhält; sie sei potentiell in der Materie enthalten, durch ihren Übergang zur Aktualität geschehe keine Neuschöpfung. Er hält die Lehre von der Anfangslosigkeit der Materie in der entschiedensten Form aufrecht. Durchaus abweisend verhält er sich gegen den Einfall des Avicenna, durch Vermittlung der Sphärengeister das Wissen von den BeSeine Auf. sonderheiten (singularia) für die erste Intelligenz zu ermöglichen. Wie er fassung vom gütlichen den Begriff des Willens und der Entschließung von Gott streng fernhält, so lehnt er auch die Frage, ob Gott die Kenntnis der Besonderheiten besitze, mit ebensolcher Entschiedenheit ab, wie die, ob sein Wissen die Universalien zum Gegenstande habe. Die Fragestellung sei nach beiden Seiten hin von vorneherein unzulässig. Sie habe ein Wissen im Sinne des menschlichen Intellekts zur Voraussetzung. Dies sei jedoch ein kausal bedingtes, passives Wissen, während das'Wissen Gottes ein von jenem total verschiedenes, er- 
habeneres sei. Der erste (göttliche) Intellekt als die reinste Aktualität, dessen Sichselbstdenken die Ursache alles Seins sei, schließe die Totalität allen Daseins, als von ihm verursacht, in einheitlicher Weise in sich ein. Und wie sein Wissen ein erhabeneres ist, so ist auch das Sein, auf das es bezogen ist, ein Sein erhabenerer Art als jenes, das den Gegenstand des menschlichen Erkennens bildet. Die Unterscheidung zwischen Singularem und Universalem müsse demnach mit Bezug auf das Wissen Gottes vollends vermieden werden. Als Resultat dieser originellen Erwägung ergibt sich dem Averroës ein voller Einklang mit dem seinem wahren Sinne nach zu erfassenden Koranwort (Sure XXXIV, V. 3): „Es entgeht ihm nicht das Gewicht eines Stäubchens in den Himmeln und auf Erden, noch etwas Kleineres oder Größeres als dies.“ Und wenn wir Gott über die Erkenntnis der Besonderheiten im Sinne des menschlichen Wissens erheben, so sei es nicht Mangel, was wir von ihm aussagen; vielmehr die Anerkennung, daß er über die Mangelhaftigkeit eines unvollkommenen Erkennens hoch erhaben sei.

Mit dieser Auffassung vom Verhältnis des göttlichen Wissens zu allem Seienden kommt Averroës hart an die Linie sûfischer Lehren; und er ist sich dessen bewußt, daß er mit diesem Gedankengang an die Weltauffassung jener Mystiker streift. „Dies ist“ - so schließt er seine Darstellung — „der Sinn des Spruches der Alten: 'der Schöpfer sei die Totalität alles Daseienden'; und in diesem Sinne steigern die sûfischen Lehrer das gewöhnliche islamische Glaubensbekenntnis zu der Formel: 'Es gebe nichts anderes als ihn selbst'. Jedoch dies alles gehört zu den Kenntnissen derer, die festen Fuß im Wissen gefaßt haben, und bildet nicht Gegenstand der religiösen Belehrung. Wer es an unrichtigem Orte feststellt, ist ebenso im Unrecht wie einer, der es Würdigen vorenthält."

Wodurch Averroës den größten Eindruck auf die Philosophie des Mittelalters übte, ist seine Lehre von der Einheit des Intellekts, ferner von der Möglichkeit des materiellen Intellekts, die separaten Formen zu begreifen und mit dem aktiven Intellekt sich zu vereinigen. Was Averroës hierüber lehrte, ist noch vor dem Studium seiner eigenen Schriften durch die heftige Polemik bekannt geworden, welche die Scholastiker, allen zuvor Albertus Magnus und Thomas von Aquino, dagegen führten. Seine Lehre geht darauf hinaus, daß es keinen individuellen Intellekt gebe; es sei derselbe Geist, der in allen Individuen sich offenbart, individuell sei bloß die Teilnahme der letzteren an diesem einheitlichen Geist (Monopsychismus). Nur dieser - wie man nun weiter gedeutet hat - Gesamtgeist der Menschheit sei unsterblich, in seiner Einheitlichkeit und Allgemeinheit ewig fortdauernd. Es könne daher von individueller Fortdauer der Seele, wie sie Avicenna noch ermöglicht, keine Rede sein. Es ist dies die Lehre de unitate intellectus, die von den Anhängern des arabischen Philosophen im Abendland gepflegt, von den kirchlichen Autoritäten bekämpft und wiederholt mit Bann belegt wurde

Wie aber Averroës' Seelenlehre einerseits die Fortdauer der individuellen 
Conjunctio des Seele ausschließt, so schafft er andererseits der geistigen Persönlichkeit hohen

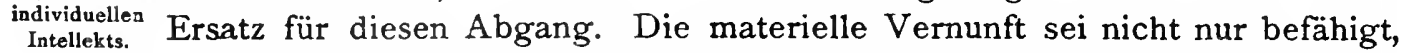
durch die Einstrahlung des tätigen Intellekts die intelligible Kenntnis in sich dauernd $z u$ erzeugen und dadurch sich zum erworbenen Intellekt zu steigern: sondern die wissenschaftliche Vertiefung, die Abstreifung aller unvollkommenen, durch die Einbildungskraft getrübten Formen, die Erhebung zu der reinen Erkenntnis der Begriffe durch Bekämpfung der Sinnlichkeit ermögliche es dem Menschen sogar schon während seines Lebens, die höchste Aktualiràt seines Intellekts $z u$ erreichen, die Vereinigung mit dem tätigen Intellekt. Darin liegt die höchste Glückseligkeit, die der Mensch erstreben kann. Unzweifelhaft wieder ein Sprung ins Mystische. So hat der große arabische Peripatetiker, der sich die Aufgabe gestellt hatte, den Aristotelismus von allem fremden Beiwerk zu reinigen, die ,nach menschlichen Kräften anzustrebende Gottähnlichkeit", die in dieser Schule von jeher als Ziel der Philosophie galt, in der Möglichkeit dieser Vereinigung (conjunctio) gefunden, deren Voraussetzung selbst dem noch tief im Neuplatonismus befangenen Alfârâbî als „eitles Altweibergeschwätz“ galt. In jedem Zeitalter müsse diese Vereinigung an einem oder dem anderen Menschen notwendig zur Wahrheit werden. Denn alles Potentielle muß notwendig zur Tatsächlichkeit werden. So folgt auch aus der Potentialität dieser Vereinigung deren mindestens an einigen Individuen sich bewährende Aktualität. Aristoteles war nach Averroës' Meinung sicherlich ein solcher mit dem tätigen Intellekt völlig vereinigter Menschengeist. Galt er ihm doch als der Mann, an desseq Vollkommenheit in keinem Zeitalter je ein Mensch heranreichte; den die Natur hervorgebracht, um die höchste Stufe menschlicher Vollkommenheit zu vergegenwärtigen.

Man kann kaum einen Unterschied finden zwischen dem durch Averroës dem menschlichen Intellekt gesetzten Hochziel und der neuplatonischen Rückkehr der individuellen Seele zu ihrem himmlischen Ursprung, zur Weltseele. Der Unterschied liegt bloß in der Terminologie und der philosophischen Entwickelung der Begriffe, nicht im Wesen der ausgesteckten Vollkommenheitstufe der Seele.

Vorlänfer des

Averroës hatte damit auch keinen überraschenden Gedanken ausgeAverroës. sprochen. Im Sufismus war die Absorption des individuellen Seins in die göttliche Realität, die völlige Vernichtung der Persönlichkeit durch Askese und kontemplative Versenkung als Gegenstand mystischer Sehnsucht schon längst ausgesprochen und durch Tausende verzückter Schwärmer innerhalb des Islams als höchstes Seelenziel betrachtet. Avicenna hat in seinen mystischen Traktaten wiederholt von der durch Intuition zu erreichenden Vereinigung mit der Gottheit gesprochen und den geistigen Stufengang, der zu ihr führt, gezeichnet. Aber selbst auf dem Boden der reinen Philosophie waren kaum ein halbes Jahrhundert vor Averroës die durch ihn mit großem Gewicht ausgestatteten Gedanken, die er selbst in mehreren Abhandlungen wiederholt auseinandersetzte und auch durch seinen Sohn zusammenfassen 
lieB, bereits verkündet worden. Averroës ist damit nicht originell, sondern der Nachfolger eines anderen Denkers, des Ibn Bâddscha (Avempace, † I 38 in Fez), der sich auch viel um die physikalischen Schriften des Aristoteles bemühte. So wie jener' bereits vor Averroës die Einheit der fortdauernden Seelen ausgesprochen hatte, so hat er auch in seiner "Leitung des Vereinsamten "' mit einem Zug von Polemik gegen jene, die die geistige Erhebung der Menschen von mystischer Erleuchtung erwarten, die stufenweise Vervollkommnung der Vernunfterkenntnis dargelegt und als ihr Ziel die Vereinigung der von den Schlacken der sinnlichen Trübungen gereinigten Seele mit der Welt der reinen Intelligibilität, des Göttlichen, erwiesen. Das Mittel, das dahin führt, sei nicht mystische Schwärmerei, sondern Schärfung der intellektuellen Kraft; das Ziel nicht die das Selbst vernichtende Verzückung, sondern das Sichdurchringen zur höchsten Realität des Geistes.

Es war dies die Zeit, in der im westlichen Islam das Problem der Vereinigung des geistig erhöhten Menschen mit der Welt der reinen Geistigkeit die Denker in hervorragender Weise beschäftigt $z u$ haben scheint. Denn auch ein älterer Zeitgenosse des Averroës, sein Freund und Protektor Abu Bekribn Tufeil aus Guadix ( + I 185 ), Arzt am Hofe der Almohaden, hinter- Ibn Tufeil ließ eine Lösung dieser Frage in Form einer philosophischen Erzählung. Von Avicenna entlehnte er den Namen ihres Helden Hajj b. Jakzân (der Lebende, Sohn des Wachenden), der, ein Vorläufer des Robinson, auf einer verlassenen Insel, fern vom Verkehr der Menschen, von frühester Kindheit an alle Erfahrung und Erkenntnis durch spontane Betrachtung und Reflexion aus sich selbst erzeugt. Daher der Name „Philosophus autodidactus", unter dem er seit dem 17. Jahrhundert seinen Einzug in die Weltliteratur gehalten hat. Auf seine eigenen Beobachtungen angewiesen, von aller Mitteilung abgeschnitten, erkennt Hajj in fortschreitender Selbstbelehrung das Wesen der Natur, steigt er von besonderen zu allgemeinen Begriffen auf, von der Erde zu den Himmeln; er erkennt. die Einheit des ganzen Kosmos und seine Abhängigkeit von der ersten Ursache. Aus der Erkenntnis des Universums lenkt sich sein Geist auf die Prüfung seiner selbst, und er erkennt seine göttliche Natur, die durch die Materie getrübt sich von ihrem Ursprung entfernt hatte. Er findet die Müglichkeit der Einkehr in die Welt der reinen Geistigkeit in der Entäußerung von allem, was den Sinnen und der Einbildungskraft angehört. Stufenweise gelangt er nun durch Askese und Ekstase zu der Vereinigung mit dem Göttlichen, indem er die einzige Realität erkennt, die sich in allem Existierenden, je nach dem Grade seiner Reinheit spiegelt. Für den von der Materie losgelösten Geist verschwindet der Begriff der Vielheit; er erkennt das göttliche Wesen in den Erscheinungen der Alleinheit, zu der er sich selbst erhoben hat. Er erkennt sich selbst als reinen Geist vereint mit der Welt der Unkörperlichkeit, in der ihm die Vision der Gottheit zuteil wird.

Diese Lösung des Problems der Vereinigung wäre allerdings nicht nach dem Geschmack des Ibn Bâddscha gewesen. Sie entspringt „östlicher 
Weisheit". Ihre Vorbilder sind aus der neuplatonischen Literatur leicht nachzuweisen. Und auch Averroës hat ein anderes Bild von der Vereinigung des materiellen mit dem tätigen Intellekt geformt. Aber in eine: schr wichtigen Beziehung hat auch er einen Gedankenweg eingeschlagen, auf dem er dem Ibn Tufeil nahekam. Im Anhang seiner Erzählung läßt dieser seinen Helden auf einer benachbarten Insel mit der religiösen Gesellschaft in Berührung treten und den Versuch unternehmen, ihr seine Weltanschauung beizubringen. Die Vergeblichkeit dieses Versuchs führt ihn bald zur Überzeugung, daß die Philosophie nicht Sache der Massen, und daß es ungebührlich sei, diese in ihren Traditionen zu stören, die sich als Mittel zur Erreichung des sittlichen Lebens bewähren. Philosophie und Religion seien zwei parallele Pfade, die zum selben Ziele führen.

Verbältnis von Philosophie und Religion bei Averroës.

Zweifältige Wabrheit.
Auch Averroës will diese beiden Gebiete streng gegeneinander abgrenzen und das Volk nicht mit Dingen stören, die dessen Horizont überragen. Nicht als ob er Philosophie und Religion als gegeneinander strebende Sphären des intellektuellen Lebens betrachtet hätte, deren äußerliche Annäherung etwa Erfordernis gesellschaftlicher Zweckmäßigkeit sei. Weit entfernt eine solche Gegensätzlichkeit zuzugeben, lehrt er vielmehr die innere Identität der in Philosophie und Religion ausgeprägten Überzeugungen. Sie seien Milchschwestern und bieten in verschiedenen Methoden für verschiedene intellektuelle Reifestufen bestimmte Demonstrationen derselben Wahrheiten. Wem der Weg apodiktischer Beweisführung verschlossen ist, müsse die Wahrheit in ihrer religiösen Form aufnehmen. Das Wissen, das man durch Offenbarung erlangt hat, sei überdies eine Ergänzung der durch die Vernunft zu erlangenden Kenntnisse. Der wahre Philosoph hält es für sündhaft, die Prinzipien der Religion zu bestreiten. Innerhalb der Religionen ist Averroës bereit, dem Islam den Rang hoher Vollkommenheit zuzuerkennen; auch die Unübertrefflichkeit des Korans wird zugestanden. In seinen philosophischen Schriften fehlt es nicht an bekräftigenden Zitaten aus dem Koran, freilich im Sinne philosophischer Anwendung. Im besonderen ist es die erziehende Fähigkeit der Religion, die ihn dazu bestimmt, ihrem lehrenden Beruf Rechte neben der wissenschaftlichen Erkenntnis einzuräumen. Die Religionslehren seien Quellen der Tugenden; wer in ihnen fortschreitet, ist ,in absolutem Sinne" ein Vorzüglicher zu nennen. Averroës fordert sogar die Bestrafung jener, die den traditionellen Überzeugungen der Menschen in den Weg treten.

Darin unterscheidet sich der Philosoph von den Kalâmlehrern. Diese fordern die Ausschließlichkeit ihrer eigenen spekulativen Resultate in der Erfassung der religiösen Erkenntnisse. Aber auch zu den Lösungsversuchen seiner philosophischen Vorgänger, besonders zu Avicenna, steht Averroës in bewußtem Gegensatz. Während jener das Bestreben betätigt, durch Abbiegung der aristotelischen Lehren ihren Widerstreit gegen das Dogma abzuschwächen, lehnt Averroës das Zugeständnis des Widerstreites von vornherein $\mathrm{ab}$ und findet keine Veranlassung $z u$ harmonisierenden Umdeutungen der philosophischen Lehre. Es ist demnach - wie jüngst wieder Léon 
Gauthier aus den Schriften des Averroës nachgewiesen hat - nicht richtig, ihn als den Vater der Theorie von der „zweifältigen Wahrheit“ zu kennzeichnen. Diese ist erst von seinen späteren Anhängern, den Averroïsten, durch Mißverständnis seiner wahren Absicht, an seine Lehre angelehnt worden.

V. Die späteren Schicksale der Philosophie im Islam. Mit Averroës, der größten Gestalt der arabischen Philosophie, ist ihre Geschichte auch im Westen zu Ende. Vom 13. Jahrhundert an hat kein nennenswerter Verfall der Philosophie seit dem r3. JahrDenker die Überlieferung der peripatetischen Philosophie im Islam selbbundert ständig weiterentwickelnd aufgenommen. Nur die Logik wird in Kommentaren und Handbüchern nach dem alten Schema weitergepflegt; selbst die verknöchertsten Schultheologen erkannten in ihr die unentbehrliche Disziplin für ihre spitzfindige Geistesübung. Es hat freilich nicht an frommen Stimmen gefehlt, die auch vor ihr als dem Vorhof des Unglaubens warnten. Doch auch in der Bearbeitung der Ethik sind die aus der Blütezeit der philosophischen Studien ererbten Begriffe in Anwendung geblieben, und sie werden in diesem Sinne in den niemals fehlenden Kompilationen immer von neuem vorgetragen. Die übrigen Teile der Philosophie aber werden in der Literatur nur spärlich gepflegt. Sie haben keine Stelle im höheren Unterricht. Um die alten Quellenschriften, aus denen Avicenna und Averroës geschöpft hatten, kümmert sich kaum jemand mehr. Ihre Handschriften schwinden vollends aus dem Verkehr und sind zumeist nur in ihren hebräischen Übersetzungen erhalten geblieben. Wie wenig Nachfrage nach ihnen im 13 . Jahrhundert zu erwarten war, wird aus einer schwermütigen Betrachtung ersichtlich, zu der diese Zustände den bedeutendsten arabischen Historiker der Philosophie und der exakten Wissenschaften, den hochgebildeten Wesir des Fürstentums Aleppo, D sch a màl al-dīn al-Kiftî ( $\dagger$ I $2+8)$, veranlaßten, dessen Werk (1903) von J. Lippert im arabischen Original veröffentlicht ist. Er erzählt, der christliche Philosoph Jahjâ b. 'Adî († 974), ein Schüler Alfârâbîs und Kommentator aristotelischer Schriften im ro. Jahrhundert, habe einmal aus dem Nachlaß eines Christen die Kommentare des Alexander zu der Auscultatio physica und der Apodeiktika um 120 Dinare erstehen wollen; als er den Kaufpreis überbrachte, habe er die Schriften nicht mehr vorgefunden, da sie inzwischen an einen Mann aus Chorasan um 3000 Dinare abgegeben waren. Auszüge aus der Sophistik, Rhetorik und Poetik hätte er um 50 Dinare nicht erlangen können. „So viel Wert legten die Menschen in jenen Zeiten auf die Erwerbung der Wissenschaften; bei Gott, würde man heute soiche Bücher denen anbieten, die mit diesen Wissenschaften großtun, sie würden sie nicht des hundertsten Teiles jenes Preises für wert halten.“

Mehr Glück hatte der Kalâm, dessen theologische Lehrstücke in ihrer Fortdauer des asch'aritischen Formulierung von der Orthodoxie rezipiert wurden, und deren Kalâm. man sowohl für eine tiefere Interpretation des Korans als auch in der Polemik der Sekten bedurfte.

In diesem Zusammenhang hat man auch die alten ontologischen und 
metaphysischen Fragen immer wieder verhandelt. Die beiden bedeutendsten Kalâmtheologen der nachghazâlischen Zeit waren sunnitischerseits der große

Fachr al-dîn al-Râzî (t I209).

Nasîr al-dîn al-Tûsi (t 1273 ). Korankommentator Fach r al-dîn al-Râzî in Herât († I 209), der außer seinen Kalâmwerken auch gegen die Theorien der Philosophen (Avicennas Erkenntnistheorie) polemisch wirkte; schi' itischerseits der als Mathematiker und Astronom berühmte Nasîr al-dîn al-Tûsî († I 273), Erbauer der Sternwarte in Merâgha. Beide haben es zustande gebracht, einen Synkretismus zwischen Kalâm und aristotelischer Philosophie zu schaffen, indem sie aus dem System der letzteren alles ausschieden, was sie in den Verruf der Religionswidrigkeit gebracht hatte. Sie gaben jedoch nicht dieselben Lösungen der behandelten Fragen; es ist nicht wenig interessant, aus den Glossen des Tûsî zu einem kurzen Kompendium des Fachr al-dîn (al-muhassal) die Unterscheidungspunkte der beiden Richtungen nebeneinander kennen zu lernen. In dieser Kompromiß-Philosophie kann von der Ewigkeit der Welt, von der geistigen Umdeutung des koranischen Paradieses und der Hölle, von einer Bemäkelung der auf das Individuelle sich erstreckenden Allwissenheit und Vorsehung der „ersten Ursache“ keine Rede sein. In der spekulativen Begründung des Gegenteils leisten ihnen die Resultate, die das Kalâmstudium durch ein halbes Jahrtausend aufgespeichert hatte, die besten Dienste.

In dieser orthodoxen Philosophie klingt der Aristotelismus im Islam aus. Und mit jenen beiden Religionsphilosophen gelangt auch der Kalâm auf seinen Höhepunkt. Das Werk des Tûsî ist Textbuch für eine ganze Literatur von Kommentaren, Superkommentaren und Glossen. Seit dem I 3. Jahrhundert ist ausschließlich der Kalâm die aktuelle Philosophie des Islams. Er hat auch in dem höheren theologischen Unterricht (als 'ilm usûl al-dîn d. h. Wissenschaft von den Wurzeln der Religion) bis zum heutigen Tage seine Stelle behalten, sich jedoch seither von den für die eigentlicne Theologie indifferenten Fragen immer mehr und mehr losgelöst.

Die alten Stoffe des Kalâm sind in größerer Fülle in der mu'tazilitischen Schule Gegenstand der Verhandlung geblieben. Es ist eine falsche literaturgeschichtliche Anschauung, daß die mu'tazilitische Schule seit dem Siege Mutazilitischer der Richtung des Asch'ari vollends verfallen sei. Sie lebt vielmehr unter
Standpunkt der den schi'itischen Religionsphilosophen bis zum heutigen Tage weiter fort;
schitischen schi'tischen Dogmatik. sie herrscht beispielsweise - wie die in neuerer Zeit in großer Anzahl nach Europa (besonders Berlin und Mailand) gelangten Handschriften bezeugen in der Theologie der Zeiditen in Südarabien. Das lebendige Interesse für sie unter den Schi'iten in Persien und Indien wird durch den hohen Umfang bewiesen, in dem mu'tazilitische Werke und Kommentare die lithographischen Pressen dieser Länder beschäftigen.

Von einer Fortentwickelung der Philosophie im Islam kann jedoch seit ihrer Festlegung im 13. Jahrhundert trotz der Fülle des erzeugten Schrifttums an selbständigen Schriften sowie Kommentar- und Glossenwerken nicht die Rede sein. Die Epigonen klügeln unablässig an den Formeln der früheren produktiven Generationen und verschlingen sie in die Wirrnis ihrer 
oft sehr unklaren Spitzfindigkeit, ohne das Denken wesentlich in neue Bahnen $z u$ lenken, die Erwerbungen der Vergangenheit auch innerlich zu bereichern oder aus neueren wertvollen Gesichtspunkten zu beleuchten.

Der Einfluß der europäischen Bildung auf einige Länder des Orients hat Einflus earopädiesen theoretisch-philosophische Anregungen nicht zugeführt. Es sind zuscher Bildung. meist Naturwissenschaften, Medizin und technische Kenntnisse, deren europäische Methoden und Resultate aus dem Gesichtspunkte der praktischen Nutzbarkeit Eingang in den Kreis der modernen orientalischen Kultur gefunden haben. Wie sie von der großen Vergangenheit selbst ihrer eigenen philosophischen Literatur nur eine ganz verschwommene Vorstellung bewahrt haben, sind die europäischen großen Philosophen auch den Gebildetsten nur in oberflächlicher Weise bekannt geworden. Tieferes Interesse bekunden sie zumeist für die soziologischen Fragen. In ihrer jetzt in übersprudelndem Maße erzeugten Literatur von populär-wissenschaftlichen Zeitschriften tritt uns zwar sehr häufig Berufung auf Schriften moderner Denker entgegen; von einer organischen Verarbeitung der Philosophie ist jedoch vorerst kaum etwas zu merken. Reaktion gegen die materialistischen Richtungen in der europäischen Philosophie bekundete sich (1885) in einer in Urdusprache, dann auch persisch und arabisch erschienenen und seinerzeit in islamischen Kreisen vielverbreiteten Flugschrift des bekannten Agitators Dschemâladdîn a1Afghānī († I 897), eines der Begründer des panislamischen Gedankens.

Die emsigen Druckerpressen in den großen Städten des Islams liefern nur sehr selten Dokumente der älteren philosophischen Literatur. Zu den Ausnahmen gehören zuerst eine in Konstantinopel erschienene und von Mehren als Grundlage für seine Avicennastudien benutzte Sammlung von Abhandlungen, denen erst jüngst ( $19 \mathrm{II})$ wieder Ausgaben kleinerer Traktate des Philosophen gefolgt sind. Wegen ihres harmlosen, zum Teil auch theosophischen Inhaltes hatten sie nicht zu befürchten, Ansto $B$ in der offiziellen Ulemâwelt zu erregen. Auch die Destructio des Ghazâlî mit der Gegenschrift des Averroës (Kairo, 1884/5), ferner ein Nachdruck der von Markus Josef Müller veranstalteten Ausgabe der kleinen Abhandlungen des Averroës über "Theologie und Philosophie" (1895) sind den gebildeten islamischen Kreisen durch Druckausgaben zugänglich gemacht worden. Weniger Bedenken empfand man von jeher vor der Veröffentlichung sufischer Literatur. Ihr steht die starre Orthodoxie eher mit verständnisloser Scheu als mit abweisender Feindseligkeit gegenüber.

Hingegen wurde in Kairo der Druck der Abhandlungen der Lauteren, der mit einem Bande seinen Anfang nahm (1889), wie man sagt, aus orthodoxen Bedenken unterbrochen. Freilich sind wir dafür durch eine komplette Ausgabe ( 4 Bände) in Indien (Bombay) entschädigt worden.

Als wahre Überraschung konnte allerdings die Ausgabe eines Teiles des arabischen Originals von Averroës' Epitome der Metaphysik gelten, die ein für die ältere Literatur eifrig begeisterter Damaszener, Mustapha al-Kabbânî in Kairo (1903) veröffentlicht hat. 


\section{B. Die judische Philosophie.}

Einwirkung der arabischen Philosophie au das Judentum.

Rationalistische Bewegungen. Mu'taziliten. Mutakallimûn.
I. Kalâm in der jüdischen Literatur. Die philosophische Literatur der Araber hat einen mächtigen unmittelbaren Einfluß geübt auf die Entwickelung der Philosophie bei den mittelalterlichen Juden. Seit seinem Eintritt in den arabischen Kulturkreis reflektieren sich im Judentum alle geistigen Bewegungen, die sich in der islamischen Welt kundgeben. Die drei philosophischen Richtungen, die wir bei unserer Darstellung der islamischen Philoso 'hie zu kennzeichnen hatten, weisen bald nach ihrem Entstehen sehr hervorragende Vertreter auch im Judentum auf.

Rationalistische und sektiererische Kundgebungen innerhalb des persischen Judentums haben schon vom 8. Jahrhundert an das Fundament der traditionellen Lehren zu erschüttern gewagt. Im neunten schritt der kühne Kritiker Hajjûjah aus Balch in seinen 200 Einwendungen sogar bis zur Bemänglung der Bibel vor. Der Anschluf an die in ihrer Umgebung entstandenen philosophischen Methoden sollte nun mäßigend und regelnd eingreifen und die religiöse Überlieferung dem Sinne der Denkgläubigen nahebringen.

Bereits zu Beginn des ro. Jahrhunderts findet der mu'tazilitische Kalâm einen berufenen jüdischen Vertreter in Dâwâd b. Merwân ibn al-Mukammis, dessen „Zwanzig Abhandlungen“ jetzt durch die Entdeckung Harkavys immer mehr bekannt werden. Mit Unrecht nehmen ihn, dessen Karaiten. konfessioneller Charakter manches Rätsel bietet, die Karäer für sich in Anspruch. Im Kreise der letzteren haben innerbalb des Judentums die mu'tazilitischen Doktrinen die entschiedenste Anwendung gefunden. In Josef a 1 Basîr (erste Hälfte des 1. Jahrhunderts) und in A bu-1-Faradsch Furkân b. Asad, mit seinem hebräischen Namen Jeschû'ah b. Jehûdah (Mitte des II. Jahrhunderts) weist die karaïtische Gemeinde bedeutende Vertreter der mu'tazilitischen Denkweise aus der Zeit ihrer Blüte auf. Sie verhandeln dieselben ontologischen, ethischen und religionsphilosophischen Probleme, die den alten Kalâm beschäftigen.

In rabbinischen Judentum ist der Kalâm in dieser Zeit durch den Gâôn Sa'adjah b. Joseph $\left(† 94^{2}\right)$ vertreten, dessen wichtigstes durch S. Landauer im arabischen Original herausgegebenes Werk in der Hauptsache die Anpassung der mu'tazilitischen Religionsphilosophie an die Tradition des Judentums darstellt. Ungleich den karaïtischen Vertretern der dogmatischen Spekulation, die ihren islamischen Vorbildern mit großer Treue folgen und z. B. auch die Atomenlehre innerhalb ihres Systems zur Geltung bringen, hat sich jedoch Sa'adjah mehr individuelle Freiheit in der Aneignung der Kalâmmethode bewahrt. Er weist die Atomenlehre zurück, lehnt hingegen aristotelische und platonische Einwirkunger nicht vollends ab.

Der Rationalismus, der währen`̇ der gâônischen Periode in der jüdischen Theologie vorherrscht (Samuel b. Chofnî) und sich in der vernunftgemäßen Auslegung der Heiligen Schrift und in der Abweisung abergläubiger Vorstellungen bekundet, ist als Folge des Einflusses mu'tazilitischer Denkweise zu erklären, die sich von Mesopotamien aus, wo sie zuallererst hervortritt, bis nach Nord- 
afrika verbreitet. Der Kairawâner Theologe R. Nissim b. Jakob (erste Hälfte des i r. Jahrhunderts) hat in der Vorrede seines unter dem Titel „Clavis talmudica" von Jakob Goldenthal (Wien, 18+7) herausgegebenen talmudischen Werkes ein Glaubensbekenntnis im Sinne der mu'tazilitischen Lehre abgelegt und in demselben Buche sowie in anderen Werken auch sonst dieselben Anschauungen namentlich über die Attributenlehre, über den Begriff der göttlichen Gerechtigkeit hervortreten lassen.

II. Neuplatonische Einflüsse. Sehr rasch fand die neuplatonische Neuplatoniker. Philosophie Eingang in den Kreis jüdischer Denker. Es ist schon gesagt worden, daß im Io. Jahrhundert, ebenfalls in Kairawân, der Arzt Isak Isrâêli, sonst kein konsequenter Anhänger dieser Richtung, starke neuplatonische Beeinflussung merken läßt und im 11. Jahrhundert der jüdische Dichter Salomo b. Gebîrol (Avencebron) der hervorragendste Förderer des Neuplatonismus in arabischer Sprache ist, nicht nur in seiner von aller konfessionellen Beziehung unabhängigen "Lebensquelle‘, sondern auch in seinen Bibelerklärungen, soweit uns Fragmente aus diesen erhaiten sind. In denselben Kreis gehört auch eine auf Grund unbestimmter Indizien für das 11.-12. Jahrhundert in Anspruch genommene, in einem Unikum der Pariser Nationalbibliothek erhaltene arabische Schrift eines unbekannten Verfassers (Pseudo-Bechaji), der mit starker Benutzung der Schriften der Lauteren und anderer diesem Kreise angehöriger Werke (z. B. der an den Namen des Hermes Trismegistos geknüpften „Zurechtweisung der Seele“) unter dem Titel „Wesen der Seele“ (ma'ânî al-nafs) die Theorien der neuplatonischen Seelenlehre an das Alte Testament und an talmudische Sprüche anlehnt. Im I 2. Jahrhundert pflegen Josef b. Saddîk († I I 99) aus Cordova mit seinem "Mikrokosmos", der Mathematiker und Astronom Abraham b. Chijja (Savasorda) aus Barcelona († ca. 1 136) mit seiner „Betrachtung der Seele“, der Bußdichter Moses b. Ezra aus Granada († I 39 ) mit seinem „Gewürzbeet", der große Bibelerklärer Abraham b. Ezra aus Toledo $\left(t_{1}{ }^{6} 67\right)$ in selbständigen Schriften und in exegetischen Werken den Ideenkreis eines jüdischen Neuplatonismus. Um dieselbe Zeit steht auch Bechaji b. Josef b. Pakuda in Saragossa, in dessen Gotteslehre die Gesichtspunkte und die Methode des Kalâm überwiegen, in der asketischen Ethik seiner „Herzenspflichten" und mit seinen Vorstellungen vom Ursprung der Menschenseele unter dem Einfluß neuplatonischer (sûfischer) Anschauungen.

Es ist nicht nebensächlich, daß es eben Spanien ist, wo diese Richtung des Geistes eine reiche literarische Entfaltung erfährt. Sie ist aber nicht auf diesen Kreis beschränkt. Denn selbst aus dem südarabischen Judentum ist aus dem 12. Jahrhundert ein neuplatonisches Werk in arabischer Sprache von Nathan äl al-Fajjû mî unter dem Titel „Garten der Intellekte“(bustân al'ukûl) erhalten, das ein eingehendes Studium der muslimischen Neuplatoniker bekundet. Im allgemeinen kann das hohe Interesse der jüdischen Literatur an diesem $\mathrm{Zweige}$ der hellenistischen Philosophie nicht übersehen werden. Es 
offenbart sich in den häufigen hebräischen Übersetzungen arabischer Werke dieser Schule und in dem Einfluß, den sie - wie 2 . B. die Übersetzung der

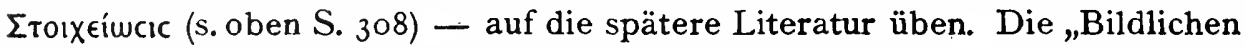
Kreise" des Ibn al-Sîd a1-Bataljûsî (aus Badajoz, † I 127 in Valencia) sind außer ihrer hebräischen Übersetzung (herausgegeben von D. Kaufmann I 880) auch in hebräischer Transkription des arabischen Urtextes erhalten; während wir eine pseudo-empedokleische Schrift über „die Fünf Substanzen“ (Kaufmann I 899) nach Verlust des Originals nur noch in hebräischer Übersetzung besitzen.

Seither ist die allegorische Schriftauslegung eine geeignete Gelegenheit zur Bewährung neuplatonischer Gesichtspunkte geblieben, die bis zur jüngsten Schicht der jüdisch-arabischen Schrifterklärung zur Geltung kommen. In selbständiger Form hat sich der jüdische Neuplatonismus seit dem 12 . JahrKabbâlah; hundert zur Kabbálah entwickelt, deren leitender Gedanke hauptsächlich die Emanationslehre ist. Sie entwickelt sich abseits von der aristotelischen Philosophie, die seit dem 12. Jahrhundert großen Einfluß auf die jüdischen Denker übt, und gegen deren rationalistische Bestrebungen und Ziele der kabbalistische Mystizismus eine Gegenströmung bildet. Ihr wichtigstes literarisches Denkmal ist der Zóhar (Glanz), ein dem Mischnahlehrer R. Simon b. Jochai zugeschriebenes Pseudepigraphon aus dem 13. Jahrhundert (verfaßt von Mose de Leon, + 1305), dessen Gedanken ohne Zweifel auf ältere Überlieferungen zurückgehen.

Opposition gegen die Philosophio.

Jehudah ha-Lêwi $(t \times 140)$.

III. Aristotelische Philosophie. Die aristotelische Richtung der Philosophie bürgerte sich seit dem I2. Jahrhundert in den Gedankenkreis der jüdischen Wissenschaft ein, aus dem sie die Methode des Kalâm vollends verdrängt. Noch ehe sie jedoch in demselben Geist, wie sie von den muslimischen Vorbildern gepflegt ward, zu bestimmter literarischer Ausprägung gelangte, ward ihr von dem frommen Dichter Jehûdah ha-Lêwi aus Toledo ( I $_{1}$ 140) der Krieg erklärt. Ihre Berechtigung, zu den religiösen Überlieferungen in ein regelndes Verhältnis zu treten, wird ihr in dem apologetischen Werke al-Chazarî bestritten, das in dialogischer Form die Besprechungen des nach religiöser Wahrheit suchenden Chazarenkönigs mit einem jüdischen Gottesgelehrten darstellt. Mit großer Entschiedenheit läßt der Verfasser den Rabbi die Mängel und die Unzulänglichkeit der Philosophie darlegen. Durch D. Kaufmanns Nachweisungen ist es festgestelit, daß der Grundgedanke dieses Werkes auf Anregungen zurückzuführen ist, die der Verfasser aus Ghazâlîs Bekämpfung der Philosophie (bben S. 320) geschöpft hatte. Jehûdah ha-Lêwi schließt die Vernunft aus dem Gebiete der Kriterien religiöser Erkenntnis aus. Das religiöse Bekenntnis sei ausschließlich auf die historisch bezeugten Religionstatsachen, auf die Überlieferungen des jüdischen Volkes und auf inneres Seelenerlebnis gegründet. Aus dem Gesichtspunkt der religiösen Ziele stellt er - wieder mit Ghazâlî — die philosophische Ergründung metaphysischer Erkenntnisse als völlig nutzlos und hinderlich hin: intuitives Innewerden der Gottheit und gemütsinnige Gemeinschaft mit ihr sei anzustreben. 
Nichtsdestoweniger hat er sich mit einzelnen Fragen der Dogmatik (Attributenlehre, Willensfreiheit) in positiv-theoretischer Weise auseinandergesetzt und dabei, jedoch ohne festen Anschluß an ein bestimmtes System, die Wege des Kalâm und der Philosophie beschritten. Auch dem Neuplatonismus konnte er nicht aus dem Wege gehen. Wenn er auch mit aller Philosophie auch die Emanationkonstruktion grundsätzlich abzulehnen scheint, steht er dennoch in seinen Grundanschauungen unter starkem Einfluß derselben; ein entscheidender Gedanke seines Werkes, die Einwirkung des göttlichen Logos (amr ilâhî) auf den erwählten Teil der Menschheit, ist aus der Emanationslehre erwachsen.

Das älteste Produkt der aristotelischen Philosophie in der jüdisch-ara- Abraham ibn bischen Literatur ist der „Erhabene Glaube“ von Abraham ibn Dâud aus Toledo ( $f$ 1 180$)$. Mit dem Ziele, die philosophische Anschauung von der Willensfreiheit mit den religiösen Lehren in vollen Einklang zu bringen sendet er dieser Untersuchung ein Kompendium der wichtigsten Kapitel des arabischen Aristotelismus voraus, wie er zu seiner Zeit zuletzt durch Avicenna formuliert war. Von einer Darstellung der Grundbegriffe der Physik und Metaphysik (einschließlich der Seelenlehre) geht er auf die philosophische Entwickelung der Glaubenslehren: Gottesidee, Prophetie, Willensfreiheit über. Die Grundlehren der Philosophie werden unter dem Gesichtspunkt des religiösen Glaubens in Betracht gezogen. Immer kommt es ihm auch hauptsächlich darauf an, die Übereinstimmung jener Theorien mit der Heiligen Schrift nachzuweisen, die nach seiner Ansicht ein volksgemäßer Ausdruck der philosophischen Wahrheiten ist. Selbst die Kategorienlehre des Aristoteles findet er im I39. Psalm angedeutet. Wie Sa'adjah eine religiöse Philosophie auf Grundlage des Kalâm aufgebaut hatte, so wollte Abraham ibn Dâud die Möglichkeit der Darstellung der Religionswahrheiten auf aristotelischem Grunde demonstrieren; den Denkgläubigen ein Mittel bieten, ihr religiöses Bewußtsein durch die gleichzeitige Erfassung der philosophischen Wahrheiten zu stärken. Er ist darin aber, namentlich in der Schöpfungslehre und den ethischen Gedanken, nicht immer in der Lage, auf platonische Hilfe zu verzichten.

Der „Erhabene Glaube“, dessen arabisches Original verloren ist, war eine wackere Vorarbeit für das Werk, das, dieselben Aufgaben in umfassender Weise lösend, den Höhepunkt der aristotelischen Religionsphilosophie im Judentum darstellt: für die "Wegweisung der Unschlüssigen" des großen jüdischen Aristotelikers Mose b. Maimûn (Maimonides, I $_{124}$ ), der auch in anderen kleineren Schriften, namentlich den "acht Kapiteln" sich als treuer Anhänger der aristotelischen Philosophie in der Seelenlehre und Ethik erwiesen hatte. Charakteristisch für ihn ist sein konsequenter Kampf gegen die Mutakallimun, ihre Methode und ihre Lehrsätze. Die Darstellung ihrer Prinzipien und die Polemik gegen sie nimmt eine so hervorragende Stelle in seinem Werke ein, daß lange Zeit, ehe ihre Schriften selbst besser zugänglich wurden, die betreffenden Abschnitte Maimûnîs als die hauptsächlichste Quelle für die Kenntnis ihrer Ansichten und ihrer Methode galten. Er unternimmt es, die wichtigsten Lehrpunkte der Religion, für deren Demon- 
stration er die Methode der Mutakallimûn als vollends unzulänglich erweist, auf Grund der aristotelischen Wahrheiten (die er in 25 Propositionen zusammenfaßt) darzutun und so den Einklang der Religion mit den Lehren der Philosophie den „Unschlüssigen“ gegenüber herzustellen. Besonderes Gewicht legt er außer der Einzigkeit auf die Immaterialität der ersten Ursache, Gottes, die er in strenger Weise gegen alle populären Vorstellungen, die ihm dem Atheismus gleichkommen, als einzig mögliche Form der Gottesvorstellung selbst den breitesten Massen beibringen will. In seiner Schrifterklärung befolgt er, in bezug auf anthropomorphistische und materialistische Textworte, die von den Mu'taziliten auf ähnliche Schwierigkeiten des Korans und der Tradition angewandte Methode der vergeistigenden Auslegung (ta'wîl), durch deren methodische Durchführung ihm oft Meisterstücke philosophischer Exegese gelingen. Aristoteles gilt ihm als „der Fürst der Philosophen“. Freilich hat auch er, da er die peripatetischen Lehren auf Grund der Kommentatoren und seiner arabischen Vorgänger aufgenommen hat, dem Aristoteles manches ihm nicht Zugehörige nachgesagt. Trotz seines Bestrebens, mit dem arabischen Aristotelismus immer in Einklang zu sein, und trotzdem er sein Weltbild möglichst nach dessen Anschauungen entwirft, kommt er mit ihm nicht bei allen religiösen Grundlehren durch. Aristoteles sei ihm eine Autorität für alles Sublunarische, in bezug auf die supralunaren Dinge müsse er sich von ihm trennen. Besonders zwei Fragen sind es, in denen er den von den Aristotelikern festgehaltenen Lehrsätzen widerspricht. Er hält die Lehre von der Ewigkeit der Welt mit Galen für eine offene Frage der Philosophie; die aristotelische These sei philosophisch nicht bewiesen; er hält darum fest an dem Gedanken der Schöpfung aus Nichts als einer grundlegenden Lehre der prophetischen Tradition, für die sich wohl nicht zwingende philosophische Beweise, aber jedenfalls doch der Berücksichtigung werte Argumente beibringen lassen. Dann trennt er sich von den Aristotelikern auch in ihrer Ablehnung des auf das Besondere sich erstreckenden göttlichen Wissens und Vorsehens. Von dieser Negation schließt er das menschliche Geschlecht aus, dessen Individuen an der göttlichen Vorsehung nach Maßgabe ihrer intellektuellen Würdigkeit teilhaben. Mit diesen Einschränkungen der aristotelischen Lehrsätze hat er jedoch die Anhänger des traditionellen Glaubens nicht befriedigen können. Andere Religionsvorstellungen hat er rücksichtslos mit den bei den Philosophen des Islams gangbaren Auffassungen ausgeglichen. Die Fortdauer der Seele und die Seligkeit der Frommen faßt er in rein geistigem Sinne auf; sie bezieht sich auf den von den intelligibeln Begriffen gebildeten voûc éríkтптoc; die niedrigen Seelenformen seien vergänglich wie die Körper. Von der Annahme der Einheit der fortdauernden Seelen hat er durch Ibn Bâddscha Kenntnis, ohne sich aber dieser Anschauung anzuschließen. Desselben Philosophen Auseinandersetzung über die Vereinigung der individuellen Seele mit der intelligibeln Welt scheint ihn beeinflußt zu haben, wenn er diese Vereinigung (ittihâd) auf die Patriarchen und Moses anwendet. Eine Theorie des Prophetismus (wobei er jedoch Moses eine Ausnahmestellung 
einnehmen läßt) und der verschiedenen Vollkommenheitsstufen dieser Seelengabe hat er auf Grund der bereits von Alfârâbî niedergelegten Auffassung (Mitwirkung der Einbildungskraft und des Intellekts) entwickelt und an die Worte der religiösen Texte angelehnt. Seine philosophischen Religionsanschauungen stellt er als dogmatische Resultate an die Spitze seiner Gesetzkodifikation (Mischneh Tôrah).

Maimûnî hat die Werke seines maghrebinischen Zeitgenossen Averroës noch nicht gekannt, als er sein philosophisches Werk in Ägypten schrieb. Erst an seinen Nachfolgern im Abendlande hat sich die Wirkung des Averroïsmus bewährt; besonders an dem auch als Astronom berühmten Lêwi b. Gerson (Magister Leo Hebraeus) aus Bagnols († I 344) (verf. „Gotteskämpfe“), der auch in seinen Aristoteleskommentaren sich treu an Averroës anschließt. In der Ausgleichung der religiösen mit den peripatetischen Lehren geht er weit über Maimûnî hinaus und findet z. B. die Annahme einer Urmaterie mit der biblischen Schöpfungslehre für vereinbar. In die Reihe dieser jüdischen Averroïsten gehört auch Moses b. Josua Narboni, genannt Maestro Vidal († I 362), Kommentator des Werkes Maimûnis, der auch einige Traktate des Averroës in tiefgehenden Kommentaren bearbeitet und durch seine philosophische Unabhängigkeit bei den Vermittlern viel Anstoß erregt hat.

Mit dem Spanier Chasdai Crescas ( $t$ nach 1410; verf. „Das Licht Adônai's") beginnt, eine Nachwirkung der Ideen Ghazâlî's, die Reaktion der jüdischen Religionsphilosophie gegen die aristotelische Grundlage, auf de: sich ihre hervorragenden Vertreter bis nun bewegt hatten. Die Werke dieser nachmaimunischen Denker sind in hebräischer Sprache abgefaßt.

Sehr bedeutenden Einfluß haben spanische und südfranzösische Juden Übersetzertätigauf die Verbreitung der Schriften der arabischen Philosophen durch deren $\begin{aligned} & \text { keit der Juden. } \\ & \text { Ibinfub auf }\end{aligned}$ Übersetzung ins Hebräische geübt. Außer der mit dem 12. Jahrhundert be- die christliche ginnenden Tätigkeit in der Übersetzung der in arabischer Sprache abgefaßten Werke der bisher genannten jüdischen Philosophen bis Maimûnî, wobei die Familie der Tibbôn aus Lunel durch drei Generationen eifrige Arbeit entfaltete, haben sie auch rom 12.-15. Jahrhundert die Kenntnis der peripatetischen Philosophie durch Übersetzung und Kommentierung der Werke der arabischen Philosophen gefördert. Eine große Anzahl der seit lange im Original verlorenen Werke auch dieser Literatur sind nur durch die hebräischen Übersetzungen bekannt geblieben, sowie auch die lateinischen Übersetzungen der meisten dieser Bücher auf die hebräischen Übertragungen gegründet sind, die die Einwirkung der arabischen Philosophie auf die scholastische Literatur des Mittelalters vermittelt haben. Den ganzen Umfang dieser Arbeiten hat Moritz Steinschneider nach vielen Monographien in seinem monumentalen Werke „Die hebräischen Übersetzungen des Mittelalters und die Juden als Dolmetscher" (Berlin I 893) im einzelnen dargestellt. Der Einfluß der jüdischen Philosophen (besonders Isak Isrâêli, Avencebron, Maimûnî) auf die christliche Scholastik ist des näheren von M. Joel und Jacob Guttmann nachgewiesen worden. 


\section{Literatur.}

A. Die islamische Philosophie.

Das neueste Handbuch für die Geschichte dieser Philosophie ist: T. J. DE BOERS Geschichte der Philosophie im Islam (Stuttgart, I9OI), englische Übersetzung von EDwaRD R. JONES (London, 1903). - Über die Arbeit der Araber auf dem Gebiete der Logik, C. PrantL, Gesch. d. Logik im Abendlande II. Bd. (Leipzig I86I) S. 297-396.

S. 302. Kalam: M. Th. HouTsMA, De strijd over het dogma in den Islam tot op el-Asch'ari (Leiden, 1875); M. SCHREINER, Zur Geschichte des Asch'aritentums (Leiden, 1890); M. Horten, Die philosophischen Systeme der spekulativen Theologie im Islam (Bonn, 1912); I. GoldzIHER, Vorlesungen über den Islam (Heidelberg 1910) Ill. Abschnitt. S. HoROVITZ, Über den Einflub der griech. Philosophie auf die Entwicklung des Kalâm (Breslau, I909). - Uber indische Berührungspunkte M. HORTEN, Indische Gedanken in der islamischen Philosophie (Vierteljahrschrift für wiss. Philosophie und Soziologie XXIV Bd. I9I I).

S. 309. Die Enzyklopädie der Lauteren ist in deutscher Sprache in einer Reihe von Publikationen F. Dietericis (Die Philosophie der Araber im 10. Jahrhundert n. Chr., 8 Bde. [Leipzig, 1865-79]) bearbeitet worden. Über den Ursprung ilırer Benennung als ichwân al-safâ „Der Islam" I S. $22 \mathrm{ff}$.

S. $31 \mathrm{I}$. Ibn Gebirol: vgl. M. WitTManN, Zur Stellung Avencebrols im Entwicklungsgang der arabischen Philosophie (Beitr. zur Gesch. d. Philos. d. Mittelalters, Bd. V, Heft I [Münster, 1905]).

S. 312. Uber Safismus: ThOLUCK, Ssufismus sive Theosophia Persarum pantheistica (Berlin, 1821); ADALBERT MERX, Idee und Grundlinien einer allgemeinen Geschichte der Mystik (Heidelberg, 1893); Einleitung und Anmerkungen zu Selected Poems from the Diwāni Shamsi Tabriz ed. R. A. Nicholson (Cambridge, 1898); desselben Abhandlung The Origin and developement of Sufism (in Journ. of the R. Asiat. Society 1906). I. GoldzIHER, Vorlesungen, IV. Abschn. - D. H. WrinfIELD, Masnavi-i.Ma'navi, the spiritual couplets of Maulána Jalálu.'dín Rúmi (London 1887), ferner Einleitung zu „Lawâ'ih“ des Dschâmî: „On the influence of Greek philosophy upon Sufism" (London, 1906). C. E. WiLson, The Masnavi... Book Il (2 Bde., Übersetzung u. Kommentar, London 1910). - R. A. Nicholson, The Kashf al-Mahjūb, the eldest Persian treatise on Sûfiism by ... al-Hujwiri, translated (Leiden.London I9II). M. Horren, Die Philosophie der Erleuchtung nach Suhrawardi (Halle I912).

S. 314-319. T. J. DE BOER, Zu Kindi und seiner Schule (Arch. f. Gesch. d. Philos. I899 XIII. Bd.). M. Steinschneider, Alfarabi (St. Petersburg, i869); MAX HoRTEN, Buch der Ringsteine Alfârâbîs (Beitr. zur Gesch. der Philos. d. Mittelalters, Bd. V, T. 3 [Münster 1906]); B. HANEBERG, Zur Erkenntnislehre von Ibn Sina und Albertus Magnus (Abhandlungen der philos.-philol. Klasse der K. bayerischen Akad. d. Wiss. XI. Bd. [1868]); CARRA DE VAUX, Avicenne (Paris, 1900). M. HORTEN, Die Metaphysik Avic. übers. und erläutert (Halle 1907). C. SAUTER Avic.'s Bearbeitung der aristotelischen Metaphysik (Freiburg i. B. 1912). Die theosophischen und mystischen Schriften des Avicenna hat F. MEHREN in einer Reihe von Abhandlungen in der Löwener Zeitschrift Muséon, Jahrg. $1883 \mathrm{ff}$, und in den Traités mystiques l'...Avicenne, 5 Teile (Leiden, 1889-95) bekanntgemacht. Vgl. die Avicennaliteratur bei MarTiN WINTER, Über Avicennas Opus egregium de anima (München, 1903).

S. 320. T. J. DE BOER, Die Widersprüche der Philosophen nach Al-Ghazālī und ihr Ausgleich durch Ibn Roschd (Straßburg, I 894); CARRA DE VAux, Gazăli (Paris, 1902).

S. 321 . Renan, Averroès et l'Averroïsme, (1. Ausg. Paris, I852; 4. Ausg. I882). M. Horten, Die Metaphysik des Averroes (Halle 1912).

S. 325. LÉON GAUTHIER, Roman philosophique d'Ibn Thofaïl (Alger, 1900); desselben: Ibn Thofail, sa vie, ses œuvres (Paris, 1909); La Théorie d'Ibn Rochd sur les rapports de la religion et de la philosophie (ebenda).

\section{B. Die jüdische Philosophie.}

S. 330ff. S. MUNK, Mélanges de philosophie juive et arabe (Paris, 1859); TH. BLoch, Geschichte der Entwicklung der Kabbalah und der jüdischen Religionsphilosophie (Trier, 
1894); D. Neumark, Geschichte der jüdischen Philosophie des Mittelalters nach Problemen dargestellt I. 11. (Berlin 1907. 1910). D. KaufmanN, Geschichte der Attributenlehre in der jüdischen Religionsphilosophie (Gotha 1877); M. Schreiner, Der Kalâm in der jüdischen Literatur (Berlin, 1895); M. JoEL, Beiträge zur Geschichte der Philosophie, 2 Bde. (Breslau, I876); die Monographien J. Gutrmanns über Abr. ibn Daud (Göttingen, 1879), Sáadjah (Göttingen, 1882), Ibn Gebirol (Göttingen, I 889); Isak Isrâêlî (Münster 1911); L. G. Lḱvy, La Métaphysique de Maïmonide (Dijon, 1905); P. J. Muller, De godsleer der middeleuwsche Joden (Groningen, 1898); S. Horovitz, Die Psychologie bei den jüdischen Religionsphilosophen des Mittelalters (Breslau, I893-1912); W. BACHER, Die Bibelexegese der jüdischen Religionsphilo. sophen des Mittelalters (Budapest, I 892).

S. 331. Jüdischer Neuplatonisınus; I. GoldziHer, Buch vom Wesen der Seele (Abh.d. K. Ges. d. Wiss. zu Göttingen N. F. Bd. IX nr. I, Berlin 1907).

S. 332. Jeh. Haitêwi: Julius Guttmann, Das Verhältnis von Religion und Philosophie bei JEHUdA HALEvi (Festschrift für Isr. Lewy, Breslau I9II, S. 327-358). Neuplatonismus desselben I. Goldziher, Revue des Études juives Bd. L (1905), S. 32-4I.

S. 335. Averroismus bei den Juden s. Renans Averroès et l'Averroïsme, 4. Ausg., S. 173-196.

ibid. J. Gutrmans, Die Scholastik des 13. Jahrhunderts in ihren Beziehungen zum Judentum und zur jüd. Literatur (Breslau 1902).

\section{Nachträge zum zweiten Abdruck.}

Aus den Fortschritten, die auf dem in diesem Aufsatz umfaßten Gebiet hervorgetreten sind, müssen besonders die auf die Vertiefung der Erkenntnis des Șüfitums abzielenden Bestrebungen und Leistungen hervorgehoben werden. Nachdem das vielverzweigte S. bisher zumeist als einheitliches Gedankenwerk auf seine gemeinsamen Charakterzüge dargestellt worden ist, werden nun immermehr die Systeme seiner großen Vertreter auf ihre Besonder. heiten untersucht und vorgeführt. Neben seinen Texteditionen und das Süfiwesen im allgemeinen kennzeichnenden Schriften (zuletzt besonders: The Mystics of Islam, London 1914 in The Quest Series) hat R. A. Nicholson in seinen Studies im Islamic Mysticism (Cambridge 1921) die Systeme einger hervorragender islamischer Mystiker (Abū Sa'ìd ibn Abil.Chejr [967-1049], 'Abdalkarīm al-Dschïlí [1365 - Anf. des 15. Jahrh.], 'Omar ibn al.Färiḍ [II82 Dis 1235] in einer auch weiteren Leserkrcisen zugänglichen Weise im Speziellen be handelt. - Hierher gehören die Abschnitte der in diesem Werke (Teil I, Abt. III.) bereits gewürdigten Arbeit von Tor Andrae über die sūische Auffassung von Muhammeds Wesen, wobei ein wichtiger Exkurs über das System des Ibn-al.'Arabi hervorzuheben ist. Ein anderer schwedischer Gelehrter H. S. NYBERG hat der im arabischen Original ron ihm zuerst herausgegebenen „Kleineren Schriften des Ibn al'Arabi“ (Leiden, 1919) eine deutsche Ein. leitung über das Gedankensystem dieser zentralen Gestalt der islamischen Mystik [1 $165-1240]^{5}$ in seinen hauptsächlichen Zügen vorangehen lassen, wofür bereits früher der spanische Gelehrte Miguel Asin y Palacios einige Untersuchungen geboten hatte. - Den Gegenstand eingehenden Studiums des französischen Gelehrten Lours MASsignoN bildet die Lehre und die Wirkung des zu Bagdad i. J. 922 unter der Beschuldigung der Blasphemie grausam hin. gerichteten Mystikers Al.Hallādsch. Nach reichen Vorarbeiten s. Der Islam 1913 Bd. IV, S. $165 \mathrm{ff}$ ) ist gegenwärtig von ihm eine erschöpfende Halladsch-Monographie unter der Presse. Richard Hartmann hat in einer speziellen Studie das süfische System des Kuschejri (986-1074) dargestellt (Berlin 1919, Türk. Bibl. Bd. 18); der römische I'rofessor C. A. Nallino hat durch seine Studie iuber Ibn al-Fārid (Rivista degli studi orientali 1919 Bd. VIII) neben Nicholson (s. oben) das Verständnis der Ideen. dieses arabischen Mystikers in eingehender Weise gefördert. - Dem Șūfi Einer späteren Epoche 'A bclal wahhāb al.Scha'rānì (st. 1565) hat A.v. Schmidt eine erschöpfende Monographie in russischer Sprache gewidmet (St. Petersburg I914).

Über die Gestaltung der Koranauslegung im Sinne des Süfismus Goldziher, Die Richtungen der islamischen Koranauslegung, Abschn IV (Leiden 1920.

Die Literatur über jüdische Philosophie des Mittelalters ist durch J. Husik's A Historv of Mediaeral Jewish Philosophy (New York 1918 erweitert worden.

Die Kultur der Grorenwart. I. 5. = Aal 


\title{
DIE CHRISTLICHE PHILOSOPHIE DES MITTELALTERS.
}

\author{
VON \\ Clemens Baeumker.
}

Einl.eitung.

Ein etwa tausendjähriger Zeitraum ist es, welchen die Darstellung der Philosophie der christlichen, germanisch-romanischen Völker des Mittelalters zu durchwandern hat.

Zwar geht das Leben in dieser Epoche, wenn wir von den Stürmen, die ihren Eintritt bezeichnen, absehen, einen langsameren Gang, als ihn die politische und Kulturgeschichte der Neuzeit aufweisen. Darum sind auch der mittelalterlichen Philosophie solch schnelle und tiefgreifende Wechsel fremd, wie sie in der neueren Philosophie aus dem Humanismus, aus der Entwickelung der mathematischen und der exakten Wissenschaften, aus den Ideen der Aufklärung oder denen der romantischen Zeit in rascher Folge erwachsen. Leicht sieht daher der ferner stehende Betrachter in der gesamten mittelalterlichen Spekulation, die gewöhnlich unter dem Namen der Scholastik zusammengefaßt wird, eine in sich gleichartige Erscheinung. Dem schärfer blickenden Auge dagegen zeigt das kulturelle Leben und mit ihm die Philosophie auch im Mittelalter ein langsames, aber unaufhaltsames Drängen, eine allmähliche Verschiebung. Heben sich auch nicht einzelne Persönlichkeiten in scharfen Wendungen voneinander ab, wie etwa Sokrates Platon Aristoteles im Altertum, oder Descartes Spinoza Leibniz, Kant Hegel Herbart in der neueren Philosophie, so sind doch auch im mittelalterlichen Geistesleben und in der mittelalterlichen Philosophie die Ideenrichtungen in einer allmählichen, bald unmerklichen, bald mehr sprunghaften Umgestaltung begriffen. Es ist wie im Leben so manches Einzelnen, wo nicht plötzliche Schicksalswendungen und innere Erschütterungen, die den tiefsten Seelengrund aufwühlen, sondern die leichten Verschiebungen der täglichen Einflüsse und das langsame Erstarken der inneren Kraft den Lebensabschnitten eine veränderte geistige Physiognomic aufdrücken. 
I. Charakteristik der mittelalterlichen Philosophie. I. Ihr for-Charakteristik maler Charakter. Nichtsdestoweniger lassen sich an der Philosophie der der mittelalterchristlichen Völker des Mittelalters gewisse gemeinsame Grundzüge nachweisen, welche in den allgemeinen Kulturbedingungen der Zeit wurzeln. Sie sind freilich $z u$ einem guten Teile mehr formaler Art. Nicht so sehr den Inhalt der einzelnen Systeme, als die Weise des Philosophierens haben wir ins Auge zu fassen. Aber doch nur zunächst; denn am Ende ergibt sich aus der allgemein verbreiteten Methode des Forschens auch eine ziemlich weitgehende Gemeinschaft des Gedankenkreises selbst.

Das Mittelalter ist die Jugendzeit der romanisch-germanischen Völker. Das Jugendalter aber trägt, zumal in seinem Beginn, den Charakter der Rezeptivität. Auch das geistige Leben des Mittelalters weist diesen rezeptiven Zug auf. In der Rezeptivität gegenüber der höheren Bildung der Antike und des christlichen Altertums zeigen sich die ersten Regungen jenes Lebens, die dann allmählich zu größerer Selbständigkeit hinführen: in der Grammatik von Donat zu Alexander de Villa dei, in der Baukunst vom romanischen zum gotischen Stil, in der Theologie von Exzerpten aus Augustinus zur Summa theologica des Aquinaten, und ähnlich auf manchem anderen Gebiete. Insbesondere die Philosophie des Mittelalters ist so aus anfäıglicher rein rezeptiver Aneignung antiker und patristischer Gedanken zu eigenen Anschauungen herangewachsen. Noch lange nach ihrem rein rezeptiven Beginn tritt jener Zug. andauernd als ein gewisser Stoffhunger zutage. Dieser treibt bis tief in die Höhezeit des mittelalterlichen Philosophierens hinein stets wieder dazu an, neu sich darbietenden Stoff aufzunehmen, mag er nun mehr tropfenweise zufließen, wie in der älteren Zeit, oder in mächtigem Strome, wie um die Wende des I2. und I3. Jahrhunderts, als glückliche Umstände die Bekanntschaft mit der arabischen Wissenschaft und dem Ganzen der aristotelischen und der späteren neuplatonischen Lehren vermittelten.

Freilich ist diese immer wieder sich vollziehende Rezeption neu gewonnenen Stoffes nicht als eine bloß äußerliche Nebeneinanderhäufung oder eine mechanische Einschachtelung zu denken. Wenigstens bei den einheitlicher angelegten Geistern finden wir mehr oder minder eine wirkliche Assimilation des wissensdurstig aufgenommenen Stoffes, ein organisches Wachstum. Aber ganz fehlend ist jener rezeptive Zug nirgendwo. Auch die großen Denker des Mittelalters sind im ganzen mehr durch die Art der von ihnen vollzogenen Synthesen in ihrer Eigentümlichkeit charakterisiert und voneinander unterschieden, als daß sie es unternähmen, nach durchgängiger Erschütterung des Überlieferten ihrer jedesmaligen Sonderart entsprechend von Grund aus neu zu bauen.

Aus einem solchen nie ganz vcrwischten Grundzuge des mittelalterlichen Philosophierens begreift sich auch seine Hingabe an die Autorität, die maß- $\alpha$ ) Unterordnung gebende Bedeutung, welche man den Denkern des griechisch-römischen Altertums und der patristischen Zeit einräumt, denen man die grundlegenden Gedanken und die Anregung zur Weiterführung der Spekulation verdankt. Willig

a) Vorherrschende Rezeptivititit. 
ordnet man sich jenen Autoritäten unter, und wo man sich gezwungen sieht, ihnen zu widersprechen, entzieht man sich doch nur schwer ihrer trotz des Widerspruchs - und selbst in diesem - stets aufs neue sich aufdrängenden Bedeutung. Wie Zwerge, die auf den Schultern der Riesen stehen, erscheinen dem Bernhard von Chartres die Zeitgenossen gegenüber den Alten. In Augustin, Platon und dann besonders Aristoteles werden wir die wichtigsten dieser Autoritäten kennen lernen.

Übrigens ist diese Hingabe an anerkannte Lehrer — ,authentisch“ pflegte man ihre Schriften zu nennen - nicht eine völlig sklavische. Selbst gefeierten Autoritäten überlassen sich die selbständigeren mittelalterlichen Denker nicht unbedingt. Das beweisen sie durch ihre tatsächliche Stellungnahme wie durch ganz bestimmte Erklärungen. So erinnert Albert d. Gr. daran, daß auch die Weisen sich täuschen können. Denen, die durch die Berufung auf eine philosophische Autorität eine Sache entschieden glauben, hält der kritische Duns Scotus entgegen, daß die Philosophen keineswegs alles, was sie behaupten, auch wirklich bewiesen haben. Sehr hübsch redet Alanus von Lille von der „wächsernen Nase“ (nasus cereus) der Autorität, die man hierhin ur,d dorthin drehen könne; ja Adelhard von Bath vergleicht diejenigen, welche, ohne ihre eigene Vernunft zu gebrauchen, bloß der Autorität folgen, den unvernünftigen Tieren, die sich die Fessel umwerfen lassen und blindlings dem Halfter folgen. Und wenn Roger Bacon als eine der hauptsächlichsten Irrtumsquellen das gewohnheitsgemäße Zutrauen auf unzulängliche Autoritätsbeweise aufstellt und mit Platon bekennt, daß ihm Sokrates lieb, aber noch lieber die Wahrheit sei, so erinnert er hier, wie auch sonst in so manchem, an seinen Landsmann Bacon von Verulam und dessen Kampf gegen den unkritischen Autoritätsglauben als eines der vier „Idole“, die der Naturerkenntnis entgegenstehen.

§) Bedeutung der Tradition.

Der im ganzen mehr der Aufnahme und Verarbeitung gegebener Erkenntnis als dem Aufschließen neuer Pfade philosophischen Forschens zugewandte Sinn des Mittelalters und seine verehrende Hochschätzung der von weisen Meistern dargebotenen Schätze hatten zur naturgemäßen Folge, daß in der Entwickelung der mittelalterlichen Philosophie trotz der Verschiedenheit der Systeme doch die traditionellen Grundlagen gegenüber den eigenartigen und persönlichen Elementen den umfassenderen Raum einnehmen. Es wiegt die Tradition vor gegenüber dem besonderen Werke des Einzelnen. Und zwar zeigt sich diese Erscheinung nicht nur innerhalb der einzelnen Schulen, sondern, wenn schon in minderem Maße und nicht ausnahmslos, auch in dem Verhältnis der einzelnen Schulen zueinander. Auch die Begründer neuer Richtungen, wenigstens soweit dieselben einen weitergehenden Einflub gewinnen, stehen selbst durchweg im Zusammenhang der Tradition. Beruht doch ihre Eigentümlichkeit nicht zum wenigsten auf der besonderen Art, in der sie die auseinander und nebeneinander hergehenden Ströme der Überlieferung zu einer neuen Gesamtauffassung vereinen. - Von Wert ist dieser allgemeine Zusammenhang sowohl durch den bedeutungsvollen Gehalt vieler 
gemeinschaftlich anerkannter Lehren wie dadurch, daß so auch der an sich weniger hervorragenden Persönlichkeit eine gehobene Stellung verliehen wird. Der Nachteil besteht darin, daß diese Gleichförmigkeit es bei überaus vielen nicht zu einem inneren Erleben der letzten Fragen kommen und so die produktive Kraft im subtilen Ausspinnen von Spezialitäten sich verlieren läßt.

Man sieht leicht - es erscheint nicht überflüssig, dies schon hier hervorzuheben - , wie aus dem Überwiegen des gemeinsamen traditionellen Gutes in der mittelalterlichen Philosophie für unsere Darstellung eigentümliche Schwierigkeiten erwachsen müssen, welche die Geschichtschreibung der antiken und der modernen Philosophie nicht kennt. Soll von der Gesamtanschauung auch nur der bedeutendsten Denker ein einigermaßen vollständiges Bild gegeben werden, so sind fortwährende Wiederholungen unvermeidlich. Beschränkt sich dagegen der Bericht, um solche Wiederholungen zu vermeiden, auf das Charakteristische und Unterscheidende, so entsteht ein ganz falsches Bild; die einzelnen rücken viel zu weit auseinander, und die Systeme selbst werden dürftig und leer. Das allgemein Zuständliche macht in der mittelalterlichen Spekulation einen ebenso wichtigen Faktor aus, wie das wechselnde historische Geschehen, der dauernde Gemeinbesitz, wie die neu auftretenden Aufgaben. Es ist daher in der folgenden Geschichtsentwicklung versucht, beiden Unzuträglichkeiten durch einen Mittelweg zu entgehen. Wie wir mit einer zusammenfassenden Charakteristik beginnen, so ist auch das gemeinsame Material in einer Analyse der Quellen kurz skizziert. Weiterhin ist dann von dem System eines typischen Vertreters des mittelalterlichen Denkens, als welcher wegen seiner fortwirkenden Bedeutung Thomas von Aquino gewählt wurde, eine ausführlichere Darstellung gegeben, in welcher in der besonderen individuellen Ausprägung auch der gemeinsame Grundbestand zu lebendigerer Anschauung gebracht wird. Bei den übrigen geschichtlichen Erscheinungen dagegen wurde nur das Eigenartige hervorgehoben, wodurch die Richtungen charakterisiert werden und die Entwickelung bestimmt wird. So ist freilich ein Mißverhältnis hinsichtlich des den einzelnen Erscheinungen gewidmeten Raumes entstanden; aber die Notwendigkeit muß jenen Verstoß gegen die künstlerische Abrundung entschuldigen.

Der Grund für eine solche Schätzung der Tradition liegt, außer in der psychologischen Natur des mehr rezeptiven und zugleich korporativen mittelalterlichen Geistes, auch in der Stellung, welche das Mittelalter zur Philosophie überhaupt einnimmt. Ihm ist das Philosophieren nicht so sehr, wie zumeist der mehr subjektiv gerichteten Neuzeit, die Art, wie in dem Spiegel einer charakteristischen, eigenartigen und tiefen Persönlichkeit das Weltbild widerscheint. Es ist ihm vielmehr das Weiterführen einer Summe von objektiven Wahrheiten. Denn die Wahrheit erscheint ihm nach Augustin als eine über dem Menschen stehende objektive Realität, die gefunden und, wenn sie gefunden ist, weiter übermittelt werden will. In der Bindung an einen objektiv gegebenen gemeinsamen idealen Besitz erblickt man vor allem die 
Kultur des Geistes. Nicht das Philosophieren, sondern die Philosophie soll darum gelehrt werden, im Gegensatz zu Kants bekanntem Programm.

Daß aber diese philosophische Wahrheit in ihrer Ganzheit schon ein für allemal gefunden sei und nur weitergegeben zu werden brauche - in welchem Falle das mittelalterliche Philosophieren überhaupt keine Forschung mehr, sondern bloß eine didaktische Tätigkeit gewesen wäre - : von dieser Ansicht sind wenigstens die bedeutenderen mittelalterlichen Denker doch entfernt. Eine jede Zeit soll daran arbeiten, die objektiv giltige und zuletzt im absoluten göttlichen Geiste begründete Wahrheit weiter in den Besitz der Menschheit zu bringen. Darum begegnet uns nicht selten ausdrücklicher Tadel solcher Lehrer, die nicht selber an der Weiterentwicklung der Wissenschaft arbeiten. Herbe Worte gegen derartige fruchtlose Tätigkeit spricht in der Glanzperiode des mittelalterlichen Denkens Dante in seiner "Monarchie" aus. Aber schon im 12. Jahrhundert mahnt Adelhard von Bath, daß die "Modernen“ nicht schweigen dürfen, im Glauben, die Alten hätten bereits alles gesagt. Und wenn wir vorhin Bernhard von Chartres die Zeitgenossen mit Zwergen auf den Schultern der Riesen der Vergangenheit vergleichen sahen, so betont derselbe Bernhard, daß eben von solchem erhöhten Standpunkte aus diese $Z$ werge doch mindestens um ein weniges weiter sehen können als jene Riesen.

b) Schulmäßiger Betrieb.

a) Name „Scholastik".

Form de hanges.
Das Überwiegen des traditionellen Elementes in dem mittelalterlichen Philosophieren steht im engsten Zusammenhange mit dem schulmäßigen Betriebe, welcher dasselbe beherrscht. In einer Zeit, in welcher auf allen Gebieten das Individuum hinter der Gemeinschaft, die Einzelpersönlichkeit hinter der Korporation zurücktrat, mußte naturgemäß auch der Zusammenhang der Schule eine besondere Bedeutung gewinnen. So ist auch die mittelalterliche Philosophie in erster Linie Schulwissenschaft. Gerade hierauf beruht die übliche Bezeichnung der mittelalterlichen Philosophie und Theologie als "Scholastik", „scholastische“ Philosophie, „scholastische“ Theologie. Während nämlich die Frühzeit des Mittelalters das Wort scholasticus für den Lehrer - gelegentlich auch für den Schüler — der „sieben freien Künste" des Triviums und des Quadriviums gebraucht, mitunter sogar (z. B. bei Notker), um den "scholasticus" als Grammatiker dem Philosophen entgegenzustellen, wird später damit ein jeder bezeichnet, der sich schulmäßig mit der Wissenschaft, insbesondere der Philosophie und der Theologie, beschäftigt. Wo eine historische Erscheinung nach ihrer Ideenrichtung und ihrer formalen Ausgestaltung aus dem Rahmen dieser schulmäßigen Überlieferung ganz herausfällt, wie die Mystik und gewisse pantheistische Systeme, wird man sie daher wohl der Philosophie des Mittelalters, aber nicht der Scholastik zurechnen können.

In der älteren Periode der Scholastik ist der Schulzusammenhang noch ein loserer. Er besteht mehr in der Gleichartigkeit des überall stattfindenden Schulbetriebes, wie diese auf Grund übereinstimmender Autoritäten, Methoden und Grundanschauungen sich von selbst ergibt, als in einer bewußten und beabsichtigten Schulenbildung. Anders wird dies, als in den erblühenden 
Universitäten und bei der Lehrgestaltung in den neuen mittelalterlichen Orden das korporative Element zu durchgängiger Geltung gelangt. Jetzt entstehen jene streng geschlossenen Schulen, wie vor allem die der Thomisten und der Scotisten, denen später die Occamisten gegenübertreten. Versammlungen der Universitätslehrer und Generalkapitel der Orden bestimmen, was in ihrem Kreise gelehrt oder nicht gelehrt werden soll, nicht nur auf theologischem Gebiete, sondern zum Teil auch in der Philosophie. Bestimmte Lehrer, der Ruhm ihrer Orden, werden von diesen als maßgebend für den Orden selbst erklärt. Der äußere Umstand der Zugehörigkeit zu einer bestimmten korporativen Gemeinschaft kann über die einzuschlagende Ideenrichtung entscheiden. Infolge solcher Umstände tritt die Weiterführung der Probleme selbst, an der das i 3. Jahrhundert energisch arbeitete, zurück hinter der näheren Bestimmung und Verteidigung der Schulmeinungen. Nur durch das Aufkommen des Nominalismus und im Zusammensto $B$ mit ihm werden einige neue, zum Teil moderne Fragen aufgerührt, ohne indes zu einer anerkannten Lösung $z u$ gelarigen.

Durch den Zusammenhang mit dem Schulbetriebe wird, wenigstens innerhalb der ausgebildeten Scholastik, nicht nur der sachliche Gehalt der mittelalterlichen Philosophie, sondern in steigendem Maße auch ihre formale Gestaltung und die Form ihrer Darstellung beeinflußt. Die Schriftstellerei bietet mehr und mehr das Bild des Schulbetriebes, wie er in fest gewordenen Formen in den Sälen der Universitäten und Ordenskonvente sich abspielt. $\mathrm{Da}$ werden Lehrbücher geschrieben, Texte kommentiert und Disputationen schriftlich fixiert. Das Buch dient der Vorlesung oder geht in nachträglicher Überarbeitung aus ihr hervor. Oft auch werden uns Nachschriften von Schülern (reportata, reportationes) geboten.

Dieser entwickelte Schulbetrieb aber führte zu einer anderen Form der Gedankenentwicklung und zu einer anderen Art des Ausdruckes. Man strebt jetzt nach einer möglichst scharfen schulmäßigen Fassung der Begriffe sowie nach einer feinen Unterscheidung derselben, wie ihrer vor allem die Disputation bedarf. Damit steht im Zusammenhange die Ausbildung einer reichgegliederten, biegsamen Terminologie, welche, wenn auch nicht selten in veränderter Bedeutung, zu einem großen Teil auch in die neuere Philosophie, ja selbst in die Sprache des Lebens übergegangen ist. Man denke an Ausdrücke wie subjektiv und objektiv, a priori und a posteriori, Essenz und Existenz (in deutscher Wiedergabe Wesenheit und Dasein) und zahllose andere. Die Beweisführung nimmt mit Vorliebe die streng syllogistische Form an, welche nicht dem Finden eines Neuen, wohl aber dem schulmäßigen Beweise des Gefundenen dienen kann. Für eine solche Gedankenentwickelung war natürlich nicht mehr der rhetorische und poetische Stil, der nach spätantiken Mustern in vielen Erzeugnissen des frühen Mittelalters gepflegt wird, das passende Gewand. Er macht einer schlichten, nicht selten dürren und trockenen, abstrakten Prosa Platz. Nur um den logischen Gelialt der sich bietenden Probleme bekümmert, verschmäht die mittelaiterliche Spekulation jetzt 
die künstlerische Form und damit die persönliche Eigenart. Mit dem Fortgang der Zeit wird der Vortrag mehr und mehr formelhaft, und die Formeln selbst erstarren zuletzt. Hier setzt die Reaktion des ästhetischen Geistes des Humanismus ein, von der auch die Neuscholastik eines Bañez, eines Canus, eines Suarez ergriffen wird.

Man kann jene Entwicklung bis zu einer gewissen Grenze nicht nur tadeln. In Dingen, in welchen der Verstand zu entscheiden hat, ist es nicht immer gut, viele schöne Worte zu drechseln. Unklarheit und Willkür des Denkens verbergen sich leicht hinter der das Gemüt oder die Phantasie bestrickenden Phrase. Auch darf man die in der späteren Zeit stets wachsende ästhetische Verwahrlosung nicht gleichmäßig der ganzen Scholastik zur Last legen. Thomas von Aquino z. B. hat wenigstens in seinen Hauptwerken einen zwar schlichten, aber doch durchsichtigen und lebendigen Stil, der ebenso weit entfernt ist von der gezierten Dunkelheit eines Eriugena oder Bernhard Sylvester, wie von der im I4. und i5. Jahrhundert bis zum Unerträglichen überhand nehmenden stilistischen Roheit und Verwilderung.

c) Unpersönlicher Charakter

Der abstrakte, unpersönliche Ton, welcher die entwickelte mittelalterliche Schulwissenschaft beherrscht, ist nicht etwas bloß Äußeres. Die Spekulation des Mittelalters selbst ist eine unpersönliche. In seiner Denkweise tritt das Persönliche hinter dem abstrakt Allgemeinen zurück, das psychologisch Wirksame hinter der Dialektik des von Raum und Zeit losgelösten Intellektes. Und daß es im Grunde nicht nur rein individuelle, sondern zugleich auch typische Elemente sind, welche aus dem inneren Erleben eines Problems, das den ganzen Menschen ergreift, bei einer wahrhaft bedeutenden Persönlichkeit entspringen: diese Einsicht ist der mittelalterlichen Philosophie fremd. In ihr herrscht die Schule, und in der Schule der abstrakte Verstand. Darum ruft auch diese rein intellektualistisch und unpersönlich gerichtete Schulwissenschaft als Ergänzung die Mystik, den Weg des individuellen Lebens und der Kontemplation, auf den Plan. Denn wenn sich die mittelalterliche Mystik auch noch so sehr - was man oft verkannt hat - hinsichtlich ihrer Lehre fast überall auf die Scholastik stützt, so ist der Geist doch ein anderer: der lebendige Hauch persönlichen Lebens.

So wenig wie stärkere individuelle Akzente kennt die Scholastik ausgeprägte na tionale Eigentümlich keiten. Nur leichte Andeutungen solcher Unterschiede, gewissermaßen Vorwegnahmen neuzeitlicher Entwickelung, kann man lie und da herausfühlen: bei Abälard, bei Albert, bei Bacon und wenigen anderen.

1) Scholastische Noch mit einigen Worten sei die scholastische Methode besprochen,
Methode. wie sịch dieselbe im mittelalterlichen Schulbetriebe entwickelte. - Wir gedachten der Hochschätzung der Autorität als eines Charakterzuges der mittelalterlichen Denkweise. Die Autorität aber bewegt sich nicht stets in derselben Richtung. Das trat besonders auf dem Gebiete hervor, im Zusammenhange mit dem das mittelalterliche Philosophieren erwuchs, auf dem theologischen. Die Sammlungen von Aussprüchen der Kirchenväter — „Sentenzen“ nannte 
man die Aussprüche und darnach auch die Sammlungen selbst - zeigten, daß die Meinungen angesehener Autoritäten nicht selten, wenigstens anscheinend, diametral sich entgegenstanden. Ein vorwiegend kritisch gerichteter Geist wäre hierdurch vielleicht zur Verwerfung der Autorität überhaupt oder gar zum Skeptizismus geführt worden. Dem mittelalterlichen Denken lag ein solches Aufgeben der Autorität gänzlich fern. Um aber in diesem Auseinanderdrängen der Stützen etwas behalten zu können, woran es sich anklammerte, mußte es den Widerspruch als einen bloß scheinbaren erweisen. Der absolute Gegensatz mußte in einen bloß relativen aufgelöst werden. Dazu bedurfte es logischer Unterscheidungen und einer dialektischen Bearbeitung der Begriffe und Sätze.' Wenn ein solches Verfahren als praktisch geübte 'Technik auch schon früher bei der Behandlung kanonistischer Rechtsfragen sich nachweisen läßt, insbesondere bei Bernold von Konstanz ( $f$ I IOo), so ist doch Abälard es gewesen, der für das Verfahren die erste auf Regeln gebrachte Anweisung gab und dadurch in der Scholastik diese hier bald allgemein herrschende Methode begründete. Diese aber erweiterte von selbst ihren Geltungsbereich. Entgegenstehende Argumente boten sich nicht nur in den Aussprüchen der Autoritäten. Sie ergaben sich ebenso aus allgemeinen Schulgegensätzen, ja aus der Diskussion der Sache selbst. Das zeigte auch Aristoteles, der 'große Lehrmeister des Mittelalters, der nicht selten mit solchen sachlichen Schwierigkeiten („Aporien“) seine Darstellung eröffnet. So entwickelte sich das übliche scholastische Schema, welches von Einwendungen und von Gegeninstanzen gegen diese Einwendungen - beides gern auf Grund von Zitaten aus anerkannten Autoritäten - ausgeht, dann die Ansicht des Verfassers selbst entwickelt und zuletzt die Einwendungen 1öst. Nach dem Titel einer Schrift Abälards hat man ihm den Namen der „Sic- et Non-Methode“ gegeben. Thomas von Aquino hat in seinem großen konstruktiven Werke, der theologischen Summe, diesem Schema die klassische Form verliehen. Seitdem herrscht es, soweit nicht Kommentare, sondern selbständige Abhandlungen vorliegen, fast allgemein.

Dieses Schema aber ist wieder nicht bloße Darstellungsform, nicht bloß ein äußeres Kleid für den mittelalterlichen Gedanken. Auch hier offenbart sich in der Form die Eigenart der spekulativen Denkweise des Mittelalters selber. Indem die Anerkennung autoritativ gestützter Wahrheiten und das eigene rege dialektische Streben sich vereinen, mußte die vorherrschende Geistesart eine harmonistische, eine konkordistische werden. Zwar sind auch kritische Stimmungen dem Mittelalter durchaus nicht fremd. Schritt für Schritt z. B. kritisiert Duns Scotus die Ansichten des Thomas von Aquino und des Heinrich von Gent, und bei Occam bildet wieder die Polemik gegen die scotistische Metaphysik einen Charakterzug. Aber im ganzen wiegt, solange die Scholastik sich noch lebensvoll entwickelt, der synthetische Zug vor. Durch Umbilden und Umdeuten, durch Mildern und Ausgleichen, auch durch teilweises Ausscheiden und Einschränken vereinigt man Auseinanderoder doch Nebeneinandergehendes. Augustin und die hellenische Philosophie, 
Platon und Aristoteles, Griechen und Araber werden verbunden, wobei natürlich die Art der Synthese eine vielfach wechselnde ist.

Und nicht nur bei Autoritäten und verschiedenen Richtungen in der Überlieferung verfährt man so. Auch die in der Sache selbst gegebenen verschiedenen Motive verfolgt man nicht so sehr in ihrem Auseinanderstreben, sondern bemüht sich, durch logische Unterscheidungen und dialektische Bearbeitung sie zusammenzubiegen, wie im gotischen Gewölbe- und Strebensystem die auseinandergehenden Schiebungen gebunden erscheinen. In dieser Art sucht man z. B., um auf einen einzelnen typischen Fall hinzuweisen, auf dem Gebiete der Psychologie die Diskrepanz biologischer und rein intellektualistischer Elemente, die bei Aristoteles die Einheit des Seelenlebens zuletzt doch wieder gesprengt hatte, durch die Unterscheidung kompleter und inkompleter Substanz, von rein seelischen Vermögen und solchen des menschlichen Kompositums usw. zu überwinden.

Vor allem aber betrifft dieser harmonistische Zug die beiden Gebiete: natürliche Vernunfterkenntnis und Offenbarungsglaube. Damit sind wir bei einem weiteren Merkzeichen der mittelalterlichen Philosophie angelangt: f) Glaube und ihrer vielfach bis zur Abhängigkeit sich steigernden engen Beziehung zur Theologie, und der Art, wie sie das Verhältnis von Glauben und Wissen faßte.

Aus dem Ursprunge der mittelalterlichen Philosophie erklärt es sich, daß sie in engem Zusammenhange mit der Theologie sich entwickelte. Als a) Herrschaft in der harten Not der Völkerwanderung die antiken Rhetorenschulen unterder Theologie. gingen - philosophische Lehrer gab es schon längst nicht mehr —, da war keine andere Macht vorhanden, welche durch ihre geistigen Interessen und durch die Festigkeit ihrer Organisation für die Pflege der Wissenschaften eine Heimstätte hätte offen halten können, als die Kirche. Ihre große Kulturtat war es, die germanisch-romanischen Völker, wie zu christlicher Sitte, so zu höherer Geistesbiłdung zu erziehen. So sind auf lange Zeit hinaus Geistliche die Träger der intellektuellen Bildung gewesen. Selbst Ärzte und Juristen sind, wenigstens in der älteren Zeit, meistens Kleriker. Darum trägt die höhere wissenschaftliche Bildung auf lange Zeit ein vorwiegend geistliches Gepräge und ist in ihrer Ausgestaltung durch den Gesichtspunkt des Klerikers bestimmt. Es fehlt auf wissenschaftlichem Gebiete das Interesse für eine allgemeine weltliche Kultur. Ja in manchen rein asketisch gerichteten Kreisen kostet es ein hartes Ringen, um neben den theologischen Studien auch dem profanen Wissen, neben den Kirchenvätern auch den heidnischen Schriftstellern den Platz zu sichern, den doch Augustin und Hieronymus in oft angeführten Stellen der antiken Wissenschaft und Kunst gewahrt wissen wollten.

Dieser spezifisch geistliche Charakter der mittelalterlichen, insbesondere der frühmittelalterlichen Wissenschaft macht sich besonders auf philosophischem Gebiete geltend. Eine gesonderte Philosophie gibt es anfangs nur in dem engen Rahmen des Triviums. In diesem aber hatte die antike Ưberliefe- 
rung nicht den sachlichen philosophischen Problemen, sondern nur den formalen Fragen der Dialektik ein bescheidenes Unterkommen geschaffen. Im übrigen trat das erwachende philosophische Denken zunächst in den Versuchen, theologische Aufgaben zu bewältigen, ans Licht: Versuche, welche durch den vorwiegend intellektualistischen Charakter der herrschenden Religionsströmung naturgemäß hervorgerufen werden mußten. So führt der philosophische Trieb zur spekulativen Begründung der Glaubenslehren, die nicht nur als ein positiv Gegebenes hingenommen, sondern auch in ihrem inneren Zusammenhange und in ihrer Vernunftgemäßheit begriffen werden sollen. Der Glaube soll in einem Wissen sich vollenden. Anselms „Credo, ut intelligam" - er hat es seinerseits Augustin entnommen - hat jenen Bestrebungen die Formel gegeben. Sie will nicht, wie eine mißverständliche Auffassung sie oft gedeutet hat, die Natur des Wissens als solchen bestimmen und Methode und Umfang der Philosophie überhaupt angeben, sondern will dem Theologen ein über das bloß Positive hinausgehendes spekulatives Ziel setzen.

Durch diese Versuche einer Rationalisierung der Dogmen wurde nun v) Theologische freilich nicht selten der herkömmliche Sinn der theologischen Sätze ver- Reaktion gegen schoben. Bei Anselm selbst zwar, trotzdem er fast alle Glaubenssätze, auch die kirchlichen Lehren von der göttlichen Dreieinigkeit und der Erlösung, zu Postulaten der Vernunft macht - die freilich hier das „Wie“ nicht durchdringen könne -, tritt ein solcher Konflikt mit dem theologischen Glaubensbewußtsein der Kirche seiner Zeit nicht zutage, wohl aber war dies schon bei Eriugena, dem kühnen spekulativen Kopfe des 9. Jahrhunderts, und bei Abälard, dem Begründer der scholastischen Methode, der Fall. Anhänger der alten theologischen Lehrweise erheben sich daher stets von frischem gegen die allmählich sich durchsetzende Neuerung. Bereits im Ir. Jahrhundert schelten die Mönche Othlo von Regensburg, Petrus Damiani und Manegold von Lautenbach die „Dialektiker“, die, wie Damiani tadelt, nicht zugeben wollen, daß Gottes Allmacht Gewesenes nichtgewesen machen könne - übrigens eine persönliche Schrulle des Petrus Damiani, der zuliebe er das Prinzip des Widerspruchis für unanwendbar auf Gottes Wirken erklärt. Im folgenden Jahrhundert bringt Bernhard von Clairvaux die beiden führenden unter den Dialektikern, Abälard und Gilbert de la Porrée, zur kirchlichen Verurteilung. Handelt es sich bei Bernhard zum Teil um wirkliche kirchliche Interessen, so geht Walter von St. Viktor weit darüber hinaus. Nicht nur jene beiden, sondern auch den kirchlich ganz korrekten Bischof von Poitiers und den Petrus Lombardus, dessen "Sentenzen“ - eine Ironie der Geschichte - bald das viel kommentierte theologische Grundbuch des Mittelalters werden sollten, stellte er in einer heftigen Schrift gegen die „vier Labyrinthe Frankreichs" als die Verderber der gläubigen Denkungsart hin. Der in St. Viktor gebildete Absalon, Abt von Springkirchbach ( $\dagger_{1}$ 203), führt den Gegensatz ins 13. Jahrhundert hinüber. Hier gewinnt er eine neue Form in den neugegründeten Orden der Dominikaner und Franziskaner. 
Vielen eifrigen Ordensmännern erscheint die intensivere Beschäftigung mit der Philosophie als ein Abfall von dem religiösen und theologischen Ideal. Noch Albert der Große muß sich mit scharfen Worten gegen die Bekämpfer seiner Bestrebungen wenden. Erst durch die Anerkennung, welche Thomas von Aquino allgemein gewinnt, wird der Sieg der philosophiefreundlichen Richtung unter den Theologen entschieden.

So ist die Opposition der traditionellen Theologie gegen die Dialektik nicht zu ihrem Ziele gekommen. Auch die entwickelte Scholastik des I 3. Jahrhunderts ist durch eine weitgehende Rationalisierung des kirchlichen Dogmas charakterisiert, und wenn wir die philosophischen Anschauungen dieser Periode ermitteln wollen, so müssen wir sie zu einem großen Teile theolologischen Schriften entnehmen. Aber doch wirkt der jener Opposition zugrunde liegende Gedanke in zweifacher Hinsicht bei der Folgezeit nach: in der Grenzbestimmung des der Vernunft Erreichbaren und in der Auffassung des Verhältnisses von Theologie und Philosophie.

Petrus Damiani, der eben erwähnte extreme Supranaturalist, ist es, der im lateinischen Mittelalter zuerst das Wort von der Philosophie als „Magd“ (ancilla) der Theologie gebraucht $z u$ haben scheint. Er verlangt, daß die profane Wissenschaft die heilige nicht meistere, sondern ihr als Dienerin untergeben sei. Auch sonst begegnet uns öfter Ähnliches im Munde der Theologen: bei Johannes von Salisbury, Albert, Thomas, Bonaventura, Ramon Lull, Gerson und anderen, jedoch meist ohne die schroffe Form, in der Damiani den Anspruch dahinwirft. Man muß dabei den Geist der Zeit ins Auge fassen. Ein einheitlicher, religiös und theologisch gerichteter Zug beherrscht bis auf die Zeit des Nominalismus zumeist die gesamte Weltanschauung und den Wissensbetrieb der Kreise, in denen die Wissenschaft vorwiegend betrieben wird. Das Prinzip der Arbeitsteilung und der Vertiefung in ein begrenztes Gebiet liegt fern; das zusammenfassende Streben und das Prinzip unterordnender Gliederung wiegt vor. Man faßt alles Erkennen als ein zusammengeordnetes, auf den höchsten Menschheitszweck gerichtetes abgestuftes Ganzes auf, in welchem die niedere Stufe der höheren dient. So hatte schon Aristoteles das Verhältnis der niederen Wissenschaften zu der "Weisheit", d. h. der Metaphysik, als das einer Dienerin bezeichnet, und Philo, der alexandrinische Jude, hatte diesen Gedanken weiter ausgeführt, indem er dabei zugleich dem aristotelischen Begriffe der Weisheit den modifizierten Sinn eines von der Gottheit ausgehenden höchsten Wissens gibt. Hatte schon die Stoa seit Poseidonios die Disziplinen der enzyklopädischen Bildung als Propädeutik der Philosophie untergeordnet, so setzt Philon dieses Rangverhältnis der Dienerin und der Herrin nach oben hin fort, indem er es auch auf die Beziehung von Philosophie und „Weisheit" überträgt. Wie dem philosophierenden Theologen Philon, so ist auch jenen theologischen Denkern des Mittelalters die Theologie die Krönung des Wissensgebäudes. Freilich ist jetzt das Positive und Normgebende in dieser Theologie ein viel Mannigfaltigeres geworden. Nicht mehr bloß Moyses wird, wie bei Philon, 
mit einem stoisch gefärbten Platon verbunden. Der Kreis der inspirierten Schriften hat sich erweitert; die Tradition der Kirchenväter und zahlreiche Lehrentscheidungen von allgemeinen Konzilien und Partikularsynoden sind hinzugekommen.

Übrigens ist im Mittelalter auch auf den Gebieten, wo Theologie und Philosophie, Vernunft und Offenbarung sich gegenseitig einschlossen, das philosophische Denken nicht immer ein bloßes Nachrechnen gegebener Auflösungen gewesen. Wie in der patristischen Zeit die platonisch-stoische Philosophie mit zu dem Ausbau der theologischen Lehrsätze diente, so ist an der weiteren Konsolidierung dieser Lehre im Mittelalter wieder die Philosophie selbst, insbesondere mit ihren aristotelischen Begriffen, beteiligt. Auch bei jenen Theologen besteht $z$ wischen Theologie und Philosophie nicht ein einfaches Subalternationsverhältnis, sondern das Verhältnis der Wechselwirkung, der gegenseitigen Zusammenarbeit.

Als zweite Folge der positiv-theologischen Reaktion gegen die philo- $\delta$ ) Grenzbestimsophische Spekulation bezeichneten wir die Grenzbestimmung des der Ver- mung von nunft Erreichbaren. Schon bei Wilhelm von Auxerre wird eine solche verheologie und sucht. Dieselbe geht in der Form einer fortschreitenden Verengung vor sich. Im Gegensatz zu Anselm ist bei Albertus Magnus und Thomas das innergöttliche trinitarische Leben nicht mehr Vernunftwahrheit, das Erlösungswerk nicht mehr Vernunftpostulat. Es gibt Mysterien des Glaubens, hinsichtlich derer die Vernunft erhobene Einwendungen als unbegründet auflösen kann, auch zeigen kann, daß die Sätze des Glaubens ihren eigenen Fragen entgegenkommen, ohne aber imstande zu sein, demonstrative Beweise dafür zu geben. Wohl ist sie dagegen fähig, aus sich heraus und mit ihren eigenen Mitteln über die Natur des Menschen, über die allgemeinen Bestimmungen der Wirklichkeit und über Gott als Ursache der Schöpfung ausreichende Bestimmungen zu bieten. Mit Hilfe schon des natürlichen Lichtes der Vernunft vermag der Philosoph eine Metaphysik aufzubauen von dem, was in der Weltschöpfung begründet ist, sowie von der letzten Ursache derselben, der Gottheit, soweit nicht deren Wesen an sich, sondern ihre Ursächlichkeit in Betracht kommt.

Dieses metaphysische Lehrgebäude, das bei Thomas in machtvoller Geschlossenheit entwickelt ist, wurde in der Folgezeit dann freilich - einzelne Gegenströmungen, wie bei Raymundus Lullus und Raymund von Sabunde, abgerechnet - mehr und mehr zugunsten des ausschließlichen Glaubensgebietes eingeschränkt. Duns Scotus z. B. erkennt die Unsterblichkeitsbeweise wenigstens nicht als stringente an. Bei dem Nominalisten Occam erscheint die Einheit Gottes, ja im Grunde auch seine Existen/, als bloße Glaubenswahrheit. Die Metaphysik ist einem kritischen Empirismus gewichen, der für die tiefergehenden Fragen allein auf den übernatürlichen Glauben verweist. Man begreift daraus die Macht, mit welcher dem entgegen in der Zeit der Renaissance der Platonismus die Gemüter ergreift.

Die Abgrenzung eines über die Vernunftbeweise hinausgehenden Glau- 
bensgebietes von dem Gebiete des Vernunfterkennens ist übrigens nicht allein Resultat einer Reaktion der positiven Theologie. Auch das philosophische Denken sucht von sich aus seine Selbständigkeit zu gewinnen. Dazu trug vor allem der mächtige Aufschwung bei, den das mittelalterliche Philosophieren durch das Bekanntwerden der metaphysischen, naturphilosophischen und psychologischen Schriften des Aristoteles sowie der arabischen und jüdischen philosophischen Literatur nahm. Hier lag nicht mehr bloß eine Logik, sondern eine ausgeführte Philosophie vor; diese aber war, soweit nicht der mohammedanische Kalâm und die jüdische Religionsphilosophie in Betracht kam, ohne Beziehung zur Theologie entwickelt. In der Artistenfakultät, namentlich der zu Paris, fand sie begierige Aufnahme.

ह) "Doppelte Wahrheit"“.

Ablebnung der "doppelten Wahrbeit" in der fuibrenden Scholastik.
Daraus ist zuerst ein scharfer Gegensatz hervorgegangen. Er spricht sich aus in der Annahme einer "zwiefachen Wahrheit", in dem Satze, daß etwas wahr sein könne in der Philosophie, falsch in der Theologie, und umgekehrt. Ansätze zu einer solchen Ansicht fanden sich schon früher bei christlichen Denkern, die durch eine weitgehende Allegorisierung oder durch sonstige Deutungskünste den üblichen Glaubensformeln einen esoterischen Sinn gaben. So lehrt Eriugena eine Schöpfung aus nichts; allein das Nichts ist ihm, wie der Vedantaphilosophie und der Kabbala, das über alles bestimmte Sein erhabene unendliche göttliche Wesen. Besonders aber hatte die arabische Philosophie in dieser Weise zur mohammedanischen Glaubensquelle, dem Koran, Stellung genommen. Nach Averroës ist der gewöhnliche Gläubige an die bildhafte Hülle des philosophischen Gedankens, wie sie im Koran vorliegt, als an die Wahrheit gebunden; der Mann der Demonstration dagegen ist gehalten, sie fallen zu lassen und der philosophischen Wahrheit zuzustimmen. Mit dem Averroismus verbreitet sich jene Formel dann auch im lateinischen Abendlande. Ihre Auffassung war freilich nicht stets dieselbe. Bald stellt sie der bildhaften Einkleidung den bildlosen Inhalt gegenüber, bald soll sie widerstreitende Sätze, mit denen philosophische und theologische Autoritäten sich gegenüberstehen, decken. Übrigens ist sie auch im letzteren Falle nicht immer der Ausdruck charakterloser Unwahrheit oder Feigheit. Oft auch spricht sich die innere Zwiespältigkeit des zwischen entgegengesetzte Strömungen gestellten Menschen darin aus.

Es ist begreiflich, daß jener Satz von der doppelten Wahrheit dem heftigsten Widerstande begegnete. Die psychologische Beschaffenheit des mittelalterlichen Geistes war eine viel zu einheitliche, um ihm allgemein und dauernd zuzustimmen. Versammlungen der Pariser Magister verwerfen ihn; Albert, Thomas und viele andere finden, daß er den Widerspruch in den Urquell der Wahrheit, in Gott selbst, hineintrage. Dem im Glauben stehenden und von seiner Wahrheit erfüllten Denker ist es a priori gewiß, daß das in den Glaubensquellen fortlebende Wort der göttlichen Offenbarung einerseits, die Stimme Gottes in Natur und Vernunft andererseits sich nicht widersprechen können, und daß jeder Widerspruch darum, wie Thomas mit Augustin und Maimonides lehrt, nur ein scheinbarer sein könne, durch Mißverständnisse 
entweder des Theologen oder des Philosophen herbeigeführt. Nicht als ob man den Glauben zum Ausgangspunkte des Philosophierens machte - das geschieht nur in der theologischen Spekulation -; aber die Kirchenlehre erscheint in den Fragen, in welchen sich Glauben und Wissen berühren, vor allem in den metaphysischen, àls Maßstab für die wertende Beurteilung. Die Dogmen sind nicht konstitutive, wohl aber regulative Prinzipien. Sie liefern nicht den Inhalt des philosophischen Denkens - philosophische Fragen sollen philosophisch, nicht theologisch behandelt werden, verlangt Albert -; wohl aber schließen sie es zwischen Richtlinien ein. Wo uns auch in den Kreisen der theologischen Denker gewisse Anklänge an die Entgegensetzung einer theologischen und einer philosophischen Wahrheit begegnen, wie bei Duns Scotus und im Nominalismus, da soll im Grunde nur gesagt werden, daß beim Theologen, indem er neue Gebiete hineinziehe, auch die Betrachtungsweise eine andere werde, und daß daher ein in der Beschränkung richtiger Satz für jenen seine unbeschränkte Geltung verlieren könne. Wohl verlangt auch Scotus eine schärfere Sonderung von Theologie und Philosophie; aber voll hat den Satz von der "doppelten Wahrheit" erst Johann von Janduno und dann wieder in der Renaissance Pietro Pomponazzo erneuert.

Umgekehrt finden wir bei Raymundus Lullus eine Erneuerung des älteren Standpunktes. Er erläutert das Verhältnis des Glaubens und des Wissens durch den Vergleich mit einem Manne, der eine Leiter hinansteigt. Zuerst muß der eine Fuß - der Glaube - die unterste Sprosse betreten, dann kann der zweite - das Verstehen - nachfolgen. Indem dieser Vorgang sich Stufe um Stufe wiederholt, steigen credere und intelligere in einträchtigem Bündnis.

2. Die mittelalterliche Philosophie nach ihrem Inhalt. Durch jene Einheit von Wissen und Glauben, durch die Verbindung von Theologie und Philosophie erhält nun auch die mittelalterliche Weltanschauung ihr charakteristisches Gepräge; denn die Weise des Denkens bestimmt zugleich die Grundzüge seines Inhaltes.

Wenn wir von der mittelalterlichen Weltanschauung reden, so sehen wir hier ganz davon ab, zu untersuchen, wie das mittelalterliche Leben in seinen Gesinnungen und Motiven, in seinen Bestrebungen und Zuständen sich tatsächlich gestaltete. An dieser Stelle halten wir uns allein an das, was die führenden Geister, und zwar diese, soweit sie zugleich als philosophische Denker auftreten, als ideale Forderung aufstellen und durch ihre wissenschaftliche Spekulation zu begründen trachten. Und auch hier beschränken wir uns darauf, zu entwickeln, wie im Geiste jener Denker der Sinn des Lebens sich ausdrückt, wie sie die Werte für die Beurteilung dessen, was wirklich ist, gewinnen, und worin sie diese zielgebenden Werte finden. Die Zergliederung der rein theoretischen Elemente des mittelalterlichen Weltbegreifens dagegen möge dann in Form einer Übersicht über die Gegenstände der mittelalterlichen Philosophie sich anschließen.

Nirgendwo sind Theologie und Philosophie im mittelalterlichen Geiste

a) Allgemeine Weltanschauung

c) Lhr trans zendenter Charakur. 
so unlösbar miteinander verbunden wie da, wo man die Werte des Lebens und seiner individuellen und sozialen Gestaltungen festzusetzen sucht. Das religiöse Interesse im allgemeinen gibt hier der Weltanschauung die Grundrichtung, die besondere theologische Erfassung des Religiösen in ihrer spezifisch mittelalterlichen Form bestimmt die Ausführung. Darum wird das diesseitige Leben und Schaffen in erster Linie als Vorstufe für das Jenseits betrachtet. Dem Jenseitszwecke sind alle individuellen und sozialen Diesseitszwecke unterzuordnen. Sie haben nur einen relativen Wert. Der Jenseitszweck aber geht über das hinaus, was der bloßen Natur erreichbar ist. Über dem Reiche der Natur schwebt das der Gnade, die im Diesseits erhebt, im Jenseits vollendet. Weil alle Diesseitszwecke jenem Jenseitszwecke unterworfen erscheinen, so ist eine gesonderte Betrachtung des irdischen Lebens in seiner immanenten Entwickelung und nach seinen immanenten Werten dem mittelalterlichen Denken ursprünglich fremd. Das Diesseits wird von Haus aus unter den transzendenten Gesichtspunkt gestellt. Dieser transzendente Gesichtspunkt aber für die Wertung alles rein Menschlichen weist, wenigstens von Haus aus, nicht zwei Stufen auf, die der natürlichen Theologie und die der positiven Religion, sondern die Offenbarungstheologie selbst nimmt die philosophische Spekulation in sich auf und umfaßt in einer Schau Natürliches und Ưbernatürliches. Darum gibt es auch im Mittelalter eine rein philosophische Ethik als selbständiges System, wie bei Aristoteles und in der Stoa, kaum. Ausnahmen kommen vor. So ist die moralische Abhandlung des Martin von Braga, ebenso das Werk, welches Wilhelm von Conches seinem Zögling Heinrich Plantagenet, dem späteren englischen Könige, widmete, nicht von theologischen Gesichtspunkten beherrscht, und Kommentare zur Ethik des Aristoteles, wie Albert, Thomas, der vielberufene Buridan und andere sie schrieben, fügten sich einem Kreise philosophischer Vorlesungen ein. Aber Abhandlungen, wie die genannten, werden von uns als Abweichung von dem Herrschenden empfunden, und jene Kommentare entbehren selten des theologischen Einschlages, können auch meistens nicht als selbständiger Ausdruck der Lebensauffassung ihrer Verfasser angesehen werden, so wichtig sie immerhin für diese sind.

Die theologische Betrachtung sweise der Scholastik aber hat ihre Eigenart darin, daß sie eine intellektualistisch orientierte ist. Sie geht - natürlich im großen und ganzen genommen - nicht aus, wie die Mystik, von einer Versenkung in das religiöse Erlebnis der Gottesgemeinschaft, auch nicht, wie etwa der spätere Pietismus, von einer Zergliederung des Sündenbewußtseins und des daraus entspringenden Heilsverlangens der Menschenseele, sondern sie stellt in den Vordergrund die Dogmen von Gott, dem Schöpfer, dem Erlöser, dem Vollender. Diese, nicht psychologische, sondern dogmatische Art der scholastischen Theologie bestimmt nun auch die besondere Weise, in der man die Spekulation über Sinn und Ziel des Lebens ausgestaltete. Den Ausgangspunkt bilden nicht psychologische Analysen, sondern metaphysisch-dogmatische Sätze von Gott und des Menschen Ver- 
hältnis zu ihm. Demgemäß erscheint das Sittengesetz, soweit es ein natürliches ist, als Ausfluß des ewigen Gesetzes im Geiste Gottes, und die Ethik hat feststehende, objektiv gültige Regeln aufzusuchen, denen natürlich nicht nur die äußere Handlung angepaßt werden soll, sondern die auch in die innere Gesinnung aufzunehmen sind. Die Auffassung der ganzen Weltordnung als einer theonomen ist der mittelalterlichen Weltanschauung nicht nur Ergebnis, sondern ursprüngliche Voraussetzung.

Innerhalb dieser Rahmens gibt es freilich der Schattierungen gar viele. $\gamma$ ) Asketisch. Eine überwiegend asketische Richtung steigert die Betonung des Jenseitszweckes in dem Maße, daß alles Irdische nur als Hemmung empfunden wird. Nicht allein das Haften am Irdischen, sondern auch die theoretische Beschäftigung mit ihm erscheint schon als Unvollkommenheit und weltliche Gesinnung. - Dieser rein religiösen Stimmung gegenüber, die an Augustins "Gottesstaat" sich orientiert, bringt das Eindringen der aristotelischen Gedankenwelt einen tiefgreifenden Wandel. Nicht nur eröffnet die neugebotene Menge reich gegliederter psychologischer, ethischer und soziologischer Begriffe und Sätze eine Fülle neuer Einzelaussichten, sondern, was weit wichtiger war, das aristotelische Prinzip der inneren Zielstrebigkeit in Natur und Menschenleben gab für die Betrachtung der individual-ethischen und soziologischen Probleme ein ganz neues Hilfsmittel, das zudem mit der rein religiös bedingten Auffassung nicht allzu schwer in Beziehung gebracht werden konnte. Es ließ sich der Gedanke eines allumfassenden Systems der Zwecke durchführen, das vom Diesseits ins Jenseits, von der Natur ins Reich der Gnade reichte, und doch in der Abstufung der Werte auch dem Niederen seine relative Bedeutung nicht nur ließ, sondern sie noch bekräftigte. Jetzt konnte man das Natürlich-Sittliche an der vernünftigen Natur des Menschen messen und als deren Entfaltung betrachten; denn diese vernünftige Natur, die menschliche Persönlichkeit, wird jetzt im Unterschiede von der unvernünftigen Natur als ein wenigstens relativer Selbstzweck gewertet. Nun konnte man auch im Staate die Vollendung der natürlichen Anlage des Menschen als eines Gemeinschaftswesens sehen. Bezeichnend ist es, wie Thomas von Aquino jetzt den Theologen und den Philosophen gegenüberstellt. Es ist der Theologe, der in der Sünde die Beleidigung Gottes ins Auge faßt; der Philosoph dagegen leitet ihre Verwerflichkeit aus dem Widerspruch ab, in welchem sie zur Vernunft steht.

So wird, an sich betrachtet, in der entwickelten Scholastik die theologische und die philosophische Betrachtungsweise unterschieden. Aber darum bildet selbst die entwickelte Scholastik nicht auch eine rein philosophische Weltanschaung aus. Wo es sich um die Deutung des Lebens und seiner Aufgaben handelt, da beschränkt die Philosophie sich auf die untergeordnete Sphäre. Erst die Theologie unternimmt es, das Rätsel nach dem Sinn und der wahren Bestimmung des Lebens zu lösen, und nur in der Unterordnung unter das Transzendente im Sinne der Offenbarungsreligion gewinnt das Diesseitige Wert und Stellung. 
b) Charakter und Gegenstände der spekulativen Weltbetrachtung.

u) Metaphysischer Grundzug des mittel-

alterlichen Welt. begreifens.

Auch dem spekulativen Weltbegreifen der Scholastik ist durch das Hervorwachsen des philosophischen Interesses aus der Forschung des Theologen die bleibende Form mitgegeben. Die Triebkraft nämlich, welche überall dem philosophischen Denken des Mittelalters die charakteristische Richtung verleiht und damit bestimmt, was vom Strome lebendiger Gedankenentwickelung innerlich ergriffen werden kann, was nur mitgeführt wird oder ganz beiseite bleibt, diese herrschende Triebkraft im mittelalterlichen Geiste ist der Sinn für die dem scholastischen Theologen im Blute liegende Metaphysik. Das mittelalterliche Weltbegreifen ist metaphysisch.

Nun ist diese metaphysische Denkrichtung freilich nicht allein aus dem Bunde der Theologie und Philosophie entsprungen. Insofern sie einer eindringenden Beschäftigung mit der Fülle des Konkreten, empirisch Gegebenen abhold ist und mit Vorliebe in der Welt der Abstraktionen sich bewegt, lag sie dem mittelalterlichen Geiste auch wegen all der anderen methodischen Momente der damaligen Forschungsart nahe, die auf eine solche Bevorzugung des Abstrakten hindrängten. Ganz begreiflich war es ja, daß eine Zeit, in welcher anfangs die Fortführung überkommener Gedankenreihen, dann die Durcharbeitung und organische Weiterbildung derselben sowie die Ausgleichung der verschiedenen Ströme der Überlieferung die Hauptaufgabe der wissenschaftlichen Tätigkeit bildeten, weniger Sinn hatte für die Erforschung der äußeren Natur und ihrer Gesetze sowie für die analytische Betrachtung der empirischen Ausgestaltung des individuellen und sozialen Menschenlebens und für die kritische Untersuchung der historischen Wirklichkeit. Naturgemäß wog in ihrem Forschen die abstrakte Denkweise vor. Aber daß gerade die Metaphysik es war, worin diese abstrakte Denkweise bis auf die Zeit eines Occam und anderer Nominalisten hin stets wieder die Gegenstände ihrer Vorliebe suchte, das war eine Folge des Zusammenhanges von Theologie und Philosophie. Wie von selbst verstand es sich, daß das bestimmte Interesse dieser abstrakten Gedankenarbeit durch die theologische Richtung, welche der mittelalterlichen Geisteskultur überall ihren Stempel aufdrückt, vor allem den letzten Fragen der theoretischen Weltanschauung und damit den metaphysischen Untersuchungen zugewendet wurde. Gott als letzte Ursache und als letztes Ziel der Dinge: das ist das gemeinschaftliche Problem der Theologen und der Philosophen.

p) Die Gerrenstinde der mittelalterliche
Philosophte. I. Metaphysik.

Durch diesen metaphysischen Charakter des Denkens werden nun wieder die Gegenstände der mittelalterlichen Philosophie und ihre Behandlungsart bestimmt.

Den Ehrenplatz nimmt natürlicn die Metaphysik selbst ein. Sie erscheint als die Königin der natürlichen Wissenschaften. Noch erstrahlt ihre Krone, von der Kant meint, daß sie inzwischen zur Dornenkrone geworden sei, in hellstem Glanze. Erblickte doch auch Aristoteles, der philosophische Lehrer der Hochscholastik, obwohl weit mehr empirisch gerichtet als Platon, in der Metaphysik die Grundwissenschaft für alles Erkennẹn und die eigentliche Aufgabe des Philosophen. Schon in der werdenden Scholastik, die eine 
besondere Philosophie fast nur als Logik oder Dialektik kennt, nimmt eines ihrer Hauptprobleme, die Frage nach der Natur der Allgemeinbegriffe, im Streit des Nominalismus und Realismus zugleich auch eine metaphysische Wendung. In der Hochscholastik aber ist die Metaphysik sowohl als gesonderte philosophische Disziplin - die mit Vorliebe an die Erläuterung der aristotelischen „Metaphysik“ angelehnt wird —, wie im Zusammenhange theologischer Spekulation zu Systemen von ebenso gewaltiger Größe wie von fein durchgeführter Gliederung entwickelt, gleich den gotischen Domen, in denen die Zeit ihre künstlerische Gestaltungskraft zum Ausdrucke brachte. Viele der damals aufgestellten metaphysischen Probleme, Begriffe und Unterscheidungen haben ihre unverwüstliche Lebenskraft auch dadurch bewiesen, daß sie, sei es in der ursprünglichen oder in umgestalteter Form und in neuen Zusammenhängen, auch in der neueren Philosophie immer wieder durchbrechen.

Auch Psychologie und Ethik tragen im Mittelalter diesen metaphysischen Charakter. Das Seelenwesen und sein Verhältnis zum Leib, die Natur seiner Vermögen und deren Abgrenzung interessieren die Denker mehr als die genaue Beschreibung und Zergliederung der empirisch gegebenen psychischen Tätigkeiten. Während ferner Aristoteles in seiner individualen und sozialen Ethik für die Normbestimmung des Sittlichen und des Gerechten den Maßstab mehr empirisch dem zu entnehmen pflegt, was die Besten und Weisesten seines Volkes übereinstimmend lobenswert finden, sucht die mittelalterliche Ethik und Rechtsphilosophie für das moralische und rechtliche Vernunftgesetz in einer lex aeterna die metaphysische Grundlegung zu gewinnen. Erst im späteren Nominalismus schwindet, wie wir sahen, mehr und mehr dieser metam physische Geist, um einerseits einem theologischen Supranaturalismus, andererseits einem philosophischen Empirismus und einem einseitigen Ausbau logischer Subtilitäten (bei den „Terministen“) Platz zu machen.

Hinter dem positiven Aufbau der Metaphysik tritt die erkenntnistheo- 2. Zurücktreten retische Kritik, hinter der Entwickelung des Objektiven die Prüfung des Subjektiven zurück. Von vornherein ist man überzeugt, durch das Denken an das Sein heranzukommen. Die Theorie der substanzialen Formen dient dazu, die Auffassung des Erkennens als eines Abbildens festzuhalten. Freilich fehlen kritische Erörterungen keineswegs völlig. Bestimmte Untersuchungen über die Natur des menschlichen Erkennens und seine Beziehungen zur Wirklichkeit durchziehen die ganze Geschichte der Scholastik. Es braucht nur auf den Streit des Nominalismus und Realismus hingewiesen zu werden, in dem Logik, Metaphysik und Erkenntnistheorie sich ein Stelldichein geben. Der subjektive Einschlag beim Erkenntnisprozeß wird hierbei nicht ganz übersehen. Aber eine systematische Pflege findet die Erkenntnistheorie nicht. Der Sinn des Mittelalters ist zu positiv oder dogmatisch - d. h. dogmatisch im antiken Sinne, in welchem das Wort nur den Skeptizismus ausschließen soll -, um bei einem jeden metaphysischen Grundbegriff und Grundprinzip das Bedürfnis einer erkenntnistheoretischen Auseinandersetzung, möge diese nun 
zur Bestätigung oder zur Begrenzung führen, zu empfinden. Es fehlt der skeptische Gegensatz. Bezeichnend ist es, daß das Werk des Sextus Empiricus über die pyrrhonische Skepsis in einer mittelalterlichen lateinischen Übersetzung vorliegt, aber so gut wie nirgends berücksichtigt wird. So kommt es, daß man bis ins feinste die Natur und die Arten der Substanz, ihr Verhältnis zum Akzidens usw. untersucht, aber auf die Motive, die zur Bildung des Substanzbegriffes führen, nicht näher eingeht. Ebenso bestimmt man nach dem Vorgange des Aristoteles die mannigfachen Arten der Ursache und die Weise der Kausalität einer jeden, untersucht mit dem Neuplatonismus die Verkettungen in einer Ursachenreihe und behandelt eingehend das Zusammenwirken der zweiten Ursachen mit den ersten; das Kausalgesetz selbst aber erscheint, wie übrigens auch noch bei Descartes, als metaphysisches Axiom. Denn wenn es auch mit Aristoteles auf das Verhältnis von Akt und Potenz zurückgeführt wird, so liegt den Aufstellungen über dieses Verhältnis das Kausalgesetz selbst schon zugrunde. Auch die Anwendung des Zweckbegriffes auf die Natur und die Begründung der teleologischen Naturansicht wird, wie bei Aristoteles, mit einigen Bemerkungen abgetan. Gerade bei solchen letzten Fragen fehlt noch die erkenntnistheoretische Rechtfertigung. Erst als der Nominalismus die scholastische Metaphysik zur Auflösung brachte, traten energischere Motive zu einer solchen Prüfung auf. Nicht nur eine Reihe metaphysischer Sätze wird hier bestritten, $z$. B. von Occam, sondern die Grundlagen der mittelalterlichen Metaphysik selbst werden in Zweifel gezogen. Jetzt greift Nikolaus von Autrecourt den Substanz- und Kausalbegriff selber an, mit Einwendungen, die zum Teil an Locke, Hume und Kant erinnern. Wenn Pierre d'Ailly es für denkbar erklärt, daß unsere Wahrnehmungsvorstellungen von der Welt fortbeständen, wenn diese selbst auch in das Nichts zurücksänke, so glauben wir Descartes reden zu hören. Aber zu einer durchgeführten Erkenntnistheorie ist es auch damals nicht gekommen. Die eine Partei erschöpft sich in der Negation, die andere erkennt nicht die Bedeutung der Probleme, welche den ihnen unbegreiflichen Negationen zugrunde lagen. Hier fördert erst eine neue Zeit Problemstellungen, die schon lange sich emporrangen, rein zutage.

3. Pflege der Begriffskunst. Logik.

Metaphysisches Denken hat allezeit nicht so scharf auf die Analyse empirischer Tatsachen, als auf die Durchbildung der Begriffe Wert gelegt. Werden diese Begriffe auch in einer besonnenen Metaphysik an die empirische Grundlage angeknüpft, so gewinnen sie doch selbst dann leicht selbständiges Leben. Wie in der Leibniz-Wolffschen Metaphysik, so ist dieses auch in der mittelalterlichen der Fall. In der Begriffskunst hat die mittelalterliche Philosophie eine hervorragende Stärke. Es ist bereits darauf hingewiesen, wie eine große Zahl dieser scholastischen Begriffe mitsamt der zugehörigen Terminologie schon durch ihr unverwüstliches Nachleben auch in der neueren Philosophie ihre Bedeutung bewiesen hat. Dabei handelt es sich durchaus nicht ausschließlich um antikes oder patristisches Lehngut, sondern vielfach um eigenartige mittelalterliche Gebilde. Diesen hat die ununterbrochene 
Durchbildung im Laufe einer langen Schultradition zugleich eine vorbildliche Schärfe, Feinheit und Bestimmtheit verliehen.

Aber auch die Kehrseite darf nicht übergangen werden. Indem man im Kampfe der Schulen vom Boden gemeinschaftlicher Voraussetzungen aus mit Hilfe einer immer schärferen Zuspitzung der Begriffe und einer stets gesteigerten Feinheit der Unterscheidungen sich gegenseitig zu überbieten trachtete, ist man nicht selten zu einer empirielosen, kritisch nicht gezügelten Begriffskunst gelangt, bei der die schlichten sachlichen Probleme schließlich in lauter Feinheiten zerrieben werden und der Verstand sich in Begriffsspielerei verliert. Namentlich bei den Epigonen - und deren gab es zu allen Zeiten, auch im Mittelalter - ist dieses der Fall. Die letzten Probleme in sich selbst selbständig $z u$ erleben, haben diese völlig verlernt; die Grundanschauungen und die Grundbegriffe nehmen sie als ein Gegebenes hin und schmieden nun im Reiche verstiegener Abstraktionen ihr Rüstzeug für Disputation und Wortgezänk. Sie vor allem sind es, die dem Begriff der "Scholastik“ und des „Scholastischen“ die übliche Nebenbedeutung weltabgewandter Begriffsspalterei gegeben haben.

Ihr formales Instrument hatte jene Begriffskunst in der Logik. Auch diese trägt im Mittelalter spezifische Züge. Die mittelalterliche Logik konnte nicht Methodenlehre der empirischen Forschung sein; denn diese empirische Forschung selbst ist noch zu wenig entwickelt. Darum hat das induktive Denken in der Scholastik keine Darstellung gefunden, die seinen besonderen Aufgaben gerecht würde. Alles dagegen, was diejenige Form des Denkens, welche in einer Pyramide vorausgesetzter fester Begriffe auf- und absteigt, von Mitteln begrifflicher Kombination und begrifflicher Unterscheidung verwenden kann, ist mit virtuoser Exaktheit entwickelt. Es sei nur auf die Technik des Syllogismus hingewiesen, auf die Systematik der syllogistischen Modi und deren kunstvolle Terminologie, die in den Vokalen und Konsonanten der Barbara, Celarent, Darii, Ferio, der Cesare, Camestres usw. eine Beschreibung der Modi und zugleich eine Anweisung bietet, die Modi der übrigen Figuren auf die der ersten zurückzuführen; ferner auf die Lehre von den logischen Bedeutungsverhältnissen der Wörter (von ihrer „Supposition“). Natürlich darf man in jener Syllogistik nicht eine praktische Anweisung zum Denken und zum Auffinden der Wahrheit suchen. Rein theoretisch aber hat sie Berechtigung, wenngleich nicht verkannt werden soll, daß gar vieles darin, wie in den anderen Bestandstücken dieser Logik, überflüssiger Ballast ist. Mehr und mehr ausgeartet ist dann die logische Schulweisheit im späteren Mittelalter, besonders im Nominalismus. Wenn hier von den "Terministen" die logische Bedeutungslehre, die Lehre von der Supposition der Termini mit Einschluß der „Ampliation" und der "Restriktion“, bis ins Ausschweifende entwickelt wird, wenn uns in den „Obligatoria“ immer neue Anweisungen für den Disputationskomment geboten werden, dann haben wir solchen Gebilden müßigen Scharfsinns gegenüber eine starke Empfindung des Überdrusses. Wir verstehen das Gefühl der Befreiung, das der Humanismus bei der Rückkehr zu dem einfacheren Aristoteles und Cicero empfand. 
1. Zurücktreten der empirischen Forschung

Daß dem metaphysischen Hochflug, den die mittelalterliche Philosophie besonders in den machtvollen Systemen des I 3. Jahrhunderts nahm, die beobachtende und zergliedernde Versenkung in das Einzelne der physischen und geschichtlichen Wirklichkeit und deren empirischen Tatbestand nicht gleichkam, wurde schon mehrfach berührt. Ein eigentlicher historischer in Geschichte Sinn fehlt dem Mittelalter, das mehr in der Abstraktion und dem Allgemeinen, als in der Betrachtung des Besonderen und Persönlichen lebt und gegenüber der begrifflichen Deduktion der Inhalte des Gewordenen auf das historische Begreifen des Werdens selbst keinen Wert legt. Verleitet von der ewigen Gültigkeit zeitloser abstrakter Wahrheiten, faßt man gern die Produkte historischer Entwickelung als ein von Anfang an Vorhandenes. Manches, was in den Ideen und Einrichtungen auf politischem, kirchlichem und sonstigen Gebieten erst allmählich sich ausgebildet hat, wird in die Vergangenheit zurückprojiziert. Fragen, die nur historisch zu lösen sind, sollen durch begriffliche Deduktion von oben herab entschieden werden. Historische Kritik fehlt noch fast gänzlich; eher greift man zu den seltsamsten Erklärungsversuchen vermeintlich historischer Tatsachen. Mancher scheut, seiner Theorie zuliebe, selbst vor Erdichtungen, ja Fälschungen nicht zurück und findet Gläubige dafür.

So ist auch die philosophische Auffassung des Mittelalters, gleich der der Aufklärungszeit, unhistorisch. Auch sie hat bei der Wertung vergangener Geistesarbeit kemen Sinn für die relative Berechtigung, welche auch dem Unvollendeten und Einseitigen im Werdegang zukommen kann. Sie liebt es, wie in der Theologie so auch in der Philosophie, alles mit absoluten Maßstäben nach seinem abstrakten Wahrheitsgehalt zu messen. Und doch sind die zu einer Zeit geltenden Maßstäbe der philosophierenden Vernunft ja selbst in den Strom des Werdens hineingestellt.

Begreiflicherweise hat das Mittelalter bei dieser Denkweise nur ein geringes Interesse für die Geschichte der Philosophie, ebenso wie es keine theologische Dogmengeschichte kennt. Die philosophischen Leistungen der Vorgänger werden benutzt wie ein antiker Tempel, dem man nicht nur Quadern, sondern auch behauene Säulen mit ihren Kapitälen entnimmt, ja den man vielleicht, wie Agrippas und Hadrians Pantheon, ohne weiteres unter leichten Umänderungen für den eigenen Gebrauch herrichtet, ohne über seine Geschichte und seine kunsthistorische Stellung sich weitere Gedanken zu machen. Freilich darf hier nicht alles in Bausch und Bogen beurteilt werden. Ganz abgebrochen ist in der Zeit zwischen Altertum und Humanismus aucn auf philosophiegeschichtlichem Gebiete der Faden der Überlieferung nicht. Boten doch auch z. B. Augustin in seinen Büchern vom Gottesstaate und Hrabanus Maurus in seiner Schrift über das Universum mancherlei historische Notizen dieser Art. So hält denn auch Roger Bacon es für nötig; in sein Opus maius einen knappen philosophiegeschichtlichen Abriß einzuschieben, der vor allem die Griechen behandelt, übrigens auch der Araber Erwähnung tut. Eine Liste von Phitosophrn reiht Konrad ron Mure seinem ,Fabularius"(1272/73) ein. Die Biouraphien des laertius Diogenes kannte man in einer, wie es scheint, im 12. 
oder 1 3. Jahrhundert entstandenen lateinischen Übersetzung. Walter Burleigh hat danach, sowie nach. Cicero und anderen lateinischen Autoren, eine Philosophengeschichte verfaßt. Allerdings zeigen gerade die zahlreichen Irrtümer und Verwechselungen in dieser historischen Kompilation, wie weit man von wissenschaftlicher Exaktheit entfernt ist. Da kann es uns denn natürlich nicht mehr wundern, wenn ein gelehrter, aber unhistorischer Polyhistor, wie Albertus Magnus, den Sokrates und den Platon zu Stoikern macht und unter den Epikureern den Hesiod aufzählt. Doch fehlt es auch im Mittelalter nicht ganz an vereinzelten Ansätzen zu literarhistorischer Kritik. So wenn der ebengenannte Albert von der angeblichen Autorität des "Hermes Trismegistus" sich nicht verblüffen läßt, ja auch eine Augustin zugeschriebene psychologische Schrift als unecht erkennt, und wenn Thomas das Buch ,über die Ursachen" dem Aristoteles abspricht und als Kompilation aus dem Neuplatoniker Proklus erweist.

Auch auf dem Gebiete der Natur ist die Überzeugung von dem Werte des Tatsächlichen und von der Notwendigkeit einer steten Kontrolle an der Erfahrung nur mäßig entwickelt. Völlig geruht hat freilich das Interesse für empirische Forschung auf naturwissenschaftlichem Gebiet, sowie für Mathematik und mathematische Naturbetrachtung, auch in jener Zeit keineswegs. Gewiß liebte man eine oft spielende geistliche Symbolik der Natur, wie sie z. B. der "Physiologus" in seinen Tierfabeln bietet, oder Hrabanus Maurus, wenn er in seiner Schrift über das Universum jedesmal auch über die mystische Bedeutung der Dinge handelt. Aber wenn man annimmt, der asketische und supranaturalistische Geist des Mittelalters habe allgemein in der wissenschaftlichen Beschäftigung mit der Natur und mit natürlichen Dingen ein Unrecht erblickt, so liegen hier fast durchweg Mißverständnisse vor. Mit Ehren vertreten Gerbert, Nemoranus, Bradwardin u. a. die Mathematik. Die Optik und andere Zweige der mathematischen Physik finden bei Grosseteste, Roger Bacon, Peckham, Witelo verständige Pflege. Das zur Charakteristik des Mittelalters oft herbeibeschworene naive Weltbild des Kosmas Indikopleustes, jenes Reisenden und späteren ägyptischen Einsiedlers des 6. Jahrhunderts, welcher die Erdoberfläche sich als ein flaches Parallelogramm vorstellt, überdeckt von dem auf vier Wänden aufliegenden gewölbten Himmelsdach, ist keineswegs aus der mittelalterlichen Denker. Für diese hatten vielmehr schon Isidor von Sevilla und Beda die Lehre von der Kugelgestalt der Erde festgelegt, die auch an Albert dem Großen - der auch die ron Laktanz u. a. aus theologischen Gründen bestrittenen Antipoden energisch verteidigt - , an Thomas von Aquino, Vinzenz von Beaurais, Roger Bacon u. a. entschiedene Anhänger hatte. Alberts Werke über die Pflanzen und seine Tiergeschichte weisen neben dem Übernommenen auch eine Reihe selbständiger Beobachtungen und systematischer Gedanken auf. Und wenn das Mittelalter auch keine auf mathematischer Theorie sich aufbauende Technik kennt, so legen doch seine gewaltigen Architekturwerke nicht nur nach der ästhetischen, sondern auch nach der statischen Seite hin Zeugnis 
$\mathrm{ab}$ von einem empirisch erworbenen sicheren Instinkt und einem reichen technischen Können, das auch hier in einem schulmäßigen Zusammenhange, dem der Hütten, überliefert und erweitert wird.

Bei all dieser Anerkennung darf indes nicht übersehen werden, daß die beiden Grundlagen der über eine bloße Beschreibung hinausgehenden modernen Naturwissenschaft dem Mittelalter doch fremd sind: das die Bedingungen vereinfachende und der Kontrolle unterstellende Experiment und die quantitative Bestimmung vermittels entwickelter mathematischer Methoden und Hilfsmittel. Wo, etwa von den Alchimisten, experimentiert wird, da sind diese Experimente doch planlos dem Zufall anheimgestellt. Selbst in dem älteren Sinne des Wortes „Experiment", in welchem dasselbe die planvolle überlegende Beobachtung des freien Naturverlaufes bedeutet, kommt es nur wenig zur Anwendung. Jedenfalls aber hat das philosophische Denken sich jener wahren Grundlagen der Naturerkenntnis nicht bemächtigt und ihre Bedeutung für Forschung und Wissensbetrieb nicht klargestellt. Nicht nur die einzelnen Sätze auf dem Felde der Physik und Chemie, der Biologie, der Astronomie und Meteorologie usw. sind es darum, die dem Mittelalter fehlen, sondern vor allem die allgemeinen Methoden und Anschauungsweisen, durch die seit dem 16. Jahrhundert auf allen diesen Gebieten die Fülle der Einzelentdeckungen sowie der zusammenfassenden und weiterfördernden Theorien herbeigeführt wurde, welche der modernen Kultur die geistige und materielle Naturbeherrschung ermöglichten.

Infolgedessen ist das Mittelalter weder zu einer klaren Einsicht in das Wesen und die Tragweite der Naturgesetzlichkeit, noch zu den rechten Mitteln ihrer Erfassung gelangt. Auch im Studium der Natur herrscht eine dialektische Begriffsphilosophie, welche sich mit dem Festhalten an der Autorität und der durch diese gedeckten Weisheit der Bü cher verbindet. Die Dinge selbst treten zurück. A ber Begriffsdistinktionen, auf unzulängliche Induktionen gestützt, anstatt chemischer Analysen, Syllogismen aus vermeintlichen Axiomen anstatt experimenteller Forschung konnten zu einem wirklichen Wissen von den Gesetzen und Gestaltungen der Natur nicht führen. Mit den zunächst der künstlerischen Produktion entnommenen bequemen Begriffen von Akt und Potenz, von Form und Materie z. B. ließen sich der Forschung wohl Programme und Richtlinien, aber kein Inhalt geben. Wo sie als Erklärung selber gelten sollen, da verbauen sie dem Eindringen in die realen Ursachen und ihre Wirkungsweise nur den Weg. Ebenso ist die der griechischen und mittelalterlichen Philosophie so charakteristische teleologische Betrachtungsweise auch auf dem Gebiete des Naturgeschehens und des natürlichen Werdens keineswegs ohne Wert. Stets aufs neue wieder tut sie ihre Bedeutung dar, indem sie der Forschung als heuristisches Mittel und ordnendes Prinzip dient und für die harmonische Verkettung zusammenwirkender Kausalreihen wenigstens hypothetische Versuche einer Erklärung aufzustellen erlaubt. Aber damals glaubte man gar zu oft durch angebliche Axiome teleologischen Charakters, wie den Satz, daß die Natur es nie an dem Nötigen fehlen lasse, 
das Naturgeschehen selbst wissenschaftlich schon begründet zu haben. Man weiß, wie gerade dieser Mißbrauch des teleologischen Gedankens in der Periode der sich entwickelnden neuen Wissenschaft den Gegensatz weckte, der zur Ausbildung oder Erneuerung einer zunächst freilich gleichfalls noch einseitigen mechanischen Natur- und Weltanschauung führte.

Der Mangel naturwissenschaftlicherForschungsmethoden und diefehlende 5. Psychologie. Einsicht in die Wichtigkeit der exakten Bearbeitung eines möglichst vielseitigen empirischen Tatsachenmaterials mußten sich naturgemäß auch auf dem psychologischen Gebiete geltend machen. Schon oben wurde darauf hingewiesen, daß die Analyse der psychischen Erscheinungen und ihrer empirischen Gesetze hinter der metaphysischen Konstruktion zurücktrat. Und wenn auch gelegentlich einmal sogar Hypothesen psychophysischer Natur aufgestellt werden, z. B. über die Lokalisation psychischer Funktionen in den Gehirnventrikeln, so sind doch im einzelnen die anatomischen und physiologischen Vorstellungen ebenso unzureichend wie die physikalischen Erklärungen von Licht, Farbe, Wärme usw. Um so mehr möge hier hervorgehoben werden, das es immerhin zu Ansätzen zu einer introspektiven Analyse der psychischen Phänomene selbst nicht ganz fehlt. So suchte Johannes von Salisbury in oft freilich überschätzten Ausführungen das Ineinandergreifen niederer und höherer Erkenntnisfunktionen zu begreifen. Thomas von Aquino untersucht die Affekte und benutzt die Einheit des Selbstbewußtseins in seiner Polemik gegen Averroës. Im Anschluß an Alhacen entwickeln Witelo und Bacon die bei der Auffassung der Tiefendimension wirksamen assoziativen Vorgänge. Durandus, Occam und andere Spätere bemühen sich, frei von apriorischer Konstruktion die bei der Begriffsbildung tatsächlich wirksamen psychischen Elemente zu ermitteln.

Was endlich die praktische Philosophie anlangt, die man nach aristo- 6. Praktische telischer Einteilung in Ethik, Politik und Ökonomik gliederte, so haben wir den in ihr herrschenden Geist und ihren Entwickelungsgang schon geschildert. Wir haben ihren transzendenten Zug, ihre enge Beziehung zur Theologie, ihre metaphysische Methode aufgezeigt, aber auch hervorgehoben, wie viele neue Anregungen gegenüber dem ausschließlich asketischen Standpunkte man aus dem aristotelischen Zweckgedanken, aus der aristotelischen Tugendlehre und der aristotelischen Gesellschaftsphilosophie schöpfte. Es braucht nur auf die Naturrechtslehrer des 16. und 17. Jahrhunderts hingewiesen zu werden, um die Bedeutung der mittelalterlichen Philosophie für die Kontinuität der philosophischen Entwickelung auch auf diesem Gebiete zu belegen.

So viel zur Charakteristik der mittelalterlichen Pnilosophie des europäischen Mittelalters nach Entstehung, Denkweise und Hauptgegenständen. Unsere Zergliederung dürfte gezeigt haben, was wir von jener zu erwarten haben, und was sie zu bieten nicht imstande ist. So werden wir, scheint es, von vornherein vor zwei Extremen bewahrt: vor der Überschätzung, die in der mittelalterlichen Philosophie eine absolute Wahrheitsregel erblicken 
möchte, wie vor der Unterschätzung, die ihr jeden Kulturwert am liebsten ganz absprechen möchte.

Besondere Bedeutung der Quellen für die Scholastik.

a) Plato und platonischer Ǩreis.
II. Die Quellen der mittelalterlichen Philosophie. Es wurde schon früher hervorgehoben, daß die mittelalterliche Philosophie als Schulwissenschaft, für welche der rezeptive Charakter und die Hochschätzung der Autorität, das Überwiegen des traditionellen Elementes gegenüber der persönlichen Eigentümlichkeit und eine weitgehende Übereinstimmung in den Grundanschauungen hervorstechende Züge abgeben, von dem Historiker eine andere Weise der Darstellung verlangt, àls wie sie für die antike und die moderne Philosophie sachgemäß ist. Der Geschichtschreiber der Scholastik hat Wert darauf zu legen, auch das Gemeinschaftliche und Übereinstimmende herauszuarbeiten, um so das eigentümliche Verhalten der Schulen und Schulhäupter den Strömen der Tradition gegenüber klarlegen und dadurch dem einzelnen seine Stellung anweisen zu können. Schon die vorstehende Charakteristik bot Gelegenheit, wichtige Elemente dieses gemeinsamen Bestandes zu entwickeln. Weiteres wird sich aus einer Analyse der $Q$ uellen der Scholastik und ihrer Bedeutung für die mittelalterliche Philosophie ergeben.

Zweifach war das übernommene Material, welches dem Mittelalter zu seinem Philosophieren die Anregung gab und ihm einen großen Teil des Inhaltes übermittelee: die griechische Philosophie und die patristische Spekulation. Später trat als dritte Quelle die orientalische Philophie der Araber und Juden hinzu. Aber diese war selbst nicht durchweg originell, sondern auch ihrerseits durch die griechische Philosophie bedingt. Wir werden ihrer später im Zusammenhange mit der von ihr angefachten neuen Bewegung gedenken.

I. Die griechische Philosophie. Durch die griechische Philosophie hat das mittelalterliche Denken zweimal bestimmende Anregungen erfahren, in seinem Beginn und wieder in der Gärungsperiode, welche die Scholastik des i 3 . Jahrhunderts einleitet.

In der Zeit der werdenden Scholastik ist es vor allem Plato, vor dessen übermächtiger Größe man sich als lernender Schüler beugt. Ihn preist Adelhard von Bath als "Fürsten aller Philosophen", und noch für Alanus von Lille ist Plato der "Philosoph" schlechthin, während Aristoteles damals höchstens in logischen Schriften, wie bei Notker von St. Gallen, als solcher auftritt. Seinem durch Cicero und Chalcidius (wenigstens zum Teil) in das Lateinische übertragenen Timäus entnimmt man die Lehre von den Ideen und dem weltordnenden Geiste (dem „Noys"), von der formlosen Materie und den Elementen und vielfach auch die poetische Schilderung der Weltbildung. Später kam die Bekanntschaft mit den Dialogen Meno und Phädo hinzu. Sie wurden im 12. Jahrhundert in Sizilien durch Henricus Aristippus aus S. Severina in Calabrien auf Wunsch des Großadmirals Majo und des Erzbischofs Hugo von Palermo ins Lateinische übertragen. Dem platonischen Kreise gehörten auch Apulejus und der diesem zugeschriebene, 
mit dem Scheine tiefgründiger Wrisheit prunkende „Asclepius" an; ferner Macrobius, dessen Kommentar zum "Traum des Scipio“ eine Hauptquelle nicht nur für metaphysische Begriffe, sondern auch für Zahlenspekulationen sowie für astronomische und musikalische Kenntnisse war; Chalcidius, mit dem das ganze frühere Mittelalter die aristotelische Definition der Seele als Entelechie des Körpers verwarf, um sich der auch von Augustin gebilligten intellektualistischen Psychologie Platos anzuschließen, und vor allem Boethius, der aristotelische Logik mit platonisierender Metaphysik und pythagoreisierender Zahlenspekulation verband, und dessen Bedeutung für die werdende Scholastik sehr hoch anzuschlagen ist. Auch der spezifische Neu. platonismus mit seiner Lehre von der über alle Kategorien erhabenen, unfaßbaren und unnennbaren Natur des ersten Prinzips, von den Stufen der Schöpfung und der Verkettung der Ursachen fand wenigstens indirekt Eingang, zuerst durch den noch zu nennenden Pseudo-Areopagiten Dionysius, dann durch den auf Proklus zurückgehenden Liber de causis und im 1 3. Jahrhundert durch die lateinische Übersetzung einiger Schriften des Proklus selbst.

Aristoteles ist der älteren Scholastik nur der Logiker. Man hatte von ihm im allgemeinen Gebrauch allein das Organon, welches Boethius zusammen mit der Einleitungsschrift (der "Isagoge") des Neuplatonikers Porb) Aristoteles und aristote. lische Überlieferung. phyr wenigstens zum Teil übertragen und in Kommentaren und selbständigen Schriften erläutert und ergänzt hatte. Und selbst von diesem Organon kannte man lange nur die ersten beiden kleinen Schriften, die in der Übersetzung des Boethius vorlagen, bis im 12. Jahrhundert durch neue Übersetzungen von Jacobus aus Venedig (1128) und von dem schon genannten Aristipp aus S. Severina in Calabrien - der auch das vierte Buch der Meteorologie aus dem Griechischen ins Lateinische übertrug - auch die größeren Schriften des Organons zugänglich gemacht wurden. Noch nicht definitiv geklärt ist die Frage der sogenannten „Ethica vetus", einer Übersetzung des zweiten und dritten Buches der Nikomachischen Ethik, die möglicherweise noch in die vorscholastische Zeit zurückreicht. Durch indirekte Überlieferung bei Chalcidius, Boethius u. a. war auch eine Reihe anderweitiger metaphysischer, naturphilosophischer und psychologischer Begriffe des Aristoteles bekannt und zum Teil sogar geläufig; aber man konnte sie nicht aus der Quelle schöpfen und verhielt sich ihnen gegenüber vielfach ablehnend.

Anders wird dieses, als um die Wende des I 2. und I3. Jahrhunderts mit der arabischen Philosophie auch deren Quelle, Aristoteles, in allen seinen philosophischen Hauptschriften - zu denen auch manches Unechte trat zugänglich wird, in arabisch-lateinischen wie in griechisch-lateinischen Versionen, von denen und deren Verfassern später noch näher gesprochen werden wird. Jetzt ist nicht mehr Plato, sondern Aristoteles gemeint, wenn, wie z. B. unzählige Male bei Thomas von Aquino, ein Satz des "Philosophus“ als Gewähr angeführt wird. Aristoteles ist der „Philosoph“, wie sein arabischer Erklärer Averroës (Ibn Ruschd) der „Kommentator“. Sein Seelenbegriff und seine Theorie der psychischen Vermögen und Tätigkeiten, 
seine Lehre vom Sein, dessen Arten, Prinzipien und Ursachen, seine Anschauungen von Potenz und Akt, Form und Materie, vom Werden und Vergehen, von Raum, Zeit und Bewegung gelangen ebenso zur Herrschaft wie seine Lehre von den dianoëtischen und ethischen Tugenden, vom Menschen als sozialem Wesen und vom Aufbau der Gesellschaft. Waren doch auch für eine Schulphilosophie die klaren Begriffe und fest formulierten Sätze des Stagiriten um vieles brauchbarer als die mehr für die einzelne spekulativ veranlagte Persönlichkeit und deren Entwickelung zu allen Zeiten fördersamen Anregungen Platons. So wird nunmehr Aristoteles „der Meister derer, die da wissen", wie Dante ihn feiert. Ganz vergessen ist freilich auch jetzt die Autorität Platos nicht. Nur durch die Kenntnis zweier Philosophen, meint Albert der Große, hierin dem Alfarabi folgend, des Aristoteles und des Plato, ist die Vollendung in der Philosophie möglich; ja noch Bonaventura zeigt gelegentlich eine unverkennbare Vorliebe für Plato gegen Aristoteles, und Heinrich von Gent findet, daß Platos Gedanken mehr dem christlichen Glauben entsprechen als die des Aristoteles. Aber erst die künstlerisch veranlagte Renaissance stellt Plato, den Künstlerphilosophen, mit Entschiedenheit wieder voran. Bezeichnend ist es, wie, im Gegensatz zu Dante, schon Petrarka (in den „Trionf“) im Zuge derer, die der „Fahne des Ruhmes“ folgen, dem Plato vor Aristoteles den Platz einräumt.

c) Sonstige antike Quellen

Neben den Genannten kommen natürlich manche andere in Betracht. Senekas sentenzenreiche Moralabhandlungen, Ciceros sprachgewandte eklektische Bearbeitungen griechischer Philosophen, das geschraubte Lehrbuch der sieben freien Künste von Marcianus Capella wurden, namentlich in der älteren Zeit, ebenso fleißig gelesen wie die vom stoischen Nominalismus beeinflußte, wohl fälschlich dem Kirchenvater Augustin beigelegte Schrift über die Kategorien und die unter dem Namen des Apulejus gehenden „Perichermeniae". Auch das Lehrgedicht des Lucretius Carus, welches Epikurs Philosophie in feierlichen Hexametern verkündet, ist bekannt, nicht minder die auch an philosophischen Notizen reiche Sammelschrift des Aulus Gellius, die "Attischen Nächte“. Selbst die in die Philosophie einschlagende physiognomische Literatur kannte man aus einer z. B. von Alfredus Anglicus benutzten, etwa dem vierten nachchristlichen Jahrhundert angehörigen lateinischen Kompilation. Während aber Cicero z. B. auf Ethik und Staatsphilosophie, die Schrift über die Kategorien auf die Entwickelung des Nominalismus einen merklichen Einfluß ausübten, ist die epikureische Naturphilosophie des Lukrez so einflußlos geblieben, wie die früher schon erwähnte Skepsis des Sextus Empiricus und das gleichfalls erwähnte Geschichtswerk des Diogenes Laertius.

Bedeutsamere Einwirkungen gingen dagegen von den griechischen Medizinern, Mathematikern, Astronomen und auch Aristoteleserklärern aus, welche durch das Medium der arabischen Kultur hindurch dem lateinischen Abendlande zugänglich wurden. Sie werden uns später begegnen.

2. Die patristischen Quellen. Die zweite gleich bedeutungsvolle 
Quelle für die mittelalterliche Philosophie bildet die patristische Literatur. Nicht nur bei Albert und Thomas, bei Vincenz von Beauvais und anderen theologisch gerichteten Schriftstellern treten den Aussprüchen der „Philosophi“ die der "Sancti“ zur Seite, sondern z. B. auch bei Wilhelm von Conches und noch bei Marsilius von Padua, dem Vorkämpfer der kaiserlichen Allgewalt gegenüber der kurialistischen Theorie. Unter diesen „Sancti“ aber ist es vor allem Augustin, dessen Autorität im Vergleiche zu der des Aristo- $\alpha$ ) Augustin. teles und Plato das gleiche, nicht selten auch ein überwiegendes Gewicht hat. Nicht nur für die Frühscholastik, die zu einem guten Teil von ihm lebt, ist er von der höchsten Bedeutung. Auch als im I3. Jahrhundert durch das Vordringen des Aristotelismus eine neue Denkweise sich verbreitet, bleibt nicht nur ein Teil der Schulen der augustinischen Tradition im ganzen getreu, sondern selbst von der siegreichen Richtung werden nicht wenige zum Gemeingut gewordene Grundanschauungen in den neuen Aristotelismus hinübergenommen. Thomas von Aquino ist die Synthese von Augustin und Aristoteles.

Die Art, wie das Mittelalter sich zu Augustin stellt, und wie etwa ein moderner Historiker sein Bild auf sich einwirken lassen wird, ist freilich nicht ganz dieselbe. Augustin repräsentiert nicht nur eine Summe von Lehren; er ist, und zwar auch als Denker, eine Persönlichkeit von scharf umrissener Sonderart. Diese Persönlichkeit aber isoliert sich nicht in eigenwilliger Selbstherrlichkeit; vielmehr ist es ein großes Gemeinsames, das sie mit ihrem warmen Herzen, ihrem tiefen und weiten Intellekte in sich durch- und auslebt. So vereinigt sich in Augustin das psychologisch Anziehende konkreter, individueller Eigenart mit dem allgemein Bedeutsamen, das er als geistiger Organisator des Kirchentums, als philosophischer und theologischer Denker geschaffen hat.

Für den modernen Betrachter ist es gerade das persönlich Eigenartige Augustins, wovon er am unmittelbarsten ergriffen wird. Das mehr unpersönliche Mittelalter dagegen, vor allem die Schulwissenschaft desselben, hält sich mehr an seine fertigen objektiven Sätze. Manches daher, was uns als das Siegel seiner persönlichen Eigenart von besonderem Werte ist, hat damals keinen oder doch keinen allgemeinen Eindruck gemacht. Das gilt sogleich von der Methode seines Philosophierens. Als ein Denker, dem Philosophieren nicht allein abstrakte Verstandesüberlegung; sondern ebensosehr ein innerliches Erleben ist, geht Augustin erst durch die psychologische Analyse hindurch zum Aufbau der Metaphysik. Zur Einkehr in das Innere fordert er uns auf, um dort die in den Geist einstrahlende Wahrheit und deren Urquell, die Gottheit, zu finden. Wohl ist ihm die Mystik, insbesondere die der Viktoriner, hierin gefolgt, in etwa auch Anselm und die ältere Franziskanerschule; im allgemeinen dagegen nimmt die Scholastik in der Weise der klassischen griechischen Philosophie nicht psychologische Erfahrungen, sondern die physische Welt zum Ausgangspunkt. Und wenn Augustin, um die akademische Skepsis zu überwinclen, in der Selbstgewißheit des denken- 
den Subjektes die erste Stufe für eine sichere Fundierung des Wissens aufzeigte, so blieb diese dem Philosophieren der Neuzeit wieder so bedeutungsvoll gewordene Begründung dem Mittelalter mit wenigen Ausnahmen schon deshalb fremd, weil ihm kein skeptischer Gegensatz den Stachel der Notwendigkeit steten erkenntnistheoretischen Besinnens eindrückte.

Um so nachhaltiger hat dagegen der Inhalt der einzelnen Begriffe und Sätze Augustins auf die Scholastik eingewirkt. Platonische Tendenzen weiterführend und näher bestimmend sieht Augustin, im Gegensatz zu allem Nominalismus, im Unterschiede auch von der aristotelischen Abstraktionstheorie, in der Wahrheit eine im Menschen sich kundtuende, aber über ihm stehende objektive Macht. In einer Art von geistiger Anschauung findet die Seele in sich die obersten Regeln des Wahren, Guten und Schönen. Die Wahrheit ist kein Erzeugnis des Verstandes, sondern eine Realität, natürlich eine solche idealer Natur. - Diese augustinische Lehre von der Wahrheit ist es, welche im Mittelalter zu d $\leftrightarrow r$ realistischen Wertung der Denkinhalte, die wir bei der Darstellung des Kampfes zwischen Realismus und Nominalismus näher kennen lernen werden, den nachhaltigsten Anstoß gegeben hat. Auch Bonaventuras Erkenntnistheorie beruht fast ganz auf ihr.

Alle endliche $W$ ahrheit aber, und ebenso alle endliche Güte, lehrt Augustin weiter, verlangt als $\mathrm{Maß}$ und letzten Grund ein Absolutes. Sie weist hin auf eine substanziale Wahrheit und Güte, auf Gott. Damit hat Augustin in einer eigentümlichen Modifikation platonischer Anschauungen dem Gottesbeweis diejenige Form gegeben, welche in mannigfachen Wendungen die ganze frühere Scholastik beherrscht und auch später neben der aristotelischen Betrachtungsweise einhergeht.

Noch manches - wenn es auch nicht stets neue Gedanken waren - ist so zunächst aus der augustinischen Gotteslehre Gemeingut der Scholastik geworden und wirkt zu einem guten Teile noch jetzt in aller theistischen Metaphysik nach. So die Art, wie das unbegreifliche göttliche Wesen als erhaben über alle endlichen Kategorien, insbesondere auch über die aristotelische Kategorie der Substanz, gefaßt wird, die Fassung der platonischen Ideen als gestaltender göttlicher Gedanken und ursprünglicher Ursachen, der Versuch, durch psychologische Analogien das trinitarische göttliche Leben dem menschlichen Vorstellen näher zu bringen. Nicht minder Augustins Schöpfungsbegriff, welcher, ohne die göttliche Allwirksamkeit aufzugeben, doch damit eine Evolution der Natur selbst aus den in sie gelegten Keimformen verbindet, vergleichbar dem Versuche Kants, durch die „verbesserte Physikotheologie“ seiner vorkritischen Zeit Schöpfung und Naturmechanismus zu vereinen.

Wie Augustin so auf dem Gebiete des Seins alle Ordnung dem idealen Vorbilde im göttlichen Denken entstammen läßt, so - wiederum in eigenartiger Weiterführung eines antiken Begriffs - auf dem Gebiete des Sollens dem "ewigen Gesetze" als der Grundlage des Naturrechtes. Ein Gebot, welches diesem Rechte der Natur widerstreitet, ist nicht nur, wie dies schon die antike Rechtsphilosophie lehrte, unvernünftig, sondern zugleich unver- 
bindlich. Jenes ewige Gesetz aber ist von Gott nicht nach bloßer Willenswillkür gesetzt, sondern wird von ihm selbst als der Ausdruck der Heiligkeit seines notwendigen göttlichen Wesens erkannt. Dieser Begriff einer in sich notwendigen lex aeterna ist auch für die Scholastik zur Grundlage der Philosophie der Sittlichkeit und des Rechtes geworden. Erst der spätere Nominalismus setzt an seine Stelle die ausschließliche Sanktion durch den göttlichen Willen. Aber noch Leibniz verficht gegen Pufendorf und Cocceji den auf Augustin zurückgehenden Begriff der thomistischen Scholastik. Und ebenso hält derselbe Leibniz in seiner Theodicee den Gedanken lebendig, durch welchen die gesamte Scholastik in Anschluß an Augustin der selbst hier freilich wieder unter neuplatonischer Anregung steht - die Tatsache des Übels und der Sünde mit der göttlichen Allwirksamkeit zu vereinigen sucht. Es ist die Fassung der Sünde und des moralischen Übels als eines nur Negativen in einem sonst positiven physischen Sein: eine Auffassung, durch welche das Böse als solches auf einen bloßen Mangel an Kraft, eine Unkraft zurückgeführt und dadurch außerhalb des Bereiches des von der alles durchziehenden göttlichen Kausalität Verursachten gesetzt werden soll.

War der Einfluß der augustinischen Gotteslehre auf die Scholastik ein dauernder, so hat Augustins Psychologie eine durchgängige und allgemeine Herrschaft nur in ihrer ersten Periode gehabt. Mit Plato teilt Augustin den strengeren anthropologischen Dualismus, nach welchem Leib und Seele nicht, wie in der mehr biologisch gehaltenen Psychologie des Aristoteles, als zwei Teilprinzipien einer Substanz, sondern als zwei Substanzen sich gegenüberstehen. Darum ist die Wahrnehmung nicht, wie in der aristotelischen Psychologie, ein einheitlicher, zugleich physischer und psychischer Vorgang, sondern eine Tätigkeit der Seele allein im Organe. Ebenso steht das vernünftige Denken nicht in der engen Beziehung zur Sinneserfahrung, wie später die entwickelte Scholastik im Anschluß an Aristoteles es lehrt. Wenn Augustin im Gregensatz zu Aristoteles dem Willen in manchem eine Vorzugsstellung vor dem Verstande einräumt, so hat er hierin nicht nur in der älteren Scholastik, sondern auch später an Alexander von Hales, Albert dem Großen, Heinrich von Gent, Duns Scotus u. a. Anhänger gefunden.

Von hoher Bedeutung für die mittelalterliche Weltanschauung war das Bild, welches Augusti. in der "Civitas Dei“ mit machtvollem Griffel von Anfang, Fortgang und endlichem Ziel der Menschheitsgeschichte entwirft. Aber hier treten die rein philosophischen Züge ganz hinter den spezifisch religiösen und kirchlichen zurück. Stark beeinflußt von der historisch gegebenen Erscheinung des Römerreiches und seines jahrhundertelangen Kampfes gegen das Christentum, sieht Augustin in der Welt, deren Begriff er mit der Bibel und der asketischen Literatur im ethischen, nicht im allgemein kulturellen Sinne faßt, und in ihren staatlichen Einrichtungen, wie sie am glänzendsten im Römerreiche sich entfaltet haben, das Reich der gottesfeindlichen menschlichen Selbstsucht. Durch die Verfolgungen dieser 
Welt hindurch pilgert das Gottesreich, d. h. die Zahl der durch Gottes Gnadenerbarmung Auserwählten, dahin, bis es am Ende der Zeit in die göttliche Sabbatruhe einkehrt. Erst durch die Sünde ist die Notwendigkeit obrigkeitlicher Zwangsgewalt in die Welt gekommen. Im Stande der Unschuld würde die Menschheit, wie schon die Stoiker Posidonius und Seneka es vom goldenen Zeitalter zu berichten wußten, ohne Zwangsgewalt die rechte Ordnung innegehalten haben. - Der nach Adams Fall in Christus wieder erneuerten Menschheit ist die Kirche gegeben, in welcher der durch die Weihung der Taufe in ihre Gemeinschaft Aufgenommene als Glied am mystischen Leibe Christi ein durch die Gaben des heiligen Geistes vermitteltes Leben zu führen bestimmt ist. Immer wieder in seinen theologischen Schriften kommt Augustin auf diesen für seine ganze Auffassungsweise entscheidenden Kirchenbegriff zurück. Er ist für die Scholastiker, insbesondere auch für Thomas von Aquino, die Hauptgrundlage geworden, auf der sie ihre Lehre von dem inneren Lebensprinzip der Kirche aufbauten. - Auch die Geschichtsphilosophie Augustins, seine Teleologie der Weltgeschichte, mit Christus als Mittelpunkt, und deren Periodisierung, beherrscht das Mittelalter. Rupert von Deutz, Otto von Freising, Hugo von St. Viktor, Gerhoh von Reichersperg, sie alle und noch viele andere sind völlig davon abhängig. - Welchen Einfluß aber die augustinische Gegenüberstellung und Wertung des Weltlichen und Geistlichen als des Reiches der Welt und des Reiches Gottes ebenso auf die asketische Stimmung und geistliche Reform im Mittelalter, wie auf den Streit $z$ wischen Papsttum und Kaisertum und die Ausbildung des in Gregor VII. zur Höhe gelangten Systemes der obersten Kirchengewalt gehabt hat, das kann ich als allgemein bekannt hier um so eher übergehen, als darin nicht so sehr eine Ausbildung eigentlich philosophischer Motive, sondern solcher von spezifisch religiöser und allgemein kulturhistorischer Art vorliegt.

Von gleicher maßgebender Wichtigkeit wie Augustin ist kein zweiter Vertreter der patristischen Literatur für die Scholastik geworden. Viele liefern einzelne Bausteine: Hieronymus für die Lehre vom Gewissen, Ambrosius für die Tugendlehre, Gregor von Nyssa für die Lehte vom Idealmenschen und der Natur der Körperwelt. Die dem Boethius zugeschriebenen theologischen Schriften und auch Johannes Damascenus, dessen von Burgundio von Pisa um die Mitte des I 2. Jahrhunderts in das Lateinische übersetztes schulmäßiges Werk „über den rechten Glauben“ bereits dem Petrus Lombardus bei Abfassung seiner "Sentenzen“ vorlag, sind die Quelle zahlreicher Definitionen. Der zweimal in das Lateinische übersetzte Nemesius gibt mancherlei historisches Material. Gestaltende prinzipielle Gedanken aber werden all diesen nicht entnommen oder sie üben, wie bei Gregor von Nyssa, nur einen vereinzelten Einfluß aus.

insbesondere

In etwa anders ist dieses bei dem als vermeintlichem Apostelschüler hochverehrten Dionysius (Pseudo-) Areopagita, dessen Werke schon im 9. Jahrhundert durch Scotus Eriugena ins Lateinische übertragen wurden 
und zu dessen Werken Grosseteste, Albert d. Gr., Thomas von Aquino u. a. Kommentare verfaßten. Wie Dionysius durch seine Schriften über die himmlische und die kirchliche Hierarchie neben Augustin die Theorie der kirchlichen Ordnung festigen half, so hat er als christlicher Neuplatoniker Scholastikern und Mystikern einen nicht unwesentlichen Einschlag neuplatonischer Gedankenelemente zugeführt. Vor allem geschah dieses durch seine mystische Theologie, welche über alle eingrenzenden Formen und Bilder hinaus zur bildlosen Anschauung Gottes im innersten Heiligtum der Seele (dem „Seelenfünklein" bei Thomas von Aquino, Bonaventura und Eckhart) führen will. Doch auch Grundgedanken der neuplatonischen Metaphysik sind durch ihn dargeboten, z. B. vom Bösen als Negation und insbesondere der Gedanke von der Abstufung des Seins, bei der jedesmal das mittlere Glied die Eigentümlichkeiten der beiden angrenzenden verbindet, und in der niederen Stufe das zerstreut und verteilt enthaiten ist, was die höhere in Einheit einbeschließt.

Gehen wir nach der Charakteristik der mittelalterlichen Philosophie und der Analyse ihrer Quellen nunmehr dazu über, ihren Entwickelungsgang in knappen Zügen zu zeichnen.

\section{A. Die Zeit der werdenden Scholastik.}

I. Beginn der mittelalterlichen Philosophie. Schwer ist es, für die Philosophie der christlichen Völker des Mittelalters einen bestimmten Anfang zu bezeichnen. Sie setzt nicht ein als ein völlig Neues, wie die der Griechen. Auch steht keine übermächtige Persönlichkeit, wie Descartes, als Grenzmarke an ihrer Spitze. Zwischen den letzten großen Erscheinungen der antiken und patristischen Philosophie, dem Neuplatonismus und Augustin einerseits und zwischen dem Neuauftreten eigenartiger mittelalterlicher Systeme anderseits, liegen Jahrhunderte, in denen das philosophische Denken wie ein matter Wasserlauf dahinschleicht, ohne zu versiegen, aber auch ohne an Fülle merklich zuzunehmen. Das sind die Jahrliunderte, in denen das Römerreich zusammenbricht und nach manchem Auf- und Abwogen die neuen Völkergestaltungen sich konsolidieren, welche aus dem Zusammenstoß der germanischen Welt mit Römern und Griechen sowie mit lateinischen oder latinisierten Provinzialen hervorgehen.

Für ein selbständiges philosophisches Denken, das neue Probleme oder doch wenigstens neue Antworten auf alte Probleme sucht, war in dieser größten Krisis, welche unsere abendländische Kultur je betroffen hat, keine psychologische Möglichkeit gegeben. Es fehlte das Milieu, in welchem ein solches Denken allein Wurzel schlagen und die für sein Gedeihen nötige Wirksamkeit und Aktivität gewinnen kann. Die alte Kultur war längst in ihren Spätherbst eingetreten, der keine frischen Triebe mehr ansetzt; die neuen Volkselemente aber standen noch auf der Stufe elementarischen Ringens um die äußeren Lebensbedingungen, innerhalb dessen der zarte Organismus der freien Geistesbildung nicht gedeiht. So konnte die kulturelle 
Aufgabe der Zeit zunächst keine eigentlich wissenschaftliche, sondern nur eine didaktische sein. Weil selbständige Forschung unmöglich war, mußte man sich begnügen, vorab das Erbe der alten Kultur nach Möglichkeit in die neue Welt hinüber zu retten.

Auf dem klassischen Boden Italiens, im Reiche Theodorichs des Ostgoten, fand der erste Zusammenstoß der neuen Volksgebilde mit der Boethius. alten Kultur statt. Boethius, der so sympathische letzte noch echt römische Denker, weist zwar in seinem Fühlen und Empfinden, in der Stimmung, die sein im Kerker entstandenes philosophisches Trostbüchlein durchzieht, in seiner auch den modernen Menschen tief ergreifenden erhabenen Resignation durchaus persönliche Akzente auf; aber hinsichtlich des Inhaltes seines Wissens ist er vorwiegend Sammler, nicht selbständiger Forscher. Er hinterläßt der werdenden Zeit sein Vermächtnis der alten Philosophie und der mathemathischen Wissenschaften. Cassiodorus, der sich vom Staatsdienst Cassiodorus. an Hofe des Ostgotenkönigs in seine Stiftung Vivarium zurückzieht und dem klösterlichen Leben, welchem Benedikt von Nursia die asketischpraktische Regel gegeben hatte, das wissenschaftliche Interesse einflößt, beginnt die Reihe der enzyklopädischen Schriftsteller, welche dem rein didaktischen Bedürfnis dieser Frühzeit das zunächst erforderliche Hilfsmittel darboten. Als nach dem Untergange der Goten die Stürme der Langobardenzeit aufs neue die Kultur Italiens bedrohen, da konsolidiert Papst Gregor

Gregorius. der Große nicht nur die Verhältnisse der Kirche, sondern hält zugleich die Gedanken Augustins lebendig. - In Spanien, wo unter den Sueven Martin

Isidor von Braga in Senekas Weise schrieb, baut unter den Westgoten Isidor von von Sevilla u. a. Sevilla auf der antiken philosophischen und fachwissenschaftlichen Tradition seine umfänglichen Enzyklopädien des Wissens auf, die für den Angelsachsen Beda wie für den Franken Hrabanus Maurus die Vorlage bildeten. Zugleich stellt er in seinen "Sentenzen" ein theologisches Lehrbuch in Form einer Mosaik aus Väterstellen zusammen, welches das Muster einer ganzen Reihe ron Lehrbüchern gleichen Namens wird, von Isidors Landsmann Tajus an bis zu Peter den Lombarden, dem Verfasser des verbreiteten 'Textbuches für den theologischen Unterricht im Mittelalter. - Auf dem Boden des Frankenreiches, wo die einst berühmten alten Rhetorenschulen noch bis in die neue Zeit dahingelebt hatten, aber in der wilden Merowingerzeit gleichfalls erloschen waren, knüpft Karls des Großen kundiger Berater, der Angelsachse Alkuin, das Band wieder an und erneuert in einer ersten $\begin{gathered}\text { Karolingiscli. Renaissance die Schulen höherer Geistesbildung. Mit der üblichen enzyklo- } \\ \text { Krnaissance. } \\ \text { Alkuin. }\end{gathered}$ pädisehen Schriftstellerei für den didaktischen Zweck verbindet er bereits eingehendere psychologische Einzeluntersuchungen, welche zeigen, wie sehr auf dem Grebiete der Psychologie nicht Aristoteles, sondern die platonischaugustinischen Anschauungen das frühere Mittelalter beherrschen.

II. Von Eriugena bis Alanus. An spekulativer Begabung übertrifft alle Genannten der im Frankenreiche an der Hofschule Karls des Kahlen 
wirkende Ire Johannes Scotus (oder Scottus) Eriugena („Erigena“ ist verderbte Form). Wie ein zweiter Origenes hat er ein System der philosophischtheologischen Weltanschauung entworfen, in welchem die theologischen Sätze in ihrer Begründung durchweg in philosophische Spekulation aufgelöst erscheinen. Dadurch begründete er jene für das frühere Mittelalter charakteristische rationalistische Auffassung, welche den Glauben in all seinen Gebieten von der bloßen gläubigen Annahme des Satzes als solchen durch das Mittel vernünftigen Denkens zum Wissen seiner inneren Begründung erheben will. Daß hierbei im Unterschiede von Anselm, dessen "Credo, ut intelligam" sonst jenen Standpunkt im Prinzipe teilt, in Eriugenas Spekulation der Sinn der dogmatischen Sätze gegenüber der traditionellen Lehre nicht selten sich verschiebt - es ist das besonders hinsichtlich der Lehren von der Trinität und der Schöpfung der Fall —, wurde schon oben bei unseren allgemeinen Betrachtungen über das Verhältnis von Glauben und Wissen im Mittelalter bemerkt.

Das philosophische System Eriugenas selbst, in vielem auf den von ihm ins Lateinische übertragenen Dionysius Pseudo-Areopagita und auf Gregor von Nyssa gestützt, trägt einen durchaus idealistischen Charakter, durch den es im Mittelalter allein dasteht. Die Formen und Bestimmtheiten an den körperlichen Dingen sind ihm die jedesmaligen Durchschlingungen und Knotenpunkte allgemeiner Begriffe: die Materie als Trägerin dieser Formen ist gleichfalls nur ein allgemeiner Begriff, der der Veränderlichkeit. So haben die individuellen körperlichen Substanzen sich in allgemeine Begriffe aufgelöst, in Gattungen und Arten, durch welche der Inhalt der obersten Gattung, das Sein oder die Substanz, gleichsam hindurchrinnt. Damit ist der eine der Standpunkte, die in dem bald entbrennenden Kampfe des Realismus und Nominalismus sich gegenübertreten, der realistische, in einseitiger Schärfe ausgeprägt. Nicht das Individuelle, sondern das Allgemeine eben als Allgemeines, so wie der allgemeine Begriff es erfaßt, wird von Eriugena für das einzig wahrhaft Reale erklärt.

Gegründet sind die uns erscheinenden Dinge in den göttlichen Ideen. Aus diesen gehen sie durch eine Entfaltung in Raum und Zeit in ähnlicher Weise hervor, wie die Ideen aus dem über alle Bestimmungen erhabenen Sein oder vielmehr Nichtsein des göttlichen Urgrundes durch eine ewige schöpferische Entwickelung hervorgegangen sind. Damit nimmt Eriugenas Lehre eine Wendung zum Pantheismus oder vielmehr Semipantheismus. So wird er der Vorgänger einer pantheistischen Richtung, die außerhalb der scholastischen Philosophie im Mittelalter stets aufs neue auftritt. Ihre schärfste Ausprägung hat diese am Ende des I 2. Jahrhunderts erfahren, in mehr idealistischer Form bei Amalrich von Bennes und den Amalrikanern, in mehr materialistischer bei David von Dinant (oder Dinan?). Dann ist sie besonders in den Kreisen der „Brüder und Schwestern vom freien Geiste“ verbreitet. Von dem Unmoralismus aber, der in diesen Kreisen durch die pantheistische Theorie gerechtfertigt werden soll, ist Eriugena völlig fern. Seine Ethik

Amalrich von Bennes und David von Dinant. 
trägt den strengen und erhabenen Charakter der areopagitischen Mystik. So konnten seine Schriften nach manchen Seiten hin, besonders durch die Lehre von den Theophanien, auch in der kirchlichen Mystik der Zisterzienser, wie bei Garnerius von Rochefort, noch späte, wenn auch mehr gelegentliche Spuren hinterlassen.

Dialektiker nach Eriugena.

Eriugena hatte sobald keinen ebenbürtigen Nachfolger. Was in der nächsten Zeit nach ihm auftritt, bedeutet philosophisch nicht viel. Es sind zumeist Schulerklärungen logischer Schriften des Aristoteles, Apulejus, Porphyr, der pseudoaugustinischen Kategorien, auch des Boethius (mit Einschluß von dessen "opuscula sacra"). Sie liegen uns namentlich in einer (noch nicht durchweg genügend veröffentlichten) Literatur von erläuternden Glossen vor, zu denen Eriugena einen starken Anstoß gab. Dazu treten einzelne zusammenhängende logische und grammatische Abhandlungen in Prosa und in Versen. Heirik und Remigius von Auxerre, Notker Labeo, der Mathematiker Gerbert (Papst Sylvester II.) und viele andere zu einem großen Teil Namenlose gehören hierher. Aber in diesen im Rahmen des Triviums gehaltenen dürren grammatisch-logischen Untersuchungen regen sich auch wichtigere erkenntnistheoretische Probleme. Hier tritt die aristotelische Ansicht, nach der die Individuen die wahre Realität darbieten, die Allgemeinbegriffe dagegen nur etwas Sekundäres enthalten, dem bei Eriugena herrschenden von Plato ausgehenden extremen Realismus entgegen. Da die in der aristotelischen Physik und Metaphysik enthaltenen gemäßigt realistischen Elemente aus Mangel an Bekanntschaft mit den einschlägigen Schriften des Stagiriten noch nicht zur Geltung kommen konnten, so bildete sich eine in manchem an den Stoizismus erinnernde extrem antirealistische Lehre aus. Nach ihr benennen wir nur deshalb viele Individuen mit einem gemeinsamen Namen, weil unserer Sprache die Menge der Wörter fehlt, um ein jedes mit einem eigenen Namen zu versehen. Die Gattungen und Arten (das „Universale“ in

Der liniversalienstreit: Realisinus und a Noninalismus. Wort und Vorstellung; daher "Universalienstreit") knüpften deshalb nicht an eine gemeinschaftliche Realität, sondern nur an einen gemeinschaftlichen Namen an. Davon bezeichnet man diesen erkenntnistheoretischen Standpunkt als "Nominalismus“. Während ihn Ältere, wie Heirik von Auxerre (9. Jahrhundert), nur erst unbestimmt entwickeln, hat er an Roscellin von Compiègne ( 1 i. Jahrhundert) einen energischen Vertreter gefunden.

Wie bei dem Charakter der mittelalterlichen Geisteskultur natürlich, tritt auch dieser der Theologie nicht entstammte Nominalismus doch sofort in $\mathrm{Zu}$ sammenhang mit theologischen Fragen. Roscellin wendet ihn auf die Trinitätslehre an und kommt zu einer Art Tritheismus. Indem sich nun hiergegen die theologische Opposition erhebt, bildet sich umgekehrt auch der philosophische Erkenntnisbegriff weiter aus. Nach dem Vorgange der patristischen Spekulation nämlich, insbesondere der Gregors von Nyssa, zogen Theologen, wie z. B. Odo von Cambrai (11. Jahrhundert), um zu erklären, wie das eine göttliche Wesen in drei Personen sei, wie Christus durch Annahme der menschlichen Natur die in Adam gefallene Nenschheit erlöst habe, die platonische 
Ansicht von der Gegenwart des Allgemeinen im Individuellen heran. Auch der augustinische Begriff der Kirche als einer über die einzelnen Mitglieder hinaus übergreifenden Lebenseinheit lag in gleicher Ideenrichtung. Überhaupt war die ganze Denkweise Augustins, wie wir sahen, eine realistische. So erhob sich die herrschende theologische Denkrichtung auch zum philosophischen Kampfe gegen den Nominalismus. Der Realismus findet entschiedene Verteidigung, d. h. der Realismus im mittelalterlichen Sinne des Wortes, in welchem er nicht nur dem erkenntnistheoretischen Systeme des subjektiven Idealismus entgegengesetzt ist, der die Möglichkeit eines transubjektiven Wirklichen überhaupt leugnet, sondern zunächst dem Nominalismus, welcher eine transubjektive Wirklichkeit anerkennt, aber die objektive Gültigkeit der besonderen Formen des Verstandesdenkens, der allgemeinen Begriffe, in Ab-

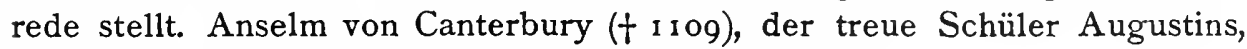
ist gegen Roscellin der Wortführer dieses Realismus.

Freilich war es der werdenden Scholastik nicht leicht, zu bestimmen, wie denn jenes Allgemeine, das der Begriff - das universale post res, wie man ihn im Anschluß an Aristoteles genannt hat - ideell gefaßt, zugleich real sein könne. Die göttliche Idee als das universale ante res kam hierfür nur indirekt in Frage; zunächst handelte es sich - um uns an jene u. a. von dem Neuplatoniker Proklus aufgestellte Dreiteilung zu halten - allein um das universale in re. Der extreme Realismus Eriugenas, welcher das Allgemeine als ein einheitliches gemeinschaftliches Sein durch alle Individuen hindurchziehen läßt, wurde, etwas modifiziert, von Wilhelm von Champeaux erneuert, aber von diesem selbst, gegenüber Abälards scharfer Dialektik, aufgegeben. Eine Reihe von Vermittelungsversuchen - Johannes von Salisbury zeichnet ein Bild von ihrer Mannigfaltigkeit - - tritt auf, in denen bald das realistische, bald das nominalistische Element überwiegt, bei Abälard, Walter von Mortagne, Adelhard von Bath, Gilbert de la Porrée; eine durchschlagende Lösung aber wird nicht erreicht. Und doch handelt es sich nicht um eine Schulspitzfindigkeit, sondern um eine Frage von hoher sachlicher Bedeutung, die, wenngleich meist unter anderen Formen, auch uns bewegt. Der Wert des Denkens überhaupt und seiner idealen Inhalte, der von einem die objektive Geltung des Vernunftdenkens auflösenden subjektivistischen Relativismus bedroht wird, bildete im Grunde schon damals das Problem, welches, wenn auch nur von einer einzelnen und nicht gerade der entscheidendsten Seite her, in jenem Universalienstreite zur Verhandlung kam.

Mit neuen Mitteln, wie sie durch das Bekanntwerden des ganzen Aristoteles und seiner arabischen Erklärer gegeben wurden, hat dann die entwickelte Scholastik jenes Problem wiederaufgenommen. Indem man ein aristotelisches Prinzip weiterführte, sah man in dem Typischen und Gleichförmigen der Natur, das in ihren Gestaltungen wie in ihrem Wirken sich zeigt und das Thomas von Aquino zu dem aristotelischen Formprinzip in Beziehung setzt, den sachlichen Berechtigungsgrund, auf den hin der Verstand die in der körperlichen Welt nur vervielfältigt in den einzelnen Individuen exi- 
stierenden Wesenheiten in den einen gemeinschaftlichen Art- oder Gattungsbegriff zusammenfaßt. In mancherlei Wendungen (bei Thomas in der von dem arabischen Philosophen Avicenna gegebenen Formulierung) herrscht dieser gemäßigte Realismus während der Hochperiode der Scholastik. Erst das ausgehende Mittelalter erneuert, als Reaktion gegen den durch Duns Scotus stärker betonten Realismus, wieder den Nominalismus, jedoch in einer ganz neuen Form. Wir werden derselben später gedenken.

Wir sprachen von Anselm als dem spekulativen Theologen, welchen seine augustinische Richtung zugleich zum Gegner des Nominalismus machte. Anselm Auch seines "Credo, ut intelligam" und des Sinnes dieses Satzes gedachten von Canterbury. wir. Auf seine spekulative Lehre näher einzugehen, ist hier im allgemeinen nicht erforderlich, da sie fast durchweg auf Augustin fußt, dem er auch die Gottesbeweise seines „Monologium“ entnommen hat. Ein anderer GottesbeDerontologische weis dagegen, der des „Proslogium“, ist ihm eigentümlich und hält in der
Gottesbeweis.

Geschichte der Philosophie vor allem die Erinnerung an Anselms Namen wach. Man nennt ihn gewöhnlich mit einem durch Kant eingebürgerten Namen den „ontologischen" Gottesbeweis. Derselbe will aus dem bloßen Begriffe Gottes seine Existenz erweisen. Da jeder versteht, was das Wort „Gott“ bedeutet, nämlich - mit Augustin - das Wesen, über das hinaus ein größeres nicht denkbar ist, so ist ein solches Wesen zunächst im Verstande. Weil aber ein Wesen, das im Verstande und in der Wirklichkeit existiert, größer ist als ein solches, das nur im Verstande ist, so verlangt die nachgewiesene Existenz im Verstande bei dem Wesen, über das hinaus ein größeres nicht denkbar ist, daß dasselbe zugleich in Wirklichkeit ist, d. h. daß Gott existiert. - Der Gedanke Anselms ist im Mittelalter öfter wiederholt, wie von Wilhelm von Auxerre, Alexander von Hales, Fitzacre, später von Vasquez. Auch Bonaventura, Albert der Große, Siger von Brabant, Ägidius von Rom, Thomas von Straßburg u. a. nähern sich ihm an. Aber in Wahrheit beruht er entweder auf einem einseitigen, haltlosen Begriffsrationalismus, oder er enthält direkt einen Trugschluß. Auf den letzteren hat nicht erst Kant gegenüber der Erneuerung des Argumentes durch Descartes, Leibniz und Mendelssohn hingewiesen. Wie Anselms Zeitgenosse Gaunilo, so hebt ihn vor allen Thomas von Aquino mit aller Schärfe hervor, und seine ganze Schule ist ihm darin gefolgt. Es geht darum nicht an, den ontologischen Gottesbeweis schlechthin als den „scholastischen“ zu bezeichnen. - Nicht der ontologische Gottesbeweis, wohl aber der Gedankengang des Monologiums findet sich auch bei Honorius Augustodunensis. Im übrigen ist dieser in allem Wissen seiner Zeit wohlbewanderte Gelehrte für seine Zeit besonders wichtig durch eine Reihe enzyklopädischer Werke, in denen er trotz einiger Bedenken über die Erlaubtheit profaner Studien das überlieferte Naturwissen der Alten mit Fleiß zusammenträgt und auch von Eriugena manches Positive entnimmt. In seinen dogmatischen Traktaten regt sich bereits, wie bei Lanfrank und Anselm, die dialektische Methode.

Hatte Anselm durch seine klare Zusammenfassung und selbständige 
Wiedergabe der augustinischen Gedanken die inhaltliche Richtung angegeben, in welcher die Scholastik sich zunächst vorwiegend bewegt, so schuf Abälard ( $\left.\mathrm{II}_{1} 4_{2}\right)$ ihr die Form. Die Anwendung der dialektischen Methode Abälard. auch auf die Theologie, zu der schon früher, wie bei Lanfrank und Anselm, sich Ansätze finden, wird durch ihn zum Prinzip erhoben. Abälard will nicht nur die augustinische Tradition fortsetzen. In seinem beweglichen, reizbaren Geiste, der Scharfsinn mit reichempositiven Wissen verbindet, wird alle Überlieferung flüssig. Väterstellen setzt er wie ein "Ja“ und „Nein" gegenüber, nicht, um durch den Nachweis des Widerspruchs alle Autorität als eitel zu erweisen, sondern um durch die Bearbeitung und Distinktion der Begriffe, durch den Hinweis auf die Verschiedenheiten von Ort und Zeit und Zusammenhang den Widerspruch aufzulösen und zu harmonisieren. So hat er, wie schon früher gezeigt wurde, die scholastische Methode begründet. - Als systematischer Geist, der nicht in der Einzelkritik aufgeht, bringt Abälard durch Neuordnung auch des alten Stoffes frischeres Leben in die Literatur der Sentenzen und Summen. Nicht nur Peter der Lombarde, dessen „Sentenzen“ allmählich zum Textbuch für den theologischen Unterricht wurden, sondern auch ein späterer Papst, der Magister Roland Bandinelli, als Papst Alexander III., stehen in der ganzen Form stark unter dem Einflusse des vielbekämpften Mannes. Nach der inhaltlichen Seite hin ist dagegen der Einfluß Abälards auf die Scholastik nicht von nachhaltiger Wirkung gewesen. Finden sich doch auf rein philosophischem Gebiete selbständige Gedanken von sachlicher Bedeutung, etwa von der Ethik abgesehen, bei ihm wenig. Sein spekulativer Ausbau des Dogmas aber, der ihn mit Bernhard von Clairvaux in harte Konflikte brachte, vor allem seine Trinitätslehre, welche den Unterschied der göttlichen Personen auf die Attribute der Macht, Weisheit und Güte zurückführte und in der platonischen Trias von Vater, Weltbildner und Weltseele die christliche Lehre wiederfand, wurde von der kommenden Scholastik aufgegeben. Abälards dialektischer Geist hingegen beherrscht von nun an die mittelalterliche Schulwissenschaft und hält auch in den theologischen Erörterungen das philosophische Interesse lebendig. Ein mitstrebender Geistesverwandter Abälards ist hier Gilbert de la Porrée († 1154), der Interpret des Boethius, dessen Schule ein höchst charakteristisches theologisches Sentenzenwerk entstammt, und von welchem auch Otto von Freising († I 1 58), der berühmte Historiker und Geschichtsphilosoph, der-in seiner philosophischen Menschheitsbetrachtung auf Augustinus fußt, die Anregung zur Pflege der dialektischen Spekulation erhielt.

Ist Abälard der kühn vorandrängende Neuerer, so repräsentieren die Die Viktoriner. Viktoriner - Augustiner-Chorherren von St. Viktor bei Paris - das konHugo, Richard. servative augustinische Element. Hugo von St. Viktor $\left(f_{1} 1_{4} I\right)$, in Deutschland gebürtig, ist vor allem als Theologe bedeutend. Für die mittelalterliche Schultheologie, soweit sie den traditionellen Bahnen folgt, hat er den Grund gelegt. Wie wichtig sein Einfluß auch sonst auf die Ausbildung der spezifisch geistlichen mittelalterlichen Weltanschauung war, sieht man u. a. dar- 
aus, daß in Papst Bonifaz' VIII. kirchenpolitischem Programm, der Bulle „Unam sanctam", die Hauptsätze über das Verhältnis weltlicher und geistlicher Gewalt aus einer von Hugos Schriften stammen. Für die Philosophie kommt vor allem seine augustinische Psychologie in Betracht, die zugleich

Die ältere Mystik der Viktoriner.

Thomas Gallus.

Walter von St. Viktor.

Die Schule von Chartres.

n Salisbury. zur Grundlage der viktorinischen Mystik wurde. Richard von St. Viktor ( $千$ I I 73) ist ihm in dieser Richtung gefolgt. Namentlich die mystische Lehre vom Seelengrund, in dem die Gottheit wie in einem Heiligtume thront, hat er ausgebildet. Thomas Gallus, später Abt von Vercelli ( $\left.f_{1} 246\right)$, verband dann diese augustinische Mystik der Viktoriner mit der des Areopagiten und leitet zu Bonaventura sowie zu der späteren Entwickelung der Mystik bei Eckhart, Tauler, Ruysbroeck sowie auch bei Nikolaus von Kues über. Wie in der Schmähschrift Walters von St. Viktor gegen die „vier Labyrinthe Galliens" die traditionelle Richtung polemisch, aber erfolglos, Stellung nimmt gegen die neue dialektische Schule, das ist früher bereits gesagt worden. Eine eigenartige Stellung nimmt die Philosophie der Schule von Chartres ein. Sie ist humanistisch angehaucht, wie auch der etwas ältere Spanier Peter von Compostella, der Verfasser einer Enzyklopädie der freien Künste in Form eines $Z$ wiegesprächs des Verfassers mit Vernunft und W.elt, das nach der Weise des Marcianus Capella und des Boethius in die Prosa Verse einmischt, die freilich schon einen Übergang von den antiken Metren zu den gereimten mittelalterlichen Rhythmen bilden. Bernhard von Chartres ( $†$ um I 125) weiß seine Schüler für das Studium der Alten zu begeistern und erneuert Platos Ideenlehre; sein Bruder Thierry von Chartres, der sich um eine erweiterte Benutzung des aristotelischen Organons im Unterricht verrdient macht, sucht durch pythagoreisierende Zahlenspekulation der göttlichen Trinität und dem Hervorgang der Welt aus der Gottheit beizukommen; Bernhard Sylvester von Tours entwirft in phantasievoller Art auf Grund des Platonischen Timäus ein Bild vom Ursprung der großen und der kleinen Welt, des Universums und des Menschen. Aus der Schule von Chartres geht auch der in den Alten wohl bewanderte Johann von Salisbury († 1180) hervor, der von den dialektischen Kämpfen der Zeit uns ein eingehendes Gemälde bietet. Seine Auffassung vom Staate, in der er Cicero und der pseudo-plutarchischen „Institutio Traiani“ folgt; war für die politische Theorie des Mittelalters nicht ohne Bedeutung, namentlich auch für das schon von Manegold von I.autenbach zur Zeit Gregors VII. und besonders lebhaft wieder in den Kämpfen des 16. und 17. Jahrhunderts erörterte Problem der Stellung des Volkes zum tyrannischen Herrscher. Seine psychologische Betrachtungsweise dagegen, die das Werden der psychischen Phänomene in ihrem organischen Aufbau verfolgt, muBte der aristotelisch-arabischen Psychologie weichen. - Eine solche humanistische Richtung, die jedoch weiter geht und im Gegensatz zur Dialektik in den alten römischen Autoren ihr Bildungsidleal findet, hat später an der Universität Orléans ihren Sitz. Auch Dichter haben den Gegensatz unter das Volk gebracht, wie Henri d'Andéli in der "Bataille des sept arts" und in gewisser Hinsicht auch Rustebuef. 
Von dem Humanismus der Schule von Chartres und ihrer phantasievollen Art der Welt- und Lebensbetrachtung ist auch Alanus von Lille ( + I 203) ausgegangen. Doch sind seine sprachgewandten Schriften ,über die Klage der Natur" und der "Antiklaudian“ zugleich von moralisierender Tendenz getragen. Als der Magister dann den Zisterzienserhabit anlegte und zugleich an der diesem Orden übertragenen Propaganda bei den Albingensern Südfrankreichs teilnahm, hat er in seiner Schrift „Contra Haereticos“ einer mehr logisch-rationalistischen Spekulation sich gewidmet, welche die Sätze des katholischen Glaubens durch Vernunftgründe dem Gegner andemonstrieren wollte. Dagegen nicht von ihm, dem sie fälschlich öfter zugeschrieben wird, sondern von seinem Zeitgenossen Nikolaus von Amiens rührt die „Ars fidei" her, welche in ihrer Anordnung sogar die mathematische Methode anwendet, indem sie von Definitionen, Heischesätzen und Axiomen zu den Propositionen fortschreitet. Ähnliches hatte schon früher eine dem Boethius zugeschriebene theologische Schrift versucht; später führte Bradwardin († I 349) das gleiche Verfahren durch. Vorgänger für den ordo geometricus seiner Ethik hatte Spinoza also schon vor Descartes im Mittelalter.

Der in Chartres gepflegten Gedankenwelt stehen auch zwei naturkundige Männer des I 2. Jahrhunderts nahe, Ade1hard von Bath (er wendet auch der Psychologie des Tieres seine Aufmerksamkeit zu) und der feingebildete Wilhelm von Conches, in der Physik ein Anhänger der Korpuskulartheorie. Wichtig aber sind sie vor allem dadurch, dab bei ihnen, wenn auch noch nicht auf philosophischem, so doch auf naturkundlichem Gebiete, zuerst in größerem Umfange die neuen Wissensquellen zur Einwirkung gelangen, welche das Bekanntwerden mit dem Orient dem Abendlande gebracht hatte. Sie leiten damit zur zweiten Periode der Scholastik über.

\section{B. Die Zeit der entwickelten Scholastik.}

I. Die neue Bewegung; erste Versuche. Es kann hier nicht unsere Aufgabe sein zu erzählen, wie der arabische Orient die Schätze griechischer Philosophie, Medizin, Mathematik, Astronomie und sonstiger Naturwissenschaft sich zu eigen gemacht und auf diesem Fundamente weiter gebaut hat. Seit dem I1. Jahrhundert hat denn auch das Abendland sich bemüht, dieses Besitzes teilhaft zu werden. Den Anfang machte ein vielgewanderter, des Arabischen kundiger Mönch von Monte Cassino, der aus Karthago gebürtige Konstantinus A frikanus. Zum Nutzen der Mediziner von Salerno zunächst übertrug und bearbeitete er in der zweiten Hälfte des I I. Jahrhunderts nicht nur Schriften arabischer Ärzte, wie des Ali ibn Abbas „Pantegni“, sondern auch solche des Hippokrates und Galen („Tegni“" und „Megategni“). Nicht lange danach übertrug Adelhard von Bath die Geometrie des Euklid. Andere folgten nach. Einen ungeheuren Aufschwung nahm diese Übersetzertätigkeit, als nach dem Sturze Toledos die ganze Fülle der wissenschaftlichen Schätze der Araber in die Hände der Christen fiel. Von fleißigen Über-

Adelhard von Bath. Wilhelm von Conches
Einflus des neuen Materials. 
setzern, wie Gerhard von Cremona, Johannes Hispanus, Gundissalinus, Michael Scottus, Hermannus Alemannus u. a., wurden jetzt nicht nur nach und nach die bisher unbekannten wichtigsten Werke des Aristoteles (nebst Unechtem, z. B. dem vielbenutzten Liber de causis) und einiger griechischer AristotelesErklärer (Alexander, Themistius), sowie eine Reihe von Werken griechischer Mathematiker und Astronomen (insbesondere der "Almagest" des Claudius Ptolemaeus) aus den arabischen Versionen in das Lateinische übertragen, sondern auch die bedeutendsten arabisch schreibenden Philosophen mohammedanischen Glaubens: Alkendi, Alfarabi, vor allem Avicenna (Ibn Sina) und Averroës (Ibn Ruschd), der „Kommentator“ des Aristoteles, auch Algazels Ưbersicht über Avicennas Lehre u. a., ferner die Juden Israeli, Avencebrol (Ibn Gebirol) und der u. a. auch für Thomas von Aquino so wichtige Maimonides. Daß freilich die Werke griechischer Autoren nur auf diesem Umwege bekannt waren, das empfand man schon bald als einen Notbehelf. Wie schon im I 2. Jahrhundert der Kreis der bis dahin bekannten direkt aus dem Griechischen übersetzten Werke nicht unwesentlich erweitert war (damals sind von den schon früher erwähnten griechischen Philosophen die platonischen Dialoge Meno und Phädo, das ganze Organon des Aristoteles und das vierte Buch seiner Meteorologie, sowie Sextus Empiricus, von den kirchlichen Schriftstellern Nemesius und Johannes von Damaskus hinzugekommen), so veranstalteten jetzt Robert Grosseteste (Robert von Lincoln), Wilhelm Moerbeke und andere Übersetzurrgen des Aristoteles und anderer Autoren (z. B. des Ethik-Kommentars des Byzantiners Eustratius) direkt aus dem Grie= chischen. Selbst mit einigen Schriften des Neuplatonikers Proklus wurde man durch Wilhelm von Moerbeke bekannt. Im einzelnen besteht hier freilich noch viel Unsicherheit, welche die Forschung erschwert, namentlich hinsichtlich der verschiedenen arabisch-lateinischen und griechisch-lateinischen Übersetzungen der aristotelischen Werke. Während z. B. das vierte Buch der Meteorologie in griechisch-lateinischer Übersetzung (durch Aristipp), das erste bis dritte sowie die Physik in arabisch-lateinischer Übersetzung (durch Gerhard von Cremona) bereits in den achtziger Jahren des zwölften Jahrhunderts und noch früher vorlagen, ist hinsichtlich der Metaphysik und der Psychologie vieles noch ungeklärt. Doch das kann hier nicht weiter verfolgt werden.

Kaum zu übersehen war die Menge des Stoffes, welche so dem AbendStreit um die lande zugänglich und von ihm in seinem Stoffhunger begierig ergriffen aristotelische Metaphysik und Naturphilosophie. wurde: in den formalen Teilen der Philosophie wie in den sachlichen Disziplinen, insbesondere in der Metaphysik, der Naturphilosophie und der Psychologie sowie in der Naturbeschreibung und Astronomie - arabische und neuplatonische Gedanken sowie solche der arabischen und jüdischen Religionsphilosophie. Wie mannigfach dieses neue Material ist, das sieht man so recht, wenn man die Sammelwerke, in denen Isidor von Sevilla und seine Nachfolger das Wissen des ausgehenden Altertums dem früheren Mittelalter überlieferten, mit den neuen enzyklopädischen Kompilationen vergleicht, in denen 
Gundissalin von Segovia (1 2. Jahrhundert), Robert Kilwardby ( 1 2 78 ) und am umfassendsten Vinzenz von Beauvais ( $t$ 1264) jenen Reichtum zusammenzufassen, zu ordnen und $z u$ sichten suchen, um von der großen Enzyklopädie, dem „Opus maius", des Roger Bacon hier zu schweigen, da darin ein selbständiger Geist über dem verarbeiteten Stoffe waltet.

Naturgemäß rief dieses begierig ergriffene neue Material eine mächtige Gärung der Geister hervor. Aber man geht irre, wenn man meistens annimmt, daß dadurch eine völlige Umgestaltung herbeigeführt, daß der Zusammenhang mit den bisherigen Entwickelungstendenzen unterbrochen und auf verändertem Boden eine völlige Neubildung erfolgt sei. Nur auf einzelnen Gebieten, vornehmlich auf dem der Naturphilosophie und der Psychologie, in manchem auch auf dem der Staatsphilosophie, kommen in größerem oder geringerem Maße neue Betrachtungsweisen und Begriffe zur Geltung, die früher zwar nicht gänzlich unbekannt, aber doch wenigstens nicht durchgedrungen waren. In den eigentlichen Weltanschauungsfragen aber fand eine solche gänzliche Neubildung so wenig statt, wie überhaupt der Zusammenstoß der abendländischen Völker mit den morgenländischen eine derartige völlige Umwälzung im Gefolge hatte, darin höchst ungleich der gewaltigen Bewegung der Völkerwanderungszeit, welche in die Bildung der germanischromanischen Völker auslief. Wie in der gesamten Kultur der mittelalterlichen Völker, in der Wissenschaft so gut wie in der Kunst und in der feineren Gestaltung des Lebens, schon mit dem I2. Jahrhundert der neue Aufschwung zuerst langsam heranreift, dann energisch voranschreitet, so geht auch die Neubelebung des philosophischen Geistes schon in die Zeit Abälards, der Viktoriner, der Schule von Chartres und des Alanus zurück. Nicht erst das Eindringen der arabischen Wissenschaft in die okzidentalische Welt und das damit verbundene Bekanntwerden des ganzen Aristoteles hat diese Neubelebung herbeigeführt. Jene Ereignisse des wissenschaftlichen Lebens fügen sich vielmehr als ein Glied, freilich als ein höchst bedeutsames und wirkungsvolles Glied, in eine ganze Reihe von Vorgängen ein, bei denen innere Bewegungen und äußere Anregungen sich begegnen und zusammenwirkerd sich vereinigen. Darum stand auch das abendländische mittelalterliche Denken nicht ratlos und wahllos, jedem Ansturm unterliegend, dem Neuen gegenüber. Sein Organismus, wie er vornehmlich aus dem Nährboden der augustinischen Anschauungen, mit reichlicher Durchsetzung aristotelischer und neuplatonischer Bestandteile, erwachsen war, hatte sich bereits hinreichend gefestigt und zu freier Beweglichkeit ausgestaltet. So war er imstande, trotz aller Überschüttung mit Stoff nicht nur dem Neuen gegenüber sich in seiner eigenen Wachstumsrichtung zu erhalten, sondern auch das viele ihm Konforme sich zu assimilieren, ja unter Beibehaltung seines Gesamttypus sich doch neue entwickelungskräftige Triebe einpflanzen zu lassen. Freilich ging dieser Prozeß nicht ohne heftige Stürme vor sich, in denen Altes und Neues zunächst fremdartig aufeinanderstößt. Dann treibt der von uns bereits geschilderte harmonisierende und konkordistische Sinn des Mittelalters zur Ausgleichung der 
alten und der neuen Autoritäten. Das Nichtassimilierbare in der neuen Gedankenwelt soll ausgeschieden, das Vereinbare in gegenseitige Beziehung gebracht werden. Nicht selten allerdings ist dieser Ausgleich ein bloß scheinbarer, erreicht nur dadurch, daß man unhistorisch, wie das Mittelalter es nun einmal ist, die Autoritäten ihrer geschichtlichen Bestimmtheit entkleidet und den Sinn ihrer Sätze nach Bedürfnis zurechtstutzt. Augustin einerseits, Aristoteles andererseits müssen sich mancherlei gewaltsame Umdeutungen, manche Abschwächungen oder auch freie Ergänzungen ihrer Gedanken gefallen lassen.

Erste Versuche einer Synthese des neuep Materials.

Gundissalin.

Wilhelm von Auvergne.

Die Bewegung an der Parise Universität.

Der erste Versuch einer Synthese des Neuen und des Alten tritt uns schon im I 2. Jahrhundert bei dem bereits mehrmals genannten Archidiakon von Segovia, Dominicus Gundissalinus, entgegen. Seine erst seit kurzem veröffentlichten fleißigen, aber unselbständigen Schriften - sie handeln über die Seele und über ihre Unsterblichkeit, über den Hervorgang des Universums, über die Einheit und das Eine, über die Einteilung der Philosophie (eine Enzyklopädie der Wissenschaften) - stellen sich fast durchweg als eine, übrigens meist nach eigenem Plane disponierte Art von Mosaik aus Boethius und Isidor, Alfarabi, Avicenna, Avencebrol (Gebirol) und anderen dar. Auch Augustin und Aristoteles werden erwähnt. Aber Gundissalins Verdienst, als erster eine neue Epoche eingeleitet zu haben, wurde verdunkelt, als umfassendere und selbständigere Werke der gleichen Richtung erschienen, wie die zwischen 1 23 I und 1236 verfaßte umfangreiche Schrift De universo von Wilhelm von Auvergne, dem Lehrer zu Paris und späteren Bischof daselbst ( $t$ 1 249). Hat dieser doch eine Schrift seines bescheidenen spanischen Vorgängers, die Abhandlung über die Unsterblichkeit der Seele - sie enthält vielleicht das Beste, was über die Frage vom Standpunkte der mittelaiterlichen Metaphysik aus geschrieben ist -, mit leichten Umänderungen unter seinem Namen veröffentlicht.

Mit Wilhelm von Auvergne sind wir nach Paris versetzt. Hier, an der seit Philipp Augusts Privileg (1200) mächtig aufblühenden und die anderen Pflegestätten scholastischer Wissenschaft überflügelnden Universität vollziehen sich die Kämpfe, welche die Entstehung der Hochscholastik begleiten. Hier zuerst treten jene neuen Schriften, aus denen schon zuvor Gundissalin in abgelegener Stille seine Werke kompiliert hatte, auch in den $\mathrm{Ge}-$ sichtskreis der Schule und dadurch der breiteren Öffentlichkeit. In der Metaphysik und Physik des Aristoteles aber und seiner von der neuplatonischen Emanationslehre beherrschten arabischen Ausleger - für die erste Zeit kommt vor allem Avicenna in Betracht, seine metaphysischen und naturphilosophischen Schriften sowie das Kompendium seiner Lehre, das Algazel verfaßt hatte, um sie zu bekämpfen; erst weit später kommt auch der durch Michael Scottus übersetzte Averroës hinzu -, sowie in der Psychologie dieser Kommentatoren war vieles enthalten, was ebensosehr mit der herkömmlichen Philosophie wie mit der kirchlichen Lehre im Widerspruch stand. Nur der Geist als solcher, so hatte Averroës gelehrt, d. h. eine der Intelligenzen der "Hochwelt", die über der "Natur" steht und eine gemeinsame für alle Menschen ist, ist 
das Unsterbliche für die Menschheit; die einzelnen Menschenseelen kommen, um zeitweilig an jener gemeinsamen Intelligenz teilzuhaben und dann wieder $z u$ vergehen. Wie die Intelligenz, so ist auch - das hatte schon Aristoteles gelehrt - die sichtbare Schöpfung ewig und ohne zeitlichen Anbeginn. In dieser Welt aber, so lehrten manche, ist alles durch einen notwendigen Kausalnexus determiniert. Was in den Gestirnen geschrieben steht, kann durch keine freie EntschlieBung des Willens durchbrochen werden. Als lateinischen "Averroismus" bezeichnet man jetzt gewöhnlich mit einem Sammelnamen diese Bewegung, die im einzelnen sehr mannigfaltig ist und manches aufweist, das nicht dem Averroës eigentümlich ist, sondern aus Avicenna stammt oder aus dem „Führer der Verirrten“ des jüdischen Philosophen Maimonides gefolgert wurde.

Wohl mit unter der Erregung, welche der Pantheismus und Antinomismus Amalrichs und der Amalrikaner hervorgerufen hatte, vermeinte man anfangs auch hier mit Verboten der naturphilosophischen und metaphysischen Schriften des Aristoteles, in denen man die Quellen der genannten und ver. wandter Lehren sah, den sich verbreitenden neuen Ideen Einhalt gebieten zu sollen. Vergebens natürlich. Jene Verbote wurden bald unwirksam, und es leitete sich die einzig erfolgreiche, die geistige Auseinandersetzung ein. . Albert und Thomas vor allem haben daran gearbeitet, die aristotelische Metaphysik geistig zu erobern. So stehen sie in der Mitte zwischen zwei Extremen. Nach zwei Fronten hin führen sie den Kampf: hier gegen die „Averroisten“, welche sich mit dem schon oben behandelten Satze zu decken suchen, daß etwas wahr sein könne in der Philosophie, falsch in der Theologie, und umgekehrt; dort gegen diejenigen, welche der neuen Bewegung nur widerwillig folgen und die, obwohl sie selbst nicht umhin können, aus der geistigen Luft, in der auch sie atmen, mancherlei in sich aufzunehmen, doch sich dagegen sträuben, die moderne Richtung als berechtigt anzuerkennen. Nicht nur der Averroismus, welcher die Unsterblichkeit der Seele leugnet, wird von den mancherlei Lehrverboten aus jener Zeit betroffen, sondern auch gegen den Aristotelismus eines Thomas von Aquino richten verschiedene Anhänger der traditionellen Lehre ihre Verwerfungsurteile. So schon in einzelnem der Kanzler der Pariser Universität Stephan Tempier, noch mehr aber Thomas' Ordensgenosse Robert Kilwardby, Erzbischof von Canterbury, und dessen Nachfolger Johann Peckham.

II. Augustinische Theologie und aristotelische Philosophie.r. Die traditioDie Entwicklung der traditionellen theologischen Richtung im einzelnen zu gische Richtung. verfolgen ist nicht dieses Ortes. Den „Sentenzen“ eines Hugo von St. Viktor, Peter des Lombarden, Gandulf von Bologna, Peter von Poitiers, Robert Pulleyn, Robert von Melun waren ähnlich geartete zusammenfassende Schriften, meist unter dem Namen „Summen“ gefolgt: von Peter von Capua, dem Magister Präpositinus von Cremona, Simon von Tournay, Gaufrid von Poitiers, Philipp von Greve, Wilhelm von Auxerre u. a. In der umfassenden Summe des Alexander ron Hales ( $t_{1245}$ ), der als hochberühmter theologischer 
Johann von la Rochelle

\section{Albert als} Theolog

Hugo von Straßburg.

$$
\text { pend }
$$
Da nimmt es kein wunder, daß des Alexander von Hales Schüler und OrdensBonaventura. genosse Johannes Fidanza oder Bonaventura († $\dagger_{274}$ ), obwohl mit Thomas von Aquino befreundet, bei seiner Vorliebe für die „sententia communis“ in den Grundzügen seiner Lehre doch der alten augustinischen Richtung weit näher steht als der aristotelisch gerichteten Metaphysik und Psychologie des Aquinaten. Augustinisch ist es z. B., wenn Bonaventura mit Vorliebe die menschliche Erkenntnis als ein Nachdenken göttlicher Gedanken im Lichte der ewigen Wesenheit eines jeden Dinges, wie diese im göttlichen Geiste ist, betrachtet, und wenn er ferner auch in den Geistwesen, insbesondere auch in der menschlichen Seele, zur Erklärung der Veränderlichkeit und des Wandels eine Materie - natürlich keinen körperlichen Stoff, sondern eine rein geistige Materie - als Träger der Form glaubt annehmen zu müssen. An Augustin schließt sich auch die Mystik seines "Itinerarium mentis in Deum" an, welche der Spur Gottes in der Natur, seinem Bilde im Menschengeiste nachgeht, um so zur Versenkung in das Göttliche in einer alle Unruhe stillenden ekstatischen Vereinigung zu gelangen. Mat tha eus von A quasparte und lohann Peckham setzen Bonaventuras Richtung fort. Ebenso teilt der berühmteste theologische Lehrer aus dem Weltklerus an der Pariser UniversiHeinrich tät, Heinrich von Gent († I 293), diesen Augustinismus und das in ihm entvon Gint. haltene platonische Element auch auf philosophischem Gebiete, insbesondere auf dem der Psychologie. Entschieden verwirft er den aristotelischen Begriff der Seelenvermögen als von der Substanz der Seele verschiedener Potenzen. 
Gedächtnis - der Augustinismus versteht darunter das ruhende Bewußtsein der Seele von sich und ihrem Besitz —, Vernunft und Wille sind ihm die drei Richtungen, in denen - ein Bild der göttlichen Dreieinigkeit - das eine Seelenwesen seine Tätigkeit entfaltet. Mit Augustin redet er von einem die menschliche Vernunft erleuchtenden göttlichen Lichte, durch welches diese für die höhere Wahrheitserkenntnis befähigt wird. Die spezifischen Begriffe des thomistischen Aristotelismus bekämpft er durchweg. Den Begriff einer rein potenziellen Urmaterie z. B., die in keiner Weise, auch nicht durch die göttliche Allmacht, ohne eine von ihr verschiedene und doch ihr die Existenz verleihende Form bestehen könne, verwirft er so gut wie die thomistische Vorstellung, nach der die Seele nicht nur dem Körper Leben und Empfinden mitteilen, sondern zuvor noch, als „Form der Körperlichkeit“, die aus sich rein potentielle „Urmaterie“ erst zum Körper machen soll.

Diesen vom Aristotelismus nur in Einzelheiten mehr oder minder beeinflußten Theologen, die auch in ihrem philosophischen Denken dem Augustinismus im ganzen getreu bleiben, steht die aristotelische Richtung ge- 2. Die aristogenüber. Wie wir sahen, tritt sie von Anfang an in zwei Formen auf. Die eine will eine Synthese von Aristoteles und Augustin, die andere den reinen Aristotelismus, und zwar diesen nach der Auffassung der arabischen Philosophen. Als Führer der konkordistischen Richtung begegneten uns bereits Albert und Thomas. Einen typischen Vertreter der zweiten Richtung haben neuere Quellenveröffentlichungen in Siger von Brabant kennen gelehrt. Neben ihm wird mit Namen noch Boetius der Däne genannt.

Zuerst als Lehrer der Philosophie in Paris hoch angesehen, dann angeklagt und außer Landes gegangen, mit Albert und Thomas in literarischem Streit begriffen, von Dante dagegen gefeiert, hat der vom Schicksal hart getroffene, um 1282 zu Orvieto von seinem Sekretär ermordete Siger von Brabant als aristotelische Lehre jenen lateinischen Averroismus vertreten, von dem wir oben schon bemerkten, daß er in vielem nicht gerade durch Averroës, sondern mehr noch durch Avicenna bestimmt ist. Siger hält zwar daran fest, dab Gott auch die bewirkende Ursache der Welt ist; aber die Schöpfung ist ewig. Die Individuen wechseln; die Arten bleiben, wie sie ewig waren. Die vernünftige Seele faßt Siger mit der arabistischen Lehre als eine im Organismus nur wohnende Substanz und vertritt die averroistische Theorie von der Einheit des Intellektes. Sein psychologischer Determinismus schließt sich an Avicenna an. Freilich salviert sich Siger in solchen Fällen, indem er wenigstens äußerlich die theologische Wahrheit über die philosophische stellt; aber wirklich Ernst ist es ihm mit dem Schwanken doch wohl nur dort, wo, wie hinsichtlich der Frage nach der Individualität oder Gemeinschaftlichkeit des a u fnehmenden Verstandes, die Ansichten der griechischen und arabischen Aristoteleserklärer selbst auseinandergehen.

Es lag nicht nur in dem harmonistischen Zuge des mittelalterlichen b) Die konkordiDenkens und in seiner vorwiegend theologischen Tendenz begründet, son- ${ }^{\text {st }}$ dern auch in der widerspruchsvollen Lage der Geguer, daß mit historischer 
Notwendigkeit die Vorherrschaft sich bald entschieden den von Albert und Thomas vertretenen konkordistischen Bestrebungen zuwenden mußte. Und historisch begreiflich ist es, daß jene Männer auch nach der anderen Front hin, gegen die in dem alten Geleise verbleibenden Theologen, den Sieg errangen. Auch das Mittelalter ist keine Zeit völliger Stagnation oder gar des bloßen Rückschritts. Was in ihm wirklich lebt, entfaltet sein Leben in fortschrittlicher und weiterbildender Bewegung, mag auch das Zeitmaß dieser Bewegung zumeist ein langsameres sein als in anderen Perioden. Im I3. Jahrhundert aber vertreten gegenüber denen, die ganz in der Tradition verbleiben, Albert und Thomas das erneuernde und voranstrebende Element. So erscheinen sie ihrer Zeit als neue Meister, deren Namen zusammen mit denen eines Aristoteles und der großen arabischen Philosophen genannt werden. Während es sonst in jener Zeit nicht üblich ist, Lebende oder jüngst Verstorbene mit Namensnennung zu zitieren, begegnen uns z. B. bei Siger von Brabant an mehr als einer Stelle die Namen des Albertus Coloniensis und des Thomas de Aquino, der ,,in der Philosophie ausgezeichneten Männer". Wie sehr diese Schätzung insbesondere des Thomas von Aquino auch in weitere Kreise gedrungen, zeigt der Würzburger Magister Heinrich ,der Poet". In seinem Gedicht über die römische Kurie nennt er den damals am Hofe Urbans IV. tätigen Thomas zwar nicht ausdrücklich mit Namen. Aber gemeint ist Thomas, wenn der Dichter von einem Manne spricht, der, wenn die ganze philosophische Literatur verbrannt wäre, der Erfinder einer neuen Philosophie werden könnte und das Gebäude der Philosophie auf bessere Weise wieder aufrichten würde.

Albert d.Gr. Albert zuerst hat den Aristotelismus in den Kreisen der anerkannten Schule heimisch gemacht. Geboren 1193 (nach anderen 1206 oder I 207) zu Lauingen an der Donau aus dem schwäbischen Rittergeschlechte von Bollstädt, in Italien gebildet, früh dem Dominikanerorden beigetreten, dessen berühmtester Lehrer er wurde, bis der Name seines Schülers Thomas den seinen noch überstrahlte, ist er an den verschiedensten Orten als Lehrer tätig gewesen, in Hildesheim, Freiburg, Straßburg, Regensburg, vor allem in Paris und in Köln, wo er auch I 280 gestorben ist. - Obwohl Albert als Denker einen nicht geringen Scharfsinn beweist, auch in der empirischen Naturbeobachtung hervorragt und selbst des mystischen Tiefsinns nicht entbehrt, so liegt sein Hauptverdienst, das ihm von der bewundernden Nachwelt den Namen des "Großen" eintrug, doch in der Sammlung und übersichtlichen Zusammenfassung eines gewaltigen und überaus vielseitigen Gedankenmaterials. Staunenswert ist das Wissen auf dem Gebiete der patristischen, griechischen, arabischen und jüdischen Literatur, welches ihm bei seinem Bestreben, Altes und Neues zu verbinden, zu Gebote steht. Freilich ist er bei der Benutzung desselben nicht immer ein scharfer Kritiker noch auch ein streng systematischer Kopf. Nicht selten überwiegt der Polyhistor in ihm. Darum kann bei ihm noch Verschiedenartiges ohne durchgängige Beziehung zueinander beisammen wehnen. Es zeigt sich das nicht etwa darin, daß in seinem Aufbau 
des Organismus der Wissenschaften Philosophie und Theologie zwei selbständige Disziplinen bilden. Albert will nämlich, daß man bei philosophischen Fragen philosophisch, nicht theologisch, vorgehe, während er umgekehrt Dogmen, wie die von der göttlichen Dreieinigkeit und der Fleischwerdung des Wortes, aus der Sphäre der reinen Vernunftspekulation ausschließt, und gelangt dadurch wenigstens prinzipiell zu derjenigen Unterscheidung von Philosophie und spekulativer Dogmatik, die wir früher als für die zweite Periode der Scholastik charakteristisch hinstellten. Aber ein wirklicher Mangel an Geschlossenheit des Denkens ist es, wenn auch die philosophischen Begriffe, mit denen Albert in seiner spekulativen Dogmatik arbeitet, vielfach andere sind als die seiner philosophischen Schriften, in denen das neuplatonische Element neben dem aristotelischen eine wichtige Rolle spielt. Dem averroistischen Satze von der Einheit des Intellektes in der ganzen Menschheit freilich und sonst noch manchen averroistischen oder auch neuplatonischen Eigenlehren ist er von Anfang an entgegengetreten. Allein eine eigentliche Synthese der verschiedenen Begriffsgebiete wird von Albert erst in späteren, den Aristoteleskommentaren gegenüber mehr selbständigen Werken unternommen und selbst da keineswegs ohne Rest durchgeführt.

Ein näheres Eingehen auf Alberts philosophisches System erübrigt sich hier. Seine Anschauungen, soweit sie in der Metaphysik und theoretischen Psychologie einen modifizierten Aristotelismus bieten, werden uns bei seinem Schüler Thomas wieder begegnen, der hier ganz auf ihnen fußt. Auf anderen Gebieten, insbesondere dem der philosophischen Ethik und der Staatslehre, kommt er, im Gegensatze zu Thomas von Aquino, über eine unselbständige Reproduktion des Aristoteles nicht hinaus. Wir können daher auf die Darstellung der antiken Philosophie selbst verweisen. Am meisten Eigenart zeigt Albert auf dem Felde der Naturwissenschaft und der Naturphilosophie. Hier vertritt er Ansichten, z. B. über die Art des Verbleibens der Elemente in den Mischungen, die einer an die Dinge selbst sich haltenden Betrachtungsweise immerhin doch näher stehen als die rein begrifflich zugespitzten seines Schülers Thomas von Aquin. In der physiologischen Psychologie erweist er sich wenigstens als eifriger Sammler, in der Tier- und besonders der Pflanzenkunde - wir würdigten bereits früher seine Tätigkeit auf diesem Felde zugleich als selbständiger Beobachter.

Die an Albert sich anschließende Schule der „Albertisten“ - U1rich

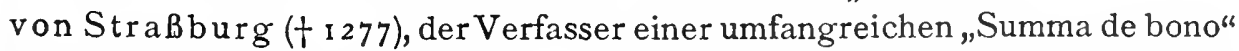
ist ihr bedeutendster Vertreter - tritt bald ebenso hinter Thomas und den Thomisten zurück wie die ältere Franziskanerschule des Alexander von Hales und Bonaventura hinter Duns Scotus, wenn auch immerhin noch in der zweiten Hälfte des 15. Jahrhunderts an der Kölner Universität die „schola Albertistarum" als philosophische Richtung fortbesteht.

Eine ähnliche wissenschaftliche Stellung wie Albert, doch in durchaus selbständiger Weise nimmt der Engländer Robert Grosseteste (Greathead), f 1243 als Bischof von Lincoln, ein. Wir haben von ihm eine Reihe von Werken 
selbständiger Natur, philosophische und psychologische Monographien, sowie Kommentare zu aristotelischen Schriften und zu einer Schrift des PseudoAreopagiten, welche ebensosehr die volle Beherrschung des alten und des neuen Materials wie Sinn für Mathematik und physikalische Wissenschaft sowie für die Sprachen erkennen lassen. Wir kommen auf ihn zurück.

Der klassische Vertreter aber der konkordistischen Richtung ist Thomas von Aquino. Als einflußreichsten und auch jetzt noch am meisten nachwirkendem Vertreter der Scholastik widmen wir ihm eine besondere Betrachtung.

III. Thomas von Aquino (I225-I 274). Thomas von Aquino vollendet mit systematischem Geiste, was Albert begonnen hatte. Geboren um 225 als Sohn des Grafen Landolf von Aquino auf dem Schlosse Roccasicca, vorgebildet zu Monte Cassino und Neapel, gegen den heftigen Widerstand der Familie Mitglied des Dominikanerordens geworden, erhielt Thomas zu Köln durch Albert seine wissenschaftliche Weihe. Als gefeierter Lehrer - „doctor famosissimus" nennt ihn z. B. schon sein Zeitgenosse Gottfried von Fontaines wirkt er an den verschiedensten Orten: in Paris, dem Mittelpunkte der scholastischen Bewegung, in Köln, Rom, Neapel usw. Ein Teil seiner Schriften, insbesondere sein Sentenzenkommentar und zahlreiche "Quästionen", ist unmittelbar aus dieser Lehrtätigkeit und den mit ihr verbundenen Disputationen hervorgegangen. Andere, namentlich die Kommentare zu Aristoteles, zum liber de causis und zu Dionysius Pseudo-Areopagita, stehen wenigstens in Beziehung dazu, während ein weiterer Teil, insbesondere die theologische und die philosophische Summe und zahlreichere kleinere Schriften, wie die vom Fürstenregiment, den Charakter selbständiger literarischer Werke trägt. Gestorben ist Thomas auf der Reise zum Konzil von Lyon in der Zisterzienserabtei Fossa nuova bei Terracina, am 7. März I 274.

I. Die allgemein Stellung des Thomas von Aquino.

thomistische Ontologie.

Die prinzipielle Stellung des Aquinaten ist nach entscheidenden Gesichtspunkten hin bereits dargelegt. So sahen wir, wie er - in Übereinstimmung mit Albert - das Verhältnis von Glauben und Wissen, von Natur und Übernatur bestimmt. Auch seine Stellung in der Universalienfrage lernten wir kennen. Und wenn wir die mittelalterliche Philosophie als eine vorwiegend, obgleich nicht ausschließlich, metaphysisch gerichtete charakterisierten, so gilt das auch von der thomistischen.

Durch Geschlossenheit des Ganzen und Feinheit der Einzeldurchführung erhält das metaphysische System bei Thomas eine für ihre Zeit und in ihrer Art klassische Formulierung. Aristotelisch ist die herrschende Strömung in dieser Gedankenwelt. Zugleich aber führt diese Strömung nicht nur viele augustinische, auch manche neuplatonische Elemente mit sich fort, sondern sie erhält aus der augustinischen Tradition noch darüber hinaus in den letzten Fragen der Weltanschauung ihre entscheidende Direktion. Rein aristotelisch ist zunächst der Ausgangspunkt der Untersuchung über die allgemeinsten Prinzipien des Wirklichen. Ging die platonische Betrachtungsweise von vornherein darauf aus, der Flamme gleich zum Höchsten aufzusteigen und aus 
diesem idealen Maßstabe die Bestimmungen des Seienden zu treffen, so wollte dagegen die aristotelische Metaphysik ihren Begriff des Seins, seiner Prinzipien, Ursachen und Arten, aus der Analyse des in der Erfahrung gegebenen Wirklichen gewinnen. So auch Albert als Aristoteliker und Thomas. Das Seiende, von dem die Metaphysik, die „Wissenschaft rom Seienden als Sei- ${ }^{\text {phy }}$ enden", ausgeht, ist ihnen nicht das absolute und höchste Sein - Gott ist nur als letzte Ursache des Geschaffenen Gegenstand der Metaphysik --, sondern das von dem empirisch Gegebenen abstrahierte Sein, gegen dessen Gleichsetzung mit der objektiven Realität als solcher sich noch keine ernstlichen erkenntnistheoretischen Bedenken geltend gemacht haben. Darum gehen auch die metaphysischen Kategorien zunächst nur auf dieses endliche Seiende. Das gilt auch von dem Begriffe des primären Seienden oder von der Kategorie der Substanz, deren aristotelische Definition Thomas bestimmter auszugestalten sucht. Bezeichnend ist es, daß mit der aus der Renaissance stammenden platonischen Reaktion gegen den scholastischen Aristotelismus auch sofort ein Wandel der ontologischen Grundrichtung eintritt. Die cartesianische Definition der Substanz, die Grundlage seiner und Spinozas rationalistischer Metaphysik, nahm wieder ihren Ausgang nicht von dem empirisch gegebenen Wirklichen, sondern von dem in höchster Vollendung gedachten Sein, dem Sein, welches zu seiner Existenz überhaupt keiner Ursache bedarf.

Der theologische Gesichtskreis eines Albert und Thomas bringt es nun aber mit sich, daß trotz dieses Ausganges ihrer Ontologie vom empirisch gegebenen Sein die Frage nach dem Göttlichen von ihnen in weit höherem $\mathrm{Maße}$ in den Vordergrund gerückt wird als von Aristoteles, bei dem die Gottheit in erster Linie nur unter dem naturphilosophischen Begriffe des ersten Bewegers eingeführt wird. Wie in der Philosophie Augustins so kommt auch in der thomistischen Metaphysik bei jeder tiefer durchgeführten Untersuchung jene letzte Frage stets wieder zum Durchbruch. Die thomistische Metaphysik trägt darum auch in ihren allgemeinen Untersuchungen einen ausgeprägt theistischen Charakter. Da nun aber die Begriffe dieser Metaphysik dem Endlichen angepaßt sind und darum dem Absoluten gegenüber sich als inadäquat erweisen müssen, so gelangt eine Schwierigkeit, die latent schon bei Aristoteles vorhanden war und bei Straton von Lampsakus zu einer naturalistischen Wendung der peripatetischen Schule geführt hatte, in der thomistischen Metaphysik zu derselben scharfen Zuspitzung, mit welcher dieselbe schon vorher, z. B. bei Augustin, aufgetreten war. Bereits Augustin hatte in schlagenden Sätzen die Unmöglichkeit dargetan, das göttliche Wesen und Wirken anders zu den aristotelischen Kategorien in Beziehung zu setzen, als indem aller anschauliche Gehalt derselben zertrümmert wird. Eine ähnliche Schwierigkeit war in der Stellungnalıme des Maimonides zu der von arabischen und jüdischen Theologen viel umstrittenen Lehre von den göttlichen Attributen zum Bewußtsein gekommen. Und schon der Pseudo-Areopagite hatte mit dem Neuplatonismus gelehrt, daß man von Gott eher sagen könne, was er nicht sei, als was er sei. So sucht denn Thomas von der Ontologie 
aus zu einer natürlichen Theologie durch die Verbindung mehrerer Gesichtspunkte, positiver und negativer, zu gelangen. Nicht in seinem Ansich, seinem inneren Wesen, lehrt er, sondern nur unter dem Gesichtspunkte der Weltursache fällt Gott in den Gesichtskreis des metaphysischen Vernunftschlusses. Wenn so auf dem „Wege der Ursächlichkeit" von den endlichen Vollkommenheiten auf deren Ursache geschlossen (darüber unten) und das bedingungslos Wertvolle in der geschöpflichen Vollkommenheit gemäß dem „Wege der Steigerung" (via eminentiae) der ersten Ursache in unendlichem Maße beigelegt wird, dann muß doch der "Weg der Negation“ - die "negative Theologie" des Areopagiten - hinzutreten, auf dem erkannt wird, daß die dem Endlichen entnommenen Bestimmungen in Wahrheit der Gottheit eher abzusprechen als beizulegen sind. Daher bleibt nur eine gewisse analoge Weise - die Scholastik hat den zwischen der logischen Eindeutigkeit und der bloBen Mehrdeutigkeit in der Mitte stehenden aristotelischen Begriff der Analogie näher zu entwickeln gesucht -, nach der Gott durch unsere metaphysischen und psychologischen Begriffe gedacht werden kann. Nur in analoger Weise kann er Substanz genannt, kann von seinem Verstande, seinem Willen usw. geredet werden. Selbst der allgemeine Begriff des Seins umfaßt nur in analoger Weise das endliche und das unendliche Seiende. Darum ist die Gottheit nicht ein Allgemeines, das sich in den Dingen differenziert, und darum schließt die Existenz eines Endlichen, das von dem alle Vollkommenheit doch schon einschließenden Unendlichen unterschiedlich ist, keinen Widerspruch ein; denn bloß Analoges kann nicht addiert werden.

Wesenheit und Dasein.

Den tiefsten Grund für diese Unvergleichbarkeit, welche zwischen dem Göttlichen und Kreatürlichen bis in das Tiefste des Seins hinein einen unaufhebbaren Unterschied setzt, erblickte die thomistische Metaphysik in dem verschiedenen Verhältnis, in welchem Wesenheit und Dasein in dem einen und in dem anderen Falle zueinander stehen. Augustinische Gedanken verbinden sich bei dieser Spekulation mit Begriffsunterscheidungen, die in solcher Form von der arabischen Philosophie, zuerst wohl von Alfarabi, ausgeprägt waren. Nur Gott existiert durch sein Wesen. Es ist sein Wesen, zu sein, und sein Wesen bedarf daher keiner äußeren Ursache. In allem Endlichen dagegen - so hatte Alfarabi gezeigt - ist die Frage, was das Ding sei, und $o b$ es sei, ist die Wesenheit und das Dasein verschieden. Das Endliche, lehrte Thomas mit Augustin, ist nicht das Sein, sondern hat nur teil am Sein. Es ist nicht durch sein Wesen schon da, sondern durch die Ursachen, welche ihm die Existenz verleihen. Auf diese Weise hat - vor allem durch die Synthese mit augustinischen Gedanken - der auch von der Scholastik des 13. Jahrhunderts stark betonte Satz des Aristoteles, daß die Gottheit als erster, unbewegter Bewegter lautere Energie (actus purus) sei, während in allem ihr Nachgeordneten dem Akte die Potenz, der Wirklichkeit die Möglichkeit beigemischt ist, eine neue Wendung und Vertiefung erfahren. 
durch sein Wesen seiend, sondern am Sein nur teilhabend, bedarf alles Endliche der Ursache. Die Ursachen und Wirkungen aber, lehrt Thomas im Anschluß an einen unter anderem im Liber de causis entwickelten neuplatonischen Gedanken, stellen eine stufenförmige und zugleich übergreifend sich verkettende Reihe dar, in welcher das Höhere die tieferreichende Wirkung ausübt. Darum ist die aller näheren Bestimmung zugrunde liegende und alle nähere Bestimmung durchziehende allgemeinste Vollkommenheit, das Sein oder die Existenz, von der höchsten und umfassendsten Ursache, d. h. von der ersten Ursache, gesetzt, die alles in das Sein ruft und die Kraft und das Wirken aller niederen Ursachen im Sein erhält. Auf diese Art überwindet Thomas denn auch das äußerliche, mehr deistisch als theistisch gedachte Verhältnis, in welchem bei Aristoteles der erste Beweger zur Natur steht. Nicht als in sich beschlossener und darum bloß äußerer, in astronomischer Erhabenheit thronender Beweger steht Gott einer ihm innerlich fremden Natur gegenüber. Vielmehr ist er, obwohl von der Welt, die durch seine Kraft hervorgegangen ist, unterschieden, doch einem jeden Dinge als Schöpfer und Erhalter alles Seins und Wirkens im Innersten gegenwärtig.

Bleibt so Thomas in den eigentlichen Fragen der Weltanschauung durchauṣ der von Augustin her überlieferten traditionellen Metaphysik getreu, so sind im übrigen die ontologischen Grundbegriffe und Grundsätze bei ihm durchgehends die aristotelischen, oder sie sind doch auf aristotelischer Grundlage erwachsen. Nur vereinzelt wirken platonische Anregungen oder theologische Spekulationen der Kirchenväter nach, wie bei dem Begriffe der Ewig- Metaphysische keit und anderer Formen zeitloser Dauer, oder bei den mannigfachen Unterscheidungen, die sich um den patristischen Begriff der Hypostase gruppieren: Suppositum, Subsistenz, Person (als Hypostase einer vernünftigen Natur) usw. Aber solche dem heutigen Philosophen fremd klingende und leicht leer erscheinende Begriffsformulierungen erwuchsen auch nicht so sehr aus rein philosophischen Antrieben, als vielmehr aus den Bedürfnissen einer den Glaubensinhalt begrifflich durchbildenden theologischen Spekulation. Ganz aristotelisch sind dagegen die Kategorien, die, zehn an der Zahl, als oberste Gattungen des Seienden aufgestellt werden; aristotelisch die vier Ursachen: bewirkende, Formal-, Material- und Zweckursache, die bei jedem Werden untersucht werden sollen. Nicht minder ist aristotelisch das allesdurchziehende Begriffspaar der beiden einander entgegengesetzten und doch stets aufeinander bezogenen Seinsprinzipien Akt und Potenz, mit deren Hilfe auch das Kausalgesetz entwickelt wird, und die mit dieser gegenseitigen Beziehung von Akt und.Potenz im Zusammenhange stehende teleologische Weltansicht, die überall, in der Natur, dem Geistesleben und der Menschheitsentwickelung eine immanente $Z$ weckmäßigkeit sich auswirken sieht.

In der Naturphilosophie und der Anthropologie führt der aristotelische Einfluß wie bei Albert, so auch bei Thomas gegenüber der früheren Scholastik zu einer tiefgreifenden Umgestaltung. Übrigens gehen hier, namentlich auf 
den gleichen Weg. Was Thomas namentlich charakterisiert, ist die rückhaltlose Entschiedenheit, mit der von ihm - unter Loslösung von der bei Aristoteles und Albert noch stärker mitwirkenden beobachtenden und induktiven Methode - die aristotelischen Gesichtspunkte nach der rein begrifflichenSeite hin aus und zu Ende gedacht werden.

Die aristotelische Naturphilosophie suchte durch die beiden wie Akt und Potenz sich zueinander verhaltenden Prinzipien Form und Materie eine Erklärung zu gewinnen einerseits für die gleichbleibende typische Gesetzmäßigkeit in der Ausgestaltung und Wirkungsweise der Naturdinge, ihre zweckvolle Ordnung und vernunftgemäße Begreiflichkeit, andererseits für ihr Werden und Vergehen, ihre individuelle Verschiedenheit und ihre zufälligen Unvollkommenheiten. Albert und Thomas übernehmen diese Auffassung. Während aber bei Aristoteles und zum Teil noch bei Albert die Begriffe Form und Materie eine ziemliche Dehnbarkeit besitzen, wird in der thomistischen Naturphilosophie die stramme Ordnung der Begriffe als zureichenErste Materie. der Ausdruck der so vielgestaltigen Natur selber gefaßt. Der bei Aristoteles an einer einzigen Stelle seiner Metaphysik vorkommende Begriff einer Materie, die aus sich weder Substanz noch ein Quantum noch sonst etwas unter die Kategorien Fallendes ist, sondern dieses alles nur der Möglichkeit nach, jener im Neuplatonismus weiter ausgebildete, von Augustin übernommene Begriff eines bloß potentiellen Etwas, das unter der das Sein verleihenden Form dennoch ein Wirkliches ist, wird ein von der späteren thomistischen Schule mit Leidenschaft verfochtenes Bestandstück der Naturphilosophie. Eine zweite Unterscheidungslehre ist dann die Einheit der Form, welche

Einheit der Form.
Thomas der seit Gilbert de la Porrée herrschenden und durch das Ansehen Avicennas und Avencebrols weiter gestützten Pluralitätstheorie entgegenstellt. Jede Vielheit substanzialer Formen würde die Einheit der Substanz zerstören. Beim Auftreten einer höheren Form muß darum die niedere sich in die „Potenz" der Materie zurückziehen, bis sie beim Schwinden jener höheren dann selbst wieder aus der Potenz auftauchen kann. Auch im Menschen hat diese strenge Einheit der Form Geltung. Seine Wesensform, die Seele, gibt nicht nur Vernünftigkeit, Empfindungsfähigkeit und physisches Leben, sondern macht auch noch dazu, daß die materia prima im Menschen überhaupt $z u$ einem mit physikalischen und chemischen Kräften begabten physischen Körper wird. Den Scotisten gegenüber, die einwandten, daß nach dem Tode trotz der Trennung der Seele von der materia prima der Leib doch noch zunächst fortbestehe, mußten die Thomisten dann zu einer "forma cadaverica" ihre Zuflucht nehmen. Solche und ähnliche in der späteren Zeit immer freigebiger verwendete Erklärungsversuche, wie die Eduktion der Form aus der Potenz der Materie und ihre Reduktion in diese, die akzidentellen Dispositionen, welche die gesetzmäßige Aufeinanderfolge der von der wirkenden Ursache eduzierten Formen bedingen sollen: alles das waren denn freilich nur Wörter, die sich als Lösungen von Problemen gaben, welche sie in Wahrheit nur verhüllten. Es lag denselben eine unzulängliche Verwəndung des 
an sich ja unentbehrlichen teleologischen Gedankens zugrunde, die später zum Kampfe der aristotelisch-scholastischen Teleologie und der zum Teil gleichfalls einseitig auftretenden mechanischen Naturansicht führte.

Der wertvolle Beitrag zur Erkenntnis des Organismus, welcher trotz aller Mißgriffe der aristotelische Begriff der Entelechie und der immanenten Teleologie dennoch gebracht hatte, war auch der Anthropologie zustatten gekommen. Nachdem bei Plato die ethisch-metaphysische Wertung geherrscht hatte, war jetzt bei der Analyse des Menschenwesens die Durchführung des biologischen Gesichtspunktes möglich geworden. Albert — dieser wenigstens in seinen philosophischen Schriften - und Thomas folgen hierin dem Aristoteles. Jetzt ist nicht mehr, wie bei Augustin und noch bei Hugo von St. Viktor, die Seele allein der wahre Mensch. Leib und Seele stehen sich nicht wie zwei abgeschlossene Substanzen gegenüber, die als die weitest voneinander abstehenden nur durch die göttliche Allmacht miteinander verbunden werden können: ein bei Descartes wieder auftretender Gedanke, den wir auch bei Thomas' Zeitgenossen Bonaventura finden. Vielmehr schließen beide als Akt und Potenz, als Form und Materie eine innere Beziehung zueinander ein. Sie sind zwei Seinsprinzipien in einer vollständigen Substanz, einer menschlichen Person. Die menschliche Seele, das Prinzip des vernünftigen Lebens, ist zugleich Prinzip des sensitiven und vegetativen Lebens im beseelten Organismus. Daß, hierin über Aristoteles und Albert hinausgehend, Thomas ihr zugleich die Funktion zuschreibt, die materia prima zum Körper zu machen, wurde schon erwähnt. Durch diese neue Anthropologie hat zugleich eine alte neuplatonische Vorstellung, die auf verschiedenen Wegen dem Mittelalter zugekommen war, eine Verstärkung erfahren: die Idee eines harmonischen Stufenbaues in Universum, wo stets ein mittleres Glied das Obere nit dem Niederen verbindet. Nunmehr erscheint der Mensch, dieser Mikrokosmus, welcher die Geisteswelt und die Körperwelt vereint, nicht mehr als die gewaltsame Aneinanderpressung entgegengesetzter Elemente, sondern als ihre organische Synthese.

Damit ist - nicht so sehr auf Grund empirischer Analyse als aus all- Plyssisches und gemeinen metaphysischen Voraussetzungen - auch für die Auffassung der Psschisches in psychischen Tätigkeiten ein veränderter Standpunkt gegeben. Die Sinneserkenntnis erscheint nicht mehr, wie in der platonisch-augustinischen Psychologie, als ein rein geistiges Phänomen, das, wenn auch durch einen körperlichen Vorgang veranlaßt, doch als solches ausschließlich seinen Sitz in der Seelensubstanz hat. Sie ist für Thomas, wie für Aristoteles, Tätigkeit des zusammengesetzten menschlichen Ganzen, des beseelten Organismus. Wie freilich bei diesem psychologisclien Vorgang das Verhältnis des Psychischen und des Physischen näher gedacht werden soll, ob etwa im Sinne einer der modernen Parallelismustheorien oder in welcher sonstigen Weise, das bleibt beim Mangel eines schärferen Eindringens in die psychischen, physiologischen und physikalischen Phänomene in der Scholastik ebenso unbestimmt wie bei A ristoteles. Auf das beg riffliche Denken dehnt Thomas jenen psychophysischen

und in der Verstandes erkenutnis. 
Charakter nicht aus. Für die hyperorganische Natur dieses Denkens werden die hergebrachten aristotelischen Argumente angeführt. Sein Subjekt ist der immaterielle Verstand. Nichtsdestoweniger steht nach anderer Seite hin auch diese Verstandestätigkeit mit dem Ganzen des Menschen in engem Zusammenhange. Sein Objekt nämlich, den vom Individuellen abstrahierenden allgemeinen Begriff, gewinnt der Verstand nur auf Grund der individuellen Anschauungsbilder oder "Phantasmen", welche durch die innere sinnliche Vorstellungskraft der Seele vorgeführt werden. Sonac’l ist auch die vernunftbegabte menschliche Seele in den allgemeinen biologischen Zusammenhang gestellt, ohne indes, wie die Tierseele und die "Seele" (d. h. das Lebensprinzip) der vitalistisch genommenen Pflanze, darin aufzugehen. Obwohl der Vernunft der Stoff ihrer Betätigung durch das sinnlich-organische Leben geboten wird, so überragt sie doch dieses.

Stellung des Intellektes zum Seelenwesen.

Das Mittel, solch verschiedenartige Funktionen in der einen Seele zu vereinigen, bietet Thomas zunächst der von Aristoteles übernommene Begriff des „Vermögens“. Durch die Aufstellung solcher ursprünglicher wirkungskräftiger Qualitäten oder Vermögen, die von der ihnen zugrundeliegenden Substanz und untereinander verschieden sind, unterscheidet sich diese aristotelisch gerichtete psychologische Theorie scharf von der früheren augustinischen. Freilich ergaben sich gerade von diesem veränderten Standpunkte aus neue Fragen. War doch bei Aristoteles das Verhältnis, in welchem der von außen kommende Intellekt - es wird ein tätiger und ein aufnehmender unterschieden - zu der Seele selbst steht, durchaus nicht klar bestimmt. Griechische und arabische Interpreten hatten darum die verschiedensten Erklärungen geboten. Den einen war die (aktive) Vernunft ein von der Gottheit ausstrahlendes Licht, andern eine der Intelligenzen, die auf Grund der neuplatonischen Emanationslehre eine so große Rolle in der arabischen Philosophie spielten. Die dem individuellen Menschen selbst eigene Vernunftkraft war daher manchen nur eine Beschaffenheit, die erst durch die Berührung mit einem von außen einstrahlenden Licht erworben wird. Thomas wendet sich mit Recht gegen diese phantastischen Vorstellungen und zeigt, wie sie die - durch das Bewußtsein bezeugte - Zugehörigkeit der Denkakte zum Einzelsubjekte unmöglich machen. Die vernünftige Tätigkeit ist eine Funktion der individuellen Menschenseele; die Vernunft ein dem individuellen Menschen eigenes Vermögen. Ihre überorganische Natur - so hatte schon Avicenna die Schwierigkeit zu lösen versucht - erklärt sich dadurch, daß nur die niederen Vermögen der Seele insofern zukommen, als sie Entelechie des organischen Körpers ist, die vernünftigen Vermögen, Verstand und vernünftiger oder freier Wille, dagegen in der Seele als solcher ihren Ursprung haben.

Nunmehr kann die thomistische Psychologie trotz des aristotelischen Ausgangspunktes wieder in die Bahnen des platonischen Phädo einlenken. Geht aus der menschlichen Seele eine hyperorganische Tätigkeit hervor, so erschöpft sich auch ihr Sein nicht darin, daß sie dem Stoffe, dem sie Gestaltung verleiht, als vollendetes Teilprinzip der Menschensubstanz innewohnt. Ob- 
wohl sie, an sich betrachtet, nicht schon eine vollendete Substanz ist, so kommt ihr als „subsistierender Form" doch schon in sich eine gewisse unvollendete Substanzialität zu. Während die Tierseele nur im Stoffe und im physischen Zusammenhange existiert, besteht die vernünftige Seele schon in sich und teilt so auch dem Organismus den Bestand mit. Darum wird die Seele auch nicht dem natürlichen Vergehen (der Korruption) unterworfen sein: weder akzidentell, wenn der Leib schwindet, da sie den Bestand nicht erst durch die Verbindung mit der Materie hat; noch an sich, da sie natürliche Quelie des Seins ist und deshalb wenigstens durch einen natürlichen Prozeß nicht von diesem Sein getrennt werden kann. Die Annahme aber, daß Gott, die letzte Quelle und der Erhalter alles Seins, sie der Vernichtung (Annihilation) anheimfallen lasse, würde der unendlichen Weisheit ein zweckloses Tun beilegen. Auf jene Inkorruptibilität weist auch das natürliche Verlangen der Seele hin, deren Vernunft eine zeitlose Erkenntnis des Seienden hat. - Es wurde schon bemerkt, daß Duns Scotus, der strenge Kritiker der thomistischen Philosophie, diese und ähnliche Erwägungen nicht als demonstrative Beweise gelten läßt, wohl aber als solche, welche die Unsterblichkeitshoffnung schon auf dem Standpunkte des natürlichen Erkennens zu einer durchaus vernünftigen machen.

Indem Thomas die averroistische Lehre von der Einheit des Intellektes in der ganzen Menschheit bekämpft und die Individualität auch auf die ver. nünftige Natur des Menschen ausdehnt, streift er zugleich ein Problem, das die Scholastik viel beschäftigt hat, das der Individualität und des Individua- Individuations. tionsprinzipes. Man verstand darunter die Frage, wie es metaphysisch mög- prinsip, ins. lich sei, daß nicht jede Vielheit des Seins eine spezifische ist, daß vielmehr eine Vielheit gleichartiger Individuen nebeneinander besteht. Der Geist als solcher, lehrte Thomas mit Avicenna im Gegensatz zu der herrschenden Ansicht der Theologen, ist einer solchen Dutzendexistenz nicht fähig. Seine Natur und Existenzweise ist dafür eine $z u$ reiche und $z u$ wirkungskräftige. In der Geisteswelt - Thomas spricht im allgemeinen lieber theologisch von Engeln als von den dem Neuplatonismus entnommenen "Intelligenzen" der arabischen Philosophie - ist jedes Individuum eine Art. In der die Form an die Materie bindenden Körperwelt dagegen bietet der in sich keine Einheit einschließende, die Form aufnehmende Stoff die Möglichkeit, daß zu verschiedenen Zeiten und an verschiedenen Orten gleiche ausgestaltete Prinzipien - Entelechien oder Formen - in eimer Mehrzahl gleichartiger Individuen wirklich sind. Die Materie ist das Individuationsprinzip (aristotelisch). Wäre der Intellekt der Menschen eine gesondert existierende Intelligenz, so hätte daher Averroës recht mit seiner Lehre von der Einheit desselben. Aber die Vernünftigkeit ist der menschlichen Seele selbst immanent, und diese Seele, in der vernünftige und organische Funktionen sich verflechten, trägt und behält in sich die natürliche Beziehung zum Leibe, dem sie zugeordnet ist, und zu dem individuierenden materiellen Prinzip. - So die thomistische Lehre, die freilich auch in der Scholastik selbst vielen Widerspruch erfahren hat. 
Menschliche

Person und Persönlichkeit.

teilung der Seelenvermögen.

Erkenntnisvermögen.

Nach einer von Boethius gegebenen Definition (die man auf theologischem Gebiete freilich nur in modifizierter Form oder gar nicht gelten ließ) bezeichnet die Scholastik die „individuelle Substanz der vernünftigen Natur" als Person. Menschen sind daher Personen. Als solche betrachtet Thomas sie als (relative) Selbstzwecke, im Unterschied von den Sachen, die im Systeme der $Z$ wecke dem Menschen untergeordnet sind. Als vernünftiges Wesen ist der Mensch Herr seines Tuns und darum nicht bloßes Instrument. Durch seine Vernunft, die zur Erkenntnis der gesamten Wirklichkeit bestimmt ist, wird der Mensch gewissermaßen zum Mikrokosmus. - So kommt bei Thomas auch der Begriff der Persönlichkeit zur Geltung. Aber man darf nicht übersehen, daß dieser Begriff noch einen völlig abstrakten Charakter trägt. Hier ist die Persönlichkeit schon darin erschöpft, Individuum der vernünftigen Menschengattung zu sein. Die psychologische Analyse und die ästhetischethische Wertung der Persönlichkeit im Sinne einer eigengestalteten, reichen und entwicklungsfähigen ursprünglichen Sonderart, im Sinne einer Fülle des individuellen geistigen Lebens, welche die „Persönlichkeit“ von der bloße Nummern darstellenden Menge sich abheben läßt, liegt nicht im Gesichtskreise und Forschungsgebiet der „unpersönlichen“ Scholastik.

Die Analyse der psychischen Zustände und Tätigkeiten erscheint bei Thomas, wie in der herrschenden Richtung der Scholastik überhaupt, vorwiegend unter den metaphysischen Gesichtspunkt der von Aristoteles ausgehenden, bei den Arabern, insbesondere bei Avicenna, zum Teil näher ausgebildeten Vermögenstheorie gestellt. Diese Vermögen sind zwar in der thomistischen Psychologie keineswegs als willkürlich schaltende, unter sich ein Intrigenspiel aufführende Mächte gedacht; aber dem psychischen Geschehen selbst und der Gesetzmäßigkeit der psychischen Phänomene näher nachzugehen, dazu ist jene doch nicht gelangt. Der Hauptnachdruck wird auf die scharfe Sonderung und Gliederung der Vermögen gelegt, welche, wie bei Aristoteles, durch die Systematisierung der Objekte gewonnen werden soll.

Wenn wir von dem rein Physiologischen absehen, so werden zwei Hauptgruppen von Vermögen unterschieden, die des Erkennens und die des Strebens. Beide sondern sich wieder in zwei scharf voneinander sich abhebende Stufen, die sinnliche und die vernünftige. Das Erkennen wird als ein Abbilden, ein bildhaftes Erfassen in der sinnlichen oder intelligiblen "Spezies" (= Bild) erklärt. Der Anstoß zu demselben erfolgt durch eine vom Objekte ausgehende Bewegung. Denn der Sinn ist ein passives, rezeptives Vermögen. Die Vernunft aber entwickelt ihre Begriffe auf Grund der Sinneswahrnehmung. Für sie gilt der scholastische Satz: Nichts ist im Intellekte, was nicht vorher im Sinne war; ein Satz, der freilich mehrfach, namentlich hinsichtlich des nicht aus der Sinneserfahrung abstrahierten, sondern aus ihrer kausalen Erklärung hervorgegangenen Gottesbegriffs, bei Thomas eine tiefgreifende Modifikation erfährt, bei Bonaventura in seiner Allgemeingültigkeit sogar überhaupt geleugnet wird. Ist so das Erkennen 
für Thomas ein Aufnehmen, so geschieht doch, wie ein anderes scholastisches Axiom sagt, alles Aufnehmen nach der Weise des Aufnehmenden. Schon in den äußern Sinn geht darum das äußere Objekt nicht in seiner realen Körperlichkeit ein, sondern verfeinert, bildhaft, „vergeistigt“. Immer freilich bleibt das Sinnenbild, auch das der innern Anschauung (das "Phantasma“), noch räumlich und zeitlich determiniert, noch individuell. Erst die nicht mehr an die individuierende Materie gebundene Vernunft vermag auf Grund jenes Sinnenbildes den allgemeinen Begriff, das von Zeit und Raum unabhängige Wesen, zu erfassen. Da aber das Sinnenbild nicht unmittelbar auf die rein geistige Vernunft einzuwirken vermag, so bedarf es hierzu der „erleuchtenden" Kraft eines aus sich selbst stets zur Tätigkeit bereiten, spontanen Vermögens, des im Anschluß an Aristoteles so genannten „tätigen Verstandes" (intellectus agens), der aus dem durch die Sinneswahrnehmung dargebotenen Material das dem Verstande Konforme aussondert. Aus dem Anschauungsbilde oder Phantasma, welches als Bild des ganzen realen Gegenstandes mehr enthält, als dem nur die Akzidentien erfassenden Sinne an ihm bewußt ist, abstrahiert er das eigentliche Wesen und bringt so zusammen mit dem Substrat seiner Tätigkeit, dem Phantasma, das intelligibele Erkenntnisbild (species intelligibilis) hervor. Jetzt kann der „mögliche Verstand" (intellectus possibilis) dieses intelligibele Bild in sich aufnehmen und darin den allgemeinen Begriff des Dinges erkennen. - Geht so weit Thomas in allem Wesentlichen mit Aristoteles, so schlagen doch auch augustinische Anregungen verstärkend und ergänzend in die aristotelische Lehre vom „tätigen Verstande“ ein. Derselbe wird gefaßt als ein in der Menschenseele ausgeprägter Reflex des vorbildlichen göttlichen Denkens, sein natürliches Licht als eine Anteilnahme an dem göttlichen Lichte, als ein von diesem dem Menschengeiste eingeprägtes Siegel. Dieses aus dem tätigen Verstande und seiner Spontaneität (nur das Wort, nicht die Sache ist Thomas fremd) fließende natürliche Licht ist der Grund für die Leichtigkeit, mit welcher der Verstand, sobald ihm erst aus der Erfahrung die für die Vernunftbetätigung, erforderlichen Begriffe zugekommen sind, die allgemeinen Denkprinzipien die Grundlagen alles Urteilens uud Schließens, in Funktion treten läßt. Darum können - und hier gehen wieder einmal Fäden von der Scholastik zu Descartes, - jene durch das natürliche Licht der Vernunft deutlichen Prinzipien in gewisser Weise als angeboren bezeichnet werden, während sie in anderer Weise freilich von der Sinneserfahrung her erworben sind. Es gilt das auch von den sittlichen Prinzipien, die als habituelle Anlage der (praktischen) Vernunft von Natur eignen („Synderesis“) und beim Handeln in dem konkreten Urteil des Gewissens zum Bewußtsein gelangen.

Die hier kurz skizzierte Erklärung, welche Thomas in Durchführung aristotelischer und augustinischer Motive von dem Prozeß des Erkennens gibt, kam auf das beste den Bedürfnissen der Zeit entgegen. Mit ihrem Bestreben, $z$ wischen Sensualismus und Intellektualismus den rechten Weg zu finden, bezeichnete sie nicht nur einen großen Fortschritt gegenüber der vor- 
hergehenden Periode der Scholastik, sondern sie ist auch an sich, wenn wir sie im Zusammenhange des thomistischen Systemes, insbesondere seiner metaphysischen Begriffe, betrachten, durchaus klar in ihrem Aufbau und folgerecht in ihrer Ausgestaltung. Aber einen, freilich erklärlichen, großen Mangel hat sie: sie ist nicht so sehr durch die Analyse der inneren Erfahrung gewonnen, als vielmehr in wesentlichen Punkten aus den Postulaten einer realistischen Erkenntnistheorie, welche noch nicht die Schärfe der Kritik an sich erfahren hat, und aus einer als gegeben schon vorausgesetzten metaphysischen Anthropologie heraus konstruiert. Daher werden ihre Sätze sofort zu Problemen, wenn jene Grundlagen selbst in Frage gezogen werden, und wenn das Einzelne an den empirischen, von der analysierenden Selbstbeobachtung gefundenen Tatsachen gemessen werden soll. So ist es begreiflich, daß gerade von dieser psychologischen Seite her die schon mit Durandus anhebende, am umfassendsten bei Occam durchgeführte nominalistische Kritik des Geltungswertes unseres Erkennens und damit auch der Metaphysik ihren Ausgang genommen hat.

Strebevermögen. Wie das Erkennen, so weist auch das Streben zwei scharf geschiedene Stufen auf: das sinnliche Begehren und das vernünftigè Wollen. Alles Streben geht aus einem natürlichen Triebe nach dem, was das Sein erhält und vervollkommnet, hervor. Nur was - mit Recht oder bloß scheinbar - als ein Gut erkannt wird, kann daher Gegenstand eines bestimmt gerichWillensfreibeit. teten Strebens bilden. Während aber jener Zug in der Sphäre des Sinnenlebens unmittelbar ein Begehren auslöst, sieht die Vernunft die Begrenztheit und Einseitigkeit aller endlichen Güter ein. Darum ist der vernünftige Wille über den Mechanismus der Sinnlichkeit erhaben. So wurzelt die Freiheit des Willens in der rein geistigen Vernunft. Diese Freiheit des Geistigen würde an sich einen intellektuellen Determinismus nicht ausschließen. Ihm will Thomas entgehen, indem er die Vernunft nur in der Weise der $\mathrm{Zweck-}$ ursache den Willen erregen läßt. Der allbewegende Wille bleibe so doch Herr der Tätigkeit, die er setzen oder unterlassen könne. - Jener Freiheit des vernünftigen Willens sind übrigens durch seine Natur Schranken gesetzt. Es widersteitet seiner Natur, etwas in jeder Beziehung als übel Erkanntes $z u$ wählen. Und wenn die Vernunft, der im Diesseits das Gute (im ontologischen Sinne) nur seiner allgemeinen, abstrakten Natur nach gegeben ist, das unendliche Gut, von dem jenes nur ein blasses Abbild bietet, intuitiv anschauen könnte, so würde auch der freie Wille sich diesem höchsten Gute ohne Schwanken zuwenden und in ihm die volle beseligende Ruhe finden. Indes das ist ihm nur in der seligen Schauung Gottes möglich. Aber daß in jenem höchsten, urendlichen Gute auch das Gut im allgemeinen, abstrakten Sinne, durch welches der Wille in Bewegung gesetzt wird, seinen letzten Grund hat: das gibt dem innersten Verlangen der Menschennatur schon hienieden die durch nichts gestillte Sehnsucht nach den Unendlichen, jenen Zug zum Göttlichen, in welchem in einer gewissen dunkeln, begrifflich noch nicht geklärten Weise auch ein Wissen um Gott dem Menschen von Natur 
eingepflanzt ist. Wir kommen damit zum Abschluß der theoretischen Plilosophie, der philosophischen Gotteslehre.

Die bestimmte Einsicht und ein sicheres philosophisches Wissen von Gott, soweit solches überhaupt innerhalb der schon oben entwickelten Begrenzung möglich ist, ist der Vernunft nach Thomas nicht schon in jenem Zuge zum Guten gegeben, sondern wird erst durch Schlubfolgerungen gewonnen. Bei der Entwicklung dieser Gottesbeweise läßt Thomas, entsprechend der intellektualistischen Richtung der mittelalterlichen Scholastik, die ethischen Gesichtspunkte hinter den metaphysischen durchaus zurücktreten. Der Gottesbegriff erscheint philosophisch ganz auf die Erklärung des Seins gestützt', um dann seinerseits für die Geltung der sittlichen Gesetze, welche in der gottebenbildlichen vernünftigen Natur des Menschen sich kundgeben, einen letzten Verpflichtungsgrund zu bieten. Diese metaphysische Betrachtung aber ist bei Thomas eine durchaus aposteriorische, die vom erfahrungsgemäß Gegebenen aus einen das kausale Erklärungsbedürfnis befriedigenden Abschluß zu gewinnen sucht. Den ontologischen Beweis Anselms, welcher apriorisch aus dem Begriffe Gottes auf seine Existenz schließen will, verwirft Thomas, wie wir sahen. Er übergeht auch all die anderen mannigfach variierten Argumente früherer und gleichzeitiger Scholastiker (z. B. Wilhelms von Auvergne und Bonaventuras), welche unter der Nachwirkung eines weitgehenden erkenntnistheoretischen Realismus durch rein begriffliche Erwägungen $z u$ ihrem Ziele zu gelangen suchen, indem sie zu dem einen Einteilungsgliede einer logischen Distinktion das andere auch in der Realität als Ergänzung verlangen, zu dem unvollkommenen Sein ein vollkommenes, zu dem vorübergehenden ein bleibendes, zu dem veränderlichen ein unveränderliches usw. Nur e in e Erwägung aus diesem Kreise hält Thomas bei: den augustinischanselmischen Gedanken, daß zu den empirisch gegebenen niederen Graden der Vollkommenheit und des Seins vom Denken ein Höchstes als Maß der Annäherung verlangt werde. Allein durch Ausnutzung eines peripatetischen Prinzips gibt er diesem Gedanken eine kausale Wendung. Auch den im Anschluß an Ambrosius (Ambrosiaster), später auch an Johannes von Damaskus, schon der früheren Scholastik geläufigen teleologischen Nachweis einer weltordnenden Intelligenz wiederholt er anhangsweise; aber dieser beruht ja von vornherein auf der Grundlage kausaler Erwägung. An die Spitze dagegen treten bei ihm drei, dem Aristoteles und dem arabischen Aristotelismus entnommene, in durchsichtiger Prägnanz entwickelte Deduktionen, in denen der kausale Gedanke klar zutage tritt. Nur der erste ist auch schon bei Albert in seinem Spätwerk, der theologischen Summe, erwähnt. Die beiden anderen hat erst Thomas in die lateinische Scholastik eingeführt. Gerade sie sind von da an feste Bestandstücke der theologischen Metaphysik geworden. Der astronomisch-kosmischen Weltbetrachtung des Aristoteles entstammt das erste Argument. Durch den $Z$ wischengedanken, daß nichts ursprünglich sich selbst bewegen könne, da keine Potenz sich selbst aktualisiere, wird aus der Tatsache der Bewegung auf einen ersten unbewegten Beweger geschlossen. Im

5. Die

thomistische Gotteslehre.

Der Gottesbeweis bei Thomas.

Gegep den ontologischen Beweis.

Nene Gottes-

beweise bei Thomas. 
zweiten Berveise wird mit Avicenna aus der Unmöglichkeit eines unendlichen Rückganges in den bewirkenden Ursachen die Forderung einer ersten bewirkenden Ursache abgeleitet, die den Grund ihrer Existenz in sich selbst hat. Mit Alfarabi endlich und anderen arabischen Denkern, deren Beweisführung Maimonides zusammengestellt hatte, wird aus der Zufälligkeit und bloßen Möglichkeit aller Weltdinge auf ein notwendiges Sein als Grund der Wirklichkeit des in sich bloß Möglichen gefolgert. Denn wenn nichts notwendig, sondern alles ausnahmslos nur möglich wäre und darum auch nicht sein könnte, so hätte, wenn anders dieses „können“ nicht ein leeres Wort bleiben soll, einmal eine Zeit sein müssen, wo überhaupt nichts war und wo dann auch nichts mehr entstehen konnte.

$\mathrm{Zu}$ beachten ist, daß Thomas in jenem zweiten Argument (mit Avicenna) die Reihe der bewirkenden Ursachen, deren Unendlichkeit er als denkwidrig bezeichnet, nicht als eine Reihe gleichartiger Glieder faßt. Das bekannte Beispiel vom Huhn und vom Ei erläutert seinen Gedanken gar nicht. Er hat dabei vielmehr eine Reihe verschiedenartiger Ursachen im Sinn, die in Graden sich aufbauen, ,wie wenn der Stein vom Stock, der Stock von der Hand bewegt wird usw.". In einer unendlichen Reihe aufeinanderfolgender Glieder innerhalb eines solchen Grades dagegen - wie wenn z. B. eine Hand unendlich viele Hämmer nacheinander verbrauchte - findet Thomas keinen Denkwiderspruch. Daraus ergibt sich für ihn ein Doppeltes. Einmal fällt bei ihm von vornherein die erste Ursache nicht in die Reihe der Weltdinge selbst hinein. Sie ist der Welt transzendent. Auf der anderen Seite ist der zeitliche Anfang der Welt, den die arabischen Motekallimun und die Mehrzahl der christlichen Scholastiker als eine von der Vernunft geforderte Wahrheit betrachteten, nur ein Satz des Glaubens und keine notwendige Forderung des Vernunftdenkens. Auch eine ewige Schöpfung würde an sich keinen Denkwiderspruch einschließen. Thomas hat diesen Satz, mit dem er zwischen der üblichen scholastischen Lehre und den Averroisten eine ähnliche Stellung einnimmt wie vor ihm Maimonides, gegen allen Widerspruch („contra murmurantes") bis zuletzt aufrechterhalten.

6. Die

thomistische Ethik.

Schon die Besprechung der thomistischen Willenslehre hatte uns zu der Grundlegung seiner Ethik geführt. Die Feder, welche alles menschliche Leben in Spannung hält, ist das Streben nach dem Guten, d. h. nach dem Vervollkommnenden, dem das Sein Fördernden. Denn alles vernünftige Tun ist zielstrebend. Ziel aber kann nur sein, was, wenn auch nur scheinbar, der inneren Bestimmung der Natur entgegenkommt. Deshalb liegt das wahrhaft mensch-

Das mensch- liche Ziel in der Entwickelung dessen, was das spezifische Wesen des Menliche Ziel. schen als Menschen ausmacht, d. h. seiner vernünftigen Natur, die ihn von dem ein bloßes Sinnenleben führenden Tiere unterscheidet. Höchstes Ziel wird darum die Erreichung des Höchsten sein, zu dem dieses vernünftige Menschenwesen überhaupt aufsteigen oder erhoben werden kann. Nun hat aber die Tätigkeit den Vorzug vor dem bloß ruhenden Können, und die Vernunft hat, weil auf das abstraktere Objekt gehend, den Primat vor dem begehrenden, wenn 
auch vernünftig begehrenden Willen. Darum ist die Betätigung der Vernunft das Wertvollste im Menschen. Sie ist zugieich das, was sein wahres Glück ausmacht, neben dem alles Außere nur akzessorischen Wert hat. Die Tätigkeit der Vernunft aber ist erst dann zu ihrem Ziele gelangt, wenn sie erreicht hat, was alle ihre Weiten und Tiefen ausfüllt. Dazu reicht keine Erkenntnis von etwas Endlichem, auch nicht die Gewißheit bloß vom Dasein eines unendlichen Gottes und die bildhafte Erkenntnis von ihm, sondern allein die erkennende und im Erkennen liebende Erfassung des göttlichen Wesens selbst, in dem auch alles andere Sein begründet ist. Darum ist die selige Schauung Gottes das letzte Ziel des Menschen. Es zu erreichen, langen freilich nicht die Kräfte der Natur. Jene zugleich den Willen durchglühende Schauung Gottes ist nur im Jenseits, im unendlichen göttlichen Lichte möglich. Gott selbst ist es, der die menschliche Vernunft in sich einformt und sie überformt, und der sie so zu einer höheren Stufe des Seins und der Tätigkeit gnadenvoll erhebt. Glaube, Hoffnung und Liebe, die drei göttlichen Tugenden, in denen der göttliche Geist die Menschenseele schon hienieden durchwaltet, müssen auf jene übernatürliche Anschauung vorbereiten, bis der Glaube in Schauen, die Hoffnung in Besitz übergeht, die Liebe zu Gott und zu allem Guten um Gottes willen aber, die höchste der Tugenden, sich unwandelbar vollendet.

Die Vollkommenheit des christlichen Lebens besteht darum nach Thomas in der Gottes- nnd Nächstenliebe. Über dieses Ziel hinaus gibt es kein höheres Ideal des christlichen Lebens. Auch nicht etwa die „evangelischen Räte" der Armut, der Ehelosigkeit und des Gehorsams. Die Befolgung dieser Räte, wie das Ordensleben sie verlangt, führt Thomas - sehr im Gegensatz zu der Exaltation der "Spiritualen“ und anderer — aus, erleichtert die Erreichung jenes Zieles; aber die „Räte“ stehen darum nicht über den Geboten. Deshalb ist ein Stand, der die Befolgung jener Räte zur freiwillig übernommenen Pflicht macht, als Stand betrachtet ein solcher der Vollkommenheit; denn wer ihn eingeht, verpflichtet sich dadurch, nach Vollkommenheit in Gottes- und Nächstenliebe zu streben, und findet in der Befolgung seiner Regel eine Schule und Übung zu diesem Ziel. Aber weder verleiht der Stand an sich schon dem Einzelnen die Vollkommenheit, noch ist diese sittliche Vollkommenheit überhaupt an jenen "Stand der Vollkommenheit" gebunden. Auch außerhalb jenes Standes, lehrt Thomas, ist sie zu erreichen.

Die Gnade aber hebt die Natur nicht auf, sondern vollendet sie. Darum hat der Mensch die Aufgabe, seine Menschennatur nach dem, was das Wertvolle in ihr ist, auszuwirken. Seine Vernunft und sein vernünftiges Wollen sing durch Übung dahin zu bringen,. daß sie ihre dem Zwecke des Menschen entsprechende Tätigkeit leicht und gut ausüben. In dieser habituellen Beschaffenheit besteht die erworbene Tugend. Mit Aristoteles unterscheidet Thomas die Tugend, d. h. Tüchtigkeit, des intellektuellen Gebietes und die des Willens, der sich der Vernunft unterordnet und ihr gemäß handelt: dianoëtische und ethische oder sittliche Tugend. Das Wesen der sittlichen Tu-

Natürliche Tugend.
Die Vollommenheit des christlichen Lebens. 
gend sieht er mit Aristoteles in der Bereitschaft, die rechte Mitte einzuhalten. Seine Tugendlehre im einzelnen durchzugehen, würde zu weit führen. Dem harmonistischen Charakter des Mittelalters gemäß reiht er in mehr oder minder durchgeführter Systematisierung die verschiedenen überlieferten Einteilungen aneinander; die platonischen Kardinaltugenden, die schon Ambrosius in die theologische Spekulation übernommen hatte, die aristotelischen Bestimmungen der einzelnen dianoëtischen und ethischen Tugenden, insbesondere auch die Lehre vọn der austeilenden und der ausgleichenden Gerechtigkeit, und noch manches andere mehr theologischen Ursprungs.

Regel des sittlichen Verbaltens. :

in Veraunft

und ewigem Gesetz.

7. Die thomistische Gesellschafts. lohro.

Die Regel des sittlichen Verhaltens, welche den Gegensatz des Guten und des Bösen bestimmt, hat nach Thomas eine doppelte Quelle, eine nähere und eine ursprüngliche. Das natürliche Sittengesetz hat, wie es subjektiv durch die Vernunft erkennbar ist, so auch objektiv sein $\mathrm{MaB}$ zunächst an der Vernunft, d. h. an der vernünftigen Beschaffenheit und der dadurch begründeten individuellen und sozialen Bestimmung der Menschennatur. Denn in dem Organismus der Zwecke, der sich aus der Unterordnung alles Endlichen unter Gott als den universalen Zweck ergibt, ist die besondere Stellung des Menschen durch seine Natur als vernünftiges Einzel- und Gattungswesen bestimmt. Gut ist, was dieser vernünftigen Natur gemäß ist; böse ist jedes gegen die Vernunft streitende Wollen. Dabei ist zur moralischen Güte einer Handlung erforderlich, daß sie sowohl nach ihrer Art und ihren Umständen, wie nach ihrer Absicht, also nach Werk und nach Gesinnung, gut sei, während schon das Fehlen eines einzigen dieser Bestandteile für das Böse genügt. Begegnen wir hier dem aristotelischen Moralprinzip, so sieht Thomas die eigentliche Wurzel des Sittengesetzes im göttlichen Gesetz, welches als Gesetz der sittlichen Handlungen zu der lex aeterna als dem göttlichen Gesetze des gesamten Universums gehört, und von dem das Vernunftgesetz im Menschen, die "Synteresis", ein Ausdruck ist. Daß diese höchste Sittenregel, das Naturgesetz des Sittlichen (bonum commune divinum) nach Thomas nicht - wie bei dem späteren Nominalismus - von einer göttlichen Willkür gesetzt, sondern in der absoluten göttlichen Heiligkeit begründet ist, wurde schon früher im Anschluß an die historische Grundlegung dieser scholastischen Lehre durch Augustin bemerkt. Auch wurde hervorgehoben, daß Thomas gelegentlich auf eine Verschiedenheit der Behandlungsweise ethischer Fragen bei dem Theologen und dem Philosophen aufmerksam macht. Der Moralphilosoph faßt die Sünde ins Auge, insoweit sie der Vernunft widerstreitet, der Theologe dagegen betrachtet sie vorzüglich als Beleidigung Gottes. Bei Thomas selbst herrscht das Theologische vor. Aus dem theologischen Gesichtspunkte einer pastoralen Beurteilung des Sünders hat er denn auch die weitläufigen Ausführungen über Sünden und Laster in seiner theologischen Summe gestaltet. Ich übergehe sie und wende mich zum Schluß der thomistischen Gesellschaftslehre zu.

Auch diese ist charakterisiert durch die Verbindung aristotelischer und augustinischer Gedanken. Dem Augustinismus und der herrschenden theo- 
logischen Auffassung überhaupt entstammt die Wertung des Weltlichen und des Geistlichen. Scharf wird betont, daß dem Staate nur ein zeitlicher Diesseitszweck zukomme, während der Kirche die Aufgabe zugewiesen wird, Der Kirchenbegriff bei den ewigen Jenseitszweck zu vermitteln und die Möglichkeit seiner Erreichung auch in der Ordnung der Welt sicherzustellen. Ganz augustinisch ist es, wenn bei Thomas in dem Begriff der Kirche das namentlich seit Bellarmin sich vordrängende juristische Element noch in Unterordnung unter das dogmatisch-mystische und ethische erscheint. Das Wesen der Kirche wird von ihm in der Vermittelung des Gnaden- und Glaubenslebens erblickt, das ihrem Haupte Christus entstammt und durch das Walten des heiligen Geistes getragen ist, und in der dadurch herbeigeführten sittlichen Heiligung. Dementsprechend wird auch der hierarchische Aufbau der im Laufe der Zeit mehr und mehr konsolidierten Kirche vorwiegend aus dieser dogmatischethischen Betrachtungsweise, weniger aus den Gesichtspunkten des kanonischen Rechtes, hergeleitet. Ein näheres Eingehen auf diesen Kirchenbegriff des mittelalterlichen Theologen und seine Konstruktion des innerkirchlichen Organismus würde hier abführen.

Dagegen sei ein Blick auf die Folgerungen geworfen, die Thomas auf Die theokratiGrund jener Wertung des Jenseitigen und des Irdischen, des Geistlichen und ${ }_{\text {bei Themas. }}^{\text {schen }}$ des Weltlichen für das öffentliche Leben zieht. Man wird ganz besonders hier es nötig haben, Thomas im Zusammenhange seiner Zeit zu betrachten. Denn nur zum Teil, soweit nämlich jene Sätze rein ethischer und religiöser Natur sind, sprechen sich in ihnen zumeist allgemein christliche Anschauungen aus; wie wenn es heißt, daß man einem wider das Gewissen verstoßenden Gebote oder Gesetze nicht folgen dürfe u. dgl. Wo sie dagegen in das politische Gebiet erklärend und regelnd hinübergreifen wollen, da sind sie vorwiegend aus der historisch gewordenen und historisch bedingten Zeitanschauung erwachsen. Die Wortführer dieser spezifisch mittelalterlichen kirchlich-politischen Theorie allerdings vermeinten darin ein absolut Gültiges zu haben. Indem man politische Ansprüche, welche durch die tatsächliche Entwickelung der Dinge in weiten Kreisen zur Anerkennung gebracht waren, in theoretischer Weise auf ursprünglich religiös-ethisch gedachte allgemeine Grundsätze über den Wert des Geistlichen und des Weltlichen, sowie auf allegorisch gedeutete oder doch vom Zusammenhange losgeiöste Bibelstellen stützte und daraus deduktiv und a priori zu erweisen suchte, verquickte man geschichtlich zu erklärende und darum nur temporäre tatsächliche Verhältnisse mit einer vermeintlich allgemeingültigen und naturnotwendigen Begründung, wie ähnliches seit der Erneuerung römisch-rechtlicher Anschauungen übrigens auch auf der Gegenseite geschah. So erhielt der jahrhundertelange Kampf, der zwischen jenen Forderungen und den Forderungen der sich ausgestaltenden Mächte weltlicher Kultur, zwischen den auf Universalität Anspruch erhebenden beiden obersten Institutionen des Papsttums und des Kaisertums, sowie vielfach auch zwischen weltlicher und geistlicher Gewalt überhaupt entbrannte, die Tragik eines welthistorischen Prozesses, 
der nicht auf einer bloßen Zufallskonstellation beruhte, sondern gewissermaßen mit einer inneren psychologischen Notwendigkeit dramatisch sich entfalten mußte. Der geschichtlichen Ausgestaltung dieses Streites und den einzelnen Phasen seiner konkreten Erscheinung steht Thomas freilich fern. Der Waffenlärm der Zeit dringt nur wie von weitem in seine Erörterungen. Aber die theokratischen Grundanschauungen seiner Zeit und seines Kreises teilt erklärlicherweise auch er. In geistlichen Dingen soll da, wo man unter dem Geśetze Christi lebt, der weltliche Herrscher bei seinen Anordnungen dem Priester unterworfen sein. Denn der Staat habe die Bürger zur Tugend zu führen; die Tugend aber müsse dem jenseitigen Ziele des Menschen dienen, für das dem Priester die Fürsorge anvertraut sei. "Vasallen der Kirche“ nennt er in Absicht darauf einmal die Fürsten. Ein wegen Glaubensabfalls von der kirchlichen Gemeinschaft ausgeschlossener Fürst soll daher von selbst der Herrschaft verlustig gehen; seine Untertanen sind vom Eide der Treue entbunden. Und wenn Thomas auch im Gegensatze zu verschiedenen anderen, z. B. zu Duns Scotus, zwangsweise Taufen von Juden und Heiden verwirft und es beklagt, daß man die ersteren vielfach von fast allem bürgerlichen Erwerb ausschließe und sie so dem den Christen verbotenen Geldgeschäft in die Arme treibe, so ist doch der segensreiche und befreiende moderne Gedanke der bürgerlichen Toleranz, den das Mittelalter überhaupt nicht und ebenso die Neuzeit noch auf lange Zeit hin nicht kannte, auch ihm fremd. Von der Kirche, der sie durch die Taufe verpflichtet seien, abgefallene Häretiker sollen zwangsweise zurückgeführt und bei beharrlicher Weigerung an Vermögen und Leib bestraft werden. In rein weltlichen Dingen dagegen schreibt Thomas, hierin immerhin gemäßigter als die extremen Verfechter einer aittestamentlichen priesterlichen Theokratie, wenigstens dem Priester als solchem eine Gewalt nicht zu. Freilich wird dieser Satz an dem für das Mittelalter entscheidendsten Punkte sofort wieder durchbrochen. Das Oberhaupt der Kirche soll, wie es wenigstens an einer Stelle in Thomas Jugendwerk, dem Sentenzenkommentar, heißt, als Stellvertreter Gottes den Gipfel wie der geistlichen so auch der weltlichen Gewalt innehaben. Doch bleibt dies bei Thomas nur eine gelegentliche Bemerkung. Die Durchführung jener extrem kurialistischen, den Dualismus der beiden Gewalten prinzipiell aufhebenden Theorie, wie sie später bei Augustinus Triumphus ( +1328$)$ und Alvarus Pelagius $(+1352)$ gegenüber der imperialistischen des Marsilius von Padua ( $†$ I 342/43), des Verfechters der Lehre von der Volkssouveränität und der Entstehung des Staates durch Vertrag, und des Occam († I 349) erfolgt, ist ihm noch fremd. Und spezifisch juristische Streitigkeiten, wie die über die direkte oder indirekte Gewalt des Papstes den weltlichen Regierungen gegenüber, über den direkten oder indirekten göttlichen Ursprung der Gewalt des weltlichen Herrschers u. dgl., kümmern ihn überhaupt nicht.

Die aristotelische Staatslehre bei Thomas.
So bedeutungsvoll jene Sätze über das Verhältnis von Geistlichem und Weltlichem für die Charakteristik der Zeitanschauungen auch sein mögen, so ist in ihnen doch nichts besonders Eigenartiges. Unzählige Male waren sie 
seit Gregor VII. und Johannes von Salisbury von seiten der kirchlichen Partei verkündet. Aber das ist eine besondere Leistung. von Thomas: mit diesen in der Linie von Augustins ,Gottesstaat" liegenden Anschauungen entschlossen und durchgehends Elemente einer wieder aufgegriffenen antiken Tradition verbunden zu haben, welche eine gerechtere Würdigung der Aufgaben und der natürlichen Stellung des Staates ermöglichten. Ein neues Moment positiver Stellungnahme zu der natürlichen Gesellschaftsorganisation und zu deren Vollendung, dem Staate, war damit auch im Kreise der theologisch und scholastisch denkenden Geister heimisch gemacht. Dieser der mittelalterlichen Theorie eingepflanzte neue Gedankenkern hat nicht nur die Einseitigkeit rein spiritualistischer Deduktionen gemildert, sondern er hat später auch, losgelöst von dem geistlichen Gedankenkreise, dem Thomas ihn eingefügt hatte, der selbständigen Entwickelung einer weltlichen philosophischen Staatstheorie für lange Zeit die typische Richtung gegeben.

Es ist die Gesellschafts- und Staatslehre des Aristoteles, die durch Thomas eine bis in die Gegenwart nachwirkende Erneuerung erfährt. Antike Elemente haben auch vorher schon auf diesem Gebiete nicht gefehlt. Es soll nicht von der im Zusammenhange mit der politischen Entwicklung sich vollziehenden Wiederbelebung wichtiger Bestandteile der römischen Rechtsanschauungen und des römischen Staatsrechts und von der darauf gerichteten Arbeit der Legisten gesprochen werden; denn für Thomas, dessen Denken das spezifisch Juristische überhaupt fernlag, haben diese römischrechtlichen Theorien vom Staat, die sich wenigstens als Ganzes seinem kirchenpolitischen System nicht einfügten, keine positive Bedeutung. Aber auch die Staatsphilosophie des Altertums war schon vorher nicht ganz unbekannt. So wurde schon früher auf die Abhängigkeit hingewiesen, in der Johannes von Salisbury zu Cicero und Pseudo-Plutarch steht. Jetzt aber trat auch des Aristoteles geniales Werk vom Staate in den Gesichtskreis der abendländischen Welt, später als die anderen Hauptwerke des Stagiriten. Nicht durch die Vermittelung der Araber und begleitet von den Erläuterungen arabischer Kommentatoren, sondern unmittelbar aus dem Griechischen, in der Übersetzung des Wilhelm von Moerbeke, war es ihr zugekommen. Allein sie hatte mittlerweile gelernt, selbständig ihre Aufgabe zu erfüllen. Albert, Thomas, Siger von Brabant und andere erläutern alsbald die aristotelische Politik in Wort oder Schrift. Niemand aber unter diesen hat einen solchen Einfluß auf die Rezeption der aristotelischen Gesellschaftslehre gehabt, wie Thomas. Die innere Durcharbeitung und selbständige Bewältigung dieser Lehre ist sein eigenstes Verdienst. Sein (unvollendeter) Kommentar, der möglicherweise noch vor dem seines einstigen Lehrers Albert verfaßt ist, analysiert selbständig das aristotelische Werk, wenn auch Thomas als ein dem politischen Leben fernstehender abstrakter Denker naturgemäß mehr den philosophischen Deduktionen des Aristoteles als seiner empirischen und induktiven Grundlage gerecht wird. Kann dieser Kommentar, der zunächst objektiv über die Lehre des Aristoteles Bericht gibt, selbst in den allein echten ersten Büchern naturgemäß nicht in 
allem für Thomas' eigene Überzeugung in Anspruch genommen werden, so zeigt uns die theologische Summe und insbesondere die Schrift vom Fürstenregiment, wie weit Thomas die aristotelischen Prinzipien herübergenommen und verarbeitet hat.

Mit Aristoteles und im Sinne seiner teleologischen Weltanschauung betrachtet Thomas den Menschen als ein von Natur zur Gesellschaft bestimmtes Wesen. Er ist von Natur ein animal sociale oder politicum, welches als solches schon durch seine Sprachfähigkeit charakterisiert ist. Durch die engeren Organisationsstufen der Hausgemeinschaft und der Gemeinde hindurch vollendet sich diese seine Naturbestimmung im Staate. Zuerst bringt die Not des Lebens als treibende Kraft jene Naturbestimmung zur Verwirklichung. Der Mensch, der natürlichen Waffen und der mannigfaltigen natürlichen Werkzeuge des Tieres entbehrend, kann nur in der Vereinigung die Unzulänglichkeit des Einzelnen überwinden. Aber die menschliche Gemeinschaft ist, im Unterschiede von den Tierstaaten der Ameisen, Bienen usw., von vornherein nicht eine solche bloß der körperlichen Kräfte. Alle wahrhaft menschliche Tätigkeit wird geleitet von der Vernunft. Die Vernunft aber kann als ein zu Beginn noch unbeschriebenes Blatt im Gegensatz zu dem fertigen tierischen Instinkte $z u$ ihrer rechten Vollendung erst dadurch kommen, daß die Erfahrungen vieler gesammelt werden. Das Bedürfnis der Ergänzung. und Zusammenarbeit, welches den Menschen zur sozialen Gemeinschaft und zum Staate treibt, ist sonach nicht durch einen unvernünftigen Naturtrieb hervorgerufen, sondern geht aus der Natur des Menschen als eines Vernunftwesens hervor. Darum ist denn auch der Staat, wenngleich zunächst wegen der Notdurft des Lebens entstanden, doch nicht um des bloßen Lebens willen da. Er dient nicht bloß dem Leben, sondern dem gut leben, der Vollendung des Lebens. Nicht nur die Sicherung der materiellen Güter ist seine Aufgabe, sondern zugleich die Pflege der natürlichen intellektuellen und ethischen Güter, die wir als Kulturgüter bezeichnen, und die Thomas unter dem Namen der (intellektuellen und moralischen) Tugend zusammenfaßt. ZurErhaltung des Wohlstandes und der Kultur aber ist der Friede nötig, der auf der Sicherung des Staates gegen den äußeren Feind und auf der geordneten Rechtspllege im Innern beruht. Friede, Bürgertugend und Wohlstand zu bewahren und so das Gemeinwohl zu verwirklichen, ist darum die Aufgabe des Staates.

Die Erfüllung dieser Aufgabe aber setzt voraus, daß im Staate ein mit der Regierungsgewalt bekleidetes Organ besteht, welches das Gemeinwohl ins Auge faßt und die Tätigkeit der Vielen zu diesem einen gemeinsamen Ziele hinlenkt. Eine Obrigkeit wird also von der natürlichen Ordnung der Dinge und von der menschlichen Natur selbst gefordert. Weil aber diese Ordnung und diese Natur - so führt der Theologe Thomas den Gedankengang des Philosophen Aristoteles weiter - gottgewollt und gottgesetzt ist, so stammt die obrigkeitliche Gewalt, wenn ihre Erwerbung auch der menschlichen Geschichte anheimfällt, doch in ihrem letzten Rechtsgrunde von Gott. Der Gehorsam gegen die Obrigkeit ist darum sittliche Pflicht. Selbst wenn 
der Befehl an sich unberechtigt ist, aber nicht gegen das Sittengesetz verstöBt, verlangt die Aufrechterhaltung der staatlichen Ordnung, ihn zu befolgen. Nur dem unsittlichen Befehl hat man passiven Widerstand entgegenzusetzen. Der aktive Widerstand dagegen, der Aufruhr, ist niemals erlaubt. Wenn freilich der Herscher das Gemeinwohl zugunsten seines Privatwohles auf das schwerste schädigt und dadurch zum Tyrannen wird, so ist er es, der sich gegen die staatliche Ordnung auflehnt. Hier erkennt Thomas in den extremsten Fällen ein Recht der Notwehr für die Völker an. Zum Äußersten aber, nämlich zur Tötung des Tyrannen, zu schreiten, das bleibt wenigstens den Privaten in jedem Falle untersagt. - In der Einteilung der Regierungsformen schließt sich Thomas an Aristoteles an. Dabei aber bevorzugte er weit stärker als dieser die Monarchie. Es leitet ihn dabei der im Geiste des platonischen Realismus gedachte Satz, daß vor dem Vielen die Einheit stehen müsse. Übrigens will Thomas die Monarchie mit den nötigen Sicherungen gegen despotische Ausartung versehen wissen. Diese sollen zugleich dem aristokratischen und dem demokratischen Prinzip einen Anteil an der Staatseineinrichtung gewähren. So kommt auch er, wie Polybius und Cicero, auf die "gemischte“ Verfassung, die „Politie“, des Aristoteles hinaus, freilich mit dem Unterschiede gegen diesen, daß bei ihm, der Zeitentwickelung entsprechend, das monarchische Prinzip das oberste und gestaltgebende bildet.

Indem Thomas so die naturgemäße Entstehung und die selbständige Aufgabe des Staates im Anschluß an Aristoteles feststellt, bezeichnet er auf dem Gebiete der praktischen Philosophie einen Wendepunkt innerhalb der Scholastik. Der Staat und die weltliche Gewalt auch außerhalb der Kirche sind ihm nicht mehr vom Bösen, wie dieses die Vertreter einer asketischen und zugleich theokratischen Weltanschauung in Weiterführıng des augustinischen Gedankens von der Feindschaft zwischen dem irdischen Staat und dem Gottesstaat unter mancherlei unklar schillernden Redewendungen oft behauptet hatten. Wenngleich auch Thomas als mittelalterlicher Mensch, soweit das Geistliche mit in Betracht kommt, die theokratische Idee nicht aufgibt, so stellt er doch mit Entschiedenheit den Satz auf, dab die gesellschaftliche Ordnung und die obrigkeitliche Gewalt nicht aus der Sünde geflossen seien. Dieser entstammt nur die Knechtschaft. Jene gesellschaftliche Gliederung selbst aber würde - so kleidet sich der Gedanke von der in der göttlichen Naturordnung begründeten Notwendigkeit und Berechtigung des Staates bei ihm theologisch ein - auch dann sich ausgebildet haben, wenn die Menschheit nicht in Adam gefallen wäre, sondern im Stande der ursprünglichen paradiesischen Unschuld verharrt hätte.

Blicken wir auf unsere Analyse der thomistischen Philosophie zurück, so sehen wir, daß, entsprechend dem Geiste und der Form der mittelalterlichen Philosophie überhaupt, auch sie nicit so sehr in selbständiger und ursprünglicher Anregung ihre Stärke hat, als in der Entschlossenheit und Folgerichtigkeit, mit welcher Thomas zu den bestehenden wissenschaftlichen Stömungen der Zeit Stellung nahm und die von ihrem Flusse mitgeführten

Geschichtliche Stellung der thomistischen Gesellschaftsiehre. 
Elemente, die traditionellen und die neu hinzugekommenen, mit ebenso weitreichendem wie sicherem Blicke zu einem wohlabgerundeten philosophischen System zusammenfügte. Indem aber seine durch Klarheit der Begriffe und tiefe, wenngleich nicht grüblerische Erfassung der Probleme ausgezeichnete Synthese nicht nur dem harmonistischen Zuge des Mittelalters überhaupt entgegenkam, sondern zugleich dem kirchlich-theologischen Bedürfnis entsprach, waren alle Bedingungen gegeben, welche die thomistische Lehre trotz des vielfältigsten Widerstandes doch bald zur vorherrschenden des Mittelalters machen mußten.

Die thomistische Schule und Thomas nahestehende Richtungen.

Aegidius von Lessines.

Gottfried von Fontaines.

Thomas von StraBburg. manus.

Im Dominikanerorden fand trotz des Widerspruchs der älteren Generation, wie des Robert Kilwardby, Thomas bald Anhänger. Als einer der ersten verteidigte Aegidius von Lessines in einer 1278 verfaßten Schrift die thomistische Lehre von der Einheit der Form gegen Kilwardby und Peckham. Durch Beschlüsse mehrerer Generalkapitel wird Thomas zum Lehrer des Ordens erhoben. Aber auch über diesen hinaus gewinnt er zahlreiche Freunde. Gottfried von Fontaines, einer der angesehensten Pariser Lehrer aus dem Weltklerus, tritt in fast allen strittigen Punkten, wie hinsichtlich der rein potenziellen Urmaterie, der Unbeweisbarkeit eines zeitlichen Weltanfanges für die Vernunft, der Unterscheidung der SeelenAegidius Ro. vermögen von der Seelensubstanz usw., auf die Seite von Thomas. A egidius Colonna von Rom ( $t$ 1316) begründet bei den Augustinermönchen die schola Aegidiana, welche zwar in verschiedenen Punkten, wie hinsichtlich der Gotteserkenntnis und des Nachbildes der göttlichen Dreieinigkeit in der Seele und auch sonst in der Theologie ihren Augustinismus stärker betont als der Aquinate, in der Philosophie aber die peripatetische Denkweise desselben sich zu eigen macht. Thomas von Straßburg ( $f$ I 357 zu Wien) hat diese ägidianische Lehre in einem schulgerechten Sentenzenkommentar zu klarer Darstellung gebracht. In dem Augustinerorden selbst fand sie freilich bald einen starken Wettbewerb an der nominalistischen Lehre, die durch Gregor von Rimini (er folgte Thomas von Straßburg als Ordensgeneral und starb ${ }_{1} 35^{8} \mathrm{zu}$ Wien) eingeführt wurde. Luther als Augustinermönch hat seine scholastische Ausbildung nicht im Sinne der älteren ägidianischen Schule, sondern im Sinne des durch Gregor von Rimini eingeführten Nominalismus genossen, der damals in Deutschland vorzugsweise in der Fixierung gelehrt wurde, welche er durch den Tübinger Gabriel Biel († 1495) erfahren hatte. - Auch die Staatstheorie hat Aegidius in seiner Schrift vom Fürstenregiment zur Darstellung gebracht. Doch kommt bei ihm hier und noch mehr in kanonistisch-theologischen Schriften die von Bonifaz VIII. praktisch vertretene und von Aegids Freund Augustinus Triumphus ( $\left.\dagger_{1328}\right)$ theoretisch durchgebildete kurialistische Auffassung in extremerer Weise zum Ausdruck als bei Thomas. Mit ähnlichen Prinzipien, wie sie hier zugunsten einer universellen päpstlichen Theokratie geltend gemacht werden, insbesondere mit der viel verbreiteten platonisierenden mittelalterlichen Spekulation von der Stellung des Einen vor und über dem Vielen, begründet $D$ ante Alighieri 
( $f_{132}$ ), insbesondere in seiner "Monarchie“, die universale Obergewalt, Dante. welche dem Kaiser, dem Bringer und Hort des Friedens beim Streite der Fürsten und Städte, in den weltlichen Angelegenheiten über die gesamte Menschheit und über alle Länder der Erde zukomme. Gott hat dem Menschen als einem $z$ wischen dem Vergänglichen und dem Unvergänglichen inmitten stehenden Wesen ein zweifaches Ziel gesetzt, das irdische Glück, welches durch die natürliche moralische und intellektuelle Tugend erreicht wird, und die ewige Seligkeit, zu der die theologischen Tugenden des Glaubens, der Hoffnung und der Liebe hinführen. Darum bedarf es eines zweifachen Führers, des Kaisers und des Papstes. Aber wenngleich der letztere, da ihm das höhere Ziel zur Besorgung anvertraut ist, an Würde auch höher steht als der weltliche Oberherr, so sind doch in ihrem eigenen Rechtsbereich beide Gewalten selbständig. Ohne gegenseitige Übertragung stammen beide von Gott, die geistliche durch unmittelbare göttliche Einsetzung, die weltliche durch das natürliche menschliche Recht. In der Verquickung beider Gewalten erblickt Dante eine der Grundursachen der religiösen Verderbnis der Zeit. Aber wie glühende Worte der Anklage er gegen Bonifaz VIII. darum auch richtet: wo er des Tages von Anagni gedenkt, da ist ihm der französische Philipp ein zweiter Pilatus, und seine Schergen haben im Statthalter Christi Christum selbst gefangen. Im übrigen sind die theologischen und philosophischen Anschauungen Dantes, vor allem die seiner erhabenen "Göttlichen Komödie“, trotz mancherlei leichterer Nuancierungen, die insbesondere die Einwirkung der arabistischen Philosophie (Avicenna) erkennen lassen, doch in ihrem Grunde so durchaus thomistisch, dafi man aus den Werken des Aquinaten einen Kommentar zu ihnen zusammenstellen kann.

In der späteren Zeit entwickelt die thomistische Schule eine lebhafte Polemik gegen Scotisten und Nominalisten. Hervé de Nédellec (Hervaeus Natalis, I $_{3}$ 23), Capreolus ( $f$ 1444), der „Fürst der Thomisten“, übrigens in erster Linie Theolog, der Aristoteleserklärer Dominicus von Flandern († um 1500) und der Erklärer der Summa theologica, Thomas de Vio aus Gaeta (daher Cajetanus, +1534 ) seien genannt. Im übrigen kann ich auf die Geschichte der thomistischen Schule im Mittelalter hier so wenig eingehen wie auf deren Erneuerung nach dem Konzil von Trient, wo im Gegensatz zu dem freieren Thomismus eines Gabriel Vazquez ( $t$ 1604), Franz Suarez $(\dagger+16$ ) und anderer die Dominikaner, vorab Franz von Vittoria ( $t$ i546) und Bañez ( $\dagger$ I604), den strengen Thomismus wiederherzustellen suchten.

IV. Die naturwissenschaftliche Richtung. Schon in der allgemeinen Charakteristik der mittelalterlichen wissenschaftlichen Denkweise wurde darauf hingewiesen, daß zwar beim Mangel wissenschaftlicher Experimentiermethoden und einer durchgängigen quantitativen Bestimmung durch fruchtbare mathematische Hilfsmittel von einer exakten Naturwissenschaft im modernen Sinne zur Zeit der Scholastik nicht gesprochen werden kann, daß aber andererseits die oft behauptete völlige Gleichgültigkeit gegen die Erforschung 
der Natur nicht bestand. Meist gelangte das Interesse für die Natur freilich nicht weiter als bis zu einem empirielosen Philosophieren über die Natur, welches der Vertiefung in die Natur nur hinderlich ist, da es eine Frage schon gelöst glaubt, wo das Problem in Wahrheit erst anfängt. Indes haben wir doch in Honorius Augustodunensis, Adelhard von Bath und Albert von Bollstädt schon Vertreter einer auch auf die Naturbeobachtung selber gerichteten Forschungsart kennen gelernt. Besonders in England findet diese empiristisch und mathematisch orientierte philosophische Denkweise Pflege. So bei Alexander Neckam ( fredus Anglicus), der in seiner um i215 verfaßten Schrift über die Bewegung des Herzens eine physiologische Psychologie vertritt und die fälschlich dem Aristoteles beigelegte Schrift des Nikolaus von Damaskus ïber die Pflanzen in das Lateinische übertragen hat, und bei dem zuletzt in Magdeburg lebenden Franziskaner Bartholomaeus Anglicus. Mathematische Bildung läßt eine von dem mehrfach erwähnten Joh ann Peckham († I 292) verfaßte Schrift über die Perspektive erkennen. Ein ganz hervorragender Vertreter dieser Studien ist Robert von Lincoln (Grosseteste), dessen schon oben als eines an Vielseitigkeit mit Albert dem Großen vergleichbaren Geistes gedacht wurde. Überragt ihn Albert auf dem Gebiete der naturwissenschaftlichen Beobachtung, so ragt dagegen Robert auf dem Felde der mathematischen Wissenschaften, insbesondere der Astronomie und Optik, hervor. Ganz neuplatonisch ist seine Lehre von dem alles durchziehenden und formenden Licht. Robert zeichnete sich auch aus durch Sprachkenntnisse, insbesondere im Griechischen, und durch jenes philologische Interesse, welches das Studium an der Universität Oxford, im Gegensatz zum Pariser Studium, charakterisierte.

Ihre Vollendung erfährt diese Richtung durch den englischen FranzisRoger Bacon. kaner Roger Bacon († I 294), den Schüler Grossetestes, dessen jener öfters mit Dankbarkeit gedenkt. Bacons geistiger Charakter ist nicht der gewöhnliche mittelalterliche. Er gehört zu den wenigen Denkern des Mittelalters, die überall, in Lob und Tadel, bei der Herübernahme fremder, wie bei der Ausbildung eigener Anschauungen, einen ausgeprägten persönlichen Charakterzug erkennen lassen. Wie Abälard und Duns Scotus, wenn auch in anderem Sinne als diese, ist er ein durchaus kritischer Geist. Schon früher wurde hervorgehoben, daß er keineswegs unbeselen der Autorität sich beugt, vielmehr in der kritiklosen Hingabe an die herkömmlichen Autoritäten ein verhängnisvolles Hindernis der Wahrheitserkenntnis erblickt. Wo aber für ihn die Autorität in Frage kommt, insbesondere die des auch von ihm hochangesehenen Aristoteles, da will er durch kritische Prüfung gegenüber falschen Übersetzungen und irrigen Erklärungen die wahre Bedeutung festgestellt sehen. Ein lebhafter Sinn für philologische Arbeit ist ihm eigen. Des Griechischen und des Hebräischen ist er kundig und hat beide Sprachen grammatisch behandelt. Und auch das liegt in dem kritischen Zuge seines Geistes, daß er lieber tadelt als anerkennt, und gern als Richter - nicht selten als überscharfer Richter - über wissenschaftliche und sittliche, politische und kirchliche Zustände auftritt. Wie sein späterer 
Landsmann Bacon von Verulam ist er durchdrungen von der Notwendigkeit der empirischen Forschung. Der abstrakte Beweis zwingt uns zwar, die Schlußfolgerung zuzugeben; aber er bietet nicht, wie die Erfahrung, die Gewißheit der unmittelbaren Anschauung des Tatbestandes, welche unsere Zweifel beruhigt. Nur auf dem Wege der Erfahrung lassen sich zugleich die vielen naturwissenschaftlichen Irrtümer beseitigen, welche von der bloßen Bücherweisheit weitergegeben und mit scheinbaren Argumenten gestützt werden. Auch auf das innere, insbesondere das religiöse Leben, auf die Glaubens-, Tugendund Gnadenerfahrung, dehnt Bacon sein Erfahrungsprinzip aus. Mit diesem empiristisch-kritischen Sinne hängt der Nachdruck zusammen, welchen auch Bacon gleich Grosseteste auf das Sprachstudium legt. Nur die Kenntnis des Hebräischen, Griechischen und Arabischen führt zum quellenmäßigen Verständnis der heiligen Schriften sowie der Werke des Aristoteles und des Avicenna, durch welche die Philosophie erneuert ist. Übrigens tritt hinter dem Empirischen das Rationale bei Bacon nicht zurück, wenn er auch keine klare prinzipielle Grenzbestimmung beider Faktoren gibt. Ja in manchem schließt er sich an die im theologischen Sinne umgeformte platonisierende Erkenntnislehre an, welche die ältere Franziskanerschule im Anschluß an Augustin vertritt. Wie Locke, verbindet er empiristische und rationalistische Elemente. Vor allem legt er der Mathematik hohen Wert bei. Namentlich in der Optik, wo besonders der Araber Alhazen (Alhaitam) sein Lehrer ist, gibt er den Beweis mathematischer Schulung. Wenn wir noch hinzufügen, daß Bacon - auch hierin ein Vorgänger Bacons von Verulam - das Talent besitzt, die Stoffmassen zu ordnen und zu systematisieren, so daß sein „Opus maius“, das an Selbständigkeit des Denkens die Enzyklopädien eines Gundissalin und Vincenz von Beauvais, auch die Kilwardbys, weit überragt, auch als Sammelwerk nicht ohne Wert ist, so dürften die wichtigsten Charakterzüge des Philosophen und Schriftstellers herausgehoben sein.

Der Inhalt seiner philosophischen Lehre verbindet Grundanschauungen der älteren Franziskanerschule mit Lebren der Araber, insbesondere Avicennas und Alhazens (nicht des Averroës). Zwei Beispiele mögen ihre Eigenart zeichnen. Mit der älteren Franziskanerschule läßt Bacon das höhere Wissen des Menschengeistes durch eine aus den göttlichen Urbildern der Dinge kommende Erleuchtung vollendet werden. Diese auf Augustin gestützte Erklärung der Erkenntnis findet er wieder in der Lehre Alfarabis und Avicennas von der Erleuchtung der "möglichen" menschlichen Vernunft durch eine über den Menschenseelen stehende Intelligenz, den „tätigen Verstand“; ja er will die dunklen Sätze des Aristoteles selbst in diesem Sinne verstanden wissen. Während wir hier einer metaphysisch konstruierenden Psychologie begegnen, führt Bacon ein anderes Mal im Anschluß an Alhazen in die Analyse des empirischen Seelenlebens einen der thomistischen Schule und überhaupt der Mehrzahl der Scholastiker fremden Begriff ein. Es sind die unbewußten Schlüsse, gewohnheitsmäßige Assoziationen, durch welche die sofortige Auffassung und Deutung des Wahrnehmungsinhaltes bedingt ist. 
Auch Heinrich Bate von Mecheln, der Verfasser eines für die Geschichte der Psychologie nicht unwichtigen Speculum divinorum et quorundam naturalium (verfaßt $z$ wischen I 30 I und I 304 ), zugleich in Verbindung mit dem Juden Chajjim Übersetzer hebräiscber Werke, möge an dieser Stelle genannt werden.

Neuplatonismus in Verbindung mit Naturphilosophie.

Dietrich von Freiberg.

Anderswo verbindet sich, wie später in der Zeit der Renaissance, das naturwissenschaftliche Interesse gern mit einer neuplatonischen Richtung, die ja auch der arabischen Philosophie nicht fremd ist. Dadurch erhalten selbst die zahlreichen Elemente, welche natürlich auch diese Denker der aristotelischen Philosophie und Naturlehre entnehmen, nicht selten eine charakteristische Umbiegung. Schon Albert der GroBe trägt gar manches Neuplatonische vor, wenn auch mehr als Ansicht der Philosophen oder doch nur als eingeschobene Episode, was bei Thomas ganz ausgeschieden ist. U1rich von StraBburg, der als Hauptvertreter der Schule der „Albertisten“ bereits genannt wurde, nahm diese Vorliebe für eine neuplatonisierende Denkweise mit herüber. Namentlich in seiner Lehre vom Intellekt, in seiner Lichtmetaphysik und in seiner Theorie des Guten tritt dieselbe hervor. Noch weit stärker ist der neuplatonische Einschlag bei Alberts und Ulrichs Ordensgenossen, dem Meister Dietrich von Freiberg (in Sachsen), einem äußerst fruchtbaren Schriftsteller, der 1 265-69 Lehrer in Paris war und an verschiedenen Orten Südwestdeutschlands wirkte. Ein tüchtiger Naturkundiger, der u. a. eine für seine Zeit recht scharfsinnige Erklärung des Kegenbogens bietet, macht er sich die neuplatonische Emanationslehre so weit zu eigen, als das mit seiner christlichen Theologie nur irgend vereinbar war. Zur vollen Entfaltung kommt dann dieser Neuplatonismus in den scholastischen lateinischen Schriften des gleichfalls dem Dominikanerorden angehörigen Meister Eckhart, der der Naturwissenschaft freilich fernsteht, aber uns noch als Mystiker beschäftigen wird. So kann man wohl nicht mit Unrecht von einer eigenen, von Albert ausgehenden, im Dominikanerorden heimischen, besonders in Südwestdeutschland gepflegten, neuplatonisch gefärbten Scholastik sprechen. - Eine ähnliche Stellung wie Dietrich nimmt ein der in Padua gebildete Witelo. naturkundige Schlesier Witelo (geb. um I 230), der wahrscheinliche Urheber einer neuplatonisch gehaltenen Schrift über die Intelligenzen, der zugleich eine optische Schrift, die Alhazens Theorie mit eigenen Beobachtungen verbindet, verfaßt hat. Witelo ist vor allem interessant durch die neuplatonische Lichtmetaphysik der „Perspektive“ und der Schrift über die Intelligenzen, die er mit Grosseteste und Ulrich teilt, sowie durch seine an Alhazen sich anlehnenden, mit Bacon sich berührenden psychologischen Theorien über die Bedeutung der assoziativen Ergänzung bei der Wahrnehmung, z. B. bei der optischen Auffassung der Tiefendimension.

V. Duns Scotus. Im Gegensatz zum Dominikanerorden, in welchem Albert und Thomas eine neue Denkweise begründeten, hatte man innerhalb des Franziskanerordens an der von Alexander von Hales und Bonaventura begründeten Richtung festgehalten. Peckham, in manchen Punkten auch 
Roger Bacon, sind uns bereits als Beleg dafür begegnet. Namentlich auf dem Gebiete der Erkenntnistheorie, wo man die augustinische Denkweise entschiedener beibehielt, und auf dem Gebiete der Naturphilosophie und metaphysischen Psychologie, wo man die Einheit der Form bekämpfte, ferner mit Alexander und Bonaventura auch in der Seele und den reinen Geistwesen die Unterscheidung von Materie und Form annahm, bewegt sich der Gegensatz gegen den Thomismus. Zugleich ist man der Verwendung philosophischer Sätze in der Theologie weniger geneigt. Wo man aber der Philosophie einen Platz einräumt, steht man vielfach stärker als die thomistische Schule unter dem Einfluß der arabischen Philosophie, insbesondere des Avicenna. Die bedeutendsten unter diesen auf Bonaventura folgenden Lehrern aus dem Franziskanerorden sind der ruhig klare Matthäus von Aquasparta

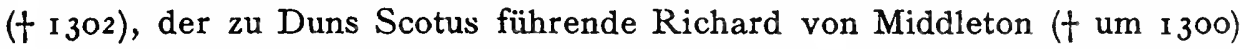
und der in die apokalyptischen Träumereien des Abtes Joachim von Fiore († I 202) tief verstrickte, um das Ideal evangelischer Armut eifrig kämpfende Petrus Johannis Olivi ( 1 298), nach dem die menschliche Seele drei von einer gemeinsamen geistigen Materie getragene Formen, eine vegetative, eine sensitive und eine intellektive, in sich befaßt, von denen nur die beiden ersteren, nicht auch die letztere, an der Wesensgestaltung des Menschen als Körperwesen teilhaben - eine wunderlich komplizierte Lehre, die damals viele theologische Streitigkeiten veranlaßt hat und auch die Kirchenversammlung zù Vienne ( 13 I 2 ) beschäftigte.

Einen neuen Aufschwung und eine selbständige Orientierung gewinnt die Spekulation innerhalb des Franziskanerordens durch Johannes Duns Scotus, den Begründer der jüngeren Franziskanerschule. Wann und wo er geboren wurde, ist unsicher. Um die Stätte seiner Geburt stritten sich England, Schottland und Irland. Gebildet in Oxford, dort („Opus Oxoniense") und in Paris („Reportata Parisiensia“) als Lehrer tätig, ist Scotus nach kurzer Wirksamkeit in Köln hier im Jahre I 308 gestorben. - Scotus ist noch mehr Charakteristik als Bacon ein kritisch vorgehender Geist. In ausführlichen Auseinander- ${ }_{\text {Philosophie. }}^{\text {der scotischon }}$ setzungen mit Thomas und Heinrich von Gent, Alexander von Hales, Gottfried von Fontaines, Aegidius u. a. läßt er allmählich seine eigene Ansicht hervortreten. Diese hält die Grundanschauungen der älteren Franziskanerschule meist fest, verbindet aber damit eine Fülle eigener Ideen, die mit großer Subtilität in einer ziemlich formlosen Sprache vorgetragen werden. Die scharfe Begriffsdistinktion ist seine Stärke, mag sie nun direkt bei den sachlichen Problemen oder bei der Verarbeitung ihrer historischen Lösungsversuche einsetzen. Für Scotus haben diese begrifflichen Unterschiede, auch wo sie von dem Anschaulichen so gut wie völlig losgelöst sind, reale Be- Realismus, deutung. Sein erkenntnistheoretischer Standpunkt nähert sich mehr als der von Thomas einem outrierten Realismus, ohne indessen diesen in dem alten Sinne der Frühscholastik zu erneuern. Auch nach Scotus sind nur Individuen wirklich. Aber in diesen Individuen sind die verschiedenen Wesensgrade (,gradus entitatis") in ihrer Sonderheit und Reihenfolge schon vor- 
gängig zum Denken real angelegt. Um eine solche schon vorgängig zum Denken vorhandene reale Unterscheidung zu bezeichnen, bei der es sich nicht um die Gegenüberstellung von Ding und Ding oder von physischen Komponenten, wohl aber um die sachliche Verschiedenheit besonderer Seiten an einem Dinge handelt, hat Scotus ein besonderes Wort, die in den Begriffsfehden der Scholastiker vielberufene „distinctio formalis“. Durch eine derartige Distinktion sind in dem individuellen Dinge sein Gattungswesen und Individuations. seine Individualität unterschieden. Aber auch diese Individualität wird von prinzip.

Scotus, der durchaus nicht der Vertreter des Individualismus ist, zu dem man ihn und die Franziskanerschule überhaupt neuerdings hat machen wollen, wieder gänzlich in die Sphäre eines die logischen Abstraktionen realistisch hypostasierenden Denkens gerückt. Wie die spezifische Differenz der Natur die spezifische Einheit gibt und innerhalb ihrer Stufe die weitere Teilbarkeit in Arten von ihr ausschließt, so und in keiner anderen Weise macht die zu der spezifisch vollständig bestimmten Natur hinzutretende individuelle Differenz, welche dem Dinge sein individuelles „Dieses-sein“, seine „Häcceität", verleiht, daß in einem derartig bestimmten Wesen nun überhaupt keine weitere logisch-metaphysische Teilung mehr möglich ist, sondern nur noch eine solche in physische Bestandteile. Aus der Hinneigung des Scotus zu realistischer Deutung logischer Begriffsgliederungen erklärt es sich, daß er nicht nur, wie die Franziskanerschule es längst tat, in der Geistwelt analog zu der Körperwelt einen Unterschied von Materie und Form macht, sondern daß er die erste Urmaterie als eine allen Wesen gemeinsame betrachtet, welche die Geistwelt und die Körperwelt durchzieht. Mit dieser Theorie, welche in weitestem Umfange den allgemeinen Begriff der Möglichkeit und Veränderlichkeit hypostasiert, kehrt er zu einer Grundlehre des jüdischen Philosophen Ibn Gebirol (Avencebrol) zurück, die von Albert und Thomas nicht zum wenigsten wegen ihres extremen Begriffsrealismus bekämpft wurde.

Trotz dieses weitgehenden Realismus schränkt Scotus, wie schon früher grenzen. bemerkt, den Geliungsbereich der menschlichen Vernunft viel enger ein als Thomas. Nicht nur die von Thomas als übervernünftig anerkannten Mysterien der Trinität und Inkarnation, sondern auch Gottes Leben, seine Vernunft, sein Wille, sein Vorauswissen, seine Vorausbestimmung und vieles andere sind kein Gegenstand strenger Vernunftbeweise, so wenig wie die Unsterblichkeit der Seele und das göttliche Gericht. Alles das ist der Vernunft, zumal der schon durch den Glauben erleuchteten Vernunft, zwar durchaus glaubhaft; sie ist aber nicht imstande, es durch demonstrativen Beweis - und der mathematische Geist der Oxforder Schule ließ Scotus an einen demonstrativen Beweis strengere Anforderungen stellen als Thomas tat aus evidenten Prinzipien als sichere Wahrheit zwingend abzuleiten. Nur der Glaube kann hier Gewißheit geben. Auch sonst schlägt Scotus die Bedeutung der Philosophie niedriger an. Einem Hineintragen philosophischer Sätze in die Theologie ist er nicht hold. Philosophie und Theologie will er schärfer geschieden wissen und bereitet so die nominalistische Trennung beider vor. 
Dieser theologische Positivismus des Scotus tritt auch in seiner Einschränkung des Naturrechtes, soweit dieses streng erweisbar sein soll, hervor. Nur die ersten Gebote des Dekalogs, welche das unveränderliche Verhältnis des Geschöpfes zum Schöpfer betreffen, sind nicht erst durch den göttlichen Willen gesetzt, sondern streng notwendig. Anders die zweite Gesetzestafel, die das Verhältnis der Menschen zueinander regelt. Als tatsächlich geltend ist $z$ war auch hier die jetzige moralische Weltordnung gesetzt; aber sie ist nicht in sich unbedingt notwendig. Es ließe sich wenigstens der absoluten Möglichkeit nach auch eine andere Weltordnung denken, in der z. B. die Tötung nicht ausgeschlossen, die monogamische Ehe und das unverletzliche Eigentum nicht nötig wären. Darum konnte Gott beim Opfer Abrahams, bei der Vielweiberei der Patriarchen, bei der Mitnahme der goldenen Gefäße aus Ägypten von solchen Geboten dispensieren; nie aber von der ihm schuldigen Verehrung. - Daß schon Duns Scotus, wie spätere Nominalisten, die „ewigen Wahrheiten" nur vom göttlichen Willen abhängig sein lasse, daß es nach ihm der göttliche Wille sei, welcher die Ideen der Dinge hervorbringe: diese und ähnliche Behauptungen gehören zu den vielen Mißverständnissen der scotistischen Lehre.

Aus der Psychologie des Duns Scotus ist vielberufen, aber auch vielfach übertrieben seine Lehre vom Primat des Willens. Mit vielen anderen Scotistische Psychologie. Philosophen und Theologen des Mittelalters - an nächsten steht ihm Richard von Middleton - lehrt Duns, daß der Wille über dem Intellekte stehe, im Gegensatz zu Thomas und seiner Schule. Aber diese Überordnung ist urPrimat des Willens. sprünglich gar nicht psychologisch gedacht, sondern im Sinne eines Werturteils. Welches Vermögen ist vornehmer und edler, fragte die Scholastik, der Intellekt oder der Wille? Der Intellekt, antwortete Thomas, und sucht dies mit den Mitteln der scholastischen Begriffskunst darzutun. Die Vollkommenheit eines Vermögens nämlich hängt in erster Linie von der Vollkommenheit seines Objektes ab. Nun ist etwas, je einfacher und abstrakter es ist, um so vollkommener. Der Verstand aber, der das Wahre erkennt, indem er alles seinem abstrakten Begriffe nach nimmt, und der in dieser abstrakten Weise auch das Gute, d. h. das Förderliche, erfaßt, auf welches der Wille nach dessen konkreter Realität hinzielt, hat ein einfacheres und abstrakteres Objekt und ist daher auch vollkommener als der Wille. Aus diesem Grunde setzte Thomas mit Aristoteles die Glückseligkeit des Menschen, welche durch seine höchste Vollkommenheit gegeben ist; in die Betrachtung der Wahrheit, die in der Betrachtung Gottes als der Urwahrheit ihren Höhepunkt hat. Als Theologe wandte er den Gedanken auch auf das jenseitige Gebiet der Gnade an. Auch bei der ewigen Seligkeit, dem letzten Ziele des Menschen, soll das Wesentliche in der intellektuellen Schauung bestehen; nur die mit der Seligkeit verbundene und zu dem Wesentlichen an ihr hinzutretende Wonne hat ihren Sitz im Willen. Anders Scotus, dessen eigene Deduktion übrigens meist von theologischen Gesichtspunkten ausgeht. Weil die Tugend der Liebe vollkommener ist als der Glaube und die Hoffnung, weil die Liebe 
inniger mit Gott vereinigt als das Erkennen, weil der Haß gegen Gott schlimmer ist als das Nichtwissen von ihm, so hat auch der Wille den Vorrang vor dem Erkennen. Dieser Vorrang zeigt sich nun auch darin, daß der Wille den Intellekt beherrscht, da er ihn zur Tätigkeit antreibt, während der Intellekt dem Willen dient, indem er ihm sein Objekt darstellt: psychologische Sätze, die auch Thomas und die Thomisten nicht leugnen, ohne daß sie indes die gleiche Folgerung auf den höheren Rang des Willens daraus zögen. So bedeutet der Primat des Intellektes bei Thomas, der des Willens bei Scotus einen Vorzug dem Range und der Würde nach. Schon dieser Unterschied zwischen beiden Denkern verleiht ihrer ganzen Welt- und Lebensanschauung überall da ein verschiedenes Gepräge, wo es sich um Werturteile handelt.

Eine vielverbreitete Auffassung hat jenem Gegensatze eine noch weitergehende Bedeutung gegeben und verlegt den Streit um den Primat auch sogar in erster Linie - auf das psychologische Gebiet. Nicht nur dem Range nach, sondern auch im psychologischen Organismus erscheine bei Thomas der Intellekt, bei Scotus der Wille als die Grundkraft der Seele. Dementsprechend lehre Thomas einen intellektualistischen Determinismus, während Scotus eine rein indeterministische Willenslehre vertrete. Nach Scotus, wird uns versichert, lege der Verstand dem Willen nur das Objekt vor, bleibe aber mit seinem Urteil der Willensentscheidung gänzlich äußerlich. Die Kraft der Motive gehe in die Gesamtkausalität des Willensaktes nicht ein, während umgekehrt der Wille nicht nur den Verstand zur Tätigkeit treibe oder von derselben abhalte, sondern auch den Inhalt der Erkenntnis bestimme. Die thomistische Psychologie sei intellektualistisch, die scotistische voluntaristisch. - Auch erkenntnistheoretisch sucht man jene Gegenüberstellung durchzuführen. Im Gegensatz zu dem an Leibniz erinnernden erkenntnistheoretischen Intellektualismus des Aquinaten soll Scotus die Überzeugungen, für welche die theoretische Vernunft keine ausreichenden Beweise darbiete, auf den sittlichen Willen begründen: ein Gegenstück zu Kants Primat der praktischen Vernunft.

Es wäre Unrecht zu leugnen, daß die auf diesen Ton gestimmten neueren Darstellungen nicht mit viel Geist und mit einem feinen psychologischen Gefühl für Charakteristik sehr anschauliche und fein durchgeführte historische Gemälde gezeichnet haben. Leider verdanken dieselben ihren Ursprung mehr der subjektiven Konstruktion des logischen Zusammenhanges und der psychologischen Entstehung der Lehre, als einer streng objektiven Analyse des (freilich recht verwickelten) geschichtlichen Tatbestandes, beruhen auch zum Teil auf einer nur unvollständigen Kenntnis des weitläufigen Quellenmaterials. Manches kann ich nur ganz kurz berühren, vor allem die erkenntnistheoretische Gleichsetzung des Willensprimates bei Scotus mit dem Primate der praktischen Vernunft bei Kant, welche - wie hier freilich nicht näher nachgewiesen werden kann - gänzlich unzutreffend ist. Aber auch die Art, wie der Streit um den Primat des Intellektes oder des Willens für den Nachweis einer durchgängigen Verschiedenheit $z$ wischen der thomistischen und scoti- 
stischen Psychologie, namentlich hinsichtlich des Freiheitsproblems, benutzt wird, ist von starker Übertreibung nicht frei. Vieles von dem, was sich nur bei Scotus finden soll, lehrt auch Thomas, und umgekehrt werden Gedanken des Thomas dem Scotus abgesprochen, welche diesem keineswegs völlig fremd sind. So wird der augustinische Satz, daß der Wille der allgemeine Beweger ist, der auch den Verstand zur Tätigkeit antreibt oder ihn ruhen läßt, ganz ebenso von Thomas vertreten. Nicht minder wird der angeblich spezifisch scotistische Satz, daß der Wille selbst dann, wenn der Verstand ihm etwas als ein allseitig Gutes vorstellt, doch nicht in Tätigkeit zu treten brauche, auch von Thomas gelehrt; denn die Nötigung, von welcher Thomas in diesem Falle spricht, soll sich nach ihm nur auf die Art des Aktes, nicht auf die Ausübung desselben beziehen. Und umgekehrt lehrt - was man bestritt -, wie Thomas, so auch Scotus, daß dem Willen ein notwendiger Zug nach dem innewohnt, was als gut, d. h. als fördernd und beglückend erscheint; nur markiert er seinen Gegensatz gegen Thomas dadurch, daß er diese natürliche Regung des Willens nicht auch als ein Wollen, bezeichnen will, indem er den Namen des „Wollens“, wenigstens im eigentlichen Sinne, für die freie Willenstätigkeit aufspart. Daß aber das Verstandesurteil nach Scotus keine motivierende Kraft besitze, daß umgekehrt der Wille sogar auf den Inhalt der Verstandeserkenntnis unmittelbaren Einfluß habe: diese und andere ähnliche Behauptungen können nur einfach als Irrtümer bezeichnet werden.

Aber nichtsdestoweniger liegt jenen Darstellungen auch da, wo sie irren, das richtige Gefühl zugrunde, daß der Geist der scotistischen Psychologie ein anderer ist als der der thomistischen. Scotus liegt es vor allem am Herzen, die Willensfreiheit nicht beeinträchtigen zu lassen. Die Freiheit des Willens wird von ihm stark akzentuiert, stärker noch als von Thomas. Gerade deshalb wollte er es, wie wir sahen, wenigstens als kein eigentliches Wollen gelten lassen, wenn er zugab, daß dem Willen in der Tat ein nezessitiertes natürliches Begehren nach dem Guten (im metaphysischen Sinne) eignet, sondern beschränkte das eigentliche Wollen auf die aktive und daher freie Willenstätigkeit, mit Ausschluß der passiven Willenserregung. So betont er denn, dab selbst da, wo der Wille dem vollkommen klar erkannten Gute sicher und ohne Schwanken sich zuneigt, wie etwa in der himmlischen Seligkeit, er dies nicht gezwungen oder bloß passiv, sondern in eigener freibleibender Aktivität tut. Thomas dagegen legt das größte Gewicht auf die Bedeutung, welche die Vernunft, die die Begrenztheit aller endlichen Güter erkennt, für den Willen und für die Begründung einer sittlichen Freiheit hat. Bei Thomas ist die Vernunft Grund, der Wille Träger der Freiheit während letztere bei Scotus den Willen als Träger und Grund hat. Vielfach können wir sehen, wie Scotus und Thomas, wenn schon in der Sache selbst ziemlich einig, sie doch von entgegengesetzten Enden anfassen. So lehrt Scotus: der Wille ist frei; denn wenn er auch in seinem natürlichen Verlangen auf nichts anderes gerichtet ist als auf das, was sich seiner Erkenntnis als ein Gut darstellt, so braucht er doch selbst einem allseitig Guten gegenüber einen Willens- 
akt nicht zu setzen, sondern kann sich der Tätigkeit völlig enthalten. Was hier als nachträgliche Einschränkung auftritt, bildet in einer ähnlichen Erörterung bei Thomas den Hauptsatz. Gegenüber dem, was von der Vernunft als allseitig gut erkannt wird, beginnt dieser, ist der Wille genötigt; aber und jetzt kommt nachträglich, was bei Scotus die Hauptsache war -: diese Nötigung determiniert nur die Art des Aktes für den Fall, daß er überhaupt gesetzt wird, hinsichtlich der Ausübung des Aktes selbst bleibt der Wille dagegen frei. - Schon Scotus selbst im Eifer seiner Polemik hat diesen Sachverhalt gelegentlich übersehen und ist dadurch eine Quelle falscher historischer Beurteilungen geworden.

Gewiß soll nicht in Abrede gestellt werden, daB, wie in der Psychologie überhaupt, so auch hinsichtlich der Willenspsychologie zwischen Thomas und Scotus mancherlei Verschiedenheiten bestehen, auf die im einzelnen einzugehen indes von keinem besonderen Interesse ist. Aber der durchgreifende Unterschied $z$ wischen beiden liegt nicht auf dem Gebiete der Psychologie als Naturwissenschaft, sondern betrifft vielmehr die Wertung der im geistigen Leben tätigen Kräfte. In seiner eigen€n Verstandestätigkeit, zumal wo sie nicht eine theologische ist, vor allem Kritiker, schätzte Scotus bei seiner Geistesbetrachtung höher als die Kontemplation, in der Thomas das geistige Leben gipfeln läßt, die praktische Tat. Ihm, dem Zertrümmerer fremder Vernunftspekulation, steht die Betätigung des Willens über der des Intellektes. - Dieser Unterschied der Wertung ist, wie noch bemerkt sein möge, auch für die scotistische Theologie charakteristisch. Kündigt er sich doch schon in der Begriffsbestimmung derselben an; die Theologie, die Thomas in erster Linie als.spekulative Wissenschaft -- wenn auch als "Wissenschaft" im weiteren Sinne - faßt, ist für Scotus weit mehr eine praktische Disziplin, eine auf dem Glauben an die Offenbarung und ihrer Erkenntnis beruhende Technik oder Kunstlehre.

Scotisten. Die zahlreichen Schriftsteller der scotistischen Schule, ein Antonius Andreae, Franciscus de Mayronis ( +1325$)$, der wegen seines philosophiegeschichtlichen Werkes schon früher erwähnte Walter Burleigh (Burlaeus), ein Lychetus, Trombeta, Mauritius Hibernicus, ein Mastrius ( +1673 ), Belluti $(\dagger+676)$ u. a., sind von keinem selbständigen philosophischen Interesse.

VI. Andere Richtungen. Schon die allgemeine Charakteristik der mittelalterlichen Philosophie bot Veranlassung, der mittelalterlichen Logik, ihrer technischen Hilfsmittel für die Syllogistik und ihrer logischen Bedeutungslehre (Supposition der Termini) zu gedenken. Diese spezifisch Logiker. mittelalterliche Logik hat in Paris durch das Zusammenwirken von Philosophen und Grammatikern ihre Form erhalten. Abälard und der Grammatiker Petrus Elias (Helyas, I I./ 1 2. Jahrhundert) haben Anstöße dazu gegeben; der am Petit Pont zu Paris lehrende Engländer Adam, Bischof von St. Asaph, hatte weiter gearbeitet. Ein anderer Engländer, der Pariser Lehrer und spätere Bischof von Lincoln, William von Shyreswood († 1249), faßte die 
Schultradition zusammen, die auch in zahlreichen anderen "Summulae" dargestellt wurde. Die kanonische ist unter diesen die des Petrus Hispanus Petrus Hispanus geworden, der wahrscheinlich mit dem auch als fleißiger medizinischer Schriftsteller bekannten späteren Papst Johannes XXI. (einem Portugiesen, $f_{1}$ 277) identisch ist. Unzählige haben sein Handbuch kommentiert; ins Griechische hat es im 15. Jahrhundert Georgios Scholarios übertragen.

Die logischen Methoden der mittelalterlichen Logik waren wohl geeignet, schon gewonnene Erkenntnisse in ihrem begründenden Zusammenhange zu klären, weniger dagegen, neue Wahrheiten zu finden. Der Hauptweg für letzteres, die Induktion, fand aus früher schon berührten Gründen im Mittelalter keine Pflege. Wohl aber begegnet uns auf dem rein begrifflichen Gebiete ein interessanter Versuch einer solchen ars inveniendi, der zwischen den schon bestehenden Begriffen möglichst viele Kombinationen herstellen und dabei möglichst viele Frageformen auffinden will, um so, nachdem eine sachliche und logische Prüfung zur Scheidung der richtigen oder doch möglichen Kombinationsergebnisse von falschen Sätzen geführt hat, zu einer möglichst vollständigen und auch Neues enthaltenden Systematik des Wissens zu gelangen. Diese Kombinatorik als eine Art begrifflicher Experimentierkunst ist durch Ramon Lu11 (Raymundus Lullus, + 1315) ausgebildet. Er gibt ihr Lullus. zugleich eine Art mathematischer Form, indem er die hauptsächlichen Dingbegriffe und Prädikate durch Buchstaben ausdrückt, und sucht weiterhin das Aufsuchen der Kombinationen durch das Drehen von Zeichen-Ringen und anderen Hilfsmitteln zu mechanisieren. Diese Lullische Kunst fand viele Anhänger. Noch in der späteren Zeit haben Agrippa von Nettesheim, Giordano Bruno - dem sie freilich mehr als mnemotechnisches Hilfsmittel dient -, Joh. Heinr. Alsted, der Lehrer des Comenius, u. a. sie gepflegt. Ja. man kann sagen, daß ihre Grundanschauungen in Leibnizens scientia generalis sowie in der modernen rechnenden Logik und den logischen Maschinen von Stanley Jevons u. a. wieder aufgelebt sind. - Gab Lullus hier Eigenes, so ist dagegen der sein ganzes, vom feurigsten Missionseifer beseeltes literarisches Wirken leitende Versuch, die ganze christliche Glaubenslehre den Mohammedanern und insbesondere den Averroisten als Vernunftforderung zu erweisen und sie so dem Christentum zu gewinnen, ein Rückfall zu einem seit Alanus von Lille verlassenen Standpunkt. Nur Raymund von Sabunde bringt noch einmal in der I. Hälfte des I 5. Jahrhunderts,ähnliches. Aber das sinnige Werk des in Toulouse lehrenden.spanischen Arztes, dem der französische Skeptiker Michel de Montaigne eine charakteristische Apologie widmet, trägt doch einen ganz anderen Charakter als die rein logischen Demonstrationen Lulls. Wenn er von der äußern Natur zum Menschen sich wendet, der als Mikrokosmos die Einheit des Makrokosmos bildet, um dann zur göttlichen Einheit als dem letzten Ziel aufzusteigen und so im Buche der Natur den Widerschein dessen zu finden, was das Buch der heiligen Schrift verkündet, so erinnert er in der ganzen Art seiner kontemplativen Versenkung mehr an die augustinische Mystik der Viktoriner, als an die Dialektik des in Die Kultur der Gegrniart. 1. 5. 2. Aufl.

Rationalismus des Lullus.

Raymund von Sabunde. 
mancher Disputation mit den mohammedanischen Gelehrten streitenden Glaubensverkündigers Lullus.

Als einzeln stehende Erscheinungen seien kurz erwähnt die beiden beBaconthorp. freundeten englischen Denker Baconthorp $(\dagger 1346)$, der in den Detailerklärungen gern Averroës folgt, seine Lehre von der Einheit des Intellektes aber bekämpft, und der gelehrte, auch als Mathematiker hervorragende

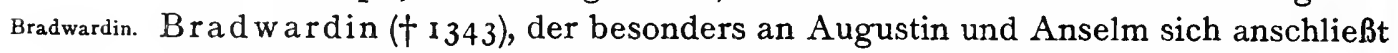
und namentlich die totale Abhängigkeit der $z$ weiten Ursache von der ersten Wiclif. gegenüber allen „Pelagianern“ klarzulegen sucht; ferner Wiclif († 1384), den wir hier mehr wegen seiner logischen und psychologischen Abhandlungen und wegen seines erkenntnistheoretischen Realismus (den später auch Johannes Hus an der Prager Universität gegen den Nominalismus der deutschen Lehrer vertrat) nennen, als wegen seiner über Bradwardin weit hinausgehenden theologischen Stellung.

VII. Der Nominalismus des späteren Mittelalters. Der einzige wirklich originelle Geist unter den Philosophen der Spätscholastik (von der Mystik sehen wir hier $\mathrm{ab}$ ), der einzige, der mit ursprünglicher Kraft eine durchgängige Neuformung des Stoffes und ein selbständiges, für mehr als $z$ wei Jahrhunderte Richtung gebendes System aus einem Gusse zu bieten a) Occam. verstand, ist der Engländer Wilhelm von Occam ( $f$ I349 in München). Seine Beteiligung an den Streitigkeiten seines Ordens um das mönchische Lebensideal, seine daraus hervorgegangene, von leidenschaftlicher Übertreibung nicht immer freie Stellungnahme in dem Kampfe, den die mit geistlichen Mitteln fremde politische Interessen besorgenden avignonesischen Päpste, insbesondere Johannes XXII., gegen seinen Beschützer Ludwig den Bayern führten, bleiben hier außer Betracht: nur der Erneuerer des Nominalismus ist hier zu schildern. Denn wenn auch der von Thomas herkommende Dominikaner Durandus von St. Pourçain $\left(\begin{array}{r}\mathrm{I} 332) \\ )\end{array}\right.$ Scotus ausgehende Minorit Petrus Aureoli $(\dagger \mathrm{I} 322)$ schon einzelne nominalistische Elemente aufweisen, so hatten doch die späteren Nominalisten vollkommen recht, wenn sie Occam als den Eröffner (venerabilis inceptor) ihrer Schule feierten.

Der Nominalismus Occams ist von einer gänzlich verschiedenen Prägung

wie derjenige der Frühscholastik. Zwei Motive haben vor allem zu ihm geführt: ein erkenntnistheoretisch-metaphysisches und ein psychologisches. Das erstere geht aus von dem Widerspruch gegen den durch Scotus wieder neu gesteigerten Realismus. Denn Scotus, nicht der seinem Orden fremde Thomas, ist es, den Occam als Minorit überall vor sich hat. Scotus hatte das Allgemeine in dem Dinge als einen selbständigen realen Wesensgrad gefaßt, der schon vorgängig zum Denken durch die von ihm angenommene formale Distinktion von der Individualität verschieden ist. Occam zeigt die Unhaltbarkeit dieser Annahme. Während für Scotus die gemeinsame Natur das Ursprüngliche ist, zu dem die Form des individuellen Dieses-seins (haecceitas) 
erst hinzutritt, hat nach Occam die Frage nach dem Prinzip der Individuation keinen Sinn. Die Naturursachen, welche das Ding hervorbringen, bringen es als individuelles Ding hervor. Eine besondere Ursache der Individualität gibt es nicht. - Das psychologische Motiv ist gegeben durch die schon von Durandus begonnene Kritik der durch den "aktiven Verstand“ abstrahierten intelligibeln „Bilder" (species) und überhaupt der Auffassung des menschlichen Erkennens als eines geistigen Nachbildens der Wirklichkeit. Zwischen das äußere Ding und den Erkenntnisakt schiebt sich kein vermittelndes, dem "aufnehmenden Verstande" eingeprägtes Bild ein. Die sinnlichen und die intellektiven Vorstellungen sind nicht Bilder, sondern nur Zeichen der sie verursachenden Objekte außer uns, freilich natürliche Zeichen, die von den realen Objekten auf naturgemäße Weise hervorgebracht werden -- keine künstlichen Zeichen, wie die Wortzeichen und Schriftzeichen, die wir für jene natürlichen Repräsentanten weiterhin wieder einsetzen —, aber doch immerhin nur Zeichen, die uns nicht weiter in das innere Wesen der Dinge einführen, als die Einwirkung der Dinge auf uns reicht. So sind die Vorstellungen als innere Worte und die akustischen und graphischen Wortzeichen als äußere Worte für Occam gewissermaßen Rechenpfennige, mit denen wir widerspruchsfreie Denkoperationen vollziehen. Der vom Realismus des I3. Jahrhunderts fast als selbstrerständlich angenommene bildhafte Charakter des Erkennens wird bestritten: ein Vorspiel zu der modernen Entwickelung, welche von der Verwerfung des objektiven Charakters der Sinnesqualitäten bei Galilei, Hobbes und Descartes bis zur "Kritik der reinen Vernunft“ führte. Da jene Rechenpfennige im übrigen etwas Unbestimmtes an sich haben und darum als Zeichen für eine Vielheit von Individuen stehen können, so kommt ihnen eine Allgemeinheit zu. Eines Allgemeinen in den Dingen, eines universale in $\mathrm{re}$, bedürfen wir dagegen nicht. Nichtsdestoweniger sind unsere allgemeinen wissenschaftlichen Urteile - auf deren Gültigkeit die Realisten so großen Wert legen -, soweit sie den sachlichen Gehalt unserer Vorstellungen (die intentio prima) bestimmen, keine Urteile bloß über unsere Vorstellung; denn die Vorstellung steht hier unmittelbar als allgemeines Zeichen für eine Vielheit von realen Dingen. Wenn ich z. B. sage, daß „der Mensch“ sterblich sei, so meine ich nicht irgendeine gemeinsame Natur, ebensowenig bloß meine Vorstellung vom Menschen oder gar die Lautverbindung Mensch; ich lege vielmehr das Prädikat allen einzelnen wirklichen oder möglichen Menschen bei, für deren jeden die Vorstellung oder das Wort als Zeichen stehen kann. Worauf es nun freilich beruht, daß dieser Gebrauch allgemeiner Zeichen uns zur Beherrschung der wirklichen Natur führt, worin die typische Naturgesetzlichkeit bestehe, und ob es eine solche überhaupt gebe, welche Motive uns zur Bildung der über die äußeren und inneren Phänomene hinausführenden, die Allgemeinerkenntnisse tragenden Kategorien der Substanz und der Kausalität führen: diese und andere tiefere Fragen der Erkenntnistheorie hat Occam, wie schon bei der Charakteristik der mittelalterlichen Philosophie hervorgehoben wurde, ebensowenig gestellt, als wie etwa der dort gleichfalls 
erwähnte scharfsinnige Nikolaus von Autrecourt, der in seinen kühnen Negationen die wichtigsten erkenntnistheoretischen Probleme der Neuzeit anschnitt, irgendeinen positiven Lösungsversuch für diese aber nicht unternommen hat. Für das Mittelalter selbst hat der Nominalismus doch vorwiegend als Element der Dekomposition gewirkt. Im einzelnen dagegen bietet Occam in seiner logischen, psychologischen und metaphysischen Analyse der Erkenntnis manchen feinen Beitrag, der freilich nur zu oft unter einem Wuste unnützer oder doch uns völlig fremdartig anmutender Untersuchungen"vergraben ist. So wenn er Begriffe unterscheidet, deren Inhalt in einer einheitlichen (anschaulichen) Vorstellung gegeben ist (inkomplexe Begriffe), und solche, die nur durch die Verbindung einer Vielheit von Bestimmungen vermittels eines Urteils zustande kommen können (komplexe Begriffe). Einen scharfen Blick hat er für die Kompliziertheit psychologischer Fragen. So wenn es sich um das Zusammenwirken von Vorstellung als Zeichen, von Wortzeichen und von Schriftzeichen handelt. Aber für eine wirkliche Durchführung der sich daraus ergebenden psychologischen Fragen und GesetzmäBigkeiten fehlt es ihm freilich noch an den nötigen Voraussetzungen und Methoden, die erst durch eine lange Arbeit der Neuzeit gewonnen werden konnten.

Intuitives und abstraktive Wissen.

Occams Empirismus.

In mehrfachem Betracht von besonderer Wichtigkeit war Occams Unterscheidung eines intuitiven und eines abstraktiven Wissens. Die ältere, metaphysisch konstruierende Theorie des Erkennens erblickte im Denken ausschließlich ein mit allgemeinen Inhalten auf abstraktem Felde operierendes Verfahren. Occam sieht ein, daß das Denken als prädikativ bestimmende Erfassung von Gegenständen sich nicht nur in der Verbindung und Trennung abstrakter Inhalte, sondern schon in der Erfassung des in der äußeren Erfahrung und der Selbstreflexion gegebenen Einzelnen und Konkreten betätigt. Die sinnliche Wahrnehmung ist nicht die einzige intuitive Erkenntnis; es gibt vielmehr auch ein (von Occam freilich psychologisch nicht ausreichend analysiertes) intuitives Wissen als Denktätigkeit. Und zwar setzt hier Occam, wie Augustin und Descartes, die intuitive Gewißheit des Wissens von sich selbst über die unserer Erkenntnis der Außenwelt, wenngleich auch die Selbsterkenntnis nicht das Seelenwesen, sondern nur die Seelentätigkeiten erfaßt. Die abstraktive Erkenntnis dagegen, die in mancherlei Schlüssen mit abstrakten Begriffen operiert, steht überhaupt unter der intuitiven. Unterscheidungen der Wissensarten, die Locke und Hume machen, kündigen sich hier an.

Damit ist zugleich auf den empiristischen Charakter von Occams Erkenntnislehre hingewiesen. - Das Dasein Gottes ist weder unmittelbar aus seinem Begriffe gewiß (ex terminis), wie Anselm wollte, noch a priori, d. h. aus der Ursache, da ein göttliches Wesen keine Ursache haben kann. Aber auch der aposteriorische Beweis aus der Wirkung erzielt nur Wahrscheinlichkeit, da er Voraussetzungen einschließt, wie z. B die Unmöglichkeit einer unendlichen Reihe, die nicht streng evident zu machen sind. Ebensowenig kann die Einheit Gottes zwingend erwiesen werden; denn es sind auch rerschiedene Welten mit verschiedenen Urhebern denkbar. Man sieht, wie bei 
diesem Empirismus Occams Verhältnis zu Scotus sich umwendet. Hinsichtlich der Lehre von den Universalien des Scotus schärfster Gegner, hat er in Rücksicht auf die Einschränkung der Vernunfterkenntnis den von jenem eingeschlagenen Weg entschlossen weiter verfolgt.

Für alle solche gegenüber der Erfahrung transzendenten Fragen werden Philosopiuie und wir von Occam auf den Glauben verwiesen. Die Vernünftigkeit des GlauTheologie bei bens darzulegen, ist ein leeres Unterfangen. Selbst die Bindung durch das Prinzip des Widerspruchs, die Occam theoretisch festhält, wird praktisch sehr gelockert. Unaufhörlich betont er dagegen die absolute Macht Gottes, nicht selten in geradezu anstößig klingenden Redewendungen. Wie um ein gläubiges Gemüt zu ärgern, und doch in Wirklichkeit nicht aus diesem Motive, sondern in starrer Konsequenz seiner theoretischen Voraussetzungen, schreckt er nicht davor zurück, zu behaupten, daß Gott auch als Esel hätte zur Welt kommen oder mit der Natur eines Steines oder eines Holzes sich hätte hypostatisch vereinigen können. Es ist, als sollte dem Theologen die Aufgabe gestellt werden, weniger die wirklichen Dogmen verständlich zu machen, als vielmehr nachzuweisen, daß nach der absoluten Macht Gottes auch die größten Torheiten den Gegenstand des Glaubens bilden könnten. An die Stelle von Anselms "Credo ut intelligam", können wir auch sagen, ist das vielberufene „Credo, quia absurdum est" getreten. Derartigen Dingen war schon Augustin entgegengetreten, wenn er den Einwand, ein allmächtiger Gott müsse z. B. auch spazieren gehen können, als kindisch nachwies. Übrigens finden sich ähnliche Albernheiten, wie jene Occams, wenigstens in Frageform auch sonst und auch außerhalb der nominalistischen Schule. So z. B. noch im 17. Jahrhundert bei dem Thomisten Nazarius. Immerhin harmloser war es da, wenn z. B. Aegiđius von Rom untersucht, ob ein Engel in einem unteilbaren Raumpunkt sein und dort eventuell mit noch einem anderen Engel zusammenexistieren könne - von wo es freilich nur noch ein Schritt ist bis zu der schwerlich bloß scherzhaft gemeinten Entdeckung weiser "Meister" in einer zu Unrecht Eckhart beigelegten begardischen Schrift, daß tausend selige Geister im Himmel auf einer Nadelspitze sitzen könnten. Es läßt sich nicht leugnen, daß hier die spätere Scholastik zur Karikierung selbst reichlichen Anlaß gegeben hat.

Im Zusammenhange mit dieser Vorstellung Occams von der absoluten occams Ethik. Macht Gottes (die er von seiner geordneten Macht unterscheidet) steht es auch, wenn er wenigstens prinzipiell einen an sich bestehenden Unterschied von Gut und Bös aufhebt. In noch viel weitergehendem Maße als für Scotus ist es für Occam denkbar, daß Gott ganz andere Moralvorschriften auf dem Gebiete der natürlichen Sittlichkeit durch seinen Willen sanktioniert hätte. Dementsprechend meint er denn auch, daß Gott seiner absoluten Macht nach selbst aller Liebe bare Handlungen reinsten Eigennutzes für verdienstlich hätte erklären können. Das ist dann in Wahrheit jene heteronome Moral, die man oft irrtümlich als die allgemein christliche angesehen hat.

Noch sei der metaphysischen Psychologie Occams gedacht. Nach seinem 
Grundsatz, daß man nicht ohne Not das Seiende vervielfältigen dürfe, gibt er die thomistische und scotistische Lehre von einer Vielheit real verschiedener Seelenpotenzen wieder auf und kehrt zu der frühscholastischen Auffassung zurück, die in den Vermögen der Seele nur ihre verschiedenen Tätigkeitsweisen erblickte. Den Aufbau der menschlichen Natur selbst dagegen denkt er trichotomisch. Der durch die Körperform gestaltete Leib ist in seinen einzelnen Organen Träger der vegetativ-sensitiven Seele, die durch den sittlichen Kampf, zu dem sie Veranlassung gibt, ihre Verschiedenheit von dem höchsten Prinzip des Menschenwesens, der (nicht mehr an die räumliche Unterscheidung der einzelnen Körperteile gebundenen) intellektiven Seele erkennen läßt. Es ist die Unterscheidung von Seele und Geist, die in der Philosophie der Renaissance z. B. Telesio erneuert und die Bacon von Verulam von diesem herübernimmt.

b) Spätere Nominalisten. Pariser Lehrer, wird die psychologische Analyse der komplizierten Willensvorgänge und des Zusammenwirkens der dabei tätigen Faktoren angeregt. Weil zwischen Wille und Verstand kein realer Unterschied ist, so ist, folgert Buridan u. .. Buridan, der Wille nicht freeier als der Verstand. Nur die Seele ist frei. Thre Freiheit schließst indes eine psychologische Determination durch das stärkere Motiv nicht aus. Wohl aber kann die wollende Seele die Richtung der vernünftigen Motivbetrachtung ändern. Sie kanı auch ihre Tätigkeit ganz unterlassen oder doch aufschieben. Der zwischen $z$ wei gleich anziehenden Heubündeln verschmachtende „Esel des Buridan" findet sich nicht in seinen Schriften. Dies mythische Tier scheint zur Verspottung von Buridans psychologischem Determinismus frei nach Aristoteles von seinen Gegnern erfunden zu sein. Andere Nominalisten sind die Logiker Albert von Sachsen († 1340) und Marsilius (Marcelius) von Inghen ( +1396$)$, Nicolas d'Oresme ( +1382$)$, der große Nationalökonom des 14. Jahrhunderts, welcher die aristotelische Politik für Karl V. von Frankreich in die Landessprache übertrug, der Dominikaner Robert Holkot ( $t$ r 349) und der schon erwähnte Augustiner-Eremit Gregor von Rimini ( 1358 ), der in Wien lehrende Heinrich von Hessen der ältere (Heinrich Heinbuch von Langenstein, † I 397), in der Philosophie auch der Pariser Kanzler Johannes Gerson ( $(1429)$. Auf die eigenartigen Nicolaus erkenntnistheoretischen Versuche des Nicolaus von Autrecourt, der die von Autrecourt und Unmöglichkeit darlegt, das Kausalgesetz und viele andere Sätze auf das erste Pierre d'Ailly. logisch-metaphysische Denkgesetz, das des Widerspruchs, zurückzuführen, und damit die Kritik des Kausal- und des Substanzbegriffs einleitet, wurde schon früher hingewiesen; nicht minder auf die Parallele zur cartesianischen Begründung des Zweifels an der Außenwelt, die man bei Pierre d'Ailly (Petrus Alliacus, $\dagger_{1425}$ ) finden kann. Nicolaus von Autrecourt nimmt auch sonst eine eigenartige Stellung ein. Er verficht die Atomistik, indem er zugleich der Naturphilosophie des Aristoteles den Krieg erklärt, nimmt eine Art von Seelenwanderung an und verkündet aufs neue die antike stoische 
Lehre von der ewigen Wiederkehr aller Dinge. Die Zusammenfassung der nominalistischen Lehre durch Gabriel Biel ( $t$ I495), einen auch um die Biel. Entwickelung der Nationalökonomie verdienten Tübinger Professor, hat durch ihre schulgerechte Form weite Verbreitung gewonnen und ihm den freilich nicht recht zutreffenden Namen des „letzten Scholastikers" eingetragen.

VIII. Die Mystik des spätern Mittelalters. Wie von Anfang an die auf verstandesmäßiges Begreifen ausgehende Scholastik eine kontemplative mystische Bewegung neben sich hat, so ist das gleiche auch im späteren Mittelalter der Fall.

Ich sehe hier ab von der an Amalrich und die Amalrikaner anknüpfen- Schwestern und den Pseudomystik der Brüder und Schwestern vom freien Geiste (swestri- Brüder von ones), die auch in manchen begardischen Kreisen Platz greift. Nicht die wenig originelle pantheistische Metaphysik, die Lehre von dem göttlichen Allsein, dem Nichts der Kreatur und dem natürlichen Christuswerden des innerlichen, gegen alles Äußere gleichgiltigen Menschen, gibt dieser das charakteristische Gepräge. Was vielmehr am meisten hervorsticht, sind die antinomistischen und libertinistischen Lebensgrundsätze, für die man in jenen metaphysischen Anschauungen den spekulativen Unterbau zu gewinnen suchte. Die Selbstvergötterung erscheint als Rechtfertigung für ein über die herkömmliche Moral namentlich in sexueller Beziehung sich hinwegsetzendes, des gewaltsamen Zuges dagegen entbehrendes Übermenschentum.

Solche sittliche Verwahrlosung wird auf das schärfste bekämpft von dem Die spekulative

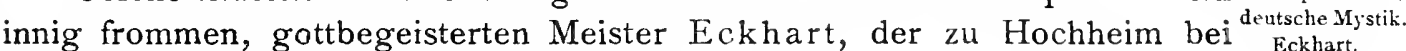
Gotha geboren, früh in den Dominikanerorden getreten, in mehreren Häusern seines Ordens, besonders in Straßburg und Köln, zeitweilig auch an der Pariser Universität, als Lehrer oder auch in Ordensämtern tätig war und 1327 zu Köln gestorben ist. Gewiß kann, meint Eckhart jener Pseudomystik gegenüber, derjenige, welcher Gott und seine Liebe hat, tun, was er will. Aber wer etwas gegen Gottes Gebot tut und doch behauptet, daß er Gottes Liebe habe, der betrügt nur sich selbst. Auch in der spekulativen Grundlegung von Eckharts Mystik herrscht trotz mancher Berührung in Gedanken, mehr noch im Ausdruck und in besonders scharf zugespitzten Sätzen, doch ein anderer Geist als bei jenen. Das ergab sich schon daraus, daß Eckhart zugleich mitten in der Scholastik, insbesondere der thomistischen seines Ordens, steht. Infolgedessen bringt er die metaphysischen Grundlagen seiner Mystik in den Zusammenhang der Scholastik und bestrebt sich, sie in den Begriffen dieser zu fassen. Freilich rücken hierbei die neuplatonischen Elemente stark in den Vordergrund, die auch bei den Landsleuten Eckharts unter seinen Ordensgenossen, bei Albert und noch mehr bei Ulrich von Straßburg und Dietrich von Freiberg, nicht fehlen, und die wenigstens in eincm gewissen Maße an dem Aufbau der Scholastik überhaupt teilgenommen haben. Die Schriften des Pseudo-Areopagiten Dionysius gaben für diesen Neuplatonismus von alters her die hauptsächlichste Vermittelung ab. Im Anschluß an ihn 
hatte, wie wir sahen, im I3. Jahrhundert Thomas, der Abt von Vercelli, auch der herkömmlichen augustinischen Mystik eine veränderte Orientierung gegeben. Daneben kommen gewisse Gedanken Avicennas bei Eckhart zu entscheidender Geltung. Auch auf den Neuplatoniker Proklus beruft er sich nicht selten.

Als scholastisch gebildeter Lehrer hat Eckhart seine Anschauungen in mehreren lateinisch abgefaßten Schriften niedergelegt, von denen uns erst neuerdings manches bekannt geworden ist. Wirkungsvoller als sie waren die Predigten und Unterweisungen in deutscher Spracie, mit denen sich Eckhart, wie viele andere neben ihm, an die des Lateinischen nicht so kundigen Klosterfrauen und an die Laien wandte. Beides ergänzt sich: die durch den Anschluß an die Tradition verständlichere Terminologie der lateinischen Schriften und die vielseitigere, zugleich auch individuellere und gefühlswärmere deutsche Darstellung.

Eckharts Gotteslehre.

Die spekulative Grundlage von Eckharts Mystik bildet seine Gotteslehre und seine Psychologie. Gott, als reiner Akt und ewige Vollendung, ist ewiges Sein und ewiges Leben zugleich. Ohne die „Relationen“ gedacht, in denen nach der Scholastik die göttliche Dreipersönlichkeit besteht, in der „bloßen Lauterkeit göttlichen Wesens", ist er die unbegreifliche und unaussprechliche „Gottheit", für welche die Eigenschaften, wie Güte und Gerechtigkeit, nur gewissermaßen wie ein umgelegtes Kleid sind. Als formenlose Unermeßlichkeit, als das von keinen Grenzen eingeschränkte unendliche Sein, kann er auch als das „Nichts“ bezeichnet werden (wie bei Eriugena), d. h. als nichts von dem unserem Verstande erfaßbaren begrenzten So- oder Dieses-sein. In dieser "Gottheit" setzt die ewige Geburt des Sohnes, des Bildes des Vaters, und der Hervorgang des heiligen Geistes, des Liebesbandes, die wesensgleiche Dreipersönlichkeit des einen Gottes als substanzielle Beziehung ("Relation"). Indem aber Gott der Vater sein ewiges Wort spricht und so den Sohn als sein wesenseines Bild zeugt, spricht er zugleich die ewigen Urbilder, die Ideen. In ihnen hat ein jedes Ding sein ewiges Leben, vom Engel und dem Menschen bis zum untersten hin. Aber diese Dinge stehen zu den Ideen nicht im Verhältnis des Besondern zum Allgemeinen oder der inaividuellen Determination zum Gattungswesen. Die Schöpfung ist bei Eckhart nicht, wie man ihn oft verstand, eine Entfaltung der Idealwelt ihrer Substanz nach. Ihrem Wesen nach sind die Dinge Nachbilder der ewigen Urgründe, nicht wesenseins mit diesen. Freilich ist es dabei dasselbe ewige "Jetzt", in dem Gott das ewige Wort spricht und die Welt schafft. Aber dies wird von Eckhart so erklärt, daß Gott nicht nach der freburt des Sohnes auf die Schöpfung der Welt wartet. Denn ein "Früher" als Zeitunterschied gibt es nur auf. der Seite der in den Fortgang der Zeit gestellten Welt. In Gott aber ist alles, auch was in der Welt zeitlich auseinanderliegt, ein ewiges Jetzt. - Während so das Wesen des Endlichen vom göttlichen Wesen durchaus unterschieden wird, verhält es sich nach Eckhart anders mit dem Sein der Kreatur. Avicenna folgend, 
unterscheidet er nämlich in allem Geschöpflichen scharf das Wesen und das Sein oder die Existenz. Nichts Endliches hat aus sich das Sein. So lehrte nun freilich auch die Scholastik allgemein, insbesondere auch die thomistische Scholastik. Das Sein der Kreatur bezeichnete sie darum als ein "mitgeteiltes" Sein. Das aber verstand sie in dem Sinne, daß, wie das Wesen des Endlichen ein Abbild der Ideen ist, so auch ihr Sein eine schwache Nachahmung des göttlichen Seins, ein von der göttlichen Macht getragenes und erhaltenes Analogon zu dem göttlichen Sein darstelle. Weiter geht Eckhart, auch hier an Avicenna (und den Pseudo-Areopagiten) sich anschließend. Das Sein, durch welches die endlichen Dinge sind, ist bei Eckhart nicht ein Analogon des göttlichen Seins; es ist vielmehr das göttliche Sein selber, das Überströmen des göttlichen Seins. Alles Seiende ist seiend durch das Sein, und dieses Sein ist Gott, führt er in seiner großen lateinischen Schrift aus, ein Satz, an welchen übrigens auch bei Wilhelm von Auvergne und sonst vereinzelt in der Scholastik gewisse Anklänge sich finden. Darum aber fallen gleichwohl Gott und Kreatur nicht zusammen. Denn das, worin das Wesen der Kreatur an sich besteht, die bloße Möglichkeit, daß bloße Nichts, affiziert das alles zum Dasein rufende göttliche Sein, welches mit dem göttlichen Wesen sachlich identisch ist, nicht auch seinerseits innerlich. Obwohl alles in Gott ist, bleibt er doch selbst von der Unvollkommenheit der Kreatur unberührt. - Es ist begreiflich, daß diese nur aus Eckharts philosophischen Begriffen verständliche Auffassung bei Freunden wie bei Gegnern vielfache Mißverständnisse gefunden hat. Sehr genau hat sie Nikolaus von Kues erfaßt. Für ihn ist sie ein wesentlicher Bestandteil des eigenen Systems geworden.

Über die Natur der Seele, über ihr Verhältnis zum Leibe und die Architektonik ihrer Kräfte denkt Eckhart in allem Wesentlichen wie Albert und Thomas, wenn auch gewisse augustinische Elemente bei ihm stärker hervortreten als sonst in der Dominikanerschule. Anders wird dies, wenn das Verhältnis zur Sprache kommt, in dem die Seele zu Gott in der inneren Schauung steht. Ein doppeltes Antlitz hatte Algazel der Seele zugeteilt, das eine nach oben gerichtet, das andere dieser Welt zugekehrt; und auch die augustinische Mystik hatte Ähnliches verkündet. Eckhart beruft sich auf den „heidenischen Meister" und auf „St. Augustin", um seine Lehre vom Seelengrunde oder dem Seelenfünklein zu entwickeln, worin die von allem Äußeren sich abkehrende Seele zu bildloser Schauung Gottes gelangen soll. Hierbei aber nimmt seine Spekulation eine Wendung, durch die er im Anschluß an die neuplatonische Mystik des angeblichen Areopagiten und noch über diesen hinaus von der thomistischen und augustinischen Psychologie weitabgeführt wird. Im Grunde der Seele, in den ihre natürlichen Kräfte nicht reichen, lehrt Eckhart, ist ein Funken göttlicher Vernünftigkeit, ein "ungeschaffenes und unschaffbares Licht", das zwar mit jenen natürlichen Kräften im Seelenwesen vereint ist, aber in sich mehr mit Gott gemein hat als mit irgendeiner Seelenkraft. Für Eckhart ist das "Seelenfünklein" ein göttlicher Kein, durch den die Seele weit über das ihren Kräften Natür- 
liche erhoben wird. Freilich kann er äußerlich seine Gedanken an die scholastischen Lehren von der wirkenden Vernunft und der Synteresis, an das Vermögen intuitiver Schauung bei Hugo von St. Victor und insbesondere an die Mystik Richards von St. Viktor vom Seelengrunde anknüpfen. Findet sich doch selbst der Ausdruck „Seelenfünklein“ (scintilla animae) auch bei Bonaventura und Thomas. Aber der "ungeschaffene Funke" Eckharts will doch mehr sein als dies. Er gemahnt uns an Plotin, an gewisse gnostische Vorstellungen von einem der höheren Welt entstammenden Lichtkeime in den Seelen der Pneumatiker, an kabbalistische Ideen von einem göttlichen Heiligtume als Sitz Gottes in der Seele. Eine andere Überlieferung bricht hier durch, die trotz der zuletzt von Eckhart gemachten Anstrengungen sich der kirchlichen Scholastik nicht restlos einfügen ließ.

Eckharts Ethik. Im Seelengrunde läßt Eckharts Mystik mit dem Areopagiten die geheimnisvolle Vereinigung der Seele mit Gott sich vollziehen. Nach der Abkehr von allem Außeren und Bildhaften, woran Sinne, Einbildungskraft und Verstand gebunden sind, nach dem Abschied von aller selbstischen Eigenheit, geht die von Gott gerührte Seele, wie Paulus, in einen Zustand der Entzückung ein. In jenem ungeschaffenen Lichte, das als „Seelenfunke“ ihr eingepflanzt ist, wird sie bis in den Grund aller Dinge entrückt, noch über den Unterschied der göttlichen Personen hinaus, bis in die "stille Wüste“ des göttlichen Wesens oder der "Gottheit", in die kein Unterschied hineinscheint, sondern wo alles in seliger Einheit verbunden ist. Der Seelengrund geht in den göttlichen Grund ein, der, selber unbeweglich, allem Bewegung und Leben verleiht. So wird in der mystischen Schau die Seele selbst in das Ewige, Unveränderliche, Zeitlose hineingestellt. Hier vollzieht sich die ewige Geburt des göttlichen Wortes als Wiedergeburt. Die Seele wird christförmig und Christus in dem Frommen wiedergeboren. Auch äußere Werke sind von Wert, aber nur als Vorbereitung. Zurück tritt auch die Betrachtung des Leidens Jesu, die, wie z. B. bei Ubertino von Casale (mit dessen „Baum des gekreuzigten Lebens" Dante manche Berührungen aufweist), nach dem Vorgange Bernhards von Clairvaux den Hauptinhalt der franziskanischen Mystik bildet. Eckharts Mystik ist eine rein intellektualistische. Intellektualistisch ist die Art, wie er nicht nur philosophisch die Welt zu begreifen, sondern auch das persönliche religiöse Erlebnis, die Unmittelbarkeit des religiösen Ergriffenseins, zu deuten sucht. Darin ist er seiner besonderen scholastischen Richtung, im Gegensatz zur franziskanischen Scholastik, getreu geblieben.

Die von Eckhart begründete spekulative deutsche Mystik wird fortgeTauler. setzt von Tauler, dem gewaltiger Prediger in Straßburg ( Seuse. dem sinnigen Heinrich Seuse (Suso, +1366 zu Ulm). Doch suchen beide die pantheistische Färbung der Eckhartschen Metaphysik und Psychologie abzustreifen und legen überhaupt mehr Gewicht auf das Praktische als auf das Spekulative. Noch mehr gilt letzteres von den vielen anderen Vertretern der Mystik in Köln, Freiburg, Straßburg - wo Rulman Merswin († 1382) sein 
Buch von den neun Felsen schrieb -, Unterlinden bei Colmar und sonst. Auch in spekulativer Hinsicht nicht unbedeutend ist dagegen der große vlaemische Mystiker, der „doctor ecstaticus“ Jan van Ruysbroeck, der ebenso die Verirrungen der begardischen Richtung bekämpft, wie er mit den oberdeutschen Mystikern in regem Gedankenaustausch stand.

Auch in den romanischen Ländern besteht die Mystik fort, hier mehr in b) Romanische der Form, welche die Viktoriner und Bonaventura ihr gegeben hatten. Auf Mystik. Bonaventura verweist der in der Philosophie der nominalistischen Erkenntnislehre huldigende Johann Gerson († 1429) als auf den besten Lehrer, wie Gerson. in der Theologie, so auch im mystischen Geistesleben.

IX. Übergang zur neuern Zeit; Nikolaus von Kues. Am Ausgang der mittelalterlichen Philosophie, soweit sie noch den Trieb selbständiger Weiterbildung hat, steht Nikolaus von Kues (140I-64). Für das Gebiet der Verstandeserkenntnis einer nominalistischen Erkenntnislehre zugetan, welche das Wissen nur zu „Konjekturen“ gelangen läßt, versenkt er sich zugleich mit Dionysius, Bonaventura und Meister Eckhärt in das dem Begriff unerfaßliche Unendliche, in dem nach Dionysius die Gegensätze sich einen (coincidentia oppositorum), und gelangt so mit Augustin zu der Forderung des „gelehrten Nichtwissens", der docta ignorantia. Seine Metaphysik verbindet die mannigfachsten Elemente des mittelalterlichen Denkens, erhält aber ihr charakteristisches Gepräge durch den Anschluß an Meister Eckhart, sowie an Plato und den ihm bereits in weiterem Umfange bekannten Neuplatonisnıus. Kündigte das letztere schon von ferne die humanistische Renaissance an und läßt uns in Nikolaus den Mann des Übergangs ahnen, so bringt die umfassende mathematische und astronomische Bildung des $\mathrm{Ku}$ saners als bedeutsames Glied in der Entwicklung der mathematischen Wissenschaften, von denen aus der alte Wissensbegriff und der alte Wissenschaftsbetrieb sich umgestalten sollten, ein völlig Neues. Einerseits führt sie zu metaphysisch-geometrischen Spekulationen, die in neuer 'Weise alte theologische und philosophische Fragen 1ösen wollęn. Andererseits aber führt sie zugleich zu einem völlig veränderten astronomischen Weltbild und durchbricht damit die aristotelische Weltanschauung, die so viele Jahrhunderte die Naturbetrachtung beherrscht hatte. Von dem allgemeinen Bewegungsgesetz des Universums kann auch unsere Erde nicht ausgenommen sein; sie ist einer unter zahllosen bewegten Sternen. Aber nicht nur die Erde, auch unsere Sonne. Damit war der Blick in das Unermeßliche erweitert, weit über den Fixsternhimmel hinaus, von dem noch später der geniale Kopernikus unser Sonnensystem begrenzt sein ließ. Der Kusaner führte zu der Schau, von der aus eine neue Welt zu entdecken war. 


\section{Literatur.}

Der schulmäßige Zug und das harmonisierende Streben der mittelalterlichen Denkweise brachten es mit sich, daß in älterer wie in neuerer Zeit (SUARE.Z, VAZQUEZ usw.) die scholastischen Schriftsteller ihre sachlichen Erörterungen mit manchmal noch jetzt nützlichen doxographischen Übersichten zu dem jedesmaligen Problem verbunden haben. - Die biound bibliographische Untersuchung, überhaupt das Literaturgeschichtliche, wurde gefördert durch OUdin, FABRICIUS, ECHARD und QUÉTIF, WADDING, die Histoire littéraire de la FRANCE, GRÖBER, DENIFlE, EHRLE u. a. Zu Quellenuntersuchungen reizten vor allem die Schätze der Pariser Bibliotheken; A. Jourdain, Cousin, Rousselot, HaURÉAU, dann Jeiler, Denifle, Ehrle, De Wulf, Mandonnet, Baeumker, Grabmann u. a. haben dieselben gefördert. Die von BAEUMKer in Verbindung mit von Hertling und BAUMGARTNER herausgegebenen „Beiträge" suchen die Kräfte zu vereinen. Die historische Synthese folgte; $u$. a. haben sich Haureau, Ch. Jourdain, REmusat, Ritter, Ueberweg und seine Fortsetzer, Kaulich, Prantl, Werner, Stöckl, Picavet, De Wulf, Siebeck, ManDONNET, GRABMANN, ENDRES dafür verdient gemacht. Ich lasse die Titel einiger noch jetzt nützlicher oder doch zu ihrer Zeit bedeutungsvoller Werke folgen.

Für das Literarische und die äußere Geschichte: J. A. FABRICIUS, Bibliotheca Iatina mediae et infimae latinitatis (1734, neueste Ausg. 1853). G. GRÖBER, Abriß der lateinischen Literatur des Mittelalters (1897). E. NoRDEN, Antike Kunstprosa II ('21909). M. Manitius, Gesch. d. lat. Lit. d. Mittelalters' I (I9I I). Denifle-Chatelain, Chartularium Universitatis Parisiensis (1889ff.). DENIFLE, Die Universitäten des Mittelalters bis 1400. I (1885). H. FELDER, Geschichte der wissenschaftlichen Studien im Franziskanerorden bis um die Mitte des 13. Jhdts. (1904), und dazu F. X. Seppelt in: Kirchengesch. Abhandl., hrsg. von Sdralek, IV (1906).

Darstellende Werke und Quellenuntersuchungen: V. Cousin, Fragments de philosophie de moyen.âge (zuerst in Ouvrages inédits d'Abélard, 1839). RousSELor, Études sur la philosophie dans le moyen-âge (1840-42). RITTER, Geschichte der Philosophie VII. VIII (I844f.). B. Hauréau, De la philosophie scolastique (1850); Histoire de la philos. scol. (1872-80); Notices et extraits (1890-93). W. KaULICH, Gesch. d. scholast. Philos. I (1863). A. StöckL, Gesch. d. Philos. d. Mittelalters (1864-66). J. E. Erdmann, Gesch. d. Philos. I ( ${ }^{4} 1897$, bes. von Benno Erdmann). Ueberweg-Heinze, Grundriß der Gesch. d. Philos. II ( ${ }^{8}$ 1905). Windelband, Gesch. d. Philos. $\left({ }^{5}{ }^{1912}\right)$. M. DE Wulf, Histoire de la philosophie médiévale ( ${ }^{4}$ I912). Introduction à la philosophie néo-scolastique (1904). PICAvet, Esquisse d'une histoire générale et comparée des philosophies médiévales ('1907). CH. Jourdain, Excursions historiques et philosophiques à travers le moyen-âge (1888). R. LANE PoOLE, Illustrations of the History of medieval Thought (1884) K. WERNER, Die Scholastik des späteren Mittelalters (188 I ff.). O. Willmann, Gesch. d. Idealismus. II ( ${ }^{2}$ I907). Pran'tL, Gesch. d. Logik im Abendlande. II-IV (186I-70; II² 1885). H. SIEBECK, Zur Psychol. der Scholastik (Archiv f. Gesch. d. Phil. I-III). EUCKEN, Lebensanschauungen der großen Denker $\left({ }^{8} \mathrm{I} 91 \mathrm{I}\right)$. P. MANDONNET, Siger de Brabant et l'averroïsme au XIII siècle ( ${ }^{2} 19 \mathrm{II}$; ein bahnbrechendes Werk von hohem Werte, für das aber meine Ausfuihrungen Philos. Jahrb. XXIV, I9I I. S. 369 ff. 517 ff. zu vgl.). Jos. A. EndRES, Gesch. d. mittelalterl. Philos. in christl. Abendlande (1908). H. O. TAYLOR, The Mediæval Mind. A History of the Development of Thought and Emotion in the Middle Ages (IgI I). CL. BAEUmker, Der Anteil des Elsaß a. d. geistigren Bewegungen des Mittelalters (19I2). Sehr viel Neues auf Grund der Handschriften bringt das ausgezeichnete Werk von M. Grabmann, Die Geschichte der scholastischen Methode. I-II (I909-1911). BACH, Die Dogmengeschichte des Mittelalters (1873-75). HARNACK, Lehrbuch der Dogmengeschichte. III ('igo9). SEEBERG, Lehrbuch der Dogmengeschiclıte II (1898). REUTter, Gesch. d. religiösen Aufklärung im Mittelalter (1875-77). PROSPER DE MARTIGNÉ, La scolastique et les traditions franciscaines 
(1888). G. ROBERT, Les écoles et l'enseignement de la théologie pendant la première moitié du XIle siècle (1909). I. Verweren, Das Problem d. Willensfreilheit i. d. Scholastik (1909). G. voN Hertling, Wissenschaftl. Richtungen und wissenschaftliche Probleme im 13. Jahrh. I9Io). F. Strunz, Gesch. d. Naturwissenschaften im Mittelalter (1910).

Sammlungen und periodische Publikationen: Migne, Patrologia latina, Denifle und EHRLE, Archiv f. Literatur- u. Kirchengesch. d. Mittelalters (1885-1900). BARACH, Bibliotheca philosophorum mediae aetatis (1876. 78). BAEUMKer (in Verbindung mit voN HERTLING und Baumgartner), Beitr. zur Philos. d. Mittelalters; Texte u. Untersuchungen (1 $89 \mathrm{~g}$ ff.; Bd. XII im Erscheinen). De Wulf, Les philosophes belges; Textes et Etudes (I902 ff.). TRAUBE, Quellen und Untersuchungen zur lateinischen Philologie des Mittelalters (1905 ff.).

S. 340. Benutzte Stellen: Albertus de an. I, I, 6. Scotus IV. sent. d. 43, 2. Joh. Saresb. Metal III, 4. Bacon, Op. maius I c. 3. Alanus ab Insulis, Migne, PL. 2 Io, $333 \mathrm{~A}$.

S. $347 \mathrm{ff}$. TH. HeItz, Essai historique sur les rapports entre la philosophie et la théologie de Bérenger de Tours à S. Thomas d'Aquin (1909). I. A. ENDrEs, Petrus Da. miani u. d. weltl. Wissenschaft (BAEUMKeRs Beitr. VIII, 3). Von Walters Schrift jetzt ein Teil veröffentlicht bei B. GEyER. Die Sententiae divinitatis (Beitr. VII, 2-3).

S. $362 \mathrm{ff}$. Plato im Mittelalter: CH. Huit in den Annales de philos. chrét. Sér. II. t. XX-XXII. - Aristoteles im Mittelalter: TALAMO, L'aristotelismo nella storia della filosofia $\left({ }^{8} 1900\right)$. Literarisch: A. JOURDAIN, Recherches critiques sur l'âge et l'origine des traductions latines d'Aristote ('I843). MARCHESI, L'Etica Nicomachea nella tradizione latina Medievale (1904). Für Johannes Damascenus hat DE GHELLINCK Einzelnachweise gegeben (Revue des Questions historiques 1910, Byzant. Zeitschr. 1912). - Zu S. 314 benutzte Stellen: Albertus met. I 5, I 5. Bonavent. hexaëm. 6. Heinrich von Gent, S. theol. 25, 3.

S. 366. Zur Geschichte des Gottesbeweises im Mittelalter: BaEUmker, Witelo (Beitr. III, 2) 286 ff. Arch. f. Gesch. d. Phil. XXII (1909), I32 ff. Grunwald, Beitr. VI, 3. Daniels, Beitr. VIII, I-2.

S. 37I. Die Form „Eriugena" gleichzeitig und unabhängig als richtig erwiesen von Traube und Baeumker. - Monographien über Eriugena von Staudenmaier (1834), Christ. lieb (1860), HUber (I861), Buchwald (1883), A. Gardner (1900), DrÄSEke (I902), RAND (1906). - Amalrikaner: Arbeiten von Krönlein (1847) und BAEUMkER (1893).

S. 372 f. Monographien über Roscellin von F. PICAvet (I9I1), über Wilhelm von Champeaux von Lefevre (1898); über Adelhard von Bath von WilLner (Beiträge IV, I); über Anselm von L. Vigna (1899) Domet de Vorges (I901), A. Daniels (1909), J. Fischer (Beitr. X, 3), Fr. Baeumker (Beitr. X, 6), N. Balthasar (I912).

S. 374. Die Definition Anselms stammt aus Augustin de doctr. christ. I c. 7 n. 7 . Honorius Augustodunensis: Monographie von ENDres (1906).

S. 375. Abälard: Remusat, Abélard (1855); Deutsch, Peter Abälard (1883). ZIEGler, (1884). Denifle in seinem "Archiv" I (1885). H. LigeARD, Le rationalisme de Pierre Abélard (1911). Eine Ausgabe der wiederaufgefundenen schon von Rémusat benutzten wichtigen Glossen Abälards von J. Geyer ist zu erwarten.

S. 375f. Rolands Sentenzen hrsg. von M. GietL (189I), Sentenzen aus der Schule Gilberts von B. GEYER (Beitr. VII, 2-3). - Über Otto von Freising als Philosophen Arbeiten von Schmidlin (1904. 1906); über Hugo von St. Victor von LiebneR (1832), Hauréau (1 859), Ostler (Beiträge VI, I), BertazzI (I9I 2); über Thomas Gallus von DENIFLE (Z. f. kath. Theol. 1882); über die Schule von Chartres: Clerval, Les écoles de Cliartres au moyen-âge (1895) und E. NorDEN, Antike Kunstprosa ( $\left.{ }^{2} 1909\right)$, S. 724 f. - SchaARSCHMIDT, Johannes Saresberiensis (1862). Neue Ausgabe von Johannes „Policraticus" durch WebB (1909). - Des Petrus Compostellanus Schrift De consolatione rationis hrsg. von PEDRo Blanco (Beiträge VIII, 4).

S. 377. Alanus: Monogr. von Baumgartner (Beiträge II, 4).

S. $377 \mathrm{ff}$. VAt. Rose in Hermes I (1886). WÜSTENFFLD, Die Übersetzungen arabischer Werke ins Lateinische (1877). STEINSCHNEIDER, Die hcbräischen Übersetzungen des Mittel- 
alters (1893). BRown, Michael Scott (1897). BAEUmker, Ausgabe von Avencebrols Fons vitae (Beiträge I, 2-4). Gutrmann, Die Scholastik des' 13. Jahrhunderts in ihren Beziehungen zum Judentum und zur jüd. Literatur (1902). BARDENHEWER, Die pseudo-aristotel. Schrift über das reine Gute (1882).

S. $379 \mathrm{f}$. Wie das Mittelalter die Autoritäten harmonisierend umbiegt, zeigt trefflich G. v. Hertling, Augustinus-Zitate bei Thomas von Aquin (Sitzungsber. d. Münch. Ak. d. W. 1905).

S. 380. Gundissalinus: Monographien von Correns, BỨLOW, BAUR (Beiträge I, I, II, 3, IV, 2-3) und BaEUmker (1 899).

S. $38 \mathrm{I}$ ff. Kampf der alten gegen die neue Richtıng: EHRLE, Innsbrucker Ztschr. f. kath. Theol. XIII. Archiv für Literaturgesch. d. Mittelalters V. Prosper de MARTIGnE (s. oben); Mandonnet, Siger de Brabant et l'averroisme du XIIIe siècle I ( ${ }^{2}{ }^{1913}$ ). - Zu der Sen. tenzen- und Summenliteratur reichstes Material nach den Handschriften bei GrabmanN, Gesch. d. scholast. Methode II. - Alexander von Hales: ENDRES (Philos. Jahrb. I. 1888). Eine neue Ausgabe seines Werkes durch die Editoren in Quaracchi ist in Vorbereitung. - Matthaeus von Aquasparta: Grabmann (1906).

S. 382. Bonaventura: Auch durch sachliche und philosophiegeschichtliche Erläuterungen ist von großem Wert die neue Ausgabe von Fidelis a FANNA, IgNatius JeILER und Hyacinth Deimel (Quaracchi 1882-1902). - Heinrich von Gent: DE Wulf, Histoire de la philosophie scolastique dans les Pays-bas (1895).

S. $383 \mathrm{ff}$. Siger von Brabant: Monographien von BaEumker (Beitr. II, 6), MaNDONnet (in Philos. belges VI-VII. Dazu Mandonnet in Revue thomiste I9i I und BaEumKER in Philos. Jahrb. I9II), und B. NARDI (I9I2); Artikel von DONCCEUR (Rev. des sciences phil. et théol. 1910). - Albert: Monographien von SIGHART (1857), voN HERTLING (1880; die erste kritische Arbeit für Albertus), SCHNEIDER (Beiträge IV, 5-6), FronOBER (1909), H. Stadler (I9II), H. Lauer (I9II), Gaul (Beitr. XII, I). Zur Biographie P. DE Lö̈ (Analecta Bollandiana XXIX-XXXI). Das Geburtsjahr 1207 nach MANDONNET und ENDRES. - Über Hugo von Straßburg und Ulrich von Straßburg Genaueres durch PFLEGer und Grabmann (Z. f. kath. Theol. 1904. 1905), sowie Cl. Baeumker, Der Anteil des Elsaß a. d. geistigen Bewegungen d. Mittelalters (1912). Über Grosseteste FELTEN (1887) und STEveN. SON (1899). Ausgabe seiner philosophischen Schriften von L. BaUR (Beitr. IX).

S. 384. H. Grauert, Magister Heinrich der Poet und die römische Kurie (Abh. d. Münch. Ak. d. Wiss. 1912), S. 110-139.

S. 386. Thomas von Aquino: Ch. Jourdain, La philosophie de St. Thomas d'Aquin (1858). K. Werner, Der hl. Thomas von Aquin (1858f.). Gonzalez, Die Philos. d. hl. Thomas von Aquin, deutsch von Nolte (1885). I. A. ENDRES, Die Zeit der Hochscholastik. Thomas von Aquin (1910). M. Grabmans, Thomas von Aquin. Eine Einführung in seine Persönlichkeit und Gedankenwelt (1912). Cosmus AlamannuS, Summa philosophiae ex variis D. Thomae Aquinatis libris in ordinem cursus philosophiae accommodata, neu hrsg. von Bringmann u. a. (1888ff.). E. Plassmann, Die Schule des hl. Thomas von Aquino (1857-62). Anderes von Dummermuth (1886), Eucken (1886), Adeodatus (1887), Gardair (1892-1901), P. Mandonnet (1910), Mausbach (I9II), D. Prümmer (Igil), Renz (Beiträge $X, 1-2$ ), Kuhllmann (1912), JansSen (I9I2), Steinbüchel (Beitr. XI, I) usw. Nuitzlich ist SCHÜTZ, Thomas-Lexikon $\left({ }^{2} 1895\right)$.

S. 390. Bafumker, Das Problem der Materie in der griech. Philos. (1890). - Über die scholastische Frage nach der Einheit der Form: DE WULF, Les philosophes belges I, Introduction.

S. 393. Glossner, Das Prinzip der Individuation nach der Lehre des hl. Thomas (I 887).

S. 398. Die Frage nach der Möglichkeit der Weltewigkeit bei Maimonides, Albert und Thomas: ROHNer (Beit. XI, 5).

S. 399. Ethik: Mausbach, Ausgewä! te Texte zur allgem. Moral aus den Werken des hl. Thomas von Aquin (1905). - Vollkommenheit des christlichen Lebens nach Thomas; DENifLe, Luther I (1904), S. I 43 ff. 
S. 40I. Grabmann, Die Lehre des hl. Thomas von Aquino von der Kirche als Gottes. werk (1903).

S. 403. Baumann, Die Staatslehre des hl. Thomas von Aquino (1873). Monographien von Thömes (1875), WALTHER (Das Eigentum nach Thomas von Aquino [1895]). F. Schaub (1898) und M. MAURENBRECHER (1898).

S. 406. Ägidius von Lessines: DE WULF (Les Philosophes belges I). Gottfried von Fontaines: DE WUlF und A. Pelzer (Les Philos, belges II).

S. $407 \mathrm{f}$. Dante: Monographien von SCARTAzZini, HetTinger, Kraus, Vossler, H. KELSEN; zu seiner Philosophie auch NARDI, Sigieri di Brabante nella Divina Commedia (1912).

S. 408. Hervaeus: KreBS (Beitr. XI, 3-4). Suarez: Werner, Franz Suarez und die Scholastik der letzten Jahrhunderte (1861. 1889).

S. 408. Bacon: Ausgaben von Brewer, Bridges, Nolan und Hirś's, DUHem, Steele, Rashdall; Monographien von Charles (I86I), VOGL (IgO6), LONGWEll (I9IO), HövER (IgII), MANSER (I9I2).

S. 4Io. Meister Dietrich von Freiberg: KREBS (Beiträge V, 5-6), mit Nachtrag Revue néo-scol- XVIII, 1911, 516 ff.). Witelo: BAEUMKer (Beiträge III, 2 und dazu hinsichtlich des Biographischen die Nachträge Histor. Jahrb. XXXIII, 1912, S. 359 ff.).

S. 410ff. Scotus: SeEberg, Die Theologie des Johannes Duns Scotus (1900). Über seine Willenslehre KaHL, Die Lehre vom Primat des Willens bei Augustinus, Duns Scotus und Descartes (1886). SIEBECK (Z. f. Phil. u. phil. Kritik 112) und MINGeS (Beiträge V, 4 und VII, I) und: der Gottesbegriff des Duns Scotus (1906). Die spekulative Grammatik des Scotus neu herausg. von GarcIA (1902). Von demselben ein Lexicon scholasticum philosophico-theologicum zu Scotus (1910).

S. 417. Petrus Hispanus: STAPPER, Papst Johannes XXI. (1898). Lullus: O. KeICHeR (Beitr. VII, 4-5).

S. 418. Aureoli: DreILING (Beitr. XI, 6). Occams Erkenntnislehre: SIEBECK, Archiv f. Gesch. d. Philos. X. Kuhtmann, Zur Geschichte des Terminismus (I9II).

S. 421. Benutzte Stellen: Aegid. I sent. d. 37 ps. 2 princ. I q. 2; Eckehart bei Fr. PFEIfFER, Deutsche Mystiker, II 474, 32.

S. 422. Nicolaus von Autrecourt; RAShDall (1907), LAPPE (Beitr. VI, 2).

S. $423 \mathrm{ff}$. Mystik: A. JUNDT, Histoire du panthéisme populaire au moyen-âge (1875). Preger, Gesch. d. deutschen Mystik (1785-92). H. DelacrorX, Essai sur le mysticisme en Allemagne au XIVe.s. (1900). CL. BAEUMKer, Der Anteil des Elsaß a.d. geist. Bewegungen d. Mittelalters (1912). - Blumenlesen: Denifle, Das geistliche Leben (1873); A. Spamer, Texte aus der Mystik des 14. u. 15. Jhdts. (1912).

S. 423. Eckhart: Arbeiten von BACH (1864), LASSON (1868), Denifle (sein Archiv II), Jostes (1895), Pummerer (1903), Ph. Strauch (1912), und (uber die Handschriften) O. Simon (1906), A. Spamer (Braunes Beitr. z. Gesch. d. deutsch. Sprache u. Lit. 1908), E. Diederichs (1912); Ausgaben von Pfeiffer, Sievers, Birlinger, Jostes, Butrtner und Ph. Strauch.

S. 425. Für das Verhältnis des Cusaners zu Eckhart von Bedeutung: E. VANSTEENBERGHE, Le „De Ignota Litteratura" de Jean Wenck de Herrenberg contre Nicolas de Cuse (Beitr. VIII, 6).

S. 426. Tauler: Denifle, Das Buch von geistl. Armuth, bisher bekannt als Joh. Taulers Nachfolgung des armen Lebens Jesu (1877). Vorläufige Ausgabe des echten Tauler von F. VeTter (Deutsche Texte XI. 19lo). Monographien von C. SCHMIDT (1841), Denifle (1879), Siedel (1911). - Suso: Ausgaben von Diepenbrock, Denifle, ScholZ und BiHLMEYER (1907). - Merswin: K. RiedER, Der Gottesfreund vom Oberland eine Erfindung des Straßburger Johanniterbruders Nikolaus von Löwen (1905). - P. P. STRAUCH, Margaretha Ebner u. Heinrich v. Nördlingen (1882). 


\section{Nachträge zum zweiten Abdruck.}

Die überaus reiche Arbeit der letzten Jahre auf dem Gebiete der mittelalterlichen Philosophiegeschichte galt nicht nur einzelnen Philosophen in großer Zahl, sondern brachte auch mancherlei Neues für umfassendere Kollektiverscheinungen und Gesamtbewegungen. So für die Rezeption der Aristotelischen Schriften im Abendlande, wo der Weg über die byzantinische Welt (einschließlich des sizilischen Reiches) gegenüber dem über die arabische sich als bedeutungsvoller und weit eher einsetzend herausstellte, als früher angenommen wurde, und als Gegenstück dazu für die auch im Hochmittelalter andauernde platonische bzw. neuplatonische Seitenströmung, die in der von mir so genannten "Lichtmetaphysik" einen besonders charakteristischen Zug aufweist. Im Zusammenhange damit trat auch deutlicher die Art der "artistischen" Philosophie - der Philosophie der philosophischen Fakultät — nach ihren Zusammenhängen mit mathematisch-naturwissenschaftlichen und medizinischen Studien hervor, als dieses bei der früher vielfach üblichen Beschränkung auf das an Bedeutung freilich weitaus überwiegende zugleich theologisch orientierte Denken möglich war. Dies kam denn auch der Erkenntnis des spätmittelalterlichen Nominalismus in seiner vorbereitenden Bedeutung für die neuere Philosophie (insbesondere in erkenntnistheoretischer Hinsicht) und die neue Naturwissenschaft zugute.

Wie das Gesamtbild der mittelalterlichen Philosophiegeschichte durch die unermüdliche Quellenarbeit der letzten vier Dezennien, die vor aller hicr nicht seltenen, wenn auch noch so geistreichen apriorischen Konstruktion und vor einer romanhaften Phantasieeinfühlung in den mittelalterlichen Geist sich zu bewahren hatte, sich in vielem Einzelnen völlig neu gestaltet hat, zeigen die ausgezeichnete Neubearbeitung von FR. UEBERWEG's Grundriß der Geschichte der Philosophie der patristischen und scholastischen Zeit ( ${ }^{10}$ 1915) durch M. BAUMGaRTNER (mit reichsten Literaturnachweisen) sowie die kurze, aber inhaltreiche Dar. stellung von M. (iRabmann, Philos. d. Mittelalters (1921). Ebenso die treffliche neue (2.4.3.) Auflage des das Mittelalter behandelnden III. Bandes des Lehrbuchs der Dogmengeschichte von R. Seeberg (1913). Andere Gesamtdarstellungen: J. M. Verweyen, Die Philosophic des Mittelalters, nach l'roblemen dargestellt (1917, $\left.{ }^{2} 1921\right)$, und W. KINKEL, Allgemeine Gesch. d. Philos. II. Das Ringen um Gott im Mittelalter (1921). Seiner vergleichenden Geschichte der mittelalterlichen Philosophieen hat Fr. PICAveT zur Erläuterung und Begründung Essais sur l'histoire générale et comparée des Théologies et Philosophies Médiévales (1913) folgen lassen. Von M. DE WULF's Histoire de la Philosophie Médiévale erschien eine deutsche Übersetzung durch RUD. EISJ.ER (1913), von R. L. POOLE's Illustrations of the History of Medieval Thought eine (yerkürzte) 2. Aufl. (1920). Die „Ehrentitel der scholastischen Lehrer" stellt FR. EHRLE erläuternd zusammen (S.-B. d. Münch. Ak. 1919). - Zur P sychologie der mittel. alterlichen Scholastik und Mystik bietet W.WORRINGER, Formprobleme der Gotik ( ${ }^{8-12}$ 1920), $114 \mathrm{ff}$. interessante, wenn auch nicht in allem zutreffende Betrachtungen, denen die verwandte Analyse des an Notker Labeo erläuterten "Mittelalterlichen Menschen" durch P. TH. HoFF. MANN (1922) angereiht sein möge. - Zu bestimmten Disziplinen: E. HochsteTter, Die subjektiven Grundlagen der scholastischen Ethik (1915), und das wichtige Werk von R. W. und A. J. CARlye, A History of Medieval Political Theory in the West, I 1903, II 1906, III 1916. 
Zu den Aristoteles. Übersetzungen und der Rezeption des Aristoteles: literarisch - außer H. Denifle (Chartular. Univers. Parisiens.) und P. Mandonnet (Siger de Brabant 'I, I9II) - : L. BAUR, Grosseteste (19I2); CL. BAEUMkER, Die Stellung des Alfred von Sareshel (1913), S. 26-48; M. Grabmann, Forschungen über die lateinischen Aristotelesübersetzungen des XIll. Jahrhunderts (I916. Beitr. 2. Gesch. d. Phil. d. M.-A.-s. XVIl 5-6; Hauptwerk); Abhandlungen von Parthenius Minges (Philos. Jahrb. 1914), CH. H. HaSkins (Harvard Studies I914), Cl. BaEUMker (Philos. Jahrb. 1914) und B. Geyer (ebd. 1917). Ide en. geschichtlich: A. SCHNEIDER, Die abendländ. Spekulation des XII. Jhdts. in ihrem Verhältnis zur aristotelischen und jüdisch-arabischen Philosophie (1915. Beitr. XIII, 4). - Zur platonischen Strömung: Cl. BaEumKer, Jer Platonismus im Mittelalter (1916). Zusammen. fassend: $\mathrm{CH}_{\mathrm{H}} \mathrm{H}$. Haskins, The Greek element in the Renaissance of the Twelfth Century (American Historical Rev. 1920). Zu den neuplatonischen Quellen (S. 368): Einfluß des Makrobius: M. Schedler (1916. Beitr. XIl, I). - Die für die Entwicklung der scho. lastischen Methode bedeutsame Wechselwirkung von Theologie und kanonischem Recht behandelt neben anderen Fragen J. DE GHELLINCK, Le mouvement théologique du XIle siècle (1914). Über naturwissenschaftliche und nominalistische Bewegung.s. unten.

Wichtigere Arbeiten zu Einzelerscheinungen: A. Zur Zeit der werdenden Scholastik (S. $360-377$ ).

J. A. ENDres, Forschungen zur Gesch. d. frühmittelalterl. Philosophie. (1915. Beitr. XVII, 2-3). - Eriugena (371): A. SChNEIDER, Die Erkenntnislehre des Joh. Eriugena (1921). Honorius Augustodonensis (374): Fr. BAEUMker (1914. Beitr. XIII, 6). - Abaelard und seine Zeit (S. $375 \mathrm{f}$.): B. GEYER, Die Stellung Abaelards in der Universalienfrage, nach neuen handschriftl. Texten (1913. Beitr. Suppl.-Bd. IOI-I28. Die zwischen Nominalismus und Realismus vermittelnde "Status"-Lehre ist schon von Abaelard ausgebildet). Von einer Ausgabe bisher unedierter logischer Schriften Abaelards (zweier der "Dialektik" als drittem voraufgehender logischer Kurse) nach Hss. in Mailand und Lunel bisher zwei Hefte (Beitr. XXI, 1919. 1921). - Für die noch ganz auf augustinischer Grundlage ruhende Sentenzenliteratur der Frühzeit: Fr. BlienetZRIEDER, Anselms von Laon systematische Sentenzen (19I9. Beitr. XVIII, 2-3). - Richard von St. Viktor (376): J. EBNER (i917. Beitr. XIX, 4). - Johann von Salisbury (376): Über s. Erkenntnispsychologie A. SCHNEIDER (1913, Festschr. Hertling. Frühınittelalterlicher Platonismus und Naturwissenschaft (S. 377): Den an den Timaeus an. knüpfenden Liber de naturis inferiorum et superiorum des Daniel von Morley gab der für die Geschichte der mittelalterlichen Medizin und ihrer wissenschaftlichen Zusammenhänge hochverdiente K. Sudhoff heraus (Arch. f. Gesch. d. Naturwiss. u. d. Technik VIlI). Dazu A. BiRKenMajer, Eine neue Hs. des Liber etc. (ebd. IX, 1920).

B. Zur Zeit derentwickelten Scholastik (S. 377-427). II. Augustinische The ologie und aristotelische Philosophie (S. 38I ff.) - Kritiscle Ausgabe der Sentenzen des Petrus Lombardus von den Franziskanern in Quaracchi (1916), von denen auch eine solche der Summa des Alexander von Hales erscheint. - Bonaventura (382): E. LUTz (Asthetik) und L. BAUR (Naturrecht) I913 (Beitr. Suppl.-Bd.). Anderes: Bonaventura.Heft der Franzisk. Studien 1921. - Für die mittelalterliche Psychologie vermittelt Hieron. Spetrmann nähere Bekanntschaft mit dem Gegner des Thomas von Aquino John Peckham (1917, 1918, 1919. Beitr. XIX. XX. Franz. Stud. II). - Siger von Brabant (S. 383): MI. ChossaT, St. Thomas d'Aquin et Siger de Brabant (Rev. de phil. 19I4). Cl. BAEUMKER, Alfred v. Sareshel S. $15 \mathrm{ff}$. M. Grabmann, Echte Schriften des h. Thomas v.A.S. 140 ff. - Die Werke des Siger von Courtrai herausg. von G. Wallerand (1913. Philos. belges VIl1). - Klärung und Erweiterung erfuhr insbesondere das Bild Alberts des Großen (S. 384 f.): Fr. PangerL, Studien über Albert d. Gr. (1912). M. Grabinann, Drei ungedruckte Teile der Summa de creaturis. Aus den Hss. nachgewiesen und gewürdigt (1919; Albert als Dogmatiker und Systematiker der Moral vor Thomas). Fr. PEISTER, Kritische Studien zum Leben und zu den Schriften Alberts d. Gr. (1920. Dazu 1920 u. 1921 Nachweis weiterer Werke Alberts: De natura boni und De inquisitione haereticorum). Kritische Ausgabe von De animalibus nach dem Auto-

Die Kultuk der Gggenwakt. I. 5. 2. Auf. 
graph (mit Quellennachweisen und zoologischen Bestimmungen) von G. STADIER (I916. 192 I. Beitr. XV. XVI). Daß daǵegen die Philosophia pauperum (an deutschen Stadtschulen beliebter Physikabriß) dem Albert von Orlamünde gehört, zeigte M. GRABManN (1918. Beitr. XX, 2), der auch die dem greisen Albert zugeschriebene praktisch-mystische Schrift De adhaerendo Deo als Werk des oberpfälzischen Benediktiner's Johann von Kastl (um 1410) erwies (Tüb. Quartalschr. 1920). - G. v. HeRTling's Albertus Magnus erschien in 2. Aufl. 1914 (Beitr.XIV, 5.6).

III. Thomas von Aquino (S. 386-407). - Literarhistorisches: P. MANDonNeT et J. Destraz, Bibliographie thomiste (1921. In der Einleitung Chronologie des Lebens und der Werke). Zur Biographie: D. PrÜmmer, Fontes vitae S. Thomae (1911 ff., als Beigabe zur Revue thomiste). Zur Quellenfrage Abhandlungen von MiAndonnet (1912), PrümmeR (1912), Pelster (1920). Anderes Biographische von Mandonnet (1914), Grabmann (1920), Birkenmajer (Beitr. XX, 5). Beziehung zu Siger v.Brabant s. oben. - Werke: Die (in den späteren Bänden vortreffliche) neue römische Ausgabe hat die Summa theol. vollendet und die S. cont. gent. nach dem Autograph gebracht. Einführung in die S. theol. von M. GRAB MANN (1919). Echtheitsfragen, Chronologie usw.: A. MichelitsCH, Thomas-Schriften (1913). 1'. Manionnet, Les écrits authenthiques de S. Thomas d'A. ('1910). M. Grabmann, Die echten Schriften des hl. Th. v. A. (1920. Beitr. XXll, 1-2). - Sachliches: E. RolfeS, Die Philosophie von Thomas v. A. (1920; systematische Anthologie in Übersetzung). E. GILSON, Le thomisme (1920). PH.WicksteEd, The reaction between Dogma and Philosophy illustrated from the works of Thomas Aquinas (1921). G. SchulemanN, Das Kausalprinzip in d. Philos. des h. Th. v. A. (1915. Beitr. XIII, 5). - Wahrheitsbegriff: M. Baumgartner (1913. Beitr., Suppl.-Bd.). Zeit und Ewigkeit: Fr. Beemelmans (1915. Beitr. XVII, 1). - A. D. Sertillanges, La philos. morale de St. Th. d'A. (1916). W. MülLER, Der Staat in seinen Beziehungen zur sittl. Ordnung bei Th. v. A. (1916. Beitr. XIX, I). O. Schilling, Das Völkerrecht nach Th. v. A. (I919). Vgl. auch E. TröltSc.H, Die Soziallehren der christl. Kirchen u. Gruppen (1908. 1909. Gesammelte Schriften 1. 1912).

Zu S. 406. Kampt um die Lehre des Aquinaten in den ersten fünfig Jahren nach seinem Tode: Abhandlungen von Ehrle (1913), Mandonnet (1913), Grabmann (1912). - Gottfried von Fontaines: Von den Quodlibeta Bd. Il, herausgegeben von DE WULF und J. Hoffmans (1914, Philos. belges 111 ). Sein Intellektualismus: DE Wulf (1913. Beitr. Suppl..Bd.). - Dante: Bei Gelegenheit des Dante-Jubiläums von 1921 wurde Dante auch als Scholastiker und Mystiker in zahlreichen Abhandlungen gefeiert.

IV. Die naturwissenschaftliche Richtung (S. 407-410). - Zu S. 408. Alfred von Sareshel: Cl. BAEumker, Die Stellung des Alfred von Sareshel (Alfredus Anglicus) u. seiner Schrift I)e motu cordis in der Wissenschaft des beginnenden XIIl. Jahrh. (I9I3). - BarthoIomaeus Anglicus: A. SchneIder, Metaphysische Begriffe des B. A. (1913. Beitr. Suppl--Bd.). Robert von Lincoln: L. BAUR, Die Philosophie des Robert Grosseteste, Bischofs von Lincoln (1917. Beitr. XVIlI, 4-6). - Über Petrus Peregrinus von Maricourt (von dem eine Epistola de Magnete) Fr. Picavet, Essais (s. o.) und ERH. SchlunI) (Archiv. Francisc. hist. 1911); über den irländıschen Naturforscher und Übersetzer Michael Scottus: A. H.QuerFELD, Michael Scottus u. s. Schrift De secretis naturae (1919).

Zu S. 408. Roger Bacon: STEELE setzte die Ausgabe unedierter Schriften fort. Die vollständige Metaphysik wurde von NOGARA, PELZER, BANNISTER aufgefunden. Roger Bacon Essays, collected by A. G. LiTTLE (1914. Darin rom Herausgeber Leben und Bibliographiej. Über Bacons Naturphilosophie, insbesondere seine Universalienlehre und seine Lehre von Materie und Form, Ci.. BaEumker (1916); über seine Augustin, Aristoteles, Avi cenna verbindende Lehre vom intellectus agens O. KeICHER (1913. Beitr.. Suppl.-Bd.).

Zu S. 4 Io. Meister Dietrich von Freiberg: Weitere Handschriften-Nachweise von A. BIRKFNMAJER (Beitr. $X X, 5$. Die Schrift vom Regenbogen herausgegeben von J. WüRschmir (1914. Beitr. X1I, 5-6). - Witelo: Nachweis zweier neuer Schriften (über die Dämonen und über die Buße) und neue Lebensdaten durch A. BIRKlenMajer (1921).

V. Zu S. 410. Duns Scotus: M. Heidegger, Die Kategorien- und Bedeutungslehre des Duns Scotus (1916). - Die Unechtheit der "Grammatica speculativa" erwies M. (irabmanN (1922). 
Zu S. 411. Olivi: Über den Sinn der gegen ihn gerichteten Definition des Konzils von Vienne neue Arbeiten von B. JANSEN (1908. 1920), von dem auch auf Grund der Vorarbeiten von Fr. EhrLe eine Ausgabe der Texte im Erscheinen.

VI. Zu S. 417. Ramon Lull: 1. H. PROBST, Catactère et origine des idées du bienheureux Raymond Lulle (1912). La Mystique de Ramon Lull et l'Art de Contemplacio (1914. Beitr. XIII, 2-3, mit Ausgabe).

VIl. Der Nominalismus des späteren Mittelalters (S. 418-423). - Zusammenhänge mit der religiösen Bewegung der Reformationszeit (Luthers Entwicklungsgang), die Erkenntnis der Vorbereitung der neuen mathematischen Naturwissenschaft des 16. Jahrhunderts durch die (übrigens keineswegs ausschließlich nationalfranzösische) Nominalistenschule in Paris (neuer Bewegungsbegriff, Erdbewegung), logische Untersuchungen der Gegenwart, zu denen das Spätmittelalter Parallelen aufwies (Bedeutungslehre), Studien über die Geschichte der Universitäten (Zwei-Wege-Streit) und deren gegenseitige geistige Beeinflussung baben neuerdings dem Nominalismus des späteren Mittelalters besondere Beachtung zugewendet. Für die theologischen Zusammenhänge - außer H. HERMELINCK, Die theologische Fakultät in Tübingen 1477-1544 (1906) - : O. SCHFEL, Martin Luther, I ${ }^{3}$ (1921). Nach der naturwissenschaftlichen Seite: P. Duhem, Études sur Léonard de Vinci. Ceux qu'il a lus et ceux qui Iont lu. I-III. 1906-1913 (insbes. Buridan, Nicolas d'Oresme, Albert von Sachsen, Themo, Marsilius von Inghen). Ders. Le système du monde IV (1916). - Der Tractatus de latitudine formarum (Intensitätsbegriff) des Nicolas d'Oresme herausg. von H. WiEleItNER (1913, Bibl. math.). - K. MiCHALSKI, Les courants philosophiques à Oxford et à Paris pendant le XIV.s. (I921). GeRH. RITTER, Studien zur Spätscholastik. I. Marsilius von Inghen und die okkamistische Schule in Deutschland (1921). - Über Petrus Aureoli (S. 418): R. Dreillmg (I913. Beitr. XI, 6). Gregor von RPmini (S. 422): J. WÜRSDÖRFER (1917. Beitr. XX, 1); Johann von Mirecourt: K. Michalski (I921) und A. Birkenmajer (Beitr. XX, 5); Albert von Sachsen: A. Dyroff. (1913, Beitr., Suppl.-Bd.), A. Birkenmajer (Beitr. XX, 5), G. Heidingsfreldfr (1921. Beitr. XXl1. 3-4).

Zu S. 418 . Occam. „Venerabilis inceptor" war nach FR. EHRLE ursprünglich eine in England bei Religiosen übliche Bezeichnung für den ersten theologischen Grad vor dem Lizentiat-Magisterium (das Ockham nicht erwarb).

VllI. Die Mystik des spätern Mittelalters (S. 423-427) - J.BERNHART, Die philos. Mystik des Mittelalters von ihren antiken Urspringen bis zur Renaissance (1922). - M. GrabmanN, Neu aufgefundene lateinische Werke deutscher Mystiker (1922). PH. STrauch, Paradisus anime intelligentis (Paradis der fornuftigen sele). Deutsche Texte des M.-A.s. XXX (1919). Über Benediktinermystik dieser Zeit: M. GRabmanN (Benedikt. Monatsschr. 1920). Johann von Kastl: s. ob. bei Albert d. Gr. Kampf zwischen Intellektualismus und Irrationalismus in Tegernsee: E. VANSTEENBERGHE, Autour de la „Docte ignorance". Une controverse sur la Théologie mystique au XVe s. (19I5. Beitr. XIV, 2-4). $-\mathrm{Zu}$ dem dabei beteiligten Tegernseer Bernhard von Waging: M. Grabmann (Franzisk. Stud. VIII, 1921). - Die Bedeutung der spätmittelalterlichen Mystik in Deutschland für die zu Leibniz führende Entwicklung wurde neuestens mehrfach hervorgehoben, z. B. von P. PETERSEN, Geschichte der Aristotel. Philos. im protestant. Deutschland (1921), G. Heimsoeth, Die sechs großen Themen der abendl. Metaphysik u. d. Ausgang des Mittelalters (1922).

IX. Ubergang zur neueren Zeit (S. 427). - Nikolaus von Kues: VANSTEENBERGHE (s. o., mit Briefwechsel). Verbindung von Schoiastik und Humanismus: K. Michel. Raphael von Pornaxio (I9I 5. Beitr. XVlIl, I), 


\title{
DIE NEUERE PHILOSOPHIE.
}

\author{
Von \\ WiLhelm Windelband.
}

Einleitung. So verschieden die Ansichten darüber sein mögen, in welchen Zeitpunkt am sachgemäßesten die Grenze zwischen Mittelalter und Neuzeit zu setzen ist, so einig wird man darin bleiben müssen, als das Übergangszeitalter zwischen beiden die Jahrhunderte zu betrachten, die wir mit dem Namen der Renaissance zu bezeichnen gewöhnt sind; denn sie haben uns die beiden Momente gebracht, welche das unterscheidende Wesen des modernen Denkens bestimmt haben: das bewußte Verständnis der griechischen Begriffswelt und das methodische Schaffen der Naturforschung. Und nicht im Gegensatze zueinander sind diese beiden Momente erwachsen, sondern vielmehr in der innersten Gemeinschaft einer notwendigen geistigen Entwickelung. Diesen Prozeß zu verstehen, ist die unerläßliche Voraussetzung für das Einleben in die Motive des modernen Denkens.

\section{A. Die Philosophie der Renaissance.}

Ansichtea der Renaissance.

Die Renaissance teilt mit anderen entscheidenden Zeitaltern der Menschheitsgeschichte das Geschick, daß jedes intellektuell bewegte und erregte Geschlecht ein eigenes Verhältnis zu ihr sucht, und so sind die Vorstellungen über ihr Wesen auch heute wieder in Fluß. Schon der Name ist ja eine historische Ansicht: die Wiedergeburt soll die des klassischen Altertums sein, und die Bezeichnung bedeutet, daß diese als das Maßgebende für den wissenschaftlichen, künstlerischen, politischen und religiösen Charakter dieser Jahrhunderte betrachtet wurde. Es fragt sich, ob diese Wiedergeburt wirklich den Kern der gewaltigen Bewegung enthält, die das Leben der europäischen Völker in diesem Zeitalter durchgemacht hat, oder ob darin nur eine nebensächliche und vorübergehende Äußerung eines tieferen und unmittelbar schöpferischen Lebens zu sehen ist, die vielleicht sogar eine zu überwindende Hemmung bedeutet habe. Je mehr solche Fragen in der Gegenwart auftauchen, um so mehr muß gerade die Geschichte der Philosophie das $\mathrm{Maß}$ und die Art der Bedeutung feststellen, welche die antike Tradition für das Wesen der Renaissance besitzt. 
Gewiß war diese ein revolutionäres Zeitalter, vor allem in der Meinung ihrer Träger, die sich als Neuerer und Originale fühlten und verkündeten. Originalität Das Bewußtsein eines Bruchs mit der bisherigen Geschichte geht stark und ad historisch leidenschaftlich durch jene Jahrhunderte. Aber die historische Forschung erkennt, daß auch darin die geschichtliche Kontinuität nicht abreißt, daß auch das Kühnste und Neueste eine meist unbewußte Umbildung von Motiven ist, die schon lange bestehen, schüchtern vielleicht und still, aber desto innerlicher und kräftiger wirksam. Deshalb zeigt gerade die Renaissance, wie diese historische Kontinuität den allmächtigen Hintergrund der europäischen Geschichte bildet, und wie die modernen Völker, sie mögen sich stellen wie sie wollen, mit den Traditionen innerlich belastet sind und bleiben. Es kommen immer wieder Zeiten, in denen diese Belastung als ein unbequemer Druck gefühlt wird und mit leidenschaftlicher Spannkraft abgeworfen werden soll; aber was dann Neues heraufsteigt, läßt immer wieder bekannte Züge anderer Traditionen erkennen. Diese unabwendbare Notwendigkeit des weltgeschichtlichen Zusammenhanges tritt in der philosophischen Entwickelung der Renaissance mit typischer Deutlichkeit zutage.

I. Der Streit der Traditionen. Die neuhumanistische Geschichtskonstruktion hat den Beginn der neuzeitlichen Kultur gern als eine höhere Antike und mittelalterliche Vereinigung der gegensätzlichen Geistesrichtungen von Altertum und Mittelalter verstehen wollen. Eine solche Gegensätzlichkeit besteht aber durchaus nicht durchgängig und am wenigsten in bezug auf die philosophische Entwickelung. In dieser Hinsicht war vielmehr die mittelalterliche Wissenschaft im Okzident wie im Orient nur die geradlinige Fortführung der Richtung, in die das griechische Denken ausgemündet war, und die mittelalterliche Philosophie nur die Tochter und Schülerin des Altertums. Wenn die griechische Philosophie von ihren rein theoretischen, physischen und metaphysischen Anfängen her sich allmählich zur ethischen Lebensweisheit umgebogen und schließlich in die religiöse Weltansicht gewandelt hatte, mit der sie sich in Patristik und Neuplatonismus ausgabelte, so blieb die mittelalterliche Philosophie in allen Geschicken, die sie dem Wechsel und dem Wachstum der Überlieferung verdankte, religiös interessiert und orientiert. Von Platon und den Stoikern an läuft eine ununterbrochene Linie gegenseitiger Annäherung und Anpassung von Philosophie und Religion bis zu Averroës, Maimonides und Thomas von Aquino. Aber diese Linie überschreitet nun ihren Höhenpunkt in der mittelalterlichen Philosophie des Abendlandes selbst. Je reicher die wissenschaftliche Tradition - vor allem durch die Rezeption des Aristotelismus - an Kenntnissen und begrifflicher Verarbeitungsfähigkeit sich gestaltet, um so fraglicher wird die Möglichkeit der gesuchten Ausgleichung $z$ wischen der wissenschaftlichen Überlieferung und der religiösen Überzeugung.

Darum bilden die Untersuchungen über das Verhältnis der natürlichenPhilosophie und Religion zur Offenbarungsreligion den historisch notwendigen Abschluß einer Theologie. 
jahrhundertelangen Entwickelung, und die verschiedenen Ergebnisse, zu denen dabei die orientalische und die okzidentalische Philosophie gelangten, sind eine bedeutsame Voraussetzung für das Denken der Zukunft. Die arabischen Denker sahen mit weitem Blick über das ringende Leben ihrer Zeit in den positiven Religionen die durch geschichtliche Momente bestimmten, in der sinnlichen Vorstellungsform aufgebauten Vorstufen zu dem reinen Ideal einer, sei es begrifflich gedachten, sei es mystisch geschauten, allgemein menschlichen Natur- und Vernunftreligion: dagegen wollten die christlichen Mönche des Abendlandes in einer solchen Vernunftreligion nur die durch die sinnliche Erkenntniskraft dès Menschen begrenzte Vorstufe für ihre auf göttliche Offenbarung zurückgeführte, die einzige Wahrheit für sich in Anspruch nehmende positive Religion anerkennen. In diesem Verhältnis war es begründet, daß für das Denken des Abendlandes die Vernunfterkenntnis auf das Durchdringen der höchsten religiösen Geheimnisse verzichten mußte, und $\mathrm{da} B$ deshalb Theologie und Philosophie wieder auseinandergingen. In mannigfachen Begriffsformen hat die Wissenschaft des 14. und 15. Jahrhunderts den auf der Höhe des scholastischen Denkens (bei Duns Scotus) eingetretenen Riß erweitert und vertieft, und während in denselben Zeiten das religiös geschlossene System des mittelalterlichen Lebens auseinanderging und neben der geistlichen Kultur überall eine weltliche Kultur sich aus der erwachenden Selbständigkeit der Volksseelen entwickelte, schied auch die Wissenschaft sich in eine Theologie, die das Übersinnliche zum Gegenstande und die Offenbarung zum Erkenntnisgrunde haben sollte, und in eine Philosophie, welche die Welt, d. h. die Natur und den Menschen nur mit dem „natürlichen Lichte“, d. h. mit Erfahrung und Vernunft zu begreifen als ihre Aufgabe erkannte. Diese Scheidung des Übernatürlichen und des Natürlichen, diese "doppelte Wahrheit" der Weltansicht, dieses Nebeneinanderbestehen und dabei doch Ineinandergeflochtensein geistlicher und weltlicher Kultur hat die Renaissance von dem ausgehenden Mittelalter übernommen. Ein reiches weltliches Leben blüht auf, das sich der Herrschaft der religiösen Macht entzieht: aus dem Nebeneinander des Geistlichen und des Weltlichen wird ein Gegeneinander, und in der Philosophie löst sich die Weltwissenschaft als die rein theoretische Erkenntnis von der herrschenden Tradition ab: sie wird eine der Formen der weltlichen Emanzipation von der Kirche als Opposition gegen ihr wissenschaftliches System. So verschieben sich das Interesse und der Gegenstand der Philosophie: sie wird theologisch indifferent und schlieBlich auch religiös indifferent, sie wird Naturwissenschaft, wie sie es in ihren Anfängen bei den Griechen gewesen war.

Aber der Weg dazu hat durch die Erneuerung der antiken Philosophie geführt. An die Autorität gewöhnt, fällt das Denken der Renaissance aus der Tradition, die es abgeworfen, in eine andere, und der Drang nach Neutm, nach neuer Methode und nach neuem Inhalt der Erkenntnis, greift in seiner ersten Erregung zu dem ÄItesten. Es war das Zeitalter der Humanismus. Was man bisher von der antiken Literatur besessen, für die Philosophie zum 
Teil in sehr unvollkommener Überlieferung und Übersetzung aus zweiter und dritter Hand besessen hatte, das fand mit einemmal seine mächtige Erweiterung und Berichtigung durch die neulateinische Bewegung und durch die byzantinische Tradition. Die Originale des griechischen Denkens wurden in dem Umfange bekannt, wie wir sie der Hauptsache nach noch heute haben. Mit der aufgeregten Begeisterung der Zeit sah man in ihnen die weltliche Philosophie, nach der man sich sehnte, und so ist die erste, vorläufige Erscheinung der modernen Philosophie die humanistische Erneuerung der alten gewesen.

Mit eigenartiger Verwickelung spielt in diesen Kampf der Traditionen Platonismus und der alte Gegensatz der Häupter der griechischen Philosophie herein. Schon im Mittelalter hatte sich die Stellung von Platonismus und Aristotelismus in den wunderlichen Gängen der Überlieferung merkwürdig genug verschoben. Aristoteles galt zunächst als der Vater der Dialektik, als der Typus begrifflicher Metaphysik, und der erste Vorstoß der humanistischen Bewegung im I 2. Jahrhundert hatte ihm gegenüber Platons Timaios als den Inbegriff realer Erkenntnis und das Vorbild sachlicher Naturforschung auf den Schild gehoben. Dieses verschiefte Verhältnis wiederholte sich in der Renaissance mit vergrößerten Dimensionen. Denn inzwischen war von der klassischen Scholastik Aristoteles für die höchste Autorität in Sachen der Vernunfterkenntnis erklärt und seine Lehre auf allen Gebieten auch inhaltlich zur entscheidenden Geltung gebracht worden. Das große teleologische Entwickelungssystem hatte die Einstellung einer reichen Weltkenntnis in einen umfassenden Zusammenhang erlaubt: man fand einen Stufenbau der Schichten des Lebens, worin von den niedersten materiell-mechanischen Zuständen aus durch das organische und seelische Leben hindurch zum Geistigen der $\mathrm{Zu}-$ sammenhang führen sollte, daß jedesmal das Niedere die Bedingung für die Entfaltung des Höheren, der Stoff für die Verwirklichung der Form sein sollte: und darüber hatte dann der Thomismus noch die Oberschicht des Geistlichen über dás Geistige, der Offenbarung über die Vernunft, der Gnade über die Natur gesetzt. So galt Aristoteles als der mit der Kirchenlehre einstimmige Philosoph, seine Lehre als der sachliche Unterbau und das formale Prinzip aller Dogmatik. Wenn sich deshalb die oppositionelle Philosophie der Renaissance gegen die herrschende Tradition erklärte, so wurde ihr Feldgeschrei der Kampf gegen Aristoteles, und in demselben Maßue, wie dieser erschallte, wurde nun im Gegensatz dazu bei Platon die Quelle neuer und besserer Einsicht gesucht. Es kam hinzu, daß von Platons Lehre jetzt erst der größere Teil und damit das Ganze bekannt wurde; und den Ausschlag gab doch in letzter Instanz die kongeniale Auffassung, mit der das künstlerisch bewegte und schönheitstrunkene Geschlecht den Zauber der platonischen Darstellung genoß und an dem Fluge seiner metaphysischen Phantasie teilnahm.

Den Mittelpunkt für die Erneuerung des Platonismus hat die Floren- 1'latoniker und tiner Akademie gebildet, die sich über ein Jahrtausend hinweg als die Fort- Neuplatoniker. 
setzung der athenischen fühlte. Aber mit dieser Anknüpfung und mit der unvermeidlichen Abhängigkeit von der byzantinischen Tradition stellte sich von selbst eine Auffassung des platonischen Systems ein, die wesentlich durch den Neuplatonismus bestimmt war. Im Grunde genommen sind alle Platoniker des Humanismus bis in das 17. und 18. Jahrhundert hinein Neuplatoniker gewesen. Ihnen allen gelten die Ideen, Platons ewige Gestalten, als die urbildlichen Gedanken Gottes; und ihnen allen wird die mythische Naturbetrachtung Platons zu einer teleologischen Metaphysik und Naturphilosophie. Marsilius Ficinus hat seine Kunst geistvoll interpretierender Übersetzung an Plotin ebenso geübt wie an Platon, und die theosophischmagische Naturlehre, wie sie schließlich Franzesco Patrizzi in seiner Nova de universis philosophia (159I) vortrug, war eine schwärmerische Versenkung in die Schönheit des von der göttlichen Idee durchlebten Universums.

Aristoteliker. Gegen den Ansturm des Platonismus hatte der Aristotelismus um so schlimmeren Stand, als er in sich durch die interpretatorischen Verschiedenheiten der Tradition gespalten war. Der Auffassung der christlichen Scholastik hatten bereits die neuplatonischen und arabischen Übersetzer und Erklärer, denen sie ihre Kenntnis der aristotelischen Philosophie zum weitaus größten Teile verdankte, ihren Stempel aụfgedrückt. Jetzt traten die Gegensätze zwischen den beiden Hauptrichtungen der Interpretation schärfer hervor An die beiden bedeutendsten Kommentatoren, Alexander Aphrodisias einerseits und Averroës andererseits, schlossen sich weitverzweigte Schulen, zwischen denen die naturalistischen und pantheistischen Nuancen in der Umbildung der aristotelischen Lehren von dem Verhältnis des Stoffs zur Form, der Natur zur Gottheit oder von dem Wesen der menschlichen Seele und der Art ihrer Unsterblichkeit vielfach hin und her erörtert wurden. In diesem Streit $z$ wischen Averroisten und Alexandristen erscheint als die bedeutendste Persönlichkeit das Haupt der letzteren, Pietro Pomponazzi (1462-1524). Solchen Ausdeutungen gegenüber suchten die großen humanistischen Philologen, wie Rudolph Agricola, Faber Stapulensis oder Julius Caesar Scaliger eine möglichst reine und von der Tradition unbeeinflußte Erkenntnis des aristotelischen Systems zu gewinnen, und diese humanistische Auffassung des Stagiriten ist für die Verwendung maßgebend geworden, welche seine Lehre seit Melanchthon in der Philosophie der protestantischen Kirchen gefunden hat

Kampf gegen das Mönchslatein und die Syllogistik.

Gegen Scholastik und Aristotelismus führte jedoch der Humanismus seinen Angriff noch energischer von der formalen Seite her. Hier ging der Stoß von der lateinischen Profanliteratur aus, die ja den ersten Ursprung des italienischen Humanismus gebildet hatte, und diese Opposition setzte bei der Sprache ein. Die Humanisten gingen von ihrem Neuklassizismus aus im Namen des Geschmacks gegen das Mönchslatein vor, das sie als barbarisch brandmarkten. Das Latein des Mittelalters war ja freilich nicht schön, aber es war - zum Teil wenigstens - stark und charaktervoll, eine lebende Sprache, die ihre Kraft in einer etwas barocken, knorrigen Terminologie be- 
wies. Indem die Humanisten dies freilich schon in der Erstarrung begriffene Latein auf eine seiner ehemaligen Entwickelungsstufen, mochte diese noch so -formvollendet sein, zurückschraubten, haben sie es vollends zu der toten Sprache gemacht, die es jetzt ist. Zu dem glücklichen Erfolg, den sie zunächst gegen die sprachliche Form der mittelalterlichen Wissenschaft errangen, kam noch ein anderes und berechtigteres Moment. Das war der Kampf gegen die Methode. Wiederum war es ein historischer Irrtum, daß man die syllogistische Methode der Scholastik als aristotelische Dialektik bezeichnete; aber der Überdruß an der öden Wortweisheit, an der unfruchtbaren Begriffsspalterei, die das scholastische Denken in der Tat charakterisierten, war durchaus begründet, und wenn Humanisten, wie Laurentius Valla, Ludovico Vives und auch Erasmus von solchen ergebnislosen Diskussionen zu einfacher und unmittelbarer Beschäftigung mit den Sachen riefen, wenn sie mit Ernst und Spott gegen diese Unfruchtbarkeit der syllogistischen Methode zu Felde zogen, so trat auch darin der frische Zug der Zeit zutage, der die Wissenschaft aus der Zelle des Mönches mitten in das bewegte Leben hineinstellen wollte.

So sucht man die natürliche Logik des gebildeten Weltmannes, den geschmackvoll erzogenen gesunden Menschenverstand, und man findet ihn in der populären Philosophie der lateinischen Literatur, insbesondere bei Cicero. Aus Grammatik und Rhetorik sollten die rechten Regeln des Denkens geschöpft werden, und eine vorwiegend sprachliche Bildung mit ihrem ästhetischen Formalismus erklärte es für die Aufgabe des gebildeten Menschen, sachgemäß über die Dinge reden zu können. In dieser Richtung bewegte sich die viel Aufsehen erregende Reform der Logik, die Pierre de la Ramée in seinen Institutiones dialecticae (1543) versuchte und die in Frankreich und Deutschland eine Zeitlang großen Erfolg hatte.

Für diese freiere weltmännische Art des Philosophierens lag es nun nahe, von den Subtilitäten und künstlichen Problembildungen auf dem theologisch-metaphysischen Gebiete sich abzuwenden und statt dessen eine Lebensphilosophie zu suchen. Auch diese aber bot die antike, namentlich die lateinische Literatur in der Gestalt der stoischen Lebensauffassung dar Wie im Altertum, so wurde auch jetzt wieder der Stoizismus die philosophische Moral des gebildeten Menschen. Er konnte es um so mehr werden, als in ihm von vornherein begrifflich vieles von dem Besten und Wertvollsten formuliert worden war, was inzwischen in der christlichen Lebensführung tatkräftige Verwirklichung gefunden hatte. So geht durch die ganze Literatur der Renaissance und noch weit darüber hinaus eine mannigfache Entwickelung der ethischen und anthropologischen Begriffe der Stoiker; die ganze Auffassung vom Menschen, von seiner Aufgabe, seinen Affekten und Leidenschaften ist in dieser Weise bestimmt; die Herrschaft der Vernunft über die natürlichen Triebe wird in immer neuen Wendungen, selbst später noch von den großen Systemen, als das sittliche Ideal proklamiert, und die markvolle Ausschmiedung des Begriffs der Persönlichkeit, die den innersten Hait der 
stoischen Ethik bildete, wurde von dem Zeitalter der großen Individualitäten mit der lebhaftesten Sympathie ergriffen.

Skepsis. $\quad$ Aber je fester diese Lebensweisheit sich einsenkte, um so kritischer und gleichgültiger wurden die Kreise der humanistischen Bildung gegen alles metaphysische Grübeln. Auch diese Indifferenz gehört $z u$ dem weltmännischen Philosophieren, und sie fand ihre Nahrung wiederum an Ciceros akademischem Skeptizismus. Gern machte man sich deshalb, den unfruchtbaren Begriffsspaltereien der Scholastik gegenüber, aus der alten Literatur die ausgesprochen skeptischen Argumente zu eigen: die Unzulänglichkeit und Vieldeutigkeit der sinnlichen Wahrnehmung, die Relativität aller Meinungen, die Unsicherheit aller allgemeinen Prinzipien auf dem Gebiete der theoretischen Erkenntnis. Dieser weltmännische Skeptizismus bestimmt schon die souveräne Freiheit, mit der Erasmus über den konfessionellen Streitigkeiten stand. Derselbe Skeptizismus findet später seine glänzendste literarische Gestalt in den Essays von Michel de Montaigne; er paart sich mit stoischer Selbsteinkehr bei dessen Freunde Pierre Charron und tritt uns mit eindrucksvoller Lebhaftigkeit bei François Sanchez entgegen. Gerade bei dem letzteren aber drängt deutlich über das große Fragezeichen hinaus, mit dem jede Erwägung schließt, überall die Sehnsucht, all dieses Begriffsgerede loszuwerden und mit unbefangener Aufnahme an die Natur selbst heranzutreten. Die Verzweiflung an den Autoritäten, der Überdruß an dem Buchwissen und der Drang in die weite, herrliche Welt hinaus - alle diese Stimmungen, denen Goethe im ersten Faustmonolog den ergreifenden Ausdruck gegeben hat, sind die echten Grundmotive in dem philosophischen Ringen der Renaissance.

Empirismus und Nominalismus.
II. Die Anfänge der Naturforschung. So geht die moderne Wissenschaft aus der langen und strengen Lehrzeit des Mittelalters mit demselben irrtümlichen Gefühl hervor, mit dem so oft der begabte Schüler aus der Schule scheidet, als habe er nichts in ihr gelernt, und mit leidenschaftlicher Erregung sind die Geister der Renaissance von dem Bedürfnis erfüllt, nun in unmittelbarem Leben vollkommen neu anzufangen und ein eigenes Wissen selbst zu erwerben. Dieser Trieb wies sie von selbst auf den Weg ernster Erfahrungsarbeit, und in die empiristische Tendenz war schließlich auch die Scholastik aus ihrer dialektischen Bewegung heraus eingemündet. Auch in ihr hatte es nicht an solchen gefehlt, welche gegenüber der riesigen Masse des Buchwissens, das mit der aristotelischen und der hippokratischen Überlieferung, zum größten Teile auf dem Umwege über die arabische Gelehrsamkeit auf sie eindrang, auch zu.eigenen Beobachtungen oder gar Experimenten sich gedrungen fühlten: Albert bei den Dominikanern, Roger Bacon bei den Franziskanern hatten wegen solcher Studien den Verdacht der Zauberei auf sich gelenkt. Aber was sie begannen, wurde weiterhin durch die scotistische Metaphysik und die nominalistische Logik begünstigt. Wenn die sinnliche Welt als der alleinige Gegenstand der philosophischen 
Erkenntnis übrigbleibt, so stellt sie sich als das Reich des Besonderen, des Zufälligen, Tatsächlichen, begrifflich Unableitbaren dar: das einzelne aber weiß man eben nur durch Erfahrung. Und wenn dann dies einzelne als das wahrhaft Seiende gedacht wird, so sind die allgemeinen Begriffe, mit denen wir es zusammenfassend denken, nur Namen, nur Erkenntnismittel, denen an sich nichts Wirkliches entspricht. So hängen Individualismus und Nominalismus in der Spätscholastik auf das engste zusammen und neigen überall zu den Anfängen empirischer Forschung. Aber es hat sehr lange gedauert, bis man damit etwas Erfolgreiches anzufangen wußte.

Das lag in erster Linie an der Verquickung des Nominalismus mit der Terminismus terministischen Erkenntnistheorie. Aus der epikureisch-byzantinischen Überlieferung hatte man die Zeichenlehre übernommen, wonach die Vorstellungsinhalte von den sinnlichen Empfindungen an bis zu allen Arten ihrer Verknüpfung und Umformung eben nur Vorstellungsweisen und Erscheinungen sein sollen, die im Bewußtsein als Zeichen für eine andersartige Wirklichkeit gelten. Dieser Phänomenalismus ließ kein rechtes Zutrauen an der äußeren Erfahrung aufkommen und gab ihrer Auffassung zunächst ein skeptisches Gepräge. Man weiß nicht, was die Dinge selbst sind; wir kennen eigentlich nur unsere eigenen Empfindungszustände: das ist die Einschränkung, mit der unter immer wechselnden Formen gerade in der Philosophie der Renaissance die empiristische Richtung sich ausspricht.

Den Vorteil davon hatte die empirische Psychologie. Von allem Er- Psychologie. fahrungswissen ist die Selbsterkenntnis der seelischen Zustände weitaus das gewisseste. Diese Auffassung finden wir gerade bei den Humanisten, die so laut und leidenschaftlich den Ruf erheben: zu den Sachen! Typisch ist in dieser Beziehung besonders Ludovico Vives; ähnlich verhält sich der Nominalist Marius Nizolius, und bei den Skeptikern, wie Charron und Sanchez, tritt dasselbe, bei dem ersteren in moralisierender Tendenz, bei dem anderen in rein theoretischer Weise zutage. Diese methodologische und erkenntnistheoretische Bevorzugung der inneren Erfahrung ist ein Grundzug geblieben, welcher der neueren Philosophie lange nachgegangen ist.

Dazu kommt nun aber während der ersten Zeiten ein kindliches Unge- Phantastischo schick in der Anstellung und Verarbeitung der Erfahrung. Es fehlt eben darin noch alle Schulung, und so stellt sich bei dem leidenschaftlichen Erkenntnisdrang ein unsicheres Tasten ein. Das hat namentlich darin seinen Grund, daß man von dem Einzelwissen doch gleich wieder zu allgemeinen Theorien drängt und dabei in der Art der ältesten griechischen Denker der vorschnellen Verallgemeinerung verfällt. Wir erkennen das besonders an Bernardino Telesio, der mit Recht als der Hauptvertreter des naturwissenschaftlichen Empirismus der Renaissance gilt und der in der cosentinischen, später nach Neapel verlegten Akademie viel fleißige Forschungsarbeit angeregt hat. Aber seine eigene Naturphilosophie (1565) ist eine phantastische; an die alten Milesier erinnernde Weltkonstruktion aus den gegensätzlichen Beziehungen von Wärme und Kälte Licht und Finsternis usw. Das müh- 
same Buchstabieren der Empirie war eben noch nicht nach dem Geschmack der Zeit. Die Sehnsucht der Naturerkenntnis, welche die Geister ergriffen hat, geht auf das Ganze. Schauen wollen sie, in einem seligen Blicke die Gesamtheit der Natur umfangen. Darin spricht einerseits die lange metaphysische Gewöhnung des Denkens, andererseits die ästhetische Phantasie einer künstlerisch bewegten Zeit.

Theosophie.

Gerade dadurch begreift sich die Form der Naturauffassung, worin sich zunächst der Riß zwischen Philosophie und Theologie zu verdecken schien. Die Natur als Einheit, als künstlerisch vollkommenes Ganzes war für den Flug der Phantasie leicht als Erscheinung der Idee, des Geistes, des göttlichen Geistes zu denken. Hier bot sich deshalb von selbst der Neuplatonismus dar, und hierauf beruhte dessen weithin sich èrstreckende Wirkung. Es gab eine alte Formel von der doppelten Offenbarung Gottes im Liber scriptus und im Liber vivus. Sie wurde gern ergriffen, um mit aller Anerkennung der Offenbarungslehre eine naturtrunkene Schönheitsphilosophie des Universums zu verbinden, um die ästhetische Weltfreudigkeit der Renaissance streitlos neben die Heilslehre der Kirche zu stellen. So wie Patrizzi sind viele, viele andere diesen Weg einer theosophischen Naturphilosophie gegangen. Aber ihre Harmonisierung mit der Heilslehre war nur scheinbar; denn eigentlich war sie ästhetischer Pantheismus. Sie schwelgte in der Anschauung des harmonischen Ganzen; die Welt war ihr göttliches Leben, sinnlich erscheinendes Ideenwirken, ein kunstvolles Ineinander von geistigen und sinnlichen Kräften. Sie stand im faustischen Zeichen des Makrokosmus.

Magie. Aber zum Schauen kommt das andere, das Genießen. Der Lebensdurst der Renaissance, der ungebändigte Trieb nach Selbstentfaltung, das Mitwirkenwollen am sausenden Webstuhl der Zeit, das gibt eine ungeheure Aufregung und einen prophetischen Drang. Man will die Natur beherrschen, sie sich zu eigen machen nicht bloß im Gedanken, sondern auch im Leben. Das Regnum hominis bricht an. Mit cien neuentdeckten Weltteilen scheint dem Europäer der ganze Planet zur Verfügung gestellt, das Neuartige des Tropenlebens steigert die exotische Phantasie und die Neigung zur Abenteuerlichkeit. Es ist allen solchen Offenbarungen gegenüber eine Frühlingsstimmung in der Zeit: „Man weiß nicht, was noch werden mag." Aber auch die Beherrschung der Natur wird nur erst ersehnt und unklar geahnt; an das große Geheimnis der Natur wagt man sich nur mit den Geheimnissen der Magie. Auch darin steckt neuplatonische Tradition mit ihrem astrologischen Wesen, mit der Vorstellung von den Gestirngeistern und ihrem Walten in irdischen Dingen. Es ist merkwürdig, wie die Männer der Renaissance, die mit so starker Kritik dem dogmatischen Glauben gegenüberstehen, so wehrlos gegen den Aberglauben sind. Man bringt System in dieses magische Treiben; Männer, wie Johann Reuchlin, wie der phantastische Neuplatoniker Pico von Mirandola, der seltsame Mailänder Arzt Hieronymus Cardanus oder der merkwürdige Abenteurer Agrippa von Nettesheim lassen uns die Bedeutung erkennen, welche die Zeit diesem wunderlichen Treiben 
zuerkannte, und für die Medizin sollte daraus eine totale Reform durch $\mathrm{Pa}$ racelsus (Theophrastus Bombastus von Hohenheim aus Einsiedeln 1493-154 I) Paracelsus entwickelt werden. Denn die ärztliche Kunst bestehe wesentlich in der Kenntnis der guten und bösen Geister und ihrer Einwirkung auf den Lebensgeist, den Archeus. In großen Zügen, mit kühner Phantasie und zugleich mit einer Fülle von Kenntnissen wird hier das magische Ineinander aller Wirklichkeit nach stoisch-neuplatonischem Vorbild neu gedichtet. Insbesondere üben die chemischen Geheimnisse ihren Reiz aus; man sucht den Übergang der Metalle ineinander, und das Goldmachen ist der sehr reale Zweck, der dabei verfolgt wird. Aber die Alchimie, deren Lehrstuhl Paracelsus eine Zeitlang in Basel einnahm, wollte vor allem der Medizin zugute kommen. Die paracelsischen Ärzte reisten, wie er selbst, auf den Märkten herum, ihre Tinkturen und Salben anzupreisen, und ihre Hoffnung ging darauf, den „Stein der Weisen" $z u$ finden, das Allheilmittel für alle Krankheiten und Gebrechen, den Schlüssel zu allen Geheimnissen der Natur und die Macht über alle Geister im Himmel und auf Erden.

Der magische Pantheismus enthielt aber noch ein traditionelles Moment, Pythagoreische das zu höherer Wirksamkeit berufen war: die pythagoreische Zahlenspekulation. Durch neuplatonische und orientalische Überlieferung vermittelt, aber auch unmittelbar durch die humanistischen Studien nahegeiegt, hat sie den glänzenden Aufschwung der Mathematik hervorgerufen. Das Interesse daran war metaphysisch gefärbt. Es bestand in dem Glauben, daß das göttliche Buch der Natur in Zahlen geschrieben sei. Darin lag, wie dereinst im Altertum, die dunkle Ahnung von der mathematischen Gesetzmäßigkeit der Natur, und so formte sich die ästhetische Bewunderung des Universums zu einem rational geprägten Ausdruck. Wiederum aber, wie im Altertum, war es die Welt der Gestirne, in der man diese Ahnung der mathematischen Weltordnung zuerst in eine klare und bestimmte, eine erfahrungsmäßig nachweisbare Erkenntnis umzusetzen imstande war. So ist aus der Astrologie die Astronomie und damit diese die erste Form der modernen Naturwissenschaft geworden. Genau diese Motive sind es gewesen, mit denen Koper- Kopernikus nikus die mathematische Ordnung am Himmel suchte und fand. Das in der platonischen Akademie bereits geformte Problem, welche gleichmäßige Bewegungsart der Wandelsterne angenommen werden müsse, um ihre scheinbare Unordnung begreiflich zu machen, dies mathematische Projektionsproblem fand nun seine Lösung, indem Kopernikus den heliozentrischen Standpunkt der Weltbetrachtung einnahm. Die mächtigen Wirkungen, welche diese Umwälzung für die Auffassung des Menschen von seiner Stellung in der Welt gehabt hat, verstehen sich für uns heute von selbst: damals zeigte sich ihre Ahnung in der Scheu, mit der alle kirchlichen Mächte sich von der neuen Lehre abwandten, und positiv in der Energie, mit der die großen Systeme der Philosophie diese Folgerungen zu Ende gedacht haben. Das methodisch Bedeutsame an dieser Entwickelung liegt eben darin, daß die mathematische Ordnung der Welt nicht mehr bloß phantastisch geahnt, mystisch 
konstruiert und ästhetisch bewundert, sondern erfahrungsmäßig nachgewiesen und verstandesmäßig begriffen wurde. Genau denselben Übergang Keppler. zeigt Johann Keppler, der das von Kopernikus hinterlassene Problem der Himmelsmechanik löste. Auch er geht von dem Triebe aus, die Weltschönheit durch den erfahrungsmäßigen Nachweis der mathematischen Harmonie zu begreifen. Und wenn er durch seine mühsame Induktion an der Beobachtung des Planeten Mars jene drei Grundgesetze gewann, die noch heute seinen Namen tragen, so war er sich der philosophischen Bedeutung dieser Forschungsweise durchaus bewußt. Er erkannte, daß das Verständnis der mathematischen Ordnung sich wesentlich auf dasjenige in der Natur bezieht, was für unsere Auffassung in den meßbaren Formen der Quantität gegeben ist. Sie bilden das wahre Objekt der Erkenntnis, und sie müssen deshalb auch als die wahre Realität gelten. Die ewigen Wahrheiten der Mathematik haben ihren Ursprung in Gott; sie finden ihre Verwirklichung in der Bewegung der Gestirne, und der menschliche Geist hat seine Aufgabe in ihrer Wiederholung.

Mechanik. Das sachlich Bedeutsamste aber in der kopernikanischen Weltauffassung war die Erkenntnis der Gleichartigkeit des gesamten physischen Universums. Indem die Erde als einer der Planeten in den umfassenden Zusammenhang des Sonnensystems eingestellt wurde, brach der Himmel, der nach dem ptolemäischen System sich über ihr gewölbt hatte, zusammen. Jene Scheidung der Welt in eine Region siderischer Vollkommenheit und eine andere Region terrestrischer Unvollkommenheit war überwunden, und die Gleichmäßigkeit des substantiellen Bestandes und der Bewegungsgesetze mußte für die gesamte physische Welt verlangt werden. Deshalb lag in der neuen Weltanschauung die unvermeidliche Notwendigkeit, das Prinzip der mathematischen Gesetzmäßigkeit nicht, wie es die alten Pythagoreer und nach ihnen Aristoteles getan hatten, auf die Gestirnwelt zu beschränken, sondern es auch für die Bewegungen des irdischen Daseins fruchtbar zu machen. So ist in Analogie mit der Astronomie und in der intimsten Beziehung zu ihr die Mechanik als die Grundwissenschaft der modernen Naturforschung erwachsen. Ihr

Lionardo und Galilei.
Führer ist Lionardo da Vinci, der geniale, Kunst und Wissenschaft umspannende und vermittelnde Geist, ihr Vollender Galileo Galilei. In seinem schönen Brief an die Großherzogin Christine von Lothringen hat er das friedliche Verhältnis einer auf Erfahrung und Vernunft begründeten Naturerkenntnis $z u$ den moralischen Zwecken der religiösen Offenbarung und Lehre in klassischer Weise ausgesprochen. Aber wenn das Buch der Natur in mathematischen Zeichen geschrieben ist, so sollen diese nicht durch mystische Spekulation, sondern durch Erfahrung erkannt werden. Diese Erfahrung jedoch ist nicht die gemeine Wahrnehmung, sondern die Feststellung dessen, was in ihr eine mathematische Größe ist, des Meßbaren. Diese zahlenmäßige Bestimmung wird mit Hilfe des Experiments durch die Isolierung der einfachen Elemente der Körperwelt gewonnen. Wenn die „resolutive Methode" bis zu deren Darstellung vorgedrungen ist, so gilt es, um die Ver- 
knüpfung wiederherzustellen, in der „kompositiven Methode“ die mathematisch formulierbare Abhängigkeit der Größen voneinander festzustellen, die eine als die Funktion der anderen zu definieren. Wenn Galilei auf diese Weise in den Fallgesetzen die Grundlage für alle spätere naturwissenschaftliche Theorie schuf, so gab er zugleich die metaphysischen und erkenntnistheoretischen Folgerungen dieses neuen wissenschaftlichen Verfahrens. Sie fielen zum Teil mit den Auffassungen zusammen, die von anderen Voraussetzungen her im Altertum durch Demokrit gewonnen worden waren. Wenn die quantitativen Bestimmungen ihrer experimentellen MeBbarkeit wegen das einzige Objekt der mathematischen Naturtheorie sind und demgemäB auch als das eigentliche Wesen der dadurch zu erkennenden Körperwelt angesehen werden müssen, so gelten die qualitativen Bestimmungen der Wahrnehmung, die Empfindungen der einzelnen Sinne, nur noch als Erscheinungen im wahrnehmenden Bewußtsein. Die Lehre von der Subjektivität der Sinnesqualitäten konnte hier ohne die skeptischen Wirkungen angenommen werden, die sie vor solcher durch die Mechanik gewährten Ergänzung hatte und haben mußte. In diesem Sinne erneuert sich gegen Aristoteles und die Scholastik auch nach dieser Richtung die Weltansicht Demokrits, die dem Mittelalter in Gestalt der epikureischen Tradition zwar bekannt geblieben, aber unsympathisch gewesen war und mit der humanistischen Literatur auch auf anderen Wegen wieder zur Anerkennung gelangte. Die inneren Kräfte und Formen der peripatetischen Naturansicht, die Qualitates occultae, wurden aus der Theorie bald grundsätzlich ausgeschieden. Das an sich Wirkliche der Welt sind die Atome und ihre Bewegung. Aber die Quantifikation der Wirklichkeit bezieht sich bei Galilei weniger auf das Sein als auf das Geschehen. Die mathematischen Funktionen, die den In hait der Naturerkenntnis ausmachen, sind Maßverhältnisse der Bewegung, und die Naturgesetze sind mathematische Funktionen von Bewegungsgrößen. So bildet sich in den Bedürfnissen der Naturforschung der neue Kausalitätsbegriff: nur Bewegungen gelten als Ursachen, nur Bewegungen als Wirkungen, und ein Gesetz bedeutet ein konstantes Größenverhältnis zwischen ihnen. Das Grundprinzip aber dieser Gesetze ist das der quantitativen Gleichheit von Ursache und Wirkung.

III. Das politische und religiöse Leben der Renaissance. Die Individualismus. wissenschaftlichen Bewegungen, die in dieser Weise einer weltlichen Philosophie teils historische, teils naturwissenschaftliche Richtungen wiesen, hatten ihre Resonanz in den allgemeinen Lebenszuständen der Zeit. Es ist bekannt, wie die allmähliche Lockerung der autoritativen Einheit ein reiches Aufschießen der Individualitäten, der Eigenart von Personen und Nationen mit sich führte. Diese Dezentralisation des geistigen Lebens zeigt sich auch in der Wissenschaft darin, wie für ihren Betrieb neben Paris zuerst in Oxford und Bologna, dann in Prag und Heidelberg, endlich in der ganzen Zahl der protestantischen Universitäten neue Heimstätten erwuchsen. Dazu kommt, 
daß auch die modernen Sprachen in der Wissenschaft zu Worte gelangen: je neuer und radikaler die Gedanken werden, um so mehr wirft man das der Verknöcherung anheimfallende Latein $a b$, und wie Bruno italienisch und Böhme deutsch, so schreibt Descartes französisch. Eine ähnliche Dezentralisation zeigt sich im religiösen Leben: neben Rom werden Wittenberg, Genf, London, Münster eigene Zentren. Den Kern aber der vielspältigen religiösen Bewegung bildet der Drang nach Verinnerlichung des frommen Gefühls und nach Anerkennung seiner individuellen Ursprünglichkeit gegen die autoritativ-traditionelle Festlegung und die institutionelle Veräußerlichung. Ein großer Strom, der unter der Oberfläche des mittelalterlichen Daseins sich Mystik. mächtig erhalten hatte, tritt hier an das Tageslicht: es ist die Mystik. Die äußerst verwickelten Verhältnisse der Tradition hatten ihr in den Verschiebungen der mittelaiterlichen Wissenschaft ein seltsames Verhältnis zur Scholastik gegeben. Von Plotin und Augustin her laufen die beiden Lösungsrichtungen des religiösen Problems mit zahlreichen Verschlingungen nebeneinander her; dort die unmittelbare Beziehung des Menschen zu Gott, die individuelle Versenkung in das Urwesen als die Krönung und Versöhnung des persönlichen Lebens, - hier die Vermittelung durch die göttliche Heilsanstalt, in der die Gesamtheit des Menschengeschlechts mit ihrer substantiellen Einheit das gemeinsame Weltgeschick der Erlösung gewinnen soll. Dieser Grundgegensatz gibt auf beiden Seiten die Färbung für die anthropologischen und psychologischen Theorien ebenso wie für die allgemeinen Umrisse der Metaphysik und Theologie. Darin machen sich tiefste Gegensätze des unmittelbaren Lebens und der Überzeugung noch mehr geltend als die der literarischen Überlieferung und der begrifflichen Schulung: nichts ist dafür charakteristischer als die Tatsache, daß zur selben Zeit, aus demselben Orden, von denselben Voraussetzungen her die Scholastik und die Mystik des Mittelalters ihre höchste Blüte in Thomas von Aquino und Meister Eckart getrieben hatten. Aber während die Scholastik mit diesem ihrem Abschluß sich zu der Versteinerung und Unfruchtbarkeit verurteilte, in der sie trotz aller Galvanisationsversuche und scheinbarer Assimilationslust bis auf den heutigen Tag verharrt und prinzipiell verharren muB, lagen in der tiefen Gemütserregung und der persönlichen Ursprünglichkeit der deutschen Mystik die Keime eines neuen Lebens, das mit seinem inhaltlichen Reichtum und seiner unmittelbaren Flüssigkeit immer neue Motive für das philosophische Denken abgegeben hat. Die Mystik ist schöpferisch, weil sie ihrem Wesen nach individuell und persönlich ist: darin liegt ihre weltgeschichtliche Überlegenheit über die Scholastik.

Es ist das Schicksal der römischen Kirche geworden, daß sie in der Renaissance unfähig war, die ungeheure Geistesfülle, mit der die Zeit herandrängte, ähnlich zu bewältigen, in sich aufzunehmen und unter ihre Lehre zu beugen, wie es seinerzeit mit dem Aristotelismus den Bettelmönchen gelungen war: jetzt schien ihr nur übrigzubleiben, unter Führung der Jesuiten sich hinter dem Thomismus zu verschanzen und für ihren Wissenschaftsbe- 
trieb die Sprache der Humanisten sich anzueignen und virtuos auszubilden. In dieser Weise erlebte die Scholastik eine Nachblüte auf der iberischen Halbinsel, wo an der Universität Coimbra der ganze Bestand dieses Lehrsystems kodifiziert wurde, und wo es in Suarez seine glänzende schriftstellerische Vertretung gefunden hat.

Aus der lebendigen Bewegung der Mystik, wie sie sich in Deutschland Reformation. und hauptsächlich am Rhein entwickelte, ist die Reformation hervorgegangen. Luther, der zu jener in den nächsten persönlichen und literarischen Beziehungen stand, hat mit der genialen Vertretung des Rechts dieser persönlichen Frömmigkeit, mit der Verfechtung der Freiheit des Christenmenschen den Volkssturm entfesselt, der zugleich als eine politische Bewegung gegen die Fremdherrschaft der Welschen gerichtet war. So ist die deutsche Reformation selbst das Ergebnis der Geistesfreiheit ihrer Zeit: aber sie ist nur zum Teil diesem Ursprunge treu und die Hüterin dieses ihres Rechtes geblieben. Ihr Geschick ist es geworden, daß die mystische Bewegung sich nur mit Hilfe des Staates in der öffentlichen Welt durchsetzen und nur durch eine neue Kirchenbildung sich befestigen konnte. Die ganze innere Geschichte des Altprotestantismus ist dieser Streit zwischen seiner mystischen Innerlichkeit und den Notwendigkeiten seiner äußeren Organisation. In dem Kampf gegen die Schwarmgeister und vor allem gegen das Täufertum stieß die neue Kirche wesentliche Bestandteile ihrer eigensten historischen Grundlage von sich, und so trat die Scheidung ein, daß die mystische Bewegung selbst wieder von der Oberfiäche des öffentlichen Lebens in das Innere zurücktrat und in der Stille im Volke fortrollte, während die kirchliche Gestaltung der Reformation in den Händen der gelehrten Führer zu einer neuen dogmatischen Erstarrung führte. So kam es, daß die Vertreter der mystischen Bewegung durch das 16. Jahrhundert hindurch, ein Osiander, ein Schwenckfeld, ein Sebastian Franck bis zu Valentin Weigel hin ihren Kampf gegen den Buchstabenglauben mit aller Leidenschaft gegen die „gelehrten Verderber" der Reformation gerichtet haben.

Auch diese hatte ihren Bund mit dem Humanismus gemacht, und es war nicht nur das Bedürfnis nach der von dem Geschmack der Zeit verlangten Form, das sie zu ihm führte, sondern die tiefere Verwandtschaft, daß beide aus derselben Weltfreudigkeit ihrer Zeit hervorgegangen waren. Wie der Humanismus in den groben Persönlichkeiten und geistigen Leistungen des Altertums und allüberall auch in den geheimnisvollen Erscheinungen der Natur, so fand die Reformation auch im weltlichen Menschentum, im bürgerlichen Leben, in den staatlichen Ordnungen den Hauch des göttlichen Wesens und die Zeichen einer gottgewollten Ordnung. Die „Entprofanisierung" des Irdischen, die Mündigkeitserklärung des Laientums bedeutete eine sittliche Weltfreudigkeit, die zugleich rückhaltiosen Welternst in sich trug: das war die tiefste Wechselbeziehung zwischen der Reformation und dem Humanismus mit seiner Ausmündung in die neue Naturforschung.

In der wissenschaftlichen Ausbildung der reformatorischen Prinzipien 
Aristotelismus und Augustinismus.

Weltliche Staatslehre. wiederholte sich freilich der allgemeine Vorgang, daß der neue Wein zunächst in den alten Schlauch gefüllt wurde, daß der Drang nach Ursprünglichkeit sich in die Sackgasse einer Tradition verirrte. Wie Melanchthon das philosophische Bedürfnis seines theologischen Systems bei dem humanistisch interpretierten Aristotelismus deckte, wie $Z$ wingli unter dem EinfluB des aufstrebenden Neuplatonismus stand, so hat der Denker unter den Reformatoren, Calvin, seine strenge und düstere Lehre aus der Weltanschauung Augustins aufgebaut. Auch hierin wiederholte sich ein eigentümlicher Antagonismus aus der mittelalterlichen Wissenschaft, und wie damals, so wurde der große Kirchenvater' auch im I6. und 17. Jahrhundert zu dem Hort aller freieren Richtungen, die sich zu dem aristotelisch-thomistischen System im Gegensatze wußten. Wie Luther in seiner ersten Zeit persönlich dem Augustinismus nahegestanden hatte, so sprachen sich die Versuche, welche in der deutschen gelehrten Welt zu einer. überkonfessionell christlichen Philosophie, z. B. von Nicolaus Taurellus, gemacht wurden, in den Formen augustinischer Gedanken aus, und in dem Frankreich des 17. Jahrhunderts ist für die freieren Kreise auch innerhalb der katholischen Welt, für die Jansenisten von Port Royal oder die Oratorianer, Augustin der bestimmende Geist. So sind auch hier die lebendigen Triebe für die inneren Gegensätze der Zeit, soweit sie theoretisch in die Erscheinung treten, in die Formen gegensätzlicher Tradition gekleidet.

Dasselbe gilt schließlich auch für die Diskussion über die Formen des öffentlichen Lebens und ihre philosophische Bedeutung. Schon mit dem 13. Jahrhundert beginnt und im I4. steigert sich die Lockerung der ständischen, feudalen Gesellschaftsordnung des Mittelaiters. Auch die Völker und die Stände erleben ihre pohtische und soziale Emanzipation und das Aufkeimen selbstbestimmter Sondertätigkeiten. Und da das alles weltliche Lebenskräfte sind, die zu frischer Entwickelung gelangen, so erscheint auch diese Bewegung als die Auflösung der kirchlichen Lebensordnung und als eine Ablösung des Weltlichen vom Geistlichen. Das vollzieht sich auch theoretisch schon in der Mitte der scholastischen Bildungskreise. Selbst Dante hat trotz seines Thomismus in seiner "Monarchia“ das Imperium ebenbürtig neben das Sacerdotium gestellt; und dieselben Franziskaner, die im eigensten Interesse der kirchlichen Glaubenszucht Theologie und Philosophie prinzipiell nach Gegenständen und Methoden so scharf zu sondern suchten, unter ihnen namentlich die Richtung der Spiritualen, gehen auch zu der rein weltlichen Betrachtung des öffentlichen Lebens, zunächst des Staates, über. Bei Occam und Marsilius von Padua erneuert sich, freilich noch in der unklaren Hülle scholastisch-aristotelischer Begriffsformen, die epikureische Staatslehre des Naturalismus, die den Staat als ein Ergebnis der Bedürfnisse der Individuen, als ein Kunstprodukt der über die Leidenschaften siegenden Überlegung behandelt. Von da an streiten in der bewegten Literatur der Renaissance die verschiedensten Richtungen der Staatstheorie miteinander, und es kommt in ihnen die ganze Mannigfaltigkeit der Interessen $z u$ Wort. 
Während bei Nicolo Macchiavelli die rein politische Auffassung des Staates Macchiavelli. im Anschluß an die Ideale der klassischen Literatur sich mit Leidenschaft gegen jede Form einer Unterordnung des Staates unter die Kirche und vor allem gegen die politische Stellung und Macht der Kirche selbst wendet und mit dem stolzen Gefühl, die Erbschaft der alten Römer anzutreten, auf den Gedanken des Nationalstaates ausgeht, ist der gröBere Teil der staatsrechtlichen Untersuchungen bei den Protestanten wie bei den Katholiken mit der aktuellen Frage des Verhältnisses von Staat und Kirche beschäftigt. Es handelt sich dabei nicht nur um das vielfach hin und her gewendete Problem, inwieweit der Staat als eine natürliche oder als eine göttliche Lebensordnung betrachtet werden solle. Wenn in der einheitlichen Weltauffassung der universellen Teleologie, für die Thomas auch in dieser Hinsicht die überall weiterwirkenden begrifflichen Formen gefunden hatte, beide Seiten jener Alternative zugleich bejaht werden konnten, so wurde das um so schwieriger, je weiter in der Vorstellung der Zeit Geistliches und Weltliches auseinandertraten. Aber die Bedeutsamkeit dieser Probleme erhöhte sich mit der Spaltung der Konfessionen, die bei der Zusammenfassung von Angehörigen verschiedenen Glaubens in einem und demselben Staate, bei dem Glaubenswechsel des Herrschers oder bei sonstigem Herrschaftswechsel das Verhältnis der Obrigkeit zu der Religionsübung ihrer Untertanen und zu den kirchlichen Organisationen in steigende Schwierigkeiten verwickelte. Das sind die Interessen gewesen, welche die Theorie auf das Problem der Souveränitàr. Souveränität und auf die verschiedenen Lehren vom Herrschaftsvertrage geführt haben. Hier tauchen bei den Monarchomachen die Lehren von dem Volk als dem einzigen Träger der ursprünglichen und natürlichen Souveränität auf, wenn auch namentlich bei einem Manrıe wie Althus mehr die Stände und die Städte als die Individuen es sein sollen, auf deren Herrschaftsvertrag der Staat mit seiner Rechtsordnung beruht. Aber, wenn es sich auch dabei noch mehr um die „Freiheiten“ ais um die Freiheit handelt, jedenfalls wird hier - und seit der Zeit des Abfalls der Niederlande tritt dieser Gedanke immer kräftiger hervor - die Konsequenz gezogen, daB, wenn von seiten des einen Kontrahenten, der Obrigkeit, die Bedingungen nicht mehr erfüllt werden, wenn nicht mehr nach dem Willen und zum Wohle des Volkes regiert wird, auch der andere Teil, die Untertanen, sich an den Staatsvertrag nicht mehr gebunden erachten. Dieser Lehre von der Aufhebbarkeit des Herrschaftsvertrages trat freilich ein Mann von der Reife des historischen Urteils, wie Bodin, mit der Vertretung des Rechts und der Unteilbarkeit der „Majestät“ entgegen. Aber jene Lehre von dem Rechte der Auflehnung, wesentlich im Sinne der religiösen Überzeugung verfochten, war jedesmal den konfessionellen Minoritäten sympathisch. Sie riefen, wie immer und überall, nach Freiheit, solange sie sich unterdrückt fanden ohne so viel Gewicht darauf zu legen, wenn sie einmal selbst ans Ruder kamen. In ähnlichem Sinne sind auch die Jesuiten, von der Lehre des Thomas abweichend, dazu fortgeschritten, in dem gegen die Kirche rebellischen 
Staat nicht mehr eine natürlich-göttliche Ordnung, sondern nur noch eitel Menschenmachwerk zu sehen: damit büßte er seine metaphysische Wurzel und Würde ein und sank zu einem Vertrage herab, der aufhebbar ist und aufgehoben werden muß, wenn es Gott, d. h. die Kirche, befiehlt.

Toleranz.

Solche in der Theorie wie in der Praxis sich abspielenden Streitigkeiten führten bei den uninteressiert Beobachtenden und Nachdenkenden zu der weittragenden Folgerung, daß der Staat sich um die religiöse Überzeugung seiner Bürger nicht zu kümmern habe. Auch diese Scheidung trieb auf das unausweichliche Gesamtergebnis der streitvollen Zustände hin, auf die Toleranzbewegung. Sie hat ihre Ursprünge in sehr verschiedenartigen und sehr verschiedenwertigen Motiven: die sublime, im Sinne der Mystik aller kirchlichen Organisation abholde Frömmigkeit, der Freiheit fordernde Ruf unterdrückten und verfolgten Glaubens, das mantelträgerische Strebertum charakterloser Politiker, die völlige religiöse Indifferenz des Unglaubens - alles das fand sich unter Umständen in dieser Forderung der Konfessionslosigkeit des Staates zusammen. Besonders nahe aber lag sie denen, die dem Staate andere irdische Aufgaben genug zu stellen wußten. So ist die erste eindrucksvolle literarische Erscheinung der Toleranzbewegung durch die soziale AufSozialeTheorien. fassung vom Wesen des Staates charakterisiert. Die Utopie von Thomas
Morus. Morus, die in der Ausführung ihres Staatsideals auch wieder auf ein antikes Vorbild zurückgeht, auf Platon, ist in ihren Motiven durch den Eindruck des sozialen Elendes und durch die Überzeugung bedingt, dab die Verwilderung und die Verderbnis der Massen nicht durch drakonische Strafen, die nichts fruchten, sondern dadurch zu bekämpfen sei, daß die Quellen des Verbrechens verstopft werden, - durch eine neue Gesellschaftsordnung und eine neue Erziehung. Schon hier wird die Ungleichheit des Besitzes, wird das Geld als der Grund aller Übel angeklagt, wird mit der Aufhebung aller Standesunterschiede die rechtliche Gleichheit aller Bürger verlangt und aus dem, was Platon von der herrschenden Kaste als einen unumgänglichen Verzicht verlangt hatte, ein gleicher Anspruch aller auf die materiellen und geistigen Güter der Gesellschaft gemacht. In der einfachen Lebensordnung der glückseligen Insel, deren Bewohner alle agrarisch und industriell gleichmäßig vom Staate beschäftigt und erhalten werden, sollen auch alie Bekenntnisse friedlich beieinander wohnen und gemeinsam in einem staatlichen Gottesdienste ihre Rechnung finden, der auf einer allgemeinen, rein menschlichen Gottesverehrung aufgebaut ist. Nur in sehr unbestimmten Linien und noch ohne jede lehrhafte Ausführung des einzelnen erscheint hier eine vernünftige und natürliche, allen Menschen gleich zukommende Religion in Sicht. Ähnliche Vorstellungen, nur mit entschiedener Ablehnung des utopischen Staats- und Gesellschaftsideals, finden sich bei Bodin, dessen interessanter Dialog Heptaplomeres die Vertreter der drei christlichen Konfessionen, des Judentums, des Mohammedanismus und des Polytheismus sich schließlich über eine gemeinsame reine Gottesverehrung einigen läßt. 


\section{B. Die naturwissenschaftlich-metaphysischen Systeme.}

Dies sind die Grundzüge des riesigen Ringens zwischen Altem und Neuem in der Renaissance. Auf einem mächtigen Kulturdünger sprießt eine Fülle frischer und lebenskräftiger Keime empor. Allüberall Ansätze und ein Wissen davon: hier will sich Neues, Ungeahntes gebären. Daher ein Vorwalten der Phantasie, der antizipierenden Postulate, ein Programmentwerfen, ein Projektemachen, und daher auch zu nicht geringem Teile eine Großsprecherei und eine Selbstüberschätzung, als ob alles das, was man von sich verlangt, was man sich zutraut, nun auch wirklich schon geleistet wäre. In manchem Betracht gilt das auch für die philosophischen Lehren, in denen das von der Phantasie beflügelte Denken den Abstand zwischen seiner Aufgabe und seiner Leistung zu gering einschätzt und im Gefühle der Neuheit seines Weges schon an dem in der Ferne winkenden Ziele angekommen zu sein sich einredet. Erst allmählich hat diese leidenschaftliche Aufgeregtheit kühlerer Stimmung Platz gemacht: an die Stelle der metaphysischen Phantasie tritt mit der Zeit die ernste methodische Besinnung und das Bedürfnis sorgfältigster Prüfung der Tragkraft der Voraussetzungen, auf denen sich die philosophischen Theorien aufbauen sollen. Inhaltlich aber sind alle irgendwie bedeutsamen Lehren, welche die neuere Philosophie aus der Stimmung der Renaissance und aus dem Ertrage ihrer wissenschaftlichen Bewegung heraus entwickelt hat, durch die Richtung auf die Naturerkenntnis bestimmt und ebendeshalb in immer höherem Maße von demjenigen Momente abhängig, welches sich als das einzig standhaltende für die begriffliche Sicherheit erwiesen hatte, dem Prinzip der Mechanik. Bis gegen Ende des 17. Jahrhunderts hat dies Zeitalter der naturwissenschaftlichen Metaphysik gedauert, und man darf den Fortschritt der großen metaphysischen Systeme, die es gezeitigt hat, gerade in dieser schrittweisen Szientifikation, in dieser Umwandlung phantasievoller Naturbetrachtung in mathematisch-mechanische Erkenntnis finden. Immer aber waltet darin der Trieb zum Ganzen; es sind alles Systeme von großen Linien, von umfassender Allseitigkeit des Inhaltes und von einheitlicher Konzentration der gedanklichen Form.

I. Nicolaus Cusanus. Alle diese Eigenarten finden sich in einer noch unentwickelten und zum Teil ungeschiedenen Vereinigung vorbildlich, ja man darf sagen vorahnungsvoll, bei einem Manne, der auf der Schwelle zwischen Mittelalter und Neuzeit in dem einen Sinne das letzte System der mittelalterlichen Philosophie und im anderen Sinne das erste System der neueren Philosophie geschaffen hat. Es ist Claus Chrypffs aus Cues, ein Sohn des Mosellandes, der, bei den Fraterherren in Deventer und auf der Universität Padua als Jurist und Theologe gebildet, nach kurzer Anwaltspraxis, die er in Mainz übte, in die geistliche Laufbahn überging und als Kardinal und Bischof von Brixen 1464 gestorben ist. In seinen zahlreichen Schriften kommt neben allem Veralteten und Trockenscholastischen die Fülle des neuen

Stellung des Cusaners. 
Geisteslebens keimhaft zutage; und so unfertig sie sind, so bedeutungsvoll entwickeln sich die zukunftsreichen Prinzipien aus einer Betrachtungsweise, die schon ein ausgesprochenes Interesse für die erkenntnistheoretischen Probleme erkennen läßt.

Docta Von den drei Stufen der Erkenntnis, deren Annahme eine-geläufige ignorantia. Lehre in den mittelalterlichen Theorien war, ist der "Sinn" auf das Einzelne, Singuläre, Konkrete und damit zufällig Wirkliche gerichtet, das eben als solches nicht erdacht und erklügelt, sondern nur erlebt und erfahren werden kann. Aber die Vorstellungen dieser Erlebnisse sind undeutlich und verworren. Deshalb muß der „Verstand“, die ratio, hinzutreten, der diese sinnlich gegebenen Momente unterscheidet und verknüpft, der sie im Urteil bejaht und verneint und dessen fundamentales Prinzip die Unvereinbarkeit der Gegensätze, der Satz des Widerspruches ist. Im Sinne der nominalistischen Logik betrachtet der Cusaner die Formen verstandesmäßiger Verknüpfung, die allgemeinen Begriffe als die Hilfsmittel des Denkens, denen keine Realität in dem Sinne wie den Gegenständen der Erfahrung zukommt. Als die höchsten Formen gelten dem mit der pythagoreischen Literatur umfangreich vertrauten Denker die Zahlen, und die Mathematik als die Lehre von ihrer rationalen Vereinbarkeit ist deshalb die vollkommenste Verstandeserkenntnis. Aber ebendiese weist über sich selbst hinaus. Gerade die mathematischen Größen zeigen, daß Verschiedenheiten und Gegensätze, die im Endlichen scharf gesondert sind, im Unendlichen zusammenfallen, wie der Kreisbogen und die zugehörige Sehne, wie die Hypotenuse und die Kathete. Dieser Zusammenfall der Gegensätze (coincidentia oppositorum) im Unendlichen übersteigt alle Verstandeseinsicht und steht mit ihr in Widerspruch. Dafür muß deshalb das dritte Erkenntnisprinzip, die intelligentia, eintreten, die jenseits alles dem Verstande begreiflichen diskursiven Wissens liegt und insofern eine Unwissenheit darstellt, aber eine höhere, bewußt begründete: die docta ignorantia.

Eadlichkeit und Unendlichkeit.

Eine solche im späteren Mittelalter nicht seltene Verknüpfung von nominalistischen und mystischen Erkenntnisprinzipien ist bei dem Cusaner dadurch charakterisiert, daß das Entscheidende in diesem Gegensatz bei ihm die Beziehung der ratio auf das Endliche und der intelligentia auf das Unendliche ist. Die docta ignorantia steht über den Gegensätzen verstandesmäßiger Bejahung und Verneinung. Sie weiß, daß alle begrifflichen Erkenntnisse des Endlichen nicht die letzte Wahrheit enthalten, dab sie in ihrer Einseitigkeit recht und doch ebenso auch unrecht haben. Die wahre Einsicht ist auf die Einheit der Gegensätze und eben damit auf das Unendliche gerichtet, und wenn sensus und ratio die Welt als den Inbegriff der endlichen, voneinander verschiedenen und in bestimmten Beziehungen zueinander befindlichen Dinge begreifen, so hat die docta ignorantia die unendliche Gottheit zu ihrem Gegenstande.

Diese erkenntnistheoretisch-metaphysische Bewertung des Begriffspaares Gottes.

Unendlich und Endlich ist ein bedeutsames und spezifisch-moternes Element 
in dem Denken des Cusaners. Der griechische Geist hatte dereinst nur in dem Begrenzten die Vollkommenheit und die wahre Realität finden können; ihm war das Unendliche als das 'gedanklich Unbestimmte und das Unfertige auch das Unwirkliche oder das Minderwertige und Minderwirkliche. Mit der Zeit hat sich diese Wertung der beiden Begriffe aus einer Reihe von metaphysischen und religiösen Motiven geradezu umgekehrt und vertauscht. Aber angesichts des Fortwirkens der platonisch-aristotelischen Begriffsformen war das nicht mit voller Ausdrücklichkeit herausgekommen, und erst bei dem Cusaner ist dieser Wertwandel derartig abgeschlossen, daß die neue Fassung des Verhältnisses als die bis auf den heutigen Tag geltende und uns als selbstverständlich erscheinende festgelegt ist. Gott als das unendliche, über alle Gegensätze erhabene Wesen und die Welt als den Inbegriff der voneinander verschiedenen endlichen Einzeldinge zu bezeichnen, ist eine allgewohnte Ausdrucksweise geworden.

Für den Cusaner liegen in diesen Bestimmungen eine Anzahl von Voraus- Gott und Welt. setzungen, die zu einer Verknüpfung pantheistischer und theistischer Motive führen. Wenn Gott als das unendliche Sein angesehen wird, das in der Welt sich zu der Fülle der endlichen Dinge zersplittert, deren Gegensätze in ihm aufgehoben sind, so betont Nicolaus doch um so energischer die Verschiedenheit von Gott und Welt. Wenn auch die Dinge der Welt ihr Sein nur von Gott haben, so ist die Seinsart eben verschieden. In Gott fallen Möglichkeit und Wirklichkeit, essentia und existentia, zusammen, er heißt das "Kann-ist" (possest): bei den Kreaturen dagegen bedeutet ihre essentia nur ihre Idee in Gott als ihre Möglichkeit; ihre existentia dagegen wird immer erst durch eine besondere Ursache hervorgerufen, und diese ist wieder ein einzelnes endliches Ding. Darin eben besteht die Zufälligkeit des endlichen Dinges. Wäre es nur aus Gott und aus seiner Wesenheit abzuleiten, so wäre es notwendig wie Gott selbst. Deshalb ist zunächst die Welt als der Inbegriff der Einzeldinge zwar der Essenz nach, aber nicht der tatsächlichen Wirklichkeit nach mit Gott gleich. Außerdem aber folgt, daß deshalb auch das Weltall ebenfalls unendlich, aber in einem anderen Sinne unendlich sein muß. Nicolaus nennt die letztere die abgeschwächte, die privative Unendlichkeit, das interminatum. Während Gott selbst als raumlos und zeitlos unendlich zu denken ist, gilt das Universum als in Raum und Zeit unbegrenzt, und die endlose Reihe des Endlichen, deren Inbegriff seine Totalität ausmacht, bleibt an allen ihren Punkten mit dem wahrhaft Unendlichen inkommensurabel und aus ihm rational nicht ableitbar.

In diesem metaphysischen Zusammenhange gilt nun selbstverständlich Universum und auch das einzelne Endliche seiner Essenz nach als göttlichen Wesens. Gott selbst ist wie das Größte - das Universum - so auch das Kleinste - das Individuum. Darin besteht die höchste coincidentia oppositorum. Es ist in der Welt überall dasselbe und doch wieder an jeder Stelle etwas Besonderes. Nicht zwei Dinge der Wirklichkeit sind einander völlig gleich: und doch ist in jedem der Essenz nach das Ganze, d. h. auch alle übrigen Dinge enthalten. 
In omnibus partibus relucet totum. So ist nach dem Worte des arabischen Philosophen Alkendi jedes Individuum ein Spiegel des Universums; überall ist dem Wesen nach alles. Omnia ubique. Und weil so alles aufeinander hinweist, so besteht $z$ wischen den Dingen eine göttliche Harmonie.

Nicolaus und Leibniz.

Dies alles führt der Cusaner zum Teil in der Hülle phantastischer Zahlenspekulationen aus: aber es stecken darin eine Menge Zukunftsgedanken, die sich in reiferer Form durch die späteren Systeme lindurchziehen. Dasselbe gilt für die Folgerungen, die sich aus dieser Weltanschauung für den Menschen und seine Erkenntnis ergeben. Auch dieser ist ein parvus mundus, ein Mikrokosmus, der mit seinem eigenen Wesen alle Dinge in sich trägt - als seine Vorstellungsweisen, seine coniecturae. Diese Bewußtseinswelt entspricht der Realität, ohne sie abzubilden: sie ist eine innere aus dem Wesen des Menschen bestimmte Neuschöpfung. Damit erscheint auch das terministische Moment in dieses System aufgenommen, das als der Embryo der modernen Philosophie in seiner eigenartigen Mischung von Theismus und Pantheismus, von Mystik und Naturphilosophie, von mathematischem Platonismus und terministischem Nominalismus den großgedachten Versuch ausgleichender Harmonisierung darstellt. Ein solcher Versuch war im Beginn, wo sich die Geister schieden, nicht haltbar, aber er konnte nach der Scheidung zum Schluß in höherer Form wiederkehren: und das geschah bei Leibniz. In der Renaissance selbst treten die Momente, zu Sondergestaltungen getrennt, als italienische Naturphilosophie und deutsche Mystik auseinander. erkenntnis zugewendeten Denkens ist bei den Italienern durch zwei Dominikaner vertreten, die, beide ihrem Orden entflohen, als Schicksalsgenossen und tragische Gestalten vor der Nachwelt stehen und doch grundverschieden in ihrem Wesen und Denken von denselben Grundlagen aus sich entwickelt haben. Der ältere von ihnen, Giordano Bruno aus Nola in Kampanien, verdankt seine geistige Freiheit dem Cusaner und den Anregungen von Telesio, vor allem aber dem Kopernikanismus, der seine ganze Phantasie ergriff und sich bei ihm zuerst in ein gedankliches System umsetzte. Das trug ihm Verdächtigungen und Untersuchungen ein, bis er von Neapel nach Rom und dann weiter nach Oberitalien flüchtete. Ein unstetes Wanderleben hat ihn dann durch die Länder und die verschiedensten Kreise geistigen Lebens geführt. Weder in Genf noch in Paris hat er sich den kirchlichen Anforderungen unterwerfen mögen; selbst in Oxford und London, in dem freien Lande der Elisabeth, wo er die Gunst der Großen genoß, hat die Leidenschaftlichkeit seines Auftretens und der übertriebene Radikalismus seiner Sprache ihm keine dauernde Freistatt gelassen, und ebenso ist an den verschiedenen deutschen Universitäten, in Marburg, Wittenberg, Prag, Helmstedt seines Bleibens nie lange gewesen. Dazu kam das Suchen nach Verlegern und die Abenteuerlichkeit seines Wesens. Endlich hat ihn der Lockruf eines Landsmannes nach Padua gezogen, und da er dort die von ihm erwartete magische 
Kunst des Goldmachens nicht lehren konnte, so erfüllte sich sein Geschick, indem er an die Inquisition verraten, von Venedig nach Rom ausgeliefert und nach langer Haft und Folterung zum Feuertode verurteilt wurde. Der Märtyrer ist von der Nachwelt nicht nur durch weitgehende Anerkennung, sondern zum Teil durch Überschätzung entschädigt worden. Man hat leicht übersehen, daß die begriffliche Struktur seiner Lehren, das im eigentlichen Sinn Philosophische, sich in stärkster Abhängigkeit von Nicolaus Cusanus befindet. Dafür hat der Nolaner die glänzende Phantasie voraus, die blühende Darstellung, die lebhafte Ausmalung und dazu die rücksichtsloseste Verkündigung, die fanatische Polemik, die leidenschaftliche Behauptung, kurz alles, was Eindruck macht. Vor allem seine italienischen Schriften, die meist der glücklichen Zeit seines Aufenthalts in London ihren Ursprung verdanken, besitzen in ihren prosaischen Teilen nicht minder wie in den poetischen den hinreißenden Schwung, mit dem sie die Nachwelt ergriffen haben; aber auch die lateinischen Lehrgedichte zeigen vielfach eine äußerst glückliche Anlehnung an ihr großes antikes Vorbild, Lukrez.

Im ganzen ist der Eindruck dieser temperamentvollen Erscheinung sicher Kopernikanis groß, blendend und begeisternd. Trotz aller Nebenseiten des Renommistischen, des Agitatorischen, des Verbitterten und zum Teil selbst Frivolen bleibt die gewaltige Macht der Weltanschauung bestehen. Brunos Lehre ist tatsächlich der kosmologische Ausbau und der metaphysische Unterbau des Kopernikanismus mit den Begriffsformen des Cusaners. Durch alle Schriften Brunos geht ein Grundgefühl der Erlösung aus den doppelten Fesseln des Sinnenscheins und der dogmatischen Tradition; von der Beschränktheit des bisherigen Weltvorstellens öffnet sich der Ausblick in unendliche Weiten und ein leidenschaftlicher Auftrieb in ungeahnte Ferne. Die Lehre des deutschen Astronomen ist ein Triumph der Vernunft und ihrer freien Selbständigkeit über die sinnliche Vorstellungsweise, die durch die Herrschaft des Dogmas geweiht und befestigt war. Aber die heliozentrische Vorstellung des Kopernikus weist über sich selbst hinaus in die Unendlichkeit des Universums zu der Vorstellung der unendlichen Vielheit der Sonnenwelten, die in dem unendlichen Ablauf der Zeiten, in ihrem Entstehen und Vergehen blühendes und welkendes, aber immerwährendes Leben überall aufweisen. Damit nimmt Bruno das demokritisch-epikureische Weltbild, das durch die Vorherrschaft des aristotelischen Systems fast zwei Jahrtausende lang verdunkelt gewesen war, in leuchtenden Linien wieder auf und zeichnet mit dithyrambischer Phantasie die Grundzüge der Weltauffassung, zu der sich die heutige Naturforschung bekennt.

Weniger originell ist Bruno, wo er die begrifflichen Voraussetzungen Universalismus. für eine solche Kosmologie zu bestimmen sucht. Das unendliche Leben des Universums ist der Erguß des unendlichen Wesens selbst, der Gottheit. Für das Verhältnis von Gott und Welt braucht auch Bruno das Begriffspaar essentia und existentia, aber ebensooft auch das aus der averroistischen Tradition stammende Begriffspaar natura naturans und natura naturata, und 
darin tritt eine entschieden stärkere Betonung des pantheistischen Momentes zutage. Noch mehr wird deshalb bei Bruno die Allgegenwart des göttlichen Wesens in allem Endlichen betont und damit insbesondere die physische Homogeneität der Welt metaphysisch begründet. In dieser Aufhebung der alten Wertscheidung von Himmel und Erde besteht der Ersatz für die Verweisung der Erde und des Menschen aus dem Mittelpunkte der Dinge. Gottes Wesen lebt auch in dem entlegensten Weltwinkel. So verklärt sich die astronomische Betrachtung zu einem universalistischen Optimismus der Weltanschauung, der über alle Unvollkommenheit und alles Leid zur Anschauung des Ganzen emporhebt. Das wahrhaft Wirkliche ist allüberall, in allen Hüllen und Gestalten die eine göttliche Urkraft. Die begeisterte Verehrung für das in sich harmonische Universum ist der heroische Enthusiasmus, den Bruno poetisch gefeiert hat.

Individualismus. Die Lehre von der coincidentia oppositorum läßt auch hier das einheitliche Weltwesen in dem Gegensatz des Größten und des Kleinsten erscheinen: aber im Laufe seiner Entwickelung scheint Bruno der Lehre vom Minimum ein immer wachsenđes Interesse zugekehrt zu haben. Jedenfalls dämmert bei ihm, wie vielleicht schon bei dem Cusaner, die Vorstellung vom unendlich Kleinen als der doch bestimmten und das Ganze bestimmenden Größe, der Gedanke, der bei Galilei zum Begriffe der unendlich kleinen Impulse und später bei Newton wie bei Leibniz zu dem des Differentials geführt hat. Das physikalische Minimum, das Atom, wird bei Bruno aus der epikureisch-demokritischen Tradition übernommen; aber der Atomismus finde bei ihm nicht wie bei Galilei die Verwendung für eine mathematische Theorie, sondern fließt vielmehr ohne begriffliche Schärfe in die Grundvorstellung des Vitalismus ein, zu der auch die aus der Stoa und dem Averroismus herübergenommene Auffassung beitrug, daß der unendliche Weltäther, das Urfeuer, alle Keime in sich enthalte und sie nach demselben Gesetz zu ihrem Sonderdasein entfalte. Damit verwandelt sich der physikalische Atomismus in eine zugleich universalistische und individualistische Metaphysik. Das metaphysische Minimum ist die Monade, das ursprüngliche Einzelwesen, welches doch seiner Essenz nach mit dem Universum identisch ist. Wie im Organismus die belebende Seele überall ganz und doch in den verschiedenen Organen mit verschiedener Tätigkeitsweise waltet, so die göttliche Urkraft des Weltalls in allen Individuen: jedes davon es selbst, verschieden von allen anderen und doch ein Spiegel der Welt, - jedes darum auch in seiner Lebenstätigkeit auf das Ganze ebenso bezogen wie auf sich selbst, so wie die Sterne sich zugleich um die eigene Achse und um die Sonne drehen. Alle diese Gedanken, insbesondere auch die Vorstellungen von den die Gestirnbewegungen bestimmenden Kräften treten bei Bruno noch in anschaulicher phantasievoller Form auf. Sie haben ebendarin ihre packende und anregende Macht besessen, und es stecken in ihnen doch schließlich schon alle die großen begrifflichen Probleme der theoretischen Naturforschung, für die dem spekulierenden Mönche nur noch die Geduld des Experiments und die Ruhe 
der Mathematik fehlten. Dafür waltet bei ihm die prächtige Energie der Gesamtauffassung - ein Mut, sich in die Welt zu wagen -, eine leidenschaftliche Ausweitung der Seele in die göttliche Unendlichkeit.

Nicht so farbig und glänzend, aber auch kühn und weitreichend sind die Gedanken bei Brunos ernstem Ordensbruder, Tommaso Campanella. Auch er war ein Kind des heißen italischen Südens, zu Stilo in Calabrien geboren, in noch jüngeren Jahren als Bruno zum Dominikaner geworden und ebenso kräftig wie dieser von Telesio beeinflußt. Bei ihm kam eine ausgebreitetere Gelehrsamkeit hinzu, die sich namentlich auch auf die antike Literatur bezog, und die Masse und Sicherheit seines Wissens machte ihn bald magischer Künste verdächtig. Noch mehr aber schadeten ihm die großsprecherischen Gedanken, mit denen er die politisch-soziale Umwälzung rühmte, zu der die Philosophie führen müsse. Nur so ist es begreiflich, daß die spanische Regierung in seiner Heimat einen Mann, der ihren religiösen Interessen auf keine Weise im Wege war, mit zäher Grausamkeit verfolgt hat. Als Führer einer Verschwörung wurde er schließlich verhaftet, und es begann eine lange, schwere Leidenszeit: durch ein halbhundert scheußlicher Kerker geschleppt, hat er die Folter standhaft und robust ertragen, Dichtungen, durch deren Trost er sich aufrechterhielt, im Gedächtnis bewahrt und Besuchern überliefert, später aber, als ihm das Schreiben gestattet war, Werk auf Werk in die Öffentlichkeit gesandt. Nachdem schlieblich der Papst Urban VIII. seine Haft erst gelindert und dann aufgehoben hatte, mußte er vor neuen Verdächtigungen der Spanier unter dem Schutz der französischen Gesandtschaft enttliehen. In Frankreich traf er mit Gassend zusammen, wurde durch diesen nach Paris in den Kreis von Mersenne eingeführt und war unter der Gunst Richelieus mit einer Gesamtausgabe seiner Werke, die den Titel "Instauratio magna scientiarum" führte, beschäftigt, als ihn der Tod im Jahre 1639 überraschte. Seine überaus zahlreichen Schriften betreffen die mannigfachsten Gegenstände naturwissenschaftlicher und historischer Art; auch über praktische Dinge, wie Steuerfragen und allgemeine politische Probleme, sodann über Metrik und Poetik hat er sich geäußert; selbst eine Tragödie, die Maria Stuart als katholische Glaubensheldin feiert, befindet sich darunter.

Für seine Philosophie ist der gelehrte und enzyklopädische Charakter entscheidend, seine lateinische Darstellung demgemäß der traditionellen noch verwandt, das inhaltliche Gesamtinteresse aber durchaus auf die Interpretation der Natur als der lebendigen Gottesoffenbarung gerichtet. Dabei ist ein spezifisch-moderner Zug die eingehend erkenntnistheoretische Grundlage des Systems, und hierin tritt die Verknüpfung des nominalistischen und terminalistischen Sensualismus mit skeptischen und phänomenalistischen Folgerungen ähnlich wie bei Vives und Sanchez hervor. Alle Erkenntnis ist Empfindung; sie beruht nicht nur inhaltlich auf Empfindung, sondern alles, was man Denken, Urteilen und Schließen nennt, ist ebenso wie alle Erinnerung immer nur wieder Empfindung in wiederholter, mittelbarer, verwickelter, umgebildeter Form. Aber der Wert der Empfindung ist wieder nur der, daß 
wir direkt nur unsere eigenen Zustände, andere Dinge dagegen nur durch diese und in diesen empfinden. Eigentliche Erkenntnis haben wir nur von uns selbst: an den Dingen erkennen wir nicht, wie sie an sich selbst sind, sondern nur, wie sie auf uns wirken. Wenn aus solchen Elementen des zeitgenössischen Denkens bei Campanella gleichwohl ein umfassendes System der Philosophie erwachsen ist, so hilft dazu das Postulat der Welteinheit: der Mensch ist der parvus mundus, und aus seiner Selbsterkenntnis müssen durch Analogie die drei Primalitäten aller Wirklichkeit, das posse nosse velle, $d . h$. Macht, Wissen und Wollen erschlossen werden. Diese Proprinzipien finden sich in ihrer Vollkommenheit bei Gott, als dessen Allmacht, Allweisheit und Allgüte; in der Welt aber mischt sich das Sein mit dem Nichtsein, dessen Primalitäten entsprechend die der Ohnmacht, des Nichtwissens (der Bewubtlosigkeit) und der Bosheit sind. Dieser neuplatonische Grundgedanke von der Welt als der Mischung von Sein und Nichtsein entwickelt sich bei Campanella in ein System der Weltschichten nach der alten Vorstellungsweise und verquickt sich infolgedessen auch mit dem astrologischen und magischen Aberglauben, dem dieser Dominikaner in schwer begreiflicher Ausdehnung unterworfen ist. So sehr er aber in allen diesen Fragen hinter der freieren Auffassungsweise Brunos zurückbleibt, so teilt er doch mit ihm den Universalismus, den Zug zum Ganzen. Alles in der Welt hat trotz seiner Eigenartigkeit diese Bindung an ein Höheres und Allgemeineres; das ist die natürliche Religion, ein allgemeines Verhältnis des Gehorsams, der Einordnung in ein Ganzes.

Sozialphilosophie.

Dies Prinzip wird nun von Campanella - und darin besteht das Neue und Selbständige bei ihm - von der Metaphysik her auf die menschliche Gesellschaft angewendet und bestimmt seine ethischen, politischen und sozialen Ideen. Selbsterhaltung durch Vereinigung ist der Grundgedanke, unter dem er die verschiedenen Motive aus der historischen, der natürlichen, der theologischen Auffassung von Staat und Recht zusammenzufassen gesucht hat, und jene metaphysischen Grundgedanken führen dabei auf eine höchst bedeutsame und interessante Formulierung. Wenn alles velle auf das posse, aller Wille auf Macht gerichtet ist, so ist das posse nur möglich durch das nosse, die Macht nur durch das Wissen. Deshalb soll aus dem neuen Wissen, das Campanella wie seine ganze Zeit mit fieberhafter Sehnsucht erstrebt, eine neue Machtgestaltung der Gesellschaft zur Erreichung ihrer irdischen Glückseligkeit hervorgehen. Der Mensch will und soll die Welt beherrschen und seine Macht über die Natur ausdehnen: er kann das nur durch sein Wissen, aber nicht durch das alte kontemplative, unpraktische Wissen, sondern durch das neue, das sich an die Sachen selbst wendet, durch die Realphilosophie des neuen Sensualismus. So will Campanella ein Umgestalter werden, aus der Philosophie soll eine neue und bessere Gesellschaftsordnung erwachsen, die den Menschen befriedigt, und die ruhmredige Verkündigung dieses Programms hat ihn in den Ruf eines Revolutionärs gebracht, den er so schwer büßen mußte. 
Die Utopie des Sonnenstaates, die Campanella als Anhang zu seiner Sonnenstaat. Realphilosophie veröffentlicht hat, zeigt in ihrer Einkleidung ähnlich wie bei Thomas Morus eine Anlehnung an Platons "Gesetze" und an seinen „Kritias". Auch hier breitet sich auf einer Insel das Leben eines Volkes aus, das zu einer vollkommenen und friedlichen Gestaltung seines Gesamtlebens gelangt ist. Im Mittelpunkte konzentriert sich in einem monumentalen, mathematisch abgezirkelten Ringe von Palästen, die den Riesentempel umgeben, alles Leben des Volkes. Hier ist der Sitz der Wissensmacht. Denn in diesem Staate gibt es keine anderen Unterschiede der Individuen, als die sie ihrem Wissen verdanken. Im übrigen herrscht völlige Gleichheit. Es ist ein Reich der allgemeinen Arbeit und des allgemeinen Lebensgenusses: und beides, Arbeit und Genub, wird durch das Wissen geregelt. Dabei ist es für die Wucht der Renaissancestimmung höchst charakteristisch, daß dieser Mönch keine Scheidung von weltlichem und geistlichem Leben kennt, beide vielmehr in seiner Nookratie eine ungetrennte Einheit bilden. An der Spitze soll ein Priesterfürst stehen, Sol oder Metaphysicus, und unter ihm drei Unterfürsten, die jene drei Primalitäten vertreten: Macht, Weisheit und Liebe. Auf sie verteilen sich die verschiedenen Lebensschichten der Gesellschaft, in denen alles bis auf das Kleinste von Behörden und Beamten geordnet ist. Nach platonischem Muster wird die Züchtung der Rasse durch staatliche Bestimmung der Paarung, die gemeinsame Staatserziehung des so erzeugten Geschlechtes dargestellt. Auch die Erziehungslehre Campanellas ist dabei höchst charakteristisch und modern. Er ist der erste, der nicht nur das trivium und quadrivium, sondern auch die humanistische Bildung verwirft und dafür Mathematik und Naturforschung als die Grundlagen aller Erziehung proklamiert. Der sensualistische Philosoph will zu einem grotesken Anschauungsunterricht die langen Wände der Paläste verwendet wissen, auf denen in lehrhafter Ordnung der orbis pictus gemalt sein und vor denen es lustige Stunden spielenden Lernens im Freien geben soll. So erwirbt dann die Jugend praktische Vorbildung für die verschiedenen Berufe, auf die der Staat die Individuen je nach ihrer Begabung verteilt und für deren Ausübung er alles Material besitzt und verwaltet, wie er auch alle Arbeit und allen Anteil am Ertrag gleichmäßig verteilt. In einer so vollstä̀ndig sozialistischen Gesellschaftsordnung, die natürlich auch eine Gemeinschaft des Wohnens und des Speisens einschließt, wird die Realwissenschaft durch den Fortschritt ihrer Entdeckungen und Erfindungen, durch den immer glücklicheren Bau kleiner und großer Maschinen die Beherrschung der Natur immer leichter und spielender gestalten und ein behagliches Gesamtleben schon durch einen vierstündigen Arbeitstag ermöglichen: in den vier Stunden freilich wird ordentlich geschafft und nötigenfalls mit Prügeln nachgeholfen. Das ist in charakteristischer Naivität die neue Ordnung der Dinge; deren Bild dieser erste moderne Sozialist gezeichnet hat.

Allein Campanellas Ideen reichen über die soziale Ordnung der einzelnen Papstum und Staaten hinaus: alle zusammen haben neben dem Komfort des irdischen Da- 
seins, den jeder einzelne für seine Mitglieder herbeischafft, noch eine gemeinsame Aufgabe in der religiösen Einheit der Menschheit. Deren Lösung aber verlangt eine oberste, allen anderen gebietende politische Macht, die „Monarchie", und diese muß ihrer Bestimmung zufolge im Dienste des Papsttums stehen. In solchem Sinne führte Campanella seinen Streit gegen den Gedanken des unabhängigen weltlichen Nationalstaates und gegen Macchiavelli als dessen Vertreter. Der sozialistische Mönch verlangt in der Weltpolitik die Befestigung der Suprematie des römischen Stuhls durch das spanische Weltreich, dem nach göttlichem Ratschluß die Schätze der neuen Welt dazu dienen sollen, die Ketzer auszurotten. Darin gipfeln die politischen Lehren dieses Mannes, dessen Pläne ebenso unausgeglichen sind wie seine Persönlichkeit selbst in ihrer rätselhaften Mischung von Gelehrsamkeit und Phantasterei, von Gedankenkühnheit und Pedanterie, von' Neuerungssucht und Aberglauben, von Begeisterung und Beschränktheit.

Mystik und Paracelsismus.

III. Jákob Böhme. Das Gegenstück zu solcher Ausladung der naturphilosophischen Anschauung bildet die innerliche Entwickelung des religiösen Gefühls in der deutschen Mystik. Aber auch diese hat ihre Vollendung zu einem umfassenden System der Philosophie nur dadurch gefunden, daß sie die Interessen der beginnenden Naturwissenschaft in sich aufzunehmen vermochte. Je mehr das mystische Denken für sich allein, in seiner Opposition gegen die neue Konfession ebenso wie gegen die alte, alles „Historische“ von sich wies, um so mehr endete es bei einer zarten, dünnen und unbestimmten Vorstellungsweise, der es an der Kraft der gedanklichen Bewältigung des Empirischen fehlte. Die Ergänzung, deren deshalb die Mystik bedurfte, hat sie im Paracelsismus gefunden. Auch diese phantastisch an die Reform der Medizin sich knüpfende Naturphilosophie lebte als eine Volksbewegung in der Stille, von der offiziellen Wissenschaft der Universitäten verbannt, in der Gestalt von Flugblättern und Traktätchen durch wandernde Handwerksburschen von Herberge zu Herberge getragen. So kamen Mystik und Paracelsismus in stetige Berührung, und das theosophische Moment, das dieser magischen Naturphilosophie gleichfalls innewohnte, vermittelte (man sieht das schon in den Schriften von Valentin Weigel) die Verbindung zwischen beiden Bewegungen um so mehr, als ja beide schließlich in der neuplatonischen Tradition unbewußt ihre gemeinsame Quelle hatten.

Als wandernder Handwerksbursche hat der Görlitzer Schuster Jakob Böhme diese gärenden Gedanken in sich aufgenommen und sie nachher in dem stillen und ehrsamen Leben, das er als Meister in seiner Heimatstadt führte, grübelnd in sich verarbeitet. Dann aber ist es über ihn gekommen wie eine Offenbarung, und er hat, was in ihm wogte, hervorgesprudelt in seiner „Aurora“. Was er nachher noch zur Auseinandersetzung zum Teil mit den paracelsischen Ärzten, die ihn aufsuchten oder literarisch interpellierten, zum Teil mit den Angriffen, denen or von orthodoxer Seite her nicht ent- 
ging, in allerlei Schriften niedergelegt hat, ist wohl zur Ausführung und geschlosseneren Gestaltung seiner Lehre von Bedeutung, kommt aber an die Ursprünglichkeit und die packende Gewalt des Grúndbuches nur selten heran. Mit bewußtem Gegensatze gegen die Gelehrsamkeit fühlt Böhme sich in der Ursprünglichkeit seines religiösen Denkens als Reformator und Prophet, und ebendeshalb gibt er seine Offenbarung in der Muttersprache. Freilich ist sein Deutsch wunderlich genug, zum Teil mit lateinischen Brocken durchsetzt, die meist paracelsische Ausdrücke sind. Dazwischen ringt er der Sprache originelle Bildungen ab, und diese Prägungen bewegen sich in der Richtung, in der Meister Eckart zuerst die deutsche Sprache philosophisch zu reden gelehrt hatte. Die ganze Darstellung ist ungeschult, ohne beweisende Form, ein Hervorsprudeln der Anschauung, oft sehr dunkel und unfertig, manchmal durch prächtige Gedankenblitze erhellt und zu schönen und tiefen Sätzen scharf geformt - eine eigenartige Mischung von Tiefsinn und Dilettantismus, ein Autodidaktentum, das, von überkommenen Gedanken erfüllt, doch der eigenen Gestaltungskraft sich bewuBt ist. Gilt ihm doch die Sprache als der natürliche und notwendige Ausdruck des Denkens zugleich für die Quintessenz aller Wirklichkeit. Denn diese ist geistiger Natur, das Körperliche ist nur ihre äußere Hülle. Wenn dieser idealistische Grundziug der Mystik eine Erinnerung an Meister Eckart darstellt, so besteht doch zwischen diesem und dem Görlitzer ein prinzipieller Unterschied. Bei jenem bedeutete alles Entstehen und Vergehen auch der äußeren Welt, alles Werden und Entwerden einen Prozeb des Erkennens, bei diesem ist es ein solcher des Willens. So intellektualistisch die mittelalterliche Mystik war, so voluntaristisch tritt die neuzeitliche auf. Und dieser voluntaristische Grundzug ist bei Jakob Bōhme rein religiösen Charakters. Er durchdringt die ganze Natur mit religiösen Vorstellungen und will nach ihnen nicht nur Ursprung und Geschick, sondern auch das ganze Wesen der Dinge verstanden wissen. Aus dem Paracelsismus entnimmt er die Kenntnisse, die Begriffe, die Ausdrücke: aber ihnen allen gibt er eine religiöse Deutung, und den letzten Sinn der religiösen Kategorien bilden die Willensbestimmungen des Guten und des Bösen.

Der Ernst des Sündenbewußtseins und des Erlösungsbedürfnisses, derDasWeltproblem die intimste Triebfeder der deutschen Reformation gebildet hatte, ist so auch das entscheidende Motiv ihres philosophischen Systems. Dessen Zentralproblem aber mußte deshalb das Böse um so mehr werden, als der pantheistische Zug in der mystischen Tradition die Realität des Gottwidrigen unbegreiflich zu machen schien und für die Theosophie somit die schwierigste Aufgabe darin erwuchs, Gott als den metaphysischen Grund des Bösen zu begreifen, ohne seiner Heiligkeit Abbruch zu tun. Böhme geht dazu von der Betrachtung der Gegensätzlichkeit in der Welt aus und spitzt sie auf jenen religiösen Grundgegensatz zu: „Es ist nichts in der Welt, so nicht Gutes und Böses inne ist.“ Deshalb mul dieser Gegensatz schon in Gott selbst gesucht werden, und er ist in ihm nur dadurch zu verstehen, daß der Grund 
aller Dualität in der Notwendigkeit der Offenbarung steckt, die zum Wesen Theogonie. Gottes gehört: nur am Gegensatz ist Offenbarung möglich; wie das Licht nur an der Finsternis, so ist das Gute nur am Bösen, so Gottes Liebe nur an seinem Zorn offenbar. Es muß also in Gott etwas sein, das diese Selbstentzweiung und Selbstgebärung möglich macht, ein unoffenbares, bloßes Sein, unbestimmt und inhaltlos, der Urgrund und Ungrund, das ewig Eine, das nicht Licht noch Finsternis, kein Wesen, keine Person, Alles und Nichts bedeutet. Aber darin steckt der „Drang“, der Offenbarungsdrang, der noch gegenstandslose Wille, die bloße "Sucht" - die Sucht zu begehren. Sie erfüllt sich in dem „Insichschauen“, in dem Selbstbewußtsein als der ersten Selbstdarstellung des Urwillens. So wird die Schiedlichkeit im Wesen Gottes gewonnen, die Scheidung in die schauende Weltkraft und den geschauten Weltinhalt. Die metaphysische Theogonie, die Böhme in dieser Weise mit eigner Prägung gibt, erinnert ebenso an die erste Philosophie des Christentums, die Gnosis, wie an die neuplatonische Emanation, an die plotinische Trennung des Einen in den voûc und das vontóv. Das Objekt der Selbstanschauung Gottes (die platonische Ideenwelt) ist die Weisheit (die copía der Gnostiker) oder, wie Böhme sagt, die Wohne Gottes. Der letzte Sinn dieser Konstruktion ist aber der, in dieser zeitlosen, ewigen Selbsterzeugung Gottes die Selbstoffenbarung des Urwillens zum weltschaffenden Geist darzustellen, und in Böhmes tiefdringendem Versuche, das Verhältnis dieser metaphysischen Urpotenzen begreiflich zu machen, war das Bedeutsame und Zukunftsreiche die dialektische Ausschmiedung der Beziehungen zwischen dem Urwillen und der Weisheit, worin dieser sich selber offenbar wird und damit das Urbild der Welt aus sich heraus gestaltet. Das Problem alles Idealismus, wie die geistige Urwirklichkeit in bezug auf die Ursprünglichkeit und die Vorgewalt des Intellekts oder des Willens zu denken sei, ist hier bei Böhme an seiner Wurzel erfaßt und mit der ahnungsvollen Kraft grübelnder Phantasie zu einem grotesken Weltgemälde ausgebildet worden.

Kosmogonie. Je weiter nun Böhme von dieser Theogonie in die Kosmogonie hinabsteigt, um so mehr verknüpfen sich die mystisch-religiösen mit paracelsischnaturphilosophischen Vorstellungen. Die Natur in Gott wird als ein Reich von sieben Gestalten oder „Qualen“ entwickelt, die, wiederum in zwei Gruppen von je dreien mit einer Zwischenform, dem Feuer, gegliedert, in ihrer Reihenfolge das Aufsteigen von der Materialität, die aus Halten und Fliehen besteht, zum Feuer und Licht und weiter zum geistigen Leben darstellen. Es sind zugleich die Reiche der Engel, die das göttliche Urwesen in seinen verschiedenen Sonderverwirklichungen bedeuten. Aber dies alles bleibt noch in der Region der zeitlosen metaphysischen Wesenhaftigkeit. Die Wirklichkeit dagegen, die wir erleben, in ihrer Zeitlichkeit und Einmaligkeit, beginnt mit dem Bruch in der ewigen Welt, mit dem Sündenfall Luzifers. Dafür ist in den metaphysischen Bestimmungen nur die Möglichkeit, eben durch die Anderheit und die Schiedlichkeit im göttlichen Wesen gegeben; daß dieser RiB eintritt, daß Himmel und Hölle sich scheiden und als Mittelreich zwischen 
ihnen die irdische Welt geschaffen wird, das ist eine unbegreifliche Tatsache, aber eben damit der Grund aller empirischen Wirklichkeit. Die metaphysische Vorgeschichte zu der mosaischen Genesis - als solche will Böhme seine Theosophie aufgefaßt wissen - erklärt also zwar die Möglichkeit, aber nicht die Notwendigkeit der Weltschöpfung. Nur so viel hat das Grübeln gewonnen, daß diese Sinnenwelt als das sündige Zerrbild der idealen Natur in Gott verstanden wird, und daß die Mischung des Guten und des Bōsen in ihr, das Überwuchern der Grundzüge des göttlichen Wesens durch das Andersartige und Entgegengesetzte, daß diese durchgängige Wertdualität der irdischen Wirklichkeit begreiflich erscheint. In diese Grundvorstellung schmelzen dann die Lehren von dem magischen Zusammenhang aller Dinge, die neue astronomische Weltansicht und die Lehre von der weltbedeutenden Individualität des Mikrokosmus ein. Aber so viele Elemente des zeitgenössischen Denkens sich Böhme dabei mit sehr naiver und autodidaktischer Verarbeitung $z$ eigen macht, so bleibt doch der neuplatonische Kern der großen Überlieferung, in der er mit seinem mystischen Denken unbewußt steht, darin mächtig, daß der rückläufige Prozeß der Erlösung, die Ethik. Rückkehr der Natur in Gott, auch ihm als eine Entmaterialisierung, als eine Flucht aus der Welt in das Überirdische erscheint. Es ist, wie wenn das Geschick der Reformation sich darin ausprägte, daß in diesem ihrem philosophischen System von Luthers Weltfreude und weltdurchdringender Kraft nichts mehr zu spüren ist, daß vielmehr eine Stimmung des Pessimismus, der Weltverachtung und Weltverneinung über dem Ganzen liegt. Die alte mystische Verinnerlichung, das Abstreifen der entstellenden Materialität bildet den ethischen Grundzug der Böhmeschen Lehre, und wenn er zu schildern sucht, wie schließlich die sündige Welt sich zu Gott zurückfinden soll, so ist es die Verklärung der Natur, worin das materialische Wesen der Dinge, die vier Elemente mit Sonne, Mond und Sternen, wieder vergehen und die reinen Gestalten der göttlichen Selbstanschauung wieder unverhüllt hervortreten sollen - am Ende der Zeiten, wenn die ganze dramatische Episode von Sündenfall und Erlösung geschlossen ist. Damit endet die gnostische Dichtung des religiösen Idealismus, der erste Versuch, die Naturerkenntnis in das Innenleben hineinzuziehen und die Welt nur aus psychischen Kategorien, die eben hier noch wesentlich die religiösen sind, restlos zu begreifen.

IV. Francis Bacon. Böhmes Lebensende fiei in den Beginn des reli- Methodologiscbe giösen Bruderkrieges, der Deutschlands Wohlstand und Kultur zertreten, Nerbegrüidung den glücklichen Beginn von Kunst und Kunsthandwerk zur Verkümmerung, die Wissenschaft zur Erstarrung verurteilen sollte. Die Entwickelung der Philosophie ging mit der des geistigen Gesamtlebens auf den Westen Europas über, wo in England, Frankreich und den Niederlanden die größere politische Reife auch eine größere Selbständigkeit des Denkens, eine Unbeirrtheit von der Tradition, eine ursprüngliche Kraft philosophischer Neu- 
schöpfung mit sich brachte. Erst hier ist deshalb die eigentlich wissenschaftliche Neugestaltung der modernen Philosophie zu suchen. Denn so viele sachliche Keime der neuen Weltanschauung in der italienischen.Naturphilosophie wie in der deutschen Mystik aufstrebten, so fehlte es ihnen doch durchgängig an scharfer begrifflicher Formung: diese ist erst aus der methodologischen Opposition gegen die alte Wissenschaft, aus der geschulten Frage nach Aufgabe und Wesen der Erkenntnis hervorgegangen. In diesen Anfängen aber prägen sich uralte Gegensätze menschlicher Erkenntniswege in den neuen Formen aus, welche mit den methodischen Bestandteilen der beginnenden Naturforschung gegeben waren. So stehen sich die baconische Erfahrungsphilosophie und der cartesianische Rationalismus der Mathematik gegenüber.

Bacons Persönlichkeit.

Das Zeitalter der Elisabeth, das England zur protestantischen und kulturellen Vormacht erhob, hat der Nation nicht nur ihren größten Dichter, sondern auch einen ihrer eindrucksvollsten Philosophen geschenkt. Als eine Blüte reichen und vielgestaltigen Lebens erwächst neben Shakespeares ewiger Dichtung die programmatische Philosophie der Zeit. Thr Verkünder, Francis Bacon, erscheint mit seinem politischen Strebertum, mit seinem rücksichtslosen Utilismus, mit seiner blendenden Rhetorik recht eigentlich als das in das Getriebe der Zeit getauchte Gegenstück zu der inneren Reife und Überlegenheit, zu der rein menschlichen Hoheit und zu der tiefen Wahrheit des großen Dramatikers. Von dem Leben des Kanzlers, der als Baron von Verulam die höchsten Ziele seines Ehrgeizes erreicht hatte, um dann nach schmerzlichem Sturz sich in seine wissenschaftliche Muße verbannt zu sehen, lassen sich die Flecken der Charakterlosigkeit nicht abwaschen; aber seine Sünden sind die seiner Zeit, und seinem die praktische Welt durchdringenden Geiste war es beschieden, diese ihrer selbst noch unsichern Motive auf eine charakteristische Formel zu bringen. Diesem Renaissancekinde, dessen heiß erstrebte persönliche Lebenserfolge auf der Überlegenheit seiner Intelligenz beruhten, ging in vollem Bewußtsein die Bedeutung auf, welche im Gefüge der modernen Welt der geistigen Bildung zukommt. Tantum possumus quantum scimus. Für Bacon ist das Wissen kein Selbstzweck: die aristotelische $\theta \epsilon w p i \alpha$ und die mystische Intuition sind ihm gleich unsympathische Erzeugnisse der Buch- und Stubengelehrsamkeit des Mittelalters, Früchte klösterlicher Beschaulichkeit und selber unfruchtbar wie die Nonnen. Die neue Wissenschaft will wirklich mitten ins Leben treten. Wissen ist Macht, und diesen Gedanken wendet Bacon ins Große: nicht dem Menschen gegen den Menschen, sondern der Menschheit im Ringen mit der Natur sollen die Waffen des Wissens gegeben werden. Seine Wissenschaft will im Dienste der Kultur stehen, Naturbeherrschung durch Naturerkenntnis ist ihr Stichwort. Was die Magie geträumt hat, das leistet am hellen Tag die erfinderische Kunst der Zeit. Bussole, Uhr, SchieBpulver, Buchdruckerei haben die Umgestaltung der Welt begonnen, und wenn, was da gelegentlich und zufällig geleistet worden ist, erst die Sache einer bewußten und im Zu- 
sammenhange geübten Kunst geworden sein wird, dann bricht das neue Zeitalter der Menschheit an. Auch Bacon hat dies Ideal in Gestalt einer Utopie ausgesprochen. Seine unvollendete Nova Atlantis hat das soziale und politische Moment nicht ausgeführt und nur zu zeigen gesucht, wie die Überlegenheit eines Normalvolks auf seiner Erfindungskunst beruhe. Er schildert ein kluges Inselvölkchen, das durch Sendlinge von allen Entdeckungen und Erfindungen erfährt und sie daheim im Hause Salomonis systematisch vervollkommnet. Die programmatische Phantasie entwirft Teleskope und Mikroskope, Telephone und Mikrophone, Dampfwagen und Luftschiffe, chemisch konzentrierte Nahrungsmittel, Präservative gegen Krankheiten usw. Auch hier ist, wie bei Campanella, die praktische Wissenschaft darauf aus, mit ihrer Naturerkenntnis das Menschenleben so leicht und behaglich, so glücklich und genußfähig wie möglich zu machen, und hätte Bacon geleistet, was er hier programmatisch skizziert, so wäre er über die ganze moderne Lebenstechnik noch ein gut Stück hinaus.

Durch diese $Z$ wecke ist Bacons ganzes wissenschaftliches Werk, die Naturalismuz Instauratio magna oder das Regnum hominis bestimmt; denn das systematische Erfinden beruht auf dem Wissen, auf der Interpretation der Natur: und von all den vielen Wissenszweigen, welche der bisherige Globus intellectualis aufweist, bleibt für Bacon nur die empirische Naturforschung übrig. Mit ausgesprochenem Naturalismus gilt ihm nicht nur die übliche Beschränkung der Philosophie auf die Naturerkenntnis, sondern er schließt auch deren theosophische Behandlung, wie er sie bei Bruno, Campanella oder Paracelsus findet, grundsätzlich aus. Das Tafeltuch ist völlig zerschnitten, gar keine Fäden mehr laufen zwischen dem religiösen Vorstellen und dieșer Philosophie, die nichts sein will als Physik und physikalische Anthropologie. Freilich ist die naturalistische Wissenschaft von Bacon ebenfalls nur in der Art eines weit ausschauenden Programms und mit zum Teil sehr glücklicher Formulierung ihrer Aufgaben und Ziele verkündet worden; in der Ausführung aber ist sie nicht nur durch die Unzulänglichkeit der Kenntnisse, über die Bacon zu seiner Zeit verfügte, und der Vorstellungen, die er $z u$ ihrer Deutung bereit fand, sondern mehr noch durch die Einseitigkeit seiner methodologischen Auffassung am rechten Erfolge gehindert worden. Denn es ist tatsächlich schwer zu verstehen, wie der englische Kanzler an der mathematischen Grundlegung der naturwissenschaftlichen Theorie, die durch Keppler und die ersten Schriften Galileis doch bereits gewonnen war, so vollkommen verständnislos vorübergegangen ist. Er mochte wohl mit seiner Abneigung gegen alle metaphysische Begriffsdeuterei auch in der mathematischen Theorie, die ja in gewissem Sinne aus der traditionellen Zahlensymbolik herauswuchs, etwas Ähnliches wittern: jedenfalls hat er nur die eine Seite von der Originalität und fruchtbaren Kraft der modernen Naturforschung gesehen, die methodische Erfahrung, und so energisch er dieser Anforderung gerecht zu werden versucht hat, so sehr blieb er doch wegen der Vernachlässigung der Mathematik in einem einseitigen Empirismus hangen. 
Empirismus. Daß alles Naturwissen auf Erfahrung sich gründen muß, findet Bacon namentlich schon durch Telesio richtig hervorgehoben, aber die Interpretation der Natur, auf die es doch zuletzt hinauskommen soll, ist durch die bisherige Verarbeitung der Erfahrungen nicht erreichbar. Sie operiert mit den Formen des Syllogismus und sachlich mit dem aristotelischen Prinzip der Zweckmäßigkeit. Deshalb ist nach Bacon für die neue Naturwissenschaft das alte Organon unzulänglich, und er stellt ihr das neue entgegen. Das alltägliche Wahrnehmen jedes beliebigen Menschen ist in dieser rohen Form nicht geeignet, zum richtigen Verständnis der Natur zu dienen. Die Philosophie muß sich zuerst fragen, wie aus diesem Rohstoff die wissenschaftlich brauchbare, die reine Erfahrung herauszuschälen ist. In erster Linie gilt es dabei, alle die Trugbilder, die Idole auszuscheiden, mit denen der Vorstellungsmechanismus die reine Erfahrung durchsetzt und entstellt. Da sind zunächst die Idola specus, die persönlichen, individuellen Wahrnehmungsfehler, die, so zahlreich sie an sich sind, durch Vergleichung leicht eliminiert werden können, - weiterhin als Idola theatri die autoritativen Meinungen, die man an die Deutung des Erlebten heranbringt, - und ebenso die Idola fori, welche den Menschen mit den unwillkürlichen Voraussetzungen umspinnen, die er mit dem Einleben in eine entwickelte Sprache, mit der Anwendung ihrer Wörter und ihrer Verknüpfungsweise, ohne es zu ahnen, übernimmt: aber weitaus am gefährlichsten erweisen sich die Idola tribus, sie verstecken sich in der Denkweise und Deutungsweise, die dem Menschen durch seine eigene Natur, die er überall wiederzufinden vermeint, besonders in der Gestalt der teleologischen Auffassung alles Geschehens eingepflanzt sind. Alle diese Trugbilder müssen aus dem naiven Wahrnehmen ausgeschieden werden, damit die reine Erfahrung für die Wissenschaft hergestellt werde. Nur so wird man von der Herrschaft der alten Lehre frei werden, nur so endlich von den Worten zu den Sachen kommen.

Die Reinigung der Erfahrung von den unlauteren Bestandteilen, die ihr teils aus natürlichen, teils aus historischen Gründen beigemischt sind, geschieht nun am sichersten und vollständigsten durch das Experiment. Von dessen Bedeutung für die Naturforschung, von der Notwendigkeit seiner systematischen Anwendung und von dem Erfordernis einer wissenschaftlichen Leitung und Anordnung des Experimentierens zeigt das baconische Programm eine außerordentlich lebhafte und deutliche Vorstellung, wenn auch der Mangel des Verständnisses für die mathematische Theorie und für die wesentliche Bedeutung des Messens ihm den vollkommenen Einblick in den logischen Charakter des Experiments versperrte. Diese Grenzen der baconischen Methode kommen noch deutlicher zutage, wenn der Philosoph in dem aufbauenden Teil seines Organons von der Verarbeitung der reinen Erfahrung durch die induktive Methode handelt. Bacon hat hier das große Verdienst, mit aller Energie gegen die vorschnellen Verallgemeinerungen protestiert zu haben, denen die Phantasie auch seiner Zeitgenossen so vielfach wieder unterlag. Dem deutenden Geiste sollen nicht Flügel angesetzt, 
sondern Blei angehängt werden: er soll es lernen, mit mühsamer Allmählichkeit von den Tatsachen erst zu den niederen Allgemeinheiten und dann nur Schritt für Schritt zu den höheren und höchsten Gattungsbegriffen aufzusteigen. Es wäre eine historische Ungerechtigkeit, den Urheber dieser elementaren Vorschriften deshalb geringzuschätzen, weil sie uns heute ebenso selbstverständlich erscheinen, wie sie zu seiner Zeit neu und nötig waren. Aber andererseits ist nicht $z \mathrm{u}$ verkennen, daß sich Bacon in seiner Behandlung der Induktion das Wertvollste eben dadurch verschlossen hatte, daß er seine Theorie davon nur mit den Mitteln der formalen Logik aufbauen wollte und gerade damit wieder in die scholastisch-aristotelischen Formen zurückfiel, von denen er die Wissenschaft freimachen wollte. Seine Theorie der Induktion geht von der scotistischen Formenlehre aus und läuft im wesentlichen darauf hinaus, mit den Hilfsmitteln der Enumeration und der Exklusion (Tabula praesentiae und Tabula absentiae) durch möglichst vollständige und abgestufte Vergleichung (Tabula graduum) die dauernden "Formen" oder „Naturen“ $z$ u finden. Nur die Lehre von diesen Formen oder Naturen ist ihm eine berechtigte Art der Metaphysik. Sowenig er also darin originell ist, so ist doch auch wieder nicht zu übersehen, dab sich in diesen Untersuchungen die Einsicht Bahn bricht, in den Naturgesetzen, welche auf solchem Wege der Induktion als die allgemeinsten Formen der physischen Wirklichkeit aufgesucht werden sollen, die dem modernen Denken wesentliche Umgestaitung der platonischen Ideenlehre zu erkennen. Wie der griechische Denker in den reinen Gestalten die bleibenden Formen des Seins, so sucht die moderne Naturforschung in den Naturgesetzen die bleibenden Formen des Geschehens, und alle Probleme, die sich um die platonische Ideenlehre in bezug auf die Art der Wirklichkeit jener reinen Formen und auf ihr Verhältnis zu den einzelnen Erscheinungen schon im Altertum entwickelt haben, mußten sich in der Folge mutatis mutandis an der metaphysischen und erkenntnistheoretischen Ausbildung des Begriffes der Naturgesetze wiederholen. Bacon hat dies sein Verhältnis zu Platon, das seiner Lehre einen ungewollten Anklang an den Rationalismus gab, wohl gesehen, aber er hat es in seiner Scheu vor allen spekulativen Irrgängen der Philosophie nicht weiter verfolgt.

Der Forschungswert der in dieser Weise formulierten Methode war nun Programm der freilich für sich allein geringfügig. Gelegentlich mochte es Bacon wohl Naturforschung. glücken, durch kühne Analogieschlüsse zu brauchbaren Ergebnissen zu gelangen; wie er denn an dem typischen Beispiel im Novum organon zu der Definition gelangte, Wärme sei eine durch Hemmung auf die kleinsten Teile der Körper verteilte Bewegung. Aber im allgemeinen blieb seine Physik sachlich den Italienern gegenüber, einem Lionardo oder Galilei, rückständig. Statt mathematischer Einsichten bietet er nur allgemeine Postulate. Er übernimmt den demokritischen Atomismus und die quantifikatorische Naturauffassung und verlangt, daB alle Physik in letzter Instanz nichts anderes sein solle als Mechanik der Atome. Origineller, obgleich ebensowenig exakt 
im einzelnen durchgeführt, vielmehr nur programmatisch in Aussicht gestellt ist Bacons Anwendung derselben Prinzipien auf die empirische Psychologie, welche die Seelenzustände als gesetzmäßige Verbindungen elementarer Bewußtseinserscheinungen, d. h. der den Atomen zugeschriebenen Perzeptionen begreifen soll. Und derselbe methodische Grundzug geht durch den ganzen Entwurf seiner Anthropologie, die, in Individuallehre und Gesellschaftslehre geteilt, die theoretischen Disziplinen als die Grundlage für die praktischen behandeln soll. So gilt in der Somatologie die Erkenntnis des Lebens, die Physiologie, als bestimmt für die Anwendung in der Medizin: diese praktische Naturwissenschaft hat ihre Aufgaben als Diätetik, Pathologie und Makrobiotik, weiterhin aber auch als Kosmetik, Athletik und Genußkunst. Mit tiefem Blick weist Bacon dabei z. B. an dem Verhältnis von normaler und pathologischer Anatomie auf das Prinzip hin, daB auch die Krankheit als ein Ergebnis der allgemeinen Gesetze des Lebens unter veränderten Bedingungen anzusehen sei, und er stellt so mit vollkommen deutlichem Bewußtsein eine naturwissenschaftlich begründete Medizin der verrotteten Routine der Fakultäten und der leichtfertigen Phantasie der Charlatane entgegen. In dem psychologischen Teil der Individuallehre erhält die Mechanik der Perzeptionen ihre praktische Wendung in der Logik und der. Ethik als den Lehren vom rechten und nützlichen Gebrauch des Verstandes und des Willens. Und endlich erhebt sich über diese ganze Reihe der in Aussicht gestellten Wissenschaften noch die letzte Aufgabe: auch die menschliche Gesellschaft mit ihren Lebensformen als ein Ergebnis natürlicher Gesetzmäßigkeit zu verstehen.

Religiöse Indifferenz.

Das war also das Programm des Naturalismus und Empirismus, und von dieser Philosophie gab es freilich keinen Zugang zu supranaturalistischen Vorstellungen. Sie war religiös gänzlich unbestimmt. Die Lehren der Religion konnten daneben nur als etwas völlig Andersartiges, damit gar nicht in Beziehung Stehendes aufrechterhalten werden. Daher leugnet Bacon folgerichtig jede Möglichkeit einer philosophisch-rationalen Begründung theologischer Dogmen. Für ihn gibt es keine Natur- oder Vernunftreligion; bei ihm sind Wissen und Glauben nach Gegenständen und Gründen gleichmäßig und vollständig geschieden. Das Wissen ist auf die Natur, das Glauben auf das Übernatürliche gerichtet; das Wissen gründet sich auf Erfahrung und Vernunft, das Glauben auf Offenbarung und Autorität. Um von Gott und der unsterblichen Seele zu hören, muß man aus dem Kahn der Wissenschaft in das Schiff der Kirche steigen. Daher darf das Wissen nicht in den Glauben hineinreden und an den Regeln nicht mäkeln, von deren Befolgung der Gewinn der Seligkeit abhängt. Ja, dieser Glaube wird um so verdienstlicher sein, je unvernünftiger und widervernünftiger sein Inhalt ist. Aber auf der anderen Seite hat dann auch der Glaube nicht in das Wissen hineinzureden; der reine Naturalismus der empiristischen Philosophie lehnt für seine Untersuchung der Natur und des Menschen jedes Interesse des Glaubens $a b$, und gerade die prinzipielle Verwerfung der Teleologie ist das cha- 
rakteristische Zeichen dafür. Denn die Teleologie gilt als der theologische Rest, der aus der alten Metaphysik in der Naturauffassung zurückgeblieben ist. So ist bei Bacon die doppelte Wahrheit wirklich geworden: eine Philosophie, die von der übernatürlichen Welt nichts weiß, und ein Glaube, der mit der Welterkenntnis nichts zu schaffen hat. Diese prinzipielle und radikale Trennung ist das Bedeutsame und Wesentliche: Bacons Philosophie ist religiös völlig indifferent.

V. Descartes. Die religiöse Indifferenz ist vielleicht der einzige sachlich prinzipielle Punkt, worin der Begründer des französischen RationalisDescartes' Porsonlichkeit. mus mit dem englischen Kanzler übereinstimmt. Im übrigen stehen die beiden Männer, die man gern als die wissenschaftlichen Begründer der modernen Philosophie nebeneinanderstellt, in Charakter, Leben und Denkart einander grundverschieden gegenüber. Dort war es der mitten im Leben tätige, auch das Wissen praktisch wertende Emporkömmling, der aus dem Reichtum der Erfahrung seine Erkenntnis sammeln wollte; hier ist es der einsame Grandseigneur, der nur seinem Wissenstriebe lebt und ihn aus der mathemathischen Selbstbesinnung heraus befriedigt. René Descartes, Seigneur du Perron hat selbst mit schlichter Größe und durchsichtiger Klarheit die Schicksale seines Geistes geschildert: wie er die Jesuitenschule mit tiefer Unbefriedigtheit über den zusammenhanglosen Wissenstoff und mit der Ahnung von dem einzigen Werte der Mathematik verließ, wie er dann, für die militärische Laufbahn bestimmt, an mehreren Feldzügen ziemlich harmlosen Anteil hatte, Welt und Leben beobachtete und immer von Zeit zu Zeit sich in die Einsamkeit flüchtete, um in sich selbst die Wahrheit zu suchen, die ihm weder die Schule noch das Leben gegeben hatte. Diesen Hang zur Einsamkeit vermochte selbst der Umgang mit dem Gelehrtenkreise, der sich in Paris um den liebenswürdigen Mathematiker und Theologen Mersenne gebildet hatte, nicht dauernd zu überwinden. Descartes flüchtete für zwei Jahrzehnte nach Holland, um nach Abbruch aller Beziehungen und durch mehrfachen Wechsel des Aufenthaltes bald in einsamen Landschlössern, bald in den Städten, am liebsten in stilleren Vorstädten nur seiner Selbstbelehrung und der Ausbildung seiner Gedanken zu leben. Es war ein tragisches Ende, als die widerwärtigen Streitigkeiten, in die er durch den Eifer seiner Anhänger und durch die gehässigen Angriffe der gomaristischen Orthodoxie verwickelt wurde, ihn schlieBlich bestimmten, seine Freistatt aufzugeben und dem Rufe der Tochter Gustav Adolfs nach Stockholm zu folgen, wo ihn bald der Tod ereilte.

Mit der scheuen Zurückgezogenheit seines Wesens hing es auch zu- Mathematisch sammen, daß er nach jeder Richtung bemüht war, alle äußeren Konflikte zu vermeiden und der Darstellung seiner Lehre jede der herrschenden Vorstellungsweise zuwiderlaufende Spitze zu benehmen. Es war in ihm nicht das geringste Bedürfnis zu wirken und $z u$ belehren, ihn beseelte nur der Egoismus des Forschens, und eine kühle Rationalität, eine überlegene In- 
differenz gegenüber dem Menschengetriebe spricht sich in seiner ganzen Persönlichkeit aus. Im Leben wie in der Wissenschaft ist bei ihm das Methodische überall das Wesentliche und das Entscheidende. Unbefriedigt von dem zusammengewürfelten Kram der Kenntnisse, sucht er die Einheit und damit die Sicherheit des Wissens neu zu gewinnen und zu begründen, und da vor seiner Kritik nur die Mathematik standhält, so wendet sich sein spezifisches Interesse der mathematischen Naturforschung zu: er geht den Weg Galileis. Wie er selbst $z u$ den Begründern der analytischen Geometrie gehörte, so wendete er diese Denkart allen übrigen Gegenständen zu und bildete sich die Regeln der Forschung: man solle sich von den "Vorurteilen freimachen, nur annehmen, was man deutlich erkannt habe, alle Probleme in möglichst einfache zerlegen, in richtiger Ordnung vom Leichteren zum Schwierigeren aufsteigen und sich der Vollständigkeit aller Momente in der Behandlung jeder Frage methodisch versichern. Wenn diese Regeln der Naturforschung nicht ohne Anklänge an die Baconische Induktion sind, so zeigt sich doch Descartes' ganz andersartige Auffassung darin, $\mathrm{daB}$ ihm eine sichere und einleuchtende Darlegung der einfachsten und fablichsten Gegenstände nur in der Mathematik vorzuliegen scheint. Er ist der mathematisch denkende Philosoph. Ihm wird die Mathematik zum Ideal und Vorbild aller Wissenschaft, in der methodischen Sicherheit des Findens und in der Gewißheit des Beweisens.

Der grundsätzlicbe 2 weifel.

Das charakteristische, der Galileischen Naturforschung entsprechende Moment ist bei Descartes das Ziel der Methode, die Auffindung der einfachen und selbstverständlich sicheren Elemente aller Erkenntnis überhaupt. Diese Aufgabe löst er in der genialen Darstellung seiner Meditationen durch eine systematische und vollständige Durcharbeitung der gesamten Vorstellungen, Meinungen, Kenntnisse und Theorien des Menschen. Mit dem skeptischen Sinn, der ihm durch das eben gereift ist und der ihm auch aus der Literatur seiner Zeit und insbesondere seines Volkes entgegenweht, wendet er den grundsätzlichen $Z$ weifcl so lange an, bis etwas gefunden wird, was gegen allen Zweifel standhält. Dieser methodische Zweifel, der aus dem rein theoretischen, aber um so mehr echten, wahren und ernsten Bedürfnis nach $\mathrm{Ge}$ wißheit folgt, soll die einzelnen Gegenstände, die er durchläuft, nicht leugnen, sondern nur so lange problematisch machen, bis ein absolutes Prinzip der Gewißheit gefunden ist. Deshalb sind die üblichen Argumente des Skeptizismus, die Relativität und Subjektivität der sinnlichen Wahrnehmungen, die Unsicherheit der Unterscheidung zwischen Traum und Wachen, die Abhängigkeit der wissenschaftlichen Theorien von der Organisation des menschlichen Geistes, für Descartes nur die Stufen, auf denen seine Analyse zu dem Punkte zweifelloser Gewißheit vordringt.

Cogito sum. Als das einfache und selbstverständliche Grundprinzip aller Wahrheit bleibt danach die Seinsgewißheit des Bewußtseins übrig. Aller Inhalt der Vorstellung kann irrig oder wenigstens zweifelhaft sein: die Realität des Vorstellens selbst ist über allen $\mathrm{Zweifel} \mathrm{erhaben;} \mathrm{sie} \mathrm{wird} \mathrm{gerade} \mathrm{durch} \mathrm{den}$ 
Zweifel selbst bewiesen, der ja nur eine Art des vorstellenden Bewußtseins darstellt. Im Anklang an einen Augustinischen Gedankengang findet so Descartes, daß das Einfache und unzweifelhaft Selbstverständliche in allem Wissen die Realität des Geistes selber ist. Nach der Methode der Naturforschung entdeckt der große Metaphysiker das Prinzip der erkenntnistheoretischen Priorität des Geistes, und damit beginnt ein Grundzug idealistischer Weltbetrachtung, dem die moderne Philosophie hat treu bleiben müssen, so mannigfach auch die Formen gewesen sind, worin sie ihn später ausgeprägt hat. Aber die cartesianische Formel "cogito sum" hängt an der sprachlichen Notwendigkeit der Beziehung auf das Ich als das bewuBte Wesen. Alles was ich denke, mag falsch sein: dab ich denke, bleibt wahr. Dennoch hat Descartes sich alle Mühe gegeben, den Sinn seines Prinzips von jeder psychologischen Deutung auf das empirische Selbstbewußtsein freizumachen. Die intuitive SelbstgewiBheit des BewuBtseins enthält nichts von dem einzelnen Selbstbewubtsein des empirischen Menschen in sich. Das "Ich" der Meditationen ist das geistige Subjekt überhaupt und hat mit dem inhaltlichen Selbstbewußtsein des individuellen, philosophierenden Menschen nur den sprachlichen Ausdruck gemein, aber sachlich nichts zu schaffen. Der Grundsatz "cogito sum" ist nicht das Ergebnis einer inneren Erfahrung, sondern vielmehr der Ausdruck einer rationalen Grundwahrheit, welche ihre unmittelbare Evidenz eben ihrer Einfachheit, d. h. ihrer vollkommenen Klarheit und Deutlichkeit verdankt. Damit ist ein der Mathematik analoges Prinzip der metaphysischen Erkenntnis gewonnen: die einfachen rationalen Elemente alles Wissens, die der Selbstgewißheit des Bewußtseins an Klarheit und Deutlichkeit ihres Inhalts gleichkommen, bezeichnete Descartes in einer vor Mißverständnissen nicht geschützten Weise als die eingeborenen Ideen, ohne doch mit diesem Ausdruck eine genetische oder psychologische Bedeutung verbinden zu wollen.

Der überempirische und metaphysische Sinn des cartesianischen Grund- Gottesbeweis. satzes tritt am deutlichsten darin zutage, daB aus ihm sogleich die Überzeugung von der überragenden, die Gesamtheit des Wirklichen umspannenden Realität des Geistes gewonnen wird. Das ist die Bedeutung der eigentümlichen Verbindung, in welche Descartes seine Erkenntnistheorie mit den Beweisen für das Dasein Gottes gebracht hat. Auch hier liegt eine Ahnlichkeit mit den Gedanken Augustins vor, nur mit dem Unterschiede, daß sie die religiöse Energie, die sie bei dem Kirchenvater besaßen, hier gegen eine rein theoretische Konsequenz ausgetauscht haben. Doch ist dabei nicht zu verkennen, dab die Darstellung Descartes', die sich in seiner persönlich vorsichtigen Weise den herrschenden Vorstellungen anpabt, seinen Gedankengang in eine Anzahl von künstlichen Verwickelungen gezwungen hat, die seinen eigensten Sinn unkenntlich zu machen drohen. Wenn bei der Prüfung der bisher geltenden Vorstellungen auch die gesichertsten aller Erkenntnisse, die mathematischen, es sich gefallen lassen mubten, dab sie vorläufig für problematisch erklärt wurden, so fand Descartes dafür die Wendung, 
der Mensch könne nicht wissen, ob er nicht vielleicht von einem täuschenden Dämon, dem er etwa sein Dasein verdanke, derartig eingerichtet worden sei, daß er gerade da irren müsse, wo er lediglich der Notwendigkeit seines vernünftigen Wesens zu folgen überzeugt sei. Dieser täuschende Dämon muß dann im Fortgange der Untersuchung durch den wahrhaftigen Gott vertrieben werden. Der Philosoph zeigt in scholastischen Begriffsformen, daß die Vorstellung Gottes als des vollkommensten und wirklichsten (allerrealsten) Wesens bloß dadurch, daß sie im menschlichen Geiste sich tatsächlich vorfindet, die Realität dieses höchsten Wesens beweise, und er behandelt die Wahrhaftigkeit, die zu den selbstverständlichen Prädikaten Gottes gehört, als die Gewähr dafür, daß das lumen naturale, die unmittelbare Evidenz des vernünftigen Bewußtseins nicht in die Irre führen könne. Damit ist in der Form der Vorstellung vom göttlichen Geiste, aus dem die rationale Wahrheit des endlichen Geistes stamme, der überempirische und metaphysische Charakter für die Realität des Geistes, die in dem "cogito sum" ausgesprochen werden sollte, zur deutlichen Entfaltung gebracht.

Irrtumslehre. Je mehr man in diesen Sinn der cartesianischen Meditationen eindringt, um so mehr versteht man die Ergänzung, welche diese Grundlehre des Rationalismus durch eine Erklärung der Möglichkeit des Irrtums verlangte und bei Descartes erfahren hat. Denn nach diesen Voraussetzungen kann der Irrtum, dessen Tatsächlichkeit gerade den Stachel für das nach Wahrheit ringende Denken des Philosophen bildete, aus dem reinen geistigen Wesen nicht erklärt werden. Er ist eine Erscheinung, die nur in dem endlichen Geiste und auch in diesem nur durch die Verbindung des rationalen Wesens mit anderen Potenzen möglich ist. Wenn die Selbstgewißheit des lumen naturale auf der Klarheit und Deutlichkeit seiner Ideen beruht, die ebendeshalb für den einzelnen Geist als eingeboren gelten, weil sie der göttlichen, d. h. der allgemeinen Notwendigkeit des Geistes ihre Geltung verdanken, so findet der endliche Geist daneben in sich auch die Fülle der unklaren und verworrenen Vorstellungen, die seiner Verbindung mit dem Leibe entspringen. Aber diese unklaren Vorstellungen sind nicht an sich Irrtümer, sie werden es erst durch das Urteil, das sie als wahre bejaht. Das irrationale Moment aber, das in dem falschen Urteil enthalten ist, kann nicht in der Vorstellungstätigkeit allein gesucht werden, sondern nur in dem Willen, der an der Zustimmung oder Verwerfung, welche das Urteil enthält, mit seiner Freiheit beteiligt ist. In diesem vertieften Sinne kommt Descartes auf die Urteilslehre der Skeptiker und Stoiker des Altertums zurück und

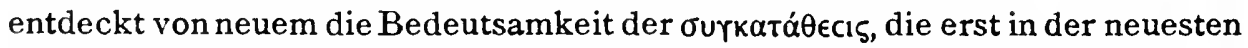
Zeit von der logischen Theorie wieder in den Vordergrund gezogen ist. Nur die vollkommen klaren und deutlichen Elemente der rationalen Erkenntnis führen den Zwang der Evidenz bei sich, daß ihnen die Zustimmung nicht verweigert werden kann und mit einer über alle Willkür hinausgehenden Notwendigkeit zuerkannt werden muß und tatsächlich zuerkannt wird. Wo dagegen im endlichen Geiste unklare und verworrene Vorstellungen vor- 
handen sind, da sollte die Vernunft die Zurückhaltung des Urteils verlangen, und wer diese Zurückhaltung mit voller Weisheit $z u$ bewahren imstande wäre, der würde auch vor allem Irrtum geschützt sein. Aber wie das Bedürfnis des Handelns den Menschen treibt, auch da zu urteilen, wo er noch keine völlig adäquate Erkenntnis gewonnen hat, so führt auch die Ungeduld und das Behauptungsbedürfnis der Forschung den endlichen Geist zu willkürlicher Bejahung und Verneinung unklarer und verworrener Vorstellungen. So gibt der große Rationalist seine Erklärung des Irrtums, und er fügt daran, der Denkweise seiner Zeit gemäB, sogar noch eine Theodicee des Irrtums, indem er die Gottheit dafür zu rechtfertigen sucht, daß die menschliche Natur in ihrer Verknüpfung von Geist und Leib, in ihrer Verbindung der rationalen Ideen mit den unklaren und verworrenen Vorstellungen der Sinnlichkeit den urteilsbereiten Willen zum Irrtum zu verleiten geeignet ist. Die Nichtigkeit, die unabwendliche Nebennotwendigkeit, die Nützlichkeit des Irrtums werden dabei, wie sonst in der Theodicee zur Rechtfertigung aller Übel, ins Feld geführt: das Entscheidende ist, daß die Willkürfreiheit, das liberum arbitrium indifferentiae, für den Irrtum wie für die Sünde verantwortlich gemacht wird. Für den Denker ist die Erkenntnis die Tat des Willens und der Irrtum dessen Fehler.

Gesichert sind damit zunächst alle rein rationalen Wahrheiten, die logischen Selbstverständlichkeiten, die Grundsätze des lumen naturale, von Rationale Wahrboiten. denen Descartes zwar einzelne Beispiele, wie den Satz der Kausalität, aber keine erschöpfende Darstellung gibt, - weiterhin die daraus fließenden begrifflichen Erkenntnisse, z. B. der ontologische Beweis für das Dasein Gottes, und endlich alle mathematischen Wahrheiten, für welche der Philosoph in einer für lange Zeit vorbildlichen Weise den rein rationalen Charakter in Anspruch nimmt. Allein auch für die Erkenntnis der Erfahrungswelt ergeben sich die entscheidenden Folgerungen aus diesen Grundzügen der rationalistischen Erkenntnistheorie. Zunàchst muß, da der Ursprung auch unserer sinnlichen Wahrnehmungen in dem allgemeinen Zusammenhange der Welt gesetzmäßig begründet ist, angenommen werden, daß auch in diesen Vorstellungen von der Körperwelt unter allen Umständen etwas Wahres sein muß. Aber das darf freilich nur in denjenigen Inhalten der Wahrnehmung gesucht werden, welche klar und deutlich gedacht werden können. Nun ist Erkenttis der unsere Auffassung der Körper, soweit sie Empfindungen der einzelnen Sinne Korperwelt. enthält, wie Farben, Gerüche usw., in diesem ihrem imaginativen Charakter derartig bestellt, daß sie in alle Wege etwas gefühlsmäßig Unbestimmtes behält: die Empfindungen ermangeln der Klarheit und Deutlichkeit und sind deshalb keine wahren, d. h. das wirkliche Wesen der Körper enthaltenden. Vorstellungen. Dagegen ist die Auffassung der Körper intellektiv; sofern sie mathematisch bestimmbare Größen enthält, wie Ausdehnung, Gestalt, Bewegung usw.: und eine solche rational-mathematische Vorstellung erkennt somit den Körper, wie er ist. In dieser Weise nimmt Descartes mit scotistischen Unterscheidungen die Lehre von der Subjektivität der Sinnesquali- 
täten im demokritisch-galileischen Sinne auf. Der Körper ist nicht, wie ich ihn empfinde, sondern wie ich ihn denke, und ich denke ihn als ausgedehnt im Raum, alle seine anderen quantitativen Bestimmungen sind Modi dieser seiner räumlichen Ausdehnung. Daher ist das wesentliche Attribut der Körper die Ausdehnung; sie sind ausgedehnte Dinge (res extensae) in demselben Sinne wie die Seelen bewubte Dinge sind (res cogitantes). Denn alle Tätigkeiten, welche die Seele in sich vorfindet - und Descartes zählt gerne auf: Empfindung, Urteil, Bejahung, Verneinung, Begehren, Verabscheuen, Lust und Unlust -, sind sämtlich modi des BewuBtseins, für das Descartes die Ausdrücke cogitare und penser anwendet, ohne selbstverständlich dabei die spezifische Bedeutung im Auge zu haben, die wir im Deutschen mit Denken bezeichnen: das letztere nennt Descartes intelligere. Somit bleiben RäumDualismus. lichkeit und Bewußtsein als die beiden allgemeinen Attribute der endlichen Substanzen übrig, und diese beiden schlieBen sich derartig aus, daß dadurch die beiden Arten von Substanzen nicht nur begrifflich unterschieden, sondern auch auf $z$ wei völlig voneinander getrennte Welten verteilt werden. Im Wesen der Seele als res cogitans ist nicht das Geringste von räumlicher Ausdehnung, im Wesen des Körpers als res extensa ist nicht das Geringste von Bewußtsein vorhanden. Die Scheidung der unräumlichen Seele von dem bewußtlosen Körper, dieser schroffe Dualismus ist das Charakteristische der cartesianischen Metaphysik, ihre Größe und ihre Schwäche.

Mochanistischo Naturphilosophie.
Der Dualismus erlaubte die konsequente Ausführung einer rein mechanischen Naturphilosophie, und Descartes hat sich diesen Vorteil nicht entgehen 1assen. Er forderte den Ausschluß aller Zweckursachen aus der Erklärung der Naturerscheinungen; er verlangte die Auffassung des Körpers als eines lediglich ausgedehnten Wesens oder als eines begrenzten Raumstückes, d. h. die Gleichsetzung des physischen Körpers mit dem mathematischen. Deshalb gilt ihm die Körperwelt als ebenso unendlich wie der Raum und auch wie dieser ins Unendliche teilbar: mit der Ablehnung des Atombegriffes verbindet sich eine Corpusculartheorie und die Leugnung des leeren Raumes. Danach ist jede Bewegung eines Körpers zugleich die von anderen und hat nur den relativen Charakter einer Ortsveränderung. Für diese Auffassung kann aber die Ursache der Bewegung nicht im Körper selbst stecken, da er kein Innen hat; er bringt keine Bewegung hervor, er bekommt sie nur von einem anderen, der sie dabei verlieren muß. Die Bewegung selbst kann also nur von der schöpferischen Weltursache, von Gott, herstammen, und aus dessen. Unveränderlichkeit folgt, daß die Summe der Bewegung in der Natur weder vermehrt noch vermindert werden kann. Alles Geschehen in der Körperwelt ist die Übertragung der Bewegung von einem Raumteil auf den anderen, und die Naturgesetze sind die Regeln dieser Übertragung. Ihre Grundform ist die mechanische mit der Gleichheit zwischen Verlust und Gewinn, zwischen StoB und Gegenstoß, zwischen Druck und Gegendruck, mit dem Gesetz der Trägheit, wonach der in Bewegung begriffene Körper darin beharrt, solange nicht eine Ursache hinzutritt, die 
sie in Richtung und Geschwindigkeit ändert oder aufhebt. Mit der Ausführung dieser Grundgedanken in der Mechanik und Hydromechanik, in der Optik, Dioptrik usw. gehört Descartes zu den führenden Naturforschern seiner Zeit, und für die allgemeine Weltauffassung sind hauptsächlich zwei seiner Anwendungen bedeutsam geworden. Die Verfassung des physischen Kosmos sollte danach rein mechanisch verstanden sein, alle Wirkung von Körper auf Körper erschien nur durch Berührung, nicht durch actio in distans mögllch. Das führte in Verbindung mit der Leugnung des leeren Raumes zu der Hypothese des Weltäthers und zu der Annahme von dessen Wirbelbewegung, aus der sich die Verhältnisse des astronomischen Systems erklären sollen. Diese Wirbeltheorie, die später durch Fontenelles „Entretiens sur la pluralité des mondes" popularisiert wurde, hat ihre Herrschaft bis zu dem Vordringen der Newtonschen Theorie ausgeübt und reicht mit ihren prinzipiellen Wirkungen bis in die neueste Naturphilosophie hinein. Der zweite Hauptpunkt war die rein mechanische Erklärung der Organismen, die sich aus dem Postulat der Einheit der Körperwelt ergab. An diesem Punkte mußte es sich entscheiden, ob man die Finalursachen aus der Erklärung der Körperwelt wirklich loswerden könne. Die Physiologie der Zeit war damit an der Arbeit, und die Entdeckung vom Mechanismus des Blutkreislaufs, die dem Engländer Harvey gelang, schien einen großen Schritt weiter zu führen. Descartes dachte dies Postulat folgerichtig zu Ende; er verallgemeinerte das Prinzip der Reflexbewegungen und erklärte die tierischen Organismen ausnahmslos für Automaten. Er sah in ihren zweckmäßigen Reaktionen nur Nervenprozesse, nicht Empfindungen oder Willenstätigkeiten; er konnte den Tieren keine Bewußtseinszustände zutrauen, denn dazu gehört eine res cogitans, eine Seele.

Diese Lehre verlangte nun freilich, wie dereinst bei den Victorinern des Anthropologie. 12. Jahrhunderts, eine ganz exzeptionelle Stellung des Menschen, für den die wunderbare Verknüpfung angenommen werden mußte, daß er ein Wesen sei aus zwei Substanzen bestehend, die so miteinander verbunden sind, dak sie aufeinander wirken. Die Wirkung der Seele auf den Leib bleibt bei Descartes etwas unbestimmt. Seine Naturphilosophie mußte die Tendenz haben, auch anthropologisch aus dem Leiblichen die Finalursáchen zu eliminieren und das Prinzip der Reflexbewegungen aligemein zu machen; aber das ethische Interesse verlangte den Zusammenhang der Handlungen mit dem Willen und durfte dessen Kausalität nicht ausschließen. Bleibt deshalb die Lehre des Philosophen an diesem Punkte unfertig und unsicher, so iag das Problem viel deutlicher und sicherer auf der anderen Seite, bei dem Einfluß des Leibes auf die Seele. Die res cogitans hat aus sich selbst nur ihre eingeborenen Ideen, die unmittelbar evidenten Wahrheiten logischer und mathematischer Erkenntnis. Alle imaginatio dagegen, alles sinnlich Bildhafte in ihren Ideen verdankt sie, da in ihr selbst nichts Ausgedehntes ist, dem Einflusse ihres Körpers. Hierfür sucht Descartes eine physiologische Erklärung, indem er der Seele einen punktuellen Sitz im Gehirn (in dem 
Conarium, der sog. Zirbeldrüse) anweist, dem Reflexzentrum, an dem, wie man damals meinte, die Empfindungen zusammenkommen und von dem die Bewegungen ausgehen. Den Vorgang in den Nerven stellt er sich im Sinne der alten Physiologie als eine Bewegung feiner Fluida, der spiritus animales $(\pi v \epsilon u ́ \mu \alpha \tau \alpha)$ vor, und aus dieser Bewegung sollen der Seele nicht nur die Empfindungen und damit ihre ganze sinnliche Vorstellungsweise, sondern zugleich auch ihre dunklen und verworrenen Gefühle und Leidenschaften zuwachsen. An diese Hypothese knüpft der Philosoph auch die Begründung seiner ethischen Lehre, in der sich sachlich der die Zeit beherrschende Einfluß der Stoa geltend macht. Die Affekte und Leidenschaften beweisen als Leidenszustände der Seele ihre Abhängigkeit vom Leibe; aber auch ihre Mannigfaltigkeit muß für die wissenschaftliche Betrachtung dem methodischen Prinzip unterworfen werden, daß ihre einfachen Grundformen aufgesucht werden und ihr genetischer Zusammenhang verstanden wird. So führt Descartes das baconische Programm einer mechanisch-naturwissenschaftlichen Erklärung der Seelenzustände an den Affekten und Leidenschaften durch, die er in völlig stoischer Weise gemeinsam als Störungen der Seele behandelt. Er findet sechs primäre Passionen: die Verwunderung (das Staunen: admiratio), Liebe und Haß, Begierde, Lust und Unlust. Aus diesen Grundformen ergeben sich die partikularen Passionen durch die Beziehungen auf besondere Gegenstände und Verhältnisse. Und so entwickelt der Philosoph in einer für die folgenden Zeiten vorbildlichen Weise eine Theorie des Gemütslebens, welche in ihren einzelnen Bestimmungen für die Wertungsweise seiner Zeit außerordentlich charakteristisch ist. Diesen Störungen und Leidenszuständen gegenüber erhebt sich das Ideal geistiger Freiheit, des Rückgangs der Seele auf ihr eigenstes und innerstes Wesen, die vernünftige Erkenntnis. So kommt Descartes' Persönlichkeit, die reine Intellektualität seiner Weltund Lebensanschauung, die Unterwerfung aller Wirklichkeit unter die Klarheit und Deutlichkeit der Vernunfteinsicht auch an dem ethischen Abschluß seiner Lehre entscheidend zutage.

VI. Descartes' Zeitgenossen und Schüler. Bevor Descartes die in seiner holländischen Einsamkeit verfaßten Meditationen drucken ließ, gab er sie dem Pariser Gelehrtenkreise zur Kenntnis und Prüfung, und deren Einwürfe mit den Erwiderungen des Philosophen bildeten nachher den umfangreicheren Teil der Veröffentlichung. Sie sind im einzelnen wenig bedeutend, und das Übergewicht des großen Philosophen, der auch hier wesentlich seine Gedanken nur zu wiederholen hat, bleibt durchgängig fühlbar; aber sie geben uns ein lebendiges Bild von der Mannigfaltigkeit philosophischer Richtungen, $z$ wischen denen die neue Philosophie als eine überragende Erscheinung emporwuchs, und auf die sie dann ihre bestimmenden Einflüsse ausgeübt hat.

Hobbes. Der verhältnismäßig bedeutendste unter diesen Korrespondenten Descartes' ist ein Engländer, Thomas Hobbes, ein Schüler der Oxforder Uni- 
versität, der in persönlichen Stellungen Italien und Frankreich bereist hatte und als freier Schriftsteller mit starkem politischen Interesse und unabhängiger Beurteilung die Fragen der Zeit behandeln konnte. Seine eindrucksvolle und originelle Erörterung der politischen Probleme hat lange übersehen lassen, daB sie nur ein Glied in einem umfassenden philosophischen System ist; und da man den Engländer an Bacon anschloß, so ist seine viel engere Beziehung zu Galilei und Descartes und zu der von diesen begonnenen mathematischen Philosophie erst in neuerer Zeit richtig gewürdigt worden. Um die eigenartige Stellung von Hobbes zu verstehen, muB man auf den Nominalismus und Terminismus zurückgehen, den er auf der Universität eingesogen, in der Problembildung seiner Zeit zur Geltung gebracht und in die neuere Philosophie hinübergeführt hat. Das zeigt sich zunächst in dem Radikalismus, mit dem er die Philosophie von aller Theologie und theologisierender Metaphysik abgelöst und auf eine rein weltliche Naturerkenntnis beschränkt hat. Bei ihm ist die religiöse Indifferenz ohne Reservation, ohne Verhüllung und Mantelfaltung; und die praktische Bedeutung des Wissens, die er mit Bacon vertritt, findet bei ihm die Wendung, daß auch im Menschenleben nicht Gefühle und Leidenschaften, sondern Erkenntnisse herrschen sollen: damit regen sich die prinzipiellen Überzeugungen der Aufklärung. Sie entspringen bei Hobbes einer neuen Verknüpfung sensualistischer Ele- Terminismus. mente, wie sie durch den Vorgang des feiner entwickelten Nominalismus angebahnt worden war: mit dem Umschlag des Sensualismus in Phänomenalismus, mit der Einsicht, die Hobbes mit Campanella teilt, daß in den Wahrnehmungen eine Bewußtseinswelt als Zeichen für eine unbekannte Wirklichkeit vorliegt, verbindet sich die Folgerung, daf die menschliche Erkenntnis auf den Zusammenhang desjenigen angewiesen ist, was sie aus ihrer eigenen Gesetzmäßigkeit hervorbringt. Den Typus dieser erzeugenden Tätigkeit des Intellekts aber bildet das mathematische Denken, weil es in seiner Entwickelung der Verhältnisse und Beziehungen von dem primären Wahrheitswerte der Elemente, mit denen es dabei operiert, völlig unabhängig ist. In diesem Sinne prägt Hobbes den Grundgedanken des spätscholastischen Terminismus aus, da $B$ alles Denken ein Rechnen mit Begriffen ist, die ihrerseits nur Zeichen für die Dinge darstellen, und daß die Übereinstimmung des Bewußtseins mit sich selbst der oberste Grundsatz für die Logik ist, deren Formensystem danach zuletzt einen mathematischen Ausdruck muß finden können. Damit ist ein Zug angelegt, der in der Entwickelung der modernen Logik eine große Rolle gespielt hat, die Tendenz zum „logischen Kalkü1" und die Angleichung der logischen Sätze an mathematische Formeln. Bei Hobbes ist dies mehr angedeutet als ausgeführt und ist dem Grundgedanken die sachliche Wendung gegeben, daß sich aus den Einbildungsvorstellungen der sinnlichen Wahrnehmung die in ihrer Wahrheit davon unabhängige Konstruktion der räumlichen und zeitlichen Größen und Gesetze entwickelt. Und mit dieser logischen und mathematischen Spontaneität ist für Hobbes die Grundstruktur aller Weltvorstellung, ihr formaler Grundriß als das allein rational Gewisse 
gegeben. Nur in diesen Formen ist die Wirklichkeit dem Denken zugãnglich: deshalb besteht alles empirisch Wirkliche als der bewegte Körper Materialismus. in Raum und Zeit, und deshalb ist die Philosophie für Hobbes nichts weiter als Körperlehre, die sich in drei Stufen mit der Natur im allgemeinen, mit dem Menschen und mit dem Staat als dem bedeutsamsten unter den „künstlichen Körpern" zu beschäftigen hat.

Antbropologie. Während dabei die Physik sich ganz in den Bahnen Galileis und Descartes' bewegt, da ja. Hobbes kein Forscher und Experimentator, sondern wesentlich Dialektiker war, so besteht seine Originalität in der nicht mehr bloß programmatischen Anwendung der naturalistischen Prinzipien auf die Anthropologie. Er hat darin vor Bacon die Sorgfalt der Einzeluntersuchung und vor Descartes den Vorteil des Radikalismus voraus, der vor keiner Konsequenz zurückzuschrecken brauchte, wenn es galt die rein mechanische Erklärung der organischen Welt auch auf den Menschen auszudehnen und die körperliche Notwendigkeit aller seiner Tätigkeiten nachzuweisen. Der dialektische Materialismus geht psychologisch in eine sachliche Form über: für das Wissen gibt es keine Geister. Das Bewußtsein (cogitare) ist eine Tätigkeit, ein Akzidens, das nur an einem Dinge wirklich sein kann; Dinge aber sind eben Körper, und deshalb ist auch das Bewußtsein mit allen seinen Modi eine Funktion des Leibes. Die physiologische Psychologie erhält somit die Aufgabe, die Seelenzustände aus ihren leiblichen Grundlagen durch das Beharren ihrer Elemente nach bestimmten Gesetzen zu begreifen. So geht alles Vorstellungsleben auf die Verknüpfung der primären sinnlichen Inhalte zurück, und die Assoziation der Ideen ist das allgemeine Prinzip, wodurch sich auch die scheinbar von diesen Anfängen verschiedenen Tatsachen der höheren intellektuellen Entwickelung erklären. Insbesondere gilt das nominalistische Prinzip der Zeichentheorie (Semeiotik) für das Verständnis der Gattungsbegriffe, bei denen die Sprache zur Fixierung des Assoziationsprozesses herangezogen wird. Nach demselben Prinzip führt Hobbes auch die Theorie des Gemütslebens aus, und hier entwirft er nach cartesianischem Vorbild das System der Affekte und Leidenschaften aus sechs Grundformen, die eine etwas andere Gliederung zeigen, indem den drei attraktiven $\mathrm{Zu}$ ständen, Lust, Iiebe und Begehren, die drei repulsiven, Schmerz, Haß und Furcht, gegenübergestellt werden. In der ganzen bunten Mannigfaltigkeit der Passionen, die dann durch Vorstellungsassoziationen aus jenen Grundformen entwickelt werden, bezieht sich doch schließlich alles Bejahen und Verneinen auf zwei große Güter: Macht und Ehre, und diese beiden sind in letzter Instanz die dem gesellschaftlichen Zusammenleben angepaßten Formen eines und desselben Grundtriebes: der Selbsterhaltung. Aus diesem einfachen Grundelement muß mit mechanischer Notwendigkeit die Gesamtheit des Fühlens und Wollens, einschließlich des moralischen, abgeleitet werden, und eine indeterminierte Freiheit des liberum arbitrium hat in diesem System keinen Raum. Alles Wollen ist notwendig als positives oder negatives Mittel zur Selbsterhaitung, und erst auf dem sozialen Standpunkt kann die Unter- 
scheidung eintreten, daß das, was zugleich dem Ganzen förderlich ist, gut und das, was im Gegensatz zu dessen Interesse steht, schlecht genannt wird. Wenn das Individuum sich den Normen der Gesellschaft unterwirft, wenn es sittlich fühlt, will und handelt, so ist das nur dadurch möglich, daß es darin sein eigenes wohlverstandenes Interesse erkannt hat. Sittlichkeit ist kluge Selbsterhaltung: das ist das Selfish system, das mit seinem Radikalismus der stetige Stachel für die moralphilosophische Entwickelung des I 8. Jahrhunderts gewesen ist.

Es wurde dazu um so mehr, als die auf diesem Boden entwickelte Staatslehre von Hobbes die eindrucksvollste seiner Leistungen war. Eine demonstrierende synthetische Wissenschaft sollte diesen künstlichen Körper, den Staat, als ein Artefakt des überlegenden Willens begreifen, und die Voraussetzung dafür war der ethische und soziologische Atomismus: denn der konstitutive Wille konnte dabei nur der der Individuen sein. Ihr natürlicher $\mathrm{Zu}$ stand mubte als der gesellschaftslose und staatslose gelten, er bestand im Widerstreit der Selbsterhaltungstriebe, in dem bellum omnium contra omnes. Mit der Rücksicht auf die Spärlichkeit der Lebensbedingungen, die diesen Kampf notwendig macht, ist in dieser Lehre für das englische Denken eine prinzipielle Betrachtungsweise begonnen, die später bei Malthus zur Grundlage der nationalökonomischen und bei Darwin zu der der biologischen Theorie geworden ist. In jenem Naturzustande der Anarchie entspringt der natürliche und historisch tatsächliche Staat nur durch Gewalt, durch die physische Übermacht des einzelnen über die anderen: aber er findet seine Rechtfertigung erst in der vernünftigen Überlegung, durch die der rationale Staat, die civitas institutiva, begründet wird. Denn nach der menschlichen Natur erzeugt sich im status naturalis bei jedem die Furcht und die Sehnsucht nach Frieden, und daraus geht der Staatsvertrag hervor, durch den erst ein vernünftiger Geselligkeitszustand begründet wird. Während die früheren Theorien diesen Geselligkeitszustand entweder als einen natürlichen oder einen von Gott verordneten vorausgesetzt und erst die Verfassung durch den Herrschaftsvertrag oder Subjektionsvertrag begründet wissen wollten, wird bei Hobbes schon die Gesellschaft selbst durch einen Vertrag zwischen den an sich selbstherrlichen Individuen gegründet. Freilich war das Prinzip der Souveränität des Individuums in seiner weltgeschichtlichen Bedeutung calvinistischen Ursprungs und bestimmte als solches schon die großen politischen Bewegungen Englands, die Hobbes als Philosoph erlebte und beobachtete: aber er gab diesen Gedanken eine rein weltliche Form, in der sie sich sogar gewissermaßen gegen ihren religiösen Ursprung wendeten. Denn der Herrschaftsvertrag, der die Form des Staates bestimmt, kann nun nach Hobbes kein anderer sein als der absolutistische: die persona civilis, der Staat, verlangt absolute Einheit auch in einer persona naturalis, in dem autokratischen Herrscher, auf den alle Rechte der Individuen unwiderruflich übertragen werden. Diese Theorie des Königtums, deren Vorbild für Hobbes offenbar die absolute Monarchie Ludwigs XIV. gewesen ist, hat jedoch für ihn rein 
weltlich politische Bedeutung und tritt deshalb dem legitimistischen Royalismus der Stuarts ebenso entgegen wie dem puritanischen Republikanismus. Hobbes bestreitet jede religiöse Färbung des politischen Wesens und trifft damit, im Widerspruche zu allen Parteien, den entscheidenden Punkt in den leidenschaftlichen Kämpfen der englischen Revolution. Seiner Ansicht nach gehört zu den Opfern, welche der Staat von dem Individuum verlangt, auch das der Privatmeinung, und nur als solche gilt ihm die Religion. Nach epikureischem Muster sieht er in allem Glauben an Übernatürliches nur die von der Furcht diktierte Ausfüllung der Lücken unseres Naturwissens. Da keine Religion rational $\mathrm{zu}$ begründen ist, so kann die einzelne ihre bindende Kraft nur dem Machtgebote des Staates verdanken, dessen Souverän die Religionsübung in seinem Herrschaftsbereich $z u$ bestimmen und gegen alle Privatmeinungen aufrechtzuerhalten hat. Nach dem Prinzip „cuius regio eius religio" schließt die Omnipotenz des absolutistischen Staates jede Toleranz aus, und der persönliche Indifferentismus, mit dem Hobbes den religiösen Fragen gegenüberstand, hatte ihn gegen die Gefahren solcher extremen Folgerungen blind gemacht.

Gassend. Die doktrinären Einseitigkeiten, zu denen Hobbes auf allen von ihm behandelten Gebieten fortschritt, sind charakteristisch für die rationalistische Denkart, deren Führer Descartes gewesen ist: sie machen es begreiflich, daß weniger bedeutende Geister, die solchen extremen Folgerungen auszuweichen wünschten, den Geltungsbereich des mathematischen Rationalismus zu verengern bemüht waren. Das ist das gemeinsame Motiv für eine Anzahl sonst sehr verschieden gefärbter Richtungen, in denen sich der cartesianische Mathematizismus mit skeptischen und andererseits mit mystischen Elementen verbinden konnte. In ersterer Hinsicht ist zunächt der Provençale Pierre Gassend (Gassendi) zu nennen, eine charakteristische Erscheinung der freieren französischen Geistlichkeit jener Zeit, die der modernen Wissenschaft und dem Leben eine offene Teilnahme entgegenbrachte und diese mit der kirchlichen Stellung und Anschauung durch ein skeptisches Verhalten zu den metaphysischen Fragen zu vereinigen wußte. Der Kanonikus von Dijon, welcher Professor der Rhetorik und der Theologie gewesen war, verkehrte in dem cartesianischen Kreise in Paris und stand in persönlichen Beziehungen zu Campanella wie zu Hobbes, zu Descartes dagegen in einem etwas gereizten und gespannten Verhältnis. Aber die Anerkennung der neuen Mechanik als der zur Herrschaft berufenen Wissenschaft ist ihm mit den Größeren gemein, und er nimmt sich ihrer gegen den jesuitisch-thomistischen Aristotelismus an. Es ist höchst interessant, wie der katholische Priester von diesem Standpunkte aus die „Rettung“ Epikurs unternahm, um mit freiem historischem Blick nicht nur die theoretische Bedeutsamkeit des antiken Atomismus, sondern auch die feinen und besonnenen Züge der epikureischen Moral, ihren Sinn für die geistigen Freuden von Kunst und Wissenschaft, ihre Urbanität und ihren Geschmack anzuerkennen. Diese naturalistische Welt- und Lebensauffassung, die offenbar auch die seinige war, glaubte nun 
Gassend vor dem religiösen Bewußtsein nur dadurch verantworten zu können, $\mathrm{da} ß$ er das menschliche Wissen genau darauf beschränkte und es aus allen eigentlich metaphysischen Fragen verwies. Hierauf beruhte sein Gegensatz gegen Descartes, der durch das natürliche Licht Gott und die geistige Welt erkennen wollte, und gegen den Rationalismus, der den Umkreis des sinnlichen Wissens prinzipiell überschritt. Die Wissenschaft darf nur so weit recht haben, als sie von der Natur handelt, und soll sich des Grübelns über Gott und die geistige Welt enthalten. So verknüpft sich die Anerkennung der neuen Naturforschung mit dem weltmännischen Skeptizismus, der seit Montaigne ein Grundzug der französischen Literatur geblieben war und im humanistischen Anschluß an den Akademizismus auch mancheriei weitere Darstellungen gefunden hatte. Seine Vereinbarkeit mit einem vollen Orthodoxismus tritt namentlich eindrucksvoll bei dem gelehrten Bischof von Avranches, Pierre Daniel Huet, hervor, der mit Bekämpfung des cartesianischen Rationalismus den typischen Bund zwischen Sensualismus und Orthodoxismus vertritt, nach welchem die Beschränkung der menschlichen Erkenntnis auf die Sinnenwelt den Wissensdurst in die Arme des Glaubens treibt. Es sind dieselben Argumente, welche Bossuet in seiner Polemik gegen den Rationalismus der Protestanten und der Deisten angewendet hat.

Die strengen Anforderungen, welche der cartesianische Mathematizis- Pascal. mus an alles Wissen stellte, waren in der Tat geeignet, gerade das ernste und gewissenhafte Denken auf die Grenze seiner Erkenntnisfähigkeit aufmerksam zu machen. In diesem Motiv wurzelt der Skeptizismus bei einer der edelsten und reinsten Gestalten jener Zeit, bei Blaise Pascal, der schon in früher Jugend seinem vollkommen selbständigen Studium der Mathematik bedeutende Leistungen abgewonnen, durch seine mächtig wirksame Satire der Lettres provinciales den Kampf gegen die jesuitische Moral eröffnet und sodann im Kloster Port Royal bis zu seinem frühen Tode ein streng asketisches Leben einsamer Betrachtung geführt hatte, deren Ergebnisse in den nicht zum Buchabschluß gediehenen Pensées sur la religion niedergelegt sind. Das Geheimnis seiner Wirkung auf das geistige Leben besteht dauernd nicht in seiner Lehre, sondern in dem Zauber der Persönlichkeit, der reinen selbstlosen Seele, die von tiefer und inniger Liebe zu Gott und den Menschen erfüllt ist, dieses von der Wissenschaft nicht befriedigten, aber von tiefer mystischer Gläubigkeit gesättigten Gemüts. Mit der Verstandesklarheit, die ihren glänzenden Scharfsinn nicht nur an den abstraktesten Problemen der Mathematik entwickelt, sondern auch die Wirklichkeit des Menschenlebens sicher durchschaut und mutig darin für eine hohe sittliche Überzeugung eintritt, verbindet sich in Pascal zu harmonischer Ausgleichung eine Zartheit und Weichheit des Fühlens und eine intuitive Sicherheit des inneren Lebens. Alle mathematische Wissenschaft, lehrt er uns, hat ihre genau bestimmten Grenzen am Raum und in den Axiomen, Vorstellungen, die vollkommen klar und doch unbegreiflich, unableitbar sind. Und wie dahinter keine Theorie dringt, so genügt andererseits auch das mathematische Wissen nicht, um die bunte 
Mannigfaltigkeit des Lebens zu durchdringen: für sie müssen wir uns mit dem Esprit de finesse begnügen, dem taktvollen Verständnis, mit dem wir uns in der Welt orientieren. Zum letzten lebendigen Wesen der Dinge dringt, trotz aller ihrer Klarheit, weder die demonstrative noch die intuitive Erkenntnis, sondern nur das religiöse Gefühl, das in sich unbeweisbar und unwiderlegbar gilt. Aber es bezieht sich deshalb in seiner theoretischen Unbestimmtheit auch auf kein Dogma, keinen Begriff und keinen Satz: es ist unmittelbares Leben, Leben der Liebe und des Vertrauens. Über den irdischen Leidenschaften, worunter die höchste der Ehrgeiz ist, der den Menschen in die Welt der Geschäfte und in die Arbeit der Wissenschaft treibt, um Macht, Ansehen, Ruhm zu gewinnen, steht die Liebe, die ihn zu Gott führt. Das ist Pascals Lehre - es ist seine Lebensgeschichte.

Pascal ist die eigenartigste Erscheinung in der auch sonst nicht seltenen Verknüpfung von cartesianischen Gedanken mit skeptischen und mystischen Auffassungen: mochte diese bei den ihm nahe stehenden Jansenisten von Port Royal, den freisinnigen katholischen Theologen der Zeit, in ihrem Anschluß an Augustin begründet sein, mochte sie bei einem von J. Böhme ergriffenen Mystiker wie Pierre Poiret zu entschiedenster Opposition gegen den Rationalismus führen - immer handelt es sich darum, die mathematische Naturforschung bei aller Anerkennung ihrer Leistungen durch ein Bedürfnis nach unmittelbarer Erfassung der lebendigen Wirklichkeit einzuschränken, und in letzterer Hinsicht machten dann die ethisch-religiösen Motive sich in ihrer eigenen Bedeutung gegenüber der kühlen und indifferenten Rationalität des cartesianischen Denkens geltend. Und doch bot gerade dazu der Cartesianismus selbst mit seiner ausgesprochenen Dualität der physischen und der geistigen Wirklichkeit die beste Handhabe. In diesen Motiven liegen die entscheidenden Gründe dafür, daß die cartesianische Schule die Wendung zu den metaphysischen Lehren machte, welche man mit dem Namen des Okkasionalismus bezeichnet.

Okkasionalismus.

Die nächsten Anlässe freilich zur Entwickelung dieser Lehren schienen rein theoretischer Natur zu sein. Bei den deutschen und holländischen Gelehrten am Niederrhein, unter denen verhältnismäbig der vollkommenste Anschluß an Descartes' Philosophie stattfand und die auch als Universitätslehrer sie in zusammenhängender Darstellung zu entwickeln versuchten, lenkte sich die Aufmerksamkeit von selbst auf den schwachen Punkt jenes Dualismus. In der Anthropologie lag die Achillesferse des Systems. Der Kausalzusammenhang zwischen Leib und Seele wurde das entscheidende Problem. Die einen, wie Clauberg, zeigten an den Vorgängen der Wahrnehmung, die anderen, wie Cord e moy, an denen der zweckmäßigen Leibesbewegung die Schwierigkeiten des von Descartes gelehrten influxus physicus, und ein Mann wie Louis de la Forge schritt sogleich zu den allgemeineren Fragen, wie überhaupt endliche Dinge wirken, d. h. Neues in die Welt bringen können, und wie sich das mit der alleinigen Kausalität Gottes, die das Entscheidende der christlichen Philosophie sei, vertrage. Alle diese Motive konzentrieren 
sich in der Entwickelung des unglücklichen, früh gestorbenen Arnold Ge u lin cx und besonders in den beiden Auflagen seiner Ethik. Das sittliche Ideal vernünftiger Selbstbestimmung verlangt die theoretische Grundlage der wahren Selbstbesinnung, die uns lehrt, daß der Geist nur das hervorbringen kann, was er selber klar und deutlich einsieht, und daß er andererseits auch nur das klar und deutlich einsieht, was er in sich aus seinem eigenen Wesen schafft. Gerade dieser rationale Grundgedanke aber hat hier noch nicht den aufklärerischen Mut zur Umgestaltung der Außenwelt, sondern wird umgekehrt zum Motiv einer zarten Vertiefung der Seele in sich selbst, die in der Außenwelt nichts ausrichten kann und deshalb auch sich darin nicht versuchen soll: Ubi nihil vales, ibi nihil velis. Die mystische inspectio sui ist zugleich die despectio sui, die Grundtugend der Demut, welche Gott walten läßt und vertrauensvoll zuschaut, was er in uns und außer uns wirkt.

Die theoretische Begründung dieser Ethik geht von jenem Grundprinzip Kausalitätslehre. aus, daß die unklaren und verworrenen Vorstellungszustände der Sinnlichkeit nicht aus dem Geiste stammen, der sie in sich nur vorfindet; aber von den Körpern können sie auch nicht herrühren, da eine solche Einwirkung dem substantiellen gegenseitigen Ausschluß von Körper und Seele zuwiderläuft. Wo die verschiedenen Substanzen der endlichen Welt aufeinander einzuwirken scheinen, da ist das nur durch die übergreifende Kausalität Gottes erklärlich, der die einzige wahrhaft wirkende Ursache ist. Die endlichen Dinge sind im Verhältnis zueinander nicht wirkende Ursachen, sondern nur Gelegenheitsursachen, welche die Tätigkeit der göttlichen Wirkung auslösen. Anfänglich entwickelte Geulincx diese Theorie wesentlich an dem Verhältnis von Leib und Seele. Bei den heterogenen Substanzen, den ausgedehnten auf der einen, den bewußten auf der anderen Seite, schien die gegenseitige Einwirkung unmittelbar unbegreiflich und unmöglich zu sein. Hier brauchte man Gott als den einzig Wirkenden, der bei Gelegenheit der sensiblen Erregung des Leibes in der Seele die Wahrnehmung und bei Gelegenheit der bewußten Absicht am Leibe die zweckmäßige Bewegung hervorruft. Der Ablauf körperlicher Vorgänge untereinander und ebenso die Entwickelung geistiger Zustände auseinander erschien noch, wie im Cartesianismus, begreiflich oder wenigstens nicht problematisch. Erst später hat namentlich die Ausführung der physikalischen Theorie Geulincx dazu geführt, daß er auch im Übergang der Bewegung von einem Körper auf den anderen dasselbe Problem entdeckte: die Schwierigkeit besteht nicht in der Heterogeneität der Substanzen, sondern schon in der Substantialität selbst. So erweiterte sich das System der Gelegenheitsursachen auf die Gesamtheit des Geschehens zwischen endlichen Dingen. Keine endliche Substanz ist wirkende Ursache in bezug auf die Zustände der anderen: sondern in allen ist es die Gottheit, welche bei Gelegenheit der Zustände der einen die entsprechenden der anderen hervorruft. Mit dieser Vertiefung der Lehre war aber noch eine weitere Umgestaltung verbunden. In der anfänglichen Darstellung erschien die Vermittelung Gottes zwischen den verschiedenen Sub- 
stanzen als ein Eingreifen von Fall zu Fall, und das führte namentlich zu dem theologischen Bedenken, daß die Gottheit dadurch auch zum Vollstrecker der bösen Absichten des menschlichen Geistes gemacht würde. Deshalb ersetzte Geulincx im Fortgange seines Denkens dies permanente Wunder der übergreifenden Einwirkung durch die Annahme einer von der Gottheit ein für allemal bestimmten Ordnung der Zustände der endlichen Substanzen. Er erläuterte das an dem Uhrengleichnis, das später auch Leibniz für die Illustration der Probleme verwendet hat. Die Bedeutung der okkasionalistischen Begriffe liegt somit hauptsächlich in der Erkenntnis der Irrationalität des Kausalverhältnisses. Es ist logisch niemals zu begreifen, weshalb der $\mathrm{Zu}$ stand der einen Substanz in einer anderen Substanz eine Zustandsveränderung soll herbeiführen können. Das Wesen der Naturgesetzlichkeit besteht lediglich in der tatsächlich konstanten Zeitordnung der Zustände, welche nur in der Gesamtordnung des Geschehens, in der Welteinheit, in der übergreifenden unendlichen Substanz, in Gott begründet sein kann. In dieser Form des Okkasionalismus war den endlichen Substanzen, von denen die cartesianische Philosophie geredet hatte, jede eigene Wirksamkeit abgesprochen: sie wirkten nicht aufeinander, nicht einmal die ein und derselben Gattung angehörigen besaßen diese Fähigkeit. Und wenn man diesen Gedanken bis ans Ende verfolgte, so mußte man erkennen, daß damit die Substantialität der Einzeldinge überhaupt aufgegeben war und nur noch die der unendlichen Substanz übrig blieb.

Malebranche. Diese Konsequenz hat Nicole Malebranche gezogen, bei dem die metaphysische und erkenntnistheoretische Präponderanz des Begriffes der Gottheit als der allgemeinen Naturordnung, die schon bei Descartes angelegt war, in voller Schärfe hervortritt. Die unendliche Substanz ist das ganze unendliche Sein; alles, was ist, ist nur durch Gott und in ihm als Partizipation an seinem Wesen. In neuplatonischen Gedankenformen behandelt Malebranche, ähnlich wie gelegentlich schon Geulincx, Gott als den „Ort der Geister": alles, was sie tun und denken, tut und denkt er. Deshalb ist für Malebranche das Problem der Verantwortung ebenso unlösbar wie für Augustin: die Freiheit ist ein Geheimnis. Die Körper dagegen können als wirkliche Dinge freilich nicht in Gott als der geistigen Urwirklichkeit enthalten sein: aber sie müssen von ihm geschaffen sein nach dem Urbilde in seinem Geiste, und dies Urbild erklärt auch, daß wir die Körper erkennen können. Es geschieht nicht direkt, weil weder Geister auf Körper, noch Körper auf Geister wirken, sondern indirekt, indem wir an Gottes Ideen Anteil haben, nach denen er die Körper geschaffen hat. So gilt es, daß wir "alle Dinge in Gott schauen". Damit aber sind aus den res cogitantes nur noch modi cogitationis, aus den res extensae nur noch modi extensionis geworden, und die cogitatio ist das Wesen Gottes, die extensio die ideale Körperwelt im göttlichen Geiste. Gott ist die einzige wahrhafte Substanz im Sein wie im Wirken. Was aber so der Okkasionalismus bei seinem Herauswachsen aus dem cartesianischen Problem Schritt für Schritt gewonnen hat, das war vor 
ihm aus der unmittelbaren Energie eines großen Denkers mit Einem Schlage erreiclit worden: das war die Leistung Spinozas.

VII. Baruch Spinoza. Der Spinozismus bildet in der Entwickelung Bedeutung des des modernen Denkens einen notwendigen und entscheidenden Durchgangspunkt. Die künstlerische und religiöse Bewegung der Renaissance hatte zu einer Verinnerlichung des geistigen Lebens geführt, die dessen selbständige Energie zu immer tieferer und ausgesprochenerer Selbstbehauptung führte: auf der anderen Seite aber war die neue Leistung der Wissenschaft gerade darauf gerichtet, die gesamten Erscheinungen der Natur lediglich als gesetzmäßige Bewegungen der Körper zu verstehen und jeden Einfluß geistiger Kräfte aus ihrer Erklärung auszuschließen. Deshalb mußte sich für das philosophische Nachdenken der Dualismus von geistiger und körperlicher Welt, den das Mittelalter in religiöser Vorstellungsform ausgebildet hatte, zu begrifflicher Deutlichkeit verschärfen. Man darf sagen, daß in Descartes'Lehre die Nebeneinanderstellung der mathematischen Physik und einer auf die Erkenntnistheorie des Selbstbewußtseins gegründeten Metaphysik dieser geistigen Lage den schärfsten Ausdruck gegeben hat. Eben damit aber war das Problem des Verhältnisses der beiden Potenzen in eine neue Phase getreten, und schon Descartes selbst hatte in der übergreifenden Stellung der unendlichen Substanz die Vermittelung zwischen den unvereinbaren Gegensätzen von geistiger und körperlicher Wirklichkeit gesucht. Dabei übernahm der große Rationalist in seiner vorsichtigen Denkweise die Vorstellung von der Gottheit aus den überlieferten religiösen Anschauungen, und sowenig er selbst dabei in seinem Innersten religiös interessiert sein mochte, so wenig ging er doch daran, die Gottesvorstellung nach den metaphysischen Motiven umzugestalten, für die er ihrer bedurfte. So kam es, was in der okkasionalistischen Entwickelung seiner Schule zutage trat, daß dieser überlieferte Gottesbegriff mit seiner überwiegenden Bestinmung clurch die Merkmale der Geistigkeit den Anforderungen nicht genügen konnte, die aus der Lage der metaphysischen Probleme daran gestellt werden mußten. Sie verlangten eine Gestaltung des Gottesbegriffs, welche inhaltlich über den Gegensatz des Geistigen und des Körperlichen hinausgehoben werden mußte, gerade wenn sie die Möglichkeit gewähren sollte, die Vereinbarung der Gegensätze in der Gesamtstruktur der Dinge begreiflich zu machen. In dieser Weise trieb die sachliche Notwendigkeit der metaphysischen Entwickelung von dem Theismus der cartesianischen Lehre auf eine pantheistische Philosophie zu, die in einer jenseits des Gegensatzes von Geist und Materie liegenden Urwirklichkeit die letzte Einheit beider Weltsphären suchen mußte, aber ebendeshalb für diese Einheit keine der qualitativen Bestimmungen der Erfahrung mehr übrig hatte, sondern sie nur noch mit rein begrifflichen Momenten auszustatten vermochte. Es ist nun höchst merkwürdig, daß diese aus dem Cartesianismus erwachsende Aufgabe ihre Lösung durch einen Mann finden sollte, der, von tiefster und ursprünglichster Religiosität crfüllt, sein ganzes I.eben 
in den Dienst des Gedankens stellte, von dem Gegenstande seines mystischen Gefühls eine vollkommen rationale Erkenntnis zu gewinnen. Der Spinozismus, der sich als fertige Lehre wie das unpersönlichste aller Systeme darstellt, ist doch aus der allerpersönlichsten Frömmigkeit herausgewachsen, und die streng rationale Außenseite des demonstrierenden Systems birgt in sich die heiße Inbrunst einer gottseligen Überzeugung.

Spinozas Persönlichkeit.

Aus der portugiesischen Judengemeinde in Amsterdam, der er durch seine Geburt angehörte, war Spinoza wegen seiner durch die Philosophie der Zeit genährten Überzeugungen mit dem großen Bannfluch ausgestoßen, und in keine andere menschliche Lebensgemeinschaft ist er eingetreten. In völlig auf sich selbst gestellter Einsamkeit, in stolzer Armut hat er das schlichte L.eben der Bedürfnislosigkeit und der strengen Rechtlichkeit geführt, und auch die Berührung mit älteren oder jüngeren Männern, die sich seine Freunde nannten, hat für dieses vö1lig in sich geschlossene Leben des Gedankens kaum einen tieferen Eingriff bedeutet. Selbst die Erfahrung der Unzuverlässigkeit solcher Freunde, die Spinoza bei der Veröffentlichung seines Theologisch-politischen Traktats machte, sind an seinem ruhigen Geiste, soweit wir sehen, abgeflossen und haben nur die Wirkung gehabt, daß er seine Lehre, von der nur einzelne vorher Bruchstücke gekannt hatten, als Ganzes erst der Nachwelt überliefert hat. Und auch das ist nur zum Teil geschehen; denn neben der „Ethik“, in der wir jetzt die methodisch straffe Konzentration seiner Gedanken vor uns haben, plante er eine Darstellung seiner Philosophie, wie es scheint, in freierer und ausführlicherer Behandlung, deren schriftstellerische Art in dem Bruchstück über die Vervollkommnung des Intellekts (Tractatus de intellectus emendatione) $z u$ erkennen ist und an deren Abschluß den kranken Philosophen der Tod gehindert hat.

Religion und Philosophie.

\author{
und
} hältnis (er Wissenschaft zur Religion gëhrt, und seine eigene mystische Frömmigkeit hat ihm die Doppellösung dieses Problems an die Hand gegeben. Während seine Philosophie nichts anderes ist und sein will als die wissenschaftliche Erfüllung des sein ganzes Leben durchdringenden religiösen Triebes, während ihm somit Philosophie und Religion in letzter In$\operatorname{stan} z$ dasselbe sind, hat er in jenem einzig zu seinen Lebzeiten (wie es scheint, aus besonderem politischen Anlaß) veröffentlichten Traktat die Grenzlinie $z$ wischen der Wissenschaft und der positiven Religion mit scharfer Sicherheit gezogen. Er folgt dabei zum Teil Gedanken, die auf der Höhe der mittelalterlichen Philosophie von den arabischen und jüdischen Denkern, insbesondere von Maimonides, ausgesprochen worden waren, und nimmt dazu die Motive aus der Toleranzbewegung des i6. und 17. Jahrhunderts auf; er gibt ihnen mit scharfer Prägung die Form, daß Wissenschaft und Bibelkritik. positive Religion ineinander nicht hineinzureden haben: aber er findet auch den Standpunkt der Wissenschaft gegenüber den Urkunden der positiven Religion, indem er zeigt, daß sie wie alle Gegenstände der literarischen 
Überlieferung nach historisch-kritischer Methode verstanden, erklärt und interpretiert werden müssen. Er ist damit der Schöpfer der historischen Bibelkritik geworden: und sein Ergebnis, daB der Zweck und der bleibende Wert religiöser Urkunden die sittlich religiöse Erbauung sei, und daß der Kreis der theoretischen Vorstellungen, worin diese Aufgabe erfüllt wird, selbst keinen Lehrzweck und keine dauernde Lehrbedeutung besitze, darf als die reinste Formulierung der Toleranzbewegung und der freien Religiosität des 17. und 18. Jahrhunderts betrachtet werden.

Die persönliche Überzeugung Spinozas, worin von vornherein die innige Mystik und Verschmelzung von Mystik und Rationalismus enthalten ist, richtet sich auf die kontemplative Gottesliebe als das höchste unter allen Gütern des Lebens. Sie erfaßt in unmittelbarer und reiner Intuition ihren Gegenstand. Gott ist das Gewisseste von allem: deshalb braucht diese Philosophie nicht erst ihren Ausgangspunkt zu suchen, sondern sie hat ihn in dem Begriffe der Gottheit als der einzig wahren Wirklichkeit: Deus sive natura. Allein die Erhebung über die Enttäuschungen des Lebens, die Spinoza bei der Wissenschaft sucht, kann deshalb doch nur darin gefunden werden, daß alles Wirkliche als etwas in diesem einzig wahrhaft Wirklichen Begründetes begriffen wird. Für Spinoza kann somit die Welt selbst nichts anderes sein als Gott in seinem ausgebreiteten Wesen, und insofern entwickelt sich bei ihm die ausgesprochenste und durchgeführteste Form des Pantheismus. Gott und Welt Pantheismas werden nicht in das Verhältnis der schöpferischen Ursache zu ihrer Wirkung, sondern in das des Wesens zu seinen Zuständen gebracht. Es ist das Eigenartige der spinozistischen Lehre, daß in der Struktur ịhrer Weltanschauung die Kategorie der Kausalität vollständig zugunsten derjenigen der Inhärenz zurücktritt. Gott oder die Natur ist die Substanz, die einzige, die dieses Namens wahrhaft würdig ist, weil sie allein in sich ist und aus sich begriffen wird. Sie ist das Ding aller Dinge; denn die einzelnen Dinge, die res, mögen sie als Seelen oder als Körper erscheinen, sind nur die Modi dieser einen unendlichen Substanz. Daher ist das Verhältnis der Notwendigkeit zwischen dem Wesen und seinen Zuständen nicht das lebendige Verhältnis des Wirkens und nicht die zeitliche Beziehung zwischen Ursache und Wirkung, sondern vielmehr das logische Verhältnis zwischen Grund und Folge. Der konsequente Rationalismus erkennt nur diese Beziehungsform der Dependenz an: diese logische Form der „Kausalität“ fällt nun aber für den Denker, der aus der naturwissenschaftlichen Bewegung des Cartesianismus herkommt, mit der mathematischen zusammen. Mit formelhafter Wiederkehr wird bei Spinoza jeder notwendige Zusammenhang mit demjenigen verglichen, der zwischen dem Wesen des Dreiecks und der Gleichheit seiner Winkelsumme mit zwei Rechten besteht.

Hieraus erklärt sich die methodische Form, die nicht nur für die Dar- Geometrische stellung, sondern auch für die Denkweise des Spinozismus charakteristisch Methode. geworden ist. Die sachliche Aufgabe, die er der Philosophie stellte, alle endlichen Dinge aus dem Wesen Gottes in derselben Crdnung abzuleiten, 
wie sie wirklich darin enthalten sind, ließ ihn den Lehrgang der euklidischen Geometrie als die Form des deduktiv beweisenden Systems ergreifen. Wie schon Descartes mit seiner Auffassung von der Mathematik als der einzig wahrhaft demonstrierenden unter den bestehenden Wissenschaften von seinen Freunden beim Wort genommen und dazu veranlaßt worden war, die Grundlehren seiner Philosophie versuchsweise in dieser Form darzustellen, so goß Spinoza nicht nur seine unter dem Vorbehalt der eigenen Ansichten vorgetragene Darstellung der cartesianischen Lehre, sondern er preßte auch in der Ethik die Gedanken der eigenen „philosophia“ in diese schwerfällige Form von Definitionen, Axiomen, Lehrsätzen, Demonstrationen, Scholien und Korollarien. In der felsenfesten Überzeugung von der Wahrheit seiner Lehre stellte er sie als einen streng logischen Zusammenhang von Folgerungen aus den anfänglichen Voraussetzungen dar, und hierin besteht nicht zum wenigsten der Zauber, mit dem er jeden gefangennimmt, der sich in die scheinbar so einfachen und harmlosen Begriffsbestimmungen des Anfangs hineingefunden hat. Ist Gott oder die Natur das Wesen und die Welt der Inbegriff seiner Zustände, worin sich dieses Wesen ohne jeden Rest einer bloßen Möglichkeit verwirklicht, so ist nichts in dieser Welt, was anders sein könnte, als es ist, und die Gesamtheit dieser Modi bedeutet danach nichts anderes als ebendieses Wesen selbst.

Das wichtigste Merkmal im Begriffe der Gottheit oder der Welt ist für Spinoza die Unendlichkeit. Und gerade darin besteht das Charakteristische dieser Grundform des modernen Pantheismus. In der Ausführung der Weltanschauung unter dem Gesichtspunkte der Kategorie der Inhärenz folgt daraus, daß die eine Substanz aus unendlich vielen Attributen besteht, von denen jedes selbst wieder eine unendliche Wesenheit bedeutet. Aber die Substanz setzt sich nicht aus diesen Attributen zusammen, sie ist vielmehr das eine Urding, das alle diese Eigenschaften in sich vereinigt; und jeder der Zustände oder der Modi muß deshalb mit seinen besonderen Bestimmungen in seiner Weise ebenfalls allen jenen unendlichen Attributen angehören. Es ist dieselbe Welteinheit, die sich in der Gesamtheit aller ErAttributs. scheinungen im ganzen wie im einzelnen clarstellt. Von dieser Daseinsfülle der Gottheit sind nun zwar dem Menschen nur zwei Attribute bekannt: das Bewußtsein (cogitatio) und die Räumlichkeit (extensio). Aber diese beiden Erscheinungsweisen Gottes sind deshalb bei Spinoza nicht etwa nur Vorstellungsweisen im menschlichen Geiste (denn dieser selbst ist ja nur ein Modus in dem einen der Attribute, der cogitatio), sondern reale Daseinsarten der Substanz. So sind auch alle endlichen Dinge ihrer Essenz nach in dem göttlichen Wesen enthalten, uns aber nur in den beiden Erscheinungsarten als Modi des Bewußtseins und als Modi der Räumlichkeit bekannt. So ist weiterhin der Zusammenhang der endlichen Dinge in dem Wesen Gottes ursprünglich gegeben und mit diesem selbst gleich: aber für unsere Erkenntnis stellt er sich in den beiden völlig getrennten Reihen des Zusammenhangs der Ideen einerseits und der Körper und ihrer Bewegungen anderer- 
seits dar. Die Attribute sind die getrennten, voneinander begrifflich unabhängigen Eigenschaften der Substanz und deshalb auch aller endlichen Modi. Aber der Zusammenhang der Modi in dem einen Attribut muß genau derselbe sein wie in dem anderen Attribut. Diese Auffassung pflegt man jetzt den Parallelismus der Attribute zu nennen: sie ist in der Tat Spinozas Parallelismus. eigenartige Lösung der okkasionalistischen Probleme. Sie lehnt freilich jede Art gegenseitigen Einflusses von Bewußtsein und Körperlichkeit ab, und sie behandelt beide, die körperliche und die bewußte Ausdrucksweise, als die zusammengehörigen Bestimmtheiten jedes endlichen Dinges ebenso wie der unendlichen Substanz, deren Modus es ist. Sie betrachtet deshalb auch die Ordnung der körperlichen Vorgänge als identisch mit der Ordnung der Bewußtseinsvorgänge, ohne der einen oder der anderen von ihnen die Priorität zuzuschreiben oder die eine zur Begleiterscheinung der anderen herabzusetzen: der Spinozismus in seiner historischen Ursprünglichkeit darf weder materialistisch noch idealistisch gedeutet werden. Aber für ihn ist auch jede der beiden parallelen Ordnungen nicht das zeitliche Verhältnis von Ursachen und Wirkungen, sondern vielmehr der logisch-mathematische Zusammenhang von Gründen und Folgen. Dieser, in dem ewigen Wesen der Substanz selbst mit allen seinen Besonderheiten enthalten, wird in der unendlichen Mannigfaltigkeit der Attribute verschieden "ausgedrückt“. So trägt die Welteinheit die Fülle des einzelnen als einen mit ihr selbst gegebenen und von ihr nicht abzutrennenden Zusammenhang in sich, und dies Verhältnis zeigt sich wieder in jedem einzelnen Attribut als dasjenige der unendlichen Modi zu den endlichen. In jenen ist das allgemeine Wesen des Attributs, in diesen die Eigenart seiner besonderen Bestimmbarkeiten ausgedrückt, und deshalb besteht die „doppelte Kausalität" für jede einzelne Wirklichkeit in der Welt darin, daß sie einerseits von der allgemeinen Gesetzmäßigkeit ihres Attributs, andererseits von einem anderen Endlichen abhängig ist, das ihr in der Ordnung des Ganzen vorhergeht.

Hinter solchen scholastischen Formen und Formeln verbirgt sich bei Spinoza die warme Überzeugung von der Allgegenwart des göttlichen Einheit dos Natürlichen and Wesens in der Gesamtheit der natürlichen und der geistigen Wirklichkeit. Aber indem die göttliche Substanz auf diese Weise alle Bestimmungen der Realität in sich vereinigt, kann sie selbst in ihrer Totalität durch keine davon bezeichnet werden, und alle anthropomorphen Versuche, der Gottheit als ihre spezifische Bestimmung Eigenschaften wie die des Verstandes oder des Willens beizulegen, werden von Spinoza mit großer Energie zurückgewiesen: die höhere Einheit, die gleichmäßig in den Formen des geistigen wie des körperlichen Daseins sich darstellt und die diese doppelte Ausdrucksweise ihres Wesens bis in jede kleinste Zustandsgestaltung hinein aufrechterhält, ist selber nicht nach einer der beiden Seiten hin charakterisiert: und doch würde man Spinoza mißverstehen, wenn man diese Einheit als ein unbekanntes An-Sich betrachten wollte, das selbst noch wieder von den Attributen real unterschieden wäre. Wie das Ding nichts anderes ist als die Ge- 
samtheit seiner Eigenschaften, so Gott nichts anderes als die Summe seiner Attribute: substantia infinita constans infinitis attributis. Die Einheit des Natürlichen und des Geistigen, des Ausgedehnten und des Bewußten, die Spinoza findet, ist keine dritte, auch keine unbekannte Qualität, sondern es ist der Wesenszusammenhang zwischen beiden, der sich wie im Ganzen so auch in jedem kleinsten Teile des Universums offenbart.

Antiteleologische Daraus folgt, daß die mathematische Notwendigkeit des ZusammenNaturlebre. hanges, womit die Gesamtheit der endlichen Modi in dem Wesen Gottes enthalten ist, in den Erscheinungen des geistigen Daseins ebenso anerkannt werden muß wie in denen des körperlichen. Wenn es überhaupt nichts gibt, was anders sein könnte, als es ist, wenn alles Endliche durch die doppelte Kausalität der allgemeinen Gesetzmäßigkeit und der Determination durch ein anderes Endliches eindeutig bestimmt ist, so ist aller Zufall aus den Vorgängen des Geschehens und zugleich alle Willkür aus dem Ablauf des seelischen Geschehens ausgeschlossen: beide, Zufall und Willkürfreiheit, sind asyla ignorantiae, Täuschungen, die an den Grenzen menschlicher Erkenntnis der göttlichen Notwendigkeit der Dinge entstehen. Aber Spinoza hat die Konsequenzen der mathematisch-naturwissenschaftlichen Weltbetrachtung noch weiter auch in dem Sinne gezogen, daß er von der adäquaten Erkenntnis des Wirklichen, die in der Wissenschaft gewonnen werden soll, jede Wertansicht ausgeschlossen hat. $\mathrm{DaB}$ die Naturlehre auf die teleologische Betrachtung und gar auf die teleologische Erklärung unter diesen Voraussetzungen vollständig verzichten mußte, verstand sich von selbst, und was Bacon, Hobbes und Descartes in dieser Hinsicht gelehrt hatten, konnte von Anthropologie. Spinoza nur mit verstärkter Zuspitzung wiederholt werden; aber das eindrucksvollste und das erregendste in seiner Lehre war die Anwendung desselben Prinzips der wertfreien Untersuchung auf die Vorgänge des seelischen Lebens, - der mit vollem Bewußtsein durchgeführte Versuch, auch das menschliche Fühlen und Wollen so zu behandeln, als ob man es mit Linien, Flächen und Körpern zu tun hätte, und die Affekte und Leidenschaften der Menschen „nicht zu begeifern noch zu belachen, sondern zu begreifen“. Der einsame, weltferne und weltdurchschauende Denker geht mit naivem Ernst und überlegener Kühle daran, die Masken der Selbsttäuschung von dem Getriebe des Menschenlebens abzureißen, und sein unbeirrter Naturalismus gewinnt dabei ungewollt das Pathos einer ins Innerste dringenden Ehrlichkeit und Rücksichtslosigkeit. In dieser vielbewunderten Theorie der Gemütsbewegungen geht Spinoza von dem Begriffe des Selbsterhaltungstriebes aus, den er zwar Hobbes entnimmt, aber doch zugleich im Sinne des Parallelismus der Attribute umdeutet. Wie der Körper seine Macht und Wirksamkeit dadurch bewährt, daß er sich gegenüber der Einwirkung der anderen in seiner eigenen Gestalt aufrechterhält, so ist derselbe Conatus in der Seele der Trieb nach Selbsterhaltung und Selbstentfaltung. Alles Endliche hat in seiner Bestimmtheit durch anderes etwas Negatives an sich: seine positive Realität besteht in dem Sein-Wollen, dem Suum esse conservare. Der Selbsterhal- 
tungstrieb also ist die ursprüngliche Begierde, und sie richtet sich als Begehren auf alles, was das eigene Dasein fördert, als Verabscheuen gegen alles, was dies hemmt oder beeinträchtigt. Nichts wird begehrt, weil es gut, oder verabscheut, weil es schlecht ist, sondern weil es begehrt wird, heißt es gut, weil es verabscheut wird, schlecht. Neben der Begierde (appetitus) als dem Urphänomen stehen die Affekte der Lust am Fördernden und der Unlust am Hemmenden (laetitia und tristitia), und an diese drei Grundformen schließen sich die Gegensatzpaare von Liebe und $\mathrm{HaB}$, Hoffnung und Furcht, um so die Grundlage für eine eingehende Entwickelung aller besonderen "Passionen" in dem Sinne zu gewinnen, wie Descartes und Hobbes es bereits versucht hatten. In der reinen, kühlen Analyse Spinozas müssen sich die sublimsten Gebilde des Gemüts es gefallen lassen, auf ihre elementaren Motive zurückgeführt zu werden, und alle Schleier der bewußten Heuchelei wie der unbewußten Selbsttäuschung werden schonungslos zerrissen.

Ähnlich verfährt der Philosoph mit dem öffentlichen Leben. Auch seine Staatslehro. Staatslehre schließt sich eng an Hobbes. Er beginnt mit einer streng naturalistischen, lediglich quantitativen Bestimmung des Rechtsbegriffes. Jeglicher Anspruch geht und gilt so weit als die Kraft, ihn durchzusetzen: das Recht reicht so weit wie die Macht, wie die Energie der Selbsterhaltung. Deshalb erscheint auch hier das Urrecht der Selbsterhaltung, auch hier das bellum omnium contra omnes als dessen erstes Ergebnis, auch hier die Rettung daraus durch den Gesellschaftsvertrag, auch hier der Staat als die klug erdachte Maschine zur Ausgleichung dieser Gegensätze. Doch geht Spinoza nicht bis zu den extremen Folgerungen von Hobbes; er ist dem Absolutismus abhold, dem Republikanismus geneigt und besonders dem aristokratischen zugetan: er genoß die Freiheit der Niederlande, aber er sah den ochlokratischen Wahn beim Schicksal der Brüder de Witt. Indessen ist auch er gegen jede politische Inszenierung und Aktivität konfessioneller Tendenzen, und nicht ohne Beziehung zu den zeitgenössischen Kämpfen zwischen den holländischen Parteien der Regenten und der Predikanten verlangt er in seinem Tractatus politicus, daB die positiven Religionen und Konfessionen sich in der Öffentlichkeit nicht breit machen, daß hier, was für das gemeinsame Leben an religiösem Kultus erforderlich ist, von der Regierung bestimmt sein soll. Im letzten Grunde kommt also auch darin die mystische Frömmigkeit mit dem religiösen Indifferentismus überein.

Wie zwischen dem mystischen Ziel und der rationalistischen Methode, Moral. so bestand in Spinozas Denken zwischen der wertfreien Einsicht in die göttliche Notwendigkeit aller Dinge und dem Grundmotive des Suchens nach dem höchsten Gut und nach der vollkommensten Lebensgestaltung ein tiefinnerer Gegensatz: und doch ist es ihm gelungen, diese Kluft zu überbrücken und von der Metaphysik des Pantheismus her eine Ethik zu gewinnen, die dem sittlichen und religiösen Motiv seiner Philosophie völlig Genüge tat. Mit einer seltsamen und doch in ihrer begrifflichen Ableitung sich wie selbstverständlich darlegenden Gedankenverschlingung kommt Spinoza zu seinem 
Begriff der „Tugend“. Sie ist ihm im antiken Sinne (virtus) gleich der Tüchtigkeit, also hier der Fähigkeit zur Selbsterhaltung und Selbstförderung, der Macht. Sie ist somit nach der Attributenlehre eine Vollkommenheit zugleich des Körpers und der Seele. Der letzteren Tüchtigkeit aber besteht in den richtigen, den klaren und deutlichen Vorstellungen. So sind Wissen, Tugend und Macht identisch, und die Erweiterung, welche die Kraft und die Machtsphäre des Körpers durch das Wissen erfährt, dieses baconische Motiv, spielt in den spinozistischen Tugendbegriff ebenso hinein wie das sokratische. Mit dieser Voraussetzung aber verbindet sich der Gegensatz von Aktivität und Passivität, der mit der Realität und der Negativität des endlichen Wesens zusammenfällt. Wie der Körper sich in dem Maße passiv verhält, als sein Zustand durch die Einwirkungen anderer Körper bestimmt ist, so sind in der Seele die solchen Zuständen des Leibes entsprechenden Vorgänge sinnlicher Wahrnehmung und Gemütserregung die passiven Affekte, in denen der Mensch der Sklave der Dinge und im Zustand des Leidens ist, selbst wenn solche passiven Affekte vorübergehend freudiger Art sind. Die aktiven Affekte dagegen erwachsen nur aus der reinen Selbstbetätigung der Seele. Es sind die Affekte der Erkenntnis, lauter freudige Affekte. Freilich hat nicht alles Erkennen diesen Wert: nicht die inadäquate Stufe der Erkenntnis, die niederste, deren Ursprung die sinnliche Wahrnehmung bildet, - eher schon die höhere, wenigstens zum Teil adäquate Erkenntnis, die gedankliche Verarbeitung der Sinnesdaten zu allgemeinen Begriffen, - vor allem aber die höchste Erkenntnis, die intuitive, deren Gegenstand Gott und die ewige Notwendigkeit ist, mit der, wie alle Dinge, so auch alle unsere menschlichen Erlebnisse aus seinem Wesen folgen. Diese allein adäquate Erkenntnis enthält in sich die Überwindung der Leidenschaft, sie ist es und sie allein, die den Menschen von der Knechtschaft der Welt erlöst und ihn wahrhaft frei macht. Die Behauptung dieser Freiheit als des sittlich religiösen Ideals ist wohl vereinbar mit der Leugnung der Willkürfreiheit der Indifferenz. Sie bildet den Schlußstein in dem Begriffsbau des spinozistischen Systems. Die Erkenntnis Gottes ist die Erlösung; denn sie ist zugleich die Liebe zu Gott und damit das höchste Gut: sie ist das Walten Gottes selbst in uns, der Amor intellectualis quo deus se ipsum amat.

Leibniz' Stellung und Persöulich-

VJlI. Leibniz. Die Entwickelungslinie der großen Systeme läuft mit Leibniz auf ihren Ausgangspunkt zurück. Alles, was mit noch ungeschiedener Vieldeutigkeit bei Nicolaus Cusanus im Keimen begriffen war, ist bei dem großen Beginner der deutschen Philosophie zu klarer Ausgestaltung gelangt. Seine Lehre hat sich auf der breitesten Grundlage gelehrter Bildung, historischer und naturwissenschaftlicher Kenntnisse mit offenem Sinn für alle Motive des metaphysischen Denkens und mit einer synthetischen Genialität entwickelt, aus der ihre beherrschende Stellung für die Weiterentwickelung begreiflich wird. Aus dem Universitätsleben seiner Zeit erwachsen, aber durch die Engheit und Erstarrtheit der akademischen Zustände 
seiner Heimatstadt Leipzig abgestoßen, hat er in mannigfachen diplomatischen Stellungen bei dem Mainzer Kurfürsten, am Braunschweig-Lüneburgischen, am Berliner Hofe eine überaus reiche und vielseitige, aber auch eine sich zersplitternde und zerstreuende Tätigkeit entfaltet. Mit staunenswerter Allseitigkeit hat er überall weit über das jeweilige Amt linaus mit äußeren und inneren Staatsangelegenheiten sich betraut gesehen, und neben seinen politischen und publizistischen Beschäftigungen geht eine polyhistorische Arbeit auf allen Wissensgebieten einher, wie sie niemals wieder in einem Menschen vereinigt gewesen ist. Von der Mathematik an, in deren Entwickelung er durch die Grundlagen der Infinitesimalrechnung .schöpferisch eingriff, durch die historischen Disziplinen, für die er mit zahlreichen Sammlungen tätig war, und durch alle Zweige der Naturforschung, in die er mit eigener Arbeit theoretisch und praktisch eingriff, reicht diese Universalität bis in die Philosophie, für deren prinzipielle Gestaltung er die Motive der antiken und der mittelalterlichen Denkrichtungen mit den Anforderungen der neuen Naturforschung zu verbinden wußte. Nirgends und niemals erscheint er als Dilettant. Immer und überall schöpft er aus dem vollen und steht mitten im Zuge der sachlichen Untersuchungen. In dieser Monade spiegelt sich in der Tat das wissenschaftiche Universum seiner Zeit. Er ist eine Akademie in einer Person. Der Begründer und erste Präsident der Berliner Akademie, der auch in Dresden, in Wien, in St. Petersburg ähnliche Gründungen anregte, hatte den Gedanken einer Genossenschaft europäischer Akademien als den Schlußpunkt für die Organisation des wissenschaftlichen Lebens erkannt. Aber die große Zersplitterung dieser riesigen geistigen Kapazität machte sich auch in der äußeren Erscheinung seiner Philosophie geltend, welche keine adäquate literarische Gesamtdarstellung gefunden hat, sondern in zahllosen Abhandlungen, die zum Teil nur Fragmente geblieben sind, in massenhaften Entwürfen und in einer beispiellos ausgebreiteten Korrespondenz zerstreut ist. Es ist ein Akt historischer Pflichterfüllung, daß die vereinigten Akademien Europas jetzt sich zu einer Herausgabe seiner Werke verbunden haben.

Die philosophische Entwickelung von Leibniz ist wesentlich durch zwei Interessen bestimmt: die methodische Richtung der euklidischen Methode, Philosopbie. die aus dem Cartesianismus sich herausgebildet und bei Spinoza ihre schematische Form gefunden hatte, und die sachlichen Probleme der Substanzenlehre in ihrer Beziehung auf die philosophische Erklärung der Natur. Beide Momente haben von Anfang an zusammengewirkt, aber zunächst stand das logische im Vordergrund. Leibniz interessierte sich für die nominalistischterministische Semeiotik, und der Entwurf einer philosophischen Zeichensprache zur Durchführung des Rechnens mit Begriffen hat ihn im Zusammenhang mit den Bedürfnissen seiner Zeit, die das sterbende Latein durch eine lautlose Weltsprache zu ersetzen wünschte, sein ganzes Leben lang beschäftigt. Die Tendenz aller dieser Versuche mußte darauf gerichtet sein, die einfachen Grundelemente aller Erkenntnis, die „ersten Wahrheiten“ zu ge- 
winnen und aus ihnen durch logische Kombination alle andere, alle zusammengesetzte Wahrheit abzuleiten. Das führte einerseits auf das von Galilei in der Physik und von Descartes in der Metaphysik angewendete Prinzip der einfachen und elementaren Momente der Wirklichkeit und andererseits auf den

Ewige und zufallige Wahrheiten. vorbildlichen Beweisgang der mathematischen Methode. Aber in bezug auf die ersten Wahrheiten stieb Leibniz dabei auf einen, seiner Zeit in dieser Form neuen und doch ihr sachlich sehr geläufigen Gegensatz, den der allgemeinsten und der besondersten Wahrheiten, der Axiome und der Tatsachen. So unterschied er die ewigen, geometrischen oder metaphysischen Wahrheiten von den tatsächlichen Wahrheiten und nannte sie auch gern die notwendigen und die zufälligen. Zuerst bedeutete die letztere Bezeichnung nur die logische Unterscheidung, wonach die ewigen Wahrheiten aus der Unmöglichkeit des Gegenteils nach dem Satz vom Widerspruch, die tatsächlichen dagegen, bei denen das Gegenteil denkbar bleibt, nach dem Satz des zureichenden Grundes vom Menschen erkannt werden sollen. Dabei wurde wohl die unbedingte Notwendigkeit der ersteren und die bedingte Notwendigkeit (= Zufälligkeit) der letzteren mit der Cartesianischen Unterscheidung des Klaren vom Dunklen, des Deutlichen vom Verworrenen in Zusammenhang gebracht. Aber wenn danach für den göttlichen Intellekt auch das Tatsächliche eine unbedingte, widerspruchslose und die Möglichkeit des Gegenteils ausschließende Wahrheit haben sollte, so erkannte Leibniz darin die Gefahr des Spinozismus, d. h. der Lehre von der göttlichen Notwendigkeit alles Wirklichen: und so hat er sich später zu einer realen Unterscheidung der metaphysischen und der tatsächlichen Wahrheit um so mehr entschieden, als dazu auch die sachlichen Motive seines Philosophierens trieben.

Diese Motive waren ebenso naturphilosophischen wie metaphysischen Charakters: sie beruhten auf den Umbildungen, welche die Grundbegriffe der Substanz und der Kausalität innerhalb der Cartesianischen Schule erfahren hatten. Sie schienen Leibniz dabei nicht ohne Recht die Fähigkeit zur Erklärung der Natur eingebüßt zu haben. Das zuerst Bestimmende war für ihn, daß er die Cartesianische. Formulierung des Gesetzes von der Erhaltung der Bewegung unzulänglich fand. Wenn er darüber mit seiner Unterscheidung von toter und lebendiger $\mathrm{Kraft}$ hinauszugehen versuchte - diese Unterscheidung, die nachher so viel diskutiert worden ist und in der, wie wir jetzt sagen würden, das Verhältnis von potentieller und kinetischer Energie sich ankündigte - , so führte das den Philosophen zu der Behauptung, daß der Körper nicht nur ein toter Träger der.Bewegung sei, sondern ihr lebendiger Quell. Der Cartesianische Begriff der res extensa ist der mathematische Körper; der wirkliche, der physikalische Körper ist mehr, ist ein Kraftquell, ein wirkendes Ding. Hier liegt der Fehler Descartes'; er hat damit begonnen, den endlichen Dingen die Wirksamkeit abzusprechen, die ein wesentliches Merkmal des Substanzbegriffes bleiben muß; seine endlichen Dinge sind denaturierte Substanzen, keine wahrhaften mehr. Das ist 
im Okkasionalismus Schritt für Schritt ausdrücklicher erkannt, im Spinozismus mit voller Konsequenz ausgesprochen: die endlichen Dinge sind nur Modi der einen unendlichen Substanz. Man muß also entweder Spinozist werden und alles Wirken der endlichen Dinge entschlossen verneinen, oder man muß das Merkmal der Wirksamkeit als ein konstitutives, ja als das konstitutive Merkmal in den Begriff auch der endlichen Substanz aufnehmen. Die Entscheidung dieser Alternative fäl1t bei Leibniz nicht nur persönlich aus seiner Abneigung gegen den Pantheismus, sondern auch sachlich aus Gründen der mechanischen Theorie.

La substance est un être capable d'action - une force primitive. Sub- Immaterialität stanzen sind Kräfte: aber Kraft ist nichts Ausgedehntes oder gar Materielles, sie ist etwas Unräumliches, Überräumliches, Immaterielles. Der Körper als Substanz ist nicht physisch, sondern metaphysisch. Die Koordination von res extensae und res cogitantes ist aufzuheben. Das Wesen des Körpers ist immateriell; sein ausgedehntes, undurchdringliches Gebilde, d. h. seine Behauptung eines Raumteils, ist nur seine Kraftwirkung, seine Erscheinung. Diese Erscheinung faßt unsere sinnliche Erkenntnis in ihren unklaren und verworrenen Wahrnehmungsvorstellungen auf; unser rationales Denken erkennt den Körper klar und deutlich als das, was er ist - eine immaterielle Kraft. So kommt eine platonische Struktur der Weltanschauung heraus, ein Dualismus der Metaphysik, der dem der Erkenntnisarten entspricht, die intelligible Welt der Substanzen im Unterschiede von der sinnlichen Welt ihrer Wirkungen: für diese Auffassung ist also der Raum weder mit dem Körper identisch, wie Descartes lehrte, noch dessen reale Voraussetzung, wie Newton meinte, sondern ein Krafterzeugnis der Substanzen, ein phaenomenon bene fundatum.

Darnach aber kann der Mechanismus der körperlichen Bewegungen Begriff der nur für die Wirkungen der Substanzen zutreffen, das Mechanische nur als Erscheinungsform dem Immateriellen untergeordnet sein, das seinem innersten Wesen nach Leben ist. An die Stelle des Atoms oder des Korpuskels tritt wieder die aristotelische Entelechie, die in der inneren Entwickelung begriffene Substanz. Ihr Leben muß deshalb in den Vorstellungen bestehen: aber was soll sie vorstellen? Die Beantwortung dieser Frage ergibt das Intimste der Leibnizschen Weltanschauung. Seine Abneigung gegen den pan1theistischen Universalismus der einen Substanz führt ihn zur Anerkennung der vollen Realität der endlichen Substanzen, zu einer pluralistischen und individualistischen Weltansicht. Aber die Welt kann auch nicht in lauter Einzelwesen zerfallen, die nichts miteinander gemein haben. Die Einheit in der Mannigfaltigkeit ist nur möglich durch die Identität des Teiles mit dem Ganzen nach dem Prinzip des Cusaners. Jeder Teil ist das Ganze, nur in besonderer Art. Das Ganze aber, die Gesamtheit der übrigen, kann in Einzelnen nur so enthalten sein, daß jedes andere in ihm vertreten sein muß als Vorstellung. Die Vorstellung ist die einzige Art, wie wir erleben, daß eine Vielheit eine Einheit bildet. Solch eine Einheit ist jedes Weltwesen, jede 
Monade“. Auf diesen Begriff der Monade als des Spiegels der Welt wendet nun Leibniz in der glücklichsten Weise die Motive aus der okkasionalistischen Bewegung an. Er macht für das Einzelwesen völlig Ernst mit der Substantialität: ,,in se est“. Die Monaden erfahren keine Einflüsse voneinander, sie haben keine Fenster; kein Zustand der einen ist durch einen der anderen bedingt. Ihre Existenz ist rein innerlich, ihre Kraft immanent. Ihre Zustände sind ihre Vorstellungen, und das Prinzip des Wechsels dafür liegt in ihnen selbst, in der tendance de l'une perception à l'autr .

Prästabilierte Harmonie.

Worin diese Tendenz besteht, wird sogleich deutlich, wenn wir die andere Seite des Verhältnisses betrachten. Der Schein der Einwirkung muß, wie bei den Okkasionalisten und bei Spinoza, durch das Prinzip der Korrespondenz oder des Parallelismus erklärt werden. Dies Prinzip ist hier darin begriffen, daß den Lebensinhalt aller Monaden dasselbe ausmacht - das Universum selbst. Daher schlagen alle diese Uhren stets dieselbe Stunde. Jede Monade lebt sich selbst und damit das Universum aus: darum stimmen sie alle stetig überein. Das ist die harmonie préformée (préestablie) des substances. Der Unterschied aber $z$ wischen diesen Monaden steckt nicht im Inhalt, sondern in der Intensität des Vorstellens und stellt sich in dessen Klarheits- und Deutlichkeitsgraden dar. Das ergibt eine unendliche Variabilität des gemeinsamen Lebensinhaltes, eine Abstufung der Wesen durch die feinsten, unendlich kleinen Nuancen, das Gesetz der Kontinuität, wonach die Natur keinen Sprung macht, und somit ein großes Entwickelungssystem, ein Stufenreich der Dinge, wie bei Aristoteles und Thomas. Die untere Grenze dieses Systems bilden die niederen Monaden, die nur verworrene und unklare Vorstellungen haben, die Substanzen, die miteinander die Materie ausmachen, - die obere Grenze ist die eine höchste Monade, die das Universum mit vollkommener Klarheit und Deutlichkeit vorstellt, ebendeshalb nur eine, weil mehrere, die diesen höchsten Grad der Vollkommenheit erreichten, nach dem principium identitatis indiscernibilium identisch sein müßten. Zwischen der Materie und Gott ist die unabsehbare Masse der mittleren Monaden ausgebreitet, die teils unklare und verworrene, teils aber auch klare und deutliche Vorstellungen besitzen. Dazu gehört der Mensch, seine Seele. Für diese alle besteht die innere Tätigkeit in dem Übergange aus der Unklarheit und Verworrenheit in die Klarheit und Deutlichkeit, in dem inneren Drange, der aus dem dumpfen Bestande des Seelengrundes zu seiner lichten Selbsterfassung treibt. Diese Tendenz ist jenes Tätigkeitsprinzip der Monade, und damit erscheint bei Leibniz das Weltgeschehen als ein Prozeß der - Aufklärung.

Nach demselben Verhältnis faßt Leibniz auch die Gruppenbildung der Substanzen, den Schein ihrer mehr oder minder dauernden Zusammengehörigkeit auf, wie er sich namentlich in den organischen Wesen darstellt. Jede solche Gruppe hat ihr vinculum substantiale, das sie zu einer Einheit höheren Grades verbindet, in einer Zentralmonade, der Seele, welche die Monaden in ihrer nächsten Umgebung und deren Verhältnisse mit ausge- 
sprochen größerer Klarheit und Deulichkeit vorstellt als die weitere Umwelt. Dies ist auch die Beziehung der menschlichen Seele zu ihrem Leibe, eine Beziehung also, die nur den anthropologisch wichtigen Spezialfall der prästabilierten Harmonie überhaupt ausmacht. Aber die menschliche Seele hat deshalb, wie alle mittleren Monaden, wenn sie stetig das ganze Universum vorstellen soll, offenbar sehr viel mehr Vorstellungen, als sie weiß, Vorstellungen, die wirklich sein und ihre Wirksamkeit ausüben müssen, ohne bewußt zu sein. Nach dem Prinzip der Infinitesimalrechnung sind sie Vorstellungen von unendlich kleiner Intensität. Leibniz nennt sie petites perceptions und ist sich ihrer universellen Bedeutung als Voraussetzung seiner Monadologie vollkommen bewußt. Für den Prozeß der Klärung und Verdeutlichung, womit diese unbewußten Bestandteile in den bewußten Besitz der Seele erhoben und von ihr angeeignet werden, hat er den Namen Apperzeption eingeführt.

Die Lebenseinheit der Monaden setzt aber weiterhin nicht nur eine voll- Determinismu: kommene Determination des Ablaufs ihrer Zustände in dem Sinne voraus, daß damit, wie im Spinozismus, die Ablehnung aller Begriffe von Willkürfreiheit, Wunder und Zufall geboten ist, sondern sie verlangt auch eine letzte Ursache in der höchsten Monade, in Gott. So stark Leibniz für die endlichen Substanzen die Merkmale ihrer Unabhängigkeit voneinander im Sein und Wirken und ihrer immanenten Kausalität betont, so hält er doch die Überordnung der unendlichen Substanz aufrecht. Ihre Harmonie ist nur zu verstehen, wenn sie alle von der einen geschaffen sind. Aber diese Urmonade ist nun eben nicht mehr die bloße Substanz und causa sui, sondern das lebendige geistige Urwesen, das in seinem Verstande das Reich der Möglichkeiten übersieht, um aus dessen unendlicher Menge diejenige zu wählen, die der vernünftige Wille bevorzugt. Die Welt also könnte anders sein, wenn Gott sie anders gewollt hätte. Sie besteht nicht, wie bei Spinoza, mit der logischen Notwendigkeit des Nichtandersseinkönnens, sie ist keine vérité éternelle, sondern vérité de fait. Gott ist notwendig, die Welt ist zufällig. Gott besitzt die Freiheit einer von den Vorstellungen nicht determinierten Wahl, er hat sie bei der Schöpfung der Welt angewendet. Daher sind auch die Gesetze, die er ihr mitgegeben hat, die mechanischen, nicht geometrische, auf dem Satz des Widerspruchs beruhende, sondern tatsächliche, zufällige, für uns nur empirisch erkennbare Wahrheiten: lois de convenance. Sie sind von Gott gewählt zur Erfüllung der Zwecke seiner Weltschöpfung, und so muß sich der Mechanismus der Teleologie unterordnen. Die Welt erfüllt den ihr von Gott gesetzten Zweck gerade durch die gesetzmäßig mechanische Notwendigkeit ihrer Funktionen. So führt nicht nur der aristotelisch-kosmologische, sondern vor allem der physikotheologische Beweis zur Erkenntnis des Daseins Gottes.

Aber diese Gedanken verlangten ihre Rechenprobe. Ist denn diese optimismus. Welt wirklich so gut und schön, wie es danach angesichts der göttlichen Güte und Allmacht erwartet werden müßte? Die alten Probleme der Theo- 
dizee, die schon den Stoikern und Neuplatonikern zu schaffen gemacht hatten, mußten Leibniz um so mehr beschäftigen, als er seine Lehre gegen Pierre Bayle zu verteidigen hatte, den skeptischen Gegner aller Vernunftreligion. Wie kommt das Übel, das Elend und die Sünde in die Welt? Mit dem Elend, dem physischen Übe1, findet sich Leibniz durch die alten Argumente ab. Diese Übel bestehen nur für die sinnliche Empfindlichkeit und Begehrlichkeit; nur Scheinübel und Scheingüter sind es, welche den Eindruck der Ungerechtigkeit des Weltlaufs hervorbringen. Die physischen Übel sind zum Teil unvermeidliche Nebenwirkungen an sich zweckmäßiger Natureinrichtungen, zum Teil moralische Erziehungsmittel und im ganzen unerläßliche Folgen der Sünde. Schwieriger steht es für die Theodizee mit diesem moralischen Übel selbst, mit der Sünde. Wohl ist auch hier darauf hinzuweisen, daß das Gute nur neben dem Bösen möglich ist, weil beide Wertprädikate nur für die alternative Beurteilung Sinn haben, und weiterhin darauf zu vertrauen, daß der göttliche Weltplan schließlich auch das Böse zum Guten wenden wird. Aber die letzte Rechtfertigung muß Leibniz doch noch tiefer suchen. Auch das moralische Übel folgt aus dem metaphysischen Übel, der Unvollkommenheit der endlichen Dinge. Eine Welt muß aus endlichen Dingen bestehen, und solche sind ihrem Wesen nach unvollkommen. Um diese logische, ewige Wahrheit war bei der Weltschöpfung nicht herumzukommen. Bei keiner Weltmöglichkeit waren Unvollkommenheiten der endlichen Wesen $z u$ vermeiden. Wenn wir deshalb auch von Gott wegen seiner Weisheit und Güte annehmen müssen, daß er diejenige unter den möglichen Welten gewählt hat, welche die geringste Unvollkommenheit und Übelhaftigkeit bei sich führte, so konnte diese Welt doch nicht eine vollkommen übellose sein. Leibriz leugnet nicht die Übel in der Welt, aber er behauptet, sie seien so gering als irgend möglich, und somit diese Welt die beste unter den möglichen. Das allein bedeutet der Name Optimismus. Freilich, daß unsere wirkliche Welt die beste unter den möglichen sei, kann nicht empirisch bewiesen werden, weil wir sie nicht mit den übrigen Möglichkeiten, die wir ja nicht kennen, zu vergleichen mögen, sondern es kann nur begrifflich aus der Güte und Weisheit Gottes als des vollkommensten Wesens oder der absoluten Monade postuliert werden.

\section{Die Philosophie der Aufklarung.}

Geist des 18. Jabrhunderts.

Die Ausbildung der großen metaphysischen Systeme, die sich, insbesondere seit Descartes, im engsten Zusammenhange mit der modernen Naturforschung und an der Hand der mathematisch-mechanischen Probleme vollzogen hatte, war von Schritt 20 Schritt ein Triumph des rein weltlichen Denkens, ein sich immer mehr in sich selbst verstärkender Versuch, eine Weltanschauung lumine naturali, d. h. lediglich mit den Mitteln der natürlichen Erkenntnis zu gewinnen. Solange, wie noch bei Bacon, die Hauptsache dieser natürlichen Erkenntnis in der sinnlichen Erfahrung gesucht wurde, konnte neben der naturalistischen Weltansicht noch das Reich des 
Ubersinnlichen als Erkenntnisgegenstand der Offenbarung im Sinne einer problematischen Ergänzung bestehen bleiben: sobald aber innerhalb der natürlichen Erkenntnis das logisch-mathematische Denken in den Vordergrund trat und dessen stolze Selbstgewißheit die Quelle alles übrigen Wissens in einer allumfassenden geistigen Realität fand, erhob sich die neue Weltweisheit zu dem Anspruche, die Gesamtheit des Wirklichen restlos zu durchdringen und die Wahrheit für sich allein in Anspruch zu nehmen. Mit diesem siegreichen Bewußtsein trat die Philosophie beim Beginn des 18. Jahrhunderts die Herrschaft in dem geistigen Leben der europäischen Völker an. Eine Anzah1 von Grundüberzeugungen schien in der Naturforschung und in der durch sie bestimmten rationalen Philosophie gewonnen zu sein, und während die religiösen Weltanschauungen in unfruchtbarem Kampfe das öffentliche Leben durchwühlten, glaubte die wissenschaftliche Philosophie reif und befestigt genug zu sein, um mit ihren Prinzipien das Leben vernünftig zu gestalten. Die Vernunft hatte den Mut, sich in sich selber zu behaupten und sich im äußeren durchzusetzen. Das ist der allgemeine Charakter des gewaltigen Zeitalters, dem man den Namen der Aufklärung gegeben hat und das sich in diesem Sinne selbst das philosophische Jahrhundert nannte, der Zeit, die sich zutraute, aus der Vernunftserkenntnis heraus ihre Lebensverhältnisse zu regeln und an die Stelle des natürlich oder geschichtlich Gewordenen das von der Vernunft Erkannte und Verlangte, an die Stelle des Zeitlichen das Ewige zu setzen. Aus den Einsichten der Metaphysik sollten Werte des Lebens werden, und das Leben selbst verlangte, unter das Gesetz der Vernunft gestellt zu werden.

Aus diesem Grundzuge erklären sich alle Eigenarten der Aufklärungs- Grundzüge der philosophie: ihre genauen Beziehungen zu der allgemeinen Literatur, vermöge deren sie mehr und mehr lehrend und werbend in das Bewußtsein weiter Kreise eindrang, aber auch in demselben Maße an Strenge und Sicherheit des wissenschaftlichen Wesens verlor, - ihr durchgängiges Bestreben, das vernünftig Erkannte zum Wertprinzip für die Beurteilung des Bestehenden zu machen und es mit aller Gewalt und Rücksichtslosigkeit zur Geltung $z u$ bringen, - ihre Neigung, auf das Menschenleben, das sie zu regeln berufen schien, alle ihre Betrachtung und Untersuchung zu konzentrieren und so zuletzt sich aus der Weite der metaphysischen Systeme, von denen sie herkam, aus der intellektuellen Bemeisterung des Universums auf eine psychologische Besinnung und auf eine praktische Anthropologie zu verengern. Alle diese Züge sind schon bei dem Manne angelegt, der, gerade weil er nicht mehr ein geschlossenes System von großen Linien geschaffen, sondern der neuen Behandlungsweise der Probleme die schriftstellerisch wirksamste Form gegeben hat, als der führende Geist der Aufklärungsphilosophie gelten darf: John Locke.

I. Die psychologische Methode. Wie dereinst in Griechenland zụr Locke. Sophistenzeit, so leitet sich auch in dieser Aufklärung die neue Denkart 
durch die Überzeugung ein, daß der erste und der letzte Gegenstand menschlicher Erkenntnis der Mensch sei. Wenn Descartes das Selbstbewußtsein als die erste Gewißheit aller metaphysischen Erkenntnis gerade in dem Sinne gewonnen hatte, daß darin die übergreifende Wahrheit einer universellen geistigen Realität enthalten ist, so wird für das I 8. Jahrhundert dieses Selbstbewußtsein zu dem empirischen Wissen des einzelnen Menschen von sich selbst und seinen inneren Zuständen, von seinen Vorstellungen und seinen Wertungen, seinen Ideen und seinen Emotionen. Lockes „Essay concerning human understanding“ verdankt seine bestimmende Bedeutung für die gesamte folgende Philosophie wesentlich dem Umstande, daß er die Gedanken von der Welterkenntnis durch das natürliche Licht aus der lapidaren Darstellung der cartesianischen Metaphysik in die Sprache der empirischen Psychologie übersetzt hat. Von dem Streit der metaphysischen Systeme will er sich frei halten, um scheinbar voraussetzungslos nach der Entstehung und Entwickelung der Vorstellungen und der Wertungen zu fragen und danach ihre Berechtigung und das Maß ihrer Geltung zu beurteilen. Aber diese psychologische Methode entfaltet sich mit naiver Selbstverständlichkeit in dem Rahmen einer populären Weltansicht, welche die Züge der cartesianischen Metaphysik an sich trägt. Kogitative und nichtkogitative Substanzen stehen sich als die Welt der Geister und der Körper gegenüber; die erkennende Seele weiß intuitiv und mit voller Sicherheit nur von sich selbst und ihren eigenen Zuständen; von den Körpern weiß sie nur insoweit, als deren Zustände sich durch den Wahrnehmungsprozeß in die seelischen Zustände der Empfindung umgesetzt haben; sie weiß eigentlich immer nur, daß da draußen etwas ist, ein Ding, eine Substanz, aber nicht, was diese Substanz an sich selbst ist. Oder wenigstens sie weiß nur, daß die nichtkogitative Sub$\operatorname{stanz}$, der Körper, die quantitativen Bestimmungen des ausgedehnten, raumerfüllenden und im Raum beweglichen Dinges besitzt. Diese Eigenschaften werden dann (nach dem Vorgang von Robert Boyle) die primären Qualitäten der Körper genannt, während die Bestimmungen der einzelnen Sinne wie Farben, Töne usw. als sekundäre Qualitäten nur den Sinn einer Wirkung der Körper auf die wahrnehmende Seele haben. So wird die Lehre von der Subjektivität der Sinnesqualitäten im Sinne von Galilei, Descartes und Hobbes aufgenommen und bekommt den skeptischen Anstrich, daß die Erkenntnis der Außenwelt zum mindesten als mit problematischen Bestandteilen durchsetzt erscheint.

Erkenntnislehre. Diese terministische Wendung des cartesianischen Prinzips führt bei Locke wie bei den älteren Nominalister zu der Präponderanz der inneren Wahrnehmung, die für die ganze Aufklärungsphilosophie maßgebend geblieben ist. Das ganze Geschäft dieser Philosophie richtet sich auf die Selbsterfahrung des Menschen von dem Ursprung seiner Ideen und Emotionen. Vor dieser psychologischen Betrachtung erscheint das Selbstbewußtsein nicht mehr wie bei Descartes als in sich erfüllt von einer weltumspannenden Wahrheit, sondern vielmehr von Fall zu Fall in seinen einzelnen Zuständen be- 
stimmt durch die Einwirkungen der Außenwelt. Insofern allerdings richtet sich die Polemik des ersten Buches von Lockes Essay, worin die Existenz eingeborener Prinzipien im Geiste bestritten wird, auch gegen die cartesianische Lehre, während sie in ihren einzelnen Argumentationen mehr die stoischen Auffassungen der zeitgenössischen Neuplatoniker im Auge hat. Das Entscheidende aber war, daß damit die Philosophie grundsätzlich auf den Standpunkt der genetischen Psychologie gestellt wurde: der Aufbau des Seelenlebens aus einfachen Elementen wurde das wesentliche Objekt der philosophischen Untersuchung; der Ehrgeiz des systematischen Denkens, das sich nicht mehr auf das Universum zu werfen sich getraute, fand hier ein neues Feld seiner Betätigung. Dabei kehrte zunächst in Lockes Erkenntnislehre der Dualismus der cartesianischen Metaphysik als der Gegensatz äußerer und innerer Erfahrung (sensation und reflection) wieder und fand jene folgerichtige Wertung, daß die intuitive Erkenntnis der reflection adäquater und sicherer sei als die der sensation. Aber die Psychologie der Erkenntnis führte bei der Betrachtung der Verbindung dieser Elemente zu einer neuen Wertung des rationalen Momentes. Das logische Denken ergab in der Auffassung der Verhältnisse zwischen den Ideen eine demonstrative Erkenntnis: und wie dereinst bei Occam, so erschien auch hier die demonstrative Wahrheit eben nur als ein Verhältnis der Vorstellungen untereinander und damit prinzipiell ausgeschlossen von jeder Beziehung auf eine transzendente Realität.

Eine solche Erkenntnistheorie stellte somit ebendieselbe metaphysische Lebensansicht. Weltansicht in Frage, die sie in ihrer naiven Popularität voraussetzte. Aber gerade diese selbstverständliche Anlehnung an das allgemeine Bewußtsein, die schlichte, wasserhelle Klarheit der Darstellung, die verständige Abwägung des praktisch Erreichbaren und die sichtliche Vermeidung aller Kühnheit und aller Tiefgründigkeit eines lebensfremden Grübelns, - das waren typische Vorzüge, die Locke zum Liebling der Aufklärung gemacht haben, obwohl von seinen Darlegungen nur methodisch-formale Anregungen, keine irgendwie eindrucksvollen sachlichen Prinzipien ausgehen konnten. Er formulierte mit glücklicher Klarheit und Einfachheit die Durchschnittsansicht des gebildeten Menschen, wie sie sich allmählich aus der gesamten wissenschaftlichen Bewegung niedergeschlagen hatte; er wendete das Prinzip der mechanischen Erklärung auch auf seine genetische Psychologie an, wenn er aus den einfachen Elementen die gesamten Komplexe von Ideen und Emotionen abzuleiten unternahm; er blieb mit der allgemeinen Meinung im Einklang, wenn er auf ethischem Gebiete die Autorität eines herrschenden, lohnenden und strafenden Willens, mochte es der der Gottheit oder des Staates oder der Sitte sein, zum ausschlaggebenden Prinzip machte; er fand sich in der Religionsphilosophie mit dem thomistischen Prinzip zurecht, das eine weitgehende Übereinstimmung zwischen natürlicher und geoffenbarter Religion behauptete und für die Geheimnisse der Offenbarung keinen Widerspruch gegen die Einsichten des natürlichen Lichtes anerkannte; er wurde in der Staatslehre zum wirksamen Lehrer der Prinzipien der konstitutionellen 
Monarchie, bei deren Begründung durch Wilhelm von Oranien er mitgewirkt hatte. So leitete er überall das aufklärerische Philosophieren ein, das keine neuen schöpferischen Prinzipien erzeugte, wohl aber den erworbenen Schatz der neuen Erkenntnis mit seiner psychologischen Methode durcharbeitete, für das allgemeine Bewußtsein flüssig machte und zu praktischer Lebensgestaltung überführte. Deshalb begegnet man seinem Vorbild und seiner Einwirkung auf allen den Wegen, in denen sich diese große kulturelle Entwickelung durch die ganze Literatur des i 8 . Jahrhunderts hindurch ausgelebt hat.

Nominalismus. II. Die Erkenntnistheorie. Die psychologische Auflösung des metaphysischen Denkens, welche in Lockes Untersuchungen angelegt war, vollzog sich bei seinen englischen Nachfolgern im wesentlichen an der Kritik der beiden Grundibegriffe, denen die naturwissenschaftliche Metaphysik eine neue und scharfe Prägung gegeben hatte: der Substanz und der Kausalität. Das Prinzip aber, nach welchem diese Kritik geübt wurde, lag wesentlich in der Frage, inwieweit die begrifflichen Voraussetzungen, die in jenen metaphysischen Kategorien stecken, durch die psychologische Entwickelung der Vorstellungen begründet erscheinen. Dabei war in letzter Instanz die ebenfalls von Locke aufgenommene nominalistische Grundansicht entscheidend, wonach die Allgemeinvorstellungen ihren Wahrheitswert nur aus den von der Empfindung vermittelten Einzelvorstellungen erhalten sollten, aus denen sie genetisch erwachsen.

Substanzbegriff. Die zersetzende Kraft dieses Prinzips machte sich zuerst an dem Begriffe der Substanz geltend, - vermöge der einfachen Besinnung darauf, daß das „Ding“" selbst im Unterschiede von seinen Eigenschaften kein Objekt der Empfindung, sondern nur eine begriffliche Form der Deutung von der Zusammengehörigkeit der Empfindungen ist. Hatte schon Locke gelehrt, die Substanz sei nur der unbekannte Träger wahrgenommener Eigenschaften, Berkeley. so fand Bischof Berkeley, daß diese Annahme des Unbekannten ebenso unnötig wie unbegründet sei, - daß das, was man ein Ding nennt, niemals etwas anderes bedeute und bedeuten könne als einen mehr oder minder konstanten Komplex von Eigenschaften, und daß es eine Schulfiktion sei, dahinter noch ein metaphysisches Etwas wie eine Substanz zu suchen. Berkeleys Kritik beschränkte sich aber auf die übliche Annahme der nichtkogitativen Substanzen, der Körper. Diese verloren ihm damit ihren metaphysischen Boden, ihr Sein war nur noch gleichbedeutend mit ihrem Vorgestelltwerden esse = percipi); sie verwandelten sich in Komplexe von Ideen. Deshalb hat man diese Lehre Berkeleys damals Idealismus genannt, die Auflösung der Körperwelt in "Ideen“. Es war die unvermeidliche Konsequenz jener Präponderanz der inneren Wahrnehmung, die in Lockes psychologischer Wendung der cartesianischen Selbstbewußtseinslehre angelegt war, und die metaphysische Realität der Körperwelt, die nur noch problematisch gegolten hatte, wurde nun ausdrücklich verneint. Nur durch die Unterscheidung der von 
Gott gegebenen Ideen und der von Gott gewollten Ordnung dieser Ideen von den willkürlichen Zusammenfügungen der Ideenelemente in den endlichen Geistern vermochte Berkeley einen Rest des Gegebenen und Wirklichen in der Außenwelt zu retten. Aber dieser Idealismus behandelte die Ideen als die Tätigkeiten und Zustände der Geister: er behielt also die res cogitantes, den unendlichen göttlichen Geist und die endlichen Einzelgeister, als metaphysische Substanzen übrig, und insofern zeigt Berkeleys Weltanschauung ein spiritualistisches Gepräge, das an die Lehre von Malebranche erinnert und ihr angenähert werden konnte.

Die vollständige Auflösung des Substanzbegriffs gelang erst dem Scharf- Hume. sinn des größten Denkers der Aufklärungszeit: David Hume. Sie begründete sich bei ihm durch das Prinzip des Sensualismus, daß in der Seele keine Idee sein könne, die nicht das Abbild irgendeiner „Impression“, eines Erlebnisses innerer oder äußerér Wahrnehmung, sei. Nun wird aber das „Ding“ durch keine Art von Empfindung wahrgenommen: die seiner Idee zugrunde liegende Impression kann deshalb nur in dem Eindruck des sich wiederholenden, gleichmäßigen Tuns bei dem Erlebnis derselben Empfindungsverbindungen best then. Diese Kritik gilt aber für alle Şubstanzen, für die kogitativen ebenso wie für die nichtkogitativen: auch das Ich ist nur ein Bündel von Vorstellungen.

Dieselbe Argumentation trifft auch für die Kategorie der Kausalität zu. Kausalität. Schon die Okkasionalisten hatten verstanden, daß $z$ wischen Ursache und Wirkung kein logisches, analytisch einzusehendes Verhältnis besteht: aber auch die Wahrnehmung zeigt immer nur das post hoc, niemals das propter hoc. Die „Impression“ für die Idee der Kausalität steckt also weder in der einzelnen Wahrnehmung noch in der Zeitfolge der Wahrnehmungen, sondern wieder nur in dem Eindrucke der gewohnheitsmäBig wiederholten Reihenfolge von Vorstellungstätigkeiten. Hier wie bei der Substantialität ist das wahrhaft zugrunde liegende Erlebnis nicht ein Verhältnis zwischen den Dingen oder ihren Zuständen, sondern nur ein solches zwischen den Vorstellungstätigkeiten: es beruht auf der Assoziation, die sich durch Gleichzeitigkeit oder unmittelbare Folge der Vorstellungen zwischen diesen erzeugt, der Berührungsassoziation. So steht Humes durch ihre Wirkung auf Kant berühmt gewordene Kausalitätskritik im genauesten Zusammenhang mit den Prinzipien der Assoziationspsychologie, welche im Gefolge der Lehre von Hobbes sich in England weiter entwickelt hatte und in Männern wie Hartley und Priestley ihre klassischen Vertreter gefunden hat.

Das Ergebnis dieser tiefeinschneidenden Untersuchungen war für Hume, Positivismus. $\mathrm{daB}$ er die durch die Begriffe der Substanz und der Kausalität vermittelten Deutungen der Erfahrung als etwas niemals vollkommen zu Begründendes darlegte: unter diese Kritik fielen aber nicht nur alle metaphysischen Systeme, sondern auch alle Theorien der Naturforschung. In diesem Sinne hat man Hume auch hinsichtlich seiner philosophischen Lehren meist als Skeptiker charakterisiert. Aber es ist zu bedenken, daß seine Kritik nur die theoretiscke Wissenschaft, die sich auf der Erfahrung aufbauen wollte, mitsamt ihren 
metaphysischen Zuspitzungen traf und treffen wollte, daß Hume dagegen die Erfahrung selbst als vollgültig anerkennt und als praktisch brauchbar bestehen 1äßt, soweit sie ganz ehrlich und ohne die Einmischung erschlichener Begriffsverhältnisse wie der Substantialität und der Kausalität, sich auf die Feststellung von Tatsachen, auf die einzelnen Erlebnisse und ihre räumlichen und zeitlichen Zusammenhänge beschränkt. In diesem Sinne ist er der Begründer des Positivismus in der modernen Philosophie. Er beschränkt das Wissen auf die Tatsachen und lehnt jede begriffliche Deutung, die hinter den Tatsachen metaphysische Zusammenhänge sucht, grundsätzlich ab. Die einzige rationale Erkenntnis, die danach für ihn übrigbleibt, ist die der Mathematik, insofern als darin nur die immanenten Quantitätsverhältnisse zwischen den Vorstellungen untersucht und keine Behauptungen über die metaphysische Realität ausgesprochen werden.

Condillac. Zu ähnlichen positivistischen Ergebnissen gelangte die erkenntniskritische Bewegung in Frankreich. Hier wirkten die Lockeschen Anregungen im Gegensatz zum cartesianischen Rationalismus durch die Verstärkung seiner empiristischen und sensualistischen Gegner, und von Anfang an spielten dabei die skeptischen Neigungen in dem Sinne ihre Rolle, wie sie von Gassend schon in weltmännischer Weise mit den naturwissenschaftlichen Theorien verbunden worden waren. Die Abneigung gegen metaphysische Systembildung galt hier zum Teil als Sache des feinen Geschmackes und wurde in dieser Weise mit dem „Point de système“ auch von Anhängern der Newtonschen Mechanik wie etwa Maupertuis empfohlen. Es kam die Wirkung von Pierre Bayle und seiner Bestreitung aller theoretischen Erkenntnis des Übersinnlichen hinzu, und so blieb schließlich hier als Philosophie nur noch die Analyse de l'entendement humain übrig, der man später, weil sie wesentlich doch im Lockeschen Sinne eine Lehre vom Aufbau der Ideen war, den Namen Ideologie gegeben hat. Ihr bedeutendster Vertreter ist Condillac, der zuerst nur die Lockesche Lehre bei seinen Landsleuten einführte und verteidigte, dann aber ihr in seinem Traité des sensations ein durchaus sensualistisches und positivistisches Gepräge gab. Er führte darin mit Hilfe der später viel zitierten Fiktion von der sukzessive belebten Bildsäule aus, daß nichts in der Seele sei, was nicht irgendwie durch die Sinne ihr zugeführt wäre, und entwickelte die ganze Reihe einerseits der Ideen bis $z u$ den abstrakten Begriffen und Sätzen, andererseits der Emotionen bis zư den feinsten Formen des moralischen Fühlens und Wollens aus der allmählichen Umbildung und Verknüpfung der seelischen Urgebilde, der Empfindungen. Er gründete darauf ganz im Sinne der alten Semeiotik, der sich schon Locke in seiner Sprachphilosophie angeschlossen hatte, seine positivistische Methodologie. Alles Erkennen beruht darauf, daß der Inhalt der Wahrnehmung im Bewußtsein analysiert, seine Bestandteile nach ihrer Isolierung mit lautlichen oder graphischen Zeichen eindeutig fixiert und dann die mit der Bedeutung dieser Zeichen gegebenen Verhältnisse derselben in Gleichungen oder gleichungsartigen logischen Formen dargelegt werden. So ist das 
wissenschaftliche Denken ein Rechnen mit den Zeichen für die menschlichen Vorstellungen; aber ebendeshalb bleibt seine Beziehung zu einer transzendenten Wirklichkeit vollkommen problematisch. Damit mündet auch die Erkenntnistheorie der ideologischen Schule, wie sie Condillac in seinem posthumen Werk Langue des calculs niedergelegt hat, in eine durchweg antimetaphysische Auffassung.

Die deutsche Philosophie des i 8. Jahrhunderts stand diesem Ergebnis Wolf. anfänglich so fern wie möglich, näherte sich aber ihm ebenfalls mit schnellen Schritten. Die Lehre von Leibniz hatte durch Christian Wolff die systematische Gestalt gewonnen, die ihr in des Philosophen eigener Darstellung mangelte. Aber sie hatte dabei einen Teil ihrer Feinheit und ihrer inneren Lebendigkeit um so mehr eingebüßt, als das tiefste und bedeutendste Werk von Leibniz, die Nouveaux Essais sur 1'entendement humain, nicht an die Öffentlichkeit getreten war und bis über die Mitte des Jahrhunderts hinaus verborgen blieb. Leibniz hatte darin mit fortlaufender Kritik des Lockeschen Essays seine eigene Lehre von dem Verhältnis der zufälligen zu den ewigen Wahrheiten, des empirischen Wissens zu dem rationalen, als einen EntwickelungsprozeB nach den Prinzipien seiner Monadologie begriffen. Diese feinste Lösung des Problems des Eingeborenen in der Seele blieb unbekannt und unwirksam. Wolff vermochte nur rationale und empirische Wahrheit einander äußerlich gegenüberzustellen, in der Meinung, daß sie von verschiedenen Ausgangspunkten her in der Sache zusammentreffen müßten, und $\mathrm{da} B$ es deshalb von jedem Gegenstande eine rationale und eine empirische Wissenschaft gebe, die in ihren Ergebnissen schließlich übereinstimmten. Er hatte dann mit dem Geschick, aber auch mit der Pedanterie eines erfolgreichen Kathedermannes dies System der Wissenschaften entworfen und in einem weitläufigen Komplex von Lehrbüchern, teils deutschen, teils lateinischen, ausgeführt. Eine erzieherische Gründlichkeit ging von diesen Lehrbüchern und von der Tätigkeit seiner zahlreichen Schüler, die sie zum Teil noch vermehrten, an den deutschen Universitäten aus. Aber in der Entwickelung seiner Schule brach sich Schritt für Schritt das empirische Moment immer mehr Bahn, um allmählich die Reste des metaphysischen Denkens zu verdrängen. Darin machten sich von Anfang an und in steigendem Maße die Einflüsse der englischen und der französischen Literatur geltend: aber es war doch auch von vornherein in Deutschland das Grundmotiv der Aufklärung wirksam gewesen, das auf Nutzbarmachung und Popularisierung der Wissenschaft ausging. So hatte Christian Thomasius seinen Kampf gegen Vorurteile und Mißbräuche mit wirksamer Agitation geführt, und selbst die Wolffsche Lehre hatte den Ehrgeiz, ebenso gemeinnützig wie sicher begründet zu sein.

In der wissenschaftlichen Bewegung der Erkenntnislehre, die sich aus Rationalismus und neben der Wolffschen Schule entwickelte, war die immer neu gewendete in Deutschland. Frage die nach dem Verhältnis $z$ wischen den rationalen und den empirischen Momenten der Wissenschaft, und gerade die psychologistische Betrachtungs- 
weise lief darauf hinaus, wieviel von seinen Einsichten der Mensch dem Wesen seines eigenen Denkens, und wieviel er der Einwirkung der Außenwelt verdanke. In den rationalen oder im eigentlichen Sinne philosophischen Teilen seines Systems hatte Wolff mit virtuoser Handhabung der sogenannten geometrischen Methode aus den formalen Grundprinzipien die sachlichen Erkenntnisse mit scheinbar streng syllogistischem Fortschritt herzuleiten versucht. Dieser geometrischen Methode traten zum Teil im Anschluß an den englischen Empirismus die Leipziger Erfahrungsphilosophen Rüdiger und Crusius mit dem wichtigen Argument entgegen, zwischen Mathematik und Philosophie bestehe der fundamentale Unterschied, daß die Erkenntnis der ersteren auf selbsterzeugte Vorstellungsgebilde, die der letzteren dagegen auf die gegebene Wirklichkeit gerichtet sei. Andere wie Heinrich Lambert in seinem "Organon" versuchten den Geltungsbereich der einen und der anderen Erkenntnisweise gegeneinander abzugrenzen, ohne dabei zu festen und haltbaren Ergebnissen zu gelangen. Mehr und mehr aber siegte dabei im Laufe der Zeit der Empirismus über den Rationalismus, und den wesentlichsten Beirag zu diesem Vorgange lieferte die immer mehr sich ausbreitende Herrschaft der empirischen Psychologie als der Grundwissenschaft. Sie bedentete damals nicht viel anderes als eine auf Selbstwahrnehmung und Selbstbeobachtung begründete Sammlung von Tatsachen des Seelenlebens, und sie kam damit der allgemeinen Neigung der zeitgenössischen Literatur entgegen, in welcher die Beschäftigung des Individuums mit sich selbst und mit anderen Individuen das Hauptinteresse ausmachte. Die eirzige Richtung, in der diese deskriptive Psychologie einen Anlauf zur theoretischen Verarbeitung der Tatsachen machte, war die Aufsuchung psychologischer Gattungsbegriffe, die sich in dem System der sogenannten Vermögen der menschlichen Seele darstellten. In dieser Richtung lag denn auch der bemerkenswerteste Ertrag der ganzen Bewegung, den wir darin zu suchen haben, daß die Stellung des Gefühls als einer psychologischen Grundfunktion neben dem Vorstellen und dem Wollen aus ästhetischen Motiven erkannt und von Männern wie Sulzer, Mendelssohn und Tetens immer deutlicher hervorgehoben wurde.

Empirische Psychologie nun aber die anthropologische Verengerung der Aufklärungsphilosophie. Wohl gewann diese damit eine gewisse Breite der Erfahrung auf dem Gebiete des menschlichen Lebens und damit einen lebendigen Zusammenhang mit dem allgemeinen Bewußtsein und der allgemeinen Literatur: aber sie verlor darnit auch den Mut des darüber hinausführenden Denkens, und jene skeptischen Folgerungen, zu denen die englische und die französische Aufklärung fortschritt, leisteten immer mehr der metaphysischen Timidität Vorschub, mit der man sich von den aussichtslosen Grübeleien über die letzten Probleme zu einer praktischen Behandlung dessen, was den Menschen an-

Popularphilosophie. geht, wenden zu sollen meinte. Die Popularphilosophie, welche diesem Zuge folgte, hatte das große Verdienst, durch schlichte und geschmackvolle Dar- 
stellung in der Tat die Aufklärung zu verbreiten, deren sie sich rühmte, und sie hatte darin einen ganz unermeßlichen kulturellen Wert. Aber um ihre wissenschaftliche Tiefe und um ihre innere Klarheit stand es nicht ebenso gut. Auch ihre wirksamsten Vertreter wie Abel, Moses Mendelssohn und Friedrich Nicolai machten sich nicht klar, daß, wenn sie mit geringschätziger Ablehnung der, wie sie meinter, künstlichen und verstiegenen Systeme der Metaphysik immer nur an den gesunden Menschenverstand ihrer Leser appellierten, sie dabei im Grunde genommen mit den ganz unkritisch aufgenommenen Voraussetzungen derWeltansicht des gemeinen Bewußtseins operierten.

Über dieses Verhältnis kam in letzter Instanz auch der Versuch nicht Schotten. hinaus, den unter der Führung von Thomas Reid die schottischen Philosophen unternahmen, um den Tatbestand des gesunden Menschenverstandes wissenschaftlich nach induktiver Methode zu kodifizieren. Im lebhaften Gegensatze gegen die Entwickelung, welche die englische Philosophie von Locke bis zu Hume durchgemacht hatte, und gegen die dem gemeinen Bewußtsein paradoxen Folgerungen, zu denen Berkeley und Hume ihnen gekommen zu sein schienen, lehnten sie sich an die Ergebnisse der moralphilosophischen Bewegung an, worin die Ursprünglichkeit des ethischen und des ästhetischen Gefühls erkannt zu sein schien, und in der Meinung, daß auf allen Gebieten eine solche letzte Gemeinsamkeit in dem Wesen des menschlichen Geistes gegeben sein müsse, wollten sie diesen "Commonsense" auf dem Wege vergleichender Analyse des tatsächlichen Erkennens, Fühlens und Wollens ausfindig machen. Gerade damit aber blieben sie in der empirischen Feststellung von Durchschnittsmeinungen stecken, und so umsichtig und feinfühlig sie ihre ausgebreiteten Analysen ausspannen, so erhob sich doch ihre Leistung niemals über die Behauptung unfruchtbarer Selbstverständlichkeiten.

III. Die Moralphilosophie. Auch die ethische Entwickelung der Aufklärung steht durchweg unter dem Zeichen der psychologistischen Methode. Mehr noch als auf den anderen Gebieten sind auf diesem die Englärder die Führer gewesen, und bei ihnen enthielt das "Selfish system" von Hobbes vermöge seines rücksichtslosen Naturalismus die dauernde Anregung zu einer entgegengesetzten Begründung und Erklärung des sittlichen Lebens. War dort der Versuch gemacht, auf den Selbsterhaltungstrieb alle Formen des Wollens zurückzuführen und auch das sittliche Wollen als die durch die gesellschaftlichen Verhältnisse bedingte Willensweise des wohiverstandenen Interesses darzulegen, so reizte das die Gegner zur Aufsuchung ursprünglicher Motive des sittlichen Lebens in der menschlichen Natur. Hier fand daher die Behauptung von dem Eingeborensein prinzipieller Bestimmungen in der Seele mehr Anerkennung als im Bereiche des theoretischen Lebens. In der Lehre von Cumberland führte dies Bestreben noch während des I 7. Jahrhunderts zu scharfer Formulierung. Und doch bestand zwischen den gegensätzlichen Auffassungen auch hier die Gemeinschaft, daß die Fundamente der Ethik unabhängig von aller religiösen Metaphysik im Wesen des 
Menschen gesucht werden sollten. In der Tat stießen während der großen und reichen Entwickelung, die damals die Moralphilosophie in England gefunden hat, die Lebensauffassungen der modernen Welt heftig aufeinander: denn es handelte sich nach den Wandlungen, welche die Weltansicht durch die wissenschaftlichen Kämpfe des 16 . und 17. Jahrhunderts erfahren hatte, un die Besinnung darauf, welche Aufgaben und welche Aussichten eine rein weltliche Philosophie für den Menschen zu begründen vermochte. Lange Zeit war die Menschheit gewohnt gewesen, die Vorschriften ihrer Moral auf die übersinnlichen Beziehungen des Menschen zu gründen. Je mehr diese aus dem Bereiche der theoretischen Philosophie ausgeschlossen wurden, je mehr überhaupt die Möglichkeit der metaphysischen Erkenntnis in Frage gestellt war, um so mehr kam es darauf an, eine von den theoretischen Voraussetzungen der Weltansicht unabhängige Begründung der Moral zu finden.

Bayle. Dies Bestreben tritt in der Aufklärungsphilosophie auch da hervor, wo es sich nicht wie in der Hauptlinie der englischen Moralphilosophie auf dem psychologischen Wege befindet. Von charakteristischer Bedeutsamkeit ist in diesem Sinne die Stellung von Pierre Bayle, dem großen Gelehrten, welcher der modernen Welt die erste Enzyklopädie gegeben hat. Er schließt in gewissem Sinne die Reihe der französischen Skeptiker, die aus der Stimmung der Renaissance und des cartesianischen Rationalismus erwachsen waren, mit der eindrucksvollen Energie des prinzipiellen Zweifels ab. Sein ausgebreitetes Wissen läßt ihn die in der Theologie und in der Philosophie gegensätzlichen Theorien durcheinander bestreiten. Der brennende Wahrheitsdurst, der ihn durch einen mehrfachen Wechsel der Konfession hindurchgetrieben hat, endet mit der Einsicht in seine Unstillbarkeit. Es gibt keine metaphysische Erkenntnis für den Menschen, weder in der Theologie, sofern sie eine rationale Darlegung und Begründung der Offenbarung sein will, noch in der Philosophie, die nur mit den natürlichen Mitteln von Vernunft und Erfahrung arbeiten soll. Darum hä1t Pierre Bayle jede Art von natürlicher Religion für ausgeschlossen und verkündet das Verdienst des Glaubens wegen der Vernunftwidrigkeit und Unbegreiflichkeit seines Inhalts. Aber, was der theoretischen Vernunft des Menschen versagt ist, das ist mit voller Gewißheit und unverbrüchlicher Sicherheit in der praktischen Vernunft, im Gewissen vorhanden. Die Stimme der Pflicht ist durch theoretische Einsicht nicht zu begründen noch zu bestreiten: sie spricht mit voller Selbstherrlichkeit. Darum ist die Moral des Menschen von seinen theoretischen Meinungen, von seinen wissenschaftlichen Ansichten und auch von seinen religiösen Glaubensüberzeugungen völlig unabhängig. Die Sittlichkeit ist kein Vorzug der Erkenntnis, sie beruht in sich selbst. Von dieser Auffassungsweise her gewann Pierre Bayle die Möglichkeit zu einer vorurteilslosen Würdigung der großen Charaktere der antiken Welt, zugleich aber auch die lebendige und aus seinen Schriften auf die Welt wirkende Überzeugung der Toleranz, wonach der Staat sich um die religiösen Meinungen seiner Bürger geradesowenig wie um deren sonstige Ansichten zu kümmern und sich nur an ihr 
Wollen und Handeln zu halten habe. Bei Bayle erscheint die praktische Vernunft völlig unabhängig von der theoretischen: aber seine energische Betonung dieser Selbständigkeit führt noch weder zu einer genaueren Untersuchung darüber, worin die moralische Vernunft ihrem seelischen Wesen nach bestehe, noch zu einer sicheren Umgrenzung dessen, was sie inhaltlich verlangt.

Das waren die Aufgaben, denen die englischen Moralisten im 18. Jahr- Shaftesbury. hundert erfolgreich nachgegangen sind. In beiden Richtungen hat dem neuen Geiste Lord Shaftesbury den entscheidenden Ausdruck gegeben. Sachlich konzentriert er die Lebensauffassung um die Idee der Persönlichkeit. Die weltliche Moral gipfelt in der Aufgabe des Individuums, sich selbst auszuleben, alle seine Kräfte zu entfalten, alle Seiten der in ihm gegebenen Anlage $z u$ voller Entwickelung zu bringen und damit sein Leben $z u$ harmonischer Einheit zu gestalten. Es war darin ein Abglanz des antiken Ideals der Kalokagathie, die den Menschen zugleich edel und glücklich machen sollte. Alle Gegensätze seiner Natur, die egoistischen und die sozialen, die sinnlichen und die geistigen Triebe sollten in dieser harmonischen Lebensgestaltung gleichmäßig ihr Recht finden und so das Individuum aus seiner natürlichen Anlage heraus sich zur edlen Persönlichkeit entwickeln. Dies Lebensideal der Virtuosität erhob sich in Shaftesburys künstlerischem Geiste aus einer universellen und optimistischen Anschauung, welche durchweg die Züge der Renaissance an sich trug. Eine derartige Steigerung der Individualität zur gereiften Persönlichkeit erschien nur möglich durch das Einleben des einzelnen in die großen Zusammenhänge des Weltlebens, durch den Enthusiasmus, mit dem das Individuum sein eigenes Leben als das des Ganzen fühlen und gestalten sollte. Es war eine rein weltliche und wahrhaft humane, aber nicht eine beschränkte, sondern eine universelle und kosmische Moral, die Shaftesbury in sich verkörperte, und deren Glanz von ihm aus über die Aufklärungsphilosophie bis zu den begeistert sich ihm anschließenden deutschen Dichtern wie Herder und Schiller ausströmte. Es war die höchste Formel für jenes Zeitalter, dem der einzelne Mensch und seine Innengestaltung zu harmonischem Glück das wertvollste war, - dabei in seiner ganzen Zeichnung ein durchaus aristokratisches Ideal gesteigerten Menschentums von intellektueller und künstlerischer Bildung, getragen von einem hohen Schwunge harmonischer Weltanschauung, welche die Gegensätze des körperlichen und des seelischen Lebens in die göttliche Einheit untertauchte.

Damit war aus antikem Geiste heraus mit echt griechischer Idealität Persönlichkeitseine sachliche Vertiefung der ethischen Prinzipien gegeben, die in den rein ${ }^{\text {und Volltkommen- }}$ heitsmoral. metaphysischen Formulierungen der deutschen Schule unter dem Namen der Vollkommenheit und in der praktischen Zuspitzung unter dem Gesichtspunkte der Aufklärung charakterisiert zu werden pllegten. Die Vervollkommnung des Individuums, die als die natürliche Entfaltung seines innersten Lebenstriebes, als die Betätigung seines Wesens und zugleich seines Rechts und seiner Pflicht angesehen wurde, bildet den Inbegriff dieser Lebensanschauung, 
und man versteht, wie in dem Zeitalter der Aufklärung alle Formen der Gemeinschaft, alle Arten menschlichen Lebenszusammenhanges unter dem Gesichtspunkte betrachtet und beurteilt wurden, welchen Ertrag sie für diesen letzten und höchsten Lebenszweck abzuwerfen versprächen. Selbst in den oft kleinlichen und pedantischen, manchmal recht engherzigen und kleinbürgerlichen Formen, welche diese Individualitätsmoral namentlich in der deutschen Aufklärung angenommen hat, bleibt doch das Bewußtsein von dem Recht und der Pflicht der Persönlichkeit das wertvolle und entscheidende Prinzip. Wenn bei Hobbes das Individuum in letzter Instanz nur wie ein ganz auf sich selbst gestelltes Atom immer mit seiner eigenen sinnlichen Selbsterhaltung beschäftigt schien, so kommt in der Aufklärungsmoral direkt oder indirekt das Prinzip der Monadologie zur Geltung, wonach die Persönlichkeit als metaphysische Potenz mit ihrem eigenen Leben und seiner inneren Gestaltung das Universum auslebt. Dieser metaphysische Hintergrund der rein weltlichen Persönlichkeitsmoral ist auch maßgebend, wo er, wie bei Shaftesbury, in den unbestimmteren Formen einer an die Antike oder die Renaissance angelehnten Weltanschauung auftritt.

Utilismus. Je mehr allerdings in dem Fortschritt der psychologistischen und positivistischen Bewegung diese Voraussetzungen zurücktraten und sich verdunkelten, um so mehr vertauschte diese eudämonistische Ethik das Shaftesburysche Ideal wieder mit den empirischen Interessen des Individuums, und dann blieb das letzte Wort bei der Psychologie von Hobbes, wonach der Mensch niemals etwas anderes wollen kann, als was zur Erhaltung und Förderung seines eigenen Daseins zu dienen vermag. Unter dieser psychologischen Voraussetzung nahm die englische Moral diejenige Wendung, welche man mit dem Namen des Utilismus bezeichnet. Denn unter dieser Voraussetzung bedurfte man eines Kriteriums, um unter den Motiven und den Handlungen, welche sämtlich auf die Befriedigung desLustbedürfnisses der wollenden und handelnden Individuen gerichtet sein sollten, diejenigen zu charakterisieren, welche als die sittlichen gelten dürfen: und dazu fand sich dann nur das Merkmal des Erfolges für die Lust oder Unlust der Nebenmenschen. In den Kreisen der Assoziationspsychologen mußte diese Konsequenz gezogen werden: das geschah nicht nur in England, sondern ebenso in Frankreich, wo namentlich Lamettrie und Helvetius die erzieherischen Mächte der Gesellschaft für die Umbildung der individuellen Wertungen ausführten. Denn innerhalb der empirischen Welt konnte für das Verlangen eines derartigen eventuell mit dem Glückstreben des Individuums in Konflikt tretenden Wollens und Handelns nur bei der übergreifenden Gewalt des Staates oder der Gesellschaft die Sanktion des Sittengebotes gefunden werden, welche die theologischen Utilisten wie Paley nach altgewohnter Weise in dem göttlichen Willen suchten. In beiden Fällen jedoch war es das einfachste, die Motive des sittlichen Handelns bei dem an sich naturalistisch indifferenten oder gar rein egoistischen Menschen wiederum in den Folgen für seine Glückseligkeit zu sehen, die er von der Macht des autoritativen Willens zu erwarten hätte. Aber alle diese 
auf den Lust- oder Unlusterfolg der Handlung bezüglichen Merkmale ergaben schließlich nur formale und keine allgemeingültig inhaltlichen Bestimnungen, und so blieb letzten Endes nur das Prinzip ihrer quantitativen Abmessung: übrig; als die sittliche Handlung sollte diejenige gelten, welche das größte $\mathrm{Maß}$ von Lust für die größte Anzahl herbeizuführen imstande wäre. Diese quantitative Schlußform der englischen Moralphilosophie hat Jeremy Bentham ausgeführt: die Gesichtspunkte der Rücksicht auf die allgemeine Wohlfahrt, welche bei legislatorischen Maßregeln die letztentscheidenden sein sollen, galten ihm als ausreichend auch für die Kriterien der persönlichen Sittlichkeit, und seine Lehre mit dem großen Eindruck und Einfluß, den sie zur Folge hatte, zeigt wieder am deutlichsten in der Aufklärungsphilosophie selbst den Ubergang aus der Moral der Persönlichkeit in die Moral der Masse.

Das $z$ weite Moment, worin Shaftesbury einen vorbildlichen Einfluß ausgeübt hat, betrifft die Frage der Erkenntnisquelle des sittlichen Bewußtseins. und Ästhetik. Die Ablösung der weltlichen Moral von aller metaphysischen Theorie und die Verlegung des Inhalts der Sittlichkeit in die Persönlichkeit führten zusammen dazu, daB das moralische BewuBtsein nur in dem urmittelbaren Erlebnis der Seele gegeben sein konnte, womit sie jenen Trieb der Selbstentfaltung und der inneren Steigerung in sich erfährt. Nicht somit ein theoretisches Wissen, sondern ein unmittelbares Gefüh? liefert die Inhalte des Gewissens, und es entsprach durchaus der ästhetischen Färbung von Shaftesburys Weltund Lebensansicht, daß er wie die Auffassung des Schönen, so auch die des Guten für eine Sache des Geschmacks, d. h. eines ursprünglichen beweisunfähigen, aber auch nicht beweisbenötigten Gefühls ansah. Die Analogie zwischen dem Guten und dem Schönen, zwischen dem ethischen und dem ästhetischen Geschmack ist von ihm her einer der bezeichnendsten Züge in der gesamten Aufklärungsliteratur. Die Betrachtung ihrer Ähnlichkeit und Verwandtschaft hat im Sinne Shaftesburys auch die Moral inhaltlich bestimmt und die Gestaltung des Lebens zum Kunstwerk als letzte Aufgabe des reifen Menschen erscheinen lassen: dic Aufmerksamkeit auf ihre Verschiedenheit und die Nötigung, ihre Grenzen gegeneinancer festzusetzen, hat die Anfänge der modernen Âsthetik in England ebersso wie in Deutschland bestimmt; ja sie hat über diese Anfänge hinaus auch die großen Formen der ästhetischen Theorie beeinflußt. Denn ihnen allen ging vorbereitend in der englischen wie in der deutschen Literatur die vielseitige Untersuchung darüber vorher, welches die Stellung des ästhetischen Lebens zu dem intellektuellen und dem moralischen sei. Auf der einen Seite war die Ansicht von Leibniz maßgebend, der nach seiner Unterscheidung des Sinnlichen und des Vernünftigen als des unteren und des oberen Erkenntnisvermögens die Schönheit als Vollkommenheit der sinnlichen Vorstellung, d. h. als verworrene Wahrheit definiert hatte. Von hier aus bestimmte Wolffs Schüler Alexander Baumgarten der "Ästhetik“ als der Theorie des niederen Erkenntnisvermögens ihre Stelle im System der Wissenschaften als Seitenstück zur Logik, und so hatte die Wissenschaft vom Schönen mit dem Namen, den sie von da an führen sollte, zunächst eine 
abschätzige und wenig adäquate Würdigung ihres Gegenstandes überkommen, wonach ihr das Schöne im besten Falle als das sinnliche Symbol des Wahren galt. Diese Auffassung gestaltete sich im Zusammenhange mit der neuen psychologischen Einteilung bei Männern wie Home und Burke in England, wie Meier, Sulzer und Mendelssohn in Deutschland zu der Vorstellung, daß das Schöne, seinem Wesen nach in den dunkeln Zuständen des Gefühls begründet, den Beruf habe, den Menschen aus dem rohen Zustande des sinnlichen Daseins durch Veredelung seines Empfindens zum vernünftigen Leben vorzubereiten und zu erziehen. Aber das vernünftige Leben besteht nicht nur in der Erkenntnis, sondern auch im sittlichen Wollen, und damit begründete sich die andere Seite dieser Auffassung, welche das Schöne als die gefühlsmäßige Vorstufe des Guten ansieht und den Zweck der Kunst und insbesondere der Dichtung ebenso wie in der Aufklärung auch in der Läuterung des sittlichen Wollens sucht. So lebhaft deshalb im Zusammenhange mit der englischen und der deutschen Genialitätsbewegung die ästhetische Theorie der Aufklärung die Ursprünglichkeit des Gefühls als die Quelle künstlerischen Schaffens würdigen lernte, so blieb sie doch mit ihrer Auffassung von den Zielen des ästhetischen Lebens durchaus bei der Unterstellung der Kunst unter die Aufgaben der intellektuellen und der moralischen Erziehung hängen.

Moral sense. In der speziellen Morallehre bestimmte sich das durch Shaftesbury gestellte Problem zu vielfachen Untersuchungen teils über die Ursprünglichkeit oder die Ableitbarkeit des „moralischen Sinnes“, teils über sein Verhältnis zu der den Willen regulierenden Einsicht des Verstandes. In ersterer Hinsicht wurde zwar bei den Engländern, der Einseitigkeit von Hobbes gegenüber, die Ursprünglichkeit der sozialen Veranlagung oder der sympathischen Triebe im Sinne des moralischen Geschmacks dauernd behauptet; namentlich Hutcheson führte dies im Sinne Shaftesburys breit aus und leitete damit ebenso. wie der Ästhetiker Henry Home die Bewegung ein, die mit der oben erwähnten Stellung der schottischen Schule endete. Aber andererseits legte die Assoziationspsychologie den Gedanken nahe, das Maß des Angeborenen dabei so viel wie möglich zu beschränken und die Mannigfaltigkeit der Wertungen so weit wie möglich durch die Prozesse der Übertragung in der seelischen Entwickelung zu erklären. Zum Verständnis dieser Übertragung wurde in ausgiebigem Maße der soziale Lebenszusammenhang herangezogen: Bischof Butler ging mit seiner Theorie von den Affekten der Reflexion voran und betonte die sekundäre Wertung, die in der Seele durch ihre Reaktion gegen die Wertungen entsteht, welche Handlungen und Gesinnungen bei den Mitmenschen finden. Mit feinster Analyse haben endlich David Hume und sein Freund Adam Smith diese sozial vermittelten Auszweigungen des sympathischen Fühlens und Wollens dargelegt. Und dabei kam auch die andere Frage zur Entscheidung. Es hatte ja nicht an solchen gefehlt, welche wie Clarke und Wollaston in England und die Wolffianer in Deutschland nach der altrationalistischen Auffassung von der Determination des Willens durch den Verstand auch die Motive des sittlichen Wollens nur in der vernünftigen 
Einsicht suchten, und ebensowenig fehlte es an Vertretern der ethischen Geschmackstheorie, die nur die Unmittelbarkeit des Gefühles dafür in Anspruch nehmen wollten. Zwischen beiden Extremen fanden Hume und Smith den glücklichen Ausweg, daß sie zeigten, welche bedeutsame Rolle bei den besonderen Willensentscheidungen der verstandesmäßigen Einsicht in die gegebenen Lebensverhältnisse zukommt, und wie doch alle diese vernünftigen Erkenntnisse eine bestimmende Macht über den Willen nur dadurch gewinnen, daß sie an die Unmittelbarkeit des sympathischen Fühlens appellieren.

IV. Der Deismus. Die breite Selbstrerständigung, welche die Auf- Natur- und klärungsphilosophie durch so weitverzweigte Untersuchungen über das natürliche Bewußtsein der Moralität suchte, war zum Teil durch die Bedeutsamkeit bestimmt, welche sie gerade diesen Überzeugungen für ihre Stellung zu den religiösen Problemen zuschrieb und zuschreiben mußte: sie bedurfte ihrer zuletzt unumgänglich, um einen Inhalt für dasjenige zu retten, was sie unter dem Namen der Naturreligion oder Vernunftreligion vielfach als ihren wertvollsten und wesenhaftesten Besitz verkündete. Der Deismus des 1 8. Jahrhunderts ist in der Hauptsache der Niederschlag der Toleranzbewegung und damit das positive Ergebnis der konfessionellen Streitigkeiten des 17. Jahrhunderts. Der Überdruß an diesem unfruchtbaren Hader führte schließlich überall zu einem Bedürfnis nach Verständigung und zu dem Versuche, die Gemeinsamkeiten herauszuheben, die trotz der historischen Verschiedenheiten allen Formen der positiven Religion gleichmäßig zugrunde lägen. Darauf zielten die Unionsbestrebungen auf dem Kontinent, an denen Leibniz einen so lebhaften, wenn auch praktisch erfolglosen Anteil hatte; dasselbe Ziel verfolgte in England zu Lockes Zeiten die Richtung der Latitudinarier. In beiden Fällen wollte man über die Unterscheidungslehren hinweg zu einem gemeinsamen Christentum gelangen, das man dann wohl das reine und wahre nannte und auch bald als das ursprüngliche zu betrachten anfing. Aber sobald man den Entwurf dazu machte, unterlag man der Notwendigkeit, von den geschichtlichen Überlieferungen, die sich als Offenbarung verstanden, abzusehen und jene Gemeinsamkeit lediglich auf philosophischem Wege zu suchen. Damit aber führte dies Bestreben auch über das Christentum hinaus zu der Idee einer allgemein menschlichen, einer absolut allgemeingültigen und in diesem Sinne zugleich natürlichen und vernünftigen Religion. Mit dieser Aufgabe steckte sich die Aufklärung ihr höchstes Ziel: alles, was sie als Ertrag der wissenschaftlichen Arbeit der vorhergehenden Jahrhunderte feststellen und in das allgemeine Bewußtsein überführen zu dürfen glaubte, zog sich in diesem Gedanken der Vernunftreligion zusammen, und je mehr das öffentliche Leben von den religiösen Gegensätzen zerklüftet war, um so mehr schien dieser Naturreligion die Aufgabe einer einheitlichen und vernünftigen Gestaltung des Lebens zuzufallen. In der Tat hat diese Tendenz der Aufklärungsphilosophie trotz der unüberwindlichen Schwierigkeiten ihrer Ausführung den unermeblichen Segen eines Geistes der Versöhnlichkeit, der 
Brüderlichkeit und Friedfertigkeit mit sich geführt, durch den sich jenes Zeitalter weit über alle bisherigen Perioden der menschlichen Geistesgeschichte erhebt. Dieser Ruhm einer vorbildlichen Gewissensfreiheit und einer erhabenen Reinheit der religiösen Gesinnung bleibt der Aufklärung erhalten, auch wenn man nicht verkennt, daß sie ihn zum Teil durch eine Abschwächung. und Verdünnung der Energie des wahrhaft religiösen Lebens erkaufen mußte.

Toland. Denn die Inhalte der religiösen Überzeugung, welche für diese Naturoder Vernunftreligion nach Abstreifung aller Mysterien der positiven Religion übrigblieben, waren von Anfang an verhältnismäfig schwach und mager und wurden mit der Zeit immer dünner und lebloser. Es lag in der Natur einer philosophischen Auffassung, die sich aus der Weltanschauung der Renaissance entwickelte, daß sie zunächst einen starken Zug zum Pantheismus hatte, und dieser trat deshalb in der ersten Form der Vernunftreligion bei John Toland mit voller Deutlichkeit hervor. Im Sinne von Giordano Brunos poetischem Naturalismus machte Toland die Bewunderung der Schönheit und Harmonie des Universums zum Inhalte einer Religion, deren Priesterinnen Wissenschaft und Kunst, deren Gemeinde die gesamte gebildete Menschheit sein sollte. Die Motive des religiösen Fühlens, das er in hoher Begeisterung verkündete, lagen ihrer theoretischen Struktur nach in der Auffassung der zweckvollen Zusammenhänge der Natur, in dem makrokosmischen Optimismus, der das lebendige Erbteil der Renaissance war, und man darf sagen, daß es in der Tat die Religion der Aufklärung gewesen ist, an die Schönheit und Vollkommenheit des Universums zu glauben. Dieser teleologische Charakter ist der Religionsphilosophie der Aufklärung aufgeprägt geblieben, und er spiegelt sich in ihrer Vorliebe für den physiko-theologischen Beweis für das Dasein Gottes.

Toleologischer Deismus.

Denn diese Betrachtungsweise blieb auch für diejenigen bestehen, welche dem Pantheismus, der in der überlieferten Betrachtungsweise mit dem Makel der Irreligiosität behaftet war, nicht beitreten mochten und der Gottheit den Charakter der Persönlichkeit und der Unabhängigkeit von der Welt gewahrt wissen wollten. Die cartesianische Metaphysik hatte das getan, und die Vernunftreligion, die sich an sie hielt, bezeichnete sich deshalb später als Deismus. Für diesen nahm der physiko-theologische Beweis gern die Form an, daß aus der Vollkommenheit der gesetzmäßigen Ordnung des Universums nach Analogie der technischen Werke auf eine höchste Intelligenz als ihren Urheber geschlossen wurde. Die großen Naturforscher wie Robert Boyle und Isaak Newton fanden in dieser Weise die mechanistische Erklärung der Natur mit dem religiösen Bewußtsein durchaus vereinbar. Ahnlich hatte schon Leibniz gedacht, ähnlich lehrte in Deutschland die Wolffsche Schule, und wenn das so umschriebene Verhältnis sogar die Möglichkeit offen ließ, in die Gottesvorstellung mancherlei Momente der positiven religiösen Überlieferung aufzunehmen, so war es erst recht geeignet, im Sinne der Naturreligion eine gefühlvolle Begeisterung für ein göttliches Wesen zu 
erzeugen, dessen Erkenntnis man nur aus der Bewunderung seiner Werke gewonnen zu haben glaubte. In dieser Form hat wiederum Shaftesbury den Gedanken des Deismus vorbildlich für das ganze Jahrhundert geprägt, und bei ihm verknüpft sich in der Vorstellung Gottes der Gedanke der höchsten Intelligenz zugleich mit der Idee der sittlichen Vollkommenheit und einer teleologischen $\mathrm{W}^{\top}$ eltordnung, welche die zweckvollen Zusammenhänge des natürlichen Geschehens in den Dienst der Vervollkommnung und der Glückseligkeit aller Geschöpfe stellt.

Darin besaß der Deismus eine metaphysische Überzeugung von aller- Moralischer dings begrifflich sehr unbestimmten Linien, aber eben doch eine theoretische Lehre von dem Unerfahrbaren, und deshalb teilte die Naturreligion mit der spezifisch wissenschaftlichen Metaphysik das Geschick, das unerbittlich aus der wachsenden Neigung des Zeitgeistes zu empiristischer, positivistischer und skeptischer Auffassungsweise hereinbrach. Bei der allgemeinen Abwendung vom metaphysischen Denken, bei der achselzuckenden Gleichgültigkeit gegen alles Grübeln geriet auch die Vernunftreligion, soweit sie sich in jener ersten theoretischen Fașsung dargestellt hatte, mit der Zeit immer mehr ins Schwanken. Bayles einschneidende Kritik hat ihr wohl den schwersten StoB gegeben: aber sie brachte ihr auch den besten Ersatz. Er hatte in der eindringlichsten Weise gezeigt, daß die menschliche Vernunft nicht theoretisch eine metaphysische Erkenntnis der begrifflichen Wissenschaft, wohl aber praktisch eine moralische Überzeugung des Gewissens gewähren könne. Damit verband sich die am deutlichsten von Spinoza ausgeprägte Vorstellung, daß Wesen und Zweck der Religion niemals in einer Lehre, sondern immer nur im sittlichen Wollen und Handeln gesucht werden dürfe. Unter al'en diesen Voraussetzungen verlegte sich der Standpunkt der Vernunftreligion aus der theoretischen in die praktische Vernunft, aus dem Wissen in das Gewissen. Das, was allen Religionen gemeinsam, von der natürlichen Vernunft gefordert schien, war nur noch der Inhalt des moralischen Bewußtseins, und die religiösen Vorstellungen, die unter diesem Gesichtspunkte aufrechterhalten werden konnten, beschränkten sich auf solche Momente der Weltansicht, welche als metaphysische Voraussetzung für das moralisch-religiöse Wollen und Handeln unerläßlich schienen. Den Deisten der Aufklärung genügte dazu die Annahme der Gottheit als des weisen und gütigen Schöpfers und der Unsterblichkeit.der Seele als der Voraussetzung für die gerechte Ausgleichung zwischen dem ethischen Wert und der Glückseligkeit der Persönlichkeiten, welche das irdische Leben nicht gewährt. Der Glaube an Gott und Unsterblichkeit, verbunden in der Idee der postmortalen Gerechtigkeit, blieb somit für die Aufklärung der Rest des religiösen Bewußtseins: aber er galt, wie dies besonders bei Voltaire in seinen späteren Schriften zutage tritt, nicht eigentlich als ein Gegenstand sicheren Wissens, sondern vielmehr als eine unerläßliche Forderung des Gewissens im Interesse der irdischen Ordnung des Lebens und einer sittlich befriedigenden Verfassung des Weltalls. Diese Überzeugung genügte in der Tat bei 
den erleuchteten Geistern der Zeit für eine hohe und edle Lebensführung, die, frei von allen geschichtlichen Vorurteilen, das rein und wahrhaft Menschliche in allen Verhältnissen der Einzelnen und der Völker mit bewunderungswürdigem Hochsinn zu empfinden und zu verwirklichen bereit war. Die führenden Geister machten daraus ihre Religion, und es ist begreiflich, daß sie meinten, diese reife und edle Lebensführung zur Religion der gesamten Menschheit machen zu können.

Froidenkertum. Aber gerade darin steckte das schwere soziale Problem der Aufklärung. Denn schon Toland erkannte, daß die Naturreligion, die er verkündete, und für die er phantasievoll die Form eines ästhetischen Gottesdienstes entwarf, sich nur für den gebildeten Menschen eigne und ein Vorrecht esoterischer Kreise bleiben müsse, und Shaftesbury meinte nicht nur, daß die Weisen, die überall und immerdar sich zu dieser reinen Religion bekennen, ihr Geheimnis niemals preisgeben, sondern er hielt auch die positive Religion mit allen ihren mythischen Mitteln der Verheißung und Drohung für durchaus unerläßlich zur Erziehung und Bändigung der Masse. So war es ein innerer Widerspruch in der Entwickelung dieses Deismus, wenn die Freidenker literarisch eben die Ansichten verbreiteten, von deren Gefährlichkeit für den Bestand der gesellschaftlichen Ordnung sie überzeugt waren. Sie haben sich damit in der verschiedensten Weise persönlich abgefunden: aber die Entwickelung ihrer Gedanken ging mehr und mehr auf eine zersetzende Kritik der positiven Religion aus. Wenn der Deismus meinte, die Wahrheit herausgeschält $z u$ haben, welche als reines Christentum allen Konfessionen und darüber hinaus als Vernunftwahrheit allen Religionen gemeinsam sein sollte, so mußte ihm diese Wahrheit auch als Kriterium der Beurteilung für die Wahrheitsansprüche der positiven Religionen gelten: nur was damit übereinstimmte, konnte aufrechterhalten, was davon abwich, mußte verworfen werden. Das Christentum ohne Mysterien, das so alt sein sollte wie die Schöpfung und der Mensch, erschien mit seiner natürlichen Vernunftmoral als ein Zubehör der reinen, ursprünglichen und unverfälschten Natur des Menschen: alle positiven Religionen sanken vor diesem Urteil zu Verdunklungen und Verschlechterungen einer anfänglichen Vollkommenheit her$\mathrm{ab}$, für deren Verunstaltung man nur Schwächen und Sünden des geschichtlichen Menschen als schuldige Ursachen verantwortlich $z u$ machen wußte und deren Wiederherstellung die Aufgabe der eigenen Aufklärung sein sollte. Mit größerer oder geringerer Vorsicht der Ausdrucksweise haben die englischen Freidenker diese Auffassungen entwickelt; in Deutschland verbanden sie sich wissenschaftlich mit den Tendenzen der in Spinozas Theologisch-politischem Traktat angelegten Bibelkritik und mündeten in den sogenannten theologischen Rationalismus, der alle Überlieferungen der religiösen Urkunden natürlich und moralisch auszudeuten unternahm: aber die Motive der mythischen Verdunkelung und Verunstaltung der reinen moralisch-religiösen Wahrheit konnte man, wie es am schärfsten in der geheimen Schutzschrift von Reimarus ausgesprochen würde, sich auch hier nicht an- 
ders erklären als durch priesterlichen Lug und Trug. Von einem historischen Verständnis des religiösen Lebens, wie es Hume und Lessing wenigstens in der prinzipiellen Anlage gewannen, war bei der großen Masse der Aufklärer nicht das Geringste vorhanden: sie hatten für die Vorstellungsgebilde des religiösen Lebens kein anderes Kriterium als dasjenige beweisbarer Richtigkeit, und deshalb verwarfen sie alles daran, was über die blassen Inhalte jener moralischen Weltansicht hinausging.

V. Der Abschluß der Aufk1ärung. Die Literatur des 18. Jahrhun- Fortschritt zum derts zeigt in ihrer Gesamtheit den gewaltigen Prozeß einer neuen und selbständigen Durcharbeitung aller Fragen der menschlichen Lebensansicht. An der Hand der naturwissenschaftlichen Bewegung des 16. und 17. Jahrhunderts und der damit zusammenhängenden Metaphysik war eine niemals früher geahnte Freiheit des Geistes, eine Unabhängigkeit von aller historischen Gebundenheit des Urteils gewonnen, die der vernünftigen Einsicht gestattete, sich lediglich auf sich selbst zu stellen. Die Gebilde der historischen Entwickelung in Religion, Staat, Wissenschaft und Kunst hatten ihre autoritative Macht über die Individuen verloren: mit eigener Einsicht, die sich in dem ewigen Rechte des Natürlichen verankert glaubte, konnte sich die Aufklärung von aller Herrschaft des historisch Gegebenen freimachen. Dieser Prozeß begann in der sichtlichsten Weise bei der Religion und übertrug sich von da her auf alle Gebiete des geistigen Lebens. Das Kulturleben der europäischen Völker mußte diesen Bruch mit seinen geschichtlichen Voraussetzungen durchmachen, ehe es zu einer gereiften und vertieften Auffassung von dem Wesen und Werte seiner historischen Entwickelung zurückkehren konnte. Deshalb lag es in der Art des aufklärerischen Denkens und war darin vorgezeichnet, daß es von seinen kritischen Anfängen aus immer energischer zu negativen und radikalen Ergebnissen fortschreiten mußte, und daß es erst bei deren zugespitzter Formulierung zur Besinnung und zur Umkehr kam. Diese abschließenden Formen der aufklärerischen Bewegung haben sich mit eindrucksvoller Deutlichkeit und mit glänzender Energie in der französischen Literatur und in der großen geistigen Bewegung dargestellt, deren leidenschaftliche Gegensätze, in die Tat umgesetzt, durch die französische Revolution zum Austrag gekommen sind.

In diesem Sinne hat die Aufklärung ihre höchste schriftstellerische Form voltaire. und ihre persönliche Verkörperung in Voltaire gefunden. An keinem Punkte ein im eigensten Sinne schöpferischer Denker, ist er doch der typische Philosoph der Aufklärung: denn in keinem anderen ist ihre ganze Denkweise mit allen ihren Vorzügen und allen ihren Schwächen so glänzend und so wirkungsvoll zum Ausdruck gekommen wie bei ihm. Mit der unerbittlichen Klarheit des kritischen Verstandes verbindet sich in seinen Schriften die bezaubernde Anmut anschaulich lebendiger Darstellung, und hinter dem spielenden Witz, der vor keiner Schranke der Überlieferung haltzumachen scheint, spricht doch überall ein tiefes sittliches Gefühl für Wahrhaftigkeit 
und Gerechtigkeit. Seine theoretischen Überzeugungen haben sich zuerst an der Hand der englischen Vorbilder gestaltet, deren Kenntnis er seinen Landsleuten vermittelte, und eine Zeitlang schien es, als ob er bei aller scharfen und in der äußeren Form sogar manchmal frivolen Kritik der positiven Religion zur Fahne des teleologischen Deismus schwören wollte. Aber die persönliche Erschütterung der optimistischen Lebensauffassung und die seinem klaren Verstand einleuchtende Skepsis Pierre Bayles ließen auch ihn die Reste der religiösen Vorstellung auf die Forderungen des sittlichen Bewußtseins einschränken, und je problematischer ihm jene überall da wurden, wo sie über die den Sinnen zugängliche Erfahrung hinausgingen, um so energischer und mutiger richtete er seine Tätigkeit darauf, im Bereiche des öffentlichen Lebens mit den Resten der Vorurteile aufzuräumen und die Forderungen einer rein menschlichen Moral durchgängig zu verwirklichen. Seine Demokratisierung des Freidenkertums warf alle ständischen und gesellschaftlichen Schranken nieder und rang um das Ideal, daß die in ihrer natürlichen Erkenntnis reif gewordene Menschheit die Gestaltung ihrer Geschicke selbst in die Hand nehmen solle. Aber er kämpfte dafür nur im Sinne der intellektuellen Befreiung, der rückhaltlosen Durchdringung aller Verhältnisse mit der Macht des Verstandes. Ebendeshalb war doch schließlich, trotz des moralischen Rückhaltes in seinen Überzeugungen, die Aufklärung bei ihm hauptsächlich eine Auflösung der unbefangen geltenden Vorstellungsweisen und seine Wirkung die, daß nicht nur die religiösen Dogmen, sondern auch die metaphysischen Lehren, an deren Systematik auch sein Geschmack Anstoß nahm, ihm selbst und mit ihm der großen Menge seiner Leser problematisch wurden.

Enzyklopädie.

Stärker noch tritt dieser zersetzende Fortschritt des aufklärerischen Denkens in dem großen Gesamtwerke zutage, worin das intellektuelle Leben dieses Zeitalters mit dem ganzen Reichtum seiner Einsichten und seiner Ansichten eine adäquate Kodifikation gefunden hat, in der von Denis Diderot herausgegebenen und inspirierten Enzyklopädie. In ihrer von d'Alembert geschriebenen Vorrede durchaus baconisch im Sinne einer empiristischen und naturalistischen Weltweisheit entworfen, machte das große Werk, an dem sich alle führenden Geister der französischen Literatur kürzer oder länger, offener oder vorsichtiger beteiligten, den typischen Entwickelungsgang durch, daß der Inhalt immer kritischer und radikaler sich gestaltete. Wie Diderot selbst, so schritt auch die Enzyklopädie, in der sich der gemeinsame Gedankenfortschritt des Pariser Geisteslebens niederlegte, vom Empirismus zum Sensualismus und Positivismus, vom Deismus zum Naturalismus, vom Skeptizismus zum Materialismus fort. Diese glänzende Vereinigung der gelehrten und der literarischen, der philosophischen und der wissenschaftlichen, der politischen und der sozialen Überzeugungen der Zeit hinterläßt doch in ihrer Gesamtheit den Eindruck einer inneren Auflösung, in der neben den Tatsachen des täglichen Lebens und den gelehrten Notizen nur die vagen Umrisse einer sozialen Moral als positiver Gehalt übrig bleiben. 
Den letzten Schritt in der Formung der Ergebnisse dieser Bewegung tat Système do la ein anderes Werk, das auch aus der gemeinsamen Arbeit des Kreises jener „Philosophen" hervorging: das Système de la nature. Hier tauchte aus der skeptischen Oberfläche des zersetzenden Denkens mit plumper Naivität eine neue dogmatische Lehre empor, der Materialismus. Die sensualistische Erkenntnistheorie war ja schließlich immer nur durch skeptische oder positivistische Bedenken davon zurückgehalten worden, die materialistische Weltansicht auszusprechen, die ihr in dem gesunden Menschenverstande als naive Voraussetzung zugrunde lag. Wo diese kritische Vorsicht fehlte wie bei einem Manne von der Keckheit und Rücksichtslosigkeit Lamettries, da trat die materialistische Denkart mit einer Art von unverhohlener Selbstverständlichkeit und sogar mit absichtlich zugespitztem Antagonismus gegen allen Glauben an geistige Wirklichkeit und geistige Werte zutage. Sie begründete sich dabei wissenschaftlich durch die mechanistische Welterklärung, welche im Prinzip schon bei Descartes und seinen Nachfolgern jede Erklärung physischer Vorgänge durch geistige oder seelische Kräfte verneint, welche auch das organische Leben mit allen seinen zweckmäßigen Funktionen zuletzt auf Mechanik der Atome zurückgeführt und die Annahme übersinnlicher Wesen und Wirkungen für die Gesamtheit des Universums ebenso unnötig gemacht habe wie für die Erklärung der einzelnen Organismen und ihrer Tätigkeiten. Diese Elimination des Geistigen aus der Welterklärung, diese Betrachtung des $Z$ weckmäßigen als einer nach den Prinzipien der Wahrscheinlichkeit immerhin möglichen Konstellation der mechanischen Elemente des Weltgeschehens leuchtete dem naturwissenschaftlichen Denken auch solcher Männer ein, welche wie die englischen Assoziationspsychologen Hartley und Priestley dadurch in unlösbare Widersprüche zu ihrer fromm-gläubigen Überzeugung versetzt wurden. Bei den Verfassern des Système de la nature fielen solche Skrupel fort. Sie erkannten nur das an, was die Naturforschung mit klarer Verstandeseinsicht erwiesen zu haben schien, und so formulierten sie, was bei den Enzyklopädisten noch in einem halbbewußten oder halbverdeckten Dunkel gelegen hatte, zu einem offenen und polemischen Materialismus und Atheismus.

Aber gerade damit brach die Verstandesaufklärung des 18. Jahrhunderts sich selber die Spitze ab. Wenn eine solche öde und kalte Weltansicht, wenn diese Verneinung alles seelischen Weltinhaltes sich als das letzte Ergebnis der Kultur des Intellektes verkündete, so wurden dadurch zu gegnerischer Entfaltung alle die Kräfte ausgelöst, die schon vorher mehr in der Stille als eine Gegenströmung gegen die rationalistische Aufklärung tätig gewesen wa ren. Denn so sehr das 18 . Jahrhundert in seiner Hauptentwickelung den Idealen klarer Vernunfterkenntnis und vernunftgemäßer Lebensgestaltung nachging, so wenig fehlte es ihm andererseits an tiefem und innerlichem Gemütsleben. Die Beschäftigung des Individuums mit sich selbst, die Selbstbespiegelung der Monade, entdeckte in der Tiefe des Lebens die Ursprünglichkeit des Gefühls, der Leidenschaft, der genialen Schöpfung. In der ästhetischen und in

Gefühls- und Genialitätsphilosophie. 
der moralischen Theorie war das Gefühl oder der Geschmack als eine vom Verstande unabhängige, ihm die Prinzipien der Beurteilung gebende Instanz erkannt worden, und die neue poetische Bewegung der Genialität, welche von England nach Deutschland hinüberspielte, durchbrach wie ein frischer Lebensquell das erstarrte Formelwesen, das die Aufklärung auch der Dichtung aufgezwängt hatte.

Rousseau. Die packendste Form aber und die zündende Macht über die Geister gewann diese Opposition des Gefühls gegen die einseitige Verstandeskultur wiederum in einer typischen Persönlichkeit der französischen Literatur, in Jean Jacques Rousseau. Er maß den Wert der Aufklärung an ihren eigenen Kriterien der Aufgaben des Lebens: er fragte, was diese gesteigerte und verfeinerte Zivilisation, was die Ausbildung von Kunst und Wissenschaft als Ertrag abgeworfen habe für die Glückseligkeit und die innere Befriedigung des einzelnen Menschen. Und er fand, daß diese Zivilisation, die sich rühmte, das Ergebnis des geschichtlichen Prozesses zu sein, weit entfernt, den Menschen wirklich zu vervollkommnen und glücklich $z u$ machen, vielmehr ihn stetig seiner eigenen Natur und seiner wahren Bestimmung entfremdet habe. Er setzte gegen die wertfreie, gegen die kühle und frivole Verstandesansicht der Enzyklopädisten eine leidenschaftliche Glut natürlichen Gefühls, heiß und brennend, alles niederreißend und entwertend, was an Lebensformen und Institutionen aus dem Überwiegen der Verstandeskultur hervorgegangen sei. Er hatte für sich die elementare Gewalt der Leidenschaft, den Notschrei bedrängter Massen und die Wucht einer durch keine begrifflichen Spitzfindigkeiten angekränkelten Überzeugung. So hallte sein Ruf nach Natürlichkeit über Europa, und das Geschlecht, das gewohnt war, über die Erziehung als die Umbildung des natürlichen zum gesitteten Menschen nachzudenken und seiner Erfolge darin sich zu freuen und sich zu rühmen, wurde an seiner intellektuellen Vollkommenheit, an dem vermeinten Triumph seines Geistes irre und begann sich nach neuem Leben zu sehnen.

Das Unhistorische der Aufklärung.

Geschichtsphilosophie.
Eines jedoch blieb den beiden Formen der Aufklärung, der verstandesmäßigen und der gefühlsmäßigen, gemein: das war die verständnislose Gleichgültigkeit gegen die historische Wirklichkeit. Wurde sie dort nach den Prinzipien einer abstrakten Vernünftigkeit, so hier nach elementaren Impulsen des natürlichen Gefühls gemessen. Das Vernünftige und das Natürliche standen im Bunde gegen das Historische: auf der einen Seite so, daß die Vernunft ihre Forderungen als die des ewig gleichen Wesens der Dinge dem Wechse1 der geschichtlichen Erscheinungen entgegenhielt, - auf der anderen Seite so, daß das natürliche Gefühl sich selbst den Verirrungen des historischen Prozesses gegenüber als das allein und wahrhaft Vernünftige durchsetzen wollte. In diesem Verhältnis bestand der revolutionäre Charakter der Aufklärung, und so verbanden sich alle ihre philosophischen Richtungen, um in der Theorie den Bruch mit der Geschichte zu vollziehen, den die Französische Revolution durch die Tat zu verwirklichen meinte.

Aus dieser Negation ist schließlich das positive Interesse der Aufklärung 
an dem Wesen und Wert der Geschichte erwachsen, und diese letzte Wendung des aufklärerischen Denkens hat sich unter dem unmittelbaren Eindrucke Rousseaus in der deutschen Philosophie durch Herder vollzogen. Freilich war Herder nicht der einzige, der das so lange vernachlässigte Gebiet der Geschichtsphilosophie wieder bearbeitete. Rousseau hatte das Kulturproblem in der schärfsten Form gestellt. Die ungeheuren Geschicke, die von Frankreich her die Welt zu erschüttern begannen, gaben diesen Fragen unmittelbare Bedeutung. Ihre Beantwortung knüpfte sich durchgängig an den Begriff von der unbegrenzten Perfektibilität des Menschen, den Rousseau trotz seiner pessimistischen Beurteilung der bisherigen Geschichte und ihrer Ergebnisse mit dem vollen Optimismus des aufklärerischen Glaubens aufrechterhalten hatte. Diese vertrauensvolle Seite seiner Überzeugungen wurde von allen den Männern weiterentwickelt, welche in Frankreich die philosophische Rechtfertigung der Revolution in der Weise wie St. Lambert oder Volney übernahmen. Sie alle aber waren gerade darin echte Schüler der Aufklärung, daß sie das Wesentliche in dem Fortschritt der Geschichte, der mit der Revolution seinen Höhepunkt erreicht haben sollte, doch immer bei der „Entwickelung der Ideen", bei der intellektuellen Vervollkommnung suchten und in der mehr und mehr sich ausbreitenden Herrschaft der vernünftigen Einsicht über das Leben fanden. Das war auch der Grundgedanke des bedeutendsten dieser Versuche, der von Condorcet ausging. Das Bild vom Fortschritt des menschlichen Geistes, das er skizzierte, war durchgängig in diesem Grundton gehalten, und er glaubte von dem bisherigen Verlauf der Linie her auch ihre Fortsetzung in eine bessere Zukunft konstruieren zu können, die ein reiferes und glücklicheres, an Leib und Seele höher entwickeltes Geschlecht sehen werde.

Herder war durch Rousseaus Parole und den Widerhall, den sie bei ihm Herder. wie bei den deutschen Stürmern und Drängern fand, der kühlen Verständigkeit der Popularphilosophie wie des schulmäßigen Rationalismus entfremdet; er machte gegen diese „platte“ Aufklärung das Urrecht des Gefühls und vor allem des religiösen Gefühls geltend, und er ließ sich durch diesen Gegensatz, in welchem das romantische Denken heraufdämmerte, sogar zeitweilig bis zu orthodoxem Eifern und dauernd zu gereizter Kritik gegen allen Rationalismus, insbesondere zuletzt auch den Kantischen, verleiten. Aber er hatte damit vor der großen Masse der Aufklärer das Verständnis für die Totalität des menschlichen Wesens und für die gleichmäßige Wertung aller seiner Lebensäußerungen voraus. Als er daher in seinen „Ideen zur Philosophie der Geschichte der Menschheit" daran ging, den Rousseauschen Begriff der Perfektibilität im Sinne des I.eibnizschen Entwickelungsgedankens durchzuführen, gewann er den weiten Ausblick auf die gesamte geschichtliche Entwickelung der Menschheit. Vor ihm war der einsam forschende Italiener Vico, in dessen tief grübelnden, aber unklaren Gedanken auch schon früh die Opposition gegen den aufklärerischen Rationalismus sich meldete, darauf ausgegangen, aus dem Wesen des menschlichen Geistes, der die Geschichte macht, allge- 
meine Lebensgesetze zu finden, die sich in der historischen Entwickelung aller Völker gleichmäBig bestätigen sollten: aber wenn er damit diejenigen Probleme aufrollte, die man später als völkerpsychologisch bezeichnet hat, so versperite sich Vico den Blick auf eine wirkliche Universalgeschichte durch die prinzipielle, ganz im Sinne alter Frömmigkeit gedachte Scheidung der "heiligen" von der "profanen“ Geschichte. Jetzt dagegen verfolgte Herder den Entwickelungsgang des ganzen Geschlechts von seinen ersten, durch die organische Anlage und die gesamte Umwelt bestimmten Bedingungen bis zu den Kulturentwickelungen der zivilisierten Völker als einen großen, bedeutungsvollen, in sich zusammenhangenden Gesamtverlauf. Auch er wollte damit den historischen ProzeB als eine Notwendigkeit der natürlichen Entwickelung begreifen, aber im Leibnizschen Sinne sah er gerade in diesen natürlichen Notwendigkeiten die fortschreitende und $z$ weckvolle Verwirklichung der in dem physischen Geschlecht von vornherein gegebenen Anlage zur Humanität. So feierte der optimistische Glaube der Aufklärung seinen höchsten Triumph: wie der Mensch als die Krone der Schöpfung, so erschien die Geschichte der Menschheit in dem Zusammenhang der Völkergeschicke als die Krönung des natürlichen Lebens.

\section{Kant und der deutsche Idealismus.}

Rationalismus und Irrationalismus.
Der unermeßliche Kulturwert der aufklärerischen Bewegung bestand in der Stetigkeit und Sicherheit, womit darin eine freie und vorurteilslose Weltund Lebensansicht aus dem wissenschaftlichen Denken in die Überzeugungen des ganzen gebildeten Europa allmählich durchsickerte, und die Durchsetzung der allgemeinen Literatur mit diesen Ergebnissen einer sich dem Leben zuwendenden Philosophie, die innige Beziehung zwischen dem Denken und dem Dichten war überall, und nicht zum wenigsten in Deutschland, die charakteristische Erscheinung jener großen Zeit. So kam es, daß die letzten und entscheidenden Gegensätze des geistigen Lebens eine gleichmäßige Ausprägung in der philosophischen und in der poetischen Entwickelung fanden. Diese Gegensätze aber beruhten darauf, daß jene Gleichsetzung von Natürlichkeit und Vernünftigkeit, worin sich der Glaube des Zeitalters überall darstellte, auf der einen Seite in der Klarheit verstandesmäBiger Einsicht, auf der anderen in der Ursprünglichkeit des persönlichen Gefühls gesucht wurde. Man beurteilt die "Aufklärung" falsch, wenn man in ihr nur die Entwickelung jener Verstandeskultur sieht, die allerdings ihre gewaltige Oberstömung bildet und am offensten zutage tritt: man muß auch der Unterströmung lauschen, die aus den Tiefen des Gemütslebens die freie und natürliche Entwickelung des Menschenlebens in Dichtung und Philosophie gestalten will. In der heftigen Opposition gegen die Herrschaft des Traditionellen im gesamten Leben, in der Befreiung von den Fesseln des geschichtlich Gegebenen haben beide Richtungen ihre Gemeinsamkeit: aber in ihren positiven Entfaltungen erheben sie sich mit der Zeit immer schroffer gegeneinander. Gegen den Rationalismus, der 
die Welt bis auf den letzten Rest mit seinen Begriffen durchdringen und nichts als wahr anerkennen will, was sich nicht beweisen läßt, gegen denselben Rationalismus, der auch das Leben restlos gestalten und nichts darin bestehen lassen will, was sich nicht vor der Vernunft rechtfertigen läßt, gegen diesen Rationalismus empört sich die Leidenschaft des natürlichen Gefühls mit der ganzen Irrationalität der individuellen Wirklichkeit. Dieser Gegensatz von Rationalität und Irrationalität ist schon in dem Verhältnis der führenden Geister der englischen Aufklärung, Lockes und Shaftesburys, angelegt; er kommt mit voller Energie in den beiden großen Schriftstellern der französischen Aufklärung zum Wort, in Voltaire und Rousseau, und er spielt sich in Deutschland aus dem Verhältnis der Schul- und Popularphilosophie zur Gefühlsphilosophie in den literarischen Gegensatz zwischen der regelrechten und der genialen Dichtung hinüber.

I. Kant. Von diesem Grundverhältnis aus ist die überragende Stellung Die kritische zu verstehen, in der Immanuel Kant den intellektuellen Prozeß der Aufklärung $\begin{gathered}\text { Grenz- } \\ \text { bestimmung. }\end{gathered}$ vollendet und damit überwunden hat. Mit allen Eigenheiten des Professors, dessen ganzes Leben sich in den engen Kreisen seiner heimatlichen Universität Königsberg abgespielt hat, und mit der zähen Gewalt seines systematischen und architektonischen Geistes der Gründlichkeit, der Ordnung und der Sauberkeit war er in seinem ganzen Wesen darauf gerichtet, die rationale Tendenz des aufklärerischen Denkens bis in ihre letzten Folgerungen durchzuführen und das Leben aus der dumpfen Unmittelbarkeit in die bewußte Klarheit und Deutlichkeit zu erheben: aber der tiefe Ernst und die gewaltige Wahrhaftigkeit seines Charakters ließen ihn gerade in dieser Klarheit und Deutlichkeit überall die Grenzen erkennen, an denen das Recht der irrationalen Wirklichkeit beginnt. So ist sein Lebenswerk gerade in dem Sinne die kritische Philosophie, daß er auf allen Gebieten menschlicher Vernunftbetätigung die Rationalisierung von Welt und Leben bis auf die äußerste Grenze zu treiben sucht, um dann mit fester Hand diese Grenze abzustecken und dahinter den für die Vernunft undurchdringlichen Rest in dem Lebensgrunde der Welt und des Menschen anzuerkennen. Diese bewußte Abgrenzung zwischen dem Rationalen und dem Irrationalen erscheint selbst als das letzte und höchste Ergebnis des rationalen Denkens und andererseits als die Eröffnung und Freilegung der geheimnisvollen Quellen alles inneren Lebens. Mit der reinlichen Scheidung der Gebiete des Rationalen und des Irrationalen erhebt sich die Philosophie im Begriffe zur Verknüpfung jener beiden Richtungen.des I 8. Jahrhunderts - zu derselben Zeit, wo sich ihre positive Synthesis in der größten modernen Persönlichkeit, in Goethe, vollzog.

Zur Bewältigung dieser Gesamtaufgabe hat sich Kant erst allmählich Kritische oder das leistungsfähige Mittel in der Methode geschaffen, die er im engeren ${ }_{\text {Methode. }}^{\text {transzendente }}$ Sinne die kritische oder transzendentale genannt hat. Sie erwuchs ihm aus der fortschreitenden Erkenntnis der Unzulänglichkeit aller der Wege, auf denen die Philosophie der Aufklärung den Wert und die Geltung von Prin- 
zipien des Erkennens und des Handelns aus der Einsicht in die Art ihres Ursprungs und ihrer Entwickelung im menschlichen Geiste beurteilen zu können meinte. Die psychogenetische oder, wie Kant sagte, physiologische Betrachtungsweise war den rationalistischen und den empiristischen Theorien gemeinsam gewesen. Die einen gingen in irgendeiner Form auf die Annahme ursprünglicher, eingeborener Wahrheiten im Subjekt zurück, die anderen wollten alle Gestaltungen des Innenlebens aus der Einwirkung des Objekts erklären: aber in beiden Fällen war der Verzicht auf eine Begründung adäquaten Wissens das Ergebnis gewesen. Kant machte die Schule der rationalistischen Kathederphilosophie durch und zerriß ihre Maschen Schritt für Schritt mit eigener Kraft. Er wendete sich dann den empiristischen und den skeptischen Theorien der englischen Philosophie, den großen Eindrücken der französischen Literatur und den Neigungen der zeitgenössischen deutschen Popularphilosophie zu: aber alle die liebenswürdigen und geistreichen Essays, in denen er sich von diesen verschiedenen Tendenzen der Aufklärung mitgenommen darstellt, verraten doch, daß er keiner davon jemals sich ganz zu eigen gegeben, vielmehr stets das Ziel im Auge gehabt hat, für das unbedingt rational Gültige die Voraussetzung in dem Inhalt des vernünftigen Bewußtseins selbst aufzufinden. Hinsichtlich der metaphysischen Lehren hatte er auf eine solche unbedingte Geltung früh verzichten gelernt, so wertvoll sie für die Bedürfnisse seiner religiösen und moralischen Überzeugungen gewesen wäre; dagegen meinte er, eine solche allgemeine und notwendige Geltung einerseits für die. Theorie der mathematischen Naturforschung, als deren vollkommene Form ihm Newtons Prinzipien galten, andererseits für das moralische Bewußtsein voraussetzen zu dürfen. In beiden Fällen aber ließ sich die Geltung durch genetische Betrachtungen weder begründen noch anfechten: es kam vielmehr nur darauf an, diejenigen Momente zu analysieren, auf denen sie beruht, und damit zugleich die Gegenstände zu begrenzen, auf welche sie sich zu erstrecken berechtigt ist. Diese Methode hat Kant die kritische oder die transzendentale genannt: ihre allgemeine Formel ist die Frage nach der Möglichkeit synthetischer Urteile a priori, d. h. nach der Berechtigung solcher Vernunftfunktionen, für welche eine allgemeine und notwendige Geltung in Anspruch genommen wird, ohne daß diese auf dem genetischen Wege ihrer Entwickelung aus den einzelnen Funktionen begründet werden könnte. Kant übersieht daher weder, noch leugnet er, daß die Vernunftprinzipien, die er im Sinne ihrer Notwendigkeit und Allgemeingültigkeit als a priori bezeichnet, im Bewußtsein des einzelnen wie der menschlichen Gattung zustande kommen; die Apriorität hat bei ihm niemals die psychologische Bedeutung einer genetischen Priorität im Sinne des Eingeborenseins, sondefn er fragt nach dem Geltungsrechte alles dessen, was im geistigen Leben des Menschen über die zufälligen Bestimmungen des individuellen oder des sozialen Bewußtseins hinüberzugreifen beansprucht, und er findet die Kriterien für die Entscheidung dieser Frage überall nur in dem rationalen Zusammenhange des gegenständlichen Inhaltes selbst. Seine Kritik 
wird auf diese Weise zu einer Umgrenzung des von allen zeitlichen und persönlichen Bestimmungen unabhängigen und rein gegenständlich in sich begründeten Inhaltes aller Vernunftbetätigungen des Menschen, d. h. aller Arten seiner Kulturfunktion. Hierin allein besteht der sog. subjektive Charakter der Kantischen Philosophie, vermöge dessen sie alle Probleme der sachlichen Erkenntnis aus der Art nicht ihrer Entstehung, sondern ihrer Begründung in dem vernünftigen Bewußtsein bildet und 1öst: aber deren Lösung besteht immer wieder in dem Nachweis einer in der Sache selbst liegenden und von den Bewegungen des empirischen Vorstellens unabhängigen Notwendigkeit der Begriffe. Die ganze Frage seiner Philosophie ist, wodurch und wieweit die Wertleistungen des subjektiven Lebens objektiv in einer übergreifenden Sachlichkeit begründet sind.

Diese Methode der Kritik hat Kant in seinen großen Werken zuerst auf system der das Problem der Wissenschaft und von da her auf die übrigen Seiten der Vernunft oder des Kulturlebens angewendet, auf die Sittlichkeit und das Recht, auf die Kunst und die Religion. Diese sachliche Gliederung seiner Lehren aber entspringt in der Darstellung auf dem Boden der psychologischen Einteilung, die sich in der deutschen Philosophie seiner Zeit durchgesetzt hatte. Er findet den Anspruch auf Apriorität in allen drei Grebieten des Bewußtseins: auf dem Gebiete des Vorstellens in der wissenschaftlichen Theorie, auf dem Gebiete des Wollens in den Maximen des sittlichen Lebens, auf dem Gebiete des Fühlens in den Gemeinsamkeiten des ästhetischen Urteils über Natur und Kunst, und nachdem er diese drei großen Lebensgebiete in der Kritik der reinen Vernunft, in der Kritik der praktischen Vernunft und in der Kritik der Urteilskraft durchforscht hatte, konnte er daran gehen, abschließend die Religion innerhalb der Grenzen der bloßen Vernunft zu bestimmen. In allen Fällen aber handelt es sich darum, daß die Vernunft mit kritischer Selbstbesinnung das Gebiet ihrer berechtigten Betätigung ausmißt und damit sich selber die Grenzen ihrer Wirksamkeit steckt.

Am größten erweist sich der Umkreis des rational Berechtigten auf dem Wissenschafts. Gebiete der Erkenntnis, und doch schränkt er sich auch hier gegenüber dẹn lebre. Ansprüchen, die das Denken immer gemacht hat und immer machen muß, in der eindrucksvollen Weise ein, welche bei Kants Zeitgenossen die erschütternde und zermalmende Wirkung hervorrief. Denn nichts weniger als der gesamte Umfang menschlicher Erfahrung wird von Kant der ordnenden und gestaltenden Kraft der wissenschaftlichen Theorie im Prinzip unterworfen; aber dies positive Ergebnis wird durch den Verzicht auf alle Ansprüche des metaphysischen Denkens, auf jede Art von wissenschaftlicher Erkenntnis des Unerfahrbaren erkauft. Freilich schränkt sich dabei für Kant auch der Begriff der Erfahrungswissenschaft auf die mathematische Theorie der Naturforschung ein. Nur so weit will er wahre Wissenschaft anerkennen, als Mathematik darin ist; nur die Bemeisterung der Tatsachen durch allgemeine Begriffe und Gesetze gilt ihm als rationale Wissenschaft. Die $z$ weifel- $T_{\text {ranszendentalo }}$ lose Geltung der Mathematik zunächst ist darin begründet, daB ihre Erkenntnis

Ästhetik. 
ihre Gegenstände selbst in der Anschauung durch Definition und Konstruktion erzeugt, und die damit gewonnenen Gesetzmäßigkeiten müssen auch für den ganzen Umkreis der Erfahrung gelten, weil die Formen der Anschauung, Raum und Zeit, als Voraussetzungen in jeder einzelnen Erfahrung bereits enthalten sind. Kein besonderes Nebeneinander oder Nacheinander ist in der Wahrnehmung erlebbar ohne die Einordnung ihrer Gegenstände in den einen allgemeinen Raum und die eine allgemeine Zeit. Diese Lehre von Raum und Zeit als den reinen Anschauungen oder den Anschauungen a priori hatte Kant bereits in seiner Inaugural-Dissertation mit einem feinen Anklang an die Leibnizsche Vorstellungsweise vorgetragen; Raum und Zeit galten ihm schon damals als die Formen der sinnlichen Rezeptivität, und in der Kritik der reinen Vernunft war es die Aufgabe der transzendentalen Ästhetik, zu zeigen, daß die in der reinen Mathematik erkannte Gesetzmäßigkeit von Raum und Zeit für alles Erfahrbare gelten muß, weil jede Erfahrung als eine Verknüpfung von Empfindungen deren Einordnung in räumliche und zeitliche Beziehungen zur Voraussetzung hat und gegenständlich in sich enthält. Mit dieser Geltung für das ganze Gebiet des Erfahrbaren haben Raum und Zeit empirische Realität: aber es besteht keinerlei Gewähr dafür, daß sie über die sinnliche Rezeptivität hinaus, deren Formen sie sind, eine reale Bedeutung besitzen; in diesem Sinne haben sie transzendentale Idealität, d. h. notwendige Geltung nur als Vorstellungen, über deren Verhältnis zur absoluten Realität, $z u$ den Dingen an sich, nichts ausgemacht werden kann.

Ihre entscheidende Vertiefung haben diese Untersuchungen Kants erst durch das Problem der Gegenständlichkeit erfahren, das in der transzendentalen Logik seine Lösung gefunden hat. Die Kritik der Möglichkeit der Erkenntnis führt an der Hand der naiven Vorstellung, wonach Wahrheit in der Übereinstimmung der Vorstellungen mit ihrem Gegenstande bestehen soll, zu der fundamentalen Frage, worin überhaupt die Gegenständlichkeit des Erkennens bestehen, wodurch die Beziehung unserer Vorstellungen auf Gegenstände begründet sein kann. Die entscheidende Entdeckung Kants bestand nun in der Einsicht, daß die Gegenständlichkeit niemals etwas anderes bedeuten kann als die allgemeingültige Verknüpfung von Empfindungen. Diese Verknüpfung ist immer räumlicher und zeitlicher Art, aber ihre Notwendigkeit ist nur so zu denken, daß jede besondere Koordination im Raum und ebenso jedes besondere Verhältnis in der Zeit durch eine Art der begrifflichen Synthesis begründet ist. Solche Zusammengehörigkeiten erkennen wir in der logischen Form des Urteils, welches seinen Anspruch auf Objektivität, d. h. auf gegenständliche Geltung für jedermann, darin ausspricht, daß es seine Elemente, das Subjekt und das Prädikat, in einer bestimmten begrifflichen Form miteinander verknüpft. Diese begrifflichen Formen bedeuten somit die Arten der Gegenständlichkeit, Kant nennt sie die reinen Verstandesbegriffe oder die Kategorien, und er findet sie in der „Analytik“ nach dem Prinzip, daß es so viele Kategorien geben muß wie Urteilsarten, an der Hand der von ihm für gültig angesehenen Tafel der Urteile. Nach den vier Ge- 
sichtspunkten der Quantität, Qualität, Relation und Modalität hatte er je drei Urteilsformen konstruiert, und so ergab sich ihm die systematisch gegliederte

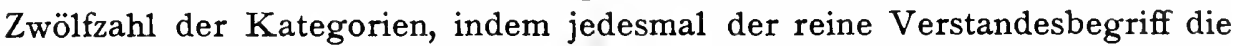
Art der Verbindung von Subjekt und Prädikat bedeuten sollte, deren gegenständliche Geltung den Erkenntniswert des Urteils ausmacht. Die Möglichkeit einer solchen begrifflichen Verknüpfung von Empfindungen beruht darauf, daß darin der sachliche Grund ihrer räumlichen und zeitlichen Anordnung enthalten ist. So wird z. B. die Sukzession zweier Erlebnisse erst dadurch gegenständlich und damit allgemeingültig, daß sie in der Kategorie der Kausalität, in der begrifflichen Verknüpfung von Ursache und Wirkung als notwendig begründet ist. Bei diesem Beispiel trifft die Auffassungsweise der Kantischen Kategorienlehre in so glücklicher Weise zu, daß man daran sieht, wie stark bei dem Philosophen persönlich in dem Entwurf dieser Lehre das Bedürfnis mitgewirkt hat, das Humesche Kausalitätsproblem zu lösen. Bei einer großen Zahl der übrigen Kategorien dagegen ist der „Schematismus“, der in der Analogie zwischen dem begrifflichen und dem zeitlichen bzw. räumlichen Verhältnis bestehen soll, lange nicht so deutlich und sicher. Aber der ganze Zweck der tiefsinnigen Untersuchungen, die Kant in dem Abschnitt über die transzendentale Deduktion der reinen Verstandesbegriffe geführt hat, läuft darauf hinaus, daß es keine Erfahrung, d. h. keine allgemeingültige, über die zufälligen Erlebnisse und Assoziationen der Individuen hinausgehende Vorstellungsverbindung geben könnte, wenn nicht die räumliche und zeitliche Anordnung der Empfindungen gegenständlich in den allgemeinen Regeln der begrifflichen Verknüpfung begründet wäre, die durch die Kategorien gedachr werden. Wenn wir unter Natur eine gesetzlich geordnete Mannigfaltigkeit des Wahrgenommenen, ein System der Erfahrung verstehen, so sind dieser Natur ihre Gesetze durch den Verstand vorgeschrieben, und die Bilder, welche unsere Sinnlichkeit in dem Miteinander und Nacheinander der Empfindungen auffaßt, erhalten erst dadurch die Bedeutung von Gegenständen, daß ihre Ordnung in begrifflichen Zusammenhängen begründet ist. Deshalb aber gelten auch die in den Kategorien gedachten begrifflichen Zusammenhänge für den ganzen Umkreis des in den Empfindungen Wahrgenommenen, und diese ihre Geltung spricht Kant in den Grundsätzen des reinen Verstandes aus, die in ihrer systematischen Totalität den Inbegriff der reinen Naturwissenschaft ausmachen sollen. Den bedeutsamsten Teil davon sehen wir in den auf den Kategorien der Relation aufgebauten "Analogien der Erfahrung": die Natur besteht aus Substanzen, deren Quantum weder vermehrt noch vermindert werden kann; ihre Zustände wechseln nach dem Grundsatze der Kausalität, wonach nichts ohne zureichende Ursache geschieht; und nach dem Grundsatze der Gemeinschaft stehen die Substanzen in durchgängiger Wechselwirkung, wonach der Zustand der einen dem der anderen sein Dasein in der Zeit nach allgemeinen Regeln bestimmt. Damit war die philosophische Grundlage für die naturwissenschaftliche Theorie gewonnen und im Prinzip die Möglichkeit einer rationalen Durchdringung der gesamten

Die Kultur drk Grgemwart. 1. 5. 2. Aufl. 
Erfahrungswelt durch die Formen einer begrifflichen Gesetzmäßigkeit begründet.

Ding - an - sich.

Aber diese ganze Deduktion galt für die Kategorien nur insoweit, als sie Formen der Synthesis für eine gegebene Mannigfaltigkeit sind. In ihr konnten die gegenständlichen Zusammenhänge vermöge des anschaulichen Schematismus als notwendig und allgemeingültig begründet werden. Allein diese gegenständliche Rationalität beschränkt sich deshalb auch auf die Erfahrung, die als solche, d. h. .als ein geordnetes Ganzes, erst in den Kategorien begründet ist. Eine andere Gegenständlichkeit als diese war nach den Voraussetzungen der Kantischen Kritik unmöglich. Wenn man daher unter dem Ding-an-sich eine Wirklichkeit denkt, die von dem erkennenden Bewußtsein, seinen Empfindungen, Anschauungen und Kategorien unabhängig ist, so können solche Dinge-an-sich niemals als Gegenstände erkannt, sondern höchstens problematisch gedacht werden. Diese negative Seite seines Ergebnisses spricht Kants transzendentaler Idealismus in der Lehre von der Unerkennbarkeit des Dinges-an-sich aus. Die Kategorien sind konstitutiv für das System der Erfahrung; über deren Grenzen hinaus gibt es keine Gegenstände der Erkenntnis. Insofern als durch die Kategorien eine über das individuelle Vorstellen hinausgreifende gegenständliche Erkenntnis begründet wird, bedeutet die rationale Erkenntnis ein überindividuelles, sachlich konstitutives Denken, und diese ihre Bedeutung formuliert Kant in dem Begriffe der transzendentalen Apperzeption oder des „Bewußtseins überhaupt“. Aber eine andere Sachlichkeit oder Gegenständlichkeit als die der rationalen $\mathrm{Zu}$ sammengehörigkeit des Gegebenen ist deshalb unerkennbar.

Transzendentale Dialektik.

Mit dem Begriffe des Dinges-an-sich setzt sich somit die Rationalität der Erfahrungserkenntnis ihre eigene Grenze. Denn nur deshalb kann die solcher Erkenntnis zugängliche Sinnenwelt als Erscheinung bezeichnet werden, weil für das Denken eine unentfliehbare Notwendigkeit zur Überschreitung jener Grenze und zur Annahme des Dinges-an-sich besteht, wenn auch das letztere nicht mehr einen erkennbaren Gegenstand bildet. Ist die Metaphysik als Erkenntnis des Unerfahrbaren und Übersinnlichen unberechtigt und in diesem kritischen Sinne unmöglich, so ist sie doch als ein immer wiederkehrendes Bestreben des menschlichen Geistes tatsächlich vorhanden, und sie muß ihr Motiv in dem Erkenntnisleben selber und in seiner notwendigen Struktur haben. In diesem Sinne handelt Kants transzendentale Dialektik von dem transzendentalen Schein. Die Tätigkeit des Verstandes in der Verarbeitung des sinnlichen Materials findet bei dessen endloser Ausdehnung niemals einen befriedigenden Abschluß; sie schreitet von Bedingtem zu Bedingtem in einem endlosen regressus oder progressus fort, und sie erreicht deshalb in dem gegenständlichen Material niemals die Totalität, die sie ihrem Wesen nach verlangen muß. Aus diesem Bedürfnis nach dem Abschluß entsteht die Vorstellung des Unbedingten und damit die Aufgabe, ein solches Unbedingtes zu erkennen. Da aber alle Gegenstände der Erkenntnis als kategorial geformte Anschaungen bedingt sind, so muß das Unbedingte 
zwar notwendig gedacht, kann aber niemals als Gegenstand erkannt werden: es ist nicht gegeben, sondern aufgegeben, und aufgegeben als ein nie zu erreichendes, aber den Fortschritt in der Erkenntnis der Gegenstände bestimmendes Ziel. Solche notwendigen, aber niemals zu lösenden Aufgaben der Vernunft nennt Kant Ideen. So bildet auf dem Boden der inneren Erfahrung die Idee der Seele zwar das regulative Prinzip für die Aufgabe, den letzten Zusammenhang aller Zustände des Bewußtseins zu verstehen, aber keinen Gegenstand der Erkenntnis: die Seele kann nicht als eine in der Erfahrung aufweisbare Substanz erkannt werden, und alle Eigenschaften, die man ihr als solcher in der rationalen Psycholngie zuschrieb, konnten nur durch Paralogismen begründet werden, durch Fehlschlüsse, welche die logische Einheit des Bewußtseins mit einer substantiellen Existenz verwechselten. Ebenso gerät die Vernunft, wenn sie von dem Weltall als einem Gegenstande der Erkenntnis nach der Richtung irgendeiner der Kategorien etwas aussagen will, in die unvermeidliche Antinomie, daß dieselben Prädikate, welche nach dem Erkenntnisbedürfnis des Verstandes bejaht werden müssen, wegen der Unendlichkeit der räumlichen und zeitlichen Erscheinung verneint werden müssen. Die kosmologische Idee wird somit, sobald sie Gegenstand der Erkenntnis sein soll, in unlösbare Widersprüche verwickelt. Für die Idee der Gottheit endlich als der unbedingten Totalität aller Wirklichkeit überhaupt läßt sich der Beweis der Existenz weder auf dem ontologischen, noch auf dem kosmologischen, noch auf dem physikotheologischen Wege führen.

Allein in allen diesen Fällen, worin die Selbsttäuschung der metaphy- Das problema sischen Systeme deutlich erwiesen wird, zeigt sich die Kritik insofern zwei- tische Ergebnis schneidig, als sie auch alle negativen Behauptungen, die sich auf die Ideen beziehen, für ebenso unrichtig erweist wie die positiven. Das Ergebnis der Erkenntnislehre ist also hinsichtlich der Dinge-an-sich vollkommen problematisch. Es bleibt bei der Notwendigkeit, das Unbedingte und Übersinnliche $z u$ denken und zugleich auf seine Erkennbarkeit durchweg zu verzichten. Kant glaubte damit durch die Aufhebung des Wissens den Raum für die Möglichkeit des Glaubens gewonnen zu haben: aber auch hinsichtlich des Glaubens hielt er mit eiserner Konsequenz an dem Bestreben fest, ihn so weit wie irgend möglich zu rationalisieren.

Eine rationale inhaltliche Bestimmung des Dinges-an-sich konnte, wenn Der kategosie der theoretischen Vernunft verschlossen war, nur in der praktischen gerische Imperativ. sucht werden, und so führte Kant die Bestrebungen der Aufklärungsphilosophie zu Ende, welche die Moral von aller theoretischen Begründung hatten unabhängig machen wollen. Aber die kritische Philosophie konnte sich dabei nicht auf ein empirisches Gefühl, sondern nur auf ein allgemeingültiges, vernünftiges Bewußtsein stützen, das als ein letzter Urteilsgrund im Inhalt des moralischen Lebens selbst gefunden werden konnte. Es galt deshalb für Kant die Frage, ob es eine notwendige und allgemeingültige Beziehung des Willens auf Gegenstände, ein höchstes Gesetz des vernünftigen Willens gebe. Solche Apriorität war aber niemals durch den immerdar empirisch gegebenen Jn- 
halt des Wollens, sondern nur durch seine Form, durch seine allgemeingültige Gesetzmäßigkeit möglich. Deshalb mußte die kritische Moral darauf verzichten, an irgendein schon bestehendes Wollen zu appellieren und die einzelnen sittlichen Regeln als die Mittel zur Erfüllung solcher Ziele abzuleiten: sie konnte weder die Glückseligkeit, noch die Vollkommenheit, noch irgendein Gebot irdischer oder überirdischer Mächte brauchen. Vielmehr fand der Philosoph das Sittengesetz dadurch charakterisiert, daß es als kategorischer Imperativ unabhängig von allem, schon bestehenden Wollen des Menschen seine Anforderungen an die Gesinnung stellt. Diese Anforderung war damit eine an alle gleichmäßig ergehende Maxime, und gerade diese Fähigkeit, für alle unter allen Umständen gleichmäßig zu gelten, wurde das Kriterium des kategorischen Imperativs. Gegenüber der ästhetischen Moral der Exklusivität war dies Prinzip des kategorischen Imperativs durch und durch demokratisch. Es verlangte, daß jede Handlung lediglich durch die Besinnung auf eine Maxime motiviert sein sollte, die sich zum Motive für alle übrigen eignen könnte. Es schied aus dem Bereiche wahrer Moralität alle Regungen des persönlichen Gefühls, alle Neigungen der individuellen Natur, alles Unmittelbare der Willensbetätigung aus und geriet in die Gefahr, mit jener strengen Maximenhaftigkeit, die zu Kants persönlichem Charakter gehörte, das sittliche Wollen und Handeln in einen prinzipiellen und durchgängigen Gegensatz zu dem natürlichen Triebleben zu bringen. Als Träger der Autonomie, als der Wille, der sich selbst das Vernunftgesetz der Pflicht gibt, erschien die Person vermöge dieser ihrer Freiheit in einer ihr eigenes empirisches Dasein überragenden Würde; denn solche Freiheit, worin die Unabhängigkeit von den empirischen Motiven mit der Bestimmtheit durch das selbstgegebene Gesetz zusammenfiel, konnte niemals in dem empirischen Charakter des Menschen, der ein Gegenstand der rationalen Erkenntnis ist, gefunden werden, sondern nur in dem intelligiblen Charakter, mit dem die

Die ethischen Postulate. Persönlichkeit der übersinnlichen Welt angehört. Der Glaube an diese Freiheit des intelligiblen Charakters ist ein der rationalen Erkenntnis unzugängliches Postulat der rationalen Sittlichkeit: und der Glaube an eine sittliche Weltordnung, an die Gottheit als ihren Gesetzgeber und an das unsterbliche Leben der Persönlichkeit treten als die Bedingungen hinzu, unter denen allein das höchste Gut, die Identität von Tugend und Glückseligkeit, verwirklicht werden kann. Alle einzelnen Bestimmungen, die Kant in seiner Sittenlehre aus diesem Ideal der Würde und Freiheit der Persönlichkeit abgeleitet hat, breiten das Prinzip der Maximenhaftigkeit in alle Verhältnisse des menschlichen Lebens aus: aber sie erkaufen den Sieg des gesetzmäßigen Handelns durch die Unterdrückung jedes Rechtes der Individualität. Das formale Prinzip der Ethik kommt ebendarin zur Geltung, daß der so stark betonte Wert der Persönlichkeit nur in seiner für alle gleichmäßig zutreffenden Maximenhaftigkeit, niemals in seiner individuellen Ausprägung anerkannt wird. gebung der Vernunft handelte, konnte die im tiefsten Grunde rationalistische 
Denkweise Kants sich mit unbeschränkter Folgerichtigkeit entfalten, und seine Durchführung der Metaphysik der Sitten zeigt in der Tugendlehre wie in der Rechtslehre diese positiv rationalistische Seite seines Wesens in der vollkommensten Ausbildung. Der Begriff der Freiheit, der dabei das alles beherrschende Zentrum bildet, fällt überall mit dem der Herrschaft eines selbstgegebenen Gesetzes zusammen: sein Geltungsbereich ist in der Moral die Gesinnung, im Recht die Handlung. Denn die Übereinstimmung mit den Forderungen des Sittengesetzes begründet für die Handlung nur ihre Legalität, welche ihre Motivation durch alle Arten der Triebe offen läßt; erst die Übereinstimmung der Gesinnung mit dem Sittengesetz, die Unterwerfung des individuellen Willens unter die für alle gültigen Maximen begründet den Charakter der Moralität. Trotz dieser Unterscheidungen bildet doch für Kant das Recht eine Verwirklichung des Sittengesetzes in dem äußeren Zusammenleben der Menschen: denn das System der Regeln, nach denen die Freiheit des einzelnen mit der aller übrigen unter einem allgemeinen Vernunftgesetz vereinbar ist, bedeutet in letzter Instanz auch nur die Begründung eines Reiches der Freiheit auf dem Boden des ursprünglich von den Naturtrieben beherrschten Menschenlebens.

Freilich führt die durchgängige Rationalität der Normgesetzgebung auf dem Gebiete des Willenslebens den Philosophen zu der scharfen Stellung seines ethischen Dualismus. Das gegebene Triebleben und der natürliche Zustand des Menschen ist im ethischen Sinne durchaus irrational. Die Befolgung der Norm erfolgt in der Gesinnung unter durchgängigem und fast für notwendig im Sinne der Verdienstlichkeit angesehenem Widerspruche zur natürlichen Neigung. Das geschichtliche Leben des Menschengeschlechts, als dessen Ziel Kant die Verwirklichung des vollkommenen Rechtszustandes in den Völkern und zwischen den Völkern betrachtet, beginnt durch den Bruch mit dem Naturzustande der ethischen Indifferenz. Sein Anfang ist der Sündenfall, die bewußte Empörung des individuellen Triebes gegen das bis dahin naiv geltende und nun zum Bewußtsein kommende Gesetz. Der Fortschritt der Geschichte ist der Sieg des Rationalen über das Irrationale: aber sein Ziel, die Herbeiführung des vollkommen rationalen Zustandes, liegt deshalb im Unendlichen.

So war das Ergebnis der beiden Kritiken die Kluft zwischen Freiheit Ästhetik. und Notwendigkeit, zwischen der Welt der Zwecke und der Welt der Naturgesetze. In beiden Fällen reichte die Rationalität so weit wie das Bewußtsein der Form, der allgemeinen Gesetze in der Theorie und der allgemeingültigen Normen im Wollen und Handeln. Für die Erkenntnis blieb der empfundene Stoff, für das Handeln das empirische Wollen als die Grenze undurchdringlicher Irrationalität bestehen. Darum wurde für Kant das ästhetische Urteil, das sich immer nur auf einzelnes bezieht und niemals auf allgemeine Regeln sich gründet und das dabei doch auf allgemeine Geltung Anspruch erhebt, zu einem so überaus wichtigen Problem. Seine Kritik der Urteilskraft untersuchte von dieser Frage aus die logische Struktur des ästhe- 
tischen Verhaltens. Er stellte fest, daß im Schönen wie im Erhabenen ein persönlich uninteressiertes Wohlgefallen an der reinen Form der Vorstellung haftet, und er meinte daher, alle die irrationalen Bestandteile des Gefühls, welche auf Reiz und Rührung hinauslaufen, aus der reinen Formwirkung des im eigentlichen Sinne Asthetischen ausschließen zu sollen. Aber schon bei der Durchführung dieses Prinzips zeigte sich, daß er damit zu dem Begriffe einer reinen Schönheit gelangte, die sich auf das Bedeuiungslose beschränkte, und daß er für alle höheren und wertvolleren Formen des ästhetischen Genusses die anhängende Schönheit, d. h. die durch einen Zweckbegriff des Bedeutungsvollen vermittelte heranziehen mußte. Und als er gar zu der Auffassung vom Wesen des Genies als der schöpferischen Kraft der ästhetischen Produktion fortschritt, da formulierte der Rationalist mit erstaunlicher Sicherheit das ihm völlig fremde und undurchdringliche Wesen des Genies in dem Begriffe einer Intelligenz, die wirke wie die Natur. Indem er dies Unbegreifliche als tatsächlich anerkannte und in seinem vollen Werte würdigte, entdeckte er in den Tiefen der Vernunft selbst eine der Klarheit und Deutlichkeit des Begriffs sich entziehende Ursprünglichkeit schöpferischer Produktion. Er vollzog damit in seiner begrifflichen Arbeit die Selbstbegrenzung des aufklärerischen Denkens und rechtfertigte die große geistige Gesamtbewegung, mit der in Sturm und Drang die irrationale Unterströmung der Aufklärung zum Durchbruch gekommen war. Er vervollständigte in der Kritik der Urteilskraft diese tiefgreifende Einsicht durch die Analogie, die er zwischen der subjektiven Zweckmäßigkeit des ästhetischen Verhaltens und der objektiven Zweckmäßigkeit der Erscheinungen des Lebens in der Natur auffand. In beiden Fällen galt ihm das Prinzip der absichtslosen Zweckmäßigkeit, deren unmittelbare Erfassung weder durch eine rationale Erkenntnis noch durch eine rationale Normsetzung begreiflich und begründet ist, als die Berechtigung zu der Betrachtung, "als ob " das irrational Gegebene sich in letzter Instanz den Systemen der rationalen Gesetzmäßigkeit zweckvoll unterordne und zu ihrer Verwirklichung füge.

Dies war denn auch der Gesichtspunkt, den Kant bei dem Abschluß seines philosophischen Systems in der Religionsphilosophie einnahm. Und doch kehrte sich dabei das Verhältnis in gewissem Sinne um. Denn zunächst freilich versuchte Kant zu zeigen, wieviel von dem religiösen Leben sich rational begründen und rechtfertigen lasse; aber eben dabei entwickelte sich mit voller Wucht die innere Lebensgewalt des Irrationalen. Von einer Begründung religiöser Vorstellungen durch wissenschaftliche Erkenntnis konnte nach den Ergebnissen der Kritik der reinen Vernunft selbstverständlich keine Rede sein. Aber auch das moralische Bewußtsein mit allen den Postulaten des metaphysischen Glaubens, den die Kritik der praktischen Vernunft entwickelt hatte, reichte doch zum Eindringen in die Welt des Übersinnlichen nur in verhältnismäßig beschränktem Maße. Kant blieb sich durchaus bewußt, daß in dem religiösen Leben ein transzendentes Verhalten vorliegt, das über alle Rationalität des theoretischen und auch des praktischen Vernunft- 
lebens hinausgeht. Seine Philosophie kannte als rationale Doktrin nur die Ethikotheologie, d. h. die Moralmetaphysik der praktischen Vernunft. Das Wesen der religiösen Überzeugung bestand ihm deshalb darin, das Moralgebot, das in Wahrheit auf der Autonomie der praktischen Vernunft beruht, so anzusehen, "als ob" es aus dem Verlangen des göttlichen Willens entspringe und dadurch sanktioniert werde. Auf der einen Seite erschien damit die Religion als ein Vehikel der sittlichen Motivation, das bei der Schwäche der menschlichen Natur begreiflich, ja unerläßlich war: auf der anderen Seite aber lag doch in dem Postulat der Gottheit als des Trägers einer sittlichen Ordnung der übersinnlichen Welt eine metaphysische Verankerung des Sittengesetzes, die Kant nicht entbehren mochte. Sie war zwar kein Gegenstand theoretischer Einsicht, aber desto mehr ein solcher des vernünftigen Glaubens, und sie bot schlieblich die einzige Handhabe, um für das sittliche Leben des Menschen die in dem Postulat der Freiheit verlangte übersinnlicl. Realität $z \mathfrak{u}$ gewährleisten. Darum bildete die Unterscheidung des intelligiblen und des empirischen Charakters des Menschen die wesentliche begriffliche Voraussetzung, an die Kant seine ethikotheologische Deutung der Mysterien der christlichen Religion anknüpfte, wie er sie wesentlich vom Standpunlte des Protestantismus mit pietistischem Einschlag verstand. Die Vorstellungen vom radikal Bösen, von der Wiedergeburt, von der vorbildlichen Gottessohnschaft, von der Erlösung durch die stellvertretende Liebe usw. wurden in ihrer theoretischen Unbegreiflichkeit und Unmöglichkeit erkannt, nach ihrer ethischen Rationalität so weit, als es irgend angehen wollte, gedeutet und blieben doch schließlich als eine Art der Beziehung des Menschen zur übersinnlichen Welt bestehen, die in den begrifflichen Zusammenhängen der kritischen Philosophie einer vollkommenen rationalen Analyse sich entzog. Nur so viel konnte gewonnen werden, daß die Notwendigkeit verstanden wurde, mit der das Menschenleben und damit die gesamte Natur so betrachtet werden müssen, ,als ob" sich im Rahmen ihrer Gesetzmäßigkeit eine höhere übersinnliche Wirklichkeit, das Reich Gottes, verwirkliche. Der letzte Sinn der vom theoretischen Wissen zu erkennenden Erscheinung war die Verwirklichung einer übersinnlichen Welt der Werte, die von der sittlichen Vernunft gefordert wurde und von der auch die religiöse Vorstellung in allgemeingültiger Weise nur so viel gewährleisten konnte, als in dem ethischen Postulat und in der darauf begründeten Beziehung zwischen der Erscheinung und dem Ding-an-sich enthalten war.

So entdeckt Kant mit der kritischen Methode auf allen Gebieten des Das Bewubt geistigen Lebens in den Funktionen des Individuums die allgemeingültigen Bestandteile seines rationalen Wesens, auf denen sich die großen Gesamtgebilde der Kultur aufbauen: Wissenschaft, Sittlichkeit, Recht, Kunst und Religion. In allen Fällen ergibt sich dabei eine schöpferische Kraft des Bewußtseins, die, weit entfernt, das Gegebene nur in sich zu wiederholen, vielmehr ihrerseits eine neue Welt nach eigener Gesetzmäßigkeit erzeugt. So ist die Erkenntnis der Wissenschaft Erscheinung in dem Sinne, daß der er- 
kennende Geist in der Ordnung der Empfindungen dem Stoffe seine eigene Gesetzmäßigkeit vorschreibt. So ist Sittlichkeit die Gestaltung des Lebens durch das von der Vernunft selbst gegebene Gesetz der Freiheit. So ist Recht die selbstgewollte Ordnung für die gegenseitige Einschränkung der Willkür unter dem allgemeingültigen Gesetz. So ist Kunst die aus der Tiefe des Genies geschaffene Gestaltung eines eigenen Gegenstandes der Anschauung und der darin enthaltenen Harmonie von Sinnlichkeit und Verstand. So ist Religion das Hereinragen der übersinnlichen Persönlichkeit des Menschen in die Bewegung seines natürlichen Willenslebens. Bei allen diesen Kulturtätigkeiten wurzelt ihre allgemeingültige Notwendigkeit in der schöpferischen Spontaneität des rationalen Bewußtseins, des „Bewußtseins überhaupt“. Aber sie alle haben ihre Grenze an dem Irrationalen, das sie einerseits voraussetzen und an das sie andererseits heranreichen, ohne darin eindringen $z u$ können. Die rationale Erkenntnis hat ihr Material für die Anwendung ihrer begrifflichen Formen in den Empfindungen, die ihr gegeben sind: und sie verlangt über sich selbst hinaus die Idee des Unbedingten, die sie als Erkenntnis nicht bezwingen kann. Sittliches und rechtliches Leben steht den natürlichen Trieben und der Willkür der Individuen mit der bezwingenden Macht seiner rationalen Maximen nicht immer siegreich gegenüber: und seine eigene Berechtigung beruht in einem übersinnlichen Leben des Menschen, das nur auf Grund des Sittengesetzes geglaubt, aber niemals begriffen werden kann. Ästhetisches Genießen und Produzieren sondert sich in seiner reinen Idealität aus den empirischen Gefühlen der Lust und Unlust heraus: seine Geltung beruht schließlich auf dem übersinnlichen Substrat der Menschheit und auf dem Geheimnis der Genialität, das keine rationale Erkenntnis durchdringen kann. Die Religion endlich in ihrer empirischen, positiven Gestalt ist mit zahlreichen Versuchen einer unzulänglichen Erkenntnis und mit allen Triebfedern des sinnlichen Willenslebens durchsetzt: in ihrem reinen Wesen reicht sie an die undurchdringlichen Geheimnisse des Übersinnlichen heran, ohne sie je völlig zu erschließen.

Zentrale Stellung von Kants Kulturphilosophie.

Den Ausgangspunkt der Kantischen Kritik bildet somit, wie man namentlich wohl seiner Ethik vorgeworfen hat, das Bewußtsein des Individuums: aber es wird überall durchforscht nach den notwendigen und allgemeingültigen Bestimmungen seiner Vernunfttätigkeit, und daraus ergibt sich in dem Verständnis ihrer sachlichen Begründung das reife Selbstbewußtsein der Kultur, deren nach der Verschiedenheit der seelischen Funktionen getrennte Systeme sich alle als die Erzeugnisse einer das Leben des Individuums und die historischen Betätigungen der Gattung überragenden, in sich selbst geltenden Vernunft erweisen. Auf diesem Verhältnis beruht die zentrale Stellung Kants in der Geschichte der neueren Philosophie. In seinem Nachdenken, das ebenso breit und umspannend wie tief und eindringend war, kommen alle Motive aus der beispiellos reichen Geistesbewegung des 18. Jahrhunderts zusammen, um durch ihre systematische Vereinigung eine vollkommen neue Gestalt zu gewinnen: und ebendeshalb war die so 
streng und methodisch in sich geschlossene Lehre der kritischen Philosophie befähigt, die ganze Mannigfaltigkeit des aus vielen Quellen genährten Geisteslebens ihrer Zeit in sich aufzunehmen und fruchtbar zu gestalten. Diesen Prozeß stellt die Entwickelung der metaphysischen Systeme dar, welche sich mit wechselnder Anlehnung an die Lebensinteressen der Zeit aus der Kantischen Philosophie herausgebildet haben. Wir bezeichnen ihr gemeinsames Wesen mit dem Namen des Idealismus: sie sind alle getragen von der Grundüberzeugung eines geistigen Lebensinhaltes der Welt, und wenn sie die Schranken, die Kant durch die Lehre vom Ding-an-sich gesetzt zu haben glaubte, zum Teil wieder durchbrachen und vom Selbstbewußtsein der Vernunft aus ein restloses Verstänđnis der absoluten Wirklichkeit gewinnen zu können meinten, so geschah das immer in der Uberzeugung, daß alle Realität zuletzt Vernunft sei. Aber ihr gemeinsames Problem war deshalb die Frage, in welchem Sinne diese Vernunft das Irrationale selber in sich berge und entfalte. Und an der Antwort auf diese Frage schieden sich die Wege derer, die die Philosophie im Sinne eines Systems der Vernunft auszubauen unternahmen.

II. Fichte. Die erste Forderung, welche von Anhängern wie von Geg- Das System der: nern Kants gleichmäßig gegen seine Darstellung der kritischen Philosophie geltend gemacht wurde, ging auf das Verständnis der inneren Einheit und Zusammengehörigkeit aller der Vernunftfunktionen, die er in dem Bestreben, ihr Recht und ihre Grenze auszumessen, sorgfältig gegeneinander abgegrenzt und in ihren Funktionen auseinandergelegt hatte. Es galt, das System durch den .Aufweis seiner inneren Einheit zu vollenden, und dies Bedürfnis trat an die Philosophie als eine um so gebieterischere Forderung heran, je mehr es in der überreichen Bewegung des Geisteslebens der Zeit begründet erschien. Mitten in der Not politischer Schwäche und Zerrissenheit schuf sich die deutsche Nation damals ein Weltreich des Gedankens·in Dichtung und Philosophie, und die Träger dieser neuen „Bildung“ waren überzeugt, daß nur aus ihr schließlich jene vernünftige Gestaltung der menschlichen Gesellschaft werde hervorgehen können, welche die Französische Revolution vergebens mit der Leidenschaft und mit der Gewalt aufzurichten versucht hatte. Für die Bewältigung des unermeBlichen Bildungssstoffes, den man damals aus der Literatur aller Zeiten und aller Völker in das eigene Leben aufzusaugen bemüht war, bedurfte man eines einheitlichen philosophischen Prinzips: und so verlangten vor allem die Romantiker von der Philosophie diese höchste und bedeutsamste Kulturleistung. Wenn man aus diesem Grunde und mit Bezug darauf, daß diese Aufgabe mit vollem Bewußtsein von den Romantikern formuliert worden ist, die nachkantische Philosophie als die romantische bezeichnet, so ist das gerechtfertigt, während alle anderen Bedeutungen des Wortes auf diese Philosophie nicht zutreffen. Denn das ist in der Tat der gemeinsame Charakter dieser Systeme: sie wollen die begriffliche Struktur des gesamten Kulturlebens in der systematischen Einheit der Vernunftfunktionen entdecken. 
Fichtes.ethischer Idealismus.

Der erste in dieser Reihe der romantischen Philosophen ist Johann Gottlieb Fichte. Er hat das System der Vernunft um das Prinzip konzentriert, das aus der Lehre Kants am eindrucksvollsten auf seine Zeitgenossen wirkte, auf das Pflichtbewußtsein des kategorischen Imperativs. Gegen alle Weichlichkeit der ästhetischen Aufklärungsmoral, gegen alles Paktieren mit gegebenen Zuständen hatte Kant die ganze Herbheit eines unbedingten Sollens, die ganze Rückhaltlosigkeit und Rücksichtslosigkeit eines Vernunftgebotes geltend gemacht, das in seiner Verwirklichung neues Leben schaffen sollte. In dieser Selbstbestimmung der Vernunft sah wie Schiller so auch Fichte das Wesen und den Wert der neuen Philosophie. Darum wurde für Fichte das ganze Universum das versinnlichte Material der Pflicht; alle Formen des Vernunftlebens entstanden ihm aus dem ursprünglichen Tun des Willens, der, wo er keinen Gegenstand seiner Betätigung vorfindet, sich ihn aus seiner Freiheit heraus zum Widerstande setzt; alle Aufgaben des einzelnen Ich bestanden ihm darin, daß es sich von seiner Naturbestimmtheit her zum allgemeinen Ich, zur reinen Vernunft erhebe und gestalte. So führte Fichte in seiner „Wissenschaftslehre" den Primat der praktischen Vernunft über die theoretische durch. In dem ewig unerfüllten Sollen fand er den Grund alles Seins, in den niemals völlig gelösten Aufgaben den Sinn und das Recht alles Gegebenen. Mit diesem hohen Idealismus durchleuchtete er das Leben des Individuums und das der Völker. Wie der Lebenswert des einzelnen darin besteht, daß er sich mit seinen höchsten Tätigkeiten zum Allgemeinen steigert, so ist auch das Recht und der Wert der Zeitalter und der Völker in der Geschichte darin beschlossen, was sie für die gesamte Menschheit bedeuten. Selbst die glühende Predigt des deutschen Nationalgedankens, die Fichte in den Reden an die deutsche Nation aus seiner in der Schule der Not geläuterten Vaterlandsliebe schuf, begründete den Wert der aus der neuen Bildung erwachsenden deutschen Nationalität durch ihre Steigerung zu einem urbildlichen und vorbildlichen, allgemein menschlichen Kulturwesen. Auf diese Weise rang sich in der philosophischen Theorie aus den kosmopolitischen Überzeugungen selbst, die Fichte mit allen großen Denkern des 1 8. Jahrhunderts teilte, die nationalistisch zugespitzte Sonderung heraus, welche das historische Leben des 19. Jahrhunderts zu charakterisieren berufen war.

Teleologische Konstruktion.

Anfänglich meinte Fichte mit dem Entwurf der Wissenschaftslehre aus dem sittlichen Willen, der ihm nicht nur als das Wesen des Ich, sondern auch als der absolute Wert und damit als der Ursprung aller Wirklichkeit galt, den gesamten Inhalt der Welt metaphysisch ableiten zu können. Er hielt dazu die Methode der teleologischen Konstruktion für tauglich, welche das Urbild der späteren Dialektik gewesen ist. Aus den Aufgaben des Bewußtseins sollten alle seine Handlungen als die Mittel zu ihrer Erfüllung in dem Sinne begriffen werden, daß jedesmal aus dem noch ungelösten Rest der Aufgabe die neue Aufgabe und damit die neue Art des Tuns entspringen sollte. Aber er stieß dabei in den Empfindungen, durch die für das BewuBtsein die erscheinende Wirklichkeit gesetzt wird, auf die grundlos freien Hand- 
lungen, deren Zweck zwar im allgemeinen verständlich, aber doch zur Erklärung ihres besonderen empirischen Inhaltes nicht brauchbar war. Hier hatte er seinerseits die Grenze der rationalen Deduktion erreicht, und von hier aus wurde ihm deshalb die Unmittelbarkeit des Lebens und das ursprüngliche Gegebensein der individuellen Realität zum Mittelpunkt seiner Gedanken. Fichte näherte sich damit sichtlich der romantischen Stimmung. Er ging freilich nicht bis zu dem Irrationalismus fort, mit dem die sogenannten Gefühlsphilosophen, Hamann und namentlich Friedrich Heinrich Jacobi, die Jacobi. Kantische Lehre bekämpften. Der letztere insbesondere meinte, Kant habe gerade selbst durch seine Kritik den Beweis erbracht, daß alles theoretische Erkennen auf das endlose Reich des Bedingten beschränkt und vom Unbedingten prinzipiell ausgeschlossen sei. Er nannte dies in seiner scharfsinnigen Kritik den notwendigen "Spinozismus" der Wissenschaft und behauptete, daß dieser mit der ursprünglichen Wahrheit des sittlichen und des religiösen Gefühls völlig unvereinbar sei. Aber auch in dem Verständnis des sittlichen Lebens stand Jacobi im ausdrücklichen Gegensatz gegen Kant. Er bestritt mit aller Schärfe die Maximenhaftigkeit von dessen Moral und machte dagegen das Recht der individuellen Lebenbestimmung und Lebensentfaltung geltend. Dieses Moment enthielt die Fortführung dessen, was zuerst Shaftesbury verkündet, was die deutsche Genialitätsbewegung in Sturm und Drang verlangt hatte, und was nun mit allseitiger Lebendigkeit in dem romantischen Bewußtsein sich durchsetzte. Für die Aufnahme dieses Momentes in den Gedankenzusammenhang der idealistischen Philosophie haben Fichte und Schleiermacher die Formel von der Bestimmung des Menschen gefunden, wonach sich das Individuum aus dem ganzen Reichtum des allgemeinen Kulturlebens je nach der Gegebenheit seiner Anlagen und Verhältnisse zur freien Persönlichkeit herausarbeiten soll.

Aber auch in der späteren Form seiner Lehre betrachtete Fichte noch Fichtes spätere immer mit dem hohen ethischen Idealismus, der seine Persönlichkeit wie seine Lehre charakterisierte, das gesamte Leben der gegebenen Wirklichkeit als die rastlose Arbeit, durch die sie sich selbst zu einer sittlichen Weltordnung gestalten soll. Allein er fand nun diese Bestimmung in einem göttlichen Urbilde begründet, dessen ewiges Sein in der freien Selbstgestaltung des empirisch Wirklichen abgebildet werden soll und deshalb in jedem einzelnen eine seiner Individualität entsprechende und seiner freien Selbstbestimmung entspringende Verwirklichung finden muß. Er denkt das Ziel des geschichtlichen Lebens als ein Reich der Vernunft und der Freiheit zugleich, worin jeder einzelne aus seinem eigensten Wesen heraus den allgemeinen Inhalt der geistigen Wirklichkeit in besonderer Weise zur Darstellung bringt. Er betrachtet deshalb den ganzen historischen Prozeß als einen Lebensverlauf, der von der dumpfen Herrschaft eines natürlich gegebenen Gesamtbewußtseins durch die Empörung der Individuen, durch ihre Irrtümer und Sünden, durch ihre Zersplitterung in die Anarchie der Meinungen und der Leidenschaften hindurch schließlich vermöge der Selbstbesinnung und inneren Klä- 
rung zu einer selbstgewollten Unterordnung unter das Vernunftgesetz und zu seiner Verwirklichung im gemeinsamen Leben führe. Er meinte, die Auflösung der inneren Gemeinschaft, die im Naturzustande der Menschheit durch die Gebundenheit der Sitte gegeben war, habe im Zeitalter der Aufklärung mit der Proklamation der Selbstherrlichkeit der Individuen ihren Höhepunkt erreicht, und er fand in der Ausbreitung der neuen Dichtung und der neuen Philosophie den Beginn der Vernünftigkeit. Er war und blieb recht eigentlich derFührer der geistigen Bewegung, welche mit vollem Bewußtsein, wie Schiller von dem „ästhetischen Staat", von der Wissenschaft und der Dichtung die Herbeiführung eines höheren und besseren Zustandes der menschlichen Gesellschaft erwartete.

Romantik.

III. Die Romantiker. Mit voller Energie entwickelte sich dies Prinzip in dem Kreise von Dichtern und Schriftstellern, die man im engeren Sinne als die Romantiker bezeichnet: aber es nahm bei ihnen, je nach dem Vorwiegen persönlicher Beziehungen, sehr bald verschiedene Färbungen an. Wenn Fichte stets den Schwerpunkt der geistig-sozialen Umbildung in der Herrschaft des philosophischen Geistes gesehen hatte, so glaubten die Romantiker zunächst in der Poesie das große Mittel zur Umgestaltung der Welt zu finden. Für sie bildete das ästhetische Leben die höchste Blüte der Vernunft. Hatte schon Kant in der Kritik der Urteilskraft die Ausgleichung zwischen der theoretischen und der praktischen Vernunft, die Aussöhnung von Freiheit und

schiller. Notwendigkeit gesucht, so war Schiller in seiner Ausführung dieser Theorie dazu fortgeschritten, in dem ästhetischen Zustande die höchste Entfaltung der sinnlich-übersinnlichen Natur des Menschen und die vollkommenste Auswirkung seines Vernunftlebens zu finden. Mit der Ausbreitung und Umbiegung dieser Gedanken wie der Fichteschen Lehre von der schöpferischen Bedeu-

Schlegel. tung des Ich entwarf die Romantik in Friedrich Schlegels Lehre von der Ironie das Ideal von der souveränen Macht der Genialität in Dichtung und Leben. Freilich wurde in dieser Zuspitzung anstatt der Freiheit als der allgemeingültigen Selbstbeschränkung des die Welt der Gegenstände erzeugenden Vernunftbewußtseins die souveräne Willkür der einzelnen Persönlichkeit untergeschoben, die in ihrer schrankenlosen Selbstbetätigung mit dem Stoffe nur spielen, ihn durch die Form vernichten und in endlosem Selbstgenuß sich daran entfalten sollte; freilich führte derselbe Gedanke, zum Teil mit Anlehnung an die Art, wie Jacobi das Recht der Individualität gegen die Kantische Moral ins Feld geführt hatte, auch zu den bedenklichen Folgerungen, wonach die Regeln der Sittlichkeit nur für den Philister mit seiner zweckbestimmten Arbeit, aber nicht mehr für die triumphierende Genialität der künstlerischen Persönlichkeit gelten sollten, die nur sich selber auszuleben den Beruf habe: aber das Wertvollere in der romantischen Bewegung war das Bedürfnis nach einem intimen Zusammenhange von Dichtung und Leben, die auf Ursprünglichkeit gerichtete Überzeugung, welche, indem sie Welt und Leben zu poetisieren, in den Tiefen der Wirklichkeit den Pulsschlag des Ge- 
mütes wiederzufinden suchte, in ihrer Weise doch zuletzt auch daran arbeitete, das geistige Wesen aller Realität zur Anerkennung zu bringen.

Vor allem betätigte sich darin der tiefe Ernst einer geistigen Selbsterziehung der Individuen, denen die ganze reiche Welt des historischen Lebens Historische Bildung. als der Nährboden galt, aus dem sie sich selbst zu ihrer vollbewußten Eigenart gestalteten. So wurde in der Tat ihr Bildungsleben zur Verwirklichung des transzendentalen Bewußtseins, eine Umschmelzung des geschichtlichen Stoffs $z u$ einem neuen Bildungssystem. Darin fand der von Herder und Goethe verlangte Gedanke der Weltliteratur seine philosophische Rechtfertigung; aus ihm entsprangen die wissenschaftlichen Anfänge der Literaturgeschichte, der Rechtsgeschichte, der Sprachgeschichte; in ihm wurzelte vermöge der poetischen Idealisierung des Griechentums der Geist des Neuhumanismus. Ein reichés und reifes Persönlichkeitsleben arbeitete sich mit vollem Bewußtsein aus dem geistigen Gesamtleben der Menschheit heraus, und an die Stelle einer trockenen Verstandesherrschaft, an die Stelle einer in kleine Lebensverhältnisse eingesenkten Sentimentalität trat eine universelle Gesamtkultur.

Allein die Energie des neuen Lebens bestand zuletzt doch in der Über-Schleiermacher. zeugung, daß sich dies Walten des Geistes als der Kern aller Wirklichkeit wußte. Die Poetisierung der Natur, die in der Dichtung von Novalis eine ebenso große Rolle spielte wie in seiner Naturphilosophie, sollte nur die Vorstufe für die Wendung des romantischen Denkens sein, welche die Totalität der Bildung, die volle Vergeistigung von Welt und Leben in der Religion suchte. Hierin hat Schleiermacher der Romantik die Wege gewiesen. Sein Appell an die Gebildeten unter den Verächtern der Religion wies sie darauf hin, daß die lebendige Einheit alles geistigen Lebens, die sie suchten, nur auf der Beziehung des Gemüts zu dem universellen Lebensgrunde aller Wirklichkeit, auf dem frommen Gefühl erwachsen könne. Seine Wissenschaftslehre zeigte die endlose Konvergenz, womit der sinnliche und der geistige Faktor in allem Wissen nach Stoff und Methode aufeinander zustreben, ohne sich jemals völlig zu decken. Seine Ethik lehrte die rastlose Arbeit, mit der die Vernunft im allgemeinen wie im individuellen Leben und in der Verknüpfung beider sich selbst aus dem natürlichen Leben herausfindet und sich darin einbildet. Aber alles dies setzte für Schleiermacher den ursprünglichen Zusammenhang des Gemüts mit dem Universum voraus, der in keinem Erkennen und Wollen, sondern nur in dem Gefühl der schlechthinigen Abhängigkeit, in dem Durchdrungensein des ganzen Lebens von dem Bewußtsein der göttlichen Bestimmung zutage tritt.

Merkwürdig genug ist das Geschick dieser notwendigen Wendung in der Romantik gewesen. Mit voller Gewalt brach damit die Sehnsucht durch, die Religiöse Totalität und Einheit des neuen Kulturlebens in der Religion zu suchen, von der Zersplitterung der Vernunfttätigkeiten $z u$ ihrer innersten Gemeinschaft den Weg zu finden. Aber die mystischen Formen, in denen sich diese Bestrebungen auch bei Schleiermacher einführten, die ganz unmittelbare Beziehung, in die dabei die voll entfaltete Individualität zu dem all-einen Wesen 
treten sollte, schien sehr bald ihre Ergänzung durch eine einheitliche Lebensgestaltung und zuletzt durch die Herrschaft einer einheitlichen Lehre zu fordern. So entwarf schon Novalis in dem entscheidenden Aufsatz „Europa oder die Christenheit" das Programm, das neue Bildungsideal den Institutionen des katholischen Lebenssystems des Mittelalters einzuimpfen: und damit war für die deutsche Romantik der AnlaB gegeben, in die Bahnen der französischen einzulenken und bei der klerikal-legitimistischen Restauration zu enden.

Neospinozismus.

IV. Schelling. Die philosophische Systematisierung des romantischen Lebens haben Schelling und Hegel vollzogen, jener, indem er der Poetisierung der Natur und dem religiösen Zuge des romantischen Denkens die begriffliche Form gab, dieser, indem er den historischen Grundzug der neuen geistigen Bewegung zu einergewaltigen, in sich geschlossenen Weltanschauung gestaltete. $\mathrm{Zu}$ den grundlegenden Bestimmungen der Kantischen Philosophie trat bei beiden der Einfluß der größten dogmatischen Lehre, des Spinozismus, hinzu, ein Moment, das schon bei Fichte, freilich mehr als eine Herausforderung des Gegensatzes, malgebend gewesen war. Jetzt prägte sich die Vergeistigung des Universums, die das Grundstreben des Idealismus ausmachte, in dem Bedürfnis aus, von den Bestimmungen des Vernunftsystems her eine neue Form für das Verhältnis der geistigen zur körperlichen Welt und für das Verhältnis der Gottheit zur Welt selbst zu gewinnen. Darin mehr als in einer Reihe àußerer terminologischer Formen liegt die Berechtigung zur Bezeichnung dieser Entwickelung als Neospinozismus. Denn in der Tat handelte es sich für Schelling wesentlich darum, dem Verhältnis der beiden Attribute, dem Verhältnis von Natur und Geist im Sinne der Wissenschaftslehre eine neue Form zu geben, und für Hegel darum, das Hervorgehen der Welt aus Gott als den Frozeß einer logischen, im Wesen des Geistes begründeten Notwendigkeit zu begreifen.

Natur. philosophie.

Schellings vielgestaltige philosophische Entwickelung begann mit der "Naturphilosophie“. Sie entsprang aus der Absicht, mit dem Gedanken der Fichteschen Wissenschaftslehre Ernst zu machen, wonach die Natur ein Produkt des Ich, ein zweckvolles System zur Erfüllung einer Aufgabe der Vernunft sein sollte. Zahlreiche Motive aus der gleichzeitigen Naturforschung, welche aus der Zersplitterung in Einzeluntersuchungen zum Verständnis des einheitlichen Zusammenhanges der Naturerscheinungen zurückstrebte, verbanden sich mit jenem aus der Philosophie stammenden Prinzip. Was Schelling und die Seinen suchten, war dasselbe, was Goethe und Herder bereits in den Spinozismus hineingedeutet hatten, die Einheit des Lebens der Natur: und für den aus der Schule des Idealismus kommenden Philosophen konnte diese Lebenseinheit nur ein zweckvoller Zusammenhang von Funktionen sein, der auf eine einheitliche Leistung im Dienste der Vernunft hinauslief. Dies Ziel des Naturlebens aber durfte kein anderes sein als das Bewußtsein. So galt die Natur bei Schelling als das System der unbewußten Vernunft, das in der Erzeugung des Bewußtseins seinen Zweck und seinen Sinn hat. Die Methode 
der teleologischen Konstruktion wurde auf eine Verarbeitung aller Schichten des physischen Geschehens oder der „Kategorien der Natur" ausgedehnt, durch die für jede einzelne Erscheinung der Natur ihr Sinn und ihre Bedeutung in der Leistung gefunden wurde, welche sie zu dem Gesamtertrag der Natur, dem Entspringen des Bewußtseins im animalen Wesen beiträgt. In diesem Aufzeigen der Bedeutung fand Schelling wie Fichte auch die Erklärung der Erscheinungen, und die vitalistisch-teleologische Betrachtung war deshalb für die Naturphilosophie wichtiger als die Untersuchung des kausalen Mechanismus, durch den sich jene zweckvollen Leistungen verwirklichen. In diesem Verhältnis liegt der Grund für den Widerspruch, den später die mechanistische Naturforschung gegen die konstruktive Gewaltsamkeit der Schellingschen Naturphilosophie erhoben hat: es besteht zwischen ihnen der Gegensatz $z$ wischen dem rein tatsächlichen Beschreiben und dem wertenden Begreifen. Für Schellings Zeitgenossen bestand der Reiz seiner Naturphilosophie gerade in dem großen Zuge der einheitlichen Konstruktion, die von der Materie und ihren mechanischen Zuständen durch die physikalischen Erscheinungen des Lichts, der Elektrizität und des Magnetismus hindurch eine einzige Linie zweckvoller Gestaltung bis zu den organischen Gebilden zeichnete, an denen schließlich in der vollkommenen „Zwerggestalt" des Menschen das Bewußtsein der Vernunft erwachen soll: und die poetische Vergeistigung der Natur, die der romantischen Dichtung vorschwebte, fand ihr willkommenes Gegenbild an dem philosophischen Versuche, das Gesamtleben der Natur als ein unbewuBtes Walten der sich selber suchenden Vernunft aufzuweisen.

War so die Natur als werdendes Ich gedacht, so mußte andererseits auch das Ich in der Mannigfaltigkeit seiner Funktionen auf sein unbewußtes Gegenspiel, die Natur, bezogen werden. Diese Umgestaltung der Wissenschaftslehre vollzog Schelling in dem System des transzendentalen Idealismus. Hier fand er in der Selbstbestimmung der praktischen Vernunft den Gegenpol zur natürlichen Wirklichkeit, ein System von Tätigkeiten, welches im moralischen, rechtlichen und geschichtlichen Leben das eigene Gesetz den gegebenen $\mathrm{Zu}$ ständen aufzuprägen berufen ist. Näher schon erschienen die Beziehungen der theoretischen Vernunft zur natürlichen Realität, durch die sie inhaltlich bestimmt bleibt, so sehr sie auch von ihren apriorischen Formen aus deren Ordnung selbständig $z u$ gestalten vermag. Das naturhafteste endlich im Leben der Intelligenz ist die künstlerische Funktion, in der die unbewußte Naturkraft der Genialität sich mitten in der absichtsvollen Bewußtheit des Erzeugens und Genießens siegreich zur Geltung bringt. So werden die Motive der Kantischen und der Schillerschen Ästhetik in das System der Wissenschaftslehre hineingehoben, um in dem unbewußt-bewußten Charakter der ästhetischen Vernunft die höchste und wertvollste Funktion innerhalb des ganzen Zusammenhanges der Vernunft zu erkennen.

In den beiden von reichem Leben strotzenden Entwickelungsreihen der Identitätssystem Naturphilosophie und des transzendentalen Idealismus waren die beiden großen Reiche der Natur und des Geistes stetig in so sinnvoller Weise aufeinander 
bezogen, $\mathrm{da} B$ von jener totalen Scheidung, welche die frühere Weltansicht $z$ wischen ihnen hatte feststellen wollen, nicht mehr die Rede sein konnte. Beide, Natur und Geist, erschienen gleichmäßig als Verwirklichung der Weltvernunft, verbunden durch stetig herüber- und hinüberlaufende $Z$ weckbeziehungen und unterschieden nur durch das $\mathrm{MaB}$ der beiden Funktionsarten einer und derselben Urvernunft. In der Natur - so lehrt Schelling in der „Darstellung meines Systems der Philosophie" —, in der realen Reihe überwiegt der unbewußte, im Geist, in der idealen Reihe der bewußte Faktor, und die einzelnen typischen Erscheinungen beider Reihen lassen sich als deren Potenzen so anordnen, das sie von den äußersten Polen der Entgegensetzung immer mehr sich der anderen Reihe nähern. So werden die Potenzen der Natur vom Raum und der Materie an immer geistähnlicher und geistiger, und im Organismus erreicht die reale Reihe ihr höchstes Gebilde, weil die zweckvolle Gesamtheit seiner Funktionen zum Träger des Bewußtseins wird. So werden andererseits die Potenzen des Geistes von der Freiheit des Sittengesetzes an immer naturhafter und kulminieren in dem Kunstwerk als dem natürlichsten und naturähnlichsten Erzeugnis intelligenter Tätigkeit. Aber in keiner der einzelnen Erscheinungen beider Reihen kommen natürliches und geistiges Vernunftwesen zur vollen Deckung oder Ausgleichung. Nur in der Totalität beider Reihen und ihrem zweckvoll verflochtenen Gesamtleben, nur in dem Universurm, das .zugleich der vollkommenste Organismus und das vollkommenste Kunstwerk ist, fallen Natur und Geist vollständig zusammen. Alle diese einzelnen, endlichen Erscheinungen in den beiden Sphären der Natur und des Geistes müssen in ihrem universellen Lebenszusammenhange als die Erscheinungen der einen unendlichen Vernunft angesehen werden, die deshalb selbst weder Natur noch Geist, weder real noch ideal, weder unbewubt noch bewußt genannt werden darf, die vielmehr als die totale Identität und Indifferenz beider Bestimmungen, als das unbestimmbar Unendliche der gesamten Entwickelung beider Keihen zugrunde liegt. Ohne Beschränkung durch die Kategorie der Substanz erhebt sich hier aus dem Schoße des Idealismus die spinozistische Idee der Gottheit: das Universum in der lebendigen und zweckvollen Wechselbeziehung der beiden Reiche von Natur und Geist wird zu einer vollständigen Entfaltung und Selbstgestaltung des göttlichen Urwesens, der Vernunft. Aber wenn Spinoza über die sachlichen Allgemeinbestimmungen der Attribute hinaus nur die leere logische Form der Substantialität übrig behalten hatte, so war es in der Gesamtrichtung des deutschen Idealismus, in der Tendenz der Vergeistigung des Universums begründet, daß jene absolute Vernunft, die als Indifferenz oder Identität den beiden Reichen des Realen und des Idealen zugrunde liegen sollte, hier doch schließlich nur als geistiges Urwesen gelten konnte. Dies entscheidende Motiv hat Hegel später als das Bestreben ausgesprochen, die Substanz zum Subjekt zu erheben, und șchon gleich nachdem er in Jena als Dozent an die Seite des jüngeren, ihm in der öffentlichen Laufbahn vorangeeilten Freundes erschienen war, wirkte er mit seinem an den großen Systemen der antiken Philosophie genährten Denken 
so stark auf Schelling ein, daß sich diesem die Potenzen der realen und der idealen Reihe in Ideen, d. h. in Selbstanschauungen Gottes verwandelten. Damit bekam die ideale Reihe wieder die Priorität und das Übergewicht über die reale, und die Phase des Versuchs ihrer vollkommen gleichwertigen Koordination war überwunden.

Die konsequente Ausführung dieses Prinzips war der Hegelschen Philosophie vorbehalten: Schelling selbst wurde, nachdem er jene Umformung der Potenzen in Ideen Gottes vollzogen hatte, teils durch die romantische Atmosphäre seiner Zeit und seiner Umgebung, teils durch den Einfluß von Männern wie Franz von Baader, die ihn auf die alte Mystik und insbesondere auf Jakob Boehme hinlenkten, von Schritt zu Schritt mehr in theosophische Bahnen gedrängt. Die metaphysische Selbständigkeit der Ideen oder der Welt neben Gott wurde ihm zu dem Zentralproblem, das er durch die religiösen Vorstellungen vom Abfall und Sündenfall zu lösen dachte. In Kants Lehre von der Freiheit des intelligiblen Charakters und in Fichtes geschichtsphilosophischer Konstruktion von dem wechselnden Verhältnis des Inđividualwillens zum Universalwillen fand er die begrifflichen Formen, um aus dem Sündenfall als der Empörung des Individuellen die Verselbständigung der Natur zur empirischen Welt abzuleiten und im geschichtlichen Prozeß der idealen Reihe die Rückkehr zu Gott als die sein Wesen und seinen Fortgang bestimmende Aufgabe zu setzen. Schließlich aber zog er die mystische Konsequenz, in diesem Hervorgang und Rückgang die Selbstentwickelung der Gottheit selber zu finden, und nachdem er sich überzeugt hatte, daB alle diese metaphysischen Verhältnisse durch ein rationales Denken nicht bezwungen werden könnten, sah er bei seinen letzten schon in die Mitte des 19. Jahrhunderts hineinragenden Spekulationen in dem bisherigen Philosophieren nur ein negatives System, dem er selbst die positive Philosophie der Mythologie und Offenbarung entgegenstellen wollte. Aus einer spekulativ konstruierten Religionsgeschichte sollten sich die dialektisch geordneten Momente des göttlichen Wesens durch die Reihenfolge der Formen ergeben, mit denen es sich in den geschichtlichen Gestaltungen des religiösen Lebens darstellt: die Entwickelung der Religionen sollte die Entwickelung Gottes selbst sein. Wenn damit ein historischer Prozeß des menschlichen Bewußtseins zu metaphysischer Bedeutung gesteigert wurde, so war das nur eine spezielle Anwendung der Methode, welche in viel universellerer Weise von Hegel be. gründet worden war.

V.Hege1. DerVollender der idealistischen Metaphysik ist Georg Friedrich Wilhelm seitdem er in die Entwickelung des Jenenser Philosophierens eingriff, mit dem höchsten aller Probleme hervorgetreten: die Welt als die notwendige Entwickelung des göttlichen Geistes zu begreifen. Und das Organon für die Lösung dieser Aufgabe war ihm die Entwickelung des menschlichen Geistes. Aber er faßte den Begriff der Entwickelung dabei wesentlich unter dem Fichte- 
schen Gesichtspunkte einer inneren Notwendigkeit logischer Struktur. Wenn der letzte Zusammenhang aller Dinge geistiger Natur ist, so werden wir ihn nur so weit verstehen, als wir ihn in unserer eigenen geistigen Bewegung erleben, aber andererseits auch nur so weit, als sich darin eine über die empirischen Bestimmungen des menschlichen Bewußtseins übergreifende universelle Notwendigkeit darstellt. In diesem Sinne spricht Hegel von der Selbstbewegung der Wahrheit im Bewußtsein als von der sachlichen Vernunftnotwendigkeit, die sich darin trotz aller Zufälligkeit des einzelnen Vorstellens geltend macht. Was Kant das Transżendentale genannt hat, ist für Hegel das Metaphysische: in dieser Deutung besteht für ihn der „Mut der Wahrheit", den er in seiner Heidelberger Antrittsrede gegen die Timidität der Erkenntnistheorie proklamierte. Aber eine solche übergreifende Wahrheit kann dem menschlichen Bewußtsein gerade nicht in denjenigen Bestimmungen zuerkannt werden, welche auf dem erfahrungsmäßigen Wesen des Menschen beruhen. Deshalb mußte der Versuch einer psychologischen und anthropologischen Begründung der Kantischen Vernunftkritik, wie ihn Fries und gar später Beneke unternahmen, im Empirischen stecken bleiben, ohne in der sachlichen Behandlung der transzendentalen Wahrheit über die Position des Kritizismus hinauszukommen. Demgegenüber begriff Hegel, daß die universelle Wahrheit, die ja, wenn sie erkannt werden soll, irgendwie im Erlebnis des menschlichen Bewußtseins sich entfalten muß, nur in den inhaltvollen Bewegungen des Gattungslebens gesucht werden kann, welche sich im historischen Prozeß über den Tätigkeiten des individuellen („,subjektiven“) Geistes als ein Reich höherer Ordnung aufbauen. Diese geschichtlich entfaltete Gattungsvernunft nannte er den objektiven Geist, und in ihm fand er zwar nicht die reine Wahrheit des absoluten Geistes, aber die Form des Lebens, worin sich dieser für die menschliche Erfahrung abspielt. In diesem Sinne darf man seine Philosophie als die historische Weltanschauung des Idealismus bezeichnen. Sie ist nach dieser Richtung durch die Überzeugung bestimmt, daß jedes Gebilde des historischen Lebens ein Moment göttlicher Wahrheit in sich trägt und eine berechtigte Stufe ihrer Entwickelung bedeutet, so daß sie zwar niemals die ganze Wahrheit, aber immer eines ihrer notwendigen Momente ausmacht. Diese Anerkennung des historischen Rechts ist aber ebendeshalb auch zugleich die Behauptung der historischen Relativität. Niemand ist weiter als Hegel davon entfernt gewesen, dem einzelnea historischen Gebilde als solchem in seiner zeitlichen Bestimmtheit den Wert der Vernunftgeltung zuzuerkennen. Die Wahrheit des Einzelnen besteht nur in der Bedeutung, die es im Zusammenhange des Ganzen besitzt. Daß „alles, was ist, vernünftig ist", gilt nur so weit, als es ein Glied in dem sinnvollen Gefüge des Ganzen ist: sobald das Einzelne herausgerissen und ihm eine absolute Bedeutung beigemessen werden soll, zerfällt es in die Nichtigkeit der historischen Zufälligkeit.

Phänomenologie. Wenn Hegel so völlig Ernst damit macht, über dem teleologischen Idealismus der Natur, worin er der Schellingschen Lehre beitrat und sie nur an 
einigen Stellen für die Zwecke seiner Gesamtauffassung umbildete, den teleologischen Idealismus der Geschichte zu errichten, so war dieses Bestreben ganz und gar aus dem Prinzip der Romantik geboren, welche die neue Bildung aus der Gesamtheit des Ideenstoffes der menschlichen Geistesgeschichte herausarbeiten wollte. In seinem genialen Erstlingswerke, der Phänomenologie des Geistes, ist jene von fruchtbaren Keimen erfüllte Atmosphäre des intellektuellen Lebens mit dem ganzen Reichtum umfassenden Wissens und tiefen Verständnisses in so vollkommener Allseitigkeit entfaltet wie in keinem anderen Buche der Zeit. Aber nicht minder großartig erweist sich dabei die Verarbeitung dieses immensen Stoffes, und in ihr besteht jene „Überwindung der Romantik", durch welche Hegel in der Zusammenfassung der Fäden des geistigen Lebens seiner Zeit das letzte Wort gesprochen zu haben schien. Denn der allumspannende Zusammenhang, in den er alle besonderen Gebilde des objektiven Geistes einfügte, und von dem aus er das Maß ihres relativen Vernunftrechtes und damit im idealistischen Sinne ihr innerstes Wesen bestimmte, war kein anderer als der logische Zusammenhang. In dieser logischen Struktur allein konnte jene vollkommene und reine Wahrheit gesucht werden, die in ihrer Gesamtheit den absoluten Geist, die Idee oder die Gottheit ausmacht. Mit der Einstellung des Geschichtlichen in eine solche rein logisch gegliederte Gesamtheit sollte erst sein innerstes Wesen und damit sein Vernunftwert begriffen werden. Nicht in dem Historischen als solchem erkannte somit Hegel das Vernünftige, sondern erst aus der Stelle, an der sich das Einzelne als ein Notwendiges in der logischen Struktur des Ganzen herausstellte, beurteilte er umgekehrt das Vernunftrecht des Geschichtlichen. Streckenweise mochte ihm deshalb die zeitliche Reihenfolge historischer Gebilde mit ihrer logischen Entwickelung zusammenfallen, und wenn man es als die Religion des logischen Idealismus bezeichnen darf, an die Vernunft in der Geschichte zu glauben, so war Hegels Überzeugung davon so sehr erfüllt, daß er sich dadurch bei seiner logischen Konstruktion der Geschichte unter Umständen wohl zu einer Vergewaltigung der Tatsachen hinreißen ließ. Aber wie dereinst in der Schellingschen Naturphilosophie, so lag doch auch hier in letzter Instanz nur der Sinn zugrunde, daß die philosophische Betrachtung der Tatsachen auf das Verständnis ihrer Bedeutung für einen höheren und übergreifenden Vernunftzusammenhang gerichtet sein müsse.

Die logische Struktur aber, deren Verständnis diese Aufgabe zu leisten vermöchte, war für Hegel die dialektische Methode. Sie erwuchs ihm nach Dialektische Nethode. den Anregungen der Fichteschen Wissenschaftslehre aus der Grundrorstellung; daß, wenn im Wesen des Geistes der Sinn der Welt und der Grund ihres Auseinandergehens in die gesonderten Gestalten der Wirklichkeit gesucht werden sollte, dies unmittelbar und unabweislich voraussetze, daß es zum Wesen des Geistes selbst gẹhören müsse, sich in sich selber zu spalten, ein anderes aus sich hervorgehen zu lassen und aus dieser Zerrissenheit wieder zu sich selbst zurückzukehren. Wenn die Mystiker gemeint hatten, und wenn mit ihnen jetzt auch Schelling meinte, eine dunkle Tiefe im göttlichen Wesen 
selbst annehmen zu müssen, um daraus seine Entfaltung in die Welt abzuleiten, so bestand die Rationalisierung der Romantik bei Hegel darin, daß er die immanente logische Notwendigkeit aufzeigen zu können glaubte, womit der Geist diese Selbstentzweiung und dadurch diese Selbstverwandlung in die bunte Gestaltenfülle der Einzelwirklichkeit von Natur und Geschichte vollbringe. Die logische Gegensätzlichkeit und ihre synthetische Überwindung wurde so das Schema der Entwickelung für die dialektische Methode, welche in steter Selbsterneuerung von einer Kategorie zur anderen fortschreiten und schließlich in der höchsten Form der totalen Selbsterfassung des Geistes sich vollenden sollte. Nach diesem Schema gliederte sich zunächst das ganze System. Die Logik entwickelte die reine Bewegung der Idee an sich selbst und durchlief in diesem Aufbau der Kategorienlehre schon die allgemeine Form ihrer Sondergestaltung in Natur und Geschichte. Die Naturphilosophie behandelte die „Idee in ihrem Anderssein", ihre Selbstentlassung zu den Gestaltungen der räumlichen und körperlichen Welt, und deren systematischer Zusammenhang wurde wiederum in ihrem Aufstreben zum organischen Leben als dem Träger des Bewußtseins gefunden. Die Geistesphilosophie endlich konstruierte die Momente des Prozesses, durch welchen das in natürliches und geschichtliches Außensein ergossene Leben der Idee zu ihrer bewußten Selbsterfassung und Selbstgestaltung zurückkehrt. So stark nun auch die Macht des dialektischen Geistes und die Feinheit des Aufsuchens der intimen Zusammenhänge und der verschlungenen Übergänge zwischen den Kategorien in Hegels Logik ist, - so selbständig und eigenartig er die Materialien der Naturphilosophie zu einer geozentrischen Weltansicht und $z u$ einer organischen Lebensansicht neu zusammengefügt hat, so ist doch zweifellos die große und eindrucksvolle und zugleich die bleibende Leistung seiner Lehre in der Geistesphilosophie zu suchen.

Lehre vom objektiven Geist.

Es gehörte zu den von Kant gezogenen Grundlinien der idealistischen Weltanschauung, daß die Wahrheit und die Realität der Vernunft im Allgemeinen und Allgemeingültigen gesucht wurde. Ebendeshalb hatte die spezifisch romantische Bewegung ihre Energie daran, das Urrecht und den selbständigen Wert der Individualität dagegen geltend zu machen. Hegel ging von Anfang an auf die Überwindung dieses Gegensatzes und auf die Durchführung des aristotelischen Gedankens aus, daß das wahrhaft und konkret Allgemeine in der individuellen Wirklichkeit enthalten und nur in ihr wirklich sei. Aber das Schema seiner Methode brachte es doch mit sich, daß alle besonderen Gestaltungen des geistigen Lebens nur als Durchgangspunkte in dem dialektischen Fortschritt der Idee erschienen. Sie besaßen ihren Eigenwert in der Stellung, die sie in diesem Fortschritt einnahmen, und wenn darin ihr konstitutives Wesen gesucht wurde, so galt für Hegel gerade die Herauslösung des Einzelnen als solchen für eine unzulängliche Reflexion, der er ihre Abstraktheit vorwarf. Und die charakteristische Folge diesis ganzen

Psychologie. Verhältnisses war dann doch die, daß die Lehre vom individuellen oder subjektiven Geiste, die sonst sogenannte Psychologie bei Hegel nur die erste 
Stufe der Geistesphilosophie bildete, und daß in ihr gezeigt werden sollte, wie der einzelne Geist erst dadurch seine wahre Wirklichkeit findet, daß er in seinem Selbstbewußtsein die Gesetzmäßigkeit des allgemeinen Geistes als das Wesentliche entdeckt. Hier wurde in dem abgeschlossenen System dasselbe Prinzip mächtig, welches schon in der „Phänomenologie“ den Leitfaden gebildet hatte: die Aufweisung der inneren Widersprüche, welche das Bewußtsein von seiner ersten sinnlichen Bestimmtheit her durch alle Stufen seiner Entwickelung hindurchtreiben, bis es erst in der vollkommenen Selbsterfassung der Vernunft zum Abschluß und zur Ruhe kommt. Dieser Prozeß führt aber das Individuum durchweg über sich selbst hinaus und in die Gestaltungen des Allgemeinen, d. h. des objektiven Geistes hinein.

Das vernünftige Wesen des Menschen verwirklicht sich nur in der Ge- Recht. meinschaft. Als die abstrakte Grundform solcher vernünftigen Gemeinschaft behandelt Hegel das Recht. Er sieht darin das System der Beziehungen, wodurch die Individuen im gemeinsamen Leben eine sie alle überragende Vernunft verwirklichen. Aber die Formen der rechtlichen Lebensgemeinschaft betreffen für sich allein nur die äußerliche Realisierung des allgemeinen Geistes: seine innerliche Verwirklichung besteht in den Prozessen, durch welche das Individuum seine Gesinnungen dem Gebot der Gattungsvernunft unterwirft, die als sittliches Bewußtsein, als Pflicht in ihm spricht und in ihm den Gegensat $z$ zwischen diesem Allgemeingültigen und seinen eigenen natürlichen Triebbestimmtheiten hervorruft: so wurde Hegel die "Moral" als individuelle Ethik zu einem Momente des dialektischen Übergangs in den großen Gesamtbewegungen des objektiven Geistes. Die Durchdringung endlich $z$ wischen Legalität und Moralität, zwischen der vernünftigen Außengestaltung des Handelns und der vernünftigen Innengestaltung des Wollens sieht Hegel im Wesen des Staats. Er betrachtet ihn als die Verwirklichung der sittlichen Idee, als die fleischgewordene Gattungsvernunft, als das vollkommene Gesamtleben, in welches das Individuum mit allen seinen Vernunfttätigkeiten aufzugehen berufen ist. Damit bekannte sich Hegel schon früh zu dem Ideal des antiken Staates, freilich nicht $z u$ den wirklichen Gebilden des historischen Griechentums, aber zu den Aufgaben, welche die antike Staatstheorie insbesondere bei Platon gestellt hatte, und welche von der poetischen Begeisterung des Neuhumanismus wieder aufgenommen wurden. Im Gegensatz gegen die historischen und namentlich gegen die psychologischen Doktrinen vom Staat, im Gegensatz gegen die Lehre von der Interessenbefriedigung lehrte Hegel den Staat als die vernünftige Verwirklichung des Volksgeistes begreifen, der alle Leistungen der objektiven Vernunft zugleich in seinen äußeren Institutionen wie in der inneren Anteilnahme der Individuen an seiner Gesamttätigkeit vereinige. Es war ein gesteigertes und tief in sich selbst befestigtes Staatsbewußtsein, das er einem Zeitalter verkündete, worin man sich gewöhnt hatte, den Staat nur als ein Gebilde historischer Zufälligkeit zu betrachten und ihm alles innere Lebensinteresse fernzuhalten. Damit hat Hegel aus der idealistischen Theorie heraus die Aufgaben des modernen Kulturstaates bestimmt 
und der politischen Entwickelung der Zukunft die Wege vorgeschrieben, die sie aus den historischen Voraussetzungen heraus zu beschreiten begonnen hat. Geschiclite. In dem ersten Entwurf war damit die Bedeutung des Staates so umfassend, seine Aufgabe so groß, daß in ihm das höchste Produkt der Vernunft in der Erfahrung, die letzte Verwirklichung des Geistes gegeben zu sein schien. Freilich genügt kein einzelner empirischer Staat der Geschichte den Anforderungen dieser Idee. Nur in der Reihenfolge der Staatenbildungen, in denen Volk auf Volk, jedes seinen Staat schaffend, auf die Bühne der Weltgeschichte tritt, konnte die volle Verwirklichung der Vernunft gesucht werden, und cleshalb vollendete sich Hegels Lehre vom objektiven Geiste in der Geschichtsphilosophie. Er betrachtete die Gesamtheit der Menschengeschicke als den Fortschritt im Bewußtsein der Freiheit, und dieser ging ihm von der orientalischen Welt, in der nur einer frei ist, zur griechisch-römischen, in der einige frei sind, und schließlich zur christlich-germanischen, in der dem Prinzip und dem Ziele nach alle frei sind. In diese Grundauffassung konstruierte Hegel mit der ganzen Virtuosität seines dialektischen Geschickes alle einzelnen Gestalten der Weltgeschichte hinein, und er bewies gerade hierin sein bewunderungswürdiges Verständnis des Wesentlichen an dem Einzelnen, indem er es durch seine Stellung im Entwickelungsgange des Ganzen zu charakterisieren unternahm. Uberzeugt, daß das Ganze ais eine sinnvolle und übergreifende Gestaltung und Zusammenfassung alles Einzelnen die Verwirklichung einer höheren Vernunft bedeutet, schreckte er nicht vor dem kühnen Versuch zurück, den Ideengehalt der menschlichen Geschichte zu einem abschließenden und einheitlichen System zu verweben.

Allein wenn Hegel zuerst gemeint hatte, im Staat die allumfassende Veribsoluten Geist. wirklichung der Vernunft sehen zu dürfen, so führte ihn der Eintritt in den romantischen Gedankenkreis und die Energie des individuellen Lebens, das er darin vorfand, über jenes antike Ideal hinaus. Er verstand das Recht der geistigen Lebensgewalten, welche dem modernen Individuum eine Sphäre eigener Betätigung über die Grenzen der Wirksamkeit des Staates hinaus sichern und welche doch nicht minder eine noch viel weiter in die Werthöhen der allgemeinen Vernunft hinaufgreifende Bedeutung besitzen. So errichtete er noch über dem Reiche des objektiven Geistes die abschließende Vernunftwelt des. absoluten Geistes. Er verstand darunter die Gesamtheit derjenigen Funktionen les Bewußtseins, in denen sich die empirische Tätigkeit des Anschauens, Vorstellens und Denkens unmittelbar mit der reinen Vernunftwahrheit der Wirklichkeit in Beziehung weiß. Diese Darstellungsformen des absoluten Geistes, der damit vollkommen "zu sich selbst kommt", sind die Kunst, die Religion und die Wissenschaft. Aber die Ausführung dieser drei abschließenden Teile seines philosophischen Systems zeigt nun wiederum in der deutlichsten Weise, daß alle Formen des individuellen Bewußtseins, in denen sich jene letzte Selbsterfassung der Idee vollzieht, durch die Bewegungen des objektiven Geistes vermittelt und bestimmt sind. Die Kategorien der Kunst werden von Hegel in einer Weise, für die in Schillers 
kulturphilosophischen Konstruktionen die Anlässe geboten waren, aus dem historischen Prozeß des Gattungsgeistes abgeleitet: und eine ähnliche, in den einzelnen Phasen sogar vielfach analoge Konstruxtion waltet in den Entwickelungen seiner Religionsphilosophie ob. Der große Zug seiner gesamthistorischen Auffassung, die im höchsten Sinne kulturgeschichtliche Behandlung aller einzelnen Erscheinungen des geistigen Lebens gibt allen diesen Teilen des Hegelschen Systems eine systematische Geschlossenheit und eine innere Harmonie, welche für jede Kulturtätigkeit auch des gegenwärtigen Lebens den Hintergrund in allgemeinen historischen Notwendigkeiten schuf. Hier schien wirklich die Einsicht gewonnen zu sein, mit der die eigene Arbeit der Zeit sich selbst aus der Gesamtheit des geschichtlichen Verlaufs als das innerlich Notwendige herausentwickeln konnte. Und dieser Eindruck vollendete sich, wenn der letzte Teil des Systems, die Philosophie der Wissenschaft, d. h. der Philosophie selber, die gleiche Struktur der historischen Konstruktion aufwies. In der Geschichte der Philosophie sollten die Kategorien der Wirklichkeit, die von der Logik aus der Selbstentfaltung der Idee abgeleitet, von der Natur- und der Geistesphilosophie in ihre Besonderungen auseinandergelegt worden waren, in der Form der begrifflichen Welterkenntnis wiedererkannt werden, und ihren logischen Zusammenschluß, ihre Vereinigung zum System bildete dann der absolute Idealismus selber.

Wir haben heute - nach langen Jahrzehnten der Verkennung - längst wieder gelernt, die dialektische Methode auch in der Gestalt der historischen System der Konstruktion als eine äußere Schale und eine zeitliche Hülle zu betrachten, die gesprengt werden muß, wenn man die Hegelsche Philosophie wieder in der wahren Bedeutung verstehen will, mit der sie auf ihre Generation gewirkt hat: als der reife Ausdruck eines gesteigerten Kulturbewußtseins, das, wie es die ganze Welt als die lebendige Entwickelung des Geistes und als die verwandte Wohnstätte des vernünftigen Bewußtseins betrachtet, so auch in der ringenden Arbeit des geschichtlichen Menschen nicht bloß das emsige Schaffen seines natürlichen Wesens, sondern eine höhere Welt geistiger Realität sieht, die sich darin aus all den Anlässen der empirischen Bewußtseinsbewegung mit ihrer ganzen inneren Wucht und ihrer weltumspannenden Bedeutung herausarbeitet. Das Entscheidende dabei ist der Gedanke, daß die Kulturtätigkeiten des Menschen, mögen sie in ihrer Sondererscheinung noch so sehr durch die natürlichen und die geschichtlichen Bedingungen der einzelnen Bewußtseinsarbeit bestimmt sein, doch in sich eine alles Zeitliche überragende Bedeutung von innerer Wahrheit besitzen. Was die religiöse Vorstellung mit der Einfügung des Menschenlebens in eine göttliche Weltordnung meint, das wollte Hegel als den begrifflichen Sinn aller geistigen Lebenstätigkeit verstehen. Und der Beweis für diesen Glauben seines Panlogismus fand er in dem Fortschritt der historischen Entwickelung, worin der Geist aus allen Unzulänglichkeiten und Widersprüchen, in die er durch seinen natürlichen Ursprung eingebettet ist, schließlich zu seinem vollgültigen Selbstbewußtsein gelangt. Diese Entwickelung ist bei Hegel die Gewähr für die 
Vernünftigkeit des Universums. Sie ist zugleich die Mahnung an jeden einzelnen, an jedes Volk, an jedes Zeitalter, mit seiner geistigen Arbeit sich selbst zu dem zu machen, was es seiner Anlage, seiner Bestimmung nach im Zusammenhange des Ganzen ist.

Herbarts Sonderstollung.

VI. Herbart. Der großen Entwickelung des idealistischen Monismus, der sich von Kants transzendentaler Logik bis zu Hegels absoluter Logik in folgerichtigem Fortschritt entwickelte, stehen andere Versuche zur Seite, dem idealistischen Grundgedanken eine weniger hochfliegende und mehr den Formen des überlieferten oder des gewöhnlichen Vorstellens entsprechende Fassung zu geben. Das letztere geschah hauptsächlich von seiten des Psychologismus, der bei Fries noch versuchte, sich auf der Höhe der transzendentalen Methode zu halten, aber bei Beneke vollständig auf den Standpunkt der Assoziationspsychologie und damit $z u$ der Behandlungsweise der Aufklärungsphilosophie herabsank. Auf der anderen Seite suchte Herbart mit Ablehnung der erkenntnistheoretischen Wendung, welche die Problemstellungen der Philosophie durch Kant genommen hatten, die begrifflichen Spekulationen der alten Ontologie wieder aufzunehmen, und er hielt die Mittel der formalen Logik für ausreichend, um mit der „Bearbeitung der Begriffe“, durch welche die Erfahrung im unbefangenen Leben und in den besonderen Wissenschaften gedacht wird, zu einwandfreien metaphysischen Positionen zu gelangen. Er erkannte das Unzulängliche und Widerspruchsvolle jener Vorstellungen bereitwillig an: aber statt darin Momente einer übergreifenden Wahrheit zu sehen, hielt er es für die Aufgabe der logischen Begriffsarbeit, solche Widersprüche fortzuschaffen und damit aus dem Reiche der Erscheinung zu der widerspruchslosen Wahrheit der absoluten Wirklichkeit vorzudringen. Die Methode "der Beziehungen, die er zu diesem Zwecke handhabte, war also trotz des gemeinsamen Ursprunges, den sie mit der dialektischen Methode in der Fichteschen Wissenschaftslehre hatte, in ihrem Ziel wesentlich das Gegenstück zur Schelling-Hegelschen Dialektik. Und ebenso war auch die Weltansicht Herbarts ihrer formalen Struktur nach der Identitätsphilosophie prinzipiell entgegengesetzt.

Die Realen. Jene Identitätsphilosophie hatte sich metaphysisch wesentlich am Leitfaden des Funktionsbegriffes entwickelt. Wie die Vernunft als ein System zweckvoller Tätigkeiten das Wesen der Urwirklichkeit ausmachen sollte, wie die dinghaften Stoffe der Natur schon bei Kant und noch ausgesprochener bei Schelling als Produkte von Kräften galten, so wurde überhaupt in dem 1ebendigen Fluß der dialektischen Bewegung alles, was die naive Vorstellung als ein „Sein" anspricht, zu einem Produkt und einem Niederschlag des ewigen Werdens gemacht. Das war folgerichtig in der Tendenz begründet, Geist und Vernunft als Wesen der Welt zu begreifen. Herbart dagegen folgte den Gewohnheiten der älteren Metaphysik, wenn er das Sein in der Form des Substanzbegriffes zum Ausgangspunkte seiner Metaphysik machte. Er fand den Widerspruch bei der Kategorie der Inhärenz gerade in demjenigen, was Kant 
als deren Wesen begriffen hatte: in der Synthesis aes Mannigfaltigen der Eigenschaften zur Einheit des Dinges. Er glaubte diesem Widerspruch zu entgehen, wenn er unter Hinweis darauf, daß jede empirisch aussagbare Eigenschaft eines Dinges immer nur eine Beziehung des Dinges zu einem oder mehreren anderen Dingen bedeutet, jene Mannigfaltigkeit in eine Vielheit von Beziehungen auflöste, die dem eigentlichen Dinge nicht an sich, sondern nur „zufällig“ zukommen sollten. Das einzelne Ding als solches, das wahrhaft Reale, sollte eine starre Einheit und Einfachheit seiner Qualität besitzen, die, an sich unbekannt, doch den gemeinsamen Grund für die erscheinende Vieiheit der Eigenschaften in der Erfahrung ausmache. Dieser Substanzbegriff setzte zur Erklärung der Welt seine Multiplikation voraus, und dem Monismus der Identitätsphilosophie gegenüber behauptete deshalb Herbarts Ontologie eine ausgesprochen pluralistische Weltanschauung. Für sie war somit die Einheit der Welt, die in der Anschauung des Vernunftlebens für die Identitätsphilosophie das Unmittelbarste und Gewisseste gewesen war, ein theoretisch unlösbares Problem, und nur in seiner Religionsphilosophie machte Herbart einen schüchternen Versuch, auf dem teleologischen Wege des Glaubens diese Lücke auszufüllen.

Der Umstand, daß Herbart jene einfachen Substanzen als "Reale“ bezeichnete, hat zu der irreführenden Benennung seiner Metaphysik als Realismus Anlab gegeben: aber dieser Name trifft auf seine Lehre in keiner der Bedeutungen $\mathrm{zu}$, welche das Wort in der geschichtlichen Terminologie besessen hat oder besitzt. Vielmehr ist innerlich die Herbartsche Ontologie dem Zuge ihrer Zeit entsprechend durchweg idealistisch. Die unerkennbare einfache Qualität der Realen verbietet, sie als Atome, als raumerfüllende Substanzen zu denken. Herbart sucht vielmehr die räumlichen Bestimmungen der erscheinenden Dinge in einer mühseligen Konstruktion aus den Beziehungen $z$ wischen den Realen $z$ u erklären, vermöge deren sie sich gegenseitig partiell durchdringen. Er betrachtet dies partielle Durchdringen als eine der Formen der Selbstbehauptung, womit die Realen sich gegen die Störung durcheinander erhalten. Die allein unmittelbar erlebte Form aber, in der wir diese Selbsterhaltungen kennen, sollen die Vorstellungen sein, mit denen sich das Reale unserer Seele gegen die Störungen durch die anderen erhält. Alle diese Störungen jedoch und Selbsterhaltungen betrachtet Herbart als Vorgänge, welche die einzeinen, an sich völlig unveränderlichen Realen nichts angehen: das "Kommen und Gehen" der Substanzen ist ein ProzeB, der sich wesentlich für das Bewußtsein und im Bewußtsein abspielt. So ist alle Lebendigkeit der Welt und aller Fluß des Geschehens aus der starren Vielheit unbekannter und unveränderlicher Substanzen in das innere Leben des Bewubtseins verlegt, aber ebendadurch aus der wahren Realität in die Erscheinung gedrängt. Ebendeshalb vermochte diese Metaphysik trotz des Scharfsinns ihrer künstlichen Begriffsbildung nicht die geringste fruchtbare Beziehung zum Leben oder zur Wissenschaft zu gewinnen. Neben der großen Bildungsbewegung der Zeit, in deren Mittelpunkte die identitätsphilosophische Ent- 
wickelung stand und deren Gesinnungen sie in mitreißender Begeisterung zum Ausdruck brachte, ging die Herbartsche Ontologie als ein Spiel unfruchtbarer Begriffsgymnastik einher; in dieser Metaphysik steckte nichts von dem großen geistigen Inhalte der Zeit: und wenn Herbarts Philosophie sich keine Eingriffe in die Erkenntnissphären der besonderen Wissenschaften erlaubte, mit keinen gewalttätigen Konstruktionen an die Natur oder an die Geschichte herantrat, so ist sie andererseits auch völlig ohne Wirkung auf diese besonderen Wissenschaften geblieben. Jene Ontologie der Realen ist heute nur noch eine historische Kuriosität.

Psychologie und Pädagogik.

Nur nach einer Seite hin hat Herbarts Lehre eine dauernde Wirkung ausgeübt: das war die Psychologie und die von ihr abhängige Pädagogik. Von den Voraussetzungen seiner Metaphysik her betrachtete Herbart die Vorstellungen als die Selbsterhaltungen der Seelensubstanz, und er wendete auf sie selbst wieder die Prinzipien seiner Ontologie an: sie sollten sich als an derselben Substanz auftretende Funktionen auch gegenseitig stören und hemmen; das Seelenleben erschien als diese Bewegung der Vorstellungen, durch die sie sich gegenseitig aus dem Bewußtsein verdrängen oder in das Bewußtsein hineinziehen. An der einzelnen Vorstellung galt dass Bewußtsein als ein Merkmal, das ihr nicht notwendig gebühre, das sie nur erhalte, wenn die Beziehungen zu den anderen Vorstellungen die günstigen Bedingungen dazu gewähren, und ohne welches sie nur noch einen Trieb zum Vorstellen bedeute. Diese metaphysische Grundlage gab der Psychologie Herbarts theoretisch ein intellektualistisches Gepräge: denn die Grundfunktion der Seele sollte die Vorstellung sein, Gefühle und Triebe galten nur als Zustände und Verhältnisse an den Vorstellungen. Zugleich schien diese metaphysische Veranlagung für die psychologische Theorie die Möglichkeit zu gewähren, die ihr Kant abgesprochen hatte, die Anwendung der Mathematik. Jenes Verhältnis nämlich der Störung und Hemmung, das zwischen den Vorstellungen bestehen sollte, hatte etwas den statischen und mechanischen Beziehungen physischer Kräfte Analoges, und so meinte Herbart, die Verhältnisse, in denen die Vorstellungen einander ihre Bewußtseinsintensität abschwächen und unter Umständen auf den Nullpunkt herabdrücken, nach Analogie der theoretischen Physik in mathematischen Formen und Formeln ausdrücken zu können. Er mußte dabei allerdings eine Anzahl willkürlicher Voraussetzungen über die Hemmungssumme und die Art ihrer Verteilung hinzufügen: aber er glaubte deren Berechtigung durch das dritte Moment seiner psychologischen Methode erweisen zu können, das er in der inneren Erfahrung fand. Mit diesen Mitteln schuf Herbart eine psychologische Theorie, welche zum erstenmal mit exakt konstruierten und klar definierten Begriffen zu arbeiten schien; je mehr dabei die metaphysischen Voraussetzungen in gewissem Sinne der naiven Vorstellungsweise vom Seelenleben entsprachen oder wenigstens nicht widersprachen, um so mehr konnte die spätere naturwissenschaftlich denkende Generation sich mit dieser Psychologie befreunden, welche mit ihren mathematisch ausged rückten Gesetzen, die durch Erfahrung verifiziert werden sollten, 
als ein Gegenstück zu der physikalischen oder chemischen Theorie angesehen werden durfte. Es kam hinzu, daß die assoziationspsychologische Methode, das Seelenleben aus streng gesetzmäßigen Beziehungen zwischen Vorstellungselementen zu konstruieren, auch bei Herbart zum ausgesprochenen Determinismus und zur Ablehnung jedes metaphysischen oder transzendentalen Freiheitsbegriffs führte. Damit aber hing endlich auch die Brauchbarkeit dieser Psychologie für die Begründung der Pädagogik als Wissenschaft zusammen. Man darf sagen, daß für deren Theorie, soweit sie überhaupt möglich ist, von Herbart die Grundlinien gezogen worden sind. Eine Lehre von der zweckvollen Leitung oder Beeinflussung der seelischen Entwickelung ist, wie jeder bewußte Eingriff in den Naturverlauf, nur durch die Erkenntnis von dessen Gesetzmäßigkeit möglich, und so muß die Psychologie die Begründung für das Wesen und die Anwendung aller Erziehungsmittel hergeben, während andererseits die wissenschaftliche Einsicht in die Erziehungsziele bei der Ethik gesucht werden mufs.

Auch in der Ethik freilich ging Herbart eigene Wege. Er billigte Kants Ethik. Absicht, sie von der Metaphysik ganz unabhängig zu machen, und wollte diese Absicht noch strenger als Kant selbst ausführen, wenn er die Moral in eine allgemeine Ästhetik einstellte, deren Gegenstand nicht Urteile über das Sein, sondern solche über den Wert des Seins bilden sollten und deren Aufgabe er darin fand, die tatsächlichen Werturteile so weit begrifflich zu bearbeiten, bis sie auf unnittelbar evidente, widerspruchslose Formen gebracht wären. Alle solche Wertungen beziehen sich auf Verhältnisse, und in der Ethik sind dies Verhältnisse des Willens. Auch auf diesem Gebiete verzichtete Herbart auf eine monistische Zuspitzung und beruhigte sich mit der Darlegung von fünf ethischen Ideen, in denen die Grundverhältnisse des Willens ihre selbstverständiliche und allgemeingültige Beurteilung finden sollten. Eine Fülle von Lebens- und Menschenkenntnis war in dieser Theorie mit verständigem Urteil gewiß verwertet: aber es fehlte auch hier der große Zug und die packende Universalität des historischen Denkens, womit die Identitätsphilosophie über die Enge des individuellen Lebens hinausgehoben worden war.

VII. Schopenhauer. Abseits von der Hauptlinie der idealistischen Be- Schopenhauers wegung steht auch Schopenhauer, aber in anderer Weise als Herbart. Der ${ }^{\text {Sonderstellung. }}$ ganze Reichtum des zeitgenössischen Geisteslebens, die Fülle der Ideen, die aus den besten Erzeugnissen aller Literaturen in die eigene Gedankenbewegung aufgenommen wurden, die intime Durchdringung philosophischen und poetischen Schaffens, welche das romantische Zeitalter charakterisierte, alles dies findet sich bei Schopenhauer in so ausgesprochener Weise wie nur bei irgendeinem anderen der hervorragenden Geister der Zeit: ja man darf sagen, daß sich diese ihre Eigenart in der Schönheit der Sprache, in der Vollkommenheit der Darstellung, in der Reife des Stils bei keinem zu so hohem MaBe entfaltet hat wie bei Schopenhauer, der unter den deutschen Philosophen der größte Schriftsteller ist, und darauf hat auch zum großen 
Teil der Zauber beruht, den seine Schriften und damit zeitweise auch seine Lehre auf die späteren Generationen ausgeübt haben. Aber diese Vorzüge lagen bei Schopenhauer wesentlich in der künstlerischen Art seines litera. rischen Schaffens: die Aufnahme dieser Bildungsmächte in die metaphysische Ansicht, ihre Erhebung zu Momenten des geistigen Weltinhaltes, wie sie in den Bedürfnissen des transzendentalen Idealismus angelegt war, wurde von Schopenhauer mit aller Energie abgelehnt, und deshalb wußten die Philosophen der Hegelschen Generation mit ihm und seiner Lehre nichts anzufangen. Er warf sich dem intellektualistischen Zuge, dem die Identitätsphilosophie gefolgt war, ebenso entgegen wie der historischen Methode, womit sie die Welt der Ideen zu gliedern und zu organisieren unternahm. Schopenhauer hielt sich an den Grundgedanken, mit dem Kant aus der Beschränkung der Erkenntnis auf die sinnliche Erscheinungswelt sich zur Rettung der metaphysischen Überzeugung, zur Befriedigung des metaphysischen Bedürfnisses an die praktische Vernunft gewendet und sich zum Willen geflüchtet hatte. Er hätte zu Fichtes ethischem Idealismus gelangen müssen, wenn bei ihm ebenso wie bei Kant in dieser Flucht zum Willen das sittliche Bedürfnis maßgebend gewesen wäre. Aber statt dessen waltet in seinem Philosophieren der romantische Trieb eines ästhetischen Schauens, das über alle Unzulänglichkeiten des theoretischen Wissens hinaus das innerste Wesen der Welt mit einem Blicke erfassen will. Diese eigenartige Verknüpfung eines voluntaristischen Grundlebens und einer ästhetisch-intellektualistischen Betrachtung desselben bildet, wie das persönliche Wesen Schopenhauers, so auch dasjenige seiner Philosophie.

Welt als wille Als der echte Schüler Kants fühlte sich Schopenhauer in der Wertung und Vorstellung. der wissenschaftlichen Erkenntnis. Auch er beschränkte sie auf die räumlichzeitliche Erscheinungswe1t, und neben den beiden reinen. Anschauungen nahm er als die einzige ursprünglich gültige Kategorie nur die der Kausalität als konstitutiv für das Erkennen an. Aber die Tätigkeit dieser Prinzipien führt immer nur von Bedingtem zu Bedingtem der einzelnen Erscheinung in anfangund endloser Reihe. Das einzige, worin sich die wissenschaftliche Erkenntnis darüber erheben kann, ist die Auffassung der immer sich gleichbleibenden Formen des Seins und des Geschehens, der Gattungsbegriffe der Gestalten und der Veränderungen, der Typen und der Gesetze - mit ein em Worte, der Ideen im platonischen Sinne. Niemand vielleicht hat die intime Verwandtschaft $z$ wischen der naturwissenschaftlichen Erkenntnis, wie sie Kant in der Kritik der reinen Vernunft formuliert hatte, mit dem Platonismus tiefer begriffen und energischer herausgearbeitet als Schopenhauer. Aber ebendeshalb gelten ihm die Ideen nur als die allgemeinen Formen der Erscheinung und selbst noch nicht als das letzte Wesen der Wirklichkeit. Dieses zu erfassen, ist nicht mehr die Sache der begrifflichen Verarbeitung der Erfahrung, sondern es bedarf dazu eines intuitiven Blickes über die Gesamtheit der Erfahrung, eines unmittelbaren Verständnisses für ihr innerstes Wesen, das nur aus dem inneren Erlebnis kommen kann. Dies innere Erlebnis aber ist das Wissen des Menschen 
davon, daß er seinem wahren Wesen nach Wille ist, - daß nicht nur die leibliche Darstellung seiner Persönlichkeit in die Welt der bloßen Erscheinungen gehört, sondern auch alle Zustände und Tätigkeiten seines Intellekts nur die der inneren Erfahrung sich offenbarende Erscheinung seines Willens bedeuten. Und da nun der Mensch nur ein Glied der gesamten Erscheinungswelt ist, da diese ihrer innersten Natur nach überall dieselbe sein muB, so ist jenes Ding-an-sich, das die Verstandeserkenntnis nicht aus der Erfahrung herausbuchstabieren kann, der Wille. Man soll ihn nach Schopenhauer nicht eigentlich die Ursache der Welt oder ihrer einzelnen Gebilde nennen, sondern lieber das Wesen, das darin erscheint, das darin zum Objekt der Vorstellung wird. Dies erkenntnistheoretische Prinzip ließ sich freilich schwer durchführen: denn wenn auch der Wille nicht als die Ursache angesehen werden durfte, die seiner Erscheinung zeitlich vorherging, so wurde er doch immer als der Grund und das Wesen betrachtet, um dessen willen die Erscheinung so ist, wie sie ist.

Der Wille stand so als Ding-an-sich der „Welt als Vorstellung“ gegen- Pessimismus über. Deshalb mußten aus seinem eigenen Wesen alle Momente der Vorstellung und damit der Rationalität gestrichen werden. Der alleine Weltwille konnte als Ding-an-sich nicht der bewußte, durch Absichten und Motive bestimmte Wille sein, den der Mensch in seiner inneren Erfahrung kennt; es blieb in ihm nur der dunkle Drang und Trieb, nur die rastlose Selbsterzeugung übrig, der Wille zum Wollen. So nannte ihn Schopenhauer den Willen zum Leben; denn das Leben selbst ist nichts als Wollen. Deshalb paart sich in der Welt, welche die Erscheinung dieses Willens ist, der Eindruck der zweckhaften Bestimmtheit, die allem Willensartigen innewohnt, mit dem der Ziellosigkeit und Unvernünftigkeit ebendieses Willens. Wo Schopenhauer die Natur als die Werkstätte des Willens betrachtet, wo er die Formen ihres Wirkens in der aufsteigenden Reihe von der mechanischen Kausalität zum organischen Leben und darüber hinaus zu den Vorgängen der bewuBten Motivation verfolgt, da schildert er, der gesamten Auffassung nach sachlich nicht viel anders als die Schellingsche Naturphilosophie und doch in viel glücklicherer, von aller scholastischen Konstruktion freierer Darstellung, die ZweckmäBigkeit des Universums bis in ihre Sondergestaltungen hinein: aber sobald er den Boden des bewußten Willenslebens des Menschen betritt, da kommt ihm die ganze Unvernunft und Ziellosigkeit dieses lediglich auf sich selbst gerichteten Wollens zur deutlichen Erkenntnis. Deshalb führt die Metaphysik des irrationalen Willens zum Pessimismus. Zum Wesen dieses Willens gehört seine Unbefriedigtheit, seine Unlust: und all sein reiches Wissen von Welt und Leben, all sein tiefes Verständnis menschlicher Wünsche und Leidenschaften, Hoffnungen und Illusionen bietet der Philosoph auf, um von der reinen Höhe seiner intellektuellen Betrachtung die Unvernunft und Unseligkeit des Willenslebens zu schildern. Für ihn selbst ist es eine Art von ästhetischem Schwelgen in der Betrachtung des Tragischen und des Tragikomischen, das ihm in dem Ringen des Willens allüberall vorzuliegen scheint. Das immer gleiche Wesen dieses Willens erlaubt daher auch nicht den Glauben, daß es 
in seiner Erscheinung einen Fortschritt, eine Entwickelung gebe; denn diese setzte ein inhaltliches Ziel, nicht bloß den Willen zum Leben, zum Ausleben voraus. Darum leugnet Schopenhauer - darin der entschiedenste Gegenfüßler Hegels - jeden Sinn und Inhalt der Geschichte; sie ist ihm inhaltlich ein ewiges Einerlei, das nur seine äußeren Formen, seine Kostüme und Masken, seine Kulissen wechselt.

Erlösungslebre. Eine Erlösung von diesem Elend gäbe es nur, wenn der Wille selbst aufhören könnte: aber das ist metaphysisch unmöglich, eben weil die Welt selbst Wille ist. Deshalb ist der Gedanke dieser Erlösung, der gerade aus dem Bewußtsein des unentfliehbaren Elends der Welt mit um so heißerer Sehnsucht aufsteigt, mit den Mitteln der metaphischen Erkenntnis bei Schopenhauer nicht zu fassen. Der Philosoph verliert sich damit in das Dunkel mystischer Postulate und hüllt diese in das Gewand der religiösen Spekulationen der indischen Philosophie. Die Verneinung des Willens zum Leben als Aufgehen in das Nichts erscheint als die niemals vollkommen zu verwirklichende Idee dieser Erlösung. Nur eine unvollkommene Vorbereitung dazu bildet für den Philosophen das moralische Leben: dessen Wesen sieht er im Mitleid und findet die metaphysische Wurzel dafür in der intuitiven Erkenntnis, womit der Einzelne in dem Anderen über alle Verschiedenheiten der Erscheinung hinweg sein eigenes und innerstes Wesen erfaßt und an der Milderung des fremden Leidens als des eigenen tätig ist. Aber wenn damit auch das moralische Leben noch in dem Willen zum Leben, in seinen Trieben und in seinem Elend stecken bleibt, so gibt es für das Individuum eine zwar nicht vollstänđige, aber doch eine vorübergehende Erlösung, wenn es in der reinen Tätigkeit des Intellekts seinen Willen zum Schweigen bringen und die Welt ohne Begier und ohne Interesse anschauen und denken kann. In der Kunst und in der Wissenschaft ist dieses Ziel zu erreichen: aber in beiden Fällen nur dadurch, daß die Betrachtung sich von dem Einzelnen, an dem der Wille haftet, zu dem Allgemeinen, zur Idee und zum Gesetz erhebt.

So sind in Schopenhauers Lehre die Elemente der idealistischen Bewegung

zu einem neuen und eigenartigen Gebilde verwoben, worin die Kunst und die Wissenschaft als die Überwindung des Weltelends erscheinen und die Verneinung des Willens als ein mystisch-religiöses Ideal im Hintergrunde schwebt. Diese Philosophie ist der vollbewußte Verzicht auf die Durchwirkung des Lebens mit den Idealen der Vernunft, eine Flucht in das Reich des Schauens und Betrachtens und darüber hinaus in das Dunkel des Nichts. Zur Zeit ihres Entwurfs war diese Lehre der gedankliche Ausdruck einer persönlichen Stimmung, die in dem tatenfrohen Drang des allgemeinen auf die Verwirklichung idealer Forderungen gerichteten Geisteslebens keine Stätte fand. Aber diese Neuentfaltung und extreme Zuspitzung des Irrationalismus bildete ein bedeutsames Gegenstück zu jenem Überwiegen des von Kant neu gegründeten Rationalismus, der in der historischen Weltanschauung Hegels seinen Triumph gefeiert hatte. In diesem antithetischen Verhältnis zwischen Hegel und Schopenhauer läuft die in einen so fruchtbaren Reichtum von Gedanken ausgebreitete 
Entwickelung des Idealismus mit einem ungelösten Problem aus. Die Philosophie des 19. Jahrhunderts hat nach manchen Irrwegen, auf denen sie zum Teil in alte, prinzipiell überwundene Vorstellungsweisen zurückfiel, sich schließlich zu diesem Problem zurückgefunden und hat mit der Frage nach dem Verhältnis des Werts zum Sein die Beziehung zwischen dem Rationalen und dem Irrationalen in der Welt von neuem in den Mittelpunkt der Philosophie gerückt.

\section{E. Die Philosophie des ig. Jahrhunderts.}

Das 19. Jahrhundert ist kein philosophisches gewesen. Es zeigt in der Allgemeine ganzen Art und Richtung seines geistigen Lebens eine völlig andere StrukCharakteristik. tur als das 18. Von der bestimmenden Macht, welche die Aufklärung für alle Interessen des wissenschaftlichen Erkennens und ebenso für die vernünftige Gestaltung des individuellen und des gemeinsamen Lebens der Philosophie zuwies und welche doch auch in der idealistischen Bewegung durchgängig für sie in Anspruch genommen wurde, ist es mit ỏer Zeit im Verlaufe des 19. Jahrhunderts immer stiller geworden. Nur in den Motiven der Lehre von Auguste Comte ist noch ein starker Nachhall davon zu spüren: aber auch in dieser zeigt sich die veränderte Konstellation darin, daß die Philosophie auf eine zentrale Selbständigkeit eigener Schöpfung verzichtet und ihre Mission an die besonderen Wissenschaften abtritt. In der Tat ist die charakteristische Eigenschaft des wissenschaftlichen Lebens im I 9 . Jahrhundert die gewesen, daß die besonderen Disziplinen, und zwar die Geschichtsforschung in demselben Maße wie die Naturforschung, eine mächtige und erfolgreiche Entwickelung gefunden haben, wobei mit dem Erwerb tatsächlichen Wissens auch eine wertvolle Bereicherung und Verfeinerung der methodischen Formen und eine Herausarbeitung allgemeiner Prinzipien verbunden war. Aber die eigentlich philosophische Denkarbeit trat dabei mehr in den Hintergrund; nur wenige umfassende Systeme der Philosophie begegnen uns, und auch deren Bedeutung liegt weit mehr in einer den neuen Bedürfnissen der Spezialwissenschaften sich anpassenden Umbildung der aus der großen Vergangenheit übernommenen Grundgedanken als in einer prinzipiellen Originalität und Neuschöpfung. Das Wertvollste, was in diesem Zeitraum für die Philosophie selbst gewonnen wurde, bestand in der Durcharbeitung ihrer Einzeldisziplinen, in der Behandlung der Grenzgebiete, auf denen sie sich mit den empirischen Wissenschaften berührt, und niemals ist das Verhältnis derPhilosophie zu den einzelnen Wissenschaften so oft und von so verschiedenen Gesichtspunkten aus behandelt worden wie im 19. Jahrhundert. Die Eingriffe, welche sich die idealistischen Systeme zum Teil in die Arbeit der Einzelwissenschaften erlaubt hatten, gaben dazu ebensoviel Anlab wie die erfolgreiche Selbständigkeit, mit der diese Disziplinen die Früchte ihrer rein empirischen Arbeit einheimsten. Diese Lebhaftigkeit in den peripherischen Gebieten ist für die Philosophie des I9. Jahrhunderts ebenso charakteristisch wie die lange Stagnation in ihrer zentralen und prinzipiellen Ausbildung. Die Folge dieser Verhältnisse ist es gewesen, 
daB zumal in Deutschland nach der fast hypertrophischen Entladung des metaphysischen Triebes eine Erlahmung und Erschlaffung des philosophischen Interesses eintrat, die. gegen die Mitte des Jahrhunderts zu einem völligen Tiefstande führte. Erst nachher ist aus der Arbeit der einzelnen Wissenschaften selbst wieder das Bedürfnis nach einer philosophischen Vertiefung, nach einer prinzipiellen Begründung und Auseinandersetzung, nach einer gedanklichen Vereinigung hervorgegangen und damit die Bewegung eingeleitet worden, welche sich zur Anerkennung und zur Erneuerung der großen Systeme der idealistischen Zeit, zuerst und vor allem Kants zurückfand. Zu gleicher Zeit aber hat die Überlebendigkeit eines über alle Erwartungen und Ahnungen hinaus unermeBlich gesteigerten Kulturlebens und die Fülle der daraus erwachsenden, an die Tiefe des Lebens greifenden Probleme von neuem ein Bedürfnis nach innerer Verständigung und einheitlicher Lebensanschauung hervorgebracht, und so hat man auch aus den Bedürfnissen des Lebens schlieBlich den Weg zur Philosophie zurückgefunden. Dieser allgemeine Zug der Eitwickelung der neuesten Philosophie tritt besonders deutlich in Deutschland zutage. Er trifft aber auch für die übrigen Nationen zu, und wir dürfen uns damit begnügen, ihn mit kurzen Strichen an der Geschichte der französischen, der englischen und der deutschen Philosophie dieses Jahrhunderts aufzuweisen. schlieblich das philosophische Interesse auf die Analyse de l'entendement humain beschränkt, die Lehre von der Entstehung und Entwickelung der Bewußtseinszustände. Auch die Geschichtsphilosophie der Revolution feierte in dieser nur den Sieg der Vernunft in der Aufklärung der Ideen, und dieser Stand der Sache fand seine amtliche Anerkennung, als durch Destutt de Tracy für die Philosophie der Name der Ideologie eingeführt wurde. In der Entwickelung dieser Ideologie legten sich aber in der Folge zwei Richtungen auseinander: die eine, welche, wie bei Destutt de Tracy selbst, in der Weise Condillacs und der Assoziationspsychologen den Mechanismus der Seelentätigkeiten aufzeigen wollte, - die andere, welche dagegen die Selbständigkeit der Seele, die Eigenart ihrer Funktion aufrechtzuerhalten versuchte. Die erste Richtung geriet nach dem Vorgange der Assoziationspsychologen schon bei Cabanis auf den Weg der physiologischen Psychologie und endete sehr schnell bei einem ausgesprochenen Materialismus. Mit einer feineren, dem damaligen Stande gemäB mehr chemischen Betrachtungsweise der Gehirnvorgänge wurde, ähnlich wie dereinst von Lamettrie, die Abhängigkeit der Intelligenz und des Willens von den Nervenzuständen, vom Alter und Geschlecht, von Krankheit und Gesundheit dargelegt, und bedeutende Mediziner, wie Pinel und Broussais, verteidigten diesen Materialismus noch spăter und sehr lebhaft gegen die spiritualistischen Philosophen. Schon hier wird überall ausgeführt, da $B$ die naturwissenschaftliche Erkenntnisweise alle Kausalverhältnisse als lediglich mechanisch, auch alle organischen Bildungen als wesentlich physikalisch und chemisch und alle psychischen Vorgänge als 
Nervenzustände $z u$ behandeln habe. Unter diesen Voraussetzungen verband sich dann die physiologische Psychologie mit der in der älteren Psychologie üblichen Lehre von den Seelenvermögen zu der Phrenologie von Gall und Spurzheim, welche jede Gruppe von seelischen Tätigkeiten als eingeborene Vermögen an bestimmte Stellen des Gehirns lokalisieren und die Stärke ihrer Ausbildung schon an der äußeren Form des Schädels erkennen wollte. Diese grobe Materialisierung der Seelenkräfte machte nicht nur bei den französischen Arzten großes Aufsehen, sondern auch als ein Gegenstand der Neugier die Runde durch die ganze gebildete und ungebildete Welt.

Die Gegenströmung gegen diese materialistische Ausbildung der Ideo- Ideologische logie ging hauptsächlich von Rousseau aus und fand noch während der Revolutionszeit eine sehr lebhafte, wenn auch wunderliche Vertretung durch den Mystiker St. Martin, der in seiner Opposition gegen die Verstandesaufklärung mit Hilfe der Gedanken von Jakob Boehme das metaphysische Wesen der Seele verteidigte, die innerlichst Wille und Gefühl sei und sich durch ihre selbständigen Reaktionen gegen die leiblichen Zustände bewähre. Ähnliche Vorstellungen wurden auch in den Kreisen der Physiologen und Mediziner geltend gemacht; sie führten bei der Schule von Montpellier, Männern wie Barthez, Bichat und Buisson, zum Teil wieder zur Annahme der Lebenskraft wie sie ähnlich zur selben Zeit in Deutschland von Stahl und den Naturphilosophen verfochten wurde. Eine ausgleichende Stellung nahm dann in der eigentlichen Ideologie Laromiguière ein, indem er die verschiedenen Stufen der Seelentätigkeit durch das verschiedene Maß der aus den sinnlichen Daten hervorbrechenden Selbständigkeit des Bewußtseins zu gliedern versuchte, von der einfachen Empfindung durch die Grundfunktion der Aufmerksamkeit und der Vergleichung zu den höheren Erkenntnisformen, und ebenso von dem natürlichen Trieb durch die Zustände der Wahl bis zu der reinen Freiheit des moralischen Lebens aufsteigen wollte, - eine Revision und Reform des Condillacismus, die dessen Grundlagen in Frage stellte, aber andererseits doch auch bei seinem positivistischen Ergebnis endete.

Die stärkste Gegnerschaft erwuchs der Ideologie aus den religiösen Religiöse Kreisen, welche für die Auswüchse der Revolution die aufklärerische Ungläubigkeit verantwortlich machen wollten. In điesem Sinne hat zuerstSt. Martin die Revolution als ein göttliches Strafgericht, ihre Schrecken als ein blutiges Sühnopfer für den Unglauben dargestellt, aber zugleich auch, - echt mystisch - für die Entwürdigung der Religion durch die Kirche. Er kämpft gegen beide Fronten, gegen Aufklärung. und Jesuitismus, gegen Unglauben und blinden Glauben, gegen Enzyklopädie und Orthodoxie. Er weist gern auf die Probleme der Sprache und der Gesellschaft hin: beide sind nicht, wie der Condillacismus will, vom Menschen erfunden und nicht, wie die Kirche will, von Gott gelehrt und geboten: beide sind mit dem natürlichen Wesen des Menschen erwachsen. So ist die Gegenrevolution von vornherein religiös gefärbt; aber ihren Erfolg hat sie nicht der mystischen Schwärmerei, sondern der ecclesia militans zu verdanken, die auch ihre Philosophie geschaffen hat. 
Traditionalismus.Den Vorstoß hat hier Chateaubriand gemacht, welcher der Revolution und ihrer Theorie vorwarf, sie habe in der Auffassung von dem Fortschritt der menschlichen Geschichte verkannt, daß darin die Religion den entscheidenden Faktor bilden müsse. Aber diese könne das nur in der Gestalt des Katholizismus sein, welcher der Träger des historischen Zusammenhanges für die Menschheit sei. So war die französische Romantik ursprünglich religiös und politisch und wurde erst von da aus wissenschaftlich und ästhetisch, während die deutsche Romantik den umgekehrten Weg gegangen ist. Aus lem Gedankenkreise von Chateaubriand stellte sehr bald Joseph de Maistre die politische Reaktion und die religiöse Restauration als die einzigen Heilmittel gegen die Revolution dar. Ihre Schuld sei die Selbstherrlichkeit der Individuen, der Unglaube und die Leidenschaft - im letzten Grunde der Abfall von der Autorität, in der allein die Wahrheit zu finden ist. Der erbsündige Mensch kann sie von sich aus mit allem Vernünfteln nicht finden, er muß sich unterwerfen. Aber die Wahrheit und die Autorität ist nur in der geschichtlichen Tradition, in der Kontinuität der größten aller Institutionen, der römischen Kirche, welche "das W.ort" als das göttliche Lebenselement der Menschheit bewahrt. In etwas mehr begrifflicher Form hat diese Gedanken de Bonald ausgeführt. Er wendet sich namentlich gegen die Gesellschafts- und Geschichtsphilosophie der Aufklärung und der Revolution. Diese habe die Gesellschaft und den historischen Prozeß als Produkte der Individuen zu erklären gesucht, in Wahrheit sei die Gesellschaft ein ursprüngliches Ganzes, als solches von Gott eingesetzt und durch sein Gebot bestimmt. Die Kirche bewahrt die Tradition der göttlichen Gesellschaftsordnung: sie verwaltet das Verbum, sie vertritt der Willkür und dem Irrtum der Individuen gegenüber die Idee der historisch entfalteten Gesamtheit. An solche Grundgedanken heftet de Bonald eine metaphysische Lehre von dilettantischem Formalismus, die auf die Durchführung der teleologischen Dreiheit von Ursache, Mittel und Wirkung hinausläuft. Hier hat offenbar diese Theorie ihre Traditon noch nicht gefunden: dieser Ultramontanismus ist das Postulat einer Tradition, die man noch nicht hat, - er weiß noch nichts vom Thomismus. Darum ging damals auch der Traditionalismus in sehr verschiedenartige Formen auseinander. Er sprach in den Streitschriften und Predigten des Prälaten Frayssinous, in den mystischen Träumereien des Dichters Ballanche ebenso wie in den ersten Schriften von Lamennais, welcher bereits in einer Weise, die wohl von Hegels Lehre vom objektiven Geist berührt war, das Gewissen als die Sprache des historischen Kollektivbewußtseins der Menschheit in dem Individuum betrachtet haben wollte, aber schon früh den Gesamtgeist demokratisch $z u$ denken anfing und dęn Traditionalismus mit dem politischen Liberalismus zu verbinden suchte.

Maine de Biran. Zwischen diesen beiden extremen und politisch orientierten Theorien der Revolution und der Gegenrevolution entwickelte sich eine ursprünglich rein wissenschaftliche Lehre, die aber auch nachher ihre politische Färbung bekam, indem sie in den Dienst der liberalen Mittelpartei trat. Es ist der Spiritualismus, der sich später Eklektizismus nannte. Sein Urheber, Frank- 
reichs bedeutendster Denker nach Descartes, war Maine de Biran. Er war von der Ideologie ausgegangen, wurde aber schon durch eine Untersuchung über das Wesen der Gewohnheit, worin er die passive und die aktive zu unterscheiden lernte, darüber hinausgetrieben, fand eine gewisse, wenn auch indirekte Anlehnung an die schottische und die deutsche Philosophie und wandte sein Hauptinteresse der prinzipiellen Differenz zwischen der äußeren und der inneren Erfahrung mit dem Bestreben zu, auf die Theorie der letzteren, die Psychologie, wesentlich die Metaphysik zu begründen. Wie Descartes nimmt er dazu seinen Ausgangspunkt im SelbstbewuBtsein: aber die Tatsache, die ihm dessen Ursprünglichkeit und metaphysische Bedeutung enthält, ist nicht das Denken, sondern das Wollen: "Je veux, donc je suis“. In polemischer Anlehnung an ideologische Theorien entwickelte er dies Selbstbewußtsein aus dem Gefühl des Widerstandes, den der Wille schon am eigenen Körper als seine Begrenzung vorfindet. In einer an Fichte anklingenden Weise erhebt sich daraus das Verhältnis von Moi und Non-Moi, Freiheit und Notwendigkeit. In der gefühiten Kraft als der metaphysischen Urtat wurzelt die Persönlichkeit mit ihrer Einheit, Freiheit und (teleologischen) Ursächlich- Spiritualismus. keit. Darin liegen dann die Grundbegriffe einer spiritualistischen Metaphysik, welche jene Merkmale der Persönlichkeit teils auf die Gottheit, teils auf die substantiellen Elemente des Universums anzuwenden versucht. In immer neuen Wendungen hat Maine de Biran von diesen Prinzipien her Seele, Leben und Welt zu durchdringen, insbesondere aber die metaphysische Theorie von der Einseitigkeit der naturwissenschaftlichen Betrachtungsweise seiner Zeit freizumachen gesucht. Eine letzte Phase seines Denkens führte ihn mit lebhafter Polemik gegen de Bonald und Lamennais zu mystischen Ausklängen, in denen er seine Lehre zu Malebranche zurücklenkte.

Die feinsinnig grüblerischen Analysen Maine de Birans traten freilich victor Cousin. in einer literarisch nicht gerade wirkungsvollen Form auf. Aber sie führten weit über die groben Einseitigkeiten und die geräuschvollen Deklamationen der extremen Theorien hinaus, und sie fanden begeisterten Anklang bei allen denen, welche sich aus ähnlichen Bedürfnissen heraus den Studien der Geschichte der Philosophie und zugleich der Aufnahme schottischer und deutscher Lehren zuwandten, so bei dem Physiker Ampère, bei Ancillon, de Gérando, Royer-Collard und Jouffroy, die nicht nur als Schriftsteller, sondern hauptsächlich auch als akademische Lehrer eine bald mehr psychologisch, bald mehr metaphysisch orientierte Geistesphilosophie vertraten. In großen Dimensionen aber geschah dasselbe durch die weithin und lange Zeit wirksame Tätigkeit von Victor Cousin, der, auf Instruktionsreisen durch Deutschland mit Schelling und Hegel in Zusammenhang gekommen, eine Zeitlang die Verfolgung der Reaktion erfuhr, dann aber mit Guizot und Villemain die glänzende Wirksamkeit in Paris eröffnete, worin er zeitweilig die Leitung des gesamten französischen Unterrichtsministeriums unter der Juli-Monarchie besaß und eine glückliche Organisation des liberalen Bildungswesens einleitete. Er führte die historische Weltanschauung gegenüber dem Radikalis- Eklektizismus. 
mus und dem starren Traditionalismus zum Siege. Er begründete darauf die politische Theorie des Liberalismus, welche auf eine freiheitliche Fortentwickelung der Institutionen ohne Bruch mit der Geschichte und ohne Unterwerfung unter ein unveränderliches Dogma gerichtet war. Er vertrat diese Gedanken siegreich in dem Kampf der Parteien um die Schule. In seiner philosophischen Lehre war sein Eklektizismus nahe daran, den Hegelschen Gedanken in einen historischen Relativismus auslaufen zu lassen, der die Entwickelung des philosophischen Denkens durch einen stetig wiederkehrenden Rhythmus der Sukzession von Sensualismus, Idealismus, Skeptizismus und Mystizismus verfolgen wollte. Seine eigene Metaphysik ging auf der einen Seite der Lehre von Maine de Biran nach und betonte im Wesen der Persönlichkeit hauptsächlich die Freiheit und die Realität des Zufälligen, das nicht notwendig und nicht allgemeingültig ist: auf der anderen Seite nahm er in den Formen des deutschen Idealismus die Unpersönlichkeit und Überpersönlichkeit der Vernunft und in ihr den Sitz der allgemeinen und notwendigen Ideen an, mit denen sich Logik, Ethik und Ästhetik, die Theorien vom Wahren, Guten und Schönen zu beschäftigen haben. Sein oratorischer und organisatorischer Einfluß hatte seine wissenschaftlich bedeutsamste Seite in der fruchtbaren Begründung und Leitung philosophie-geschichtlicher Studien. Er selbst war als Übersetzer und Herausgeber vielfach tätig und hob zum Teil schon die Schätze, welche die Pariser Bibliothek aus der lange vergessenen mittelalterlichen Philosophie birgt. Aus seiner weit ausgebreiteten Schule sind dann in den mittleren Jahrzehnten des 19. Jahrhunderts eine Menge wertvoller historischer Arbeiten hervorgegangen, während die theoretischen Leistungen seiner Schüler ohne Originalität sich zwischen den psychologistischen Ansätzen der spiritualistischen Metaphysik und den eklektischen A.usdeutungen der historischen Entfaltung der Gattungsvernunft, zwischen dem schottischen und dem deutschen Bestandteil seines Systems hin und her bewegt haben. Analog zu Cousins Einführung Schellingscher und Hegelscher Philosopheme ist in den romanischen Ländern, namentiich durch die Übersetzungen von Ahrens, auch die Lehre Chr. Fr. Krauses zur Anerkennung gelangt, der seiner zwischen Schelling und Hegel stehenden Fassung der idealistischen Prinzipien die Verbreitung in Deutschiand selbst durch eine unglückliche, vermeintlich urdeutsche Sprache versperrt hatte.

Soxialismus. Neben jenen drei philosophischen Richtungen, die in mehr oder minder intimen Beziehungen zu den politischen Parteien der Zeit standen, hat nun auch die sozialistische Bewegung, welche durch die Französische Revolution als das neue Moment des öffentlichen Lebens ausgelöst worden war, ihre philosophische Vertretung gesucht und gefunden. Es ist aber durchaus unrichtig, wenn man gemeint hat, die Wurzeln des Sozialismus in der atomistischen Gesellschaftslehre der Aufklärung suchen zu sollen; das trifft höchstens auf einige besondere Punkte, namentlich in den kommunistischen Theorien, z. B. bei Fourier zu, dessen Lehre von dem Trieb und der Attraktion als Prinzip der Triebbewegung vielleicht so gedeutet werden kann. Aber die 
eigentlichen sozialistischen Theorien gehen von vornherein, im Gegensatz zum Individualismus, von dem Begriff des Gesellschaftsganzen und des Gesamtgeistes aus. Sie standen in dieser Hinsicht dem deutschen Idealismus, wenn man etwa an Fichtes „geschlossenen Handelsstaat" denkt, durchaus nicht fern. Sie konnten deshalb später auch in Männern wie Leroux oder Reynaud sich mit christlichen oder traditionalistischen Motiven verbinden, und dieser Gedanke von dem organischen Ganzen der Gesellschaft ist wohl auch das einzige, worin man einen gewissen Zusammenhang zwischen dem Hegelianismus und dem St. Simonismus finden darf. Im übrigen sind die reformatorischen St. Simoa. Prinzipien, mit denen St. Simon den Plan der wissenschaftlichen Arbeiten des 19. Jahrhunderts. bestimmen wollte, weit mehr auf die Naturwissenschaft und die dadurch begründete Technik orientiert. Er proklamiert die physiko-politische Wissenschaft: wie er die wahre Grundlage der Gesellschaft in der Industrie und in den Arbeitern, die richtige Leitung der Gesellschaft bei den Künstlern und Gelehrten sucht, so will er die Reorganisation der durch die Revolution aufgewühlten Gesellschaft durch Naturwissenschaft und Technik bestimmen und durch die religiöse Gesinnung herbeiführen. Aber die sozialistische Religion St. Simons, das „neue Christentum“, ist eine Religion des Diesseits, eine Verbrüderung nur zum Zwecke der irdischen Glückseligkeit. Eine Fülle von Motiven des geschichtlichen und gesellschaftswissenschaftlichen Denkens in Frankreich und Deutschland, aus Rousseau und Condorcet, aus Herder und Hegel kreuzen sich in der unklaren Begeisterung St. Simons mit den Interessen der naturwissenschaftlichen Technik und Industrie. Aber seine Gedanken über das goldene Zeitalter der Zukunft zeigen überall die religiöse Färbung, welche allen Bewegungen der Restaurationszeit im Gegensatz zur Aufklärung gemeinsam war: und diese religiöse Färbung ist an den sozialistischen Theorien lange haften geblieben, nur daß hier überall jeder Kompromiß mit den positiven Religionen prinzipiell abgelehnt wurde.

Die in diesem Sinne gerichteten Lehren von St. Simons Schülern und Zeitgenossen gehören mehr der Geschichte der sozialen Bewegung selbst als der ihrer philosophischen Theorie an: aber aus diesen Gedanken und den darin schlummernden Gegensätzen ist das innere Schicksal des bedeutenden Denkers zu begreifen, der als überragende Persönlichkeit aus diesern Milieu hervortritt: Auguste Comte. Ein tüchtiger Mathematiker, mit seiner streng katholischen Familie entzweit, auf private Lehrtätigkeit und literarischen Erwerb angewiesen, erfüllte er sich zuerst mit den gärenden Gedanken der Restaurationszeit, und als er eine Zeitlang als Schüler St. Simons tätig war, entwickelte er den Grundgedanken von der Reorganisation der Gesellschaft durch die moderne Wissenschaft in einer leidenschaftlichen und geistreichen Darstellung, welche in der Polemik gegen die Aufklärungsphilosophie Hand in Hand mit dem Traditionalismus ging. Auch er machte für die Schäden der Revolution die Selbständigkeit des individuellen Urteils, die Untergrabung der Autorität und die Gewissensfreiheit verantwortlich. Jetzt aber habe das kritische Zeitalter mit seinem negativen Ergebnis sich selbst das Ende be- 
reitet, und es müsse ein organisches Zeitalter des Neuaufbaues der Gesellschaft folgen. Diese Reorganisation jedoch will Comte auf der Einheit der Überzeugung, auf der Herrschaft des Gesamtgeistes über alle Lebensfunktionen errichten. Dạs Mittelalter habe diese Aufgabe in bewunderungswürdiger Weise geleistet, aber die Grundlage dafür habe damals das theologische System gebildet, dessen Unhaltbarkeit darzulegen die Mission des kritischen Bastardzeitalters, der Reformation und der Aufklärung, gewesen sei. Die neue Organisation könne zu ihrer Grundlage nur die Wissenschaft, und zwar die positive Wissenschaft, die Wissenschaft der Tatsachen, haben. Deshalb schied sich Comte damals von St. Simon, sobald dessen Reformpläne die religiöse Wendung nahmen: er wollte die Grundlage für die neue Lebensform der Gesellschaft nur in der exakten Wissenschaft suchen. Das Zeitalter der Gewissensfreiheit und der Anarchie, die sie notwendig mit sich führe, werde erst aufhören, aber auch sicher aufhören, wenn von den Aufgaben des Menschen, vom Wesen der Gesellschaft und ihrer Geschichte eine ebenso sichere zweifellose und exakte Wissenschaft vorliege wie die Mathematik und die Physik.

Diese Wissenschaft hat Comte die Soziologie genannt, und sie aufzustellen war der wesentliche $Z$ weck, den er mit dem umfassenden Entwurf seiner Philosophie positive“ verfolgte. Die Wissenschaften hätten wie alles menschliche Weltvorstellen und Leben den Weg der drei Stadien durchgemacht, wonach sie zuerst theologisch durch übersinnliche Kräfte, dann metaphysisch durch allgemeine Begriffe und endlich positiv lediglich durch Feststellung der Tatsachen ihre Erkenntnisaufgabe gelöst hätten. Eine nach der anderen habe mit der Zeit das positive Stadium erreicht, zuerst die Mathematik, nachher die anderen. Nur die Gesellschaftslehre, die bisher entweder theologisch oder metaphysisch behandelt werde, habe den letzten Schritt noch zu tun, und sie müsse dabei dem Vorbilde der anderen Wissenschaften folgen, die das Ziel schon erreicht haben. Comtes positive Philosophie ist daher nichts anderes als das System oder, wie er sagt, die Hierarchie der positiven Wissenschaften, das System, das in der Soziologie seinen Abschluß und seine Krönung finden soll. Sie verzichtet darauf, absolute Prinzipien zu finden, sie kennt weder erste Ursachen noch letzte $Z_{\text {wecke. Sie will nur }}$ neben den einzelnen Tatsachen die allgemeinen Tatsachen feststellen, ihre dauernden und regelmäßigen Verhältnisse, die bleibenden Momente und die sich stetig wiederholenden Reihenfolgen: sie will Statik und Dynamik der Tatsachen sein. Unter diesem Gesichtspunkte behandelt.die positive Philosophie mit breiter Ausführlichkeit die sechs positiven Wissenschaften: Mathematik, Astronomie, Physik, Chemie, Biologie und Soziologie. Dieser Aufstieg geht vom Einfachen zum Verwickelten fort. Er setzt voraus, daß die einfacheren Phänomene als Momente in den verwickelteren enthalten sind; aber er betrachtet niemals die verwickelteren der höheren Stufe nur als $\mathrm{Zu}$ sammensetzung oder Ergebnis aus den Momenten der niederen Stufe, sondern er sucht durchgängig zu zeigen, daß auf jeder neuen Stufe auch etwas sach- 
lich Neues hinzutritt, was aus dem Vorhergehenden nicht abzuleiten ist und, wie es neue Methoden zu seiner Bearbeitung bedarf, so auch im Objekt etwas Eigenes besitzt. So treten z. B. in das Leben die physikalischen und chemischen Vorgänge als Momente ein, aber das Leben selbst ist etwas anderes, das aus ihnen nicht $z u$ begreifen, sondern für sich nach eigener Methode zu studieren ist. So gehen auch die Individuen und der biologische Zusammenhang des Menschengeschlechts in die Gesellschaft ein, aber diese ist etwas Überragendes, das sich daraus nicht von selbst ergibt. In dieser an das aristotelische System, nur mit Ausschluß von dessen teleologischer Struktur erinnernden Behandlung tritt Comte prinzipiell der aufklärerischen Gesellschaftsphilosophie gegenüber. Er rechnet die Psychologie des Individuums, die er übrigens durchaus als Nervenphysiologie im Sinne der Gallschen Phrenologie auffaßt, noch ganz in die Biologie herein, und es laufen von ihr keinerlei Fäden der erklärenden Theorie in die Soziologie hinüber. Er treibt diese Scheidung so weit, daß er keinen Anstoß daran nimmt, vom Standpunkt der Biologie aus das Menschengeschlecht wie alle organischen Gattungen als eine vollkommen unveränderliche Spezies zu betrachten und dabei in der Soziologie das Wesen des historischen Prozesses als eine totale Veränderung, ja als eine Umkehrung der Natur ebenderselben Gattung darzustellen. In dem biologischen Typus des Menschen überwiegt das affektive über das intellektuelle Moment und im affektiven der egoistische über den altruistischen Trieb: der Prozeß der Geschichte ist das fortschreitende Wachstum des Übergewichts unserer Menschheit über unsere Tierheit nach den beiden Seiten der Herrschaft der Intelligenz über die Triebe und unseres sympathischen Instinkts über den persönlichen Instinkt Dies zu begreifen soll die Soziologie als das ihr eigene Erkenntnismittel die „historische Methode" anwenden; aber was Comte darunter versteht, soll eine durch Theorie geleitete Beobachtung sein und ist damit zugestandenermaßen eine rein konstruktive Philosophie der Geschichte, welche ihrer generalisierenden Betrachtung unbemerkt die Wertgesichtspunkte von Comtes sczialen Idealen unterschiebt. Das statische Wesen der Gesellschaft, ihre morphologische Struktur besteht in der Kooperation der Individuen und der Familien im Fortgang der Generationen; in der Ausgleichüng der Funktionen, wodurch der Zersplitterung der Ideen und Gefühle ebenso vorgebeugt werden muß wie der der Interessen und der Tätigkeiten, entfaltet sich gerade die Reaktion des Ganzen auf die Teile. Aus diesem Grunde bedarf die Gesellschaft der Autorität, die auf der Entwickelung der intellektuellen Überlegenheit beruht und die spontane Unterordnung der Teile erforderlich macht. Weil aber die Kooperation sich ebenso auf das Erkennen und Fühlen wie auf das Handeln bezieht, so muß die Autorität in doppelter Form auftreten als die geistige und die weltliche Macht. Das Verhältnis dieser beiden Autoritäten nennt Comte das große Problem aller Geschichte. Es ist zum erstenmal im Mittelalter auf Grund der religiösen Weltanschauung gelöst: es soll jetzt von neuem gelöst werden durch die Errichtung der geistigen Gewalt der Wissen- 
schaft und der weltlichen Gewalt der Industrie. Für die soziologische Dynamik, d. h. für seine Konstruktion des historischen Prozesses, worin Comte unverhältnismäßig viel einseitiger und willkürlicher verfährt als Hegel, besitzt er wiederum nur das Hilfsmittel des Gesetzes der drei Stadien. Dabei bleibt es ein Rest der von den Philosophen der Revolution, insbesondere von Condorcet, innegehaltenen Betrachtungsweise, wenn Comte als das entscheidende Wesen des geschichtlichen Fortschritts den intellektuellen Umschwung betrachtet und ihm in seinen verschiedenen Stadien die verschiedenen Gesellschaftsformen zuordnet. So fällt mit der theologischen Denkweise die militärische Gesellschaftsordnung, mit der metaphysischen Denkweise die „legistische“ Gesellschaftsordnung, mit der positiven Denkart die industrialistische Gesellschaftsordnung zusammen.

Die Geschichte war somit für Comte eine Massenbewegung, die nach religion. dem Gesetz der drei Stadien auf die Herbeiführung des positiv-industriellen Zustandes der Gesellschaft hinauslaufen muß. Galt aber die Einsicht in diese Notwendigkeit als die wissenschaftliche Wahrheit der Soziologie, so verlor sie ebendamit den Charakter eines reformatorischen Motivs und den Sinn einer agitatorischen Erkenntnis, in welchem sie anfänglich gedacht worden war. Es erwies sich als ein innerer Zwiespalt, die neue Gesellschaftsordnung auf die wissenschaftliche Erkenntnis gründen zu wollen und diese Erkenntnis in einem historischen Gesetz zu finden, wonach sich die Bewegung zu dem gewünschten Ziele von selbst vollziehen sollte. Es fehlte dem mathematischen Denker an der elementaren Unterscheidung zwischen den Methoden der Wirklichkeitserkenntnis und den Methoden der Wertbeurteilung. Der Zwiespalt, in den er dadurch geriet, hat die intellektuelle Tragik seines Lebens gebildet. Das Bewußtsein davon stellte sich bei ihm in der Überzeugung ein, daß die Wissenschaft zwar die zukünftige Weltordnung vorzeichnen, aber sie nicht herbeiführen könne, - daß die Kräfte ihrer Verwirklichung bei den affektiven Momenten gesucht werden müßten. Die Darlegung dieser Wendung hat Comte selbst in dem Discours sur l'ensemble du positivisme gegeben. Dies interessante Selbstbekenntnis bildet den Übergang von der positiven Philosophie zur positiven Politik und Religion, und es beweist, zusammen mit den temperamentvollen Jugendschriften, die Comte am Ende der „Politique positive“ wieder abdrucken lie $\beta$, daß er so unrecht nicht hatte, wenn er die Einheit seines Lebens gegenüber den verschiedenen Gestaltungen behauptete, die seine Lehre vom Ideal der neuen Gesellschaftsordnung am Anfang und am Ende gefunden hat. Er machte jetzt nur auch seinerseits die religiöse Wendung, um derentwillen er zuerst sich von St. Simon getrennt hatte. Der Zweck seiner Religion der Humanität, die er die positive Religion nannte, weil sie alles Transzendente und Übersinnliche prinzipiell ausschließen sollte, war schließlich doch nur der, die Gefühlsmächte zu entwickeln, die den von der positiven Wissenschaft als Ziel vorgezeichneten Lebenszustand zu verwirklichen vermöchten. Damit hing es zusammen, daß seine Agitation sich nun an die Frauen und an das Proletariat wendete: und aus der Macht 
seiner Jugenderinnerungen ist es zu begreifen, daß der pedantische Gelehrte seine neue Religion in Lehre und Kultus zu einer kümmerlichen Nachahmung des römischen Katholizismus ausbildete. Damit aber hatte er sich von seinen Anfängen so weit entfernt, daß seine Anhänger mit heftigem Streit in zwei Gruppen auseinanderfielen, in die wissenschaftlichen Positivisten, deren Führer Littré war, und in die Jünger der Humanitätsreligion, die sich um Lafitte scharten.

Comtes Auflösung der Philosophie in das System der positiven Wissen- Soziologie und schaften darf in gewissem Sinne als die Parole für das wissenschaftliche Psychologie Leben in den mittleren Jarhrzehnten des 19. Jahrhunderts angesehen werden. In Frankreich zumal waren auch bei den übrigen philosophischen Schulen die allgemeinen Prinzipien nicht so lebendig und wirksam ausgeprägt, als daß sie eine kräftige Weiterentwickelung gefunden hätten. Man bediente sich ihrer mehr in der Diskussion der politischen und sozialen Probleme, und die eigentliche wissenschaftliche Arbeit zog sich auf die besonderen Disziplinen zurück. In der eklektischen Schule überwog das historische, in der positivistischen das naturwissenschaftliche Interesse. In der letzteren ist insbesondere die Entwickelung der Psychologie und der Soziologie hervorzuheben, welche zum Teil bei ihrer empirischen Ausgestaltung andere Wege gegangen sind, als Comte sie vorgezeichnet hatte. Die Psychologie nahm unter Theodule Ribot wieder den $R$ ang einer eigenen Wissenschaft ein. Mit vielseitigem Eingehen auf die englischen und die deutschen Theorien und mit der Abwägung der Verhältnisse $z$ wischen der subjektiven und der objektiven, der introspektiven und der experimentellen Methode erweiterte sie sich zu einer Fülle eindringender und interessanter Untersuchungen. Die Soziologie ihrerseits kam in Männern wie Espinas, Dürkheim, Worms und Tarde mehr und mehr von dem Charakter der geschichtsphilosophischen Konstruktion, den ihr Comte aufgeprägt hatte, ab und näherte sich mehr einer wirklich naturwissenschaftlichen Behandlungsweise. Sie wurde auf der einen Seite zur vergleichenden Sozialwissenschaft und zog auch die tierischen Gesellschaften in den Bereich ihrer Betrachtung; sie ging auf der anderen Seite den Fragen der psychologischen Erklärung der Tatsachen nach und bildete in dieser Hinsicht die Theorie der Massenpsychologie aus. Damit verbanden sich endlich die Bestrebungen, auch für die Ethik in der gesellschaftswissenschaftlichen Lehre von den Sitten und ihrer Entwickelung eine empirische Grundlage oder wenigstens eine ergänzende Ausführung zu geben. Daneben gingen so eigenartig persönlich gedachte Lehren, wie Guyaus Theorie der Moral als des extensiv und intensiv gleich gesteigerten Lebens oder wie Auguste Sabatiers feinsinnig liebenswürdige Religionsphilosophie, einher. Zugleich entwarf Hippolyte Taine, der mit der positivistischen Ideologie metaphysische Neigungen zu verbinden wußte, für seine großen historischen und ästhetischen Studien die den soziologischen Ideen nahestehende Theorie des „Milieu“. Im allgemeinen aber bewegen sich alle diese Arbeiten eben an der Peripherie der Philosophie und auf den Gebieten, in denen sie sich mit den besonderen Wissen.. 
schaften berührt. Nur von den Theorien, welche die Grundlagen der einzelnen Wissenschaften kritisch untersuchten, wie es Couturat an der Mathematik und Poincaré an der mathematisch-physikalischen Theorie unternahmen, kann man sagen, daß sie mehr in die zentrale Arbeit der Philosophie zurückstrebten.

In vollem Maße gilt dies von denjenigen Philosophen, welche von der Theorie der Wissenschaft aus direkt die·Probleme der Metaphysik wieder aufzunehmen versuchten. Die wirksamsten Anregungen gaben in dieser Hinsicht Ravaisson und Lachelier, indem sie den steril gewordenen Spiritualismus und Eklektizismus, der eine durch die Erneuerung aristotelischer Prinzipien, der andere durch die Aufnahme kantischer Moinente befruchteten. Die interessanteste und vielseitigste Entwickelung hat in dieser Richtung Charles Renouvier durchgemacht, der diesem neuen Rationalismus zuerst die Prägung des Neokritizismus gab und bei seiner tiefgrübelnden Ausarbeitung und Umgestaltung der kantischen Prinzipien die antinomische Struktur der Weltanschauung zeitweilig bis zu den rücksichtslosesten und manchmal phantastisch erscheinenden Konsequenzen verfolgte. Zuletzt aber konzentrierte sich auch seine Weltanschauung, wie er sie namentlich in der Nouvelle Monadologie niederlegte, um den Begriff der Persönlichkeit. $\mathrm{Zu}$ demselben Ziele drängen auch andere metaphysische Entwickelungen, die von ähnlichen Voraussetzungen her Leibnizsche Gedanken aufgenommen und mit den Ergebnissen der modernen Wissenschaft in Zusammenhang gebracht haben. Emile Boutroux hat mit einer feinsinnigen Durchführung des Begriffes der Kontingenz die Unzulänglichkeit der naturwissenschaftlichen Theorie der mechanischen Gesetzmäßigkeit für das Begreifen des Weltinhaltes dargelegt und dessen geistiges Grundwesen in der Freiheit gefunden. Endlich hat Henri Bergson mit einer äußerst interessanten und scharfsinnigen Mystik. Verwendung von Motiven der pragmatistischen Erkenntnistheorie eine Art von mystischer Persönlichkeitsphilosophie zu begründen begonnen. Er geht von der biologischen Betrachtungsweise aus, daß das Gehirn kein Apparat zur Aufspeicherung von Vorstellungen, sondern ein Organ der Vermittelung sensibler und motorischer Funktionen, daß also, was wir Erkenntnis der Außenwelt nennen, immer nur Mittel für unser Handeln sei: durch den Schematismus dieser Vorstellungen von der Raumwelt sei aber niemals das innerste Wesen des Geschehens zu begreifen, und um so bedenklicher erscheine es, daß die Wissenschaft sich gewöhnt habe, nach den Prinzipien der Auffassung des Räumlichen auch den Prozeß des Seelenlebens zu deuten, wie das in der Assoziationspsychologie, in der Psychophysik und anderen Theorien versucht werde. In der Natur, wie sie von der Wissenschaft aufgefaßt werde, bleibe gerade nach dem Prinzip der mechanischen Kausalität trotz aller Entwickelung doch das Wesen immer dasselbe: eine schöpferische Evolution, durch die Neues in der Welt zu Wege gebracht wird, ist nur in der reinen Innerlichkeit der Seele, in jenem höheren Ich zu suchen, das von dem niederen, in die räumliche Etscheinung ergossenen verschieden und geschieden ist. 
Und wenn sonst in der Welt von einem wirklichen Geschehen die Rede sein soll, so ist es nur dadurch möglich, daß hinter der körperlichen Erscheinung allüberall eine eigentliche geistige Wirklichkeit tätig ist.

II. Englische Philosophie. In England bewegte sich die Philosophie Mill. während der ersten Jahrzehnte des I9. Jahrhunderts durchaus in den Bahnen der psychologischen Untersuchungen, in welche sie einerseits durch die Assoziationspsychologen und andererseits durch die Schotten gelenkt worden war. Der unausgetragene Gegensatz beider Richtungen verschärfte sich durch die Verstärkung, welche beide Auffassungsweisen durch die genauere Ausführung ihrer Theorien und zum Teil auch durch die Aufnahme von Lehren der deutschen und der französischen Philosophie erfuhren. Die Assoziationspsychologie wurde in Edinburgh selbst durch die geistreichen und außerordentlich wirksamen Vorträge von Thomas Brown vertreten, der auch in seinen Untersuchungen über das Kausalproblem die Humesche Lehre durch feinsinnige Ausführungen vervollständigte. Ihre volle Ausbildung aber und ihre eindrucksvollste Gestalt erhielt die Assoziationspsychologie durch James Mill und vor allem durch seinen Sohn John Stuart Mill. Der letztere blieb freilich in seiner Entwickelung den assoziationspsychologischen Voraussetzungen nicht vollständig treu: die Auflösung des Ich in eine Reihe von Wahrnehmungen machte ihn doch an dem Punkte stutzig, wo diese Reihe von sich selber etwas weiß, und wo deshalb das Band, das sie zu einem Ganzen verknüpft, doch ein Eigenes und Selbständiges zu sein scheint. Er nahm damit, ähnlich wie auch Alexander Bain, ein Moment der Aktivität aus denselben Gründen und in derselben unabgeschlossenen Weise auf, wie das von einem Teil der französischen Ideologen in der Ausführung des Condillacismus geschehen war: aber bei Mill wirkt diese Unstimmigkeit um so bedenklicher, als er aus den assoziationspsychologischen Voraussetzungen die logische Theorie der Induktion entwickelt hat, die ihn berühmt machte. Nach dem Prinzip der Berührungsassoziation fand er die Grundform des induktiven Verfahrens in der Analogie, in dem Schluß von Besonderem auf Besonderes. Unabhängig davon waren freilich im letzten Grunde die Glanzleistungen seiner Logik: die Theorie des Experiments und die Lehre von den Methoden der empirischen Kausalschlüsse. Aber in den allgemeinen erkenntnistheoretischen Auffassungen wehrte er sich in dem Streite mit Whewell hartnäckig gegen jede Anerkennung des Apriori. Er sah auch in der mathematischen Erkenntnis ebenso wie in dem Kausalitätssatze lediglich Ergebnisse empirischer Induktion; er leugnete mit Berkeley die Realität abstrakter Ideen. Er sprach von der Möglichkeit, daß es Welträume gebe, in denen das Geschehen sich ohne jede kausale GesetzmäBigkeit abspielt, und wenn er auch vollkommen recht darin hatte, daß er diesen auf Berkeley und Hume begründeten und unmittelbar daraus entwickelten Positivismus in seiner Unabhängigkeit von Comte aufrechterhielt, so kam er doch mit diesem in der Leugnung des Absoluten und in der Behauptung der empirischen Re- 
lativität aller allgemeinen Prinzipien durchaus überein. Seine Darlegung dieser Gedanken hatte vor den wissenschaftstheoretischen Ausführungen des französischen Mathematikers eine gewisse Frische und Ursprünglichkeit der Persönlichkeit voraus: und deshalb ist diese Form des Positivismus in der späteren Literatur auch auf dem Kontinent die wirksamere gewesen. Jene starke Wirkung seiner Persönlichkeit tritt auch in seiner Art der Aufnahme des Utilismus hervor, der mit der Assoziationspsychologie seit Hobbes Hand in Hand ging und für Mill unmittelbar durch das Einleben in die Gedankenkreise Benthams gegeben war. Seine psychologische Theorie gesteht auch hier mehr im Sinne Humes eine ursprüngliche Wirksamkeit sympathischer Gefühle zu, und der mannhafte Sinn, den er in seiner reichhaltigen Behandlung politischer und sozialer Fragen bewährt hat, läßt in seiner Ethik das Moment der Pflichterfüllung und der Charakterentfaltung stark hervortreten. Der Glaube an den Fortschritt der Menschheit im Guten ist für ihn auch der wesentliche Inhalt des religiösen Bewußtseins. Seine theologischen Vorstellungen haben einen ausgesprochen pessimistischen Boden; sie sind mit einer Art von positivistischer Ehrlichkeit so dualistisch, daß er in einem göttlichen Wesen nicht die Ursache des von so viel Bösem durchsetzten Universums, sondern nur einen ordnenden und mit den Mächten des Widerstandes ringenden Geist sehen mag, an dessen Arbeit das sittliche Leben des Menschen teilzunehmen habe.

Hamilton. Die schottische Lehre zeigte sich den Einflüssen der deutschen Philosophie der Natur der Sache nach sehr viel zugänglicher. Diese Einflüsse machten sich zunächst in der allgemeineren Literatur geltend, wo namentlich Coleridge und Carlyle sie aufnahmen, der erstere mehr von der Neigung zu der. romantischen Lebensauffassung ergriffen, der letztere von dem starken Persönlichkeitsbewußtsein Fichtes, mit dessen Hilfe er sich von dem Materialismus und Utilismus der Aufklärung befreit hatte. In der Philosophie wurde besonders der Einfluß Kants wirksam, und dessen Verbindung mit dem schottischen Gedankenkreise stellt sich in den fein abgewogenen Lehren von William Hamilton dar. Nach dem Prinzip der schottischen Schule ist Hamiltons Lehre wesentlich Geistesphilosophie auf psychologischer Grundlage. Dabei heben seine Analysen der seelischen Vorgänge in ähnlicher Weise, wie es in Frankreich durch Maine de Biran geschehen war, mit stärkerem Akzent die Aktivität des Bewußtseins hervor, und die. verschiedenen Stadien, die er im ErkenntnisprozeB zu unterscheiden suchte, erweisen sich sämtlich als die sich stetig steigernden Äußerungen dieser Aktivität. Insbesondere zeigt sich dies darin, daß Hamilton durchgängig in einer Weise, welche den Kantischen Einfluß deutlich erkennen läßt, den synthetischen Charakter des Bewußtseins hervorhebt. Aber gerade daraus entwickelt er in seiner Erkenntnistheorie den relativen Charakter alles menschlichen Bewußtseins. Denken als synthetische Funktion ist Beziehung $z$ wischen Inhalten, die dadurch einander bedingen. Wie das Ich nur im Verhältnis zum Nicht-Ich, wie Existenz nur im Gegensatz zur Nicht-Existenz vorstellbar ist, so können allgemein die In- 
halte des Bewußtseins, die in diesem unterschieden werden müssen, um aufeinander bezogen $z u$ werden, immer nur als bedingte vorgestellt werden. Denken heißt bedingen. Deshalb ist das Unbedingte immer nur der Grenzbegriff der äußersten Extreme, zwischen denen sich das wirkliche Denken des Bedingten bewegt, und es ist der Fehler der metaphysischen Theorien, als welche Hamilton hauptsächlich die nachkantischen deutschen Systeme bekämpft, daß sie das Unbedingte zum Gegenstand einer Erkenntnis haben machen wollen, wozu es niemals werden kann. Das Unbedingte kann deshalb nur geglaubt werden, und Hamilton begründet diesen Glauben in einer an Kant anklingenden Weise auf das BewuBtsein der moralischen Verpflichtung. Unter seinen Schülern hat namentlich Mansel aus diesem „Agnost1zismus“ Agnostizismus. eine negative Kritik aller Theologie entwickelt und demgemäß die Gewißheit des religiösen Glaubens lediglich auf die Offenbarung der Schrift zurückgeführt. Hamilton selbst meinte in seiner Bewußtseinsphilosophie ganz nach schottischer Art die Theorie des gesunden Menschenverstandes zu entwickeln, welche im Bereiche des Bedingten und Relativen die Existenz der AuBenwelt ebenso sicher wie die der inneren Wahrnehmung und die kategorialen Auffassungen der Substantialität und Kausalität ebenso 2 weifellos wie die einzelnen Data der Erfahrung gewährleistet. Er glaubte deshalb auf dieser psychologischen Grundlage von der Gesetzmäßigkeit des synthetischen Bewußtseins auch die drei nomologischen Wissenschaften begründen zu können, welche sich auf die drei Gebiete des inneren Lebens, das Vorstelten, Wollen und Fühlen, als Logik, Ethik und Ästhetik beziehen. In diesem Sinne ist seine Philosophie trotz ihrer Beeinflussung durch Kant ein ausgesprochener Typus des Psychologismus; ja man kann gerade an ihm sehen, wie stark die psychologistischen Voraussetzungen des englischen Denkens auch die Auffassung der Kantischen Problembildungen und Begriffe durchgängig gefärbt haben. Auf dem theoretischen Gebiete tritt das darin hervor, dab Hamilton von der transzendentalen Logik der kritischen Philosophie nichts wissen will, daß er die erkenntnistheoretischen Momente sogar aus der aristotelischen Logik ausschalten möchte und deshalb der Logik nur die rein formale Aufgabe zugesteht, die Normen für die Aufsuchung der Verhältnisse zwischen den wie auch immer begründeten oder zustandé gekommenen Begriffen systematisch $z u$ entwickeln. Unter diesen Verhältnissen der Begriffe erschien ihm nach dem Vorgange der empiristischen Logik des 18. Jahrhunderts als das wichtigste die Einordnung des Subjekts in die Sphäre des Prädikats. Was die Urteile zum Ausdruck zu bringen berufen sind, ist das Verhältnis der Umfänge von Subjekt und Prädikat. Damit wurde die Quantität das bedeutsamste Merkmal am Urteil, und es ward als der Beginn einer Reform der Logik angesehen, daß Hamilton von diesen Voraussetzungen her auch die Quantifikation des Prädikats verlangte, die es allein möglich mache, alle Urteile eindeutig in der Form von Gleichungen auszudrücken. So ist dieser Einfall Hamiltons zum Ausgangspunkte für die Ausbildung des logischen Kalküls geworden, welche als eine Reform der Logik im Sinne ihrer Mathe- 
matisierung durch Männer wie Boole, Venn und Stanley Jevons systematisch betrieben und namentlich in naturwissenschaftlichen Kreisen Englands und Frankreichs zu ausgebreiteter Anerkennung gelangt ist.

Darwinismus. Der Streit zwischen John Stuart Mill und Hamilton ist das wichtigste Ereignis in der Entwickelung der englischen Philosophie des I 9. Jahrhunderts gewesen. Die Gegner hatten den Boden des Psychologismus gemein, und in ihnen kamen die alten Gegensätze von David Hume und der schottischen Schule in der Weise zum Austrag, daß sie sich zum Teil gegenseitig steigerten, zum Teil aber auch einander näherten. Diese Annäherung wurde in der Folgezeit dadurch befördert, daß beide Theorien über den Standpunkt der Individualpsychologie, den Mill und Hamilton als Jünger des 18 . Jahrhunderts gleichmäßig einnahmen, durch ein neues Denkmotiv hinausgetrieben wurden, das der englischen Philosophie zunächst in der Form einer biologischen Hypothese zugeführt wurde: durch das Prinzip der Entwickelung. Es ist bekannt, wie die bioiogische Deszendenztheorie, deren Ansätze in die Wissenschaft des I 8. Jahrhunderts zurückreichen, in den Mittelpunkt des allgemeinen Interesses durch die Gestaltung gerückt worden ist, welche sie durch Charles Darwin erfahren hat. Dabei waren es nicht eigentlich die neuen Gesichts punkte, welche Darwin für seine universelle Begründung der Deszendenzlehre einführte, der Kampf ums Dasein und die natürliche Zuchtwahl, sondern es war vielmehr das methodische Verfahren seiner Lehre, welches für diese eine prinzipielle Bedeutung auch in der Philosophie auszumachen schien Man faßte die Art, wie er die Variation der organischen Typen erklärte, sehr bald in dem Sinne auf, daß damit durchgängig die Zweckmäßigkeit der Organismen auf rein mechanischem Wege erklärt werde. Das alte Problem der Teleologie, das die philosophische Weltbetrachtung so tief und heftig bewegt hatte, schien vielen jetzt auf die einfachste Weise gelöst zu sein. Das Überleben des $Z_{w}$ eckmäBigen durch die natürliche Auslese sollte das Rätsel der organischen $Z$ weckmäBigkeit aus der Welt schaffen. Diese philosophische Verallgemeinerung der entwickelungsgeschichtlichen Deszendenztheorie wurde bald, wie in England selbst, so auch auf dem Kontinent als die große Entdeckung der Zeit gepriesen, und falls sie in sich begrifflich begründet wäre, so würde ihr dieser Wert auch dann zustehen, wenn die Darwinsche Hypothese in ihrer speziellen biologischen Ausführung hier und da sich Modifikationen gefallen lassen muß. Aber der Nachweis von dem Überleben des ZweckmäBigen ist in dieser Theorie von vornherein darin gegeben, daß das ZweckmäBige als das Lebensfähige definiert wird, und die generelle Verwendung der Hypothese führte nun zu der Täuschung, als müsse alles, was aus anderen Gesichtspunkten als zweckmäßig zu beurteilen ist, sich nun auch als das Lebensfähige und deshalb Überlebende ausweisen. Auf solchen Folgerungen hat es beruht, daß in der darwinistischen Theorie das Prinzip der Entwickelung, das in der biologischen Forschung seit Lamarck, Goethe und Kant zur Geltung gekommen war, und das in seinem philosophischen Sinne so gewaltige Systeme, wie diejenigen von Aristoteles, Thomas von Aquino, 
Leibniz, Schelling und Hegel beherrscht hatte, plötzlich wie ein Neues, wie eine Offenbarung ergriffen und enthusiastisch proklamiert wurde. In Wahrheit bestand die Neuheit bei dieser Anwendung des alten Prinzips und bei dieser mechanischen Erklärung des Zweckmäßigen darin, daß prinzipiell die Zweckmäßigkeit mit dem Erfolg der in Selbsterhaltung und Fortpflanzung erwiesenen Lebensfähigkeit identifiziert wurde. Es war der Versuch, das Wertvolle mit dem Ertrag des kausalen Mechanismus gleichzusetzen, und insofern ist die durch den Darwinismus spezifizierte Form des Entwickelungs: gedankens in der Tat die ausgeprägteste Erscheinung des naturalistischen Optimismus.

Den Beweis dafür liefert das umfassende System der Philosophie, das spencer. auf dem Prinzip eines solchen naturalistisch gewendeten Entwickelungsgedankens von Herbert Spencer schon unabhängig von Darwin entworfen und nachher mit schematischer Allseitigkeit ausgeführt worden ist. Dies System der synthetischen Philosophie darf im gewissen Sinne als der reife Abschluß des empiristischen Philosophierens der Engländer überhaupt angesehen werden und verbindet die verschiedenen Richtungen, in denen sich dieses seit Bacon auseinandergelegt hatte, zu einer geschlossenen und eindrucksvollen Einheit. Spencer nimmt die Unerkennbarkeit des Unbedingten aus der Lehre Hamiltons auf. Er betrachtet das nie völlig zu lösende Problem des Unbedingten als den gemeinsamen Gegenstand der Bemühungen aller Philosophie und aller Religion; aber er ist der Meinung, daß die Erkenntnis der Phänomene, der bedingten Erscheinungen des Unbedingten, je weiter sie sich in den besonderen Wissenschaften stetig ausdehnt, um so mehr das Gesetz der Wirksamkeit erkennen läßt, nach dem sich die eine an sich unerkennbare Kraft in die Fülle ihrer Erscheinungen entwickelt. Philosophie ist ihm deshalb in Analogie zu dem positivistischen Begriff die Synthesis aller Ergebnisse der besonderen Wissenschaften unter dem Gesichtspunkte der Entwickelung. Das Wesen der Entwickelung aber - das ist das Entscheidende und Charakteristische dieses Naturalismus - wird nicht in inhaltlichen und qualitativen, sondern wesentlich in formalen und quantitativen Bestimmungen gesucht. Im Anschluß an gewisse biologische Theorien bezeichnet Herbert Spencer das Wesen der Evolution als die Tendenz aller natürlichen Gebildę, aus dem Homogenen in das Heterogene überzugehen. Er denkt diesen Vorgang so, daß.das relativ Einfache vermöge der Vielheit der Ursachen, deren Einwirkung es unterliegt, sich zur Mannigfaltigkeit differenziert, und daß andererseits die so gestaltete Mannigfaltigkeit sich wieder zu neuer Einheit zusammenschließt und integriert. Die "höheren" Einheiten, die das Ergebnis dieser Evolution sind, unterscheiden sich von den niederen somit wesentlich durch den größeren Reichtum ihres Inhalts und durch die verwickeltere Form ihrer einheitlichen Verknüpfung. Das Leben des Universums, das die Tätigkeit der unbekannten $\mathrm{K}$ raft ausmacht, besteht danach immer darin, daß der einfache Keim sich durch die Vielheit seiner Beziehungen zur Umgebung dieser in seiner Tätigkeit und in seiner Ausgestaltung anpaßt und sich als 
ein einheitliches System solcher Differenzierungen, als die integrierte Einheit erhält. Jedes Lebenssystem der physischen wie der psychischen Welt erhält sich um so sicherer und um so länger, je mehr seine Tätigkeit in ihrer organischen Einheit seinen Lebensbedingungen angepaßt ist. Dieser biologische Grundgedanke beherrscht bei Herbert Spencer die gesamte Weltanschauung. Er bestimmt auch die psychologischen und auf ihrem Grunde die logischen und die ethischen Theorien des Denkers, der durch diese Evolutionstheorie die Gegensätze des Empirismus und des Rationalismus überwunden und in eine höhere Einheit zusammengefaßt zu haben meinte. Aber wegen der psychologistischen Auffassung und Ausprägung jenes Gegensatzes richtete sich diese Lehre Spencers doch tatsächlich mehr gegen den kritischen Idealismus, wie er in England am besten durch Thomas Green und F. H. Bradley vertreten wurde. Wenn in dem individuellen Bewußtsein theoretische Sätze und praktische Willensrichtungen, die durch. die Erfahrung und das Interesse des Individuums in keiner Weise begründet sein können, doch mit unmittelbarer Evidenz als psychische Mächte sich geltend machen, so soll das evolutionistisch daraus zu erklären sein, daß derartige Vorstellungs- und Willensweisen sich im Leben der Gattung als zweckmäßige Anpassungen an ihre eigene Existenz und ihr Verhältnis zur Umgebung entwickelt, befestigt und vererbt haben. Was für das Individuum als unbegreifliches Apriori gilt, ist von der Gattung erworben und aus ihrer Lebensgestaltung begreiflich. In letzter Instanz ist deshalb Herbert Spencers System trotz seiner metaphysischen Grundanlage und trotz der kosmologischen Weite seiner Betrachtungsweise auf den Standpunkt anthropologischer Relativität bezogen. Denn alle Wertbestimmungen des logischen Denkens, die schließlich doch die letzten Kriterien aller Erkenntnis bilden müssen, und alle Wertbestimmungen des ethischen Bewußtseins, worin das Lebensverhältnis des Individuums zur Gesellschaft sich darstellt, erscheinen als die für den Bestand des Gattungslebens passenden und deshalb überlebenden Formen und Gewohnheiten des menschlichen Bewußtseins. Sie entwickeln sich unter den Phänomenen der unbekannten Kraft mit derselben Notwendigkeit, aber auch mit keinem anderen Rechte und keinem anderen Werte als alle Manifestationen des Absoluten im ganzen Umkreise des Universums. Das ist der Grundunterschied dieses naturalistischen Entwickelungssystems von dem historischen Entwickelungssystem der deutschen Philosophie, das in der Schaffung der Kulturwerte die Selbstgestaltung des Weltgeistes begreifen zu dürfen meinte.

Pragmatismus. Deshalb entspricht es dieser in gewissem Sinne abschließenden Gestaltung der englischen Philosophie durchaus, wenn neuerdings die relativistischen Konsequenzen des Evolutionssystems ir. der philosophischen Literatur Englands und besonders auch Nordamerikas mit aller Schärfe gezogen worden sind. Wenn gerade die höchsten Prinzipien theoretischer wie praktischer Art, die sich im Bewußtsein als apriorische Grundlagen allesErkennens und Wertens darstellen, schließlich doch nichts weiter sind als Ergebnisse der Anpassung des Geistes an die Lebensbedingungen des einzelnen Menschen und der Gat- 
tung, so haben alle diese Prinzipien ihren Sinn und Wert in letzter Instanz nicht eigentlich als sachlich bestimmte Wahrheiten, sondern vielmehr als die erfolgreichen Mittel zur Orientierung des Menschen in seiner Umwelt und zur Anpassung an die Erfüllung der Bedürfnisse, die er in ihr befriedigen will. Mit solchen Überlegungen droht der theoretische Wahrheitsbegriff mit allen den Formen, die er früher angenommen, in die Brüche zu gehen. Nicht mehr die naive Aufgabe, die Vorstellung mit der Realität in Übereinstimmung zu bringen, erscheint dann als das Wesen der Wahrheit, auch nicht mehr die Übereinstimmung der Vorstellungen untereinander, wie sie wenigstens noch in der nominalistischen Semeiotik als theoretisches Kriterium aufrechterhalten worden war; sondern als wahr gelten unter dieser Voraussetzung nur die Vorstellungen, welche sich als brauchbare und wirksame Mittel zum Handeln erweisen. Für diese Vorstellungsweise sind deshalb die Namen des Pragmatismus und des Instrumentalismus aufgekommen; sie nehmen natürlich verschiedene Färbungen an, je nachdem man diesen Wahrheitswert schon bei den Auffassungen und Meinungen der Individuen in Kraft treten läßt oder ihn erst für die in der Entwickelung herangezüchtete und wissenschaftlich geschulte Denkweise der Gattung in Anspruch nimmt. In der ersten Richtung ist man damit wieder bei dem alten Individualismus der Sophisten angelangt; in der zweiten, die sich gern auch als Humanismus (besser „Hominismus") bezeichnet, geht man auf die höchsten Probleme der Erkenntnistheorie gerade in dem Sinne ein, daß man in den Grundlagen aller Wissenschaften, sogar schon der mathematischen, nichts anderes anerkennen zu dürfen glaubt als Voraussetzungen, die sich in Laufe der Entwickelung als die zweckmäßigsten für die Ordnung und die Beherrschung der Tatsachen erwiesen haben. Für diese Wendung hat sich dann auch der Name Konventionalismus eingeführt. Alle diese von demselben Grundgedanken des Relativismus beherrschten Theorien haben sich im letzten Jahrzehnt von Amerika und England aus auch nach Italien und Frankreich, in neuester Zeit auch in die philosophische Literatur Deutschlands hinübergespielt und finden auf allen diesen Wegen mancherlei interessante Aṇknüpfungspunkte an die Theorie der Werte, die aus anderen Gründen in den Mittelpunkt des philosophischen Interesses gerückt ist.

III. Deutsche Philosophie. Das deutsche Geistesleben stand in den Hegels Schule. Jahrzehnten nach Hegels Tode unter dem Banne seiner Philosophie. Sie erstreckte ihre Macht über die allgemeine Literatur und über die besonderen Wissenschaften. In dem weiten Rahmen ihrer historischen Weltanschauung und ihrer dialektischen Methode schienen die Gegensätze des politischen und des religiösen Lebens nebeneinander Raum zu haben. Während die herrschenden Kreise der Restaurationszeit in Preußen den Hegelianismus als ihre Staatsphilosophie in Anspruch nahmen, schwang der Liberalismus auch in seiner extremen Opposition die Fahne der Kritik und der Dialektik, welche den Weg zum Fortschritt im Bewußtsein der Freiheit zeigen sollte: und während 
die Hegelianer auf der Berliner Universität die Übereinstimmung der Philosophie mit der Religion im Sinne protestantischer Orthodoxie verkündeten, begann in der vom Hegelschen Geiste erfüllten Jugend der heftige Sturm gegen die erneute Herrschaft der Mächte, mit denen die Aufklärung abgerechnet $z u$ haben gemeint hatte. Durch die romantische Bewegung war zum Teil eine neue Innerlichkeit religiösen Lebens erwacht: aber durch die Verbindung mit der politischen Restauration wurde dieses Leben künstlich in das Bett der alten Kirchlichkeit hineingezogen. Deshalb hat sich die Auflösung der Hegelschen Schule, ihr Zerfall in die "Rechten" und die "Linken“ an dem religiösen Problem vollzogen, und es waren, dem starken Persönlichkeitsleben der romantischen Bildung entsprechend, wesentlich zwei Fragen, an denen die Einheit der Schule auseinanderging: die nach der Persönlichkeit Gottes und nach der Unsterblichkeit der Menschenseele. Über beide hatte Hegels eigene Lehre in so unbestimmter Dialektik gehandelt, daß die entgegengesetzten Lehren bei ihm ihre Autorität suchen konnten: die orthodoxe Theologie, die mit der Persönlichkeit Gottes, mit der Trinitätslehre und mit der Unsterblichkeit des Menschen im wörtlichsten Sinne Ernst machte, und auf der anderen Seite der Pantheismus des „Geistes", der aus der allgemeinen Bewegung den einzelnen Geist als eine zeitlich vorübergehende Erscheinung heraustreten lassen und darin zu sich selbst kommen sollte. Der Gegensatz dieser Ausdeutungen des logischen Idealismus wurde ausgelöst durch das Erscheinen von Dav. Friedr. Strauß” „Leben Jesu“ im Jahre 1835. Was in der Tübinger Schule durch die besonnene Kritik Ferdinand Christian Baurs begonnen war, hatte hier mit der Theorie des Mythos als einer Schöpfung des Gesamtgeistes seine rücksichtslose Folgerung gezogen, und an diesem Eckstein schieden sich die Geister. Auf beiden Seiten wurde der theologischphilosophische Streit bald mit der äußersten Heftigkeit geführt; auf der linken Seite verband sich mit der religiösen Kritik der politische Liberalismus, und in Arnold Ruges Halleschen Jahrbüchern fand sich die sturmbereite Jugend zu hitzigem Kampfe zusammen. Wie jede derartige Bewegung blieb auch diese in ihrer stetigen Stachelung durch den Gegensatz und die Gegenmacht nicht vor der Ausladung in die äußersten Folgerungen bewahrt.

Feuerbach.

Die typische Erscheinung in dieser Entwickelung ist Ludwig Feuerbach. Er begann in den "Gedanken über Tod und Unsterblichkeit" mit einer begeisterten Verkündung des Pantheismus, die sich ebenso an Spinoza wie an Hegel anlehnte. Aber er schritt sehr bald zur Kritik der Hegelschen Philosophie fort, die ihm noch allzutief mit dem theologischen Denken verquickt $z u$ sein schien. Er fand, daß, wenn sie wesentlich eine Philosophie des Geistes bildete und der Deutung des geschichtlichen Prozesses gewachsen war, in ihr für die Natur und das sinnliche Einzelwesen kein Raum sei. Für Hegel ist nur der Geist das Wirkliche und das Wahre, die Natur dagegen das Reich des Andersseins und der Zufälligkeit: ihm gilt nur der Begriff und das Allgemeine, nicht das Ding und das Einzelne. In Wahrheit aber, so beginnt nun Feuerbach zu lehren, ist nur das Einzelne, das den Sinnen Zugängliche wirk- 
lich, das Allgemeine ist eine blasse Abstraktion, der Geist ist die Natur in ihrem Anderssein, die in sich selbst gespaltene, sich selbst entfremdete Natur. So wird das dialektische Gebäude umgestülpt, und an die Stelle des logischen Idealismus tritt der sensuale Materialismus. In den Grundsätzen der Philosophie der Zukunft erklärte Feuerbach aller begrifflichen Spekulation ebenso den Krieg wie dem idealistischen Gedanken einer geistigen Weltsubstanz. Das wahrhaft Wirkliche ist das sinnliche Einzelwesen. Der "Geist" ist die Illusion des Individuums, das Jenseits, das es sich einbildet und womit es sich schreckt. Es ist die Grundtäuschung des religiösen Vorstellens, die auch noch in den philosophischen Begriffen hängen geblieben ist, daß das Allgemeine, welches nichts ist als ein Gebilde aus Einzelvorstellungen, für etwas an sich Wirkliches, für etwas Andersartiges, für eine zweite Welt, die Welt des Geistes, gehalten wird. Diese Illusion suchte Feuerbach in seinen späteren Schriften, die vom Wesen des Christentums oder der Religion im allgemeinen handelten, durch seine anthropologisch Erklärung der Religion zu begreifen, durch die Theorie des Wunsches. Was der Mensch selbst zu sein wünscht, das Ideal, das er sich von seinem Gattungswesen macht, das stellt er sich als eine jenseitige Wirklichkeit vor und betet es als seinen Gott an. Damit aber verlegt sich nach Feuerbachs Meinung zum Unglück der Menschheit ihr Wollen und Handeln aus der wirklichen Welt, aus dem Diesseits, aus der Natur in jene Welt der Negation, der abstrakten Transzendenz. Wenn er darin die Schuld für alle bisherigen Leiden der Menschheit findet, so will er mit seiner Philosophie der Zukunft um so mehr alles Denken und Wollen auf diese Welt der Sinnlichkeit, die allein wirkliche beschränken. Der materialistischen Theorie entspricht eine Ethik der irdischen Glückseligkeit. Mit warmem Herzen, mit der vollen Hingabe seiner ursprünglichen und starken Natur, mit einem überzeugungsvollen Glauben an die Möglichkeit des irdischen Glücks für die Menschheit hat Feuerbach diese Gedanken ausgeführt. Er begründet seine Ethik der Diesseitigkeit auf das Gefühl der Mitfreude und hat sie in einem interessanten Aufsatz, der erst nach seinem Tode veröffentlicht worden ist, gegen Schopenhauers Theorie des Mitleids verteidigt. Es steckt darin eine optimistische Lebensbejahung, die mit starker Sinnlichkeit einen besseren Zustand des irdischen Daseins für den Menschen herbeiführen will. „Der Mensch ist, was er ißt", sagte Feuerbach nicht nur im Sinne seines theoretischen Materialismus: er meinte auch, man solle den Menschen gesund und sorgenfrei machen, so werde er auch gut sein, an der Freude der anderen teilhaben und dafür wirken.

Dieser Feuerbachsche Materialismus gewann durch seine Abstammung aus den Höhen der idealistischen Dialektik eine Art von metaphysischer Legitimation und andererseits durch seine ethisch-soziale Zuspitzung auf die Bejahung diesseitigen Menschenglücks eine praktische Bedeutung. Sein paradoxes Verhältnis zum Hegelianismus trat in einer Anzahl von charakteristischen Nebenerscheinungen hervor, so z. B. in der Rechtsphilosophie von Ludwig Knapp, die mit ein€r virtuosen Handhabung feinster Dialektik die 
Zurückführung aller Erscheinungen des individuellen und des gesellschaftlichen Willenslebens auf Muskelvorgänge im menschlichen Organismus darzulegen suchte, - vor allem aber in der feinsinnigsten und liebenswürdigsten Darstellung, welche die materialistische Welt- und Lebensansicht noch zuletzt in dem Alterswerke von David Friedrich Strauß „Der alte und der neue Glaube" gefunden hat. Mit umfassender Durchführung des Entwickelungsgedankens und namentlich mit Hilfe der inzwischen zur Ausbreitung gelangten darwinistischen Theorie wurde hier die Feuerbachsche Ansicht von dem materiellen Grundwesen der Wirklichkeit in dem Sinne entwickelt, daß gezeigt wurde, wie in der organischen und der geistigen Entwickelung die Natur überall „über sich selbst hinaus strebe“. Mit dieser echt dialektischen Wendung war dann freilich auch die Konsequenz, mit der Feuerbach die Ziele des seelischen Strebens in die sinnliche Diesseitigkeit gebannt hatte, wiederum verlassen und die Anknüpfung an die geistigen Lebensinhalte der idealistischen Zeit zurückgewonnen.

Marxismus. Auf der anderen Seite verband sich die dialektische Konstruktion des Hegelianismus mit dem Feuerbachschen Materialismus bei Marx und Engels zu der Theorie des Sozialismus. Die Hegelsche Lehre hatte die Wahrheit aller Vorgänge des intellektuellen Lebens in der rationalen Selbstbewegung des geistigen Weltinhaltes gesehen, der darin zum Bewußtsein kommen sollte. Wenn man nun mit Feuerbach diesen geistigen Weltinhalt durch den materiellen ersetzte, so mußte die Hegelsche Geschichtsauffassung den Charakter annehmen, daß als die Grundwahrheit aller Prozesse des Bewußtseins die Selbstbewegung des materiellen Substrates angesehen wurde. So stellten Marx und Engels in Analogie zu Feuerbach die Hegelsche Geschichtsphilosophie auf den Kopf, indem sie als das Grundwesen aller geschichtlichen Vorgänge die Bewegung der ökonomischen Bedürfnisse und Verhältnisse betrachteten und alle Erscheinungen der intellektuellen Geschichte, des moralischen und rechtlichen, des wissenschaftlichen und des künstlerischen, des religiösen Lebens nur als die Folge- und Begleiterscheinungen des ökonomischen Prozesses behandelt wissen wollten. Diese ökonomisch-materialistische Geschichtsphilosophie bekannte sich dann auch zu dem Grundgedanken Auguste Comtes, wonach das Ergebnis des naturnotwendigen und gesetzmäBig besimmten Entwickelungsganges der Geschichte schließlich das Ideal einer industrialistischen und sozialistischen Gesellschaftsordnung sein sollte. Auch hierin kam, nur wiederum mit gänzlich veränderten Wertinhalten, der Hegelianismus mit seinem historischen Optimismus, mit seinem Glauben an die Vernunft in der Geschichte zum Ausdruck. Aber wie der französische Positivismus, so stellte auch dieser dialektische Materialismus für das Leben und Streben der Gesellschaft wie des Individuums eine durchgängige und scharf begrenzte $\mathrm{Be}$ jahung der sinnlichen Diesseitigkeit dar, und in dem gleichen Sinne hat in Deutschland auch Eugen Dühring seine materialistische Theorie vom Wert des Lebens durchgeführt.

Der metaphysische Materialismus Feuerbachs verknüpfte sich nun aber 
bei seiner weiteren Ausführung notwendig mit dem anthropologischen Ma- Populäıer terialismus, der in den physiologischen und ideologischen Theorien des 18 . Jahrhunderts begründet und von den französischen Ärzten in der ersten Hälfte des 19. Jahrhunderts ausgebildet worden war. Er erschien damit als die notwendige Schlußform einer wesentlich naturwissenschaftlichen Weltanschauung, und in dieser Form, mit diesem Anspruch trat der Materialismus in der Mitte des 19. Jahrhunderts die Erbschaft der idealistischen Systeme an, die ihre Macht über die Geister verloren hatten. Auf den Universitäten hielten sich wohl noch Hegelsche und zum Teil Herbartsche Lehren oder bildeten sich gewisse eklektische Theorien aus der Verknüpfung Fichtescher und Schellingscher Motive, wie bei Weiße, Ulrici oder dem jüngeren Fichte: in der allgemeinen Meinung aber galt der Idealismus und namentlich die Dialektik als überwunden, die Naturphilosophie wurde zu einem Scheltwort für verstiegene und phantastische Meinungen, und als wissenschaftlick sollte nur noch die mechanische Erklärung nicht nur aller körperlichen, sondern auch aller seelischen Vorgänge gelten. So haben Karl Vogt und Moleschott die Lehre von Lamettrie und Broussais mit Feuerbachschem Einschlag erneuert und die mechanisch-chemische Erklärung des Lebens und der Seelentätigkeiten durchzuführen gesucht. Als nur gar mit dem Eindringen des Darwinismus das Rätsel der organischen $Z$ weckmäßigkeit mechanisch gelöst zu sein schien, da befestigte sich der Materialismus in der Selbsttäuschung, eine auf den zweifellosen Ergebnissen der Naturforschung sicher begründete und wissenschaftlich allein gültige Weltansicht zu sein. Unbekümmert um begriffliche Schwierigkeiten, denen er in seiner Darstellung leicht aus dem Wege gehen konnte, schien er von den Tatsachen selbst gefordert zu sein und allen den Unzuträglichkeiten ein Ende zu machen, in welche sich das theologische und das metaphysische Denken der Menschheit verwickelt hatte. Die kritischen und negativen Gesichtspunkte entnahm dieser Materialismus gern den positivistischen Theorien: aber deren skeptische Vorsicht gab er preis und erstarrte so zu einem naturwissenschaftlichen Dogmatismus, der alle philoso. phischen Motive als abgetane Irrtümer von sich wies und sich gegenüber dem theologischen und metaphysischen Dualismus als die einzig einheitliche Weltanschauung, als den wahren „Monismus" proklamierte. Bei der allgemeinen Erschlaffung und Ermattung des idealistischen Geistes breitete sich diese Denkart in weite Bildungsschichten aus und erzeugte in den folgenden Jahrzehnten eine Flut von populären Schriften, von denen Büchners „Kraft und Stoff“ und in der neueren Zeit Häckels „Welträtse1" als Typus gelten dürfen.

In der Abwehr gegen die materialistische Bewegung sind die beiden bedeutendsten Systeme der Philosophie entstanden, welche Deutschland im Lotze und Hartmann 1 9. Jahrhundert gesehen hat: Lotzes teleologischer Idealismus und Hartmanns Philosophie des Unbewußten. Beide freilich sind nicht im eigensten Sinne als ursprüngliche Neuschöpfungen zu bezeichnen, sondern als verspätete Nachsprößlinge an dem Hauptstamm der idealistischen Entwickelung. Beide haben 
ihre eindrucksvolle Wirkung der schönen und formvollendeten Darstellung verdankt, mit der sie Grundgedanken der idealistischen Weltansicht der kühleren, auf tatsächliche Richtigkeit und vorsichtige Folgerung gestellten Auffassung des modernen Denkens nahezulegen wußten. Beide haben den Materialismus dadurch bekämpft, daß sie mit umfassender und tief eindringender Kenntnis der naturwissenschaftlichen Theorien deren Ergebnisse in ihre philosophische Lehre aufnahmen, um ihnen dadurch die Grenzen ihrer Bedeutung für eine abschließende Weltanschauung zu bestimmen. Bei beiden macht sich, freilich in sehr verschiedener Form, in ihrer Entwickelung das Schwergewicht des sachlich-historischen Denkens von Hegel unter Ablösung von den dialektischen Formeln der intellektualistischen Konstruktion siegreich geltend.

Lotze. Die medizinisch-naturwissenschaftliche Durchbildung Lotzes lieb ihn das Recht und die Pflicht der Theorie zu einer universellen Durchführung der mechanischen Erklärungsweise der Wirklichkeit in vollem Maße anerkennen: aber von vornherein betrachtete er diesen universellen Mechanismus nur als die Erscheinung und als die Form der Verwirklichung einer geistigen Realität. In dieser Auffassung stand er dem Vater des deutschen Idealismus, Leibniz, am nächsten, dem er auch in der polyhistorischen Vielseitigkeit seiner wissenschaftlichen Betätigung und in der schmiegsamen Aufnahmefähigkeit für die mannigfachsten Anregungen persönlich verwandt war. Auch für ihn vertiefte sich deshalb der naturphilosophische Begriff des Atoms und der ontologische Begriff des Herbartschen Realen zu der Vorstellung der Monade als der geistigen Substanz: aber die Beziehungen dieser Monaden dachte er als lebendige Wechselwirkung, welche nur in der Zugehörigkeit aller dieser Einzelsubstanzen zu einer geistigen Ursubstanz, der göttlichen Persönlichkeit, begründet sein könne. $\mathrm{Zu}$ diesen Beziehungen der Wechselwirkung rechnete er auch die Vorgänge der Erkenntnis, und wenn er darin Reaktionen der Seele gegen die Einwirkungen ihrer Umwelt erblickte, so verstand es sich ihm von selbst, daß darin die Natur dieser aufnehmenden Seele mit ihrer Gesetzmäßigkeit wirksam sein muß. Wenn aber deshalb diese Erkenntnis "nur" Erscheinung zu ihrem Inhalt hat und darauf beschränkt bleibt, so ist eben das Aufblühen dieser Erscheinungswelt in den erkennenden Geistern selbst eine metaphysische Tatsache von hervorragendster Bedeutung und von einer inneren Bedeutsamkeit, welche weit hinausragt über den Inbegriff der Veranlassungen, die dafür in dem äußeren Mechanismus des Weltgeschehens vorgelegen haben mögen. Denn in dieser inneren Lebendigkeit der bewußten Monaden gestaltet sich eine Welt der Werte, deren Verwirklichung anzuregen auch den letzten Sinn ihrer mechanischen Veranlassungen ausmacht. Auch die Vorgänge der Erkenntnis sind deshalb als zweckvolle Tätigkeiten des Bewußtseins durch die Werte zu begreifen, die dadurch verwirklicht werden sollen. Von der ersten Verarbeitung des Empfindungsstoffes zur begrifflich sich formenden Wahrnehmung an bis hinauf zu den entwickelten methodischen Zusammenhängen des wissenschaftlichen Denkens sind alle Formen des lo- 
gischen Bewußtseins aus den Aufgaben zu verstehen, die das Erkennen von Schritt zu Schritt sich selber setzen muß, um schließlich den Sinn der Welt in der Verwirklichung der höchsten Werte zu begreifen: die Prinzipien der Logik liegen, wie diejenigen der Metaphysik, in der Ethik. Diese Grundgedanken hat Lotze von früh an ausgesprochen, seitdem er in seiner „Medizinischen Psychologie" den Kampf mit dem Materialismus siegreich aufgenommen hatte. Aber die Ausführung seines Systems der Philosophie hat nur die feinsinnig durchgearbeiteten Neudarstellungen seiner Logik und seiner Metaphysik gebracht: den dritten Teil, die Ethik, das System der Werte, hat er als begriffliche Lehre nicht mehr schaffen können. Dafür sind wir durch seine philosophische Arıthropologie, den „Mikrokosmus" entschädigt worden, eines der geistreichsten und liebenswürdigsten Bücher der deutschen Literatur, worin dasjenige, was Herder im 18. Jahrhundert durch seine Ideen zu einer Philosophie der Geschichte der Menschheit versucht hatte, mit der philosophischen Vertiefung des idealistischen Denkens und mit der Bereicherung des naturwissenschaftlichen und kulturwissenschaftlichen Wissens geleistet ist, die das I9. Jahrhundert gewonnen hat. Die naturwissenschaftliche Zeichnung des Lebens und die psychologische Charakteristik des Bewußtseins bilden die Grundlage, auf der die Herausarbeitung der Kulturwerte als der wesenhafte Sinn und Inhalt des historischen Prozesses der Menschheit dargelegt wird: aus dem Stoff der Geschichte ist hier ein schier unübersehbares Material prächtig behauener Bausteine gewonnen, deren Zusammenfügung zu dem begrifflichen System der Werte dem Denker nicht mehr vergönnt gewesen ist. Aber in der ganzen Struktur der Lotzeschen Philosophie lag es begründet, daß auch dieses System niemals auf absolute und abschließende Bedeutung hätte Anspruch erheben wollen. Denn in Lotzes Auffassung vom Wesen des Erkennens, welche die berechtigten Momente des modernen Pragmatismus vorwegnahm, lag es begründet, daß die Grenzen dieses Erkennens durch die Beziehungen bestimmt sind, in denen der endliche Geist zu dem Zusammenhange des Wirklichen überhaupt steht.

Eduard von Hartmann hat seine Philosophie von vornherein als den Hartmann. dialektisch notwendigen Abschluß der idealistischen Entwickelung konzipiert und in den metaphysischen Motiven der spätesten Lehre von Schelling die Möglichkeit gesucht, den Gegensatz von Hegel und Schopenhauer, von Intellektualismus und Voluntarismus, von Rationalität und Irrationalität zu überwinden. Darum gelten ihm der Wille und die Vorstellung, das Alogische und das Logische als die beiden koordinierten Attribute des geistigen Urwesens, zu dessen Bezeichnung er deshalb - es bleibt fraglich, ob sehr glücklich - den Namen des Unbewußten wählte. Da keines der beiden Momente aus dem anderen ableitbar ist, so bleibt für das metaphysische Denken nur ihre ursprünglische Synthesis, ähnlich wie dereinst bei Spinoza diejenige von Räumlichkeit und Bewußtsein übrig. Danach schienen sich tiefe Gegensätze der bisherigen Weltauffassung in eine höhere Einheit zu fügen. Die Existenz der Welt konnte auf den irrationalen Akt des Willens 
zurückgeführt und dabei doch ihre zweckvolle Gestaltung dem logischen Moment zugeschrieben werden. Vor allem aber schienen sich Optimismus und Pessimismus streitlos $z \mathrm{n}$ vereinigen: die Welt konnte als die beste unter den möglichen gelten und blieb doch als dem Akte des irrationalen Willens entsprungen ein Übel. Ja, je mehr Hartmann mit der Hereinarbeitung der naturwissenschaftlichen Entwickelungslehre den historischen Evolutionismus des Hegelschen Momentes in seiner Lehre verstärkte, um so mehr konnte die ganze zeitliche Entwickelung der Welt als ein rationaler ProzeB gedeutet werden, der zu seinem Ziele die Selbstvernichtung haben und damit den irrationalen Akt des Urwillens wieder gut machen sollte. In religionsphilosophischer Deutung führte das zu der eigenartigen Vorstellungsweise, daß alle Kulturtätigkeit des Menschen ihren Wert schließlich als die Mitarbeit an der Selbsterlösung Grottes zu haben schien. Die Philosophie des Unbewußten hatte bei ihrem Erscheinen (1 869) in der Zeit philosophischer Stagnation und materialistischer Verarmung einen glänzenden und blendenden Erfolg, namentlich auch in den Kreisen der allgemeineren Literatur, und in dieser zog sie einen ganzen Schwarm pessimistischer Schriften nach sich, in denen die Schopenhauerschen und Hartmannschen Motive mit mannigfachen Konstellationen variiert wurden. Der Schöpfer jener Philosophie aber nahm in den folgenden Jahrzehnten mit unermüdlicher, wissenschaftlich sich immer mehr vertiefender Arbeit an der Diskussion der besonderen Probleme der Philosophie urd namentlich an deren erkenntnistheoretischer Entwickelung teil, bis er in seiner Kategorienlehre eine neue systematische Überschau des Ganzen gewann.

Riickkehr zu Noch ein drittes Moment hat zur Überwindung der materialistischen Phase des deutschen Denkens geführt: das war die Rückkehr zur Kant. Sie entsprang den Bedürfnissen der mächtig fortschreitenden Naturforschung gerade bei ihren bedeutendsten Trägern. Aus der erfolgreichen Bearbeitung der Einzelprobleme traten hier mit der Zeit die großen allgemeinen Prinzipien hervor, welche sich um die beiden einander ergänzenden Momente der Erhaltung der Energie und der Entwickelung konzentrierten. Diese Ergebnisse mußten die ernsteren Forscher wieder $z u$ einer philosophischen Prüfung der Grundlagtn alier Erkenntnis führen, und eine solche Besinnung fanden sie vermöge der Ablehnung des dialektischen Idealismus bei Kant. Auf ihn hatte auch der jetzt viel gelesene Schopenhauer immer wieder hingewiesen. Seine Vernunftkritik wurde durch die eindrucksvolle Darstellung Kuno Fischers neu bekannt, und zu ihr begannen sich große Naturforscher, wie Helmholtz, Rokitanski u. a. zu bekennen. Die Auffassung des Kritizismus von seiten der Neukantianer, als deren Typus zu dieser Zeit Albert Lange mit seiner "Greschichte des Materialismus" gelten darf, war durch die Opposition gegen die materialistische und zugleich gegen die idealistische Metaphysik wesentlich so bestimmt, daß mit der Begründung einer mathematischphysikalischen Theorie zugleich deren Beschränkung auf die Erfahrung und die Unerkennbarkeit des Ding-an-sich für die Hauptsache genommen wurde. 
Dieser agnostische Kritizismus hatte den ausgesprochenen Charakter einer naturwissenschaftlichen Semeiotik, und die physiologische Lehre von der Subjektivität der Sinneswahrnehmung, die ihm durch Kant von den Empfindungen auf die Anschauungsformen Raum und Zeit ausgedehnt zu sein schien, bildete eine Zeitlang das Hauptstück der Erkenntnistheorie. Das neu erwachte Interesse an der Philosophie war also zunächst nicht metaphysisch, sondern bis zu einem gewissen Grade sogar ausdrücklich antimetaphysisch; es war wesentlich erkenntnistheoretisch und besaß deshalb keine systembildende Kraft, sondern verteilte seine Arbeit an die Mannigfaltigkeit der philosophischen Sonderdisziplinen und Sonderprobleme. Mit diesem Verzicht auf eine zentrale Neuschöpfung und mit dieser eklektischen Ausbreitung in kritische Einzeluntersuchungen macht die Philosophie in der zweiten Hälfte des 19. Jahrhunderts in Deutschland den Eindruck eines Heeres, das sich nach einem mißlungenen Angriff $z u$ neuem Sturm erst wieder sammelt, und diese Sammlung trägt deshalb zugleich den Charakter einer historischen Besinnung an sich. Die gelehrte Arbeit wendet sich mit Vorliebe der Geschichte der Philosophie zu; insbesondere für das Studium der griechischen Philosophie bot auch die Philologie des Neuhumanismus gesteigertes Interesse und verfeinerte Hilsmittel dar. Mit voller Beherrschung der geschichtlichen Tatsachen und Methoden haben aus der Fülle der Detailarbeit heraus gerade die ursprünglich dem Hegelianismus zugehörigen Historiker der Philosophie, ein Johann Eduard Erdmann, ein Eduard Zeller, ein Kuno Fischer ihre großen Werke geschaffen.

In den erkenntnistheoretischen Untersuchungen dieser Zeit, bei denen Neukantianis. Otto Liebmann eine führende und dem ursprünglichen Kritizismus am nächsten bleibende Stellung einnahm, lassen sich verschiedene Richtungen unterscheiden. Die eine ging streng dem wissenschaftstheoretischen Interesse der Kritik der reinen Vernunft nach und hielt an der Begründung der mathematisch-naturwissenschaftlichen Theorie als ihrem höchsten Ziele mit der Einseitigkeit fest, welche in der von Hermann Cohen vertretenen Form des Neukantianismus ihre äußerste Zuspitzung gefunden hat. Eine andere deutete den Agnostizismus im relativistischen Sinne und nahm dazu Elemente des französischen und englischen Positivismus in sich auf, wie es etwa von Karl Göring, von Ernst Laas und z. T. von Alois Riehl geschah, oder wie es in dem Empiriokritizismus von Rich. Avenarius die immanent positivistische Form des sog. Conscientialismus annahm. Unabhängig von dem in so wechselnden Verschiebungen behandelten transzendentalen Probleme hat $\mathrm{Chr}$. Sigwart einen wertvollen Ausbau der Logik in methodologischer Hinsicht gegeben. Am meisten aber machte sich die Bedeutung, welche die Physiologie der Sinnesorgane für jene semeiotische Erkenntnistheorie der Naturforscher gewonnen hatte, darin geltend, daB die erkenntnistheoretische Atmosphäre der deutschen Philosophie mehr und mehr eine psychologische Färbung erhielt. Man fiel in den Irrtum der Aufklärungsphilosophie zurück, wenn man Psychologismus. die Erkenntnistheorie prinzipiell als eine Lehre von der Entstehung und der 
Entwickelung der Vorstellungen behandelte, und wenn man diese Methode dann folgerichtigerweise auch auf ethische und ästhetischeProbleme übertrug. So begann eine Periode des Psychologismus, und diese Auflösung der Philosophie in Psychologie ist wiederum den psychologischen Studien in außerordentlich hohem Maße zugute gekommen. Es verstand sich dabei von selbst, daß die nahen Beziehungen, in denen der erkenntnistheoretische Neukantianismus zur Na^urforschung stand, und namentlich die vernittelnde Stellung, welche die Sinnesphysiologie gewonnen hatte, zu einer vorwiegend naturwissenschaftlichen Behandlung dieser Psychologie Anlaß gaben.

Pischoplysik. Dazu kam noch eine besondere Anregung, die von einem sinnigen Forscher ausging, dessen Grundanschauungen ursprünglich nicht ohne Beziehungen zu der romantischen Naturphilosophie gewesen waren. Gustav Fechuer. Theodor Fechner kam von der Voraussetzung des intimen Lebenszusammenhanges zwischen Leib und Seele her und wollte dessen Gesetzmäßigkeiten mit den experimentellen Methoden der Naturwissenschaft beikommen. Er begründete die Psychophysik durch den Versuch, die psychischen Größen indirekt zu messen und auf diesem Wege das Verhältnis von Reiz und Empfindung durch ein mathematisch formulierbares Gesetz auszudrücken. Dabei lag als allgemeine Vorstellung die spinozistische Idee des psychophysischen Parallelismus zugrunde, wonach jeder Erscheinung der physischen Welt eine solche der psychischen und umgekehrt entsprechen sollte: ebendies Verhältnis sollte durch die psychophysischen Gesetzmäßigkeiten festgestellt werden. Aber jener Parallelismus war nur durchführbar, wenn ausnahmslos $z u$ allen einzelnen Erscheinungen und zu allen Zusammenhängen der Körperwelt entsprechende Korrelate in Gebilden der seelischen Wirklichkeit angenommen wurden: die Vorstellungen von einem untermenschlichen und unteranimalen, wie von einem übermenschlichen Seelenleb@n waren somit bei Fechner nicht bloß liebenswürdige und interessante Phantasien, sondern folgerichtige Anwendungen der psychophysischen Grundvoraussetzung des Parallelismus. Deshalb hat sich auch die Theorie vom psychophysischen Parallelismus durchaus als die allgemeine Hypothese der Psychophysik erhalten: sie fand im Zusammenhange mit dem panpsychistischen Nebengedanken auch außerhalb der im engeren Sinne psychologischen Kreise bei Männern wie Fr. Paulsen Anklang. Als Hauptargument pflegt für sie angeführt zu werden, daß das Prinzip der Erhaltung der Energie in der Tat die Möglichkeit der psychophysischen Kausalität ausschließt, wenn man nicht zu künstlichen und unhaltbaren Ausflüchten greifen will. Freilich verlor sich in den mit Eifer eingerichteten und betriebenen psychophysischen Laboratorien vielfachı der Sinn für die allgemeineren Fragen zugunsten der experimentellen Einzeluntersuchungen, die zum größten Teil durchaus in die Sphäre der Sinnesphysiologie gehörten und für die Philosophie nur die Bedeutung eines ihrem eigenen Wesen und Interesse widersprechenden Surrogats haben konnten. Denn wenn sich der bedeutendste Führer dieser psychophysischen Studien, Wilhelm Wundt, in der umfassenden Bearbeitung der Ethik und der 
Logik zu seinem System der Philosophie entwickelte, so lagen dessen voluntaristische Grundmotive in seiner Theorie der Apperzeption, welche von den im engeren Sinne psychophysischen Untersuchungen völlig unabhängig sich bereits in der ersten Form seiner physiologischen Psychologie entwickelt und im metaphysischen Sinne durch die allgemeine Neigung der Zeit verstärkt hatte, den Kern von Seele und Welt im Willen zu suchen.

Im ganzen befand sich die deutsche Philosophie während der letzten Nietzsche. Jahrzehnte des 19. Jahrhunderts in einem Zustande buntester Zersplitterung, der die Sammlung zu neuen Leistungen noch nicht gelungen war. Die Richtung aber, in der dies schließlich geschehen sollte, wurde durch die Stimmungen und die Bedürfnisse der Zeit bedingt, in der das deutsche Volk gewaltige Wandlungen seines äußeren Daseins erlebte und ihnen sein inneres Wesen mit hastender und aufgeregter Unsicherheit anzupassen im Begriffe war. Diesem Zustande der inneren Auflösung und leidenschaftlichen Neubildung mit seinen starken und gesuriden Lebensmotiven und mit seiner unfertigen, sich selbst zerstörenden Leidenschaftlichkeit hat der Dichterphilosoph Ausdruck gegeben, der um die Wende des i9. und 20. Jahrhunderts die blendende, bald grell beleuchtende, bald verwirrende und umnebelnde Erscheinung in der deutschen Literatur gewesen ist: Friedrich Nietzsche. Mit elementarer Gewalt kommen in seinen Dichtungen die großen Gegensätze unseres heutigen Lebens zum Wort: die durch die politische Bewegung des I9. Jahrhunderts emporgetriebene Steigerung des Nationalitätsbewußtseins und die in der mächtigen Ausweitung des politischen Lebens neu sich stärkende Idee der Humanität, - die breite Schablonenhaftigkeit des zum Selbstbewußtsein reifenden sozialen Massenlebens und der gesteigerte Persönlichkeitstrieb des gegen solche Unterdrückung sich wehrenden Individuums, - die ungeheure Belastung des modernen Bewußtseins mit der ganzen historischen Tradition, aus der es hervorgewachsen ist, und der Drang, mit völlig neuer Leistung und Gestaltung das eigene Daseinsrecht zu bewähren, der faszinierende Eindruck einer in rapider Ausgestaltung begriffenen Außenkultur und das tiefe Bedürfnis, darin und dagegen den ïbergreifenden Wert geistiger Lebenswirklichkeit aufrechtzuerhalten, - und in alledem endlich eine Überlebtheit der zu Institutionen erstarrten religiösen Lebensformen der Menschheit und dabei das heiße Drängen und Ringen nach einem unmittelbaren erlösenden und erhebenden Verhältnis des Individuums zum Universum. Alle diese Gegensätze des Zeitbewußtseins erscheinen in dem mit dem ganzen Gehalte der historischen Kultur durchtränkten Geiste Nietzsches wie in heftig strudelndem Fluß, und damit zersetzt sich ihm die ganze bisherige Wertsubstanz des menschlichen Lebens. Aus der historischen Relativität können nicht die Massen, sondern nur die großen Individuen zu neuen Werten gelangen, und wenn die Umwertung aller Werte gelingen soll, so ist das nur dadurch möglich, daß der Denker neue Werte schafft, daß er sich zum Gesetzgeber des Wertlebens der Menschheit macht. Diese neue Gesetzgebung aber bestimmt sich durch den Gegensatz des Individuums gegen 
die Massen. Sie erhebt sich deshalb über die historisch für die „Viel-zu-vielen“ geltenden Regeln, sie ist jenseits von Gut und Böse; sie gibt dem starken Individuum das Recht und die Pflicht, seinen Willen zur Macht grenzenlos zu betätigen. Für ihn soll nur als wahr gelten, was ihn in seiner Selbstbehauptung fördert, ihm ist alles erlaubt, was diese seine Selbstverwirklichung gewährleistet. Nur diese unbeirrte, freudige Lebensbejahung wird imstande sein, ein höheres und glücklicheres Geschlecht heraufzuführen. Das Übermenschentum ist von Nietzsche als das Ideal der genialen Persönlichkeit im aristokratischen Gegensatz gegen die mit dem ganzen Wust der Tradition belasteten Massen empfunden: aber es wandelt sich bei ihm in das Bild eines höheren Typus der menschlischen Gattung überhaupt. Die poetische, berückend schöne Darstellung, die Nietzsche seinen Ideen zu geben vermochte, läßt die Widersprüche der mannigfachen Gedankenmotive verschwimmen, die er aus den Zeitbestimmungen wie aus den verschiedenen kulturphilosophischen Theorien seit Rousseau in das reiche Gemälde seiner Lebensdichtung hineingewoben hat. Aber gerade weil in diesem widerspruchsvollen Schillern alle Motive des Zeitlebens ihren glänzenden Ausdruck fanden, weil namentlich der ungelöste Widerspruch zwischen den Werten der intellektuellen Kultur und dem leiderschaftlichen Drang nach tätiger Machtentfaltung den Grundton seiner prophetenhaften Dichtungen ausmachte, hat er mit seinem Progiamm der Umwertung aller Werte als der Denker seiner Zeit erscheinen können.

Allein der Gegensatz zwischen dem Apollinischen und dem Dionysischen, unter dessen Wucht Nietzsche selbst zusammengebrochen ist, enthüllt sich einerseits als der des Rationalen und Irrationalen, des Logischen und Alogischen, der in der Metaphysik von Fichte bis Hartmann gewaltet hatte, und andererseits als der Gegensatz zwischen der intellektuellen Kultur und dem naturwüchsigen Machtwillen des Individuums. Wenn die Philosophie in ihrer begrifflichen Arbeit den Problemen nachgehen sollte, welche hinter den schillernden und glitzernden Anschauungen Nietzsches als die treibenden Kräfte stecken, so mußte sie den Gedanken aufnehmen, mit dem Lotze die Aufgabe aller Metaphysik dahin bestimmt hatte, sich auf das System der Werte zu besinnen, das sich in dern ganzen Mechanismus der Erscheinungswelt verwirklicht und verwirklichen soll. Nicht der Schöpfer oder Gesetzgeber der Werte darf der Philosoph sein wollen, aber der Sucher und Gestalter der Werte: und nicht um die Machtwerte des einzelnen handelt es sich, sondern um die in der historischen Entwickelung zur Geltung gelangenden Kulturwerte, welche in einer höheren geistigen Wirklichkeit begründet sind. Diesem Zuge und diesem Bedürfnis der Zeit folgend, hat die neueste Philosophie in Deutschland die sachliche Bedeutung des Idealismus neu zu erfassen begonnen. Schon für die Auffassung Kants ist die agnostische Erkenntnistheorie mehr in den Hintergrund getreten gegenüber der Bedeutsamkeit seiner Begründung des ethischen, ästhetischen und religiösen Wertlebens und der metaphysischen Beziehụngen, worin er es zu verankern suchte. Und 
im gleichen Sinne haben die großen idealistischen Systeme Fichtes, Schellings und Hegels neue Würdigung gefunden: die äußeren Wunderlichkeiten der dialektischen Konstruktion werden als die zeitliche Hülle abgestreift, und der hohe sachliche Gehalt tritt um so wirksamer hervor. Dieser neue Idealismus, der in den mannigfachsten literarischen Erscheinungen des letzten Jahrzehnts zutage tritt, ist noch im Werden und Gären begriffen. Bald stellt er sich mehr als eine Rückkehr zu Fichte, bald mehr als eine solche zu Schelling oder Hegel dar, und wie in der allgemeinen Literatur so spielt auch in der Philosophie die Neuromantik ihre Rolle. Dem religiösen Zuge, der dieser nicht ungefährlichen Analogie gemäß in jener Bewegung waltet, hat am meisten Rudolf Eucken durch die unermüdliche Arbeit Ausdruck gegeben, womit er das Zeitalter von der Versunkenheit in den Rausch der äußeren Kultur zur Besinnung auf einen geistigen Lebensinhalt und dessen religiösen Lebensgrund aufgerufen hat.

Aber die Philosophie der Werte ist auch aus unmittelbar wissenschaftlichen Bedürfnissen denjenigen des allgemeinen Bewußtseins entgegengekommen. Denn seitdem die Wissenschaft sich für die Zwecke ihrer Welterkenntnis in die Mannigfaltigkeit der einzelnen Disziplinen hat gliedern müssen, wird der Weg der Philosophie zur bewußten Gestaltung des Kulturgehaltes ihrer Zeit immer durch die Kritik der besonderen Wissenschaften hindurchgehen müssen. Das ist mit bewußter Methode zum erstenmal durch Kant geschehen. Aber sein Begriff der Wissenschaft war durch den Hinblick auf die Begründung der mathematisch-physikalischen Theorie einseitig be. stimmt. Die gewaltige Entwickelung der geschichtlichen Wissenschaft, die das I9. Jahrhundert gebracht hat, verlangte ihre Berücksichtigung in diesem kritischen Gange des Philosophierens oder dasjenige, was Wilhelm Dilthey als die Aufgabe einer Kritik der historischen Vernunft bezeichnet hat. Allein diese Kritik darf nicht in der Timidität eines psychologischen Relativismus stecken bleiben, sie wird immer darauf gerichtet sein müssen, wie die Kantische, von dem Wechsel der historischen, anthropologisch bedingten Wertungen $z \mathfrak{u}$ den ewig gültigen Inhalten vorzudringen, die in einer übergreifenden geistigen Realität begründet sind. Die so bestimmte Ausgestaltung der kritischen Methode führt also von selbst zur Theorie der allgemeingültigen Werte, auf denen, wie die Gesamtheit des Kulturlebens, so auch die Gesamtheit aller wissenschaftlichen Arbeit aufgebaut ist. Indem die Philosophie diese Aufgabe verfolgt, steht sie in den tiefsten und reichsten Beziehungen $z u$ den übrigen Wissenschaften und zu den Lebensinhalten ihrer Zeit. 


\section{Literatur.}

Von den Gesamtdarstellungen der Geschichte der Philoscphie kommen außer Hegels Vorlesungen (Gesammelte Werke Bd. 15) hauptsächlich in Betracht: JoH. Ed. ERdmanN, Grundriß der Geschichte der Philosophie, Bd. 2, 4. Aufl., hg. von Benno Erdmann (1896); W. Windelband, Lehrbuch der Geschichte der Philosophie, 6. Aufl. (1912); R. Eucken, Die Lebensanschauungen der großen Denker, 7. Aufl. (1907); E. v. HarTManN, Geschichte der Metaphysik, Bd. 2 (I900); CH. Renouvier, Histoire et solution des problèmes métaphysiques (1901): - über die neuere Philosophie: J. E. ERdManN, Versuch einer wissenschaftlichen Darstellung der Geschichte der neueren Philosophie, 6 Bde. (1834-53); H. ULRICI, Geschichte und Kritik der Prinzipien der neueren Philosophie, 2 Bde. (1845); Kuno FISCHER, Geschichte der neueren Philosophie, 10 Bde., 4. Aufl. (1897-1904); W. WiNDELBAND, Die Geschichte der neueren Philosophie in ihrem Zusammenhange mit der allgemeinen Kultur und den besonderen Wissenschaften, 2 Bde., 5. Aufl. (1911); F. JodL, Geschichte der Ethik in der neueren Philosophie, 2 Bde., 2. Aufl. (1906); B. PuEnjer, Geschichte der christlichen Religionsphilosophie seit der Reformation, 2 Bde. (1880-83). - Für die besondere Literatur ist die bekannte Bibliographie von UEBERWEG-HEINZE, GrundriB der Geschichte der Philosophie, Bd. 3 und 4 heranzuziehen.

\section{A. Die Philosophie der Renaissance.}

MOR. CARrière, Die philosophische Weltanschauung der Reformationszeit, 2. Auf. (1887); W. Dilthey, Auffassung und Analyse des Menschen im 15. und 16. Jahrhundert (Archiv für Geschichte der Philosophie, Bd. 4 und 5).

I. G. VoGt, Die Wiederbelebung des klassischen Altertums, 2. Aufl. (1880f.); A. Della TORRE, Storia dell' academia platonica di Firenze (1902).

II. K. Lasswitz, Geschichte des Atomismus vom Mittelalter bis Newton, 2 Bde. (1890); W. Dilthey, Der entwicklungsgeschichtliche Pantheismus (Archiv für Geschichte der Philo. ophie, Bd. 6).

III. Jak. BuRCKhardT, Die Kultur der Renaissance in Italien, 4. Aufl. (1886); K. HaGeN, Deutschlands literarische und religiöse Verhältnisse im Reformationszeitalter, 3 Bde. (1868); G. JellineK, Allgemeine Staatslehre, Bd. I, 2. Aufl. (1906).

B. Die naturwissenschaftlich-metaphysischen Systeme.

W. Dilthey, Das natürliche System der Geisteswissenschaften im 17. Jahrhundert (Archiv für Geschichte der Philosophie, Bd. 6 und 7): E. KASSIRER, Das Erkenntnisproblem in der Philosophie und Wissenschaft der neueren Zeit (2. Auf. I9I).

I. Rich. Falckenberg, Grundzüge der Philosophie des Nicolaus von Cusa (I 880).

II. D. Berti, Giordano Bruno, sua vita e sue dottrine (1889); BaLdachinI, Vita e filosofia di Tommaso Campanella, 2 Bde. (1840 und 43).

III. H. A. FechneR, Jac. Böhme, sein Leben und seine Schriften (1853).

IV. Ch. DE Remusat, Bacon, sa vie, son temps, sa philosophie (1854); E. A. Abbort, Francis Bacon, an account of his life and works (1885).

V. Fr. Boullier, Histoire de la philosophie cartésienne, 3. Aufl. (1868).

VI. F. Tönnies, Hobbes' Leben und Lehre (1896); J. G. DREydorfF, Pascal, sein Leben und seine Kämpfe (1870); V. Grraud, Pascal (1900): E. Pfleiderer, Arnold Geulincx als Hauptvertreter der okkasionalistischen Metaphysik und Ethik (1882); J. P. N. LAND, Arnold 
Geulincx und seine Philosophie (1895); F. PrLlnN, Malebranche et ses critiques (L'année philosophique Bd. 3).

VII. P. CaMerer, Die Lehre Spinozas (1877).

VIII. E. Dillmann, Eine neue Darstellung der Leibnizschen Monadenlehre (1891);

E. CASSIRER, Leibniz' System in seinen wissenschaftlichen Grundlagen (1902).

\section{Die Philosophie der Aufklärung.}

LECKY, History of the rise and influence of the spirit of rationalism in Europe, 2 Bde. 6. Aufl. (1873); ED. ZELLER, Geschichte der deutschen Philosophie seit Leibniz (1873).

I. E. GRIMM, Zur Geschichte des Erkenntnisproblems von Bacon zu Hume (1890); G. v. Hertuing, Locke und die Schule von Cambridge (1892).

II. FR. JODL, Leben und Philosophie Dav. Humes (1872); M. DessorR, Geschichte der neueren deutschen Psychologie, I Bd., 2. Aufl. (1902).

III. E. TroeltSCh, Die englischen Moralisten (Herzogs Enzyklopädie, 3. Aufl., S. 436 ff.); C. v. Gizycki, Die Philosophie Shaftesburys (1876); R. Eucken, Bayle und Kant (Beiträge zur Einführung in die Geschichte der Philosophie [1906] S. 82 ff.); H. LOTZE, Geschichte der Ästhetik in Deutschland (1868).

IV. VICT. LECHLER, Geschichte des englischen Deismus (1841).

V. Dav. Fr. Strauss, Voltaire (1870); G. Desnolresterres, Voltaire et la société au 18. siècle (1873); K. Rosenkranz, Diderot, sein Leben und seine Werke (1866); J. MORLEY, Diderot and the Encyclopaedists (1878); R. FESTER, Rousseau und die deutsche Geschichts philosophie (1890); H. HÖFfDING, Rousseau und seine Philosophie (1897); R. HaYM, Herder nach seinem Leben und seinen Werken, 2 Bde. (1877-85); E. KUhnemans, Herder 2. Auf. (1912); BEN. CROCE, La filosofia di Giamb. Vico (I9II).

D. Kant und der deutsche Idealismus.

Fr. HARMS, Die Philosophie seit Kant (1876).

I. G. SimMEL, Kant (1904).

II. E. LASK, Fichtes Idealismus und die Geschichte (1902); XAvier LÉon, La philosophie de Fichte (1902); FR. Medicus, Fichte (1905); R. UNGER, Hamann. und die Aufklärung (1912); F. A. SCHMID, Fr. H. Jacobi (1908).

III. R. HAYM, Die romantísche Schule (1870); RIc. HUCH, Die Blütezeit der Romantik (1901), Ausbreitung und Verfall der Romantik (1902); OsC. EwalD, Die Probleme der Romantik (1904).

IV. ED. v. HartmanN, Schellings philosophisches System (1897).

V. K. Rosenkranz, Hegel als deutscher Nationalphilosoph (1870); Rud. Haym, Hegel und seine Zeit (1857); W. Wallace, Prolegomena to the study of Hegels philosophy (1890).

VI. G. Hartenstein, Die Probleme und Grundlehren der allgemeinen Metaphysik (1836); W. KinkeL, J. Fr. Herbart, sein Leben und seine Philosophie (1903).

VII. R. HAYM, Arthur Schopenhauer (1864); R. LEHMANN, Schopenhauer, ein Beitrag zur Psychologie der Metaphysik (1894); E. GrIESEBACH, .Schopenhauer (1897); G. Simmel, Schopenhauer und Nietzsche (1907).

E. Die Philosophie des 19. Jahrhunderts.

J. Tr. MERz, History of European thought in the $19^{\text {th }}$ century, 2 Bde. (1904).

I. H. Ravaisson, La philosophie en France au 19 e siècle (1868, deutsch I 889); L. Ferraz, Histoire de la philosophie en France au I gième siècle, 3 Bde. (1880-89); É. BouTroux La philosophie en France depuis 1867 (Verhandlungen des III. Internationalen Kongresses für Philosophie in Heidelberg 1908).

II. D. Massón, Recent English philosophy, 3. Auf. (1877); Har. Höfrding, Einleitung in die englische Philosophie der Gegenwart (1890).

III. W. WindELBAND, Die Philosophie im deutschen Geistesleben des I9. Jahrhunderts (1909). 


\title{
REGISTER
}

\author{
Von Dr. Richard Böhme.
}

Bei mehrfach angeführten Namen und Stichworten sind die Hauptstellen durch einen Stern bezeichnet.

Abälard, Peter. 271. 345. 373. 375. 379. 408. 416.

Abbilder der Dinge unmittelbarer Gegenstand derSinneswahrnehmung nach Epikuros. 185. - _ - Occams Bekämpfung der Vorstellungen als. 419.

'Abdaikâdir al-Dschîlânî. $32 \mathrm{I}$.

Abel, Jakob Friedrich von. 505.

Aberglaube. 3. 5. 14. 76. 260. 318. 440. 456. Abhängigkeit,Schlechthinige, Schleiermachers.

537.

Abraham b. Chijja. 331.

Abraham b. Ezra. 331 .

Abraham ibn Daud. 333.

Absalon, Abt von Springkirchbach. 347.

Absolute, Das, bei Thomas. 387 .

-, - , s. Seiende, Das wahrhaft.

Absolutismus. 477. 489.

Absorption in der Natur nach der indischen Philosophie. 37. 44 .

Abstraktion. 152. 255. 500. 567.

Abu-l-Faradsch Furkan b. Asad. 330.

Abu Sa'îd Abu-1-Cheir. 319.

Adam, Bischof von St. Asaph. 416.

Adelhard von Bath. 340. 342. 362. 373. *377. 408.

Adiaphora nach der Stoa. 219.

Aegidius Colonna von Rom. 374. *406. 4 II. 421.

- von Lessines. 406.

Aenesidemus. 181. ${ }^{*} 236$.

Ästhetik, Stellung der, in der Wissenschaft. 509.

-, Allgemeine, ñach Herbart. 551 .

\#. Transzendentale. 524. "529.

Äther. 162.

Affekte. 12. 124. 167. 223. 474. 476. 488.490.

Affektionen. 185. 186.

Agnostizismus. 569.581 .582$.

-, s. auch Skepsis.

Agricola, Rudolf. 436.
Agrippa von Nettesheim. 417. 440.

Ahnenverehrung. 60.

Ailly, Pierre d'. 356. 422 .

Akademie, Alte platonische. $178 \mathrm{ff}$.

-, Mittlere -. 178. $228 \mathrm{ff}$.

-, Neuere -. 178. 200. 230 ff.

-, Florentiner -. 435.

akl. 303.

Akt, Aktualität. I53. 156. ${ }^{*}$ 57. 160. 205. 251. 356. 360.388 .389 .

Alanus von Liile. 340. 362. "377. 379. 417.

Albert von Sachsen. 422.

Albertisten. $385.4 \mathrm{II}$.

Albertus Magnus. 323. 340. 344. 348. 349. 350. 352. 359. $364 \cdot 367 \cdot 369 \cdot 374 \cdot 381.382$. $383 .{ }^{*} 384.389 .390 .391 .397 .403 .408 .410$. 423. 425.438.

Alchimie. $44 \mathrm{I}$.

Alembert, Jean d'. 516 .

Alexander von Aphrodisias. 26r. 275. 308. 315. 322. 327. 378. 436.

Alexander von Hales. 367. 374. *381. 382. 385. 410. 411 .

Alexander III., Papst. 375.

Alfâtâbí. *315. 316. 317. 322. 324. 335. 364 . 378. 380. 388. 398. 409 .

Alfredus Anglicus. 408.

Algazel. 425.

Alhazen (Alhaitam). 361. 409. 410.

al-Kiftî, Dschamâl al-din. 327.

al.Kindî. 314. 315. 316. 317. 378. 452.

Alkuin. 370.

Allegorien Avicennas. 319.

All-Eine, Das s. Brahma.

All-einslehre des Parmenides. "I06. 110.

Allgemeinbegriffe, Erkenntniswert der, nach Aristoteles. I52. 544.

_, _ _ nach der Auf klärungsphilosophie. 500.

-, -, - nach Nikolaus von Kues. 450.

-, -, - nach Spinoza. 490. 
Allgemeinbegriffe, Frage nach der Natur der. 355. 373. $4 \mathrm{I} 2$.

Almagest des Claudius Ptolemaeus. $3 ; 8$.

„Als-ob" Kants. 530. 531.

Alsted, Johann Heinrich. $4 \mathbf{I} 7$.

Althus, Johannes. 447.

Altprotestantismus. 445 .

Altruismus in der stoischen Ethik. 226.

- im Utilismus. 508. 509. 510.

Alvarus Pelagius. 402.

Amalrich von Bennes. 371. 381. 423.

Ambrosiaster. 397.

Ambrosius von Mailand. 276. 280. *290. 368 . 400.

Ameinias. 106.

Ammonius Sakkas. 242. 248. 287. 315.

Ampère, André Marie. 559.

Ampliation. 357.

amr. 318. 333 .

Analogie, Begriff der. 388. 567.

Analytik, Transzendentale, Kants. $524 \mathrm{fi}$.

Anamnesis der Seele. I34.

Anaxagoras. 96. 105. 110. *1 I4. I16. 266.

Anaxarchos. I8I.

Anaximandros. 1.96. 99.101 .102 .103 .107 .115$.

Anaximenes. I. 96. ${ }^{*}$ I00. IO2. II 2 .

Ancillon, Jean Pierre Frédéric. 559.

Andéli, Heinrich d'. 376.

Andreae, Antonius. 416.

Andronikos von Rhodos. 177. 201.

Annahme nach Aristoteles. 167.

Anpassung. 572.573 .

Ansai, Yamazaki. 82.

Anschauung. 7 .

- im Unterricht nach Campanella. $45 \%$.

Anschauungsbilder nach Thomas. 392. *395.

Anselm von Canterbury. 272. 347. 349. 37 I. 373. *374. 4I8. $42 \mathrm{I}$.

Anthropologie Descartes'. 473.

- Hobbes'. 476.

- Platons. 139.

- Spinozas. 488 .

-, Thomistische. 391 .

Antignostiker. ${ }^{*} 269.285$.

Antinomien Kants. 527.

Antinomismus im späteren Mittelalter. 371. 381.423.

Antiochos von Askalon. I78. 200. 233. ${ }^{*} 234$.

Antipatros von Tarsos. 200. 230.

Antipoden. 359.

Antisthenes. I23. 124. *125.

Anthithese bei Hegel. 543 .

ānvīkșikī. 32. 34 .

Apathie, Stilpons Ideal der. 127.

一, Stoisches - - 225. 236. 247.

»Apfelbuch $\ll .308$.

Apodeiktik, Aristotelische. I 5 I.

Apokatastasis. 288. 289.

Apollinaris von Hierapolis. 265.
Apollonios von Tyana. 239.

Apologeten, Verhältnis der, zur Philosophie. 265 f. 276.282 .

Apoproēgména. 220.

"Aporien". 345.

Apostellehre. 265.

Apperzeption, Fechners Theorie der. $5^{3} 3$.

- nach Leibniz. 495.

-, Transzendentale, Kants. 526.

Apriori nach Kant. 523. 527.

-, Mills Ablehnung des. 567.

- in Spencers Philosophie. 572.

Apriorität der allgemeinen Formen nach Pla. ton. 129.

- der Kategorien nach Platon. I30.

Apuleius von Madaura. 362. 364.

Arbeitstag, Vierstündiger, nach Campanella. 457 .

arbitrium liberum s. Willensfreiheit.

Archelaos. I09.

Archytas. 105.

Aristides von Athen. 265. 266. 27 I.

Aristippos. 123. *124. 182.

Aristippus, Henricus. 362. 363 .

Ariston von Chios. 200. 222. 230.

Ariston von Keos. 177 .

Aristoteles. Aristotelismus. 7. 26. 49. 68 . 97. 98. IIO. III. II2. I14. I18. 138. ${ }^{*} 148-175$. I 77. I 78. 180. I8I. 204. 205. 209. $217 \cdot 229.237 \cdot 248.249 \cdot 253 \cdot 258 \cdot 262$. 274. 288. 296. 3c8. 314. 316. 324. 334. 338. 340. $346.348 .350 .352 .355 .356 .{ }^{*} 363.365$. $367.372 .373 \cdot 378.380 .381 .383 \cdot 386.387$. 388. 389. 390. 391. 392. 394. 395. 398. 400. 403. 404. $4^{n} 5$. 406. 408. 409. 410. 414.423. 435. 446. 494. 544 .

Aristotcliker der Renaissance. 436.

Aristotelismus, Arabischer. 307.313.333. 398. -, Jüdischer. $332 \mathrm{ff}$.

-, Scholastischer. $363 \cdot 365 .{ }^{*} 383$ ff. $444 \cdot 478$. Aristoxenos. 175 .

Arius. Arianismus. 279. 288.

Arius Didymus. 235.

Arkesilaos. 178. 181. 200. ${ }^{* 228.231 .232 . ~} 234$

Armut. 399.

Arnobius. 266. 277.279.

Artbegriffe. 155.373 .

al-Asch'arî, Abu-l-Hasan. 305.

Asch'ariten. 305. 306. 328.

ashâb al-adl wal-tauhîd. 303 .

Asclepius des Apuleius. 363 .

Askese. Asketentum. 46. 313. 325.

Assoziation der Ideen. 476.

Assoziationen, Gewohnheitsmäßige, nach R. Bacon. 409. $4 \mathrm{II}$.

Assoziationspsychologie. 5or. 510. 548.55 r. 556. 567.568.

Astrologie, Stellung der Philosophie zur. 317. 318. 
A taraxie. 183. 193.

Atemregulierung des Yogin. 47.

Athanasius. 279. 280.288.

Atheismus. 190. 517 .

Athen als Sitz dergriechischen Philosophie. Io9.

Athenagoras von Athen. 265. 267. 274. 278.

Atlantis, Nova, Fr. Bacons. 463.

Atman. 31. 37. 44. 45.

Atome, Atomistik. 50. "118ff. 160. 163. 176. 422. 443. 454. 465. 478. 493. 578 .

- Epikurs. 188.

-, Stellung der Mutakallimûn zur. 306.

Attikus (Platoniker). 279.

Atsutane, Hirata. 92.

Attribute der Substanz nach Spinoza. 486.

Aufgabe s. Problem.

Aufklärung, Weltgeschehen als Proze $B$ der, nach Leibniz. 494.

-, Philosophie des Zeitalters der. 497. 517. 518. 520.527 .555$.

Aufklärungsbewegung, lonische. 97. 122.

Aufklärungstendenz Epikurs. 190.

Augustiner, Philosophischer Thomismus der. 406.

Augustinus, Aurelius. 265. 270. "271. 272. 274. 277. 278. 28 I. 282. 284 . 29off. 339. 340. 346. 347. 350. 359. 364. *365 ff. 369. 373 . 374. 375. 376. 380. 382. 387.388 .389 .390$. 39I. 400. 403. 409. 418 . 420. 421. 425.444. 446. 469. 480. 482.

Augustinus Triumphus. 402. 406.

Aulus Gellius. 364 .

Aureoli, Petrus. $4 \mathrm{r} 8$.

"Aurora" Jakob Böhmes. 458.

Ausdehnung wesentliches Attribut der Körper nach Descartes. 472.

- Attribut der unendlichen Substanz nach Spinoza. 486.

Ausflüsse der Dinge unmittelbarer Gegenstand der Sinneswahrnehmung nach Epikuros. I85.

Auslese, Natürliche. 570.

Außenwelt. 38. 73. 293. 318. 420. 422. 481. 498. 499. 566. 569.

Ausstrahlungslehre s. Emanationslehre.

Autarkie. 127. 174.

Autorität. 52.

- nach Comte. 563.

-, Unterordnung unter die, in der mittelalterlichen Philosophie. 339 f. 345. 380.

-, - - - nach Locke. 499.

-, Verherrlichung der, im Traditionalismus. 558.

Avempace $=$ Ibn Bâddscha.

Avenarius, Richard. 58I.

Avencebron $=$ Gebirrol, Salomon ibn.

Averroës, Averroismus. 312. 315. 320. 321 . 326. 329. 335. 350. 361. 363. 378. 381. 393. 398. 409. 418.436.
Avicenna. 315. 316. 318. 320. 321. 322. 324. 325. 326. 333. 374. 378. 380. 390. 392. 393. 394. 398. 409. 4 II 424.425.

Axiome. 479.

\section{B.}

Baader. Franz von. 541 .

Bacon, Roger. 340. 344. 359. 361. 379. ${ }^{*} 408$. 410.438.

-, Francis, von Verulam. 340. 409. 422."46I. 468. 475. 476. 488.

Baconthorp, Johannes. 418 .

Bãdarāyana. 42.

Bain, Alexander. 567.

Ballanche, Pierre Simon. 558.

Bandinelli, Roland = Papst Alexander III.

Bañez, Dominicus. 344. 407.

Bantusprachen. 7.

Banzan, Kumazawa. 85 f.

Bardesanes. 268. 277.

Barlaam und Joasaph. 266.

Barnabasbrief. 265.

Barthez, Paul Joseph. 557.

Basilides. 268.

Basilius. 27 I.

Bate, Heinrich. $4 \mathrm{IO}$.

Bauhütten, Mittelalterliche. 360.

Bâtinijja. 312.

Baumgarten, Alexander. 509.

Baur, Christian Ferdinand. 574.

Bayle, Pierre. 496. 502. 506. 513. 516.

Bechaji b. Josef b. Pakuda. 33I.

Beda Venerabilis. 359. 370 .

Bedürfnislosigkeit. 123 .

Begehren nach Aristoteles. 167.

- nach der Sänkhya-Philosophie. 37.

- nach Thomas. 396.

Begehrungsvermögen der Seele. 255 .

Begierde. 168. 195. 258. 474. 476. 489 .

Begrenztes nach dem Pythagoreismus. II 3 .

Begrifie. I65.

-. Antisthenes' Auffassung der, als bloßer Gedankengebilde. 125 .

- Vollendung des wahren Wissens nach Aristoteles. 151 .

- nach Feuerbach. 575.

-, Herbarts Bearbeitung der. 548.

-, Komplexe und inkomplexe, nach Occam. 420.

- Gegenstände höherer Realität nach Pla to n. I29. 130 .

-, Primitive. 6.

-, Psychologische. 7 .

-, Scholastische Auffassung der. 373.

- Stoische - - 203. 233.

- nach Thomas. 391.395.

Begriffsforschung, Ethische. 96. 123. 128.

Bellarmin, Kardinal Robert. 401. 
Bellum omnium contra omnes. 477.489 .

Belluti, Bonaventura. $4 \mathrm{I} 6$.

Benedikt von Nursia. 370.

Beneke, Friedrich Eduard. 542. 548 .

Bentham, Jeremy. 509. 568.

Bergson, Henri. 566.

Berkeley, George. "500. 505. 567. 568.

Bernhard von Chartres. 340. 342." 376 .

Bernhard von Clairvaux. 347. 375. 426.

Bernhard von Konstanz. 345.

Beseelung der Körperwelt nach Plotin. 257.

Besonnenheit, Platons Definition der. I 42.

Bestattung. 29.

Beweger, Der erste, nach Aristoteles. "160. 205.

-, - , nach den arabischen Peripatetikern. 316.

Bewegung. 98. 99. 101. I19. 135. 253.

- als Ursache und Wirkung. 443.

-, Anaxagoras' Erklärung der. II 5.

-, Anfangs- und Endlosigkeit der, nach Ari. stoteles. "I6of. 315 .

- des Körpers, Descartes' Auffassung der. 472. 492 .

-, Diodoros Kronos' Leugnung der. I27.

-, Epikurs Argument gegen die Leugnung der. 188.

-, Melissos' Leugnung der. II2.

-, Stoische Auffassung der. 210. 213.

-, Zenons Leugnung der. IIO. III.

Bewegungsursache. II5. II6. I19. I57. I60. 239. 387. 397. 472.

Beweislehre, Aristotelische. $15 \mathrm{I}$.

BewuBtsein Attribut der Seele nach Descar. tes. 472 .

-, seine Seinsgewißheit nach Descartes. 468.

-, seine Aktivität nach $\mathrm{Hamilton.} 568$.

- nach Hegel. 542.

- nach Herbart. 550.

- Funktion des Leibes nach Hobbes. 476.

- nach Schelling. 538 .

- nach Spencer. 572.

- als Attribut der unendlichen Substanz nach Spinoza. 486.

¿Bewußtsein überhaupta nach Kant. 526. "531.

Bewußtseinswelt. 452. 456.475.

Beziehungen, Herbarts Methode der. 548 .

Bhagavadgita. 48. 53.

Bibelauslegung, Allegorische. 279. 332.

-, Rationalistische. 330.

Bibelkritik Spinozas. 484.514.

Bichat, Marie François Xavier. 557.

Biel, Gabriel." 406. "423.

Bildung. Historische, in der Romantik. 537.

Blick, Der böse. 18. 28.

Blut als Sitz der Seele. 12. 28. 70.

Blutkreislauf. 473 .

Bodin, Jean. 447. 448 .

Böhme, Jakob. 444. *458. 480. 541. 557.
Boer, T. J. de. 307.

Böse, Das, ein Nichtseiendes nach A ugustin. 296.

-, - radikal, in Kan ts Religionsphilosophie. 531 .

-, - als Weltproblem nach der neuzeitlichen Mystik. 459 .

-, - Materie nach Plotin. 255.

-, - nach der Stoa. 2I3.

-, - Sein Ursprung nach Tōju. 85.

Boethius. 275. 277. 28I. 297. 363. 368. 370 . 372. 375. 377. 380. 394.

Boetius der Däne. 383 .

Bonald, Victor de. 558 .

Bonaventura. 348. 364. 374. 376. 382. 385 . 391. 397. 411.427.

Bonifaz VIII., Papst. 376. 406. 407.

Boole, George. 570.

Bossuet, Jacques.Bénigne. 479.

Boutroux, Émile. 566.

Boyle, Robert. 512.

Bradley, F. H. 572.

Bradwardin, Thomas von. 359. 377. 418.

Brahma. 30. "31. 34. 36. 37. 39. 41. 43. 44. 45. 54. 85 .

Brhaspati. 34. 52.

Broussais, François Joseph Victor. 556. 577.

Brown, Thomas. 567.

Brüder und Schwestern vom freien Geiste. 37 I. 423 .

Brune, Giordano. 417. 444. *452. 463. 512.

Buch der Definitionen und Buch der Elemente Isrâêlis. 311 .

Buch über die Ursachen. 359. 363. 378. 386.

Buchstabensymbolik Avicennas. 319.

Buddha, Buddhismus. 33. 34. 41. 46. 53. 80. 81. 82. 85 .

-, Einfluß des, auf die chinesische Religion. 60.

-, - - auf den Sûfismus. 313.

-, _- auf den Taoismus. 76.

-, - - auf das Vedānta. 40.

Büchner, Ludwig. 577 .

Buisson, Ferdinand Edouard. 557.

Burgundio von Pisa. 298.

Buridan, Johannes. 352. 422.

Burke, Edmund. 5 ro.

Burleigh, Walter. 359. 416.

Bushidō. 87.

Butler, Joseph. 510.

C.

Cabanis, Pierre Jean-George. 556.

Cajetanus (Thomas de Vio). 407.

Calvin, Johann. 446.

Campanella, Tommaso. $\quad 455.463 .475 .478$.

Cänakya. 32.

Candragupta. 32 . 
Canus, Melchior. 344.

Capreolus. 407.

Cardanus, Hieronymus. 440.

Carlyle, Thomas. 568.

Cartesius s. Descartes.

Cārvākalehre. 5 If.

Cassiodorus. 370.

Celsus, A. Cornelius. 239. 273. 287.

Cerinth. 268.

Chalcidius. 281. 296. 363.

chalk. 318.

Charakter, Intelligibler und empirischer, des Menschen nach Kant. 531.

Charron, Pierre. 438. 439.

Chartres, Schule von. "376. 379.

Chasdai Crescas. 335.

Chateaubriand, François-René Vicomte de. 558.

al-Chazarî des Jehûdah ha-Lêwi. 332.

Chinesische Sprache. 6off.

Christentum. 249. 265. 267. 274. 511. 5 I 4.

-, Feuerbachs Schriften über das Wesen des. 575 .

-, Das neue, St. Simons. 561 .

Christus, Christologie. 270. 282. 283. 289. 292.

Chrypffs, Claus = Nikolaus von Kues.

Chrysippos von Soloi. *200. 201. 202. 203. 205. 212. 213. 216.222 .223 .224 .230 .235$.

$\mathrm{Chu} \mathrm{Hi}$ s. Tschu Hi.

Chūsai, Ōshiwo. 9I.

Cicero, M. Tullius, 234. 261. 276. 290. 291. 357. 359. 362. 364. 376. 403. 438 .

Cisterzienser. 372.

civitas institutiva. 477.

"Civitate Dei, De «ugustins. 367.

Clarke, Samuel. 510.

Clauberg, Johann. 480.

Claudianus Mamertus. 297.

Claudius Ptolemaeus. 378.

Clemens von Alexandrien. ${ }^{*} 269.27$ I. 276. 280. $* 286$

Clemens von Rom. 265.

Cocceji, Samuel Freiherr von. 367 .

cogitatio s. Bewußtsein.

"Cogito sum Descartes'. 469. 470.

Cohen, Hermann. 581 .

coincidentia oppositorum. 298. 427. 450. 45I. 454. s. auch Gegensätze, Koexistenz der.

Coleridge, Samuel Taylor. 568.

Comte, Auguste. 555. "561. 567. 576.

Conches, Wilhelm von. 352. 365." 377 .

Condillac, Étienne Bonnot de Mably; Condillacismus. 502. 556. 557.567.

Condorcet, Nicolas Caritat Marquis de. " 519 . 561. 564.

coniecturae des Menschen nach Nikolaus von Kues. 452.

Coniunctio des individuellen Intellekts mit dem tätigen Intellekt nach Averroes. 324. 325. 334 .
Conscientionalismus. $58 \mathrm{I}$.

Constantinus Africanus. $3 \mathrm{II}$.

Cordemoy, Gerauld de. 480.

Comutus. 20 I.

Cousin, Victor. 559.

Couturat, Louis. 566.

»Credo ut intelligam《 Anselms. 347. 371. 374. $42 \mathrm{I}$.

》Credo quia absurdum estk. 421.

Crusius, Chr. August. 504.

Cumberland, Richard. 505.

Cusanus $=$ Nikolaus von Kues.

Cyprian. 284 .

\section{D.}

Dämonen. 15. 18. 19. 21. 29. 2 16. 260. 288.

Damascius. 260.

Damiani, Petrus. 347. 348 .

Dante Alighieri. 342. 364. 383. 407.426. 446.

Darwin, Charles; Darwinismus. 477. 570. 577.

Dasein nach Eckhart. $424 \mathrm{f}$.

- nach Thomas. 388.

David von Dinant. $37 \mathrm{I}$.

Dâwûd. b. Merwân ibn al-Mukammis. 330 .

Deduktion. I23. I28. 151."153.

Definition. I23. 125.

Deismus. *5 1 r ff. 516.

Dekalog. 413.

Demiurg. 239. 240.

Demokritos. 24. $118.175 .181 .182,185$. 306. 443.453.

Demut. $48 \mathrm{r}$.

Denken, Begriffliches. 184 .

- nach Condillac. 502.

-, Mathematisches, nach Hobbes. 475.

- nach Occam. 420.

- nach Plotin. 250. 254.

- Primitives. $6 \mathrm{ff}$.

- nach dem Yoga. 47

- und Sein, Einheit von. 253. 546.

Denkkraft. 165.

Denkobjekte nach Plotin. 253.

- nach der Stoa. 207.

Denkseele. 164. 167.

Denshūroku Wang Yang-mings. 86.

Descartes, René. 26. 28. 265. 293. 338. 356. 374. 377. 387. 391. 395. 419. 420. 444. *467. 476. 478. 483. 486. 488. 489. 492. 493. 498.517 .559 .

despectio sui Geulincx'. 481 .

Destructio destructionis des Averroes. *32r. 329.

Destructio philosophorum Ghazalis. "320. 329. 332.

Destutt de Tracy, Antoine-Louis-Claude, Graf. 556. 
Deszendenzlehre. 570.

Determinismus. 277. $38 \mathrm{I} .383 \cdot 396.414 .422$. 495. 551. s. auch Indeterminismus.

Deus sive natura Spinozas. 484.

Deussen, Paul. 55.

Diakosmesis. 215.

Dialektik. 111. I22. 131. 146. 154. 201.204. 302. 347. 348 .

-, Transzendentale, Kants. 526.

Diatribe. 266. 276.

Diderot, Denis. 516.

Diels, Hermann. 107. 261. 262.

Diesseits. 352. 353. 401 .

Dietrich von Freiberg. "410. 423.

Differential. 454.

Dikajarchos. I75.

Dilthey, Wilhelm. 585.

Ding an sich. 54 .

-, - - nach Feuerbach. $574 \mathrm{f}$.

- - - Kant. 524. "526. 531. 533. 580.

-, Das einzelne, nach Herbart. 549.

Dinge Modi der unendlichen Substanz nach Spinoza. 485.487.

-, Wertabstufung der äußeren, nach der Stoa. 220.

-, Endliche, nach Nikolaus von Kues. 451.

-, Schauen der, in Gott nach Malebranche. 482.

Dingvorstellung. 232. 500 .

Dio von Prusa. 201.

Diodoros Kronos. 127.

Diodor von Tarsus. 277.

Diogenes von Apollonia. 109.

Diogenes von Babylon. 200. 230.

Diogenes Laertius. 261. 358.

Diogenian. 275.

Dionysius von Alexandrien. 273.

Dionysius Pseudo-Areopagita. 265. 281. 289. -297. 363. "368. 371. 376. 386. 387. 423. 425. 426. 427.

„Discours sur l'ensemble du positivisme« Comtes. 564.

distinctio formalis des Duns Scotus. 412. 418 .

Dominicus von Flandern. 407.

Dominikanerorden, Thomismus im. 406. 407. 410.

Doxa s. Meinung.

Doxographen. 262.

Drama, Chinesisches. 60.

Dreieinigkeit, Christliche. 288. 289. 347. 385 . 424.

- Philos. 243.

-, s. auch Trinität.

Dreistufensystem der wissenschaftlichen Erkenntnis nach dem arabischen Aristotelismus. 314.

- s. auch Stadien, Comites Gesetz der drei.

Dritte, Das ausgeschlossene. 294.
Dschelâl al-din Rumi. 313.

Dschemâladdin al-Afghāni. 329.

Dualismus in der aristotelischen Philosophie. 166. 205.

- Augustins. 367.

- in der Philosophie Chu His. 88.

- Descartes'. 472. 480. 483.

- Geulincx'. $48 \mathrm{r}$.

-, Ethischer, Kants. 529.

-, Metaphysischer, Leibnizens. 493.

- in der Philosophie des Lieh-tszě. 73.

- Lockes. 499.

- im Neupythagoreismus. 240.

-, Platonischer. 131.

-, Pythagoreischer. "103. 106. 113.

- des Sānkhya. "36. 38. 39. 41.

- in der Stoa. 209.

- s. auch Ying und Yang.

Dühring, Eugen. 576.

Dürkheim, Emile. 565 .

Duns Scotus, Johannes. 340. 345. 349. 351 . 367. 374. 382. 385. 393. 402. 408. 4 4 10. 418. 421.434 .

Durandus, Wilhelm. 36I. 396. 418 .

Durchdringung, Totale, der Körper nach der Stoa. 209.

\section{E.}

Eckhart, Meister. 298. 369. 376. 421 . "423. 427. 444. 459.

Edle, Der, in der konfuzianischen Ethik. 65. Eduktion der Form nach den Thomisten. 390.

Egoismus Epikurs. $197 \mathrm{f}$.

- des Yang Tschu. 68.

Ehelosigkeit. 399.

Ehrfurcht. 82.

Ehrgeiz, Ehrliebe. 173. 476.480.

Eigenschaften, Primäre und sekundäre, der Körper. I 19. 498.

s. auch Qualitäten.

Einbildungskraft. 59. 60. 258. 324. 325.

Einheit. I13. 119. I31. 250. 252.

-, Integrierte, Spencers. $57 \mathrm{I}$.

- der Form nach Thomas. 390. 406. 411.

Einkörperung der Einzelseele nach Plotin. $256 \mathrm{f}$.

Einsicht. 225. 229.

Einzelding 5. Ding, Das einzelne.

Einzelseelen nach Plotin. 256.260.

Einzelsubstanz nach Aristoteles. 154. 155.

Einzelwissenschaften, Stellung der, zur Pbilosophie im 19. Jahrh. 555.

Ekken, Kaibara. 89.

Eklektizismus. 178. 200. 228. $234 \mathrm{f} . \quad 237$. 243. 249. 309. 314.

—, Französischer, im 19. Jahrh. *559. 566. 
Ekstase bei den arabischen Peripatetikern. 313. 319. 325.

- bei Plotin. 259.

Elastizität der Körper. 177.

Eleaten s. Seinslehre, Eleatische.

Element, Das feuchte, der Urstoff nach Thales. 98.

Elemente. 52.

-, Fünf, im Hung-fan. 63 .

-, _, bei Tschou-tszě. 77.

-, Vier, des Empedokles. *116. 156. 163.

-, Stoische Auffassung der. 208.

Elias, Petrus. 416.

Emanationslehre. 244. 252.257 f. 308.310. 319. 332. 333. 392. 410.460.

Empedokles. 96. 105. $110.114 . * 115.120$. I85. 186. 309 .

Empfindungen. 124. 185. 443. 471. 532. 534.

- als einziges Erkennbares. 439. 455.

-, seelische Urgebilde nach Condillac. 502.

-, Entstehung der, aus der Bewegung der spiritus animales nach Descartes. 474.

-, Allgemeingültige Verknüpfung von, nach Kant. 524.

-, Verhältnis von Reiz und. 582.

Empiriokritizismus. $58 \mathrm{I}$.

Empirismus in der deutschen Aufklärungsphilosophie. $503 \mathrm{f}$.

- Fr. Bacons. 463.

-, Roger Bacons Stellung zum. 409. 438.

- Occams. 420.

-, Platons Stellung zum. 148.

Endliche, Das. 73.

-, - nach Nikolaus von Kues. 450.

-, - nach Thomas. $387 \mathrm{f}$.

Energie das höchste Reale nach Aristoteles.

*169. 217.

- das Wesen des Urwesens nach Plotin. 251. 253 .

-, Erhaltung der. 580. 582 .

-, Die ursprüngliche, nach Jinsai. 88.

Engel, Identifizierung der, mit den Sphären intellekten in der arabischen Philosophie. 317.

-, Reiche der, nach Jakob Böhme. 460.

Engels, Friedrich. 576.

Enneaden des Plotin. 249. 313.

Entelechie. "160. 164. 209. 390. 493.

Entendement humain, Leibnizens Nouveaux Essais sur l'. 503 .

Entwicklung, Begriff der, in der Deszendenzlehre. 570.

-, - - Hegels. 54I.

-, Kreislauf der, nach Lao-tszě und Lieh. tszě. 74.

-, Stufenweise, nach Plotin. 252.

- nach Sokō. 86.

-, Begriff der, Spencers. 571.

-, Schöpferische. 566.
Entwicklung der Natur nach der indischen Philosophie. 37. 44.

Enzyklopädie Avicennas. 319.

- Diderots. 516.

- der 》Lauteren《. 310.

Epiktet. 201. 276.

Epikuros, Epikureismus. 118. 181. "183. 200. 217. 227. 229. 234. 270. 364. 446. 478.

-, Patristische Verwerfung des. 273.

Epiphanius. 269. $27 \mathrm{I}$.

Epoché. 182. 229.

Erasmus von Rotterdam. 437. 438.

Erde, Kugelgestalt der. 359.

Erdmann, Johann Eduard. $58 \mathrm{I}$.

Erfahrung, Innere, nach Herbart. 550.

-, Humes Wertung der. 502.

-, Kants Definition der. 525. 526.

-, Innere und äußere, nach Maine de Biran. 559.

-, -, nach Schopenhauer. 553.

Erfindungskunst, Bedeutung der, nach Fr. Bacon. 463.

Eristik s. Eleaten und Sophisten.

Eriugena, Johannes Scotus. 289. 290. 344. 350. 371. 373. 374.

Erkennen nach Condillac. 502.

-, Arten des, nach Platon. 133.

- nach der Sānkhya-Philosophie. 37.

Erkenntnisprinzip der primitiven Logik. "وf. I6.

Erkenntnistheorie des Antiochos von Askalon. 235.

- des Antisthenes. 125.

- Aristipps. 124.

-, Aristotelische. 151.

- der arabischen Aristoteliker $315 \mathrm{f}$.

- der Aufklärungsphilosophie. $500 \mathrm{ff}$.

- Augustins. 293.

- Campanellas. 455.

-, Cartesische. $468 \mathrm{ff}$.

- des Duns Scotus. 411. 414. 415.

-, Epikureische. 184.

- Hamiltons. 568.

- in der indischen Philosophie. 38. 45. 50.52.

- Kants. $523 \mathrm{ff}$.

- Lockes. 498.

- des Neukantianismus. 581 .

- des Nikolaus von Kues. 450.

- Occams. $4 \mathrm{I} 8 \mathrm{f}$.

- Platons. *128. 289.

- des Pragmatismus. 572.

- Protagoras, Begründer der, in der griechischen Philosophie. I2I.

- in der Scholastik. 355f. 41 I. 439.

-- des Sokrates. I 23.

- Speusipps. 178.

-, Stoische. 20I.

-, Thomistische. 314. 
Erkenntnistheorie des Xenokrates. 179.

»Erleuchtung, Philosophie der,« Suhrawerdîs. 313.

Erlösung. 282. 288.

- nach Anselm von Canterbury. 347.

- nach der Sãnkhya-Philosophie. 37. "39.

- - Schopenhauer. 554.

- nach der Vedänta-Philosophie. 45. 56.

- der Menschheit durch Christus. 372. $53 \mathrm{r}$.

Erotik Platons. I 35 .

Erscheinung nach Kant. 531. 552.

Erscheinungswelt. 54 .

Erzeugung, Fortwährende, nach Jinsai. 88.

Erziehung, Campanellas Lehre der. 457.

-, Herbarts - - 551 .

-, Platons - -. 140. $143 \mathrm{f}$.

Espinas, Alfred. 565.

essentia Gottes und der Kreaturen nach Bruno. 453.

- $-\ldots$ nach Nikolaus von Kues. $45 \mathrm{I}$. -, quinta. 162. 316.

Essenz, Verhältnis von, und Substanz bei Aristoteles. 155. 156.

Ethik des Antiochos. 235.

-, Aristipps Begründung der. 124.

- des Aristoteles. I68fi.

- des Aufklärungszeitalters. 505.

- Augustins. 297.

- Jakob Böhmes. 46r.

-, Überwiegen der, vor der Metaphysik in der chinesischen Philosophie. 63.

- Descartes'. 474.

- Eckharts. 426.

- Ekkens. 90.

- Epikurs. 194.

- Feuerbachs. 575.

- Geulincx'. 481 .

- Herbarts. $55 \mathrm{I}$.

- Kants. $527 \mathrm{ff}$.

-, Neuplatonische arabische. 312 .

- Occams. 421.

- Philons. 247.

- Platons. I $40 \mathrm{ff}$.

- Plotins. 259.

-, Primitive. $22 \mathrm{ff}$.

-, Scholastische. 355.

- , Begründung der, durch Sokrates in der griechischen Philosophie. I 22.

- Spinozas. 489.

-, Stoische. 216.247.

-, Thomistische. 398.

Euandros. 230.

Eubulides. 127.

Eucken, Rudolf. 585.

Eudämonismus. 171. 180.

Eudemos von Rhodos. 175.

Eudorus. 235.

Eukleides. 123. 124. *126. 377.

Eulogon, Das stoische. 229.
Eunomius. 289.

Euscbius von Cäsarea. 266. 275. 277. 278. 280.

Eustratius. 378.

Evidenz der kataleptischen Vorstellung. 202. $23 \mathrm{I}$.

Evolution s. Entwicklung.

Ewige, Das, in der indischen Philosophie. 54.

Ewigkeit, Platons Auffassung der. 139. 389.

Existenz nach Eckhart. 425.

- nach Thomas. 2,58 .

- Gottes und der Kreaturen nach Bruno. 453.

- $-\ldots$ - Nikolaus von Kues. 451.

Experiment. 360. 442.464.

-, Mills Theorie des. 567.

extensio s. Ausdehnung.

\section{F.}

Fabel. 17.

Faber Stapulensis. 436.

Fallgesetze Galileis. 443

Fallrichtung, Abweichung der Atome von der vertikalen. 189.

fanâ. 31 3 .

Fatalismus s. Willensfreiheit.

Fatum nach der Stoa. 211. 212. 213. 233; s. auch Determinismus, Willensfreiheit.

Fechner, Gustav Theodor. 582.

Feng-schui-System. 78.

Feuer Urstoff nach Herakleitos. 107.

- als Begrenzendes im Pythagoreismus. 113.

Feuerbach, Ludwig. 574.

Fichte, Johann Gottlieb. ${ }^{*} 534$ ff. 538. 54 I. 552. 559. 56r. 568. 585 .

Fidanza, Johannes $=$ Bonaventura.

Fischer, Kuno. 580.581 .

Fixsternhimmei. ${ }^{*}$ I62, 180. 427.

"Fons Vitae" Avencebrons. 311. 331.

Forge, Louis de la. $48 \mathrm{c}$.

Form, Aristoteles' Begriff der. $156 \mathrm{ff}$.

-, Unterschied zwischen Materie und, nach Duns Scotus. 412.

-, das unkörperliche Wesensprinzip nach den Neupythagoreern. 240.

-., das Wesen der Dinge nach Pythagoras. I04.

- und Stoff, Korrelativität von, nach den Stoikern. 205.

-, Einheit der, nach Thomas. 390. 406. 411.

Formen, Realität und Apriorität der allgemeinen, nach Platon. I 29.

-, Dauernde, nach Fr. Bacon. 465.

- der Atome nach Epikur. 189.

- der elementaren Welt nach Alfârâbi. 316.

forma cadaverica der Thomisten. 390.

Formprinzip, seine Abstufungen nach Aristoteles. 159. 373 . 
Fortleben nach dem Tode. 60.

- $-\ldots$, Lieh-tszěs Glaube an ein. 74.

Fourier, Charles. 560.

Fragmentarischer Charakter der primitiven Sprache und des primitiven Denkens. 8.

Franck, Sebastian. 445.

Franziskanerschulen des Alexander von Hales und des Duns Scotus. 382. 385. 409. $4 \mathrm{II}$. 446.

Frayssinous, Denis Graf von. 558.

Freidenkertum. "514. 516.

Freiheit. 447. 448. 482. 490. 528. 529. 531. 532. 546.566.

Fries, Jakob Friedrich. 542. 548.

Frömmigkeit. 448.

Fürstenregiment, Ägidius Colonnas Schrift vom. 406.

-, Thomas' Schrift vom. 404.

Funktionsbegriff. 548.

Furcht. 476. 489 .

\section{G.}

Galenus. 319. 334. 377 .

Galilei, Galileo. 419. *442. 454. 463. 465.468. 475. 492. 498.

Gall, Franz Joseph. 557. 563.

Garnerius von Rochefort. 372.

Gassend (Gassendi), Pierre. 455. 478. 502.

Gattung, Gregors von Nyssa Begriff der. 289.

Gattungsbegriffe. 155. 187. 203. 207. $373 \mathrm{f}$. 476. 552 .

-, Psychologische. 504 .

Gattungstypen als zielstrebige' Kräfte nach Aristoteles. 158.

Gattungsvernunft. "545. 560 .

Gauḍapāda. 4r .

Gaufrid von Poitiers. 381.

Gaunilo. 374.

Gautama. 49.

Gauthier, Léon. 327.

Gebirol, Salomon ibn. 31 1. 331. 378. 380.390. 412.

Gefühl. 8. 167. 225. 504. 510. 511. 518.519. 521 .

-, Religiöses. 480. 521. 537.

Gefühlsphilosophie. 517 .

Gefühlszustandes, Epikurs Leugnung eines rein indifferenten. 195.

Gegenständlichkeït, Problem der, nach Kant. 524.

- des primitiven Denkens. $8 \mathrm{f}$.

Gegensätze $=$ Abgeleitetes nach Plotin. 250 .

-, Koexistenz der, nach Heraklẹitos. 108.

-, - - , in Gott nach Dionysius Ps.-Areopa. gita. 298.

-, - - - in Gott und der Welt nach Jakob Böhme. 459.
Gehirnvorgänge, Bedeutung der, nach Bergsons Philosophie. 566.

-, Wertung der, für das Seelenleben nach der französischen Ideologie. 556f.

Gehorsam. 399. 404.

Geist, Heiliger, nach Alfârâbî. 318.

-, seine Bedeutung nach A naxagoras. II 5 .

-, göttlicher und menschlicher, nach A ris to.

teles. 159. I60. 205.

- nach Augustin. 294.

-, seine Realität, nach Descartes. 469.

-, Absoluter, nach Hegel. 542. 543. 546.

-, Objektiver, nach $\mathrm{Hegel}$. 542. 543. 544 . 546. 558.

- nach Plotin. 252. $253 \cdot 254.255 .258 .281$.

-, seine Verbindung mit dem Leibe die Ur. sache der unklaren und verworrenen Vor. stellungen. 470. 471 .

-, sein Verhältnis zum Körper nach den Stoikern. 2 Io.

-, sein Vermögen nach den Stoikern. 203.

- Verhältnis von, und Natur, nach Feuer. bach. $574 \mathrm{f}$.

- , - - _ - - - Schelling. $538 \mathrm{f}$.

Geister, Hobbes' Leugnung der, für das Wissen. 476.

- nach Origenes. 288.

Geisterwelt nach Suhrawerdî. 313.

Geistesphilosophie Hegels. $544 \mathrm{ff}$.

- Schellings. 539.

Geisteswissenschaft, Begründung der, durch Sokrates. 122.

Geistige, Das, seine Einheit mit dem Natürlichen nach Spinoza. 487.

Ǵeistigkeit, Vereinigung des geistig erhöhten Menschen mit der Welt der reinen. 324. 325.

Geldgeschäft der Juden. 402.

Gemeinschaftsleben. 226.

Gemütsleben s. Affekte.

Genialitätsphilosophie. 517. 521.535.

Genie, Kants Definition des. 530.

Genußmöglichkeit, Grenzen der, nach Epikur. I 93.

Gérando, Joseph Marie de. 559.

Gerbert (Papst Sylvester II.). 359. 372.

Gerechtigkeit. 67. 70. 82. 89. 123. 142. 173. 198. 225. 233. 400 .

-, Postmortale. 513 .

Gerhard von Cremona. 378.

Gerhoh von Reichersperg. 368.

Gerson, Jean. 348. 422, 427.

Geschehen, Problem des, bei Herbart. 549.

Geschichte, Mangel eines Interesses für, im Mittelalter. 358.

-, Mangel eines Verständnisses der, in der Auf klärung. 518.

-, Hegels Bewertung der. 543.

-, Schopenhauers - - 554 . 
Geschichtsphilosophie. 519.

- Augustins. 367.

- Comtes. 563.

- Hegels. 546.

- Kants. 529 .

Geschlechtsleben. 12.

Geschmack. 5 I8.

Gesellschaft, Begriff der, nach Comte. 562 .

-, - - , nach Hegel. 545.

_, - -, nach dem St. Simonismus. 56r.

_, _ _, nach Thomas. 4or.

-, Begründung der, nach Bonald. 558.

-, - - , - Hobbes. 477.

-, Ordnung der, nach Campanella. 456.

_, _- nach der Renaissance. 446. 448.

Gesellschaftsvertrag. 489; s. auch Staatsver. trag.

Gesetz, Ewiges, nach Augustin. 367 .

-, - , Wurzel des Sittengesetzes nach Thomas. 400 .

Gesetze, Zweck der, nach Platon. 14 I.

Geulincx, Arnold. 48I.

Gewissen. 506. 513. 558 .

Gewissensfreiheit. 512.561 .562 .

Gewohnheit, Wesen der, nach Maine de Biran. 559.

Ghazâli. 320. 329. 332.

"Glaube, Erhabene" von Abraham ibn Dâûd. 333 .

-, Vernunftwidrigkeit und Unbegreiflichkeit seines Inhalts nach Bayle. 506.

-, Kants Bestreben seiner Rationalisierung. 527. 531 .

-, Gewißheit des religiösen, nach Mansel. 569.

-, Verhältnis von Wissen und, nach Fr. Ba. con. 466.

- , - - - nach Occam. $42 \mathrm{I}$.

-, _ _ - , nach der Scholastik. 346. 347. 386.

Glückseligkeit. I24. I41. "169. 174. I79. I80. 194. 197. 216. 219. 324. 413. 508.

Gnade, Reich der. 352.

Gnosis, Gnostizismus. 52. 265. 268.276 .278 . 285. 460 .

Göring, Karl. 582.

Goethe, Johann Wolfgang. 53. 438. 521.537. 538. 570.

Götter, Athenagoras' Bekämpfung vieler. 267. 274.

- als Beweger der Naturerscheinungen. 2I.

Götterlehre Epikurs. I 90 .

Götterwelt Plotins. 260.280.

Gorgias. 121 .

Gott höchster Intellekt nach Alfârâbî. 316 .

- als erster Beweger nach Aristoteles. 161. 275.

-, sein Verhältnis zur Welt nach Bruno. 453.
Gott einzige wirkende Ursache nach Geulincx. $48 \mathrm{r}$.

-, seine Unendlichkeit nach Nikolaus von Kues. 450.

- und des Menschen Verhältnis zu ihm nach der Scholastik. 352.

- als Weltschöpfer nach der Vedānta-Philosophie. $43 \mathrm{f}$.

-, Rückkehr der Natur in. $46 \mathrm{I}$.

_, - - Seele zu, nach Plotin. "258. 260. 3I3. 324.

Gottesbegriff Augustins. $294 \mathrm{f}$.

- des Averroës. 322.

- Jakob Böhmes. 460.

- Campanellas. 456.

- des christlichen Evangeliums. 281.

- des Clemens von Alexandrien. 287.

- der Deisten. 513.

- Descartes'. 483.

- des Dionysius Pseudo-Areopagita. 298.

- Eckharts. 424. 425.

- Justins. 283.

- Kants. 531 .

- Kyusōs. 83.

- Leibnizens. 495.

- Mills. 568.

- der Mutakallimûn. 305.

- der Mu'taziliten. 303.

-, Neupythagoreischer. 239. 241.

- des Okkasionalismus. 482.

- des Origenes. 287.

- Philos. 243.

- Plotins s. Urwesen.

- Spinozas. 485.486 .488$.

- des Thomas. 388 .

- Tōjus. 84.

- des Xenophanes. 102.

Gottesbeweis, Ontologischer, des Anselm von Canterbury. $374.397 .47 \mathrm{I}$.

- bei Augustin. 366.

- Descartes'. 469.

-, Kants Ablehnung eines. 527. .

-, Physiko-theologischer. 495. 512.

- bei Thomas. 397.

Gotteserkenntnis nach Gregor von Nyssa. 289.

- nach Occam. 420.

- nach Philon. 243.

- nach Spinoza. 486. 490.

Gotteslehre Augustins. 366.

- Eckharts. $424 \mathrm{f}$.

- des Thomas. $397 \mathrm{f}$.

Gottesliebe nach Spinoza. 485. 490.

Gottes- und Nächstenliebe al s Vollkommenheit

des christlichen Lebens nach Thomas. 399.

Gottesreich Augustins. 297.

- nach Kant. $53 \mathrm{I}$.

Gottfried von Fontaines. 386. "406. 411 .

Gottschauung letztes Ziel nach Thomas. 399. 413. 
Green, Thomas. 572.

Gregor von Nazianz. 271. 278.

Gregor von Nyssa. 270. 278. 280. 281. 288 . 368. 371 . 372 .

Gregor von Rimini. 406. 422.

Gregor I., der Große, Papst. 370.

Gregor VII., Papst. 368. 376. 403.

Großartigkeit nach Aristoteles. 173.

Grosseteste, Robert. 385.408 .410$.

Grund, Satz vom zureichenden. 492.

- Vernünftiger, nach der Stoa. 229.

- und Folge nach Spinoza. 485.487.

Grundaffekte, Die vier. 224.

Grundgesetze, Kepplersche. 442.

Güte Gottes nach Philon von Alexandreia. 243.

- und Gerechtigkeit Gottes nach den Mu'. taziliten. 303.

-, Angeborene, der menschlichen Niatur nach der chinesischen Philosophie. "68. 70.

Guiterlehre. I 81 .

-- des Antiochos. $235 \mathrm{f}$.

- Philons von Alexandreia. 247.

-, Stoische. *218. 233.

Güterverteilung. 174 .

Guizot, François-Pierre. 559.

Guṇa, Die drei, der Sānkhya-Philosophie. " 37. 38. 47.

Gundissalinus, Dominicus. 378.379 . 380. 409.

Gut, Das höchste, nach Kant. 528.

-, - - nach Thomas. 396.

-, - - s. auch Energie; Leben, Einstimmiges und naturgemäßes; Lust.

Gute, Das, nach Epikur. 194.

-, - als höchste Idee nach Platon. 132. 251. 252. 278 .

-, - , als Bezeichnung des plotinischen Urwesens. 250. 252.253.

-, _ nach der Stoa. 213.

\section{H.}

Haben, Kategorie des. 154.

Häcceität. 412. 418.424 .

Haeckel, Ernst. 577 .

Hajj ibn Jakzân. 319. 325.

Hajjûjah. 330.

ha-Lêwi, Jehûdah. 332.

Hamann, Johann Georg. 535 .

Hamartēmata. 221.

Hamilton, William. $568.57 \mathrm{r}$.

„Handelsstaat, Der geschlossene $\ll$, Fichtes. 561 . Handlungen, Angemessene, nach Arkesilaos. 229.

-. Freiwillige, nach Aristoteles. 171.

-. Grundlos freie. 534.

-, Tugendhafte und bloß angemessene, nach der Stoa. 229.
Han Fei-tszĕ. 75 .

Haridāsa. 46.

Harmonie nach Herakleitos. $108 \mathrm{f}$.

- nach. Pythagoras. I05.

- nach Tszĕ-szě. 66.

-, Göttliche, nach Nikolaus von Kues. 452.

-, Prästabilierte, nach Leibniz. 494. 495.

Harmonisierung in der Scholastik. 345. 379.

Hartley, David. 501. 517.

Hartmann, Eduard von. 577. $\$ 579$.

Harvey, William. 473.

Haß. 108. 474.476 .489$.

Hauchseele. io. 12. 13. 26.28.

Hedonismus. 124. 194.

Hegel, Georg Friedrich Wilhelm. 53. 54. 538. 540. 541 ff. 554. 558. 559. 561. 564. 571 . 574. 576.578 . 580.585 .

Hegemonikon nach Philon. 246.

- der Stoa. 216.222.

Heimarmene nach der Stoa. 211. 212.

Heinrich von Brabant. 378.

Heinrich von Gent. $345 \cdot 364 \cdot 367 .{ }^{*} 382.411$.

Heinrich von Hessen der ältere (Heinrich Heinbuch von Langenstein). $\mathbf{4 2 2 .}$

Heirik von Auxerre. 372.

Helmholtz, Hérmann von. 580 .

Helvetius, Claude Adrien. 508.

Helyas s. Elias.

Hemmungen in Herbarts Metaphysik. 549. 550.

Heptaplomeres Bodins. 448.

Herakleitos. 24. 96. 105. *107. 114. 120. 121 . 1 30. 131. 181. 215.237. 266. 267. 276.

Herbart, Johann Friedrich. 293. 548. 577.

Herder, Johann Gottfried. 53. 507. 519.537. 538. 561 . 579 .

Hermanus Alemannus. 378 .

Hermas, Hirt des. 265.

Hermes Trismegistus. 359 .

Hermias. 266.

Hérrschaftsvertrag. 447.477.

Hervé de Nédellec (Hervaeus Natalis). 407.

Herz als Sitz der Seele. 12. 28.

Hesiod. 359 .

hetu. 51 .

Hexis. 208. 209. 2 10. 245.

Hierokles. 201.

Hieronymos der Peripatetiker. 177.

Hieronymus, Der heilige. 271. 280. 290. 346. 368.

hikmat al-ischrâk Suhrawerdîs. 313.

Hilarius von Poitiers. 290.

Himmelserscheinungen, Bedeutung der, für die primitive Naturphilosophie. 21.

Himmelsgewölbe. 257.

Himmelskörper nach den arabischen Peripa. tetikern. 316. 317.

Hippokrates. 377.

Hippolyt von Rom. 269. 
Historie s. Geschichte.

Hi-tsz'ĕ zum Yih-king. 63. 67.

Hoai-nan-tszĕ. 76.

Hobbes, Thomas. 28. 90. 419. *474. 488.489. 498. 505. 508. 510.568.

Hochherzigkeit nach Aristoteles. 173.

Hochscholastik. $380 \mathrm{ff}$.

Hoffnung. 399. 413. 489 .

Hōkoku, Yamada. 9ı.

Holkot, Robert. 422.

Home, Henry. 5 Io.

Homogeneität der Welt nach Bruno. 454.

Honorius Augustodunensis. 374. 408.

Horovitz, S. 304.

horror vacui. 177.

Horten, Max. 305.

Hrabanus Maurus. 358. 370.

Huet, Pierre Daniel. 479.

Hugo, Erzbischof von Palermo. 362.

- von St. Viktor. 368. *375. 38I. 391.426.

Human understanding, Lockes Essay concer. ning. 498.

Humanismus. 434. 436 .

-, Verhältnis des, zum Protestantismus. 445.

Humanität. 584 .

- nach Toju. 85.

- s. auch Menschlichkeit.

Humanitätsideal des Aristoteles. 173.

Humboldt, Wilhelm v. 53.

Hume, David. 356. 420. *501. 505. 5 10. 511 . 515. 525. 567. 568. 570 .

Hung-fan. 62. 78 .

Hus, Johannes. $4 \mathrm{I} 8$.

Hutcheson, Francis. 510.

Hylozoismus. 98. 181. 199. 205.

Hypatia. 280.

Hypnotischer Zustand des Yogin. 47.

Hypokeimenon. 207.

Hypostase, Begriff der. 275.

I.

Iamblichus. 260.

Ibn Bâddscha. *325. 334 .

Ibn Haitham. 321 .

Ibn Roschd $=$ Averroës.

Ibn al-Sîd al-Bataljûsî. 332.

Ibn Sînâ = Avicenna.

Ibn Tufeil, Abu Bekr. *325. 326.

Ich der Meditation nach Descartes. 469.

-, Allgemeines, Fichtes. 534.

-, Assoziationspsychologische Auffassung des. 567.

-, Humes - - 501 .

-, Plotins Auffassung des menschlichen. 258.

-, Tōjus Idee vom allgemeinen und speziellen. 84.

- , - - vom wahren und falschen. 85 .
Ichigenki. 88.

ichwân al-șafâ. 309 .

Idealismus. 460.469.

-, Objektiver, Augustins. 293.

- Berkeleys. 500.

- in der französischen Philosophie des 19. Jahrhunderts. 566.

-, Transzendentaler, Kants. 526.

-, Spencers Bekämpfung des transzenden. talen. 572 .

-, Teleologischer. 539. 542. 543. 56r.

- des zwanzigsten Jahrhunderts. 584 .

Idealstaat, Platonischer. I44.

Idee, Natürliche, nach Epikuros. 186.

- Abbildung einer Impression nach Hume. 501 .

-, Göttliche, der Scholastik. 373.

Ideen, Assoziation der. 476.

- Augustins. 279. 294.

- nach Berkeley. 501.

-, Eingeborene, Descartes'. 469. 473.

- Eckharts. 424.

- Eriugenas. $37 \mathrm{r}$.

- Hegels. 544.

-, Fünf ethische, Herbarts. $55 \mathrm{I}$.

»-zur Philosophie der Geschichte der Mensch. heitk Herders. "518. 579.

- Kants. 527.

- im Neupythagoreismus. 241.

- nach Philon. 244.279.

-, Platonische. I29. ${ }^{1}$ 30. 147. 148. 252. 436. 460.465 .552$.

- nach Plotin. 252. 254. 256.

- Schellings. 54i.

Identität im Geiste nach Plotin. 253.

Identitätsphilosophie, Deutsche. "539f. 548 . 549.

- Tschuang-tszěs. 74 .

Ideologie. 502. ${ }^{*} 556.559 .565$.

Idolenlehre Fr. Bacons. 464.

Ignatius von Antiochien. 265.

ignorantia docta des Nikolaus von Kues. 427. 450.

Imâm-Glauben. 303

Immanenz der aristotelischen Philosophie. I48. Immaterialität der ersten .Ursache nach Maimûni. 334 .

Imperativ, Kategorischer. "527. 534 .

Impression. 50I.

Impuls, Unendlich kleiner. 454.

Indeterminismus. 396. 414. s. auch Determinismus.

Indifferentismus, Religiöser, der Baconischen Philosophie. 466.

-, - - der Hobbesschen -. 475. 478.

Individualismus. 439. 454. 507.535.

Individualität, Wertung der, in der Aufklärung. 507.508.

-, Auslöschung der, im Sûfismus. 313. 
Individuationsprinzip in der Scholastik. 393. 412. 419.

Individuum nach Kant. 532.

- - Nikolaus von Kues. 451 .

Induktion. 51. 123. 128. 151. I52. 153 . 199.

- nach Fr. Bacon. 464.

-, Mills Theorie der. 567.

-, Nichtanwendung der, im Mittelalter. 417.

Infinitesimalrechnung. 491.

influxus physicus Descartes'. 480.

Inhärenz, Kategorie der. 485. 486. 548.

Inhärenzursache. 49.

inspectio sui Geulincx'. $48 \mathrm{I}$.

》nstitutio Trajanik. 376.

Institutiones dialecticae des Pierre de la Ramée. 437.

Instrumentalismus. 573.

Intellectus agens und possibilis nach Thomas. 395.

Intellekt, Tätiger, nach Alfârâbî. 316.

-, Potentieller und Angeeigneter, nach den arabischen Peripatetikern. 316.

—, Erster (göttlicher), nach Averroës. 323.

-, Averroës' Leugnung des individuellen. 323. 380. 383. 393. 418.

-, Verhältnis von Wille und, nach Duns Scotus. 4I4.

-, Thomas' Bekämpfung der Annahme der Abtrennung des, vom Menschen. "392. 393.

-, Stellung des, zum Seelenwesen nach Thomas. 392: 395 .

-, Vereinigung des menschlichen, mit dem tätigen. 324 .

- s. auch Vernunft.

Intellekte, Separate, nach der arabischen Philo. sophie. 316. 322.

Intellektualismus der mittelalterlichen Mystik. 459.

-, Erkenntnistheoretischer, des Thomas. 395. 414.

-, Transzendentaler 290. 579.

intelligentia nach Nikolaus von Kues. 450.

intentio prima Occams. 419.

interminatum nach Nikolaus von Kues. 451 .

Intuition. 153.

Ionertum, seine Entwicklung. 97.

Irenäus. 269.

Ironie. 536.

Irrationalismus in der Aufklärung. 521 .

- der Gefühlsphilosophie. 535.

-, Kants Anerkennung des berechtigten. 529. 530. 532.

- in Schopenhauers Philosophie. 554.

Irrtumer, Entstehung der, nach Epikuros. 186. Irrtumslehre Descartes'. 470.

Isai, Tamaki. 82. 83.

Isidor von Sevilla. 359. 370.378.

Isidorus. 260.
Islam. 301. 302. 303. 307. 309. 310. 311.312. 315. 319. 320. 321. 325. 326.

Isrâêli, Isak b. Salomon. 311. 331. 378.

Issai, Sato. 9I.

istihlâk. 313 .

Iśvara. 43. 47.

》Itinerarium mentis in Deum\& Bonaventuras. 382.

\section{J,}

Jacobi, Friedrich Heinrich. 535. 536.

Jacobus aus Venedig. 363.

Jahjâ b. 'Adî. 307. 327.

Jansenisten. 446. 480 .

Jenseits. 21. 52. 352. 353. 401 .

Jenseitsreligion. 239.

Jescha'ah b. Jehudah - Abu-1.Faradsch

Furkan b. Asad.

Jesuiten. 447.

Jevons, Stanley. 417. 570.

Jichū, Tani. 82.

Jinsai, Itō. 88. 90.

Joachim von Fiore. $4 \mathrm{II}$.

Johann von Janduno. 351.

Johann von la Rochelle. 382 .

Johannes XXI., Papst. 417.

- XXII., Papst. 418.

Johannes Damascenus. 275. •298. 368. 378. 397.

Johannes Hispanus. 378.

Johannes von Salisbury. 348. 361. 373. "376. 403.

Josef al-Basir. 330.

Josef b. Saddik. 331.

Jouffroy, Théodore. 559.

Judentum, Einflub der islamischen Welt auf das mittelalterliche. 330 .

Julianus Apostata. 199.

Junshi. 9r.

Justin der Märtyrer. 265. 266. 267. 268. 269. 270. 271 . 278 . $" 282$.

Justinian, Kaiser. 260.

\section{K.}

Kabbalah. 332. 350.426.

Kalâm, Islamischer. 302. 304. 305. 3I4. 326. "327. 350.

-, Jüdischer. 330. 333 .

Kalkül, Logischer. 475.

Kampf ums Dasein. 570.

Kanāda. 49.

Kant, Immanuel. 54. 82. 293. 501. " $521 \mathrm{ff}$. 534. 535. 536. 541. 544. 548. 551. 552. 568. 569.570 .580 .

-, Rückkehr zu. 580 .

Kao Puh-hai. 67. 68. 
Kapila. 33.

Kappadozier, Die drei. $288 \mathrm{ff}$.

Karaiten. 330.

Kardinallaster, Die vier. 224.

Kardinaltugenden des Meng-tszě. 67.

一, Die vier. . 222. 224. 259. 312. 400 .

Kărikās. 35 .

Karneades. I78. 230. 234. 235. 274. 306.

Karpokrates. 268.

Katalepsis. 202. 229. 230. 235. 293. 307.

Katechetenschule zu Alexandreia. 285.

Kategorien. 6. 49.

-, Aristotelische. *154. 275.

- Eduard von Hartmanns. 580 .

-, Kantische. $524 \mathrm{ff}$.

-, Plotinische. 253.

-, Pseudo-augustinische Schrift uber die. 364. 372 .

- der Natur bei Schlegel. 539.

-, Speusipps Auffassung der. 179.

-, Stoische. 206.

-, Thomistische. 387.389 .

-, Xenokrates' Auffassung der. 180.

Katharsis nach Plotin. 259.

Katholizismus. 444. 558 .

Katorthomata. 220.

Kausalität. I5f. I9ff. 252. 294. 471 . 525. 552. 556.

-, Der Asch'ariten Leugnung der. 306.

- nach Geulincx. 48I.

-, Humes Kritik der. 501.

- nach Mill. 567.

-, Nikolaus' von Autrecourt Kritik der. 422.

-, Göttliche, nach Plotin. 251.

- nach der Renaissance. 443.

- nach der Scholastik. 356. 422.

- nach Spinoza. $485 \cdot 487 \cdot 488$.

- nach der Stoa. 2 Io.

Kautilya. 32. 33. 34. 51.

Keimkraft s. spermatikos logos.

Keisai, Asami. 82.

Keppler, Johann. "442. 463.

$\mathrm{Ki}$, der Weltstoff. 84.85 .88 .89$.

Kilwardby, Robert. 379. 381. 406.409.

Kindererzeugung, Regelung der, nach Platon. 144.

Kindererziehung in Miskaweihis Sittenlehre. 312.

Kindersprache. 9 .

Kindespflicht nach der konfuzianischen Ethik. 65.

King, Die vier. 80 .

Kirche, Erörterung des Verhältnısses von Staat und, in der Renaissance. 447.

- s. auch Katholizismus.

Kirchenbegriff Augustins. 368. 373.

- des Thomas. 401 .

Kirchenväter. 344.346 .349 . $364 \mathrm{ff}$.
Klarheit und Deutlichkeit der Vorstellung. 469. 470. 481 . 492. 493. 494.

Kleanthes. 200. 202. 213. 216. 230.

Kleinste, Das, Epikurs. 188.

Kleitomachos. 230. 233.

Knapp, Ludwig. 575.

Körper nach Berkeley. 500 .

- nach Descartes. 467.

- nach Leibniz. 492. 493.

- nach Locke. 498.

- nach Malebranche. 482.

-, Verhältnis von Seele und, nach Plotin. 257.

-. Der feine, der Sānkhya-Philosophie. 38 .

- einzige Art des Seienden nach der Stoa. 206.

Körperlichkeit Gottes und der Seele nach Tertullian. 277.

Körperseele. I1. 13. I5.

Körperwelt, Berkeleys Leugnung der metaphysischen Realität der. 500 .

-, Erkenntnis der, nach Descartes. 471.

-, Unendichkeit der, nach Descartes. 472.

-, Zeitlose Entstehung der, nach Plotin. 255.

- nach Suhrawerdi. 313 .

Kombinatorik, Scholastische. 417.

Kommentare in der indischen Philosophie. 36.

Kommunismus Platons. 144.

Konfuzius, Konfuzianismus. $\quad 64.67 .68 .69$ 71. $73 \cdot 75 \cdot 76.81 .83 .86 \mathrm{ff} .90$.

Konkomitanz in der Nyāya-SchluBlehre. 51. 52.

Konstantinus Afrikanus. 377.

Konstruktion, Teleologische, Fichtes. 534.

-, -, Schellings. 539 .

Kontingenz, Begriff der. 566.

Kontinuität, Gesetz der. 494.

Konventionalismus. 573 .

Kopernikus, Nikolaus. 427. *44t.

Kopernikanismus. $452 .{ }^{*} 453$.

Kopf als Sitz der Seele. 28. 176.

Koran. 326. 327. 350.

Korpuskulartheorie. 377. 472. 493.

Kosmas Indikopleustes. 359.

Kosmogonie. 22. 97. 100.

- Jakob Böhmes. 460 .

Kosmologie des Aristoteles. 162.

- der arabischen Aristoteliker. 316.

- der Atomisten. 120.

- Jinsais. 88.

- Philons. 245.

- Platons. 137.

- Sokбs. 86.

-, Stoische. 212. 215 .

Kosmopolitismus, Stoischer. 227.

Kosmos. 99. I01. 104. 107. 109. 113. 119. 211. 215.243 .256$.

Kräfte, Wirkende, in der Natur nach"Aristoteles. 163.176.

Kraft, Begriff der, nach Leibniz. 493. 
Krankheit. 18 .

-, Anknüpfung der, an die Schattenseele. 14.

-, Bacons Begriff der. 466.

Krantor. 178. "181.

Krates. 178. 199.

Krause, Christian Friedrich. 560 .

Kreatur, Welt der, nach Alfârâbî.

-, Sein der, nach Eckhart. 425.

Kreisbewegung. 162. 207. 316.

Krieg Vater aller Dinge nach Herakleitos. 108.

-, Stellung des Taoismus zum. 72.

Kriterion nach Augustin. 293.

-, Epikurs Lehre vom. 184. 229. 230.

- Stoische Lehre vom. "202. 229. 231. 233.

»Kritik der reinen Vernunft《 Kants. 523. 524. 530. 581 .

》- der praktischen - - - 523. 530. 531 .

»- - Urteilskraft《 —. 523. 529. 530. 536.

Kritizismus Kants. 521 .

-, Agnostischer. $58 \mathrm{I}$.

- in der französischen Philosophie des 19. Jahrhunderts. 566.

Kritolaos. 177.

Künste, Marcianus Capellas Lehrbuch der sieben freien. 364 .

Kugelgestalt der Erde. 359.

- des Kosmos. 99. 139.

Kultur, Primitive. 4.

Kulturtätigkeiten des Menschen, Bedeutung der. 547.

Kultus. 17. 18.

Kunst, Zweck der, nach der Aufklärungs. philosophie. 5 Io.

-, Stellung der, in Hegels Philosophie. 546.

-, Kants Definition der. 532.

-, Stellung der, in Schopenhauers Philosophie. 554 .

Kunstwerk, Schellings Auffassung vom. 540 .

Xynismus. 124. 126. 201.

Kyrenaıker. I 24. 195. 196.

Kyusō, Muro. 83.

\section{L.}

Laas, Ernst. $58 \mathrm{r}$.

Lachelier, Jules. 566.

Lafitte, P. 565.

Lage, Kategorie der. 154 .

Laktanz. 266. 267. 274. 276. 277. 279. 284. 293. 359.

Lakydes. 230.

Lamarck, Jean. 570.

Lambert, Heinrich. 50.4 .

-, St. 519.

Lamennais, Hugues Félicité Robert de. $55^{8}$.

Lamettrie, Julien Offray de. 508. 517. 556. 577.

Lanfrank von Canterbury. 374. 375.

Lange, Albert. 580.

Langue des calculs Condillacs. 503.
Lao-tszě. 67.71 ff. 74.76.

Laromiguière, Pierre. 557.

Laster, Stoische Auffassung der. 223.

- Thomas' - - 400.

Latein s. Mönchslatein.

Latitudinarier. $51 \mathrm{r}$.

"Lauteren“, Religiös-philosophischer Bund der. 309. 311. 312. 314. 319. 321. 329. 331.

Leben, Einstimmiges und naturgemäßes. 179. 216. 219.235.

- Kontemplatives. 319.

-, Seelisches und körperliches. Ihre ursprüng. liche Einheit nach der primitiven Psychologie. II .

-, Vernünftiges nach der Ästhetik der Aufklärung. 510 .

-, seine Gestaltung zum Kunstwerk. 509.

- als Wesen der Substanz nach Leibniz. 493.

- als Wollen nach Schopenhauer. 553.

"Leben Jesur von Strauß. 574.

Lebenseinheit der Natur. 538.

Lebenskraft. 557 .

Lebensquelle Gebîrols s. Fons Vitae.

Lebensweisheit, Maximen praktischer, bei den Naturvölkern. 24.

-, Stoische. 437.

Leere, Das. 41. I1 2. I1 207.

Legalität nach Hegel. 545 .

- Kant. 529.

Legge, James. 64. 67.

Lehrgespräch s. Dialektik.

Leib, Verhältnis von, und Seele nach Aris to. teles. I64.

- , - - - nach Augustin und Tho. mas. 391. 393 .

-, - - , - nach Descartes. 473. 480.

-., - - - nach Epikur. 19I.

-, - - , - nach Geulincx. 481.

_., _. _ - nach Philon. 247.

-, - - - - nach Plotin. 257.

-, _ - , - nach Wang Tsch'ung. 70.

-, Verbindung des Geistes mit dem, die Ursache der unklaren und verworrenen Vorstellungen. 470. $47 \mathrm{I}$.

-, Der feine, der Vedānta.Philosophie. 44. Leibniz, Gottfried Wilhelm. 338. 367. 374. 414. 417. 452. 454. 482. "490. 503. 509. 511. 512.519 .566 .571 .578$.

Leichenkonservierung. II .

Leiden, Kategorie des. 154.

Leiden der Natur nach der Sānkhya-Philo. sophie. 38. 39.

Leidenschaften. 12. 124. 167. 223. 474.

„Leitung des Vereinsamten $\propto$ Avempaces. 325.

Lektá, Stoischer Begriff der. 207.

Leo Hebraeus, Magister $=$ Lêwi b. Gerson.

Leontius von Byzanz. 275.

Leroux, Pierre. 561.

Lessing, Gotthold Ephraim. 515. 
Lettres provinciales Pascals. 479.

Leukippos. 96. 106. I10. 112. 114. "118.

Lêwi b. Gerson. 335 .

li. 61 .

Liber de causis. 359. 363. 378 . 386. 389 .

Liber scriptus und liber vivus der Offenbarung

Gottes. 440.

Liberalismus. 560.574 .

Liberalität. 172.

Lichtmetaphysik, Neuplatonische. 410.

Liebe. 474.476 .480 .489$.

- in Ekkens Sittenlehre. 9o.

- als Bewegungsursache nach Empedokles. 116.

-., Miskaweihis Lehre von der. 312.

-, Allumfassende des Moh Tih. 69.

- in Platons Seelenlehre. 135.

-, Tugend der. 413.

Liebmann, Otto. 581 .

Lieh-tszè. $73 \mathrm{f}$.

linga. 51 .

Lionardo da Vinci. 442. 465.

Littré, Maximilien Paul.Émile. 565.

Liü Puh-wei. 78.

Locke, John. 356. 409. 420. 497. 502. 505. 52 .

Logik, Aristoteles' formale. 12r. ' 148.

- Hamiltons. 569 .

- Hegels. 544.

- Kants. "522. 569.

- Mills. $56 \%$.

-, Moderne. 475.

-, Primitive. $6 \mathrm{ff}$.

-, Rhetorische, des Pierre de la Ramec. 437.

-, Scholastische. $356 \mathrm{f}$.

-, Stoische. 20r.

-, Transzendentale. 524 .

Logiker, Scholastische. 416.

Logos. 109. 278.

-, Welt des, nach Alfârâbî. 318 .

- des Johannesevangeliums. 292.

-, Teilhaben des Menschengeschlechts am, nach Justin. 267.

- nach der Patristik. 279. 280. 283. 288.

- nach Philon. $243 \mathrm{ff}$.

- nach Plotin. 258.

- nach der Stoa. 201. "203. 216. 218.222. 223. 226. 276 -

Lokāyata. 33. 34. "51.

Loth, Otto. 317.

Lotusstellung. 47.

Lotze, Rudolf Hermann. "573. 585.

Lucretius Carus, T. 199. 364. 453.

Luft, Urstoff nach Anaximenes. 100.

Lull, Ramon (Lullus Raymundus). 348. " 417.

lumen naturale. 470. 47 I. 499.

Lun-yü des Konfuzius. *65. 67. 68.

Lust. 52. 186. 258.474 .476 .489$.

- erster und letzter Zweck nach Aristipp.
Lust, Aristoteles' Auffassung der. 167. 169.

- das höchste Gut nach Epikur. *194ff. 217.

-, Platons Ablehnung der, als des höchsten

Guts. 142.

- höchster Lebenszweck nach Yang Tschu. 69.

Luther, Martin. 406. "445. 446. 461 .

Lychetus. $4 \mathrm{r} 6$.

Lykon aus Troas. 177.

Lyrik, Chinesische. 60.

Lysis. 105.

\section{$M$.}

ma 'âní al-nafs des Ps.-Bechaji. 331.

Mabuchi, Kamono. 92.

Machiavelli, Niccolo. *447. 458.

Macht. 476. 489.

Macrobius. 363 .

Männerweihe der Jünglinge, Australische. 23. 29.

Märchen. 17. 18. 28.

Mäßigkeit. 170. ${ }^{* 172.197 .225 .}$

Maestro Vidal $=$ Moses b. Josua Narboni.

Magie. 256. 260. 440 .

Mahābhārata. 32. 33 .

Mahad. 310.

Mahāyāna. 41 .

Mahdî. 3 I2.

Mahnrede an die Griechen, Pseudojustinische. 265. 280.296.

mahw. 313.

Maimûní. 304. "333. 350. 378. 387. 398. 484 .

Maine de Biran, François Pierre Gauthier.

559. 560. 568.

Maistre, Joseph de. 558.

Maja im Buddhismus. 85 .

Miajestät. 447.

Majo, Großadmiral. 362.

Malebranche, Nicole. 265. 296. ${ }^{*} 882$. 501. 559.

Mialthus, Thomas Robert. 477.

Manegold von Lautenbach. 347. $3 \% 6$.

Manichäismus. 291. 292.

Mansel, Henry Longueville. 569.

Mantik. 256.

Marc Aurel. 201.

Marcianus Capella. 36:.

Marcion. 268.

Marinus. 260.

Marius Victorinus. 275. 280. 281. 292.

Marsilius Ficinus. 436.

Marsilius von Inghen. $\mathbf{4 2 2}$.

Marsilius von Padua. 365. 402.446.

Martin, Louis Claude St. 557.

Martin von Braga. 352. 370.

Masarra, Muhammed ibn 'Abdallah Ibn. 311.

Massenpsychologie. 565 .

Mastrius, Bartholomäus. 416. 
Materialismus der Aufklärung. 517.

- des Dikaiarchos. 175.

- in Hobbes' Philosophie. 475 f.

- in der indischen Philosophie. 33. "51.

- in der Philosophie des 19. Jahrh. 556.

-, Populärer. 577.

- Sensualer. 575.

- der Stoa. 200. 276.

- des "Système de la nature «. 517.

- des Wang Tsch'ung. 70.

-, Gegensatz Augustins gegen den. 296.

-, - Dschemâladdin al-Afghānīs gegen den. 329.

-, - - des Neupythagoreismus gegen den. 239.

-, Geschichte des* von A. Lange. 580.

Materie. 44. II5. 119.

- nach Aristoteles. * ${ }^{\text {I }} 56 \mathrm{f} .205$.

-, Augustins Begriff der. 295.

-. Averroës' - 322.

-, Geistige, nach Bonaventura. 382.

-, Gegensatz von Geist und, nach dem Cartesianismus. 473. 482.483 .

-, Unterschied von Form und, nach Duns Scotus. 412.

- einziges Reales nach Epikuros. 187.

-, Gregors von Nyssa Theorie der. 290.

-, Leibnizens Vorstellung der. 494.

-. Neupythagoreische - —. 239. 240.

-, Philons - - 243.

-, Platons - - 138. 278. 312.

-, Plotins Intelligible. 252. 254. $\$ 255.256$.

-, Stoische Vorstellung der. 207.

- Stratons - - 176.

-, Erste, nach Thomas. 390.

- Vernunftbegabte, nach Tschu Hi. 77.

Mathematik, Vernachlässigung der, in Fr. Ba cons Naturalismus. 463.

-, Descartes' Stellung zur. 468. 486.

-, Bedeutung der, für Herbarts Psycho. logie. 550 .

-, Humes Stellung zur. 502.

-, Kants - - 523 .

-, Leibniz' - - 491.

-, Mittelalterliche. 359. 409.

-, Bedeutung der, für die Naturerkenntnis. 129. 441 .

-. Pascals Auffassung der. 479.

-, Unterschied zwischen Philosophie und. 504.

Matthäus von Aquasparta. 4II.

Maupertuis, Pierre Louis Moreau de. 502.

Mauritius Hibernicus. 416.

Maximus der Bekenner. 298.

Māyā. * 45. 54. 55.

Mayronis, Franciscus de. 416.

Mechanik als Grundwissenschaft der modernen

Naturforschung. 442.449 .478$.

Mechanismus, Universeller. 578 .

Medizin, Bacons Auffassung der. 466.

-, Reform der, durch Paracelsus. $44 \mathrm{I}$.
Medizin, Spirituelle, Alfârâbis. 317.

Megariker. I24. *126. 188 .

Meier, G. Fr. 510.

Meinung nach Aristoteles. 167.

- nach Epikuros. 185.

- im Gegensatz zum Wissen nach Platon. 133.

- nach den Stoikern. 202.

- nach Xenokrates. 179.

Melanchthon, Philipp. 446.

Melissos von Samos. IO9. 'III. 120.

Melito von Sardes. 265. 267. 268.

Mencius s Meng.tszě.

Mendelssohn, Moses. 504. 505. 510.

Meng-tszě. *67. 69. 70. 7 I. 83. 91 I.

Menon Platons. 362. 378.

Mensch, Wissenschaft von seinem Leben und seiner Aufgabe. 97. 121. I22. 498. 504.

- nach Com tes Biologie und Soziologie. 563.

-, Descartes' Auffassung vom. 473.

- Empedokles' Lehre der Entstehung des. II 7 .

-, Gregors von Nyssa Auffassung vom. 289.

-, Heraklits - - 109.

-, Hobbes' - - 476.

-, Rein geistiger, nach Origenes. 280 .

-. Philons Auffassung vom. 246

- Stoische - - 215.

Menschenseele nach Aristoteles. I64.

- nach Gundissalin. 380.

- nach Plotin. $256 \mathrm{f}$.

- s. auch Seele.

Menschenverstand, Der gesunde. 232. 233. 437. 505. 517.569.

Menschheit, Geschichte der. 519. 520.

Menschlichkeit. 67. 69. s. auch Humanität.

Mersenne, Marin. 455. 467.

Merswin, Rulman. 426 .

Merx, Adalbert. 313.

Mésa Kathékonta. 221.

Meßbare, Das, seine Bestimmung nach Galilei. 442.

Metakosmien Epikurs. 191.

Metaphysik, Aristotelische. 152. ${ }^{*} 154.380$.

- Augustins. $294 \mathrm{f}$.

- Berkeleys. 500.

- Campanellas. 456.

-, Cartesianische. $47 \mathrm{I}$ f.

- Victor Cousins. 560.

-, Epikureische. 187.

- Feuerbachs. 575.

- in der französischen Philosophie des 19. Jahrhunderts. 566.

-, Gassendis Ablehnung der. 479.

- Herbarts. 548.

-, Kants Stellung zur. 526 .

- Maine de Birans. 559.

-, Neupythagoreische. $24 \mathrm{I}$.

- des Nikolaus von Kues. 427. 
Metaphysik, Platonische. I06. 130.

-, Plotinische. 250.

-, Scholastische. 349. 354. 356.

- Schopenhauers. 552.

- Speusipps. 178.

- Spinozas. 486.

-, Stoische. 205.

-, Thomistische. · 386.

Methexis der Dinge an der Idee. 132; s. auch

Dinge, Schauen der, in Gott.

Methode der Beziehungen, Herbarts. 548.

—, Dialektische, Hegels. 543.

-, Geometrische, Spinozas. 485.

-, Historische, Comtes. 563 .

-, Induktive, Fr. Bacons. 464.

-, Kritische oder transzendentale, Kants. 521 .

-, Mathematisch-rationale, Descartes'. 468 .

-, Psychologische, der Auf klärungsphilosophie. 498.

-, Resolutive und kompositive. 442.

-, Scholastische. 344.

Methodius von Olympus. 278. 288.

Michael Scottus. 378 .

Mikrokosmos. 165. 310. 376. 391. 394. 417. 452. 456. 461 .

* Milrokosmus Lotzes. 579.

Milde. 170 . 172.

Milieu, Theorie des. 566 .

Mill, James und John Stuart. 567.570.

Miltiades. 265. 267. 268. 269.

ming. 61. 66.

Minucius Felix. 266. 267. 276. 284. 285.

Mirandola, Pico von. 440.

Mischung, Ursprüngliche, aller Stoffe nach Alaxagoras. 115.

Miskaweihî, Abû Ali ibn. 312.

Mitleid nach Schopenhauer. 554.

Mittelalter, seine Stellung zur Philosophie. 34 r.

Mitsukuni, Tokugara. 92.

Mitte, Die richtige, nach Aristoteles. 170 ff. 312.

sMitte nach Tszě-szě. 66.

Mittelbegriff. 51. 150.

Moderatus von Gades. 239.

modi cogitationis und extensionis. 482 .

Modi der Substanz und der Attribute nach Spinoza. 486. 493.

Mögliche, Das, nach Aristoteles. 150.

-, -, nach der Stoa. 215.

Möglichkeit s. Aktualität.

Mönchslatein, Kampf des Humanismus gegen das. 436.

Moerbeke, Wilhelm von. 378.403 .

Moh Tih. 69.

Molekulartheorie Stratons. 176.

Moleschott, Jakob. 577.

Monade nach Bruno. 454:

- nach Leibniz. 493.

- nach Lotze. 578.
Monadologie nouvelle Renouviers. 566.

„Monarchia, De爪 Dantes. 342. 407. 446.

Monarchie, Campanellas Auffassung der. 458.

-, Konstitutionelle. 499.

-, Thomas' Auffassung der. 405.

Monarchomachen. 447.

Monismus, in der Philosophie Ekkens. 89. -, Id ealistischer, s. Idealismus, 'Transzendentaler und Teleologischer.

- in der Philosophie Jinsais. 88.

-, Materialistischer. 578 .

- im Neupythagoreismus. 239.

- Plotins. 249.

- der Stoa. 200. 224.

- Stratons. 176.

Monopsychismus Averroës'. 323.

Monotheismus, Stellung der Kyniker zum. 126.

-, Strikter, der Mu'taziliten. 303.

- Stellung Plotins zum. 260.

-, Hinweis der Seele auf den, nach Tertullian. 285.

Montaigne, Michel de. 438. 479.

Moral, Heteronome. 421.

Moralität nach Hegel. 545 .

- - Kant. 529.

Moralphilosophie der Aufklärung. 505.

Moral sense. 510.

Morus, Thomas. 448. 457.

Mose de Leon. 332.

Moses. 243. 267. 348.

Moses b. Esra. 331.

Moses b. Josua Narboni. 335 .

Motekallimun s. Mutakallimûn.

Mu'ammar. jo5.

Munk, Salomon. 308. 311 .

Mure, Konrad von. 358.

Musik, Aristoxenos' Studien über die Theorie der. 175.

-, Bedeutung der, im Pythagoreismus. 104.

Musonius Rufus. 201. 286.

Mutakallimûn, lslamische. 302. ${ }^{*} 304$ ff. 314 . 317. 319. 398.

-, Rabbanitische. 330. 333 .

Mú taziliten, Islamische. 302 ff. 328 .

-, Jüdische. 330.

Mysterienkulte, Griechische. 26. 103.

Mystik. 31. 342. 344. 352. 365. 369. 376.

- im arabischen Aristotelismus. 317. 318 .

- und Cartesianismus. 480.

- im 19. Jahrhundert. 557.

- im Neupythagoreismus und Neuplatonis.

mus. 237.

- der späteren Patristik. 281. 289. 297.

- in der Renaissance. 444. 458.

-, Romanische, im Mittelalter. 427.

-, Spekulative deutsche, - —. 423. $54 \mathrm{I}$.

Mythen Platons. 146.

Mythologie. I. 2. 4. 17. 26. 
Mythologie, Charakter der, in der arabischen Philosophie. 317.

-, Fehlen der, in der chinesischen Religion. 60. Mythos Schöpfung des Gesamtgeistes. 574.

N.

Nachfolgen nach Plotin. 252.

Nāgārjuna. 41 .

Naokata, Satō. 82.

Nathanaël al-Fajjûmî. 331 .

Nationalitätsbewußtsein. 583 .

Nationalstaat. 447. 458. 534 .

Natürliche, Das, seine Einheit mit dem Geistigen nach Spinoza. 487.

Naturrlichkeit, Forderung der. 5 I 8 .

Natur, Animalische und geistige, des Menschen. 219.

-, Wirkende und leidende, nach Antiochos. 235.

- als einheitliches Ganze nach Aristote. les. $158 \mathrm{f}$.

--, Allgemeine, des Menschen nach Gregor von Nyssa. 289 .

-, Kants Auffassung der. 525.

- die der Körperwelt zugewandte Funktion der Weltseele nach Plotin. 256.

- in der Sānkhya.P.hilosophie. *37. 39.

-, Schellings Auffassung der. 538 .

-, Stoische - -. 212. 216.

-, Stratons - -. 176.

-, Reich der. 352. 353.

-, Rückkehr der, in Gott nach Jakob Böhme. 461 .

-, Verhältnis von Geist und, nach Feuerbach. 575.

-., VerhäItnis der, zur Gnade nach Thomas. 399.

natura naturans und natura naturata 453.

Naturalismus Fr. Bacons. 463.

- Spencers. 571.

Naturbeherrschung, Verlangen nach, in der Renaissance. 440.

Naturen, Dauernde, nach Fr. Bacon. 465.

Naturerklärung des Aristoteles. 163 .

-, Mechanistische. 512. 517.

-, Scholastische. 407 .

Naturerscheinungen. 20. 22. 472.

Naturforschung, Anfänge der, in der Renaissance. 438.

-, Empirische, als einziger Wissenszweig nach Fr. Bacon. 463 .

Naturgemäße, Das ursprünglich, nach der Stoa. 217.

Naturgesetze, Der Asch'ariten Ablehnungr der. 306.

- nach der modernen Naturforschung. 465. 472.
Naturgüter. I8o. 18I. 219.

Naturlehre des Empedokles. 117.

- des Epikuros. 187.

- des Francesco Patrizzi. 436.

Naturmensch. 5. 9. 10. 13. 16. 17. 18. 19.

23. 24.

-, seine Stellung zum Problem. 3.

Naturmythus. 17. 18, 21. 22. 28.

Naturphilosophie Alberts des Großen. 385.

- Jakob Böhmes. 460.

-, Chinesische. 76 .

- Descartes'. 472.

-, Franziskanische. 411 .

- Hegels. 544.

—, Ionische. 96. ${ }^{*} 97.304$.

-, Primitive. I $5 \mathrm{ff}$.

- in der Renaissance. 439.

- Schellings. ${ }^{*} 538.543 .553$.

- Spinozas. 488.

- Stratons. 175.

-, Thomistische. 389 .

Naturrecht. 366. 413.

Naturreligion s. Vernunftreligion.

Naturtrieb, Der ursprüngliche. 217. 226.

Naturwissenschaft, Verhältnis des Mittelalters zur. 349.

Naturzustand des Menschen. 4. 23.

Nausiphanes. 183.

Nazarius. 421.

Nazzâm. 305 .

Neckam, Alexander. 408.

Negation, Weg der, nach Thomas. 388.

Neikos Vater aller Dinge nach Herakleitos. Io8.

Nemesius. 272. 275. 278. 297. 368. 378.

Nemoranus. 359.

Neokritizismus Renouviers. 566.

Neospinozismus. 538.

Neuhumanismus. 537.545 .

Neukantianismus. $58 \mathrm{I}$.

Neuplatonismus. 242. 268. 274. 276. 280. 288. 296. $297.356 .363 .369 .387 \cdot 390.427 .436$. 440. 446. 458.496.

- in der arabischen Philosophie. 308. 317.

- in der jüdischen Philosophie. 331. 333.

- in der Spekulation deutscher Mystik. 423.

- Plotins. $248 \mathrm{ff}$.

- in Verbindung mit scholastischer Naturphilosophie. 410.

Neupythagoreismus. 228, ${ }^{*} 237 \mathrm{ff}$.

Neuromantik. 585.

Newton, Isaak. 454. 473. 493. 512.

Nicholson, Reynold A. 313.

Nichts, Das, nach Eriugena. 350.

Nichtsein s. Seiende, Das wahrhaft, und Sein. -, Aufgehen in das, im Sûfismus. 313 .

Nichttun s. Wu-wei-Theorie des Taoismus 7 1. 75 .

"Nichtunterscheidung von Seele und Natur im Sānkhya. *38. 39. 
Nicolai, Friedrich. 505.

Nieren als Sitz der Scele. 12. 28.

Nietzsche, Friedrich. 55. ${ }_{5} 83$.

Nigidius Figulus. 239.

Nikolaus von Autrecourt. 356. 420. *422.

Nikolaus von Damaskus. 408.

Nikolaus von Kues. 298. 376. 425. *427. *449. 453. 454. 490. 493.

Nikomachos von Gerasa. 239.

Nirwana. 54. 313.

Nissim b. Jakob. 331 .

Nizolius, Marius. 439.

Nominalismus, Nominalisten. 289. 343. 348 . 351. 354. 355. 356. 366. *372. 396. 400.406. 407. 4I3. *418. 439. 475. 498. 500. 573.

Norinaga, Motoori. 92.

Notker Labeo. 342. 362. 372.

Notwendige, Das relativ, nach Alfârâbî. 315 . Notwendigkeit. 306.

-, Bedingte und unbedingte, nach Leibniz. 492.

Novalis (Friedrich v. Hardenberg). 537.538.

Numenios von Apameia. 239. 279.

Nūs. 243. 246. 252. 253. 254. 255. 258.

259. 260. 281. S. auch Vernunft.

Nyāya. 34. 49. *50.

Nyorai. 85.

\section{o.}

Oberbegriff. 51 .

Objekt. 7. 9. 36. 37. 73. 75. 230.

Objektivität des primitiven Denkens. $7 \mathrm{f}$.

Obligatoria. 357 .

Obrigkeit. 404.

Occam, wilhelm. 345. 349. 354. 356. 361 . 396. $402 .{ }^{*} 418.446$.

Occamisten. 343 .

Odo von Cambrai. 372.

Offenbarung. 52. 270. 284. 460 .

Offenbarungsglaube. 346 .

Offenbarungsprinzip des Neupythagoreismus. 238.

Offenbarungsreligion, Verhältnis der, zur natürlichen Religion. 433.

Offenbarungstheologie. 352. 353 .

Okkasionalismus. ${ }^{*} 480 \mathrm{ff}$. 493 . 501 .

Okkultismus der $\gg$ Lauteren $\ll .310$.

- der arabischen Peripatetiker. 317.

Olivi, Petrus Johannis. $4 \mathrm{II}$.

Ontologie s. Metaphysik.

Opfer, Stellung der Cārvākalehre zum. 52.

Optik, Mittelalterliche. 359. 409.

Optimismus Brunos. 454.

- Chrysipps. 213.

- Epikurs. 196.

- Leibnizens. 496.

-, Makrokosmischer. 512.

-, Naturalistischer. 570.
Opus maius des Roger Bacon. 359. 379. 409. - Oxoniense des Duns Scotus. 411.

Oratorianer. 446.

Orden, Mittelalterliche. 343.

Ordensleben, Thomas' Stellung zum. 399.

Oresme, Nicolas d'. 422.

Organe, Körperliche, nach Aristoteles. 164.

- der Geschöpfe nach der Sānkhya-Philosophie. 38 .

Organisationsstufen nach der Stoa. 209.

Organismen, Descartes' mechanische Erklärung der. 473.

- nach Schelling. 540.

-, Zweckmäßigkeit der. 570 .

Organon des Aristoteles. 363. 376.

-, Novum, Fr. Bacons. 463. 465.

Organseelen. ${ }^{*} 12.15 .26$.

Origenes. $269 .{ }^{*} 270.271 .273 .278 .279 .280$. 282. 286. *287. 290.

Ort als Kategorie. 154.

Osiander, Andreas. 445.

Othlo von Regensburg. 347.

Otto von Freising. 368. 375.

P.

Pädagogik Herbarts. 550 .

Paley, William. 508.

Palingenesie. 215.216.

Panaitios. 200. 235. 276.

Pandit. 33.

Panlogismus. 547 .

Pantänus. 269. 271. *286.

Pantegni des Galen. 377.

Pantheismus. 191. 200. 209. 259. 276. 285 . 37 I. 38 I. 440.44 I. 452 . $454 .{ }^{*} 485$. 489 . 493 . 512. 574.

Papsttum, seine Stellung nach Campanella. 458 .

-, - - nach den Scholastikern. 402.

Paracelsismus. 458.

Paracelsus (Theophrastus Bombastus von Hohenheim). *441. 463.

Parallelismus der Attribute nach Spinoza. ${ }^{*} 487$. 488. 494.

-, Psychophysischer. 582.

- der Erscheinungen nach der chinesischen Philosophie. 63.

paramāṇu. 50.

Paris, Kämpfe um die aristotelische Metaphysik und Naturphilosophie an der Universität. 380.

Parmenides. 44. 96. 105. " 106.112 .116 .118$. I1 19. 126. 130.

Parusie der Idee. 132.

Pascal, Blaise. 479.

Passionen, Primäre, Descartes' *474. 489.

Patristik s. Kirchenväter. 
Patristische Literatur. $364 \mathrm{ff}$.

Patrizzi, Francesco. 436. 440.

Paulsen, Friedrich. 582.

Paulus. 265. 267. 271. 282.

Peckham, Johann. 359. 381. 406. 408. 410.

Pelagianer. 418.

Pensées sur la religion Pascals. 479.

Pentateuch. 242. 243. 249.

Perfektibilität, Menschliche. 519.

Perichermeniae des Apuleius. 364 .

Peripatetiker. ${ }^{*} \mathrm{I} 75$ ff. 229. 274.

Persönlichkeit im deutschen Idealismus. 535. 536.

-, Begriff der, nach Kant. 528.

-, - - nach Maine de Biran. 559.

-, - - , bei Renouvier. 566.

-, - - , nach Thomas. 394.

-, Entwicklung der, nach Shaftesbury. 507. 508.

-, Wertung der, in der Renaissance. $43 \%$.

- , - - , in der entwickelten Scholastik. 353.

- Gottes, Streit um die. 574:

-, Göttliche, nach Lotze. 578.

Person, Begriff der. 275.

- nach der Scholastik. 394.

Perzeptionen. 466.

Pessimismus. 46r. 553.

Peter von Capua. 381 .

- von Compostella. 376.

- der Lombarde. 347. 370. 375. 381 .

- von Poitiers. 381.

Petrarca, Francesco. 364 .

Petrus Hispanus. 417.

Pflanzenseele. I 59. 164.

Pflichten gegen die Gemeinschaft nach der Stoa. 225.

Pflichtenkreise, Konzentrische, nach der Stoa. 226.

Phädon Platons. 362. 378. 392.

Phänomenalismus in der Renaissance. 439. 475.

- der Skepsis. 182.

- der Sophistik. 121.

»Phänomenologie des Geistes« von Hegel. *543. 545.

Phallus. 28.

Phantasie des Naturmenschen. 9.

Phantasiegebilde. 203.

Phantasmen nach Thomas. 392. 395.

Pherekydes von Syros. 103.

Philipp von Greve. 381 .

Philodem. 199.

Philolaos. 96. 105. 109. "112. 238.

Philon von Alexandreia. 236. 237. *242. 249. 250. 269. 276. 277. 278. 279. 286. 348.

Philon von Larisa. 178. *233.

Philoponus. 275.

Philosophie, Cãnakyas Definition der. 32.

-, EinfluB der indischen, auf den Westen. 52.
Philosophie, Einklang von, und Religion nach Maimûni. 334 .

-., Grenzbestimmung zwischen Theologie und, im Mittelalter. 349.

-, Griechische, als Quelle der mittelalterlichen. $362 \mathrm{ff}$.

-, Positive, Comtes. 564.

-, Schottische. 505.

-, Stellung der, zu den Einzelwissenschaften im 19. Jahrh. 555.

-, Verhältnis der, zur Religion nach A.verroës. 326.

,--- indischen, zur Religion. 30.

-, Versuche einer überkonfessionell christlichen. 446.

- der Werte. 584 .

Philosophus autodidactus. 319. *325.

Phrenologie. 557. 563.

Physik, Mittelalterliche. 359.

Physiologie der Sinnesorgane. 582. 583 .

Physiologus. 359.

Physisches und Psychisches in der sinnlichen Wahrnehmung nach Thomas. 391.

Pietismus. 352.

Pinel, Philippe. 556.

Platon, Platonismus. 26. 28. 96. 103. I10. I1 2. I18. *123. *127-148. 155. 159. 167. 179. 204. 228. 237. 249. 251 . 252. 253. 254. 258. 259. 267. 269. $276.277 .{ }^{*} 278.285 .288$. 307. 338. 340. 346. 349. 354. 359. *362. 364 . 365. 366. 376. 391.427 .435 .448 .457 .465$.

Plotin. 52. 240. 242. *248. 280. 28I. 289. 290. 295. 308. 317. 426. 436. 444. 460 .

Pluralismus in der Metaphysik Herbarts. 549 .

Pluralitätstheorie. 390.

Plutarch von Chaeronea. 239. 271.

Pneuma. 176. 206. 208. 209. 210.212 .215$. 223. 235. 245. 277. 285. 474.

Poincaré, Henri. 566.

Poiret, Pierre. 480.

Polemon. 178. 179. "180. 199.

Politik, Verbältnis der, zur Ethik nach Aristoteles. $174 \mathrm{f}$.

-, $-\ldots,-\ldots$ nach Platon. $140 \mathrm{f}$.

„Politique positivek Comtes. 564 .

Polybios. 175. 405.

Polykarp von Smyrna. 265.

Polytheismus in Plotins Philosophie. 260.

Pomponazzi, Pietro. 351. 436.

Popularphilosophie im 2. Jahrhundert n. Chr. 276.

- des Aufklärungszeitalters. *504. $519.52 \mathrm{~J}$.

Porphyrios. 249. 260. 287. 308. 363. 372.

Porrée, Gilbert de la. 347. 373. 375. 390.

Poseidonios. 200. 235. 270. 368 .

Positivismus. 502. ${ }^{*} 561$. 568. 577. 584.

Postulate, Ethische, nach Kant. 528.

Potamon. 235. 
Potentialität, Potenz. 150. 153. 156. *157. 160. 356. 360. 388. 389 .

Potenzen in Schellings Identitätssystem. 540. 541 .

Prädestination. 319.

Prädikat, seine Beziehung auf das Subjekt. 149. 150.

_, seine Verknüpfung mit dem Subjekt nach Kant. 524.

-, seine Quantifikation nach Hamilton. 569.

Prädikation, Leugnung der Berechtigung der. 127.

Präexistenz der Seele. 134. 278. 287. 296.

Prämissen. I50. 151 .

Pragmatismus. $\quad 572.579$.

Prakrti. ${ }^{3} 37$ f. 39 .

Praktische Philosophie des Mittelalters. 36r.

Priestley, Joseph. 50I. 517.

Primalitäten aller Wirklichkeit, Drei, nach Campanella. 456. 457.

principium identitatis indiscernibilium. 494.

Prinzipien der Vernunft nach A ugustin. 294.

-, Lockes Leugnung eingeborener. 499.

-, Intelligible, Speusipps. 178.

-, Unbeweisbare. ${ }^{*} 152.167$.

Priscianus. 260.

Privateigentum, Platons Forderung der Aufhebung des, für den Wächterstand. I44.

Privatmeinung, Recht des Staats auf Opferung der, nach Hobbes. 478.

Probabilitätslehre des Kameades. *231 f. 234. 236.

Problem, Stellung des primitiven Menschen zum. 3.

Proēgména. *220. 236.

Proklos. 260. 28I. 287. 298. 308. 359. 363 . 373. 378.

Prolepsis. 186. 203.

Propädeutik. 314.

Prophetie. 318. 320. 334.

Protagoras. III. *121. 182.

Protestantismus, Verhältnis des, zum Humanismus. 445 .

Pseudo-Aristoteles. 308.

Pseudo-Bechaji. 331.

Pseudo-Empedokles. 309. 332.

Pseudo-Plutarch. 403 .

Psychisches und Physisches in der sinnlichen Wahrnehmung nach Thomas. 391.

Psychologie Aristoteles'. *165 ff. 380.

- Augustins. 296. 367.

- Fr. Bacons. 466.

- des Individuums nach Comte. 563.

- Eckharts. 425.

-, Empirische, der deutschen Aufklärungsphilosophie. 504.

-, - , der Renaissance. 439.

- Fechners. 582.

- Hegels. 544.
Psychologie Herbarts. 550.

-, Homerische. 13. 15.

-, Medizinische«, Lotzes. 579.

-, Occams 421.

-, Physiologische. 476. 556.

-, Positivistische, der Anlänger Comtes. 565.

-, Primitive. ${ }^{*}$ Ioff. 19. 21 .

-, Scholastische. $355 .{ }^{*} 361$.

-, Scotistische. 413 .

- Spinozas. 488.

-, Thomistische. 391 .

Psychologismus, Ethischer, der Aufklärungsphilosophie. 504.

- im deutschen Idealismus. 548.

- der Millschen und der Hamiltonschen Philosophie. 568. 569. 570 .

- des Neukantianismus. $58 \mathrm{I}$.

Psychophysik. 566. ${ }^{*} 582$.

Pufendorf, Samuel von. 367 .

Pulleyn, Robert. $38 \mathrm{I}$.

Purușa. 37. 39.

Pyrrhon von Elis. ${ }^{*} 181.184 .236$.

Pythagoras, Pythagoreismus. 52.96. I02. " 103 . 106. 109. I I2. 175. 178. 180. 228. 237. 308.

\section{Q.}

Quadratus. 265. 266. 271.

Qualen, Reich der sieben, nach Jakob Böhme. 460.

Qualität. 7. 154.

- nach Plotin. 254.

- nach der Stoa. 208.

Qualitäten, Primäre und sekundäre, der Körper, nach der griechischen Atomistik. IIg.

_., _ - , nach Locke. 498.

-, Sinnliche, Eigenschaften der Substanz nach Anaxagoras. II 4 .

_, -, reale Eigenschaften der Körper nach Aristoteles. I63.

-, - , ihre Fhänomenalität nach Demokrit. 182. 185 .

-, Körperlichkeit der, nach den Stoikern. 208. 210.235.

Qualitätswechsel. 160. 255.

Qualitates occultae. 443 .

Quantität. 154. 254. 442 .

\section{R.}

Räte, Evangelische, der Armut, Ehelosigkeit und des Gehorsams. 399.

Räumlichkeit Attribut der Körper nach Descartes. 472.

- s. auch Ausdehnung.

Rajas. 37. 
Rāmakrsna. 46. 48.

Ramée, Pierre de la. 437.

ratio s. Verstand.

Rationalismus, Aristoteles' Stellung zum. 153 .

- in der deutschen Aufklärungsphilo. sophie. 503 f. 519.520.

一, Cartesischer. ${ }^{*} 467$ ff. 479.480.

-, Gegensatz von, und Irrationalismus bei Hartmann. 579.

-, Platons Stellung zum. 148 .

-, Sokratischer. 123. 143.

-, Religiöser, im Islam. 303.

- , - im Judentum während der gâônischen

Periode. 330.

-, Theologischer. 514 .

Raum, Aristoteles' Definition des. I62.

-, Kants - - 524. 581 .

-, Leibnizens - - 493.

-, Philons Auffassung vom. 245 .

-, Stoische Definition des. 207.

-, Der leere. I12. I19. 176. 187. 215. 306. 472.

Ravaisson, Félix. 566.

Razan, Hayashi. 81.86.

al-Râzî, Abu Bekr-. 317 .

a]-Râzî, Fachr al-dîn. 328 .

»Reale« Herbarts. "549. 578.

Realismus. 49. 289.

- nach der Scholastik. 355. 366. 371. 372. 412. 418. 419 .

Realität der allgemeinen Formen nach Platon. 129.

- der Bewußtseinswelt nach Nikolaus von Kues. 452.

-- der Dinge nach Vaiseșika und Nyāya. 49.

-, Einzig wirkliche göttliche nach dem Súfismus. 313.325 .

-, Wahre, nach Keppler. 442.

- von Welt und Seele nach der SänkhyaPhilosophic. 37.

Recht nach Aristoteles. 173.

- - Epikur. 198.

- - Hegel. 545.

- - Kant. 529. 532.

- Spinoza. 489 .

-.. - der Stoa. 227.

-, Natürliches, nach den Kynikern. 126.

Rechtsphilosophie des Aristoteles. 173.

- L. Knapps. 575.

"Reden an die deutsche Nation«, Fichtes. 534.

Reduktion der Form nach den Thomisten. 390.

eflection nach Locke. 499.

Reflexion, Affekte der, nach Butler. 510.

Reformation. * 445. 459.

Reid, Thomas. 505 .

Reinarus, Hermann Samuel. 514.

Relation. 154. 210.
Relativität der allgemeinen Prinzipien. 56\%.

-, Historische, nach Hegel. 542.

Religion. 25.

-, Verhältnis von Philosophie und, nach Averroës. 326.

—, Freiheit der, nach Bayle. jo6.

-, Chinesische. 60.

- der Humanität, Comtes. $5 \dot{6}_{4}$.

-, Hobbes' Auffassung der. 478 .

-, Verhältnis der indischen, zur Philo. sophie. 30 .

-, Einführung der indischen, in Japan. 80.

- Kants Auffassung der. 532.

- innerhalb der Grenzen der bloßen Ver. nunft nach Kant. 523 .

-, Stellung der Kyniker zur. 126.

-, Einklang von, und Philosophie nach Maimûni. 334 .

-, Stellung der Romantik zur. 537.

-, Übereinstimmung zwischen natürlicher und geoffenbarter. 499.

-, Verhältnis von Philosophie und, nach Spinoza. 484.

- entscheidender Factor für den mensch. lichen Fortschritt nach dem Traditionalismus. 558.

-, s. auch Vernunftreligion.

Religionen, Entwickelung der, nach Schelling. 541 .

-, Wert der positiven, in der Scholastik, s. Philosophie, Christliche, des Mittelalters.

-, Shaftesbury's Ansicht von der Unerläßlichkeit der positiven, zur Erziehung der Masse. 5 I 4.

--, Bemühungen einer Union der -. 511 .

- Bestimmung des öffentlichen Kultus der, durch den Staat. 489.

Religionsphilosophie, Alexandrinische. $285 \mathrm{ff}$.

- Hegels. 547.

- Kants. 530.

Religionsvorstellungen, Harmonisierung der Philosophie mit den, bei den arabischen Philosophen. 317.

Remigius von Auxerre. 372.

Renaissance. "432. 507.

Renaissance, Karolingische. 370.

Renouvier, Charles. 566.

Reportata Parisiensia des Duns Scotus. 411.

Republikanismus. 489.

res extensae und cogitantes. 472.482 .492$. 493.

Restriktion. 357.

Reuchlin, Johann. 440.

Revolution, Französische. 515. 518. 533. 557. 560.

Reynaud, Jean-Ernest. 561.

Rezeptivität des mittelalterlichen geistigen Lebens. 339.

, Ri, die Weltseele. $84.85 .88,89$. 
Ribot, Théodule. 565.

Richard von Middleton. 411. 413.

- von St. Viktor. 376 -

Riehl, Alois. 581 .

Ripelin, Hugo. 382 .

Rokitanski, Karl Freiherr von. 580.

Roman, Chinesischer. 60.

Romantik, Deutsche. 533. ${ }^{*} 536.543 .558 .574$.

-, Französiche. 538. 558.

Roscellin. 372. 373.

Rose, Valentin. 308.

Rousseau, Jean-Jacques. 23. *518. 519. 521. 557.

Royer-Collard, Pierre-Paul. 559.

Rüdiger, Andreas. 504.

Rufinus von Aquileja. 287. 290.

Ruge, Arnold. 574.

Ruhe, Die, nach der Stoa. 2 Io.

- im Geiste nach Plotin. 254.

Rupert von Deutz. 368 .

Rustebeuf. 376.

Ruysbroeck, Jan van. $376 .{ }^{*} 427$.

Ryōch:. *84f. 91.

\section{S.}

Sa'adjah b. Joseph. *330. 333.

Sabatier, Auguste. 565.

Sabunde, Raymund von. 349. *417.

Sachbeschäftigung, Verlangen des Humanismus nach. 437.

sāhacarya. $5 \mathrm{I}$.

Saint-Simon, Henri de. *561. 562. 564.

Samuel b. Chofnî. $33^{\circ}$.

Sanchez, François. 438. 439. 455.

Sankara. 40. ${ }^{*} 42.44 \cdot 45.56$.

Sānkhya. 33. 34. * 3 6ff. 40. $41 \cdot 44 \cdot 47 \cdot 53$.

Sansāra. 38.

Sareshel, Alfred von $=$ Alfredus Anglicus.

Satornil. 268-

Sattva. 37.

Savasorda $=$ Abraham b. Chijja

Scaliger, Julius Caesar. 436.

Schang-ti. 60.

Schattenbild der Seele nach Plotin. 257.

Schattenseele. I0. *14. 26.

Schelling, Friedrich Wilheim Joseph. ${ }^{*} 538$. 543. 559. 57 I. 577. 580.585.

Schesis. 208.

Schicklichkeit. 67. 70.

Schi'iten, Mu'tazilitischer Standpunkt der Dogmatik der. 328 .

Schiller, Friedrich. 507. 534. ${ }^{*} 536.546$.

Schlechtigkeit, Angeborene, der menschlichen Natur nach Siün K'oang. 70.

-, - , - nach Sorai. 90.

Schlegel, August Wilhelm. 53.

-, Friedrich. 53. ${ }^{*} 536$.
Schleiermacher, Friedrich Ernst Daniel. 535. *537.

Schluß, Aristotelische Lehre vom. 150.

- , - - in der indischen Philosophie. 50. 52.

-, Stoische - -. 204.

--, Unbewußter, nach Roger Bacon. 409.

Schmerz. 124. 197. 476.

Schmetterlingstraum des Tschuang-tszě. 75 .

Schönheit, Kants Definition der. 530.

-, Leibnizens - - 509. 510.

Schöpfer der Welt im platonischen "Timaios". 338 .

Schëpfung, Augustins Begriff der. 295. 366.

- bei Eckhart. 424.

- bei Eriugena. 371.

-, Leugnung der, durch Jinsai. 89.

_, _ - - durch Sokō. 86.

- Thomas' Begriff der. 388.

Schöpfungsbericht, Biblischer. 296.

Scholarios, Georgios. 417.

Scholastik. 295. 296. 297. 311. *338ff. *369 ff. 444.

-, Der Name. 342.

-, Einfluß der Juden auf die christliche. 335.

-, Verhältnis der, zu Aristoteles. 275.

Schopenhauer, Arthur. I5. 54. 89. 90. *551. 576. 580.585.

Schottische Philosophie. *505. 5 10. 567. 568. 570.

Schulbetrieb der mittelalterlichen Philosophie. 342. 343 .

Schwenckfeid, Caspar. 445.

Schwere Eigenschaft der Atome nach Epikur. 188.

- - aller Körper nach Straton. 177.

Schwerkraft. II 9 .

Schwestern und Brüder vom freien Geiste $371 .{ }^{*} 423$.

Scotisten. 343. 407. 416. 438.471.

Scotus s. Duns Scotus.

'Seele, Anaximenes' A uffassung der. Ior.

-, Aristoteles' - ... ${ }^{*}{ }_{1} 63.275$.

-, Aristoxenos' - -. 175.

-, Atomistische - -. 120.

-, Augustins - -. 295. ${ }^{*} 296.367$.

-, Averroës - - 323 .

-, Avicennas - - Beziehungen des Lebens der, zu den Naturkräften. $3 \mathrm{I} \delta$.

-, _, Descartes' - —. 472.

-, Eckharts - -. 425.

-, Epikurs - -. 191.

—, Gregors von Nyssa - -. 289. 290.

- Heinrichs von Gent - - $3^{82}$.

-, Heraklits - - 109.

-, Kants - - 527.

-, Leibnizens - -. 494.

-, Maimûnis - - 334 .

-, Occams - - 422

- , Olivis - -.411 . 
Seelc. nach den griechischen Mysterienkulten. 103.

-. Philons - -. 246.

-, Platons - -. 26. ${ }^{*} 133.139$.

-, Plotins - -. 252. 254. 257. 281 .

_. _ _ - in der primitiven Psychologie.

*ioff. 19.

-,$\ldots$ in der Sānkhya-Philosophie. $37 .{ }^{*} 3^{8}$.

-, St. Martins - -. 557.

-, Scholastische - -. 355 .

-, Stoische - - 215f.

-. Stratons - -. 176.

- Tertullians - - 285.

—, Thomas' - -. 392. 394.

-, Tōjus - -. 84 .

-, - - in der Vedānta.Philosophie. 44. 45.

-, Xenokrates' - _. 180.

-. Einflu 8 des Leibes auf die, nach Descartes. 473. 480 .

-, Freiheit der, nach Buridan. 422.

- Gleichheit der, des Menschen und des Tieres nach Wang Tsching. 71 .

—, Läuterung der, nach den »Lauteren《. 309. 310.

-, Verhältnis von Leib und, nach Geulincx. $48 \mathrm{I}$.

-, Verkörperung der, in Tieren. 13.

-, Vermögen der. 12. 296. 392. 394. 406. 422. 457. 504.

"-, Wesen derk Ps.-Bechajis. 331.

- s. auch Psychologie.

Seelenfünklein Eckharts. 425 f.

Seelenleben nach Fechner. 582.

Seelenlehre, Pythagoreische. 97. *104.

Seelentätigkeit, Stufen der, nach Laromiguière. 557.

Seelenvermögen. 12. 296. 392. 394. 406.422. 457.

Seelenvorstellungen des Naturmenschen. 10.

Seelenwanderung. 14. 38. 43. 103. 117.140. 180.422.

Seelenwesen Philons. 244. 247.

Seelenwurm. 12.

Seiende, Das, nach Augustin. 294.

- - - nach l'lotin. 250.

- seine P'rinzipien nach den Stoikern. 205.

-, Das wahrhaft. 98. 100. 106. 1 10. I 2. 126. 131. 241.243 .

Seigwa, Fujiwara. *81. 82. 83.

Seikyō.Yōroku Sokōs. 86.

Sein, Heraklits Leugnung des. 108.

- in Herbarts Netaphysik. 548.

-, Das endliche und das unendliche, nach Thomas. 387.

-, Das reine. 44.

- und Denken, Einheit von. 253. 546.

- der Körper nach Berkeley. 500.

- des göttlichen Wissens nach Averroës. 323.

nsein«, Kopula. 6.8.131. 154.
Seinsbegriff Eckharts. $424 \mathrm{f}$.

- des Thomas. 387 .

Seinslehre, Eleatische. 96. "105f. 109. 114. I18. 241 .

Selbstanschauung, Göttliche. 460. 461 .

Selbstbesinnung. $48 \mathrm{r}$.

Selbstbewußtsein. 469. 470. 498. 532. 559.

Selbsterhaltungstrieb. 195. 217.218 .225 .476 . 477. *488. 489. 505. $57 \mathrm{I}$.

Selbsterkenntnis. 123.

Selbsterlösung Crottes nach Eduard von Hartmann. 580.

Selbstgewißheit des eigenen Bewußtseinserlebnisses. 293.

Selbstkultur des Individuums nach Tszě-szë. 66.

Selbstliebe. 217. 2J8. 225.

Semeiotik. 491. 502.

Semipantheismus. $37 \mathrm{I}$.

Seneca, M. Annaeus. 201. 276. 368.

sensation nach Locke. 499.

Sensualismus. 111. 121. 124. 153. 184. 201. 277. 395. 455. 475. 501. 517.

sensus s. Sinne.

„Sentenzen“ Isidors von Sevilla. 370.

- der Kirchenväter. 344.

- Peters des Lombarden. 375. 381.

Seuse, Heinrich. 426.

Sextius, Q. 239.

Sextus Empiricus. 179. 181. 236. 261. 306. 356. 364. 378.

Shaftesbury, Anthony Ashley Cooper, Graf von. *507. 508. 509. 510.513 . 514. 521.535.

Shakespeare, William. 462.

Shintoismus. 81.82 .83 .

Shissai, Miwa. 86.

Shöin, Joshida. 86.

Shōnan, Yokoi. 86.

Shōsai, Myake. 82.

Shōzan, Sakuma. 86. 91.

Shuntai, Dazai. 91.

Shuntai-Zatsuwa des Muro Kyuso. 83 .

Shyreswood, William von. 416.

Siger von Brabant. 374. ${ }^{*} 383.384 .403$.

Sigwart, Christoph. 581.

Simon b. Jochai. 332.

Simon von Tournay. 381 .

Simplicius. 260. 261.

sin. 61.

Sing-li-Philosophie. 76 .

Sinne der Geschöpfe nach der Sänkhya-Philosophie. 38 .

- nach Nikolaus von Kues. 450.

Sinnesorgane. 165. 176. 185. 186. 202. 230 . 231. 394 .

Sinnesphysiologie. 582.583 .

Sinnesqualitäten. 4 19. $443 \cdot 498$.

Sinneswahrnehmung. 109.112.114.118.120. 121. 129. 163. 176. 179.182. 1 84.201 .204$. 
230. 234. 235. 243. 258. 275. 277. 293. 296. 394. 420. $438.468 .471 .475 \cdot 490.581$. s. auch Wahmehmung.

Sinnlichkeit. 257. 258.

Sitten, Kants Metaphysik der. 529. 531.

Sittengesetz, Natürliches, nach Thomas. 400. -, Scholastisches. 353 .

-, Frage nach seiner Abhängigkeit. 508 .

-, seine Unabhängkeit nach Kant. 528.529.

Sittlichkeit, Autonomie der, nach Bayle. 506.

- nach Kant. 532.

- nach dem Utilismus. 508 .

-, Ereiheit des Genies von den Regeln der, nach der Romantik. 536.

Siün K'oang. 70.

Siva. 42. 47.

Skepsis, Pyrrhonische. *181 ff. 236.356.

Skeptizismus. 121, 178. 232. 234. 248. 438 . 479. 501 .

-, Bekämpfung des, durch Augustın. 293.

-, - - - - die Patristik. 274.

Smith, Adam. 510. 511 .

Sōgaku. 80.

Sokō, Yamaga. 86.

Sokrates. 96. 97. I10. *122. 125, 126. 128. 181. 228. 266. 267.304 .338 .340 .359$.

Sonne Mittelpunkt des Weltsystems. 441.

Sonnenfinsternis. 98 .

Sonnenstaat Campanellas. 457.

Sonnenuhr. 100 .

Sophisten. 97. *120. 228. 573.

Sorai, Butsu. 90.

Soranus. 277.

Souveränität. 447 . 477.

Sozialismus, Philosophischer deutscher, im 19. Jahrh. 576.

-, - französischer, - - - 560.

Sozialphilosophie Campanellas. 456.

Soziologie Comtes und seiner Nachfolger. 562 . 565 .

- s. auch Gesellschaft.

species intelligibilis nach Thomas. 395.

Speichel als Sitz der Seele. 12.

spermatikos logos. 212. 241. 256. 296.

Speusippos. *178. 180. 237.

Sphären, Sphärengeister nach Aristoteles. 162.

- nach den arabischen Peripatetikern. 315. 316. *319. 322.

Sphärentheorie. 100. 113.

Sphärenwelt der "Lauteren*. 310.

Sphairos des Empedokles. 116. 117. 118.

Spieltrieb der Einbildungskraft. 59.

Spinoza, Baruch; Spinozsimus. 84. 281.338. 377. $387 .{ }^{*} 83$ ff. 493.494 .513 .514 .535$. 538. 540. 574. 579 .

Spiritualen. 446.

Spiritualismus, Gnostischer. 268.

-, Monistischer. 240.

- des 19. Jahrhunderts. "558f. 566.
Spiritualismus Plotins. *257. 260.

spiritus animales. 474 .

Sprache, Chinesische. 60.

- des Kindes. 9.

- primitiver Völker. 6. 7. 8.

- Quintessenz aller Wirklichkeit nach Jakob

Böhme. 459.

Sprachen, Eindringen der modernen, in die Wissenschaften. 444 .

Sprachphilosophie. 201.

Spruchweisheit, Primitive. 24.

Spurzheim, Johann Christian. 557.

Sramana. 33.

Staat, Aegidius Colonnas Lehre vom. 406.

-, Aristoteles' - _. *174. 403 .

-, Campanellas - -. 457.

-, Dantes - - 407.

-, Han Fei-tszĕ's - - 75 .

-, Hegels - - 545 .

-, Hobbes' - -. 477.

-, Johanns von Salisbury - - 376.

-, Platons - -. 144.

-, Lehre vom, in der Renaissance. . 446.

-, seine Wertung in der Scholastik. 353.

- Verhältnis des einzelnen zum, nach der Stoa. 227.

-, Thomas' Lehre vom. 401. ${ }^{*} 402$.

Staatsideale. 448. 457. 463 .

Staatslenker, Stand der, nach Platon. 145.

Staatsordnung, Zweck der, nach Platon. 141.

Staatstheorien, Neuplatonischer Einflub auf die, im Arabertum. 312.

Staatsvertrag. 447.477.

Staatswesen, Geordneter Zustand eines, nach Tszĕ-szĕ. 65.

-, Lehren des Taoismus über das. 72.

Stadien, Comtes Gesetz der drei. 562, 564.

Stahl, Friedrich Julius. 557.

Steigerung, Weg der, nach Thomas. 388.

Stein der Weisen. $44 \mathrm{I}$.

Steinschneider, Moritz. 335.

Stilpon. 127. 199.

Stoa, Stoizismus. 124. 148. 181. *199. 235. 247. 249. 268. 269. 352. 496.

- Einfluß der, auf die arabische Philo. sophie. 305.

-, - - auf Descartes Ethik. 474.

- Quelle fur die Patristik. *275f. 285.

- Einfluß der, auf die Renaissance. 437 .

Störungen in Herbarts Metaphysik. 549. 550. Stoff nach Aristoteles. 156.

- nach Protagoras. 121.

- und Form, Korrelativität von, nach den Stoikern. 205.

- und Kraft, Untrennbarkeit von, nach Antio-

chos. 235 .

Stoffelemente Leukipps. I18.

Stoffmischung nach Empedokles. 117. 
Stoffproblem in der ionischen Naturphilo. sophie. 97 .

Stoffwechsel in der sublunarischen W'elt. 163.

Straton von Lampsakos. 175. 387 .

Strauß, David Friedrich. 574. 576.

Strebevermögen nach Thomas. 396.

Streit als Bewegungsursache nach Empedokles. I16.

Stufenbau, Harmonischer, im Universun. 391. 435. 494.

Stufenreihe der Wesen nach Plotin. $252 \mathrm{f}$.

Sturm und Drang. 530. 535.

Suarez, Franz. 344. 407. 445.

Subjekt. 36. 37. 73. 75 .

-, seine Einordnung in die Sphäre des Prädikats nach Hamilton. 569 .

-, sein Verhältnis zum Prädikat. 149. 150.

-, seine Verknüpfung mit dem Prädikat nach Kant. 524.

Subjektionsvertrag s. Herrschaftsvertrag.

Subjektivität der Sinnesqualitäten. 443. 468 . 471.498.

Substanz. 7. 49. I18. 154. 155. 205. 223 . 295. 356. 372. 387. 422. 492. 500. 540. 548 .

-, Unendliche. 482.483.485.487.

-, -, ihre Attribute nach Spinoza. 486.

Substanzatom. 306.

"Substanzen, Die Fünf", ps.empedokleische Schrift. 332 .

-, Geistige, nach den arabischen Peripatetikern. 316.

- Heterogene körperliche und seelische nach Descartes und seinen Nachfolgern. 473. $48 \mathrm{r}$.

-, Kogitative und nichtkogitative. 498.

- der Natur nach Kant. 525.

-, Realität der endlichen, nach Leibniz. 493.

Substanzialität Gottes. 277. 481 .

Substrat. 207. 210.255.

Sünde. 367.368 .400 .496$.

Sündenfall. 544 .

- Luzifers. 460 .

Sūfismus. * 3 I 2 f. 324.

al-Suhrawerdî, Sichihâb al-din. 313 .

Suiga-Shinto. 82.

Sulzer, Johann Georg. 504. 510.

Summa philosophica des Thomas. 386.

- theologica Alberts des Großen. 382. 397.

- - des Thomas. 339. 345.386. 404.

Summulae, Logische scholastische. 417.

Supposition der Wörter. 357.416.

Supranaturalismus. 348,355 .

Sūtra. 35 .

Syllogistik, Aristotelische. 150.

-, Scholastische. 357.

_, -, Kampf des Humanismus gegen die. 437.

-, Stoische. 204.

Sylvester, Bernhard. 344. 376
Symmetrie, Bedeutung der, für das chinesische Denken. 78.

Sympathie des Kosmos nach Plotin. 256.

Synesius. 272. 278. 280.297.

Synkatathesis. 202. 223. 470 .

Synteresis. 395. 426 .

Synthese, Alberts d. Gr. Versuch einer, des neuen Aristotelismus mit der traditionellen Metaphysik. 382.

- Gundissalins - - des neuen ara. bischen Materials mit den alten Vorstellungen. 380 .

- als Charakterzug von Eduard von Hart. manns Philosophie. 579.

- nach Hegel. 544.

- als Charakterzug der Scholastik. 345.

System der Ideen, Platons. 13I.

》Système de la nature $\quad 517$.

\section{$\mathrm{T}$.}

Täufertum. 445 .

Ta-hioh des Tszĕ.szé. 66.

»Taigiroku《 Ekkens. 89.

T'ai-kih. 77.

Taikyo nach Chūsai. 91 .

Taine, Hippolyte. 565.

Takaimori, Saiḡo. 86.

Tamas. 37.

tao. 64. 66. *71. 73. 75 .

Taoismus. 6o. "7I ff. 82 .

Tao-teh-king des Lao-tszě. 71 .

Tapferkeit. 142. 170. *171. 198. 225.

Tarde, Gabriel. 565.

Tathägata. 85.

Tatian. 265. 267. 268.

Taufe, Thomas' Stellung zur Zwangs-, Andersgläubiger. 402.

Tauler, Johannes. $376 .{ }^{*} 426$.

Taurellus, Nikolaus. 446 .

Tch'eng I. 77.

Technik im Mittelalter. 359.

Teleologie. 466. 467. 513. 534 .

Telesio, Bernardino. 422. "439. 452. 455. 464.

Temperamente. 194.

Tempier, Stephan. $38 \mathrm{r}$.

Tenri, die himmlische Natur. 85.

Terminismus, Terministen. 355. 357. 439. 452. 475 .

Terminologie der mittelalterlichen Philosophie. 343. 357 .

$\begin{array}{lllllll}\text { Tertullian. } & 266 . & * 267 . & 268 . & 269 . & 276 . & 279 .\end{array}$ 282. 284 .

Tetens, Johannes Nikolaus. 504.

Texte, Die indischen philosophischen. $34 \mathrm{f}$.

Thales. 1. 96. 97. 98. 100. 101.

Theismus. 483 . 
Theismus in Plotins Philosophie. 259.

Themistius. 308. 315. 322. 378 .

Theodizee Leibnizens. 496.

- in der Stoa. 213.

Theodoret. 269. 271 .

Theogonie. 3. 22.

- Jakob Böhmes. 460.

Theokratisches in Thomas' Gesellschaftslehre. 401 .

Theologie, Augustinische. $38 \mathrm{r}$.

-, Beziehungen von Philosophie und, im mittelalterlichen Geiste. $350 \mathrm{ff}$.

-, Herrschaft der, in der mittelalterlichen Philosophie. 346.

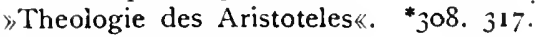

Theophilus von Antiochien. 265. 267. 269.

Theophrastos. 175 .

Theorie höchste Aufgabe des Menschen nach Plotin. 259.

Theosophie Jakob Böhmes. $\$ 60$ f.

- in der Renaissance. 440.

Theurgie. 260. 318.

Thierry von Chartres. 376 .

Tholuck, Friedrich August. 313 .

Thomas von Aquino. 278. 323. 339. 341 . 344. $345 \cdot 348$. $349 \cdot 350 \quad 352.353 \cdot 359 \cdot 361$. 363. 365.368 . 369. 374. 378. 381. 382. 383 . 384. *386 ff. 411. 412. 413. 414. 415. 416. 418. 426. 444. 447. 494. 499. 570.

Thomas Gallus. 376. 424 .

Thomas von Straßburg. 374. 40 \%.

Thomas de Vio. 407.

Thomasius, Christian. 503.

Thomismus, Thomisten. 343. 390. ${ }^{*}+06.411$. 435. 444 .

Tibbon, Familie. 335.

Tiefendimensionen. 410.

Tier, Descartes' Auffassung des, als Automaten. 473.

-, Empedokles' Lehre von der Entstehung des. 117.

-, Beziehungen des Naturmenschen zum. 13.

Tierseele. 164. 392. 393. 473 .

》Timaeusk Platons. 362. 376. 435.

Timon von Phlius. 181. 184 .

Tod, Epikurs Auffassung vom. 193.

- , seine Bedeutung für die Entstehung der primitiven Philosophie. 10. I8.

- s. auch Unsterblichkeit.

Todespflicht in Japan. 87.

Tōgai, Itō. 89.

Töju, Nakae. 84 .

Toland, John. 512. 514 .

Toleranz, Toleranzbewegung. $402 .{ }^{*} 448.484$. 506. 511 .

Tonos. 210.

Töri, Nakane. 86.

Totem, Totemismus. 13. 14.

Totenbräuche. 29.
Tractatus de intellectus emendatione Spinozas: 484.

- theologico-politicus Spinozas. 484.489 . 514.

Tradition, Bedeutung der, in der mittelalter lichen Philosophie. 340.

Traditionen, Streit der, in der Renaissance. 433.

Traditionalismus, Französischer. $\quad$ 558. 56I.

Traducianismus. 285 .

Trägheit, Gesetz der. $\$ 72$.

Transzendenz der platonischen Philosophie. 148. 278.287.

Traum, seine Bedeutung fiir die Entstehung der primitiven Philosophic. 10.

-, Epikurs Auffassung vom. 187.

》- des Scipio«, Macrobius' Kommentar zum. 363.

Triebleben, Triebregung. 214. 219.246. 529.

Trinität. 371. 372. 375. 412.574.

Tritheismus. 372 .

Trivium. 346.372.

Trombeta, Antonio. 416.

Tropen Aenesidems. 236.

Trugbilder nach Fr. Bacon. 464.

Trugschluß. 127.

- s. aucl: Schlußlehre.

Trypho. 267. 282 .

Tschang Tai. 77 .

Tscheng Hao. 77.

Tschou-tszĕ. 76 .

Tschuang-tszě. 74 .

Tschu Hi. *77. 81. 82. 83. 84. 86. 88. 89.

Tschung-yung des Tszĕ-szĕ. 64. ${ }^{* 66}$.

Tszě-kung. 69.

Tszĕ-szĕ. $64 .{ }^{*} 66$.

Tugend, Antisthenes' Auffassung der. 125.

-, Aristipps - - 125.

-, Aristoteles' Lehre von der. 169.

—, Epikurs - - - * 197.259.

-, Eukleides' Auffassung der. 127.

-, Platons Lehre von der. 136. *141.

-, Lehrbarkeit der, nach Platon. I43.

-, Plotins Lehre von der. 259.

-, Lehrbarkeit der, nach Sokrates. 123.

-, Spinozas Begriff der. 490.

-, Stoische Lehre von der. *221. 259.

-, Lehrbarkeit der, nach der Stoa. 222.

- höchstes Gut nach der Stoa. 217.

- Thomistische Lehre von er. 400.

-, Offenbarmachung der, nach Tsz ĕ.szĕ. 66.

al-Tûsî, Nasîr al-dîn. 328 .

Tyrann, Problem der Stellung des Volkes zum. 377. 405 .

Tyrannion. $\quad 177$. 
U.

Ubertino von Casale. 426.

Übel s. Theodizee.

Überlieferung s. Tradition.

Übermenschentum Nietzsches. 584 .

Übersetzertätigkeit der mittelalterlichen Juden. 335.

- der Scholastik. 377.

Uhrengleichnis. 482.

Ulrich von Strabburg. 385 .

Umwertung aller Werte, Nietzsches. 584 .

„Unam sanctam《, Bonifaz VIII. Bulle. 376.

Unbedingte, Das, nach Hamilton. 569 .

-, -, - Kant. 526. 532.

-, -, - Spencer. 571 .

Unbegrenzte, Das, der Urstoff nach Anaximandros. "99. 100.

-, -, nach dem Pythagoreismus. II 3 .

Unbewusten, Eduard von Hartmanns Philosophie des. 577.580 .

Undurchdringlichkeit der Atome. 188.

Unendliche, Das. 73.

-, - , nach Nikolaus von Kues. 450.

Unendlichkeit Gottes nach Spinoza. 486.

Unerkennbarkeit, Wissenschaftliche, der Dinge nach Karneades. *231. 232. 236.

Universalgeschichte. 520 .

Universalienstreit. 372 .

Universitäten, Mittelalterliche. 343.

- in der Renaissance. 443.

》Universo, Dek Wilhelms von Auvergne. 380 .

Universum nach Bruno. 453.

- nach Nikolaus von Kues. 451.

Unkörperliche, Das, nach den Stoikern. 206 f.

Unlust. 167. 186. 258. 474. 489.

- das höchste Übel nach Epikur. 194.

Unpersönlichkeit der scholastischen Philosophie. 344.

Unsterblichkeit der Seele. 134. 349. 393. 412. 513. 574 .

- $\ldots$, Des Averroismus Leugnung der. 381.

-, Epikurs Leugnung der. 193.

-, Feuerbachs Gedanken über Tod und. 575.

-, Ghazâlis Belämpfung der Leugnung der individuellen. 320.

- der Seele, Gundissalins Schrift über die. 380 .

-, Jinsais Auffassung der. 88.

- der Seele nach Platon. 135. 278. 284. 285.

Upanișaden. 31. 34. 36. 38. 40. 41. $43 \cdot 53$. 55. 56.

Urban VIII., Papst. 455.

Urbilder s. Ideen.

Urchristentum, sein Verhälnis zur Philosophie. 265.

Urfeuer, Göttliches. 208. "212. 215.
Urgemenge des Anaxagoras. *114f. 118.

Urkraft, Göttliche. 454 .

Urlicht. 244. 276.

Urmaterie. 335. 383. 406. 412.

Ursache. 16. 19. 252. 525 .

-, Erste. 387. 389. 418.

-, Einzige wirkende. 481 .

- Immaterialität der ersten, nach Maimûni. 334.

-, Oberste, alles Daseins nach Plotin. 250.

-, Verhältnis zwischep, und Wirkung. 5or.

Ursachen, Aristoteles' Lehre von den vier.

*157. 212.356.

-, Stoische Lehren von den. 211.

-, Stufenreihe der. 287 .

-, nach Thomas. 388.

Ursächlichkeit, Weg der, bei Thomas. 388 .

Urschlamm. 103.

Urstoff. "98. 99. 100. 107. 211.

Urstoffe nach Anaxagoras. 114.

Urteile, Synthetische, a priori. 522 .

Urteilsenthaltung, Pyrrhons Forderung der. 182. 183 .

Urteilslehre, Aristotelische. 149.

-, Kantische. 525.

-, Stoische. 202. *204. 470.

Urwesen nach Jakob Böhme. 460.

- nach Eduard von Hartmann. 579.

- nach der Identitätsphilosophie. 540.

- nach Leibniz. 495.

- nach Plotin. 250. 363.

Urwille nach Jakob Böhme. 460 .

Urwirklichkeit. 482.483.

Urzustand menschlicher Lebens- und Weltanschauung. 4.

oủcía nach Aristoteles. 155.

- nach der Stoa. 206.

Utilismus. 508. 568 .

Utilitaritätsstandpunkt Sorais. 90.

Utopia des $\mathrm{Th}$. Morus. 448.

\section{V.}

Väter, Schriften der apostolischen. 265.

Vaiśeșika. $34 .^{*} 49$.

Valla, Laurentius. 437.

Variation der organischen Typen. 570.

Vasquez, Gabriel. 374. 407.

Veda. 34. 42. 52.

Vedānta. 34. 39. *40 ff. 53. 54. 56. 350.

Verdichtung. 100. 101. 112.

Verdünnung. 100. 101. 112.

Vereinigung des geistig erhöhten Menschen mit der Welt der reinen Geistigkeit s. Coniunctio.

*Verfeinerung der Sitten « des Miskaweihî. 3 I 2.

Vernunft als Vermittlerin der unbeweisbaren Prinzipien nach Aristoteles. 152. 153. 
Vernunft, Praktische, nach Arist oteles. 167. *168. 169. 172.

-, Theoretische und schaffende, nach Aristoteles. 165. 166. 169. 392. 409.

-, Tätige, nach den arabischen Aristote. likern. 316. 324 .

-, Praktische und theoretische, nach Bayle. $506 f .513$.

-, Primat der praktischen, nach Fichte. 534 .

- kein Kriterium religiöser Erkenntnis nach Jehûdah ha-Lêwi. 332.

-, Praktische und theoretische, nach Kant. 414.

- Kriterium für die Bewertung der Handlungen nach den Mu'taziliten. 304.

- das eigentliche Wesen der Seele nach Platon. 134 .

-, Herrschaft der, über die Triebe, sittliches Ideal der Renaissance. 437.

-, System der, als Aufgabe der romantischen Philosophie. 533. 534.

-, Sich selber suchende, in der Schelling. schen Naturphilosophie. 539.

-, Unendliche, der Schellingschen Philosophie. 540 .

-, Grenzen der, nach der Scholastik. 349.

-, Menschliche, nach den Stoikern. 204. 222.

-, Stellung der, nach Thomas. 392. 395. 399. 400.

Vernunfterkenntnis. 303. 325. 350. 392. 434 . 497. 517.

Vernunftgrenzen, Einengung der, bei Duns Scotus. 412.

-, - -; bei Occam. 421 .

Vernunftkritik, Kantische. ${ }^{*} 523.542$.

Vernunftmorm in der chinesischen Philosophie. 64. 66, ${ }^{*} 71$.

Vernunftprinzipien Augustins. 294.

Vernunftreligion der Aufklärungsphilosophie. * 511 ff. 514 .

-, Bacons Leugnung einer. 466.

-, Bayles - - 506.

-, Verhältnis der, zur Offenbarungsreligion 433 .

Verstand, Aktiver. 419.

- nach Nikolaus von Kues. 450.

-, Tätiger und möglicher, nach Thomas. 395.

-, Wertung von Wille und, bei Thomas. 413 .

Verstandesbegrife, Reine, Kants. 524.

Verwunderung. 474.

Vico, Gian Battista. 519. 520.

Vidal, Maestro = Moses b. Josua Narboni.

Vielheit. I10. I12. 113. 119. 127. 131. 250. 252. 253.

Viktoriner. 376. 379. 417.473.

Villa dei, Alexander de. 339.

Villemain, Abel. 559.

Vinci, Lionardo da s. Lionardo da Vinci.
Vinzenz von Beauvais. 359. 365. 379. 409.

Vișṇu-Kṛșna. 48.

Vitalismus s. Lebenskraft.

Vittoria, Franz von. 407.

Vives, Ludovicus. 437. 439. 455 .

Vogt, Karl. 577.

Volksgeist nach Hegel. 545 .

-, Der japanische. 80. ${ }^{*} 92$.

Volksseele. 5 .

Vollkommenheitsmoral. 507. 519.

Volney, Constantin-François de. 519.

Voltaire, François-Marie Arouet de. 513 . *515. 521 .

Voluntarismus. 413.

- in der neuzeitlichen Mystik. 459.

- Schopenhauers. 552.

Vorsehung, Ghazális Bekämpfung der sich nicht auf die besonderen Momente des Weltgeschehens erstreckenden. 320.

-, Maimûnis - - - - - - - - 334 .

- nach der Stoa. 212. 233.

Vorstellung. 8. 201 .

-, Klare und deutliche, unklare und verworrene. 470. 481. 492. 493. 494 .

-, UnbewuBte. 494.

- Anschauliche, nach Aristoteles. 165. I67.

- nach Eduard von Hartmann. 579.

- nach Herbart. 549. ${ }^{*} 550$.

-, Hinlänglich überzeugende, des Karne. ades. 231 .

-, Occams Auffassung der. 419.

-, Kataleptische, der Stoiker. 202. 231. 23.3. 235. 203. 307.

vyāpti. 51 .

\section{W.}

W'ahrheit, Augustins Auffassung der. 294. 366.

-, Selbstbewegung der, im BewuBtsein nach Hegel. 542 .

- nach der Auffassung der mittelaiterlichen Philosophie. 341.

-, Relativität der, nach Protagoras. 121.

-, Absolute und niedere, nach der Vedānta-

Philosophie. 41. 43.

- der Vorstellung. 231.

-, Rationale und empirische, nach Wolff. 503 .

-, Zweifaltige. 326. $350.38 \mathrm{r}$.

Wahrheiten, Ewige, nach Augustin. 293. 294.

-, Notwendige und zufallige, nach Leibniz. 492. 503.

-, Rationale, nach Descartes. 47I.

Wahrnehmung. 7. 9. 16. 37. 50. 52. 391 . 410. 420.

-, Innere. 498. 499. 500.

- 5. auch Sinneswahrnehmung 
Wahrnehmungstheorie, Physikalische s. Demokritos und Empedokles.

Wahrscheinlichkeit, Karneades' Lehre von der. *231 f. 234. 236.

Walter von Mortagne. 373.

Walter von St. Viktor. 347. 376.

Wang.in. 80.

Wang Tsch'ung. 70.

Wang Yang.ming. *77. $81 . * 83.85 .86 .89$. 90. 91.

》Wegweisung der Unschlüssigen« Maimûnis. 333. 381 .

Weigel, Valentin. 445.458.

Weisheit. 67. 197.

- der Gnosis. 460.

-, Origenes' Methode der Entwicklung zur. 286.

-, Platons Definition der. 142.

Weissagung s. Prophetie.

Weiße, Christian Hermann. 577.

Welt, Anfang- und Endlosigkeit der, bei Aristoteles. *I6of. 315.381 .

- Obere und sublunarische, nach Aristoteles. 162.

-, Supralunarische, der arabischen Ari. stoteliker. 316.

-, Augustins Auffassung der. 295.

-, Anfang- und Endlosigkeit der, bei Aver. roes. 322.

--, Irdische, nach Jakob Böhme. $46 \mathrm{I}$.

-, Wesen der, nach Campanella. 456.

-, Ghazâlis Bekämpfung des Satzes von der Ewigkeit der. 320.

--, Eduard von $\mathrm{Hartmanns}$ Auffassung der. 580 .

-, Hervorgang der, aus Gott nach $\mathrm{Hegel}$. 538 .

-, Realität der, nach der indischen Philosophie. 37.43 .

-, Verhältnis der, zum Brahma _ _ - 31 f. 45 .

_, Zufälligkeit der, nach Leibniz. 495.

- Maimûnis Stellung zum Satze von der Ewigkeit der. 334.

- Der Mutakallim în Leugnung der Ewig keit der. 306.

- Wesen der, nach Nikolaus von Kues. 451 .

- Entstehung der grob materiellen, nach Origenes. 288 .

- Philons Leugnung der Anfangslosigkeit der. 245.

-, Intelligible, nach Philon. 244.

-, Entstehung der, nach Platon. 138 .

-, Verhältnis der sinnlichen, zu den platonischen Ideen. 132.

-, Anfang-und Endlosigkeit der, nach Plotin. 255.

-, Intelligible, nach Plotin. 252. 253.256.
Welt, Hervorgang der, aus dem Urlicht nach den pseudoklementinischen Homilien. 276 .

- als Wille und Vorstellung nach Schopen. hauer. $552 \mathrm{f}$.

- Verhältnis von Gott und, nach Spinoza. 485 .

-, Unbeweisbarkeit des zeitlichen Anfangs der, nach Thom as. "398. 406.

Weltäther. 473.

Weltall, Kants Kritik der Idee vom. 527.

-, Vorstellung vom, in der ionischen Natur. philosophie. $97 \mathrm{ff}$.

-, Stoische Vorstellung vom. 208.

Weltanschauung, Mittelalterliche. $35 \mathrm{I}$.

- Hobbes'. 475.

Weltbild, Astronomisches, Brunos. 453.

-, -, des Kopernikus. 44I.

- - - des Nikolaus von Kues. 427.

Welteinheit nach Spinoza. 486. 487.

Welten, Unendliche Zahl aufeinanderfolgen. der, nach Origenes. 288.

Welterklärung s. Naturerklärung.

Weltintellekt. 310. 312.

Weltiteratur. 537 .

Weltordnung, Sittliche, nach Fichte. 535.

-, Teleologische. 513.

- Zusammenhang zwischen der natürlichen und der sittlichen. 63 .

Weltprozeß, Unterschied seiner Auffassung im Neuplatonismus und in der Patristik. $28 \mathrm{I}$.

》Welträtselk Haeckels. 577.

Weltschöpfer. 138. 239. 240.

Weltschöpfung. 349. 424. 461.

Weltseele. 180. 209.

- bei Philon. 245.

- nach Platon. 139. 278.

- bei Plotin. *255f. 258. 260. 309. 310. 312.

- und Weitstoff in der Philosophie Töjus. 84 .

-, Böse. 240.

Werden, Aristoteles' Analyse des. * 156.157.

- Das ewige, nach Herakleitos. I05.

_, _ - nach der Identitätsphilosophie. 548.

- in der Metaphysik Herbarts. 549.

-, geleugnet von den Megarikern. 127 .

Werke, Gute, nach der Vedānta-Philosophie. 44 .

Wertbegriffe. I 29.

-, Pyrrhons Ablehnung der. I 83.

-, Spinozas - -. 488.

Werte, Lotzes System der. 579. 584 .

-, Vietzsches Umwertung aller. 584 .

-, Welt der. 531 .

Wesenheit nach Eckhart. 424.

- nach Thomas 388 .

Wesensstufen Plotins. $252 \mathrm{f}$.

Whewell, William. 567 .

Whinfield, E. H. 313 .

»Widersprüche der Philosophen« von Ghazâli. 320 . 
Wiclif, John. 418.

Widerspruch, Satz des. $I$ I. 294. 347. 422. 450. 492. 495.

Widerstand gegen die Obrigkeit, Thomas' Anschauung vom. $40 \%$.

Wiederkehr, Unendliche, des Gleichen. 288. 423.

Wilhelm von Auvergne. *380. 397. 425.

Wilhelm von Auxerre. 374. 381 .

Wilhelm von Champeaux. 373 .

Wille. 54.

- nach Augustin. 296. 297. 367.

-, sein Primat nach Duns Scotus. 413.

- nach Eduard von Hartmann. 580.

-, Höchstes Gesetz des vernünftigen, nach Kant. 527.

- zur Macht, Nietzsches. 584.

- nach Schopenhauer. 533.

- Thomas' Wertung von Verstand und. 413.

-, seine Bestimmung durch den Verstand. 510.

- Gottes nach den Asch'ariten. 306.

Willensfreiheit. 189. 202. 213. 236. 246. 277. 288. 292. 302. 303. 333. 396. 415. 476. 488. 490. 551 .

Wirbelbewegung der Atome. I $19 \mathrm{f}$.

- des Weltäthers. 473 .

Wirken, Kategorie des. 154.

Wirklichkeit, Empirische, nach Jakob Böhme. 460 .

-, Individuelle. 544.

-, Primalitäten aller. 456.

-, Unbekannte, nach Campanella und Hobbes. 456. 475.

- s. Aktualität.

Wirklichkeitsbegriff, Aristotelischer. 148.

-, Galileischer. 443.

Wirkung. 16. 19. 252. 525 .

-, Verhältnis zwischen Ursache und. ;or.

Wissen, Aristoteles' Definition des. $15 \mathrm{I}$. 155. 167.

-, Macht des, nach Fr. Bacon. 462.

-, Verhältnis von Glauben und, nach Fr. Bacon. 466.

-, Macht des, nach Campanella. 457.

-, Intuitives und abstraktes, nach Occam. 420.

- spekulative Durchdringung des Glaubens nach den Patristikern. 270. 271 .

-, Beschränkung des, auf die Ideen nach Platon. 131. 133 .

-, Platons Definition des. I $42 \mathrm{f}$.

-, Verhältnis von Glauben und, nach der Scholastik. 346.347 .386$.

-, Sokrates' Auffassung vom. 123.

-, Das höhere, der Vedān ta-Philosophie. 44.

- Das niedere, der Vedānta-Philosophie. 43 f.

-, Das begriffliche, nach Nenokrates. 179.
Wissen Gottes nach Avertoës. 322.

Wissenschaften, Mehrheit von, nach Aristo teles. 152.

Wissenschaftslehre Fichtes. $534 .{ }^{*} 543.548$

- Hegels. 547.

- Kants. 523 .

- Schellings. 539 .

Witelo. 359. $361 .{ }^{*} 410$.

Wohne Gottes, Die, nach Jakob Böhme. 460. Wolff, Christian. 503.

Wollaston, William. 510.

Wollen, Das, nach Aristoteles. 168.

-, Das bewuBte, nach der Stoa. 218. 223 .

- Das sittliche, nach der Auf klärungsmoral 505. 510.

Worms, R. 565.

»Wort, Das «. 558.

Wortspiel im Chinesischen. 62.

Wunder. *22. 25. 306. 320 .

Wunsch-Theorie Feuerbachs. 575.

Wu-wej-Theorie des Taoismus. 71. 75

$\mathbf{X}$.

Xenokrates. 178. "179. 237.

Xenophanes von Kolophon. 96. * 102. 106. 266.

\section{$\mathbf{Y}$.}

Yamatodamashii. $80 .{ }^{*} 92$.

Yang, das lichte Prinzip. 64. 77. 86. 88.

Yang Hiung. 70.

Yang Tschu. *68. 70 .

Yih-king. 63. 67. 76. 77 .

Yin, das dunkle Prinzip. 64. 77. 86. 88.

Yoga. $33 .{ }^{*} 46$.

\section{$Z$.}

Zahl, Auffassung der, im Neupythagoreismus. 239. 240

- , - - bei Nikolaus von Kues. 450.

-, - _, bei Plotin. 254.

-, Bedeutung der, im Pythagoreismus. 104. II3. 44 I.

Zahlbegriffe, Primitive. 6.

Zahlenspekulationen, Pythagoreisierende, in der Schule von Chartres. 376.

Zahlensymbolik bei den »Lauteren《. 310.

Zauber. 21. *22. 25.

Zauberkräfte. 46. 47 .

Zaubervorstellungen, Primitive. $18 \mathrm{f}$.

Zehngebote. 413 .

Zeichensprache, Leibnizens Plan einer philosophischen. $49 t$.

Zeiditen. 328. 
Zeit, Aristoteles' Begriff der. * 162.315 .

-, Epikurs - - 188.

-, Kants - . . *524. $58 \mathrm{I}$.

-, Der Mutakallimûn Leugnung der Grenzenlosigkeit der. 306.

-, Philons Begriff der. 245.

-, Platons - -. 139.

-, Stoischer - - 207.

Zeitpunkt als Kategorie. 154.

Zeller, Eduard. 262. 581 .

Zenon von Elea. 96. Ióg. *110. 121. 127. 188.

Zenon von Kition. 179. * ${ }^{*}$ 99. 202. 216.229. 277. 285.

Zenon der Sidonier. 199.

Zentralfeuer. 113.

Zentralorgan der Wahrnehmung nach Aristoteles. 165.176.

Zeugungstrieb in Platons Seelenlehre. 135.

Zeugungsvermögen nach Plotin. 251.

Ziel, Das menschliche, nach Thomas. 398. Zirbeldrüse Sitz der Seele nach Descartes. 474.

Zôhar. $33^{2}$.

Zorn. $1 ; 2$.
Zuchtwahl, Natürliche. 570.

Zufällige, Das, nach Victor Cousin. 560.

-, 一, nach der Stoa. 215. 277.

Zufäligkeit der Welt nach Leibniz. 495.

Zufall nach Spinoza. 488 .

Zustand nach der Stoa. 208. 210.

-, Natürlicher, des Menschen nach Kant. 529.

Zweckbegriff. 157. ${ }^{*} 168.356$.

Zwecke, System der, in der Scholastik. 353 . 394.

ZweckmäBige, Das, nach dem Materialismus. 517.

-, - absichtslose, nach Kant. 530.

Zweckmäßigkeit der Organismen. 570. 571.

Zweckursachen, Descartes' Ausschließung der, aus der Erklärung der Naturerscheinungen. 472.

Zweifel. 3. 25.

-, Der grundsätzliche, nach Descartes. ${ }^{*} 468$. 506.

Zwerchfell als Sitz der Seele. 12.

Zwingli, Huldreich. 446. 


\section{DIE KULTUR DER GEGENWART}

IHRE ENTWICKLUNG UND IHRE ZIELE HERAUSGEGEBEN VON PROF. PAUL HINNEBERG

bietet die besten Einführungen in die Hauptwissensgebiete in den inhaltlich vollständig in sich abgeschlossenen und einzeln erhältlichen Bänden. Geh. u. geb.

Bisher sind erschienen:

Teil I und II. Aus den geisteswissenschaftlichen Kulturgebieten

Die allgemeinen Grundlagen der Kultur der Gegenwart. (I, 1.) 2. Autl. M. 11.-, M. 13.50 Bearb. von: W. Lexis, Fr. Paulsen, G. Schöppa A. Matthias, H. Gaudig, G. Kerschensteiner, W. v. Dyck, L. Pallat, K. Kraepelin, J. Lessing, O. N. Witt, G. Göhler, P. Schlenther, K. Bucher, R. Pietschmann, F. Milkau, H. Diels. Religion. Philosophie.

Die Religionen des Orients und die altgermanische Religion. (I, 3, I.) 3. Aufl. Bearb. von Edv. Lehmann, A. Erman, C. Bezold, H. Oldenber, I. Goldziher, A. Grïinwedel, J.J. M. de Groot, H. Haas, Fr.Cumont-Gehrich, A.Heusler. Geschichte der christlichen Religion. Mit Einltg.: Die israelitisch - juidische Religion. $(1,4,1$ u.2) 2.Auf. Bearb.v.J. Wellhausen, A.Jülicher, A. Harnack, A. Bonwetsch, K. Müller, F, K. Funk, E. Troeltsch.

Systematische christliche Religion. $(1,4,2$.) 2. Aufl. M. 4.50, M. 6.-. Bearb. v. E. Troeltsch, J. Pohle, J. Mausbach, C. Kriek, W. Herrmann, K. Seeberg, W. Faber, H. J. Holtmann. Aligemeine Geschichte der Philosophie. (I, 5.) 3. Aufl. [U. d. Pr. 22.] Rcarb. von: W. Wundt, H. Oldenberg, W. Grube, T. Inouyc, H.v. Arnim, Cl. Baeumker, I. Goldziber, W. Windelband. Systematische Philosophie. (1, 6.) 3. Aut. M. 7.- M. 0.- Bearbeitet von: W. Dilthey, A. Kiehl, W. Wundt, H. Ebbinghaus, R. Eucken, B. Bauch, Th. Litt, M. Geiger, K. Oesterreich.

\section{Sprache. Literatur.}

Die griechische und lateinische Literatur u. Sprache. (I, 8.) 4. Aufl. [lnVorb.] Bearb.von: U. v. Wilamowitz-Moellendorff, K. Krumbacher, J Wackernagel, Fr. Leo, E. Norden, F. Skntsch. Die osteuropäischen Literaturen und die slawischen Sprachen. (I, 9.) M. 6.-, M. 8.Bearb. von: V.v. Jagic, A.Wesselowsky, A.Brückner, J. Máchal, M. Murko, A. Thumb, F. Riedl, E. Setälä, G. Suits, A. Bezzenberger, E. Wolter.

\section{Staat. Wirtschaft.}

Allgem. Verfassungs- $u$. Verwaltungsgesch. (II, 2, I.) MI. 6.-, M. 8.-. Bearb. von: A. Vierkandt, L. Wenger, M. Hartmann, O. Franke, K. Rathgen, A. Luschin von Ebengreuth. Staat und Gesellschaft der Griechen und Römer bis zum Ausgang des Aittelalters (II, 4, r.) Geb. M. r 3.50 Bearbeitet von: U. v. WilamowitzNoellendorf, J. Kromayer. A Heisenberg.

Allgemeine Rech'sgeschichte.I.Hälfte.(II, 7,I.) M.4.50, M. 6. - Bearb. v.: J. Kohler, L. Wenger. Systematische Rechtswissenschaft. (II, 8 . 2. Anfl. M. 9.-, M. Ir.5o Bearb. v.: R. Stammler, R. Sohm, K. Gareis, L. v. Bar, L. v. Seuffert, F. v. Liszt, W. Kahl, P. Laband, G. AnschiitzE Bernatzik, F. v. Martitz.

Allgemeine Volkswirtschaftslehre. (II, ro, r.) 2. Anf. Von W. Lexis. Geh. M. 5.-

\section{Teil III. Aus d. mathematisch. u. naturwissenschaftlich. Kulturgebieten} Die mathematischen Wissenschaften. (Band 1.) Abteilungsleiter und Bandredakteur: F. Klein. Bearb. von P. Stäckel, H. E. Timerding, A. VoB, H. G. Zeuthen. I. Lfg. (Zeuthen) geh. II. r.6o II. Lfg. (Voß u. Timerding) geh. M. 2.60 iII. Lfg. (VoB) geh. M. 2.40

Anorganische Naturwissenschaften. Physik (IlI, 3, r). Bandredaktenr: E. Warburg. Bearbeitet von F. Auerbach, F. Braun, E. Dorn, A. Einstein, J. Elster, F. Exner, R. Gans, E. Gehrke, H. Gcitel, E. Gumlich, F. Hasenöhrl, F. Henning, L. Holborn, W. Jäger, W. Kaufmann, E. Lecher, H. A. Lorentz, O.Lummer, St. Meyer, M. Planck, O. Reichenheim, F. Richarz, H. Rubens E. v. Schweidler, H.Starke, W.Voigt, E.Warborg, E. Wiechert, M. Wiea, W. Wien, O. Wiener, P. Zcemann. [Zine Neuauflage ist in Vorbercit.]

Chemie. Allgemeine Kristallographie und Mineralogie (III, 3, 2). M.10.-, M. I2.50 Bandredaktrur: Fr. Rinne, Iearh.v. K. Engler, H.Iminendorf, O. Kellner, A. Kossel, M. Le Blanc, R. Luther, E. v. Meyer, W. Nernst, Fr. Kinne, O. Wallach, O. N. Witt, L. Wöhler.

Astronomie (III, 3, 3). M. 10.-, geb. M. 12.50. Bandredakteur: J Hartmann. Bearbeitet von L. Ambronn, F. Boll, A. v. Flotow, F. K. Ginzel, K. Graft, P. Guthnick, J.v. Hepperger, H. Kobold, S. Oppenheim, E. Pringsheim.

\section{Organische Naturwissenschaften.}

Allgemeine Biologie $\left(111,4\right.$ I). M. Ir.-, M. $3.5^{\circ}$ Bandred.: C. Chun u.W. Johannsen u. Mitw. v. A. Günthart. Bearb.v.E. Baur. P. Boysen-Jensen, P. Claußen.A.Fischel, E.Godlewski, M.Hartmann, W. Johannsen, E. Laqueur, B. Lidfor B, W. Ostwald, O. Porsch,H.Przibram,E.Radi,O.Rosenberg,W.Roux, W. Schleip, G. Senn, H. Spemann, O. zur Strassen. Zellen-u. Gewebelehre, Morphologie und Entwicklungsgesch. (11I, ${ }_{4}, 2$.) r. Botan. Teil M. 5.50, M. 7.- Bandredakt.: E. StraBburger. Bearb.v.W.Benecke n. E. Straßburger. 2. Zool. Teil. M. 8,50, M. 10.50 Bandredakt: O. Hertwig. Bearbeitet von E. Gaupp, K. Heider, O. Hertwig, R. Hertwig, F. Keibel, H. Poll.

Physiologie u. Ökologie (III, 4, 3). I. Botan. Teil. MI. 5.50, M. 7. - Bandred.: G. Haberlandt Bearb. v. E. Banr, Fr. Czapek, H. v. Gurtenberg. Abstammungslehre, Systematik, Paläontol., Biogeographie (IIl, 4,4 ). M. ro.-, M. $\times 2.50$

Bandredaktenre: R. Hertwig u. R, v. Wettstein. Bearbeitet von O. A bel, I. E.V. Boas, A. Brauer, A. Hngler, K. Heider, R. Hertwig, W. J. Jongmans, L. Plate, R. v. Wettstein.

Anthropologie (III, 5). Bdred.: G. Schwalbe, E Fischer.[U.d.Pr.22.] Bearb.v,E.Fischer,R.F.Graebner, M Hoernes, Th.Mollison, A.Ploetz, Schwalbe.

Naturphilosophie und Psychologie.

Naturphilosophie (III, 7, 1). NI. 7.-, M.9.Bandredakteur: C. Stumpf.' Bearb. v. E. Becher 
Systematische Philosophie. (Die Kult. d. Gegenw., hrsg.v. Prof. P. Hinneberg. Teil I, Abt. VI.) 3. Auf. M. 7.-, geb. M. 9.-

Die Hervorhebung des Wesentlichen, die Reife des Urteils, das Fernhalten alles SchulmäBigen and Pedantischen, die Klarheit und Sorgfalt des sprachlichen Ausdrucks - dies alles drückt den einzelnen Abhandlungen den Stempel des Klassizismus auf." (Jabrb. d. Pbilosopbie.)

Naturphilosophie. (D. Kult. d.Geg., hrsg.v.Prof.P. Hinneberg. T. III, Abt.VII. Bd.I.) Unter Redakt.v. C.Stumpf. Bearb. v. E: Becher. Geh. M. 7.-, geb. M. 9.„Plilosophen wie Naturforscher werden in dem Werk Bechers reiche Belehrung und Anreguing finden "

(Literarisches Zentralblatt rür Deutscbland.)

Wilhelm Diltheys gesammelte Schriften. In 7 Bdn. Bisher erschien: Band I: Einleitung in die Geisteswissenschaften. Geh. M. 5.50, geb. M. 7.50. Band II: Weltanschauung und Analyse des Menschen seit Renaissance und Reformation. Abhandlungen zur Geschichte der Philosophie und Religion. 2. Anfl. Geb. M. 9.- Band IV: Die Jugendgeschichte Hegels und andere Abhandlungen zur Entwicklung des deutschen Idealismus. Geh. M. 8.-, geb. M. ro.-

Dilthey war mit einer wnderbaren, nahezu unhegrenzten Feinheit des Blickes für dis geschichtliche Leben und der Gabe tiefsten Hineinfüblens in dasselbe ausgestattet. Wie viele Zusammenhänge, die bis dabin dem Auge des Forschers verborgen geblieben waren, bat er aufredecktl Wo er bei seinen Studien auf eine Persönlichkeit von lebensvoller Eigenart stieB, da gewinnt seine Darstellung oft einen geradezil dramatischen Charakter.“ (Kantstudien.)

Shaftesbury und das deutsche Geistesleben. Von Prof. Dr. Chr. Fr. Weiser. Mit I Titelbild. Geh. M. 8.-, geb. M. ro.-

Es ist erfreulich, mit welcher Kraft seelischer Durchdringang der Verfasser seinen Gegenstand auffaBt nnd darstellt, wie er uns Shaftesbary als den Philosophen der Begeisterung und des Lebensglaabens zeigt. An dem Werk kann niemand vorbeigehen, der die deutsche Geistesgeschichte verfolgt."

(Hamburger Fremdenblatt.)

Einleitung in die Philosophie. Von Prof. Dr. H. Cornelius. 2. Auf. Geheftet M. 3.-, gebunden M. 4.ro

"Ein Werk, das ans der Fülle von Wissen, aus dem Reichtum von Erfahrung, aus dem Sehnen und Hungern dos Erkenntnistriebes beraus geschrieben ist.... “ (Der Tag.)

Zur Einfuhrung in die Philosophie der Gegenwart. Von Geh. Rat Prof. Dr. A. Riehl. 6. Aufi. Geh. M. 2.-, geb. M. 3.25

„....So steigt ein Stück geistiger Menschbeitsgeschicbte in seinen wesentlichen Umrissen mit herauf, und indem wir uns um dio Sache bemühen, lernen wir große Menschenken nea, die fär ans gelebt haben und uns einladen, mit ilnen zu leben.“ (Tägliche Rundschau.) Einfuhrung in das philosophische Denken. Von Privatdozent Lic. W. Bruhn. [U. d. Pr. 22.]

Das Buch stellt sicb die Aufgabe, nicht so sehr die Philosophie, sondern das Philosophieren zu lebren, den Leser hineinwachsen zu lassen iu die philosophische Probleınstellung, ihn anzuleiten aus geschichtlichem Anschauungsstoff die daraus zu gewinnende Erkenntnis selbst zu erarbeiten. So wird unnütze Vielwisserei und Abstraktion sowie oberfächlicher Dilettantismus vermieden und der kürzeste Weg zum Aufbau metbodischer Wisseuschaftlichkeit beschritten.

Der gegenwärtige Stand der Geisteswissenschaften und die Schule. Von Prof. Dr. E. Spranger. M. -.90

Einem neuen Zeitalter des Humanismus, wie es sich vor allem in der Sehnsucht der Jugend uech einer Wiedergeburt des Menscheu ankündet, will der Verfasser die Wege bereiten helfen, indem er zeigt, wie in allen gegenwärtigen Geisteswissenschaften das Hauptinteresse auf die Formen und Gestalten des Menschentums gerichtet ist. Werden in einem einleite uden „A Afruf an die PhiJologie" die Vertreter dieser Wissenschaft an ihre eigentümlich humanistischen Aufgaben erinnert, so werden andererseits die Aufgaben der Schule aufgezeigt, die sich anf dieser Grundlage ergeben.

Das Grundproblem Kants. Eine kritische Untersuchung und Einführung in die Kant-Philosophie. Von Prof. Dr. A.Brunswig. Geh.M. 1.80, geb. M.3.-

Das Buch kann als Einfuhrung in das Studium der Kantschen Pbilosophie und ibrer modernen Kritik, ja der Erkenntnistheorie und der Pbilosophie überbaupt dienen.

Philosophisches Wörterbuch. Von Studienrat Dr. P. Thormeyer. 2. Aufl. (Teubners kleine Fachwörterbücher. Band 4.) Geb. M. 2.-

Sachliche, sprachliche uud geschichtliche Erklärung aller wichtigen philosophischen Fachsusdrücke nebst deren bäufgeren Verbindungen und Zusammensetsungen sowie Darstellung der Hauptlehren der bedeutenderen Philosophen.

Verlag von B. G. Teubner in Leipzig und Berlin 
Persరonlichkeit und Weltanschauung. Psych.Untersuch. z. Keligion, Kunst und Philosophie. Mit Abbild. im Text. und auf 5 Taf. M. 3--, geb. M. 4.50 ,Verf. zeigt eino ganz hervorragende Fähigkeit, weite, zum Teil noch kaum bearbeitete Gebiete der psychologischen Welt zu liberschanen. zu ordnen und dem Leser fesselnd zu machen...." $\quad$ (PreuBische Jabrbïcher.)

Weltanschauung. Ein Führer für Suchende. Von Oberstudiendirektor Dr. Hans Richert. Geh. M. 1.25, geb. M. 2.-

Ein Einblick in Urgrund, Gestaltungen, Metboden und Typen der philosophischen Welt . anschaunngsformen nnd Wertmaßstïbe als Wegweiser für die denkende Jugend zur Gewinnung eigener Weltanschauung.

Weltanschauung und modernes Bildungsideal. Von Prof. Dr. G. F. Lipps. Geh. M. 2.10, geb. M. 3.10

,Niemals langweilig und trocken, bietet das Buch eine Fiille von Anregungen, aus denen jeder schöpfen kann, der mitarboiten will an der Ausbildnng eines Bildungsideals der Zukunft." (Zeitschrift für pädagogische Psychologie.)

Himmelsbild und Weltanschauung im Wandel der Zeiten. Von Prof.Fr.Troels.Lund. Aut. Übersetzung von L.Bloch. 4. Auf. Geb. M. 3.75

"... Es ist eiue wahre Lust, diesem kundigen und geistreichen Führer auf dem nie er. müdenden Wege durch Asien, Afrika und Europa, durch Altertum und Mittelalter bis herab in die Neuzeit zn folgen." $\quad$ (Neue Jahrbücher fur das klassische Altertum.)

Individuum und Gemeinschaft. Grundfragen der sozialen Theorie und Ethik. Von Prof. Dr. Th. Litt. 2. Auf. [In Vorb. 1922.]

Will durch die Helligkeit nnd Lebendigkeit seiner Erkenntnisse anf Einzel- und Gesamtseele wirken ond über alle Spaltangen der Gegenwart hinweg zu neuen, schöpferischen Synthesen füren."

(Vossische Zeitung.)

Der Einzelne und sein Staat. Von Privatdozent Dr. jur. et phil. W. Schulze-Sölde. Geh. M. 2.-, geb. M. 2.70

Der Verfasser stellt auf streng philosophischer Grundlage, aber in allgemeinverständlicher Form über „das Gesetz des Einzelnen“, „das Schaffen für den Staat", „das Wegen des Staates" "die Möglichkeit des Staates“, „Erziehung und Rocht", "Rocht und Macht" tiefschürfende "Untersuchungen an und sucht neue Mittel und Wege zu finden, die das Denken und Handeln des Deutschen im Hinblick auf seine Staatsbiirgersendung richtunggebend beinflussen können,

Probleme der Sozialphilosophie. Von Prof.Dr.R.Michels. Geb.M.3.70

„Dieser Band ist imstande, der Betracbtung unseres sozialen und politischen Lebens und der Betätignng in ihm neue, allgemeine, von parteipolitischer Engherzigkeit freie Gesichts punikte und damit ein Gnt zu geben, an dem keineswegs Überflüs herrscht." (StraBb. Post.)

Hegel und der nationale Machtstaatsgedanke. Als Beitrag zur politischen Geistesgesch. Von Privatdoz. Dr. H.Heller. Geh. M. 2.10, geb. M. 3.60

Zeigt, dal die vielberufenen ,imperialistischen“ Gedanken Treitschkes und seiner Zeit auf keinen Geringeren als Hegel zurückgehen, und weist dessen nachhaltigen Einfluß nicht nur auf die bedeutendsten Publizisten, Historiker und Juristen nach, sondern auch dio unmittelbare Verbindnng der Hegelschen Philosophie mit der Grdankenwelt des preuBiscbdeutschen Militärs und mit der nächsten Ungebung des großen Kanzlers.

Politik und Massenmoral. Zum Verständnis psychologisch-historischer Grundfragen der modernen Politik. Von Dr. A. Christensen. M. 1.50, geb. M. 3.-

„Die Arbeit eines scharfen Geistes, der den Dingen anf den Grund geht und der eine grofue Snmme positiven Wissens in Vorrat bat."

(Kirche und Welt.)

Theorie des objektiven Geistes. Eine Einleitung in die Kulturphilosophie. Von Dr. H. Freyer. Ca. M. 2.-

Man mul das inbaltreiche und fesselnde Bnch selbst lesen, um sich von der Fülle von Anregungen, die es vermittelt, ein Bild zn machen. Neben den Arbeiten von Jonas Cohn Adolf Dyroff, Karl Joel, Max Scheler, Georg Mehlis u, a. wird es als Zenge eines hohen Idcalismus seinen selbständigen Platz behaupten."

(Deutsche Revue.)

Geist der Erziehung. Pädagogik auf philosophischer Grundlage. Von Prof. Dr. Jonas Cohn. Geh. M. 5.-, geb. M. 6.50

Eine philosophische Kegründung der Pädagogik, dio zeigt, wie Erzieher und erziehendo Gemeinschaften znsammenwirken können und müssen, um nuter Beriicksichtigung der gegenwärtigen Kulturlage und der Eigentümlichkeiten des dentschen Volkes den Zögling zum autonomen Glied der deutschen Kulturgemeinschaft beranzubilden.

Verlag von B. G. Teubner in Leipzig und Berlin 
Humor als Lebensgefuhl. (Der große Humor.) Von Prof. Dr. H.Höffding. Eine psychologische Studie. Aus dem Dänischen von H. Goebel. Geh. M. I.90, geb. M. $3 \cdot 50$

Eine mit innerer Wärme geschriebene, durch eine Fülle feiner Beobachtungen und glänzender Beispiele aus dem Leben und der Kunst ausgezeichneto Darstellung des großen $\mathrm{Humors}$ als Weltanschauung und Lebensgefübl.

Aus der Mappe eines Glucklichen. Von Wirkl. Geh. Oberreg.-Rat Ministerialdirektor Dr. R. Jahnke. 5. Auf. Kart. M. 1.50, in Halbleder mit Goldoberschnitt M. 6.25

"... Diese Blätter können allen denen nicht warm genug empfohlen werden, die ubber wertvolle Fragen des Lebens nachdenken und sich anregen wollen." (Monatsschr. f.höh. Schul.)

Gott, Gemut und Welt. Goethes Aussprüche über Religion und religiöskirchliche Fragen. Von Geh. Rat Dr. Th. Vogel. 5. Aufl. Geb. M. 3.60

n... Wer immer, Christ oder Nichtchrist, sich mit Andacht in diese tiefe Gedankenwelt versenkt, fiblt aufs lebhafteste seine Existenz um eine Unendlichkeit erweitert." (Neue Jahrb.)

Hauptprobleme der Ethik. Von Prof. Dr.P.Hensel. 2., erw. Auf. M.2.15

„Dieses schlicht und allgemeinverständlich geschriebene Buch darf auf das Lob, nicht nur Philo. sophie, sondern auch philosophieren zu lebren, Ansprucb erheben.“ (Zeitschr.f.päd. Psychol.)

Das Erlebnis und die Dichtung. Lessing. Goethe. Novalis. Hölderlin. V. Greh. Reg.-Rat Prof. Dr.W. Dil they. 8. Aufl. Mit I Titelbild. Geb.Mr.6.-, geb. M1.7.50. In Halbleder M. 25.-

„Deu Aufsätzen Diltheys gebührt ein ganz einziger Platz in allem, was jemals über Dichtung" und Dichter geschrieben ist. Aus den tiefsten Blicken in die Psyche der Dichter, dem klaren Verständnis für die historischen Bestimmangen, in denen sie leben, kommt Dilthej zu einer Würdigung poetischen Schaffens, die jenseits aller Kritik und Literaturhistorie eine selbständig-freie Stellung einnimmt. Dies Buch muB wie eine Befreiungstat wirken." (Die Hilfe.)

Das dichterische Kunstwerk. Grundbegriffe der Urteilsbildung in der literaturgeschichte. Von Prof. Dr. E. Ermatinger. Geh. M. 4.-, geb. M. 5.85 In Halbleder mit Goldoberschnitt M. 7.-

A usgehend von einer Betrachtung iber das Ich und die Welt, entwickelt Verfasser den Unterschied $z$ wischen Gedanken- und Stofferlebnis, zwischen Idee und Mctiv und zeigt diese Gedanken angewendet auf Lyrik, Epik und Drama. Als Sy nthese von beiden erscheint das Formerlebnis: Wieinnere Form des Dichtwerkes wird betracbtet, wie die äußere Form durch das Erlebnis nach auBen wirken soll. So ergibt sich die Begriffsbestimmung des lyrischen, epischen, dramatischen Stiles. Das Buch enthält eine Fülle neuer Einsichten über den künstlerischen Proze $B$ und das Diclitwerk.

Grundlagen der Psychologie. Von Geh. Medizinalrat Prof. Dr. Th. Zieh en. In 2 Bänden: Buch I: Erkenntnistheoretische Grundlegung der Psychologie. Geh. M. 3.20, geb. M. 4.40. Buch II: Prinzipielle Grundlegung der Psychologie. Geh. M. 4.-, geb. M. 5.-

"Jede künftige Psychologie wird nacb Ziehen sich orientieren müssen. Besonders für die noch" sehr im Argen liegende psychologische Terminologie bringt unser Buch wertvolle kritische Vorträge."

Psychologisches Wörterbuch. Von Dr. F. Giese. (Teubners kleine Fachwörterbücher. Band. 7.) Geb. M. I.75

Umfaßt alles, was in den Rahmen der modernen Psychologie gehört: also nicht nur die sog. Sinnespsychologie, das Gedächtnis, Willen und Gefüblslebre, sondern auch die Gebiete der angewandten Psychologie: Intelligenzuntersuchungen, Eignungsprüfungen, Psychotechnik in lndustrie, Verkehr und Kultur. AuBerdem werden Völkerpsyclologie, Psychologie der Massenseele sowie die Grenzwissenschaften: Pathopsychologie, Hypootismus usw. bericksichtigt

Psychologie der Kunst. Darstellung ihrer Grundzüge. z., vollstïndig umgearbeitete und vermehrte Aufl. 3 Bände. I: Allgemeine Grundlegung und Psychologie des Kunstgenießens. Mit 9 Tafeln. Geb. M. 3.75, geb. M. 4.30.

III: Sy stem d. Künste. Die psycholog. Grundlagen d. einzelnen Kunstzweige. 2. A uf. [In Vorb. 22.]

„Was diesem Werke Anerkennung erworben hat, ist $z$. T. der Unstand, daß es zu den seltenen wissenschaftlichen Büchern gehört, die auch ästhetischen Wert besitzen, aus denen eine Persönlichkeit spricht, die über die ungewöhnliche Gabe der Synthese verfügt." "(Zeitschr. für Ästhetik.) Bände zur Philosophie und Psychologie in der Sammlung "Aus Natur und Geisteswelt". Ausführlicher Prospekt vom Verlag, Poststr. 3.

Verlag von B. G. Teubner in Leipzig und Berlin 
B 82 .A4 1923 SMC

Allgemeine Geschichte der

Philosophie 2., vermehrte und verbesserte' Auf 1., 2 . Abdruck. -- 
